Les manuscrits arabes des lettres de Paul 


\title{
Biblia Arabica
}

\author{
Editorial Board
}

\begin{abstract}
Camilla Adang (Tel Aviv University)
Juan Pedro Monferrer Sala (Universidad de Córdoba)

Meira Polliack (Tel Aviv University)

Sabine Schmidtke (Institute for Advanced Study, Princeton)

Alexander Treiger (Dalhousie University, Halifax, Canada)

Ronny Vollandt (Ludwig-Maximilians-Universität, Munich)
\end{abstract}

VOLUME 6

The titles published in this series are listed at brill.com/biar 


\title{
Les manuscrits arabes des lettres de Paul
}

\author{
État de la question et étude de cas \\ (1 Corinthiens dans le Vat. Ar. 13)
}

par

Sara Schulthess

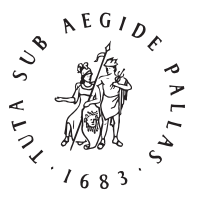

B R I L L

LEIDEN | BOSTON 
This is an open access title distributed under the terms of the CC-BY-NC License, which O P $N$ permits any non-commercial use, distribution, and reproduction in any medium, provided the original author(s) and source are credited.

Létape de la prépresse de cette publication a été soutenue par le Fonds national suisse de la recherche scientifique.

The pre-press stage of this publication was supported by the Swiss National Science Foundation.

Illustration de couverture : Vaticanus Arabicus 13, folio 103r. (c) 2018 Biblioteca Apostolica Vaticana.

Reproduced by permission of Biblioteca Apostolica Vaticana, with all rights reserved.

Library of Congress Cataloging-in-Publication Data

Names: Schulthess, Sara, author.

Title: Les manuscrits arabes des lettres de Paul : etat de la question et etude de cas (1 Corinthiens dans le vat. ar. 13) / par Sara Schulthess.

Description: Leiden ; Boston : Brill, [2018] | Series: Biblia arabica, ISSN 2213-6401; volume 6 | Revision of author's thesis (Ph. D.)—Radboud Universiteit a Nimegue, 2016. Includes bibliographical references and index.

Identifiers: LCCN 2018039474 (print) | LCCN 2018045553 (ebook) | ISBN 9789004378162 (E-Book) | ISBN 9789004377677 (hardback : alk. paper)

Subjects: LCSH: Bible. Epistles of Paul. Arabic—Bibliography. | Bible. Epistles of Paul. Arabic—Criticism, Textual. | Bible. Epistles of Paul—Translating. | Libraries—Special collections_-Manuscripts—Bibliography. | Manuscripts, Arabic_Bibliography. | Bible. Corinthians, 1st.—Manuscripts, Arabic. | Biblioteca apostolica vaticana. Manuscript. Vat. Ar. 13.

Classification: LCC Z7772.P1 (ebook) | LCC Z7772.P1 S38 2018 (print)| DDC 016.227/046-dc23

LC record available at https://lccn.loc.gov/2018039474

Typeface for the Latin, Greek, and Cyrillic scripts: “Brill”. See and download: brill.com/brill-typeface.

ISSN 2213-6401

ISBN 978-90-04-37767-7 (hardback)

ISBN 978-90-04-37816-2 (e-book)

Copyright 2019 by Sara Schulthess

This work is published by Koninklijke Brill NV. Koninklijke Brill NV incorporates the imprints Brill, Brill Hes \& De Graaf, Brill Nijhoff, Brill Rodopi, Brill Sense, Hotei Publishing, mentis Verlag, Verlag Ferdinand Schöningh and Wilhelm Fink Verlag. Koninklijke Brill NV reserves the right to protect the publication against unauthorized use and to authorize dissemination by means of offprints, legitimate photocopies, microform editions, reprints, translations, and secondary information sources, such as abstracting and indexing services including databases. Requests for commercial re-use, use of parts of the publication, and/or translations must be addressed to Koninklijke Brill Nv.

Brill has made all reasonable efforts to trace all rights holders to any copyrighted material used in this work. In cases where these efforts have not been successful the publisher welcomes communications from copyright holders, so that the appropriate acknowledgements can be made in future editions, and to settle other permission matters.

This book is printed on acid-free paper and produced in a sustainable manner. 


\section{Table des matières}

Remerciements IX

Liste des figures $\mathrm{XI}$

1 Introduction 1

1 Problématique et objectifs 1

2 Remarques épistémologiques 4

\section{PREMIÈRE PARTIE}

Les manuscrits arabes du Nouveau Testament dans la recherche contemporaine

2 État de la recherche 15

1 Les premières éditions 15

$2 \quad$ Le $19^{\mathrm{e}} \mathrm{s}$. : d'une Vorlage latine à la complexité des nombreuses familles 16

3 Le début du $20^{\mathrm{e}}$ s. : une traduction préislamique? 20

$4 \quad$ La contribution de Georg Graf (1944) 23

5 De Vööbus (1954) à Griffith (1983) : remise en question de l'existence préislamique de traductions 24

6 Les années 1990-2000: séries d'articles 27

7 Hikmat Kashouh (2012): une monographie attendue 30

8 Un nombre de publications croissant (2012-2017) 31

$9 \quad$ Les lettres de Paul, parent pauvre de la recherche 33

3 Du désintérêt à la redécouverte : analyse d'un phénomène scientifique 37

1 La critique textuelle du Nouveau Testament se détourne des manuscrits arabes 37

2 Un mépris aux racines « orientalistes »? 41

3 Évolution de la critique textuelle du Nouveau Testament et reprise du champ 46

4 L'existence de traductions préislamiques, un point de vue minoritaire $\quad 5^{1}$

$5 \quad$ Enjeux interculturels et interreligieux : Internet $\quad 5^{6}$

6 Vers quelle recherche? Hybridité/porosité entre les discours 64 


\section{DEUXIÈME PARTIE}

\section{Les manuscrits arabes des lettres de Paul}

4 Répertoire des manuscrits arabes des lettres de Paul 71

1 Introduction 71

$2 \quad$ Berlin, Staatsbibliothek 76

3 Beyrouth, Bibliothèque orientale 77

4 Bzommar, Bibliothèque du Couvent de Bzommar (Liban) $\quad 78$

5 Caire, Franciscan Center of Christian Oriental Studies 78

6 Caire, Musée copte 79

7 Caire, Patriarcat copte catholique 83

8 Caire, Patriarcat copte orthodoxe 84

9 Caire, Bibliothèque du Monastère Mar Menas 98

10 Cambridge, University Library 98

11 Charfeh, Bibliothèque patriarcale du monastère syro-catholique de Charfeh 100

12 Copenhague, Det Kongelige Bibliothek 101

13 Damas, Bibliothèque du Patriarcat syrien orthodoxe à Homs 102

14 Deir al-Muharraq, Monastère copte 102

15 Diyarbakir, Eglise syriaque orthodoxe Meryem Ana 102

16 Dublin, Trinity College Library 104

17 Duluth, University of Minnesota, Kathryn A. Martin Library, The Ramseyer-Northern Bible Society Collection 104

18 Escorial, Real Biblioteca de San Lorenzo de El Escorial 104

19 Florence, Biblioteca Medicea Laurenziana 105

20 Göttingen, Staats- und Universitätsbibliothek 106

21 Groningen, Universiteitsbibliotheek 107

22 Halle, Archiv der Franckeschen Stiftungen 107

23 Hambourg, Staats- und Universitätsbibliothek 107

24 Jérusalem, Bibliothèque du Monastère grec au Saint-Sépulcre 108

25 Jérusalem, Bibliothèque du Monastère Saint-Marc 108

26 Leiden, Universiteitsbibliotheek 108

27 Leipzig, Universitätsbibliothek 110

28 Londres, British Library 110

29 Londres, Library of the School of Oriental and African Studies 113

30 Madrid, Biblioteca Nacional 114

31 Manchester, John Rylands Library 115

$3^{2}$ Mardin, Bibliothèque de l'Archevêque chaldéen 115 
33 Milan, Biblioteca Ambrosiana 115

34 Modène, Biblioteca Estense 116

35 Mor Mattay, Bibliothèque du Monastère syriaque orthodoxe 116

36 Mossul, Frères dominicains à Mossul 117

37 Naples, Biblioteca Nazionale Vittorio Emanuele III 117

38 Oxford, Bodleian Library 117

39 Oxford, Queen's College Library 120

40 Paris, Bibliothèque Nationale de France 120

41 Princeton, University Library 124

42 Saint-Pétersbourg, Bibliothèque nationale de Russie 125

43 Saint-Pétersbourg, Institute of Oriental Manuscripts of the Russian Academy of Sciences 126

44 Sinaï, Monastère Sainte-Catherine 127

45 Vatican, Biblioteca Apostolica Vaticana 131

46 Venise, Biblioteca Nazionale Marciana 137

47 Wolfenbüttel, Herzog August Bibliothek 138

48 Manuscrits mentionnés par Graf dont nous n'avons pas retrouvé la trace ou dont nous n'avons pu consulter le catalogue $\quad 139$

5 Observations 140

1 Introduction 140

2 Bibliothèques 141

3 Dates 142

$4 \quad$ Contenu des manuscrits 151

$5 \quad$ Vorlagen selon Graf $\quad 156$

6 Manuscrits karshounis et manuscrits bilingues 159

7 Matériel 160

8 Copistes et scriptoria 160

9 Conclusion 162

\section{TROISIÈME PARTIE}

\section{La première lettre aux Corinthiens dans le Vat. Ar. 13}

6 Introduction au Vat. Ar. $13 \quad 165$
$1 \quad$ Introduction 165
$2 \quad$ État de la recherche sur le Vat. Ar. $13 \quad 166$
3 Description du manuscrit Vat. Ar. $13 \quad 176$ 
7 Édition de 1 Corinthiens dans le Vat. Ar. 13197

1 Remarques introductives concernant l'édition et ses standards 197

2 Choix d'édition : texte diplomatique 202

3 Édition digitale 203

$4 \quad 1$ Corinthiens dans le Vat. Ar. $13 \quad 207$

8 Commentaire et analyse de 1 Corinthiens dans le Vat. Ar. 13240

1 Commentaire verset par verset 240

2 Moyen arabe 449

3 Affinités textuelles $45^{8}$

4 Lexique 472

5 Conclusions 480

9 Identité(s) dans 1 Corinthiens dans le Vat. Ar. $13 \quad 485$

1 Lire une traduction: enjeux 485

2 Qui sont les ḥunafẳ dans 1 Corinthiens? 490

3 Pistes conclusives 502

Conclusion $\quad 504$

Bibliographie 509

$1 \quad$ Références du répertoire (chapitre 4) 509

2 Outils (avec les abréviations pour le chapitre 8) 517

3 Littérature secondaire 519

Annexe 540

Index des manuscrits arabes 541

Index des sources 544

Index des sujets et des noms 548 


\section{Remerciements}

Cet ouvrage est une version révisée de ma thèse de doctorat «Les manuscrits arabes des lettres de Paul. La reprise d'un champ de recherche négligé », défendue en septembre 2016 à la Radboud Universiteit à Nimègue. Elle est le fruit d'un travail de recherche mené dans le cadre du projet du Fonds national suisse de la recherche scientifique éponyme (FNS 143810). Je tiens à exprimer ma profonde reconnaissance à Claire Clivaz qui a dirigé le projet de ses débuts jusqu'à l'étape finale, l'achèvement de la thèse. Ce fut une belle aventure, riche en partage de connaissances et en émotions, et je suis très fière de cette collaboration fructueuse : qu'elle soit remerciée de l'avoir rendue possible.

Je remercie chaleureusement mon directeur de thèse à l'Université de Lausanne et co-directeur du projet, David Bouvier, et mon directeur de thèse à la Radboud University Nijmegen, Herman Teule, pour leur confiance, leur soutien et leur lecture de mon travail ; ils ont rendu cette cotutelle possible et efficace. Merci particulièrement à Herman Teule pour son accueil à Nimègue et pour nos longues sessions de travail au $17^{\mathrm{e}}$ étage de l'Erasmusgebouw. Je remercie également l'Institute of Eastern Christian Studies (IVOC) et ses collaborateurs pour leur accueil chaleureux au sein de l'institut.

Mes remerciements vont aussi au Swiss Institute of Bioinformatics, particulièrement à Vital-IT et à son directeur Ioannis Xennarios, pour leur accueil et leur soutien ainsi que pour les ressources informatiques du projet d'édition digitale Tarsian. Un grand merci à Martial Sankar pour sa précieuse collaboration.

Je tiens à remercier particulièrement mon collègue et ami Fabrice Vust pour sa relecture et pour les longues heures passées à discuter des détails de langue ; je suis heureuse d'avoir pu profiter de sa passion et de sa connaissance des langues orientales. Je remercie également Monia Touati Sarraj, qui nous accompagnés dans ce travail de relecture.

Merci à tous les collègues qui m'ont d'une manière ou d'une autre, soutenue dans mon parcours. Je mentionnerai ici : Samir Arbache et Heleen Murrevan Berg pour leur participation au jury de thèse et les précieuses discussions que nous avons eues, le comité éditorial de Biblia Arabica pour leur aide et leurs remarques, Hikmat Kashouh pour son initiation à la lecture des manuscrits arabes du Nouveau Testament, Elie Dannaoui pour tous nos échanges, à Balamand ou ailleurs, les chercheurs rencontrés à l'Université Saint-Joseph et tous ceux qui ont rendu mon séjour agréable à Beyrouth, Giuliano Lancioni pour nos discussions informatiques et son accueil à Rome, les doctorants du 
groupe DH-Lausanne, l'Institut romand des sciences bibliques et ses membres, particulièrement Albert Frey et Apolline Thromas.

Je remercie mes parents et mes sœurs, pour leur présence, toujours.

Je remercie mes amis à Neuchâtel und meine Freunde in Tübingen, besonders Dani für ihre Hilfe.

Enfin, je remercie Niklas : wir haben es geschafft! 


\section{Figures}

$1 \quad$ Marc 1,1 dans le codex Sinaïticus sur le site Sheek-3arb $\quad 5^{8}$

$2 \quad$ Recherche sur Google Images 59

3 Matthieu 18,11 dans un manuscrit arabe du Sinaï sur le site Sheek-3arb 60

4 Sin. Ar. 75 (Jean 1,1) sur le site Alta3b 63

5 Page de couverture de l'index du codex Vaticanus, par Sheek-3arb 66

$6 \quad$ Nombre de manuscrits par siècle 143

$7 \quad$ Nombre de manuscrits datés par siècle 143

8 Nombre de AGM par siècle, par Hikmat Kashouh $\quad 146$

$9 \quad$ Nombre de manuscrits selon l'ordre des corpus 151

10 Nombre de manuscrits selon la place de Hébreux 154

11 Nombre de manuscrits selon les Vorlagen de Graf $\quad 158$

12 Capture d'écran : Texte diplomatique et texte standardisé 205

13 Capture d'écran: Traduction et texte diplomatique 205 
Sara Schulthess - 978-90-04-37816-2 Downloaded from Brill.come4/26/2023 10:02:45AM via free access 


\section{Introduction}

\section{Problématique et objectifs}

Les conquêtes arabo-musulmanes entreprises depuis la moitié du $7^{\mathrm{e}} \mathrm{s}$. constituent un événement historique majeur. Elles ont bien sûr eu des aspects militaires, politiques et religieux, mais aussi des effets linguistiques. Avec l'arrivée de la langue arabe, les chrétiens en Irak, Syrie-Palestine, Égypte et au Maghreb commencèrent à utiliser cette langue dans les différentes sphères de la vie courante, en parallèle ou au détriment des langues installées telles que le syriaque, le grec, le copte et le latin. Les chrétiens commencèrent à traduire leurs Écritures probablement autour du $8^{\mathrm{e}} \mathrm{s}$. ; s'il est certain que des chrétiens étaient établis dans la Péninsule arabique avant les débuts de l'Islam, la question de savoir s'il existait des traductions écrites préislamiques reste débattue et n'est pour l'instant pas soutenue par les données documentaires. Les manuscrits les plus anciens dont nous ayons connaissance datent du $9^{\mathrm{e}} \mathrm{s}$. et les traductions qu'ils contiennent sont certainement le résultat de l'arabisation progressive des communautés melkites (ou grecques orthodoxes). Le monastère orthodoxe de Sainte-Catherine au Sinaï a conservé plusieurs de ces témoins les plus anciens. Ce travail de traduction se poursuivit sur plusieurs siècle dans le milieu melkite. Si les chrétiens syriaques orientaux et occidentaux continuèrent à utiliser le syriaque comme langue commune et comme langue liturgique, ils furent aussi acteurs de ce mouvement de traduction. Il existe notamment de nombreux manuscrits en karshouni - c'est-à-dire en langue arabe écrite en caractères syriaques, système d'écriture principalement utilisé par les communautés syriaques orientales. On rappellera aussi que la fameuse harmonie évangélique de Tatien, le Diatessaron, a été préservée dans son entièreté en arabe, traduite du syriaque par le «nestorien » Abū l-Farağ 'Abdallāh ibn aț-Tayyib ( $11^{\mathrm{e}} \mathrm{s}$.). De son côté, l'Église copte adopta l'arabe au détriment de la langue copte qui ne fut plus, à l'exception de son rôle liturgique, utilisée à partir du $11^{\mathrm{e}} \mathrm{s}$. environ. Au $13^{\mathrm{e}} \mathrm{s}$., le savant Abū l-Farağ al-As'ad Ibn al-Assāl produisit une recension des évangiles; cette recension fut rapidement remplacée par une autre recension éclectique, appelée «Vulgate alexandrine » ou «Vulgate égyptienne ». Si l'origine égyptienne de cette dernière est incertaine, elle devint très populaire parmi les Coptes mais aussi dans les autres communautés syriaques. Elle remplacera progressivement les autres versions arabes à partir de la fin du $13^{\mathrm{e}} \mathrm{s}$. Du côté d'al-Andalus, les

(C) SARA SCHULTHESS, 2019 | DOI:10.1163/9789004378162_002

This is an open access chapter distributed under the terms of the prevailing CC-BY-NC License at the time of publication. 
chrétiens arabisés commencèrent aussi rapidement à traduire en arabe les livres bibliques, comme le montre un fragment bilingue latin-arabe de la lettre aux Galates datant du $9^{\mathrm{e}}$ s. (Vat. Lat. 12900). Les traductions en arabe de la Bible hébraïque dans les communautés juives arabisées ont poursuivi une histoire similaire. Malgré des particularités, comme l'importance du judéo-arabe, il ne s'agit pas d'un phénomène indépendant. La traduction et le commentaire du Pentateuque de Sacadya Gaon (882-942), par exemple, a connu un large écho dans les communautés chrétiennes syriaques et coptes.

Les traductions arabes du Nouveau Testament établies sur plusieurs siècles au sein des communautés chrétiennes diverses ont été préservées dans des centaines de manuscrits. On a souvent classé ces manuscrits selon leur supposée Vorlage grecque, syriaque, copte ou latine. Cette démarche a ses limites : les recherches récentes manifestent des processus de traduction et de transmission compliqués. Les versions arabes attestent des influences mutuelles des langues et des traditions et sont le fruit du multilinguisme des chrétiens orientaux. Le grand nombre de manuscrits, la variété des traductions et l'histoire des transmissions font de la Bible en arabe un champ d'études riche et complexe. Et de plus peu explorées jusqu'ici : comme le dit Sidney H. Griffith : « The study of the Bible in Arabic is in its infancy. $»^{2}$ Après une dynamique initiale assez forte aux $17^{\mathrm{e}}-18^{\mathrm{e}} \mathrm{s}$., la recherche occidentale s'est rapidement détournée des manuscrits arabes du Nouveau Testament et de la Bible hébraïque. À ce phénomène s'ajoute, dans le cas du Nouveau Testament, le fait que la majorité des travaux se sont concentrés sur les traductions des évangiles, laissant peu de place à d'autres corpus néotestamentaires, comme celui des lettres de Paul. On remarque toutefois depuis quelques années un regain de l'intérêt pour les manuscrits de la Bible en arabe, avec plusieurs recherches significatives concernant les évangiles. Ce travail s'inscrit dans ce courant, avec l'ambition d'étendre la recherche au champ des manuscrits arabes des lettres de Paul.

Notre recherche sur les manuscrits arabes des lettres de Paul et sur le manuscrit Vat. Ar. 13 suit deux mouvements complémentaires: le premier consiste à comprendre le peu d'intérêt montré jusqu'à présent pour ce champ de recherche et à participer au renouveau de celui-ci; le second consiste à devenir acteur de la reprise de ce champ de recherche, en passant d'une analyse générale à l'étude d'un sujet particulier.

1 Vollandt Ronny, Arabic Versions of the Pentateuch. A Comparative Study of Jewish, Christian, and Muslim Sources, Leiden, Brill, 2015 (Biblia Arabica 2), p. 1.

2 Griffith Sidney H., The Bible in Arabic. The Scriptures of the "People of the Book» in the Language of Islam, Princeton, Princeton University Press, 2013, p. 1. 
Dans la première partie Les manuscrits arabes du Nouveau Testament dans la recherche contemporaine, nous cherchons donc à comprendre pourquoi la recherche, et particulièrement la critique textuelle du Nouveau Testament, s'est désintéressée de l'étude des manuscrits arabes du Nouveau Testament et nous constatons puis analysons le renouveau qui s'est installé depuis quelques années, notamment avec la publication de la monographie d'Hikmat Kashouh $^{3}$. Cette première partie nécessite un état de la recherche précis, établi au chapitre 2. Il est suivi d'une analyse qui met en avant les différents enjeux traversants au chapitre 3 .

Dans la deuxième partie Les manuscrits arabes des lettres de Paul, nous établissons un répertoire des manuscrits des lettres de Paul, une étape nécessaire dans la reprise de la recherche. Les lettres de Paul en arabe représentent un corpus dont la transmission a été jusqu'à aujourd'hui peu étudiée, en comparaison du corpus des évangiles. Le répertoire (chapitre 4) est suivi d'une série d'observations sur la base des données qui ont pu être récoltées (chapitre 5). Ces observations permettent de circonscrire un champ nouveau et d'esquisser de nouvelles directions pour la recherche.

Dans la troisième partie La première lettre aux Corinthiens dans Vat. Ar. 13, nous étudions un manuscrit en particulier, le Vat. Ar. 13, en nous concentrant sur une lettre de Paul, la première lettre aux Corinthiens. Nous proposons un état de la question concernant le manuscrit Vat. Ar. 13 ; une description précise du manuscrit permet notamment de proposer une chronologie possible de sa composition (chapitre 6). Dans le chapitre 7, nous éditons 1 Corinthiens; nous discutons préalablement les différentes méthodes d'édition pour les manuscrits arabes et le manque de standards pour le moyen arabe afin d'établir les critères pour notre édition. Dansle chapitre 8 , nous proposons un commentaire philologique et linguistique, d'abord verset par verset, avec traduction, puis revenons sur certains aspects textuels qui nous semblent importants. Enfin, le chapitre 9 se concentre sur la problématique de l'identité dans 1 Corinthiens et propose un essai d'exégèse du texte du Vat. Ar. 13 selon une approche d'histoire des lectures.

De nombreux points méthodologiques propres aux différents chapitres seront traités dans le corps de la thèse. Nous proposons ici quelques réflexions épistémologiques générales qui nous ont accompagnés durant le travail de recherche, notamment dans l'établissement des trois axes principaux de recherche, reflétés dans les trois parties présentées ci-dessus.

3 Kashoun Hikmat, The Arabic Versions of the Gospels, The Manuscripts and their Families, Berlin, Boston, De Gruyter, 2012 (Arbeiten zur neutestamentlichen Textforschung 42). 


\section{Remarques épistémologiques}

\subsection{La conscience du contexte de la recherche}

Dans la première partie Les manuscrits arabes du Nouveau Testament dans la recherche contemporaine, nous commençons par établir un état de la recherche le plus complet possible; on notera que plusieurs chercheurs ont déjà proposé des états de la recherche 4 et nous pouvons aussi nous appuyer sur des bibliographies spécifiques ${ }^{5}$. Notre état de la recherche a surtout pour but de mettre en évidence les évolutions et les directions prises par la recherche, afin de pouvoir déterminer les raisons sous-jacentes de celles-ci, c'est-à-dire ce mouvement allant de l'intérêt au désintérêt, qui a marqué le $20^{\mathrm{e}} \mathrm{s}$., puis à la reprise de cet intérêt depuis quelques années. C'est donc également une analyse de ce phénomène que nous essayons d'offrir. Nous devons beaucoup aux travaux d'Edward Said, qui nous ont aidé, lorsque nous avons commencé à nous intéresser au champ des manuscrits arabes du Nouveau Testament, à prendre conscience de l'ethnocentrisme des productions du monde académique dans lequel nous évoluons. Cela nous a poussé à nous intéresser à la critique post-coloniale. Il est à notre avis impossible de ne pas considérer la problématique de l'orientalisme tel que développée par Said ainsi que l'aspect (post-)colonial ${ }^{6}$ dans l'évolution de ce champ de recherche et nous tentons de le prendre en compte dans notre analyse. Nous tenons ici à préciser que nous avons conscience d'appartenir à ce même monde scientifique occidental, objet des critiques post-coloniales, que nous pouvons décrire comme privilégié.

Lapport de Said puis des post-colonial studies dans nos réflexions nous a également mené à une prise de conscience générale de l'importance des facteurs

4 Voir l'état de la recherche sur les évangiles arabes de Kashouh: Ibid., pp. 9-38. Voir aussi l'excellente introduction à la recherche sur les manuscrits arabes de la Bible de Ronny Vollandt: Vollandt, Arabic Versions of the Pentateuch. A Comparative Study of Jewish, Christian, and Muslim Sources, op. cit., 2015, pp. 3-21.

5 Nous remercions Adam McCollum de nous avoir fait parvenir sa bibliographie très complète sur la Bible en arabe ( «A Classified Bibliography of the Arabic Bible»), en attente de publication. Voir aussi Esbroeck Michel van, «Les versions orientales de la Bible : une orientation bibliographique », in : KRAšOvec Jože (éd.), The Interpretation of the Bible : the International Symposium in Slovenia, Sheffield, Sheffield Academic Press, 1998 (Journal for the study of the Old Testament 289), pp. 399-509.

6 Le terme post-colonial n'est pas utilisé pour signifier que notre époque a dépassé le colonialisme. Comme l'explique Anna Runesson: «[...] a colonisation may extend beyond the use of military force and focus on other factors that keep a country bound to the hegemonic centre. For example, the expansion of multinational companies, export of a specific lifestyle, Western academic epistemology [...]» Runesson Anna, Exegesis in the Making: Postcolonialism and New Testament Studies, Leiden, Boston, Brill, 2010, p. 23. 
sociologiques sur les champs de recherche, phénomène étudié par la sociologie de la connaissance ${ }^{7}$. Certaines disciplines universitaires sont plus sensibilisées que d'autres à cette problématique, le laboratoire ayant été par exemple régulièrement objet d'études sociologiques ${ }^{8}$. Une sensibilité à ces questions nous semble peu présente dans les disciplines théologiques ${ }^{9}$, et ce particulièrement dans le champ de la critique textuelle du Nouveau Testament.

En affirmant leur souhait de renouveler le champ de la sociologie de la connaissance, Ann Swidler et Jorge Arditi mentionnaient en 1994 déjà la nécessité de prendre en compte différentes sortes de discours:

The new sociology of knowledge [...] examines political and religious ideologies as well as science and everyday life, cultural and organizational discourses along with formal and informal types of knowledge. It also expands the field of study from an examination of the contents of knowledge to the investigation of forms and practices of knowing ${ }^{10}$.

Bien plus qu'en 1994, il nous semble qu'une certaine porosité entre les divers milieux est un des aspects déterminant de notre époque pour la sociologie de la connaissance, porosité notamment entre le discours académique et non académique, ou encore entre «Occident» et «Orient»"11, grandement due à la démocratisation du World Wide Web. Cette porosité concerne aussi

Busıno Giovanni, «Matériaux pour l'histoire de la sociologie de la connaissance », Revue européenne des sciences sociales [En ligne] XLV (139), 2007. En ligne: $<$ http://ress.revues .org/187>, consulté le 26.02.2016, § 28.

8 Voir l'historique de la sociologie de la connaissance par LAMPE Peter, New Testament Theology in a Secular World: A Constructivist Work in Philosophical Epistemology and Christian Apologetics, Londres, New York, T\&T Clark, 2012, pp. 45-48, et sa note 8, p. 46. Le laboratoire fut aussi le terrain de Bruno Latour, qui a développé la théorie de l' «acteurréseau» en sociologie de la connaissance. Voir par exemple, Latour Bruno, La Vie de laboratoire. La production des faits scientifiques, Paris, La Découverte, 1988.

9 Dans l'ouvrage que nous citons à la note précédente, Peter Lampe problématise la question de la réalité en théologie en discutant l'apport de la sociologie de la connaissance; il applique cette approche aux écrits du début du christianisme. Nous pensons ici à une application aux productions académiques contemporaines.

10 Swidler Ann et Arditi Jorge, «The New Sociology of Knowledge», Annual Review of Sociology 20, 1994, p. 305.

11 Nous utilisons «Occident» et «Orient» dans son sens géo-politique, le second étant en situation post-coloniale et néo-coloniale (voir note 6) par rapport au premier. L'« Occident » englobe l'Europe et les États-Unis et l'« Orient» désigne, dans ce travail, principalement le Proche- et le Moyen-Orient, terre d'origine des chrétiens dits orientaux. Nous restons consciente des dangers d'essentialiser l'un et l'autre de ces ensembles et des écueils méthodologiques qu'ils représentent. Létude des chrétiens «mozarabes » et de leur tradition, peu abordée dans ce travail, le démontre. 
nos disciplines. Suite à la prise de conscience de l'influence des nouvelles technologies sur le monde académique et à l'émergence du champ des humanités digitales, les frontières entre sciences sociales et sciences humaines se floutent, car il est devenu nécessaire de travailler à l'aide des outils des sciences sociales. Ces évolutions épistémologiques doivent être prises en compte dans la recherche; nous tentons de le faire, en intégrant dans notre analyse les discours non académiques que l'on trouve en ligne et en introduisant notamment la notion d'hybridité ${ }^{12}$. Ces observations nous confortent également dans la nécessité d'une recherche présente sur Internet, comme nous avons tenté de le faire avec le développement d'une édition digitale (voir aussi ci-dessous).

\section{2 $\quad$ Listes et distant reading}

Dans la deuxième partie Les manuscrits arabes des lettres de Paul, nous avons décidé de nous concentrer sur les manuscrits arabes des lettres de Paul, un corpus encore peu traité lorsque nous avons commencé à délimiter le projet de recherche. Une liste des manuscrits est une étape nécessaire pour ce champ à peine exploré. Dans son ouvrage Vertige de la Liste, Umberto Eco note que «l'énumération serait typique des cultures primitives qui ont encore une image imprécise de l'univers et se limitent à en aligner les nombreuses propriétés qu'elles savent nommer sans tenter d'instaurer entre elles un rapport hiérarchique $[\ldots] .{ }^{13}{ }^{13}$ 'il nuance son propos en notant que la liste réapparaît à toutes les époques, nous pouvons reprendre à notre compte cette remarque à propos du «monde» encore inconnu des manuscrits arabes des lettres de Paul ${ }^{14}$. Claire Clivaz, dans sa lecture de Eco, souligne également le caractère stimulant de la liste pour la science : «I consider that this 'listing effect' allowed Western knowledge to reintroduce imagination into knowledge. $»^{15}$ Cette approche de la liste est proche de la notion de distant reading ${ }^{16}$ développée par Franco Moretti. Moretti utilise le concept de distant reading, «lecture à distance », pour l'histoire et la critique littéraire : il s'agit d'étudier un corpus

12 Ces aspects, notamment les concepts de porosité et hybridité, sont discutés au chapitre 3, point 6 Vers quelle recherche? Hybridité/porosité entre les discours.

13 Eco Umberto, Vertige de la liste, Paris, Flammarion, 2009, p. 18.

14 Vollandt utilise l'expression «terra almost incognita» dans son travail sur le Pentateuque en arabe, une expression qu'il reprend de Bengt Knutsson, Volland, Arabic Versions of the Pentateuch. A Comparative Study of Jewish, Christian, and Muslim Sources, op. cit., 2015, p. IX. et la note 1.

15 Clivaz Claire, «Common Era 2.0. Reading Digital Culture from Antiquity and Modernity», in: Clivaz Claire, Meizoz Jérôme, Vallotton François et al. (éds), Reading Tomorrow. From Ancient Manuscripts to the Digital Era / Lire Demain. Des manuscrits antiques à l'ère digitale, ebook, Lausanne, PPUR, 2012, p. 45.

16 Moretri Franco, Distant Reading, Londres, New York, Verso, 2013. 
dans son ensemble, en s'éloignant du texte particulier - jusqu'à ne plus lire le texte! - et en privilégiant l'approche quantitative. Moretti résume ainsi son propos les données quantitatives:

Je commençais ce chapitre en disant que les données quantitatives étaient utiles parce qu'elles étaient indépendantes de l'interprétation; puis qu'elles étaient stimulantes parce qu'elles exigeaient souvent une interprétation qui transcende le domaine du quantitatif; ici, de manière plus radicale, nous les voyons réfuter des explications théoriques existantes $[\ldots]^{17}$.

Nous nous rallions à la liste et au distant reading quant à leur aspect stimulant ; notre utilisation des données des manuscrits des lettres de Paul ne nous a pas aidé à réfuter des théories existantes, mais celles-ci permettent de rattacher l'histoire de la diffusion des manuscrits à des éléments historiques connus et de comprendre les évolutions et les développements dans le domaine. Nous restons toutefois convaincus de la nécessité d'allier la distant reading à une close reading (c'est-à-dire l'étude du texte particulier), d'utiliser ces deux perspectives en dynamique. Moretti est lui-même conscient des difficultés de faire fonctionner l'un sans l'autre, lorsqu'il dit à la fin de Graphes, cartes et arbres : «Les modèles que j'ai présentés partagent aussi une préférence nette pour l'explication sur l'interprétation ; ou peut-être, pour le dire mieux, l'explication des structures générales sur l'interprétation des textes singuliers. Cette distinction constitue elle-même une question majeure [...]. ${ }^{18}$ Ou encore, comme le dit Aurélien Berra à propos de l'édition de textes anciens :

L'interprétation et la quantification ne sont pas opposées, bien au contraire, et il est important de les réconcilier. Un éditeur de textes anciens a conscience, plus que d'autres peut-être, de l'opération de transfert linguistique et culturel qu'il accomplit sans cesse ${ }^{19}$.

17 Moretti Franco, Graphes, cartes et arbres. Modèles abstraits pour une autre histoire de la littérature, Paris, Les prairies ordinaires, 2008, p. 64.

18 Ibid., p. 126.

19 BERRA Aurélien, «Faire des humanités numériques», in : Read/Write Book 2: Une introduction aux humanités numériques [en ligne], Marseille, OpenEdition Press, 2012. En ligne: <http://books.openedition.org/oep/238>, consulté le 07.03.2016, § 41. 


\subsection{Létude du manuscrit et de son texte en close reading \\ 2.3.1 Édition d'un manuscrit unique}

Nous restons ainsi convaincue de la nécessité de l'approche close reading en sciences humaines, qui s'ajoute à celle de renouvellement au sein du champ de la critique textuelle du Nouveau Testament. Nous décelons une certaine tension dans la discipline : il s'agit effectivement d'une approche extrêmement précise mais qui traite d'un très grand nombre de témoins textuels. L'accumulation des données peut mettre à mal la reconnaissance de l'individualité de chaque témoin ${ }^{20}$. Les productions de la critique textuelle du Nouveau Testament, que cela soit par exemple l'édition critique de référence du Nestle-Aland (NA28) ${ }^{21}$ ou son «concurrent» américain $S B L$ Greek New Testament ${ }^{22}$, dans leur recherche d'un Urtext, favorisent la méthode éclectique tout en privilégiant une famille de textes, la famille alexandrine, avec une conséquence double: premièrement, le lecteur/chercheur/étudiant lit et travaille avec un texte fictif, un texte qui n'a jamais existé dans un manuscrit; deuxièmement, certains représentants du texte du Nouveau Testament sont « défavorisés » comparés à d'autres. Ces problèmes sont discutés notamment par l'école de la narrative textual criticism, que nous abordons au chapitre 3. Du désintérêt à la redécouverte: analyse d'un phénomène scientifique.

Se pose alors la question: comment éviter ses écueils lors de l'édition? Dans son article « Pourquoi éditer un manuscrit unique ? L'édition critique des écrits apocryphes: de l'arbre au mycélium », Charlotte Touati développe une critique de l'approche généalogique et de ses arbres dans l'édition des écrits apocryphes, une critique qui s'applique à notre avis également au Nouveau Testament et à ses éditions :

20 Le rôle joué par l'informatique dans la discipline oscille aussi entre ces deux aspects. Elle permet de traiter un nombre encore plus important de manuscrits, venant soutenir la collation de manuscrits depuis de nombreuses années. Voir l'état de la recherche de Robert A. Kraft en 1995 déjà (KrAft Robert A., « The Use of Computers in New Testament Textual Criticism», in : Ehrman Bart D. et Holmes Michael William (éds), The Text of the New Testament in Contemporary Research: Essays on the Status Quaestionis, Grand Rapids, Eerdmans Publishing, 1995 (Studies and Documents 46), pp. 268-282), et sa mention du programme Collate (aujourd'hui CollateX, <http://collatex.net>, consulté le 05.04.2016). D'un autre côté, David Parker explique en quoi l'utilisation d'outils informatiques l'a mené à reconsidérer l'individualité des manuscrits (PARKER David C., «Though a Screen Darkly: Digital Texts and the New Testament», in : PArker David C. Manuscripts, Texts, Theology: Collected Papers 1977-2007, Berlin, New York, de Gruyter, 2009 (Arbeiten zur neutestamentlichen Textforschung 40), pp. 287-303).

21 Nestle Eberhard et Nestle Erwin, Nestle-Aland Novum Testamentum Graece, 28 édition, Stuttgart, Deutsche Bibelgesellschaft, 2012.

22 Holmes Michael W., The Greek New Testament. sBL Edition, Atlanta, Washington, SBL/ Logos Bible Software, 2010. En ligne :<http://www.sblgnt.com>, consulté le 06.03.2016. 
Il n'y a pas de Urtext ni de manuscrit archétype, un point à partir duquel les copies auraient commencé d'altérer ce fameux Urtext. Chaque copie contribue à écrire le texte qui se trouve donc un peu dans chaque manuscrit, mais dans aucun en particulier. Dès lors, les copies ne procèdent pas en cascade les unes des autres à partir d'un exemplaire parfait (c'est pourtant bien le processus attendu avec un stemma arborescent orienté), mais s'inscrivent dans un continuum ${ }^{23}$.

Touati rejète donc l'image de l'arbre pour la transmission textuelle; encore davantage que l'image rhizome, développée par Deleuze et Guattari, c'est celle du mycélium qui correspond le mieux à la manière dont les textes sont transmis :

La métaphore est parfaitement applicable à la philologie : une tradition textuelle appartient à un complexe culturel (mycélium) et devient visible lorsqu'elle est couchée par écrit (champignon). [...] Avec le modèle du mycélium, on considère que l'entier du « texte » ne passe pas dans le manuscrit. L'objet de la soi-disant résurgence est simplement resté latent dans l'un ou l'autre des manuscrits et se manifeste dans d'autres. C'est la mémoire culturelle ${ }^{24}$.

Pour Touati, l'édition critique appartient à la culture imprimée et la méthode doit être redéfinie au vu des possibilités offertes par le digital. C'est une opinion partagée par Claire Clivaz à propos du Nouveau Testament : «[...] digital culture has the potential to redefine entirely the way of thinking about the editing of ancient texts, particularly texts supported by a large number of different manuscripts, as is the case with Homer and particularly the New Testament. ${ }^{25}$ La culture digitale permet également de redécouvrir le manuscrit comme document; Wido van Peursen l'explicite ainsi : « The 're-awakened interest in presence' is visible in the attention paid to texts as artefacts and the material aspects of the carriers of texts, which hardly receive any attention in traditional

23 Touati Charlotte, «Pourquoi éditer un manuscrit unique? L'édition critique des écrits apocryphes : de l'arbre au mycélium », 2013, p. 7. En ligne : <http://falashas.epfl.ch/data/ sources/textes/Manuscrit.pdf>, consulté le 29.02.2016.

24 Ibid., p. 11.

25 Clivaz Claire, «Homer and the New Testament as "Multitexts" in the Digital Age? », Scholarly Research Communication 3 (3), 2012, p. 2. En ligne: <http://www.src-online.ca/ index.php/src/article/view/97>, consulté le 09.02.2016. 
textual scholarship. ${ }^{26}$ Il s'agit donc d'un recentrement sur le manuscrit et son texte. Touati dit ainsi : «Une philologie vraiment nouvelle consiste à étudier un manuscrit per se ou en rapport avec d'autres, mais pour en faire ressortir l'originalité. ${ }^{27}$ L'approche du mycélium tel que développée par Touati nous semble particulièrement pertinente dans le cas du Nouveau Testament et de sa transmission en arabe ; il est clair que la complexité de celle-ci ne peut être réduite à un arbre, ni même à plusieurs. C'est dans cette perspective que nous faisons le choix d'éditer et d'étudier la première lettre aux Corinthiens telle que transmise dans le Vat. Ar. 13 dans la troisième partie La première lettre aux Corinthiens dans Vat. Ar. 13. Nous motivons le choix de ce manuscrit dans l'introduction de cette partie (chapitre 6 , point 1 ). Cette méthode correspond à notre volonté de close reading, étudiant un texte particulier dans un manuscrit particulier. Cette étape de notre approche se différencie donc, par exemple, de celle de Kashouh, qui opte pour une approche généalogique des manuscrits arabes des évangiles ${ }^{28}$. Certains nous questionneront alors peut-être sur l'approche très textuelle du commentaire et de l'analyse (voir chapitre 8. Commentaire et analyse de 1 Corinthiens dans Vat. Ar. 13). L'édition d'un manuscrit n'exclut par la comparaison avec d'autres textes, comme le dit Touati : «Le travail du philologue pourrait être désormais de rassembler des parallèles pour élaborer son commentaire ou sa traduction, sans pour autant toucher à sa source en fac-similé. ${ }^{29}$ Dans ce travail, nous portons une attention particulière aux traditions sources, grecques et syriaques (chapitre 8), et discutons également les rapports du Vat. Ar. 13 avec deux manuscrits contemporains (chapitre 8, point 3.1). De même, dans le futur, il sera bien sûr nécessaire de comparer ce travail détaillé sur le texte du Vat. Ar. 13 avec d'autres recherches similaires sur d'autres manuscrits.

Enfin, nous souhaitons participer au dépassement des méthodes d'édition telle que définie par la culture imprimée en proposant une édition digitale de 1 Corinthiens par le Vat. Ar. 13; il s'agit pour nous de poser une modeste

26 Peursen Wido van, «Text Comparison and Digital Creativity: An Introduction», in: Peursen Wido van, Thoutenhoofd Ernst et Weel Adriaan van der (éds), Text Comparison and Digital Creativity: The Production of Presence and Meaning in Digital Text Scholarship, Leiden, Boston, Brill, 2010 (Scholarly Communication 1), p. 6.

27 Touati, «Pourquoi éditer un manuscrit unique? Lédition critique des écrits apocryphes : de l'arbre au mycélium», art. cit., 2013, p. 9, note 12.

28 Kashoun, The Arabic Versions of the Gospels, The Manuscripts and their Families, op. cit., 2012, pp. 3-4, 304-325. Kashouh applique la philogénétique aux familles des manuscrits entre elles, mais pas aux manuscrits au sein des familles.

29 Touati, «Pourquoi éditer un manuscrit unique? Lédition critique des écrits apocryphes : de l'arbre au mycélium », art. cit., 2013, p. 9. 
première pierre pour les manuscrits arabes du Nouveau Testament, en espérant que d'autres ressources disponibles en ligne viendront s'ajouter à celle-ci.

\subsubsection{Histoire des lectures}

Éditer ce manuscrit tel qu'il est, c'est donner accès à une lecture du texte du Nouveau Testament et l'inscrire dans une histoire des lectures, où chacune de ses lectures à sa valeur propre ${ }^{30}$. Une histoire des lectures se pose en contrepoint d'une vision qui veut que les témoins textuels considérés comme inutiles pour la critique textuelle du Nouveau Testament, comme ce fut longtemps le cas pour les manuscrits arabes, tombent alors automatiquement dans la catégorie de l'« histoire de la réception ». Clivaz, dans sa thèse sur Luc 22,43-44 et sa traduction manuscrite, explique à ce propos :

Et je donne sans doute raison par mes choix méthodologiques à C. Kavin Rowe qui « prédit » que de plus en plus de chercheurs du Nouveau Testament vont s'intéresser à l'histoire de la réception, par «retour du même », et par la capacité de la réception du texte à renouveler les interprétations. Je m'inscris donc dans une génération de chercheurs prêts à lire les textes non seulement dans leur contexte de production, mais aussi de réception. À mes yeux, la prise au sérieux de la réception des textes conduit en ce qui concerne le Nouveau Testament à une prise de conscience qui s'inscrit pour moi dans «la modestie» de l'historien d'aujourd'hui : nous lisons des textes dont le support matériel ne remonte pas à la fin du deuxième siècle de notre ère. Autrement dit, nous étudions les textes du Nouveau Testament déjà lus, déjà reçus, déjà interprétés et modifiés, et non pas l'exemplaire tel que sorti de la plume des auteurs ${ }^{31}$.

Si même lorsque l'on travaille avec le texte grec du Nouveau Testament, on travaille déjà avec des textes « déjà lus, déjà reçus, déjà interprétés », peut-on faire la différence entre le texte du Nouveau Testament et sa réception? Clivaz

30 Quand nous utilisons « histoire des lectures », nous pensons history of readings, et non «histoire de la lecture », c'est-à-dire history of reading. Toutefois, la pratique n'est certainement pas à séparer de l'interprétation. Voir le volume Claire, Meizoz Jérôme, Vallotton François et al. (éds), Reading Tomorrow. From Ancient Manuscripts to the Digital Era / Lire Demain. Des manuscrits antiques à l'ère digitale, ebook, Lausanne, PPUR, 2012, notamment l'introduction « Reading Tomorrow : From Ancient Manuscripts to the Digital Era Reading Practices, Intellectual Exchanges and Scientific Communication ».

31 CLIVAz Claire, L'ange et la sueur de sang (Lc 22,43-44), ou comment on pourrait bien encore écrire l'histoire, Louvain, Paris, Walpole, Ma, Brepols, 2010 (Biblical Tools and Studies 7), p. 195 . 
défend une lecture «de ce que l'on a »; dans notre cas, nous avons un texte du Nouveau Testament « déjà traduit ${ }^{32}$. Et celui-ci mérite qu'on lui accorde la chance de pouvoir renouveler les interprétations. C'est donc un essai d'exégèse du texte du manuscrit Vat. Ar. 13 qui viendra clore notre thèse au chapitre 9 . Identité(s) dans 1 Corinthiens dans Vat. Ar. 13.

32 Nous discutons la question de la traduction et de ses définitions au chapitre 9, point 1 Lire une traduction: enjeux. 
PREMIÈRE PARTIE

Les manuscrits arabes du Nouveau Testament dans la recherche contemporaine 
Sara Schulthess - 978-90-04-37816-2 Downloaded from Brill.come4/26/2023 10:02:45AM via free access 


\section{État de la recherche}

\section{Les premières éditions}

Aux $16^{\mathrm{e}}$ et $17^{\mathrm{e}}$ s., un intérêt certain pour le Nouveau Testament en arabe mena à plusieurs éditions; nous discutons l'évolution de l'intérêt pour le corpus du Nouveau Testament en arabe au chapitre 3. Du désintérêt à la redécouverte: analyse d'un phénomène scientifique ${ }^{1}$. Nous énumérons rapidement ici ces premières éditions ${ }^{2}$. L'editio princeps des évangiles fut préparé par Giovanni Battista Raimundi et édité en 1590 par la Typografia Medicea ${ }^{3}$. En 1616, Thomas Erpenius édite le Nouveau Testament à partir du manuscrit Leiden Universiteitsbibliotheek Or. $217^{4}$. Une version du Nouveau Testament, aux côtés du grec, latin, syriaque, est éditée dans la Polyglotte de Paris (1628-1645) ${ }^{5}$; cette édition est reprise dans la Polyglotte de Londres (1654-1657) ${ }^{6}$. En 1671, la Congregatio de la Propaganda Fide édite une Bible arabe complète 7 .

1 Nous limitions, à quelques exceptions près, cet état de la recherche aux études sur les manuscrits arabes du Nouveau Testament et leurs textes continus; les études sur les citations du Nouveau Testament chez les auteurs musulmans ou chrétiens, l'utilisation liturgique ou encore les traductions modernes ne sont pas comprises dans cette recherche.

2 Voir Arbache Samir, «Les versions arabes des Évangiles», Mélanges de Science Religieuse 3, 1999, pp. 85-94. En ligne: <http://bdr.proxience.net/opac_css/index.php?lvl=notice display\&id=198619 > ; Metzger Bruce Manning, «The Arabic Versions », in: The Early Versions of the New Testament: Their Origin, Transmission and Limitations, Oxford, Clarendon Press, 1977, pp. 257-268.

3 Al-Ingîl al Muqaddas. Evangelium sanctum, Rome, Ex Typographia Medicæ, 1590-1591.

4 Novum Domini Nostri Jesu Christi Testamentum arabice, ex Bibliotheca Leidesi, éditée par Thomas Erpenius, Leiden, 1616. Nous notons ici que l'article Wikipédia «Thomas van Erpe » mentionne une première édition de deux lettres de Paul, Romains et Galates, datant de 1613 . Nous n'avons pas trouvé confirmation de celle-ci dans la littérature secondaire. Cf. <https:// fr.wikipedia.org/wiki/Thomas_van_Erpe>, consulté le 01.03.16.

5 Biblia hebraïca, samaritana, chaldaïca, grceca, syriaca, latina, arabica, quibus textus originales totius Scripturce Sacrce (...), éditée par Guy Michel Lejay, imprimée à Paris par Antoine Vitré, 1628-1645.

6 Biblia Sacra polyglotta, complectentia textus originales, hebraicum, cum Pentateucho samaritano, chaldaicum, graecum ; versionumque antiquarum, samaritanae, graecae LXXII interp., chaldaicae, syriacae, arabicae (...), Londres, imprimée par Thomas Roycroft, 1657.

7 Biblia sacra Arabica: Sacrae Congregationis de propaganda fide iussu edita ad usum Ecclesiarum Orientalium: Additis è regione Bibliis Latinis vulgatis, Rome, Sacra Congregatio de Propaganda Fide, 1671. Voir FÉG HALI Paul, « The Holy Books in Arabic: The Example of the Propaganda Fide Edition», in : Binay Sara et LEDER Stefan (éds), Translating the Bible into

(C) SARA SCHULTHESS, 2019 | DOI:10.1163/9789004378162_003

This is an open access chapter distributed under the terms of the prevailing CC-BY-NC License at the time of publication. 
Le $19^{\mathrm{e}} \mathrm{s.}$ : d'une Vorlage latine à la complexité des nombreuses familles

À partir du $19^{\mathrm{e}} \mathrm{s}$., la recherche semble tourner le dos aux manuscrits arabes du Nouveau Testament, contrairement à ce que l'on aurait pu penser suite à l'apparition des premières éditions critiques du Nouveau Testament ${ }^{8}$. En 1849, Constantin Tischendorf intégrait pourtant plusieurs versions arabes à sa première édition du Novum Testamentum Graece dans la catégorie des Versiones antiquae ${ }^{9}$. De même, les premières éditions du Greek Testament de Henry Alford comptaient une version arabe ; la quatrième édition de 1859 ne la prend plus en compte, considérée à présent avec les versions perses, slavonnes et anglo-saxonnes, comme «comparatively recent translations $[\ldots]$ and not

Arabic : Historical, Text-Critical and Literary Aspects, Würzburg, Beyrouth, Ergon-Verlag, 2012 (Beiruter Texte und Studien 131), pp. 37-51.

8 Lachmann et Tischendorf sont considérés comme les chercheurs ayant rompu avec la tradition du Textus receptus grec (Metzger Bruce M. et Ehrman Bart D., The Text of New Testament. Its Transmission, Corruption, and Restoration, 4 édition, Oxford, Oxford University Press, 2005, p. 170. Aland Kurt et Aland Barbara, The Text of the New Testament: An Introduction to the Critical Editions and to the Theory and Practice of Modern Textual Criticism, $2^{\mathrm{e}}$ édition, Grand Rapids, Eerdmans Publishing Co., 1995 (Studies and Documents 46), p. 11.) Lachmann a-t-il utilisé une version arabe? Renouf sous-entend que oui (RENouf LE PAGE Peter, «On the Supposed Latin Origin of the Arabic Version of the Gospels», Atlantis : or Register of Literature and Science of the Catholic University of Ireland 4, 1863, p. 241), mais nous n'en avons pas trouvé mention.

9 S'il ne les considère pas comme fiables, il leur consacre un paragraphe entier. Tischendorf considère les versions arabes comme très anciennes : «arabicae (arr), quarum alia ab ipsis Graecis (saec. fere IV.), alia a Syria, alia a Coptis, alia a Latinis (saec. VIII.) petita est. » Il utilise deux éditions, celle d'Erpenius et celle des Polyglottes, et le texte du Vat. Ar. 13 tel que reproduit par Scholz. TIschendorf Constantin, Novum Testamentum Graece. Ad antiquos testes recensuit, apparatum criticum multis modis auctum et correctum apposuit, commentationem isagogicam praemisit ..., Leipzig, Winter, 1849, p. LXXVIII. Voir notre chapitre 6, point 2 État de la recherche sur le Vat. Ar. 13. Tischendorf continue dans les éditions suivantes d'utiliser les versions arabes; elles sont mentionnées rapidement dans l'introduction de la

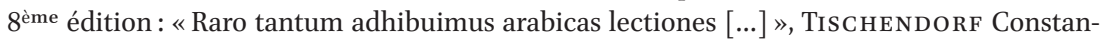
tin, Novum Testamentum Graece. Ad antiquissimos testes denuo recensuit apparatum criticum omni studio perfectum, vol. 1, 8e édition, Leipzig, Giesecke \& Devrient, 1869, pp. XV-XVI. C'est Gregory, dans les Prolegomena, qui détaille quelles versions Tischendorf a utilisées (celles utilisées pour sa première édition, citée ci-dessus, et des passages du Leipzig UB Vollers 1058 et du Saint-Pétersbourg Bibl. Nat. Ar. New Series 327), Gre gory Caspar René, Novum Testamentum graece. Ad antiquissimos testes denuo recensuit, apparatum criticum omni studio perfectum apposuit. Editio octava critica maior. Volumen III. Prolegomena IX-XIII, vol. 1, Leipzig, J. C. Hinrichs, 1884, p. 37. Gregory fait ensuite la liste de 137 manuscrits arabes du Nouveau Testament, Gregory Caspar René, Novum Testamentum graece. Ad antiquissimos testes denuo recensuit, apparatum criticum omni studio perfectum apposuit. Editio octava critica maior. Volumen III. Prolegomena IX-XIII, vol. 3, Leipzig, J. C. Hinrichs, 1894, pp. 928-947. 
from the original Greek. $\gg^{10}$ Cette tendance est observée par Peter Renouf, et serait selon lui le résultat des critiques faites à l'encontre de l'utilisation des versions arabes de la part de l'Edinburgh Reviewer, mais surtout de Samuel Davidson ${ }^{11}$.

En se basant sur les éditions arabes du Nouveau Testament, Davidson remet fortement en question leur utilisation à des fins de critique textuelle. Il considère que la traduction des évangiles est inutile: "The Arabic versions of the gospels must be discarded as useless, for it was not made from the original but from the Vulgate. We should therefore consistently omit all mention of the version in question. $»^{12}$ Quant aux autres livres du Nouveau Testament, si ceux-ci ne sont pas considérés comme étant traduits du latin, ils n'en sont pas plus utiles: «The value of this version is very small. It is modern, and represents a modern form of the text. It is not worth collating for critical purposes, and may be safely neglected. $»^{13}$ L'argument principal de Davidson, celui qu'il s'agit d'une traduction des évangiles faite sur la Vulgate, est remis en question dans l'article de Renouf. De manière générale, il rappelle que la parenté du texte avec celui de la Vulgate ne constitue pas un argument négatif, étant donné l'antiquité de cette version latine. Renouf s'efforce ensuite de démontrer la proximité entre le texte arabe et le texte grec: on trouverait par exemple pour une même expression un mot dans la version grecque et la version arabe, contre plusieurs en latin; certains seraient clairement copiés sur le grec

10 ALFORD Henry, The Greek Testament: With a Critically Revised Text, A Digest of Various Readings, Marginal References to Verbal and Idiomatic Usage, Prolegomena, And a Critical and Exegetical Commentary, vol. 1, 4 e édition, Londres, Rivingtons, 1859, p. 115.

11 «The Arabic versions of the four Gospels is one of those ancient translations of Scriptures, which it has lately become fashionable among English Biblical scholars to set aside as valueless for the purposes of criticism or exegesis. » Renouf Le PAGE, « On the Supposed Latin Origin of the Arabic Version of the Gospels », art. cit., 1863, p. 241.

12 Davidson Samuel, A Treatise on Biblical Criticism: Exhibiting a Systematic View of That Science, Edimburgh, A\&C Black, 1852, p. 222. Davidson partage l'idée selon laquelle la traduction arabe des évangiles aurait été faite directement de la Vulgate latine par un certain Jean de Séville au $8^{\mathrm{e}} \mathrm{s}$. (il donne en référence les travaux de Storr et Juynboll, non publiés). Cette thèse est remise en question dans l'article de Renouf, mais aussi par Gildemeister (GIldemeister Johann, De Evangeliis in Arabicum e simplici Syriaca translatis, Bonn, Marcus, 1865), Lagarde (LAGARDE Paul, Die vier Evangelien, arabisch aus der Wiener Handschrift herausgegeben, Leipzig, F.A. Brockhaus, 1864, pp. XI-XVI), Tregelles (Tregelles Samuel P., «Arabic Versions », in: A Dictionary of the Bible Comprising Its Antiquities, Biography, Geography, and Natural History, vol. $3,2^{\mathrm{e}}$ édition, Londres, John Murray, 1893, pp. 1614-1616.) Nous ne discutons pas ce développement ici. Voir KAS HOU H Hikmat, The Arabic Versions of the Gospels, The Manuscripts and their Families, Berlin, Boston, De Gruyter, 2012 (Arbeiten zur neutestamentlichen Textforschung 42), p. 14.

13 Davidson, A Treatise on Biblical Criticism: Exhibiting a Systematic View of That Science, op. cit., 1852 , p. 228. 
(ex. : en Mt 2,11, on trouve $\lambda i \beta \alpha \nu$, contre le terme latin thus $)^{14}$; enfin, il fait la liste de nombreuses variantes où le texte arabe et celui de la Vulgate diffèrent. Il conclut ainsi : «I have now, I think, produced a considerable mass of evidence in favour of the Greek origin of the Arabic Gospels. » ${ }^{15}$

Malgré cela, la pertinence des versions arabes pour la recherche néotestamentaire reste critiquée. En 1864, Lagarde publie le texte d'un manuscrit des évangiles, Vienne öNB Or. 1544 (alors wiener hds 43). Si son édition peut être considérée comme la première édition scientifique d'un texte complet d'un manuscrit arabe du Nouveau Testament, ici les évangiles, Lagarde ne considère pas celui-ci comme utile à la recherche. « Meine ausgabe der wiener hds soll nur der grundstein sein, auf welchem die textkritik weiterbauen kann, wenn sie es überhaupt noch für der mühe werth hält sich mit den arabischen evangelienübersetzungen einzulassen $[. ..] »^{16}$ Et s'il en reconnaît l'intérêt linguistique, il raille son intérêt pour la théologie : «Wer will [...] die zeit daran wenden ? da wenigstens die theologie noch wichtigeres zu thun hat. » ${ }^{17}$ Par la suite, l'avis de Lagarde continuera d'être partagé par les chercheurs en critique textuelle, comme par exemple par Eberhard Nestle, celui-ci considérant que : «Für die Biblische Kritik und Exegese haben sie nur wenig Wert, da sie mit wenigen Ausnahmen Tochterübersetzungen sind. ${ }^{18}$

En 1865, Johann Gildemeister publie plusieurs passages des évangiles du manuscrit Londres BL Or. 1075 (Add. 14467), qu'il estime être traduit du syriaque ${ }^{19}$.

En 1888, Ignazio Guidi sort la première étude qui permettra de mettre réellement en perspective les avis divisés dans la recherche, Le traduzioni degli

14 Renouf Le Page, « On the Supposed Latin Origin of the Arabic Version of the Gospels », art. cit., 1863, p. 249. Pour son analyse, Renouf se base sur l'édition de Raimundi et celle d'Erpenius, Ibid., p. 244.

15 Renouf Le Page, « On the Supposed Latin Origin of the Arabic Version of the Gospels », art. cit., 1863 , p. 257 .

16 LAGARDE, Die vier Evangelien, arabisch aus der Wiener Handschrift herausgegeben, op. cit., 1864, p. XXXI. Nous gardons ici l'orthographe d'origine.

17 Ibid., p. XXXII. Nous gardons ici l'orthographe d'origine.

18 NESTLE Eberhard, «Bibelübersetzungen, Arabische», in : Realencyklopädie für protestantische Theologie und Kirche, vol. 3, Leipzig, Hinrichs, 1897, pp. 90-95. Voir aussi HorNe Thomas H., Davidson Samuel et Tregelles Samuel P., An Introduction to the Critical Study and Knowledge of the Holy Scriptures. Volume 4. An Introduction to the Textual Criticism, Etc. of the New Testament, $10^{\mathrm{e}}$ édition, Londres, Longman, Brown, Green, Longmans \& Roberts, 1856, p. 323.Voir les références de Vollandt: Volland Tonny, Arabic Versions of the Pentateuch. A Comparative Study of Jewish, Christian, and Muslim Sources, Leiden, Brill, 2015 (Biblia Arabica 2), pp. 3-4.

19 Gildemeister, De Evangeliis in Arabicum e simplici Syriaca translatis, op. cit., 1865. 
evangelii in arabo e in etiopico ${ }^{20}$. La première et majeure partie de l'étude est consacrée aux manuscrits arabes des évangiles et offre le premier classement des manuscrits par famille, formant respectivement cinq groupes : 1) les traductions faites à partir du grec, 2) les traductions à partir du syriaque ou corrigées selon le syriaque, 3 ) les traductions à partir du copte ou corrigées selon le copte, 4) les recensions éclectiques, 5) les traductions en prose rimée ou singulières à un autre titre. Au total, Guidi classe 68 manuscrits. Si le travail de Guidi présente certainement des faiblesses, comme celle de ne baser son analyse que sur un passage-type (Mt 1,18-25), et de ne pas tenir compte des différents types de textes grecs à la base des traductions, cette première classification est un bond en avant dans un champ méconnu en proie à des préjugés et donne aux chercheurs une base de travail commune ${ }^{21}$.

On notera que, jusqu'alors, ce sont surtout les évangiles qui ont retenu l'attention de la recherche ${ }^{22}$. Les travaux de Agnes S. Lewis et Margaret D. Gibson sur certains manuscrits arabes du Monastère de Sainte-Catherine au Mont Sinaï font exception. En 1894, Gibson édite le Sin. Ar. $155^{23}$, qu'elle date du $9^{\mathrm{e}}$ s. et estime être traduit du grec ${ }^{24}$ (voir ci-dessous, point 9 Les lettres de Paul, parent pauvre de la recherche, et notre comparaison chapitre 8, point 3.1 Comparaison avec Sin. Ar. 151 et Sin. Ar. 155). En 1899, elle édite le manuscrit Sin. Ar. 154, contenant les Actes et les lettres catholiques, qu'elle considère comme le manuscrit le plus ancien du couvent, du moins pour le texte biblique ${ }^{25}$; le manuscrit, qui date probablement du $9^{\mathrm{e}} \mathrm{s}$., contient un traité sur la nature trine de Dieu qui serait un des plus anciens textes chrétiens composés en arabe qui nous soit parvenu ; il aurait été écrit entre 755 et $788^{26}$.

20 Guid Ignazio, Le Traduzioni degli Evangelii in arabo e in etiopico, Rome, Tipografia della r. accademia dei Lincei, 1888 (Atti della reale accademia dei Lince 4).

21 Pour une critique de Guidi, voir Kashoun, The Arabic Versions of the Gospels, The Manuscripts and their Families, op. cit., 2012, pp. 12-13.

22 Nous reprenons cette question plus bas, au point 9.

23 Voir la notice 156 au chapitre 4.

24 Gibson Margaret Dunlop, An Arabic Version of the Epistles of St Paul to the Romans, Corinthians, Galatians with Part of the Epistles to the Ephesians, Londres, C. J. Clay, 1894 (Studia Sinaitica 2). Le manuscrit était déjà présenté, ainsi que le Sin. Ar. 75, dans l'article LEwiS Agnes Smith et Delmar Morgan E., «Some Ancient Manuscripts of the Arabic New Testament», in: Transactions of the Ninth International Congress of Orientalists, vol. 2, Londres, Committee of the Congress, 1893, pp. 96-98.

25 Gibson Margaret Dunlop, An Arabic Version of the Acts of the Apostles and the Seven Catholic Epistles, Londres, C. J. Clay, 1899 (Studia Sinaitica 6).

26 À propos de la question de la datation du Sin. Ar. 154, voir SAmir Samir Khalil, «The Earliest Arab Apology for Christianity», in : SAmir Samir Khalil et Nielson Jørgen S. (éds), Christian Arabic Apologetics during the Abbasid Period (750-1258), Leiden, Brill, 1994, pp. 57-114; Griffith Sidney H., The Bible in Arabic. The Scriptures of the «People of the 
En 1898, F. C. Burkitt consacre dans son article «Arabic Versions » un point aux lettres de Paul, aux Actes et aux lettres catholiques, et à l'Apocalypse. Il ne peut malheureusement que lister les quelques manuscrits connus et mentionner le premier article de Gibson ${ }^{27}$. Henri Hyvernat, qui publie en 1895 un article d'encyclopédie semblable à celui de Burkitt, souligne cette lacune dans la recherche. Dans sa partie sur les versions arabes extra-évangéliques, il fait remarquer:

On n'a pas encore suffisamment étudié l'histoire des versions de cette partie du Nouveau Testament, on se contente de dire d'une manière un peu vague qu'elle sont dérivées du syriaque. Mais il est probable qu'une étude judicieuse des manuscrits conservés dans les différentes bibliothèques d'Europe conduirait à des résultats analogues à ceux auxquels M. Guidi est arrivé pour les Evangiles ${ }^{28}$.

Enfin, on attendra 1929 pour que soit publié un premier article sur l'Apocalypse en arabe ; Georg Graf, considérant les éditions anciennes et plusieurs manuscrits, définit quatre recensions différentes ${ }^{29}$.

\section{Le début du $20^{\mathrm{e}} \mathrm{s}$. : une traduction préislamique?}

Le débat sur l'origine des traductions, qui se basait alors principalement sur les éditions, a trouvé son prolongement dans la diversité des versions arabes et la recherche se concentre à partir $\mathrm{du} 20^{\mathrm{e}} \mathrm{s}$. sur l'étude des versions et la description des manuscrits ${ }^{30}$. En 1902, Caspar R. Gregory fournit dans Textkritik

Book» in the Language of Islam, Princeton, Princeton University Press, 2013, p. 112 ; SwANson Mark N., «Fü tathlīth Allāh al-wāhid», in: Thomas David Richard et RogGemA Barbara (éds), Christian-Muslim Relations : A Bibliographical History (6oo-9oo), Leiden, Boston, Brill, 2009 (The History of Christian-Muslim Relations 11), pp. 330-333; id., «An Apology for the Christian Faith», in: Noble Samuel et Treiger Alexander (éds), The Orthodox Church in the Arab World (700-1700): An Anthology of Sources, DeKalb, Northern Illinois University Press, 2014, pp. 40-59.

27 Burkitt Francis Crawford, «Arabic Versions», in: Dictionary of the Bible: Dealing with Its Language, Literature, and Contents Including the Biblical Theology, vol. 1, Edinburgh, T\&T Clark, 1898, pp. 136-138.

28 Hyvernat Henri, «Arabes (versions) des écritures », in : Dictionnaire de la Bible, vol. 1 , Leipzig, Letouzey et Ané, 1895, pp. 845-856.

29 GraF Georg, «Arabische Übersetzungen der Apokalypse », Biblica 10, 1929, pp. 170-194.

30 En addition des recherches discutées ci-dessous, voir aussi: RömER Karl, «Studien über den Codex Arabicus Monacensis Aumer 238», Zeitschrift für Assyriologie und 
des Neuen Testamentes ${ }^{31}$ une liste de 137 manuscrits arabes du Nouveau Testament classés par pays, un travail qui sera continué par Graf en 1944. Dans son ouvrage sur la littérature des chrétiens arabisés de la Péninsule ibérique, Heinrich Goussen présente également des manuscrits bibliques arabes; il mentionne notamment la traduction des évangiles qui aurait été effectuée par Ishạāq ibn Balašk (ou Isaac Velasco ou Velasquez) qui remonterait à 946 selon les indications trouvées dans deux manuscrits munichois et un manuscrit de la cathédrale de León ${ }^{32}$. En 1910, Eugène Tisserant consacre un article à un folio bilingue latin-arabe, qui vient d'être alors transféré à la Bibliothèque vaticane et deviendra Vat. Lat. 12900 $^{33}$. Il y transcrit les folios qui contiennent Galates 1,1-15 et 3,6-24 (avec photo du f. 1v). Il conclut à propos du manuscrit: « [...] que ce ms. bilingue n'est pas l'original d'une traduction, mais qu'on y a réuni un texte latin et un texte arabe indépendants l'un de l'autre. Que cette version arabe ait pour auteur Jean de Séville ou un autre [...], peu nous importe ; [...] Un fait est du moins certain, c'est qu'il y avait avant 946, c'est-à-dire avant

Vorderasiatische Archäologie 19 (1), 1906, pp. 98-125; Euringer Sebastian, «Zum Stammbaum der arabischen Bibelhandschriften Vat. ar. 468 und 467 », Zeitschrift für Semitistik und verwandte Gebiete 7, 1929, pp. 259-273; id., "Zum Stammbaum der arabischen Bibelhandschriften Vat. ar. 468 und 467. Nachträge zum Band 7. », Zeitschrift für Semitistik und verwandte Gebiete 8, 1929, pp. 260-261. Sur les manuscrits du Sinaï : LEWIS Agnes Smith et Gibson Margaret Dunlop, Forty-One Facsimiles of Dated Christian Arabic Manuscripts, Cambridge, Cambridge University Press, 1907 (Studia Sinaitica 12); GRAF Georg, «Sinaitische Bibelfragmente », Oriens Christianus 14, 1925, pp. 217-220. Sur le Vat. Copt. 9 et son lien au traité du pseudo-Ġazālī al-Radd al-Jamīl: PADWICK Constance E., «Al-Ghazali and the Arabic Versions of the Gospels. An Unsolved Problem », The Muslim World 29 (2), 1939, pp. 130-140. La thèse de Padwick est remise en question par Kashouh, voir Kashou H, The Arabic Versions of the Gospels, The Manuscripts and their Families, op. cit., 2012, p. 35.

31 Gregory Caspar René, Textkritik des Neuen Testamentes, vol. 2, Leipzig, Hinrichs, 1902, pp. 579-592. Les manuscrits sont déjà énumérés dans les Prolegomena, voir note 9 ci-dessus.

32 Archives de la cathédrale de León codex 35, Munich Staatsbibliothek Ar. 238, Munich Staatsbibliothek Ar. 234, Goussen Heinrich, Die christlich-arabische Literatur der Mozaraber, Leipzig, O. Harrassowitz, 1909, p. 9. Il s'agit de la famille $m$ selon Kashouh, Kashoun, The Arabic Versions of the Gospels, The Manuscripts and their Families, op. cit., 2012, pp. 275-276. Voir aussi l'article de Baumstark (BAUMSTARK Anton, «Markus Kap. 2 in der arabischen Übersetzung des Isaak Velasquez », Oriens Christianus 9, 1934, pp. 226-239), l'article de Römer (RöMER, «Studien über den Codex Arabicus Monacensis Aumer 238 », art. cit., 1906), les articles que nous mentionnons dans la note 67 (López et Roisse) et le travail récent de Kassis (Kassis H. E., An Andalusian Arabic Version of the Four Gospels (Bayer. Staatsbibl., München, cod. arab. 238), Peeters, Louvain, 2016 (csco 663).

Voir la notice 184 dans le chapitre 4. 
la traduction des Évangiles par Isaac de Cordoue, un texte arabe espagnol du Nouveau Testament. $»^{34}$

Mais les chercheurs montrent surtout un intérêt particulier pour les manuscrits les plus anciens et leur datation, spéculant sur l'existence de traductions contemporaines aux débuts de l'Islam, voire précédant celui-ci (voir chapitre 3, point 4 L'existence de traductions préislamiques, un point de vue minoritaire). Cette question rejoint celle de la possible existence d'une littérature chrétienne préislamique, défendue par le chercheur Louis Cheikho dans son ouvrage de 1912, Le christianisme et la littérature chrétienne en Arabie avant l'Islam ${ }^{35}$.

Dans les années 1930, Anton Baumstark défend également dans une série d'articles l'existence d'une traduction arabe de livres bibliques par les chrétiens avant l'Islam ${ }^{36}$. Un de ses arguments est d'ordre historique: Baumstark se base sur les attestations de la présence chrétienne et du travail missionnaire en Arabie au $5^{\mathrm{e}}$ s. pour affirmer la nécessité d'une traduction : « An allen diesen Fronten christlichen Vordringens muß nach der unverbrüchlichen Praxis der Missiontätigkeit des östlichen Frühchristentums von vornherein mit einer sofortigen Übersetzung mindestens der Evangelien und des Psalters als der für die Liturgie wichtigsten Teile der Bibel in die arabische Volkssprache des neuen Missionsgebiets gerechnet werden. $»^{37}$ Un autre argument qu'il développe est la présence dans les manuscrits Vat. Borg. Ar. 95 ( $9^{\text {e }}$ s.) et Berlin Staatsbibl. Or. $1108\left(^{\mathrm{e}} \mathrm{s}\right.$ s) de rubriques liturgiques qui seraient d'origine palestinienne prébyzantine ; cela prouverait l'antiquité des traductions contenues dans ces manuscrits, le traducteur ayant indiqué la pratique de son temps ${ }^{38}$. Enfin, il

34 Tisserant Eugène et BRUyne Donatien DE, «Une feuille arabo-latine de l'épître aux Galates », Revue biblique N.S. 7, 1910, p. 335. Notre recherche actuelle sur le manuscrit Venise Marciana 379 apporte des nouveaux éléments à la question. Voir la note $108 \mathrm{ci}-$ dessous et la notice 194 dans le chapitre 4.

35 Cheıкho Louis, An-nașrāniyya wa-ādābuhā bayna 'arab al-jāhiliyya, 3 vol., Beyrouth, Imprimerie Catholique, 1912.

36 Baumstark Anton, «Die sonntägliche Evangelienlesung im vorbyzantinischen Jerusalem», Byzantinische Zeitschrift 30, 1930, pp.350-359; id., «Das Problem eines vorislamischen christlich-kirchlichen Schrifttums in arabischer Sprache», Islamica 4, 1931, pp.574-575; id., «Eine altarabische Evangelienübersetzung aus dem Christlich-Palästinensischen », Zeitschrift für Semitistik and verwandte Gebiete 8, 1932, pp. 201-209; id., « Der älteste erhaltene griechisch-arabische Text von Psalm 110 (109)», Oriens Christianus 9, 1934, pp. 55-66; id., «Eine frühislamische und eine vorislamische arabische Evangelienübersetzung », in : Atti Del XIX Congresso Internazionale Orientalisti, Rome, Tipografia del Senato, 1938, pp. 682-684.

37 Baumstark, «Eine altarabische Evangelienübersetzung aus dem ChristlichPalästinensischen », art. cit., 1932, p. 166.

38 BAUmstaRK, «Die sonntägliche Evangelienlesung im vorbyzantinischen Jerusalem », art. cit., 1930. 
s'appuie sur les citations bibliques d'auteurs musulmans anciens, tels que Ibn Isḥāq ( $8^{\mathrm{e}}$ s., œuvre transmise par Ibn Hišām, $9^{\mathrm{e}}$ s.), Ibn Qutayba, 'Alī ibn Sahl aț-Ṭabarī et al-Jāhiz ( $9^{\mathrm{e}} \mathrm{s}$.), dont l'étude de la Vorlage syriaque ancienne montrerait l'origine préislamique ${ }^{39}$. Les différents arguments de Baumstark seront discutés par Georg Graf, qui trouve les preuves insuffisantes pour conclure à une traduction préislamique ${ }^{40}$.

En 1938, Bernhard Levin s'intéresse également aux manuscrits Vat. Borg. Ar. 95 et Berlin Staatsbibl. Or. 1108 et édite les évangiles de Matthieu et de Marc. Selon lui, le texte présent dans ces manuscrits pourrait être bien plus ancien et il s'appuie comme Baumstark sur l'argument historique : «Das palästinische Christentum der Euthymiosmission hat auch wohl von frühester Zeit an die notwendigsten liturgischen Bücher in der Volkssprache besessen. ${ }^{41}$

\section{$4 \quad$ La contribution de Georg Graf (1944)}

Entre 1944 et 1953 paraissent les cinq imposants volumes de l'orientaliste allemand Georg Graf, Geschichte der christlichen arabischen Literatur. Ces volumes cherchent à inventorier la production littéraire arabe chrétienne jusqu'en $1900^{42}$. Pour son étude, Graf définit la littérature arabe chrétienne selon son contenu, et pas seulement selon l'identité de l'auteur (laissant de côté par exemple la littérature profane $)^{43}$. Son premier volume, intitulé Übersetzungen,

39 «[D]ie Tatsache einer christlich-palästinensischen Vorlage dürfte für die Entstehung des bei Ibn Ishaq bzw. Ibn Hichâm nachwirkenden arabischen Evangelientextes in noch vorislamische Zeit weisen. » BAUMSTARK, « Eine altarabische Evangelienübersetzung aus dem Christlich-Palästinensischen », art. cit., 1932, p. 209. Son élève Curt Peters cherchera également à établir l'origine «pré-Peshitta» de groupes de manuscrits: Peters Curt, «Proben eines bedeutsamen arabischen Evangelientextes », Oriens Christianus 11, 1942, pp. 189-211; id., «Von arabischen Evangelientexten in Handschriften der UniversitätsBibliothek Leiden », Acta Orientalia 18, 1940, pp. 124-137. Il soutient également l'existence de traductions préislamiques: Peters Curt, «Grundsätzliche Bemerkungen zur Frage der arabischen Bibeltexte », Rivista degli studi orientali 20 (1), 1942, pp. 129-143.

40 Graf Georg, Geschichte der christlichen arabischen Literatur, vol. 1, Rome, Biblioteca Apostolica Vaticana, 1944 (Studi e Testi 118), pp. 39-52. Voir aussi les avis de Vööbus et Griffith ci-dessous.

41 Levin Bernhard, Die griechisch-arabische Evangelien-Übersetzung Vat. Borg. Ar. 95 und Ber. Orient. Oct. 1108, Uppsala, Almqvist \& Wiksell, 1938, pp. 10-11.

42 En 1905, Graf avait publié une première contribution allant jusqu'au $11^{\mathrm{e}}$ s.: GRAF Georg, Die christlich-arabische Literatur bis zur fränkischen Zeit, Freiburg, Herdersche Verlagshandlung, 1905.

43 GRAF Georg, Geschichte der christlichen arabischen Literatur, vol. 1, Rome, Biblioteca Apostolica Vaticana, 1944 (Studi e Testi 118), pp. 2-3. 
parcourt les traductions en arabe de l'Ancien et du Nouveau Testament, des apocryphes et des pseudépigraphes, de la littérature patristique, de l'hagiographie et de la littérature liturgique. Graf offre au début de l'ouvrage une introduction très fournie sur l'histoire des chrétiens arabes; il y consacre une partie à la question de la littérature arabe présislamique, intitulée «Das Problem einer Literatur der arabischen Christen in vorislamischer Zeit ${ }^{44}$. Graf montre de manière systématique, reprenant, entre autres, les arguments de Cheikho et de Baumstark, que les éléments actuels de la recherche ne suffisent pas à affirmer l'existence d'une telle littérature. Graf suit la classification de Guidi, classant les manuscrits selon leur Vorlage; au côté des familles grecque, syriaque et copte, Graf y ajoute la famille latine et les manuscrits dont la Vorlage est inconnue (voir chapitre 5 , point 5 Vorlagen selon Graf). On trouve pour chaque version de chaque famille une courte explication historique, les principaux manuscrits et des indications bibliographiques. Graf manque parfois de systématique dans sa classification interne et dans ses références, ce qui peut rendre ardu le pistage des manuscrits ${ }^{45}$. Toutefois, cette centaine de pages sur le Nouveau Testament, mentionnant plus de quatre cents manuscrits, fournissent un concentré d'informations sur ceux-ci et sur la littérature secondaire, et le travail de Graf reste inégalé jusqu’à présent.

\section{De Vööbus (1954) à Griffith (1983) : remise en question de l'existence préislamique de traductions}

La question de la datation des premières traductions arabes du Nouveau Testament reste une problématique importante pour la recherche. Des chercheurs comme Vööbus, Blau et Griffith remettent en question les arguments de Baumstark et se positionnent pour une datation postérieure aux débuts de l'Islam.

Dans son ouvrage Early Versions of the New Testament de 1954, Arthur Vööbus consacre un chapitre aux versions arabes, au côté des versions latines, syriaques, arméniennes, géorgiennes, coptes, éthiopiennes et gothiques, et

$44 \quad$ Ibid., pp. 27-52.

45 Voir la critique de Samir K. Samir: SAmir Samir Khalil, « Pour une nouvelle histoire de la littérature arabe des Chrétiens », in : SAmir Samir Khalil (éd.), Actes du premier congrès international détudes arabes chrétiennes (Goslar, septembre 1980, Rome, Pontificio Instituto Orientale, 1982 (Orientalia Christiana Analecta 218), pp. 259-271. Et celle de Kashouh: Kashoun, The Arabic Versions of the Gospels, The Manuscripts and their Families, op. cit., 2012, pp. 23-24. 
du Diatessaron ${ }^{46}$. Il met en évidence la complexité et la diversité du phénomène de traduction en arabe: "The New Testament in Arabic is the most colorful phenomenon. Here we have to do, not with two or three versions, but with a great number of translations. ${ }^{47}$ Le propos principal de Vööbus est de démontrer la large influence de la Vieille Syriaque dans la tradition arabe, tant chez les auteurs arabes musulmans et chrétiens que dans les manuscrits du Nouveau Testament (il donne en exemple Sin. Ar. 82 et Berlin Staatsbibl. Or. Quarto 2101). Baumstark voyait en ces traces syriaques archaïques une preuve de l'antériorité à l'Islam des premières traductions des évangiles (voir ci-dessus). Pour Vööbus, la présence de la Vieille Syriaque dans les évangiles arabes atteste uniquement de l'influence de cette version jusqu'à une époque tardive et ne constitue pas une preuve en faveur d'une traduction préislamique.

En 1973, Joshua Blau traite directement de la question de l'existence préislamique d'une traduction arabe, dans son article «Sind uns Reste arabischer Bibelübersetzungen aus vorislamischer Zeit erhalten geblieben? ${ }^{48}$ Également en désaccord avec Baumstark et Levin, il analyse les manuscrits édités par ce dernier, Vat. Borg. Ar. 95 et Berlin Staatsbibl. Or. 1108, et développe une argumentation se basant uniquement sur l'aspect linguistique de leurs textes. En effet, les textes contiennent, selon Blau, à la fois des expressions d'arabe vulgaire et d'arabe classique, ainsi que des formes "pseudo-correctes ${ }^{49}$, c'està-dire se voulant classiques et élégantes, mais fausses. Une telle influence de l'arabe classique sur un traducteur qui, de toute évidence, ne le maitrise pas, ne serait pas possible avant l'Islam. Il en conclut : « Dieser Einfluss des klassichen Arabisch, der in alle Einzelheiten geht, ist nur in islamischer Zeit vorstellbar. $»^{50}$

Dans un article de 1983, Sidney H. Griffith défend, contre Baumstark notamment, l'hypothèse selon laquelle les premières traductions arabes apparaîtraient au premier siècle abbasside (env. 750-850), en Syrie-Palestine ${ }^{51}$. Griffith brosse un portrait de cette période, montrant que ce contexte offre la plus grande vraisemblance pour une première traduction des évangiles. Il

46 Vööвus Arthur, «The Arabic Versions», in: Early Versions of the New Testament: Manuscript Studies, Stockholm, Estonian Theological Society in Exile, 1954, pp. 271-297.

47 Ibid., p. 288.

48 BLAU Joshua, «Sind uns Reste arabischer Bibelübersetzungen aus vorislamischer Zeit erhalten geblieben?», Le Muséon 86, 1973, pp. 67-72. Voir aussi BlAU Joshua, «Über einige christlich-arabische Manuskripte aus dem 9. und 10. Jahrhundert », Le Muséon 75, 1962, pp. 101-108.

49 Ce que Blau définit comme étant du moyen arabe, voir à ce propos le chapitre 8, point 2 Moyen arabe.

$50 \quad$ BLAU, «Sind uns Reste arabischer Bibelübersetzungen aus vorislamischer Zeit erhalten geblieben? », art. cit., 1973, p. 70.

51 Griffit H Sidney H., «The Gospel in Arabic: An Inquiry into its Appearance in the First Abbasid Century », Oriens Christianus 67, 1983, pp. 126-167. 
souligne le manque de documents remontant avec certitude avant le $g^{\mathrm{e}} \mathrm{s}$., tandis que nous avons des manuscrits datés par la suite (par ex. Sin. Ar. New Find Parch. 14 et 16 daté de $873^{52}$ ou Sin. Ar. 72 de 897). Il soutient également que les références chrétiennes chez les auteurs musulmans anciens comme Ibn Isḥāq ne peuvent être considérés comme des références explicites à des textes bibliques existants en arabe. Par contre, les sources musulmanes plus tardives, comme Ibn Qutayba ou aț-Ṭabarī, montrent que les évangiles étaient disponibles en arabe au $9^{\mathrm{e}} \mathrm{s}$. Enfin, selon Griffith, la situation des communautés melkites en Syrie-Palestine, éloignées de Constantinople, en fait le milieu le plus probable pour les premières traductions (à ce propos, voir chapitre 5, point 3 Dates).

Contre l'avis de ces derniers, on trouve l'article de Raif Georges Khoury qui s'intéresse principalement aux mentions de textes bibliques chez les premiers auteurs musulmans ${ }^{53}$. Il se base notamment sur le témoignage du yéménite Wahb Ibn Munnabih, qui vécut au $7^{\mathrm{e}}$ ou au $8^{\mathrm{e}}$ s., cité par Ibn Hišām. Khoury résume la situation ainsi : «[...] ces citations déformées, islamisées dans leur ensemble, nous ont quand même conservé assez de parties, même s'il ne s'agit parfois que de petits fragments de versets bibliques, qui nous ramènent à un fonds archaïque d'une Bible arabe qui a sans doute dû exister en période préislamique [...]. ${ }^{54}$ Alors qu'il souligne lui-même que cela « est bien loin de constituer une Bible complète ${ }^{55}$, Khoury pense que la littérature des premières générations islamiques « forme bien un témoignage évident, en faveur de l'existence d'une Bible arabe archaïque ${ }^{56}$. On regrettera que Khoury ne discute pas les critiques de Graf ou de Griffith à propos des témoignages des auteurs musulmans anciens.

En parallèle aux articles traitant directement de cette problématique, on trouve en 1967 un article de Aziz S. Atiya présentant le manuscrit Sin. Ar. 514, qui présente plusieurs particularités ${ }^{57}$. Il s'agit d'un quintuple palimpseste en trois langues différentes : la couche du dessus est en arabe et contient des traités hagiographiques. La deuxième couche est en arabe, la troisième en grec et

$5^{2}$ Cette date est remise en question; voir la discussion au chapitre 5, point 3.3.

53 KHOURY Raif Georges, «La ou les premières bibles arabes», in: FAHD Toufic (éd.), L'Arabie préislamique et son environnement historique et culturel: Actes du Colloque de Strasbourg, 24-27 juin 1987, Leiden, Brill, 1989 (Travaux du Centre de Recherche sur le Proche Orient et la Grèce Antiques 10), pp. 549-561.

54 Ibid., p. 559 .

55 Ibid., p. 560.

56 Ibid.

57 Atiya Aziz Suryal, «Codex Arabicus (Sinai Arabic Ms. No. 514)», in: Le hmanN-Haupt Hellmut (éd.), Homage to a Bookman : Essays on Manuscripts, Books and Printing Written for Hans P. Kraus on His 6oth Birthday Oct.12, 1967, Berlin, Gebr. Mann Verlag, 1967, pp. $75^{-8}$. 
les deux dernières en syriaque ${ }^{58}$. Selon Atiya, la seconde couche pourrait être un évangile ou un évangéliaire qui remonterait à la fin du $7^{\mathrm{e}} \mathrm{s}$. ou au début du $8^{\mathrm{e}} \mathrm{s}$. : « In this case it could be the most ancient attempt at an Arabic rendering of any section of the Christian Scripture. $»^{59}$

En 1983 et 1984, Harvey Staal édite successivement les lettres pauliniennes puis les Actes et les lettres catholiques du manuscrit de Sainte-Catherine Sin. Ar. $151^{60}$. Le manuscrit contient la date de 867 et est souvent décrit comme l'un des plus anciens manuscrits d'une traduction arabe du Nouveau Testament. Il est toutefois probable que la date soit celle de la traduction et non de la copie (voir ci-dessous, point 9 Les lettres de Paul, parent pauvre de la recherche) ${ }^{61}$.

On notera encore en 1977 la contribution de Bruce M. Metzger dans Early Version of the New Testament ${ }^{62}$. Il s'agit ici d'un résumé de la recherche et non d'une nouvelle contribution, mais il est intéressant qu'un chercheur venant du milieu de la critique textuelle du Nouveau Testament consacre plusieurs pages aux versions arabes, comme nous le verrons au chapitre 3 , point $1^{63}$.

Les années 1990-2000 : séries d'articles

Au tournant du millénaire, la recherche continue sous forme d'articles. En 1992, Samir Khalil Samir, un acteur important de la recherche en littérature arabe chrétienne ${ }^{64}$, publie une étude sur la recension du savant Ibn al-'Assāl

58 Voir Brock Sebastian P., «A Palimpsest Folio of Matt 20 :23-31 (Peshitta) in Sinai Ar. 514 (“Codex Arabicus")», Orientalia. Nova Series 61 (2), 1992, pp. 102-105.

59 AтryA, «Codex Arabicus (Sinai Arabic Ms. No. 514)», art. cit., 1967, p. 78.

6o StaAl Harvey, Mt. Sinai Arabic Codex 151 I: The Pauline Epistles, vol. 1, Louvain, Peeters, 1983 (csco 452); id., Mt. Sinai Arabic Codex 151 I: The Pauline Epistles, vol. 2, Louvain, Peeters, 1983 (Csco 453); id., Mt. Sinai Arabic Codex 151 II : Acts of the Apostles, Catholic Epistles, 2 vol., Louvain, Peeters, 1984 (csco 462-463).

61 Voir la discussion au chapitre 5, point 3.3.

62 Metzger, «The Arabic Versions », art. cit., 1977. Voir la critique de Metzger par Kashouh: Kas hоu H, The Arabic Versions of the Gospels, The Manuscripts and their Families, op. cit., 2012, pp. 28-29.

63 Une thèse sur l'évangile de Marc est publiée en 1977, mais nous n'y avons pas eu accès (Garland Amy G., An Arabic Version of the Gospel According to Mark, Master of Arts diss., Catholic University of America, 1978). Voir Kashou H, The Arabic Versions of the Gospels, The Manuscripts and their Families, op. cit., 2012, p. 29.

64 Voir entre autres: SAMIR, «Pour une nouvelle histoire de la littérature arabe des Chrétiens », art. cit., 1982 ; SAM I R Samir Khalil, « L'avenir des études arabes chrétiennes », Parole de l'Orient 24, 1999, pp. 21-43; id., «Survol de la situation des recherches arabes chrétiennes », in: Monferrer-Sala Juan Pedro (éd.), Eastern Crossroads. Essays on Medieval Christian Legacy, New Jersey, Gorgias Press, 2007, pp. 371-385. 
$\left(13^{\mathrm{e}} \mathrm{s}\right.$.), où il analyse trente et un manuscrits de cette œuvre ${ }^{65}$. Un classement chronologique des manuscrits met en évidence un fait étonnant: de nombreux manuscrits datent du vivant Ibn al-'Assāl et de la génération qui suit. Sur trente et un manuscrits, dix-sept ont été rédigés au $13^{\mathrm{e}}$ et $14^{\mathrm{e}} \mathrm{s}$., comme dans le cas du manuscrit Beyrouth Bibliothèque orientale 433, qui fut copié par le neveu Ibn al-'Assāl66.

Deux articles, en 1994 et 1999, sont consacrés à la version des évangiles du traducteur andalou Ishạā ibn Balašk ${ }^{67}$. López y López suppose que ce dernier a également traduit cinq des lettres de Paul et les autres livres du Nouveau Testament, car on trouve des citations de ces livres chez le théologien musulman Ibn Ḥazm, qui utilise abondamment la version de Isḥāq ibn Balašk pour les évangiles ${ }^{68}$.

Depuis les années 2000, le chercheur Juan P. Monferrer-Sala a publié de nombreux articles sur différents manuscrits. Il édite les trois épîtres de Jean du manuscrit Escurial Ar. $1625^{69}$; il publie plusieurs articles sur le Vat. Ar. $13^{70}$; en 2005, il publie un article avec Angel Urbán Fernández sur le Paris BNF supplément grec 911, un manuscrit bilingue grec-arabe contenant l'évangile

65 SAmir Samir Khalil, «La version arabe des Évangiles d'Al-As‘ad Ibn al-'Assâl », Parole de l'Orient 19, 1994.

66 À propos de la recension d'Ibn al-'Assāl, voir chapitre 5, point 3.4 Remarques concernant les manuscrits $d u{ }_{13}^{e} s$.

67 Ló PEZ y López Ángel C., « La traducción de los Evangelios al árabe por Isaac Ben Velasco de Córdoba en el siglo X a. D. », Boletín Millares Carlo 13, 1994, pp. 79-84 ; Roisse Philippe, « Los Evangelios traducidos del latín al árabe por Isḥāq b. Balašk al-Qurțubī en 946 d.C. », in: Seco de lucena Paredes luis, Castillo Castillo Concepción, Cortés Peña Immaculada et al. (éds), Estudios Árabes. Dedicados a D. Luis Seco de Lucena (En el XXV Aniversario de su muerte), Grenade, University of Granada, 1999, pp. 147-164. Kashouh annonce en 2012 que Philippe Roisse termine sa thèse sur l'évangile de Marc dans cette version (KASHOU H, The Arabic Versions of the Gospels, The Manuscripts and their Families, op. cit., 2012, pp. 17, 34, 275); nous n'avons pas d'information à ce sujet.

68 Ló Pez y López, «La traducción de los Evangelios al árabe por Isaac Ben Velasco de Córdoba en el siglo X a. D. », art. cit., 1994, p. 82. Potthast ne pense pas qu'il s'agisse de la même traduction, Роттнаsт Daniel, « Die andalusische Übersetzung des Römerbriefs », Collectanea Christiana Orientalia 8, 2011, p. 72.

69 Ar. 1625 est le numéro de catalogue ; sa cote est Escorial Real Biblioteca Cas. 1619, voir la notice 91 dans le chapitre 4. Monferrer-Sala Juan Pedro, «An Eastern Arabic Version of the Three Epistles of Saint John (Codex Ar. 1625) Kept in the Monastery of el Escorial (Madrid) », Parole de l'Orient 27, 2002, pp. 27-49.

Voir chapitre 6, point 2 État de la recherche sur le Vat. Ar. 13. 
de Luc $^{71}$. Paul Géhin avait déjà publié en 1997 un article sur ce manuscritt ${ }^{72}$; Fernández écrit un deuxième article à son propos en $2007^{73}$.

Jean Valentin publie en 2003 un long article sur les évangiles arabes contenus dans la Bibliothèque du Monastère Sainte-Catherine au Mont Sinaï ${ }^{74}$. Il étudie vingt-cinq manuscrits, datant du $9^{\mathrm{e}}$ au $15^{\mathrm{e}} \mathrm{s}$., qu'il classe en huit groupes en se basant sur l'analyse de Mt 28. L'étude de Valentin montre à nouveau la complexité des versions arabes, le chercheur se demandant comment « démêler l'écheveau » des différentes versions, et soutient l'importance d'une méthode qui distinguerait la langue et le type de texte du modèle utilisé par le traducteur ${ }^{75}$.

En 2005, Samir Arbache publie avec Philippe Roisse un article sur les versions de Marc 1,1-11 en arabe, présentant sept types de textes différents ${ }^{76}$.

Enfin, en 2007, Hikmat Kashouh publie deux articles. Le premier article cherche à démontrer l'ancienneté de la version contenue dans un manuscrit du $19^{\mathrm{e}}$ s., version qui serait plus ancienne que le Vat. Ar. 13 ( $9^{\mathrm{e}}$ s. $)^{77}$. Dans le recueil de David R. Thomas The Bible in Arab Christianity, son article étudie en

71 Urbán Fernández Angel et Monferrer-Sala Juan Pedro, «Some Regards on Textual Criticism in a Greek-Arabic Ms. BnF Suppl. grec 911 (A.D. 1043) », Parole de l'Orient 30, 2005, pp. 72-102. Voir aussi Monferrer-Sala Juan Pedro, « Kērýssō and its Arabic Renditions in a Bilingual Gospel of Luke (BnF 'Supl. grec 911', 1043 CE)», in : SAm IR Samir Khalil et Monferrer-Sala Juan Pedro (éds), Graeco-Latina et Orientalia: Studia in Honorem Angeli Urbani Heptagenarii, Cordoue, Beyrouth, Oriens Academic, 2013 (Syro-Arabica 2), pp. 221-236.

72 GÉHIN Paul, « Un manuscrit bilingue grec-arabe, BnF, Supplément grec 911 (année 1043) », in: DÉroche François (éd.), Scribes et manuscrits du Moyen-Orient, Paris, Bibliothèque nationale de France, 1997 (Études et recherches / Bibliothèque nationale de France), pp. 162-175.

73 Urbán Fernández Angel, «An Unpublished Greek-Arabic MS of Luke's Gospel (BnF Suppl. grec 911, AD 1043): A Report», in : Monferrer-Sala Juan Pedro (éd.), Eastern Crossroads. Essays on Medieval Christian Legacy, New Jersey, Gorgias Press, 2007 (Gorgias Eastern Christianity Studies 1), pp. 83-95.

74 VALEntin Jean, « Les évangéliaires arabes de la bibliothèque du Monastère Ste-Catherine (Mont Sinaï) : Essai de classification d'après l'étude d'un chapitre (Matth. 28). Traducteurs, réviseurs, types textuels », Le Muséon 116, 2003, pp. 415-477. Valentin prépare actuellement une édition critique de l'évangile de Marc à partir des manuscrits traités dans son article (nous remercions Herman Teule pour cette information).

75 Ibid., p. 475 .

76 Arbache Samir et Roisse Philippe, «Marc 1, 1-11 arabe. Versions anciennes de SyriePalestine et d'al-Andalus», Mélanges de Science Religieuse 2, 2005, pp. 65-78. En ligne: $<$ http://bdr.proxience.net/opac_css/index.php?lvl=notice_display\&id=205053 >.

77 Kashoun Hikmat, «The Arabic Gospel Text of Codex Beirut, Bibliothèque orientale, 430 : Is It Recent or Archaic? », Parole de l'Orient 32, 2007, pp. 105-121. 
détail les versets Jean 1,1 et Jean 1,8 de 40 manuscrits des évangiles, regroupés en 15 familles, article dont le contenu annonce sa monographie ${ }^{78}$.

\section{$7 \quad$ Hikmat Kashouh (2012) : une monographie attendue}

En 2012, Kashouh publie une large étude sur les manuscrits arabes des évangiles, The Arabic Versions of the Gospels. The Manuscripts and their Families ${ }^{79}$. Kashouh répertorie et classe plus de 200 manuscrits des évangiles - il se limite aux «manuscripts containing the continuous text of the Arabic Gospels », provenant de vingt-et-une bibliothèques ${ }^{80}$. Ils classent les manuscrits en vingt-quatre familles de texte. Parmi celles-ci, on trouve la famille $a$, traduction d'origine grecque, comportant les manuscrits Sin. Ar. 72 (897), Sin. Ar. 74 (9 e s.), Vat. Borg. Ar. 95 ( $9^{\mathrm{e}}$ s.), Berlin Staatsbibl. Or. 1108 (1046); la famille $b$, d'origine grecque également, est aussi intéressante : elle contient le palimpseste Sin. Ar. New Finds Parch. 8,28, qui daterait du $8^{\mathrm{e}}$ ou $9^{\mathrm{e}} \mathrm{s}$. Enfin, la famille $h$ contient le manuscrit Vat. Ar. 13, qui joue un grand rôle dans l'argumentation de Kashouh ; pour ce dernier, la traduction copiée dans le Vat. Ar. 13 précède les débuts de l'Islam. Il soutient ainsi l'existence d'une traduction arabe préislamique du Nouveau Testament ${ }^{81}$.

This study is the first work which deals with dating the AGM [Arabic Gospel manuscritpts] based on the manuscripts themselves through comparison and textual and linguistic analysis. Historical and sociological data play a secondary role, and their function is to confirm the dating which has been determined through the examination of the manuscripts.

78 Kashoun Hikmat, «The Arabic Versions of the Gospels. A Case Study of John 1,1 and 1,18 », in : Thомаs David Richard (éd.), The Bible in Arab Christianity, Leiden, Brill, 2007 (The History of Christian-Muslim Relations 6), pp. 9-36.

79 La version soutenue de la thèse est accessible en ligne depuis $2010:<\mathrm{http} / / /$ ethos.bl.uk/ OrderDetails.do?did=1\&uin=uk.bl.ethos.496010 >, consulté le 10.10.2017. Elle présente certaines différences, notamment au niveau de la datation de la traduction de Vat. Ar. 13,

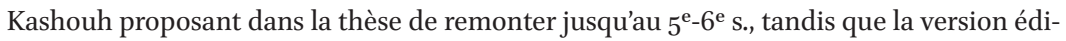
tée chez De Gruyter contient une datation plus basse, $6^{\mathrm{e}}-7^{\mathrm{e}} \mathrm{s}$.

8o Il en propose une liste abrégée: Kashoun, The Arabic Versions of the Gospels, The Manuscripts and their Families, op. cit., 2012, pp. 46-77.

81 Voir chapitre 6, point 2 État de la recherche sur le Vat. Ar. 13, ainsi que le chapitre 3, point 4 L'existence de traductions préislamiques, un point de vue minoritaire. 
This study suggests that the Gospels could have been first translated into Arabic in either the sixth or early seventh century ${ }^{82}$.

Si le travail de Kashouh a été critiqué pour ses conclusions concernant l'existence de traductions préislamiques ${ }^{83}$, il s'agit d'une étape importante dans la recherche, une entreprise de cette dimension n'ayant pas été menée à bien depuis Graf en 1944. La vue d'ensemble offerte sur les manuscrits arabes des évangiles est utile pour toute recherche future et permet de mettre en évidence la complexité de la tradition, au vu du nombre de familles décrites.

Un nombre de publications croissant (2012-2017)

On trouve en parallèle ou à la suite de la thèse de Kashouh un nombre important de publications. Joséphine Nasr édite en 2011 trois manuscrits, Leiden Universiteitsbibliotheek Or. 561 ( $15^{\text {e }}$ s.), Vat. Ar. 18 (daté de 993) et Vat. Ar. 17 (daté de 1009) contenant une traduction arabe en prose de l'évangile de $\mathrm{Luc}^{84}$. Les manuscrits contiennent les quatre évangiles. La traduction, d'origine syriaque, utilise la prose rimée dans le style du Coran ou de la poésie arabe. Dans un article de $1985^{85}$, Samir émettait l'hypothèse qu'il puisse s'agir de la traduction dont 'Abdišū' bar Brikhā a eu connaissance, la traduction d'Ibn Dādīšū', lorsqu'il compose son évangéliaire en prose rimée ${ }^{86}$.

En 2012, Samir Arbache édite l'évangile de Luc dans le Sin. Ar. 72, manuscrit daté de $897^{87}$. Arbache s'intéresse depuis de nombreuses années au Sin. Ar. 72, auquel il a consacré sa thèse, qui était restée non publiée jusqu'à présent ${ }^{88}$.

82 Kashoun, The Arabic Versions of the Gospels, The Manuscripts and their Families, op. cit., 2012, p. 326.

83 Voir chapitre 6, point 2 État de la recherche sur le Vat. Ar. 13.

84 NASR Joséphine, Une traduction arabe de l'Évangile de Luc, Beyrouth, CEDRAC, 2011 (Patrimoine arabe chrétien 26).

85 SAmir Samir Khalil, «Une réponse implicite à l'ǐḡāz du Coran: l'Évangéliaire rimé de 'Abdišū'», Proche-Orient Chrétien 35, 1985, pp. 225-237.

86 L'évangéliaire en prose rimée a été édité en 2007 : Khoury Sami et SAmir Samir Khalil, L'Évangéliaire arabe rimé de 'Abdǐšü'de Nisibe (†1318), Beyrouth, CEDRAC, 2007 (Patrimoine arabe chrétien 19-20).

87 Arbache Samir, L'Évangile arabe selon saint Luc: texte du VIIIe siècle, copié en 897, Bruxelles, Safran, 2012.

88 Аввасне Samir, Uneversion arabe desévangiles:Langue, texte et lexique, Ph.D., Université Michel de Montaigne Bordeaux III, 1994. Voir aussi : Arbache Samir, Le tétraévangile Sinai arabe 72, ses rubriques liturgiques et son substrat grec, Mémoire de licence, Université catholique de Louvain, 1975 . 
En 2013 parait le livre de Griffith, The Bible in Arabic. The Scriptures of the «People of the Book» in the Language of Islam. L'ouvrage de Griffith se veut une synthèse des connaissances sur le Bible en arabe :

So while the present study makes no substantive contribution to the study of the Bible in Arabic per se, its purpose is to call attention to the progress that has been made by others in this undertaking, to provide an overview of the significant topics in early Islamic history in which the Bible has a major part, and not least to highlight the social and interreligious developments that resulted from the very fact of having the scriptures of the «People of the Book» in the language of Islam ${ }^{89}$.

Il reprend ainsi plusieurs des questions importantes de la recherche au vu des nouvelles publications, se prononçant à nouveau en faveur des premières traductions datant du premier siècle abbasside. On remarquera que Griffith, malgré le titre généraliste de son livre, se concentre principalement sur les traductions les plus anciennes ${ }^{90}$.

En 2014, Samuel Moawad publie une édition critique des quatre évangiles selon la version de Ibn al-Assāl, se basant sur huit manuscrits ${ }^{91}$.

Enfin, une édition du Munich Staatsbibliothek Ar. 238 qui contient la version andalouse des évangiles de Isḥāq ibn Balašk été publié en $2016^{92}$. MonferrerSala complexifie le dossier en éditant une autre version «mozarabe» des évangiles préservée dans le manuscrit fragmentaire Qarawiyyīn 730, qui serait plus ancienne ${ }^{93}$.

Monferrer-Sala a quant à lui publié ces dernières années différents articles importants pour l'étude du Vat. Ar. 13 que nous discutons au chapitre 6, point 2 État de la recherche sur le Vat. Ar. 13.

89 GRIFFIt H, The Bible in Arabic. The Scriptures of the «People of the Book» in the Language of Islam, op. cit., 2013, p. 2.

9o Herman Teule regrettait l'absence de mention des productions faites en Mésopotamie du Nord et de l'Est entre le $11^{\mathrm{e}}$ et le $14^{\mathrm{e}} \mathrm{s}$. dans sa conférence sur la traduction des évangiles par 'Abdišū' bar Brikhā du 22 avril 2015 (<http://www.unil.ch/nt-arabe/colloque-2015/>, consulté le 8.02.2016.

91 Moawad Samuel, Al-As'ad Abū al-Farağ Hibat Allāh ibn al-'Assāl: Die arabische Übersetzung der vier Evangelien, Le Caire, Alexandria School, 2014.

92 Kassis, An Andalusian Arabic Version of the Four Gospels (Bayer. Staatsbibl., München, cod. arab. 238), op. cit., 2016.

93 Monferrer-Sala Juan Pedro, Evangelio Árabe fragmentario de Marcos (Ms. Qarawiyyīn 730) : una traducción árabe andalusí del siglo X. Edición diplomática y estudio preliminar, Cordoba, UCOPress, CNERU, CEDRAC, 2016 (Syro-Arabica). 


\section{$9 \quad$ Les lettres de Paul, parent pauvre de la recherche}

Comme nous pouvons le constater après cet état de la recherche sur les manuscrits arabes du Nouveau Testament, les études concernant les lettres de Paul sont particulièrement peu nombreuses, la recherche s'étant dans l'ensemble concentrée sur les évangiles. En effet, les chercheurs semblent considérer que les évangiles furent traduits en premier, et davantage que les autres livres du Nouveau Testament (voir à ce propos chapitre 4, point 1). Nous montrons pourtant dans la deuxième partie de notre thèse que le corpus paulinien en arabe représente une tradition tout aussi importante.

Le manuscrit Sin. Ar. 155 est le premier manuscrit des lettres pauliennes à faire l'objet d'une étude approfondie. Gibson en édite le texte en $1894^{94}$. Le manuscrit, trouvé au Monastère Sainte-Catherine Mont Sinaï en 1892, comprend Romains, Corinthiens, Galates et une partie d'Éphésiens (1,1-2,9); la première partie du manuscrit contient le Siracide. Le codex daterait du $9^{\mathrm{e}} \mathrm{s}$. et contient une traduction faite à partir du grec. Le manuscrit serait une copie d'un modèle plus ancien. Graf relèvera que la suite du texte, de Éphésiens 2,9 à Timothée 2,12a ainsi que Hébreux, se trouve dans le manuscrit Londres BL Or. $8612^{95}$.

Dans son article «Arabic Versions», Burkitt signale, au côté du Sin. Ar. 155, le Vat. Ar. 13 ( $8^{\mathrm{e}}$ ou $9^{\mathrm{e}} \mathrm{s}$.), traduit du grec, ainsi qu'un manuscrit se trouvant à Saint-Pétersbourg, Bibl. Nat. Ar. New Series $327^{96}$. Datant de 892, ce dernier manuscrit, apporté par Tischendorf «de l'Est», contient le corpus paulinien. Cette version serait faite à partir d'une «Nestorian copy of the Peshîttâ » ${ }^{97}$.

Dans sa liste des manuscrits arabes du Nouveau Testament, Gregory propose 41 manuscrits contenant le texte paulinien, allant de quelques fragments

94 Gibson, An Arabic Version of the Epistles of St Paul to the Romans, Corinthians, Galatians with Part of the Epistles to the Ephesians, op. cit., 1894. Il nous faut mentionner ici une thèse non publiée: BoyD R.H., The Arabic text of I Corinthians in «Studia sinaitica no. II »; a Comparative Linguistic and Critical Study, Princeton, Princeton University, 1942. Lauteur y défendrait l'origine préislamique du texte. Blau trouve sa conclusion infondée, voir BLAU Joshua, «The State of Research in the Field of the Linguistic Study of Middle Arabic », Arabica (28), 1981, p. 194.

95 Krenkow F., « Two Ancient Fragments of an Arabic Translation of the New Testament», Journal of the RoyalAsiatic Society (New Series) 58(2), 1926, pp. 275-285. En ligne :Cambridge Journals Online, <http://journals.cambridge.org/article_Soo35869Xooo69288>, consulté le 11.11.2014. Voir la notice 117 dans le chapitre 4.

96 Voir la notice 150 dans le chapitre 4.

97 BurkitT, « Arabic Versions », art. cit., 1898. 
au corpus complet ${ }^{98}$. Graf poursuit ce catalogue, ajoutant une centaine de manuscrits pauliniens à la liste de Gregory, et esquisse une classification selon les Vorlagen (voir point 4 La contribution de Georg Graf (1944)) ${ }^{99}$.

Il faut attendre 1983 pour retrouver l'étude complète d'un manuscrit arabe de lettres de Paul : Harvey Staal édite le Sin. Ar. 151, qui contient le corpus paulinien, ainsi que les Actes des Apôtres et les lettres catholiques ${ }^{100}$. Il transcrit et traduit les quatorze épîtres pauliniennes. Le manuscrit contient un colophon datant de l'an 867, mais la composition de l'entier du manuscrit s'est faite dans un laps de temps plus large : deux autres colophons attestent de deux révisions entre 1030 et 1035. En plus du texte biblique, le manuscrit comprend des indications liturgiques, des gloses et de nombreux commentaires. Il est intéressant de noter que le second scribe a parfois inséré la formule « musulmane » Bismillāh ar-rạ̣mān ar-raḥim ( « au nom de Dieu clément et miséricordieux »), qui commence les sourates du Coran. D'après l'étude de Staal, la traduction reflète de toute évidence une Vorlage syriaque ${ }^{101}$.

Avant l'édition de Staal, Joseph Nasrallah mentionnait le Sin. Ar. $15^{1}$ dans un article ${ }^{102}$. Il y relève notamment l'homonymie du traducteur du Sin. Ar. 151 mentionné dans le colophon, Bišr ibn al-Sirrī, avec l'auteur, qui serait plus tardif, d'une traduction et d'un commentaire de l'évangile de Matthieu et Marc, et d'une préface et d'un commentaire de Daniel, mentionné dans l'introduction de la recension des évangiles de Ibn al-'Assāl. En 2004, Sebastian P. Brock s'intéresse au commentaire présent dans le Sin. Ar. 151. Il y note l'influence syriaque orientale : « [...] the Commentary in Sinai Arabic 151 offers another example of the ways in which the East Syriac exegetical tradition - including material deriving from Theodore of Mopsuestia - became available in Chalcedonian circles [...]. » ${ }^{103}$ Brock s'intéresse aussi à l'identité du traducteur, Bišr ibn al-Sirrī ; contrairement à Nasrallah, Brock pense qu'il s'agit de la même personne que l'auteur mentionné par Ibn al-'Assāl.

98 Gregory, Textkritik des Neuen Testamentes, op. cit., 1902, pp. 579-592.

99 GRAF, Geschichte der christlichen arabischen Literatur, op. cit., 1944, pp. 170-181.

100 StaAl, Mt. Sinai Arabic Codex 151 I: The Pauline Epistles, op. cit., 1983; StaAl, Mt. Sinai Arabic Codex 151 I: The Pauline Epistles, op. cit., 1983; StAAL, Mt. Sinai Arabic Codex 151 II : Acts of the Apostles, Catholic Epistles, op. cit., 1984.

101 Voir la discussion concernant la datation du manuscrit au chapitre 5, point 3.3.

102 Nasrallah Joseph, «Deux versions Melchites partielles de la Bible du IXe et du Xe siècles », Oriens Christianus 64, 1980, pp. 202-215. À propos de la recension d'Ibn al-'Assāl, voir chapitre 5, point 3.4 Remarques concernant les manuscrits du 13 s.

103 Ввоск Sebastian P., « A Neglected Witness to the East Syriac New Testament Commentary Tradition: Sinai Arabic MS 151 », in : Ebied Rifaat et Teule Herman (éds), Studies on the Christian Arabic Heritage, Louvain, Peeters, 2004 (Eastern Christian Studies 5), p. 215. 
Dans un article de 2005, Paul Féghali commente également le Sin. Ar. 151. Il confirme l'origine syriaque (Peshitta) de la traduction; la langue et le vocabulaire refléteraient les $9^{\mathrm{e}}-10^{\mathrm{e}} \mathrm{s}$. Pour Féghali, les commentaires s'apparentent à l'École théologique d'Antioche, avec un intérêt évident pour les discussions christologiques, qui marquèrent le christianisme oriental. Il ne semble pas avoir connaissance des conclusions de Brock quant à l'influence syriaque orientale ${ }^{104}$.

En 2011, Daniel Potthast s'intéresse à la lettre aux Romains dans le manuscrit Madrid BN $4971^{105}$. Il fait le point dans son article sur la situation des lettres en Paul en arabe dans la tradition andalouse chrétienne lors de l'« âge d'or » des traduction andalouses qui se situerait entre 850 à 950, notant le peu de témoins pauliniens. Il existe le manuscrit Madrid BN 4971 et le folio de la lettre aux Galates, Vat. Lat. $12900^{106}$, ainsi que six citations de Ibn Ḥazm, provenant de Romains, 1 Corinthiens, Galates et Philippiens. Le manuscrit Madrid BN 4971 contenait à l'origine vraisemblablement le Nouveau Testament complet, dont il reste aujourd'hui des fragments des évangiles et les lettres de Paul, avec lacunes (Tite et Philémon sont par ailleurs manquants). Potthast, qui édite la lettre aux Romains, pense que le texte, bien que le manuscrit soit plutôt récent, reflète bien une traduction andalouse ancienne, qui traduit fidèlement une recension hispanique de la Vulgate ${ }^{107}$.

Dans notre récente recherche sur le Venise Marciana Gr. 379, nous montrons que la traduction arabe qui s'y trouve est parente de celle présente dans le Vat. Lat. 12900 et le Madrid BN 4971. Ce manuscrit, qui contient toutes les lettres de Paul à l'exception de Philémon, représente donc un nouveau châ̂non important pour l'étude des traductions «mozarabes » faite à partir du latin ${ }^{108}$.

104 FÉG HALI Paul, «Les épîtres de Saint Paul dans une des premières traductions en arabe », Parole de l'Orient 30, 2005, pp. 103-130.

105 Роттнаsт, «Die andalusische Übersetzung des Römerbriefs », art. cit., 2011.

106 Voir les notices 121 et 184 dans le chapitre 4.

107 PоттнаST, «Die andalusische Übersetzung des Römerbriefs », art. cit., 2011, p. 83. À propos de la partie évangélique de Madrid BN 4971 l'article: Monferrer-Sala Juan Pedro, «Scripture and Translation an Arabic Fragment of the Gospel of Mark Preserved in Ms 4971 BNM », Journal of Eastern Christian Studies 70 (1-2), 2018, pp. 35-62.

108 Venise Marciana Gr. 379 est l'objet d'une recherche en ligne: <https://humarec.org>, consulté le 26.05.2017. Le projet est soutenu par le Fonds national suisse de la recherche (no. 169869). À propos de la traduction arabe, voir : Schulthess Sara, «Important Comments on the Arabic Translation», HumaRec, 02.05.2017, <https://www.humarec .org/index.php/continuous-publications-blog/25-important-comments-on-the-arabictranslation>, consulté le 26.05.2017. 
On mentionnera encore l'article de Monferrer-Sala de 2015 sur la lettre à Philémon du Vat. Ar. 13. Il considère l'épître traduite à partir du grec et du syriaque (à ce propos, voir chapitre 6, point 2 État de la recherche sur le Vat. Ar. 13 et chapitre 8, point 5.2. Une traduction aux origines multilingues $)^{109}$.

Enfin, en 2017, Vevian Zaki a publié un article consacré à une version d'origine grecque avec influence du syriaque, que l'on retrouve dans six manuscrits : Sin. Ar. 155 et Londres BL Or. 8612 (qui formaient un ensemble à l'origine); Sin. Ar. 73 et Paris BNF arabe 6725 (un manuscrit fragmentaire, qui contient une partie du Sin. Ar. 73) ; Sin. Ar. 159 et Sin. Ar. $160^{110}$.

109 Monferrer-Sala Juan Pedro, «The Pauline Epistle to Philemon from Codex Vatican Arabic 13 (Ninth Century CE): Transcription and Study », Journal of Semitic Studies 60 (2), 2015, pp. 341-371.

110 ZAKI Vevian, «The Textual History of the Arabic Pauline Epistles: One Version, Three Recensions, Six Manuscripts », in : HJÄLm Miriam L. (éd.), Senses of Scripture, Treasures of Tradition. The Bible in Arabic among Jews, Christians and Muslims, Leiden, Brill, 2017 (Biblica Arabica 5). 


\title{
Du désintérêt à la redécouverte : analyse d'un phénomène scientifique
}

\author{
$1 \quad$ La critique textuelle du Nouveau Testament se détourne des \\ manuscrits arabes
}

L'impression globale laissée par l'état de la recherche est plutôt négative. De manière générale, l'état des connaissances des manuscrits arabes du Nouveau Testament reste limité, le nombre de recherches étant restreint au vu de l'importance de cette tradition ${ }^{1}$. Kashouh dénombre plus de 210 manuscrits arabes du texte continu des évangiles, nous répertorions 197 manuscrits du texte continu des lettres de Paul (voir la partie Les manuscrits arabes des lettres de $P a u l)$. Il est évidemment difficile de « quantifier» le désintérêt de la recherche. À titre d'exemple, nous pouvons voir qu'une recherche sur la base de donnée Bibliographie biblique informatisée de Lausanne avec la vedette-matière «Critique textuelle du Nouveau Testament: Versions anciennes: Versions arabes» donne 15 résultats seulement (dont six références datant d'après 2011). À titre de comparaison, une recherche avec «Critique textuelle du Nouveau Testament: Versions anciennes : Versions arméniennes » obtient 61 résultats, une recherche «Critique textuelle du Nouveau Testament: Versions anciennes : Versions géorgiennes » obtient 27 résultats ${ }^{2}$.

Cet état de fait est souvent regretté par les chercheurs ; c'est par exemple le cas de Griffith, lorsqu'il écrit dans l'introduction à The Bible in Arabic :

1 À propos de l'importance de la tradition arabe chrétienne, voir par exemple: SAMIr Samir Khalil, «Rôle des Chrétiens dans la civilisation arabe», in : Monferrer-SAlA Juan Pedro (éd.), Eastern Crossroads. Essays on Medieval Christian Legacy, New Jersey, Gorgias Press, 2007, pp. 3-30 ; id., «La littérature arabe médiévale des Chrétiens », in : Aвumal ham Montserrat (éd.), Literatura Árabe-cristiana, Madrid, Universidad Complutense, 2001, pp. 21-49; SAU G ET Joseph-Marie, «La littérature arabe chrétienne ancienne: son intérêt pour les études sur l'Orient ancien», in: Duval-Arnould Louis et Rilliet Frédéric (éds), Littératures et manuscrits des chrétientés syriaques et arabes, Rome, Biblioteca Apostolica Vaticana, 1998 (Studi e Testi 389), pp. 147-174.

$2<$ https://bibil.unil.ch/>, recherche effectuée le 20.01.2016.

(C) SARA SCHULTHESS, 2019 | DOI:10.1163/9789004378162_004

This is an open access chapter distributed under the terms of the prevailing CC-BY-NC License at the time of publication. 
The study of the Bible in Arabic is in its infancy. There are hundreds of extant manuscripts containing portions of the Bible in Arabic translations produced by Jews and Christians in early Islamic times and well into the Middle Ages. But until now, with some notable exceptions, they have been of little interest to either biblical scholars or even to historians of Judaism, Christianity, or Islam ${ }^{3}$.

Pourtant, le désintérêt n'a pas toujours été de mise. Au $17^{\mathrm{e}} \mathrm{s}$., les versions arabes de la Bible hébraïque et du Nouveau Testament, sous leurs formes éditées (voir chapitre 2) suscitaient l'intérêt des chercheurs. Ronny Vollandt suggère trois facteurs d'intérêt à cette époque ${ }^{4}$. (1) L'utilité pour la critique textuelle : « First, they played a crucial role in the new erudite discipline of Philologia Sacra, being considered an important source for textual criticism of the Bible. $»^{5}$ Il donne comme exemple Franciscus Junius, qui en 1578 déjà utilisa une traduction arabe des Actes et des épîtres aux Corinthiens pour les comparer au Textus receptus grec ${ }^{6}$. (2) L'intérêt linguistique : «in the 17 th century grammars and texts in Arabic were not easily obtainable, thus Arabic translations of biblical portions aptly substituted as textbooks for students of the language. $»^{7}$ Les chercheurs pouvaient ainsi étudier de manière synoptique les versions arabes et les langues sources, ce qui facilitait l'apprentissage de la langue arabe. Cet intérêt est illustré par le travail de Thomas Erpenius, qui fut le premier à éditer le Nouveau Testament complet en arabe et qui publia plusieurs grammaires arabes ${ }^{8}$. (3) L'intérêt missionnaire: «Third, biblical translations into Arabic were perceived as a necessary instrument for missionary agitation in

3 Griffith Sidney H., The Bible in Arabic. The Scriptures of the «People of the Book» in the Language of Islam, Princeton, Princeton University Press, 2013, p. 1.

4 Vollandt Ronny, «Some Historiographical Remarks on Medieval and Early-Modern Scholarship of Biblical Version in Arabic : A Status Quo », Intellectual History of the Islamicate World 1, 2013, pp. 25-42.

5 Ibid., p. 31. Voir aussi Miller Peter N., « Les origines de la Bible Polyglotte de Paris : Philologia Sacra, contre-Réforme et raison d'État», XVIIe siècle 49, 1997, pp. 57-66.

6 Vollandt, «Some Historiographical Remarks on Medieval and Early-Modern Scholarship of Biblical Version in Arabic: A Status Quo », art. cit., 2013, p. 31, voir note 18. Voir aussi FüCK Johann W., Hartmann Richard et Sche el Helmuth, Die arabischen Studien in Europa bis in den Anfang des 20. Jahrhunderts, Leipzig, Otto Harrassowitz, 1955, pp. 44-45.

7 VollandT, «Some Historiographical Remarks on Medieval and Early-Modern Scholarship of Biblical Version in Arabic : A Status Quo », art. cit., 2013, p. 32.

8 Michaud Louis-Gabriel, "Thomas van Erpe», in: Biographie universelle ancienne et moderne : histoire par ordre alphabétique de la vie publique et privée de tous les hommes avec la collaboration de plus de 300 savants et littérateurs français ou étrangers, vol. $12,2^{\mathrm{e}}$ édition, 1843-1865. 
the Near East. $»^{9}$ Les intérêts missionnaires au Proche-Orient ont notamment poussé l'Église catholique romaine à s'intéresser à l'arabe et à son usage par les chrétiens ${ }^{10}$. Le projet d'éditer une Bible en arabe fut à ses débuts soutenue par le pape Grégoire XIII (1572-1585), un des acteurs importants dans le rapprochement de l'Église catholique avec les Églises d'Orient, en particulier avec l'Église maronite, un rapprochement qui mena à la fondation du Collège maronite en 1584 chargé de former une partie du clergé maronite à Rome ${ }^{11}$. Le Collège fut un des moteurs dans le projet d'édition d'une Bible en arabe. L'édition dite de la Propaganda Fide, organe pontifical d'évangélisation fondé à la fin $\mathrm{du}_{16} 6^{\mathrm{e}}$ s., fut éditée finalement en 1671. Elle devait refléter un texte arabe de la Bible conforme à la Vulgate en vue de son usage en Orient; selon Paul Féghali, celle-ci devait prévenir un mouvement protestant en Orient, l'orientaliste néerlandais Thomas Erpenius ayant édité un Nouveau Testament arabe en $1616^{12}$.

Nous avons vu dans le chapitre précédent qu'au début du $19^{\mathrm{e}}$ s., lors de l'établissement des premières éditions critiques modernes du Nouveau Testament, les versions arabes - sous leur forme éditée principalement, à l'exception de la première édition de Tischendorf qui mentionne le manuscrit Vat. Ar. 13 - sont intégrées comme témoins textuels. Elles ont toutefois été rapidement écartées par la suite, une conséquence de l'opinion que celles-ci seraient trop récentes,

9 Vollandt, «Some Historiographical Remarks on Medieval and Early-Modern Scholarship of Biblical Version in Arabic: A Status Quo », art. cit., 2013, p. 33.

10 Dans la monographie sur les études arabes en Europe, Fück explique: «Aber die Missions- und Unionsbestrebungen der römisch-katholischen Kirche ließen sich ohne sprachlich geschulte Missionare nicht durchführen und waren der erste Anlaß zu einem ernsthaften Studium der arabischen Sprache im Abendlande, welches im spanischen Frühhumanismus seine Blüte erreichte und ein Jahrhundert später in der Mediceischen Druckerei den arabischen Typendruck schenkte. » FüCK, HaRtmann et ScheEL, Die arabischen Studien in Europa bis in den Anfang des 20. Jahrhunderts, op. cit., 1955, p. VII.

11 Les liens entre l'Église catholique romaine et les Églises orientales, principalement avec l'Église maronite et l'Église dite nestorienne, s'intensifient au $16^{e} \mathrm{~s}$. L'union avec Rome d'une partie de cette dernière donnera naissance à l'Église chaldéenne à la moitié du $16^{6} \mathrm{~s}$. Sur ces deux communautés, voir par exemple: Mouawad Ray J., Les Maronites. Chrétiens du Liban, Turnhout, Brepols, 2009. Teule Herman, Les Assyro-Chaldéens. Chrétiens d'Irak, d'Iran et de Turquie, Turnhout, Brepols, 2008. Sur l'activité missionnaire du Vatican, voir Heyberger Bernard, Les chrétiens du Proche-Orient au temps de la réforme catholique (Syrie, Liban, Palestine, XVIIe-XVIIIe siècles), Rome, École française de Rome, 1994 (Bibliothèque des écoles françaises d'Athènes et de Rome 284).

12 FÉG HALI Paul, «The Holy Books in Arabic :The Example of the Propaganda Fide Edition », in: Binay Sara et Leder Stefan (éds), Translating the Bible into Arabic: Historical, TextCritical and Literary Aspects, Würzburg, Beyrouth, Ergon-Verlag, 2012 (Beiruter Texte und Studien 131), pp. 37-38. Voir aussi : Vollandt Ronny, Arabic Versions of the Pentateuch. A Comparative Study of Jewish, Christian, and Muslim Sources, Leiden, Brill, 2015 (Biblia Arabica 2), pp. 129-132. 
ou encore parce qu'elles ne seraient pas des traductions faites directement depuis le texte grec. C'est l'avis exprimé par exemple par Davidson ou encore Nestle (voir chapitre 2, point 2); de même, si Gregory se donne la peine de répertorier cent trente-sept manuscrits arabes du Nouveau Testament, il ne les tient pas pour intéressants : «Die drei letzten [les versions géorgienne, perse et arabe] haben meiner Meinung nach noch nicht bewiesen, dass man etwas Wertvolles für die Kritik des griechischen Textes aus ihnen holen kann. »13 Par la suite, les chercheurs en critique textuelle du Nouveau Testament semblent avoir intégré cette appréciation. On trouve en 1990 des propos très semblables à ceux prononcés au tournant du $19^{\mathrm{e}} \mathrm{s}$., par exemple dans l'ouvrage de David Ewert: «Since the Arabic versions are so late, they are not useful as witnesses to the original text of New Testament. ${ }^{14}$ Les manuels de critique textuelle $\mathrm{du}$ Nouveau Testament accordent rarement davantage que quelques lignes aux versions arabes ${ }^{15}$; c'est le cas pour l'ouvrage de référence des Aland, qui offre une courte notice sur laquelle nous reviendrons plus bas ${ }^{16}$. Dans l'ouvrage plus récent édité par Bart Ehrman et Michael Holmes, considéré comme important pour la discipline ${ }^{17}$, les versions arabes sont mentionnées dans une unique note de bas de page ${ }^{18}$. La maigre contribution des chercheurs en critique textuelle du Nouveau Testament explique en partie la situation de l'état de la recherche,

13 Gregory Caspar René, Textkritik des Neuen Testamentes, vol. 2, Leipzig, Hinrichs, 1902, p. 486.

14 EWERT David, A General Introduction to the Bible: from Ancient Tablets to Modern Translations, Grand Rapids, Zondervan, 1990, p. 171.

15 Peters le notait déjà en 1942: «Die arabischen Bibelübersetzungen haben sicher jene stiefmütterlich Behandlung nicht verdient [...]. Man nehme nur irgendein Handbuch der alt- oder neutestamentlichen Einleitungswissenschaft zur Hand [...]. In den meisten Fällen wird man finden, dass, wenn der Verfasser den arabischen Texten überhaupt einen Platz in der Sonne gönnt, dieser Platz so klein und so abgelegen ist, dass man meinen sollte, ihm eigentlich keine besondere Aufmerksamkeit schuldig sein.» Peters Curt, «Grundsätzliche Bemerkungen zur Frage der arabischen Bibeltexte », Rivista degli studi orientali 20 (1), 1942, p. 129.

16 Aland Kurt et Aland Barbara, The Text of the New Testament: An Introduction to the Critical Editions and to the Theory and Practice of Modern Textual Criticism, $2^{\mathrm{e}}$ édition, Grand Rapids, Eerdmans Publishing Co., 1995 (Studies and Documents 46), p. 214.

17 Voir la liste des ouvrages essentiels selon le site Evangelical Textual Criticism, qui est un des sites les plus actifs au sujet de la critique textuelle du Nouveau Testament: <http:// evangelicaltextualcriticism.blogspot.de/2012/og/top-ten-essential-works-in-new.html>, consulté le 31.01.2016.

18 Pour comparaison, un article de 40 pages est consacré aux versions arméniennes, plus de 30 pages à la version géorgienne et plus de 20 pages à la version gothique. EHRMAN Bart D. et Holmes Michael W., The Text of the New Testament in Contemporary Research: Essays on the Status Quaestionis. Second Edition, Leiden, Brill, 2012 (New Testament Tools, Studies and Documents 42), voir la note 58, p. 247. 
ceux-ci n'ayant plus contribué, à partir de la seconde moitié du $19^{\mathrm{e}} \mathrm{s}$. au champ d'étude des manuscrits arabes du Nouveau Testament.

\section{Un mépris aux racines « orientalistes »?}

Une question se pose alors: le fait que les manuscrits arabes du Nouveau Testament soient considérés par la recherche néotestamentaire comme trop récents ou leurs traductions comme secondaires suffit-il à expliquer cette exclusion? Premièrement, on remarquera que, de manière générale, une datation tardive d'un manuscrit ne devrait pas, selon les principes méthodologiques de la critique textuelle même, suffire à exclure celui-ci, les critères internes tels que la qualité du texte pouvant être tout aussi importants ${ }^{19}$. C'était déjà une des critiques de Renouf en réponse à Davidson en 1863 (voir chapitre 2, point 2) : «A manuscript of the third or fourth century may possibly contain the most absurd readings, even though written in the most splendid uncials. And a rudely executed cursive MS. of the tenth or twelfth century may, on the other hand, have been copied from an extremely ancient uncial MS. of the highest critical authority. ${ }^{20}$ Deuxièmement, classer les traductions arabes comme secondaires ou tertiaires, parce qu'elles ne seraient pas faites sur le texte grec du Nouveau Testament, c'est ne pas prendre en compte les résultats de la recherche : depuis 1888 au moins avec l'ouvrage de Guidi, il est établi qu'il existe des groupes de manuscrits traduits directement depuis le grec; par la suite, plusieurs chercheurs se sont concentrées sur les manuscrits traduits du grec - au détriment de la tradition se basant sur le syriaque, comme le regrette Kashouh21.

Une remarque de Gregory sur les versions orientales laisse entrevoir une autre raison. Dans sa partie consacrée aux versions du Nouveau Testament, celui-ci fait la distinction entre les «östliche Übersetzungen», comprenant les versions syriaque, égyptienne, éthiopienne, arménienne, géorgienne, perse

19 Seuls les manuscrits grecs antérieurs au $5^{\mathrm{e}} \mathrm{s}$. sont directement intégrés dans la catégorie I («Manuscripts of very special quality») selon la méthode des Aland. Pour les autres manuscrits, c'est l'étude de leur texte qui détermine leur importance, Aland et Aland, The Text of the New Testament: An Introduction to the Critical Editions and to the Theory and Practice of Modern Textual Criticism, op. cit., 1995, p. 159.

20 Renouf le Page Peter, «On the Supposed Latin Origin of the Arabic Version of the Gospels », Atlantis : or Register of Literature and Science of the Catholic University of Ireland 4, 1863 , p. 258.

21 Kashou H Hikmat, The Arabic Versions of the Gospels, The Manuscripts and their Families, Berlin, Boston, De Gruyter, 2012 (Arbeiten zur neutestamentlichen Textforschung 42). 
et arabe, et les «westliche Übersetzungen », comprenant les versions latine, gothique, slavonne, saxonne, francique et tchèque ${ }^{22}$. En introduction, il dit alors à propos des versions orientales :

Jesus ist im Osten geboren, hat im Osten gelebt, hat eine östliche Sprache geredet [...]. Jesus war Semit, doch ist das Neue Testament in seiner Einkleidung nicht semitisch sondern griechisch, und verbindet sich dadurch mit dem zwar indischen aber auch in der Folge europäischen, westeuropäischen Sprachstamm. [...] Die östlichen Übersetzungen stehen dem Text des Neuen Testamentes und stehen uns, indem wir sie befragen, ferner als die westlichen Übersetzungen.

Gregory semble donc ici discriminer les versions «orientales» au profit des versions «occidentales». Or les critères de Gregory pour distinguer les premières des secondes ne sont pas clairs. On pourrait supposer qu'il fait ici une distinction géographique, ou peut-être confessionnelle ${ }^{23}$. Gregory lui-même semble cependant motiver linguistiquement cette distinction, vu qu'il mentionne l'origine sémitique et indo-européenne. Cette approche n'est pourtant pas fondée linguistiquement, des langues telles que l'arménien ou le perse étant déjà reconnues comme indo-européennes à l'époque de Gregory ${ }^{24}$.

Ces propos, qui nous semblent donc infondés, ne sont pas sans évoquer certains aspects de l'orientalisme tel que décrit par Edward Said à propos de nombreuses productions universitaires de l'époque. La thèse de Said est qu'aux disciplines de l'orientalisme en tant que recherche sur l'Orient en général ou dans tel domaine particulier, «se rattache une conception plus large de l'orientalisme: style de pensée fondé sur la distinction ontologique et épistémologique entre 'l'Orient' et (le plus souvent) 'I'Occident'. » ${ }^{25}$ Cet orientalisme est à la fois la cause et le résultat d'une position dominante de l'Occident sur l'Orient, s'immisçant tant dans les discours politiques, dans la littérature, dans la culture générale ou dans les productions académiques; Said souligne

22 Gregory, Textkritik des Neuen Testamentes, op. cit., 1902.

23 Les communautés des versions mentionnées étant, à l'exception de l'Église géorgienne, orthodoxes orientales.

24 Par exemple: Bopp, Franz, Vergleichende Grammatik des Sanskrit, Şend, Armenischen, Griechischen, Lateinischen, Litauischen, Altslawischen, Gotischen und Deutschen, Berlin, 1833-52 ; SCHLEIER, August, Compendium der vergleichenden Grammatik der indogermanischen Sprachen (Kurzer Abriss der indogermanischen Ursprache, des Altindischen, Altiranischen, Altgriechischen, Altitalischen, Altkeltischen, Altslawischen, Litauischen und Altdeutschen), 2 vols., Weimar, H. Boehlau, 1861-62.

25 Said Edward W., L'Orientalisme. L'Orient créé par l'Occident, $2^{\mathrm{e}}$ édition, Paris, Seuil, 2005, p. 15 . 
d'ailleurs «l'échange continuel entre l'orientalisme universitaire et l'orientalisme de l'imaginaire ${ }^{26}$. Dans cette perspective, la philologie joue un rôle important, notamment l'approche comparative et le classement des langues en familles, qui offrent une structure à la pensée orientaliste. Ainsi, la distinction linguistique faite entre langues sémitiques et langues indo-européennes devient petit à petit ontologique :

[...] par la suite, le philologue trouve la possibilité de relier ces racines linguistiques, comme l'ont fait Renan et d'autres, à la race, à l'esprit, au caractère et au tempérament pris à leurs racines. [...] C'est ainsi que le comparatisme, dans l'étude de l'Orient et des Orientaux, est devenu synonyme de l'inégalité ontologique apparente entre l'Occident et l'Orient ${ }^{27}$.

La langue arabe aura particulièrement à souffrir des préjugés à l'égard des langues sémitiques, considérée comme «simple» et «mécanique » ${ }^{28}$. De plus, comme le fait remarquer Camille Héchaïmé à propos de la recherche sur l'Arabie préislamique au début du $20^{\mathrm{e}} \mathrm{s}$. : « Le grand public, même cultivé, tant en Orient qu'en Occident, était alors persuadé dans son ensemble, que tout ce qui était arabe était musulman. Le monde savant lui-même partageait en partie cette conception, que les progrès de la science orientaliste commençaient à peine à ébranler. ${ }^{29}$

Des préjugés à racines « orientalistes » selon le sens donné par Said sont à notre avis apparents dans les propos de Gregory ; pour le reste de la recherche, nous ne pouvons que le supposer sur la base de son absence, mais il est fort possible que ce contexte ait poussé la recherche néotestamentaire à se désintéresser des versions arabes. Ce qui est certain, c'est que les spécialistes de la critique textuelle du Nouveau Testament ne considèrent plus les manuscrits arabes comme faisant partie de leur champ de recherche. Pour cela, l'avis des Aland sur les versions arabes est parlant: «But unfortunately the arabists of today are hardly concerning themselves with the transmission of the New Testament, although there are many interesting problems here $[\ldots] »^{30}$. On voit

\footnotetext{
$26 \quad$ Ibid.

27 Ibid., p. 175 .

28 ERrington Joseph, Linguistics in a Colonial World: A Story of Language, Meaning, and Power, Malden, Blackwell, 2008, p. 73 .

29 Нес наїме́ Camille, Louis Cheikho et son livre «Le christianisme et la littérature chrétienne en Arabie avant l'Islam », Beyrouth, Dar el-Machreq, 1967 (Langue et littérature arabes 38 ), p. 187 .

30 Aland et Aland, The Text of the New Testament: An Introduction to the Critical Editions and to the Theory and Practice of Modern Textual Criticism, op. cit., 1995, p. 214.
} 
que selon eux, les manuscrits arabes du Nouveau Testament sont du ressort des arabisants. De fait, les contributions importantes du $20^{\mathrm{e}}$ s. ne sont pas le fruit de néotestamentaires, mais bien d'orientalistes.

On notera encore qu'il s'agit majoritairement d'orientalistes venant de sphères catholiques romaines - Louis Cheikho, Ignazio Guidi, Georg Graf, Anton Baumstark -, ce qui s'inscrit ici dans la tradition de la culture orientaliste catholique romaine née au ${ }_{16}{ }^{\mathrm{e}} \mathrm{s}$. autour de la Bible en arabe. De même que les velléités d'influence de la part de l'Eglise catholique romaine ont favorisé à l'époque le développement de l'orientalisme à Rome, il est fort probable que la renaissance de la mission catholique au sein de l'empire ottoman à partir de la seconde moitié du $19^{\mathrm{e}} \mathrm{s}$. jusqu'à la seconde guerre mondiale ait pu contribuer à garder en vie du côté catholique romain l'intérêt pour les versions arabes ${ }^{31}$. Dans ce contexte, il est toutefois étonnant que la France se soit pas représentée parmi les chercheurs, elle qui était en charge depuis le $17^{\mathrm{e}} \mathrm{s}$. de la protection consulaire des religieux catholiques envoyés dans l'Empire Ottoman et qui peu à peu s'attribuera la protection des catholiques orientaux, étendant ainsi son influence jusqu'à l'avènement du mandat français syro-libanais (1920-1943) ${ }^{32}$.

L'effet de la mission protestante américaine, dont le champ d'action se concentra en Syrie ottomane, ne fut pas similaire. Le développement de celle-ci peut être notamment retracé grâce à l'ouvrage de Henry H. Jessup, arrivé à Beyrouth en 1856. La mission américaine donna naissance à une nouvelle traduction de la Bible, la Bible Van Dyke-Smith. Il s'agit d'une des traductions les plus répandues et les plus lues dans le monde arabe; elle a notamment été adoptée par l'Église copte. L'entreprise de traduction dura plus de 20 ans, jusqu'en 1865. Dans son ouvrage sur la traduction Van Dyke-Smith, David D. Grafton montre qu'elle s'inscrit dans les débats scientifiques de l'époque autour de la critique textuelle de la Bible et du texte original ${ }^{33}$. La mission américaine ne semble toutefois pas avoir favorisé une recherche scientifique sur les manuscrits arabes du Nouveau Testament. Jessup décrit ainsi l'entreprise de traduction de la Bible en arabe : «To give the Word of God to forty millions of perishing sinners $[\ldots]$ : in short, to give them a Christian literature,

31 Sur cette période, voir Riffier Jean, Les oeuvres françaises en Syrie (1860-1923), Paris, L'Harmattan, 2000, pp. 25-48. Voir aussi Fraze Charles A., Catholics and Sultans. The Church and the Ottoman Empire (1453-1923), Londres, New York, Cambridge University Press, 1983 .

32 Cloarec Vincent et Laurens Henry, Le Moyen-Orient au $20^{e}$ siècle, Paris, Armand Colin, 2003, pp. 16-17.

33 Grafton David D., The Contested Origins of the 1865 Arabic Bible: Contributions to the Nineteenth Century Nahda, Leiden, Boston, Brill, 2015 (History of Christian-Muslim Relations 26), pp. 121-154. 
or that germinating commencement of one $[\ldots] .{ }^{34}$ Cela reflète pour le moins une méconnaissance de l'histoire des traductions bibliques arabes, sans parler de l'histoire du christianisme oriental de manière générale. La description de l'arrivée en Syrie de la mission américaine faite par Grafton va dans ce sens :

The Americans arrived in Syria and then had a steep cultural learning curve, although they rarely recognized this. [...] It does not appear from their writings that these early missionaries recognized that any form of cultural interactions would prove important for their work. Rather, references to Syrian culture of the day were littered with derogatory and negative comments. In fact, their naiveté regarding Syrian culture was one reason for their lack of early success in gaining convert ${ }^{35}$.

Cette situation va évoluer et Grafton note à quel point la traduction Van DykeSmith est le fruit d'une collaboration avec les différentes communautés locales:

At the end, not only does the [received tradition] «silence» the «native helpers », but it also silences the translation's « suprareligious » context (Evangelical, Catholic, Sunni Muslim, American, and Syrian interaction) which has been publicly overlooked. The so-called Van Dyck translation was truly a marker of boundary crossing ${ }^{36}$.

Malgré cela, la recherche sur les manuscrits n’a pas été stimulée par cette importante initiative. Dans son rapport sur les « existing Arabic versions of the Scriptures », Eli Smith fait l'état des éditions mais ne mentionne pas les traditions manuscrites ${ }^{37}$; par la suite, le milieu américain protestant ne semble pas avoir été un terrain favorable à la recherche sur les manuscrits arabes du Nouveau Testament, avant de nombreuses années du moins ${ }^{38}$.

34 Jessup Henry H., Fifty-Three Years in Syria, vol. 1, New York, Fleming H. Revell Co., 1910, pp. 68-69. Comme le note Grafton, cet ouvrage appartient au genre de l'historiographie missionnaire, Grafton, The Contested Origins of the 1865 Arabic Bible, op. cit., 2015, p. 1.

35 Grafton, The Contested Origins of the 1865 Arabic Bible, op. cit., 2015, p. 64.

36 Ibid., p. 234.

37 Smith Eli et Van Dyck C.V.A., Brief Documentary History of the Translation of the Scriptures Into the Arabic Language, Beyrouth, American Presbyterian Mission Press, 1900, pp. 1-4.

38 Dans un autre cadre, on peut mentionner l'American Foundation Mt. Sinai Expedition, avec le catalogue des manuscrits arabes de Atiya (AтіYA Aziz Suryal, The Arabic Manuscripts of Mount Sinai : A Hand-List of the Arabic Manuscripts and Scrolls Microfilmed at the Library of the Monastery of St. Catherine, Baltimore, John Hopkins Press, 1954). Il y a aussi le travail 


\section{Évolution de la critique textuelle du Nouveau Testament et reprise du champ}

Comme nous l'avons signalé ci-dessus (voir chapitre 2, point 7 et suivant), on assiste depuis les années 2010 à une forte reprise de la recherche, illustrée par de nombreuses publications et différents projets. Il est intéressant de constater que cette reprise a lieu également dans le champ des études néotestamentaires. Par exemple, en 2015, une session consacrée à la Bible en arabe est créée à l'occasion du Annuel Meeting de la Society of Biblical Literature ${ }^{39}$, alors que les présentations sur le sujet étaient jusqu'alors dispersées dans d'autres sessions ${ }^{40}$; il en va de même en 2015 pour la rencontre de l'European Association of Biblical Studies, qui organise pour la première fois une session The Bible in Arabic in Judaism, Christianity, Islam ${ }^{41}$, qui sera renouvelée en 2016. C'est dans ce contexte de reprise que s'inscrit également le projet de recherche, accepté par le Fonds national suisse de la recherche scientifique en 2012 et conduit de 2013 à 2016, dont le présent travail est l'aboutissement ${ }^{42}$.

Dans ce contexte de reprise, la publication de la thèse de Kashouh est significative: en effet, celle-ci s'inscrit bien dans le cadre de la discipline de la critique textuelle du Nouveau Testament, méthodologiquement (dans son approche phylogénétique notamment) ${ }^{43}$, aussi bien qu'institutionnellement. En effet, la thèse a été dirigée par David C. Parker, acteur important de la recherche actuelle, et elle a été publiée dans la série Arbeiten zur neutestamentlichen Textforschung ${ }^{44}$ qui est éditée par l'Institut für neutestamentliche

de Harley Staal (qui fut publié en Europe, dans la série Corpus Scriptorum Christianorum Orientalium (voir références dans la note 60 au chapitre 2).

39 Program Unit: Biblia Arabica : The Bible in Arabic among Jews, Christians, and Muslims, voir <http://www.sbl-site.org/meetings/Congresses_Abstracts.aspx?MeetingId=27>, consulté le 21.01.2016. <http://www.sbl-site.org/meetings/congresses_pastmeetings.aspx>, consultéle 21.01.2016. $<$ https://www.eabs.net>, consulté le 31.07.2018. Le site, réactualisé, a pour l'instant retiré les anciens programmes.

42 Fonds FNS 143810, <http://p3.snf.ch/Project-143810>, consulté le 09.04.2016.

43 Kashoun, The Arabic Versions of the Gospels, The Manuscripts and their Families, op. cit., 2012, p. 306. À propos de cette méthodologie inspirée des sciences de la vie: LiN Yii-Jan, The Erotic Life of Manuscripts : New Testament Textual Criticism and the Biological Sciences, Oxford, Oxford University Press, 2016. Malgré la nouveauté des méthodes qui nécessitent un appui informatique, Lin souligne qu'il s'agit d'une continuité : «Whatever the 'original text' or Ausgangstext may be, the continuing search for origins, as alive today as in the nineteenth century, has fueled textual criticism's use of phylogenetics for tracing the genetic ancestry of texts. »Ibid., p. 118 . 
Textforschung de Münster, responsable notamment de l'édition critique de référence du Nouveau Testament, le Nestle-Aland (NA28) ${ }^{45}$.

La critique textuelle du Nouveau Testament aurait-elle changé d'avis à propos des manuscrits arabes du Nouveau Testament? Depuis les années 9o, plusieurs chercheurs, tels que Bart Ehrman, Eddon J. Epp ou David C. Parker, ont donné une direction nouvelle à la critique textuelle du Nouveau Testament. Ehrman, dans The Orthodox Corruption of the Scriptures ${ }^{46}$, cherche à démontrer le travail de « corrections dogmatiques » des scribes, des modifications qui seraient déjà présentes dans les témoins textuels les plus anciens; son travail souligne l'importance de prendre en compte des critères autres que seulement textuels pour reconstruire l'histoire du texte. L'ouvrage, qui a rencontré un succès public et continue d'être très discuté aujourd'hui, a eu beaucoup d'impact sur la discipline. Robert Hull définit ainsi l'apport de Ehrman :

Ehrman's book appeared at a time when critical studies and related disciplines had begun to emphasize variety over consensus, multivalence over uniformity in early Judaism and Christianity. [...] In short, Ehrman's book (and its popularized successor, Misquoting Jesus [2005]) helped to make New Testament textual criticism relevant to a postmodern readership ${ }^{47}$.

On remarquera toutefois que Ehrman oppose un texte «altéré » à un «texte original»- supposant ainsi qu'un «texte original» du Nouveau Testament a circulé. Or d'autres chercheurs ont également remis en cause une critique textuelle du Nouveau Testament qui serait seulement une recherche du texte original, allant jusqu'à remettre en cause la notion même de texte original : "One of the most distinctive developments in New Testament textual criticism in the postmodern era and beyond is a broadening of its focus beyond the recovery of the original text to the history, motives, and effects of textual variation. $»^{48}$ Rompant avec la quête du texte original, le chercheur peut

45 <http://egora.uni-muenster.de/intf/index_en.shtml>, consulté le 21.01.2016. NestLE Eberhard et Nestle Erwin, Nestle-Aland Novum Testamentum Graece, 28 édition, Stuttgart, Deutsche Bibelgesellschaft, 2012.

46 Ehrman Bart D., The Orthodox Corruption of Scripture: The Effect of Early Christological Controversies on the Text of the New Testament, New York, Oxford, Oxford University Press, 1993.

47 Hull Robert F., The Story of the New Testament Text: Movers, Materials, Motives, Methods, and Models, Atlanta, Society of Biblical Literature, 2010, p. 154. La référence citée est: Ehrman Bart D., Misquoting Jesus: The Story Behind Who Changed the Bible and Why, New York, Oxford University Press, 2005.

48 Hull, The Story of the New Testament Text, op. cit., 2010, p. 154. Eldon J. Epp a largement contribué à la discussion, voir par exemple : Epp Eldon J., « The Multivalence of the Term 
« reconnecter» avec le texte tel qu'il a été transmis par le manuscrit ${ }^{49}$. Dans cette perspective, Parker défend que les textes ne sont pas des «archives of traditions but living texts $»^{50}$. Il est le premier à utiliser le terme de narrative textual criticism, qu'il définit ainsi : «It represents a move away from the traditional atomizing of texts into variant readings, towards a reconstitution of the fragments into an intelligible whole. ${ }^{51}$ Epp complète et popularisera cette notion: «This is the terminology introduced recently to describe a current approach among some New Testament textual critics who view textual variants, especially those readings rejected in critical editions, as informative about issues of concern in the early churches. $»^{52}$ Cette «nouvelle école $»^{53} \mathrm{a}$ vu le jour en réaction à l'abandon de certaines variantes et sûrement à une certaine «canonisation académique» du standard text du Nestle-Aland, qui privilégie un certain type de texte, le type alexandrin ; Parker s'est par exemple beaucoup investi dans la recherche sur le codex de Bèze, qui contient un type de texte différent, le type dit « occidental $»^{54}$. C'est aussi le cas de Epp ${ }^{55}$. Jusqu’à présent, c'est l'attention portée aux différents témoins grecs qui était en jeu dans ce débat. Mais la problématique concerne tout autant les versions du Nouveau Testament, qui sont, elles aussi, les témoins du living text du Nouveau Testament.

“Original Text" in New Testament Textual Criticism », Harvard Theological Review 92, 1999, pp. 245-299.

49 Voir aussi chapitre 1, point 2 Remarques épistémologiques et chapitre 9, point 1 Lire une traduction: enjeux.

50 Parker David C., The Living Text of the Gospels, Cambridge, Cambridge University Press, 1997, p. 117.

51 Parker David C., «Review. The Orthodox Corruption of Scripture. By Bart Ehrmann, Oxford University Press, 1993. », Journal of Theological Studies 45 (2), 1994, p. 704.

52 Epp Eldon J., «It's All About Variants: A Variant-Conscious Approach to New Testament Textual Criticism », Harvard Theological Review 100 (3), 2007, p. 288.

53 Des critiques avaient déjà été émises précédemment. En 1936, Donald W. Riddle écrivait déjà : «The legitimate task of textual criticism is not limited to the recovery of approximately the original form of the documents, to the establishment of the 'best' text, nor to the 'elimination of spurious readings'. It must be recognized that every significant variant records a religious experience which brought it into being. This means that there are no 'spurious readings' : the various forms of the text are sources for the study of the history of Christianity. » Riddle Donald, «Textual Criticism as a Historical Discipline », Anglican Theological Review 18, 1936, p. 222.

54 Parker David C., Codex Bezae: An Early Christian Manuscript and Its Text, Cambridge, Cambridge University Press, 1992. Pour Parker, le texte du codex « is as old as the beginnings of the Gospel traditions », Ibid., p. 280.

55 Epp Eldon J., The Theological Tendency of Codex Bezae Cantabrigiensis in Acts, Cambridge, Cambridge University Press, 1966 (Society for New Testament Studies Monograph Series 3). 
Un autre facteur qui pourrait expliquer l'intérêt renouvelé des néotestamentaires pour les versions arabes est l'arrivée des postcolonial studies au sein des biblical studies. Les approches post-coloniales en sciences bibliques ont commencé à se développer dans les années $90^{56}$. Ces approches sont variées et contextuelles, mais se construisent dans l'ensemble en opposition avec l'approche du «dominant», en l'occurence l'ethnocentrime occidental de la recherche. Nous partageons ici la définition de Rasiah S. Sugirtharajah:

Postcolonialism, it has to be stressed, has a multiplicity of meanings, depending on location. It is seen as an oppositional reading practice, and as a way of critiquing the totalizing forms of Eurocentric thinking and of reshaping dominant thought. It is a mental attitude rather than a method, more a subversive stance towards the dominant knowledge than a school of thought ${ }^{57}$.

Les approches post-coloniales sont notamment très critiques vis-à-vis de la méthodologie historico-critique, dont la critique textuelle est une étape nécessaire. Anna Runesson explique notamment que : « [s]ince the real reader and contemporary culture are two important parameters in postcolonial exegesis, it follows that the heart of the postcolonial criticism is directed against the historical critical claim to universality. ${ }^{58} \mathrm{Il}$ n'y a pas eu jusqu'ici à notre connaissance d'analyse post-coloniale de la recherche en critique textuelle du Nouveau Testament, ni de tentative de produire, de manière assumée du moins, une critique textuelle post-coloniale du Nouveau Testament. Il est toutefois possible que le climat de remise en question dû à l'arrivée des postcolonial studies en sciences bibliques ait eu son impact sur le champ de recherche de la critique textuelle du Nouveau Testament et le prépare à reconsidérer une tradition orientale négligée.

Last but not least, l'arrivée du digital dans la recherche n'est certainement pas étranger à notre problématique. Dans un article de 2011, Claire Clivaz montre à quel point la critique textuelle du Nouveau Testament et son idéal de « texte original» est liée à une culture imprimée que l'ère digitale remet en question :

56 Sugirtharajah Rasiah S., «The Late Arrival of the "Post" : Postcolonialism and Biblical Studies », in : Exploring Postcolonial Biblical Criticism : History, Method, Practice, Chicester, Wiley-Blackwell, 2011, pp. 31-56.

57 Sugirtharajah Rasiah S., Postcolonial Reconfigurations: An Alternative Way of Reading the Bible and Doing Theology, Londres, SCM Press, 2003, p. 15.

58 Runesson Anna, Exegesis in the Making: Postcolonialism and New Testament Studies, Leiden, Boston, Brill, 2010, p. 63. 
Two principal changes are brought about by digital culture in the editing of ancient texts : the end of the stabilized, printed text, with the potential loss of its history and its variants ; and the emergence of a collective and interactive authorship of the critical edition, based on the possibility of online access to the manuscripts ${ }^{59}$.

Dans la continuité des critiques déjà émises dans le cadre du narrative textual criticism, la mise à disposition en ligne des images des manuscrits du Nouveau Testament permet la redécouverte du texte hors de l'édition imprimée; cela permet aussi de populariser une discipline qui s'essoufflait. Concernant les ressources en ligne pour les manuscrits arabes du Nouveau Testament, on trouvait jusqu'à récemment uniquement les images de microfilms de manuscrits, comme c'est par exemple le cas pour la collection du Sinaï ou les collections du Caire ${ }^{60}$. Depuis peu, on trouve également un nombre croissant de manuscrits numérisés. C'est le cas grâce aux collections numériques des bibliothèques ${ }^{61}$ ou à des projets spécifiques ${ }^{62}$. Si ces ressources restent encore limitées, cet accès facilité permet de donner du relief à ces traditions. Cela s'ajoute aux changements épistémologiques généraux liés aux manuscrits grecs du Nouveau Testament discutés ci-dessus et participe aux facteurs qui ont permis de reconsidérer les manuscrits arabes ${ }^{63}$.

59 Clivaz Claire, «Homer and the New Testament as "Multitexts" in the Digital Age?», Scholarly Research Communication 3 (3), 2012, p. 3. En ligne: <http://www.src-online .ca/index.php/src/article/view/97>, consulté le 09.02.2016. Voir aussi Clivaz Claire, «Internet Networks and Academic Research: the Example of the New Testament Textual Criticism », in: Clivaz Claire, Gregory Andrew et Hamidovic David (éds), Digital Humanities in Biblical, Early Jewish and Early Christian Studies, Leiden, Brill, 2013 (Scholarly Communication 2), pp. 151-173.

6o Collection des microfilms du monastère Sainte-Catherine au Sinaï: <https://www .loc.gov/collections/manuscripts-in-st-catherines-monastery-mount-sinai/>; collections des microfilms du Patriarcat copte orthodoxe, du Patriarcat copte catholique, du Musée copte, au Caire, et du Monastère Saint Marc à Jérusalem, <http://cpart.mi.byu.edu/home/ manuscripts/>, consultés le 31.01.2016. Voir notre article sur les ressources en ligne datant de 2014: <http://wp.unil.ch/nt-arabe/2014/04/quelles-ressources-digitales/>, consulté le 31.01.2016.

61 Par exemple: Digital Vatican Library, <http://digi.vatlib.it> ou la collection de la British Library, <http://www.bl.uk/manuscripts/>, consultés le 26.05.2017.

62 Par exemple: le travail de conservation du Hill Museum \& Manuscrit Library, <http:// www.hmml.org>; la base de donnée PAVONe, un projet de l'Université de Balamand, $<$ http://pavone.uob-dh.org>; notre project HumaReC sur le Venise Marciana Gr. 379, $<$ https://humarec.org $>$. Liens consultés le 26.05.2017.

63 Voir aussi chapitre 1, point 2 Remarques épistémologiques. 


\section{L'existence de traductions préislamiques, un point de vue minoritaire}

Une problématique qui réapparaît de manière récurrente au cours de l'histoire de la recherche est celle des toutes premières traductions en arabe du Nouveau Testament et plus largement de l'existence d'une littérature arabe chrétienne préislamique. Un positionnement en faveur d'une existence de traductions préislamiques, que nous pouvons considérer comme minoritaire, n'est pas sans problème, car en filigrane peuvent se dessiner différents enjeux identitaires. Peu de chercheurs ont défendu cette opinion. Au sein de la recherche européenne, Baumstark fut le dernier à prendre position en faveur de traductions préislamiques et plusieurs chercheurs, Georg Graf le premier, ont invalidé ses arguments (voir chapitre 2). Avant Baumstark ${ }^{64}$, le chercheur libanais Louis Cheikho s'était prononcé en faveur de traductions préislamiques ; plus récemment, on trouve ce positionnement chez Irfan Shadid ${ }^{65}$ et Hikmat Kashouh.

Dans son ouvrage de 1903, Louis Cheikho argumente en faveur d'une littérature chrétienne avant l'Islam. Il s'appuie pour cela sur la numismatique, l'épigraphie et l'archéologie; il utilise ensuite comme sources littéraires le Coran, les hadīts, l'historiographie syriaque, grecque et arabe, et enfin la poésie préislamique dont il considère une grande partie comme d'origine chrétienne. Les arguments de Cheikho ont été étudiés en détail par Camille Hechaïmé, qui résume: «Un examen détaillé et comparé des différentes sources, tant monumentales que littéraires, nous a amenés à conclure que le christianisme n'était pas aussi répandu en Arabie préislamique que l'enthousiasme de Cheikho ne le laissait croire. ${ }^{66}$ Selon lui, l'« enthousiasme » de Cheikho n'est pas sans rapport avec la biographie de celui-ci, qui était originaire d'une famille assyro-chaldéenne de Mardin. Héchaïmé décrit ainsi la situation de Cheikho :

64 Baumstark ne semble pas connaître les travaux de Cheikho, il ne le cite pas dans ses articles (références en note 36 au chapitre 2).

65 Nous ne discuterons par Irfan Shahid ici. Dans ses volumes Byzantium and the Arabs retraçant le $4^{\mathrm{e}}, 5^{\mathrm{e}}$ et $6^{\mathrm{e}} \mathrm{s}$. (publiés par Dumbarton Oaks entre 1984 et 2010), il soutient que des textes bibliques auraient été traduits en arabe au $5^{\mathrm{e}} \mathrm{s}$., voire au $4^{\mathrm{e}} \mathrm{s}$. déjà. Cette position est très minoritaire. Griffith expose et discute les propos de Shahid: GRIf Fith, The Bible in Arabic. The Scriptures of the «People of the Book» in the Language of Islam, op. cit., 2013, pp. 47-49.

66 Hechaїме́, Louis Cheikho et son livre "Le christianisme et la littérature chrétienne en Arabie avant l'Islam », op. cit., 1967, p. 188. 
Qu'on se rappelle la situation des chrétiens du Proche-Orient dans les dernières années de l'Empire Ottoman: les vexations auxquelles ils étaient soumis, l'état précaire dans lequel ils se trouvaient, les massacres périodiques qui venaient clairsemer leurs rangs, massacres que Cheikho a connus de près. Qu'on se rappelle en outre que ces chrétiens ne manquaient pas de tirer fierté du fait que c'est parmi les leurs, au Liban comme en Égypte, que la Renaissance intellectuelle arabe avait vu le jour. Qu'on ajoute à ceci le raidissement des milieux intellectuels musulmans conservateurs contre cette manifestation d'activité chrétienne, et l'on comprendra que la thèse d'un chrétien sur le rôle de ses coreligionnaires en Arabie, fût quelque peu passionnée ${ }^{67}$.

Dernièrement, Hikmat Kashouh s'est prononcé en faveur d'une traduction des évangiles datant d'avant l'Islam; selon lui, le texte de certaines parties du Vat. Ar. 13 remonterait au $6^{\mathrm{e}}$ ou début du $7^{\mathrm{e}} \mathrm{s}$. Dans la version originale de la thèse, accessible en ligne, Kashouh proposait de remonter jusqu'au $5^{\mathrm{e}-6^{\mathrm{e}}} \mathrm{s}^{68}$ Les conclusions de Kashouh ont fait l'objet de plusieurs critiques, notamment de la part de Griffith (voir chapitre 6, point 2 État de la recherche sur le Vat. Ar. 13). On regrettera que Kashouh ait fait de cette datation haute une des conclusions principales de son travail ${ }^{69}$, qui, comme dans le cas de l'ouvrage de Cheikho, est très complet et une mine d'informations bienvenue. On rejoindra l'avis de Hechaïmé, qui disait à propos de l'œuvre de Cheikho : «On retiendra surtout que le plus grand tort causé à la thèse de Cheikho, fut justement sa thèse ellemême. À vouloir trop prouver, trop défendre, notre auteur s'est vu pris dans ses propres filets. ${ }^{70}$

Le contexte de Kashouh peut être dans une certaine mesure comparé à celui de Cheikho. La situation des chrétiens au Proche-Orient reste sensible. La guerre civile en Syrie et l'émergence de l'« État islamique» ou encore les attaques répétées contre les Coptes en Égypte ont donné dans l'actualité récente une tragique visibilité médiatique à la situation des chrétiens au Proche-Orient. Or les difficultés concrètes dues à la condition minoritaire et le malaise que certaines communautés chrétiennes peuvent ressentir n'est pas une nouveauté. En 2003, Heyberger le notait déjà :

\footnotetext{
$67 \quad$ Ibid., p. 139.

68 Voir notre note 79, chapitre 2.

69 Kashoun, The Arabic Versions of the Gospels, The Manuscripts and their Families, op. cit., 2012, p. 328.

70 Hеснаїме́, Louis Cheikho et son livre «Le christianisme et la littérature chrétienne en Arabie avant l'Islam», op. cit., 1967, p. 195.
} 
Alors que les chrétiens n'ont jamais été aussi nombreux en chiffres absolus, ils se sentent marginalisés par la disparité démographique, qui réduit constamment leur proportion dans la population totale. [...] Partout, les chrétiens ont un sentiment de déclin et ressentent l'angoisse du nombre. Cette inquiétude s'explique en partie par la hantise des départs forcés et des massacres organisés dans un passé présent. Elle traduit un malaise identitaire face à des sociétés qui affichent de plus en plus fortement leur caractère islamique et leur volonté d'uniformisation. Elle est surtout entretenue par les données objectives de la démographie : la différence de fécondité des chrétiennes par rapport aux musulmanes et la puissance des flux d'émigration ${ }^{71}$.

Si l'on suit l'avis d'Hechä̈mé, le discours du chercheur Kashouh, comme du chercheur Cheikho à l'époque, pourrait chercher une forme de reconnaissance d'une tradition minoritaire en se basant sur l'argument d'antériorité. L'importance prise par cette question de l'antériorité de la littérature arabe chrétienne n'est pas sans rappeler un argument de l'apologétique juive et chrétienne contre l'historiographie grecque, celui de l'ancienneté des Écritures. Plusieurs auteurs juifs, comme Philon d'Alexandrie ou Flavius Josèphe, et chrétiens, comme Tertullien ou Théophile d'Antioche ${ }^{72}$, confrontent les Grecs en défendant l'antériorité de Moïse sur Homère. Ainsi, Tertullien écrit dans son Apologétique:

L'autorité de ces documents leur est donc assurée tout d'abord par leur haute antiquité. Chez vous aussi, on prouve la crédibilité d'une chose par son antiquité, aussi respectable que la religion. Ce qui donne l'autorité aux Écritures, c'est leur antiquité très haute. En effet, le premier prophète, Moïse [...] est trouvé antérieur d'environ 400 ans à l'époque où le fameux Danaus, le plus ancien chez vous, émigrait à Argos. [...] Ensuite, d'autres

71 Heyberger Bernard, Chrétiens du monde arabe: un archipel en terre d'Islam, Paris, Editions Autrement, 2003, p. 18. En 2003, Heyberger situe la population chrétienne au Liban autour de $40 \%$ et de $6 \%$ en Égypte, en Syrie et sur l'ensemble du Proche-Orient. Selon les estimations de la cia sur le World Factbook, on trouve les chiffres de $40 \%$ de Chrétiens au Liban, $10 \%$ en Égypte, $10 \%$ en Syrie et 0,8 \% en Irak, <https://www.cia.gov/ library/publications/the-world-factbook/>, consulté le 29.01.2016.

72 Voir Bertho Benjamin, «Judaïsme, historiographie et apologétique chez Théophile d'Antioche: d'Abraham à Flavius Josèphe», in: Clivaz Claire, Mimouni Simon et Pouderon Bernard (éds), Les judaïsmes dans tous leurs états aux Ier-IIIe siècles (les Judéens des synagogues, les chrétiens et les rabbins). Actes du colloque de Lausanne, 12-14 décembre 2012, Brepols, Turnhout, 2015 (Judaïsme ancien et origines du christianisme 5), pp. $275^{-295}$. 
prophètes ont annoncé beaucoup de choses, et ils sont aussi plus anciens que votre littérature ${ }^{73}$.

On voitici un lien fort entre antériorité et autorité.Si nous pouvons certainement faire une analogie avec Cheikho et d'autres, en recherche de reconnaissance pour la tradition littéraire arabe chrétienne, la situation est différente du côté musulman. La compréhension musulmane de la Bible poursuit une histoire compliquée, faite de réception et d'affranchissement vis-à-vis de ce texte. Une traduction en arabe de la Bible avant le Coran est-elle concevable ? Le Coran se désigne comme un texte en « langue arabe claire » ${ }^{74}$; il ne fait pas état de textes littéraires en arabe le précédant, sans toutefois l'exclure explicitement. Comme l'explique Jacques Langhade: «[...] aucune ouvre littéraire digne de ce nom ne mérite d'être mentionnée en arabe avant le Coran dans la mesure où il n'en est pas fait état $»^{75}$. Une tradition sunnite mentionnerait toutefois une traduction de la Bible en arabe au temps de Muhammad; il s'agit d'un hadīt de 'Ā'iša, dans lequel le cousin de Hadijja, Waraqa ibn Nawfal, lit l'Évangile - Injill ${ }^{76}$ - en arabe : «The Prophet returned to Khadija while his heart was beating rapidly. She took him to Waraqa bin Naufal who was a Christian convert and used to read the Gospel in Arabic. ${ }^{77}$ Dans un autre hadīt, Waraqa copierait en arabe

73 Tertullien, Apologétique 19,1. Traduction tirée de Apologétique, texte établi et traduit par J. P. Waltzing avec la collaboration de A. Severyns, Paris, Les Belles Lettres, 1998, p. 97 (voir aussi par exemple Justin, Première Apologie, 23, l).

74 Coran 16:103; 26:195.

75 LANG HADE Jacques, «La langue du Coran et du Hadīt », in : Du Coran à la philosophie: La langue arabe et la formation du vocabulaire philosophique de Farabi, Beyrouth, Presses de l'Ifpo, 2014 (Études arabes, médiévales et modernes), pp. 17-82.

76 Injull, qui dérive, peut-être par l'intermédiaire du guèze, de $\varepsilon \dot{u}-\alpha \gamma \varepsilon \dot{\varepsilon} \lambda ı$, est le terme arabe pour désigner la révélation de Jésus Christ et les Écritures propres aux chrétiens. Il se trouve dans le Coran et ferait alors référence aux évangiles, mais il est utilisé par extension pour désigner le Nouveau Testament. Cf. CARra DE VAux B. et Anawati Georges C., «Indjill», in : Encyclopaedia of Islam, $2^{\mathrm{e}}$ édition, Brill Online, 2016. En ligne : <http:// referenceworks.brillonline.com/entries/encyclopaedia-of-islam-2/indjil-COM_0373>, consulté le 09.02.2016.

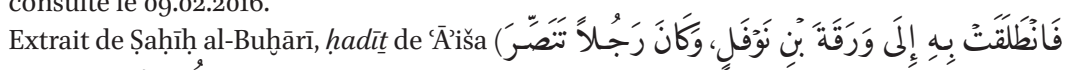

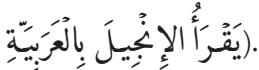

Disponible en ligne: <https://sunnah.com/bukhari/6o/66>, consulté le 10.02.2016. Traduction anglaise de Muhsin Kahn, volume 4, livre 55, no. 6o5 (Référence donnée pour l'arabe: Sahih al-Bukhari 3392, In-book reference: Book 6o, Hadith 66). Griffith discute cette tradition dans Griffith Sidney H., «The Gospel in Arabic: An Inquiry into its Appearance in the First Abbasid Century», Oriens Christianus 67, 1983, pp. 144-149; GRIF Fith, The Bible in Arabic. The Scriptures of the «People of the Book» in the Language of Islam, op. cit., 2013, pp. 45-46. Voir aussi RoBinson B., «Waraḳa b. Nawfal», in: 
à partir de l'Évangile : « He used to write al-kitāb al-'arabī, and he would write down from the Gospel from the Gospel bi-l-arabiyya whatever God wanted him to write. ${ }^{78}$ Si cette tradition témoigne de la présence et de l'influence du christianisme dans la région mecquoise, il est difficile de juger de sa valeur historique pour la question de la traduction en arabe préislamique ; l'histoire de Waraqa est en effet la seule mention d'un évangile arabe préislamique selon les sources musulmanes ${ }^{79}$. Ce témoignage nous intéresse ici car il montre qu'une traduction biblique préislamique ne pose pas de problème en soi dans la tradition musulmane ${ }^{80}$.

Mais les développements concernant la littérature arabe chrétienne préislamique deviennent problématiques lorsqu'ils sont utilisés pour remettre en question l'originalité et l'intégrité du Coran, par exemple en supposant une dépendance textuelle. Il est intéressant de constater que sur Internet certains internautes utilisent la tendance majoritaire de la recherche soutenant une traduction après l'Hégire comme un argument contre ceux qui défendent une dépendance textuelle entre la Bible et le Coran. Sur le site internet Islamicawareness, un site internet anglais créé en 1999 déjà et mis à jour régulièrement, on s'appuie sur les recherches de Héchaïmé, Griffith ou Padwick, pour montrer l'impossibilité que la Bible soit source du Coran: «It is quite clear from the above discussion that the influence of Christian Jahiliyyah poets as well as the lack of presence of the Bible, either the Old Testament or New Testament in Arabic, suggests that the Qur'ân is not borrowed from the Bible. ${ }^{81}$ Ou encore, comme l'exprime un internaute sur un forum consacré à l'Islam : «The Bible

Encyclopaedia of Islam, $2^{\mathrm{e}}$ édition, Brill Online, 2016. En ligne : $<\mathrm{http} / / /$ referenceworks.brill online.com/entries/encyclopaedia-of-islam-2/waraka-b-nawfal-SIM_7863>, consulté le 09.02 .2016 .

78 Traduction de Griffith, à partir de l'édition de Ludolf Krehl, Griffith, «The Gospel in Arabic: An Inquiry into its Appearance in the First Abbasid Century », art. cit., 1983, p. 144. Ce hadīt est aussi transmis avec une différence significative: Waraqa écrirait bil-ibrāniyya, en hébreu ou en caractères hébreux (c'est cette version que l'on trouve dans la traduction de Muhsin Kahn $\langle$ http://sunnah.com/bukhari/1/3>, consulté le 10.02.2016.) Certains ont suggéré qu'il s'agirait en fait de caractères syriaques. Griffith considère cette hypothèse comme improbable, Ibid., p. 145.

79 Griffith, «The Gospel in Arabic: An Inquiry into its Appearance in the First Abbasid Century », art. cit., 1983, p. 144.

8o Griffith suggère même que cette tradition s'explique par une volonté de montrer que Muhammad avait connaissance d'un évangile non corrompu, voir notre explication à propos du tahrīf ci-dessous. Ibid., p. 148.

81 <http://www.islamic-awareness.org/Quran/Sources/BBbible.html>, consultéle 10.02.2016. Voir aussi les pages suivantes: <http://www.islamic-awareness.org/Quran/Sources/>; <http://tazkirahepiebeck.blogspot. com/ 2009/o1/how-quran-differs-from-bible.html>, consultés le 10.02.2016. 
was never translated into Arabic language. Who claims this, Muslims, Hindus, atheists? No, it is the Christians who says the Bible was not translated into Arabic until 1oth century. Which is 100 of years after the Holy Quran was compiled. So why do Christians still say Quran ist copied ? ${ }^{82}$

On peut se demander si la thèse de Kashouh ne s'intègre pas dans ce contexte particulier, qui est celui du discours autour de la Bible en arabe dans les interactions islamo-chrétiennes sur Internet. Depuis 1990, Internet se démocratise et est devenu un lieu d'expression central aussi dans la sphère du religieux. En l'an 2000 déjà, on estimait à un million le nombre de pages web à caractère religieux ${ }^{83}$. Du point de vue du dialogue interreligieux, Internet est ainsi le nouveau lieu de débats, mais également de productions de discours polémiques. Du côté musulman, les sites «amateurs » fleurissent, le plus souvent à tendance salafiste, un phénomène déjà relevé en 2000 :

Enfin, dès la fin des années 1990 et l'apparition de l'Internet interactif, apparaissent de nouvelles rubriques, tels des réservoirs de fatwas en ligne, des cours d'instruction religieuse et des sites de questions-réponses axés sur la vie quotidienne musulmane dans des sociétés modernes, qui marquent l'entrée en scène de ce que certains auteurs ont nommé les «nouveaux oulémas». [...] Olivier Roy [...] note déjà, en 2000, que sur la toile, «aucune autorité ne s'impose en tant que telle» et formule des hypothèses sur les raisons faisant du message salafiste le plus apte à constituer une ummah virtuelle ${ }^{84}$.

Plusieurs sites développent une rubrique d'apologétique antichrétienne; celle-ci répond à différentes attaques. En effet, de l'autre côté, plusieurs sites chrétiens de type evangelical qui s'en prennent à l'Islam de manière virulente

82 <http://www.islamic-life.com/forums/quran-hadith-prophet-muhammad/quranborrow-plagiarizebible-1802>, consulté le 09.02.2016. Orthographe corrigée. La page a malheureusement disparu depuis.

83 Duteil-Ogata Fabienne, Jonveaux Isabelle, Kuczynski Liliane et al., « Le religieux sur Internet: textes et contextes», in: Duteil-Ogata Fabienne, Jonveaux Isabelle, KuCZYNski Liliane et al. (éds), Le religieux sur Internet, Paris, L'Harmattan, 2015, p. 10.

84 Ibid., p. 15. Voir aussi Roy Olivier, « La communauté virtuelle. L'internet et la déterritorialisation de l'islam », Réseaux 18 (99), 2000, pp. 219-237. 
se sont développés ${ }^{85}$. Cette production est analysée et ressentie ainsi : «One sign of Evangelicalism's growing power is its expanding use of the Internet since $9 / 11$. The past four years have witnessed an 'Internet war' involving both secularists and radical fundamental Evangelists against Muslims in organized and informal forums (e.g. the Yahoo Islam chatrooms). ${ }^{86}$

Dans ce contexte, nous avons pu observer avec intérêt la reprise sur les sites musulmans d'un lieu polémique classique, celui de la falsification des Écritures, at-tahrī̄f, qui est réactualisé à l'aide de la critique textuelle du Nouveau Testament ${ }^{87}$. Le concept de tahrîf trouve ses origines dans le Coran, mais uniquement dans l'idée d'une falsification du sens, de mésinterprétation du texte. L'idée de falsification textuelle, qui soutient que le texte biblique, juif ou chrétien, a été corrompu par les hommes, se développe par la suite et sera utilisée de manière virulente par certains théologiens, comme par exemple par Ibn Hazm au $11^{\mathrm{e}} \mathrm{s}^{88}$ Le site Islamic-Awareness, cité ci-dessus, est intéressant à ce propos. La page d'accueil indique le but du site : «The primary purpose of Islamic-Awareness website is to educate Muslims about the questions and issues frequently raised by the Christian Missionaries and Orientalists. ${ }^{89}$ Dans la rubrique «Bible», on trouve des informations sur les manuscrits du Nouveau Testament mais aussi diverses ressources sur la critique textuelle du Nouveau Testament, y compris des articles de Ehrman, Epp ou Parker concernant les débats méthodologiques et épistémologiques. Dans l'article intitulé «Who is afraid of textual criticism?», l'auteur expose que la critique textuelle telle que développée dans la recherche occidentale moderne a démontré que le texte biblique a subi les altérations des scribes et ne représente plus la parole de Dieu. On remarquera dans la conclusion l'utilisation de la notion du « living text » développée par Parker :

85 Smith Jane I., Muslims, Christians, and the Challenge of Interfaith Dialogue, Oxford, Oxford University Press, 2007, p. 110.

86 ShafiQ Muhammad et Abu-Nimer Mohammed, Interfaith Dialogue: A Guide for Muslims, Washington, International Institute of Islamic Thought, 2007, p. 16.

87 Voir nos articles: Schult Hess Sara, « The Role of the Internet in New Testament Textual Criticism : the Example of the Arabic Manuscripts of the New Testament», in : CLIVAz Claire, Gregory Andrew et Hamidovic David (éds), Digital Humanities in Biblical, Early Jewish and Early Christian Studies, Leiden, Brill, 2013 (Scholarly Communication 2), pp. 71-82 ; id., « Tahrîf in the Digital Age», in : Clivaz Claire, Dilley Paul et Hamidovic David (éds), Ancient Worlds in a Digital Culture, Leiden, Brill, 2016 (Digital Biblical Studies 1), pp. 214-230.

88 ACCAD Martin, «Corruption and/or Misinterpretation of the Bible, the Story of the Islâmic Usage of Tahrîf », NEST Theological Review 24 (2), 2003, pp. 67-97.

89 <http://www.islamic-awareness.org>, consulté le 10.02.2016. 
We have discussed the response of Muslims and Christians to the textual criticism of the Qur'an and the Bible. Muslims have always been careful of how the Qur'an should be read and written. Detailed rules were formulated to achieve the transmission both orally and written. The Christian Bible on the other hand did not have any such rules and had to live a life of «living text» which was constantly changing at the whims and fancies of the scribes and the leaders of the Church. And naturally when textual criticism was applied, the Church was up in arms. Very soon it was realized that the beast of textual criticism is here to stay. And the modern day Christians missionaries boastfully say, « Who is afraid of textual criticism ?»90

Par ailleurs, nous avons connaissance de plusieurs sites développant la notion de taḥrîf à l'aide d'images de manuscrits du Nouveau Testament. Voici un exemple d'utilisation d'images de manuscrits ${ }^{91}$ :

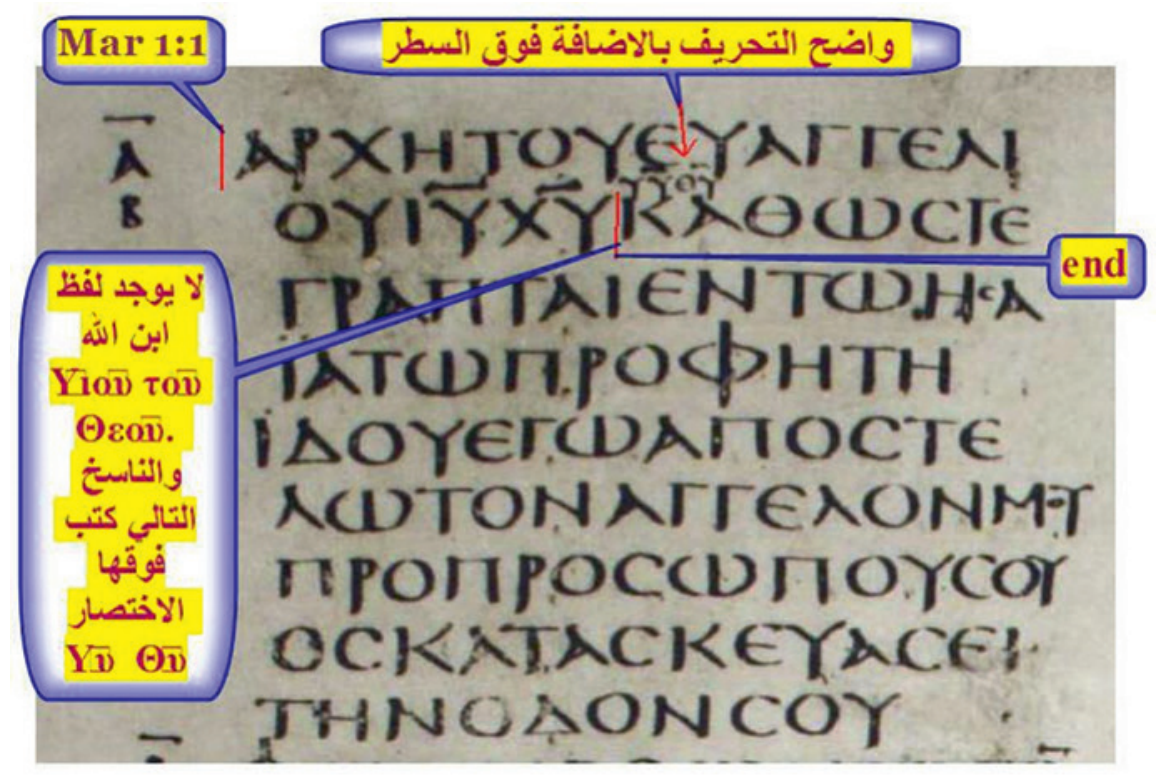

FIGURE 1 Marc 1,1 dans le codex Sinaïticus sur le site Sheek-3arb

9o <http://www.islamic-awareness.org/Bible/Text/textcriticism.html>, consulté le 31.01.2016.

91 Le site Sheekh-3arb, qui contenait de nombreux développements sur le tahrïf à partir de manuscrits grecs du Nouveau Testament, n'est plus accessible depuis quelques mois. Il se trouve certainement aujourd'hui à une autre adresse. Il est toutefois consultable sur le site d'archives web Wayback Machine: <https://web.archive.org/web/20140703080949/http:// www.sheekh-3arb.net/vb/showthread.php?t=2127\&ppage=3>, consulté le 09.02.2016. 
Il s'agit de Marc 1,1 dans le codex Sinaïticus ${ }^{92}$. On voit ici que le qualificatif viov̂ $\theta$ عôे a été ajouté par un scribe au dessus de la ligne; il s'agirait d'un cas manifeste de tahrīif. Cet exemple n'est pas un cas isolé93. Une recherche avec les termes تحريف مخطوطات الذّاب المقدس (falsification des manuscrits des Écritures saintes) révèle de nombreuses utilisations similaires :

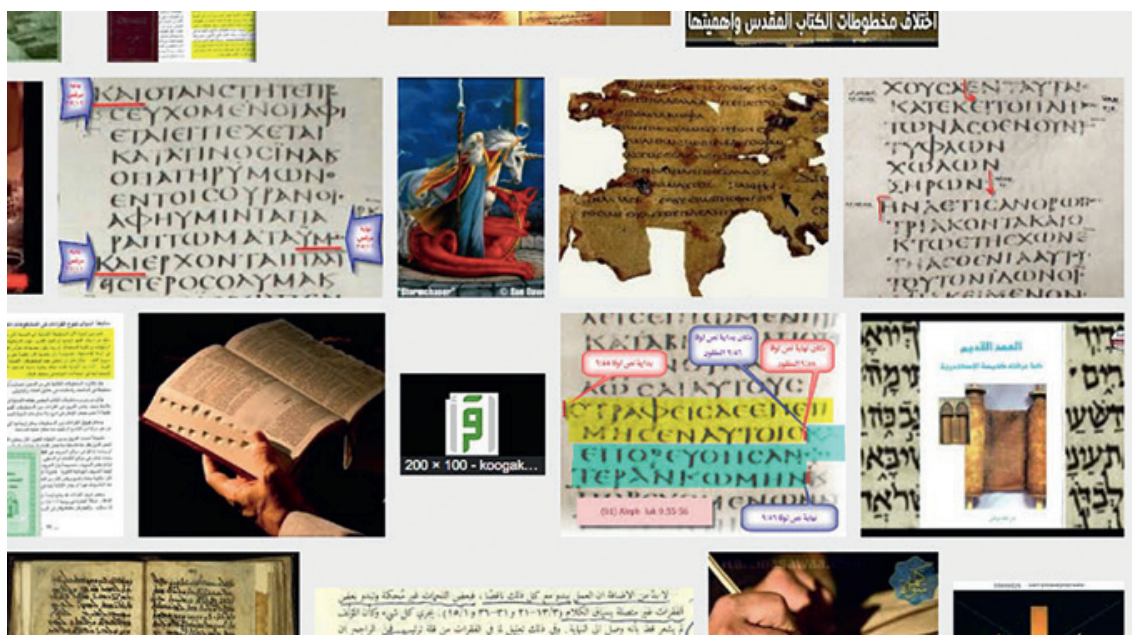

FIGURE 2 Recherche sur Google Images

De l'autre côté, plusieurs sites apologétiques chrétiens ont pris connaissance de la discussion autour du tahrî́f et tentent d'y répondre. On trouve par exemple sur le site Answering-islam.org un article «New Testament Textual Criticism and the True Significance of the Variants » qui commence ainsi :

For many years since the internet debates have been unfolding (and for centuries prior to the internet age), Muslims and Christians have been grappling with the all-important matter of the integrity (or lack thereof) of the Biblical text. In light of recent attacks on the integrity of the Biblical text, especially the New Testament, this essay seeks to examine

92 <https://web.archive.org/web/20121031205824/http://www.sheekh-3arb.net/vb/ showthread.php?t=2127\&page=3 $>$, consulté le 21.02.2016. À propos des variantes de Marc 1,1, voir Wasserman Tommy, «The Son of God Was in the Beginning (Mk 1:1)», Journal of Theological Studies 62 (1), 2011, pp. 20-50.

93 Autre exemple:<https://web.archive.org/web/20141222201019/http://www.answeringchristianity.com/abdul-rahman_klimaszewski/3_old_manuscripts.htm>, consulté le 31.07.2018. 
the implications of the textual variations that exist in the New Testament manuscript tradition ${ }^{94}$.

Dans cette forme d'interaction qui se développe sur Internet entre internautes chrétiens et internautes musulmans, il est intéressant de constater que la Bible en arabe joue un rôle régulier. On trouve parfois des manuscrits arabes au côté des manuscrits grecs dans la démonstration du tahrīif. C'est par exemple le cas ici ${ }^{95}$, dans une démonstration à partir de Matthieu 18,11, où il est question d'un manuscrit du Mont Sinaï du $9^{\text {e }}$ s. $^{96}$

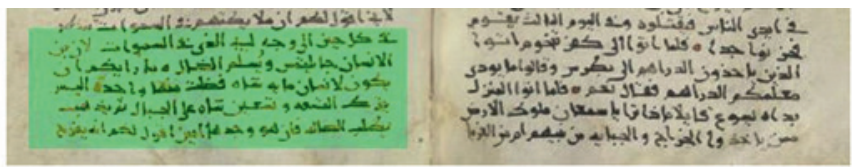

وقد قطعنا منها العدد المطلوب المظلل باللون الاخضر

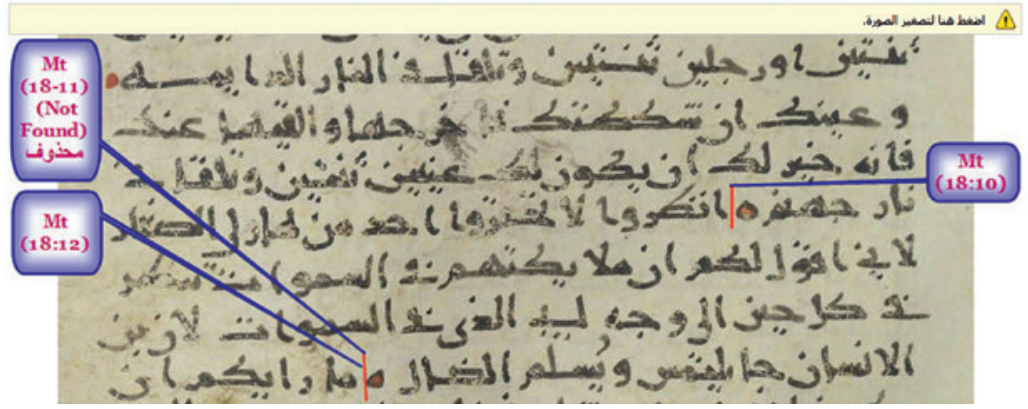

FIGURE 3 Matthieu 18,11 dans un manuscrit arabe du Sinaï sur le site Sheek-3arb

94 <http://www.answering-islam.org/authors/wildcat/nt_variants.html>, consulté le 31.01.2016.

95 <https://web.archive.org/web/20140703032851/http://www.sheekh-3arb.net/vb/ showthread.php?t=2127\&page $=2>$, consulté le 10.02.2016. Voir note 91 ci-dessus.

96 Le manuscrit arabe ne suit pas le texte majoritaire : « car le Fils de l'Homme est venu pour

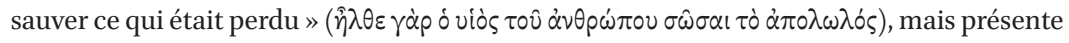
«car le Fils de l'homme est venu chercher et sauver les perdus») لان ان الانسان جاء (يلتمس ولسلم الضال (probablement par harmonisation sur Luc 19,10). Voir SCHULTHEss Sara, «Les manuscrits du Nouveau Testament, le monde arabe et le digital : l'émergence d'un discours hybride», in : Clivaz Claire, Meizoz Jérôme, Vallotton François et al. (éds), Reading Tomorrow. From Ancient Manuscripts to the Digital Era / Lire Demain. Des manuscrits antiques à l'ère digitale, ebook, Lausanne, PPUR, 2012, p. 340. 
Ailleurs, on trouve une image du même manuscrit comme exemple de témoins ne présentant pas la péricope de la femme adultère (Jean 7,53-8,11) ${ }^{97}$. Dans un autre article, on le trouve dans le cadre de la discussion de Jean 7,8 et de la présence de ởx ou de ở $\pi \omega$ devant $\alpha \nu \alpha \beta \alpha i v \omega^{98}$; il est intéressant de voir que l'auteur a ici connaissance d'une variante très minoritaire, qui ne présente pas la leçon en question (probablement à cause d'un homoioteleuton) ${ }^{99}$. Dans ces trois cas, le même manuscrit est utilisé. Il s'agit du Sin. Ar. 72, dont ni la date ni la cote ne sont données. Il est intriguant de voir qu'il circule des images en couleur de manuscrit, alors même que les microfilms du manuscrit ne sont a priori pas disponibles en ligne ${ }^{100}$.

Un autre cas de figure où il est fait référence au Nouveau Testament arabe et à ses manuscrits est les discussions autour du nom d'Allāh. Dans un premier cas, il y est fait référence de manière positive pour montrer que le nom Allāh utilisé par les musulmans désigne Dieu dans un sens monothéiste, et pas un autre dieu, vu qu'on le trouve aussi dans les manuscrits arabes bibliques:

Upon comparing the images, one should be able to clearly see that the word Allah appears in both the Qur'ânic and Arabic Bible images. Indeed, the word Allah appears throughout Arabic translations of the Bible, since it is simply the Arabic name for Almighty God. Insha'llah, the examples

97 <https://alta3b.wordpress.com/2009/07/20/taw7eed/>; <http://www.ebnmaryam.com/ $\mathrm{vb} / \mathrm{t} 32465 . h t m l>$, consultés le 10.02.2016. Voir aussi <http://scholarly-faith.blogspot.de/ 2009/o6/blog-post_03.html>, consulté le 10.02.2016 (sur cette page, Schulthess, «The Role of the Internet in New Testament Textual Criticism: the Example of the Arabic Manuscripts of the New Testament», art. cit., 2013, p. 73). Voir Arbache Samir, Le tétraévangile Sinai arabe 72, ses rubriques liturgiques et son substrat grec, Mémoire de licence, Université catholique de Louvain, 1975, p. 33. Étonnamment, Kashouh ne mentionne pas l'absence de la Pericope Adulterae dans sa description du manuscrit du Sin. Ar. 72. Kashoun, The Arabic Versions of the Gospels, The Manuscripts and their Families, op. cit., 2012, p. 87.

98 <https://alta3b.wordpress.com/2010/02/>; voir aussi <https://alta3b.wordpress.com/ 2009/07/18/john7-8_2/>, consultés le 10.02.2016. Il s'agit ici des variantes oủx et oü $\pi \omega$ devant $\alpha v \alpha \beta \alpha i v \omega$.

99 Cette variante, présente dans les minuscules 33, 397, 565, 579, n'est par exemple pas mentionnée dans les «lectiones minores » du NA28. L'auteur se base notamment sur le commentaire des évangiles en ligne de Wieland Willker, <http://www-user.uni-bremen .de/wie/TCG/TC-John.pdf> (TVU 119), consulté le 10.02.2016.

100 Les images du microfilm (mais pas de photos couleur) sont disponibles depuis peu sur le site de la Library of Congress : <https://www.loc.gov/item/oo279385986-ms/>, consulté le 26.05.2017. Auparavant sur <http://e-corpus.org $>$. 
below will help quell the doubts of those who have been duped into believing that Muslims worship a different god - either by the hostile media or by Christian missionary propaganda ${ }^{101}$.

Une réponse à cette utilisation de la Bible arabe se trouve sur le site apologétique Answering-islam, dans un article intitulé «The Arabic Bible - Islam's Friend or Foe ?». L'appui de la Bible en arabe y est jugé insuffisant :

Thus, just because the Greeks called Zeus ho theos this doesn't mean that Greek speaking Muslims are worshiping Zeus since they also call Allah ho theos. Nor would this imply that Greek speaking Muslims are worshiping the Father and Jesus Christ the Son as Allah despite the fact that both the Greek New Testament and the Greek translation of the Quran use the same words to describe them all. In the same exact way, just because an Arabic translation of the Holy Bible uses the word Allah this doesn't mean that Christians and Muslims are worshiping the same God ${ }^{102}$.

À l'inverse, on trouve ailleurs des utilisations négatives de la Bible en arabe. Sur un autre site, dans la rubrique tahrîf, la question suivante est posée: doit-on traduire la fin de Jean 1,1 par « et le verbe était Dieu (Allāh)», ou « et le verbe était un dieu (ilāh)», ce qui remettrait en question la divinité du Christ? Une première page s'intéresse aux manuscrits grecs, se basant sur la présence ou l'absence de l'article ó devant $\theta \varepsilon^{\prime} \varsigma^{103}$. Une autre page se base sur des manuscrits arabes du Nouveau Testament ${ }^{104}$. L'auteur de cette page utilise l'article de Hikmat Kashouh sur Jean 1,1 et 1,7; l'article montre notamment que certains anciens manuscrits ont à la fin du verset le nom ilāh et non allāh. Kashouh explique le terme ilāh par une interprétation littérale du grec $\theta$ cós sans article et semble au courant de l'utilisation de ce détail à des fins polémiques :

The literal-approach scribes who translated $\theta$ cós by ilâh ([a] God) and ¿ $\theta$ rós by allâh ([the] God). This differentiation may possibly have caused a misrepresentation belief that the Christianity firmly holds especially in

\footnotetext{
101 <http://www.islamic-awareness.org/Quran/Sources/Allah/BibAllah.html>, consulté le 31.01.2016.

102 <http://www.answering-islam.org/authors/shamoun/allah_bible.html>, consulté le 31.01.2016.

$103<$ http://alta3b.wordpress.com/2009/04/06/translation_jn-1-1/>, consulté le 31.01.2016.

104 <http://alta3b.wordpress.com/2011/11/o3/jn1-1_arabic-mss/>, consulté le 31.01.2016.
} 
an Islamic milieu. The earlier versions of the Gospels seem to prefer this translation ${ }^{105}$.

Ce qui est ici intéressant, c'est que l'auteur de la page en ligne ne se contente pas de copier les informations de l'article de Kashouh. Il les complète en ajoutant les images des microfilms de manuscrits arabes de la collection de Sainte Catherine, disponibles en ligne ${ }^{106}$, dont il a sélectionné les versets :

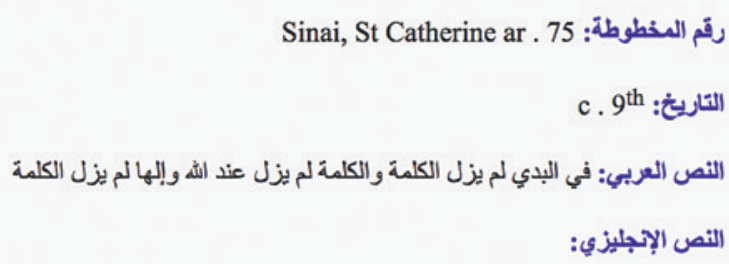

In the beginning the word never ceased to be (masc.) and the word never ceased to be (masc.) with (at, near, by) Allah, and the word never ceased to be (masc.) ilah.

\section{Sinai MF UCL Arabe 75}

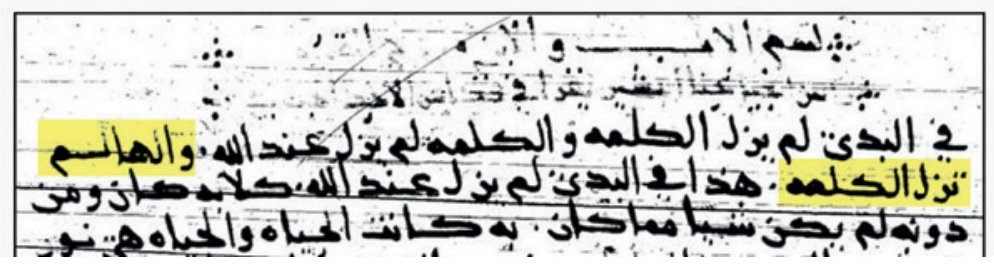

FIGURE 4 Sin. Ar. 75 (Jean 1,1) sur le site Alta3 $b$

On notera enfin que le Nouveau Testament en arabe joue un rôle important dans l'activité missionnaire d'organisations chrétiennes evangelical américaines. Le nom de domaine <www.arabicbible.com $>^{107}$ est possédé par un groupe baptiste dont le but est l'évangélisation auprès des populations arabophones et musulmanes: «Arabic Bible Outreach Ministry is a Christian mission organization with a passion to extend the Word of God to the Arab

\footnotetext{
105 Kashoum Hikmat, «The Arabic Versions of the Gospels. A Case Study of John 1,1 and 1,18», in: Thомаs David Richard (éd.), The Bible in Arab Christianity, Leiden, Brill, 2007 (The History of Christian-Muslim Relations 6), p. 29.

106 Disponible sur <https://www.loc.gov/collections/manuscripts-in-st-catherines-monastery -mount-sinai/>, consulté le 31.07.2018. Auparavant sur <http://www.e-corpus.org>.

107 Il s'agit de la première entrée lorsque nous cherchons « Arabic Bible » à l'aide du moteur de recherche Google, recherche effectuée le 28.01.2016 (depuis <http://www.google.com>, sans login).
} 
and Muslim world. Its vision is to see vibrant and reproducing churches in the Arab world and among large Muslim communities in North America. »108 Un de leurs buts est le suivant: «To win the lost among our kinsmen - the Arabs - by working through the World Wide Web». Un des moyens promus est une bonne connaissance et l'accessibilité de la Bible en arabe ; on trouve ainsi sur le site différentes ressources, comme l'édition de la Van Dyke en ligne, sous plusieurs formats, notamment une version audio, ainsi que l'histoire de sa création. Sur le site, un manuscrit est mis à l'honneur, le codex Sin. Ar. ${ }^{151^{109}}$. Il y est présenté comme «the oldest Arabic translation of the Bible in existence which was done in $867 \mathrm{AD}$. » Le site ne développe pas davantage à propos de la tradition des manuscrits arabes du Nouveau Testament, mais les propos tenus au sujet du Sin. Ar. 151 ne sont pas sans rappeler l'«enthousiasme » décrit par Héchaïmé quant au propos de Cheikho:

Considering the seriousness of the situation in the Middle East, the Al Sirri [nom du traducteur du Sin. Ar. 151] manuscript from AD 867 takes on great importance. It helps everyone to understand the tremendous roots of Middle Eastern Christianity. It should be a boost to the self image of Eastern Christians as they face eviction from such lands as Lebanon ${ }^{110}$.

Nous ne pouvons exclure que ces discours concernant la tradition biblique arabe, bien que ceux-ci ne soient pas académiques mais émis dans des contextes polémiques, participent d'une certaine manière à la reprise de la recherche dans ce domaine. À propos du cas précis de Kashouh, il est par exemple très probable que celui-ci ait connaissance de la réception de son article sur Internet. On notera aussi que l'institution qui l'emploie, l'Arabic Baptist Theological Seminary de Beyrouth ${ }^{111}$, est recommandée sur le site missionnaire de Arabic Bible Outreach Ministry que nous mentionnons plus haut.

\section{Vers quelle recherche? Hybridité/porosité entre les discours}

Concernant l'avenir de la recherche, nous pensons que la recherche sur les manuscrits arabes du Nouveau Testament va continuer dans le même mouvement actuel, avec un nombre de publications et de projets de recherche allant

\footnotetext{
108 <http://www.arabicbible.com/about-us/aboutus.html>, consulté le 03.03.2016.

109 À propos du Sin. Ar. 151, voir la notice 155 dans le chapitre 4, et chapitre 8, point 3.1 Comparaison avec Sin. Ar. 151 et Sin. Ar. 155.

110 <http://www.arabicbible.com/arabic-bible/codex.html?showall=1>, consultéle 31.01.2016.

111 <http://www.abtslebanon.org>, consulté le 31.01.2016.
} 
croissant. De même, il y aura certainement davantage de ressources mises en ligne, notamment les images des manuscrits, comme c'est déjà le cas pour les manuscrits grecs ${ }^{112}$. Dans la même veine, le nombre de productions que l'on peut nommer par défaut «non académiques » va continuer à augmenter. Le phénomène que nous décrivons ci-dessus est déjà non négligeable. La page Facebook Islamic Biblical Criticism Team, est suivie par plus de 61'ooo utilisateurs de Facebook; pour comparaison, le groupe Facebook New Testament Textual Criticism compte environ 5'400 membres; la page Evangelical Textual Criticism est elle suivie par 1'80o utilisateurs environ ${ }^{113}$. Quelle peut être l'influence de ce phénomène sur la recherche? Nous mentionnons ci-dessus la possibilité que les publications en ligne, qui reflètent des enjeux identitaires culturels et religieux, aient poussé à la reprise de la recherche. Qu'en est-il d'une interaction directe avec la recherche? Dans notre article «Tahrififin the Digital Age », nous développons l'idée d'hybridité avec le discours académique ${ }^{114}$. Sur le site Islamic-awareness.org, on trouve en tout cas la volonté d'utiliser des références scientifiques et actuelles: «The dating of the manuscripts listed below represent consensus among the scholars. As the New Testament scholarship progressed, the dating was changed in some cases and we have followed the latest dating that has been accepted by the majority of the scholars. $»^{115}$; «Lastly, we have made sure that we use the references of Judeo-Christian scholars of repute not the apologetical literature for very obvious reasons »116. On trouve aussi quelques cas d'interactions avec la recherche. Par exemple, sur le forum du groupe Yahoo Biblical Textual Criticism, auquel participent, parmi d'autres, des chercheurs en critique textuelle du Nouveau Testament tels que Bart D. Ehrman ou Daniel B. Wallace, un utilisateur qui se définit comme co-editeur du Arabic Textual Criticism Journal propose une comparaison entre le texte grec de Marc, en se basant sur le commentaire de Wieland Wikler, et le Sin. Ar. $72^{117}$. Or le Arabic Textual Criticism Journal s'avère être lié au site

112 Pour les manuscrits grecs du Nouveau Testament, on relèvera ici le travail de l'INTF, $<$ http://ntvmr.uni-muenster.de $>$, et celui du CSNTM, <http://www.csntm.org $>$. Liens consultés le 07.03.2016. Concernant les manuscrits arabes, voir notre note 62 ci-dessus (le site PAVONe est consultable depuis mai 2017).

113 Islamic Biblical Criticism Team, <http://facebook.com/isbct/>; New Testament Textual Criticism, <https://www.facebook.com/groups/11404207692/>; Evangelical Textual Criticism, <https://www.facebook.com/EvangelicalTextualCriticism/>. Liens consultés le 26.05.2017.

114 Schulthess, «Tahrïf in the Digital Age », art. cit., 2016.

115 <http://www.islamic-awareness.org/Bible/Text/Mss/>, consulté le 07.03.2016.

116 <http://www.islamic-awareness.org/Bible/Text/>, consulté le 07.03.2016.

117 <https:/groups.yahoo.com/neo/groups/textualcriticism/conversations/topics/6127, consulté le 07.03.2016. 
mentionné plus haut Sheekh-3arb.net ${ }^{118}$. Sur le site Center for the Study of the New Testament Manuscripts, l'index proposé pour le codex Vaticanus a été établi par les utilisateurs de Sheekh-zarb.net également, comme le montre la page de couverture ${ }^{119}$ :

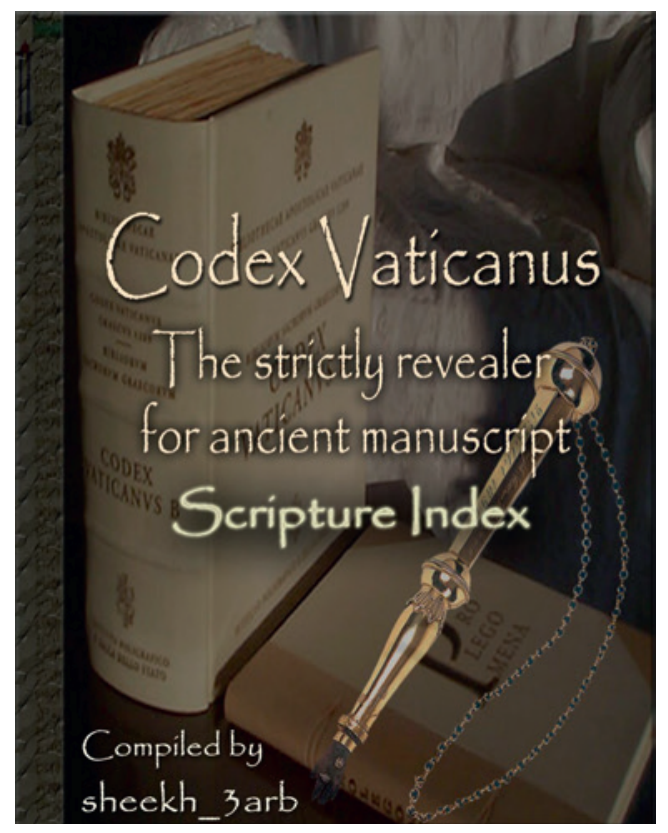

FIGURE 5

Page de couverture de l'index du codex Vaticanus, par Sheek-3arb

Nous avons déjà décrit ce phénomène comme une forme d'hybrid scholarly discourse ${ }^{120}$. Nous nous basons notamment sur le concept de «culture hybride» telle que décrit par Yvonne Spielmann. Spielmann a surtout pour objet les médias et l'esthétique dans la culture japonaise, mais son analyse de l'hybridation serait propre à la globalisation et au monde digital en général:

118 Ladresse du Arabic Textual Criticism Journal le montre: <http://tcjournal.sheekh-3arb .net>, aujourd'hui consultable ici : <https://web.archive.org/web/201411171516o6/http:// tcjournal.sheekh-3arb.net>, consulté le 07.03.2016, voir note 91 ci-dessus.

119 L'index se trouvait sur le site de Sheekh-3arb.net, aujourd'hui consultable ici : <https://web .archive.org/web/20121107131117/ http://www.sheekh-3arb.net/Library/Programs/e-sword/ sheekh-3arb-modules/The-strictly-revealer-for-ancient-manuscript.pdf $>$, consulté le 07.03.2016, voir note 91 ci-dessus. Il est aussi proposé par le CSNTM, <http://images.csntm .org/Manuscripts/GA_03/Vaticanus-Scripture-Index.pdf>, consulté le 07.03.2016.

120 Voir nos articles Schulthess, «The Role of the Internet in New Testament Textual Criticism : the Example of the Arabic Manuscripts of the New Testament », art. cit., 2013; Schulthess, «Tahrîf in the Digital Age », art. cit., 2016. 
[...] Hybridation [kennzeichnet] besondere Formen der kulturellen Interaktion, die sich in Zwischenbereichen abspielen, wo verschiedene Einflüsse koexistieren und die Auseinandersetzung mit Differenz zu einer Vielfalt führt, die das Ineinandergreifen von Gleichzeitigkeiten (etwa euroamerikanisch modern und asiatisch-pazifisch modern) wiederspiegelt ${ }^{121}$.

En 2015, Clivaz remettait toutefois en question l'utilisation régulière du terme «hybridité » dans le contexte des humanités digitales, ici dans les questions de corporéité : «Qu'est-ce que l'hybridité ? Un terme que l'on entend souvent et qu'on rencontre beaucoup. [...] Je ne crois pas que cela soit le bon mot pour essayer de penser ce qui est à l'œuvre. »122 En effet, l'hybridité, qui vient d'ubris', ne peut désigner que «quelque chose qui excède ce que je peux croire, ce que je peux penser, ce que je peux comprendre. ${ }^{123}$ Clivaz plaide pour parler de «porosité » dans le cas du lien entre l'Homme et les technologies digitales: «Que cela nous plaise ou non, nous sommes au-delà du schéma d'hybridité pour être dans un schéma de porosité avec le monde digital » ${ }^{124}$.

Dans notre cas, ces remarques à propos des concepts d'« hybridité» et de «porosité» nous confirment qu'il s'agit ici encore d'«hybridité». À notre avis, tant que le discours restera à but apologétique, l'hybridité ne peut être dépassée. Or, la page Facebook Islamic Biblical Criticism Team, par exemple, إثات صدق العقيدة الإسلامية : annonce clairement comme première mission الخاصة بتريف جميع الكتب الساوية السابقة musulmane en démontrant la falsification [taḥrīf] de l'ensemble des Écritures célestes précédentes ${ }^{125}$. Du côté de la recherche en critique textuelle du Nouveau Testament, les réactions sont vives lorsqu'il y a la prise de conscience de ce type de discours, comme le montre un article et la discussion qui suit sur le site Evangelical Textual Criticism, entretenu par Peter M. Head, Tommy Wasserman et d'autres chercheurs, à la suite de l'annonce d'un «Islamic

121 Spielmann Yvonne, Hybridkultur, Berlin, Suhrkamp, 2010, p. 50.

122 Clivaz Claire, «Mais où est le corps? L'Homme augmenté comme lieu des Humanités Digitales », in : L'homme augmenté (eTalks), Lausanne, Swiss Institute of Bioinformatics, éditions VITAL-DH, 2015. En ligne: <http://etalk2.vital-it.ch/?dir=Clivaz>, consulté le 07.03.2016. Référence de la citation : <http://etalk2.vital-it.ch/?dir=Clivaz\#63>, consulté le 07.03.2016.

123 Ibid. Ici, <http://etalk2.vital-it.ch/?dir=Clivaz\#64>, consulté le 07.03.2016.

124 Ibid. Ici, <http://etalk2.vital-it.ch/?dir=Clivaz\#68>, consulté le 07.03.2016.

125 <https://www.facebook.com/isbct/info/?tab=page_info>, consulté le 07.03.2016. 
apologetics book on NTTC »126. Dans cet article, rédigé par P. J. Williams, il est intéressant de voir que Williams redirige à la fin les lecteurs vers un article sur la recherche textuelle sur les manuscrits du Coran et le livre de Keith E. Small à ce sujet ${ }^{127}$. Cette dernière remarque semble soutenir un propos du genre: «pourquoi s'occuper de notre tradition alors qu'ils' ne font pas de critique textuelle du Coran? ». Dans les commentaires, le débat est alors lancé, avec plusieurs réactions anonymes, autour de la question de savoir qui est le plus apologétique: Sami Ameri, l'auteur du soi-disant «Islamic apologetics book on NTTC », lorsqu'il s'essaie à la critique textuelle du Nouveau Testament, ou Keith E. Small, lorsqu'il s'essaie à la critique textuelle du Coran?

Dans une revue de l'ouvrage de Spielmann, Guido Koller pose cette question à propos de la culture hybride: «Hybridity correlates elements from different scientific and cultural contexts and discourses. The blurring of practices deconstructs existing science cultures. Does this mean that a new global science culture is going to be established ? $»^{128}$ Il nous semble que l'hybridité est encore trop «hybride» pour parler d'une nouvelle culture scientifique globale, dans notre cas du moins. Il faudrait pour cela dépasser le discours apologétique, car l'échange, d'un côté comme de l'autre, reste jusqu'à présent conflictuel. Mais une chose est claire, c'est que ces questions font bien évidemment réfléchir sur le positionnement du chercheur et sur l'autorité de son discours académique. Comme le remarque Clivaz: «Whereas print culture has helped to unify the appreciation of authoritative voices, web culture has lead to diversifying and multiplying the opinions. $»^{129}$

$126<$ http://evangelicaltextualcriticism.blogspot.ch/2013/o2/islamic-apologetics-book-onnttc.html>, consulté le 07.03.2016.

127 <http://evangelicaltextualcriticism.blogspot.de/2011/o7/textual-criticism-and-quranmanuscripts.html>, consulté le 07.03.2016. L'ouvrage en question est: SMALL Keith E., Textual Criticism and Qur'an Manuscripts, Plymouth, Lexington Books, 2011.

128 Koller Guido, «Hybridity, a Cultural and Scientific Model for the Future », 2013. En ligne : <http://wethink.hypotheses.org/926>, consulté le 07.03.2016.

129 Clivaz Claire, When «Humanities» Goes beyond History and Sociology in Digital Biblical Studies, Présentation orale, Society of Biblical Literature, International Meeting, St-Andrews, 08.07.2013. 


\section{DEUXIÈME PARTIE}

\section{Les manuscrits arabes des lettres de Paul}


Sara Schulthess - 978-90-04-37816-2 Downloaded from Brill.come4/26/2023 10:02:45AM via free access 


\section{Répertoire des manuscrits arabes des lettres de Paul}

\section{Introduction}

Un répertoire des manuscrits arabes des lettres de Paul est une étape nécessaire pour l'étude de ce corpus. En effet, comme nous avons pu le constater dans notre état de la recherche (voir chapitre 2, point 9 Les lettres de Paul, parent pauvre de la recherche), très peu d'études se sont penchées jusqu'à présent sur les manuscrits arabes des lettres de Paul ; ce manque d'intérêt semble venir de l'idée communément partagée par les chercheurs selon laquelle (1) les lettres de Paul en arabe ont été traduites plus tardivement que les évangiles, et (2) qu'elles ont été moins répandues que les évangiles. C'est par exemple l'avis de Graf, qui écrit: "Immer wird man auch finden, dass dort, wo die Notwendigkeit des kirchlichen Gebrauchs den Anlass zur Bibelübersetzung gab, den Evangelien and den Psalmen der Vorrang zukam. » ${ }^{1}$ Un avis partagé par d'autres chercheurs, comme le montre ce propos de Henninger: «Wie zu erwarten, gehören die Evangelien zu denjenigen biblischen Büchern, die zuerst (und auch später am häufigsten) übersetzt wurden. $»^{2}$ Plus récemment, Sidney Griffith semble davantage conscient de l'importance des autres livres bibliques au côté des évangiles :

The Gospels were of course not the only portions of the Bible translated by Christians into Arabic in the early period of the ecclesiastical translation movement though, as we mentioned above, the oldest surviving and dated translation is in fact a Gospel text. In the same era translations of the Epistles of St. Paul were made, as well as translations under Christian auspices of the Torah, the Psalms and other portions of the Bible 3 .

Malgré cela, il soutient la plus grande popularité des évangiles :

1 GRAF Georg, Geschichte der christlichen arabischen Literatur, vol. 1, Rome, Biblioteca Apostolica Vaticana, 1944 (Studi e Testi 118), p. 85.

2 Henninger Joseph, «Arabische Bibelübersetzungen vom Frühmittelalter bis zum 19. Jahrhundert », Neue Zeitschrift für die Missionswissenschaft 17, 1961, p. 213.

3 Griffith Sidney H., The Bible in Arabic. The Scriptures of the "People of the Book» in the Language of Islam, Princeton, Princeton University Press, 2013, p. 120.

(C) SARA SCHULTHESS, $2019 \mid$ DOI:10.1163/9789004378162_005

This is an open access chapter distributed under the terms of the prevailing CC-BY-NC License at the time of publication. 
[...] Arabic translations of the scriptures done by Christians before the 1500's consisted almost entirely of translations of individual books or of compilations of related books, such as the books of the Torah, the Psalms, the Gospels, the Epistles of St. Paul, or the Acts of the Apostles, along with the so-called «Catholic Epistles ». To judge by the number of surviving manuscripts containing these translations, the Pentateuch, the Psalms, and the Gospels were the most popular, but translations were also made of less popular books, as we shall see ${ }^{4}$.

Ainsi, un répertoire des manuscrits arabes des lettres de Paul permet de jeter un début de lumière sur ce champ méconnu. Premièrement, il s'agit d'un outil que les futures chercheuses et chercheurs pourront utiliser afin de déterminer leur objet de recherche ou afin de le contextualiser. Deuxièmement, il permet de proposer quelques observations globales, allant dans le sens de ce que certains appellent la «codicologie quantitative» (chapitre 5); ces observations permettront notamment d'invalider les préjugés de la recherche mentionnés ci-dessus.

Notre approche est similaire à celle de Hikmat Kashouh dans sa constitution de l'«Abridged List of the Arabic Gospel Manuscripts» (ALAGM) Comme dans son cas, il ne s'agit pas ici d'établir un catalogue des manuscrits, mais de fournir les informations de base pour chaque manuscrit, à l'image de la Kurzgefasste Liste de Gregory-Aland ${ }^{6}$. Ainsi, notre répertoire se présente comme un pendant à la ALAGM de Kashouh pour les lettres de Paul ${ }^{7}$.

\subsection{Limitations et difficultés}

D'emblée, nous nous sommes concentrés, comme Kashouh, sur les textes continus et n'avons pas intégré les lectionnaires à notre répertoire. Cette décision est évidemment liée à la volonté de limiter les données et rejoint une distinction qui a par ailleurs toujours été faite pour l'étude des manuscrits du Nouveau Testament ${ }^{8}$. Nous avons conscience que cette distinction est

4 Ibid., p. 129.

5 Kashoun Hikmat, The Arabic Versions of the Gospels, The Manuscripts and their Families, Berlin, Boston, De Gruyter, 2012 (Arbeiten zur neutestamentlichen Textforschung 42), pp. 38-81.

6 Aland Kurt (éd.), Kurzgefaßte Liste der griechischen Handschriften des Neuen Testaments, $2^{\mathrm{e}}$ édition, Berlin, Boston, De Gruyter, 2011.

7 Cela est le cas seulement pour le répertoire. Comme nous l'expliquons au chapitre 1. Introduction, notre étude ne cherche pas à établir le classement des manuscrits selon leur famille, comme c'est la cas de l'étude de Kashouh, mais à étudier un manuscrit particulier.

8 Dans sa thèse de 2010 sur l'évangile de Jean, Christopher R. D. Jordan remarque que «the whole Gospel lectionary tradition has been set to one side in New Testament Textual 
discutable, vu le rôle certain qu'ont joué les lectionnaires dans les Églises orientales pour la transmission du texte du Nouveau Testament. De plus, c'est uniquement la forme et non le contenu qui différencie les textes continus des lectionnaires: nous montrons au chapitre 6 que le Vat. Ar. 13 contient des marques de lecture et était utilisé dans un contexte liturgique (chapitre 6, point 3.8 Indications de lectures). Dans une seconde étape, les lectionnaires devraient donc être impérativement intégrés à la recherche. Or la recherche des manuscrits contenant le texte continu des lettres de Paul présente déjà quelques difficultés ${ }^{9}$. Le nombre important de manuscrits, répartis dans de nombreuses bibliothèques, est un vrai défi pour le chercheur au vu des instruments à disposition. Tout d'abord, il est rare de travailler avec des catalogues spécifiques à la littérature arabe chrétienne, les manuscrits étant souvent englobés dans la «masse» des manuscrits arabes de toute provenance et discipline - quand ils ne sont pas réunis avec d'autres langues sous la rubrique générale des «manuscrits orientaux». De plus, les manuscrits arabes sont aussi à chercher en dehors des catalogues de manuscrits arabes : premièrement, il y a un nombre conséquent de manuscrits bilingues (grec, latin, syriaque, copte); deuxièmement, les manuscrits en karshouni sont généralement répertoriés dans les catalogues de manuscrits syriaques - ce dernier point étant, à notre avis, le problème principal. Pour les bibliothèques européennes, nous avons pu nous aider du « Répertoire des bibliothèques publiques et privées d'Europe contenant des manuscrits arabes chrétiens » de Jean Simon ${ }^{10}$, qui inclut les manuscrits en karshouni, ainsi que de la bibliographie de Graf, «Bezeichnungen der Handschriften nach den Katalogen $»^{11}$.

Criticism », et que Westcott et Hort regrettaient déjà cet état de fait en 1896 : « Comparatively few Lectionaries have as yet been collated. Some of these have been found to contain readings of sufficient value and interest to encourage further enquiry in what is as yet an almost unexplored region of textual history [...] », JoRDAN Christopher Robert Dennis, The Textual Tradition of the Gospel of John in Greek Gospel Lectionaries from the Middle Byzantine Period, Ph.D., University of Birmingham, 2010, pp. 1-2. En ligne: <http:// etheses.bham.ac.uk/578/>, consulté le 24.12.2015.

9 Pour les difficultés liées au catalogage, SAміr Samir Khalil, «La tradition arabe chrétienne. État de la question, problèmes et besoins », in: Actes du premier congrès international d'études arabes chrétiennes (Goslar, septembre 1980), Rome, Pontificio Instituto Orientale, 1982 (Orientalia Christiana Analecta 210), pp. 24-36. Kashoun, The Arabic Versions of the Gospels, The Manuscripts and their Families, op. cit., 2012, pp. 38-39.

10 Simon Jean, «Répertoire des bibliothèques publiques et privées d'Europe contenant des manuscrits arabes chrétiens », Orientalia N.S. 7, 1938, pp. 239-264.

11 GRAF, Geschichte der christlichen arabischen Literatur, op. cit., 1944, pp. XXIX-XXXV. 
1.2 Méthode

Le répertoire a été établi à l'aide de la littérature secondaire ${ }^{12}$, des catalogues des bibliothèques et de bases de données en ligne ${ }^{13}$. Dans un premier temps, nous avons retrouvé dans les catalogues les manuscrits qui étaient mentionnés par Graf, Gregory, Horner, Goussen, etc ${ }^{14}$., afin de donner la cote actuelle et de si possible compléter les informations. Enfin, nous avons compilé les catalogues des bibliothèques susceptibles de contenir des manuscrits arabes des lettres de Paul; nous avons aussi compilé les catalogues des collections syriaques de ces bibliothèques, car nous incluons dans notre liste les manuscrits en karshouni. Dans la mesure du possible, nous avons également compilé les catalogues pour les manuscrits coptes, les manuscrits coptes-arabes étant nombreux. Une bibliographie spécifique pour les catalogues est donnée en fin d'ouvrage ${ }^{15}$.

Nous rendons dans notre répertoire les informations suivantes :

- «Cote »: La première information consiste en la cote du manuscrit, comprenant le lieu où se trouve la bibliothèque, la bibliothèque (que nous abrégeons parfois), la collection (si nécessaire) et le numéro du manuscrit. Dans le cas de bibliothèque apostolique du Vatican et de la bibliothèque du Monastère Sainte-Catherine au Mont Sinaï, nous ne donnons pas le nom de la bibliothèque, car les manuscrits sont connus sous une cote simple telle que « Sin. Ar. 155 » et «Vat. Ar. $155 »$.

- «No. catalogue» et «Autre cote»: Dans de nombreux cas, les manuscrits sont connus dans la littérature secondaire par leur numéro dans le catalogue ou par des cotes plus anciennes, il est donc important de les mentionner.

- « Contenu du manuscrit» : Nous mentionnons les différents corpus présents dans le manuscrit dans l'ordre (sans indications de folios). Nous donnons ensuite entre parenthèses l'ordre des livres bibliques, si ces informations sont disponibles. Voir nos observations au chapitre 5 , point 4 .

12 Avec comme point de départ: GRAF, Geschichte der christlichen arabischen Literatur, op. cit., 1944; Gregory Caspar René, Textkritik des Neuen Testamentes, vol. 2, Leipzig, Hinrichs, 1902.

13 Principalement <http://www.fihrist.org.uk> et <http://www.hmml.org $>$, consultés le 07.03.2016, ainsi que les catalogues en ligne des bibliothèques.

14 Voir la liste dans Bibliographie: 1 . Références du répertoire.

15 Dans la version non retravaillée de la thèse, on trouve en annexe une bibliographie des catalogues consultés dans lesquels nous n'avons pas trouvé de manuscrits (Annexe 1 : catalogues consultés sans résultats, Schulthess Sara, Les manuscrits arabes des lettres de Paul. La reprise d'un champ de recherche négligé, $\mathrm{PhD}$ dissertation, Lausanne/Nijmegen, Université de Lausanne/Radboud Universiteit Nijmegen, 2016, pp. 459-469. En ligne: $<$ http://hdl.handle.net/2066/159141>). 
- «Date » : Nous indiquons les siècles et, le cas échéant, l'année suit entre parenthèses. Voir nos observations au chapitre 5 , point 3 .

- «Copiste» et «Destinataire»: Si ces informations existent, nous donnons ici le nom du copiste et/ou du destinataire. Voir nos observations au chapitre 5 , point 8 .

- «Langue/écriture »: Il est ici indiqué si le texte arabe est accompagné du texte dans une autre langue. Nous indiquons aussi dans cette rubrique si le texte est écrit en karshouni ${ }^{16}$. Nous n'indiquons pas le type d'écriture arabe utilisée, car cette information est rarement donnée dans les catalogues (sans parler de la difficulté à faire entrer les écritures arabes dans des catégories fixes). Voir nos observations au chapitre 5, point 6.

- «Description » : Nous donnons, selon les informations disponibles, dans cet ordre: le support (voir chapitre 5 , point 8 ); le nombre de folios; la taille des folios; la taille de la surface écrite; le nombre de lignes; le nombre de colonnes.

- «Vorlage»: Ici, nous donnons la catégorie selon laquelle Graf a classé le manuscrit. Dans quelques cas, nous reportons la Vorlage donné par le catalogueur. Pour davantage d'explications, voir chapitre 5 , point 5 .

- «Origine »: L'origine est donnée s'il y a une mention géographique dans les annotations ou si un chercheur/catalogueur suggère une origine sur la base de son observation; lorsque les manuscrits sont bilingues copte-arabe, nous indiquons comme origine «Égypte» suivi d'un «? »17. Nous utilisons les origines suivantes : Égypte, Palestine, Syrie, Liban, Irak, Turquie, Espagne, Europe. Nous les utilisons par commodité, bien qu'elles ne correspondent généralement pas à la réalité historique de l'époque de production, car elles permettent de désigner des régions géographiquement plus restreintes.

- «Remarque/s » : Nous ajoutons ici toute information ne correspondant pas aux rubriques précédentes.

- «Bibliographie»: Les références bibliographiques sont généralement données sous forme raccourcie ; la forme complète se trouve dans la bibliographie en fin d'ouvrage.

De manière générale, nous prenons le parti de ne pas extrapoler d'informations. Par exemple, si la notice ou la description d'un chercheur n'indique pas que le support d'un manuscrit est le papier, nous ne complétons pas cette information même si cela est vraisemblable lorsque le manuscrit est tardif.

16 Nous n'indiquons pas le type d'écriture syriaque utilisée, car cette information est rarement donnée dans les catalogues. Cela serait à compléter à la suite d'une consultation des manuscrits.

17 En effet, certains manuscrits copto-arabes proviennent par exemple de Jérusalem. 
Le répertoire est ordonné par ville/lieu et par bibliothèque. Tous les liens ont été consultés dernièrement le 31.07.2018.

2

\section{Berlin, Staatsbibliothek}

1. Berlin Staatsbibl. Diez A oct. 162

- No. catalogue : Ahlwardt 10175

- Contenu du manuscrit : 1. Évangiles incomplets (Mt (sans 1,1-10,28), Mc, Lc, Jn) ; 2. Lettres de Paul (Rm, 1 Co, 2 Co, Ga, Ep, Ph, Col, 1 Th, 2 Th, 1 Tm, 2 Tm, Tt, Phm, He) ; 3. Actes des Apôtres ; 4. Lettres catholiques (Jc, 1 P, 2 P, 1 Jn, 2 Jn, 3 Jn, Jude); 5 . Apocalypse.

- Date:13 (1264 et 1273)

- Description : Papier ; 349 folios ; 180×135 mm ; surface écrite 120×750 mm ; 1 colonne ; 18 lignes.

- Vorlage : Syriaque (3)

- Bibliographie: GCAL I, p. 177; Gregory, p. 587, no. 69; Ahlwardt, pp. 527-30, no. 10175 ; LAgARDE, p. XVII ; KASHOUH, p. 47, pp. 276-28o ; <http://orient-digital.staatsbibliothek-berlin.de/receive/SBBMSBook_ islamhs_00003421>.

2. Berlin Staatsbibl. Or. Folio 115

- Contenu du manuscrit : Lettres de Paul incomplètes (Col, 1 Th, 2 Th, Phm, He (sans 9,22-10,18; 12,16-fin), 1 Tm, 2 Tm, Tt).

- Date: 14

- Langue/écriture : copte-arabe

- Description : Papier ; 105 folios ; $267 \times 178 \mathrm{~mm}$; surface écrite $222 \times 134 \mathrm{~mm}$; 32-33 lignes ; 2 colonnes.

- Vorlage: Copte (2)

- Origine : Égypte?

- Remarque : Berlin Staatsbibl. Or. Folio 116, Copenhague Kong. Bibl. Or. 19 et Berlin Staatsbibl. Or. Folio 115 constituaient à la base un seul manuscrit.

- Bibliographie: GCAL I, p. 178 ; Gregory, p. 545, no. 13 (copte); Horner, XLI-XlII ; SCHWARTZE Moritz Gotthilf, Psalterium in dialectum Copticae linguae Memphiticam translatum, Leipzig, 1843.

3. Berlin Staatsbibl. Or. Folio 116

- Contenu du manuscrit: Lettres de Paul incomplètes (Rm (sans 1,16-18.2024), 1 Co (sans 3,15-4,6), 2 Co).

- Date: 14

- Langue/écriture : copte-arabe 
- Description: Papier; 88 folios; $262 \times 176 \mathrm{~mm}$; surface écrite $215 \times 134 \mathrm{~mm}$; 32-33 lignes ; 2 colonnes.

- Vorlage: Copte (2)

- Origine:Égypte?

- Remarque: Berlin Staatsbibl. Or. Folio 116, Copenhague Kong. Bibl. Or. 19 et Berlin Staatsbibl. Or. Folio 115 constituaient à la base un seul manuscrit.

- Bibliographie: GCAL I, p. 178; Gregory, p. 545, no. 14 (copte); Horner, pp. XLI-XLIII; SChWARTZE Moritz Gotthilf, Psalterium in dialectum Copticae linguae Memphiticam translatum, Leipzig, 1843.

4. Berlin Staatsbibl. Or. Quarto 612

- No. catalogue: Ahlwardt 10201

- Contenu du manuscrit: 1. Fragments de Phm, de Jc, de Ac et de Lc; 2. Lectures; 3. Fragments de Ph et de $1 \mathrm{P}$; 4. Prières; 5 . Fragments de Jn; Fragments des Psaumes.

- Description:Papier ; 30 folios ; 205×145 mm ; surface écrite env. 150×100 mm ; env. 13 lignes; différents folios de différents manuscrits reliés ensemble.

- Bibliographie: AH LWARDT, pp. 563-564.

\section{Beyrouth, Bibliothèque orientale}

\section{Beyrouth BO 441}

- Autre cote : 841

- Contenu du manuscrit: Nouveau Testament sans Apocalypse.

- Date:17 (1649)

- Copiste :Yūsuf al-Mașūr fils du pèlerin Anțūniūs

- Destinataire : Le diacre 'Abd an-Nūrban

- Description: Papier ; 260 folios ; 240×160 mm ; 33 lignes.

- Vorlage: «Unbestimmter Herkunft»

- Bibliographie: GCAL I, p. 139, p. 177. СHeIкHO, pp. 163-164.

6. Beyrouth BO 1358

- Contenu du manuscrit: Lettres de Paul.

- Date: $17(1640,1642)$

- Description: Papier; 386 folios (à l'origine); $253 \times 180 \mathrm{~mm}$; surface écrite 200×100 mm; 17 lignes.

- Remarque : Folios manquants au début, à la fin et dans le corps de l'ouvrage.

- Bibliographie:KHALIFÉ, p. 19. 
7. Bzommar 215

- Contenu du manuscrit: 1. Lettres de Paul ; 2 . Apocalypse.

- Date:18 (1766)

- Copiste : Diacre Yūsef Almusawwer

- Description : Papier ; 120 folios ; 300×210 mm ; 19 lignes ; 1 colonne.

- Bibliographie : <http://www.vhmml.us/research2014/catalog/detail.asp? $\mathrm{MSID}=133622>$.

\section{Caire, Franciscan Center of Christian Oriental Studies}

8. Caire f ccos Ar. Christ. 5

- Contenu du manuscrit: 1. Lettres de Paul; 2. Lettres catholiques; 3. Actes des Apôtres.

- Date:19

- Description : 150 folios ; $345 \times 243$ mm ; 15 lignes.

- Bibliographie:MAcombeR 1, p. 2.

9. Caire fCcos Ar. Christ. 9

- Contenu du manuscrit: 1. Lettres de Paul ; 2. Lettres catholiques; 3. Actes des Apôtres.

- Date: 18 (1767)

- Description : 175 folios ; 324×220 mm ; 18-19 lignes.

- Bibliographie : Macomber 1, p. 3.

10. Caire f ccos Ar. Christ. 12

- Contenu du manuscrit: 1. Évangiles incomplets (à partir de Mt 26,10) ; 2. Lettres de Paul incomplètes (jusqu'à $\mathrm{Ph} 4,4$ ).

- Date:19

- Description : 151 folios ; $295 \times 215 \mathrm{~mm} ; 24$ lignes.

- Bibliographie: MacombeR 1, p. 4.

11. Caire F ccos Arab. Christ. 16

- Contenu du manuscrit: 1. Lettres de Paul ; 2. Lettres catholiques; 3. Actes des Apôtres.

- Date: 18

- Description : 258 folios ; 206×155 mm ; 18 lignes.

- Bibliographie: MAсомвеR 1, p. 5 .

12. Caire FCCos Arab. Christ. 79

- Contenu du manuscrit: 1. Lettres de Paul ; 2. Lettres catholiques; 3 . Actes des Apôtres. 
- Date: 19

- Description : 187 folios ; 206×155 mm; 18 lignes.

- Bibliographie: MAcomber 1, p. 17.

13. Caire Fccos Arab. Christ. 186

- Contenu du manuscrit: 1. Introduction aux lettres de Paul ; 2. Lettres de Paul ; 3. Lettres catholiques ; 4. Actes des Apôtres.

- Date:19 (1882)

- Description : 300 folios ; 230×161 mm; 15 lignes.

- Bibliographie: MaсомвеR 1, p. 40.

6

\section{Caire, Musée copte}

14. Caire Mus. Copt. Bibl. 3

- No. catalogue: Graf 3 ; Simaika 34; Macomber CMA 2-10

- Autre cote : Old 55 ; New 33

- Contenu du manuscrit: 1 Lettres de Paul (Rm, 1 Co, 2 Co, Ga, Ep, Ph, Col, 1 Th, 2 Th, 1 Tm, 2 Tm, Tt, Phm, He) ; 2 . Lettres catholiques (Jc, 1 P, 2 P, 1 Jn, 2 Jn, $3 \mathrm{Jn}$, Jude) ; 3 . Actes des Apôtres.

- Date: $18(1740)^{18}$

- Copiste : Yūsuf Yáqūb al-Mallāwānī

- Description: Papier; 211 folios ; 220×150 mm; surface écrite $170 \times 100 \mathrm{~mm}$; 17-18 lignes ; 1 colonne.

- Origine : Égypte (Mar Minā)

- Bibliographie: Graf, p. 2 ; SimaikA 1, p. 20 ; MAcomber 2, vol. 1, roll A-2, item 10.

15. Caire Mus. Copt. Bibl. 5

- No. catalogue: Graf 5 ; Simaika 26 ; Macomber CMA 2-4

- Autre cote : Old 57 ; New 25

- Contenu du manuscrit: 1. Lettres de Paul (Rm, 1 Co, 2 Co, Ga, Ep, Ph, Col, 1 Th, 2 Th, He, 1 Tm, 2 Tm, Tt, Phm) ; 2. Lettres catholiques (Jc, 1 P, 2 P, 1 Jn, 2 Jn, 3 Jn, Jude) ; 3 . Actes des Apôtres.

- Date: 17 (1659)

- Langue/écriture : Copte-arabe

- Description: Papier; 189 folios, 340×210; surface écrite $270 \times 170 \mathrm{~mm}$; 40 lignes ; 2 colonnes.

- Vorlage: Copte (2)

18 Ici, les indications concernant la date divergent: Graf propose 1495, Simaika et Macomber 1740. 
- Origine : Égypte?

- Bibliographie: Graf, p. 2 ; Simaika 1, p. 17 ; Macomber 2, vol. 1, roll A-2, item 4.

16. Caire Mus. Copt. Bibl. 94

- No. catalogue : Graf 151; Simaika 4; Macomber CMA 20-6

- Autre cote: Old 146; New 4

- Contenu du manuscrit: 1. Lettres de Paul (Rm 1 Co, 2 Co, Ga, Ep, Ph, Col, 1 Th, 2 Th, He, 1 Tm, 2 Tm, Tt, Phm) ; 2. Lettres catholiques (Jc, 1 P, 2 P, 1 Jn, 2 Jn, 3 Jn, Jude) ; 3 . Actes des Apôtres.

- Date:13 (1249)

- Copiste : Le moine Gabriel

- Destinataire : Našū Abū Šākir ibn as-Sanī ar-Rāhib

- Langue/écriture: Copte-arabe

- Description: Papier; 221 folios ; 240×170 mm; surface écrite 200×140 mm; 33 lignes; 2 colonnes.

- Vorlage: Syriaque (2)

- Origine :Égypte?

- Bibliographie: GCAL I, p. 176 ; Graf, p. 246 ; Simaika 1, p. 8 ;MACOMber 2, vol. 1, roll A-20, item 6.

17. Caire Mus. Copt. Bibl. 100

- No. catalogue: Graf 673; Simaika 7; Macomber CMA 1-5

- Autre cote: Old 152 ; New 7

- Contenu du manuscrit: 1. Lettres de Paul (Rm à partir de 3,8, 1 Co, 2 Co, Ga, Ep, Ph, Col, 1 Th, 2 Th, He, 1 Tm, 2 Tm, Tt, Phm); 2. Lettres catholiques (Jc, 1 P, 2 P, 1 Jn, 2 Jn, 3 Jn, Jude) ; 3 . Actes des Apôtres.

- Date: 13

- Langue/écriture: Copte-arabe

- Description: Papier ; 283 folios ; $380 \times 280 \mathrm{~mm}$; surface écrite $300 \times 200 \mathrm{~mm}$; 31 lignes; 1 colonne.

- Vorlage: Syriaque (2)

- Origine : Égypte?

- Remarque:Il manque de nombreux folios; Graf lui attribue la cote Bibl. 101.

- Bibliographie: GCAL I, p. 177 ; Graf, p. 246 ; Simaika 1, p. 8 ; MACOM BER 2, vol. 1, roll A-1, item 5 .

\section{Caire Mus. Copt. Bibl. 101}

- No. catalogue: Graf 672 ; Simaika 18 ; Macomber CMA 20-7 ${ }^{19}$

19 La cote diffère selon Graf, qui lui donne la cote Bibl. 100 (car il donne à Bibl. 100 la cote Bible 101), et Macomber, qui lui donne la cote Bibl. 171. La description du manuscrit est absente de Macomber. 
- Autre cote : Old 153 ; New 17

- Contenu du manuscrit: 1. Lettres de Paul (Rm à partir de 8,27; He après Phm) ; 2. Lettres catholiques ; 3 . Actes des Apôtres.

- Date:13

- Description : 324 folios ; 200×130 mm ; surface écrite $160 \times 90 \mathrm{~mm} ; 14$ lignes.

- Vorlage: Syriaque (2)

- Bibliographie: GCAL I, p. 177 ; GRAF, p. 246 ; SimAIKA 1, p. 14.

19. Caire Mus. Copt. New 57 (A)

- No. catalogue: Macomber см в 1-8

- Contenu du manuscrit: 1. Lettres de Paul (Rm, 1 Co, 2 Co, Ga, Ep, Ph, Col, $1 \mathrm{Th}, 2 \mathrm{Th}, 1 \mathrm{Tm}, 2 \mathrm{Tm}, \mathrm{Tt}, \mathrm{Phm}, \mathrm{He}) ; 2$. Lettres catholiques incomplètes (Jc, 1 P, 2 P, 1 Jn) ; 3. Actes des Apôtres incomplets.

- Date: 15

- Description : Papier ; 104 folios ; 250×140 mm; surface écrite $180 \times 100 \mathrm{~mm}$; 15 lignes ; 1 colonne.

- Remarque :Les folios sont dans le désordre ; plusieurs folios sont manquants.

- Bibliographie : MAcomber 2, vol. 2, roll B-1, item 8.

20. Caire Mus. Copt. New 63 (B)

- No. catalogue : Macomber См B 1-14B

- Contenu du manuscrit: 1 . Lettres de Paul (Rm 1 Co, Ph, Col, 1 Th, 1 Tm); 2. Lettres catholiques incomplètes (Jc, 1 P, 2 P, 1 Jn, 2 Jn, 3 Jn, Jude) ; Actes des Apôtres incomplets.

- Date:16-17

- Description: Papier; 34 folios ; $320 \times 220 \mathrm{~mm}$; surface écrite $250 \times 170 \mathrm{~mm}$; 1 colonne.

- Bibliographie: MAсом BER 2, vol. 2, roll B-1, item 14B.

21. Caire Mus. Copt. New 150 (E)

- No. catalogue : Macomber см в 3-13E

- Autre cote : Old 6448 (E)

- Contenu du manuscrit : Fragment de Rm (8,8-21 ; 12,8-16,11).

- Date: 18

- Description: Papier; 9 folios ; 200×140 mm; surface écrite $160 \times 100 \mathrm{~mm}$; 1 colonne.

- Bibliographie : MAсом ве R 2, vol. 2, roll B-3, item 13E.

22. Caire Mus. Copt. New 458 (Q)

- No. catalogue : Macomber см в 7-27Q

- Autre cote : Old 6533 (Q)

- Contenu du manuscrit : Fragment de 1 Co $(15,37-16,19)$.

- Date: 16 
- Description: Papier; 2 folios; 220 $\times 140 \mathrm{~mm}$; surface écrite $180 \times 110 \mathrm{~mm}$; 15 lignes, 1 colonne.

- Remarque: Un folio du même manuscrit se trouve dans Caire Mus. Copt. New $57(A)$.

- Bibliographie: MAcomber 2, vol. 3, roll B-7, item 27Q.

23. Caire Mus. Copt. New 465 (I)

- No. catalogue : Macomber см в 16-17I

- Autre cote: Old 6536 (I)

- Contenu du manuscrit: Fragments des lettres de Paul (2 Co 10,15-12,9; Ep 5,26-6,9; Ph 2,29-3,9).

- Date:18-19

- Description: Papier; 4 folios; 210×150 mm; surface écrite $160 \times 100 \mathrm{~mm}$; 13 lignes, 1 colonne.

- Bibliographie: MAсом BER 2, vol. 4, roll B-16, item 17 I.

24. Caire Mus. Copt. Old 6421 (R) et (U)

- No. catalogue: Macomber см в 8-5R et 8-5U

- Contenu du manuscrit: Fragment de 1 Co (12,8-28); Fragment de Col $(3,16-4,2)$.

- Date:15-16

- Description: Papier; 1 folio ; 220-240 $\times 130-150 \mathrm{~mm}$; surface écrite $170 \times$ $100 \mathrm{~mm} ; 13$ lignes ; 1 colonne).

- Bibliographie : MAcomber 2, vol. 3, roll B-8, item 5 R et item 5 U.

25. Caire Mus. Copt. Old 6430 (C)

- No. catalogue: Macomber см в 8-13C

- Contenu du manuscrit : Fragment de 1 Co (10,2-12).

- Date: 18

- Description: Papier; 1 folio ; 200×150 mm; surface écrite $160 \times 100 \mathrm{~mm} ; 13$ lignes, 1 colonne.

- Bibliographie: Macomber 2, vol. 3, roll B-8, item 13 C.

26. Caire Mus. Copt. Old 6437 (E)

- No. catalogue: Macomber смв 8-20E

- Contenu du manuscrit : Fragment de 1 Co (12,31-14,39).

- Date:17-18

- Description: Papier ; 4 folios; 190×140 mm; surface écrite $150 \times 90 \mathrm{~mm} ; 13$ lignes, 1 colonne.

- Bibliographie: MAcomber 2, vol. 3, roll B-8, item 2oE. 


\section{Caire, Patriarcat copte catholique}

27. Caire Patr. Copt. Cath. 2-4

- No. catalogue : Macomber CCP 2-4

- Contenu du manuscrit: 1. Lettres de Paul (Rm, 1 Co, 2 Co, Ga, Ep, Ph, Col, 1 Th, 2 Th, He, 1 Tm, 2 Tm, Tt, Phm) ; 2. Lettres catholiques (Jc, 1 P, 2 P, 1 Jn, 2 Jn, 3 Jn, Jude); 3 . Actes des Apôtres.

- Date:18 (1787)

- Langue/écriture: Copte-arabe

- Description : Papier ; 456 folios ; $340 \times 230 \mathrm{~mm}$; surface écrite $250 \times 140 \mathrm{~mm}$; 2 colonnes.

- Origine : Égypte?

- Bibliographie : MAсомвеR 3, roll 2, item 4; images : <https://archive.org/ stream/CCP2-4/CCP\%202-4\#page/no/mode/2up $>$.

28. Caire Patr. Copt. Cath. 3-3A

- No. catalogue : Macomber CCP 3-3A

- Contenu du manuscrit : 1. Introduction aux lettres de Paul ; 2. Lettres de Paul (Rm, 1 Co, 2 Co, Ga, Ep, Ph, Col, 1 Th, 2 Th, 1 Tm, 2 Tm, Tt, Phm, He) ; 3 . Lettres catholiques (Jc, 1 P, 2 P, 1 Jn, 2 Jn, 3 Jn, Jude) ; 4. Actes des Apôtres.

- Date: 18 (1719)

- Copiste : Le diacre Rāfa'īl, fils du prêtre 'Abd as-Sayyid, fils d'Iskārūs

- Description : Papier ; 195 folios ; 300×180 mm; surface écrite $240 \times 130 \mathrm{~mm}$; 1 colonne.

- Origine : Égypte (Ahmīm)

- Remarque : Le manuscrit est relié avec un autre manuscrit, Caire Patr. Copt. Cath. 3-3B, qui contient un commentaire sur l'évangile de Jean par Jean Chrysostome.

- Bibliographie : MAсомве R 3, roll 3, item 3A ; images : <https://archive.org/ stream/CCP 3 -2/CCP\%203-2\#page/no/mode/2up $>$.

29. Caire Patr. Copt. Cath. 5-12

- No. catalogue : Macomber CCP 5-12

- Contenu du manuscrit: 1. Lettres de Paul (Rm, 1 Co, 2 Co, Ga, Ep, Ph, Col, 1 Th, 2 Th, 1 Tm, 2 Tm, Tt, Phm, He) ; 2. Lettres catholiques (Jc, 1 P, 2 P, 1 Jn, 2 Jn, 3 Jn, Jude) ; 3 . Actes des Apôtres.

- Date : $14(1327 / 1328)$

- Description : Papier ; 226 folios ; 230×160 mm; surface écrite $180 \times 120 \mathrm{~mm}$; 13-15 lignes; 1 colonne.

- Origine : Égypte (Caire)

- Bibliographie : MAсомBe R 3, roll 5, item 13. 
30. Caire Patr. Copt. Cath. $5^{-13}$

- No. catalogue: MAcomber CCP 5-13

- Contenu du manuscrit: 1. Introduction aux lettres de Paul ; 2. Lettres de Paul (Rm, 1 Co, 2 Co, Ga, Ep, Ph, Col, 1 Th, 2 Th, 1 Tm, 2 Tm, Tt, Phm, He) ; 3 . Lettres catholiques (Jc, 1 P, 2 P, 1 Jn, 2 Jn, 3 Jn, Jude) ; 4. Actes des Apôtres.

- Date :18 (1780)

- Description : Papier ; 280 folios ; $220 \times 160 \mathrm{~mm}$; surface écrite $180 \times 100 \mathrm{~mm}$; 14 lignes ; 1 colonne.

- Bibliographie : MAcomber 3, roll 5, item 13.

31. Caire Patr. Copt. Cath. 9-6

- No. catalogue : Macomber CCP 9-6

- Contenu du manuscrit: 1. Lettres de Paul (Rm, 1 Co, 2 Co, Ga, Ep, Ph, Col, 1 Th, 2 Th, 1 Tm, 2 Tm, Tt, Phm, He) ; 2 . Lettres catholiques (Jc, 1 P, 2 P, 1 Jn, 2 Jn, 3 Jn, Jude) ; 3 . Actes des Apôtres.

- Date:19

- Description: Papier; 222 folios; 220 $\times 170$; surface écrite $170 \times 100 \mathrm{~mm}$; 15 lignes ; 1 colonne.

- Remarque : Les folios ont été reliés dans le désordre et quelques-uns sont manquants ; le dernier folio contient un hymne en arabe, probablement en l'honneur de saint Georges.

- Bibliographie : MAсомвеR 3, roll 9, item 16.

32. Caire Patr. Copt. Orth. Bibl. 141

- No. catalogue : Simaika 184; Macomber PAT 12-5

- Contenu du manuscrit: 1. Introduction; 2. Lettres de Paul (Rm 1 Co, 2 Co, Ga, Ep, Ph, Col, 1 Th, 2 Th, 1 Tm, 2 Tm, Tt, Phm, He); 3. Lettres catholiques (Ja, 1 P, 2 P, 1 Jn, 2 Jn, 3 Jn, Jude) ; 4. Actes des Apôtres.

- Date:19 (1865)

- Copiste : Le diacre 'Āzar ibn Bağdādī

- Destinataire : Anbā Marqus, Métropolitain d'Alexandrie et de Buhayra

- Langue/écriture : Copte-arabe

- Description : Papier ; 331 folios ; $460 \times 310 \mathrm{~mm}$; surface écrite $340 \times 210 \mathrm{~mm}$; 32-33 lignes ; 4 colonnes.

- Origine : Égypte

20 Les images des manuscrits du Patriarcat copte sont disponibles en ligne : $<$ https://cpart .mi.byu.edu/home/manuscripts/cop/>. 
- Remarques : Le manuscrit contient trois traductions arabes (trois colonnes); la première a la Vorlage syriaque (2), la deuxième a la Vorlage copte (2), la troisième ressemble à la traduction de Caire Patr. Copt. Orth. Bibl. 143, que Graf classe aussi selon la Vorlage copte (2).

- Bibliographie:Simaika 2, p. 79 ; MAcomber 4, vol. 1, roll A-12, item 5.

33. Caire Patr. Copt. Orth. Bibl. 142

- No. catalogue : Graf 289; Simaika 125; Macomber PAT 12-6

- Contenu du manuscrit: 1. Lettres de Paul (Rm 1 Co, 2 Co, Ga, Ep, Ph, Col, 1 Th, 2 Th, He, 1 Tm, 2 Tm, Tt, Phm) ; 2. Lettres catholiques (Ja, 1 P, 2 P, 1 Jn, 2 Jn, 3 Jn, Jude) ; 3 . Actes des Apôtres.

- Date:18 (1790)

- Copiste : Archiprêtre Ṣalīb, ministre au Saint-Sépulcre à Jérusalem

- Langue/écriture:Copte-arabe

- Description: Papier; 261 folios; $360 \times 250 \mathrm{~mm}$; surface écrite $270 \times 170 \mathrm{~mm}$; 29-30 lignes ; 2 colonnes.

- Vorlage: Copte (2)

- Origine: Palestine (Jérusalem)

- Bibliographie:GCAL I, p. 178; Graf, p. 110 ;Simaika 2, p. 79 ;MAComber 4, vol. 1, roll A-12, item 6.

\section{Caire Patr. Copt. Orth. Bibl. 143}

- No. catalogue: Graf 291; Simaika 180 ; Macomber PAT 12-7

- Contenu du manuscrit : Lettres de Paul ( $\mathrm{Rm}_{1} \mathrm{Co}, 2 \mathrm{Co}, \mathrm{Ga}, \mathrm{Ep}, \mathrm{Ph}, \mathrm{Col}, 1 \mathrm{Th}$, 2 Th, He, 1 Tm, 2 Tm, Tt, Phm).

- Date:19 $(1853)^{21}$

- Copiste : Anbā Yūhannā, évêque de Samannūd

- Langue/écriture:Copte-arabe

- Description: Papier; 209 folios; 310×230 mm; 230×130; 20-22 lignes; 1 colonne.

- Vorlage: Copte (2)

- Origine : Égypte (Samannūd)

- Remarque : Il s'agit de la même traduction que dans Caire Patr. Copt. Orth. Bibl. 141.

- Bibliographie: GCAL I, p. 178 ; Graf, p. 111 ; Simaika 2, p. 77 ; MAComber 4, vol. 1, roll A-12, item 7 .

21 Graf et Simaika ne sont pas d'accord sur la date. Graf donne 1846 et Simaika 1853. 


\section{Caire Patr. Copt. Orth. Bibl. 144}

- No. catalogue: Graf 290; Simaika 121; Macomber PAT 12-8

- Contenu du manuscrit: 1. Lettres de Paul (Rm 1 Co, 2 Co, Ga, Ep, Ph, Col, 1 Th, 2 Th, He, 1 Tm, 2 Tm, Tt, Phm) ; 2. Lettres catholiques (Ja, 1 P, 2 P, 1 Jn, 2 Jn, 3 Jn, Jude); 3 . Actes des Apôtres.

- Date :18 (1788)

- Langue/écriture : Copte-arabe

- Description : Papier ; 216 folios ; $370 \times 260 \mathrm{~mm}$; surface écrite $280 \times 130 \mathrm{~mm}$; 36-37 lignes ; 2 colonnes.

- Vorlage: Copte (2)

- Origine : Égypte?

- Remarque : Il s'agit de la même traduction que dans Caire Patr. Copt. Orth. Bibl. 147 .

- Bibliographie: GCAL I, p. 178 ; Graf, p. 110 ; Simaika 2, p. 54 ; MACOMbeR 4, vol. 1, roll A-12, item 8.

36. Caire Patr. Copt. Orth. Bibl. 146

- No. catalogue : Simaika 87 ; Macomber PAT 12-10

- Contenu du manuscrit: 1. Lettres de Paul (Rm 1 Co, 2 Co, Ga, Ep, Ph, Col, 1 Th, 2 Th, He, 1 Tm, 2 Tm, Tt, Phm) ; 2. Lettres catholiques (Ja, 1 P, 2 P, 1 Jn, 2 Jn, 3 Jn, Jude) ; 3 . Actes des Apôtres.

- Date :18 (1753-1754)

- Langue/écriture: Copte-arabe

- Description : Papier ; 354 folios ; $410 \times 300 \mathrm{~mm}$; surface écrite $320 \times 220 \mathrm{~mm}$; 26 lignes ; 2 colonnes.

- Vorlage : Syriaque (2)

- Origine : Égypte?

- Bibliographie:Simaika 2, p. 40 ; MAcomber 4, vol. 1, roll A-12, item 10.

37. Caire Patr. Copt. Orth. Bibl. 147

- No. catalogue: Graf 288 ; Simaika 74 ; Macomber PAT 12-11

- Contenu du manuscrit: 1. Lettres de Paul (Rm 1 Co, 2 Co, Ga, Ep, Ph, Col, 1 Th, 2 Th, He, 1 Tm, 2 Tm, Tt, Phm) ; 2. Lettres catholiques (Ja, 1 P, 2 P, 1 Jn, 2 Jn, 3 Jn, Jude); 3 . Actes des Apôtres.

- Date : 15 (1433-34)

- Langue/écriture : Copte-arabe

- Description : Papier ; 389 folios ; $340 \times 260 \mathrm{~mm}$; surface écrite $250 \times 130 \mathrm{~mm}$; 25 lignes ; 2 colonnes.

- Vorlage: Copte (2)

- Origine : Égypte? 
- Remarque: Le texte est le même que celui de Caire Patr. Copt. Orth. Bibl. 144 .

- Bibliographie: gCAL I, p. 178 ; Graf, p. 110 ; Simaika 2, p. 35 ; MAComber 4, vol. 1, roll A-12, item 11.

\section{Caire Patr. Copt. Orth. Bibl. 148}

- No. catalogue : Graf 295; Simaika 97; Macomber PAT 13-1

- Contenu du manuscrit: 1. Introduction aux lettres de Paul; 2. Lettres de Paul ; 3. Lettres catholiques ; 4 . Actes des Apôtres

- Date: 18 (1770)

- Destinataire: Un certain Thomas.

- Description : 239 folios; $320 \times 220 \mathrm{~mm} ; 17$ lignes.

- Vorlage: Syriaque (2)

- Bibliographie: GCAL I, p. 178; Graf, pp. 111-112; Simaika 2, p. 44; MAcomber 4, vol. 1, roll A-13, item $1^{22}$.

\section{Caire Patr. Copt. Orth. Bibl. 149}

- No. catalogue : Graf 294; Simaika 53 ; Macomber PAT 13-2

- Contenu du manuscrit : 1. Introduction aux lettres de Paul ; 2. Lettres de Paul (Rm 1 Co, 2 Co, Ga, Ep, Ph, Col, 1 Th, 2 Th, 1 Tm, 2 Tm, Tt, Phm, He) ; 3 . Lettres catholiques (Ja, 1 P, 2 P, 1 Jn, 2 Jn, 3 Jn, Jude) ; 4. Actes des Apôtres.

- Date: 17 (1691)

- Destinataire : Anbā Ġabriyāl, évêque de Jérusalem

- Description: Papier; 154 folios; 300×210 mm; surface écrite $230 \times 140 \mathrm{~mm}$; 19 lignes ; 1 colonne.

- Vorlage: Syriaque (2)

- Bibliographie: GCAL I, p. 178; Graf, p. 111 ; Simaika 2, p. 27 ; MAComber 4, vol. 1, roll A-13, item 2.

40. Caire Patr. Copt. Orth. Bibl. 150

- No. catalogue : Graf 584; Simaika 71; Macomber PAT 13-3

- Contenu du manuscrit: 1. Introduction aux lettres de Paul par al-Mu'taman abū al-Isḥāq ibn al-'Assāl ; 2. Lettres de Paul (Rm 1 Co, 2 Co, Ga, Ep, Ph, Col, 1 Th, 2 Th, 1 Tm, 2 Tm, Tt, Phm, He) ; 3. Lettres catholiques (Ja, 1 P, 2 P, 1 Jn, 2 Jn, 3 Jn, Jude) ; 4 . Actes des Apôtres.

- Date:18 (1720)

- Copiste : Archiprêtre Ǵabriyāl, ministre à l'Eglise de la Sainte Vierge à Ḥārat Zuwayla

22 Les informations sur le Caire Patr. Copt. Orth. Bibl. 148 n'ont pas pu être récupérées par Macomber. 
- Destinataire : Diacre Sađd Abū Mīhāāil de Girgā

- Description: Papier; 255 folios ; 300 $\times 210 \mathrm{~mm}$; surface écrite $220 \times 130 \mathrm{~mm}$; 17 lignes ; 1 colonne.

- Vorlage: Syriaque (2)

- Origine : Égypte (Ḥārat Zuwayla, Caire)

- Bibliographie: GCAL I, p. 177 ; Graf, p. 217 ; Simaika 2, p. 34 ;MACOMber 4, vol. 1, roll A-13, item 3 .

41. Caire Patr. Copt. Orth. Bibl. 151

- No. catalogue: Graf 311; Simaika 202 ; Macomber PAT 13-4

- Contenu du manuscrit :1. Introduction aux lettres de Paul ; 2. Lettres de Paul (Rm, 1 Co, 2 Co, Ga, Ep, Ph, Col, 1 Th, 2 Th, 1 Tm, 2 Tm, Tt, Phm, He) ; 3 . Lettre du Pseudo-Denys à Timothée; 3. Lettres catholiques (Jc, 1 P, 2 P, 1 Jn, 2 Jn, 3 Jn, Jude); 5 . Actes des Apôtres.

- Date:15-16

- Description: Papier ; 326 folios ; 230×150 mm; surface écrite $190 \times 120 \mathrm{~mm}$; 15 lignes ; 1 colonne.

- Vorlage: Syriaque (2)

- Bibliographie: GCAL I, p. 177 ; Graf, p. 115 ; Simaika 2, p. 84; MACOMber 4, vol. 1, roll A-13, item 4.

42. Caire Patr. Copt. Orth. Bibl. 152

- No. catalogue : Graf 307 ; Simaika 13; Macomber PAT 13-5

- Contenu du manuscrit: 1. Lettres de Paul (Rm, 1 Co, 2 Co, Ga, Ep, Ph, Col, 1 Th, 2 Th, 1 Tm, 2 Tm, Tt, Phm, He) ; 2. Lettres catholiques (Jc, 1 P, 2 P, 1 Jn, 2 Jn, 3 Jn, Jude) ; 3 . Actes des Apôtres.

- Date:14(1356)

- Description: Papier; 151 folios; 240×160 mm; surface écrite $200 \times 120 \mathrm{~mm}$; 18 lignes ; 1 colonne.

- Vorlage: Syriaque (2)

- Bibliographie: GCAL I, p. 177 ; Graf, p. 114 ; Simaika 2, p. 10 ; MACOMber 4 , vol. 1, roll A-13, item 5 .

43. Caire Patr. Copt. Orth. Bibl. 153

- No. catalogue : Graf 309; Simaika 7 ; Macomber PAT 13-6

- Contenu du manuscrit: 1. Lettres de Paul (Rm, 1 Co, 2 Co, Ga, Ep, Ph, Col, 1 Th, 2 Th, 1 Tm, 2 Tm, Tt, Phm, He) ; 2. Lettres catholiques (Jc, 1 P, 2 P, 1 Jn, 2 Jn, 3 Jn, Jude) ; 3 . Actes des Apôtres

- Date:13 (1299)

- Description: Papier; 239 folios; 250×170 mm; surface écrite $200 \times 110 \mathrm{~mm}$; 16 lignes; 1 colonne.

- Vorlage: Syriaque (2) 
- Origine : Égypte (Monastère de Saint Antoine)

- Bibliographie: gCAL I, p. 177 ; Graf, p. 115 ; Simaika 2, p. 7 ; MAcomber 4 , vol. 1, roll A-13, item 6.

44. Caire Patr. Copt. Orth. Bibl. 154

- No. catalogue: Graf 303; Simaika 3; Macomber PAT 13-7

- Contenu du manuscrit: 1. Un folio de l'introduction de Ibn al-Assāl; 2. Lettres de Paul (Rm, 1 Co, 2 Co, Ga, Ep, Ph, Col, 1 Th, 2 Th, 1 Tm, 2 Tm, Tt, $\mathrm{Phm}, \mathrm{He}$ ); 3 . Lettres catholiques (Jc, 1 P, 2 P, 1 Jn, 2 Jn, 3 Jn, Jude) ; 4. Actes des Apôtres.

- Date:13 (1253)

- Description: Papier; 158 folios ; $260 \times 200 \mathrm{~mm}$; surface écrite $200 \times 120 \mathrm{~mm}$; 18-19 lignes ; 1 colonne.

- Vorlage : Syriaque (2)

- Bibliographie:GCAL I, p.176;GRAF, pp.113-114;SIMAIKA 2, p. 4 ;MACOMBER 4, vol. 1, roll A-13, item 7 .

\section{Caire Patr. Copt. Orth. Bibl. 155}

- No. catalogue: Graf 306; Simaika 160 ; Macomber PAT 13-8

- Contenu du manuscrit: 1. Lettres de Paul (Rm, 1 Co, 2 Co, Ga, Ep, Ph, Col, 1 Th, 2 Th, 1 Tm, 2 Tm, Tt, Phm, He) ; 2. Lettres catholiques (Jc, 1 P, 2 P, 1 Jn, 2 Jn, 3 Jn, Jude) ; 3 . Actes des Apôtres.

- Date:19(1805)

- Copiste : Le diacre Ibrāhīm Abū Tabl, fils de Simān al-Ḩawānīkī

- Destinataire : 'Awaḍ, moine du monastère de Saint Antoine

- Description: Papier; 211 folios; 260×190 mm; surface écrite 190×130 mm; 5 lignes ; 1 colonne.

- Vorlage: Syriaque (2)

- Bibliographie: gCAL I, p. 177 ; Graf, p. 114 ;SIMAikA 2, p. 70 ; MAComber 4, vol. 1, roll A-13, item 8 .

46. Caire Patr. Copt. Orth. Bibl. 156

- No. catalogue : Graf 587; Simaika 203; Macomber PAT 13-9

- Contenu du manuscrit: 1. Lettres de Paul (Rm à partir de 3,28, 1 Co, 2 Co, Ga, Ep, Ph, Col, 1 Th, 2 Th, 1 Tm, 2 Tm, Tt, Phm, He) ; 2. Lettres catholiques (Ja, 1 P, 2 P, 1 Jn, 2 Jn, 3 Jn, Jude) ; 3 . Actes des Apôtres.

- Date:18 (1719)

- Description: Papier; 188 folios ; 270×200 mm; surface écrite $220 \times 140 \mathrm{~mm}$; 15-19 lignes. ; 1 colonne.

- Vorlage: Syriaque (2)

- Bibliographie:GCAL I, p. 177 ;GRAF, p. 517-518;SIMAika 2, p. 85 ;MACOMBER 4, vol. 1, roll A-13, item 9 . 
47. Caire Patr. Copt. Orth. Bibl. 157

- No. catalogue: Graf 293 ; Simaika 179 ; Macomber PAT 13-10

- Contenu du manuscrit: 1. Lettres de Paul (Rm, 1 Co, 2 Co, Ga, Ep, Ph, Col, 1 Th, 2 Th, 1 Tm, 2 Tm, Tt, Phm, He) ; . Lettres catholiques (Jc, 1 P, 2 P, 1 Jn, 2 Jn, 3 Jn, Jude); 3 . Actes des Apôtres ; 4. Extraits d'un discours de Jean Chrysostome, en l'honneur de Saint Pierre et Saint Paul (cf. Sin. Ar. 409.2).

- Date:19 (1846)

- Copiste : Le prêtre Girgis, moine à Saint-Antoine

- Destinataire : Mīhaīl al-Habašì, fils de l'archiprêtre Barsūm

- Description: Papier; 159 folios ; $310 \times 220 \mathrm{~mm}$; surface écrite $220 \times 140 \mathrm{~mm}$; 16-18 lignes ; 1 colonne.

- Vorlage : Syriaque (2)

- Origine : Égypte (Saint-Antoine)

- Bibliographie : gCAL I, p. 176 ; Graf, p. 111 ; Simaika 2, p. 77 ; MAComber 4, vol. 1, roll A-13, item 10.

48. Caire Patr. Copt. Orth. Bibl. $15^{8}$

- No. catalogue: Graf 297; Simaika 102 ; Macomber PAT 13-11

- Contenu du manuscrit: 1. Lettres de Paul (Rm, 1 Co, 2 Co, Ga, Ep, Ph, Col, 1 Th, 2 Th, 1 Tm, 2 Tm, Tt, Phm, He) ; 2. Lettres catholiques (Jc, 1 P, 2 P, 1 Jn, 2 Jn, 3 Jn, Jude); 3 . Actes des Apôtres ; 4. Apocalypse

- Date:18 (1778)

- Copiste : Archiprêtre Ṣalīb, ministre au Saint-Sépulcre à Jérusalem

- Destinataire : Hannis Abū Yūḥannā, secrétaire du dīwān à Damietta

- Description: Papier; 135 folios ; $310 \times 230 \mathrm{~mm}$; surface écrite $230 \times 150 \mathrm{~mm}$; 19 lignes ; 1 colonne.

- Vorlage : Syriaque (2)

- Origine : Palestine (Jérusalem)

- Bibliographie: GCAL I, p. 176 ; Graf, p. 112 ; Simaika 2, p. 46 ; MAcombeR 4, vol. 1, roll A-13, item 11.

49. Caire Patr. Copt. Orth. Bibl. 159

- No. catalogue: Graf 292 ; Simaika 75 ; Macomber PAT 13-12

- Contenu du manuscrit: 1. Lettres de Paul (Rm, 1 Co, 2 Co, Ga, Ep, Ph, Col, 1 Th, 2 Th, 1 Tm, 2 Tm, Tt, Phm, He) ; 2. Lettres catholiques (Jc, 1 P, 2 P, 1 Jn, 2 Jn, 3 Jn, Jude); 3 . Actes des Apôtres.

- Date:18 (1722)

- Copiste : Marqūriyūs ibn Yūḥannā

- Description : Papier ; 180 folios ; 300×210 mm ; surface écrite $230 \times 140 \mathrm{~mm}$; 17 lignes ; 1 colonne.

- Vorlage: Syriaque (2) 
- Bibliographie: gCAL I, p. 176 ; Graf, p. 111 ; Simaika 2, p. 35 ; MAComber 4, vol. 1, roll A-13, item 12.

50. Caire Patr. Copt. Orth. Bibl. 160

- No. catalogue: Graf 302 ; Simaika 126 ; Macomber PAT 13-13

- Contenu du manuscrit: 1. Lettres de Paul (Rm, 1 Co, 2 Co, Ga, Ep, Ph, Col, 1 Th, 2 Th, 1 Tm, 2 Tm, Tt, Phm, He) ; 2. Lettres catholiques (Jc, 1 P, 2 P, 1 Jn, 2 Jn, 3 Jn, Jude); 3 . Actes des Apôtres.

- Date: 18 (1792)

- Description: Papier ; 230 folios ; 230×170 mm; surface écrite $170 \times 110 \mathrm{~mm}$; 15 lignes ; 1 colonne.

- Vorlage : Syriaque (2)

- Bibliographie : gCAL I, p. 176 ; Graf, p. 113 ; Simaika 2, p. 56 ; MAComber 4, vol. 1, roll A-13, item 13 .

51. Caire Patr. Copt. Orth. Bibl. 161

- No. catalogue: Graf 301; Simaika 22 ; Macomber PAT 13-14

- Contenu du manuscrit : 1. Lettres de Paul incomplètes (1 Co, 2 Co, Ga, Ep, Ph, Col, 1 Th, 2 Th, 1 Tm, 2 Tm, Tt, Phm, He) ; 2. Lettres catholiques (Jc, 1 P, 2 P, 1 Jn, 2 Jn, 3 Jn, Jude) ; 3 . Actes des Apôtres.

- Date:13-14

- Description: Papier; 165 folios ; 230×140 mm; surface écrite $180 \times 120 m m$; 15 lignes ; 1 colonne.

- Vorlage : Syriaque (2)

- Bibliographie : GCAL I, p. 176 ; GrAF, p. 113 ; SimaikA 2, p. 14 ; MACOMber 4, vol. 1, roll A-13, item 14 .

52. Caire Patr. Copt. Orth. Bibl. 162

- No. catalogue: Graf 308 ; Simaika 116 ; Macomber PAT 13-15

- Contenu du manuscrit: 1. Introduction aux lettres de Paul par Ibn al-'Assāl et introduction anonyme 2. Lettres de Paul (Rm, 1 Co, 2 Co, Ga, Ep, Ph, Col, 1 Th, 2 Th, 1 Tm, 2 Tm, Tt, Phm, He).

- Date:18 (1786)

- Copiste : prêtre 'Abd as-Sayyid

- Description : Papier ; 246 folios ; 220×160 mm; surface écrite $170 \times 100 \mathrm{~mm}$; 15-21 lignes ; 1 colonne.

- Vorlage : Syriaque (2)

- Origine : Égypte (Saint-Bišoy)

- Bibliographie : gCAL I, p. 176 ; GrAF, p. 114 ;SIMAIKA 2, p. 52 ;MACOMber 4, vol. 1, roll A-13, item 15 . 
53. Caire Patr. Copt. Orth. Bibl. 163

- No. catalogue : Graf 313 ; Simaika 178 ; Macomber PAT 14-1

- Contenu du manuscrit: 1. Lettres de Paul (Rm, 1 Co, 2 Co, Ga, Ep, Ph, Col, 1 Th, 2 Th, 1 Tm, 2 Tm, Tt, Phm, He) ; 2. Lettres catholiques (Ja, 1 P, 2 P, 1 Jn, 2 Jn, 3 Jn, Jude); 3 . Actes des Apôtres.

- Date:19 (1846)

- Copiste : Ibšāy Mattā

- Description: Papier; 414 folios ; $150 \times 120 \mathrm{~mm}$; surface écrite $120 \times 80 \mathrm{~mm}$; 11 lignes ; 1 colonne.

- Vorlage : Syriaque (2)

- Bibliographie : gCAL I, p. 177 ; Graf, p. 116 ; Simaika 2, p. 77 ; MACOMber 4, vol. 2, roll A-14, item 1.

54. Caire Patr. Copt. Orth. Bibl. 164

- No. catalogue: Graf 314; Simaika 204 ; Macomber PAT 14-2

- Contenu du manuscrit: 1. Introduction aux lettres de Paul incomplète; 2. Lettres de Paul (Rm, 1 Co, 2 Co, Ga, Ep, Ph, Col, 1 Th, 2 Th, 1 Tm, 2 Tm, Tt, Phm, He) ; 3. Lettres catholiques (Ja, 1 P, 2 P, 1 Jn, 2 Jn, 3 Jn, Jude) ; 4. Actes des Apôtres.

- Date:16

- Description : Papier ; 236 folios ; 200×140 mm; surface écrite $160 \times 100 \mathrm{~mm}$; 15 lignes ; 1 colonne.

- Vorlage : Syriaque (2)

- Bibliographie: GCAL I, p. 177 ; GrAf, p. 116 ;SimAika 2, p. 85 ;MACOMber 4, vol. 2, roll A-14, item 2.

55. Caire Patr. Copt. Orth. Bibl. 165

- No. catalogue : Simaika 205; Macomber PAT 14-3

- Contenu du manuscrit: 1. Introduction aux lettres de Paul incomplète; 2. Lettres de Paul (Rm, 1 Co, 2 Co, Ga, Ep, Ph, Col, 1 Th, 2 Th, 1 Tm, 2 Tm, Tt, Phm, He) ; 3. Lettres catholiques (Ja, 1 P, 2 P, 1 Jn, 2 Jn, 3 Jn, Jude) ; 4. Actes des Apôtres.

- Date:16-17

- Copiste : Sim‘ān ibn Mihāȳīl

- Description : Papier ; 256 folios ; $210 \times 150 \mathrm{~mm}$; surface écrite $160 \times 110 \mathrm{~mm}$; 12-14 lignes ; 1 colonne.

- Vorlage : Syriaque (2)

- Bibliographie:Simaika 2, p. 85 ; MACOMBER 4, vol. 2, roll A-14, item 3.

56. Caire Patr. Copt. Orth. Bibl. 166

- No. catalogue: Graf 305 ; Simaika 99 ; Macomber PAT 14-4 
- Contenu du manuscrit: 1. Introduction aux lettres de Paul ; 2. Lettres de Paul ; 3 . Lettres catholiques ; 4 . Actes des Apôtres : 5 . Apocalypse.

- Date:19 (1805)

- Copiste:'Abd as-Sayyid

- Description: 261 folios; 210 $\times 150 \mathrm{~mm} ; 13$ lignes.

- Vorlage: Syriaque (2)

- Origine : Égypte (Saint-Bišoy)?

- Bibliographie: GCAL I, p. 177; Graf, p. 114;Simaika 2, p. 45; MACOMber 4, vol. 2, roll A-14, item $4^{23}$.

\section{Caire Patr. Copt. Orth. Bibl. 167}

- No. catalogue: Graf 298; Simaika 164; Macomber PAT 14-5

- Contenu du manuscrit: 1. Introduction aux lettres de Paul; 2. Lettres de Paul ; 3 . Lettres catholiques ; 4. Introduction aux Actes des Apôtres ; 5 . Actes des Apôtres.

- Date: 17

- Description : 261 folios; 190 $\times 140 \mathrm{~mm} ; 13$ lignes.

- Vorlage: Syriaque (2)

- Bibliographie:GCAL I, p. 176;GrAF, p. 112-113;SIMAIKA 2, p. 71; MACOMBER 4, vol. 2, roll A-14, item $5^{24}$.

58. Caire Patr. Copt. Orth. Bibl. 168

- No. catalogue : Simaika 206 ; Macomber PAT 14-6

- Contenu du manuscrit:1. Introduction aux lettres de Paul ; 2. Lettres de Paul (Rm, 1 Co, 2 Co, Ga, Ep, Ph, Col, 1 Th, 2 Th, 1 Tm, 2 Tm, Tt, Phm, He); 3 . Lettres catholiques (Ja, 1 P, 2 P, 1 Jn, 2 Jn, 3 Jn, Jude) ; 4. Actes des Apôtres.

- Date: 17

- Copiste : Un certain Nașrallāh

- Description: Papier; 228 folios; 200×150 mm; surface écrite $100 \times 60 \mathrm{~mm}$; 1 colonne.

- Vorlage : Syriaque (2)

- Bibliographie:Simaika 2, p. 86; MAcomber 4, vol. 2, roll A-14, item 6.

23 Les informations sur le manuscrit Caire Patr. Copt. Orth. Bibl. 166 n’ont pas pu être récupérées par Macomber.

24 Les informations sur le manuscrit Caire Patr. Copt. Orth. Bibl. 167 n'ont pas pu être récupérées par Macomber. 
59. Caire Patr. Copt. Orth. Bibl. 169

- No. catalogue: Graf 586 ; Simaika 72 ; Macomber PAT 14-7

- Contenu du manuscrit: 1. Lettres de Paul ; 2. Lettres catholiques; 3. Actes des Apôtres.

- Date: 18 (1719)

- Copiste : Archiprêtre Ġabriyāl, ministre à l'Eglise de la Sainte Vierge à Hāārat Zuwayla

- Destinataire : L'enseignant Girgis Ahnūh

- Description : 182 folios.

- Vorlage : Syriaque (2)

- Origine : Égypte (Hārat Zuwayla)

- Bibliographie:GCAL I, p.177;GRAF, p. 217-218;SIMAIKA 2, p. 34 ;MACOMBER 4, vol. 2, roll A-14, item $7^{25}$.

6o. Caire Patr. Copt. Orth. Bibl. 170

- No. catalogue: Graf 304 ; Simaika 100 ; Macomber PAT 14-8

- Contenu du manuscrit: 1. Introduction sur Paul ; 2. Lettres de Paul (Rm, 1 Co, 2 Co, Ga, Ep, Ph, Col, 1 Th, 2 Th, 1 Tm, 2 Tm, Tt, Phm, He) ; 3. Lettres catholiques ; 4 . Actes des Apôtres.

- Date : 18 (1775)

- Description : Papier ; 224 folios ; 220×160 mm; surface écrite $170 \times 110 \mathrm{~mm}$; 14 lignes ; 1 colonne.

- Vorlage : Syriaque (2)

- Bibliographie: GCAL I, p. 177 ; GrAf, p. 114 ;Simaika 2, p. 46 ; MACOMBER 4, vol. 1, roll A-14, item 8 .

61. Caire Patr. Copt. Orth. Bibl. 171

- No. catalogue: Graf 310 ; Simaika 56 ; Macomber PAT 14-9

- Contenu du manuscrit : 1. Introduction aux lettres de Paul ; 2. Lettres de Paul (Rm, 1 Co, 2 Co, Ga, Ep, Ph, Col, 1 Th, 2 Th, 1 Tm, 2 Tm, Tt, Phm, He) ; 3 . Lettres catholiques (Ja, 1 P, 2 P, 1 Jn, 2 Jn, 3 Jn, Jude) ; 4. Actes des Apôtres.

- Date: 17 (1695)

- Copiste : Archiprêtre Yawāsif à l'Eglise de la Sainte Vierge à Hāarat Zuwayla

- Destinataire : Un certain Mattā

- Description : Papier ; 256 folios; $210 \times 150 \mathrm{~mm}$; surface écrite $160 \times 110 \mathrm{~mm}$; 12-14 lignes ; 1 colonne.

- Vorlage : Syriaque (2)

- Origine : Égypte (Hārat Zuwayla)

- Remarque : Même introduction qu'au Caire Patr. Copt. Orth. Bibl. 167.

25 Les informations sur le manuscrit Caire Patr. Copt. Orth. Bibl. 169 n'ont pas pu être récupérées par Macomber. 
- Bibliographie: gCAL I, p. 177 ; Graf, p. 115 ;Simaika 2, p. 29 ;MACOMber 4, vol. 2, roll A-14, item 9 .

62. Caire Patr. Copt. Orth. Bibl. 173

- No. catalogue : Graf 299 ; Simaika 12 ; Macomber PAT 14-11

- Contenu du manuscrit: 1. Lettres de Paul (Rm, 1 Co, 2 Co, Ga, Ep, Ph, Col, 1 Th, 2 Th, 1 Tm, 2 Tm, Tt, Phm, He) ; 2. Lettres catholiques (Jc, 1 P, 2 P, 1 Jn, 2 Jn, 3 Jn, Jude) ; 3 . Actes des Apôtres.

- Date:14 (1346)

- Copiste : Le prêtre de Tūmā ibn aṣ-Ṣafā du monastère Abū Yuhannis Kāmā

- Description : Papier; 255 folios ; 230×170 mm; surface écrite $180 \times 120 \mathrm{~mm}$; 13 lignes ; 1 colonne.

- Vorlage: Syriaque (2)

- Origine : Syrie (Abū Yuhannis Kāmā, région de Damas)

- Bibliographie: GCAL I, p. 176 ; Graf, p. 113 ; Simaika 2, p. 10 ; Macomber 4, vol. 2, roll A-14, item 11.

63. Caire Patr. Copt. Orth. Bibl. 174

- No. catalogue : Graf 300 ; Simaika 10 ; Macomber PAT 15-1

- Contenu du manuscrit: 1. Lettres de Paul (Rm, 1 Co, 2 Co, Ga, Ep, Ph, Col, 1 Th, 2 Th, 1 Tm, 2 Tm, Tt, Phm, He) ; 2. Lettres catholiques (Jc, 1 P, 2 P, 1 Jn, 2 Jn, 3 Jn, Jude); 3 . Actes des Apôtres.

- Date:14 (1329)

- Description: Papier; 225 folios; 240×170 mm; 190×120 mm; 15 lignes; 1 colonne.

- Vorlage : Syriaque (2)

- Origine : Égypte (Saint-Mercure)

- Bibliographie: GCAL I, p. 176 ; Graf, p. 113 ; Simaika 2, p. 9 ; Macomber 4, vol. 2, roll A-15, item 1.

64. Caire Patr. Copt. Orth. Bibl. 178

- No. catalogue : Graf 585; Simaika 119 ; Macomber PAT 15-5

- Contenu du manuscrit: 1. Lettres de Paul; 2. Lettres catholiques; 3. Actes des Apôtres.

- Date:18 (1788)

- Copiste : Anțūnī Sacd de al-Jīzā

- Description : 128 folios ; 300 $\times 220 \mathrm{~mm} ; 17$ lignes.

- Vorlage : Syriaque (2)

- Bibliographie: gCAL I, p. 177 ; Graf, p. 217 ; Simaika 2, p. 54 ; MACOMber 4, vol. 2 , roll A-15, item $5^{26}$.

26 Les informations sur le Caire Patr. Copt. Orth. Bibl. 178 n'ont pas pu être récupérées par Macomber. 


\section{Caire Patr. Copt. Orth. Bibl. 195}

- No. catalogue : Simaika 123; Macomber PAT 16-6

- Contenu du manuscrit: 1. Lettres de Paul (Rm, 1 Co, 2 Co, Ga, Ep, Ph, Col, 1 Th, 2 Th, 1 Tm, 2 Tm, Tt, Phm, He) ; 2. Lettres catholiques (Ja, 1 P, 2 P, 1 Jn, 2 Jn, 3 Jn, Jude) ; 3 . Actes des Apôtres ; 4. Index.

- Date:18 (1789)

- Copiste : Rizqallāh 'Abd al-Masīh, enseignant à Maḥrūsīya et Girgā

- Description: Papier; 124 folios ; 330×210 mm; surface écrite $260 \times 150 \mathrm{~mm}$; 19-23 lignes; 1 colonne.

- Vorlage: Syriaque (2)

- Origine:Égypte

- Bibliographie: Simaika 2, p. 55 ; Macomber 4, vol. 2, roll A-16, item 6.

66. Caire Patr. Copt. Orth. Bibl. 208

- No. catalogue: Simaika 104; Macomber PAT 17-2

- Contenu du manuscrit : 1. Introduction aux lettres de Paul ; 2. Lettres de Paul (Rm, 1 Co, 2 Co, Ga, Ep, Ph, Col, 1 Th, 2 Th, 1 Tm, 2 Tm, Tt, Phm, He); 3 . Lettres catholiques (Ja, 1 P, 2 P, 1 Jn, 2 Jn, 3 Jn, Jude) ; 4. Actes des Apôtres.

- Date:18 (1780)

- Copiste : Archiprêtre Mūsā, ministre à l'Eglise de la Sainte Vierge à Ḥārat Zuwayla

- Destinataire : Le diacre Ḥinayn ibn Tādrus

- Description: Papier; 154 folios ; $310 \times 220 \mathrm{~mm}$; surface écrite $240 \times 140 \mathrm{~mm}$; 19 lignes ; 1 colonne.

- Vorlage: Syriaque (2)

- Origine : Égypte (Ḥārat Zuwayla)

- Bibliographie:Simaika 2, p. 47 ; Macomber 4, vol. 2, roll A-17, item 2.

67. Caire Patr. Copt. Orth. Bibl. 213

- No. catalogue : Simaika 52 ; Macomber PAT 17-7

- Contenu du manuscrit: 1. Introduction aux lettres de Paul par al-Mü'tamin abū al-Isḥāq ibn al-'Assāl et introductions anonymes ; 2. Lettres de Paul (Rm, 1 Co, 2 Co, Ga, Ep, Ph, Col, 1 Th, 2 Th, 1 Tm, 2 Tm, Tt, Phm, He); 3 . Lettres catholiques (Ja, 1 P, 2 P, 1 Jn, 2 Jn, 3 Jn, Jude) ; 4 . Actes des Apôtres.

- Date:17 (1691)

- Copiste :Yūsuf, fils de Ġabriyāl al-Buqī

- Description: Papier; 157 folios ; 330×200 mm; surface écrite $240 \times 150 \mathrm{~mm}$; 18-2o lignes; 1 colonne.

- Vorlage: Syriaque (2)

- Bibliographie:Simaika 2, p. 27 ; Macomber 4, vol. 2, roll A-16, item 6. 


\section{Caire Patr. Copt. Orth. Bibl. 214}

- No. catalogue : Macomber PAT 17-8

- Contenu du manuscrit: 1. Introduction aux lettres de Paul ; 2. Lettres de Paul (Rm 1 Co, 2 Co, Ga, Ep, Ph, Col, 1 Th, 2 Th, 1 Tm, 2 Tm, Tt, Phm, He) ; 3 . Lettres catholiques (Ja, 1 P, 2 P, 1 Jn, 2 Jn, 3 Jn, Jude) ; 4. Actes des Apôtres.

- Date:16

- Description : Papier ; 259 folios ; 220×160 mm ; surface écrite $170 \times 100 \mathrm{~mm}$; 15 lignes ; 1 colonne.

- Vorlage : Syriaque (2)

- Bibliographie: MAcomber 4, vol. 2, roll A-17, item 8

69. Caire Patr. Copt. Orth. Bibl. 215

- No. catalogue : Macomber PAT 17-9

- Contenu du manuscrit :1. Évangiles avec introduction (Mt, Mc, Lc, Jn);2. Actes des Apôtres ; 3. Lettres de Paul avec introduction (Rm, 1 Co, 2 Co, Ga, Ep, Ph, Col, 1 Th, 2 Th, 1 Tm, 2 Tm, Tt, Phm, He) ; 3 . Lettre apocryphe aux Laodicéens ; 4. Lettres catholiques (Ja, 1 P, 2 P, 1 Jn, 2 Jn, 3 Jn, Jude) ; 5 . Apocalypse.

- Date : 20 (1937)

- Copiste : Archiprêtre Tādrus al-Buwaytī, moine au Monastère Saint-Paul

- Description: Papier; 301 folios; $360 \times 240 \mathrm{~mm} ; 240 \times 160 \mathrm{~mm}$; 21 lignes; 1 colonne.

- Vorlage : syriaque (2)

- Origine : Égypte (Saint-Paul)

- Bibliographie : MAcombER 4, vol. 2, roll A-17, item 9.

7o. Caire Patr. Copt. Orth. Theol. 76

- No. catalogue : Graf 296; Simaika 255 ; Macomber PAT 24-8

- Contenu du manuscrit: 1. Introduction aux lettres de Paul ; 2. Lettres de Paul, avec commentaires ; 3. Lettre du Pseudo-Denys à Timothée ; 4. Actes des Apôtres avec commentaire.

- Copiste : Girgis ibn Mīnā

- Description : 385 folios.

- Vorlage : «Unbestimmer Herkunft»

- Remarque : S'agit-il d'un commentaire (Simaika) ou d'un texte continu, avec commentaire (Graf)?

- Bibliographie : GCAL I, p. 181; Graf, p. 112 ;Simaika 2, p. 106 ;MACOMber 4, vol. 2, roll A-24, item $8^{27}$.

27 Les informations sur le Caire Copt. Patr. Theol. 76 n'ont pas pu être récupérées par Macomber. 
71. Caire Bibl. Mar Menas Bibl. 1

- No. catalogue : Bibl. 1

- Contenu du manuscrit: 1. Lettres de Paul; 2. Lettres catholiques; 3. Apocalypse; 4 . Actes des Apôtres.

- Date: 18

- Description : 201 folios ; 210×160 mm ; surface écrite $165 \times 115 ; 17$ lignes.

- Bibliographie : KhAter, p. 1.

10

\section{Cambridge, University Library}

72. Cambridge UL Add. 2621

- No. catalogue : Hand-List 72

- Contenu du manuscrit: 1. Lettres de Paul ; 2. Lettres catholiques; 3. Actes des Apôtres.

- Date:14 (1353)

- Copiste : Cyril, serviteur de l'Eglise de Suyūt

- Description : 149 folios ; 242×157 mm; 19 lignes.

- Vorlage : «Unbestimmter Herkunft»

- Origine : Égypte (Suyūț)

- Remarque : Il manque 20 folios.

- Bibliographie: GCAL, p. 181 ; BROWNE, p. 12-13; <https://www.fihrist.org.uk/ catalog/manuscript_9069>.

73. Cambridge UL Add. 3212

- No. catalogue : Hand-List 74

- Contenu du manuscrit: 1. Lettres de Paul incomplètes (2 Co 6,3-fin); 2. Lettres catholiques; 3 . Actes des Apôtres $(1,13-28,20) ; 4$. Fragment de la lettre apocryphe du Ps.-Dionysius à Timothée sur le martyr de Pierre et Paul.

- Description : 259 folios ; 195×136 mm ; 13 lignes.

- Vorlage : «Unbestimmter Herkunft»

- Remarque: Il manque les 70 premiers folios et d'autres au 259 folios d'origine. Cambridge UL Add. 3212 est-il la suite du manuscrit Cambridge UL Add. 3213 ?

- Bibliographie : GCAL I, p. 181 ; BROWNE, p. 13 ; <https://www.fihrist.org.uk/ catalog/manuscript_9159>. 
74. Cambridge UL Add. 3213

- No. catalogue : Hand-List 75

- Contenu du manuscrit: 1. Lettres de Paul incomplètes (Rm 5,18-2 Co 6,2); 2. Conclusion d'un ouvrage plus moderne.

- Date:12-13

- Description : 55 folios; $183 \times 130 \mathrm{~mm} ; 13$ lignes.

- Vorlage : «Unbestimmter Herkunft»

- Remarque :Voir remarque sur le Cambridge UL Add. 3212.

- Bibliographie: GCAL I, p. 181; BRowNE, p. 13; <https://www.fihrist.org.uk/ catalog/manuscript_9160>.

75. Cambridge UL Add. 3226

- No. catalogue: Hand-List 71

- Contenu du manuscrit :1. Évangiles ; 2. Actes des Apôtres ; 3. Lettres de Paul ; 4. Lettres catholiques ; 5 . Apocalypse.

- Date:17 (1688)

- Description: Papier; 256 folios; $160 \times 96 \mathrm{~mm}$; surface écrite $130 \times 75 \mathrm{~mm}$; 25 lignes.

- Vorlage: «Unbestimmter Herkunft»

- Bibliographie: GCAL, 181 ; BRowne, p. 12 ; KASHOUH, p. 49, p. 211 ; <https:// www.fihrist.org.uk/catalog/manuscript_9171>.

76. Cambridge UL Add. Y 9

- Contenu du manuscrit: Miscellanées en arabe, persan et turc; ff. 168r-175v contiennent une partie de $\mathrm{Rm}(5,1-9,7)$.

- Vorlage: «Unbestimmter Herkunft»

- Bibliographie: GCAL I ; Nicholson, p. $293^{28}$.

77. Cambridge UL Dd. $15 \cdot 4$

- No. catalogue : Hand-List 76

- Contenu du manuscrit: Colossiens.

- Date:16-17

- Copiste:William Bedwell de Stortford

- Destinataire : L'évêque Bancroft

- Langue/écriture: Latin-arabe

- Description : 64 folios; $102 \times 72 \mathrm{~mm} ; 11$ lignes.

- Vorlage: «Unbestimmter Herkunft»

- Origine : Europe (Bishop's Stortford)

28 Le catalogue de Nicholson est disponible en ligne, mais uniquement les pages paires (!). Nous n'avons pas pu consulter la notice de Cambridge UL Add. Y 9 ; le manuscrit n'est pas non plus dans la base de donnée <http://www.fihrist.org.uk/>. 
- Remarque : La traduction arabe (ff. 53-63) suit la traduction latine (ff. 19$46 \mathrm{v})$.

- Bibliographie: GCAL I, p. 181; BROWNE, p. 13-14; <https://www.fihrist.org .uk/catalog/manuscript_9383>.

11 Charfeh, Bibliothèque patriarcale du monastère syro-catholique de Charfeh

\section{Charfeh Bibliothèque patriarcale Ar. 2/9 1011}

- Contenu du manuscrit: 1. Évangiles; 2. Lettres de Paul; 3. Lettres catholiques ; 4 . Apocalypse ${ }^{29}$.

- Date:18 (1718)

- Description: 1081 folios $^{30}$.

- Vorlage: «Unbestimmter Herkunft»

- Origine : Syrie (Alep)

- Remarque: Il s'agit de trois codices; Armalet ne proposant qu'une notice pour les trois manuscrits, nous les réunissons ici également.

- Bibliographie: GCAL 1, p. 139; ARMAlet, p. 317-318.

79. Charfeh Bibliothèque patriarcale Ar. 2/16 1718

- Contenu du manuscrit : Nouveau Testament.

- Date:18 (1784)

- Description:Papier.

- Vorlage: «Unbestimmer Herkunft»

- Origine: Irak (Bagdad)

- Remarque: Il s'agit de trois codices; Armalet ne proposant qu'une notice pour les trois manuscrits, nous les réunissons ici également.

- Bibliographie: GCAL I, p. 138 ; ARMALET, 319.

80. Charfeh Bibliothèque patriarcale Syr. 2/16

- Contenu du manuscrit: Lettres de Paul.

- Date:19(1800)

- Langue/écriture : karshuni

- Description : 376 folios.

- Vorlage : Syriaque (3)

- Remarque: Delaporte donne une description précise d'un manuscrit en karshuni contenant les lettres de Paul ; le nombre de folios ne correspond

29 Armalet ne mentionne pas les Actes des Apôtres, ce que Graf relève également («ohne Apg ?»); est-ce un oubli?

3o Armalet utilise le terme de șafha. S'agit-il des folios ou des pages? 
toutefois ni au Charfeh Bibliothèque patriarcale Syr. 2/16, ni à Charfeh Bibliothèque patriarcale Syr. $2 / 17^{31}$.

- Bibliographie: gCal I, p. 177 ; Armalet, p. 35 ; Delaporte 1, p. 32.

81. Charfeh Bibliothèque patriarcale Syr. $2 / 17$

- Contenu du manuscrit: Lettres de Paul.

- Date:1915

- Copiste : Bašāra Șūmī, chorévêque syriaque de Mardin ( ?)

- Langue/écriture: karshuni

- Description: 443 folios

- Vorlage: Syriaque (3)

- Origine:Turquie (Mardin) (?)

- Remarque : voir remarque sous Charfeh Bibliothèque patriarcale Syr. 2/17.

- Bibliographie: gCAL I, p. 177 ; ARMALET, p. 35.

82. Copenhague Kong. Bibl. Or. $19^{32}$

- Contenu du manuscrit : Lettres de Paul incomplètes (Ga, Ep, Ph).

- Date:14

- Langue/écriture : copte-arabe

- Description: Papier; 31 folios ; $268 \times 180 \mathrm{~mm}$; surface écrite $222 \times 134 \mathrm{~mm}$; 32-33 lignes; 2 colonnes.

- Vorlage: Copte (2)

- Origine:Égypte?

- Remarque: Berlin Staatsbibl. Or. Folio 116, Copenhague Kong. Bibl. Or. 19 et Berlin Staatsbibl. Or. Folio 115 constituaient à la base un seul manuscrit.

- Bibliographie: GCAL I, p. 178; GregorY, p. 545; Horner, p. Xli-XliI ; Cod. Or. Bibl. Reg. Hafniensis, 80 ; ERICHSEN John, Udsigt over den gamle Manuscript-Samling i det store Kongelige Bibliothek, Copenhague, 1786, p. 5 .

31 Le manuscrit karshouni no. 8 de Delaporte a 190 feuillets de $205 \times 145 \mathrm{~mm}$ et contient $\mathrm{Rm}$, 1 Co, 2 Co, Ga, Ep, Ph, Col, 1 Th, 2 Th, 1 Tm, 2 Tm, Tt, Phm, He. Graf mentionne Delaporte, sans attribuer sa notice à l'un ou l'autre des manuscrits.

32 Nous n'avons pas trouvé de cote plus récente du manuscrit (voir John Erichsen, Udsigt over den gamle Manuscript-Samling i det store Kongelige Bibliothek, Kopenhagen, 1786, p. 5); dans le catalogue Codices Orientales Bibliothecae Regiae Hafniensis, le manuscrit n'est pas numéroté et porte seulement le titre Codex arabico-copticus. 


\section{Damas Patr. Syr. $1 / 18$}

- Contenu du manuscrit : 1. Lettres de Paul ; 2. Lettres catholiques.

- Date:13

- Description : 200 $\times \mathbf{1 4 0} \mathrm{mm}$.

- Remarque : À la fin d'Hébreux, une note dit : «Sāwīrus ibn al-Muqaffa' a dit : 'Je l'ai copiée et je l'ai comparée avec ma copie que j'avais comparée avec les copies grecque, syriaque et copte à l'aide de l'Anba Sīnā, évêque de Ṭāḥā.' »

- Bibliographie : DōlabĀNī, p. 561 .

\section{Deir al-Muharraq, Monastère copte}

\section{4. [sans cote]}

- Contenu du manuscrit : 1. Lettres de Paul incomplètes (1 Co à partir de 16,12, 2 Co, Ga, Ep, Ph, Col, 1 Th, 2 Th, He, 1 Tm, 2 Tm, Tt, Phm) ; 2 . Lettres catholiques (Ja, 1 P, 2 P, 1 Jn, 2 Jn, 3 Jn, Jude) ; 3 . Actes des Apôtres.

- Date: 12

- Langue/écriture : copte-arabe

- Origine : Égypte?

- Description : Papier ; 417 folios ; $357 \times 263 \mathrm{~mm}$; surface écrite $256 \times 182 \mathrm{~mm}$; 24 lignes, 2 colonnes.

- Vorlage: Copte (2)

- Bibliographie: CGAL I, p. 178 ; HorNER, p. XX-XXII.

15 Diyarbakir, Eglise syriaque orthodoxe Meryem $\mathrm{Ana}^{33}$

\section{Diyarbakir Meryem Ana 1/17}

- Autre cote : 124

33 Les manuscrits suivants contiennent des passages de lettres de Paul, mais les informations sont trop succinctes pour déterminer s'il s'agit de textes continus ou de leçons :

Diyarbakir Meryem Ana 133: <http://www.vhmml.us/research2014/catalog/detail.asp? MSID=123415 > Diyarbakir Meryem Ana 8/13, $96:<$ http://www.vhmml.us/research 2014/catalog/detail.asp?MSID=124511>; Diyarbakir Meryem Ana $78:<\mathrm{http} / / \mathrm{www}$ .vhmml.us/research2014/catalog/detail.asp?MSID=124516>; Diyarbakir Meryem Ana 41, 65, 3/6: <http://www.vhmml.us/research2014/catalog/detail.asp?MSID=124577> ; Diyarbakir Meryem Ana 9/12, 180, 88: <http://www.vhmml.us/ research2014/catalog/ 
- Contenu du manuscrit : Lettres de Paul.

- Date:16 (1586)

- Langue/écriture : karshouni

- Description : Papier ; 148 folios ; 105×120 mm; 1 colonne.

- Origine: Palestine (Jérusalem)

- Bibliographie : <http://www.vhmml.us/research2014/catalog/detail.asp? MSID $=124499>$.

\section{Diyarbakir Meryem Ana $1 / 18$}

- Autre cote : $316 ; 254$

- Contenu du manuscrit : Lettres de Paul.

- Date:19

- Copiste : Le diacre George, fils de Pierre le prêtre

- Langue/écriture : karshouni

- Description: Papier ; 129 folios ; 330×240 mm.

- Origine : Turquie (Amid)

- Bibliographie : <http://www.vhmml.us/research2014/catalog/detail.asp? MSID $=124542>$.

\section{Diyarbakir Meryem Ana 261}

- Contenu du manuscrit: Lettres de Paul.

- Date:20 (1935)

- Copiste:Jacob, fils de Joseph Ahtiyar

- Langue/écriture : karshouni

- Description: Papier; 344 folios ; 337×215 mm; 1 colonne.

- Origine : Turquie (Amid)

- Bibliographie : <http://www.vhmml.us/research2014/catalog/detail.asp? $\mathrm{MSID}=124549>$.

\section{Diyarbakir Meryem Ana 272}

- Autre cote : 118

- Contenu du manuscrit: 1. Lettres de Paul ; 2. Lettres catholiques; 3. Actes des Apôtres.

- Date:18 (1784)

- Description: Papier ; 176 folios ; $255 \times 170 \mathrm{~mm}$.

- Remarque: Le manuscrit est d'origine grecque orthodoxe.

- Bibliographie : <http://www.vhmml.us/research2014/catalog/detail.asp? MSID $=124560>$

detail.asp?MSID=125027> ; Diyarbakir Meryem Ana $322 ; 47 ; 66 ; 3 / 12:<$ http://www .vhmml.us/ research2014/catalog/detail.asp?MSID=125033>. 


\section{Dublin Trinity College 1531}

- Contenu du manuscrit: 1. Historiae (Joseph, Ephrem le Syrien, Saint-Basile le Grand, Martian, Job, Abraham, fils de Jonadab, Saint Paul, captivité de Babylone); martyre de Marine; Historia ilusionis effigiei Jesus Christi per Judeos in urbe Tiberiade; récit d'Euphrosine ; 2. Fragment de la lettre aux Hébreux $(1,10-2,5)$.

- Description : $178 \times 127 \mathrm{~mm}$.

- Vorlage : «Unbestimmter Herkunft»

- Bibliographie: GCAL I, p. 181; Аввотт, p. 409.

17

Duluth, University of Minnesota, Kathryn A. Martin Library, The Ramseyer-Northern Bible Society Collection

9o. [sans cote]

- Contenu : Lettres de Paul.

- Date:15

- Bibliographie :<http://www.d.umn.edu/lib/bible/displays/rare/paulineepistles.htm $>$.

91. Escorial RB Cas. 1619

- No. catalogue : Derembourg Ar. 1625

- Contenu du manuscrit : 1. Cantique des Cantiques ; 2. Lettres de Paul incomplètes (Rm, 1 Co incomplet, Ga incomplet); 2.1 Pierre incomplet; 3. Actes des Apôtres ; 4. 1-3 Jean ; 5 . Apocalypse.

- Description : Papier; 148 folios ; 140×90 mm.

- Vorlage : «Unbestimmter Herkunft»

- Bibliographie: GCAL I, p. 180 ; Derembourg, p. 169-170 ; MonferrerSAlA Juan Pedro, «An Eastern Arabic Version of the Three Epistles of Saint John (Codex Ar. 1625) Kept in the Monastery of el Escorial (Madrid) », Parole de l'Orient 27, 2002, pp. 27-49. 


\section{Florence BML Or. 2}

- Autre cote : No. 4

- Contenu du manuscrit : 1. Évangiles (Mt, Mc, Lc, Jn) ; 2. Lettres de Paul (Rm, ${ }_{1}$ Co, 2 Co, Ga, Ep, Ph, Col, 1 Th, 2 Th, 1 Tm, 2 Tm, Tt, Phm, He) ; 3. Lettres catholiques (Ja, 1 P, 2 P, 1 Jn, 2 Jn, 3 Jn, Jude) ; 4. Apocalypse.

- Date: 17 (1611)

- Copiste : Anțūn aṣ-Ṣahyūnī, moine et archipresbytre d'Ehden

- Destinataire : Ioannis Raymundi

- Langue/écriture : Syriaque-karshouni

- Description : Papier; 326 folios.

- Vorlage : Syriaque (3)

- Origine : Liban (Ehden)

- Bibliographie: GCAL I, p. 138, p. 177 ; Gregory, p. 589, no. 85 ; Assemani, pp. 51-52 ; SCHOLZ, p. 87 .

93. Florence BмL Or. 3

- Autre cote : No. 1

- Contenu du manuscrit: Lettres de Paul incomplètes (Rm, 1 Co, 2 Co, Ga, Ep).

- Description : Papier; 88 folios.

- Vorlage : Syriaque (2)

- Bibliographie: GCAL I, p. 176 ; Gregory, p. 589, no. 86 ; Assemani, p. 52 ; SCHOLZ, p. 87, pp. 89-91.

\section{Florence вмL Or. 14}

- Autre cote : No. 61

- Contenu du manuscrit: 1. Lettres de Paul Paul (Rm, 1 Co, 2 Co, Ga, Ep, Ph, Col, 1 Th, 2 Th, 1 Tm, 2 Tm, Tt, Phm, He) ; 2. Lettres catholiques (Ja, 1 Jn, 2 Jn, 3 Jn, 1 P, 2 P, Jude) ; 2 . Actes des Apôtres

- Description : Papier; 188 folios.

- Vorlage : Syriaque (2)

- Origine : Égypte (Alexandrie)

- Bibliographie: GCAL I, p. 176 ; Assemani, p. 58 ; SCHolz, pp. 87-88.

95. Florence BML Or. 24

- Autre cote: No. 226

- Contenu du manuscrit: 1. Lettres de Paul incomplètes (1 Tm, 2 Tm, He); 2. Lettres catholiques incomplètes (Ja, 1 P, 2 P, Jude).

- Copiste : Guillelmus

- Destinataire : Ioannis Raymundi

- Description : Papier; 80 folios. 
- Vorlage: Grec $(1)^{34}$

- Bibliographie: GCAL I, p. 172; Gregory, p. 589, no. 91; Assemani, pp. $64-65$; SCHOLZ, p. 91.

96. Göttingen SU в orient. $125^{5}$

- No. catalogue : Arab. 104

- Contenu du manuscrit :1. Introduction aux lettres de Paul par Al-Mu'taman ibn al-Assāl ; 2. Introduction à la vie de Paul ; 3. Lettres de Paul (Rm, 1 Co, 2 Co, Ga, Ep, Ph, Col, 1 Th, 2 Th, 1 Tm, 2 Tm, Tt, Phm, He); 4. Lettres catholiques; 5. Actes des Apôtres; 6. Lettre du Ps.-Dionysius à Timothée sur le martyr de Pierre et Paul.

- Date:17-18

- Description : Papier ; 318 folios ; 255×165 mm ; 15 lignes.

- Vorlage: Syriaque (2)

- Origine : Égypte (Saint-Bišoy)

- Bibliographie : GCAL I, p. 176 ; Gre gory, p. 588, no. 71b ; MeYer, pp. 360-361.

97. Göttingen SU B orient. $125^{6}$

- No. catalogue: Arab. 105

- Contenu du manuscrit: 1. Lettres de Paul; 2. Lettres catholiques; 3. Actes des Apôtres incomplet $(1,1-10,26 ; 25,9-24 a ; 26,27-27,10) ; 4$. Introduction aux lettres de Paul par Al-Mu'taman ibn al-'Assāl (incomplète) ; 5. Lettre de Ps.Dionysius à Timothée sur le martyr de Pierre et Paul (incomplète).

- Date:13 (1268?)

- Description: Papier ; 247 folios ; 220×150 mm; 13 lignes.

- Vorlage: Syriaque (2)

- Origine :Égypte (Saint-Bišoy)

- Remarques: La date est peut-être copiée de la Vorlage.

- Bibliographie: gCAL I, p. 176 ; MeYer, pp. 360-361.

34 Graf mentionne aussi Florence BML or. 24 à la page GCAL I, p. 176, dans la catégorie des manuscrits à la Vorlage syriaque (2). 


\section{Groningen Universiteitsbibliotheek 460}

- Contenu du manuscrit: 1. Extraits en arabe de La foi orthodoxe de Jean Damascène (68 et 98-10o); 2. Lettres de Paul (sans Rm, 1 Co et 2 Co); 3. Lettres catholiques.

- Date:16-17

- Copiste:Jacobus Christmannus

- Description: Papier ; 133 folios ; 108 ×157 mm.

- Vorlage: Copte (autre)

- Bibliographie: GCAL I, p. 181; Brugmans, p. 250 ; Voorhoeve, p. 51.

99. Halle Archiv der Franckeschen Stiftungen Q 81

- Autre cote : Q 81a-g (ancienne cote)

- Contenu du manuscrit: 1. Lettres de Paul incomplètes (Phm, He); 2. Lettres catholiques (Ja, 1 P, 2 P, 1 Jn, 2 Jn, 3 Jn, Jude) ; 3 . Apocalypse ; 5 . Genèse 1-4 en malais.

- Date: 18

- Copiste : Petrus van der Vorm

- Description: Papier; 117 folios ; 318×210 mm; surface écrite $210 \times 125 \mathrm{~mm}$; 16 lignes.

- Origine: Europe

- Bibliographie: PABst, pp. 160-161.

\section{Hambourg, Staats- und Universitätsbibliothek}

100. Hambourg SU в Orient. 19

- No. catalogue : Brockelmann 299

- Autre cote: V; Hinckelmann $15^{0}$; Morgenweg 148; Wolf $15^{2}$.

- Contenu du manuscrit: 1. Introduction à la grammaire arabe ; 2 . Philémon en arabe, écrit en arabe et en caractères hébreux; 3. Philémon en latin; 4. Glossaire; 5. Extraits du Coran, en arabe et en caractères hébreux; 6. Extraits du Coran en latin ; 7 . Glossaire.

- Date: 16 
- Copiste: Petrus Kirstenius

- Langue/écriture : arabe en caractères arabes et en caractères hébreux

- Description: Papier; 85 folios; $100 \times 80 \mathrm{~mm}$; surface écrite $83 \times 53 \mathrm{~mm}$; 10-11 lignes.

- Vorlage: Syriaque (2)

- Remarque : Il s'agirait d'une copie de Vat. Ar. 23.

- Origine : Europe

- Bibliographie : Brockelmann, p. 158, no. 299 ; Vollandt Ronny, « Codex orientalis 19 », Manuscript Cultures 6, 2014, pp. 56-58.

\section{Jérusalem, Bibliothèque du Monastère grec au Saint-Sépulcre}

\section{Jérusalem, Saint-Sépulcre 119}

- Contenu du manuscrit: 1. Fragments hagiographiques et d'histoires ecclésiastiques ; 2. Fragments des lettres de Paul ; 3. Fragments d'une homélie de Jean Chrysostome sur l'Esprit Saint.

- Description : Papier; 73 folios.

- Bibliographie: KoIKY $\Lambda \mathrm{I} \Delta \mathrm{H} \Sigma$, p. 100.

\section{Jérusalem, Bibliothèque du Monastère Saint-Marc}

102. Jérusalem, Bibl. Saint-Marc 263

- Contenu du manuscrit: 1. Lettres de Paul ; 2. Lettres catholiques; 3 . Actes des Apôtres ; 4. Lettre du Ps.-Dionysius à Timothée sur le martyr de Pierre et Paul.

- Date: 16

- Description : Papier ; 184 folios ; 270×185 mm ; 21 lignes ; 1 colonne.

- Bibliographie : <http://www.vhmml.us/research2014/catalog/detail.asp? $\mathrm{MSID}=135917>$.

\section{$26 \quad$ Leiden, Universiteitsbibliotheek}

103. Leiden Universiteitsbibliotheek Acad. 2

- Autre cote: De Jong Or. 142

- Contenu: 1. Lettres de Paul (Rm, 1 Co, 2 Co, Ga, Ep, Ph, Col, 1 Th, 2 Th, 1 Tm, 2 Tm, Tt, Phm, He) ; 2. Lettres catholiques (Ja, 1 P, 2 P, 1 Jn, 2 Jn, 3 Jn, Jude); 3. Actes des Apôtres. 
- Date:11 (1079)

- Description: Papier; 360 folios.

- Vorlage: Syriaque (2)

- Bibliographie: GCAL I, p. 176 ; Gregory, p. 586, no. 41 ; Voorhoeve, p. 50 ; DE Jong, pp. 180-183, no. 142 ; WITKAM 1, p. 9.

104. Leiden Universiteitsbibliotheek Or. 217

- No. catalogue : de Goeje 2369

- Autre cote : Arabe $217 ; 217$ Scaliger

- Contenu du manuscrit : 1. Évangiles ; 2. Lettres de Paul (Rm, 1 Co, 2 Co, Ga, Ep, Ph, Col, 1 Th, 2 Th, 1 Tm, 2 Tm, Tt, Phm, He); 3. Lettres catholiques; 4. Actes ; 5 . Apocalypse.

- Date:14-15

- Description : Papier ; 262 folios.

- Vorlage : Syriaque (2)

- Remarque : Il s'agirait du manuscrit à la base de l'édition d'Erpenius en 1616.

- Bibliographie: GCAL I, p. 175 ; Gregory, p. 586, no. 43 ; Voorhoeve, p. 50 ; WitKam 2, vol. 1, p. 96 ; DE GoEJE, p. 79 ; LAGARDE, p. X, p. XIX.

105. Leiden Universiteitsbibliotheek Or. 2083

- No. catalogue : de Goeje 2827

- Autre cote : Arabe 1129

- Contenu du manuscrit : 1. Extraits de Rm (1,2 et début de 3).

- Date: 1608

- Copiste : Jacobus Christmannus

- Description: Papier; 5 folios.

- Vorlage : «Unbestimmter Herkunft»

- Origine : Europe (Heidelberg)

- Remarques: Graf mentionne un manuscrit Leiden Or. 2827, copié à Heidelberg en 16o8. Il s'agit certainement du même manuscrit (nous ne sommes pas parvenu à remonter à l'origine de la cote donnée par Graf).

- Bibliographie: GCAL I, p. 181; Voorhoeve, p. 51; De Goeje, p. 326 ; WitKam 2, vol. 3, p. 33 .

\section{Leiden Universiteitsbibliotheek Or. 14447}

- Autre cote : Arabe 4670

- Contenu du manuscrit : Nouveau Testament.

- Date:19 (1855)

- Copiste : Mīkāāil fils de Ibrāhīm al-Hūūī

- Description : Papier; 360 folios, 900×650 mm; surface écrite $700 \times 400 \mathrm{~mm}$; 19 lignes.

- Vorlage : édition de Richard Wats, Londres, 1820 
- Origine : Syrie (Binu)

- Bibliographie:WitкAM 2, vol. 15, p. 212 ; WitкAM 3, p. 532.

\section{$27 \quad$ Leipzig, Universitätsbibliothek}

\section{Leipzig UB Vollers 1058-01}

- Autre cote : Codex Tischendorf XXXVII

- Contenu du manuscrit: 1. Fragments des lettres catholiques (1 P 5,10-14; 2 P ; 1 Jn 1,1-4 ; 5,19-21 ; 2 Jn 1-8) ; 2 . Fragments des lettres de Paul (1 Co 14,1638, 2 Co 7,5-8,7; 11,9-30; Ep 6,13-24) ; 3. Fragment d'un commentaire de $\operatorname{Rm} 1,4-5,14 ; 2$ Co 3,6-Ga 2,11).

- Date:13

- Description : Papier ; 17 folios ; $277 \times 207 \mathrm{~mm}$; surface écrite $208 \times 130 \mathrm{~mm}$; 16 lignes.

- Vorlage : Syriaque (2)

- Bibliographie: GCAL I, p. 176 ; Vollers, p. 373 ; Gregory, p. 588, no. 78 ; TISCHENDORF, pp. 71-72; notice en ligne (avec images): <http://www .islamic-manuscripts.net/receive/IslamHSBook_islamhs_ooo146o6>.

108. Leipzig UB Vollers 1058-o2

- Autre cote : Codex Tischendorf XXXVIII

- Contenu du manuscrit: Fragments des lettres de Paul (2 Co 3,7-4,15; Ep 6,8b-24; Ph 3,18-4,23; Col ; 1 Th 1,1-9).

- Date:13

- Description: Papier; 8 folios ; $277 \times 207 \mathrm{~mm}$; surface écrite $208 \times 130 \mathrm{~mm}$; 16 lignes.

- Vorlage : Copte (1)

- Bibliographie: GCAL I, p. 176 ; GRegory, p. 588, no. 79 ; Vollers, p. 373 ; Tischendorf, pp. 71-72; notice en ligne (avec images): <http://www .islamic-manuscripts.net/receive/IslamHSBook_islamhs_ooo14607>.

109. Londres BL Arundel Or. 7

- No. catalogue: Carshun. II

- Contenu du manuscrit: 1. Lettres de Paul (Rm, 1 Co, 2 Co, Ga, Ep, Ph, Col, 1 Th, 2 Th, 1 Tm, 2 Tm, Tt, Phm, He) ; 2. Actes des Apôtres ; 3. Lettres catholiques (Ja, $1 \mathrm{P}, 1 \mathrm{Jn})$.

- Date:17 (1609-1610) 
- Copiste : Cyriaque fils d'Abdelkarim

- Langue/écriture : karshuni

- Description : Papier; 208 folios.

- Vorlage : Syriaque (2)

- Origine : Turquie (Mardin)

- Bibliographie: GCAL I, p. 176 ; Gregory, p. 583, no. 5 ; Rosen, p. 100.

110. Londres BL Arundel Or. 19

- No. catalogue : Ar. christ. 14

- Contenu du manuscrit : 1. Évangiles (Mt, Mc, Lc, Jn) ; 2. Actes des Apôtres ; 3. Lettres de Paul (Rm, 1 Co, 2 Co, Ga, Ep, Ph, Col, 1 Th, 2 Th, 1 Tm, 2 Tm, Tt, Phm, He) ; 4. Lettres catholiques (Jc, 1 P, 2 P, 1 Jn, 2 Jn, 3 Jn, Ju) ; 5 . Psaume apocryphe et cantiques.

- Date:17 (1616)

- Copiste : Talja fils du prêtre Hawrān al-Hamawī

- Description : Papier; 419 folios.

- Vorlage : Syriaque (2)

- Bibliographie: GCAL I, p. 176; Gregory, p. 583, no. 9; Cureton, pp. 14-16.

111. Londres BL Harley 5474

- No. catalogue: Ar. christ. 15

- Contenu du manuscrit: 1. Lettres de Paul (Rm, 1 Co, 2 Co, Ga, Ep, Ph, Col, 1 Th, 2 Th, 1 Tm, 2 Tm, Tt, Phm, He) ; 2. Lettres catholiques (Jc, 1 P, 2 P, 1 Jn, 2 Jn, 3 Jn, Ju); 3 . Actes des Apôtres

- Date:13 (1288)

- Description : Papier ; 210 folios.

- Vorlage: Syriaque (2)

- Bibliographie: GCAL I, p. 176; Gregory, p. 583, no. 10; Cureton, pp. 16-19.

112. Londres BL Or. 424

- No. catalogue: Copt. $75^{8}$

- Contenu du manuscrit: 1. Lettres de Paul (Rm, 1 Co, 2 Co, Ga, Ep, Ph, Col, 1 Th, 2 Th, He, 1 Tm, 2 Tm, Tt, Phm); 2. Lettres catholiques; 3. Actes des Apôtres

- Date:13 (1250)

- Copiste :Yūnas appelé Abū Sa'̄ì ben Saīd ad-Dār b. Abū al-Faḍl

- Langue/écriture: Copte-arabe

- Description : Papier; 217 folios ; $251 \times 178 \mathrm{~mm}$; surface écrite $210 \times 143 \mathrm{~mm}$; 33 lignes; verso en copte, recto en arabe.

- Vorlage: Syriaque (2)

- Origine : Égypte? 
- Remarque : Il s'agit d'une copie du Caire Mus. Copt. Bibl. 94.

- Bibliographie: GCAL I, p. 176 ; CrUM, p. 329 ; Horner, pp. X-XIII.

113. Londres BL Or. 1318

- No. catalogue: Ar. christ. suppl. 12 ; Copt. 759.

- Contenu du manuscrit: Lettres de Paul (Rm à partir de 5,10, 1 Co, 2 Co, Ga, Ep, Ph, Col, $1 \mathrm{Th}, 2 \mathrm{Th}, 1 \mathrm{Tm}, 2 \mathrm{Tm}, \mathrm{Tt}, \mathrm{Phm}, \mathrm{He}$ à partir de 13,21)

- Date:15(1416)

- Langue/écriture: Copte-arabe

- Description : 294 folios ; $267 \times 173 \mathrm{~mm}$; surface écrite 200×130 mm ; 21 lignes ; 2 colonnes.

- Vorlage: Copte (2)

- Origine:Égypte?

- Bibliographie: GCAL I, p. 178; RieU, p. 10-11; Crum 759; Horner, pp. XXXIII-XXXIV.

114. Londres BL Or. 1326

- No. catalogue: Ar. christ. suppl. 1

- Contenu du manuscrit: 1. Livres de l'AT incomplets (et apocryphes) (Ez, Dn, Si, 3 Esd, Esd, Est, Jdt, To, 2 M, 5 M) ; 2 . Histoire des Juifs par Joseph B. Gorion; 3. Suite des livres de l'AT (Jb, Sg, Qo, Pr, Ct) ; 4. Introduction aux Évangiles ; 5. Canons d'Eusèbe ; 6. Évangiles (Mt, Mc, Lc, Jn) ; 7. Apocalypse ; 8. Lettres de Paul ; 9. Lettres catholiques ; 10. Actes des Apôtres.

- Date:16 (1585-1587)

- Description : Papier ; 326 folios ; $325 \times 233 \mathrm{~mm}$; surface écrite $255^{\times 158} \mathrm{~mm}$; 29 lignes.

- Vorlage: «Unbestimmter Herkunft»

- Origine :Égypte (Caire)

- Remarque: Il s'agit d'un second volume d'une copie de la Bible (avec apocryphes).

- Bibliographie: GCAL I, p. 181; RieU, p. 1-4; KaShouh, p. 261, p. 264.

115. Londres BL Or. 1328

- No. catalogue: Ar. christ. suppl. 13

- Contenu du manuscrit: 1. Lettres de Paul (Rm, 1 Co, 2 Co, Ga, Ep, Ph, Col, 1 Th, 2 Th, 1 Tm, 2 Tm, Tt, Phm, He); 2. Lettres catholiques; 3. Actes des Apôtres.

- Date:14

- Description : 218 folios; $260 \times 178 \mathrm{~mm} ; 15$ lignes.

- Bibliographie:RieU, p. 10.

116. Londres BL Or. 3383

- No. catalogue : Ar. christ. suppl. 11 
- Contenu du manuscrit: 1. Lettres de Paul (Rm, 1 Co, 2 Co, Ga, Ep, Ph, Col, 1 Th, 2 Th, 1 Tm, 2 Tm, Tt, Phm, He); 2. Lettres catholiques; 3 . Actes des Apôtres.

- Date:13/19 (1805)

- Description : 210 folios ; $235 \times 152 \mathrm{~mm} ; 17$ lignes.

- Bibliographie:RIEU, p. 10.

117. Londres BL Or. 8612

- Contenu du manuscrit: Lettres de Paul incomplètes (Ep 2,9-1 Tm 2,12a, y compris Hébreux, probablement avant $1 \mathrm{Tm}$ ).

- Date: 9

- Vorlage: Grec (1)

- Remarque: Il s'agit de la suite du manuscrit Sin. Ar. 155. Les caractéristiques physiques du manuscrit correspondent donc certainement à Sin. Ar. 155 .

- Bibliographie: GCAL I, p. 171; Krenkow F., «Two Ancient Fragments of an Arabic Translation of the New Testament », Journal of the Royal Asiatic Society (New Series) 58 (2), 1926, pp. 275-285.

118. Londres BL Sloane 1796

- No. catalogue: Ar. christ. 16

- Contenu du manuscrit: 1 . Prologue sur les écrits en arabe et la parenté de l'arabe avec l'hébreu; 2 . Lettres de Paul incomplètes (Tt; Phm).

- Date: 17

- Langue/écriture: Arabe-latin

- Description: Papier; 65 folios.

- Vorlage : « unbestimmter Herkunft»

- Remarque : La notice de Cureton et Rieu ne précise la disposition des deux versions dans le manuscrit.

- Bibliographie : GCAL I, p. 181; Gregory, p. 583, no. 11 ; CUREton, p. 19.

\section{Londres, Library of the School of Oriental and African Studies}

\section{Londres SOAS 14086}

- No. catalogue: Gacek ar. 275

- Contenu du manuscrit: 1. Lettres de Paul; 2. Lettres catholiques; 3. Actes des Apôtres.

- Date: 17

- Description: Papier; 197 folios ; 305×215 mm; surface écrite $180 \times 125 \mathrm{~mm}$; 17 lignes. 
- Remarque: Gacek présente deux notices différentes pour Londres sOAS Ar. 14086, le no. 7 qui présente les Actes des Apôtres et le no. 275 qui présentent les lettres.

- Bibliographie: GACEK, p. 5, p. 164.

\section{Madrid, Biblioteca Nacional}

120. Madrid BN 3484

- No. catalogue: Guillén 600

- Contenu du manuscrit: 1. Fragments d'un traité grammatical arabe, avec traduction en castillan ; 2. Lettres de Paul incomplètes ( $\mathrm{Rm}, 1 \mathrm{Co}, 2 \mathrm{Co}, \mathrm{Ga}$, Ep, Ph, Col, 1 Th, 2 Th, 1 Tm, 2 Tm); 3 . Lettre aux Laodicéens entre Col et 1 Th.

- Date: 18

- Description : Papier ; 368 folios ; 220×150 mm.

- Vorlage: Latin

- Origine : Espagne

- Remarque: Les lettres de Paul et aux Laodicéens sont copiées du Madrid BN 4971.

- Bibliographie : GCAL I, p. 180 ; GuILlén, pp. 245-246 ; GousSEN, p. 10.

121. Madrid BN 4971

- No. catalogue: Guillén 238

- Contenu du manuscrit: 1. Évangiles incomplets (Mt, Mc, Lc fragmentaires, Jn complet) ; 2. Lettres de Paul incomplètes (Rm, 1 Co, 2 Co, Ga, Ep, Ph, Col, $1 \mathrm{Th}, 2 \mathrm{Th}, 1 \mathrm{Tm}, 2 \mathrm{Tm})$; 3 . Lettre aux Laodicéens entre Col et $1 \mathrm{Th}$; 4 . Fragment de Saint Jérôme sur la venue du Messie.

- Date:16 (1542)

- Description: Parchemin/Papier; 246 folios.

- Vorlage: Latin

- Origine: Espagne

- Remarque : Le manuscrit contient la date 1542 mais les folios en parchemin sont plus anciens.

- Bibliographie: GCAL I, p. 180; GuIlléN, pp. 108-109; Goussen, p. 10; Kashoun, p. 275 ; Роттнаsт Daniel, «Die andalusische Übersetzung des Römerbriefs », Collectanea Christiana Orientalia 8, 2011, pp. 65-108. 
122. Manchester John Rylands Ar. 2

- Autre cote : Wingan 702

- Contenu du manuscrit: 1. Actes des Apôtres incomplets (à partir de 1,13); 2. Lettres de Paul (Rm, 1 Co, 2 Co, Ga, Ep, Ph, Col, 1 Th, 2 Th, 1 Tm, 2 Tm, Tt, Phm, He).

- Date:14-15

- Description : 179 folios ; 235×165 mm; 15 lignes.

- Vorlage: Syriaque (2)

- Remarque : He 1,1-12,8 est placé au début des lettres de Paul à cause d'une mauvaise reliure des pages.

- Bibliographie: GCAL I, p. 176 ; MinganA, pp. 4-5 ; Bibliotheca Lindesiana, Hand-List of Oriental Manuscripts, Arabic Persian Turkish, Aberdeen, 1898, p. 18.

\section{Mardin, Bibliothèque de l'Archevêque chaldéen}

123. Mardin Bibl. Arch. $5^{6}$

- Autre cote : olim 89

- Contenu du manuscrit: 1. Lettres de Paul (Rm, 1 Co, 2 Co, Ga, Ep, Ph, Col, 1 Th, 2 Th, 1 Tm, 2 Tm, Tt, Phm, He) ; 2. Lettres catholiques (Jc, 1 P, 2 P, 1 Jn, 2 Jn, 3 Jn, Jude); 3 . Actes des Apôtres.

- Date:14 (1345)

- Description : 232 folios; $280 \times 200 \mathrm{~mm}$.

- Vorlage: Copte (2)

- Origine : Égypte (Saint-Mercure).

- Bibliographie: SCHER 1, p. 30 ; <http://www.vhmml.us/research2014/cata $\log /$ detail.asp?MSID=132235>.

\section{Milan, Biblioteca Ambrosiana}

124. Milan Bibl. Ambrosiana B 20 inf. A

- No. catalogue : Löfgren, Bibl. I.

- Contenu du manuscrit: 1. Lettres de Paul (Rm, 1 Co, 2 Co, Ga, Ep, Ph, Col, 1 Th, 2 Th, He, 1 Tm, 2 Tm, Tt, Phm) ; (2. Lettres catholiques (Jc, 1 P, 2 P, 1 Jn, 2 Jn, 3 Jn, Jude) ; 3 . Actes des Apôtres).

- Date :12-14 
- Copiste : Le prêtre Șalīb de l'Eglise de la Sainte Vierge à Hāarat Zuwayla (pour l'arabe)

- Langue/écriture: Ethiopien-syriaque-copte-arabe-arménien

- Description : Papier ; 275 folios ; $360 \times 265 \mathrm{~mm} ; 31-44$ lignes ; 5 colonnes.

- Vorlage: Syriaque (2)

- Origine : Égypte (Ḥārat Zuwayla)

- Remarque : Le codex Milan Bibl. Ambrosiana B 20 inf. B est la continuation de ce manuscrit et contient les lettres catholiques et les Actes des Apôtres.

- Bibliographie: GCAL I, p. 177 ; LÖFGREN, p. 3-5 ; SCHOlz, p. 73-74; Horner, p. XVIII-XX.

Modène, Biblioteca Estense

125. Modène Bibl. Est. I. D. 8

- No. catalogue: Bernheimer Or. 65

- Autre cote : olim $\alpha$ J. 6.3

- Contenu du manuscrit: Lettres de Paul (Rm, 1 Co, 2 Co, Ga, Ep, Ph, Col, 1 Th, 2 Th, He, 1 Tm, 2 Tm, Tt, Phm).

- Date:16 (1521)

- Copiste: Jean «Léon l'Africain»

- Description: Papier; $280 \times 300 \mathrm{~mm}$.

- Vorlage: Copte (3)

- Origine : Europe (Rome)

- Remarque : Il s'agit d'une copie du Vat. Ar. 28.

- Bibliographie: GCAL I, p. 179; BerNhEIMER, pp. 68-69.

Mor Mattay, Bibliothèque du Monastère syriaque orthodoxe

126. Mor Mattay 1

- Contenu du manuscrit: Nouveau Testament.

- Date:12 (1177)

- Copiste : le diacre Mardīna ibn Yūsuf Markīz ibn Tūma

- Langue/écriture : Syriaque-arabe

- Description : 376 folios ; $350 \times 210 \mathrm{~mm} ; 2$ colonnes.

- Bibliographie: НАвBI, p. 77. 


\section{Mossul, Frères dominicains à Mossul ${ }^{35}$}

127. Mossul Dominic. 391

- Contenu du manuscrit : Lettres de Paul.

- Date:19 (1816)

- Langue/écriture : karshouni

- Description : Papier ; 112 folios ; 235×170 mm ; 19 lignes ; 1 colonne.

- Bibliographie : <http://www.vhmml.us/research2014/catalog/detail.asp? $\mathrm{MSID}=1345^{6} 5^{>}$.

\section{Naples, Biblioteca Nazionale Vittorio Emanuele II I}

128. Naples Bibl. Nazionale Ar. 3

- Contenu du manuscrit : 1 Thessaloniciens

- Description : Papier ; 11 folios ; $300 \times 200 \mathrm{~mm}$; 10 lignes.

- Vorlage: Syriaque (2)

- Origine : Europe

- Bibliographie: GCAL I, p. 176 ; GUID I, p. 7.

\section{$3^{8} \quad$ Oxford, Bodleian Library}

129. Oxford Bodl. Arch. Seld. A. 70

- No. catalogue : Uri Ar. Christ. XXVIII

- Autre cote : 3203,70

- Contenu du manuscrit: 1. Lettres de Paul (Rm, 1 Co, 2 Co, Ga, Ep, Ph, Col, 1 Th, 2 Th, 1 Tm, 2 Tm, Tt, Phm, He) ; 2. Lettres catholiques (Ja, 1 Jn, 2 Jn, 3 Jn, 1 P, 2 P, Jude); 3 . Actes des Apôtres.

- Description : Papier; 288 folios.

- Vorlage: Copte (1)

- Origine : Égypte (Saint-Antoine)

- Bibliographie: GCAL I, p. 178; Gregory, p. 584, no 23; URI, pars II, pp. 32-33; PUSEY, p. 565 .

35 Les manuscrits ont été déplacés. Voir: <http://www.hmml.org/news--media/hmmlurgently-working-to-save-manuscripts-in-iraq-hopes-for-safety-of-collections-in-syria> ; $<$ http://www.lemonde.fr/arts/portfolio/2015/05/22/mesopotamie-les-manuscrits-sauvesde-mossoul-en-irak_4639028_1655012.html >. 
130. Oxford Bodl. Arch. Seld. B. 50 sup.

- No. catalogue: Pusey Ar. Christ. III

- Contenu du manuscrit: Phm

- Date:16-17

- Copiste:William Bedwell de Stortford

- Description:Papier; 19 folios.

- Vorlage: Syriaque (2)

- Origine : Europe (Bishop's Stortford)

- Bibliographie: Pusey, p. 443.

131. Oxford Bodl. Canonic. Orient 129

- No. catalogue: Nicoll Ar. Christ. XVII

- Contenu du manuscrit : 1. Lettres de Paul (Rm, 1 Co, 2 Co, Ga, Ep, Ph, Col, 1 Th, 2 Th, 1 Tm, 2 Tm, Tt, Phm, He) ; 2. Lettres catholiques (Ja, 1 P, 2 P, 1 Jn, 2 Jn, 3 Jn, Jude) ; 3 . Actes des Apôtres.

- Date:13 (1284)

- Description: Papier; 210 folios.

- Vorlage: Syriaque (2)

- Origine : Égypte (Saint-Antoine)

- Bibliographie : GCAL I, p. 176 ; GREGORY, p. 585, no. 32 ; NiCOLL, pp. 20-21. 132. Oxford Bodl. Hunt. 43

- No. catalogue: Uri Copt. IX

- Contenu du manuscrit: 1. Lettres de Paul (Rm, 1 Co, 2 Co, Ga, Ep, Ph, Col, $1 \mathrm{Th}, 2 \mathrm{Th}, \mathrm{He}, 1 \mathrm{Tm}, 2 \mathrm{Tm}, \mathrm{Tt}, \mathrm{Phm})$; 2. Lettres catholiques (Ja, $1 \mathrm{P}, 2 \mathrm{P}, 1 \mathrm{Jn}$, 2 Jn, 3 Jn, Jude) ; 3 . Actes des Apôtres ; 4. Apocalypse.

- Date: 17 (1682-1683)

- Langue/écriture: Copte-arabe

- Description: Papier ; 316 folios ; 297×208 mm ; surface écrite $230 \times 153 \mathrm{~mm}$; 27 lignes ; 2 colonnes.

- Vorlage: Copte (2)

- Origine: Égypte?

- Bibliographie : GCAL I, p. 178 ; URI, pars II, p. 320 ; HORNER, pp. XLV-XLVII. 133. Oxford Bodl. Laud. Or. 135

- No. catalogue : Uri Ar. Christ. XXVII

- Autre cote: A. 132

- Contenu du manuscrit: 1. Lettres de Paul (Rm, 1 Co, 2 Co, Ga, Ep, Ph, Col, $1 \mathrm{Th}, 2 \mathrm{Th}, 1 \mathrm{Tm}, 2 \mathrm{Tm}, \mathrm{Tt}, \mathrm{Phm}, \mathrm{He}) ; 2$. Lettres catholiques (1 Jn, $2 \mathrm{Jn}, 3 \mathrm{Jn}, 1 \mathrm{P}$, 2 P, Jude, Ja); 3 . Extrait d'Avicenne, en arabe et en latin.

- Description:Papier

- Vorlage: «Unbestimmter Herkunft» 
- Bibliographie: GCAL I, p. 181; Gregory, p. 584, no. 22 ; URI, pars II, pp. 32-33.

134. Oxford Bodl. Laud. Or. 24

- No. catalogue : Uri Ar. Christ. XXXIV

- Autre cote:A. 2

- Contenu du manuscrit: 1 Thessaloniciens.

- Date:16-17

- Copiste :William Bedwell de Stortford

- Description : Papier; 12 folios.

- Vorlage: Syriaque (2)

- Origine : Europe (Bishop's Stortford)

- Bibliographie: gCAL I, p. 176 ; URI, pars II, p. 33 ; PUSEY, p. 566.

135. Oxford Bodl. Marsh. 426

- No. catalogue : Payne Smith 33 ; Uri syr. XV

- Autre cote :Syr. 33

- Contenu du manuscrit : 1. Actes des Apôtres ; 2. Lettres catholiques (Ja, 1 P, 2 P, 1 Jn, 2 Jn, 3 Jn, Jude) ; 3 . Lettres de Paul (Rm, 1 Co, 2 Co, Ga, Ep, Ph, Col, 1 Th, 2 Th, 1 Tm, 2 Tm, Tt, Phm, He).

- Date: 16 (1545)

- Copiste : Le prêtre Wahaba de Hardine ; Athanasius, anciennement Ibrahim Yijmur de Nabk ; le diacre Julianus, fils d'Ibrahim Ibn Zalteh, de Nabk.

- Destinataire : Le prêtre Johannes fils du presbytre Jusuf, de Ain Halyo

- Langue/écriture : Karshuni

- Description : Papier; 204 folios.

- Vorlage: Syriaque (2)

- Origine : Liban (Hardine)

- Bibliographie: gCal I, p. 176 ; Gregory, p. 584, no. 16 ; PAYne Smith, p. 98 ; URI, pars II, p. 4 ; PUSEY, p. 563.

136. Oxford Bodl. Or. 333

- No. catalogue : Nicoll Ar. Christ. XVIII

- Contenu du manuscrit: 1 . Lettres de Paul (Rm, 1 Co, 2 Co, Ga, Ep, Ph, Col, 1 Th, 2 Th, 1 Tm, 2 Tm, Tt, Phm, He) ; 2. Lettres catholiques (Ja, 1 P, 2 P, 1 Jn, 2 Jn, 3 Jn, Jude) ; 3 . Actes des Apôtres incomplets (1,1-14,26).

- Date: 18

- Description: Papier; 100 folios.

- Vorlage : Syriaque (2)

- Bibliographie: GCAL I, p. 176 ; GREgory, p. 585, no. 32 ; NiCOLL, pp. 21-22. 


\section{Oxford Queen's College $35^{1}$}

- Contenu du manuscrit: 1. Évangiles; 2. Lettres de Paul ; 3. Lettres catholiques ; 4 . Actes des Apôtres.

- Date:16

- Description : Papier; 408 folios.

- Vorlage : «Unbestimmer Herkunft»

- Origine : Syrie (Alep ?)

- Remarque : Le manuscrit a été acheté à Alep.

- Bibliographie : GCAL I, p. 181 ; Gregory, p. 585, no. 35 ; CoXe, p. 83.

\section{Paris BNF arabe 63}

- Autre cote : Regius 378 (ancienne cote); Ancien fonds arabe 21 (ancienne cote)

- Contenu du manuscrit: 1. Lettres de Paul (Rm, 1 Co, 2 Co, Ga, Ep, Ph, Col, 1 Th, 2 Th, 1 Tm, 2 Tm, Tt, Phm, He) ; 2 . Lettres catholiques (Jc, 1 P, 2 P, 1 Jn, 2 Jn, 3 Jn, Jude); 3 . Actes des Apôtres.

- Date:14 (1340)

- Destinataire : Yūḥannā ibn Ishạāq

- Description: Papier; 188 folios ; 255×170 mm; surface écrite $180 \times 115 \mathrm{~mm}$; 17 lignes.

- Vorlage: Copte (4)

- Origine : Égypte

- Remarque : Paris BNF arabe 64, Paris BNF arabe 65 et Paris BNF arabe 66 ont le même texte.

- Bibliographie: GCAL I, p. 179; GCAL II, 462; Gregory, p. 587 no. 55 ; TroupeAu 1, pp. 42-43 ; SCHOLZ, p. 51, p. 59 ; <http://archivesetmanuscrits .bnf.fr/ead.html?id=FRBNFEADoooo89332>.

139. Paris BNF arabe 64

- Autre cote: Regius 377 (ancienne cote); Ancien fonds arabe 22 (ancienne cote)

- Contenu du manuscrit: 1. Lettres de Paul (Rm, 1 Co, 2 Co, Ga, Ep, Ph, Col, 1 Th, 2 Th, 1 Tm, 2 Tm, Tt, Phm, He) ; 2 . Lettres catholiques (Jc, 1 P, 2 P, 1 Jn, 2 Jn, 3 Jn, Jude); 3 . Actes des Apôtres.

- Date:15 
- Description: Papier; 157 folios ; 257×165 mm; surface écrite $210 \times 130 \mathrm{~mm}$; 19 lignes.

- Vorlage: Copte (4)

- Origine:Égypte

- Remarque : Texte identique à Paris BNF arabe 63.

- Bibliographie: GCAL I, p. 179; GCAL II, 462 ; GRegory, p. 587 no. 56; Troupeau 1, p. 43; SCHOLZ p. 51, p. 59 ; <http://archivesetmanuscrits.bnf .fr/ead.html?id=FRBNFEADoooo89333>.

140. Paris BNF arabe 65

- Autre cote: Séguier A. 5 (ancienne cote); Saint-Germain-des-Prés N. 244 (ancienne cote); Supplément arabe 31 (ancienne cote)

- Contenu du manuscrit: 1. Lettres de Paul (Rm, 1 Co, 2 Co, Ga, Ep, Ph, Col, 1 Th, 2 Th, 1 Tm, 2 Tm, Tt, Phm, He) ; 2. Lettres catholiques (Jc, 1 P, 2 P, 1 Jn, 2 Jn, 3 Jn, Jude); 3 . Actes des Apôtres.

- Date: 17 (1614)

- Destinataire : le diacre Yūḥannā ibn Tādrus al-Ġamrāwī

- Description: Papier; 247 folios ; 210×155 mm ; surface écrite 145×100 mm.

- Vorlage : Syriaque $(2)^{36}$

- Origine: Égypte

- Remarque : Texte identique à Paris BNF arabe 63.

- Bibliographie: GCAL I, p. 176 ; TroupeaU 1, 44 ; <http://archivesetmanus crits.bnf.fr/ead.html?id=FRBNFEADoooo89334>.

141. Paris BNF arabe 66

- Autre cote: Regius 408.2 (ancienne cote); Ancien fonds arabe 25 (ancienne cote)

- Contenu du manuscrit: 1. Lettres de Paul (Rm, 1 Co, 2 Co, Ga, Ep, Ph, Col, 1 Th, 2 Th, 1 Tm, 2 Tm, Tt, Phm, He) ; 2. Lettres catholiques (Jc, 1 P, 2 P, 1 Jn, 2 Jn, 3 Jn, Jude) ; 3 . Actes des Apôtres.

- Date:17 (1651)

- Copistes : le prêtre Matiyās ; le diacre Yūsuf ibn 'Ațiyya al-Abyārī

- Description: Papier ; 297 folios ; 215×155 mm; surface écrite $145 \times 95 \mathrm{~mm}$; 13 lignes.

- Vorlage : Copte $(4)^{37}$

36 Graf considère que Paris BNF arabe 65 est traduit du syriaque mais que Paris BNF arabe 63 et 64 sont des textes mixtes (= Copte (4)); Troupeau considère toutefois que le texte de Paris BNF arabe 65 est identique à celui de Paris BNF arabe 63 .

37 Graf considère que Paris BNF arabe 66 est de « unbestimmter Herkunft» mais que Paris BNF arabe 63 et 64 sont des textes mixtes (= Copte (4)); Troupeau considère toutefois que le texte de Paris BNF arabe 66 est identique à celui de Paris BNF arabe 63. 
- Origine :Égypte

- Remarque : Texte identique à Paris BNF, arabe 63.

- Bibliographie: GCAl I, p. 180; Gregory, p. 587 no. 6o ; Troupeau 1, 44-45; SCHOLZ 51, 6o ; <http://archivesetmanuscrits.bnf.fr/ead.html?id= FRBNFEADoooo89335>.

142. Paris BNF arabe 6274

- Contenu du manuscrit: 1. Lettres de Paul (Rm, 1 Co, 2 Co, Ga, Ep, Ph, Col, 1 Th, 2 Th, 1 Tm, 2 Tm, Tt, Phm, He); 2. Lettres catholiques (Jc, 1 P, 2 P, 1 Jn, 2 Jn, 3 Jn, Jude); 3 . Actes des Apôtres.

- Date: 18

- Description: Papier; 201 folios ; 210×150 mm; surface écrite 170×100 mm; 19 lignes.

- Origine: Syrie

- Bibliographie: Troupeau 2, 132 ; BLOCHET, 225; <http://archivesetmanus crits.bnf.fr/ead.html?id=FRBNFEADoooo89733>.

143. Paris BNF arabe 6725

- Contenu du manuscrit :1. Le premier feuillet d'un récit de la dormition de la Vierge Marie, probablement $11^{\mathrm{e}} \mathrm{s}$. ; 2 . Un feuillet d'un traité syriaque, intitulé «Livre des parties » (Ktābā de-Mnawātāa), par Šubḥā le-Māran, évêque de Karkha de-Bet Slokh; 3. Sept feuillets, contenant 2 Tm depuis 3,9 et Tt et $\mathrm{Phm}$ (folios 5-11) ; 4. Sept feuillets, contenant une partie de la version arabe des Actes des Apôtres (9,15-13,13) ; 5. Huit feuillets contenant un fragment $\operatorname{Rm}(1,1-4,19)$ (folios 20-27); 6. Huit feuillets contenant un fragment des Actes des Apôtres (7,37-9,41), du $9^{\text {e }}$ s. probablement (folios 28-35).

- Date : 9-11 (902 ou 917 pour fragments 3. et 5.)

- Copiste : Dāwūd al-'Asqalānī (folios 5-11)

- Description : Parchemin et papier (folios 1, 4, 19) ; 35 folios ; 155×111 mm ; surface écrite $130 \times 90 \mathrm{~mm}$; 16-19 lignes.

- Vorlage:Grec (1)

- Origine : Palestine (Jérusalem) (folios 5-11)

- Remarques: Manuscrit formé de fragments de six manuscrits. Le fragment des Actes des Apôtres (6.) est une partie du Sin. Ar. $154^{38}$. Les fragments pauliniens (3. et 5.) appartenaient au Sin. Ar. 73.

- Bibliographie: GCAL I, p. 171 ; TroupeaU 2, p. 132 ; Blochet, pp. 346-347; VADJA Georges, Album de paléographie arabe, Paris, Librairie d'Amérique

38 Gibson Margaret Dunlop, An Arabic Version of the Acts of the Apostles and the Seven Catholic Epistles, Londres, C. J. Clay, 1899 (Studia Sinaitica 6). Voir Vollandt Ronny, Arabic Versions of the Pentateuch. A Comparative Study of Jewish, Christian, and Muslim Sources, Leiden, Brill, 2015 (Biblia Arabica 2), p. 27. 
et d'Orient, 1958, planche 4; Troupeau Gérard, «Une ancienne version arabe de l'Épître à Philémon », Mélanges de l'Université Saint-Joseph 46, 1970, pp. 341-352 ; GÉ HIN Paul, « Manuscrits sinaïtiques dispersés I : les fragments syriaques et arabes de Paris », Oriens Christianus 9o, 2006, pp. 72-92 ; GÉ HIN Paul, «Manuscrits sinaïtiques dispersés III : les fragments syriaques de Londres et de Brirningham », Oriens Christianus 94, 2010, pp. 15-57, ici p. 56 ; Binggeli André, «Les trois David, copistes arabes de Palestine aux $9^{\mathrm{e}}-10^{\mathrm{e}}$ s. », in: Binggeli André, Boud'hors Anne et Cassin Matthieu (éds), Manuscripta Graeca et Orientalia. Mélanges monastiques et patristiques en l'honneur de Paul Géhin, Leuven, Peeters, 2016, pp. 79-117, ici p. 107; <http:// archivesetmanuscrits.bnf.fr/ead.html?id=FRBNFEADoooo33678>.

\section{Paris BNF copte 17}

- No. catalogue: Delaporte 64

- Autre cote: Gaulmin 343; Regius 332.

- Contenu du manuscrit: Lettres de Paul (Rm, 1 Co, 2 Co, Ga, Ep, Ph, Col, 1 Th, 2 Th, He, 1 Tm, 2 Tm, Tt, Phm).

- Date:12-13

- Langue/écriture: copte-arabe

- Description: Papier; 270 folios ; $320 \times 230 \mathrm{~mm}$; surface écrite $255 \times 162 \mathrm{~mm}$; 23-25 lignes; 2 colonnes.

- Vorlage: Copte (2)

- Origine:Égypte?

- Remarque: Paris BNF copte 64 a le même texte.

- Bibliographie: GCAL I, p. 178 ; Gregory, p. 586 no. 54; HorNer, p. XXIV ; Chabot, p. 354; Delaporte 2, pp. 133-134.

\section{Paris BNF copte 64}

- No. catalogue: Delaporte 25

- Autre cote: Supplément copte 13

- Contenu du manuscrit: Lettres de Paul (Rm, 1 Co, 2 Co, Ga, Ep, Ph, Col, 1Th, 2 Th, He, 1 Tm, 2 Tm, Tt, Phm).

- Date:17 (1636)

- Copiste : Un certain Ța'ama

- Langue/écriture: copte-arabe

- Description: Papier; 206 folios ; $447 \times 285 \mathrm{~mm}$; surface écrite $265 \times 177 \mathrm{~mm}$; 27 lignes ; 2 colonnes.

- Vorlage: Copte (2).

- Origine:Égypte?

- Remarque : Texte identique à Paris BNF copte 17.

- Bibliographie: GCAL I, p. 178; Horner, p. XXVI; СНABot, p. 360; Delaporte 2, pp. 134-135. 
146. Paris BNF syriaque $5^{0}$

- Autre cote : Ancien fonds 30 ; Colbert 4973.

- Contenu du manuscrit : Lettres de Paul

- Date: 12 (1187)

- Langue/écriture : syriaque-arabe

- Description : Papier ; 214 folios.

- Vorlage : Syriaque (3)

- Origine : Syrie

- Remarque : Comme le texte syriaque suit la Peshitta, nous pouvons supposer que l'ordre des lettres est Rm, 1 Co, 2 Co, Ga, Ep, Ph, Col, 1 Th, 2 Th, 1 Tm, 2 Tm, Tt, Phm, He.

- Bibliographie: gCAl I, p. 177 ;Zotenberg, p. 16.

147. Paris BNF syriaque 55

- Autre cote : Supplément 86 ; Saint-Germain 541.

- Contenu du manuscrit :1. Dix commandements et extrait de Mt en karshouni $(22,37-40) ; 2$. Quatre évangiles en syriaque; 3. Fragment en karshouni de Mt (10,16-33) ; 4. Fragment en karshouni de Ja (1,12-15) ; 5. Note en karshouni d'un moine Jean ; 6. Fragment en syriaque de Ga (5,13-6,6) ; 7. Fragment en karshouni de 1 Tm (extrait du chap. 3) ; 8. Fragment en syriaque de Rm; 9. Fragment en karshouni de Ac $(7,37)$; 10. Versets en karshouni extraits des Ps.

- Date: $13(1202 / 3)$

- Langue/écriture : syriaque et karshouni

- Description: Parchemin.

- Origine : Syrie

- Bibliographie:Zotenberg, p. 20.

148. Princeton UL Garrett ar. 3926

- No. catalogue: $5^{268.1}$

- Contenu du manuscrit : Nouveau Testament.

- Date :18-19

- Description : 209 folios ; $230 \times 145 \mathrm{~mm}$; surface écrite $152 \times 82 \mathrm{~mm} ; 17$ lignes.

- Vorlage: Mixte

- Remarque: La Vorlage serait l'édition Al-'Ahd al-jadìd li-rabbinā Yasū al-Masịh, Londres, 1727.

- Bibliographie: MACH, p. 454. 


\section{Princeton UL Garrett ar. 3916}

- No. catalogue: 5268.2

- Contenu du manuscrit : Nouveau Testament.

- Date:19

- Description : 218×170 mm; surface écrite $170 \times 111 \mathrm{~mm}$; 9 lignes; il s'agit de deux volumes (nombre de folios non donné).

- Vorlage: Mixte

- Remarque: La Vorlage serait l'édition Al-Ahd al-jadìd li-rabbinā Yasūc al-Masịh, Londres, 1727.

- Bibliographie: MACH, p. 454.

\section{Saint-Pétersbourg, Bibliothèque nationale de Russie ${ }^{39}$}

\section{Saint-Pétersbourg Bibl. Nat. Ar. New Series 327}

- Autre cote: Ar. Pet.

- Contenu du manuscrit: Fragments des lettres de Paul (Rm 6,14-16.8,35-9,3; 2 Co 2,16-8,19; 1 Tm à partir de 1,2; 2 Tm ; Tt ; He 1,1-9,15)

- Date:9(892)

- Description: Parchemin; 226 folios ${ }^{40}$.

- Vorlage: Syriaque (1)

- Bibliographie: GCAL I, p. 173 ; GREGORY, p. 591, no. 136 ; BURKITT, p. $137^{41}$; Tischendorf, pp. 13-14; Fleischer Heinrich Leberecht, Kleinere Schriften, vol. 3, Leipzig, S. Hirzel, 1885, pp. 389-391 ${ }^{42}$.

39 Il n'y a pas de catalogue édité pour les manuscrits de la Bibliothèque nationale de Russie acquis après 1852. Merci à Sofia Moiseeva pour les informations sur le Saint-Pétersbourg Bibl. Nat. Ar. New Series 327. Nous n'avons pas trouvé de manuscrits continus dans Catalogue des manuscrits et xylographes orientaux de la Bibliothèque impériale publique de St. Pétersbourg, Saint-Pétersbourg, Imprimerie de l'Académie impériale des Sciences, 1852.

40 Tischendorf et Fleischer donnent ici l'indication de 75 pages, qui semble erronée.

41 Burkitt nomme éronément le manuscrit « Greg. cod.134» (il s'agit du codex 136).

42 Publié une première fois dans: FleIsCHER Heinrich Leberecht, «Beschreibung der von Prof. Dr. Tischendorf im J. 1853 aus dem Morgenlande zurückgebrachten christlicharabischen Handschriften », Zeitschrift der Deutschen Morgenländischen Gesellschaft 8, 1854, pp. 584-587 ; FLEISCHER Heinrich Leberecht, « Beschreibung der von Prof. Dr. Tischendorf im J. 1853 aus dem Morgenlande zurückgebrachten christlich-arabischen Handschriften », Zeitschrift der Deutschen Morgenländischen Gesellschaft 15, 1861, pp. 385-387. 

Academy of Sciences ${ }^{43}$

\section{Saint-Pétersbourg Institute of Oriental Manuscripts $C 867$}

- Autre cote : coll. Gregor IV no. 8

- Contenu du manuscrit: 1. Lettres de Paul ; 2. Lettres catholiques; 3. Actes des Apôtres.

- Date:12(?)

- Description: Papier.

- Vorlage : «Unbestimmter Herkunft»

- Remarque: Une note marginale (folio 40) mentionne la date de 837, une date qui ne peut être correcte.

- Bibliographie : GCAL I, p. 172 ; SERIKOFF, p. 585-564.

152. Saint-Pétersbourg Institute of Oriental Manuscripts D 226/3

- Autre cote : coll. Gregor IV no. 3

- Contenu du manuscrit :1. Évangiles ; 2. Actes des Apôtres ; 3. Lettres de Paul ; 4. Lettres catholiques.

- Date: $17-18$

- Copiste : Abū Gālib b. Abū al-Fahd b. Abū l-Ḥasan al-Masīhī

- Description: Papier; 2 colonnes; 23 lignes.

- Vorlage: Grec (2)

- Remarque: Il s'agit d'une Bible complète en trois volumes; le Nouveau Testament est contenu dans le troisième volume.

- Origine : Syrie (Damas)

- Bibliographie: GCAL I, p. 172 ; SERIKOFF, p. 668-672.

153. Saint-Pétersbourg Institute of Oriental Manuscripts D 228

- Autre cote : coll. Gregor IV no. 9

- Contenu du manuscrit: 1. Lettres de Paul ; 2. Lettres catholiques; 3. Actes des Apôtres.

- Date:14 (1341)

- Copiste : le moine Tuma

- Description:papier.

- Vorlage : «Unbestimmter Herkunft»

- Origine : Syrie (Damas)

- Bibliographie: GCAL I, p. 172 ; SERIKOFF, p. 673.

43 Merci à Herman Teule pour les trois notices de Serikoff et son avis à leur propos. 


\section{Sinaï, Monastère Sainte-Catherine}

154. Sin. Ar. 73

- Contenu du manuscrit : Lettres de Paul incomplètes (Rm à partir de 6,20, 1 Co, 2 Co, Ga, Ep, Ph, Col, 1 Th, 2 Th, He, 1 Tm, 2 Tm jusqu'à 3,8).

- Date: 9 (902 ou 917)

- Description : Parchemin ; 96 folios ; $160 \times 110 \mathrm{~mm}$; surface écrite $140 \times 90 \mathrm{~mm}$; 17 lignes.

- Remarque : Deux fragments du manuscrit se trouvent dans Paris BNF arabe 6725 (voir notice 143 et sa bibliographie).

- Bibliographie: Atrya, p. 175; Atrya 2, p. 4; Kamil, p. 14; Zaki Vevian, «The Textual History of the Arabic Pauline Epistles: One Version, Three Recensions, Six Manuscripts», in: HJÄLm Miriam L. (éd.), Senses of Scripture, Treasures of Tradition. The Bible in Arabic among Jews, Christians and Muslims, Leiden, Brill, 2017 (Biblica Arabica 5), pp. 392-424; images : <https://www.loc.gov/item/oo279385974-ms/>.

155. Sin. Ar. 151

- Contenu du manuscrit: 1. Lettres de Paul (Rm, 1 Co, 2 Co, Ga, Ep, Ph, Col, 1 Th, 2 Th, 1 Tm, 2 Tm, Tt, Phm, He); 2. Actes des Apôtres; 3. Lettres catholiques.

- Date: 9-10

- Description : Parchemin ; 269 folios ; 255×175 mm ; surface écrite $190 \times 120 \mathrm{~mm}$; 17-21 lignes.

- Vorlage : Syriaque (autre)

- Remarque : Voir la discussion au chapitre 5 (point 3.3 ) à propos de la datation du manuscrit.

- Bibliographie: gCAl I, p. 181; AtiYA, pp. 284-285; Atiya 2, p. 6 ; Kamil, p. 16 ; StaAl Harvey, Mt. Sinai Arabic Codex 151 I: The Pauline Epistles, vol. 1, Louvain, Peeters, 1983 (csco 452); ID., Mt. Sinai Arabic Codex 151 I: The Pauline Epistles, vol. 2, Louvain, Peeters, 1983 (csco 453); ID., Mt. Sinai Arabic Codex 151 II : Acts of the Apostles, Catholic Epistles, 2 vol., Louvain, Peeters, 1984 (csco 462-463). images: <https://www.loc.gov/item/oo2793 84404-ms/>.

156. Sin. Ar. 155

- Contenu du manuscrit : 1. Siracide ; 2. Lettres de Paul incomplètes (Rm, 1 Co, 2 Co, Ga, Ep jusqu'à 2,9).

- Date: 9 
- Description : Parchemin ; 94 folios ; $200 \times 140 \mathrm{~mm}$; surface écrite $160 \times 90 \mathrm{~mm}$; 21 lignes ; 1 colonne.

- Vorlage: Grec (1)

- Remarque : Londres BL Or. 8612 constitue la suite de ce manuscrit (à partir de Ep 2,9).

- Bibliographie: GCAL I, pp. 170-171; BURKitT, p. 137; AtriY, pp. 299-300 ; Atrya 2, p. 6 ; Kamil, p. 13 ; Gibson Margaret Dunlop, An Arabic Version of the Epistles of St Paul to the Romans, Corinthians, Galatians with Part of the Epistles to the Ephesians, Londres, C. J. Clay, 1894 (Studia Sinaitica 2); images : <https://www.loc.gov/item/oo279384374-ms/>.

157. Sin. Ar. 156

- Contenu du manuscrit: 1. Actes des Apôtres; 2. Lettres de Paul ; 3. Lettres catholiques; 4. Commentaire pour les lectures de dimanches par Jean Chrysostome.

- Date:14 (1316)

- Description : Papier ; $25^{2}$ folios ; $208 \times 145 \mathrm{~mm}$; surface écrite $160 \times 100 \mathrm{~mm}$; 18 lignes.

- Bibliographie: Atrya, pp. 301-303 ; Atrya 2, p. 6 ; KAmiL, p. 16 ; images: <https://www.loc.gov/item/oo279384362-ms/>.

158. Sin. Ar. 157

- Contenu du manuscrit : Lettres de Paul.

- Date:10

- Description : Papier; 120 folios ; $240 \times 140 \mathrm{~mm}$; surface écrite $180 \times 100 \mathrm{~mm}$; 12 lignes.

- Bibliographie : AтıYA, pp. 305-306.

159. Sin. Ar. $15^{8}$

- Contenu du manuscrit: 1. Actes des Apôtres; 2. Lettres de Paul; 3. Commentaire de Jean Chrysostome sur Actes.

- Date:13 (1232)

- Description : Papier ; 181 folios ; $270 \times 200 \mathrm{~mm}$; surface écrite $200 \times 140 \mathrm{~mm}$; 21 lignes.

- Vorlage : «Unbestimmter Herkunft»

- Bibliographie: GCAL I, p. 171; Atriya, pp. 307-310 ; Atrya 2, p. 6 ; Kamil, p. 16 ; images : <https://www.loc.gov/item/oo279384428-ms/>.

16o. Sin. Ar. 161

- Contenu du manuscrit: 1. Lettres de Paul ; 2. Actes des Apôtres ; 3. Lettres catholiques.

- Date:12 
- Description: Papier ; 276 folios ; 195×120 mm; surface écrite $150 \times 90 \mathrm{~mm}$; 15 lignes.

- Vorlage: «Unbestimmter Herkunft»

- Bibliographie: GCAL I, p. 181; ATIYA, p. 315 ; KAMIL, p. 16.

161. Sin. Ar. 162

- Contenu du manuscrit: 1. Actes des Apôtres; 2. Lettres catholiques; 3. Lettres de Paul.

- Date:14 (1384)

- Description : Papier ; 291 folios ; 310×220 mm ; 220×140 mm ; 19 lignes.

- Vorlage: «Unbestimmter Herkunft»

- Bibliographie: GCAL I, p. 181; ATIYA, pp. 316-319; KAmiL, p. 16.

162. Sin. Ar. 165

- Contenu du manuscrit: 1. Lettres de Paul; 2. Actes des Apôtres; 4. Lettres catholiques ; 5 . Psaumes ; 6 . Hymnes.

- Date:15 (1488)

- Description: Papier; 274 folios ; 200×145 mm; surface écrite $190 \times 130 \mathrm{~mm}$; 14 lignes.

- Vorlage: «Unbestimmter Herkunft»

- Bibliographie: GCAL I, p. 181; AT IYA, pp. 326-330 ; KAMIL, p. 16.

163. Sin. Ar. 166

- Contenu du manuscrit : 1. Lettres de Paul ; 2. Lettres catholiques.

- Date:16 (1532)

- Description: Papier; 269 folios; $145 \times 95 \mathrm{~mm}$; surface écrite $110 \times 60 \mathrm{~mm}$; 12 lignes.

- Vorlage: «Unbestimmter Herkunft»

- Bibliographie: GCAL I, p. 181; ATIYA, pp. 331-332 ; KAMIL, p. 16.

164. Sin. Ar. 167

- Contenu du manuscrit : Lettres de Paul.

- Date:13 (1255)

- Copiste : Le diacre Yūḥannā ibn an-Nafīs Mahḍab ibn aš-Šayḩ as-Sadīd abū al-Marjā

- Description: Papier ; 144 folios ; 200×140 mm; surface écrite 160×110 mm; 16 lignes.

- Vorlage: «Unbestimmter Herkunft»

- Bibliographie: GCAL I, p. 181 ; ATIYA, p. 333-335 ; ATIYA 2, p. 7 ; KAMIL, p. 16 ; images : <https://www.loc.gov/item/oo279384453-ms/>.

165. Sin. Ar. 168

- Contenu du manuscrit: 1. Actes des Apôtres; 2. Lettres de Paul; 3. Lettres catholiques; 4 . Commentaire pour les lectures de dimanches par Jean Chrysostome. 
- Date:13(1238)

- Copiste : Le prêtre abū Šākir ibn aš-Šahār

- Description: Papier; 506 folios; 175×130 mm; surface écrite $120 \times 80 \mathrm{~mm}$; 14 lignes.

- Vorlage: «Unbestimmter Herkunft»

- Bibliographie: GCAL I, p. 181 ; ATIYA, p. 336-338 ; ATIYA 2, p. 7 ; KAMIL, p. 16 ; images : <https://www.loc.gov/item/oo279384465-ms/>.

166. Sin. Ar. 310

- Contenu du manuscrit : Lettres de Paul incomplètes (Rm, 1 Co, 2 Co, Ga).

- Date:10-11

- Description : Papier ; 95 folios ; $240 \times 145$ mm.

- Bibliographie: ATIYA 2, p. 8; KAMIL, p. 16; images: <https://www.loc.gov/ item/oo279384039-ms/>.

167. Sin. Greek New Finds MG 2

- Contenu du manuscrit: Fragments des lettres de Paul (Rm 1,1-9.24-30, 1Co 7,37-40 ; 8,1-6, 2 Co 10,14-17; 11,2-13,5, Ga 1,1-6,1; 6,11-fin, Ep 1,1-8; 1,16-2,14; 3,9-4,8; 4,30-fin, Ph 1,1-3,4; 4,12-13.17-21; Col 1,17-3,13; 3,21-fin, 1 Th, 2 Th, He 1,1-10,12, Tt 2,11-3,2; 3,8).

- Date: 9

- Langue/écriture: Grec-arabe

- Description : Parchemin ; 120 folios ; 242×182 mm ; 20-22 lignes ; 2 colonnes.

- Vorlage: Syriaque (autre)

- Remarque: Le manuscrit a été intégré à la liste Gregory-Aland et porte le numéro GA 0278.

- Bibliographie : Document inédit de Père Justin, «Exploring a Ninth Century Sinai Palimpsest ».

168. Sin. Ar. New Finds Parch. 40

- Contenu du manuscrit: Fragments des lettres de Paul (commence par Ep).

- Description: Parchemin; 6o folios; 50-80×60-85 mm; palimpseste.

- Remarque:Il s'agit d'un palimpseste, le texte recouvert est en grec, l'écriture est ancienne.

- Bibliographie: Meimarēs, p. 31 (grec), p. 30 (arabe).

169. Sin. Ar. New Finds Parch. $5^{2}$

- Contenu du manuscrit: Fragments de Rm.

- Description : Parchemin ; 11 lignes ; 267×185 mm.

- Bibliographie: Meimarēs, p. 33 (grec), p. 33 (arabe).

170. Sin. Ar. New Finds Parch. 60

- Contenu du manuscrit: Rm incomplet (à partir de 3,15).

- Description: Parchemin ; 4 folios ; 193×130 mm. 
- Bibliographie: Meimarēs, p. 34 (grec), p. 34 (arabe).

171. Sin. Ar. New Finds Pap. 35

- Contenu du manuscrit: 1. Fragments des évangiles ; 2. Fragments des lettres de Paul.

- Description : Papier ; 36 folios ; 190 $\times 140 \mathrm{~mm}$.

- Bibliographie: Meimarēs, p. 47 (grec), p. 30 (arabe).

172. Vat. Ar. 13

- Contenu du manuscrit : 1. Évangiles incomplets (Mt, Mc, Lc, fragmentaires) ; 2. Lettres de Paul (Rm, 1 Co, 2 Co, Ga, Ep, Ph, Col, 1 Th, 2 Th, 1 Tm, 2 Tm, Tt, Phm, He).

- Date:9-11

- Description: Parchemin; 179 folios; 260-278×170-180 $\mathrm{mm}$; surface écrite 200-230 $\times 125$-170 mm ; 13-21 lignes ; 1 colonne.

- Vorlage: Grec (1)

- Remarque : À propos du copiste, de l'origine et de la bibliographie, voir chapitre 6.

- Bibliographie: GCAL I, pp. 138, 147, 150, 171; Gregory, p. 590, no. 101; SCHOLz, p. 131; MAI, pp. 11-13 ; BURKITT, 137 ; <http://www.mss.vatlib.it/ guii $/$ console? service $=$ shortDetail $\&$ id $=115495>$.

173. Vat. Ar. 21

- Contenu du manuscrit: 1. Lettres de Paul (Rm, 1 Co, 2 Co, Ga, Ep, Ph, Col, 1 Th, 2 Th, 1 Tm, 2 Tm, Tt, Phm, He) ; . Lettres catholiques (Jc, 1 P, 2 P, 1 Jn, 2 Jn, 3 Jn, Jude); 3 . Actes des Apôtres.

- Date:16

- Copiste : Guillelmus de Tunis

- Description : Papier; 204 folios ; $280 \times 225 \mathrm{~mm}$.

- Vorlage: Syriaque (2)

- Remarque : Il s'agirait d'une copie de Vat. Ar. 22.

- Bibliographie: GCAL I, p. 175 ; Gregory, p. 590, no. 106 ; SCHolz, p. 131 ; MAI, pp. 71-73; <http://www.mss.vatlib.it/guii/console?service=shortDetail \&id $=115780>$.

174. Vat. Ar. 22

- Contenu du manuscrit: 1. Lettres de Paul (Rm, 1 Co, 2 Co, Ga, Ep, Ph, Col, 1 Th, 2 Th, 1 Tm, 2 Tm, Tt, Phm, He) ; 2. Lettres catholiques (Jc, 1 P, 2 P, 1 Jn, 2 Jn, 3 Jn, Jude) ; 3 . Actes des Apôtres. 
- Date:13 (1272)

- Copiste: Joseph, fils de Stéphane Ben Maina, moine à Saint Simon (Antakia)

- Description : Papier ; 201 folios ; 240×175 mm.

- Vorlage: Syriaque (2)

- Origine : Égypte (Caire)

- Remarque : Mai et Gregory donnent des dates différentes, 1472 et 1288.

- Bibliographie: GCAL I, p. 175 ; Gregory, p. 590, no. 107 ; SCHOLZ, pp. 131132 ; MAI, pp. 73-75 ; <http://www.mss.vatlib.it/guii/console?service=short Detail\&id $=116409>$.

175. Vat. Ar. 23

- Contenu du manuscrit: 1. Lettres de Paul (Rm, 1 Co, 2 Co, Ga, Ep, Ph, Col, 1 Th, 2 Th, 1 Tm, 2 Tm, Tt, Phm, He) ; 2. Lettres catholiques (Jc, 1 P, 2 P, 1 Jn, 2 Jn, 3 Jn, Jude) ; 3 . Actes des Apôtres.

- Date:13 (1274)

- Description : Papier ; 324 folios ; 185×135mm.

- Vorlage: Syriaque (2)

- Origine : Égypte (Monastère Saint-Mercure)

- Bibliographie: GCAL I, p. 175 ; GRegory, p. 590, no. 108; SCHOLZ, p. 132 ; MAI, pp. 73-75; <http://www.mss.vatlib.it/guii/console?service=shortDetail \&id $=115807>$.

176. Vat. Ar. 28

- Contenu du manuscrit: 1. Introduction aux lettres de Paul ; 2. Lettres de Paul (Rm, 1 Co, 2 Co, Ga, Ep, Ph, Col, 1 Th, 2 Th, He, 1 Tm, 2 Tm, Tt, Phm).

- Date:14 (1341)

- Copiste : Abū al-'Izz ibn al-Waḥš ad-Damanhūrī

- Description : Papier ; 183 folios ; $255^{\times 175} \mathrm{~mm}$.

- Vorlage: Copte (3)

- Origine : Égypte

- Remarque : Traduction de al-Wajīh Yūḥannā al-Qalyūbī.

- Bibliographie: GCAL I, p. 178 ; Gregory, p. 590, no. 112 ; MAI, p. 76 ; <http:// www.mss.vatlib.it/guii/console? service $=$ shortDetail\&id $=116992>$.

177. Vat. Ar. 433

- Contenu du manuscrit: 1. Introduction aux lettres de Paul incomplète; 2. Lettres de Paul (Rm, 1 Co, 2 Co, Ga, Ep, Ph, Col, 1 Th, 2 Th, 1 Tm, 2 Tm, Tt, Phm, He) ; 3. Lettres catholiques (Jc, 1 P, 2 P, 1 Jn, 2 Jn, 3 Jn, Jude) ; 4. Actes des Apôtres.

- Date:16

- Description : Papier ; 108 folios ; 295 $\times 200 \mathrm{~mm}$,

- Vorlage : Syriaque (2) 
- Bibliographie: GCAL I, p. 175 ; Gregory, p. 590, no. 119 ; MAI, p. 512 ; <http:// www.mss.vatlib.it/guii/console? service $=$ shortDetail\&id $=153479>$.

178. Vat. Ar. 513

- Contenu du manuscrit : Lettres de Paul (Rm, 1 Co, 2 Co, Ga, Ep, Ph, Col, 1 Th, $2 \mathrm{Th}, 1 \mathrm{Tm}, 2 \mathrm{Tm}, \mathrm{Tt}, \mathrm{Phm}, \mathrm{He})$.

- Date:16

- Description: Papier; 163 folios ; 205×140 mm.

- Vorlage: Syriaque (2)

- Bibliographie : GCAL I, p. 175 ; Gregory, p. 591, no. 124; MAI, p. 537 ; <http:// www.mss.vatlib.it/guii/console?service=shortDetail\&id=155602> .

179. Vat. Ar. 517

- Contenu du manuscrit: 1. Introduction aux lettres de Paul; 2. Lettres de Paul (Rm, 1 Co, 2 Co, Ga, Ep, Ph, Col, 1 Th, 2 Th, 1 Tm, 2 Tm, Tt, Phm, He); 3. Lettres catholiques (Jc, 1 P, 2 P, 1 Jn, 2 Jn, 3 Jn, Jude) ; 4 . Actes des Apôtres ; 5. Apocalypse.

- Date: 17

- Description: Papier; 192 folios; 205×150 mm.

- Vorlage: Syriaque (2)

- Bibliographie :GCAL I, p. 175 ; GregorY, p. 591, no. 125 ; MAI, p. 538 ; <http:// www.mss.vatlib.it/guii/console?service $=$ shortDetail\&id $=155603>$.

180. Vat. Ar. 568

- Contenu du manuscrit :1. Introduction aux lettres de Paul ; 2. Lettres de Paul (Rm, 1 Co, 2 Co, Ga, Ep, Ph, Col, 1 Th, 2 Th, 1 Tm, 2 Tm, Tt, Phm, He).

- Date: 17-18

- Description : Papier ; 176 folios ; $145 \times 100 \mathrm{~mm}$.

- Vorlage:Syriaque (2)

- Bibliographie:GCAL I, p. 175 ; Gregory, p. 591, no. 127 ;MAI, p. 538 ; <http:// www.mss.vatlib.it/guii/console?service=shortDetail\&id=155709>.

181. Vat. Copt. 12

- Autre cote: olim 2 ; Raymundi II

- Contenu du manuscrit: 1. Lettres de Paul incomplètes (Rm à partir de 7,1, 1 Co sans 15,6-7.24-33, 2 Co, Ga, Ep, Ph, Col, 1 Th, 2 Th, 1 Tm, 2 Tm, Tt, Phm, $\mathrm{He})$; 2. Lettres catholiques (Jc, 1 P, 2 P, 1 Jn, 2 Jn, 3 Jn, Jude) ; 3. Actes des Apôtres incomplets (sans 20,25-21,31; 24,4-15).

- Date:14-16

- Langue/écriture: Copte-arabe

- Description: Papier ; 418 folios ; 363×250-26o mm ; 24 lignes ; 2 colonnes.

- Vorlage: Syriaque (2)

- Origine: Égypte? 
- Bibliographie: GCAL I, p. 176, p. 178; HebBelynck, pp. 37-42 ; Horner, pp. XXXIX-XLI.

182. Vat. Copt. 13

- Autre cote : olim 3

- Contenu du manuscrit : Lettres de Paul (Rm, 1 Co, 2 Co, Ga, Ep, Ph, Col, 1 Th, 2 Th, He, 1 Tm, 2 Tm, Tt, Phm).

- Date: $13-16$

- Langue/écriture: Copte-arabe

- Description : Papier ; 261 folios ; 318×254 mm ; 23 lignes.

- Vorlage : Syriaque (2)

- Origine : Égypte?

- Bibliographie: GCAL I, p. 176 ; HeBBELYNCK, pp. 42-48.

183. Vat. Copt. 14

- Autre cote : olim 5

- Contenu du manuscrit: 1. Lettres de Paul (Rm, 1 Co, 2 Co, Ga, Ep, Ph, Col, 1 Th, 2 Th, He, 1 Tm, 2 Tm, Tt, Phm) ; 2. Lettres catholiques (Jc, 1 P, 2 P, 1 Jn, 2 Jn, 3 Jn, Jude); 3 . Actes des Apôtres.

- Date:14 (1357)

- Copiste : Michael, fils d'Abraham, de Pemjē

- Langue/écriture: Copte-arabe

- Description : Papier ; 351 folios ; $285 \times 198 \mathrm{~mm}$; surface écrite $203 \times 135 \mathrm{~mm}$; 17-21 lignes.

- Vorlage: Copte (1)

- Origine : Égypte?

- Remarque : La version arabe est écrite entre les lignes.

- Bibliographie: GCAL I, p. 178; HebBelynck, pp. 48-53; Horner, pp. XXXI-XXXIII.

184. Vat. Lat. 12900

- Contenu du manuscrit : Fragments de Ga (Ga 1,1-15; 3,6-24).

- Date:9-10

- Langue/écriture : Latin-arabe

- Description : Parchemin ; 2 folios.

- Vorlage : Latin

- Bibliographie: GCAL I, p. 179 ; Tisserant Eugène et Bruyne Donatien DE, «Une feuille arabo-latine de l'épître aux Galates », Revue biblique N.S. 7 , 1910, pp. 321-343; LEVI DELLA VIDA Giorgio, « Manoscritti arabi di origine Spagnola nella Biblioteca Vaticana », in : Collectanea Vaticana in honorem Anselmi M. Card. Albareda, Rome, Biblioteca Apostolica Vaticana, 1962, pp. 133-189, ici p. 179 . 


\section{Vat. Sir. 203}

- Contenu du manuscrit: Lettres de Paul (Rm, 1 Co, 2 Co, Ga, Ep, Ph, Col, 1 Th, 2 Th, 1 Tm, 2 Tm, Tt, Phm, He).

- Date:16 (1575)

- Copiste: Rabban Ephrem

- Langue/écriture : karshuni

- Description: Papier; 230 folios.

- Vorlage: Syriaque (2)

- Origine:Turquie (Mardin)

- Bibliographie : GCAL I, p. 175 ; Assemani 2, pp. 484-486.

186. Vat. Borg. Ar. 34

- Autre cote: K I 11

- Contenu du manuscrit: 1. Lettres de Paul ; 2. Lettres catholiques; 3. Actes des Apôtres.

- Date: 17

- Description : 244 folios.

- Vorlage: Syriaque (2)

- Bibliographie: GCAL I, p. 176 ; TISSERANT, p. 12.

187. Vat. Borg. Ar. 48

- Autre cote : K I 26

- Contenu du manuscrit: 1. Genèse et Exode; 2. Évangiles; 3. Actes des Apôtres ; 3 . Lettres de Paul.

- Date: 18

- Copiste: Raphael Ṭūhī

- Description: 192 folios.

- Vorlage: Syriaque (2)

- Bibliographie: GCAL I, p. 176 ; TISSERANT, p. 13.

188. Vat. Borg. Ar. 63

- Autre cote: K I 43

- Contenu du manuscrit: 1. Actes des Apôtres; 2. Lettres de Paul; 3. Lettres catholiques.

- Date: 18 (1741)

- Description : 390 folios.

- Vorlage: Grec (2)

- Remarque: La traduction se base sur la version imprimée d'Athanase IV imprimée à Alep en 1707.

- Bibliographie: GCAL I, p. 172 ;TISSERANT, p. 13.

189. Vat. Borg. Copt. $5^{1}$

- Autre cote : olim J-IV-1; Propaganda Copth. 7 ; Tuki IV 
- Contenu du manuscrit: 1. Lettres de Paul (Rm, 1 Co, 2 Co, Ga, Ep, Ph, Col, 1 Th, 2 Th, He, 1 Tm, 2 Tm, Tt, Phm) ; 2. Lettres catholiques (Jc, 1 P, 2 P, 1 Jn, 2 Jn, 3 Jn, Jude) ; 3 . Actes des Apôtres.

- Date:18(1740)

- Copiste : Le presbytre Wahabā

- Langue/écriture: Copte-arabe

- Description: Papier ; 529 folios ; 315×220 mm; surface écrite $190 \times 140 \mathrm{~mm}$; 16-24 lignes ; 2 colonnes.

- Vorlage: Copte (2)

- Origine:Égypte (Ahmìm)

- Bibliographie: GCAL I, p. 178; LANTschoot, pp. 192-199; Horner, pp. XLVII-L.

190. Vat. Borg. Copt. 71

- No. catalogue : olim J-VI-4

- Contenu du manuscrit : 1. Lettres de Paul (Rm, 1 Co, 2 Co, Ga, Ep, Ph, Col, 1 Th, 2 Th, He, 1 Tm, 2 Tm, Tt, Phm); 2. Lettres catholiques (Jc, 1 P, 2 P, 1 Jn, 2 Jn, 3 Jn, Jude) ; 3 . Apocalypse ; 4 . Benedictio.

- Date:18 (1751)

- Langue/écriture: Copte-arabe

- Description : Papier ; 440 folios ; 259×187 mm ; 10-33 lignes ; 2 colonnes.

- Vorlage: Copte (1)

- Origine: Égypte?

- Remarque : Il s'agit, pour le corpus des lettres, d'une copie du Vat. Copt. 14.

- Bibliographie: GCAL I, p. 178 ; LANTSCHOоT, pp. 317-318.

191. Vat. Borg. Sir. 47

- Contenu du manuscrit: 1. Évangiles (en syriaque et karshouni); 2. Actes des Apôtres ; 3. Lettres catholiques ; 4. Notice sur Paul; 5. Lettres de Paul ; 6. Apocalypse.

- Date:14 (1399)

- Langue/écriture: Syriaque-karshouni

- Description : 411 folios ; $270 \times 200 \mathrm{~mm}$; 44 lignes ; 2 colonnes.

- Vorlage : Syriaque (2), 176

- Bibliographie: GCAL I, p. 178 ; SCHER 2, p. $261^{44}$.

192. Vat. Sbath 651

- Contenu du manuscrit: 1. Psaumes de David incomplets; 2. Cantique des Cantiques ; 3 . Évangiles ; 4 . Apocalpyse ; 5 . Traductions de noms propres de

44 Scher ne mentionne pas les lettres de Paul, mais au vu du nombre de folios, nous pensons qu'elles sont présentes, comme mentionné par Graf (GCAL I, p. 178). 
la Bible ; 6. Actes des Apôtres ; 7. Lettres de Paul (Rm, 1 Co, 2 Co, Ga, Ep, Ph, Col, 1 Th, 2 Th, 1 Tm, 2 Tm, Tt, Phm, He) ; 8. Lettre de Jacques incomplète.

- Date:18(1700)

- Copiste : Le diacre Šakrallāh, Ḥalb Šāh ( ?)

- Description : 356 folios ; 320 $230 \mathrm{~mm}$; 16-25 lignes.

- Vorlage: «Unbestimmter Herkunft»

- Bibliographie: GCAL I, p. 181; SBATH, p. 33.

193. Vat. Sbath 1007

- Contenu du manuscrit: Miscellanées, dont, entre autres, une discussion entre un chrétien et un musulman sur Mohammed (7.), une réfutation d'une réplique contre le christianisme (9.), des recettes médicales (4., 8., 10.) et des chapitres extraits des lettres de Paul (11.)

- Date:19

- Description : 200 folios ; $160 \times 110 \mathrm{~mm} ; 13$ lignes.

- Bibliographie: SвAтн, pp. 125-126.

\section{Venise, Biblioteca Nazionale Marciana}

\section{Venise Marciana Gr. 379}

- Autre cote:Z. 11 ; Bessarionis 9

- Contenu du manuscrit: 1. Actes des Apôtres; 2. Lettres catholiques (Ja, $1 \mathrm{P}$, 2 P, 1 Jn, 2 Jn, 3 Jn, Jude); 3 . Lettres de Paul (Rm, 1 Co, 2 Co, Ga, Ep, Ph, Col, 1 Th, 2 Th, He, 1 Tm, 2 Tm, Tt, Phm).

- Date:12-13

- Langue/écriture: Grec-latin-arabe

- Description: Parchemin ; 304 folios ; 280×253 mm; surface écrite 210×50 mm; 28 lignes ; 3 colonnes.

- Vorlage: Latin

- Origine : Sicile (Troina, Monastère Saint-Michael)

- Remarque: Le manuscrit a été intégré à la liste Gregory-Aland et porte le numéro GA 460.

- Bibliographie: Gregory, p. 591, no. 131; ZANetti, p. 16 ; Mioni, pp. 16-17; $<$ https://humarec.org $>45$.

195. Venise Marciana Or. 4

- Autre cote: 13

45 Nous étudions depuis octobre 2016 ce manuscrit dans le cadre du projet HumaReC (projet FNS no. 169869). 
- Contenu du manuscrit: 1. Actes des Apôtres; 2. Lettres de Paul (Rm, 1 Co, 2 Co, Ga, Ep, Ph, Col, 1 Th, 2 Th, 1 Tm, 2 Tm, Tt, Phm, He) ; 3 . Lettres catholiques (Ja, 1 P, 2 P, 1 Jn, 2 Jn, 3 Jn, Jude).

- Description: Papier; $285 \times 200 \mathrm{~mm}$; surface écrite $225 \times 130 \mathrm{~mm} ; 148$ folios; 12 lignes ; 1 colonne.

- Vorlage: Grec selon Veludo

- Bibliographie:Veludo, f. 7 .

\section{$47 \quad$ Wolfenbüttel, Herzog August Bibliothek}

196. Wolfenbüttel нав Guelf. 31 Gud. Graec.

- No. catalogue : Köhler 4218; Fleischer Guelferbyt. 13.

- Contenu du manuscrit: 1. Lettres de Paul incomplètes $\left(1 \mathrm{Tm}^{46}, 2 \mathrm{Tm}, \mathrm{Tt}\right.$, $\mathrm{Phm}, \mathrm{He})$; 2. Lettres catholiques ; 3 . Apocalypse.

- Date: 16

- Description: Papier; 162 folios; $280 \times 215 \mathrm{~mm}$.

- Vorlage: «Unbestimmer Herkunft»

- Remarques: Le manuscrit s'est trouvé à Paris; le manuscrit Wolfenbüttel нав Guelf. $3_{11}$ Gud. Graec. est la suite du Wolfenbüttel нав Guelf. $3^{2}$ Gud. Graec.

- Bibliographie: GCAL I, p. 181; Gregory, p. 588, no. 74a ; KöHLER, p. 27; FLEISCHER, p. 77 ; <http://diglib.hab.de/?db=mss\&list=ms\&id=31-gudgraec $>$.

197. Wolfenbüttel нав Guelf. $3^{2}$ Gud. Graec.

- No. catalogue : Köhler 4219; Fleischer Guelferbyt. 12.

- Contenu du manuscrit : Lettres de Paul incomplètes (Rm, 1 Co, 2 Co, Ga, Ep, Col, 1 Th, 2 Th).

- Date:16

- Description: Papier; 234 folios ; $280 \times 215$ mm.

- Vorlage: «Unbestimmer Herkunft»

- Remarques : Le manuscrit s'est trouvé à Paris ; voir notre remarque ci-dessus à propos du Wolfenbüttel HАв Guelf. 31 Gud. Graec.

- Bibliographie: GCAL I, p. 181; GREGORY, p. 588, no. 74a; KÖHLER, p. 27; FLE ISC HER, p. $77 ;<$ http://diglib.hab.de/?db=mss\&list=ms\&id=32-gudgraec $>$.

46 Selon Fleischer, 1 Tm est présent; selon Köhler et Graf, le manuscrit commence avec $2 \mathrm{Tm}$. 
48 Manuscrits mentionnés par Graf dont nous n’avons pas retrouvé la trace ou dont nous n'avons pu consulter le catalogue

Aleppo 12 (GCAL I, p. 172); Benzel 5 (GCAL I, p. 139); Berlin Or. 169 (CGAL I, 178); Fihris 389 (GCAL I, p. 181); Norfolk 480 (GCAL I, p. 181); Vat. Syr. 194 (GCAL I, p. 180); Washington Samml. Adler 6, Washington Samml. Adler 7, Washington Samml. Adler 8 (GCAL I, p. 181); un deuxième manuscrit de Deir al-Muharraq (GCAL I, p. 178). 


\section{Observations}

Nous proposons dans ce chapitre quelques observations sur la base des données récoltées au chapitre $4^{1}$. Notre approche s'inscrit dans une perspective de « codicologie quantitative», avec des limitations. L'approche quantitative en codicologie trouve ses débuts dans les années 60 et les essais publiés en 1980 de Carla Bozzoli et Ezio Ornato constituent un des ouvrages fondateurs ${ }^{2}$. Dans le premier essai, l'analyse des données codicologiques récoltés sur un grand nombre de manuscrits permet une analyse de l'évolution de la production du livre médiéval en France du Nord ; les deux essais suivants concernent les dimensions physiques des manuscrits.

Nous pensons que trop souvent - pas toujours - l'étude du manuscrit n'a été conçue que de manière auxiliaire ou élitaire : tantôt simple moyen d'accès à l'histoire intellectuelle, tantôt sujet de monographies consacrées à un petit nombre d'objets d'art, jugés dignes d'intérêt parce qu'ils se détachent de leurs milliers de congénères fabriqués à petits moyens. C'est pourquoi nous avons opté pour une approche inversée : l'histoire intellectuelle devient, le cas échéant, un moyen d'accès à l'histoire du livre, et tout notre intérêt est concentré sur la foule anonyme des manuscrits qui peuple les rayons de nos bibliothèques. Combien de livres a-t-on écrit à telle ou telle époque du Moyen Age? À quel prix? Par quelles techniques? Ce sont là les principales questions que nous nous sommes posées en essayant de replacer le manuscrit dans son environnement matériel ${ }^{3}$.

1 Des résultats préliminaires ont été publiés dans l'article: Schulthess Sara, «Liste des manuscrits arabes des lettres de Paul : résultats préliminaires », Journal of Eastern Christian Studies 66 (3-4), 2014, pp. 153-167. Il s'agit d'une mise à jour et d'un développement à partir du répertoire dans son état actuel.

2 Bozzoli Carla et Ornato Ezio, Pour une histoire du livre manuscrit au Moyen Âge: Trois essais de codicologie quantitative, Paris, CNRS, 1983. Voir aussi Ornato Ezio, « La codicologie quantitative, outil privilégié de l'histoire du livre médiéval», in : La face cachée du livre médiéval, Rome, Viella, 1997, pp. 375-402.

3 Bozzoli et Ornato, Pour une histoire du livre manuscrit au Moyen Âge: Trois essais de codicologie quantitative, op. cit., 1983, p. 9 .

(C) SARA SCHULTHESS, 2019 | DOI:10.1163/9789004378162_006

This is an open access chapter distributed under the terms of the prevailing CC-BY-NC License at the time of publication. 
Dans notre cas, notre approche restera modeste. D'une part, nous travaillons avec un corpus réduit (197 manuscrits contre 6200 manuscrits chez Bozzoli et Ornato, par exemple). D'autre part, nous n'abordons pas, par exemple, les aspects strictement physiques, comme la question des cahiers des manuscrits ou de la dimension des feuillets (à l'exception du matériel, voir point 8). Enfin, nous débordons du cadre codicologique, vu que nous nous intéressons aussi aux aspects textuels du manuscrit (en ce qui concerne le contenu au point 4, ou les Vorlagen au point 5). Nous développons donc dans ce chapitre 5 les sujets suivants : les lieux de conservation, les dates et l'évolution de la production, le contenu des manuscrits, les Vorlagen des traductions, les langues utilisées, le support matériel et les copistes.

Bibliothèques

Les 197 manuscrits identifiés dans notre travail sont répartis dans 46 bibliothèques différentes. La bibliothèque qui contient le plus grand nombre de manuscrits est la bibliothèque du Patriarcat copte orthodoxe, avec 39 manuscrits arabes des lettres de Paul. Cette collection est plutôt récente, une grande partie de ces manuscrits ( 15 manuscrits) ayant été copiés au $18^{\mathrm{e}} \mathrm{s}$. Les manuscrits les plus anciens de la collection datent $d u 13^{\mathrm{e}}$ s.; le plus ancien manuscrit daté a été copié en 1253 (Caire Patr. Copt. Orth. Bibl. 154). En ce qui concerne les bibliothèques orientales, les autres collections importantes se trouvent dans la bibliothèque du Monastère Sainte-Catherine au Mont Sinaï (18 manuscrits) et dans la bibliothèque du Musée copte au Caire (13 manuscrits), dans la bibliothèque du Centre franciscain des études chrétiennes orientales au Caire (6 manuscrits) et dans la bibliothèque du Patriarcat copte catholique au Caire ( 5 manuscrits). Les autres bibliothèques possèdent moins de 5 manuscrits. On notera que la collection de la bibliothèque du Monastère Sainte-Catherine est composée de manuscrits particulièrement anciens du $9^{\mathrm{e}}$ ou $10^{\mathrm{e}} \mathrm{s.}^{4}$

On trouve également une grande partie des manuscrits dans des bibliothèques européennes. La bibliothèque apostolique $\mathrm{du}$ Vatican abrite 22 manuscrits. Les collections de la British Library (10 manuscrits), de la bibliothèque nationale de France (10 manuscrits), de la Bodleian Library (7 manuscrits) et de la bibliothèque universitaire de Cambridge (7 manuscrits) sont ensuite les plus importantes. Les autres bibliothèques possèdent moins de 5 manuscrits. La bibliothèque apostolique du Vatican contient le

4 Sin. Ar. 73, Ar. 151, Ar. 155, Gr. New Finds MG 2, Ar. 157, Ar. 310. 
Vat. Ar. 13, qui date certainement du $9^{\mathrm{e}} \mathrm{s}$., et un double feuillet arabo-latin (Vat. Lat. 12900) datant probablement aussi du $9^{\mathrm{e}} \mathrm{s}$. On trouve à la bibliothèque nationale de France le manuscrit Paris BNF Arabe 6725, dont des fragments des lettres de Paul sont datés de 902.

Dates

\section{1 $\quad$ Limites}

Les observations sont ici faites sur les manuscrits arabes des lettres de Paul tout en considérant également les informations à notre disposition sur les manuscrits des évangiles. Il est fort possible que ces observations s'inscrivent dans un contexte plus global concernant les manuscrits arabes chrétiens et que des tendances similaires puissent être établies pour la transmission d'autres textes, non bibliques notamment. Cet aspect devrait être approfondi.

Une étude plus complète devrait également pouvoir prendre en compte le nombre de manuscrits qui ont probablement été perdus à travers l'histoire 5 . De plus, nos observations se basent sur la présence de manuscrits à certaines époques, mais aussi sur leur absence ou leur présence limitée à d'autres; or une argumentation se basant sur l'absence de manuscrits requiert une grande prudence. Le fait que nous traitions avec un nombre de données réduit rend ces aspects d'autant plus importants (voir ci-dessus, point 1 ).

Enfin, d'autres facteurs que ceux que nous mentionnons devraient aussi être pris en compte dans l'évolution de la production. Parmi les facteurs importants, il y a notamment les facteurs économiques, comme le coût de production du manuscrit, comme le montrent Bozolli et Ornato dans l'étude quantitative sur le livre médiéval en France ${ }^{6}$. Cet aspect dépasse cependant le cadre de notre étude.

\subsection{Remarques générales}

Les manuscrits arabes des lettres de Paul qui nous sont parvenus ont étés produits dans une période s'étendant du $9^{\mathrm{e}}$ au $20^{\mathrm{e}} \mathrm{s}$. Durant ce temps, la production a été inégale. Un graphe du nombre de manuscrits par siècle permet d'observer trois «pics », au $9^{\text {e }}$ s., au $13^{\text {e }}$ s. et au $18^{\text {e }}$ s. $^{7}$

5 Bozzoli et Ornato, Pour une histoire du livre manuscrit au Moyen Âge: Trois essais de codicologie quantitative, op. cit., 1983, p. 17.

6 Ibid., pp. 13-19o.

7 Nous avons pris pour établir ce graphe la datation la plus basse des manuscrits (lorsqu'elle chevauche plusieurs siècles par exemple), un choix étant nécessaire pour des raisons pratiques. 


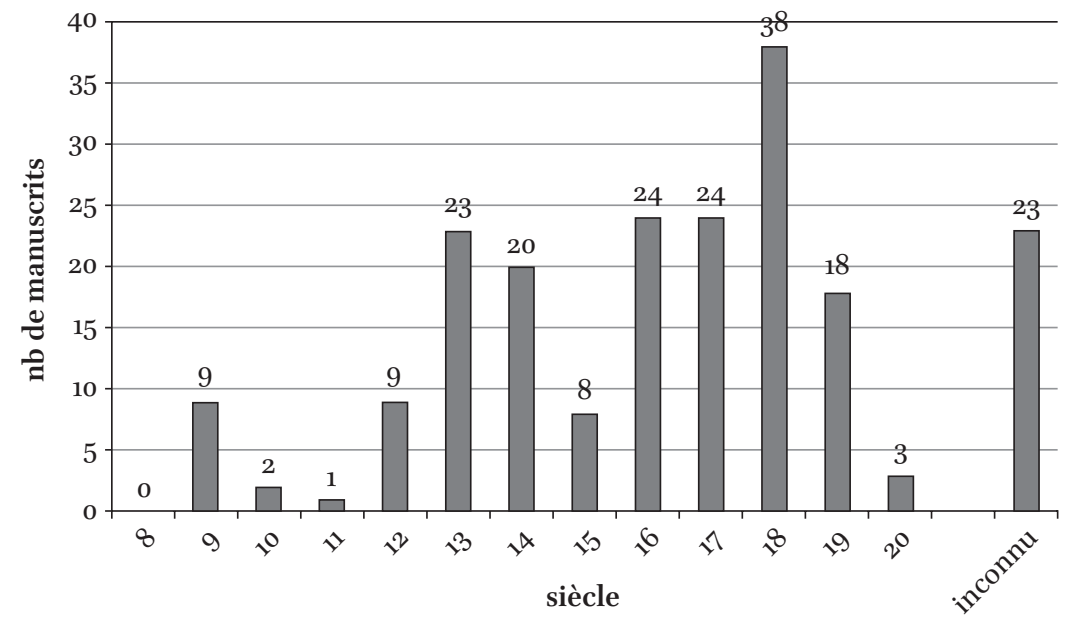

FIGURE 6 Nombre de manuscrits par siècle

Si l'on prend en considération les manuscrits qui sont datés (99 manuscrits), le graphe par siècle qui en résulte suit les mêmes tendances:

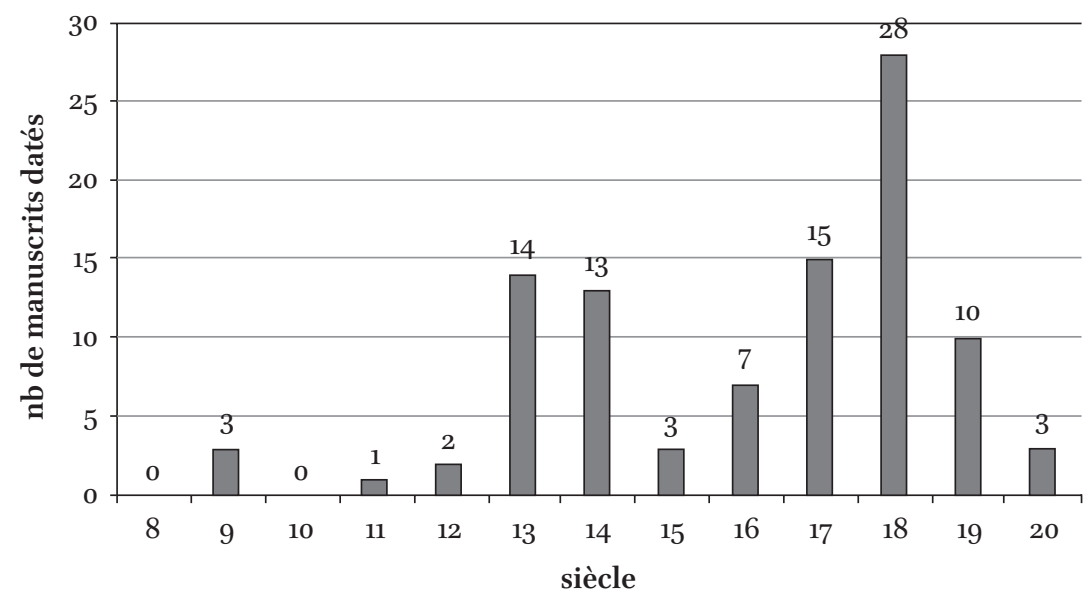

FIGURE 7 Nombre de manuscrits datés par siècle

Le premier pic du $9^{\text {e }}$ s. comprend les manuscrits les plus anciens conservés. Ils sont le fruit de l'arabisation progressive des communautés chrétiennes à la suite de l'arrivée de l'Islam et de la langue arabe. La recherche s'accorde pour dire que les communautés melkites ${ }^{8}$ ont été plus promptes à adopter la langue

8 Dans ce travail, nous utilisons l'appellation «melkite » pour désigner les chrétiens orientaux orthodoxes de rite byzantin, devenus arabophones (GRIf Fith Sidney H., The Church in the 
arabe, du moins comme langue d'écriture, comme le note Pierre Lory: «Les écrivains melkites cessèrent pratiquement d'écrire en grec à partir du $9^{\mathrm{e}} \mathrm{s}$, et les écrivains jacobites égyptiens n'écrivirent plus en copte à partir du $11^{\mathrm{e}} \mathrm{s}$. [...] En revanche, les écrivains jacobites syro-mésopotamiens et les nestoriens continuèrent à écrire en syriaque jusqu'à la fin du $13^{\mathrm{e}} \mathrm{s} .[\ldots]{ }^{9}{ }^{9}$ Le passage facilité $\mathrm{du}$ grec à l'arabe peut être dû à une perception moins « identitaire » de la langue d'Église, le grec, d'autres langues étant déjà utilisées dans les communautés monastiques ${ }^{10}$, contrairement aux autres églises orientales qui semblent avoir montré plus de résistance. Comme Griffith l'explique, «[...] Syro-Palestinians, largely Melkite in religious confession, like their brothers in Alexandria, were left without the comfort of a full church life in an indigenous language, i.e. in Coptic or Syriac [...] This fact must have aided the Arabicization of Christianity in Palestine. ${ }^{11}{ }^{1}$ 'est ainsi que les témoins les plus anciens contenant des traductions du Nouveau Testament semblent avoir été faits dans un contexte melkite $^{12}$ et se trouvent aujourd'hui dans la bibliothèque du Monastère

Shadow of the Mosque: Christians and Muslims in the World of Islam, Princeton, Princeton University Press, 2010, pp. 137-138), et non dans son sens moderne qui désigne les chrétiens orientaux orthodoxes de rite byzantin qui ont rejoint l'Église catholique romaine en 1724 .

9 Lory Pierre et Troupeau Gérard, «Les musulmans et les autres», in: Chevallier Dominique et MiQuel André (éds), Les Arabes, du message à l'histoire, Paris, Fayard, 1995, p. 219. Voir aussi Griffith Sidney H., The Bible in Arabic. The Scriptures of the «People of the Book » in the Language of Islam, Princeton, Princeton University Press, 2013, p. 111 ; id., The Church in the Shadow of the Mosque: Christians and Muslims in the World of Islam, op. cit., 2010, pp. 6o-68.

10 Le syriaque et son dérivé dialectal palestinien, mais aussi l'arménien et le géorgien, dont on trouve de nombreux témoignages écrits. GRIF Fith, The Bible in Arabic. The Scriptures of the «People of the Book» in the Language of Islam, op. cit., 2013, p. 110 ; id., «The Monks of Palestine and the Growth of Christian Literature in Arabic », The Muslim Word 78 (1), 1988, pp. 1-28.

11 Griffit Sidney H., «The Gospel in Arabic: An Inquiry into its Appearance in the First Abbasid Century », Oriens Christianus 67, 1983, p. 162.

12 Voici les témoins datés les plus anciens: Sin. Ar. New Finds Parch. 14 et 16 (contenant Marc, Luc et Jean) est daté de 873 (Le catalogue des New Finds (Meimarēs) donne l'an 859; cette date est incorrecte, voir Swanson Mark N., "Some Considerations for

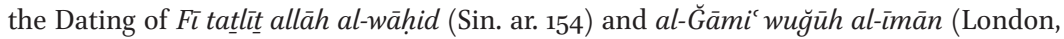
British Library Or. 4950)», Parole de l'Orient 18, 1993, pp. 115-141; Monozov Dmitry A., «К датировке древнейшей арабской рукописи Евангелия », Каптеревские чтения 6, 2008, pp. 19-23); Sin. Ar. 72 (contenant les évangiles) est daté de 897 (voir Arbache Samir, L'Évangile arabe selon saint Luc: texte du VIIIe siècle, copié en 897, Bruxelles, Safran, 2012. Arbache suppose qu'il a été copié à Saint Chariton, Ibid., p. 24); Sin. Ar. 151 (contenant les épîtres de Paul, les Actes et les épîtres catholiques) a un colophon indiquant l'an 867. Cette dernière date se rapporterait à la traduction et non au manuscrit, voir la discussion au point 3.3. 
orthodoxe de Sainte-Catherine ${ }^{13}$. Ce premier pic du nombre de manuscrits peut sembler moins conséquent que les deux suivants; il est cependant fort possible que davantage de manuscrits de cette période plus ancienne ne nous soient pas parvenus (voir ci-dessous, point 3.3).

Par la suite, l'Église copte se montra très productive : «The transition from Coptic to Arabic in spoken language also led to a very active tradition of translation and elaboration of Coptic texts into Arabic. $»^{14}$ Graf identifie le $13^{\mathrm{e}}$ s. à un «âge d'or» de la littérature arabe parmi les Coptes ${ }^{15}$, auquel peut correspondre le deuxième pic de production de notre graphe. Sur les 23 manuscrits datant du $13^{\mathrm{e}} \mathrm{s}$, 10 au moins proviennent probablement d'Égypte. Le $13^{\mathrm{e}} \mathrm{s}$. semble avoir été une période clémente pour l'Église copte, notamment sous le règne du sultan ayyoubide al-Kāmil (1218-1238). La situation change pour les coptes avec la prise de pouvoir des Mamlouks (1251) et leur situation ira en se dégradant durant les siècles qui suivirent ${ }^{16}$. Cette situation nouvelle explique peut-être la diminution du nombre de manuscrits au $15^{\mathrm{e}} \mathrm{s}$.

La renaissance de la littérature arabe chrétienne au $17^{\mathrm{e}}-18^{\mathrm{e}}$ s. pourrait expliquer le troisième pic: «Mit Recht kann man von einer Renaissance der christlicharabischen Literatur in dieser zweiten Periode der Geschichte, näherhin im 17. und 18. Jahrh. sprechen. Ihre Anfänge und Voraussetzungen erscheinen schon im 15. Jahrh. ${ }^{17}$ Si ces périodes concernent la littérature

13 Le monastère Mar Saba est souvent associé à celui de Sainte-Catherine comme ayant produit les premiers manuscrits arabes du Nouveau Testament (Griffith par exemple: «[...] it is clear that the earliest datable copies of the Gospel in Arabic are from Syria/ Palestine, largely from St. Catherine's and Mar Sabas' monasteries, in the ninth century. » Griffith, «The Gospel in Arabic: An Inquiry into its Appearance in the First Abbasid Century », art. cit., 1983, pp. 133-134). À notre connaissance, aucun des manuscrits arabes du Nouveau Testament conservés n'a été explicitement copié à Mar Saba. le Leipzig UL Or. 1059A (Tischendorf XXXI) a été ramené par Tischendorf de Mar Saba (voir KASHOU H, The Arabic Versions of the Gospels, The Manuscripts and their Families, op. cit., 2012, p. 79). En est-il originaire? On a longtemps cru que c'était le cas du Vat. Ar. 13 (voir chapitre 6, point 3.2 Le lieu d'origine du manuscrit). Cela n'empêche pas que l'activité scribale y ait été importante, voir GRIf Fit H Sidney H., « Anthony David of Baghdad, Scribe and Monk of Mar Sabas: Arabic in the Monasteries of Palestine », Church History 58 (1), 1989, pp. 7-19.

14 Wilfong Terry G., « The Non-Muslim Communities: Christian Communities », in : Petry Carl F. (éd.), The Cambridge History of Egypt. Islamic Egypt 640-1517, vol. 1, Cambridge, Cambridge University Press, 1998, p. 190.

15 GRAF Georg, Geschichte der christlichen arabischen Literatur, vol. 1, Rome, Biblioteca Apostolica Vaticana, 1944 (Studi e Testi 118), p. 8 o.

16 Cannuyer Christian, Les Coptes, Turnhout, Brepols, 1990, pp. 41-43; Wilfong, «The Non-Muslim Communities: Christian Communities », art. cit., 1998, p. 196.

17 GRAF, Geschichte der christlichen arabischen Literatur, op. cit., 1944, p. 81. 
arabe chrétienne dans son ensemble, avec notamment la littérature de controverse, il est possible qu'elles aient également vu un intérêt renouvelé pour les traductions en arabe. L'augmentation des copies est peut-être aussi liée à l'arrivée dans les communautés orientales des premières éditions du Nouveau Testament en arabe, préparées à des fins missionnaires et pratiques (édition de la Propaganda Fide en 1671 ; édition du patriarche melkite Athanase IV Dabbās d'Antioche en 1706$)^{18}$.

Il est intéressant de relever que le nombre de manuscrits de notre répertoire (197 manuscrits) est proche de celui de la liste des manuscrits arabes des évangiles de Kashouh, qui répertorie 210 manuscrits. Toutefois, il est important de noter que nous prenons en compte certaines bibliothèques en plus, notamment celles qui se trouvent au Caire. Au nombre de 210 manuscrits des évangiles s'ajoutent donc encore au minimum $5^{0}$ manuscrits cairotes ${ }^{19}$. Une évolution similaire quant à la production des lettres de Paul et des évangiles peut cependant être constatée. En effet, le graphe proposé par Kashouh ${ }^{20}$ est très similaire au graphe de la figure 6 ci-dessus :

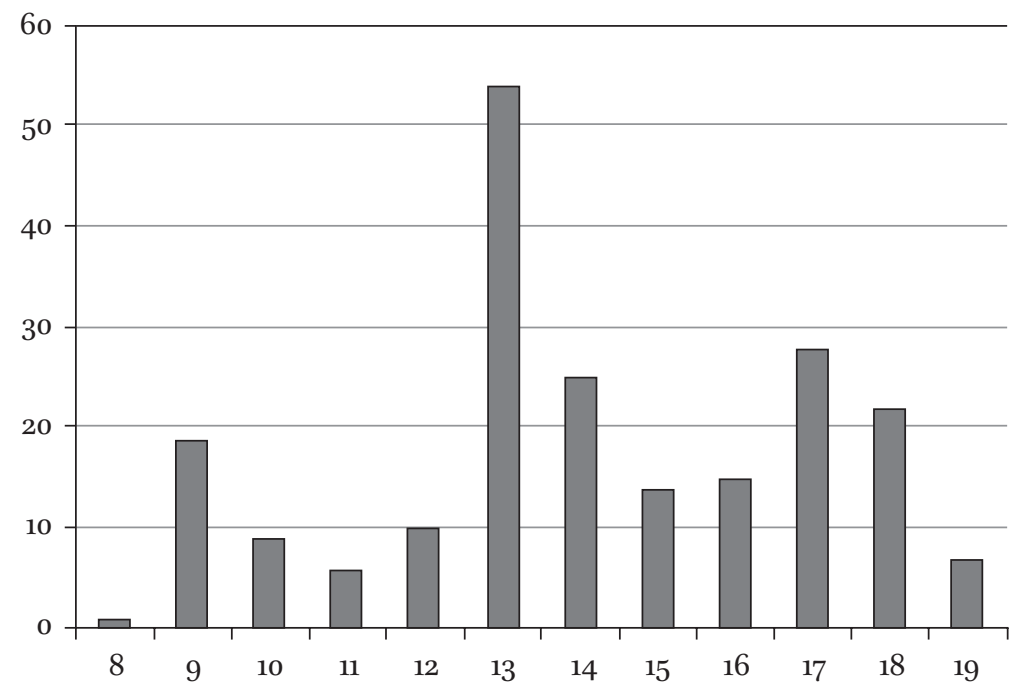

FIGURE 8 Nombre de AGM par siècle, par Hikmat Kashouh

18 Voir chapitre 3. Du désintérêt à la redécouverte : analyse d'un phénomène scientifique.

19 Kashoun, The Arabic Versions of the Gospels, The Manuscripts and their Families, op. cit., 2012, pp. 79-80.

20 Graphe: Ibid., p. 78. 
Il identifie pour les évangiles les mêmes pics de production que ceux identifiés pour les lettres de Paul :

It is clear from the chart above that in the ninth century many manuscripts were produced with a relatively high number surviving. This abundance of literature reflects the intense activity of this period. Another serious endeavour in the copying of the manuscripts seems to have taken place in the thirteenth century and continued to the fourteenth century. The majority of the manuscripts of this period are not fresh translations but copies of earlier ones, some of which have undergone light to moderate corrections. The seventeenth and eighteenth centuries represent the third period of extensive effort in copying and transcribing AGM [Arabic Gospel manuscripts] $]^{21}$.

Nous voyons donc que les lettres de Paul furent traduites puis copiées parallèlement aux évangiles, contrairement à l'avis souvent partagé par les chercheurs (voir chapitre 4, point 1 Introduction) que les lettres de Paul ont été plus tardivement et moins copiées que les évangiles.

\subsection{Remarques concernant les manuscrits les plus anciens}

Plusieurs des manuscrits les plus anciens sont datés: Saint-Pétersbourg Bibl. Nat. Ar. New Series 327, est daté de 891. Sin. Ar. 151 porte la mention de 867. Toutefois, plusieurs chercheurs supposent que le colophon de Sin. Ar. 151, qui se trouve à la fin des lettres de Paul, aurait été copié ; 867 serait donc la date de la traduction ${ }^{22}$. Alexander Treiger avance la date de la première moitié du $10^{\mathrm{e}} \mathrm{s}$. pour le manuscrit, au vu de ses similarités paléographiques avec Sin. Ar. 2, un manuscrit contenant la Bible hébraïque en arabe ${ }^{23}$. En attendant une étude détaillée de la question, nous gardons le laps $9^{\mathrm{e}}-10^{\mathrm{e}}$ s. dans le tableau. Nous avons aussi intégré à cette liste des manuscrits anciens Paris BNF Arabe 6725, dont les fragments v et III ( 15 folios en tout) appartenaient au Sin. Ar. $73^{24}$; les

\section{Ibid.}

22 BLAU Joshua, «Über einige christlich-arabische Manuskripte aus dem 9. und 10. Jahrhundert », Le Muséon 75, 1962, pp. 101-108. Voir aussi Esbroeck Michel van, «Les versions orientales de la Bible: une orientation bibliographique», in: KRAšovec Jože (éd.), The Interpretation of the Bible: the International Symposium in Slovenia, Sheffield, Sheffield Academic Press, 1998 (Journal for the study of the Old Testament 289), p. 404.

23 Treiger Alexander, «From Theodore Abū Qurra to Abed Azrié: The Arabic Bible in Context », in : HJÄLm, Miriam L. (éd.), Senses of Scripture, Treasures of Tradition: The Bible in Arabic among Jews, Christians and Muslims, Leiden, Brill, 2017 (Biblia Arabica 5), p. 40.

Voir chapitre 4, les notices 143 et 154 et leur bibliographie. 


\begin{tabular}{|c|c|c|c|c|c|c|c|}
\hline Cote & Contenu & État & Siècle & Année & Langue & Support & Fol. \\
\hline Vat. Lat. 12900 & $\mathrm{Ga}$ & partiel & $9-10$ & $\varnothing$ & latin-arabe & Parchemin & 2 \\
\hline Vat. Ar. 13 & EP & complet & $9^{-11}$ & $\varnothing$ & arabe & Parchemin & 179 \\
\hline Sin. Gr. NF MG. 2 & $\mathrm{P}$ & partiel & 9 & $\varnothing$ & grec-arabe & Parchemin & 120 \\
\hline Sin. Ar. 155 & $\mathrm{P}$ & partiel & 9 & $\varnothing$ & arabe & Parchemin & 94 \\
\hline Sin. Ar. $15^{1}$ & PAC & complet & $9-10$ & $(867)$ & arabe & Parchemin & 269 \\
\hline $\begin{array}{l}\text { Sin. Ar. } 73+\text { Paris } \\
\text { BNF Arabe } 6725\end{array}$ & $\mathrm{P}$ & complet & 10 & 918 & arabe & Parchemin & $96+15$ \\
\hline $\begin{array}{l}\text { Saint-Pétersbourg } \\
\text { BN Ar. NS } 327\end{array}$ & $\mathrm{P}$ & complet & 9 & 892 & arabe & Parchemin & 226 \\
\hline Londres BL Or. 8612 & $\mathrm{P}$ & partiel & 9 & $\varnothing$ & arabe & Non donné & Non donn \\
\hline
\end{tabular}

deux manuscrits réunis contiennent les 14 lettres de Paul. Une réévalution de la date de 902 est nécessaire selon Mark N. Swanson, qui avance l'an $918^{25}$. Les datations des autres manuscrits sont des estimations.

La situation concernant les manuscrits les plus anciens est à peu près comparable pour les évangiles : parmi les manuscrits des évangiles qu'il étudie, Kashouh considère que 13 manuscrits datent du $9^{\mathrm{e}} \mathrm{s}$. - quatre manuscrits remonteraient même au $8^{\mathrm{e}} \mathrm{s} .{ }^{26}$ Parmi ces 13 manuscrits évangéliques, seulement deux manuscrits sont datés: Sin. Ar. New Finds Parch. 14/16, daté de 873 et Sin. Ar. 72, daté de 897. On notera que le catalogue des manuscrits arabes «New Finds» du Sinaï (manuscrits découverts en 1975) n'offre pas d'estimation de date pour les manuscrits non datés ${ }^{27}$. L'estimation des dates des «New Finds», qui représentent une bonne part des manuscrits anciens avancés par Kashouh, repose sur l'appréciation de ce dernier qui a consulté les

25 SWAnson, «Some Considerations for the Dating of Fì tațlit allāh al-wāhid (Sin. ar. 154) and al-Ğāmic wuğūh al-īmān (London, British Library Or. 4950)», art. cit., 1993, p. 141. Swanson propose décembre 918 ou 917. André Binggeli corrige cela en proposant janvier 918 ou 919. BING G El André, « Les trois David, copistes arabes de Palestine aux ge-1oe s. », in: Binggeli André, Boud'hors Anne et Cassin Matthieu (éds), Manuscripta Graeca et Orientalia. Mélanges monastiques et patristiques en l'honneur de Paul Géhin, Leuven, Peeters, 2016, p. 108.

26 Vat. Ar. 13, Sin. Ar. New Finds Parch. 6, Sin. Ar. New Finds Parch. 8, Sin. Ar. New Finds Parch. 28.

27 Meimarēes Iōannēs Emm., Katalogos tōn neōn arabikōn cheirographōn tēs Hieras Monēs Hagias Aikaterinēs tou Orus Sina (en grec et en arabe), Athènes, National Hellenic Research Foundation, 1985 . 
manuscrits ${ }^{28}$. Il est fort possible que certains manuscrits des lettres de Paul du Sinaï dont la date n'a pas été estimée jusqu'à présent puissent venir joindre les rangs des manuscrits du $9^{\mathrm{e}} \mathrm{s}$. Nous pensons notamment à Sin. Ar. New Finds Parch. 40, Sin. Ar. New Finds Parch. 52, Sin. Ar. New Finds Parch. 6o, qui ont pour support du parchemin (voir point 7 Matériel).

Enfin, on rappellera que les manuscrits les plus anciens ne sont pas des autographes, comme le souligne Griffith: "In each of the instances that we shall discuss here, scholars have shown that the surviving manuscripts they have studied contain a copy of the original Arabic translation of biblical text; in no case is it thought that one is dealing with the autograph of the translation as it left the hand of the original translator. ${ }^{29}$ Nous discutons cet aspect à propos du Vat. Ar. 13 au chapitre 6, point 3 Description du manuscrit Vat. Ar. 13.

\subsection{Remarques concernant les manuscrits du 13 e $s^{30}$}

Les remarques suivantes concernent le pic des $13^{\mathrm{e}}-14^{\mathrm{e}} \mathrm{s}$. Nous savons que cette période a connu deux recensions des évangiles:

- Une recension dite savante ou critique, faite par le savant copte Al-As'ad Abū al-Farağ Ibn al-'Assāl. Cette recension est étudiée en détail par Samir K. Samir dans un article de $1994^{31}$. Il semblerait que Ibn al-Assāl ait utilisé pour sa recension des traductions arabes des évangiles faites à partir du copte, du syriaque et du grec, mais également des textes grecs et des versions coptes et arabes $^{32}$. Son œuvre date probablement de l'an 1253 .

- Une seconde recension, plus accessible, devenu très populaire et qui est connue aujourd'hui sous le nom de «Vulgate alexandrine» ou «Vulgate égyptienne». Nous trouvons la Vulgate alexandrine dans de nombreux manuscrits, sans parler de son influence d'autres traductions. C'est cette version qui est éditée par Thomas Erpenius en $1616^{33}$.

28 Kashoun, The Arabic Versions of the Gospels, The Manuscripts and their Families, op. cit., 2012, pp. 75-77.

29 Griffith, The Bible in Arabic. The Scriptures of the «People of the Book» in the Language of Islam, op. cit., 2013, p. 114.

$30 \quad$ Voir aussi nos remarques à propos de la Vorlage syriaque (2) au point 5 .

31 SAmir Samir Khalil, «La version arabe des Évangiles d'Al-As'ad Ibn al-'Assâl », Parole de l'Orient 19, 1994.

32 «On a parfois comparé cette traduction aux hexaples d'Origène. En effet, comme Origène, notre auteur a examiné attentivement diverses versions orientales des évangiles ; [...] il a signalé dans les marges de son texte toutes les variantes importantes rencontrées dans les autres versions. », Ibid., p. 444.

33 Kashoun, The Arabic Versions of the Gospels, The Manuscripts and their Families, op. cit., 2012, p. 10. 
L'histoire de ces recensions reste toutefois floue - il n'est par exemple pas clair si la Vulgate alexandrine existait avant la recension d'Ibn al-'Assā ${ }^{34}$, ou si, dans la mesure où cette recension était compliquée, la version d'Ibn al-'Assāl fut remplacée par la Vulgate ${ }^{35}$.

Le flou règne également sur une possible recension des lettres de Paul. De manière générale, les chercheurs ne mentionnent ces recensions que pour les évangiles. Or il existe une introduction aux lettres de Paul par un Ibn al-Assāl ${ }^{36}$. Alexis Mallon, cherchant à clarifier l'identité des trois frères savants coptes nommés Ibn al-'Assāl - Aṣ-Ṣafĩ Abū al-Faḍāìl, Al-As'ad Abū al-Farağ, Al-Mu'taman Abū Isḥaq-, attribue la paternité de cette introduction à Al-As'ad Abū al-Farağ, l'auteur de la recension des évangiles, ajoutant: «L'auteur avait sans doute fait pour cette partie du Nouveau Testament ce qu'il avait fait pour l'Évangile, une recension précédée d'une introduction. » Mais selon lui, « [c] ette dernière seule s'est conservée » ${ }^{37}$. Par la suite, Georg Graf exprime une opinion différente en attribuant quant à lui cette introduction à Al-Mū'taman Abū Isḥaq, dont l'œuvre principale est une somme théologique. Quant à la version qui accompagne l'introduction, il en dit ceci : «Die zugrundegelegte Übersetzung ist die der ägyptischen Vulgata ${ }^{38}$. Cette affirmation peut prêter à confusion, la Vulgate égyptienne (ou Vulgate alexandrine) désignant d'habitude la version des évangiles. Dans sa classification des lettres de Paul, Graf mentionne bien une version en usage dans l'Église copte en parallèle à la Vulgate alexandrine (voir ci-dessous Vorlagen), mais il pense que celle-ci remonte au $10^{\mathrm{e}} \mathrm{s}$. déjà 39 .

34 C'est l'avis de Samir : SAMIR, « La version arabe des Évangiles d'Al-As'ad Ibn al-'Assâl », art. cit., 1994, p. 444.

35 C'est par exemple l'avis d'Hyvernat: Hyvernat Henri, « Arabes (versions) des écritures », in : Dictionnaire de la Bible, vol. 1, Leipzig, Letouzey et Ané, 1895, p. 853.

36 Elle se trouve en tout cas dans Caire Patr. Copt. Orth. Bibl. 150, Caire Patr. Copt. Orth. Bibl. 154, Caire Patr. Copt. Orth. Bibl. 162, Caire Patr. Copt. Orth. Bibl. 213, Göttingen su B orient. $125^{5}$, Göttingen sub orient. $125^{6}$. Il est fort possible qu'il s'agisse de la même introduction dans les cas où l'on trouve une introduction aux lettres de Paul sans précision de l'auteur.

37 Mallon Alexis, «Ibn al-'Assâl. Les trois écrivains de ce nom », Journal Asiatique 10 (6), 1905 , p. 524 .

38 Graf Georg, «Die koptische Gelehrtenfamilie der Aulād al-'Assāl und ihr Schrifttum », Orientalia. Nova Series 1, 1932, p. 197. Voir aussi Graf Georg, Geschichte der christlichen arabischen Literatur, vol. 2, Rome, Biblioteca Apostolica Vaticana, 1947 (Studi e Testi 133), p. 412.

GRAF, Geschichte der christlichen arabischen Literatur, op. cit., 1944, pp. 173-177. 
Bien que cette possibilité ne soit pas soutenue par Graf ${ }^{40}$, le grand nombre des manuscrits des lettres de Paul copiés à la suite du $13^{\mathrm{e}} \mathrm{s}$. pourrait indiquer que les lettres de Paul en arabe furent également retravaillées, comme les évangiles le furent à cette période. Peut-être Al-As'ad Abū al-Farağ s'est-il aussi penché sur d'autres livres que les évangiles ou que Al-Mū'taman Abū Ishaq s'est intéressé au texte biblique lors de la composition de son introduction. D’autres facteurs ne sont bien sûr pas à exclure, le $13^{\mathrm{e}} \mathrm{s}$. étant de manière générale une période d'intense production de littérature en arabe dans l'Église copte.

\section{4}

\section{Contenu des manuscrits}

\subsection{L'ordre des corpus du Nouveau Testament}

Nous présentons ici les contenus des manuscrits en nous concentrant sur les corpus du Nouveau Testament et leur ordre d'apparition dans les manuscrits (E = Évangiles ; A = Actes des Apôtres ; P = Lettres de Paul ; C = Lettres catholiques $; \mathrm{R}=$ Apocalypse). Nous faisons également apparaître dans le graphe les

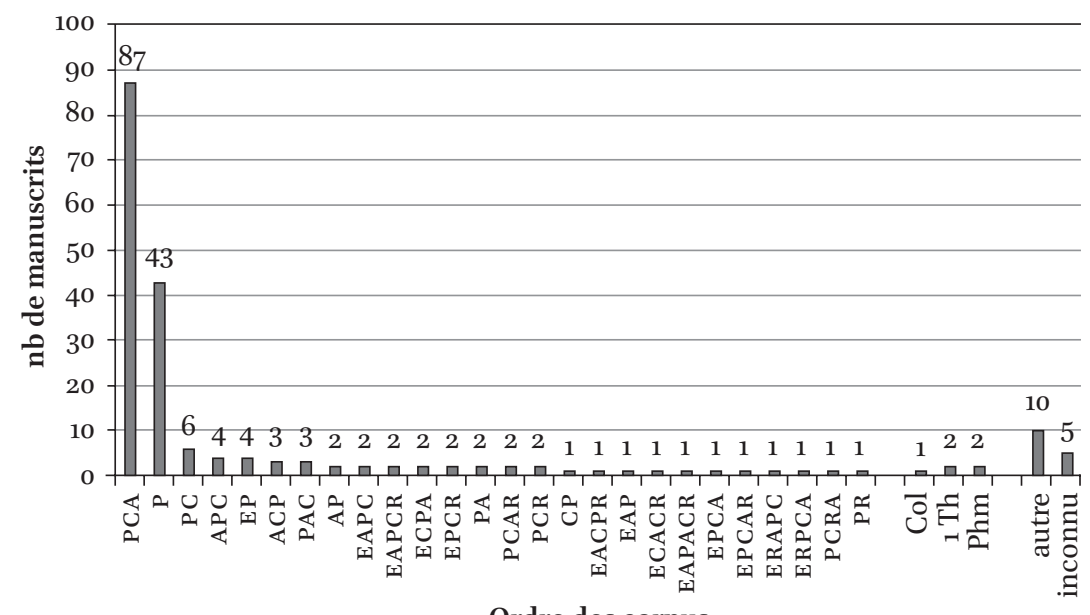

Ordre des corpus

FIGURE 9 Nombre de manuscrits selon l'ordre des corpus

40 Graf fait remonter le texte des lettres de Paul en usage dans l'Église copte au $10^{\mathrm{e}}$ s. en se basant sur le texte Severus ibn al-Muqaffa' Kitāb ad-durr at-tamin fì ìdāḥ ad-dīn; il date aussi le texte des évangiles de la Vulgate alexandrine du $10^{\mathrm{e}} \mathrm{s}$. en se basant sur le même auteur (Kitāb mișbāh al-'aql). Ibid., pp. 157, 174. Kashouh n'est pas d'accord avec l'argumentation de Graf (voir Kashoun, The Arabic Versions of the Gospels, The Manuscripts and their Families, op. cit., 2012, pp. 205-206, surtout note 2.) La comparaison devrait être également refaite pour le texte des lettres de Paul. 
manuscrits lorsqu'ils contiennent une lettre seule complète. Lorsqu'il s'agit seulement de fragments d'une lettre, ceux-ci sont compris dans «autre», car rien n'indique que la lettre se trouvait seule à l'origine. Sous «inconnu» se trouvent les manuscrits dont nous n'avons pas pu déterminer l'ordre des corpus, les informations à ce propos n'étant pas suffisantes.

Nous pouvons constater des caractéristiques qui sont communes aux manuscrits grecs du Nouveau Testament. Les Aland décrivent ainsi le cas des manuscrits grecs :

The only characteristic common to the whole manuscript tradition [...] is that the Gospels stand at the beginning and the Revelation at the end. Otherwise all variations of sequence occur, e.g., Acts-Paulines-Catholics, Acts-Catholics-Paulines (as in A B C and the majority of the manuscripts), Paulines-Acts-Catholics (as in $\boldsymbol{\aleph}$ [Codex Sinaiticus] and a group of minuscules), Paulines-Catholics-Acts - possibly reflecting theological evaluations or historical hypotheses ${ }^{41}$.

Ainsi, le principe all variations of sequences occur s'applique aussi aux manuscrits arabes du Nouveau Testament, qui peuvent présenter les corpus a priori dans tous les ordres possibles; la place des lettres de Paul y est très variable. Nous voyons toutefois que les lettres de Paul sont fréquemment transmises seules (43 manuscrits) - un cas de figure que l'on retrouve également fréquemment parmi les manuscrits grecs ${ }^{42}$.

Mais c'est surtout le nombre élevé de manuscrits présentant l'inhabituelle combinaison PCA (lettres de Paul, lettres catholiques, Actes des Apôtres) qui peut surprendre ( 87 manuscrits). Cet ordre serait typique des manuscrits coptes, sahidiques ou bohaïriques ${ }^{43}$. Il est vrai que la majorité des manuscrits présentant cette disposition se trouvent au Caire ( 52 manuscrits sur 87 manuscrits PCA). On notera que l'ordre PCA n'apparaît pas avant le $11^{\mathrm{e}} \mathrm{s}$. ; auparavant, on trouve surtout le corpus des lettres de Paul seul (7 manuscrits) $)^{44}$.

Nous trouvons quelques lettres de Paul copiées de manière indépendante: 1 Thessaloniciens dans Naples Bibl. Nazionale Ar. 3 et dans Oxford Bodl. Laud.

41 Aland Kurt et Aland Barbara, The Text of the New Testament: An Introduction to the Critical Editions and to the Theory and Practice of Modern Textual Criticism, $2^{\mathrm{e}}$ édition, Grand Rapids, Eerdmans Publishing Co., 1995 (Studies and Documents 46), p. 78.

42 Ibid.

43 Gregory Caspar René, Textkritik des Neuen Testamentes, vol. 2, Leipzig, Hinrichs, 1902, pp. 124, 137 .

44 On trouve aussi PA (Paris BNF Arabe 6725), PAC (Sin. Ar. 151), EP (Vat. Ar. 13, contenant à la base EACP) et un double feuillet de la lettre aux Galates (Vat. Lat. 1290o). 
Or. 24; Colossiens dans Cambridge UL Dd. 15.4; Philémon dans Hambourg suв Orient. 19 et dans Oxford Bodl. Arch. Seld. B. 50 sup. Il s'agit toujours de manuscrits « savants » dont l'origine est européenne.

\subsection{Autres contenus}

Le plus souvent, les lettres de Paul sont transmises avec d'autres corpus du Nouveau Testament, ou seules, selon les compositions que nous venons de décrire. On trouve également souvent des introductions aux lettres de Paul. Parmi elles, l'introduction de Ibn al-'Assāl, que nous mentionnons plus haut au point 3.4. Dans plusieurs cas, les lettres de Paul sont accompagnées d'autres textes. Ceux-ci sont de nature variée. On trouve par exemple les Psaumes ${ }^{45}$, ou encore divers textes de Jean Chrysostome ${ }^{46}$.

Dans trois manuscrits, Caire Patr. Copt. Orth. Bibl. 215, Madrid BN 3484 et Madrid BN 4971, on trouve parmi les lettres de Paul la lettre aux Laodicéens. Dans les manuscrits madrilènes, elle se trouve entre 2 Thessaloniciens et 1 Timothée. On peut supposer que la traduction, similaire dans les deux manuscrits, a été faite à partir d'un texte latin présentant la lettre aux Laodicéens, comme c'est le cas dans de nombreux manuscrits de la Vulgate ${ }^{47}$. Dans le manuscrit Caire Patr. Copt. Orth. Bibl. 215, un manuscrit récent de 1937, la lettre est placée après Hébreux, à la fin du corpus paulinien. Graf fait la liste de quelques manuscrits, au contenu varié, contenant cette version arabe ; ces trois manuscrits sont à ajouter à cette liste ${ }^{48}$.

Quatre manuscrits contiennent une version arabe de la lettre du PseudoDionysius à Timothée sur le martyre de Pierre et Paul ${ }^{49}$. Une édition de ce texte a été publiée en 1900 par Scott Watson; celui-ci dit avoir utilisé un manuscrit syrien $\mathrm{du} 17^{\mathrm{e}} \mathrm{S}$., sans donner toutefois plus d'information à ce sujet. Les manuscrits Göttingen suB orient. $125^{6}$, datant du $13^{\mathrm{e}}$ s., et Cambridge UL

45 Berlin Staatsbibl. Or. Quarto 612, Londres BL Arundel Or. 19, Sin. Ar. 165, Vat. Sbath 651 .

46 Caire Patr. Copt. Cath. 3-3A, Caire Patr. Copt. Orth. Bibl. 157, Jérusalem Saint-Sépulcre 119, Sin. Ar. 156, Sin. Ar. 157, Sin. Ar. 168.

47 Schneemelcher Wilhelm, «The Epistle to the Laodiceans », in: Schneemelcher Wilhelm (éd.), New Testament Apocrypha: Writings relating to the Apostles; Apocalypses and related subjects, $2^{\mathrm{e}}$ édition, Cambridge, James Clark \& Co, 2003, pp. 42-46.

48 GRAF, Geschichte der christlichen arabischen Literatur, op. cit., 1944, p. 271. Voir aussi Tisserant Eugène, «Mélanges IV. La version mozarabe de l'épître aux Laodicéens », Revue biblique N.S. 7, 1910, pp. 249-253.

49 Cambridge UL Add. 3212, Jérusalem Bibl. Saint-Marc 263, Göttingen sub orient. 125 Göttingen suB orient. $125^{6}$. 
Add. 3212, qui pourrait être la suite du Cambridge UL Add. 3213 et donc être daté $\mathrm{du} 12^{\mathrm{e}}-13^{\mathrm{e}}$ s., sont des témoins potentiellement intéressants pour ce texte.

\subsection{Ordre des lettres de Paul}

Nous trouvons à l'intérieur du corpus des lettres de Paul les deux ordres « classiques » suivants ${ }^{50}$ :

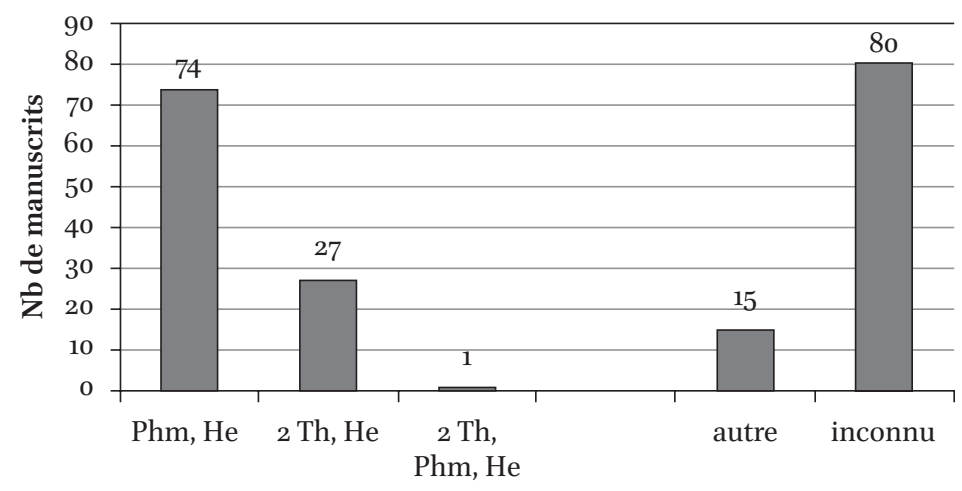

Place de Hébreux

FIGURE 10 Nombre de manuscrits selon la place de Hébreux

- Rm; 1 Co; 2 Co; Ga ; Ep; Ph; Col ; 1 Th; 2 Th ; 1 Tm; 2 Tm; Tt; Phm; He: Il s'agit de la formation dite «latine ${ }^{51}$, présente dans la majorité des manuscrits grecs et dans les versions latines. Elle témoigne de la difficulté d'Hébreux à intégrer le canon du Nouveau Testament ${ }^{52}$. C'est également l'ordre des lettres de Paul dans les versions syriaques telles que la Peshitta ou l'Harkléenne ${ }^{53}$.

50 Sous « autre » se trouvent les manuscrits qui n'ont pas Hébreux et ne sont pas concernés par le classement; sous «inconnu» se trouvent les manuscrits pour lesquels nous ignorons la place de Hébreux, les informations données dans les catalogues ou la littérature secondaire n'étant pas suffisantes.

$51 \quad$ Gregory, Textkritik des Neuen Testamentes, op. cit., 1902, p. 857.

$5^{2}$ On trouve dans les manuscrits grecs, ainsi que dans les autres traditions, bien d'autres compositions. Frede en mentionne 17 différentes, Frede Hermann Josef, «Die Ordnung der Paulusbriefe und der Platz des Kolosserbriefs im Corpus Paulinum», in: Frede Hermann Josef, Epistulae ad Philippenses et ad Colossenses, Freiburg, Verlag Herder, 1966 (Vetus Latina 24), 290-303.

53 Voir Mali Franz, «Le canon du Nouveau Testament chez les auteurs syriaques», in: Aragione Gabriella, Junod Eric et Norelli Enrico (éds), Le canon du Nouveau Testament : regards nouveaux sur l'histoire de sa formation, Genève, Labor et Fides, 2005, pp. 269-282. 
- Rm; 1 Co ; 2 Co ; Ga; Ep; Ph; Col ; 1 Th ; 2 Th; He; 1 Tm ; 2 Tm; Tt; Phm: On trouvait cet ordre déjà dans la $39^{\mathrm{e}}$ Lettre festale d'Athanase, dans le canon 6o du synode de Laodicée, et dans le codex Vaticanus et le codex Sinaïticus notamment ${ }^{54}$. La présence de Hébreux entre 2 Thessaloniciens et 1 Timothée est devenue par la suite typique de la tradition bohaïrique ${ }^{55}$.

Dans les manuscrits arabes des lettres de Paul, Hébreux se trouve le plus souvent à la fin du corpus paulinien. Cela n'est pas étonnant vu qu'il s'agit de l'ordre devenu majoritaire dans les manuscrits grecs et adopté également dans les versions syriaques. Néanmoins, on trouve souvent Hébreux après 2 Thessaloniciens. Cette dernière composition reflète certainement l'influence de la tradition copte sur les versions arabes. On pourrait donc penser que les manuscrits d'origine copte ont Hébreux après 2 Thessaloniciens. Or plusieurs manuscrits d'origine copte présentent Hébreux en fin de corpus (notamment les manuscrits coptes-arabes Caire Patr. Copt. Orth. Bibl. 141, Londres BL Or. 1318, Vat. Copt. 12). De même, certains manuscrits dont l'origine n'est pas copte ont Hébreux après 2 Thessaloniciens. On notera par exemple le Sin. Gr. New Finds MG 2, un manuscrit grec-arabe du $9^{\mathrm{e}} \mathrm{s}$. Plus étonnant encore est la présence d'Hébreux après 2 Thessaloniciens

54 Frede, «Die Ordnung der Paulusbriefe und der Platz des Kolosserbriefs im Corpus Paulinum », art. cit., 1966, p. 293. En outre, il nous faut noter que Kerschensteiner défend l'existence d'un «altsyrischen Paulustext», contemporain à la Vetus Syra, pour lequel il avance l'ordre ci-dessus (Kerschensteiner Joseph, Der altsyrische Paulustext, vol. Subsidia 37, Louvain, Secrétariat du CorpusSCO, 1970 (CscO 315).) Ce ne serait pas la première fois que l'on trouverait des points de rapprochement entre la Vetus Syra et les traductions arabes: la présence d'éléments de type Vetus Syra dans une traduction arabe des évangiles constituait une part de l'argumentation de Baumstark en faveur de l'existence d'une traduction préislamique (BAumstark Anton, «Eine altarabische Evangelienübersetzung aus dem Christlich-Palästinensischen », Zeitschrift für Semitistik and verwandte Gebiete 8, 1932, pp. 201-209.) Cet argument sera critiqué par Vööbus, qui voit en l'influence de la Vetus Syra la preuve de sa large diffusion, des siècles après son « remplacement » par la Peshitta (« [Baumstark] was right in his conclusion as long as he followed his own line of investigation, but went astray when he relied upon the well-known axiom that the Old Syriac Gospels were 'literary curiosities' and had already disappeared under Bishop Rabbula», Vööвus Arthur, «The Arabic Versions», in : Early Versions of the New Testament: Manuscript Studies, Stockholm, Estonian Theological Society in Exile, 1954, p. 286.) Les informations sur les lettres de Paul selon la Vieille Syriaque, qui n'ont survécu dans aucun manuscrit, sont trop minimes pour pouvoir tirer des conclusions à leur propos.

55 Voir Horner George William, The Coptic Version of the New Testament in the Northern Dialect, otherwise called Memphitic and Bohairic, vol. 3, Oxford, Clarendon Press, 1905. 
dans le Venise Marciana Gr. 379, un codex trilingue grec-arabe-latin datant du $13^{\text {e }}$ s. $^{56}$ et provenant de Sicile.

Le manuscrit Berlin Staatsbibl. Or. Folio 115 est seul à avoir 1 Thessaloniciens suivi de Philémon puis d'Hébreux. Cet ordre, qui n'est pas listé par Frede, est peut-être dû à l'histoire compliquée du manuscrit, qui à la base composait un seul codex avec Berlin Staatsbibl. Or. Folio 116 et Copenhague Kong. Bibl. Or. $19^{57}$.

La classification selon les différentes Vorlagen dépasse le cadre de notre étude, comme nous l'avons précédemment expliqué (voir chapitre 1). Graf, qui avait déjà connaissance d'une partie des manuscrits composant notre répertoire (131 manuscrits sont cités par Graf), fournit cependant une classification sommaire dans sa Geschichte der christlichen arabischen Literatur ${ }^{58}$. Il propose les familles de Vorlagen suivantes:

- Grec $(1)^{59}$ : Il s'agit des traductions les plus anciennes, faites au monastère Sainte-Catherine ou Mar Saba. Graf réunit dans cette catégorie des manuscrits aux traductions indépendantes les unes des autres, mais qui ont en commun une Vorlage grecque. Graf considère que les lettres de Paul dans Vat. Ar. 13 sont de cette catégorie.

- Grec (2): Il s'agit d'une traduction se basant sur un texte grec et qui sera la base de l'édition du patriarche melkite Athanase IV Dabbās en 1706 à Alep ${ }^{60}$.

- Syriaque (1): Graf classe le manuscrit Saint-Pétersbourg Institute of Oriental Manuscripts D226/3 à part ; il s'agirait d'une traduction faite sur la Peshitta, avec des aspects «nestoriens».

- Syriaque (2): Il s'agit de la traduction utilisée par l'Église copte, au côté de la Vulgate alexandrine des évangiles; c'est cette traduction qui sera éditée par Thomas Erpenius en 1616. Nous ajoutons à cette catégorie les

56 Il est possible que le manuscrit soit plus récent $\left(12^{\mathrm{e}} \mathrm{s}\right.$ ) $)$; voir notre article de blog $:<\mathrm{https} / / /$ humarec.org/index.php/continuous-publications-blog/11-articles/21-about-marcianagr-z-11-379-and-its-relatives >, consulté le 20.07.2017.

57 Horner, The Coptic Version of the New Testament in the Northern Dialect, otherwise called Memphitic and Bohairic, op. cit., 1905, pp. XLI-XLIII.

58 GraF, Geschichte der christlichen arabischen Literatur, op. cit., 1947, p. 181.

59 Les numéros que nous donnons aux catégories ne correspondent pas forcément à ceux donnés par Graf, car Graf propose parfois deux catégories différentes sous une même catégorie.

6o Graf donne la date de 1607 mais il s'agit vraisemblablement d'une erreur typographique, GRAF, Geschichte der christlichen arabischen Literatur, op. cit., 1944, p. 172. 
manuscrits cairotes inconnus à Graf que Simaika définit comme «Vulgate égyptienne ${ }^{61}$, ainsi que quelques manuscrits inconnus à Graf mais dont le texte est similaire à l'édition d'Erpenius selon les catalogueurs.

- Syriaque (3): Cette dernière catégorie comprend les manuscrits provenant aussi du syriaque mais ayant des Vorlagen syriaques différentes des précédentes ou dont le texte n’a pas été étudié par Graf.

- Copte (1): Il s'agit d'une traduction faite à partir du copte et qui était en usage au côté de la traduction de la famille Vorlage syriaque (2); il n'est toutefois pas certain que sa Vorlage soit copte et la traduction pourrait aussi s'apparenter à celle de Vorlage syriaque (2).

- Copte (2): Graf classe ici les manuscrits dont la traduction d'origine copte n’a pas été déterminée plus en détail.

- Copte (3): Il s'agit ici d'une traduction présente dans le Vat. Ar. 28, une traduction faite par le savant al-Wajīh Yūḥannā al-Qalyūbī.

- Copte (4): Graf place dans cette catégorie encore quelques manuscrits qui seraient des «Mischtexte» faits sur le copte et le syriaque.

- Latin: Selon Graf, le seul témoin de cette catégorie est Vat. Lat. 12900, qui contient un double feuillet de Galates. Notre étude montre que Venise Marciana Gr. 379, Madrid BN 4971 et Madrid BN 3484 sont de la même famille ${ }^{62}$.

- «Unbestimmter Herkunft»: Graf donne à de nombreux manuscrits la catégorie d'« unbestimmter Herkunft», n'ayant pas eu la possibilité de les étudier. Bien qu'aucune information ne soit donnée quant à la Vorlage, nous avons gardé cette catégorie dans la liste, afin que le lecteur sache que le manuscrit est mentionné ainsi chez Graf.

- Syriaque (autre); Copte (autre); Mixte: Ces appellations concernant quelques manuscrits qui sont inconnus ou non classés par Graf, mais dont le catalogueur estime qu'ils ont une Vorlage syriaque, copte ou mixte.

Nous pouvons constater (figure 11) que la grande majorité des manuscrits entrent dans la catégorie Vorlage syriaque (2). Kashouh fait le même constat concernant les manuscrits des évangiles et la Vulgate alexandrine: «Almost half of the manuscripts examined in this study contain the text of family $k$ [celle de la Vulgate alexandrine] (99/210). Another forty-two codices of the same family are mentioned in $\S \S 6.5 .1,2$ below, and still another list of twenty-two

61 Simaika Pasha Marcus, Catalogue of the Coptic and Arabic Manuscripts in the Coptic Museum, the Patriarchate, the Principal Churches of Cairo and Alexandria and the Monasteries of Egypt, Le Caire, Goverment Press, 1942.

62 Voir notre article de blog: $<$ https://humarec.org/index.php/continuous-publications-blog/ 11-articles/25-important-comments-on-the-arabic-translation>, consulté le 20.07.2017. 
manuscripts from various libraries is found in $§ 6.5 \cdot 3 \cdot{ }^{63}$ La Vulgate alexandrine va largement s'imposer après le $13^{\mathrm{e}} \mathrm{s}$. : «By the end of the thirteenth century the Arabic Vulgate superseded all other Arabic translations. » ${ }^{64}$

Graf considère deux manuscrits datant du $11^{\mathrm{e}}$ et du $12^{\mathrm{e}} \mathrm{s}$. comme étant du groupe Vorlage syriaque $(2)^{65}$, car il suppose qu'un texte des lettres de Paul était déjà établi avant le $13^{\mathrm{e}} \mathrm{s}$. (voir point 3.4). Ceux-ci seraient à vérifier en priorité pour voir si nous n'avons pas également une Vulgate arabe des lettres de Paul, à l'image de la Vulgate alexandrine pour les évangiles, qui s'impose peu à peu à partir du $13^{\mathrm{e}} \mathrm{s}$.

Si les catégories proposées par Graf que nous reproduisons ici proposent un défrichement intéressant, il est certain que nous avons probablement affaire à des Vorlagen mixtes dans la plupart des cas. Nous montrons dans la partie suivante que c'est le cas pour le Vat. Ar. 13, qui se base à la fois sur le grec et le syriaque.

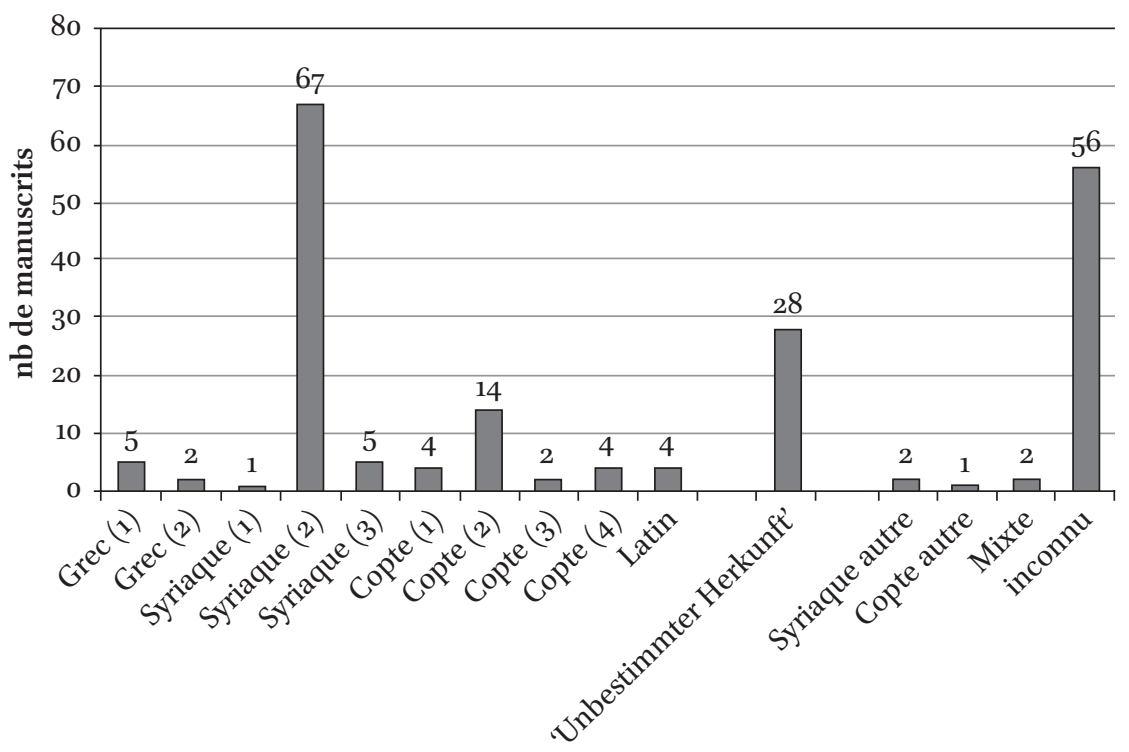

\section{Vorlagen selon Graf}

FIGURE 11 Nombre de manuscrits selon les Vorlagen de Graf

63 Kashou h, The Arabic Versions of the Gospels, The Manuscripts and their Families, op. cit., 2012, p. 207.

64 Ibid., p. 206.

65 Leiden Universiteitsbibliotheek Acad. 2 et Milan Biblioteca Ambrosiana B 20 inf. A. 


\section{$6 \quad$ Manuscrits karshounis et manuscrits bilingues}

Nous avons déjà soulevé plus haut la question des manuscrits arabes écrits en caractères syriaques, que nous avons choisi de prendre en compte dans notre répertoire (voir chapitre 4, point 1). Nous avons relevé 12 manuscrits écrits en karshouni ; parmi eux se trouvent deux manuscrits bilingues, Florence BML Or. 2 et Vat. Borg. Sir. 47, présentant une version syriaque et une version arabe en karshouni. Le plus ancien manuscrits écrit en karshouni est Paris BNF Syriaque 55, datant de 1202.

Les manuscrits présentant un texte copte et un texte arabe (sur deux colonnes ou sur deux pages) sont assez fréquents et correspondent à une manière de faire qui est attestée jusqu'au $19^{\mathrm{e}} \mathrm{s}$. Le manuscrit copte-arabe daté le plus ancien est le Caire Mus. Copt. Bibl. 94, daté de 1249.

Le seul manuscrit bilingue grec-arabe est un manuscrit du monastère Sainte-Catherine, Sin. Gr. New Finds MG 2 ; ce manuscrit est un palimpseste et date du $9^{\text {e }}$ s. $^{66}$

Un manuscrit d'un intérêt particulier est également le Venise Marciana Gr. 379 , manuscrit du $12^{\mathrm{e}}$ s. ou du $13^{\mathrm{e}}$ s. venant de Sicile, qui est l'unique

\begin{tabular}{lr} 
Langue/écriture & \\
\hline arabe & 154 \\
copte-arabe & 22 \\
karshouni & 10 \\
syriaque-karshouni & 2 \\
syriaque-arabe & 2 \\
latin-arabe & 2 \\
arabe-judéoarabe & 1 \\
arabe-latin & 1 \\
éthiopien-syriaque-copte-arabe-arménien & 1 \\
grec-arabe & 1 \\
grec-latin-arabe & 1 \\
\hline
\end{tabular}

66 Document inédit de Père Justin, « Exploring a Ninth Century Sinai Palimpsest ». Merci à Keith Small pour le contact. 
manuscrit trilingue grec-latin-arabe du Nouveau Testament dont nous avons connaissance jusqu'à présent ${ }^{67}$.

Le manuscrit Milan Bibl. Ambrosiana B 20 inf. A, qui contient les lettres de Paul, les lettres catholiques et les Actes des Apôtres en éthiopien, syriaque, copte, arabe, arménien est un objet qui demanderait également une étude particulière. La colonne arabe aurait été copiée au Monastère de la Sainte Vierge au Caire (voir point 8 Copistes et scriptoria), mais peut-être que la notice a été copiée avec le texte biblique.

Enfin, le Hambourg s в в Orient. 19 contient une traduction arabe de la lettre à Philémon écrite en caractères arabes et en caractères hébreux ; il s'agit d'une production européenne relevant de l'exercice, ce qui explique cette combinaison inattendue.

\section{$7 \quad$ Matériel}

Tous les manuscrits du $9^{\mathrm{e}}$ s. ont comme support le parchemin; seuls deux manuscrits plus tardifs $\left(12^{\mathrm{e}}\right.$ ou $13^{\mathrm{e}} \mathrm{s}$.) sont en parchemin (Paris BNF Syriaque 55, Venise Marciana Gr. 379). Trois parchemins du Sinaï (Sin. Ar. New Finds Parch. 40, Sin. Ar. New Finds Parch. 52, Sin. Ar. New Finds Parch. 6o) ne sont ni datés ni évalués quant à la date par le catalogueur ${ }^{68}$; la prédominance du parchemin parmi les manuscrits du $9^{\mathrm{e}} \mathrm{s}$. pourrait être un argument en faveur de l'antiquité de ces manuscrits du Sinaï.

À l'exception du Paris BNF Syriaque 55 et du Venise Marciana Gr. 379 mentionnés ci-dessus, on ne trouve plus de manuscrits en parchemin à partir du $10^{\mathrm{e}} \mathrm{s}$; ; cela correspond au tournant en faveur du papier en Orient qui a lieu à partir du $9^{\mathrm{e}} \mathrm{s}^{69}$

\section{$8 \quad$ Copistes et scriptoria}

Un nombre important de manuscrits porte le nom de leur(s) copiste(s) (65 manuscrits sur 197). Nous les reproduisons dans notre répertoire des

67 Le manuscrit est numéroté 460 selon le classement Gregory-Aland, <http://ntvmr.unimuenster.de/liste?docID=30460 >, consulté le 13.03.2016.

68 Voir notre remarque plus haut, au point 3.3.

69 Zerdoun Monique, «Les matériaux: support et encre», in: GÉ Hin Paul (éd.), Lire le manuscrit médiéval, $2^{\mathrm{e}}$ édition, Paris, Armand Colin, 2013, pp. 15-22. 
manuscrits, ces informations pouvant être importantes. En 1982 déjà, Samir Khalil Samir plaide pour un répertoire des copistes de la littérature chrétienne $\operatorname{arabe}^{70}$. Ces informations permettront par exemple de dater certains manuscrits, et de déterminer leur lieu d'origine.

Dans notre cas, les manuscrits Caire Patr. Copt. Orth. Bibl. 150 et Caire Patr. Copt. Orth. Bibl. 169, copiés en 1720 et 1719, semblent avoir le même copiste, l'archiprêtre Ġabriyāl, ministre à l'Église de la Sainte Vierge à Ḥārat Zuwayla au Caire. De même, les manuscrits Caire Patr. Copt. Orth. Bibl. 142 et Caire Patr. Copt. Orth. Bibl. 158, copiés en 1790 et 1778 , semblent avoir le même copiste, l'archiprêtre Șalīb, ministre au Saint-Sépulcre à Jérusalem. Dans ces cas précis, les manuscrits sont déjà datés et localisés grâce à leurs colophons ${ }^{71}$. On notera aussi le cas de manuscrits d'origine européenne copiés par des orientalistes dont on connaît l'identité. Les manuscrits Groningen Universiteitsbibliotheek 460 et Leiden Universiteitsbibliotheek Or. 2083 ont été copiés de la main de Jakob Christmann, orientaliste allemand né en 1554. Enfin, trois manuscrits Cambridge UL Dd. 15.4, Oxford Bodl. Arch. Seld. B. 50 sup. et Oxford Bodl. Laud. Or. 24 sont de la main de William Bedwell (1563-1632), un orientaliste du comté d'Essex. Dans ce cas précis, nous avons pu ajouter aux notices l'indication du 16-1 $7^{\mathrm{e}} \mathrm{s}$., qui n'était pas présente dans les catalogues.

Les données sont encore trop peu nombreuses pour pouvoir établir des résultats déterminants, mais croisées avec d'autres, elles pourront être utiles. Il en va de même pour les noms des lieux mentionnés, qui permettront de définir les lieux de copie et l'existence de scriptoria. Dans notre cas, nous pouvons par exemple remarquer l'importance du monastère de la Sainte Vierge à Ḥārat Zuwayla au Caire, qui revient une fois au $13^{\mathrm{e}}$ s. et quatre fois entre le $17^{\mathrm{e}}$ et le $18^{\mathrm{e}} \mathrm{s}$.

70 SAm r Samir Khalil, «La tradition arabe chrétienne. État de la question, problèmes et besoins », in : Actes du premier congrès international d'études arabes chrétiennes (Goslar, septembre 1980), Rome, Pontificio Instituto Orientale, 1982 (Orientalia Christiana Analecta 210), pp. 47-50.

71 Les manuscrits Caire Patr. Copt. Orth. Bibl. 162 (1785) et Caire Patr. Copt. Orth. Bibl. 166 (1805) ont comme copiste un certain 'Abd as-Sayīd ; il est possible qu'il s'agisse du même copiste mais les informations données sur 'Abd as-Sayīd sont trop limitées pour affirmer que ces manuscrits, que 20 ans séparent, ont été copiés de la même main. 
En premier lieu, ces observations permettent d'avoir une première vue d'ensemble sur la situation générale des manuscrits arabes des lettres de Paul ; nous espérons qu'elles permettront au futur chercheur de s'orienter dans ce champ méconnu de la recherche. Ensuite, ces observations nous portent à relativiser l'idée reçue présentée dans l'introduction, qui considère les traductions des évangiles comme plus anciennes et plus populaires que celles des lettres de Paul. Ce dernier aspect ayant eu pour conséquence un intérêt moindre pour le corpus paulinien, nous espérons que cette contribution à la recherche puisse motiver les chercheurs à s'intéresser davantage aux manuscrits arabes des lettres de Paul. Enfin, nous avons aussi mis évidence certains points qu'il sera intéressant d'approfondir, comme le lien entre les recensions arabes des évangiles du 1зe s. et le grand nombre de manuscrits arabes des lettres de Paul à cette même période, ou encore plusieurs manuscrits aux caractéristiques intéressantes. On mentionnera par exemple les manuscrits Sin. Ar. New Finds Parch. 40, Sin. Ar. New Finds Parch. 52, Sin. Ar. New Finds Parch. 6o, copiés sur parchemin, et qui attendent d'être datés, le manuscrit Berlin Staatsbibl. Or. Folio 115, seul à présenter 1 Thessaloniciens suivi de Philémon puis d'Hébreux, ou encore le Venise Marciana Gr. 379, seul manuscrit du Nouveau Testament trilingue grec-latin-arabe ${ }^{72}$.

Nous tenons encore à noter que les données récoltées ici gagneraient encore en intérêt à être croisées avec d'autres données, comme celles concernant les manuscrits arabes des autres livres bibliques, ou les manuscrits de la littérature arabe chrétienne en général. Il serait intéressant de pouvoir pour cela commencer à publier ces données dans des bases de données interopérables accessibles en ligne ${ }^{73}$. C'est un aspect qui dépasse le cadre de notre présent travail, mais il nous semble important de souligner l'importance de ce genre d'initiative et nous espérons pouvoir développer ces aspects par la suite.

72 Voir note 108 , chapitre 2.

73 Voir l'initiative de l'Université de Balamand, menée par Elie Dannaoui : Dannaoui Elie, «Digital Arabic Gospels Corpus », in: Clivaz Claire, Gregory Andrew et Hamidovic David (éds), Digital Humanities in Biblical, Early Jewish and Early Christian Studies, Leiden, Brill, 2013 (Scholarly Communication 2), pp. 61-70. Voir aussi notre note 62 au chapitre 3 . 
TROISIÈME PARTIE

La première lettre aux Corinthiens dans le Vat. Ar. 13 
Sara Schulthess - 978-90-04-37816-2 Downloaded from Brill.come4/26/2023 10:02:45AM via free access 


\section{Introduction au Vat. Ar. 13}

\section{Introduction}

La troisième partie du travail (La première lettre aux Corinthiens dans le Vat. Ar. 13) est consacrée au Vat. Ar. 13 et à la première lettre aux Corinthiens de ce manuscrit. Nous avons présenté dans les remarques méthodologiques introductives (chapitre 1, point 2) notre positionnement en faveur de l'étude d'un manuscrit unique, et non pas pour une édition critique se basant sur une approche généalogique du texte, celle de l'arbre, qui nous semblent problématique. L'approche généalogique, en plus des problèmes épistémologiques que celle-ci pose en sous-entendant un texte original, est d'autant plus difficile à justifier dans le cas de textes dont l'histoire de transmission est particulièrement compliquée. Dans le cas des versions arabes du Nouveau Testament, on observe des Vorlagen différentes et multiples, des « contaminations » entre familles, l'influence de pratiques liturgiques variées, etc. Dans son analyse des manuscrits arabes des évangiles, Hikmat Kashouh décrit 24 familles, avec des sous-groupes ${ }^{1}$. Cette situation remet en question, à notre avis, la finalité d'une édition critique du Nouveau Testament arabe. Dans le chapitre concernant l'édition dans le «Handbook» de l'association COMSt (Comparative Oriental Manuscript Studies), Caroline Macé dit à propos de l'édition diplomatique, ou édition documentaire : «An essential distinction needs to be made between editing a text or a work and editing a document [...]. In some cases, the unique character of a document preserving a text may prompt scholars to edit this document for its own sake. ${ }^{2} \mathrm{Si}$ on comprend bien l'intention de l'auteur, qui donne ensuite l'exemple d'un témoin unique d'un texte, on peut se demander si tout document n'a pas son « caractère unique » justifiant une édition propre. Cette idée se popularise notamment avec l'avènement du digital (voir aussi chapitre 1, point 2) et avec elle des éditions de manuscrits per $e^{3}$. De plus, le Vat.

1 Kashoun Hikmat, The Arabic Versions of the Gospels, The Manuscripts and their Families, Berlin, Boston, De Gruyter, 2012 (Arbeiten zur neutestamentlichen Textforschung 42).

2 MACÉ Caroline, BAusi Alessandro, Witakowski Witold et al., « Textual Criticism and Text Editing », in : Comparative Oriental Manuscript Studies : An Introduction, Hambourg, Tredition, 2015, p. 342. En ligne: <https://www.aai.uni-hamburg.de/en/comst/publications/hand book.html>, consulté le 31.07.2018.

3 On peut donner en exemple l'édition du Codex Sinaïticus, <http://www.codexsinaiticus .org/>, des projets tel que Homer Multitext, <http://www.homermultitext.org >, qui donne

(C) SARA SCHULTHESS, $2019 \mid$ DOI:10.1163/9789004378162_007

This is an open access chapter distributed under the terms of the prevailing CC-BY-NC License at the time of publication. 
Ar. 13 a certainement un caractère unique. Le manuscrit passionne la recherche depuis des années, notamment à cause de son ancienneté. Nous discutons cette recherche et ses conclusions dans ce chapitre 6. Par ailleurs, il pourrait s'agir du seul témoin de sa famille (voir chapitre 8, point 3.1 Comparaison avec Sin. Ar. 151 et $\operatorname{Sin}$. Ar. 155).

\section{$2 \quad$ État de la recherche sur le Vat. Ar. 13}

La première mention du Vat. Ar. 13 dans un volume imprimé est celle faite par Joseph Simon Assemani dans la Bibliotheca Orientalis Clementino-Vaticana en 1719, le Vat. Ar. 13 faisant partie des manuscrits rapportés d'Orient par Assemani. Nous reproduisons ici cette notice :

LXXI. Evangelia Matthaei, Marci, \& Lucae. Epistolae S. Pauli. In fol. membr. $178^{4}$.

À la suite de l'armistice de Bologne (1796) et du traité de Tolentino (1797), plusieurs manuscrit romains furent réquisitionnés par la France. On trouve le Vat. Ar. 13 mentionné dans un registre de ces objets conservés à la Bibliothèque nationale de Paris 5 , qui furent rendus au Vatican en 1815 (voir aussi point 2 ci-dessous) ${ }^{6}$.

En 1823, dans ses pages «über die arabischen Handschriften des N.T. zu Rom », J. M. A. Scholz propose une description de plus de dix pages du Vat.

accès aux manuscrits d'Homère et à leurs textes, ou encore le projet d'édition en ligne du Venise Marciana Gr. 379 sur lequel nous travaillons actuellement, <https://humarec .org>. Liens consultés le 27.07.2017.

4 Assemani Joseph Simon, Bibliotheca Orientalis Clementino-Vaticana :In Qua Manuscriptos Codices Syriacos, Arabicos, Persicos, Turcicos, Hebraicos, Samaritanos, Armenicos, Aethiopicos, Graecos, Aegyptiacos, Ibericos, \& Malabaricos, Jussu et Munificentia Clementis XI. Pontificis Maximi Ex Oriente conquisitos, comparatos, avectos, \& Bibliothecae Vaticanae addictos, vol. 1, Rome, Typis Sacrae Congregationis de Propaganda Fide, 1719, p. 681. Pourquoi Assemani ainsi que Mai par la suite mentionnent-ils 178 et non 179 folios ? Le folio 179, qui contient sur son verso l'épigramme que nous discutons au point 3.6.2, contient bien le desinit d'Hébreux. Scholz rétablit cela en décrivant $179 \mathrm{r}$ et $179 \mathrm{v}$.

5 Recensio manuscriptorum codicum qui ex universa Bibliotheca Vaticana (...) procuratoribus Gallorum iure belli, seu pactarum induciarum ergo, et initce pacis traditi fuere (...), Leipzig, 1803 , p. 17.

6 Vian Paolo, «"Per le cose della Patria Nostra". Lettere inedite di Luigi Angeloni e Marino Marini sul recupero dei manoscritti Vaticani a Parigi (1816-1819)», in : Miscellanea Bibliothecae Apostolicae Vaticanae, vol. XVIII, Rome, Biblioteca Apostolica Vaticana, 2011 (Studi e Testi 469), pp. 693-799. 
Ar. $13^{7}$ et il transcrit plusieurs passages du manuscrit (Mt 13,1-20 ; Mc 5,20-28 ; Lc 4,1-15; Gal 2,1-3 ; 1 Tim 3,14-16 ; Phm). Selon Scholz, il s'agit d'une traduction faite sur le grec, qui diffèrerait de la traduction éditée par Thomas Erpenius en $1616^{8}$; les notes de lectures, les chapitres et autres annotations en grec (voir points 3.7 et 3.8) correspondraient à ce que l'on trouve dans la plupart des manuscrits grecs. Scholz transcrit également le nom que se donne un copiste à la fin des lettres de Paul, Justas ben Leun ben Abilwalidi (179r), ainsi que l'épigramme que l'on trouve sur le dernier folio (179v); il explique que la note est signée, de manière cryptographique, par un certain diacre Kerikos, mais il ne s'étend pas davantage sur le contenu de la note (voir 3.6.2 Épigramme grec). Scholz est convaincu de l'antiquité du manuscrit, qu'il situe au $9^{\mathrm{e}} \mathrm{s}$. Il mentionne à l'appui de cette datation l'écriture arabe qu'il décrit comme de style kūfı et l'écriture grecque de type oncial. Il soutient aussi l'antiquité du texte; pour lui, la version «folgt also dem konstantinopolischen Texte, und zwar nicht dem spätern, sondern demjenigen, welchen wir in einigen alten Handschriften dieser Familie wiederfinden. ${ }^{9}$ Donnant quelques exemples de variantes, Scholz affirme que le texte traduit un témoin grec d'avant le $8^{\mathrm{e}} \mathrm{s}$.

Dans le catalogue des manuscrits de la Bibliothèque apostolique vaticane établit en 1831, Angelo Mai considère le manuscrit comme un « codex antiquissimus », qu'il pense lui aussi être traduit du grec. Sa notice traduit les incipit et les desinit arabes en latin et donne leur foliotation. Comme Assemani, Mai donne le folio 178 comme le folio final ${ }^{10}$.

On notera que dans son Novum Testamentum Graece de 1849, Constantin Tischendorf utilise Vat. Ar. 13 au côté de l'édition d'Erpenius et des polyglottes, tout en lui réservant un usage limité: «arabica versio e graeco Emesae in Syria facta, quam in vaticano codice reperit Scholzius et ad evangelia passim contulit. ${ }^{11}$ Tischendorf se base certainement sur les passages transcrits de Scholz, et non sur le manuscrit lui-même.

Scholz J.M.A., «Ueber die arabischen Handschriften des N.T. zu Rom », in : Biblischkritische Reise in Frankreich, der Schweiz, Italien, Palästina und im Archipel, in den Jahren 1818, 1819, 1820, 1821, nebst einer Geschichte des Textes N.T., Leipzig, F. Fleischer, 1823, pp. 117-135. À propos de la version d'Erpenius, voir chapitre 2, point 1 Les premières éditions et chapitre 5, point 6 Vorlagen selon Graf.

9 Scholz, «Ueber die arabischen Handschriften des N.T. zu Rom », art. cit., 1823, p. 127.

10 MaI Angelo, Scriptorum veterum nova collectio e Vaticanis codicibus edita, vol. 4, Rome, Typis Vaticanis, 1831, pp. 11-13.

11 Tischendorf Constantin, Novum Testamentum Graece. Ad antiquos testes recensuit, apparatum criticum multis modis auctum et correctum apposuit, commentationem isagogicam praemisit ..., Leipzig, Winter, 1849, p. LXXVII. Voir la note de Ronny Vollandt dans Vollandt Ronny, «Some Historiographical Remarks on Medieval and EarlyModern Scholarship of Biblical Version in Arabic : A Status Quo », Intellectual History of 
Samuel Davidson, dans sa critique à propos de l'utilisation de versions arabes en critique textuelle du Nouveau Testament, mentionne le Vat. Ar. 13. Il dit à propos de celui-ci : «It is no use in criticism, being neither ancient nor valuable $»^{12}$. Nous discutons les propos de Davidson et de ses contemporains aux chapitre 2, point 2 et chapitre 3, point 1 .

En 1888, Ignazio Guidi, qui considère la description de Mai incomplète, consacre une longue note de bas de page au Vat. Ar. $13^{13}$. Guidi y fait la distinction pour les évangiles entre une partie ancienne, datant du $8^{\mathrm{e}} \mathrm{s}$., et une partie plus récente, réécrite vers le $10^{\mathrm{e}} \mathrm{s}$. (ff. 1-15 et 47-55) $)^{14}$. La partie ancienne aurait une Vorlage grecque, ce que Guidi étaye en transcrivant Mt 10,28-41 et Mt 26,113. Pour Guidi, il s'agit davantage d'une paraphrase que d'une traduction ${ }^{15}$. La partie plus récente aurait quant à elle une Vorlage syriaque (Peshitta), transcription de Mt 1,18-2,12 à l'appui. Il transcrit aussi Mt 28,1-8 en note ${ }^{16}$.

En 1895, Henri Hyvernat mentionne le Vat. Ar. 13 dans son article sur les versions arabes de la Bible ${ }^{17}$. Pour Hyvernat, le manuscrit (du moins la partie concernant les évangiles), traduit du grec, serait à rapprocher du codex Tischendorf XxxI (Leipzig Univ. Or. 1059A) et du codex Borg. K. II 31 (Vat. Ar. Borg. 95). Tischendorf ayant rapporté le codex Tischendorf xxxI de Mar Saba, Hyvernat soutient que les deux autres manuscrits proviennent également de Mar Saba. Alors que le rapprochement de ces trois manuscrits n’a pas été retenu par la suite $^{18}$, l'idée que Vat. Ar. 13 vient de Mar Saba va être reprise régulièrement par la recherche (voir 3.2 Le lieu d'origine du manuscrit).

Francis C. Burkitt, dans son article de 1898, ne suit pas les avis précédents ${ }^{19}$. Pour lui, les évangiles dans Vat. Ar. 13 sont traduits du syriaque (Peshitta), et

the Islamicate World 1, 2013, p. 35, n. 36. Tischendorf continue à intégrer le Vat. Ar. 13 parmi les versions arabes dans les éditions suivantes, voir la note 9 au chapitre 2.

12 Davidson Samuel, A Treatise on Biblical Criticism: Exhibiting a Systematic View of That Science, Edimburgh, A\&C Black, 1852, p. 229.

13 Guid Ignazio, Le Traduzioni degli Evangelii in arabo e in etiopico, Rome, Tipografia della r. accademia dei Lincei, 1888 (Atti della reale accademia dei Lince 4), pp. 8-9.

14 Il s'agit en fait des folios 1-14 et 47-54.

15 « Come sorgesi è questa una parafrasi piuttosto che una traduzione [...] », GUIDI, Le Traduzioni degli Evangelii in arabo e in etiopico, op. cit., 1888, p. 9.

16 Ibid., pp. 13-14.

17 Hyvernat Henri, «Arabes (versions) des écritures », in: Dictionnaire de la Bible, vol. 1, Leipzig, Letouzey et Ané, 1895, p. 852.

18 Kashouh classe bien Leipzig Univ. Or. 1059A et Vat. Ar. Borg. 95 dans la même famille (famille $a$ ), mais Vat. Ar. 13 fait partie de la famille $h$. KAsHOUn, The Arabic Versions of the Gospels, The Manuscripts and their Families, op. cit., 2012, pp. 86-96 et 142-170.

19 BurkitT Francis Crawford, «Arabic Versions », in: Dictionary of the Bible: Dealing with Its Language, Literature, and Contents Including the Biblical Theology, vol. 1, Edinburgh, T\&T Clark, 1898, pp. 136-137. 
non du grec. Il mentionne en note les différences de main dans Mt, supposant une unité de traduction dans le texte : «Some of the missing portions of ar. vat in Mt have been supplied in a hand of the 1oth cent. From the style and vocabulary they seem to have been copied from the original MS before the leaves were lost. ${ }^{20}$ Burkitt souligne l'antiquité du manuscrit, « generally assigned to the 8 th cent. ${ }^{21}$, et du texte des évangiles de Vat. Ar. 13 : «The oldest representative of this class, perhaps the oldest monument of Arab Christianity [...]. No other Arabic versions can claim such a high antiquity. ${ }^{22}$ Les épîtres pauliniennes sont selon lui traduites du grec; il propose la même datation que pour la section syriaque $\left(8^{\mathrm{e}_{-}} 9^{\mathrm{e}} \mathrm{s} \text {. }\right)^{23}$. Burkitt soutient que le manuscrit vient de Mar Saba, reprenant certainement l'hypothèse d'Hyvernat.

Par la suite, Curt Peters (1939) et Arthur Vööbus (1954) se prononcent également contre l'avis de Guidi et soutiennent l'origine syriaque du Vat. Ar. 13. En s'appuyant sur Mt 10,28-41, Peters soutient l'origine syriaque de la partie ancienne des évangiles ainsi que la présence de leçons harmonisantes, voyant en Vat. Ar. 13 un témoin potentiellement intéressant pour l'étude du Diatessaron ${ }^{24}$. Pour Vööbus, Vat. Ar. 13 présente une version traduite du syriaque avec des leçons de la Vetus Syra, comme Sin. Arab. 82 et Berl. Or. Quart. 2102, chaque manuscrit présentant toutefois une version différente. Pour lui, « that these manuscripts were translated from Syriac becomes obvious when one examines the vocabulary and renderings. [...] By no means could their base have been the Peshitta, but only an Old Syriac type. » ${ }^{25}$ Pour appuyer son propos, Vööbus transcrit le verset Mt 1,24. Plus loin, il précise encore que Vat. Ar. 13 ne fait partie d'aucune famille et réaffirme son origine syriaque: «Ms. Vat. arab. 13 certainly goes back to a Syriac base in its older, as well as younger, part. » ${ }^{26} \mathrm{Ne} \mathrm{le}$ précisant pas, certainement inclut-il les lettres de Paul dans l'une ou l'autre des parties.

Georg Graf revient ensuite à l'avis de Guidi, classant la partie plus ancienne des évangiles dans la catégorie grecque et la partie plus récente (c'est-à-dire ff. 1-14 et 47-55) dans la catégorie syriaque. Quant à la partie paulinienne, Graf la

\footnotetext{
$20 \quad$ Ibid., p. 136.

21 Ibid.

22 Ibid.

23 Ibid., p. 137.

24 Peters Curt, Das Diatessaron Tatians : seine Überlieferung und sein Nachwirken im Morgen- und Abendland sowie der heutige Stand seiner Erforschung, Rome, Pont. Institutum orientalium studiorum, 1939 (Orientalia christiana analecta 123), pp. 48-62.

25 Vööвus Arthur, «The Arabic Versions », in : Early Versions of the New Testament: Manuscript Studies, Stockholm, Estonian Theological Society in Exile, 1954, p. 281.

26 Ibid., p. 290.
} 
considère d'origine grecque, louant la qualité de la traduction : «in sprachlicher Beziehung wertvollter [als Sin. Ar. 155] ${ }^{27}$. Graf considère que le Vat. Ar. 13 pourrait être le plus ancien manuscrit contenant une collection de livres bibliques en arabe : «Aelteste Sammelhandschrift mag einmal cod. Vat. ar. 13 gewesen sein, der in seinem unsprünglichen Bestande neben den Pss auch das N.T. ohne Apk umfasste. $»^{28}$

Le Vat. Ar. 13 fait partie des manuscrits utilisés par Joshua Blau pour sa grammaire; celui-ci n'intègre toutefois que les passages du manuscrit transcrits dans les différentes études susmentionnées. Résumant les avis de ces prédécesseurs, Blau signale que les propos de Graf concernant l'origine de la partie ancienne et de celle plus récente des évangiles « not only contradict Guidi but are even self-contradictory ${ }^{29}$. Pourquoi Blau trouve-t-il que Graf se contredit? Est-ce parce que Graf, lorsqu'il mentionne les ajouts plus récents traduits, selon lui, du syriaque, donne la date du ${ }_{11}{ }^{\mathrm{e}} \mathrm{s}$. mais aussi du $9^{\mathrm{e}} \mathrm{s}$., c'est-à-dire du même siècle que la partie plus ancienne? Les propos de Graf nous semblent toutefois parfaitement clairs : selon lui, a) la partie ancienne des évangiles $\left(9^{\mathrm{e}}\right.$ s. ou avant) est traduite du grec; b) la partie plus récente des évangiles (ajoutée au $9^{\mathrm{e}}$ et $11^{\mathrm{e}} \mathrm{s}$. par deux mains différentes) est traduite du syriaque ; c) les lettres de Paul (pas d'appréciation temporelle) sont traduites du grec. La critique de Blau à l'égard de Graf aura toutefois du succès, étant reprise par exemple par Hikmat Kashouh ${ }^{30}$ et Juan Pedro Monferrer-Sala ${ }^{31}$.

Ce dernier s'intéresse une première fois au Vat. Ar. 13, au côté du Sin. Ar. 72, dans un article de 2000, où il analyse le verset Mt 5,41b. Pour MonferrerSala, le verset Mt 5,41b est clairement traduit du syriaque et serait de nature «pseudo-diatessaronique ${ }^{32}$ : la traduction est harmonisante mais ne se base pas sur le Diatessaron. La raison pour laquelle le verset Mt 5,41b, dont Monferrer-Sala vient de montrer l'origine syriaque et non grecque, est ensuite associé à la « sección más moderna » n'est pas claire, étant donné que Mt 5,41b

27 GRAF Georg, Geschichte der christlichen arabischen Literatur, vol. 1, Rome, Biblioteca Apostolica Vaticana, 1944 (Studi e Testi 118), p. 171. Graf a eu accès au manuscrit lors de son travail de catalogage à la Bibliothèque Vaticane, voir notre note 63 ci-dessous.

28 Ibid., p. 138.

29 Blau Joshua, A Grammar of Christian Arabic, Based Mainly on South-Palestinian Texts from the First Millennium, vol. Subsidia 27, Louvain, Secrétariat du CorpusSCO, 1966 (CSCO 267), p. 33 .

3o Kashoun, The Arabic Versions of the Gospels, The Manuscripts and their Families, op. cit., 2012, p. 145 .

31 Monferrer-Sala Juan Pedro, « Dos antiguas versiones neotestamentarias árabes surpalestinenses : Sin. Ar. 72 , Vat. Ar. 13 y sus posibles Vorlagen respectivas greco-alejandrina y siriaca de la Pešițtā », La Ciudad de Dios 213 (2), 2000, p. 382.

Ibid., p. 386. 
est considéré depuis Guidi comme faisant partie de la partie ancienne du manuscrit ${ }^{33}$. On regrettera également que Monferrer-Sala appuie une partie de son argumentation sur le fait que le Vat. Ar. 13 soit originaire de Mar Saba, élément qui est à la base une simple hypothèse de Hyvernat. Les remarques qu'en tire Monferrer-Sala sont toutefois pertinentes, lorsqu'il souligne par exemple le milieu de production trilingue du manuscrit ${ }^{34}$.

En 2001, Monferrer-Sala publie un nouvel article consacré au Vat. Ar. 13. Il souligne l'aspect hybride du manuscrit, décrivant ses caractéristiques paléographiques et codicologiques et soulevant à nouveau la question des langues d'origine. Il suppose qu'un texte d'origine syriaque a été introduit dans le texte originel traduit à partir du grec lors de la restauration du manuscrit (renversant ainsi l'hypothèse de Guidi). Une telle hybridité ne pourrait être que le résultat d'une restauration qui s'est faite hors du milieu d'origine du manuscrit (« el producto manuscrito que nos hallegado muy probablemete sea labor ajena a la de los monjes de la laura de Mār Sāba » ${ }^{35}$ ), certainement faite en Europe («Una vez en Roma, si no ya antes, al proceder a la tarea de inventariado, ordenación y catalogación de todo el material, pudieron acabar fusionándose muestras pertenecientes a dos manuscritos distintos. $»^{36}$ ) S'il est possible qu'une partie de la restauration se soit faite après que le manuscrit ait quitté sa communauté (voir nos conclusions de la description du manuscrit au point 3.9), on notera que le manuscrit était déjà «hybride » bien avant (Monferrer parle de « engendro textual ${ }^{37}$ ), les lettres de Paul étant textuellement différentes des évangiles. De plus, le manuscrit avait déjà son nombre de folios actuels lorsqu'il est arrivé en Europe (voir 3.2 Le lieu d'origine du manuscrit).

Monferrer-Sala porte ensuite son attention sur les versets Mt 5,14-16, contestant la conclusion de Guidi quant à l'aspect périphrastique de la traduction :

Veíamos al principio que Guidi hablaba de «la índole parafrástica de la versión » [...] y podemos comprobar después del análisis efectuado que dicha paráfrasis [...] no es tal. Las distintas calas que he podido realizar sobre esta peculiar versión árabe me confirman en la hipótesis de que

\footnotetext{
33 Ibid., pp. 386-387.

34 Ibid., p. 381.

35 Monferrer-Sala Juan Pedro, «Una traducción árabe con "pseudoescolio exegético anónimo". Una nota de crítica textual interna a propósito del MS. Sabaítico Vaticano Arabo 13 », Boletín de la Asociación Española de Orientalistas 37, 2001, p. 76.

36 Ibid.

37 Ibid., p. 75 .
} 
estamos ante un texto de especial y rico valor desde el punto de vista tanto textual como de tradición escrituraria ${ }^{38}$.

Une étude poussée de la partie du Vat. Ar. 13 contenant les évangiles se trouve dans l'ouvrage de Hikmat Kashouh ${ }^{39}$. Le manuscrit, qui est serait le seul représentant de la famille $h$ et est désigné par $h^{1}$, joue un grand rôle dans l'argumentation de Kashouh en faveur de l'existence préislamique d'une traduction des évangiles ${ }^{40}$. Kashouh distingue cinq scribes ayant participé à la composition de celui-ci (que nous discutons en détail au point 3 Description du manuscrit Vat.Ar. 13). Comme le veut le cadre de son étude, Kashouh se concentre sur les évangiles. À propos des lettres de Paul, Kashouh souligne que la partie paulinienne est un cas différent de celui des évangiles; la traduction des lettres de Paul n'aurait pas les mêmes caractéristiques et aurait été faite indépendamment. De plus, elles auraient été traduites du grec et non du syriaque et ne présenteraient pas les traits archaïques trouvés dans celle des évangiles ${ }^{41}$. Concernant les évangiles, Kashouh concentre son étude sur la partie la partie la plus ancienne: elle est seule représentante de la famille $h$ et aurait la Peshitta comme Vorlage. $h^{1}$ (qui désigne donc la partie ancienne des évangiles) aurait été copié aux environs de 800 mais présenterait le texte le plus ancien parmi les versions arabes. Pour prouver l'antiquité du texte, Kashouh se base tout d'abord sur des arguments paléographiques : le scribe copierait une graphie très archaïque, qui présente des caractéristiques particulières, comme par exemple la forme des alifs (une conclusion que nous discutons en 3.5 Quelques aspects paléographiques). Une analyse linguistique vient appuyer l'antiquité du texte $: h^{1}$ ne présenterait pas, malgré l'origine syro-palestinienne du manuscrit $^{42}$, les caractéristiques du Early Middle Arabic décrites par Blau et de manière générale, ce témoin ne se rapprocherait d'aucun autre manuscrit:

[...] the linguistic characteristics of $h^{1}$ are crucial because they are unique and not shared with other manuscripts studied in this study, and they [...]

\footnotetext{
$38 \quad$ Ibid., pp. 81-82.

39 Kashoun, The Arabic Versions of the Gospels, The Manuscripts and their Families, op. cit., 2012, pp. 142-170.

$40 \quad$ Ibid., pp. 142-171. Voir aussi chapitre 3, point 4 L'existence de traductions préislamiques, un point de vue minoritaire.

41 Ibid., p. 153. Voir la conclusion de notre analyse de Vat. Ar. 13 au chapitre 8, point 5 .

42 Comme la plupart de ses prédécesseurs, Kashouh considère que le manuscrit provient de Mar Saba, Ibid., p. 147.
} 
strongly suggest that the archetype of $h^{1}$ was produced before the seventh century; a date when the majority of the AGM were first translated ${ }^{43}$.

Enfin, Kashouh compare le vocabulaire de $h^{1}$ et le vocabulaire coranique et conclut: $«[\ldots]$ there is clear linguistic evidence that some terms found in the text of Vatican, Ar. 13 precede the Qurān [...] $\gg^{44}$. À l'issue de ses analyses, Kashouh émet deux hypothèses :

1. The autographed text of $h^{1}$, in the Gospels only, was prepared in the sixth century in a place such as al-Hîra in Iraq, by a scholar, possibly Nestorian, who was well acquainted with the Arabic language $[\ldots] ; 2$. The autographed text of $h^{1}$, in the Gospels only, was prepared in the early seventh century and coincides with the rise of Islam. It was prepared for the Arab Christians in al-Hîra, Basra or Najrân. This version precedes all other versions of the Gospels prepared in the second half of the seventh or early eighth century. This version uses the language of the Arab Christians at the time and some terms clearly pre-date the advent of Islam ${ }^{45}$.

Bien que Sidney Griffith reconnaisse dans son ouvrage de 2013 les qualités de l'étude de Kashouh, qu'il qualifie de «breath of fresh air ${ }^{46}$, il remet sévèrement en cause les conclusions de ce dernier quant au Vat. Ar. 13. Discutant l'un après l'autre les arguments de Kashouh, il conclut:

The facts that the vocabulary in the original exemplar of the translated Gospels seems to have been strange to the later copyist, that the script lacked vowel marks, that there is no evidence of Qur'annic language in the translation, and that the Arabic writing does not feature many of the characteristics that Joshua Blau described as typical of 'old south Palestinian' Christian Arabic, do not add up to evidence that the translation was done originally in Najrān, or anywhere else in the Arabic-speaking milieu prior to the rise of Islam in the fifth or sixth century ${ }^{47}$.

\footnotetext{
43 Ibid., p. 153.

44 Ibid., p. 167.

45 Ibid., p. 169.

46 Griffith Sidney H., The Bible in Arabic. The Scriptures of the «People of the Book» in the Language of Islam, Princeton, Princeton University Press, 2013, p. 49. On remarquera ici que Griffith commente la version non éditée de la thèse, qui soutient une origine remontant au $5^{\mathrm{e}}$ ou $6^{\mathrm{e}} \mathrm{s}$; ; la version éditée est plus modérée, soutenant le $6^{\mathrm{e}}$ ou $7^{\mathrm{e}}$ s. Voir note 79 au chapitre 2.

Ibid., p. 116.
} 
Pour Griffith, les arguments présentés par Kashouh pourraient aussi correspondre à une datation plus récente (« the late seventh or early eighth century, which, as we shall also see, is the period within which a number of other early Bible translations can plausibly be thought to have been done ${ }^{48}$ ) ainsi qu'à une origine syro-palestinienne ${ }^{49}$, comme c'est le cas pour le manuscrit luimême et pour les premières traductions évangéliques en arabe.

En 2013, Monferrer-Sala publie un article qui remet en question la majorité des conclusions émises jusqu'alors sur la Vorlage de la partie la plus ancienne des évangiles. Analysant verset par verset Mt 11,1-19, il démontre l'origine à la fois grecque et syriaque de la traduction:

The foregoing analysis of the fragment of Matthew $11: 1-19$ suggests that the Arabic translator of Vat. Ar. 13 used a Greek original as the source for his version. However, in the light of the lectiones offered by the fragment, there is every reason to believe that he also made use of other versions, and more specifically of a Syriac text. Accordingly, it may be assumed that the translation was indeed based on a Greek text, as asserted by Guidi in the nineteenth century and maintained ever since. But it may additionally be postulated that the translator made use of other materials, of at least one other text which was in all probability a Syriac version, specifically of the Peshitta, with whose options the Arabic translation coincides at several points ${ }^{50}$.

Enfin, il souligne à nouveau qu'il ne partage pas l'avis de Guidi quant à l'aspect périphrastique de la traduction: « the translation may be described as 'exegetic', but certainly not 'periphrastic'. ${ }^{51}$ On notera que la conclusion de Monferrer-Sala quant à l'origine à la fois grecque et syriaque de la traduction remet en question le classement de Kashouh qui classait le texte dans la famille des traductions faites sur la Peshitta seulement.

Par la suite, Monferrer-Sala consacre deux articles à la partie plus récente des évangiles. Il publie en 2014 une étude de Mt 2,18-2352 et en 2015 une étude

\section{$48 \quad$ Ibid., p. 117.}

49 Griffith donne aussi le monastère de Mar Saba comme lieu d'origine du Vat. Ar. 13. Ibid., p. 116.

50 Monferrer-Sala Juan Pedro, «An Early Fragmentary Christian Palestinian Rendition of the Gospels into Arabic from Mar Saba (MS Vat. Ar. 13, 9th c.) », Intellectual History of the Islamicate World 1, 2013, p. 95.

51 Ibid.

52 Monferrer-Sala Juan Pedro, «Estrategias e interferencias en una traducción árabe cristiana surpalestinense (Vat. Ar. 13, S. IX)», in : Meouak Mohamed et Puente Cristina 
de Mt 3,1-1 $7^{53}$. Ces deux passages se trouvent dans les folios restaurés par la main de $S^{c}\left(9^{\text {e }}\right.$ s., voir point 3.4). Monferrer-Sala conclut que le traducteur de Mt 2,18-23 s'est basé sur au moins deux textes, un texte grec ainsi qu'un texte araméen que Monferrer-Sala renonce à identifier. À propos de Mt 3,117, il détermine que la traduction se base sur un texte syriaque tout en ayant quelques corrections faites à partir du grec. Si Monferrer-Sala ne discute pas sa conclusion de 2014 dans son article de 2015, son opposition générale entre deux corpus - la section ancienne («the oldest section of the codex Vaticano Arabo 13, based on a Greek Vorlage, exhibits a whole series of features in terms of translation ») et la section récente («this later section, based on a Syriac text, is much less complex as regards translation strategies, and much more dependent on its Syriac Vorlage, making only very minor concessions to the Greek text techniques and strategies » $)^{54}$ - nous laisser penser que ce qui s'applique à Mt 3,1-17 s'applique aussi à Mt 2,18-23.

Enfin, plus récemment, Monferrer-Sala s'est intéressé aux lettres de Paul dans le Vat. Ar. 13 en publiant un article sur la lettre à Philémon dans le Vat. Ar. 13, dans lequel il donne une transcription complète de la lettre ${ }^{55}$. Son analyse de la traduction suggère que le traducteur se base sur un texte grec tout en faisant usage de la Peshitta pour des raisons linguistiques ou exégétiques. Cette conclusion est similaire à celle que nous établissons à propos de 1 Corinthiens, grâce à l'analyse textuel du chapitre 8 .

En conclusion de cet état de la recherche, nous pouvons dire que le Vat. Ar. 13 a éveillé un intérêt peu habituel depuis le début de la recherche sur les manuscrits arabes du Nouveau Testament. Cet intérêt est lié à l'antiquité du manuscrit, antiquité qui, bien que le manuscrit soit non daté, fait l'unanimité. La recherche s'est principalement concentrée sur le texte des évangiles, suivant un mouvement général dans la recherche (voir chapitre 2, point 9 et chapitre 4, point 1); bien que copiées en partie par le même scribe, les lettres de Paul sont généralement à peine mentionnées.

L'histoire de la recherche est marquée par la recherche de l'origine de la traduction de la partie la plus ancienne des évangiles, les chercheurs proposant le grec ou le syriaque comme langue d'origine. Le désaccord sur l'origine de la

DE LA (éds), Vivir de tal suerte : Homenaje a Juan Antonio Souto Lasala, Cordoue, Madrid, Oriens Academic, 2014 (Serie Abacus 1), pp. 349-365.

Monferrer-Sala Juan Pedro, «Translating the Gospels into Arabic from Syriac: Vatican Arabic 13 Restored Section, Strategies and Goals », Arabica (62), 2015, pp. 435-458.

54 Ibid., p. 456.

55 Monferrer-Sala Juan Pedro, «The Pauline Epistle to Philemon from Codex Vatican Arabic 13 (Ninth Century CE): Transcription and Study », Journal of Semitic Studies 60 (2), 2015, pp. 341-371. 
traduction trouve en partie une explication dans l'étude de Monferrer-Sala de 2013, qui montre que le texte (du moins Mt 11,1-19) se base à la fois sur un texte grec et un texte syriaque.

Concernant les lettres de Paul, celles-ci n'avaient pas fait l'objet d'étude particulière jusqu'en $2015^{56}$. Lorsqu'elles sont mentionnées, elles sont considérées à l'unanimité comme étant traduites du grec, une conclusion que nous remettons en partie en cause au chapitre 8 .

Enfin, nous noterons que l'information selon laquelle le manuscrit a été copié à Mar Saba semble être née d'une hypothèse de Hyvernat qui a été reprise sans vérification par de nombreux chercheurs par la suite. Si nous ne remettons pas en cause le milieu d'origine melkite, le manuscrit lui-même ne porte aucune preuve de son appartenance à Mar Saba, comme nous allons le voir.

\subsection{Le lieu de conservation du manuscrit}

Le manuscrit est conservé à la Bibliothèque Vaticane et porte la cote Vaticanus Arabicus 13. Il fait partie du fonds des manuscrits arabes de la Bibliothèque Vaticane acquis progressivement à partir du $15^{\mathrm{e}} \mathrm{s} .{ }^{58} \mathrm{En} 1715$, Clément XI envoie Joseph Simon Assemani à la recherche de manuscrits orientaux. Le manuscrit fait partie des manuscrits qu'Assemani rapporte à Rome à la suite de son deuxième voyage en 1715 au Proche-Orient ${ }^{59}$. Le manuscrit est en effet mentionné dans la Biblioteca Orientalis Clementino-Vaticana parmi les «Codices Arabici, quos auctor ex oriente advexit», au numéro 71 (nous reproduisons la notice ci-dessus au point 2). Le manuscrit reçoit la cote 13, toujours

\footnotetext{
$56 \quad$ Ibid.

57 Ce sous-chapitre a été adapté en anglais et intégré dans l'article: Schult HEss Sara, «Vaticanus Arabicus 13: What Do We Really Know About the Manuscript? With an Additional Note on the Ending of Mark», Journal of Eastern Christian Studies 70(1-2), numéro spécial édité par Schult hess Sara, Te ule Herman et Ver heyden Joseph, Arabica sunt, non leguntur ... Studies on the Arabic Versions of the Bible in Jewish, Christian and Islamic Tradition, 2018, pp. 63-84. Quelques erreurs qui s'y étaient glissées ont été corrigées ici.

$5^{8}$ Une première attestation d'un noyau de 22 manuscrits arabes remonterait à 1481. VIAN Paolo, «Vaticani Arabi », in : Vian Paolo et D'Aiuto Francesco (éds), Guida ai fondi manoscritti, numismatici, a stampa della Biblioteca Vaticana. I. Dipartimento Manoscritti, Rome, Biblioteca Apostolica Vaticana, 2011 (Studi e Testi 466), p. 553.

59 Vian fait la liste des manuscrits rapportés au Vatican par Assemani mais n'y mentionne pas le Vat. Ar. 13, ce qui a rendu ardue la reconstitution des déplacements du manuscrit, Ibid., p. 557 .
} 
en usage aujourd'hui, lors du catalogage d'Assemani, qui a «fondu » la section des manuscrits acquis avant Clément XI (1700-1721) et ceux acquis pour Clément $\mathrm{XI}^{60}$. Le manuscrit a ensuite été déplacé à Paris; il fait en effet partie des manuscrits romains réquisitionnés par la France à la suite l'armistice de Bologne (1796) et du traité de Tolentino (1797), conservés à la Bibliothèque nationale de Paris et rendus au Vatican en $1815^{61}$. Ce séjour à Paris est confirmé par la présence du tampon de la Bibliothèque nationale aux f. 1r et 179v. Une courte description du manuscrit se trouve dans un registre des manuscrits romains réquisitionnés, la Recensio manuscriptorum codicum, datant de $1803^{62}$. On trouve ensuite la description faite par Angelo Mai en 1831 dans le premier catalogue imprimé des manuscrits arabes, qui reprend le travail de Joseph Simon Assemani. Aujourd'hui, la Bibliothèque Vaticane met à disposition une description détaillée du manuscrit dans son catalogue en ligne ${ }^{63}$ et, depuis peu, les images du manuscrit ${ }^{64}$.

\subsection{Le lieu d'origine du manuscrit}

Quel est le lieu d'origine du Vat. Ar. 13 ? L'épigramme en grec au f.179v (voir point 3.6.2) mentionne la ville d'Emèse, c'est-à-dire Homs, en Syrie. L'information concernant Homs est mentionnée par les chercheurs au $19^{\mathrm{e}} \mathrm{s}^{65}$ Or en ${ }^{6} 895$, Hyvernat mentionne le monastère de Mar Saba comme possible lieu d'origine du Vat. Ar. $13^{66}$ et par la suite, le manuscrit a été associé à ce monastère. Récemment, Mar Saba est mentionnée comme lieu d'origine du manuscrit par Monferrer-Sala, Kashouh ou encore Griffith (voir point 2 ci-dessus). Si nous ne remettons pas en question l'origine melkite du manuscrit (voir les conclusions

6o Seuls les trois premiers volumes du catalogue d'Assemani, Bibliothecae Apostolicae Vaticanae codicum manuscriptorum Catalogus in tres partes distributus (Rome, 1756-1769), furent édités; le volume concernant les manuscrits arabes, Vat. Ar. 13 y compris, n’a pas été publié, à cause d'un incendie. Ibid., p. $55^{8}$.

61 VIAN, «"Per le cose della Patria Nostra". Lettere inedite di Luigi Angeloni e Marino Marini sul recupero dei manoscritti Vaticani a Parigi (1816-1819)», art. cit., 2011.

62 Recensio manuscriptorum codicum qui ex universa Bibliotheca Vaticana (...) procuratoribus Gallorum iure belli, seu pactarum induciarum ergo, et initce pacis traditi fuere (...), op. cit., 1803 , p. 17 .

63 Le catalogue en ligne reprend la description faite par Georg Graf lors de son travail de catalogage à la Bibliothèque vaticane à partir de 1930, qui n’a jamais été publié, <http:// www.mss.vatlib.it/guii/console?service=shortDetail\&id=115495>, consulté le 21.08.15. VIAN, « Vaticani Arabi», art. cit., 2011, p. 561.

64 <http://digi.vatlib.it/view/MSS_Vat.ar.13>, consulté le 14.03.2016.

65 Par ex. Tischendorf, Novum Testamentum Graece. Ad antiquos testes recensuit, apparatum criticum multis modis auctum et correctum apposuit, commentationem isagogicam praemisit ..., op. cit., 1849, p. LXXVIII.

66 Hyvernat, «Arabes (versions) des écritures », art. cit., 1895, p. 851. 
du chapitre 8, point 5), aucun élément ne permet de relier directement le manuscrit au monastère de Mar Saba. D'où vient alors le Vat. Ar. 13 ? Comme nous le mentionnons au point précédent, le manuscrit fait partie des manuscrits que Joseph Simon Assemani a acquis lors de son premier voyage en Orient, un épisode qui semble également avoir été oublié par la recherche ${ }^{67}$, et qui devrait nous donner des éléments de réponse. Malheureusement, Assemani ne mentionne pas les lieux d'origine des manuscrits dans les notices des « Codices Arabici, quos auctor ex oriente advexit ». Il nous faut donc essayer de retracer le voyage que celui-ci a effectué. Les informations que l'on peut rassembler à propos de ce voyage sont maigres, et la description qu'Assemani donne luimême de son périple est imprécise ${ }^{68}$. Certains manuscrits furent acquis en Égypte et d'autres en Syrie et au Liban. En Égypte, Assemani visita le Caire, les monastères du désert de Nitrie (Saint-Macaire, Monastère des Syriens, SaintAntoine, Saint-Paul). En Syrie, il passa par Damas et Alep, ainsi que par Tripoli, et visita des monastères environnants. Les manuscrits proviennent de ces différentes étapes. Le Vat. Ar. 13 n’a donc pas été ramené en Europe depuis Mar Saba. Il est vraisemblable que le manuscrit provienne de l'étape syro-libanaise d'Assemani, le manuscrit ne portant aucun signe d'une origine copte.

Ce dernier point nous redirige vers une provenance possible de la région de Homs, qui est mentionnée dans l'épigramme du manuscrit (voir 3.6.2 Épigramme grec). La ville Ḥoms se trouve dans le Patriarcat d'Antioche et était une métropole autonome, témoin de l'importance de sa communauté orthodoxe. Elle fut occupée par les arabes à partir de 636 et était au $9^{\mathrm{e}} \mathrm{s}$. sous le régime abbasside une des villes les plus importantes de Syrie; elle fut prise par les croisés en 1099. La présence de l'Église syriaque occidentale y était aussi importante ${ }^{69}$. Les indications liturgiques dans le manuscrit indiquent

67 Comme nous le mentionnons à la note 59 ci-dessus, Vian omet le Vat. Ar. 13 dans sa liste des manuscrits d'Assemani. Monferrer-Sala pense que la manuscrit dans son état actuel est le résultat d'un assemblage de plusieurs partie fait en Europe, voir point 2.

68 Assemani, Bibliotheca Orientalis Clementino-Vaticana : In Qua Manuscriptos Codices Syriacos, Arabicos, Persicos, Turcicos, Hebraicos, Samaritanos, Armenicos, Aethiopicos, Graecos, Aegyptiacos, Ibericos, \& Malabaricos, Jussu et Munificentia Clementis XI. Pontificis Maximi Ex Oriente conquisitos, comparatos, avectos, \& Bibliothecae Vaticanae addictos, op. cit., 1719, point XI de la préface. Voir à propos du voyage d'Assemani, GEMAYEL Nasser, Les échanges culturels entre les Maronites et l'Europe: du Collège maronite de Rome (1584) au Collège de Ayn-Warqa (1789), vol. 1, Beyrouth, Impr. Y. et Ph. Gemayel, 1984, pp. 422-425. RAP HAËL Pierre, Le rôle du Collège maronite romain dans l'orientalisme aux XVIIe et XVIIIe siècles, Beyrouth, Université Saint Joseph, 1950, pp. 123-127.

69 JANin R., «Emèse», in : Dictionnaire d'histoire et de géographie ecclésiastiques, vol. 15, Paris, Letouzey et Ané, 1963. Aubert J., «Homs », in : Dictionnaire d'histoire et de géographie ecclésiastiques, vol. 24, Paris, Letouzey et Ané, 1993. Voir aussi Dussaud René, «Chapitre II. De Tripoli à Carné. — L'Émésène », in : Topographie historique de la Syrie antique et médiévale, Beyrouth, Presses de l'Ifpo, 2015 (Bibliothèque archéologique et historique 
une pratique communautaire et celui-ci a probablement été copié et utilisé dans un monastère. Celui-ci ne se trouvait pas forcément à Ḥoms même. En effet, la mention géographique peut aussi faire référence au district de Ḥoms. Si l'on sait peu de chose sur les monastères de la région ${ }^{70}$, on a connaissance du monastère maronite Mar Maron ${ }^{71}$ et aussi que, grâce à une inscription en syriaque du $8^{e}$ s., d'un ermitage melkite ${ }^{72}$.

Si nous ne pouvons déterminer avec précision l'origine du manuscrit, rien ne vient soutenir Mar Saba comme lieu d'origine du manuscrit. Par contre, une origine dans les environs de la ville de Homs, une ville importante dans le patriarcat d'Antioche, est possible (voir aussi point 3.6.2). On notera que la traduction du Sin. Ar. 151, datée de 867, vient de la ville de Damas, dont la situation peut être comparée à celle de Ḥoms.

\subsection{Le support du manuscrit et la mise en page}

Le manuscrit est écrit sur parchemin ${ }^{73}$. Cela prouve certainement l'antiquité du manuscrit, sans pouvoir être précis : comme l'explique Gacek, «[d]espite the wide-spread use of paper from the $3 \mathrm{rd} / 9$ th century on, the use of parchment in the central part of the Muslim world was still significant even in the 4/1oth century. ${ }^{74}$ La majorité des manuscrits des lettres de Paul copiés sur parchemin date toutefois du $9^{\mathrm{e}} \mathrm{s}$. (voir chapitre 5 , point 7 Matériel). Les folios sont de dimensions inégales, variant de 260 à $278 \mathrm{~mm}$ de hauteur et de 170 à $180 \mathrm{~mm}$ de largeur. Le manuscrit ne présente aucune réglure et la surface écrite

4), pp. 75-115. En ligne: OpenEdition Books, <http://books.openedition.org/ifpo/3699>, consulté le 22.03.2016; Dumper Michael et StAnley Bruce E., Cities of the Middle East and North Africa: A Historical Encyclopedia, Santa Barbara, ABC-CLIO, 2007, p. 172.

70 Nasrallah Joseph, Histoire du mouvement littéraire dans l'Église Melchite du Ve au XXe siècle, vol. II.2, Louvain, Peeters, 1988, p. 15 .

71 Suermann Harald, Die Gründungsgeschichte der maronitischen Kirche, Wiesbaden, Harrassowitz, 1998, pp. 70-72. Treige R Alexander, « Palestinian Origenism and the Early History of the Maronites: In Search of the Origins of the Arabic Theology of Aristotle», in : JANos Damien (éd.), Ideas in Motion in Baghdad and Beyond: Philosophical and Theological Exchanges between Christians and Muslims in the Third/Ninth and Fourth/Tenth Centuries, Leiden, Brill, 2015, pp. 44-80.

72 Mouterde Paul, «Un ermitage melkite en Emésène au VIIIe siècle », Mélanges de l'Université Saint-Joseph 18, 1934, pp. 101-106.

73 Kashouh donne comme support parchemin et papier; nous n'avons personnellement pas constaté la présence de papier dans le manuscrit. Kashoun, The Arabic Versions of the Gospels, The Manuscripts and their Families, op. cit., 2012, p. 65.

74 GACE K Adam, Arabic Manuscripts: A Vademecum for Readers, Leiden, Boston, Brill, 2009 (Handbook of Oriental Studies. Section 1, the Near and Middle East Ancient Near East 98), p. 195 . 
varie également, allant de 200 à $230 \mathrm{~mm}$ de hauteur et de 125 à $170 \mathrm{~mm}$ de largeur ${ }^{75}$. Le nombre de lignes est très variable, entre 13 (voir f. 6r) et 21 lignes.

La reliure n'est pas d'origine. Elle est en cuir rouge et porte sur la tranche le numéro 13, les meubles du blason des Albani (étoiles à 6 branches et trois montagnes), la famille de Clément XI, ainsi que les armes du cardinal Benedetto Pamphilj, bibliothécaire de $1704-173^{76}$.

\subsection{La composition du manuscrit et les différentes mains}

Comme nous avons pu le voir dans l'état de la recherche, la présence de différentes mains a retenu l'attention de la plupart des chercheurs qui se sont penchés sur le manuscrit. Avant de commencer l'étude des différentes mains du manuscrits, nous tenons à préciser ici que le manuscrit n'est pas un autographe. Il présente plusieurs erreurs de copie qui permettent de l'exclure, notamment de type homoeoteleuton, à la fois dans la partie ancienne des évangiles ${ }^{77}$ et dans la partie des lettres de Paul ${ }^{78}$.

Lors du départ du manuscrit pour la France, celui-ci était déjà considéré comme composé de deux parties ( «ut binus » ${ }^{79}$ ), ce qui est confirmé par le Recensio manuscriptorum codicum de 1803 qui le décrit comme « divisibilis in duas partes » et qui considère que les lettres de Paul sont d'une autre main ${ }^{80}$. La description de l'aspect composite du manuscrit s'affine par la suite, surtout avec Guidi en $1888^{81}$. Grâce à l'observation des cahiers, il délimite une partie ancienne dans les évangiles, puis constate deux mains différentes dans la partie récente. Par la suite, Graf liste quatre scribes: deux mains ayant travaillé sur la partie ancienne des évangiles, différentes mais contemporaines ${ }^{82}$, et deux

75 Kashou h, The Arabic Versions of the Gospels, The Manuscripts and their Families, op. cit., 2012, p. 65 .

76 Information donnée par Graf: <http://www.mss.vatlib.it/guii/console?service=short Detail\&id=115495>, consulté le 12.10.2017.

77 Kashoun, The Arabic Versions of the Gospels, The Manuscripts and their Families, op. cit., 2012, p. 149.

78 Voir 1 Co 1,$27 ; 2,3 ; 3,2 ; 6,12 ; 7,28 ; 9,20 ; 13,4$ au chapitre 8 , point 1 .

79 Vian, « "Per le cose della Patria Nostra”. Lettere inedite di Luigi Angeloni e Marino Marini sul recupero dei manoscritti Vaticani a Parigi (1816-1819)», art. cit., 2011, p. 781.

8o Recensio manuscriptorum codicum qui ex universa Bibliotheca Vaticana (...) procuratoribus Gallorum iure belli, seu pactarum induciarum ergo, et initce pacis traditi fuere (...), op. cit., 1803 , p. 17 .

81 GUID I, Le Traduzioni degli Evangelii in arabo e in etiopico, op. cit., 1888, p. 8.

82 GRAF, Geschichte der christlichen arabischen Literatur, op. cit., 1944, p. 147. 
mains ayant travaillé sur la partie récente des évangiles (respectivement du $9^{\mathrm{e}}$ et du ${ }_{11}{ }^{\mathrm{e}} \mathrm{s}$.) ${ }^{83}$. Rien n'est précisé à propos du scribe des lettres de Paul ${ }^{84}$.

En 2012, Kashouh distingue cinq scribes :

Here is a list of the five scribes and the texts they copied: 1st scribe (Sa), early 9th century, copied folios 15-46 (Mt $10: 27 \mathrm{~b}-26: 17 \mathrm{a}$ ); folios $55-56$ (Mk 5 :19b-6:9a); folios 83-86 (Mk 6 :9b-7:12a); folios 57-64r (Mk 7 :12b10 :29a); folios 75-82 (Lk $3: 31-7: 11)$. 2nd scribe (Sb), early 9th century, copied folios 64v-74 (Mk $10: 29 \mathrm{~b}-16: 8$ ); folios 87v-179 (Paul's Epistles and the Letters to the Hebrews); 3rd scribe (Sc) about the 1oth century copied folios 1-6 (Matthew 1:1-6:18a); 4th scribe (Sd) about the 12th century copied folios 7-14 (Matthew 6:18b-10:27a) and folios 47-54 (Mt $26: 17 \mathrm{~b}-$ $28: 11)$. Folios $47-54$ are in disorder and should be read as follows : 47, 53, $52,51,50,49,48^{85}$.

Le cinquième scribe serait : « an anonymous hand $\left(\mathrm{S}^{\mathrm{e}}\right)$ [who] made a few corrections in the text copied by $S^{\mathrm{a}}$.»

En plus des considérations paléographiques que nous traiterons plus bas, c'est surtout la signature des cahiers que l'on retrouve dans le manuscrit qui vient à l'appui des conclusions de Kashouh. En effet, comme Guidi l'avait déjà remarqué en 1888, certains cahiers sont numérotés et portent alors la signature au recto du premier folio du cahier et au verso du dernier folio du cahier. Sur ce verso, on trouve aussi عورض وصح (par exemple 94v), qui est la trace de la collation des cahiers, un phénomène répandu pour les manuscrits arabes ${ }^{86}$.

Cette numérotation nous aide à recomposer l'histoire du manuscrit: en effet, les cahiers correspondant aux mains $S^{\mathrm{a}}$ et $S^{\mathrm{b}}$ sont numérotés, tandis que les cahiers de $S^{c}$ (cahier 1 ) et $S^{d}$ (cahiers 2 et 7 ) ne le sont pas. Il semblerait donc que la numérotation soit d'origine, et que les cahiers de $S^{\mathrm{c}}$ et $\mathrm{S}^{\mathrm{d}}$ ait été ajoutés plus tard.

Nous proposons ci-dessous un tableau pour aider à visualiser ce découpage :

\footnotetext{
83 Ibid., p. 150.

84 Ibid., p. 171.

85 Kashou H, The Arabic Versions of the Gospels, The Manuscripts and their Families, op. cit., 2012, p. 145, n. 47. Une analyse partagée par Graf, <http://www.mss.vatlib.it/guii/console? service $=$ shortDetail\&id $=115495>$, consulté le 19.10.2015.

86 GACE K, Arabic Manuscripts, op. cit., 2009, p. 65.
} 


Signature No cahier folios Contenu $\quad$ Scribe Genre cahier
d'origine

\begin{tabular}{|c|c|c|c|c|c|}
\hline & 1 & $1-6$ & Mt $1,1-6,18 a$ & $\mathrm{~S}^{\mathrm{c}}$ & Ternion \\
\hline & 2 & $7-14$ & Mt $6,18 b-10,27 a$ & $S^{d}$ & Quaternion \\
\hline $\mathrm{IA}^{\prime}(=11)$ & 3 & $15^{-22}$ & \multirow{4}{*}{ Mt $10,27 \mathrm{~b}-26,17 \mathrm{a}$} & $\mathrm{S}^{\mathrm{a}}$ & Quaternion \\
\hline $\mathrm{IB}^{\prime}(=12)$ & 4 & $23-30$ & & $\overline{S^{a}}$ & Quaternion \\
\hline $\mathrm{I}^{\prime}(=13)$ & 5 & $31-38$ & & $\mathrm{~S}^{\mathrm{a}}$ & Quaternion \\
\hline \multirow[t]{2}{*}{$\mathrm{I} \Delta^{\prime}(=14)$} & 6 & $39-46$ & & $\overline{S^{a}}$ & Quaternion \\
\hline & 7 & $47-54$ & Mt 26,17b-28,11 & $\mathrm{S}^{\mathrm{d}}$ & Quaternion \\
\hline IZ' $(=17)$ & 8 & $55^{-58}$ & \multirow{4}{*}{$\begin{array}{l}\text { Mc } 5,19 b-6,9 a^{*}+ \\
7,12 b-16,8\end{array}$} & $\mathrm{~S}^{\mathrm{a}}$ & Binion \\
\hline \multirow[t]{2}{*}{$\mathrm{IH}^{\prime}(=18)$} & 9 & $59-64 r$ & & $\overline{S^{a}}$ & Quaternion \\
\hline & & $64 v-66$ & & $\mathrm{~S}^{\mathrm{b}}$ & Quaternion \\
\hline $\mathrm{I}^{\prime}(=19)$ & 10 & $67-74$ & & $\mathrm{~S}^{\mathrm{b}}$ & Quaternion \\
\hline \multirow[t]{2}{*}{$\mathrm{KA}^{\prime}(=21)$} & 11 & $75^{-82}$ & Lc $3,31-7,11$ & $\mathrm{~S}^{\mathrm{a}}$ & Quaternion \\
\hline & 12 & $83-86$ & *Mc 6,9b-7,12a & $\mathrm{S}^{\mathrm{a}}$ & Binion \\
\hline $\mathrm{M}^{\prime}(=40)$ & 13 & $87-94$ & \multirow{12}{*}{$\begin{array}{l}\text { Lettres de Paul } \\
(\mathrm{Rm} ; 1 \text {-2 Co ; Ga ; } \\
\text { Eph ; Phi ; Col ; 1-2 } \\
\text { Th; 1-2 Tim ; Tt ; } \\
\text { Phm ; He) }\end{array}$} & $S^{b}$ & Quaternion \\
\hline $\mathrm{MA}^{\prime}(=41)$ & 14 & $95^{-102}$ & & $\mathrm{~S}^{\mathrm{b}}$ & Quaternion \\
\hline $\mathrm{MB}^{\prime}(=42)$ & 15 & $103-110$ & & $\overline{S^{b}}$ & Quaternion \\
\hline $\mathrm{M} \Gamma^{\prime}(=43)$ & 16 & $111-119$ & & $\mathrm{~S}^{\mathbf{b}}$ & Quaternion* $^{*}$ \\
\hline $\mathrm{M} \Delta^{\prime}(=44)$ & 17 & $120-127$ & & $\mathrm{~S}^{\mathrm{b}}$ & Quaternion \\
\hline $\mathrm{ME}^{\prime}(=45)$ & 18 & $128-135$ & & $\mathrm{~S}^{\mathrm{b}}$ & Quaternion \\
\hline $\mathrm{M} \Sigma^{\prime}(=46)$ & 19 & $136-143$ & & $\mathrm{~S}^{\mathrm{b}}$ & Quaternion \\
\hline MZ' (=47) & 20 & $144^{-1} 5^{1}$ & & $\mathrm{~S}^{\mathrm{b}}$ & Quaternion \\
\hline $\mathrm{MH}^{\prime}(=48)$ & 21 & $15^{2-1} 59$ & & $\overline{S^{b}}$ & Quaternion \\
\hline $\mathrm{M \Theta}^{\prime}(=49)$ & 22 & $160-167$ & & $\mathrm{~S}^{\mathrm{b}}$ & Quaternion \\
\hline $\mathrm{N}^{\prime}(=50)$ & 23 & $168-174$ & & $\mathrm{~S}^{\mathrm{b}}$ & Feuillet indép. \\
\hline $\mathrm{NA}^{\prime}(=51)$ & 24 & $175^{-179}$ & & $\overline{S^{b}}$ & Feuillet indép. \\
\hline
\end{tabular}

* On trouve à la fin du quaternion le folio 119, qui contient He 11,16b-12,2a et qui devrait se trouver entre 176 et 177 .

Voici quelques remarques à tirer du tableau :

(1) Les folios 83-86 (cahier 12) ont été déplacés : ils se trouvaient à l'origine avec le cahier 8 et il n'y avait pas de lacunes de texte après Mc 6,9a ${ }^{87}$. Cela est confirmé par le fait que le cahier 8 et le cahier 12 sont les seuls binions.

87 Relevépar Graf, <http://www.mss.vatlib.it/guii/console?service=shortDetail\&id=156629>, consulté le 19.10.2015. Cet aspect est aussi développé par Monferrer-Sala. Nous ne 
(2) Seuls les cahiers de $S^{a}$ et $S^{b}$ portent une signature. Les lacunes dans la numérotation correspondent à la description des livres bibliques qui se trouvaient à l'origine dans le manuscrit donnée dans l'épigramme (point 3.6.2) : avant le cahier IA' (= 11), il y avait donc 10 cahiers contenant les Psaumes et le début de Matthieu; entre les cahiers I $\Delta^{\prime}(=14)$ et IZ' (=17), on trouvait la fin de Matthieu et le début de Marc ; entre le cahier I ${ }^{\prime}$ (=19) et le cahier KA' (=21), on trouvait le début de Luc; entre le cahier $\mathrm{KA}^{\prime}(=21)$ et le cahier M' (=40), on trouvait la fin de Luc, l'évangile de Jean, les Actes, les épîtres catholiques ${ }^{88}$.

(3) Suite à la remarque 2, nous pouvons conclure que le manuscrit était à l'origine très long ( 51 quaternions, c'est-à-dire 408 folios). Peut-on y voir un lien avec la perte de nombreux folios, s'il y avait, par exemple, plusieurs volumes?

(4) Comme noté à la remarque 2 , les cahiers copiés par $\mathrm{S}^{\mathrm{a}}$ et $\mathrm{S}^{\mathrm{b}}$ ont des signatures, ce qui laisse penser que ces deux scribes ont travaillé de manière contemporaine. De plus, si $S^{a}$ a principalement copié ce qu'il nous reste des évangiles et $S^{b}$ les lettres de Paul, une main qui semble être celle de $S^{b}$ a aussi copié quelques folios des évangiles (une partie du cahier 9 et le cahier 10). $S^{b}$ continue au verso (64v) d'un folio commencé par $S^{a}(64 r)^{89}$. Il semble donc que $S^{a}$ et $S^{b}$ ont travaillé en même temps à la copie du manuscrit; nous revenons sur ce point plus bas.

(5) Les cahiers copiés par $\mathrm{S}^{\mathrm{c}}$ et $\mathrm{S}^{\mathrm{d}}$ n'ont pas de signature et sont donc plus tardifs. Ils semblent avoir été faits pour combler les lacunes du manuscrit: en effet, on remarque que le début de Matthieu est entièrement restauré par $S^{c}$ et $S^{d}$ et que en $47 \mathrm{r}, S^{d}$ reprend là où $S^{a}$ avait terminé le folio $46 \mathrm{v}$. Toutefois, $S^{c}$ et $S^{d}$ ne sont probablement pas contemporains (voir l'estimation de Kashouh ci-dessus). D'une part, $\mathrm{S}^{\mathrm{d}}$ vocalise son texte, contrairement aux autres scribes (voir 3.5 Quelques aspects paléographiques); d'autre part, les folios copiés par $\mathrm{S}^{\mathrm{d}}$ sont les seuls à ne présenter aucune indication liturgique (voir 3.8 Indications de lecture).

(6) Le manuscrit rapporté d'Orient à la Bibliothèque apostolique vaticane par Assemani contenait déjà le nombre de folios que le manuscrit a

comprenons toutefois pas son réarrangement des folios, qui le mène à «augmenter » le nombre de folios existant (jusqu'à 183 folios). Voir MONFERrER-SALA, « Una traducción árabe con "pseudoescolio exegético anónimo". Una nota de crítica textual interna a propósito del MS. Sabaítico Vaticano Arabo 13 », art. cit., 2001, p. 72.

88 GUIDI, Le Traduzioni degli Evangelii in arabo e in etiopico, op. cit., 1888, p. 8.

89 Kashoun, The Arabic Versions of the Gospels, The Manuscripts and their Families, op. cit., 2012, p. 147. 
aujourd'hui. Les différentes étapes décrites ci-dessus ont se sont déroulées avant l'arrivée du manuscrit en Europe. Il nous faut ajouter ici que les folios portent aussi une foliotation en chiffres arabes d'une main occidentale, certainement faite lors de l'arrivée à la bibliothèque ${ }^{90}$.

\subsection{Quelques aspects paléographiques}

$\mathrm{Si}$ les changements de main ne laissent pas de doute tant celles-ci sont différentes, il n'est pas pour autant évident de tirer des conclusions sur une base paléographique. En effet, la paléographie arabe présente plusieurs difficultés, notamment celle d'être une discipline en développement, comme le regrette Déroche : «pour dire les choses de manière un peu abrupte, la paléographie des écritures arabes livresques a deux siècles de retard par rapport à ce qui s'est fait pour les manuscrits latins ou grecs. ${ }^{91}$ Dans le cas de la paléographie pour les manuscrits chrétiens arabes, on se réjouira déjà de pouvoir travailler avec l'album de manuscrits chrétiens arabes datés de Lewis et Gibson, malgré son âge honorable ${ }^{92}$. D'autres difficultés sont liées à l'écriture arabe, comme la « complexité de la détermination du changement d'un type à l'autre ${ }^{93} \mathrm{et}$ l'utilisation contemporaine de différents types d'écriture ${ }^{94}$, comme c'est le cas dans notre manuscrit pour les écritures de $S^{\mathrm{a}}$ et $S^{\mathrm{b}}$, qui, bien que contemporaines, sont très différentes. C'est donc avec prudence que nous avançons les éléments paléographiques qui suivent.

$S^{a}$ présente une écriture «brisée » au trait épais, que beaucoup ont rapproché du style kū fi (Mai, Scholz), style utilisé de la moitié du $8^{\mathrm{e}}$ au $10^{\mathrm{e}} \mathrm{s} .{ }^{95}$ Certains chercheurs n'ont pas manqué de remarquer des similitudes entre ce type d'écriture utilisé dans les manuscrits chrétiens arabes anciens et le syriaque de type estrangèlā, avec un résultat se rapprochant du küfi. C'est le cas d'Abbot, qui en note donne comme exemple la planche II de l'album Lewis-Gibson

90 Cette foliotation s'arrête au folio 178 ; comme nous le notons à la note 4 ci-dessus, la notice d'Assemani mentionne 178 folios. Le dernier folio a-t-il été égaré à un moment donné ? Il contient pourtant bien la fin d'Hébreux.

91 Déroche François (éd.), Manuel de codicologie des manuscrits en écriture arabe, Paris, Bibliothèque nationale de France, 2000, p. 227.

92 Lewis Agnes Smith et Gibson Margaret Dunlop, Forty-One Facsimiles of Dated Christian Arabic Manuscripts, Cambridge, Cambridge University Press, 1907 (Studia Sinaitica 12).

93 Déroche (éd.), Manuel de codicologie des manuscrits en écriture arabe, op. cit., 2000, p. 227.

94 Muzerelle Denis, «L'écriture », in : Géhin Paul (éd.), Lire le manuscrit médiéval, $2^{2}$ édition, Paris, Armand Colin, 2013, pp. 85-120.

95 Déroche (éd.), Manuel de codicologie des manuscrits en écriture arabe, op. cit., 2000, p. 234. 
représentant Londres BL Or. 4950, daté de $877^{96}$ (copié au monastère SaintChariton ${ }^{97}$. C'est cette planche de l'album qui nous semble en effet se rapprocher le plus de la main de $S^{a 98}$. Dans son étude de l'écriture de $S^{a}$, Kashouh en avait souligné l'antiquité, listant les traits archaïques suivants :

1. The writing of the Alef in Sa is unique among [Arabic Gospels manuscripts]. At the base of the Alef, there is a turning of the hand to the right. According to Ibn al-Nadim, a tenth century scholar from Baghdad, this peculiar form of the alef is common among manuscripts of Makkah and al-Madinah, in the south of Arabia, copied in the first and second centuries $\mathrm{AH}$ (seventh/eighth centuries AD). 2. In general, the middle 'ayn and ghayn are written with two oblique strokes only (without a horizontal stroke joining them together). 3 . The tail of the final mim is short and has a slant which makes it look like the ra'. 4 . The final ba' and ta' do not end with a vertical stroke. 5. The semi-circle (or the curve) of the final nun is pointing more forward then upward. 6. Some of the initial and independent 'ayn have the lower base extended to the right ${ }^{99}$.

Pour Kashouh, ces caractéristiques rapprochent la main de $S^{\text {a }}$ de BNF Ar. 328 : «A comparison of this kind shows not only the antiquity of $h^{1}$ (though codex BNF, Ar. 328 is older than $h^{I}$ ) but also the similar geographical milieu of both codices. ${ }^{100}$ À notre avis, la comparaison entre Sa et BNF Ar. 328 est problématique. En effet, une des caractéristiques de l'écriture hijäzī dont BNF Ar. 328 est un représentant est la suivante : « a distinct ductus, where the shafts of the alif and other letters are slanted to the right » ${ }^{101}$. L'écriture de $S^{a}$ ne présente pas d'inclinaison vers la droite, mais est bien verticale, tout comme l'écriture de la planche II. La caractéristique la plus importante de $S^{\mathrm{a}}$, que Kashouh a bien mise en évidence, est son utilisation régulière d'un alif qui se courbe en bas vers la droite, mais un tel alif courbé existe aussi dans les écritures küfí - sous

96 Аввот Nadia, The Rise of the North Arabic Script and Its Kur'annic Development, with a Full Description of the Kur'ān Manuscripts in the Oriental Institute, Chicago, University of Chicago Oriental Institute Publications, 1939, p. 20.

97 BLAU, A Grammar of Christian Arabic, Based Mainly on South-Palestinian Texts from the First Millennium, op. cit., 1966, p. 21.

98 Lewis et Gibson, Forty-One Facsimiles of Dated Christian Arabic Manuscripts, op. cit., 1907, pp. 3-4 et planche II.

99 Kashoun, The Arabic Versions of the Gospels, The Manuscripts and their Families, op. cit., 2012, pp. 145-146.

$100 \quad$ Ibid., p. 146.

101 GACE K, Arabic Manuscripts, op. cit., 2009, p. 124. 
sa forme verticale, tandis que que dans les écritures hijāzīi, il est penché vers la droite $^{102}$.

$S^{b}$ se différencie nettement de $S^{a}$ par des alifs droits et une écriture plus petite et plus souple, bien qu'encore angulaire. Elle présente toujours des caractéristiques archaïques communes à $S^{a}$ (points 3, 4, 5 et 6 de la liste de Kashouh). À notre avis, l'écriture peut être rapprochée de celle de Sin. Ar. 514, un manuscrit palimpseste dont la dernière couche, écrite en arabe, a été évaluée au ge s. ${ }^{103}$ Tout en étant différente de celle de $S^{a}$, l'écriture de $S^{b}$ reste aussi proche de l'écriture de la planche II (Londres BL Or. 4950, 877). Ces comparaisons nous rapprochent donc de la fin du $9^{\mathrm{e}} \mathrm{s}$.

On notera encore que $S^{a}$ et $S^{b}$ utilisent des points diacritiques, mais de manière irrégulière. Ils n'utilisent pas de taškill, une caractéristique partagée par les manuscrits décrits par Blau ${ }^{104}$ dans son étude sur la langue des manuscrits arabes chrétiens du premier millénaire, mais s'étend après le $10^{\mathrm{e}} \mathrm{s}$. si l'on observe les planches de Lewis-Gibson (planche VII (Sin. Ar. 69, 1065), planche XIII (Sin. Ar. 117, 1204), planche XXXIV (Sin. Ar. 135, 1558).

L'écriture de $S^{c}$ est difficile à définir: elle est plus cursive que l'écriture de $S^{b}$ mais le trait semble encore trop épais pour être considéré comme du nashi. Contrairement à $S^{\mathrm{a}}$ et $S^{\mathrm{b}}, \mathrm{S}^{\mathrm{c}}$ utilise des voyelles, mais avec parcimonie (il marque surtout la damma -). Un élément particulier sont les alifs, qui présentent une voire deux brisures, pouvant prendre la forme d'un éclair. Cette caractéristique n'apparaît pas dans l'album Lewis-Gibson.

$S^{\mathrm{d}}$ a une écriture de type nashī qui est plus largement vocalisée et présente des šaddas. Il utilise par ailleurs le système de désambiguïsation des consonnes consistant à placer sous les homographes (comme 'ayn et gayn par exemple) une lettre miniature quand il s'agit de la lettre sans point. Déroche attribue ce

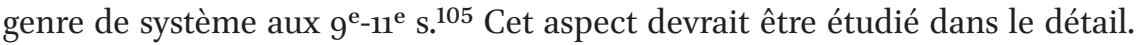
L'écriture se rapproche, selon nous, de celle de la planche XII de l'album LewisGibson, qui représente Sin. Ar. 82, daté de 1197.

102 Voir la typologique de Gacek. Ibid., p. 8.

103 Atiya Aziz Suryal, « Codex Arabicus (Sinai Arabic Ms. No. 514)», in: Le hmann-Haupt Hellmut (éd.), Homage to a Bookman: Essays on Manuscripts, Books and Printing Written for Hans P. Kraus on His 6oth Birthday Oct. 12, 1967, Berlin, Gebr. Mann Verlag, 1967, pp. 7585. Voir les images: $<$ https://www.loc.gov/item/o0279390210-ms/>. Un fragment se trouve dans la collection Schøyen: <http://www.schoyencollection.com/apocryphal-literature/ codex-arabicus-ms-579>. Voir aussi le Sinai Palimpsests Project (sur inscription) : $<$ https:// sinai.library.ucla.edu/>. Liens consultés le 01.02.2018.

104 Voir chapitre 8, point 2 Moyen arabe.

105 Déroche (éd.), Manuel de codicologie des manuscrits en écriture arabe, op. cit., 2000, pp. 239-240. 


\subsection{Souscription et épigramme}

Concernant les informations qu'ont laissés les copistes eux-mêmes dans le manuscrit, deux sont notables.

\subsubsection{Souscription en arabe (179r)}

En 179r, à la suite du desinit de l'épître aux Hébreux, le même scribe $\left(S^{\mathrm{b}}\right)$ écrit la souscription suivante :

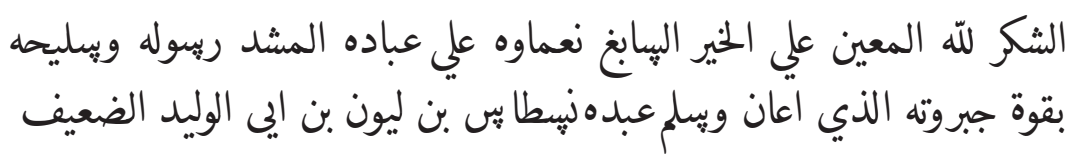

Grâce à Dieu, celui qui contribue au bien, qui abonde en grâce pour ses serviteurs, qui raffermit son envoyé et son disciple par la force de sa toute puissance, qui a aidé et qui a protégé son serviteur Nasțās ${ }^{106}$ ibn Liyūn ibn Abī al-Walīd, le faible.

Cette souscription ne nous donne pas d'autre information à part le nom du copiste, lequel n'aide pas à préciser l'origine ou la fonction du scribe. Nous ne pouvons pas non plus exclure que le scribe ait copié une souscription existante. Le nom du copiste est accompagné par certaines caractéristiques communes pour les manuscrits arabes chrétiens, mises en évidence par Troupeau : «La mention du copiste, désigné par le nom de 'abd «serviteur » [...], est toujours accompagnée d'un ou de plusieurs qualificatifs dépréciatifs, destinés à bien marquer son indignité »107; ici, le dépréciatif est الضعيف le faible»108.

\subsection{2 Épigramme grec (179v)}

Au verso (179v), on trouve le texte en grec suivant ${ }^{109}$ :

106 Scholz proposaitJustas (SCHOLZ, « Ueber die arabischen Handschriften des N.T. zu Rom », art. cit., 1823, p. 126), Mai Justus (MAI, Scriptorum veterum nova collectio e Vaticanis codicibus edita, op. cit., 1831, p. 13); Guidi propose de lire un nom propre se rapprochant d'Anastasio (Guid, Le Traduzioni degli Evangelii in arabo e in etiopico, op. cit., 1888, p. 8). Les deux premiers semblent n'avoir pas vu le point diacritique sur le nūn.

107 Troupeau Gérard, «Les colophons des manuscrits arabes chrétiens », in : Déroche François et Richard Francis (éds), Scribes et manuscrits du Moyen-Orient, Paris, Bibliothèque nationale de France, 1997, p. 227.

108 L'utilisation de cet adjectif n'est pas une surprise dans ce cadre; nous noterons aussi qu'il correspond au vocabulaire paulinien et qu'on le retrouve souvent dans le texte de 1 Corinthiens, voir ci-dessous 1,$27 ; 4,10 ; 8,7-12 ; 9,22 ; 12,22$.

109 Nous remercions David Bouvier, Christiane Furrer et Christophe Guignard pour toutes leurs pistes de travail. 
Transcription du colophon ${ }^{110}$

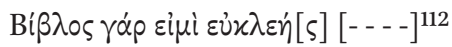

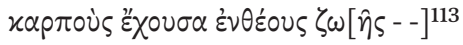

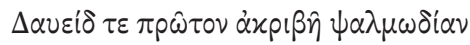

Traduction ${ }^{111}$

Je suis un livre réputé [----]

ayant les fruits divins de la vie [--]: portant ( $\varphi \varepsilon ́ p o v \sigma \alpha)$ en premier, le chant exact de David,

$x \varepsilon \dot{\nu} \alpha \gamma \varepsilon \lambda 1 \sigma \tau \hat{\omega} \nu \tau \dot{\alpha} \varsigma \varphi \dot{\alpha} \sigma \varepsilon ı \varsigma \tau \hat{\omega} \nu \tau \varepsilon \tau \tau \dot{\alpha} \rho \omega \nu$ et les récits des quatre évangélistes,

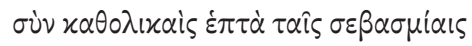

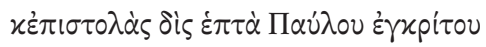

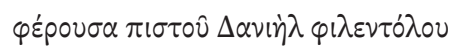

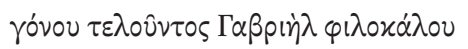

ensuite, les actes des sages apôtres, avec les sept (épîtres) catholiques, les vénérables, et les quatorze épîtres de Paul l'élu, [livre] du fils (yóvou) du fidèle Daniel philentolos, [originaire] d'Emèse resplendissante, Gabriel philokalos qui achève ['ouvrage], alors sa patrie,

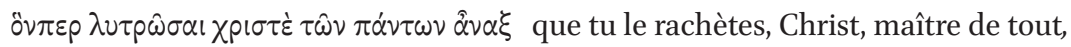

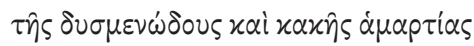

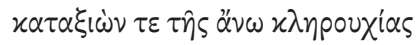

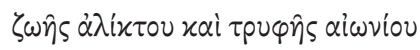

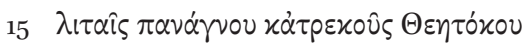

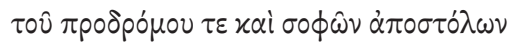

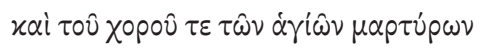

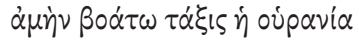

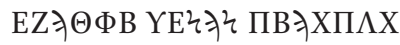
$\mathrm{C} \imath \Theta \Pi \Lambda \mathrm{N} \Lambda \mathrm{X} \dagger$

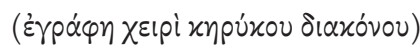
de la méchanceté et des mauvais péchés, [le] jugeant digne de la colonie céleste, de la vie éternelle et du bien-être pour l'éternité, par les prières de la toute sainte et franche Theotokos, Du précurseur et des sages apôtres, Et du chœur des saints martyrs, que l'ordre qui est céleste crie : Amen!

(écrit de la main d'un diacre prédicateur)

110 Scholz offre une transcription du colophon (ScHOLZ, «Ueber die arabischen Handschriften des N.T. zu Rom », art. cit., 1823, p. 126); Guidi le transcrit également, mais sans la signature cryptée, Guidi Ignazio, Le Traduzioni degli Evangelii in arabo e in etiopico, Rome, Tipografia della r. accademia dei Lincei, 1888 (Atti della reale accademia dei Lince 4), p. 8.

111 Dans la mesure du possible, nous essayons de respecter l'ordre des mots. Toutefois, il nous a parfois fallu pour des raisons de compréhension déplacer un mot d'une ligne à l'autre. Afin de rendre ce déplacement visible, nous avons rajouté le mot grec entre parenthèses.

112 Il manque ici 4 syllabes.

113 Il manque ici 2 syllabes. 
Le texte est écrit en majuscule ogivale inclinée, une écriture surtout répandue entre le $8^{\mathrm{e}}$ et le $9^{\mathrm{e}} \mathrm{s} .^{114}$ Cela correspond à nos remarques paléographiques à propos des écritures de $\mathrm{S}^{\mathrm{a}}$ et $\mathrm{S}^{\mathrm{b}}$. L'écriture ressemble à celle des incipit grecs (point 3.7) et de certaines indications de lecture (point 3.8).

Il est en dodécasyllabe, ce qui le rapproche du genre des «épigrammes byzantins ». Les épigrammes byzantins sont des poèmes en grec qui accompagnent souvent les manuscrits byzantins médiévaux ${ }^{115}$. Ce genre est très répandu et fait l'objet d'un projet de recherche qui établit une base de données de ces épigrammes, Database of Byzantine Book Epigrams (D ввЕ). Le dodécasyllabe y est très populaire : la base de données DввE recense plus de 3152 épigrammes en dodécasyllabe.

Le fait que le livre prenne la parole au début semble faire partie de ce genre poétique : grâce à la base de données, nous avons trouvé la même formulation dans deux manuscrits du Mont Athos, Monê Megistês Lauras $\Delta{ }_{71}\left(1^{\mathrm{e}} \mathrm{s} \text {. }\right)^{116}$ et Monê Koutloumousiou $307\left(14^{\mathrm{e}} \mathrm{s} \text {. }\right)^{117}$. On trouve par ailleurs des expressions similaires, comme par ex. őpravov घijul (Florence BML Plut. 72, Cod. 3$)^{118}$. Notre épigramme s'inscrit plutôt dans la catégorie «text-related», donnant surtout des informations sur le contenu du manuscrit ${ }^{119}$. On apprend ainsi que le manuscrit contenait initialement les Psaumes, les quatre évangiles, les Actes des Apôtres, les sept lettres catholiques, les quatorze lettres de Paul, ce qui est confirmé par l'étude des signatures des cahiers.

Il est mentionné ensuite deux noms, Daniel et Gabriel. Ceux-ci sont suivis des qualificatifs philentolos « qui aime les commandements » et philokalos « qui aime le beau», pouvant tout autant être des noms propres que des adjectifs épithètes ${ }^{120}$. Le terme yóvov exprime une relation filiale (familiale ou autre)

114 Pennot Laurent, «La paléographie grecque et byzantine au colloque de Paris (21-25 octobre 1974) », Revue des Études grecques 91 (432-433), 1978, p. 167. BADY Guillaume, «Petit album de paléographie grecque », Sources chrétiennes, HiSoMa, 2007. En ligne : <http:// www.sources-chretiennes.mom.fr/upload/doc/Album_paleo_grecque.pdf $>$, consulté le 19.10.2015.

115 Voir l'ouvrage de référence: Lauxtermann Marc D., Byzantine Poetry from Pisides to Geometres. Texts and Contexts, vol. 1, Vienne, Verlag der Österreichischen Akademie der Wissenschaften, 2003 (Wiener Byzantinische Studien 24). Nous remercions David Bouvier pour la référence. Voir aussi Bentein Klaas et Demoen Kristoffel, «The Reader in Eleventh-century Book Epigrams », in : Bernard Floris et DEmoen Kristoffel (éds), Poetry and its Contexts in Eleventh-century Byzantium, Farnham, Ashgate, 2013, pp. 69-88.

116 <http://www.dbbe.ugent.be/occ/211>, consulté le 24.03.2016.

117 <http://www.dbbe.ugent.be/occ/3686>, consulté le 24.03.2016.

118 <http://www.dbbe.ugent.be/occ/2974>, consulté le 24.03.2016.

119 Voir les catégories proposées : <http://www.dbbe.ugent.be/help>, consulté le 24.03.2016.

120 Si philokalos est attesté comme nom propre (voir notamment Lexicon of Greek Personal

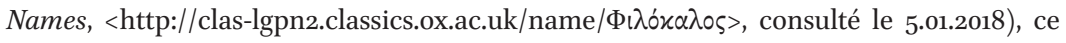
n'est pas le cas de philentolos. 
entre les deux individus. Il n'est pas possible d'affirmer avec certitude qui est le « père » et qui est le « fils », mais nous supposons que, étant donné que yóvov se trouve dans le même vers que Г $\alpha \beta p$

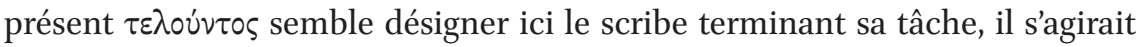
donc du scribe Gabriel philokalos, fils de Daniel philentolos.

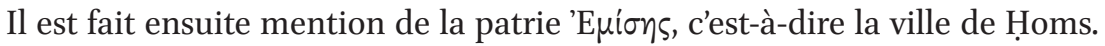
S'agit-il du lieu d'origine du manuscrit ou du scribe? Le relatif o ̃ semble relier la ville à Daniel, une caractéristique qui lui serait propre, souligné par $\alpha$ $\tau \varepsilon$. D'un autre côté, il serait quelque peu surprenant de trouver une information géographique à propos du scribe sans trouver son équivalent à propos du manuscrit, le scribe se mettant d'ordinaire au second plan ${ }^{121}$. La question de savoir si 'Exíns est la ville d'origine du scribe ou du manuscrit reste à notre avis ouverte (voir aussi 3.2 Le lieu d'origine du manuscrit).

On trouve à la fin une signature cryptographiée. Elle est déchiffrée par une

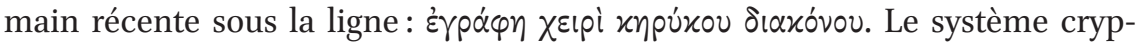
tographique fonctionne comme suit: l'alphabet (y compris les lettres numériques) est séparée en trois «ennéades » suivant les lettres utilisées pour les unités, les dizaines et les centaines. Chaque liste est inversée pour obtenir un équivalent encrypté122 :

\section{$\mathrm{EZ} \ni \Theta \Phi B$ YE々阮 ПВ

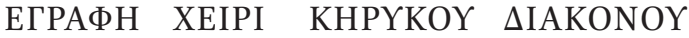

\begin{tabular}{|c|c|c|c|c|c|}
\hline \multicolumn{2}{|c|}{ Unités } & \multicolumn{2}{|c|}{ Dizaines } & \multicolumn{2}{|c|}{ Centaines } \\
\hline à encrypter $\downarrow$ & crypté $\uparrow$ & à encrypter $\downarrow$ & crypté $\uparrow$ & à encrypter $\downarrow$ & crypté $\uparrow$ \\
\hline $\mathrm{A}(=1)$ & $\Theta$ & $\mathrm{I}(=10)$ & $\xi$ & $\Pi(=100)$ & $\Rightarrow$ \\
\hline $\mathrm{B}(=2)$ & $\mathrm{H}$ & $\mathrm{K}(=20)$ & $\Pi$ & $\Sigma(=200)$ & $\Omega$ \\
\hline$\Gamma(=3)$ & $\mathrm{Z}$ & $\Lambda(=30)$ & $\mathrm{O}$ & $\mathrm{T}(=300)$ & $\Psi$ \\
\hline$\Delta(=4)$ & $\varsigma$ & $\mathrm{M}(=40)$ & $\Xi$ & $Y(=400)$ & $\mathrm{X}$ \\
\hline $\mathrm{E}(=5)$ & $\mathrm{E}$ & $\mathrm{N}(=50)$ & $\mathrm{N}$ & $\Phi(=500)$ & $\Phi$ \\
\hline$S(=6)$ & $\Delta$ & $\Xi(=60)$ & $\mathrm{M}$ & $X(=600)$ & Y \\
\hline $\mathrm{Z}(=7)$ & $\Gamma$ & $\mathrm{O}(=70)$ & $\Lambda$ & $\Psi(=700)$ & $\mathrm{T}$ \\
\hline $\mathrm{H}(=8)$ & B & $\Pi(=80)$ & $\mathrm{K}$ & $\Omega(=800)$ & $\Sigma$ \\
\hline$\Theta(=9)$ & A & $\zeta(=90)$ & I & $\exists(=900)$ & $\Pi$ \\
\hline
\end{tabular}


Scholz semble considérer xnpúxov comme un nom propre, ce qui pousse à croire qu'il s'agit d'un autre individu qui a copié un colophon dans lequel il est question de Gabriel, fils de Daniel ${ }^{123}$. xnpúxou pourrait aussi être un qualificatif (dérivé de $\varkappa \eta \rho v \sigma \sigma \omega)$ appliqué au diacre : «le diacre prédicateur »; il s'agit peutêtre d'un titre spécifique pour le diacre en charge de la prédication.

Dans tous les cas, il y a au moins deux noms de scribes différents donnés dans le manuscrit, Nasṭās ibn Liyūn ibn Abī al-Walīd en arabe en 179r et Gabriel philokalos, fils de Daniel philentolos en grec en 179v, voire trois noms si on considère le diacre Kērukos. Cela n'est pas étonnant, vu qu'au moins deux scribes sont actifs dans la copie du manuscrit dès le début de la constitution de celui-ci.

\subsection{Incipit et desinit}

Tous les livres dont le début a été préservé, c'est-à-dire toutes les lettres de Paul, ont un incipit et un desinit en arabe écrit à l'encre rouge, ainsi qu'un incipit en grec se situant dans la marge supérieure. Les incipit sont succincts ${ }^{124}$. Au début de 1 Corinthiens (103r), on trouve à l'encre rouge l'incipit arabe suivant :

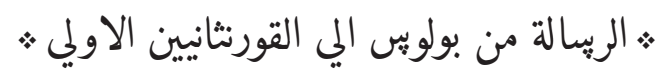

La lettre de Paul aux Corinthiens, la première

On trouve écrit dans la marge supérieure de 103r, à l'encre rouge, l'incipit grec:

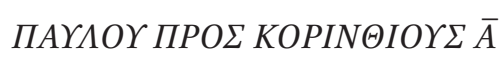

Le même incipit grec est répété dans la marge supérieure du folio $111 r$.

Les desinit des lettres de Paul présentent l'apparat euthalien en arabe, écrit à l'encre rouge. Dans le cas de 1 Corinthiens (12or), on trouve :

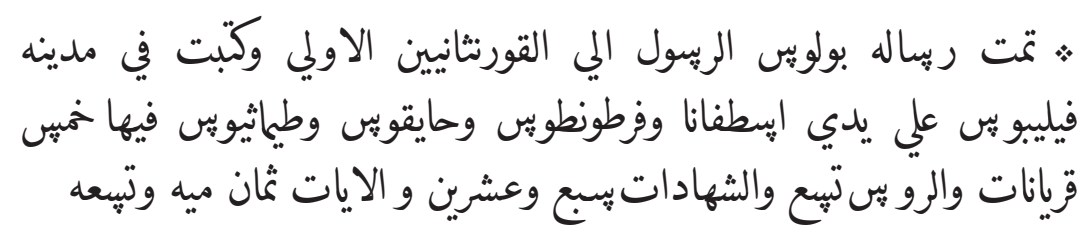

123 Scholz, «Ueber die arabischen Handschriften des N.T. zu Rom », art. cit., 1823, p. 126.

124 Au début de Romains, on trouve, en plus de l'incipit similaire à celui de 1 Corinthiens : سم الاب والابن وروح القدس. 
est terminée la lettre de Paul l'apôtre aux Corinthiens, la première, elle a été écrite dans la ville de Philippes, à l'aide de Stéphane, Fortunatus et Achaïus et Timothée; dans celle-ci se trouvent cinq leçons, neufs chapitres, vingt-sept testimonia, 809 signes.

Ce desinit correspond au texte syriaque de la version harkléenne $\left(\mathrm{sy}^{\mathrm{h}}\right)$ telle qu'éditée par Barbara Aland ${ }^{125}$. Le matériel euthalien peut toutefois avoir été transmis par le grec ou par un manuscrit de la Peshitta révisé sur sy ${ }^{\text {h126. On }}$ notera encore que la mention de la ville de Philippes appartient à la tradition majoritaire byzantine ${ }^{127}$. Jusqu'à présent, la tradition arabe n'est pas intégrée dans l'étude de l'apparat euthalien ${ }^{128}$.

\subsection{Indications de lectures}

3.8.1 Les différentes indications de lecture dans le manuscrit

Plusieurs éléments dans le manuscrit sont les témoins de son utilisation comme lectionnaire.

(1) On trouve des éléments directement dans le corps du texte, ponctué des

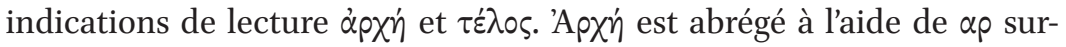
monté de $\chi ; \tau \dot{\varepsilon} \lambda \circ \varsigma$ est abrégé à l'aide de $\tau$ surmonté de $\varepsilon$ et surligné par un longe tilde $\sim$. Nous les signalons dans l'édition à l'aide de $\overline{\alpha \rho \chi}$ et de $\overline{\tau \varepsilon}$ (voir chapitre 7 , point 4). Ces abréviations ont clairement été ajoutées dans un second temps: elles se superposent à la ponctuation ou sont écrites dans la marge. Elles sont souvent écrites à l'encre rouge, comme c'est le cas dans 1 Corinthiens, ou à l'encre noire. Des notes de ce genre existent également dans des manuscrits bibliques grecs au texte continu ${ }^{129}$. Seuls les cahiers copiés par $S^{d}$ (ff. 7-14 et 47-54) n'en portent pas la trace.

125 Aland Barbara, Das Neue Testament in syrischer Überlieferung. II. Die Paulinischen Briefe. Teil 1. Römer- und 1. Korintherbrief, Berlin, New York, de Gruyter, 1991, p. 499. Voir aussi les pages $67-69$.

126 Voir l'exemple à propos du prologue euthalien donné par BRоск Sebastian P., «The Syriac Euthalian Material and the Philoxenian Version of the New Testament», Zeitschrift für die neutestamentliche Wissenschaft 70, 1979, pp. 120-130.

127 Амрноux Christian-B., «Les lieux de rédaction des lettres de Paul d'après la tradition manuscrite », BABELAO 2, 2013, pp. 87-104.

128 Voir par exemple le récent ouvrage Willard Louis Charles, A Critical Study of the Euthalian Apparatus, Berlin, New York, de Gruyter, 2009 (Arbeiten zur neutestamentlichen Textforschung 41).

129 ENGBERG Sysse, « Les lectionnaires grecs », IRHT, 2015. En ligne : <http://irht.hypotheses. org/612>, consulté le 23.05.2016. 
On trouve également des indications en grec dans la marge supérieure des pages. Celle-ci sont de plusieurs sortes, écrites à l'encre rouge ou noire, et d'au moins trois mains différentes.

(2) On trouve parmi elles, écrite à l'encre noire, des références à un calendrier liturgique, par exemple :

3v: KYPHAKH A

$16 \mathrm{v}: \Sigma$ ABBAT $\Omega \mathrm{N} \Delta$

9ov: KYPIAKH B

On trouve alors le plus souvent un $\overline{\alpha \rho \chi}$ dans le corps du texte de la page en question. La main semble plus récente que celles des indications de type (3) ci-dessous.

Comme c'est le cas pour les signes $\overline{\alpha \rho \chi}$ et $\overline{\tau \varepsilon}$, les cahiers copiés par $\mathrm{S}^{\mathrm{d}}$ (ff. 7-14 et 47-54) n'en portent pas la trace.

(3) D'autres indications fonctionnent conjointement avec les notes $\overline{\alpha \rho \chi}$ et $\overline{\tau \varepsilon}$ dans le texte. Elles donnent les premiers mots en grec de la leçon qui commence avec $\overline{\alpha \rho \chi}$. La description détaillée de celles que l'on trouve en 1 Corinthiens permet de comprendre leur fonctionnement général (voir ci-dessous). Ces indications sont écrites à l'encre rouge ou noire et ont été faites par plusieurs mains. On ne les trouve pas dans le cahier de $S^{c}$ (ff. 1-6) ni de de $S^{d}$ (ff. 7-14 et 47-54).

(4) Enfin, dans les folios 1-6 $\left(\mathrm{S}^{\mathrm{c}}\right)$, on trouve des indications de lecture en arabe dans le corps du texte, commençant par une formule telle que هذا يقرا.

En résumé, nous pouvons souligner que toutes les parties du manuscrit semblent avoir été utilisées comme lectionnaire, à l'exception des cahiers les plus récents, copiés par $S^{\mathrm{d}}$ (ff. 7-14 et 47-54). Les cahiers copiés par $S^{\mathrm{a}}$ et $S^{\mathrm{b}}$ sont les seuls à avoir les indications de type (3), de mains plus anciennes, tandis que les indications de type (2), ajoutées vraisemblablement après le travail de $S^{c}$, parcourent les cahiers de $S^{\mathrm{a}}$, $S^{\mathrm{b}}$ et $S^{\mathrm{c}}$ (le folio $15 \mathrm{v}$, par exemple, présente ainsi des indications de type (2) et de type (3) dans la marge supérieure). Ces éléments viennent soutenir la chronologie de la composition du manuscrit (voir 3.9 Conclusion).

3.8.2 Détails des indications de lecture dans 1 Corinthiens

Dans les folios contenant 1 Corinthiens (ff. 103r-120r), on trouve dans le corpus du texte les indications de type (1) $\overline{\alpha \rho \chi}$ (23 fois) et $\overline{\tau \varepsilon}$ (31 fois) écrits à l'encre rouge. Nous les signalons dans l'édition diplomatique (voir chapitre 7, point 2). Dans la marge supérieure, on trouve des indications de type (3). Il s'agit des premiers mots en grec de la leçon qui commence là où se trouve $\alpha$ pxý dans le corps du texte. Ces débuts de lecture sont le plus souvent précédés par l'indication du thème de la lecture. Au f. 108v, par exemple, on trouve ainsi EI $\Sigma$ 


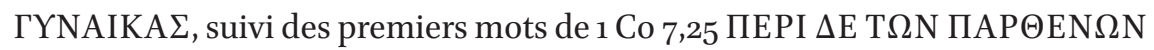

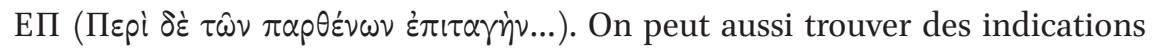
liturgiques, à l'image du type (2) ci-dessus, comme en 103v, où l'on a KYPIAKH $\bar{\Sigma} \overline{\Sigma \mathrm{P} \Omega}$, suivi des premiers mots de 1 Co 1,18: О $\Lambda$ ОГО $\Sigma$ TOY $\Sigma$ TPOҮTOY $\Sigma$ ('O

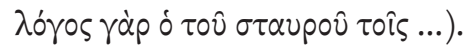

Nous transcrivons ici les indications que l'on trouve en 1 Corinthiens et les passages auxquels elles se réfèrent:

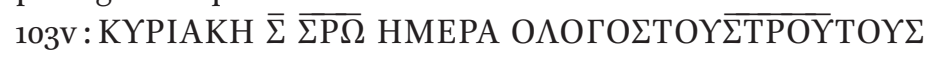

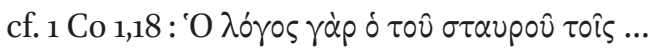

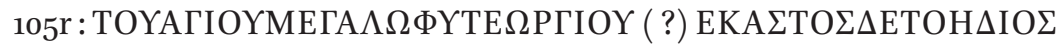

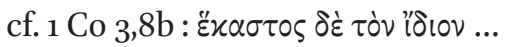

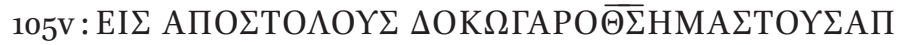

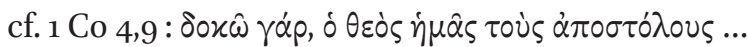

$107 \mathrm{r}$ : EI $\Sigma T O N A \Pi O \Theta E \Sigma H N T \Omega$ KPE $\Omega N($ ?) HOIKOI $\Delta$ ATEOTHA $\Delta$ HKOI

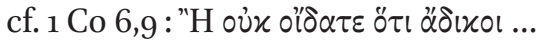

108v : EI $\Sigma \Gamma Y N A I K A \Sigma ~ П E P I \Delta E T \Omega N \Pi A P \Theta E N \Omega N E \Pi$

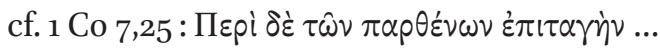

110v : EI $\Sigma T O N A \Gamma I A \Sigma M O N T \Omega N A \Gamma I \Omega N Y \Delta A T \Omega N$ OY $\Theta E \Lambda \Omega \Delta$ EYMA $\Sigma$

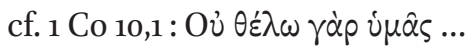

$112 v$ : ТНАГІА Е ЕГЛПАРЕ $\Lambda$ АВОNАПОТОҮ $\overline{K Y}$

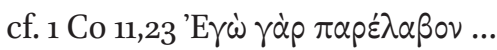

$114 \mathrm{r}: \operatorname{EI} \Sigma T \Omega N[\ldots]$ KAIEI $\Sigma[\ldots]$ YMH $\Sigma$ E $\Sigma T E \Sigma \Omega M A \overline{X Y} K A I$

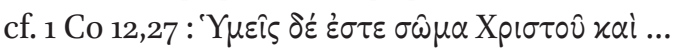

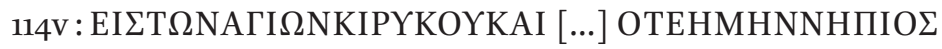

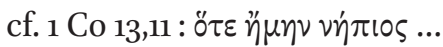

$115 \mathrm{r}$ : ЕІ $\Sigma \Pi$ ПО $Ф Н T A \Sigma$ А $\Delta$ Е $\Lambda \Phi O I M H \Pi E \Delta I A N E \Sigma \Theta$

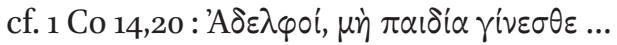

116r: $\Sigma$ ABBAT $\Omega N M E \Gamma A \Lambda \Omega \Gamma N \Omega P I Z \Omega \Delta E Y M I N A \Delta E \Lambda \Phi \Theta$

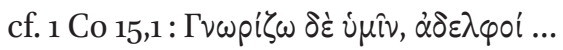

$116 \mathrm{v}$ : EI $\Sigma$ KAIKOIMIMENOI $\Sigma$ H $\Delta$ EX $\Sigma$ KHPOI $\Sigma \Sigma$ EITAI

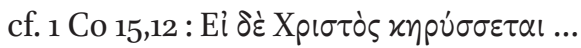

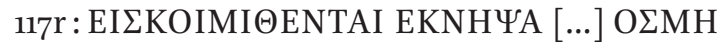

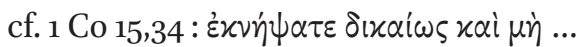

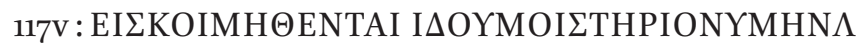

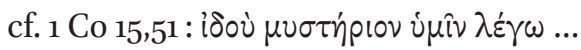

De manière générale, les indications de lecture dans le Vat. Ar. 13 demanderaient une étude minutieuse que nous ne pouvons mener ici. Dans tous les cas, elles attestent que le manuscrit a été utilisé par un clergé pour lequel le grec était une langue d'usage. Une comparaison avec des lectionnaires en circulation dans les communautés pourraient donner des indications sur la 
communauté dans laquelle le manuscrit était utilisé130. L'étude des indications de type (3) peut également présenter un intérêt pour la critique textuelle du Nouveau Testament. Ces passages peuvent être des extraits du texte grec sur lequel la traduction se base, des extraits d'un texte grec différent ou des citations de mémoire du scribe.

\subsection{Conclusion}

Une première conclusion peut être faite sur l'aspect général du manuscrit. Dans son chapitre sur la paléographie arabe, Déroche propose de faire la distinction entre graphie «soignée » et «informelle» :

[...] il a été jusqu'à présent assez peu fait usage de manière cohérente d'une distinction fondamentale entre d'une part, les graphies « soignées » (ou « calligraphiées»), réalisées par des professionnels avec le souci de la régularité et l'intention d'obtenir un résultat élégant, et, d'autre part, celles, « informelles », qui sont le fait de personnes maîtrisant insuffisamment l'écriture ou ne ressentant pas le besoin d'employer une écriture formelle ${ }^{131}$.

Dans le cas de notre manuscrit, aucun scribe ne présente une écriture régulière et il semble que la qualification d'«informelle » peut s'appliquer à l'écriture, mais aussi à d'autres aspects du manuscrit. En effet, nous avons noté l'irrégularité dans la taille des folios et dans la mise en page (point 3.3), qui ne peut pas être seulement imputée à l'histoire compliquée du manuscrit. Il serait intéressant de savoir si l'aspect général «informel » du manuscrit Vat. Ar. 13 a des parallèles chez d'autres manuscrits chrétiens de la même époque, comme c'est en tout cas le cas au niveau de l'écriture (Sin. Ar. 151, par exemple, partage ce type d'écriture «informelle»).

Concernant l'histoire de la composition du manuscrit, de nombreuses questions restent ouvertes et nous empêchent d'être conclusifs. Nous pouvons toutefois résumer ainsi plusieurs étapes:

130 Les manuscrits sinaïtiques, par exemple, présentent dans certains cas le système de lecture de l'ancienne liturgie de Jérusalem (Sin. Ar. 54, Sin. Ar. 72, Sin. Ar. 74, du 9 s., Sin. Ar. 70, du 9-10 $\mathrm{e}$ s., Sin. Ar. 97, du $12^{\mathrm{e}}$ s.) Voir Janeras Sebastià, « Les lectionnaires de l'ancienne liturgie de Jérusalem », Collectanea Christiana Orientalia 2, 2005, pp. 71-92. La thématique n'est pas nouvelle, voir BAUMSTARK Anton, «Die sonntägliche Evangelienlesung im vorbyzantinischen Jerusalem », Byzantinische Zeitschrift 30, 1930, pp. 350-359. D’autres particularités locales au sein des communautés byzantines ne sont pas exclues.

131 Déroche (éd.), Manuel de codicologie des manuscrits en écriture arabe, op. cit., 2000, p. 232. 
1. $\quad S^{a}$ et $S^{b}$ (peut-être avec d'autres scribes) copient les Psaumes, les quatre évangiles, les Actes, les sept lettres catholiques et les quatorze lettres de Paul ; cette première étape laisse comme trace la numérotation en grec des cahiers. L'épigramme grec (voir point 3.6.2) date d'une époque où le manuscrit était encore entier. Les incipit et les indications de lecture de type (3) en grec datent de cette période également (voir points 3.7 et 3.8).

2. Pour une raison inconnue, peut-être liée à la taille du manuscrit et à son utilisation régulière, des parties du manuscrit se perdent.

3. Cela mène à un travail de restauration du texte manquant (a-t-on restauré seulement les évangiles, ou le reste également?), travail auquel $S^{c}$ a participé (cahier 1). Le manuscrit est utilisé dans la communauté : comme les cahiers de $S^{a}$ et $S^{b}$, le cahier de $S^{c}$ porte des marques de lecture de type (2) (voir point 3.8).

4. Pour une raison inconnue, des parties du manuscrit se perdent à nouveau.

5. Une nouvelle tentative de compléter le manuscrit a lieu, auquel $S^{d}$ a participé (cahier 2 et cahier 7 ). Comme les parties de $S^{d}$ ne portent pas d'indications de lecture grecques, le manuscrit n'était peut-être plus utilisé dans une communauté.

6. Le manuscrit n'a pas été complété dans sa totalité ou des folios sont à nouveau perdus ; 179 folios (ou 178, voir la note 4 ci-dessus), sont rapportés à Rome par Assemani, qui les a acquis dans la région Syrie-Liban (voir point 3.2). Le manuscrit reçoit une nouvelle reliure et une nouvelle foliotation (en chiffres arabes). 


\section{Édition de 1 Corinthiens dans le Vat. Ar. 13}

Remarques introductives concernant l'édition et ses standards

Comme nous l'avons vu au chapitre précédent, 1 Corinthiens a été copié par le scribe $S^{b}$ (chapitre 6, point 3 ). Le scribe fait un usage restreint des signes diacritiques : les folios copiés par $S^{b}$ ne présentent pas de tašk kìl; de manière générale, le système de l'íjām est utilisé pour démarquer les consonnes (à l'exception de la $t \bar{a}^{\prime}$ marbūta, qui est notée sans points), mais les points diacritiques sont régulièrement décalés ou absents. C'est souvent le cas dans les textes en moyen arabe, état de la langue comprenant des caractéristiques orthographiques, morphologiques et syntaxiques que nous décrivons au chapitre 8, point 2.2.

Le moyen arabe, qui s'éloigne des standards de l'arabe «classique», est un défi pour celui qui veut l'éditer et les avis divergent parmi les chercheurs éditant des textes présentant des irrégularités. De manière générale, comme l'explique Paolo La Spisa, deux méthodes s'affrontent dans le monde de l'édition des textes arabes, qui cherchent respectivement à respecter: « le principe de fidélité (à l'auteur, aux témoins, à l'archétype) et la lisibilité du texte édité. Notamment d'un côté on choisit [...] une fidélité presque fétichiste au témoin, de l'autre on se donne la liberté d'intervenir tantôt dans le contenu tantôt dans la forme linguistique $»^{1}$. Dans le cas des textes arabes chrétiens, présentant souvent du moyen arabe, la manière de faire a généralement été la copie fidèle du texte manuscrit, comme le montre la ligne éditoriale du Corpus Scriptorum Christianorum Orientalium (csco) par exemple ${ }^{2}$. En 1981, Samir K. Samir critique cependant fortement cette méthodologie, arguant que: «le travail de l'éditeur ne consiste pas à éditer un manuscrit ou un copiste, mais un texte et un auteur. Il s'agit de rendre le texte de cet auteur aussi fidèlement intelligible que possible. $»^{3}$ Samir défend ici le rôle de l'éditeur, soulignant que son travail «ne consiste pas à transcrire un manuscrit, car alors l'appareil photographique

1 LA SPISA Paolo, « Perspectives ecdotiques pour textes en moyen arabe : L'exemple des traités théologiques de Sulaymān al Ġazzī», in : ZACK Liesbeth et Schippers Arie (éds), Middle Arabic and Mixed Arabic : Diachrony and Synchrony, Leiden, Boston, Brill, 2012, p. 193.

2 Ibid.

3 SAmir Samir Khalil, «La tradition arabe chrétienne. État de la question, problèmes et besoins », in: Actes du premier congrès international détudes arabes chrétiennes (Goslar, septembre 1980), Rome, Pontificio Instituto Orientale, 1982 (Orientalia Christiana Analecta 210), p. 78.

(C) SARA SCHULTHESS, 2019 | DOI:10.1163/9789004378162_008

This is an open access chapter distributed under the terms of the prevailing CC-BY-NC License at the time of publication. 
est bien supérieur à l'éditeur $! »^{4}$ Pour Samir, il faut donc moderniser l'orthographe ${ }^{5}$ mais aussi normaliser la grammaire, car « il est raisonnable de penser que les erreurs grammaticales, qui abondent souvent dans les manuscrits, ne sont pas imputables aux auteurs. Elles sont dues presque toujours aux copistes, qui ne sont pas nécessairement des scribes de métier [...]. » ${ }^{6}$ Pour lui, « [c]ette hypothèse [...] est confirmée par le fait qu'une même forme sera correcte dans un manuscrit et incorrecte dans un autre; ou même, sera correcte en un endroit et incorrecte en un autre endroit, dans le même manuscrit. $\gg^{7}$ Or il est tout à fait possible que ces différences entre versions viennent, au contraire, de corrections faites par les scribes. Enfin, une certaine inconsistance semble davantage être, dans le cas du moyen arabe, une caractéristique intrinsèque de celui-ci que le fruit d'erreurs ou de corrections ${ }^{8}$. La question de Samir quant au rôle de l'éditeur est tout à fait justifiée, mais imputer les différents « écarts » de la langue aux scribes est problématique. Dans le cas du moyen arabe, il ne s'agit pas d'erreurs liées à la méconnaissance de la langue mais de caractéristiques propres à l'état de la langue utilisée dans les milieux producteurs des textes (voir chapitre 8, point 2 Moyen arabe).

Les chercheurs travaillant avec des textes en moyen arabe défendent généralement une édition fidèle aux spécificités de ce dernier. Dans leur préface aux actes du colloque sur le moyen arabe tenu à Louvain en 2004, Lentin et Grand'Henry déplorent le processus éditorial qui cherche à normaliser l'arabe du texte édité et qui ne permet pas d'avoir accès aux spécificités du moyen arabe $^{9}$. Ce point de vue est également parté par Zuzka Gažáková, qui souligne : « it is important for editors of Middle Arabic texts to preserve all linguistic and orthographic particularities found in the manuscripts, regardless of how insignificant or incomprehensible they might seem. ${ }^{10}$

$4 \quad$ Ibid., p. 76 .

$5 \quad$ Ibid., p. 77 .

$6 \quad$ Ibid.

$7 \quad$ Ibid.

8 Le texte du Vat. Ar. 13 s'illustre par son alternance des formes correctes et non correctes. Voir chapitre 8, point 2 Moyen arabe.

9 LENTIN Jérôme et GRAND'HENRY Jacques (éds), Moyen arabe et variétés mixtes de l'arabe à travers l'histoire. Actes du Premier Colloque International (Louvain-la-Neuve, 10-14 mai 2004), Louvain, Peeters, 2008 (Publications de l'Institut Orientaliste de Louvain 58), pp. XI-XII.

10 MacÉ Caroline, Bausi Alessandro, Witakowski Witold et al., «Textual Criticism and Text Editing », in : Comparative Oriental Manuscript Studies : An Introduction, Hambourg, Tredition, 2015, p. 402. En ligne: <https://www.aa1.uni-hamburg.de/comst/publications/ handbook.html>, consulté le 31.07.2018. 
Si nous passons en revue les éditions de manuscrits arabes du Nouveau Testament, généralement des éditions diplomatiques, un processus de correction du texte, bien que limité, a souvent été appliqué en vue de l'édition. Nous donnons ici quelques exemples. Dans son édition du Sin. Ar. 155, Gibson explique son choix d'adapter le texte à l'orthographe moderne, tout en étant consciente de la perte d'informations que cela engendre:

The task of editing this version of the Epistles has been by no means an easy one. There were two methods which suggested themselves; the first and easiest being to print the text exactly as I read it with it many orthographical peculiarities. This method would have necessitated a profusion of foot-notes, and it is a question whether the ordinary reader would not have put it down with the remark that life is too short to puzzle oneself over crooked Arabic. The other method, the one I have adopted after consultation with Professor Robertson Smith, is to print the text in the modern orthography, which not only makes it easier for European students to read, but also renders it accessible to Christian Arabs, however unlearned, while at the same time its peculiarities are indicated both in the preface and by a few notes. I have endeavoured to carry out this plan by marking each peculiarity only in the first place of its occurrence ${ }^{11}$.

Dans son édition du Sin. Ar. 154, Gibson semble se raviser et n'annonce que peu de corrections dans sa préface : «I have made few changes in editing, the principal ones being substitute Alif Maksoureh for Alif where that is the modern usage, and to supply final $\ddot{b}$ with dots to distinguish it from the pronominal suffix. $»^{12}$

Staal, dans sa première édition de Sin. Ar. 151, propose une méthode d'édition peu intrusive :

Inasmuch as possible, the spelling found in the original manuscript has been maintained, except where there is a very obvious mistake or where there might be confusion in the reading of a particular word. Letters that have been added to the original are enclosed in parentheses. Dots that

11 Gibson Margaret Dunlop, An Arabic Version of the Epistles of St Paul to the Romans, Corinthians, Galatians with Part of the Epistles to the Ephesians, Londres, C. J. Clay, 1894 (Studia Sinaitica 2), pp. 7-8.

12 Gibson Margaret Dunlop, An Arabic Version of the Acts of the Apostles and the Seven Catholic Epistles, Londres, C. J. Clay, 1899 (Studia Sinaitica 6), p. vii. 
have been added to the «tâ marbutah » to distinguish it from the « hâ », and to the «yâ » to distinguish it from the «Alif maqsurah $»^{13}$.

Or, dans son édition complète du manuscrit de 1983, bien que publiée par csco, l'adaptation du texte est beaucoup plus poussée. Les changements faits dans le texte sont les suivants:

The voweling of the original has been included, and some more added where the reading might be ambiguous. (...) It is obvious that I have added the diacritical points missing in the original. The same is true for the hemza, since there are just a few in the codex. In the original they are usually indicated by their corresponding long vowel, which I have replaced with the hemza. I have dropped final 'alif in such words as where it is not used today. I have corrected other final 'alifs to conform with the modern spelling. (...) I have made a few other changes of words that were obviously misspelled, or where the wrong grammatical form was used. In such cases I have put the corrected word in the text, with the original in the footnotes with the words في النص. I have done this because we do expect that this manuscript will be used by a number of people in the church, and they will find it less confusing ${ }^{14}$.

Cette décision est justifiée par le vœu de s'adresser, comme Gibson ${ }^{15}$, au public «arabe chrétien ».

Plus récemment, la décision de ne pas modifier le texte semble être préférée. Pour l'exemple, Samir Arbache, dans son édition de l'évangile de Luc du Sin. Ar. 72, touche très peu au texte :

Nous le présentons dans sa nudité. Par conséquent, tout ce qui ne provient pas du manuscrit a été signalé comme tel, additions hors texte ou compléments. Ainsi nous n'y apportons aucune correction orthographique ou grammaticale. Dans de très rares cas signalés par la barre inclinée entourant un mot, nous corrigeons une faute de copiste

13 StaAl Harvey, Codex Sinai Arabic ${ }_{15}$ Pauline Epistles, Studies and Documents (Rom., I \& II Cor., Phil.), 2 vol., Salt Lake City, University of Utah Press, 1969 (Studies and Documents) part II, p. 42. L'édition de 1969 ne comprend que quatre des épîtres du manuscrit.

14 Staal Harvey, Mt. Sinai Arabic Codex 151 I: The Pauline Epistles, vol. 1, Louvain, Peeters, 1983 (CSCO 452), pp. XII-XIII.

15 Gibson, An Arabic Version of the Epistles of St Paul to the Romans, Corinthians, Galatians with Part of the Epistles to the Ephesians, op. cit., 1894, p. 8. 
évidente (Luc 8,$\left.27 ; 11,5^{2} ; 24,7\right)$, ou nous ajoutons un mot oublié (Luc $6,23)$, ou une inversion de mots $\left(\operatorname{Luc} 6,5^{8}\right)^{16}$.

Mais qu'en est-il des points diacritiques? Même lorsque la fidélité au texte est de mise, les corrections au niveau des points diacritiques sont souvent pratiquées, étant considérées comme simplement graphiques ${ }^{17}$. Or l'ajout ou le retrait de points diacritiques permettant de distinguer une consonne d'une autre (بر ت ت ث ر ب etc.) peut s'apparenter à une correction orthographique, un type de corrections que Arbache refuse pourtant. Et qu'en est-il de l'absence de points diacritiques sur certaines consonnes et qui donnent lieu à des consonnes «qui n'existent pas » comme (ce qui arrive fréquemment dans le Vat. Ar. 13) ${ }^{18}$ ? Dans le cas des textes bibliques, seul Monferrer-Sala semble pour l'instant respecter l'absence de points diacritiques dans ces cas précis. Monferrer-Sala, dans son article sur Matthieu dans le Vat. Ar. 13, n'hésite

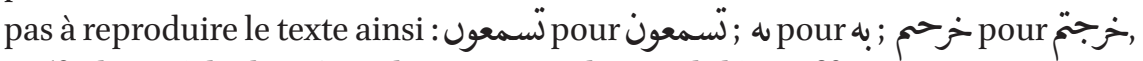
etc $^{19}$. Il procède de même dans son article sur Philémon ${ }^{20}$.

Les spécificités du moyen arabe rendent son édition difficile et comme nous l'avons vu, chaque chercheur tente de faire au mieux selon ses critères, privilégiant selon les cas la fidélité au texte ou sa lisibilité. Or, que l'éditeur se décide pour l'une ou l'autre de ces méthodes, il décide malgré tout des détails de son application. Nous trouvons ainsi toute une « palette» de textes édités. Plus que le moyen arabe en lui-même, c'est certainement ce manque de standardisation dans l'édition qui représente la plus grande difficulté pour le chercheur; c'est un des chantiers urgents de la recherche.

16 Arbache Samir, L'Evangile arabe selon saint Luc: texte du VIIIe siècle, copié en 897, Bruxelles, Safran, 2012, p. 26.

17 Il est intéressant de voir que même Blau, dans sa Grammar, corrige son objet d'étude: «All diacritic points have been restored in places where they were lacking in the Arabic manuscripts (even those of tâ marbûta and of final ya), in accordance with usual Classical orthography. » (BLAu Joshua, A Grammar of Christian Arabic, Based Mainly on SouthPalestinian Texts from the First Millennium, vol. Subsidia 27, Louvain, Secrétariat du CorpusSCO, 1966 (CsCo 267), p. 16).

18 ArbaChe, L'Evangile arabe selon saint Luc, op. cit., 2012, p. 2.

19 Monferrer-Sala Juan Pedro, «An Early Fragmentary Christian Palestinian Rendition of the Gospels into Arabic from Mar Saba (MS Vat. Ar. 13, 9th c.) », Intellectual History of the Islamicate World 1, 2013, p. 78, 81 et 82.

20 Monferrer-Sala Juan Pedro, «The Pauline Epistle to Philemon from Codex Vatican Arabic 13 (Ninth Century CE): Transcription and Study », Journal of Semitic Studies 60 (2), 2015, pp. 341-371. 
Dans le récent Handbook du COMSt, il est clairement indiqué : « In the case of a diplomatic edition based on a single, unique witness [...], all orthographic and linguistic features of the manuscript will be reproduced in the edition, even though they pertain to the period of the copy of the manuscript, which may be different from the time of composition of the work [...]. ${ }^{21} \mathrm{Vu}$ que nous avons décidé d'éditer un manuscrit (voir chapitre 1, point 2) que nous étudions avec ses particularités et que celui-ci est écrit en moyen arabe, il nous semble logique de privilégier la fidélité. Notre choix se porte donc sur une édition fidèle au texte et à ses particularités orthographiques et linguistiques, que nous appelons «diplomatique». Nous ne sommes toutefois pas insensible à l'argument de la lisibilité du texte édité, notamment pour le lecteur qui n'est pas habitué à travailler avec le moyen arabe. Nous avons développé cet aspect pour notre édition digitale (voir ci-dessous point 3).

Le texte du manuscrit est donc reproduit dans ce volume le plus fidèlement possible (point 4). Il s'agit d'une transcription du corps du texte, y compris les indications de lecture qu'on y trouve. Dans le manuscrit, àpxý est abrégé à l'aide de ap surplombé de $\chi ;$; $\varepsilon$ ¿̀ est abrégé à l'aide de $\tau$ surplombé de $\varepsilon$, surligné par un longe tilde $\sim$. Nous les signalons dans le corps du texte à l'aide de $\overline{\alpha p \chi}$ et de $\overline{\tau \varepsilon}$. Nous expliquons leur fonctionnement au chapitre 6, point 3.8. Nous ne reproduisons pas les inscriptions grecques dans la marge supérieure, que nous avons décrites au chapitre 6, point 3.8. Nous transcrivons la graphie du texte sans ajout ou correction, utilisant régulièrement sons la ponctuation à l'aide de $*$, symbole proche de celui utilisé par le scribe ${ }^{22}$.

21 MACÉ et al., «Textual Criticism and Text Editing », art. cit., 2015, p. 345. À propos des éditions critiques, cela est nuancé : «For editions based on multiple witnesses, the problem is more complicated, because the edited text will often be based on several manuscripts, as far as the variants are concerned - but on what will the 'form' of the text rely? There is no ideal solution to this problem, and most editions will be a more or less unsatisfactory compromise between two extreme positions: (1) a complete normalization of the spelling and grammar, based on assumptions about the language of the work or according to modern criteria, (2) the choice of one witness, considered the most conservative and reliable as far as the orthography is concerned, to be used as a guide to establish the form of the edited text. Here as well the editor will need to find a balance between two contradictory goals : readability for modern users of the edition, and faithfulness towards the mediaeval tradition. »

22 La ponctuation dans 1 Corinthiens est composée de deux petits traits verticaux à l'encre noire (même encre que le texte) sur lesquels on a tracé quatre points en croix $(*)$ à l'encre rouge. La ponctuation semble suivre des règles plutôt souples. Elle est placée le plus souvent avant des particules conjonctives telles que و و 
Les rares cas où le scribe trace un trait pour combler un vide en fin de ligne sont notés à l'aide de -. Les corrections apportées par un scribe dans le texte sont reproduites. Elles sont de différents types : a) ajout en dessus de la ligne $\left.(\text { ex. } 1,17)^{23} ; \mathrm{b}\right)$ texte barré $\left.(\mathrm{ex} .7,17) ; \mathrm{c}\right)$ correction à l'aide du signe diacritique \% $(\text { ex. 1,26 })^{24}$. La mise en page est également respectée : nous indiquons les changements de folios et les lignes correspondent à celles du manuscrit.

Nous avons ajouté dans le texte la division moderne en versets. Elle permettra au lecteur de s'orienter dans le texte et cette division sera reprise dans le commentaire verset par verset (chapitre 8 , point 1 ).

Nous faisons usage des crochets [ ] pour les lectures difficiles. Quand les crochets sont vides, cela signifie que nous ne pouvons déchiffrer une partie $\mathrm{du}$ texte. Nous proposons parfois une lecture entre les crochets, lorsque nous pensons distinguer le texte, toutefois sans certitude, ou lorsque nous voulons faire une suggestion en fonction de l'espace disponible et du contexte.

\section{$3 \quad$ Édition digitale ${ }^{25}$}

\subsection{Plusieurs «couches » d'édition}

En parallèle à l'édition sur papier que nous proposons ici, nous avons également développé une édition digitale accessible en ligne ${ }^{26}$. Celle-ci doit permettre l'accès à la fois au document, par l'intermédiaire des images du manuscrit ${ }^{27}$, et au texte contenu dans le document. Pour l'édition papier, nous avons préparé un texte diplomatique reproduisant fidèlement le manuscrit. Un texte standardisé et vocalisé, proposé en addition au texte diplomatique, peut être un

23 Nous reproduisons ce phénomène en mettant le texte corrigé en exposant, ex. : ولاك

24 Le scribe appose généralement le signe \% dans le corps de texte, puis écrit dans la marge la correction qu'il délimite à l'aide de \% au début et à la fin. Pour des raisons de mise en page, nous reproduisons les corrections en bas de page, en précisant dans quelle marge elles se trouvent.

25 Voir Clivaz Claire, Schult hess Sara et Sankar Martial, «Editing New Testament Arabic Manuscripts on a TEI-base : Fostering Close Reading in Digital Humanities », Journal of Data Mining and Digital Humanities, Special Issue on Computer-Aided Processing of Intertextuality in Ancient Languages, 2017. En ligne: <https://jdmdh.episciences.org/ paper $/$ view?id=3700 $>$.

$26<$ http://tarsian.vital-it.ch/>, consulté le 16.03.2016. Il s'agit du résultat d'une collaboration avec Martial Sankar (VITAL-IT, Swiss Institute of Bioinformatics, VITAL-DH Projects), que nous remercions vivement.

27 Lorsque nous avons commencé à travailler sur ce projet d'édition digitale, le Vat. Ar. 13 n'était pas accessible en ligne. Il est désormais accessible: <http://digi.vatlib.it/view/ MSS_Vat.ar.13>, consulté le 16.03.2016. 
outil intéressant, notamment pour le lecteur qui n'est pas habitué à travailler avec le moyen arabe. Un tel texte permet aussi de rendre transparents les choix faits en vue de la traduction. C'est pourquoi nous proposons, au côté de la « version» diplomatique, une «version» standardisée et vocalisée du texte. Cette deuxième version ne remplace en aucun cas la première ; il s'agit, comme la traduction française proposée chapitre 8 et dans l'édition digitale, d'un outil de travail.

Ces versions du texte s'inscrivent dans une vision de l'édition par « couche » ou par « calque » que l'on commence à trouver dans différents projets d'édition digitale. Elle est appliquée, par exemple, au français médiéval dans le projet Queste del Saint Graal ${ }^{28}$ (qui propose une version «facsimilaire», «diplomatique» et «courante» ainsi qu'une traduction), au vieil anglais avec le projet Vercelli Book Digitale (version «diplomatique» et «interprétative») ${ }^{29}$, et enfin à l'arabe dans l'Arabic Papyrology Database ${ }^{30}$. Dans l'Arabic Papyrology Database, on trouve, en amont d'une translitération, d'une traduction et d'un découpage lexical, quatre « layers » du texte en arabe : le texte tel qu'il apparaît dans le manuscrit avec la présence de crochets pour les lectures difficiles; le texte tel qu'il apparaît dans le manuscrit, sans crochets; le texte avec ajout de points diacritiques, de la šadda et de la hamza; le texte avec ajout de points diacritiques, de la šadda et de la hamza, du alif suscrit, du tanwīn et de l'írā $b^{31}$. Nous nous inspirons de ces éditions à plusieurs « couches » pour notre édition digitale, proposant un texte diplomatique et un texte standardisé et vocalisé, ainsi que la traduction française.

\subsection{Avantages de l'édition digitale}

Lédition digitale permet d'afficher l'image du folio du manuscrit et le texte de ce folio en parallèle, et de passer de manière dynamique entre la version du texte diplomatique et la version standardisée/vocalisée. Si l'utilisateur choisit d'afficher la version diplomatique, la version standardisée s'affiche quand le curseur passe sur le texte, et vice-versa :

28 <http://portal.textometrie.org/demo/>, consulté le 16.10.15. LAVREnTiEv Alexey, GuILlot-Barbance Céline et Marchello-Nizia, «Édition électronique de la Queste del saint Graal », in : Твотте r David (éd.), Manuel de la philologie de l'édition, Berlin, Boston, De Gruyter, 2015, pp. 155-176.

29 <http://vbd.humnet.unipi.it>, consulté le 16.10.15. Rosselli Del Turco Roberto, BuOMPRISCo Giancarlo, Pietro Chiara Di et al., « Edition Visualization Technology : A Simple Tool to Visualize TEI-based Digital Editions », Journal of the Text Encoding Initiative (8), 2014. En ligne : jtei.revues.org, <http://jtei.revues.org/1077>, consulté le 16.10.2015.

30 <http://www.apd.gwi.uni-muenchen.de:8080/apd/project.jsp>, consulté le 24.03.2016.

31 <http://www.apd.gwi.uni-muenchen.de:8080/apd/requisits2.jsp>, consulté le 24.03.2016. 
FIGURE 12 Capture d'écran: Texte diplomatique et texte standardisé

L'utilisateur peut également choisir d'afficher la traduction française, que l'on peut considérer comme étant une troisième «couche» de texte. Il est également possible d'afficher les textes en parallèle :

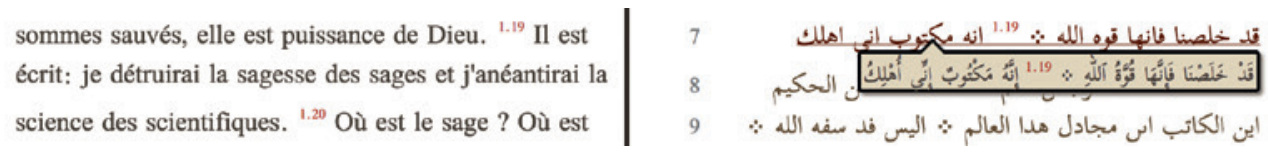

FIGURE 13 Capture d'écran: Traduction et texte diplomatique

Cette édition digitale respecte les standards du TEI XML. Il s'agit de standards XML développés par un consortium, Text Encoding Initiative (TEI), pour l'encodage de documents textuels ${ }^{32}$. Ces recommandations ont pour but que les chercheurs s'attelant à l'encodage d'un texte utilisent le même langage afin de favoriser l'échange des données. Pour l'édition d'un texte, si nous prenons par exemple le cas des interventions faites dans le texte, il a été nécessaire pour nous d'expliciter comment nous les représentions au point 2 ci-dessus. Dans la présente édition, un ajout en dessus de la ligne est représenté à l'aide de l'exposant. Par exemple :

Ceci est un bon exemple.

Le lecteur, s'il a lu l'introduction, comprendra que le «bon » se trouve ajouté au dessus de la ligne. Cet exemple peut s'encoder ainsi :

Ceci est un $<$ add place $=$ "above" $>$ bon $</$ add $>$ exemple.

La balise <add $>$ et l'attribut de celle-ci place= "above", étant standardisés, permettent d'exprimer l'information qu'il s'agit d'un ajout de texte au-dessus de la ligne, qui est ainsi facilement compréhensible et réutilisable par d'autres, humain ou machine, sans avoir recourt à des explications introductives.

32 <http://www.tei-c.org/>, consulté le 16.03.2016. 
Dans l'esprit du TEI, nos fichiers encodés sont disponibles en ligne, sous une licence Creative Commons BY 4.o, favorisant le partage du matériel, avec accréditation ${ }^{33}$.

Pour créer l'édition digitale à l'aide du texte encodé selon les standards du TEI XML, nous avons utilisé l'outil EVT créé par l'équipe du projet Vercelli Book

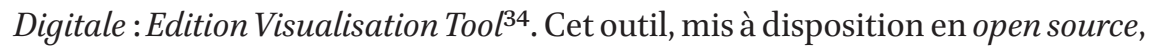
permet de créer une interface user friendly à partir des fichiers TEI XML, en se basant sur des technologies web standards tel que HTML, css et JavaScript.

33 <https://creativecommons.org/licenses/by-nd/4.0/>, consulté le 16.06.2016.

34 Edition Visualisation Tool (EVT): <http://evt.labcd.unipi.it/>, consulté le 20.07.2017 (notre édition digitale se base sur la version bêta précédant EVT 1.0, publiée le 07.03.2016). À propos de EVT, voir l'article Rosselli Del Turco et al., «Edition Visualization Technology », art. cit., 2014. Le site du projet Vercelli : <http://vbd.humnet.unipi.it>, consulté le 16.03.2017. 
(À propos de l'incipit, voir chapitre 6, point 3.7)

الر بيـالة من بولوبي الي القورنثانيين الاوليث

1.1.

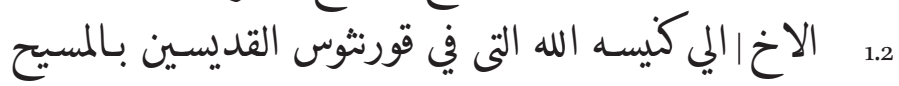

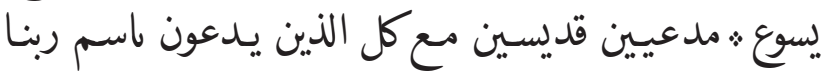

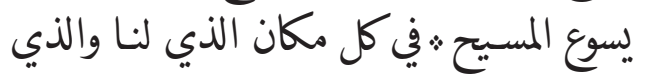
1.3 الهـم | النعمه معكم و السـلم ث من الله ابونـا وربنـا يسوع المسـيح 1.4

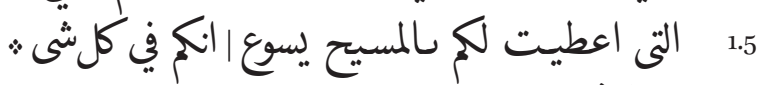
1.6 10 1.7

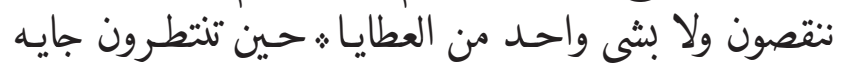
1.8 1.9

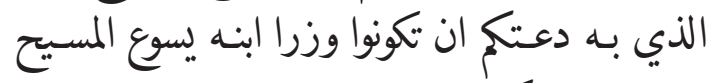

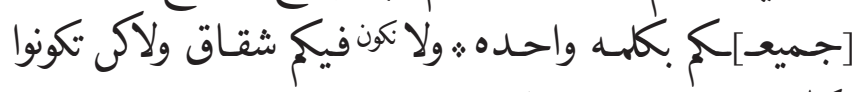
1.11 1.12

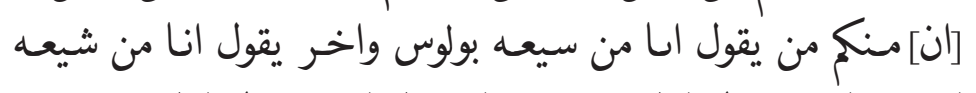

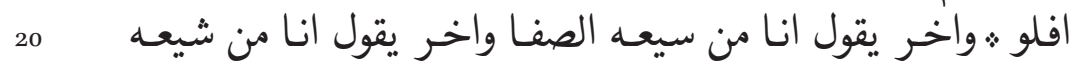

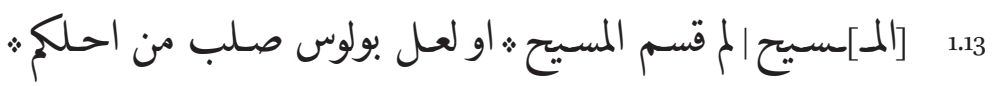




\section{folio $103 \mathrm{~V}$}

1.14

لعل باسـم بولوس اعمدتم ث | اسكر لله اني لم اعمد اسـان مـنم

1.15

1.16

1.17

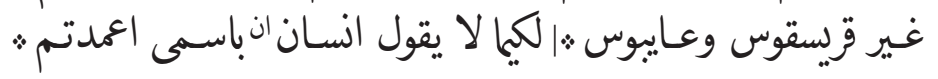

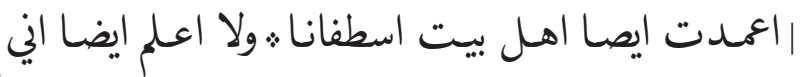

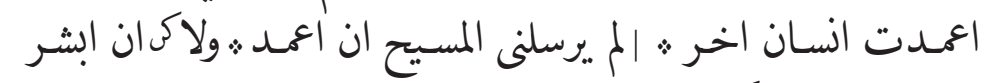

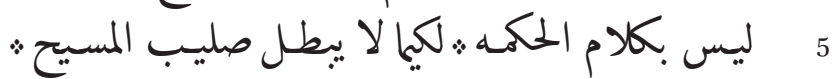

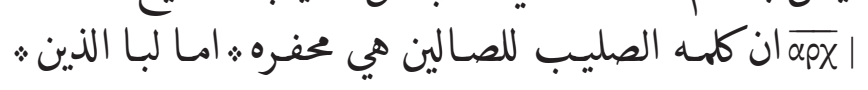

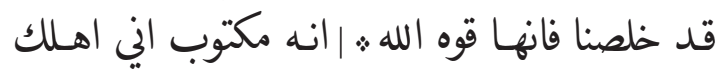

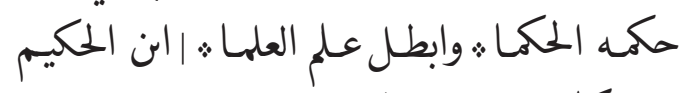

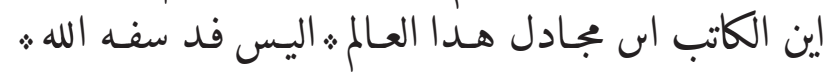
10

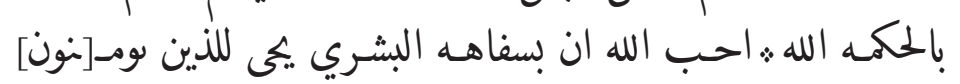

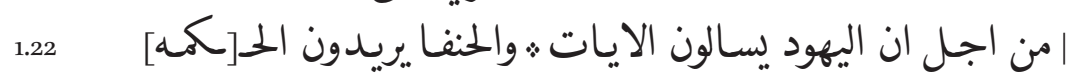

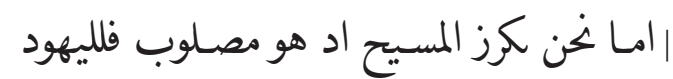

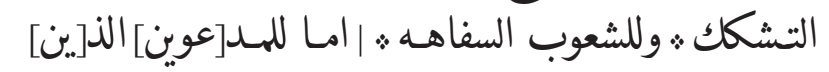

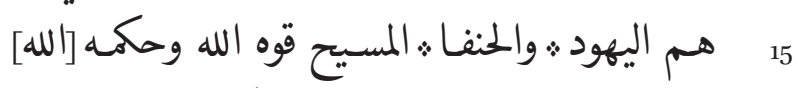

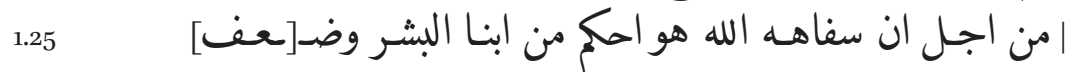

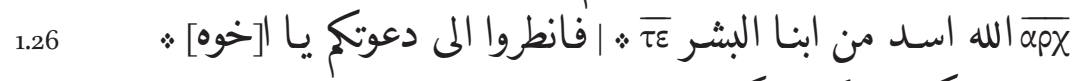

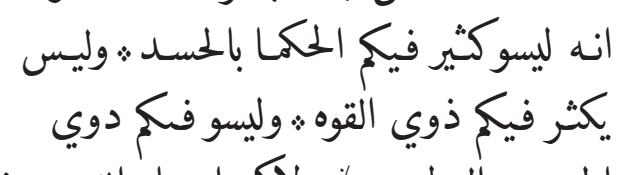
1.27

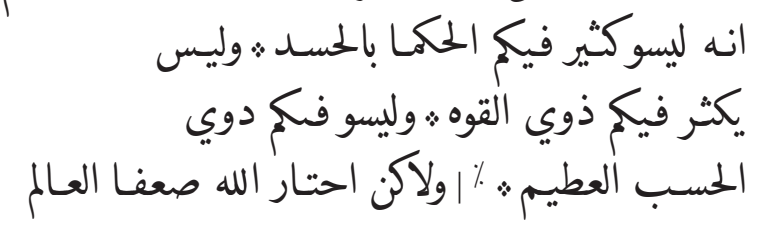




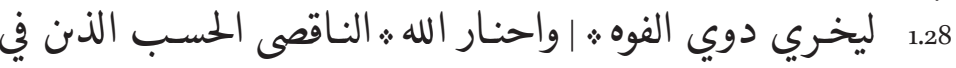

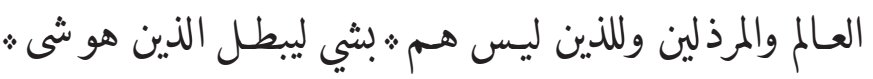

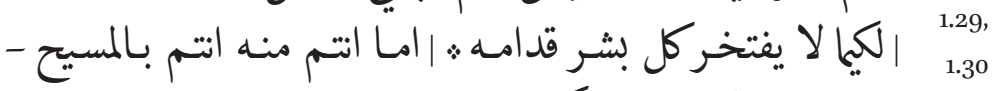

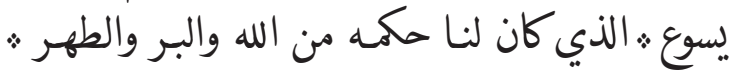
1.31

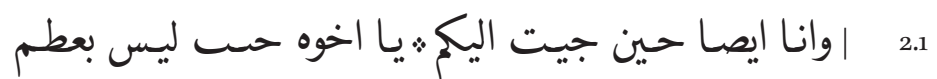
2.2

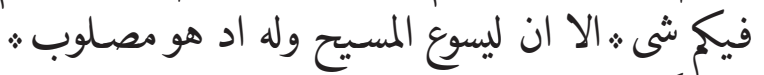
| 2.3

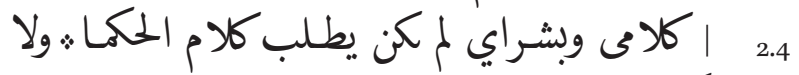
2.5 2.6

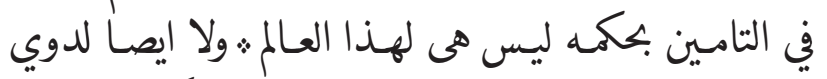

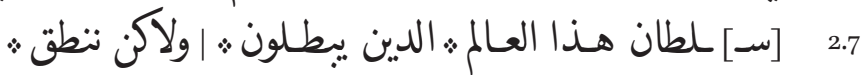

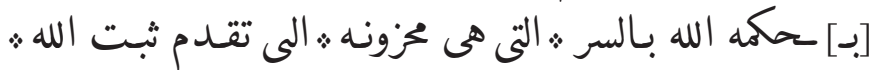
2.8

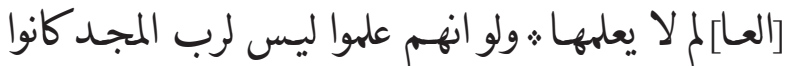

$$
\begin{aligned}
& 2.9
\end{aligned}
$$

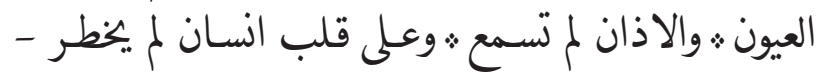


folio $104 \mathrm{~V}$

2.11

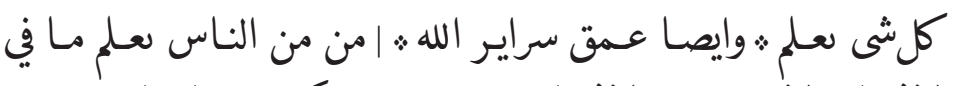

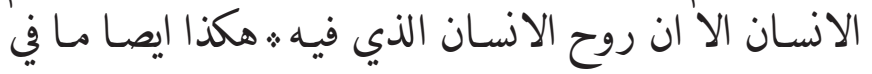

2.12

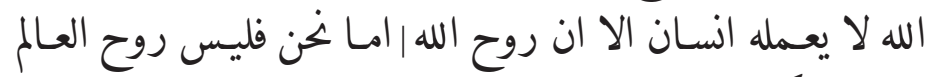

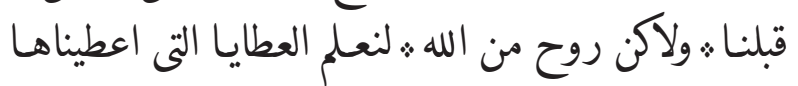
5

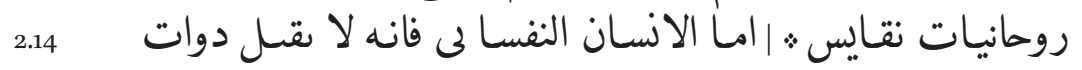

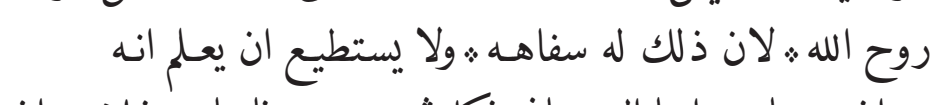

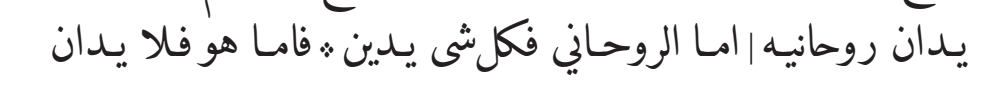

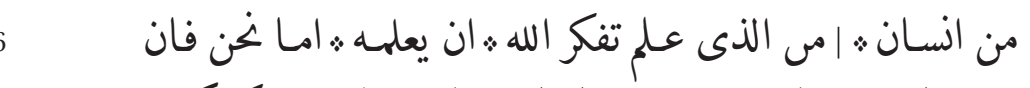

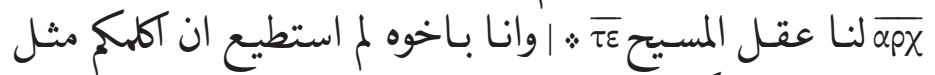
10

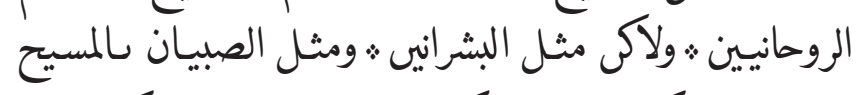

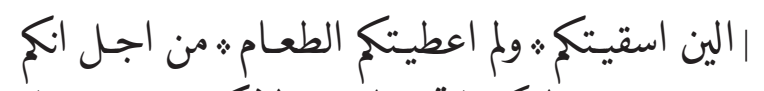

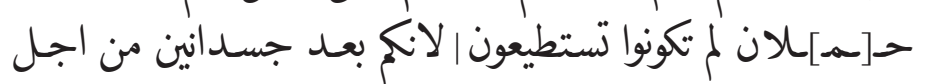

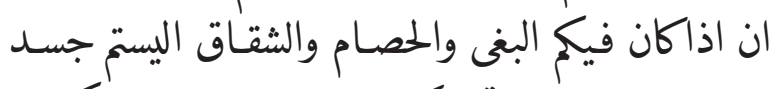
15

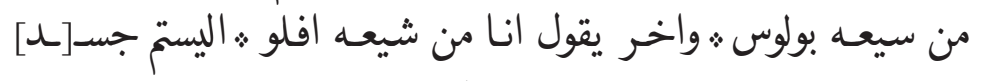

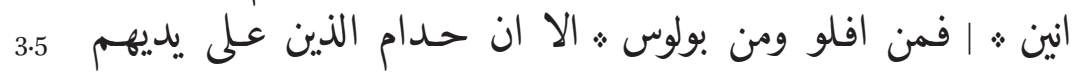

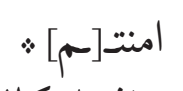

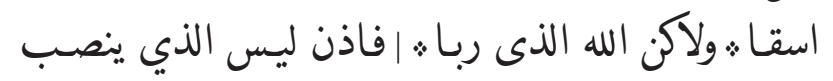
3.8

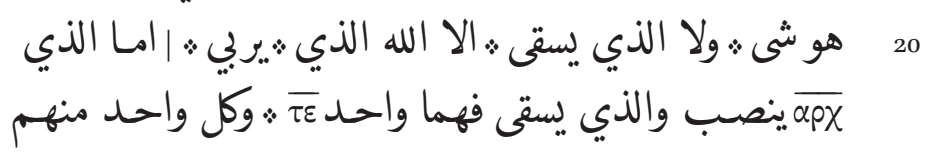




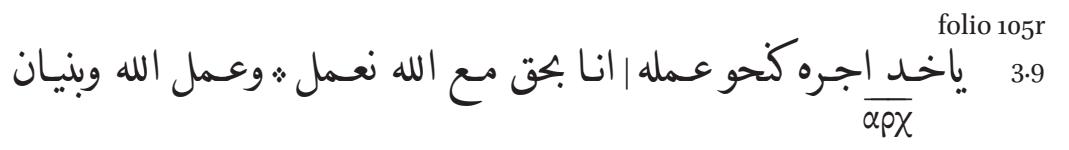

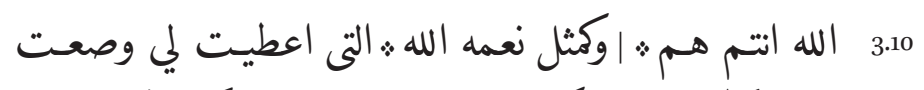

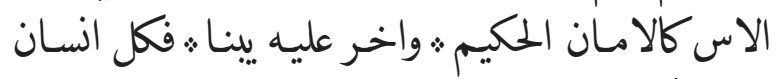
3.11

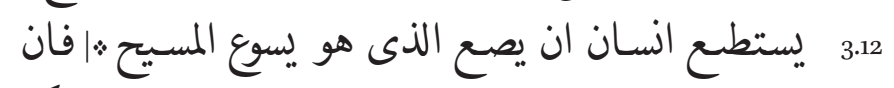

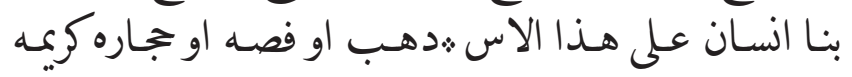

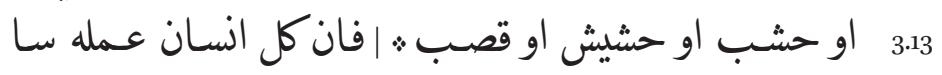

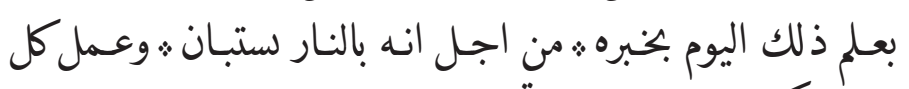

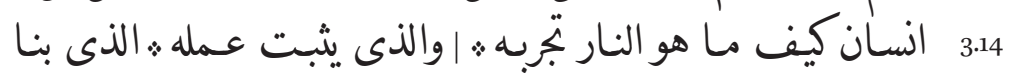

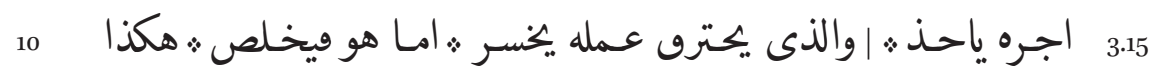

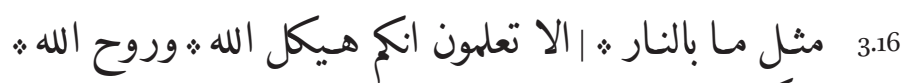
3.17

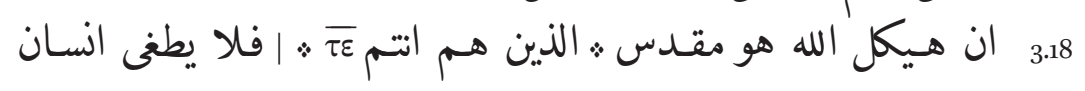

$$
\text { فنسه }
$$

مس يري منسك انه حكيم فى هذا العالم فليكون سفيه ؛

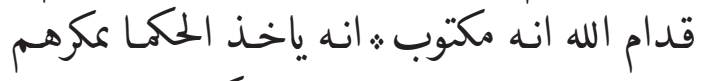
3.21 3.20, ${ }^{3.21}$

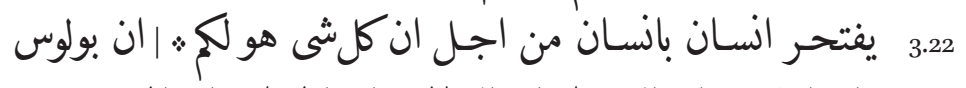

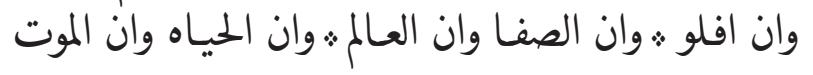
3.23 
folio $105 \mathrm{~V}$

وانتم للمسيح * والمسيح له * | هكذا ليحسبونا الناس مثلخخذام

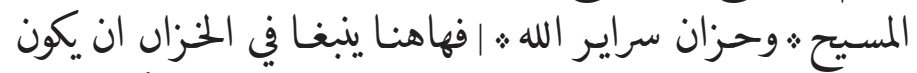

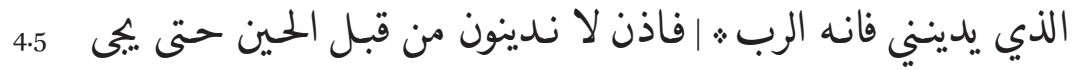

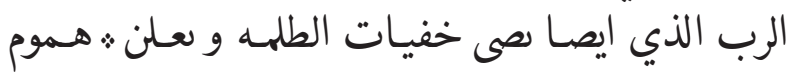

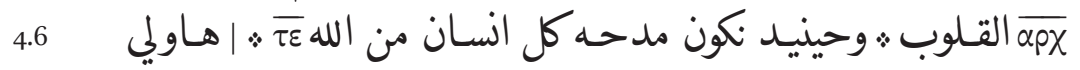

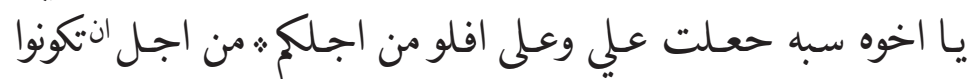
10

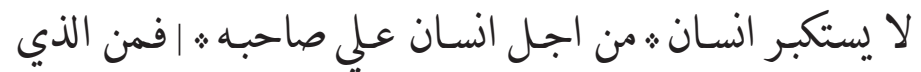

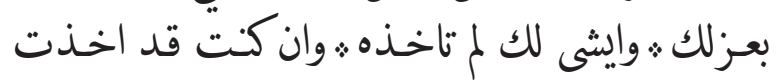

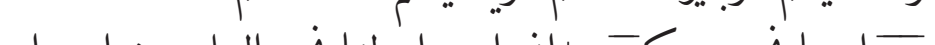

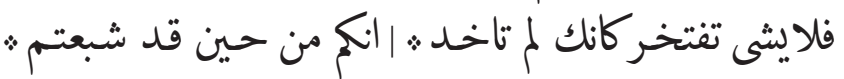

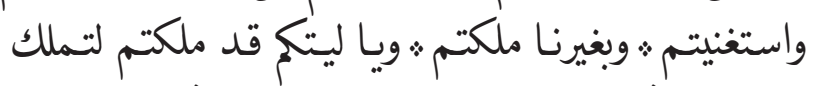

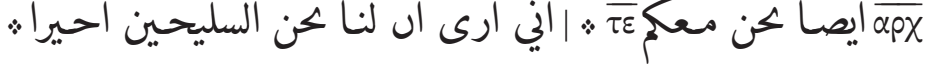

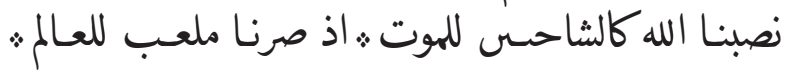

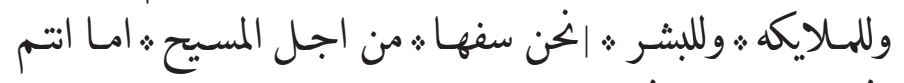

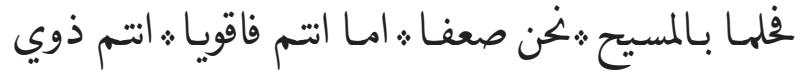

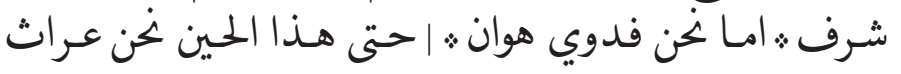
20

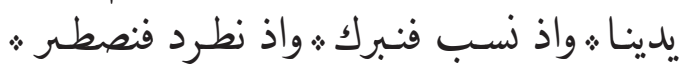




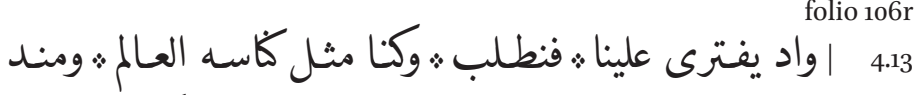

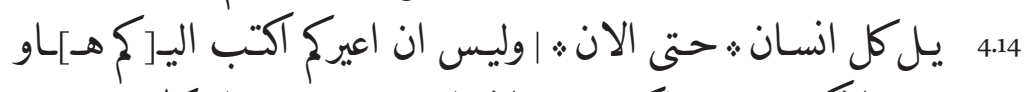

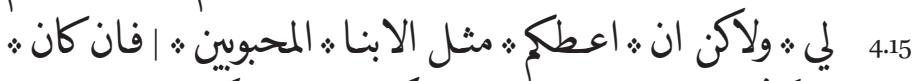

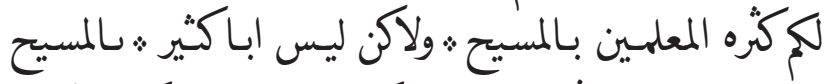

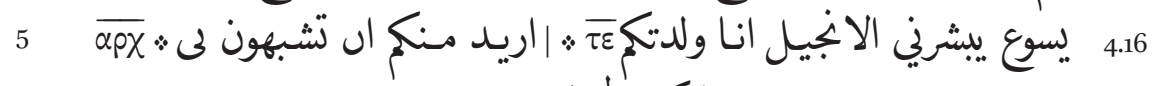

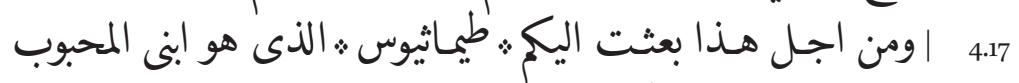

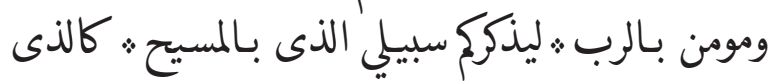

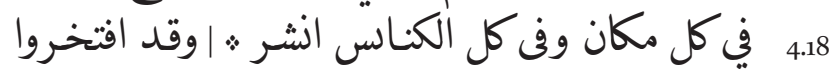

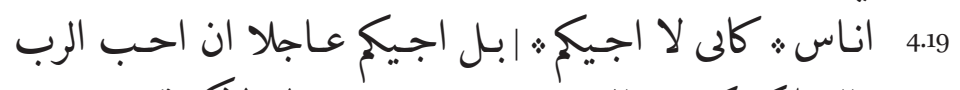
10 والعام كل كلام ه الدس هم مفتخزين فقط ولاكى قوتهم :

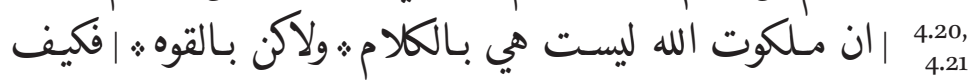

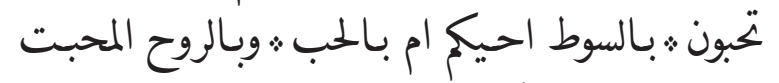

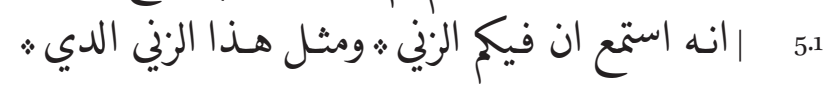

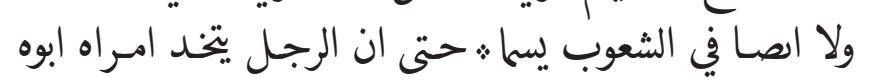

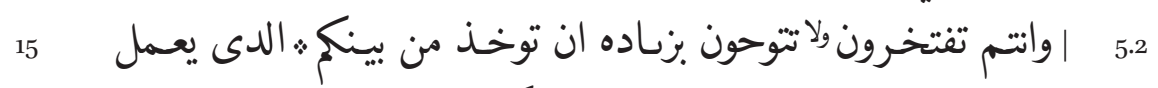

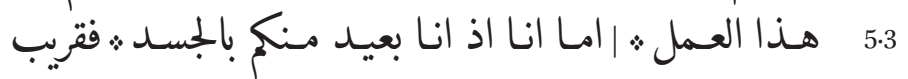

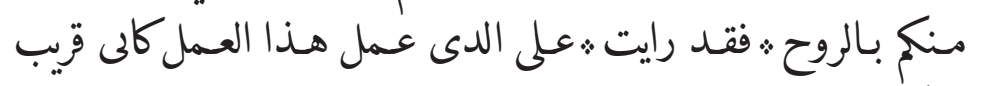
5.4 5.5

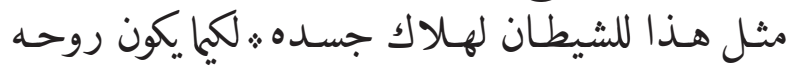


folio 106v

5.6

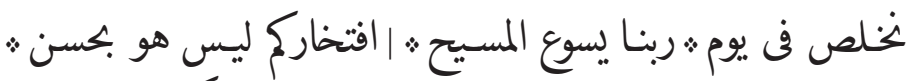

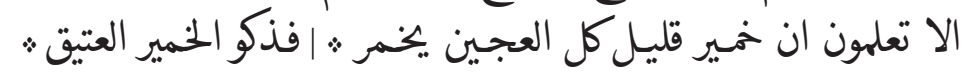

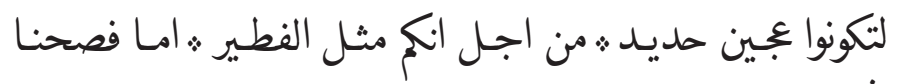

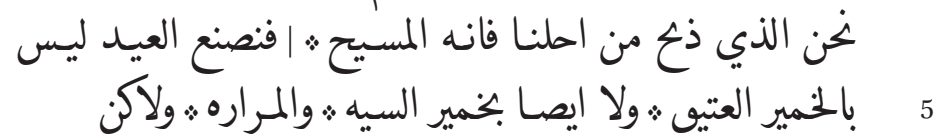

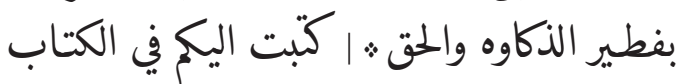

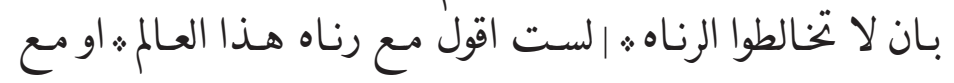

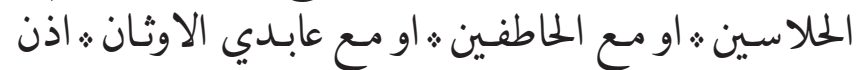

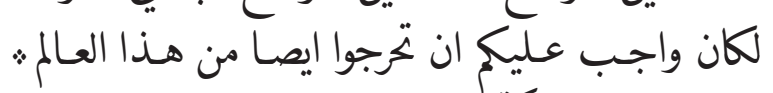
10

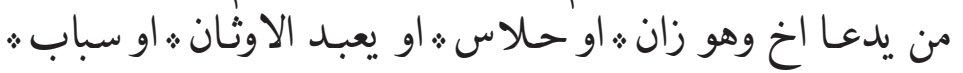

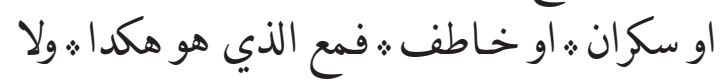

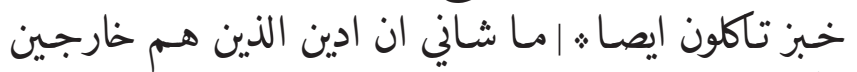

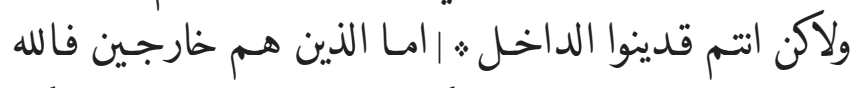

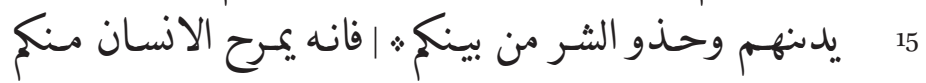

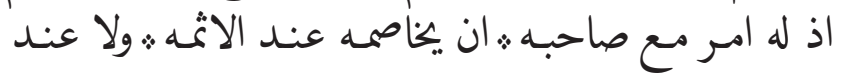

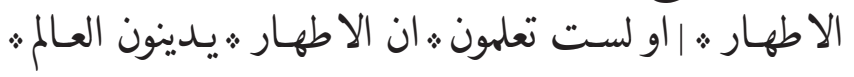

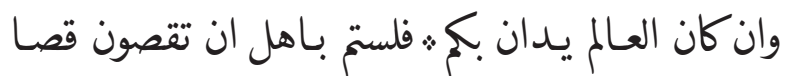

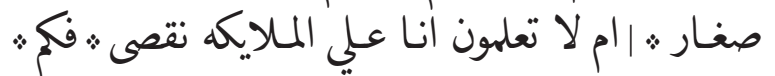
20

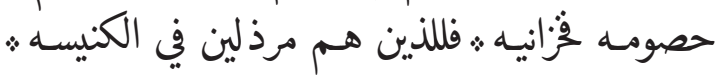


folio 107r

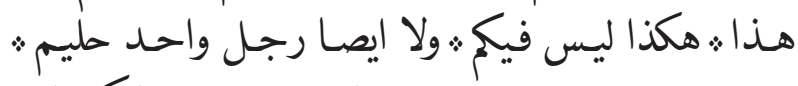

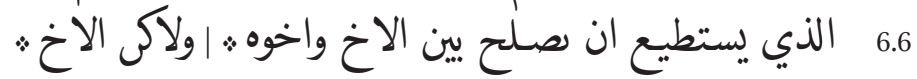

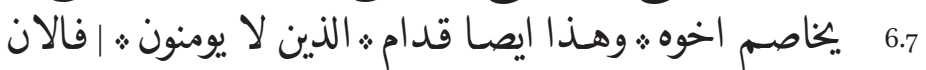

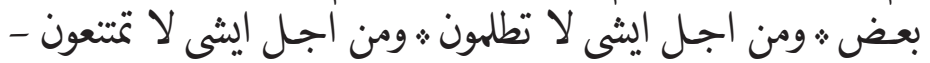
6.9

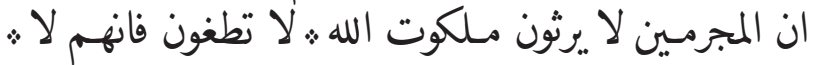

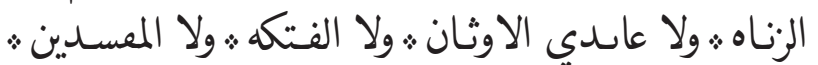

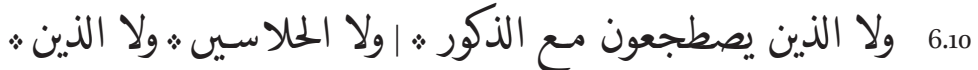

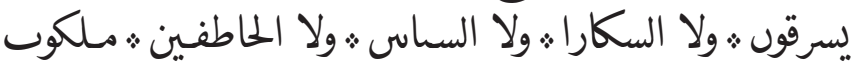

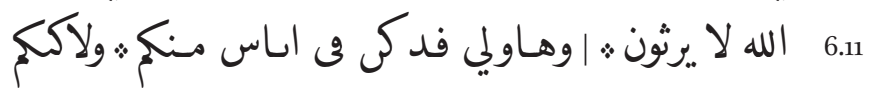
قد اغتسلتم وتقدستم وتبررتم باسم ربنا ايسوع المسيح وبـروح 6.12

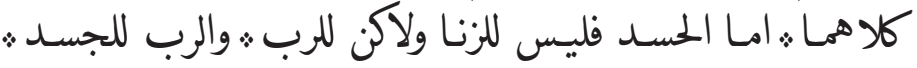

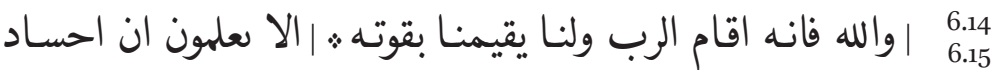
دكم هى اوصـال المسـيح : افاحـذ اوصـال المسـيح

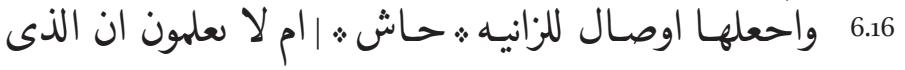

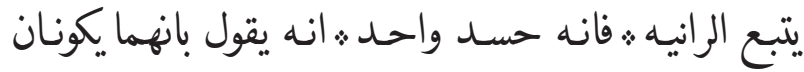

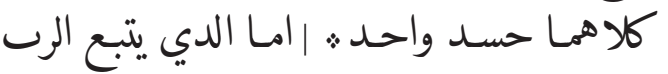


folio $107 \mathrm{v}$

6.18

6.19

6.20

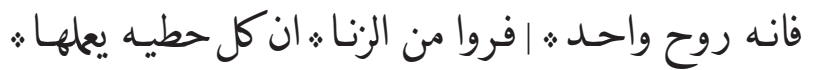

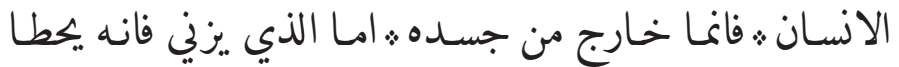

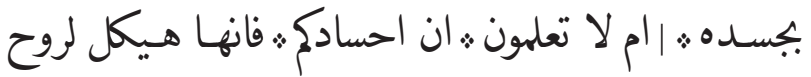

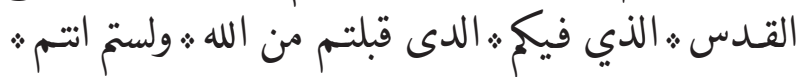
5

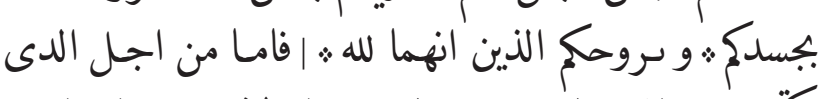

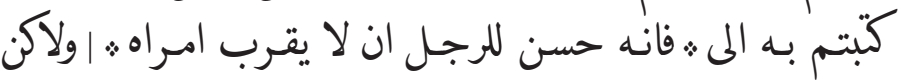

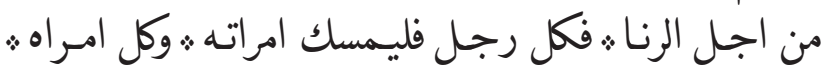

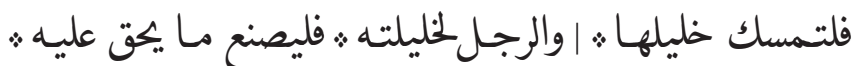
10

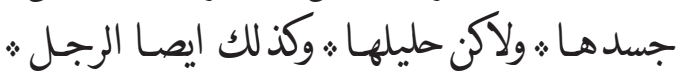

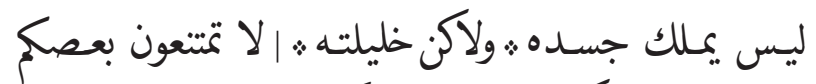

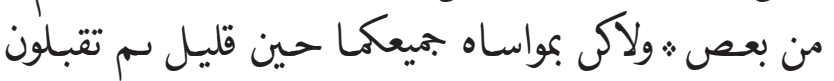

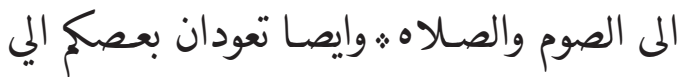

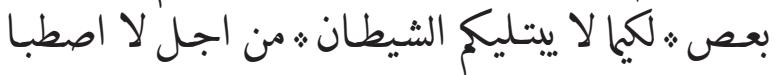

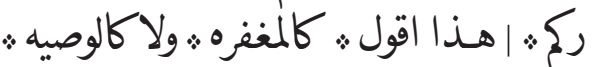

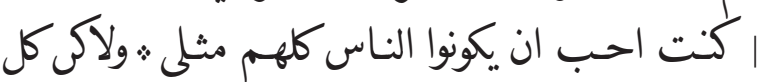

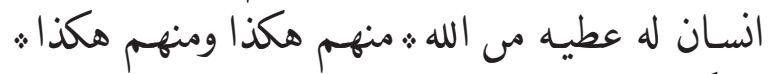

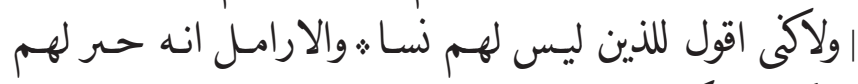

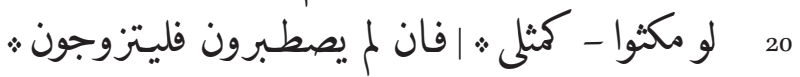

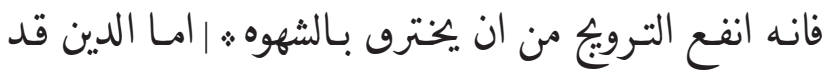




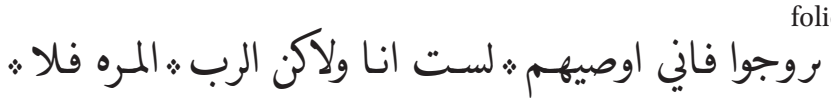

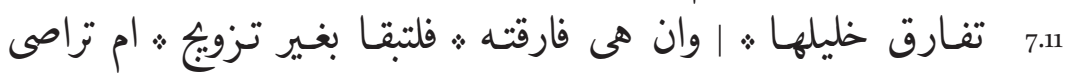

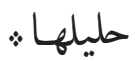

7.12 والرجل فلا يطلق حليلته ء | امـا لسـاير الـاس فاني اقول انا ليس الرباب

ان كان اخ له امراه ليست مومنه : وهى تحس ان تسكن معـه فلا .

7.13 المره التى لها روج ليس مومن ؛ وهو يحب ان يسكن معها ؛. فلا

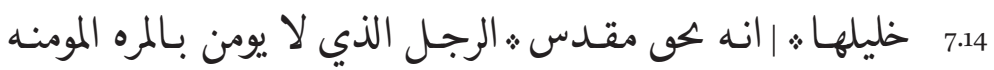

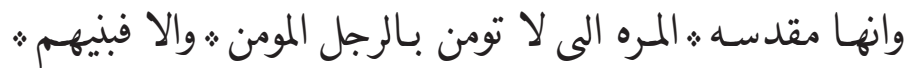

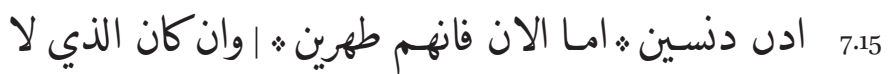

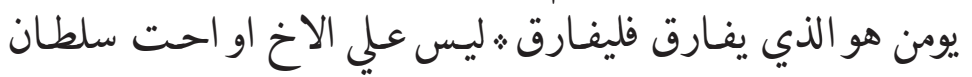

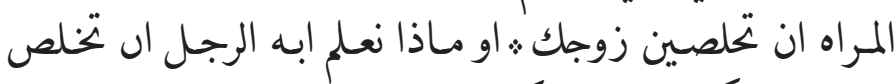

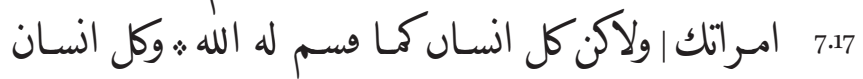

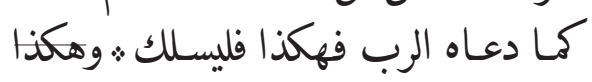

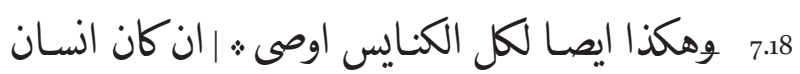

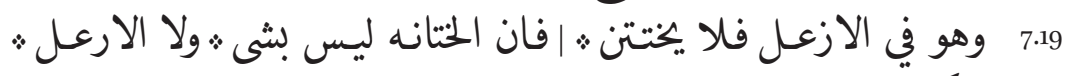

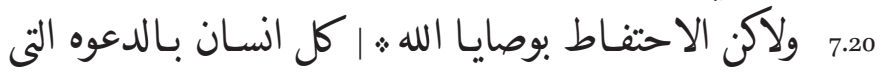

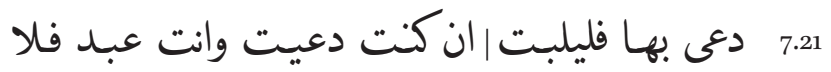

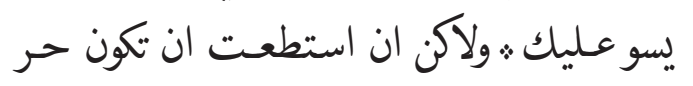
7.22 
folio $108 \mathrm{v}$

7.23

هكدا او الذي دعى وهو حر فانه عبـد للمسيح ث | انكم بثمن

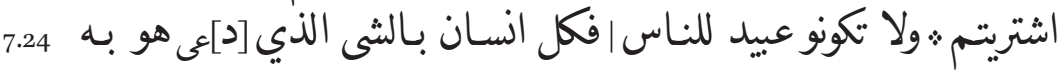

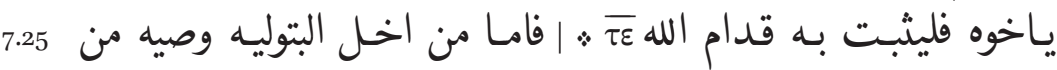
$\overline{\alpha p X}$

فليس عندي : ولاكى اشير ٪ من اجل ان الله رف علي لاكون مومنا

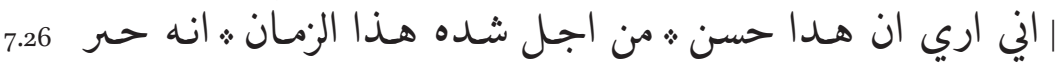

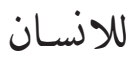
ان يكون هكداء | انت مربوط بـالمره لا تريــ تحل هـ انت محلول

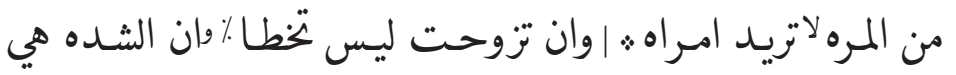

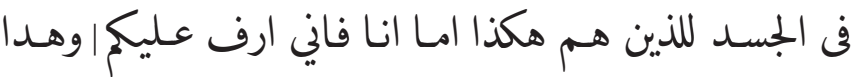

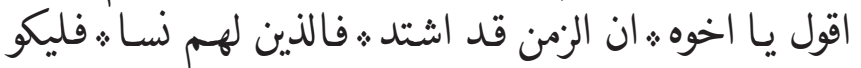
واللنين يفرحون كانهم لا يفرحون ثهوالذين يعرحون كانهم

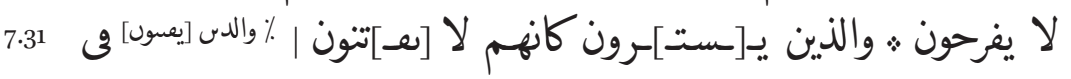
هـا العا

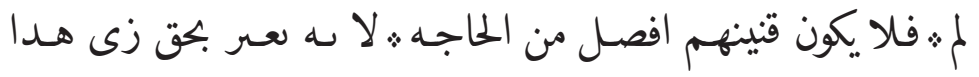

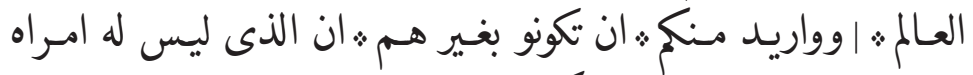

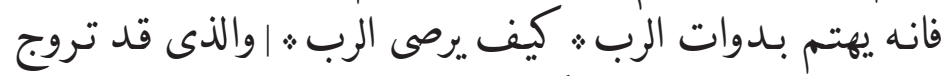

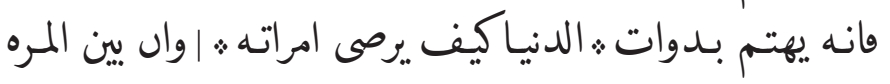

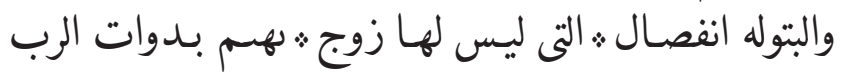

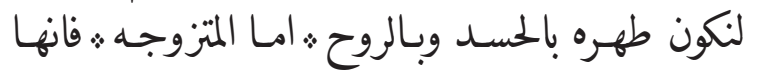
تهتم ثبـوات الدنيا ؛ كيف ترصى خليلها ؛ | هـذا -

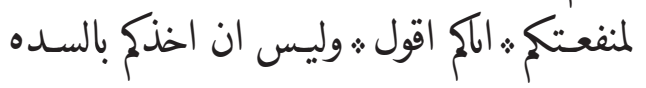




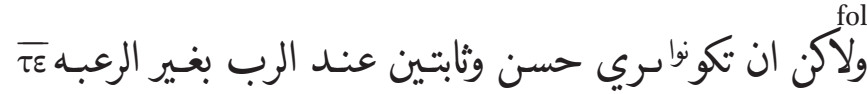

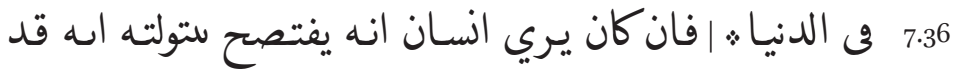

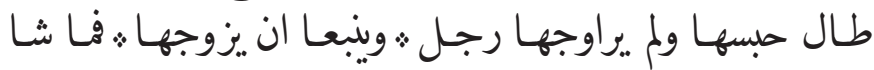

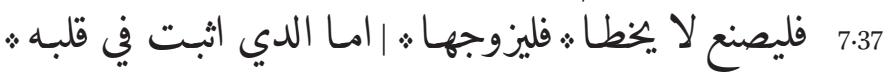
ولا يشق عليه : وهو مسـلط في هواه : وهذا صـرم فى قلبه :

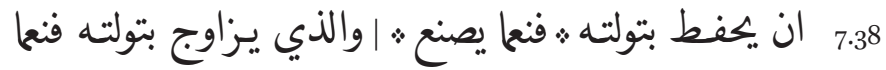

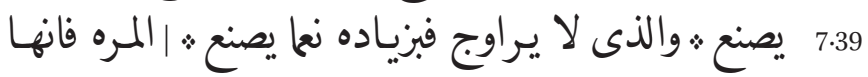

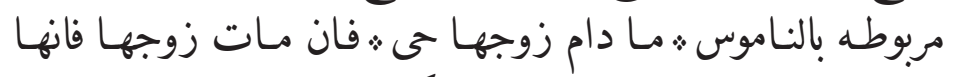

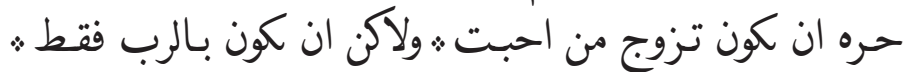
8.1 8.2 8ملم : 8.2

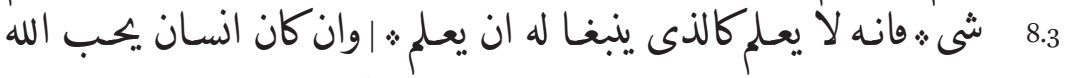

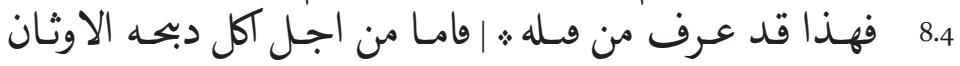

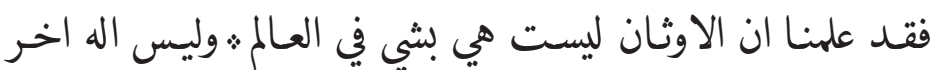

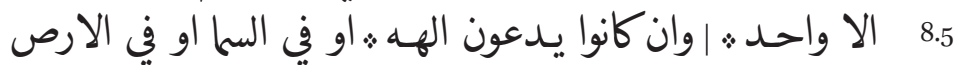
8.6

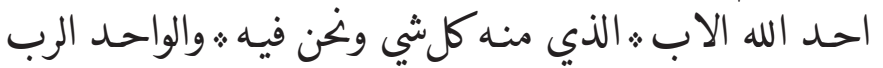

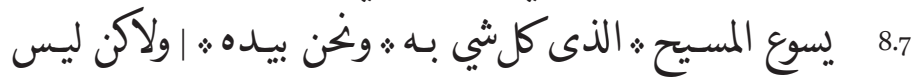

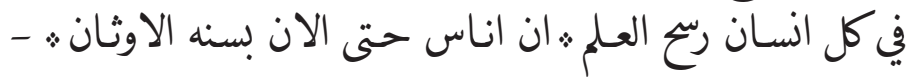

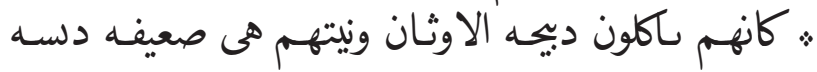


folio 109v

8.8

8.10

8.11

8.12

8.13

9.1

9.2

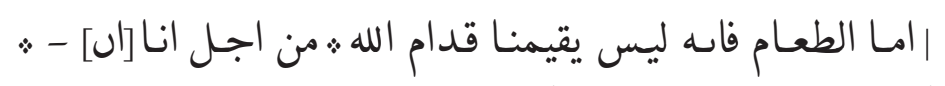

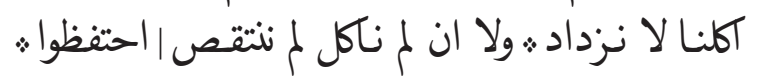

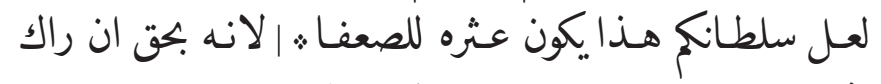

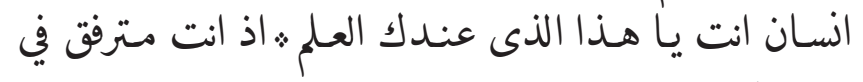
5

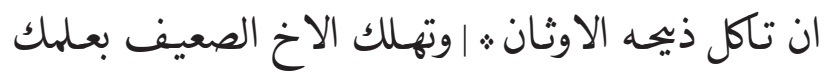

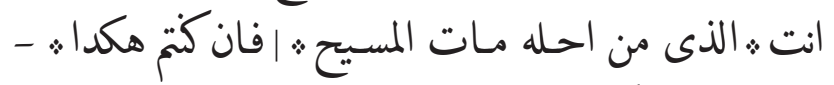

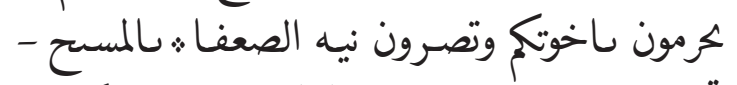

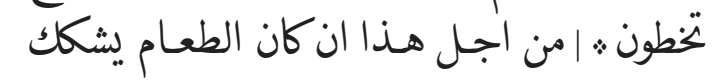
10

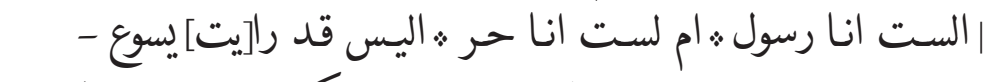

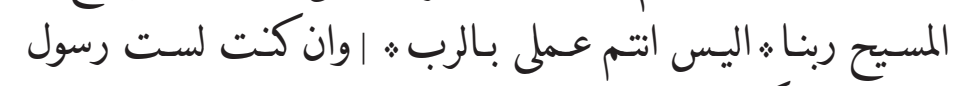

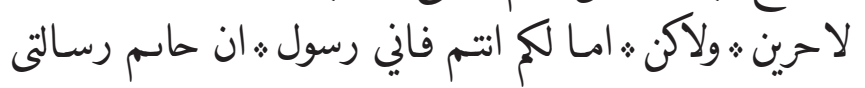

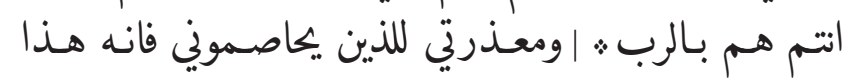

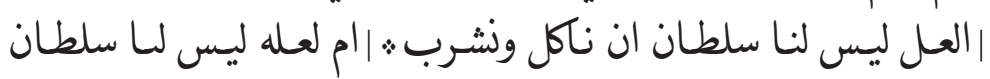

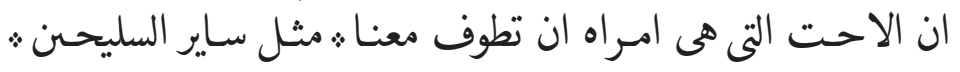

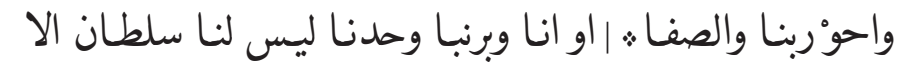

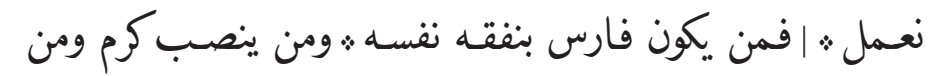

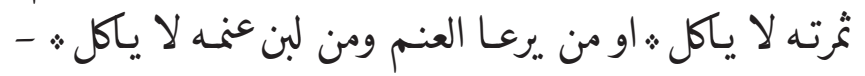
20

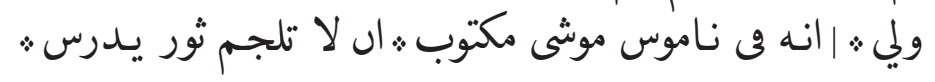




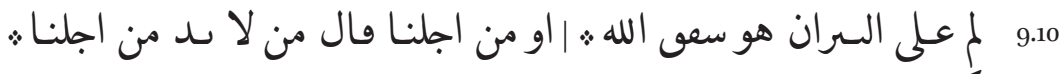

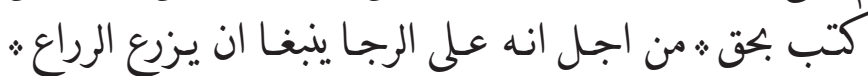

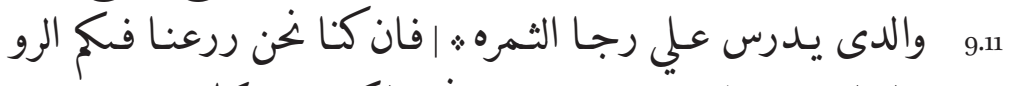
9.12

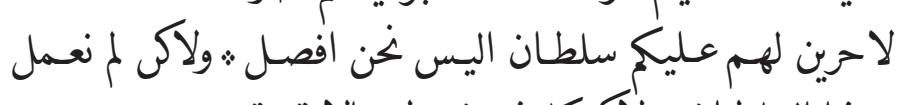

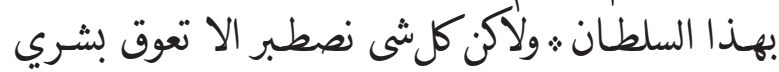

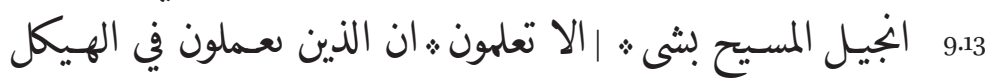

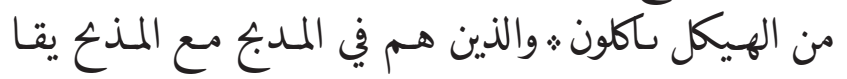

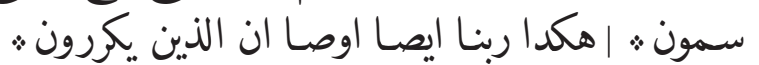

10

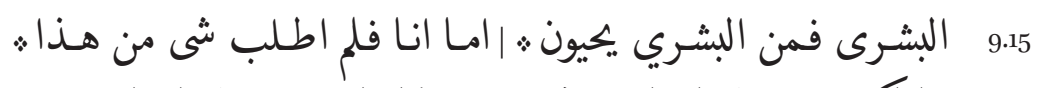

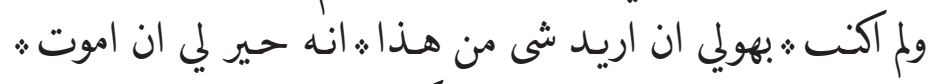

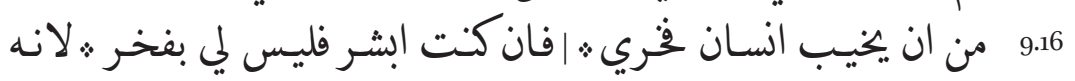

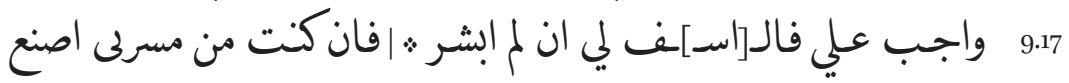

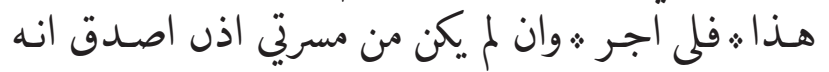

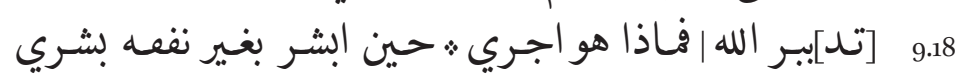

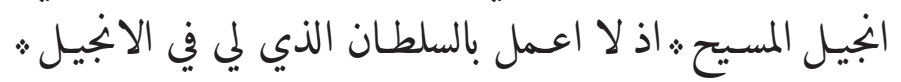

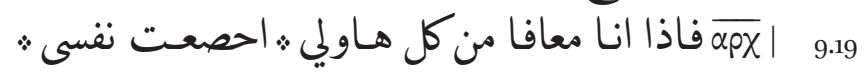
9.20

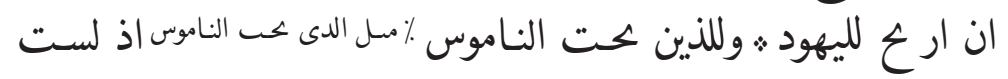

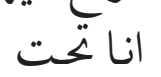

9.21 الناموس لارع للذين هـم محت الناموس \& |وللدس ليس لهم ناموس 20

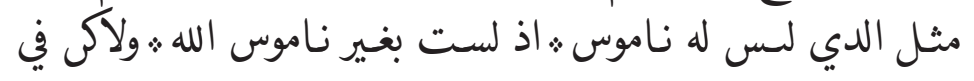


folio 11ov

ناموس المستيح * لان ارع للذين لـس لهم نـاموس : | كنت للصعفا 9.22

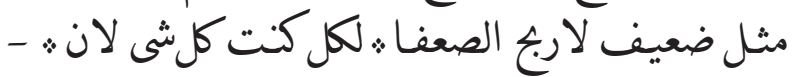

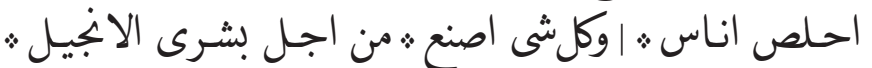
هox 5

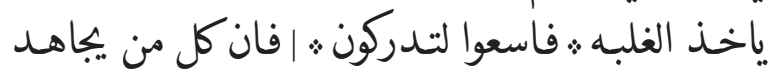

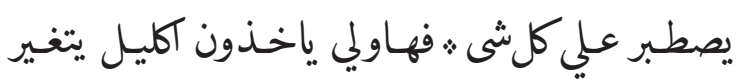

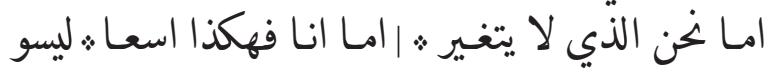

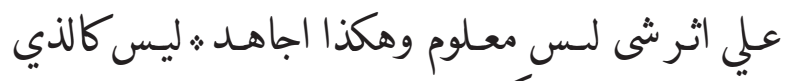
10

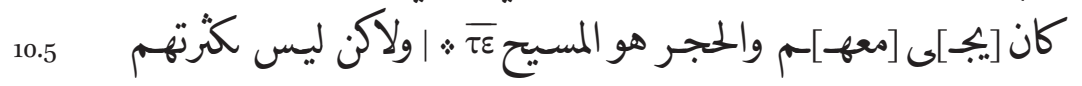
10.6

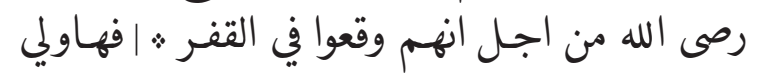

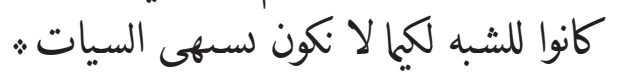

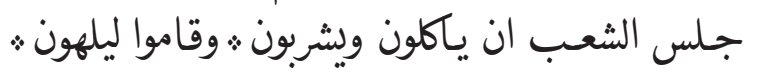


folio 1111 | ولا ايصا محسث كما ان منهـم انـاس * حنثوا ووقعوا في

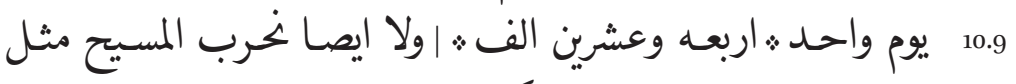

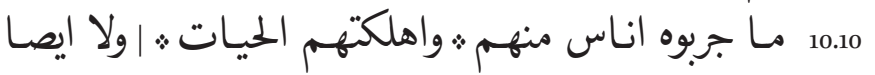

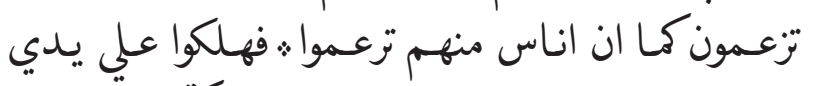
10.11 10.12

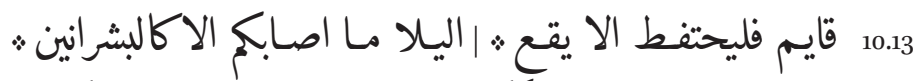

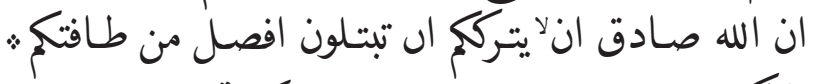

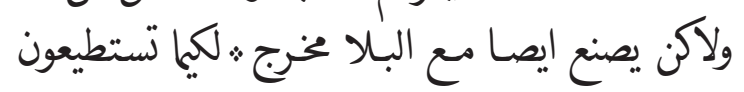

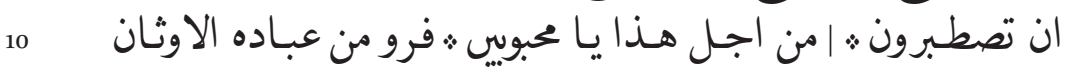
10.16 10.15

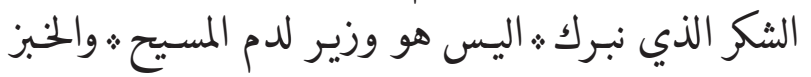

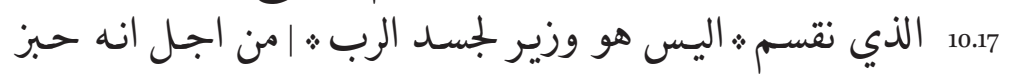
واحـ

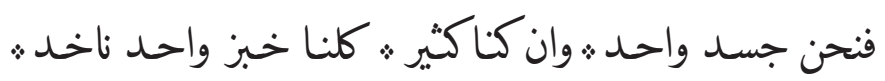

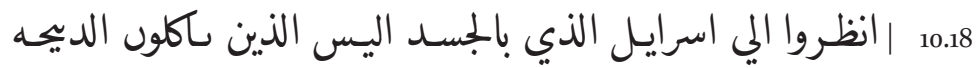

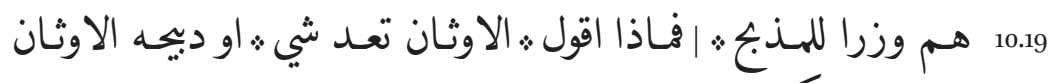

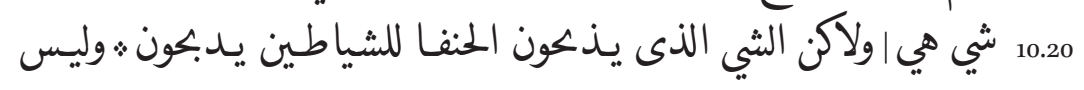
لله 10.21 10.22 20

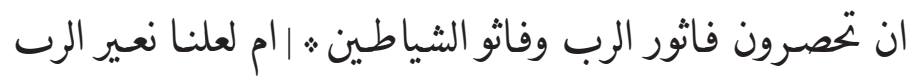




\section{folio $111 \mathrm{v}$}

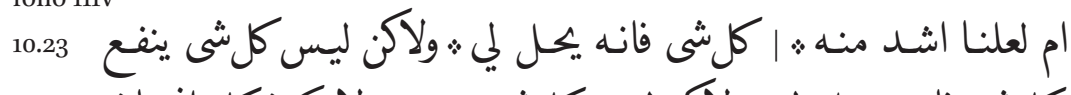

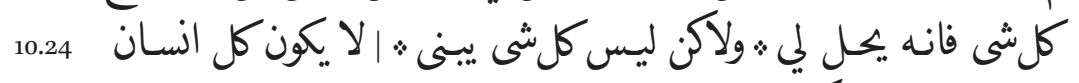

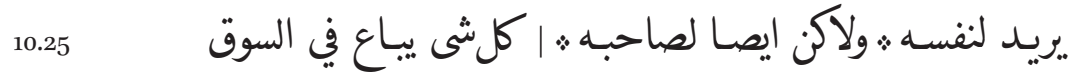

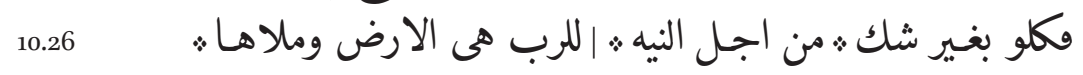
10.27

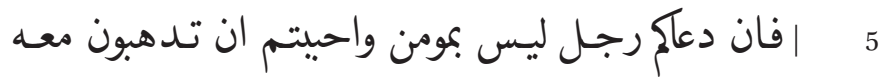

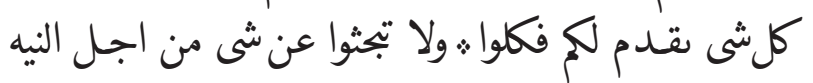

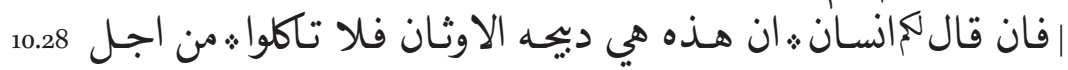

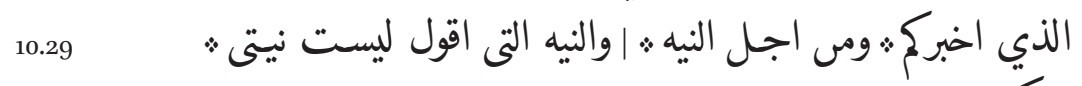

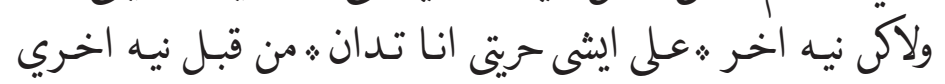

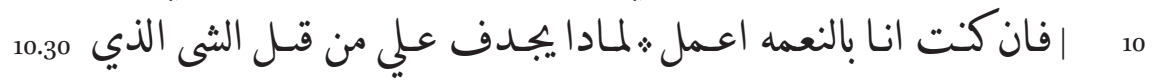

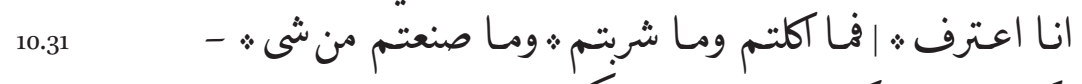
$10.3^{2}$

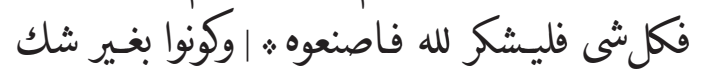
10.33

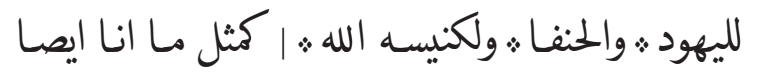

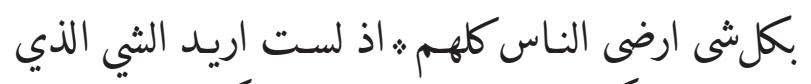

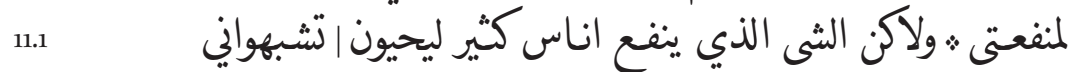
15

\section{na}

ns

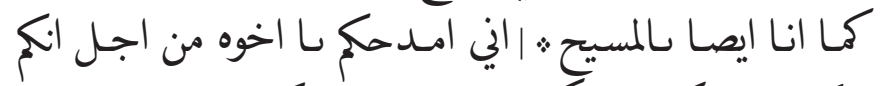

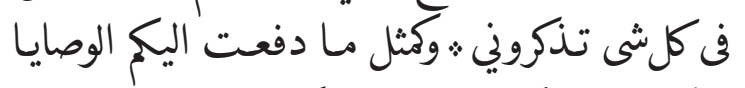

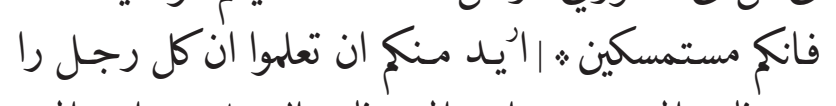

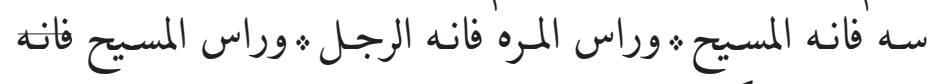
${ }^{\mathrm{n}} 4$

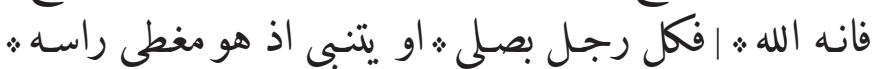


11.5 فانه يحري راسـه : اوكل امراه تصلي او تتنبـا اذ هي ث

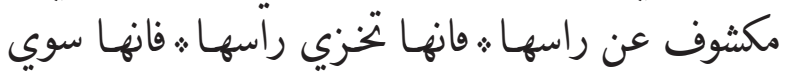

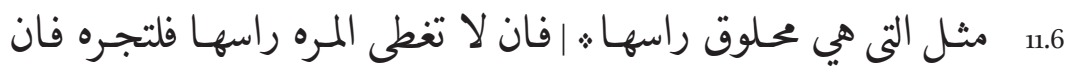
11.7

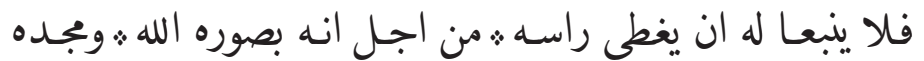
11.8 11.9 11.10 11.11 11.12

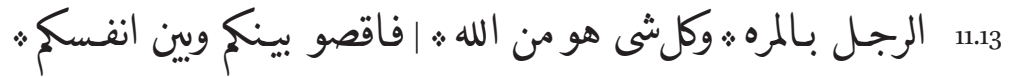

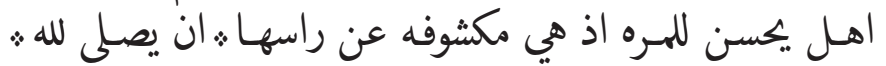

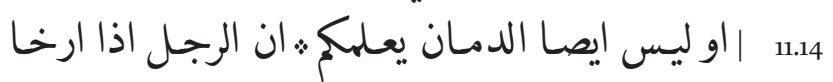
11.15

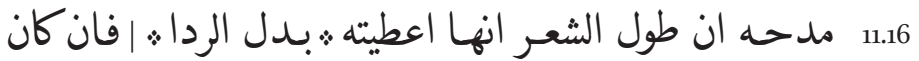

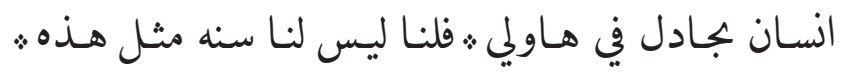

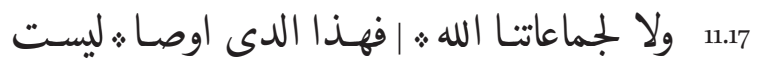

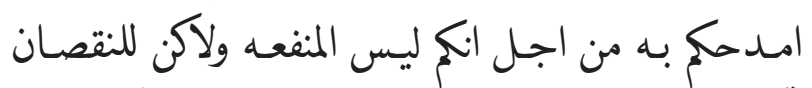
11.18

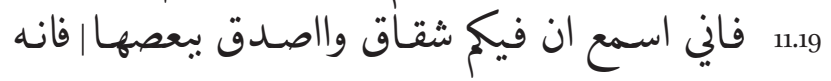


folio $112 \mathrm{~V}$

11.20

11.21

11.22

11.23

11.24

11.25

11.26

11.27

11.28

11.29

11.30

ايصاكاين ان يكون بينكم الحصام ومن اجل ان الذين هـم :

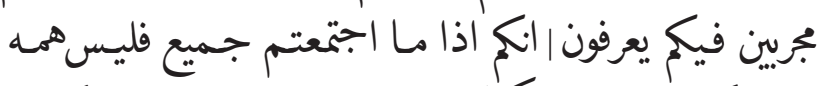

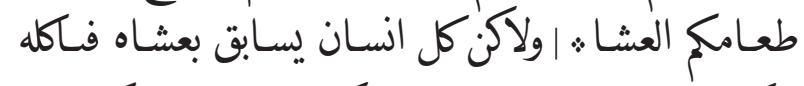

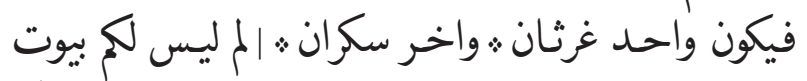

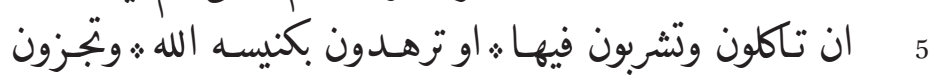

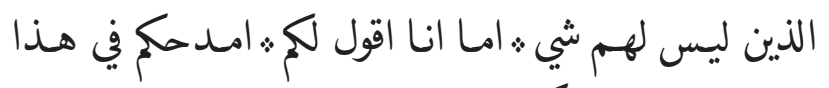

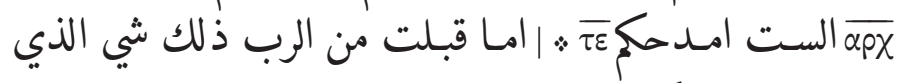

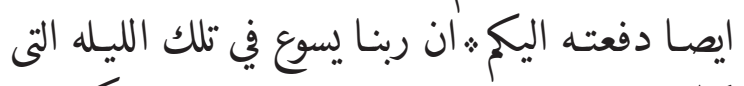

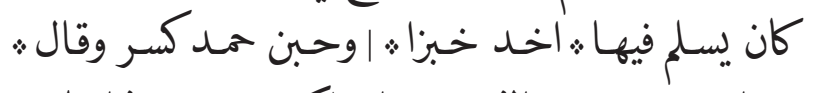
10

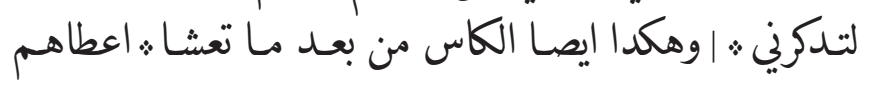

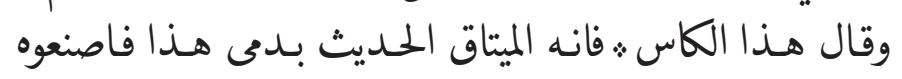

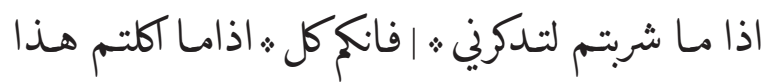

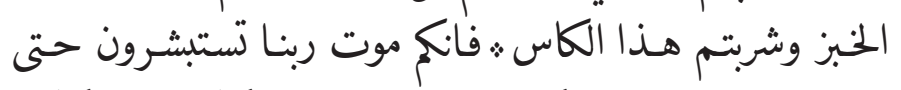
15

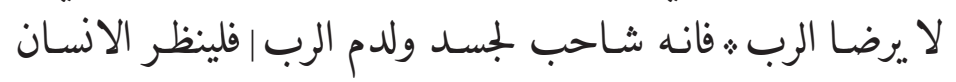

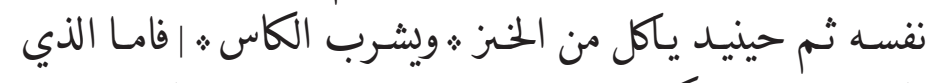

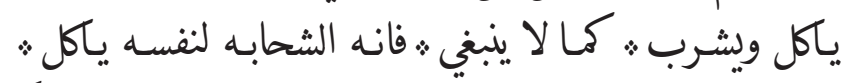

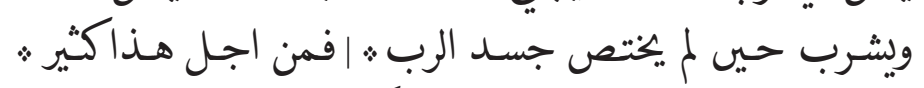
20 


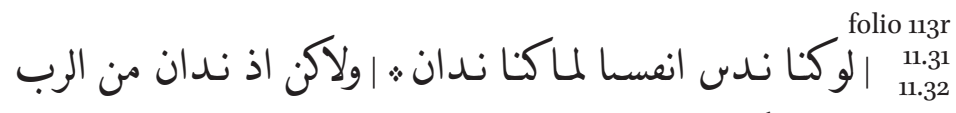

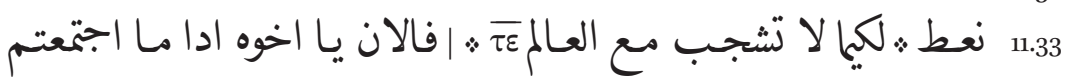
$\overline{\alpha p X}$.

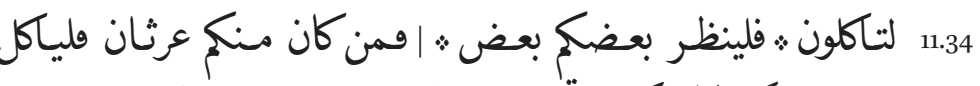

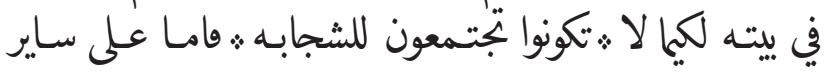
12.1

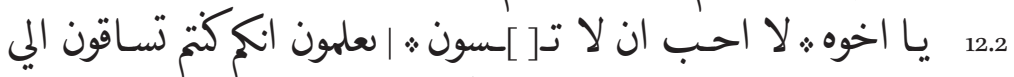

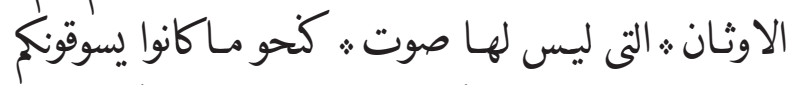

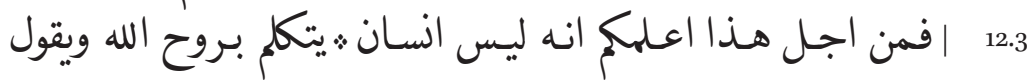

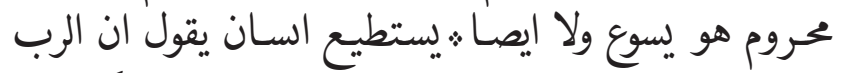

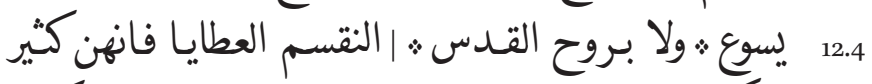

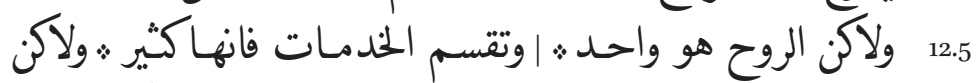

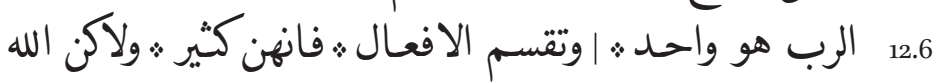
12.7

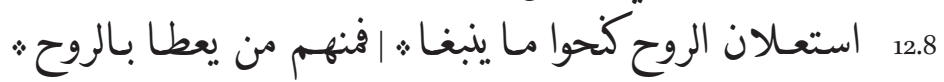
12.9

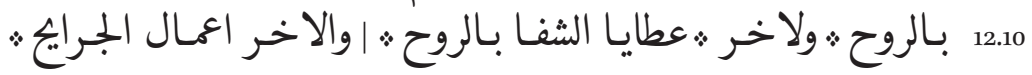

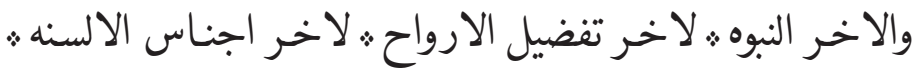

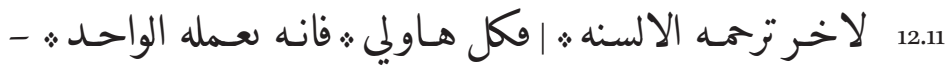

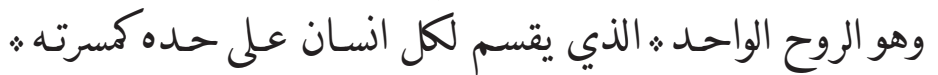
12.12 |فكما ان الجسـد : هو واححد وفيه اوصال كتئره وكل اوصال 
folio $113 \mathrm{~V}$

12.13

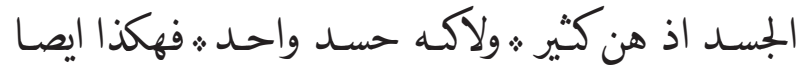

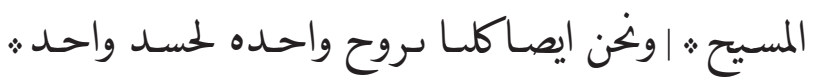

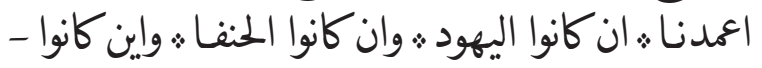

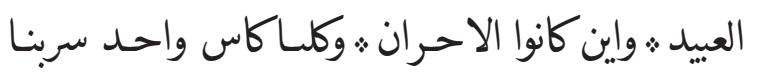

12.14

1215

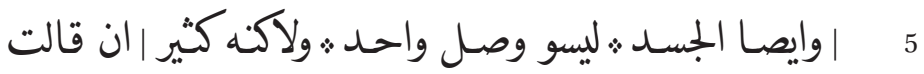

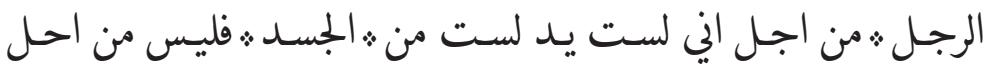

12.16

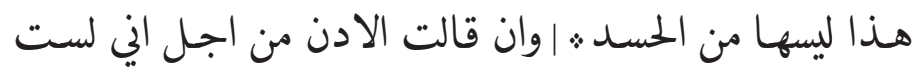

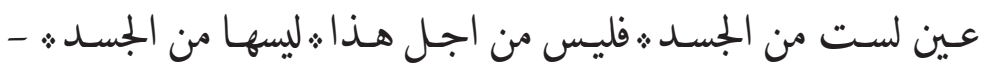

12.17

12.18

12.19

12.20

12.21

12.22

12.23

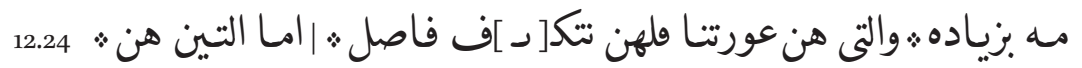

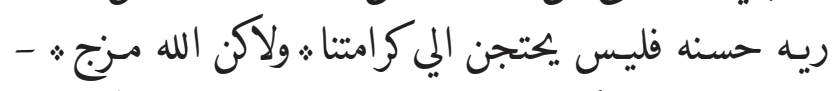

12.25

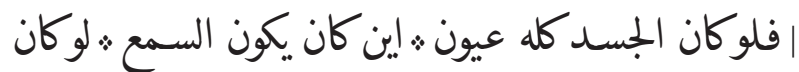
10

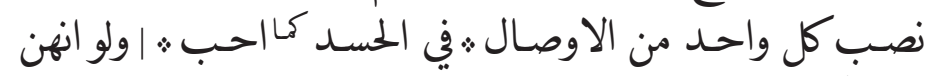

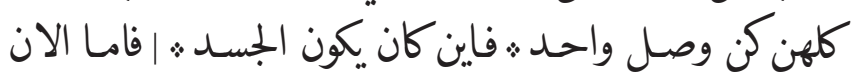

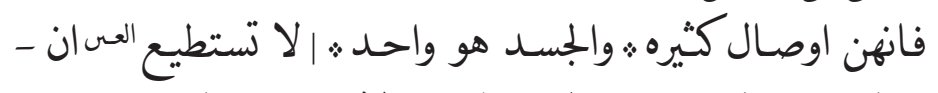

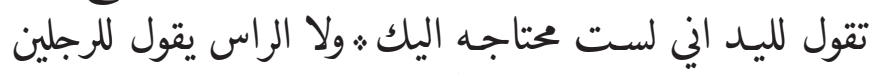

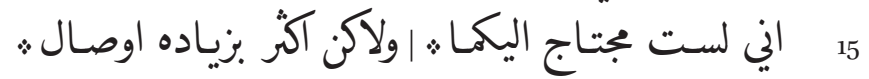

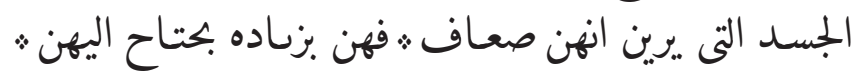

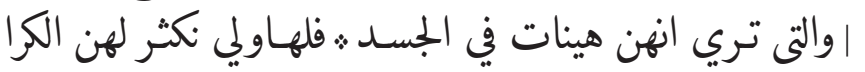
20 


$$
\text { لا يكون اختحلاف في الجسـد ولاكن الاوصـال كلهن شى ٪ }
$$
folio $114 \mathrm{r}$

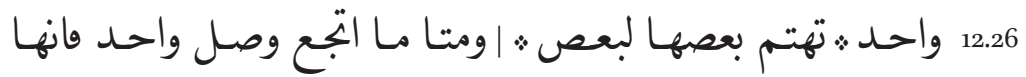

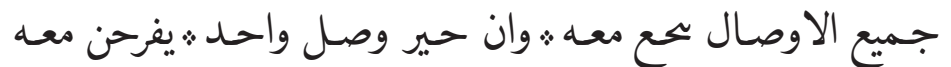

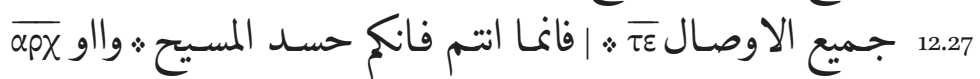

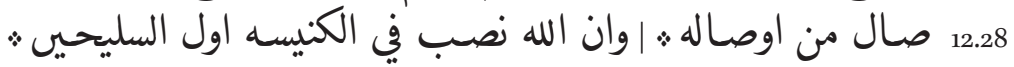

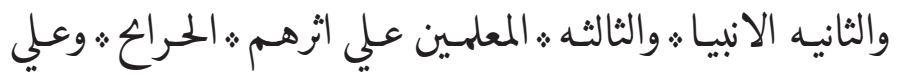

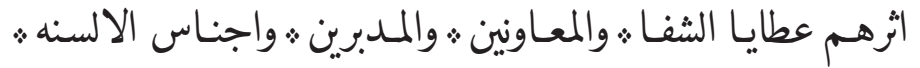

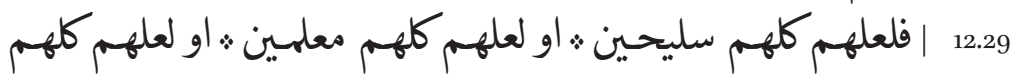

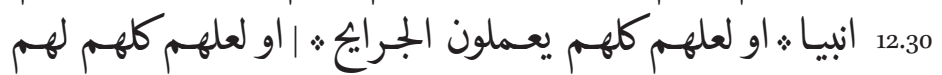

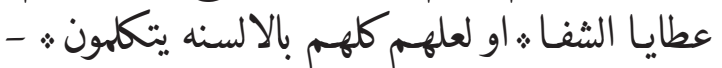
12.31 او لعلهم كلهم .يترجمون ؛ | كونوا بعـرون العطايا العطام :

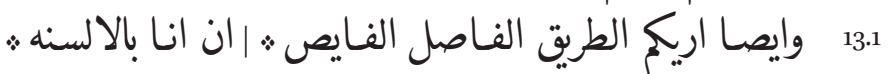

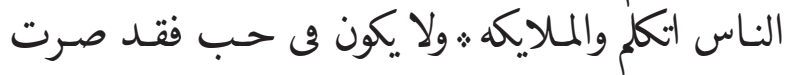

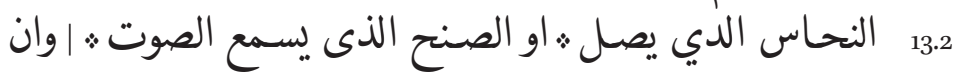

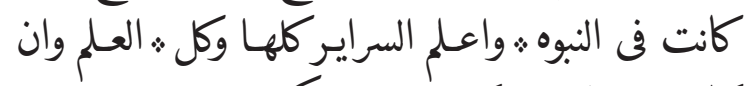

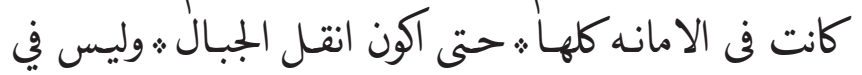

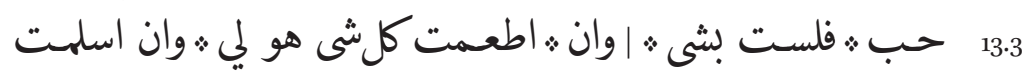

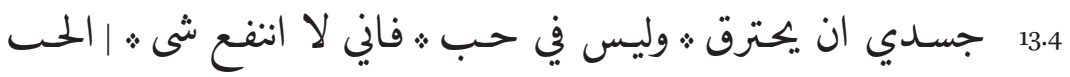

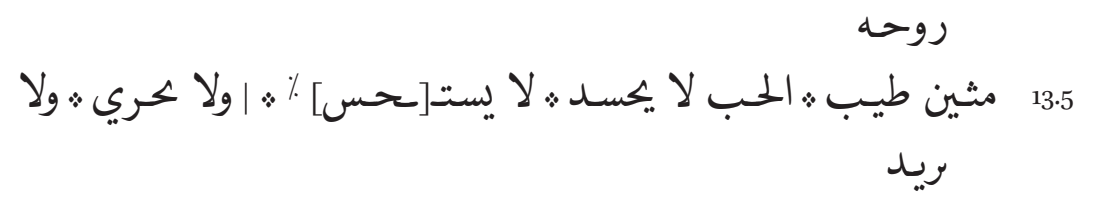
13.6 الذي له ث. ولا تتبهر *ولا يتفكر بالشر * |ولا يفرح بالاثم * ولا 
folio $114 \mathrm{~V}$

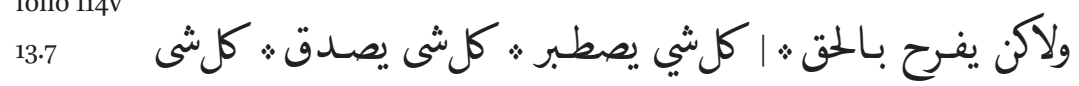

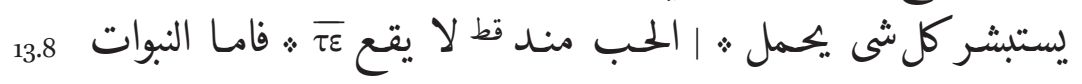

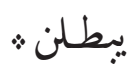

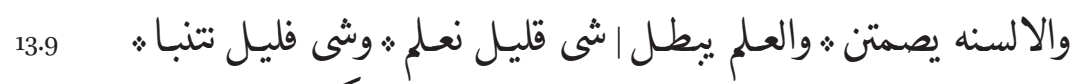

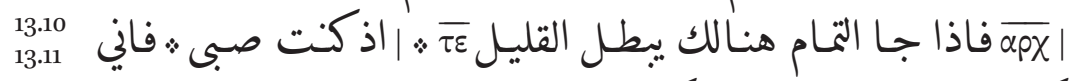

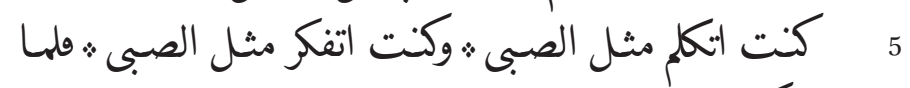

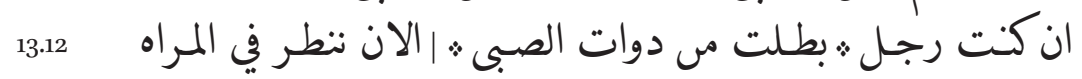

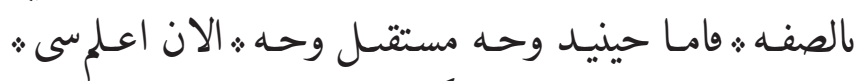

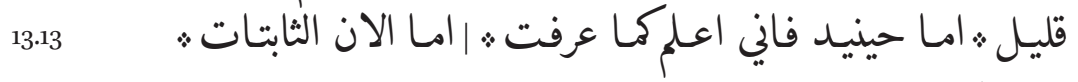

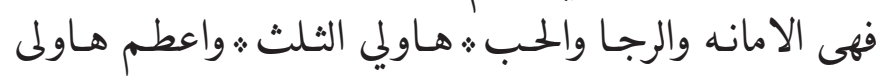

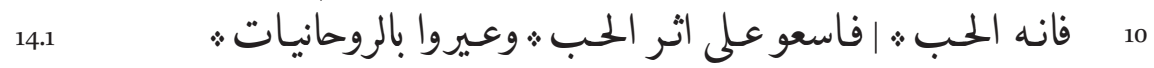

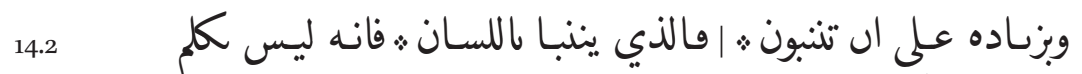

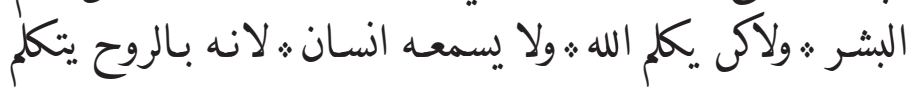

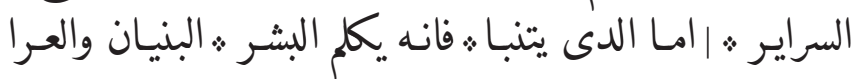

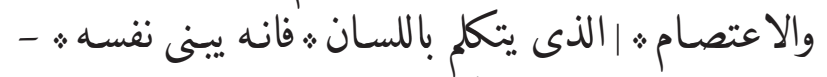

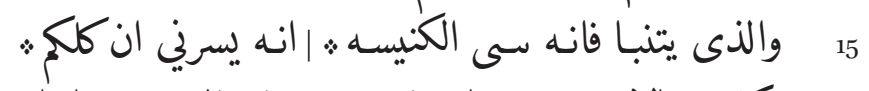

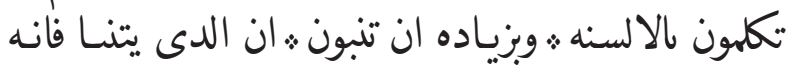

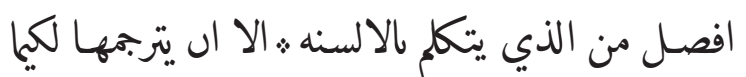
14.6 
وبعطيى الصوت ان كان انوب وان قيثار ث. ان لم يصنع

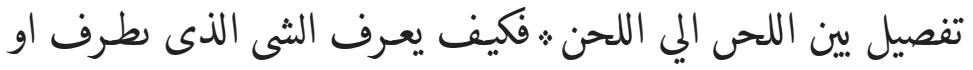

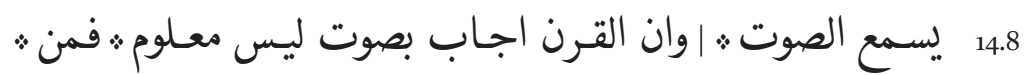

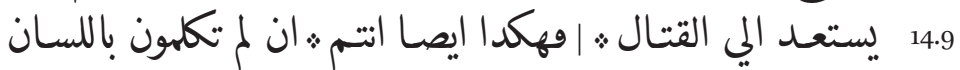

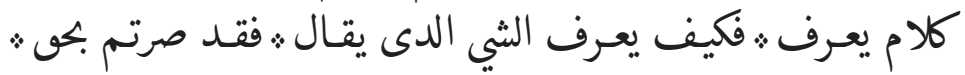

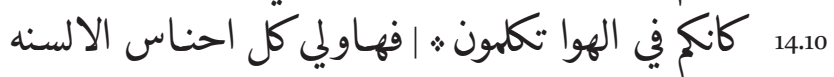

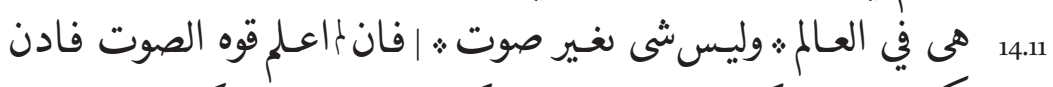

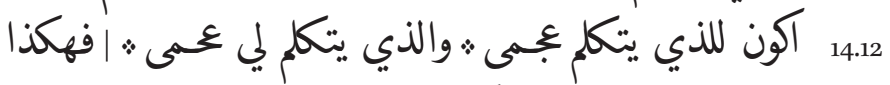

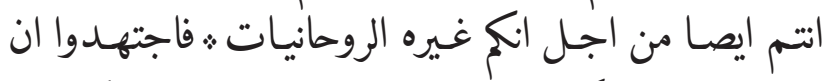

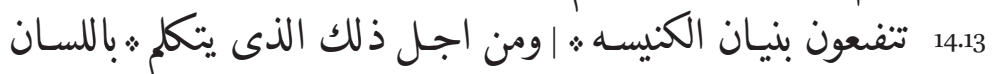

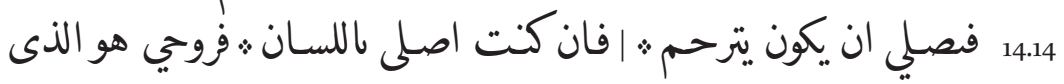

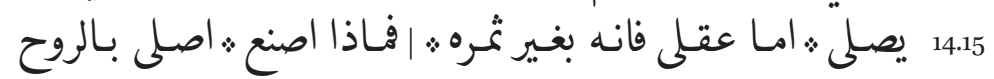

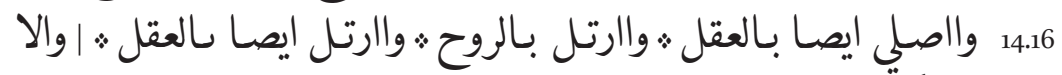

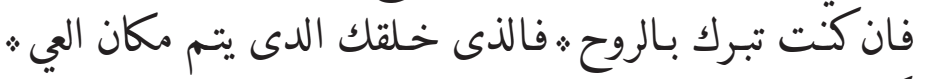

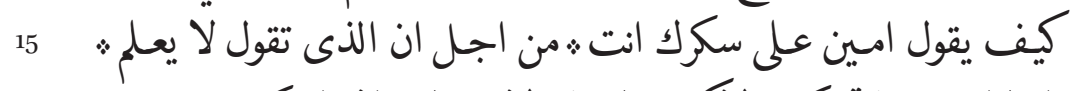

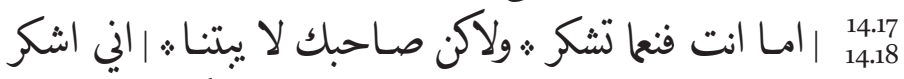
14.19

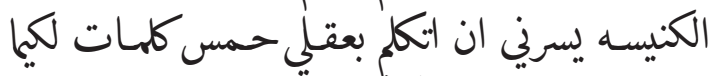
14.20 20 صبيان بعلمكم * ولاك للسر فكونوا صبيان امـا تقكركم 


\section{folio $115 \mathrm{~V}$}

14.21

فكونو تامين : افي الناموس : مكتوب ان باللسـان الاخر وبالشفاه

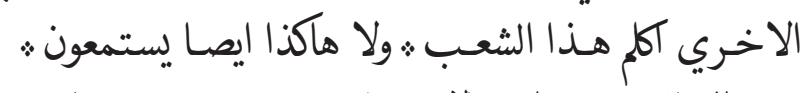

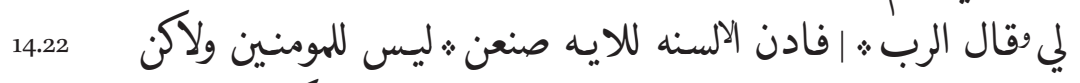

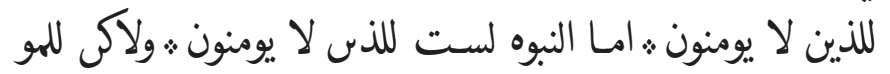
5

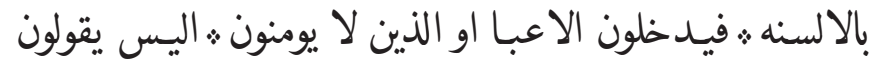

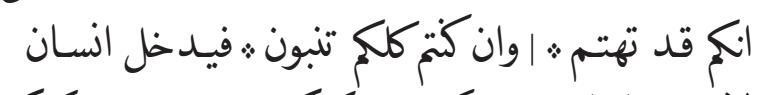

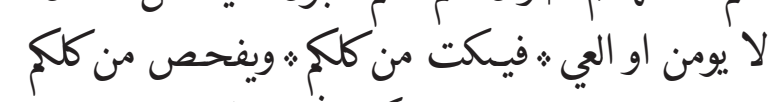

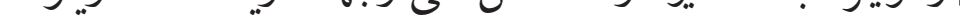
10

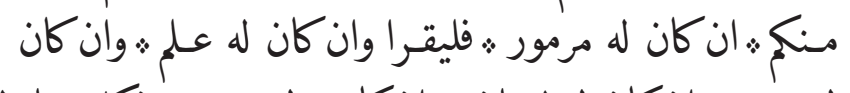

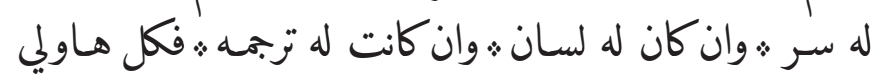

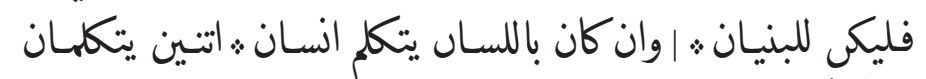

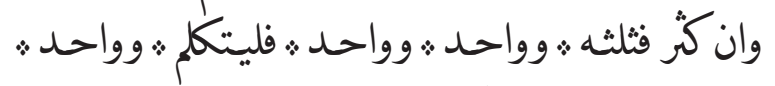

\subsection{9}

$14 \cdot 30$

$14 \cdot 31$

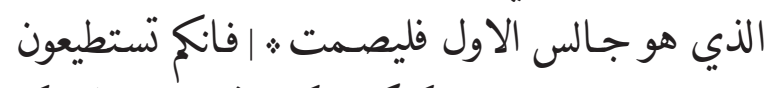

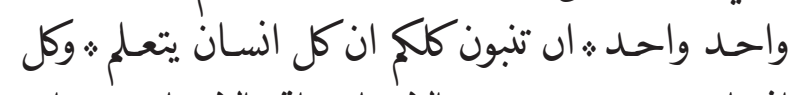

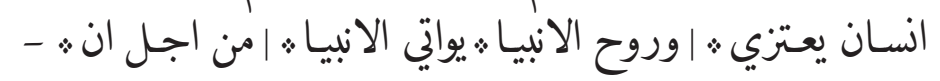


folio $116 \mathrm{r}$

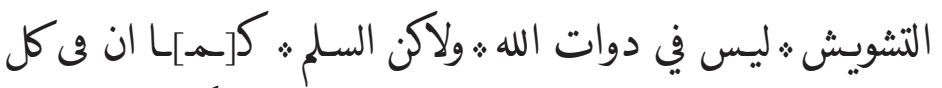

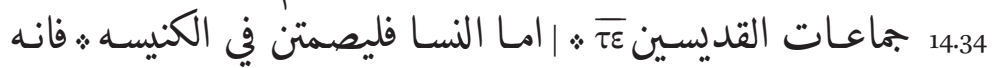

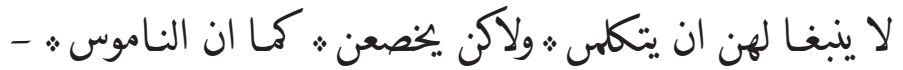

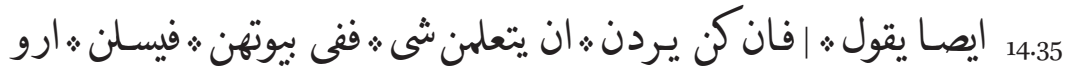

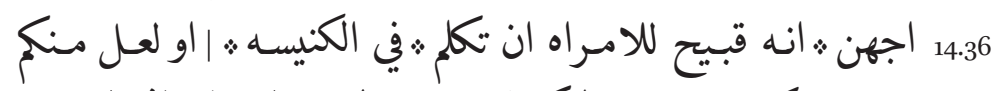

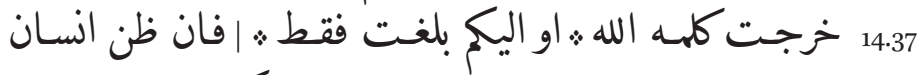

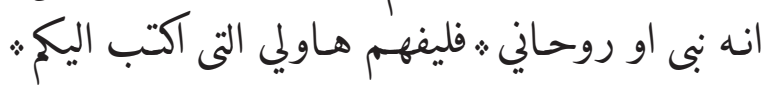

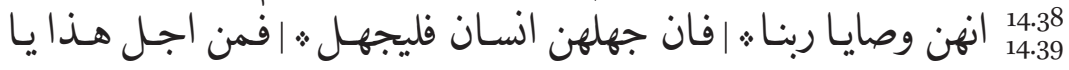

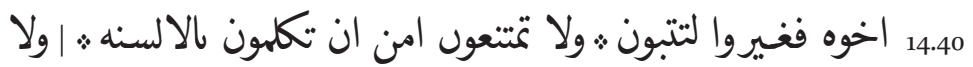

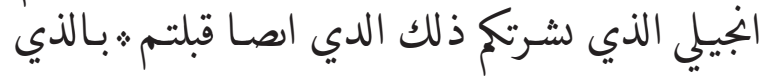

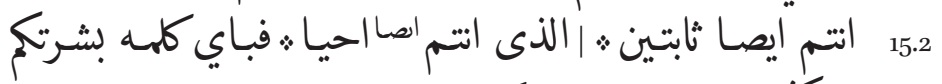

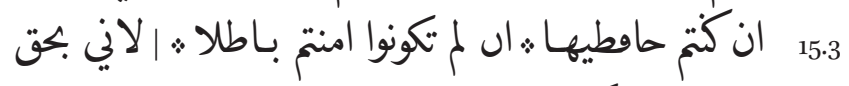

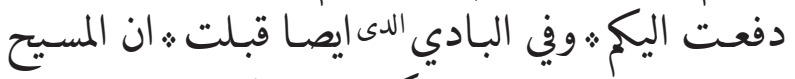

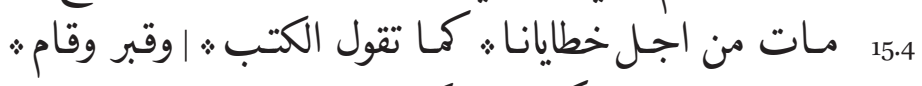

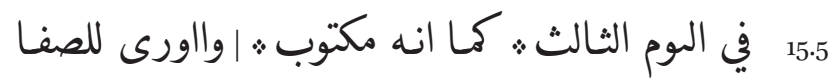

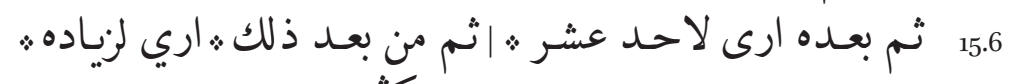

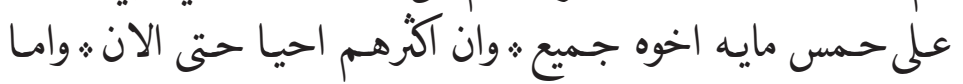

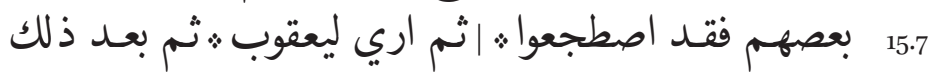


folio $116 \mathrm{v}$

15.8

$15 \cdot 9$

15.10

15.11

15.12

15.13

15.14

15.15

15.16

$15 \cdot 17$

15.18

15.19

15.20

15.21

15.22

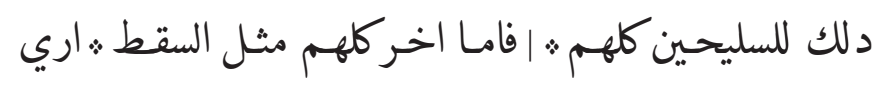

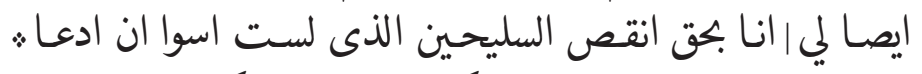

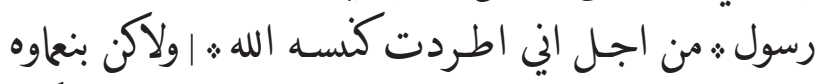

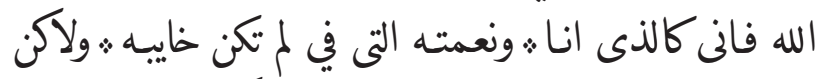

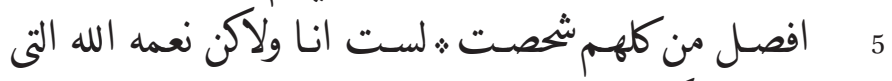

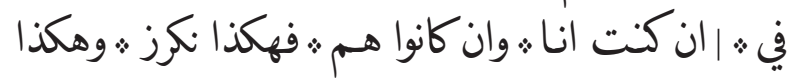

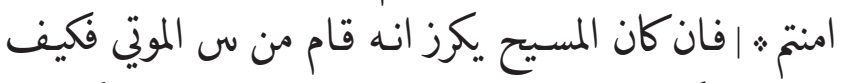

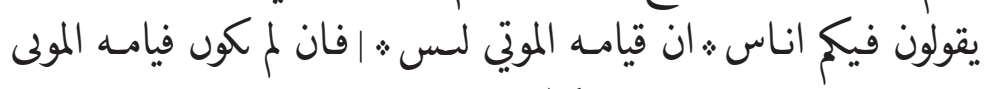

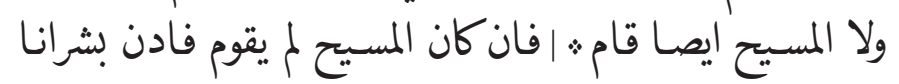
10

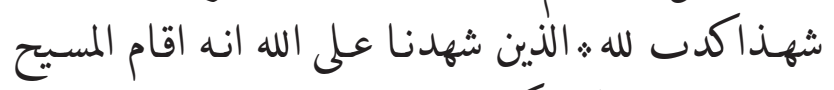

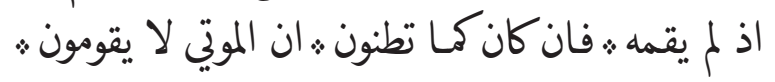

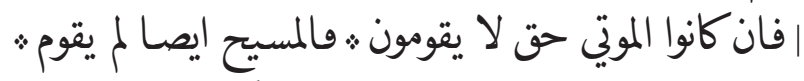

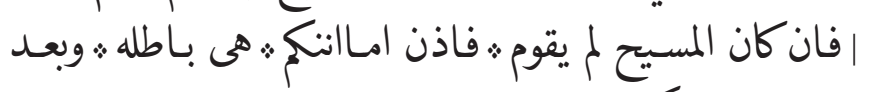
15

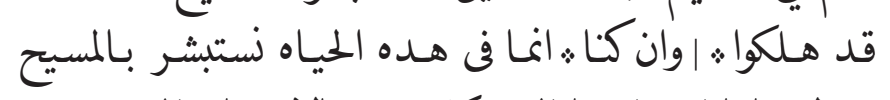

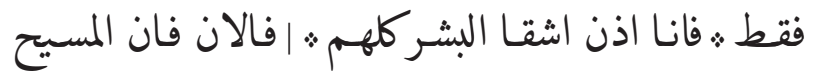

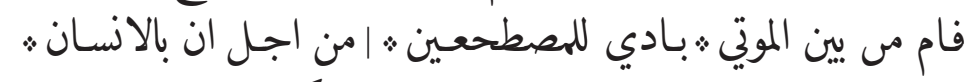

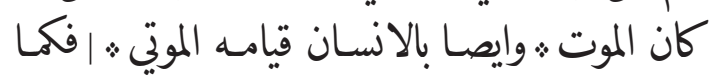
20 


\section{folio $117 \mathrm{r}$}

15.23 يجينون | كل انسان في مرتبته اياه ث. امـا البدو فهو المسـيح

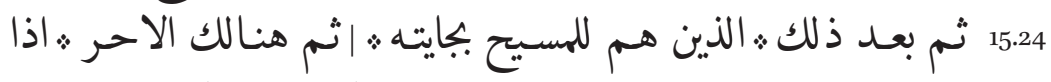

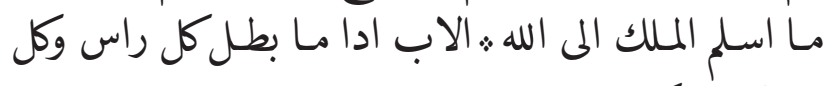

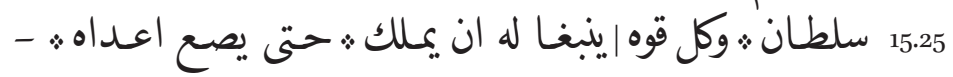

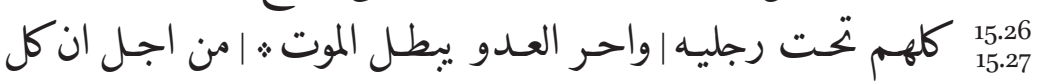

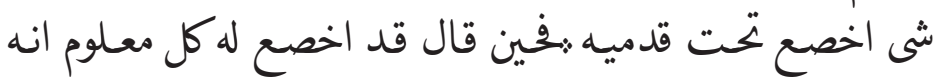

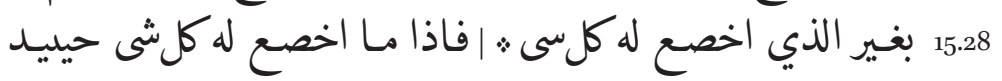

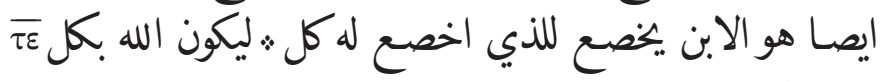

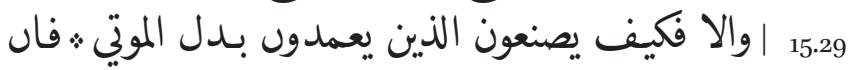

15.30

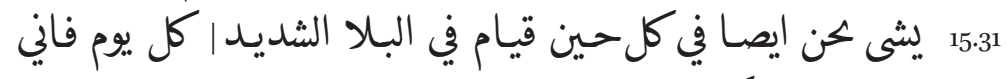

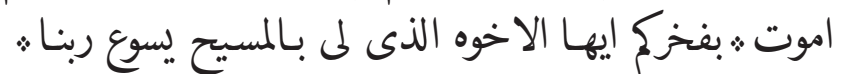

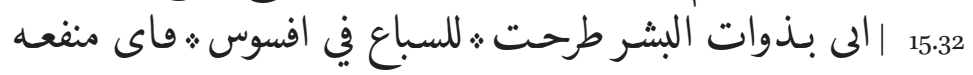

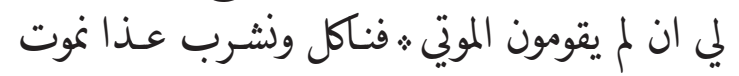

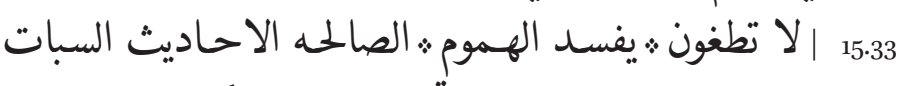

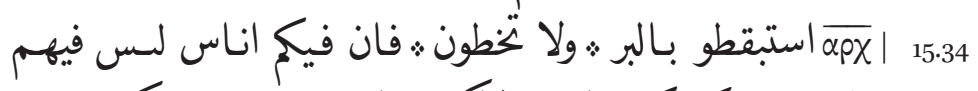

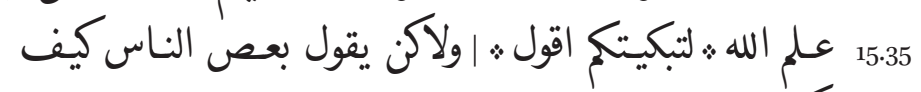

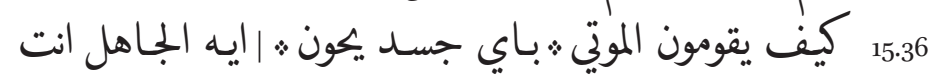

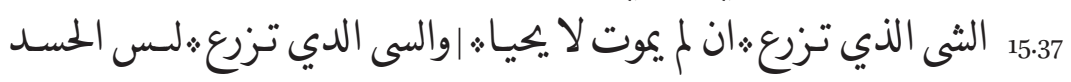


folio $117 \mathrm{~V}$

الذي يكون تزووع ثولاكن حبه عريانه حنطه ث.او بعص الانواع

15.38

$15 \cdot 39$

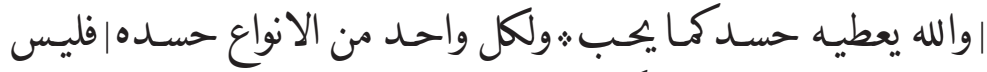

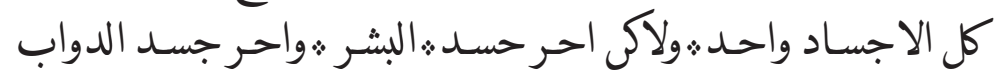

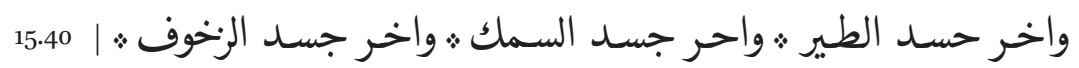

$$
\text { واجساد }
$$

5

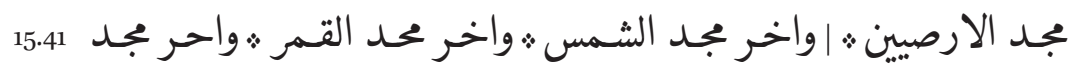

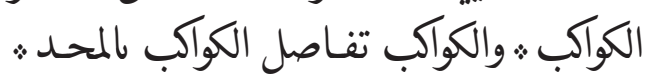

15.42

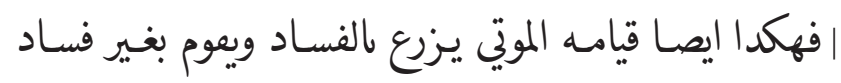

15.43

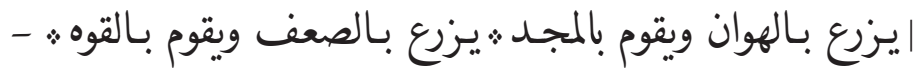

15.44

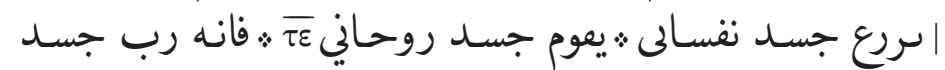
10

15.45

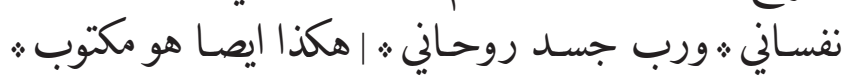

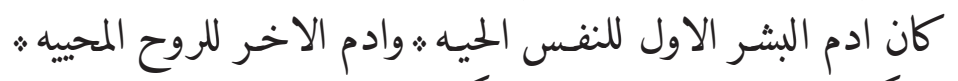
15.46

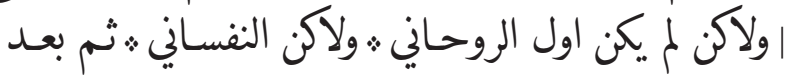

15.47

15.48

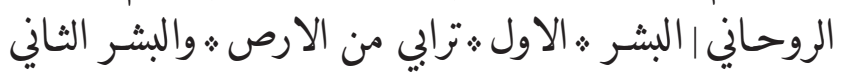
15

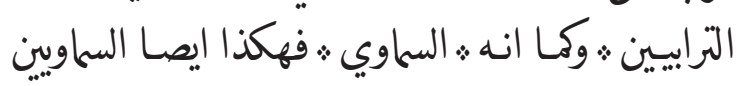

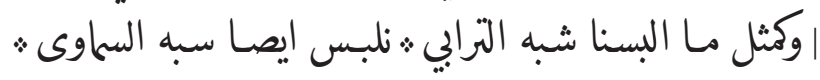

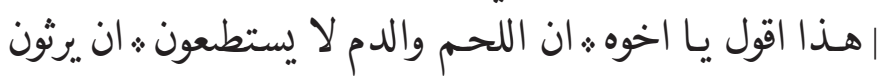
apx 20 
folio $118 \mathrm{r}$

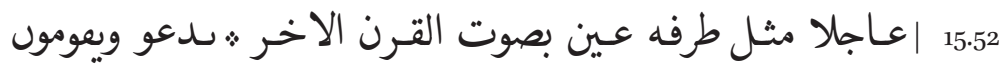

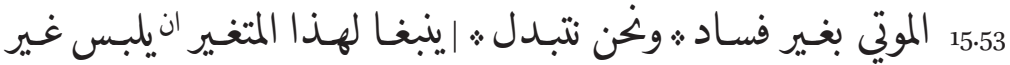

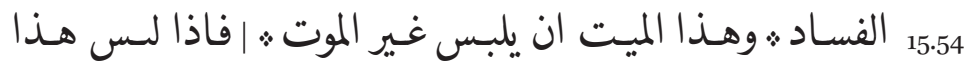

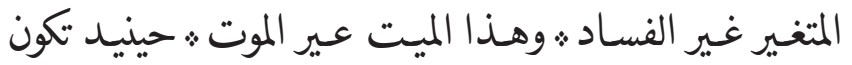
نكون الكلمه المكتوبه ث. ابتلع الموت بالغلبه :

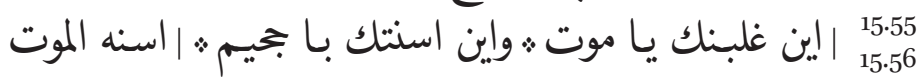

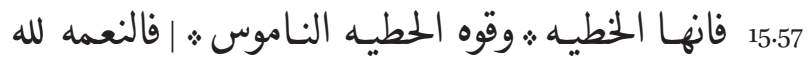

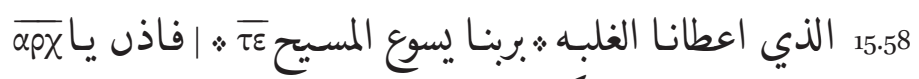

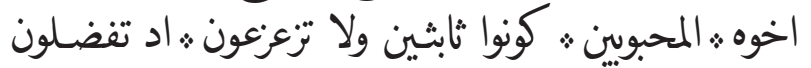

10

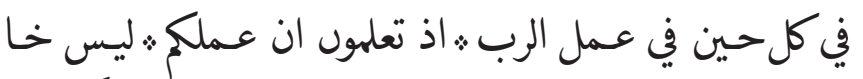
16.11

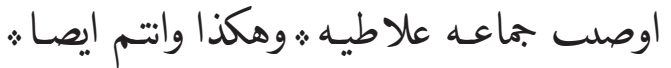
16.2

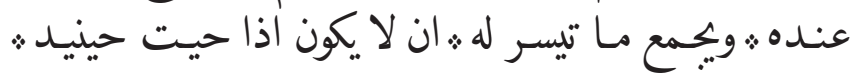

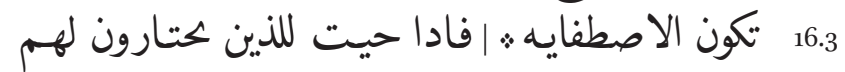

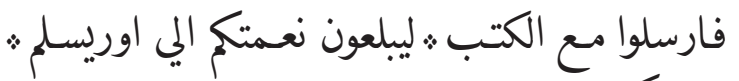

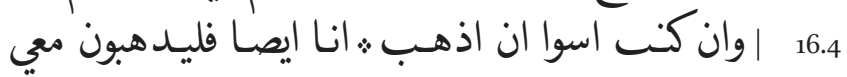

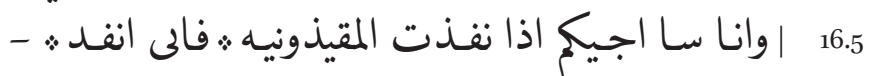

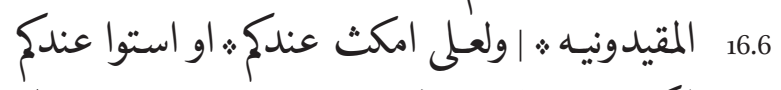

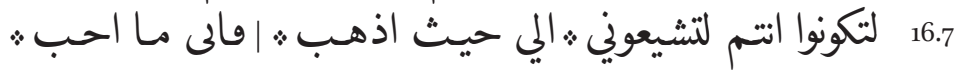


folio $118 \mathrm{v}$

16.8

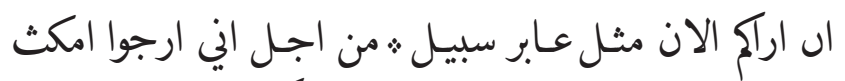

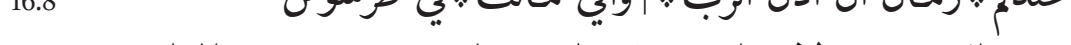

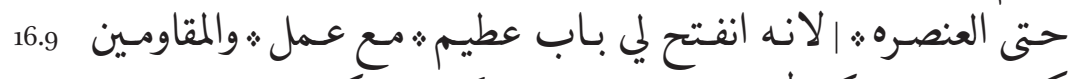
16.10

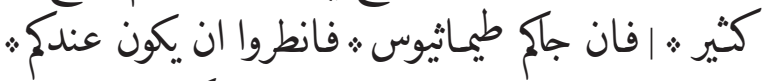
16.11

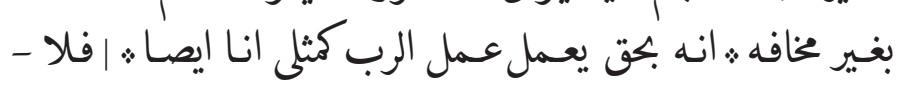
5

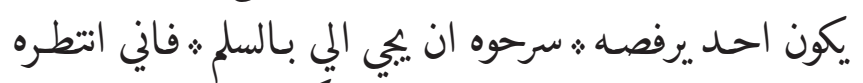
16.12

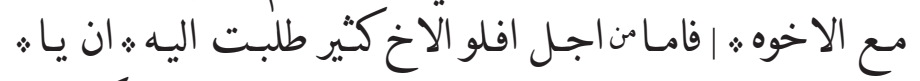

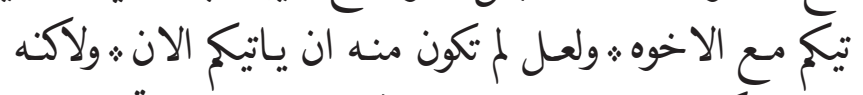

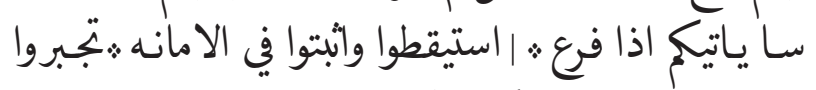
10

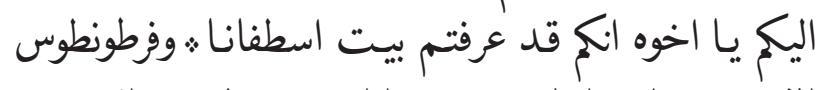

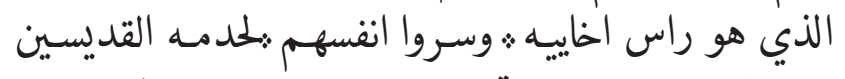

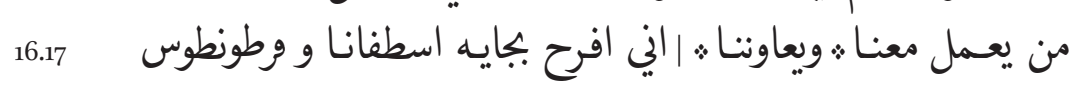

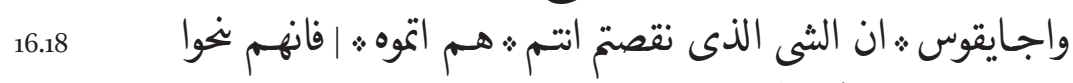

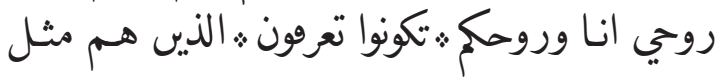
16.19

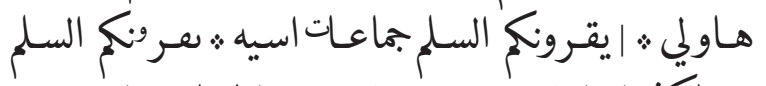

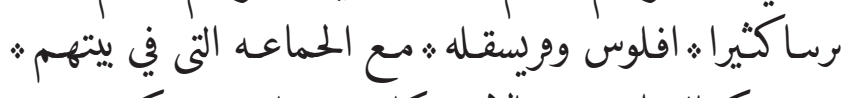

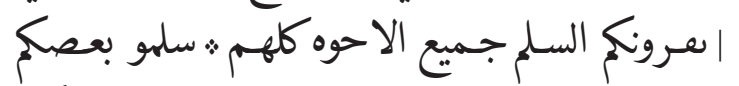
16.21

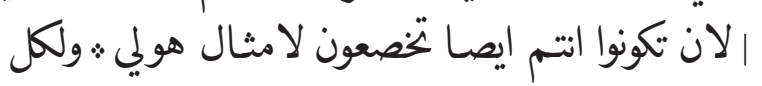




$$
\begin{aligned}
& 16.22
\end{aligned}
$$

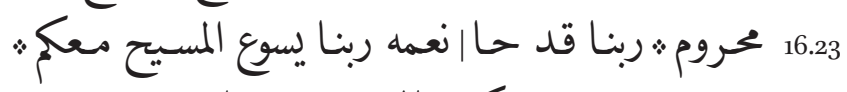

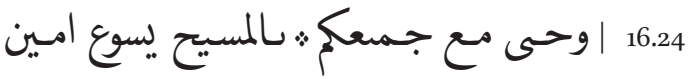

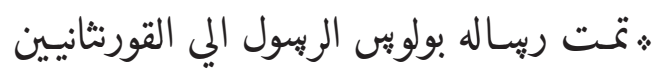

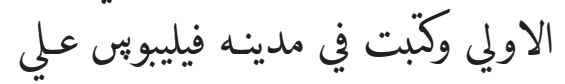

$$
\begin{aligned}
& \text { يـدي إبطفانا وفرطونطوبي وحيا }
\end{aligned}
$$

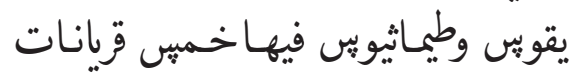

$$
\begin{aligned}
& \text { والروبي تبهع والشهادات بيسع وعشرين } \\
& \text { والايات ثمان ميه وتِّعه ولنه }
\end{aligned}
$$

(À propos du desinit, voir chapitre 6, point 3.7) 


\section{Commentaire et analyse de 1 Corinthiens dans le Vat. Ar. 13}

Nous proposons dans la partie qui suit un commentaire verset par verset. Il s'agit principalement d'une comparaison entre le texte de la traduction arabe, le texte grec et le texte de la Peshitta; la comparaison permet de mettre en évidence l'influence des traditions grecque et syriaque sur la traduction¹. Notre démarche est similaire à celle proposée par Monferrer-Sala pour des extraits de Matthieu ${ }^{2}$ et pour Philémon ${ }^{3}$ dans Vat. Ar. 13. Nous présentons aussi dans ce commentaire certaines difficultés de lecture ou de traduction que nous avons pu rencontrer. Nous faisons alors parfois référence aux deux manuscrits édités, le Sin. Ar. ${ }^{151}$ et le Sin. Ar. 155, deux manuscrits du $9^{\text {e }}$ s. (voir chapitre 5 , point 3.3 Remarques concernant les manuscrits les plus anciens). Une comparaison directe avec ces deux manuscrits est proposée en ci-dessous au point 3.1 Comparaison avec Sin. Ar. 151 et Sin. Ar. 155 .

Le texte grec est le texte de la $28^{\mathrm{e}}$ édition du Nestle-Aland (abrégé NA28):

- Novum Testamentum Graece, $28^{\mathrm{e}}$ édition révisée, éditée par Barbara and Kurt Aland, Johannes Karavidopoulos, Carlo M. Martini, et Bruce M. Metzger en coopération avec le Institute for New Testament Textual Research, Münster/Westphalia, (C) 2012 Deutsche Bibelgesellschaft, Stuttgart. Utilisée avec la permission de la Deutsche Bibelgesellschaft.

Le texte de la Peshitta est le texte publié par la British and Foreign Bible Society en 1905-1920, que l'on trouve en ligne 4 .

Lorsqu'elles concernent la traduction du Vat. Ar. 13, nous signalons les variantes présentées dans le texte grec et dans les autres versions telles que

1 Nous utilisons parfois l'expression «le traducteur » par commodité. Sans oublier la question du genre, il est tout à fait possible que la traduction soit l'œuvre de plusieurs traducteurs.

2 Monferrer-Sala Juan Pedro, «Translating the Gospels into Arabic from Syriac: Vatican Arabic 13 Restored Section, Strategies and Goals », Arabica (62), 2015, pp. 435-458.

3 Monferrer-Sala Juan Pedro, « The Pauline Epistle to Philemon from Codex Vatican Arabic 13 (Ninth Century CE): Transcription and Study », Journal of Semitic Studies 6o (2), 2015, pp. 341-371.

4 Nous reproduisions le texte mis à disposition par <http://www.dukhrana.com $>$, consulté le 09.03.2016, auquel nous ajoutons les seyyomés.

(C) SARA SCHULTHESS, 2019 | DOI:10.1163/9789004378162_009

This is an open access chapter distributed under the terms of the prevailing CC-BY-NC License at the time of publication. 
signalées par le NA28. Nous utilisons les abréviations du NA28 $8^{5}$. Nous utilisons également les abréviations suivantes :

- VA 13 (Vat. Ar. 13)

- SA 151 (Sin. Ar. 151 et son édition de référence) ${ }^{6}$

- SA 155 (Sin. Ar. 155 et son édition de référence) ${ }^{7}$

Afin d'alléger le commentaire, les références aux différents outils utilisés (dictionnaires, grammaires, commentaires, etc.) sont données de manière abrégée. Les références complètes se trouvent au point 2. Outils de notre Bibliographie.

\subsection{Chapitre 1}

1 Co 1,1

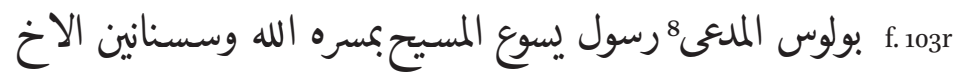

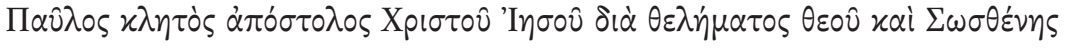
o $\alpha \dot{\delta} \varepsilon \lambda \varphi \dot{o} \varsigma$

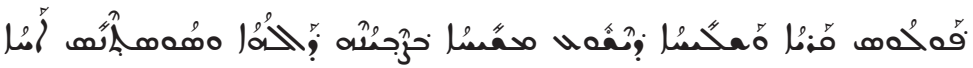

Paul, appelé envoyé de Jésus le Christ par la volonté de Dieu, et Sosthène, le frère,

À propos des noms propres, voir 4.1 Noms propres.

Le traducteur traduit différemment le terme $\alpha \dot{\pi} \sigma \dot{\sigma} \tau 0 \lambda$ ○ lorsque celui-ci est au singulier et se réfère à Paul (traduit par رسولici et en 1 Co 9,1-2) et lorsqu'il est au pluriel (traduit alors par سليحين, voir 1 Co 4,9). Il semble ainsi réserver à l'apôtre Paul, certainement pour souligner son rôle important. Cette spécificité est développée au point 4.3.1.

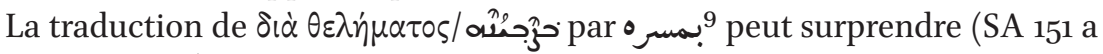
dans VA 13 exprime une idée de volonté (voir 1 Co 9,$17 ; 14,5)$.

Nous lisons dans le manuscrit سسنانين, mais il faut lire : سستانين. Une autre possibilité serait : سستثان.Voir 4.1 Noms propres.

5 Voir pour plus de précisions l'introduction du NA28.

6 StaAl Harvey, Mt. Sinai Arabic Codex 15 I: The Pauline Epistles, vol. 1, Louvain, Peeters, 1983 (CSCO 452).

7 Gibson Margaret Dunlop, An Arabic Version of the Epistles of St Paul to the Romans, Corinthians, Galatians with Part of the Epistles to the Ephesians, Londres, C. J. Clay, 1894 (Studia Sinaitica 2).

8 Voir 2.2 Éléments de moyen arabe dans Vat. Ar. 13 (1 Corinthiens) : 16) Verba tertiae infirmae.

9 « [J]oie, allégresse, contentement», KAZIMIRSKI 1, p. 1076. 


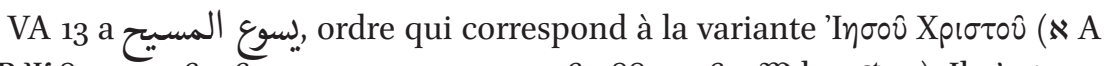
L P Y 81. 104. 365. 630. 1175. 1241. 1505. 1506. 1881. 2464. $\mathrm{M} \mathrm{b}^{\mathrm{b}}{ }^{\text {st }}$ sy). Il n'est pas exclu que le traducteur traduise dans cet ordre Xpı $\tau$ ○ิ 'Inøov̂ (P46 B D F G 33 it $\mathrm{vg}^{\mathrm{cl}}$ ) par automatisme.

1 Co 1,2

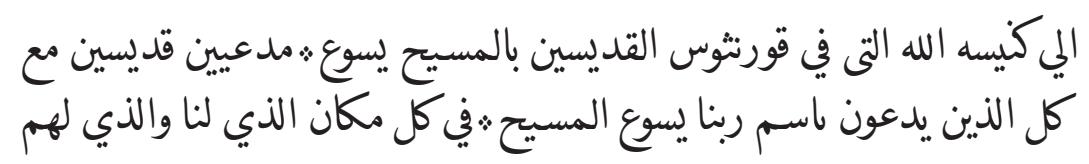

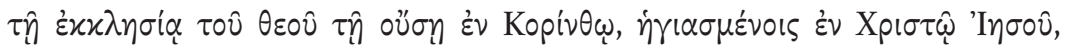

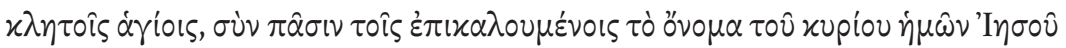
Xp

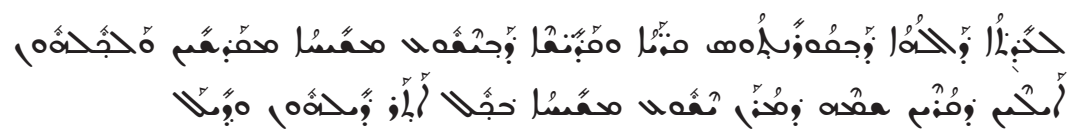

à l'église de Dieu qui est à Corinthe, aux saints en le Christ Jésus, appelés saints avec tous ceux qui invoquent le nom de notre Seigneur Jésus le Christ, en tout lieu qui est à nous et à eux,

À propos du nom propre قورنثوس, voir 4.1 Noms propres.

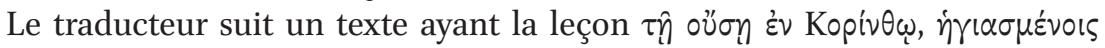

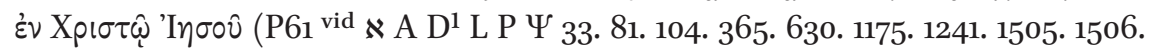
1739. 1881. $2464 \mathfrak{M}$ lat co $\mathrm{H}$ ), différent du texte édité dans NA28 (témoins : $\mathrm{P} 46$ $\mathrm{B} \mathrm{D}^{*}{ }^{2} \mathrm{~F} \mathrm{G} \mathrm{b} \mathrm{m)}$ ). Le texte de syp a encore un ordre différent, que VA 13 ne suit pas ici.

Il est intéressant de noter que le traducteur ne fait pas ici de différences

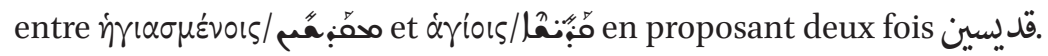

Le traducteur traduit par مع مع la préposition oùv du grec et non 》 de syp.

Avec en tout lieu qui est à nous et à eux », VA 13 inverse les possessifs.

\section{Co 1,3}

$$
\text { النعمه sعكم و السلم ث من الله ابونا وربنا يسوع المسيح }
$$

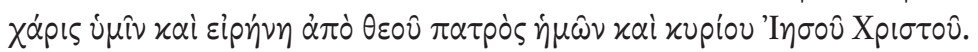




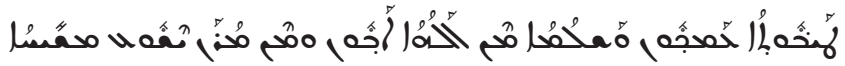

la grâce avec vous et la paix de Dieu notre père et notre Seigneur Jésus le Christ.

Le traducteur exprime les destinataires de la grâce à l'aide de la proposition comme dans syp.

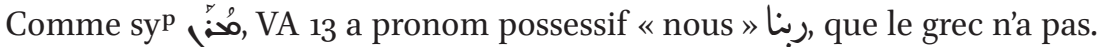
Les variations au niveau du pronom possessif avec « Seigneur » entre le grec, le syriaque et l'arabe sont très fréquentes et certainement idiomatiques. Elles ne seront plus relevées dans la suite de notre commentaire.

1 Co 1,4

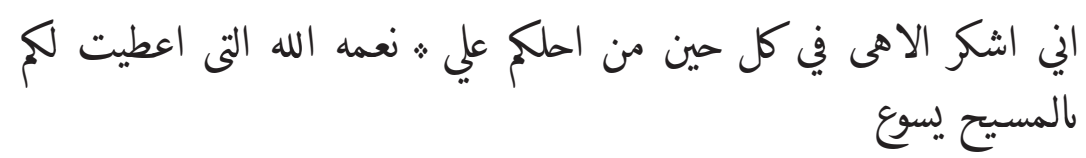

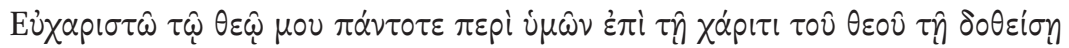

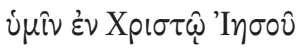

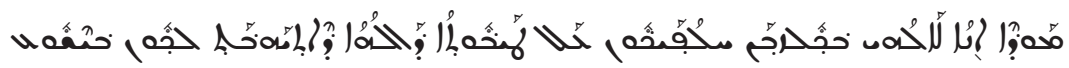

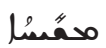

Je remercie mon Dieu à tout moment à cause de vous, pour la grâce de Dieu qui vous a été donnée en Jésus le Christ.

VA 13 soutient la variante présentant $\mu$ ov après $\tau \hat{\omega} \theta \varepsilon \hat{\omega}$ (comme $\aleph^{1}$ A C D F G L P $\Psi$ 33. 81. 104. 365. 630. 1175. 1241. 1505. 1739. 1881. 2464 M latt sy co, $\mu$ ov absent dans $\left.\aleph^{*} \mathrm{~B}\right)$.

\section{Co 1,5}

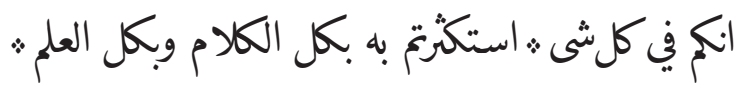

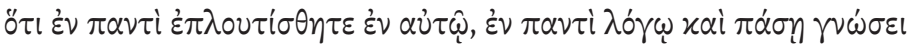

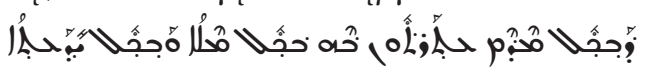

Vous, en toute chose, vous avez été multipliés en lui, en toute la parole et toute la connaissance, 
Le grec a un verbe au passif $\dot{\pi} \pi \lambda \circ 0 \tau i \sigma \theta \eta \tau \varepsilon$. Vu que la signification de la forme $\mathrm{x}$ de $\mathrm{s}$ ne correspond pas au contexte ${ }^{10}$, nous pouvons supposer qu'une tendance passive est exprimée ${ }^{11}$.

On aurait pu attendre un في pour traduire la préposition عُv, comme c'est le cas au verset suivant.

L'utilisation de 5 avec déterminé est surprenante « en toute la parole ... »; nous gardons l'expression en français car les autres utilisations de $\mathbf{6}$ montrent que le traducteur utilise avec précision la détermination ou l'indétermination.

1 Co 1,6

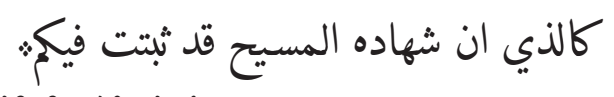

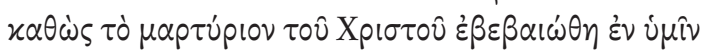

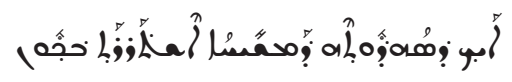

comme le témoignage du Christ a été affermi en vous,

VA 13 soutient la variante Xpı 630. 1241. 1505. 1506. 1739. 1881. 2464 M sy co, quelques témoins ont $\theta$ عov ( $B^{*} F$ G 81. $\left.\left.1175 \mathrm{sa}^{\mathrm{ms}}\right)\right)$.

\section{Co 1,7}
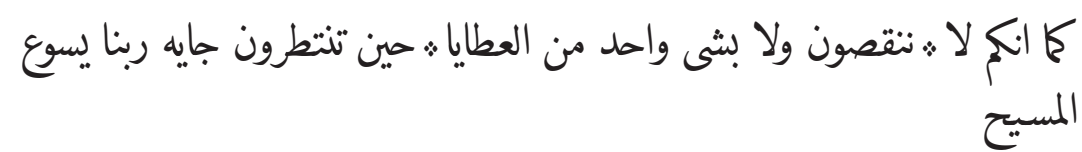

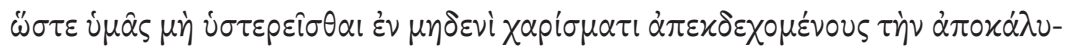

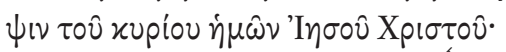

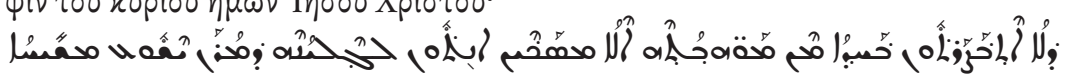

de même que vous ne manquez de rien parmi les dons, quand vous attendez la venue de notre Seigneur Jésus le Christ,

Nous traduisons انكم لا نتقصون ولا بشى واحد par «vous ne manquez de rien », littéralement : « vous n'êtes pas diminués ni en aucune chose ».

\footnotetext{
10 «Regarder comme très nombreux », KAZIMIRSKI 2, p. 867.

11 «A tenth form may be used as the passive of the first », BLAU, § 67. Toutefois, on notera que la forme I est un verbe d'état: « être nombreux, abondant ».
} 


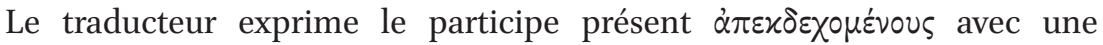
conjonction temporelle حين alors que syp a la conjonction disjonctive $\mathrm{N}$ ? «mais ».

Blau signale que l'orthographe جايه est courante: «Quite frequent is the infinitive جاية to the pattern of the infinitive of original verba tertiae hamzatae like qirâya 'reading' or genuine verba tertiae infirmae, like رجاية 'hope' » (Blau, § 78.1). On retrouve cette orthographe en 11,$26 ; 15,23 ; 16,17$.

\section{Co 1,8}

$$
\text { الذي يثتبكم ايضا حتي الاخزه : تكونوا بغير ملامه في يوم ربنا يسوع المسيح : }
$$

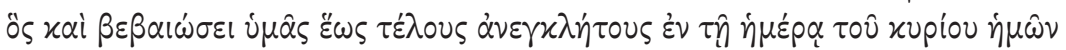
'I

\section{観}

lui qui vous affermit aussi jusqu'à la fin [pour que] vous soyez sans reproche le jour de notre Seigneur Jésus le Christ.

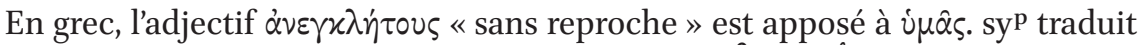

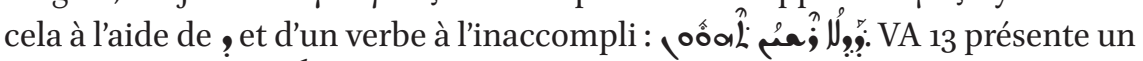
subjonctif seul :تكونوا. Peut-être est-il indirectement demandé par حتى ? Ou le traducteur souhaite-t-il exprimer une nuance finale ${ }^{12}$, certainement présente dans l'inaccompli de syp ?

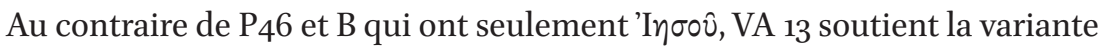

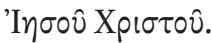

1 Co 1,9

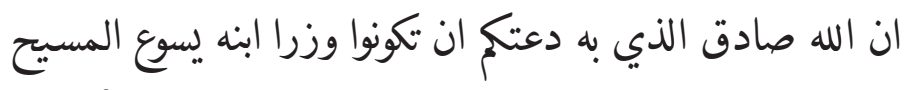

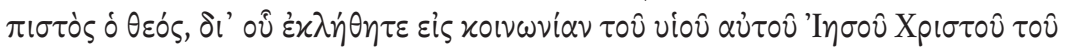
xupiov $\dot{\eta} \mu \hat{\omega} \nu$

12 En moyen arabe, l'inaccompli peut prendre un sens d'ordre ou de souhait à la ze ou ze personne du singulier. BLAU, $§ 172$. Nous ne trouvons pas dans la grammaire de Blau un emploi final de l'inaccompli seul. 


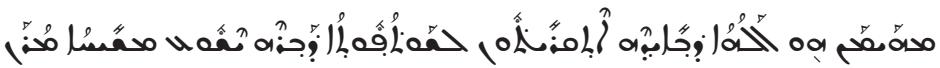

Dieu est fidèle, lui qui, par lui, vous a invités à être ministres de son fils Jésus le Christ.

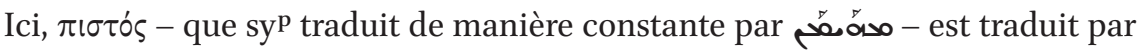
« صادق fidèle »; on retrouve صادق 10,13, à nouveau en tant qu'attribut de

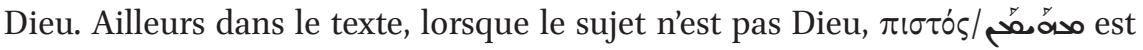

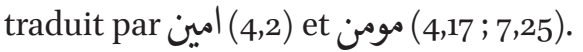

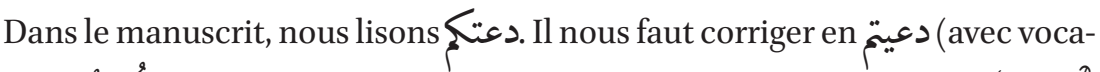

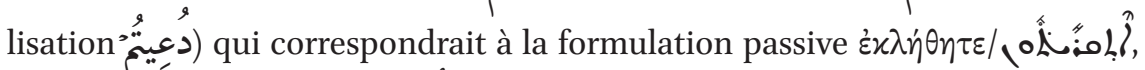

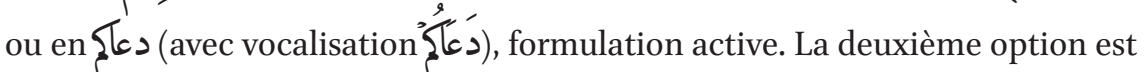
graphiquement plus proche; c'est celle que nous traduisons.

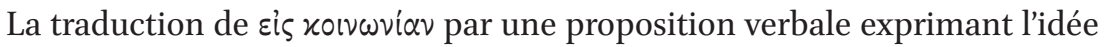
de service ان تكونوا وزرا est étonnante. Elle n'est pas d'influence syriaque car syp

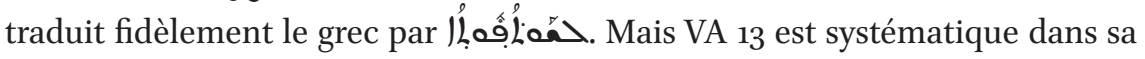

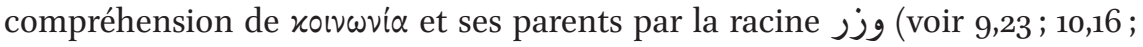
$10,18 ; 10,20)$.

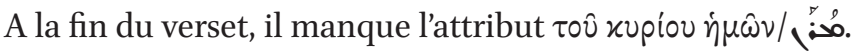

1 Co 1,10

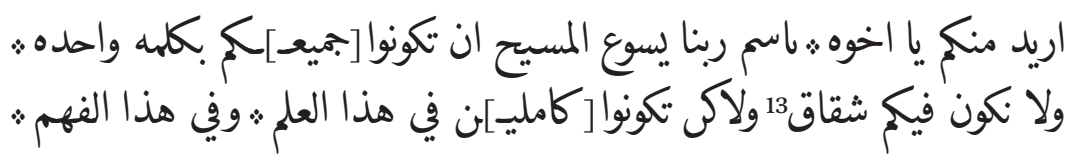

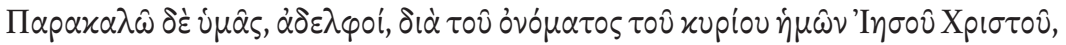

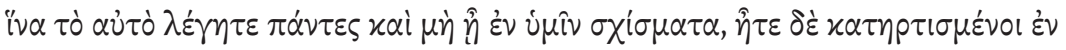

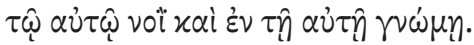

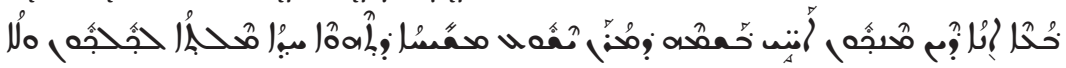

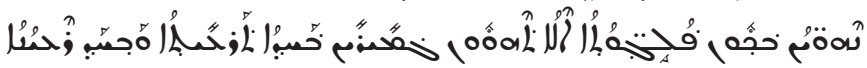

Je veux de vous, ô frères, au nom de notre Seigneur Jésus le Christ, que tous vous soyez dans une seule parole et qu'il n'y ait pas de désaccord entre vous, mais que vous soyez parfaits dans cette pensée et cette compréhension.

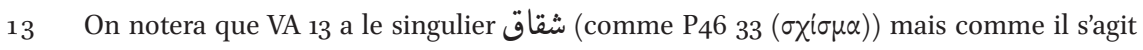
d'un nom d'action, il aurait été inhabituel d'avoir un pluriel. 


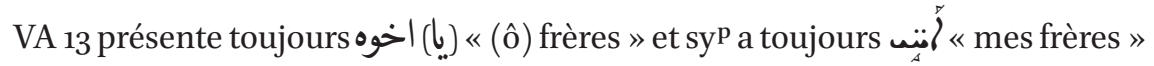
pour traduire $\dot{\alpha} \delta \varepsilon \lambda \varphi \circ i$. Le traducteur ne traduit pas le possessif les rares fois où le grec présente $\mu$ ov $(1,11 ; 11,33 ; 15,58)$. Comme il semble ici s'agir d'expressions idiomatiques, nous ne notons pas là où les trois langues divergent.

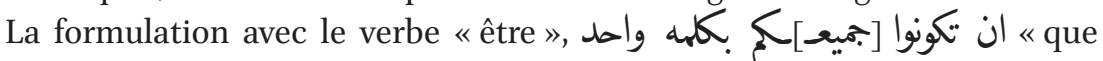
tous vous soyez dans une seule parole», s'éloigne du grec iv $\alpha$ $\pi \dot{\alpha} \nu \tau \varepsilon$ 《 que vous disiez tous la même chose» et de syp

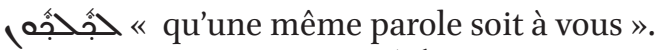

Si nous avons bien كاملين «parfaits», il s'agirait d'une traduction de syp 每 14 car le terme ne contient pas l'idée de réconciliation que peut exprimer $x \alpha \tau \alpha \rho \tau i \zeta \omega$ (cf. LIDDEL SCOTT).

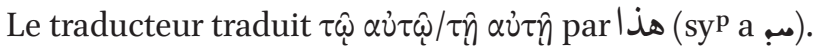

\section{Co 1,11}

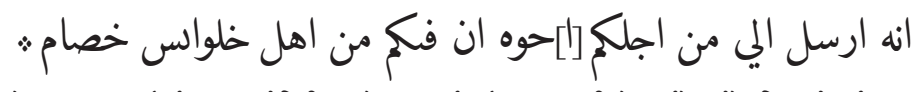

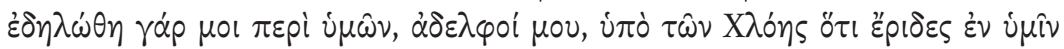
हiఠเv.

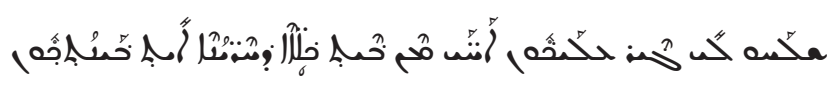

Il m’a été envoyé à cause de vous, frères, qu'il y a entre vous, de la part des gens de Chloé, dispute.

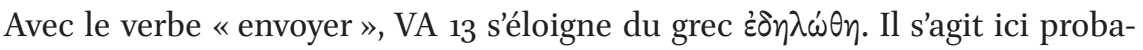
blement d'une traduction sur le syriaque : محخّ (vient de que l'on trouve dans $\operatorname{sy}^{\mathrm{p}}\left(\right.$ et sy $\left.^{\mathrm{h}}\right)$.

À propos du nom propre خلواس, voir 4.1 Noms propres.

1 Co 1,12

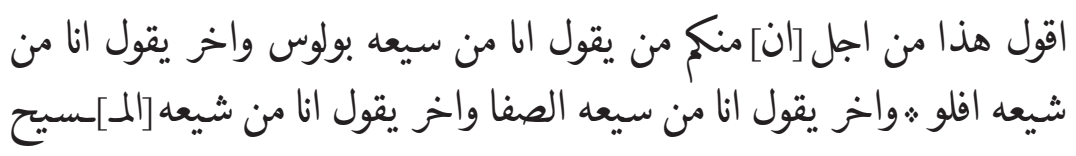

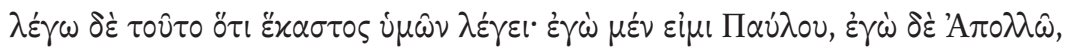

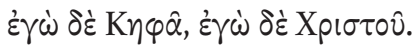

$14 \operatorname{sy}^{\mathrm{h}}($ محمدا) n'a pas non plus l'idée de réconciliation. 


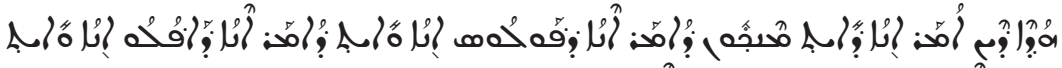 家}

Je dis cela parce que, parmi vous, quelqu'un dit : je suis de la secte de Paul, et un autre dit: je suis de la secte de Apollos, et un autre dit: je suis de la secte de Pierre, et un autre dit : je suis de la secte du Christ.

On notera l'ajout par le traducteur de سيعه « secte » (voir 3,4).

La répétition du verbe « dire » rapproche notre traduction de syp.

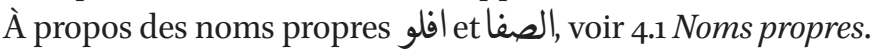

\section{Co 1,13}

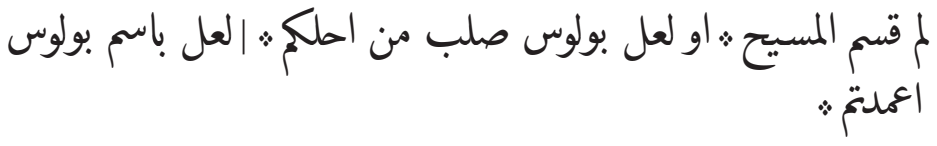

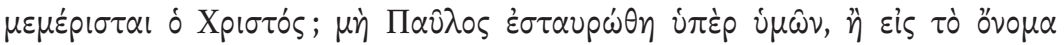

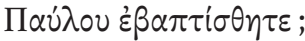

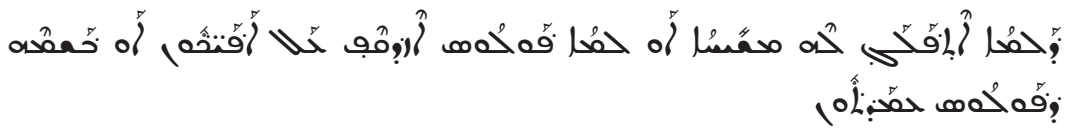

Pourquoi ? Le Christ a-t-il été divisé ? Ou est-ce que Paul a-t-il été crucifié à cause de vous? Est-ce que vous avez, au nom de Paul, été baptisés?

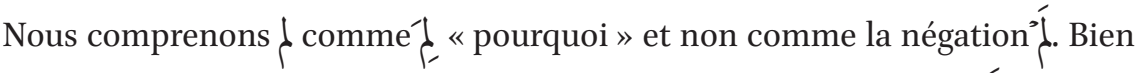
que l'on trouve un $\mu$ ì chez quelques témoins $\left(\mathrm{P}_{4} 6^{\text {vid }} 3262464^{*} \mathrm{sa}\right)$, ‘́ exige un apocopé, règle respectée ailleurs dans VA $13^{15}$. Le traducteur introduit certai-

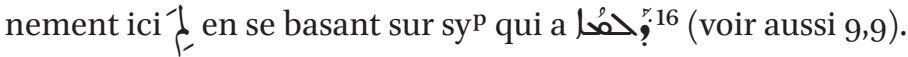

Ensuite, le traducteur utilise deux fois لعل; dans notre texte, on trouve régulièrement cette particule, qui signifie habituellement «peut-être ${ }^{17}$, pour

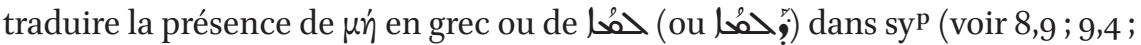
$9,5 ; 9,27 ; 10,22 ; 12,29 ; 12,30 ; 14,36)$. Nous la traduisons généralement par une

\footnotetext{
15 On trouve souvent un inaccompli à la place de l'apocopé, mais jamais d'accompli, voir 2.2 Éléments de moyen arabe dans Vat. Ar. 13 (1 Corinthiens) (point 2.2.3).

16 Dont le sens interrogatif est le suivant: «why? whether? is it not? not? in asking a question when the answer is expected to be negative », Payne-Smith, p. 93.

17 Un sens que le traducteur connaît également et utilise en 16,6 et 16,12. KAzImirsKi 2, p. 361 .
} 
tournure interrogative. On notera la difficulté suivante : en grec et en syriaque, حمُحا/ peuvent aussi prendre un sens négatif. Si لعملر dans VA 13 se calque

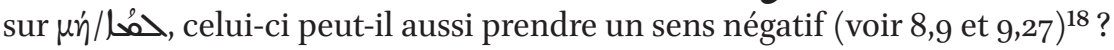

VA 13 a un en tête de la deuxième phrase interrogative, comme syp (et P46) alors qu'il omet le g en tête de la troisième phrase interrogative, pourtant présente en grec et dans syp.

Alors que l'on attendrait pour «baptiser» la forme II et pour « être baptisé » la forme $\mathrm{v}$, nous avons une forme IV qui n'est pas attestée dans les dictionnaires consultés ${ }^{19}$. Le verbe étant au passif en grec et dans syp (peal au sens passif), il s'agit probablement d'un passif ici également. Malgré cela, l'alif n'est pas en soi, à notre avis, un indicateur du passif; en effet, on trouve la forme IV dans un sens actif en 1,16. Blau n'est pas de notre avis : dans son paragraphe sur la forme vi, il donne en exemple اعمد (dans Sin. Ar. 155) qu'il traduit par « to be baptized » (BLAU, § 57.1).

\section{Co 1,14}

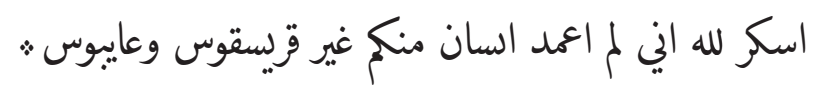

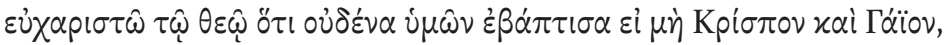

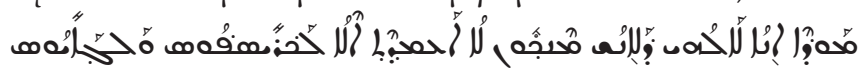

Je remercie Dieu de n'avoir baptisé aucun d'entre vous, sauf Crispus et Gaïus,

VA 13 n'a ici pas de possessif après aل (comme $\aleph^{2}$ C D F G L P Y 104. 365. 630. 1175. 1241. 1505. 1506. 1881. $2464 \mathrm{M}_{\text {lat bo }}{ }^{\mathrm{ms}}$ ) contrairement à syp et quelques autres témoins (A 33. 81. 326 ar vg $\left.{ }^{\mathrm{mss}} \mathrm{sy}^{\mathrm{h} * *}\right)^{20}$.

اعمد est ici à l'actif mais il n'est pas possible ici de déterminer la forme de اعمد ; voir notre remarque au verset précédent.

À propos des noms propres قريسقوس وعايموس, voir 4.1 Noms propres.

18 Blau atteste l'utilisation de لعل comme interrogatif; il mentionne aussi son utilisation comme interrogatif qui «introduces an indirect question which denotes an undesired action ». BLAU, § 196 .

19 Il est aussi possible qu'il s'agisse d'un alif prosthétique. Arbache Samir, « Le texte du Sinaï Arabe 72 : éléments de morphologie verbale », in : LENTIN Jérôme et GRAND'HEN$\mathrm{RY}$ Jacques (éds), Moyen arabe et variétés mixtes de l'arabe à travers l'histoire. Actes du Pre-mier Colloque International (Louvain-la-Neuve, 10-14 mai 2004), Louvain, Peeters, 2008 (Publications de l'Institut Orientaliste de Louvain 58), p. 16. Voir aussi BLAU, § 57. 
1 Co 1,15

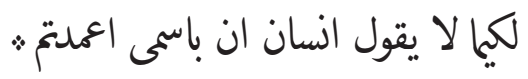

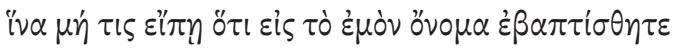

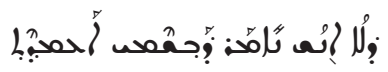

afin que personne ne dise que vous avez été baptisés en mon nom.

Pour la forme اعمدا, nous renvoyons à 1 Co 1,13. Étant donné qu'il s'agit d'une $2^{\mathrm{e}}$ personne du pluriel, cela fait de VA 13 un témoin soutenant la variante $\varepsilon \beta \alpha \pi \tau i \sigma \theta \eta \tau \varepsilon$ comme $\mathrm{P}_{4} 6 \mathrm{~N}$ A B C* 6. 33. 81. 365. 630. 1175. 1506. 1739. f* vg sy $\mathrm{f}^{\text {hmg }}$

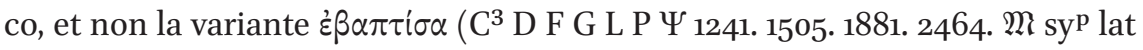
bo $\left.^{\mathrm{mss}}\right)$. Cette variante est particulièrement intéressante, car elle montre que la traduction du VA 13 se base ici sur un texte grec qui n'est pas le texte majoritaire (voir point 3.4).

$1 \operatorname{Co~} 1,16$

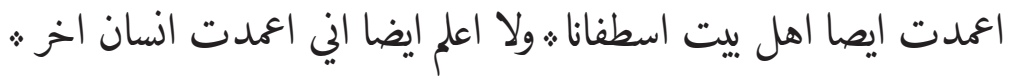

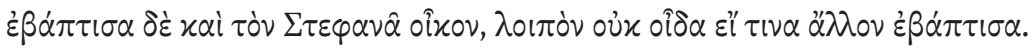

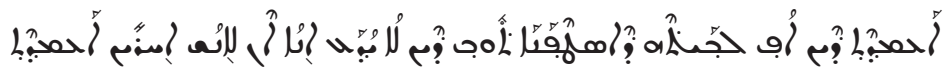

J'ai aussi baptisé les gens de la maison de Stéphane et je ne sais pas avoir baptisé quelqu'un d'autre encore.

À propos de la forme IV اعمدت, voir 1 Co 1,13.

À propos du nom اسطفاناست, voir 4.1 Noms propres.

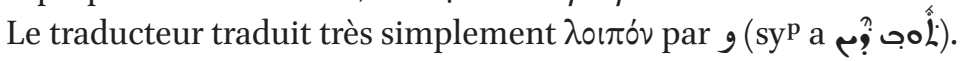

1 Co 1,17

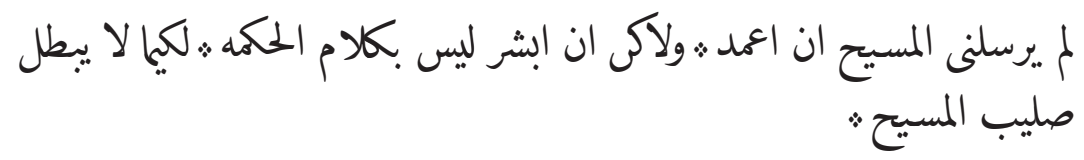

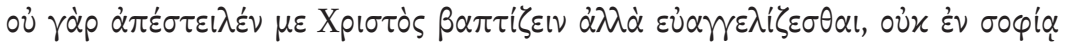

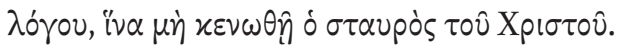




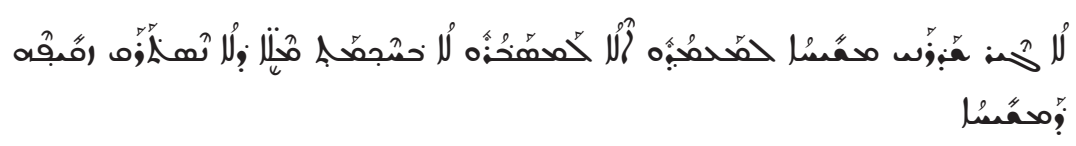

Le Christ ne m'a pas envoyé baptiser mais prêcher, pas par la parole de sagesse, afin que la croix du Christ ne soit pas annihilée.

Il manque dans VA 13 une conjonction équivalente à ráp/

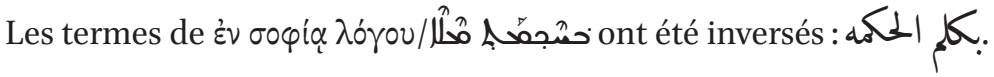

\section{Co 1,18}

\section{ان كله الصليب للصالين هي محفره ث. اما لبا الذين ث. قل خلصنا فانها قوه الله ؛}

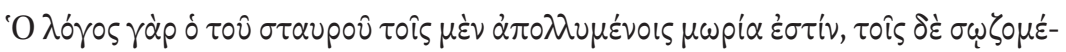

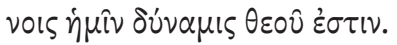

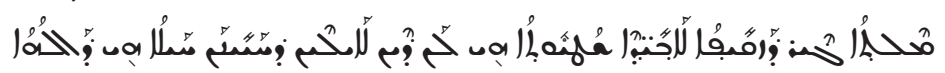

La parole de la croix pour les égarés est une honte (?), mais pour nous qui sommes sauvés, elle est puissance de Dieu.

Le terme للص est un terme coranique; on le trouve aussi en SA 155. Voir point 4.3.5 Autres termes.

Le nom محفره n'est pas répertorié dans les dictionnaires consultés et vient très vraisemblablement du syriaque

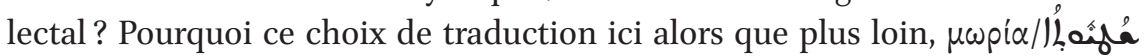
sera traduit par سفاهـ (voir par exemple 1 Co 1,21; 1,23)?

\section{Co 1,19}

$$
\text { انه مكتوب اني اهلك حكمه الحمكا : وابطل علم العلها : }
$$

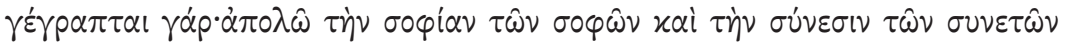
$\dot{\alpha} \theta \varepsilon \tau \dot{\eta} \sigma \omega$.

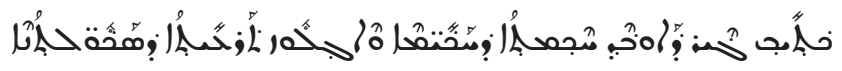

Il est écrit : je détruirai la sagesse des sages et j'anéantirai la science des scientifiques.

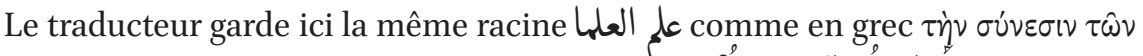

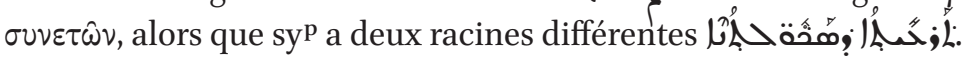


1 Co 1,20

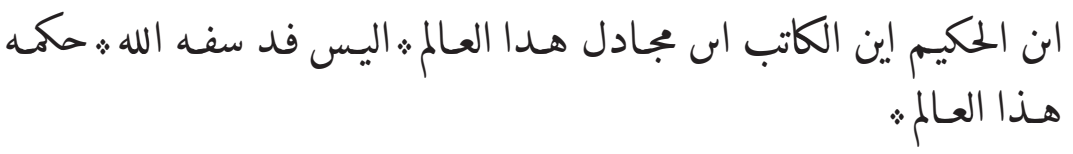

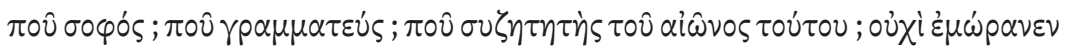

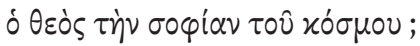

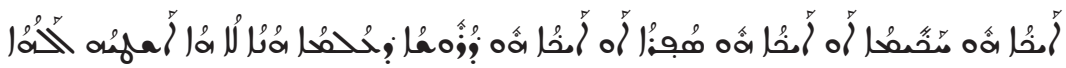

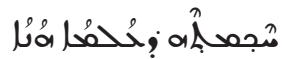

Où est le sage ? Où est l'écrivain ? Où est le dialecticien de ce siècle ? Dieu n'a-t-il pas démontré la folie de la sagesse de ce monde?

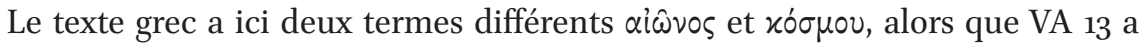
deux fois العالم, à l'image de syp21.

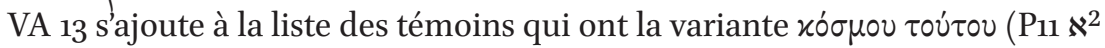
$\mathrm{C}^{3} \mathrm{D}^{1}$ F G L $\Psi$ 104. 365.1241. 1505.1739 ${ }^{\mathrm{c}}$. 1881. M sy sa $\left.{ }^{\mathrm{ms}} \mathrm{co}^{\mathrm{pt}}\right)$.

$1 \operatorname{Co~1,21~}$

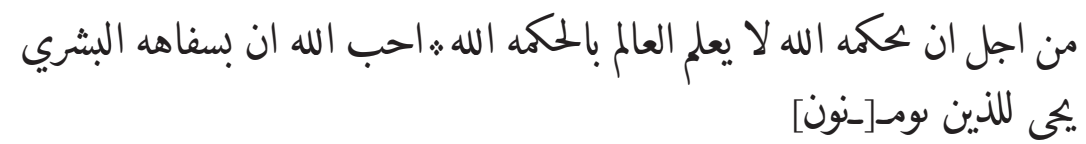

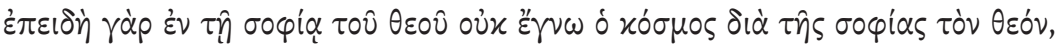

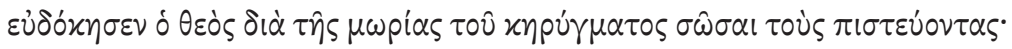

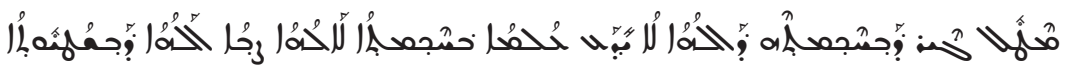

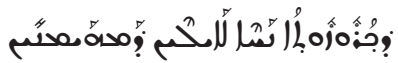

Parce que, dans la sagesse de Dieu, le monde ne connaît pas, par la sagesse, Dieu; Dieu a voulu que, par la folie de la prédication, il fait vivre ceux qui croient.

Contrairement au grec et à syp, VA 13 a ici un verbe à l'inaccompli لالا يعلم .

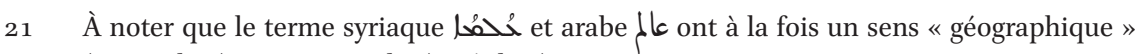
(« monde ») et « temporel » (« siècle»).

22 VA 13 rend normalement par des accomplis les aoristes en grec.
} 
1 Co 1,22

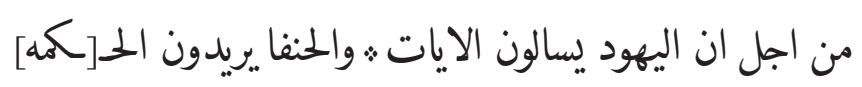

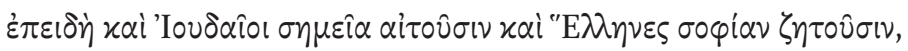

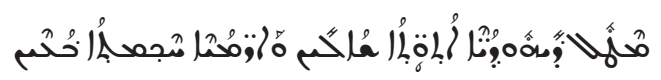

Parce que les juifs demandent des signes et les païens veulent de la sagesse,

A l'image de syp, ainsi que $\mathrm{P} 46 \mathrm{fg} 323$ vg $^{\mathrm{mss}}$, VA 13 n'a pas le premier $x \alpha$ í.

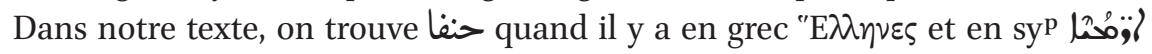

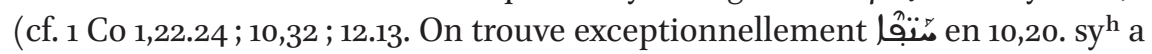

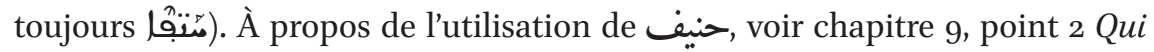
sont les hunafả dans 1 Corinthiens?

\section{Co 1,23}

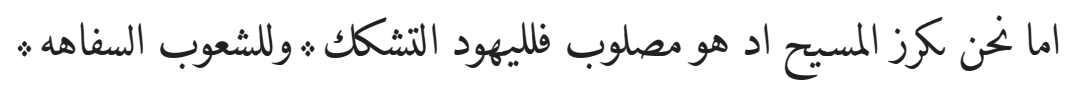

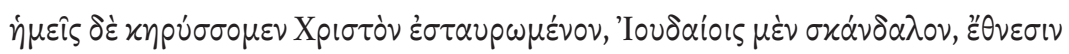
$\delta \dot{\varepsilon} \mu \omega \rho \dot{\alpha} \alpha$,

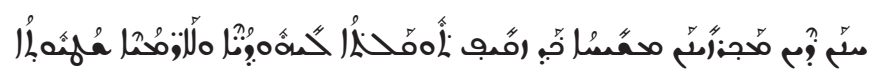

mais nous, nous prêchons le Christ comme étant crucifié, pour les juifs scandale, et pour les nations, folie,

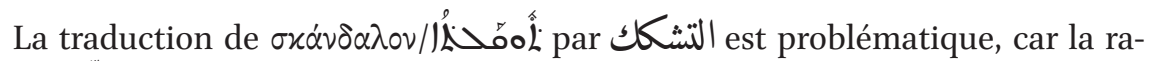
cine شك serait davantage liée au doute et à l'incertitude ${ }^{23}$. Toutefois, dans le dictionnaire Belot, qui donne aussi des termes dialectaux syriens, on trouve la signification pour شك شêtre scandalisé » (BELOT, p. 382). Au verset 1 Co 8,13,

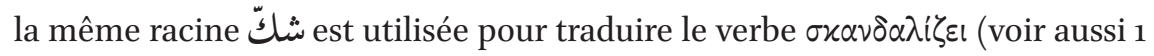
Co 10,25.32). Il s'agit donc bien pour le traducteur d'un vocabulaire exprimant le scandale.

Avec le terme للشعوب, le traducteur traduit la variante ع̋ق nouveau dans des témoins non majoritaires ( $\mathrm{A} \mathrm{B} \mathrm{C*} \mathrm{D*} \mathrm{F} \mathrm{G} \mathrm{L} \mathrm{P} \mathrm{\Psi} \mathrm{33.} \mathrm{81.} 104$. 1175. 1241. 2464. latt co), à l'inverse de la variante "E $\mathrm{\lambda} \eta \mathrm{V}_{\mathrm{l}}\left(\mathrm{C}^{3} \mathrm{D}^{2} 365.630 .1505\right.$.

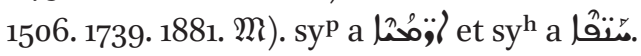

23 A la forme v : « Douter de quelque chose [...] », KAZIMIRSKI 1, p. 1256. 
1 Co 1,24

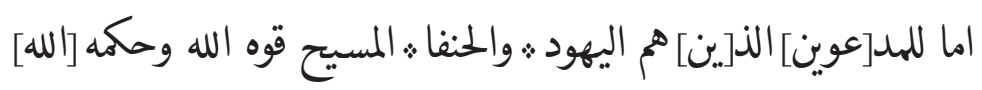

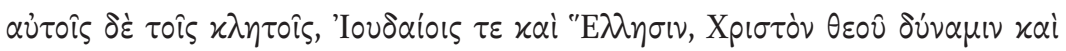
$\theta \varepsilon \circ \hat{v} \sigma \circ \varphi i \alpha \nu$.

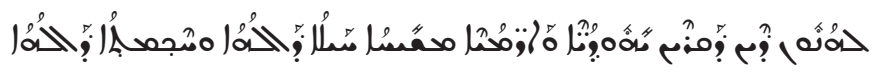

mais pour les appelés, ceux qui sont juifs et païens, le Christ est puissance de Dieu et sagesse de Dieu,

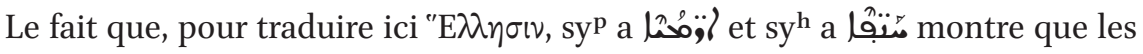
versions syriaques soutiennent vraisemblablement la variante "E $\lambda \eta \sigma \mathrm{l}$ au verset précédent.

\section{Co 1,25}

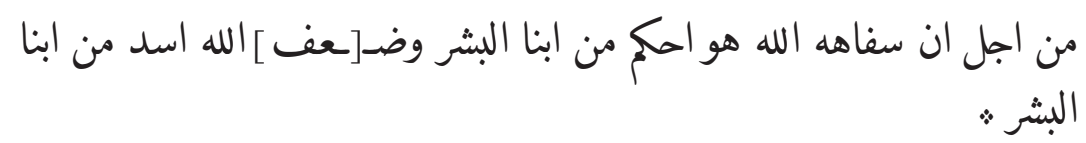

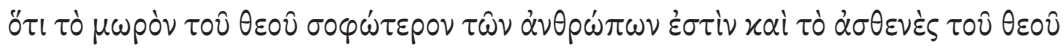

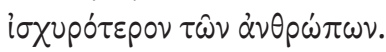

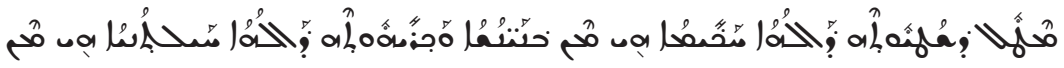

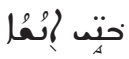

parce que la folie de Dieu est plus sage que les humains et la faiblesse de Dieu plus forte que les humains.

هو est inattendu. On attendrait هفاهه car est féminin ${ }^{24}$ هي

L'expression ابنا البشر semble d'influence syriaque 25 .

24 Sur la flexibilité du genre, voir 2.2 Éléments de moyen arabe dans Vat. Ar. 13 (1 Corinthiens): 16) Genre et nombre.

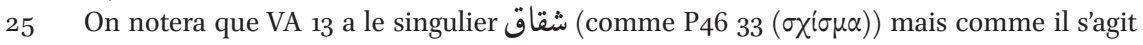
d'un nom d'action, il aurait été inhabituel d'avoir un pluriel. 
1 Co 1,26

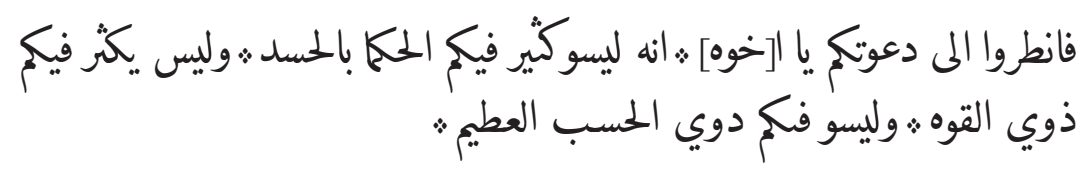

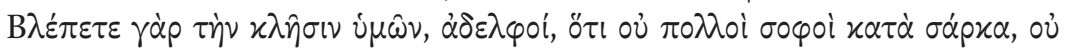

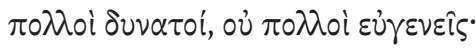

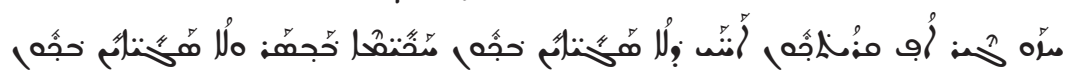

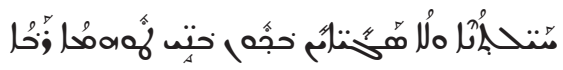

Car regardez votre appel, ô frères, il n'y a pas parmi vous beaucoup de sages en corps, et il n'y a pas parmi vous beaucoup de gens qui ont de la puissance, et il n'y a pas parmi vous de gens qui ont une grande valeur

Nous lisons ليسوا ليسو, or le pluriel ferait pas sens ici². Le copiste a-t-il mal copié ليسو apparaît ailleurs dans notre texte là où un pluriel n'est pas demandé (voir 1 Co 9,26;12,14).

VA 13 a à double reprise فيك " parmi vous » qu'il emprunte à syp حجمَ م; cela donne une orientation communautaire au reproche.

Dans VA 13, il manque un troisième كي"

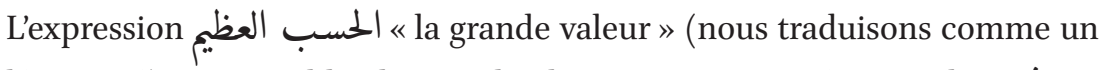
indéterminé) nous semble plus proche de syp, notamment à cause de ذوي qui traduirait حتر:

$1 \operatorname{Co~} 1,27$

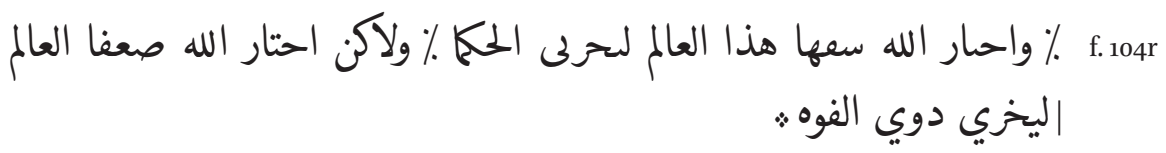

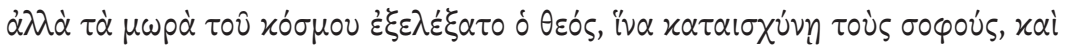

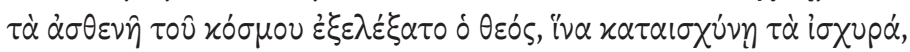

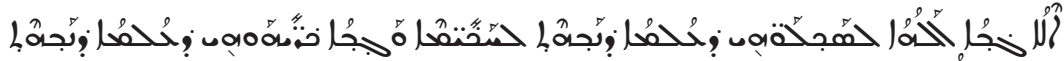

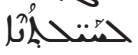

26 Voir aussi 2.2 Éléments de moyen arabe dans Vat. Ar. 13 (1 Corinthiens) : 9) alif otiosum.

27 comme négation invariable, voir 2.2 Éléments de moyen arabe dans Vat. Ar. 13 (1 Corinthiens) : 22) Négation ليس. 
mais Dieu a choisi les fous de ce monde pour discréditer les sages, et Dieu a choisi les faibles du monde pour confondre ceux qui ont la puissance,

En grec, les compléments directs de $\dot{\varepsilon}^{\xi} \xi \varepsilon \lambda \varepsilon \dot{\xi} \xi \alpha \tau$ sont des neutres pluriels. VA 13 a des substantifs masculins pluriels صeمفا et ce qui correspond à syp (sy a aussi des masculins).

Le traducteur a ajouté des démonstratifs devant «monde»: هذا العالم.

Les répétitions dans la phrase ont donné lieu à une erreur de même au même, corrigée en bas du folio à l'aide de signes diacritiques. Or la correction est inexacte, car il y a un g devant le premier membre de la phrase, puis un ورلاكن , ce qui rend la phrase illogique. Dans notre traduction, nous avons corrigé.

1 Co 1,28

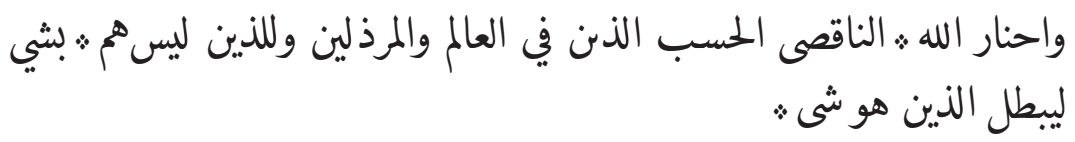

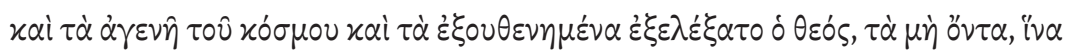

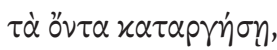

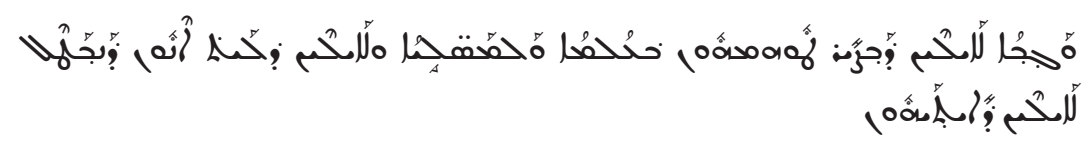

et Dieu a choisi les insuffisants en valeur qui sont dans le monde et les méprisés, et ceux qui ne sont rien, pour annihiler ceux qui sont quelque chose,

À propos du masculin pluriel, même remarque qu'au verset précédent.

L'article devant ناقصى est superflu car il est en rapport d'annexion. S'agit-il d'une erreur de copie du J pour marquer le complément direct comme pour للذين En effet, si une certaine flexibilité peut apparaître en moyen arabe quant à la règle de l'annexion, cela est rare dans notre texte $(10,16 ; 12,4)^{28}$.

En ayant gavant للذين, VA 13 soutient la variante xai (comme $\aleph^{2}$ B C C D L P $\Psi$ 81. 104. 365. 630. 1241. 1505. 1881. $2464 \mathrm{M} \mathrm{f} \mathrm{r}$ vg sy); toutefois, la présence du g peut aussi se justifier par le fait qu'il soit nécessaire en arabe.

28 De plus, la présence de l'article défini devant le status constructus est rare en moyen arabe, BLAU, § 234 . 


\section{Co 1,29}

$$
\text { كيما لا يفتخز كل بشر قدامه : }
$$

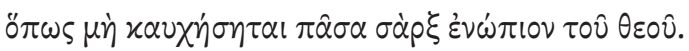

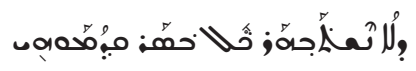

afin qu'aucun homme ne se vante face à lui.

Ailleurs dans le texte, on trouve جسد là où nous avons $\sigma \alpha ́ p \xi$ en grec (1 Co 5,5;

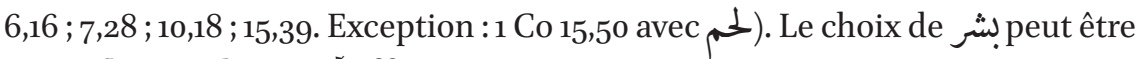
une influence de syp 29.

VA 13 a ici قدامه face à lui », comme syp et $\left(\aleph^{2 a}\right) C^{*} \Psi 629$ f vg sy .

1 Co 1,30

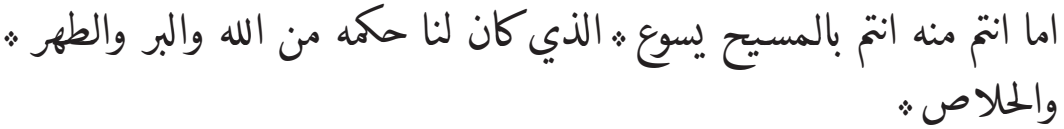

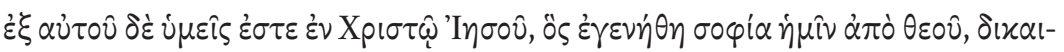

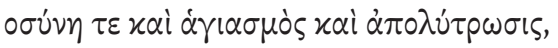

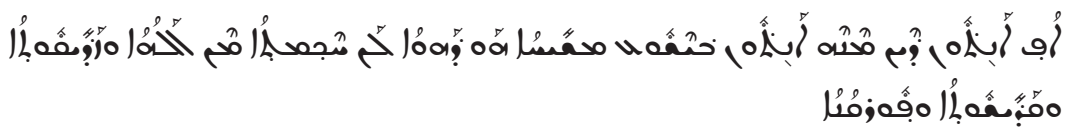

Quant à vous, à partir de lui vous êtes en le Christ Jésus, qui a été pour nous sagesse venant de Dieu, justice, pureté et salut.

syP a un en début de phrase qui ne se retrouve pas chez VA 13.

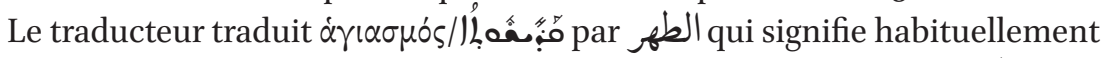
«pureté » (KAZIMIRSKi 2, p. 114). Il utilise régulièrement la racine طهر pour traduire des dérivés de ör 105 , traduite par la racine مب قa dans syp (voir 1 Co 6,1.2; 7,14.34; 16,20 ; ailleurs, on trouve la racine 1 Co 1,2; 3,17; 6,11.19; $7,14 ; 12,3 ; 14,33 ; 16,1.15)^{30}$.

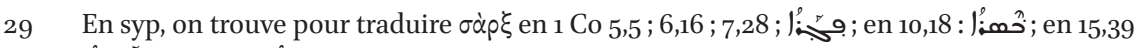

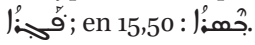

30 Ce n'est pas un phénomène unique : $S A 151$ privilégie aussi la racine en 1,$2 ; 3,17 ; 6,1.2$, etc. Blau relève le sens de « holiness » pour طهارة, BLAU 2, p. 223. Le verset 7,14 en particulier interroge sur le sens à donner à cette racine. 
1 Co 1,31

$$
\text { كم انه مكتوب : مى يفتحر فليفتخز بالرب؟ }
$$

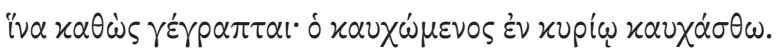

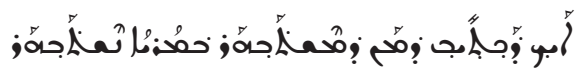

Comme il est écrit : celui qui s'enorgueillit, qu'il s'enorgueillisse dans le Seigneur.

\subsection{Chapitre 2}

1 Co 2,1

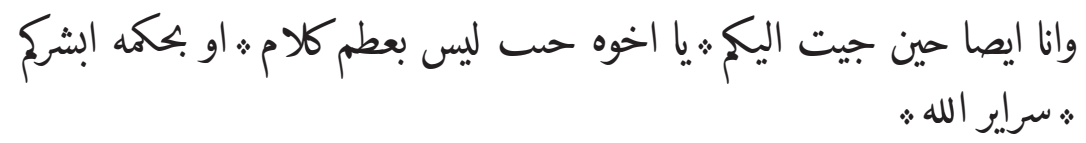

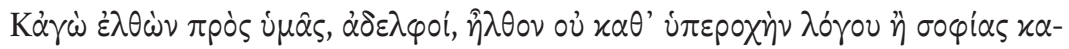

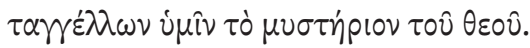

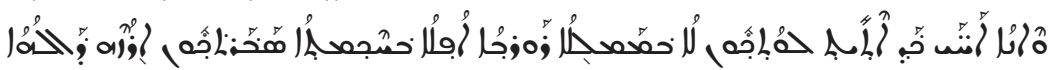

Et moi aussi, lorsque je suis venu chez vous, ô frères, je ne suis pas venu par la grandeur d'une parole ou par une sagesse vous annoncer les secrets de Dieu,

VA 13 présente une préposition (صكمه (ب) devant de comme en syp.

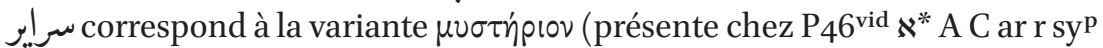

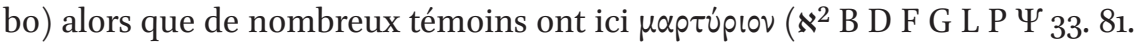
104. 365. 630. 1241. 1505. 1881. 2464. M b vg sa sy ${ }^{\mathrm{h}}$ ).

\section{$1 \operatorname{Co~2,2}$}

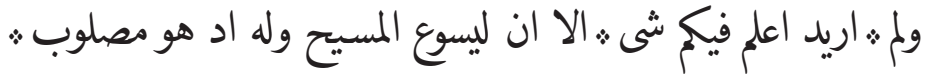

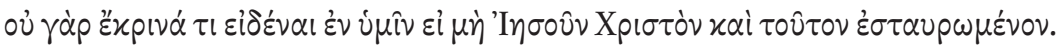

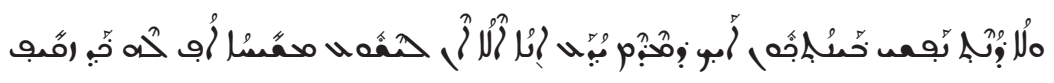

et je n'ai rien voulu savoir parmi vous, excepté Jésus le Christ, et lui en tant que crucifié. 


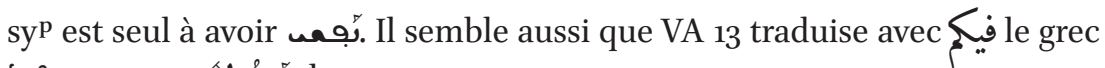

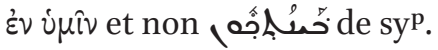

$1 \operatorname{Co~2,3}$

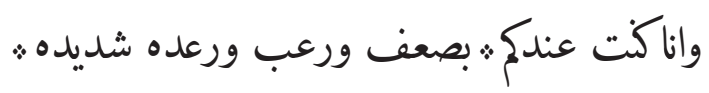

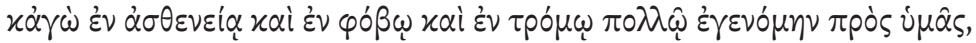

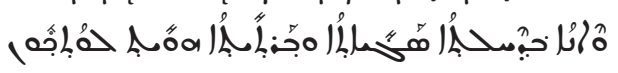

Et moi, j'ai été chez vous dans une fragilité, une peur et un tremblement violent,

Le traduction de ce verset ne se fait pas à partir de syp, qui ne traduit pas $\varepsilon^{\mathrm{c}} \mathrm{v}$ $\alpha \sigma \theta \varepsilon v \varepsilon i \underline{\alpha}$ alors que VA 13 a bien بصe.

$1 \operatorname{Co~2,4}$

$$
\text { كلا مى وبشراي لم كن يطلب كلا م الحهم : ولاكن. بدمغه الروح والقوه : }
$$

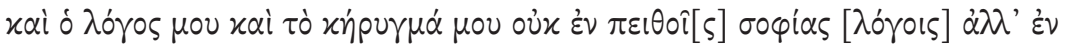

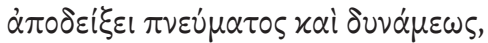

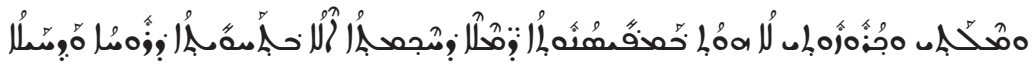

Ma parole et ma prédication n'ont pas été dans la sollicitation de la parole des sages, mais dans la marque de l'esprit et de la puissance,

On attendrait un gen début de phrase, comme xaí en grec et o dans syp.

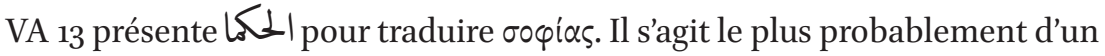

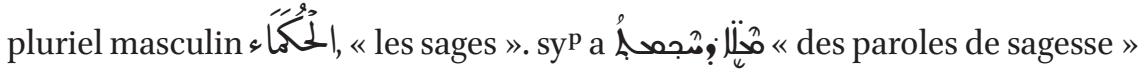

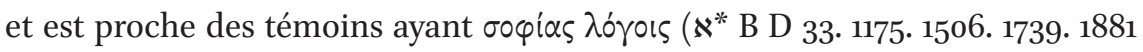
vgst). Peut-être VA 13 présente-t-il une traduction d'un témoin grec ayant la

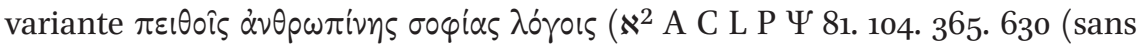

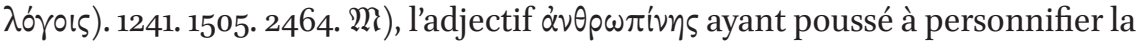
sagesse par «les sages ». 
1 Co 2,5

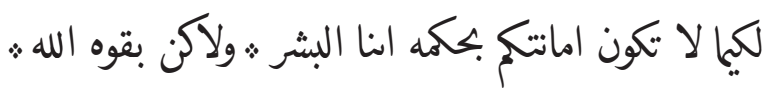

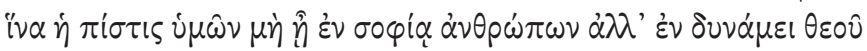

$$
\text { 家 }
$$

afin que votre foi ne soit pas dans la sagesse des humains, mais dans la puissance de Dieu.

De manière systématique, le traducteur choisit le nom féminin مانة pour tra-

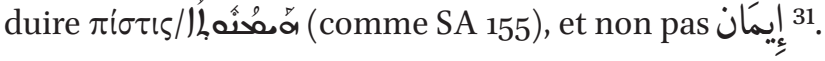

$1 \operatorname{Co~2,6}$

$$
\begin{aligned}
& \text { الحككه تنكلم في التامين بككه ليس هى لهذا العالم ثولا ايصا لدوي [سد] لططان } \\
& \text { هذا العالم ه. الدين يتطلون }
\end{aligned}
$$

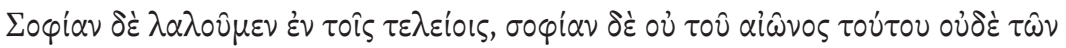

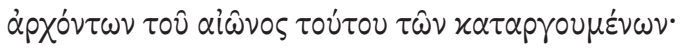

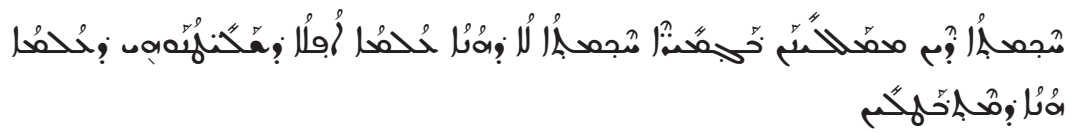

Nous parlons de la sagesse parmi les parfaits, une sagesse qui n'est pas de ce monde, ni de ceux qui ont l'autorité de ce monde, qui seront annihilés,

pourrait avoir comme sujet الحكمك : la sagesse parle ... ». Le contexte ainsi

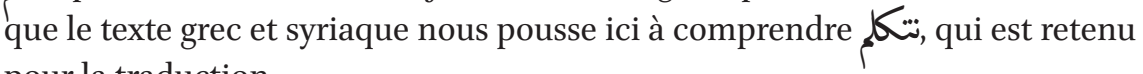
pour la traduction.

\section{Co 2,7}

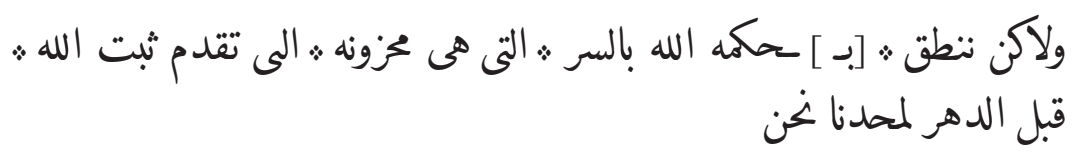

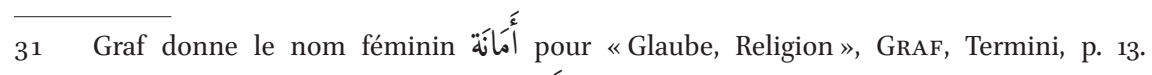
Kazimirski traduit le nom féminin أَََأَنَّ par «loyauté », «sincérité » et le nom masculin إيمَان par «foi religieuse», KAZIMIRSKI 1, p. 57. 


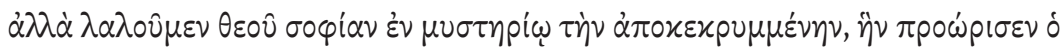

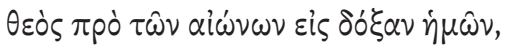

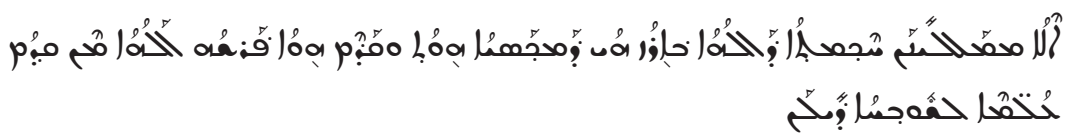

mais nous parlons de la sagesse de Dieu, dans le secret, qui est cachée, que Dieu a en avance établie avant le temps pour notre gloire à tous,

Le traducteur ici change de verbe, proposant pour « parler » نطق (alors que le grec et syp gardent le même verbe).

La présence d'une préposition بك حكم dest incertaine, mais plausible au vu du verset précédent, où l'on trouve بحكمة et de la construction demandée par نطق.

Il nous semble que VA 13 traduit par قبل الدهر le grec $\pi \rho \dot{~ \tau \omega ̂ \nu ~ \alpha i \omega ́ \omega \nu \omega \nu ; ~ n o u s ~}$

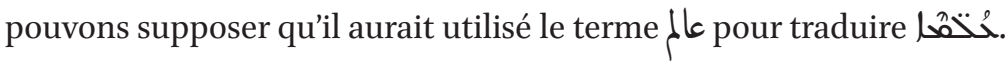

1 Co 2,8

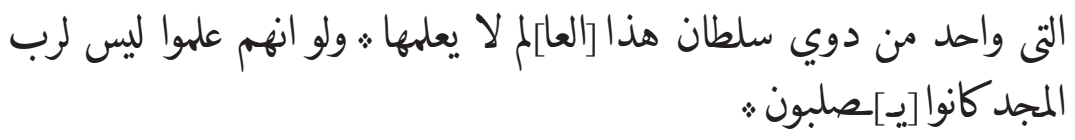

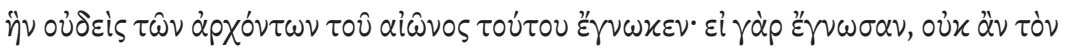

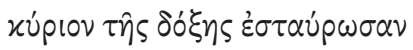

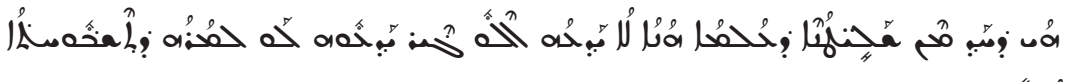
○ُ que personne de ceux qui ont l'autorité de ce monde ne comprend, et s'ils avaient connue, ils n'auraient pas crucifié le Seigneur de gloire.

1 Co 2,9

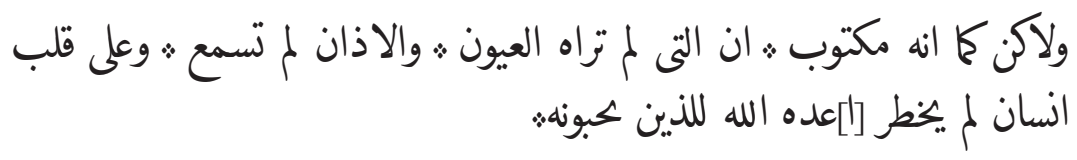

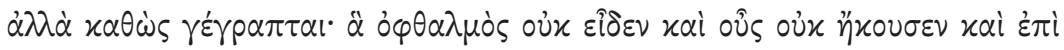

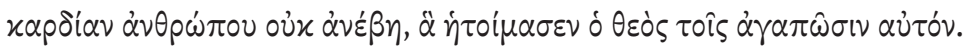




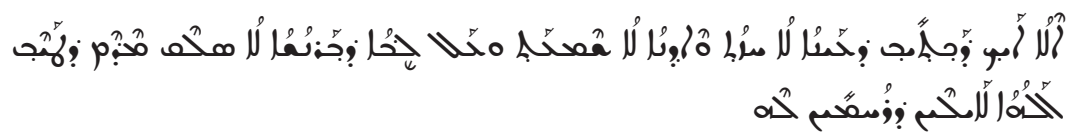

Mais, comme il est écrit: ce que les yeux n'ont pas vu, et les oreilles pas entendu, et ce qui n'est pas venu au cœur de l'homme, Dieu l'a préparé pour ceux qui l'aiment.

VA 13 a des pluriels (العيون et الاذان), grec et syp ont des singuliers. Dans ce

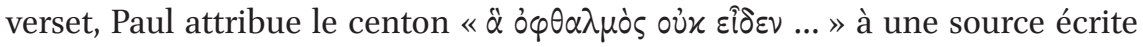
dont nous n'avons pas connaissance. Le dossier est encore ouvert aujourd'hui concernant le texte grec de $1 \mathrm{Co} 2,9^{32}$. On trouve un parallèle à ce centon dans un hadịt qudsĭ, notamment dans le recueil de al-Buhārn $\overline{1}^{33}$; un parallèle se trouve aussi dans un apocryphe, l'évangile arabe de Jean ${ }^{34}$. Il est intéressant de constater que les différents parallèles arabes utilisent la même expression que dans les versions arabes (VA 13, SA 151, SA 155), خطر على قلب, une expression qui a certainement pris la signification « monter au coeur » autour d'une tradition commune ${ }^{35}$.

\section{Co 2,10}

$$
\text { اما لنا فاعلن الله لنا بروحه : الروح| كل شى لعلم ثوايصا عمق سراير الله ؛ }
$$

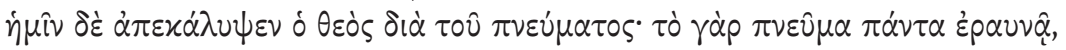

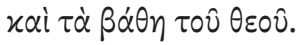

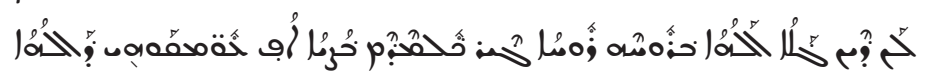

Quant à nous, Dieu nous l'a révélé par son esprit : l'esprit connaît tout et aussi la profondeur des secrets de Dieu.

32 Pour un état de la recherche complet et une approche originale de la question, voir le développement dans Clivaz Claire et Schulthess Sara, « On the Source and Rewriting of 1 Corinthians 2.9 in Christian, Jewish and Islamic Traditions (1 Clem 34.8 ; GosJud 47.1013 ; a ḥadīth qudsī) », New Testament Studies 61 (2), 2015, pp. 183-200. En ligne : Cambridge Journals Online, <http://journals.cambridge.org/article_Soo28688514000307>.

33 Dans la traduction anglaise du Sahīh al-Buhārī de Muhsin Kahn, voir vol. 9, livre 93, hadīt 598.

34 Galbiati Johannes, Iohannis evangelium apocryphum arabice, Milan, Mondadori, 1957, p. 159 ; Moraldi Luigi, Vangelo Arabo apocrifo dell'Apostolo Giovanni da un Manoscritto della Biblioteca Ambrosiana, Milan, Editoriale Jaca Book, 1991, p. 142.

35 خطر signifie premièrement « agiter », « déplacer », cf. LANE, pp. 764-756 ; KAZIMIRSKI 1, p. 593. Nous développons cet aspect dans l'article cité dans la note 32. 


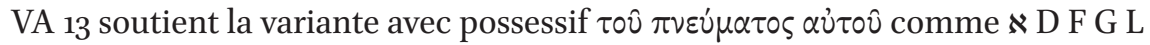
$\mathrm{P} \Psi$ 81. 104. 365. 1175.1241. 1505. 1506. 2464. $\mathrm{M}$ latt sy sa ${ }^{\mathrm{ms}}$ (possessif absent chez P46 $6^{\text {vid }} \aleph^{*}$ A B C 630. 1739. 1881 sa bo).

Contrairement au grec róp et à sy $\mathrm{p}^{\mathrm{p}}$, VA 13 n'a pas de conjonction de coordination pour introduire le deuxième membre du verset.

Alors que le grec et syp ont des verbes allant dans le sens de «chercher »

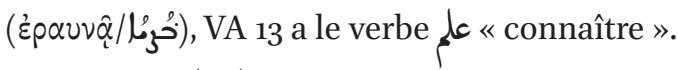

VA 13 a ع عق سراير الله la profondeur des secrets de Dieu», une leçon que nous n'avons trouvé dans aucune autre tradition ${ }^{36}$. Il s'agit d'un des seuls cas de traduction «périphrastique » dans notre épître (voir point 5.1). Le traducteur était-il gêné par l'idée que l'on puisse approcher directement « la profondeur de Dieu »?

\section{Co 2,11}

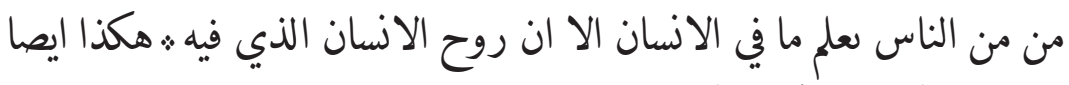

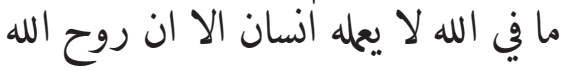

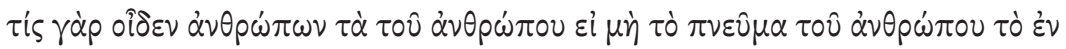

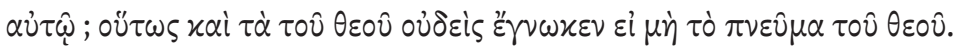

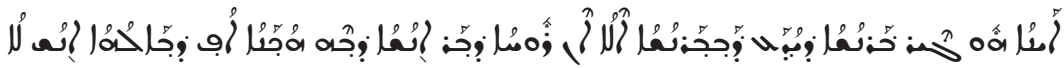

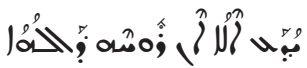

Qui, parmi les hommes, connaît ce qu'il y a en l'homme, excepté l'esprit de l'homme qui est en lui ? Ainsi, aussi ce qui est en Dieu, l'homme ne le connaît pas, excepté l'esprit de Dieu.

Le verbe traduisant $\varepsilon^{\prime} \gamma(\omega) \varepsilon \varepsilon v$ dans VA 13 est عمل Nous pensons qu'il s'agit ici d'une erreur de copie et traduisons comme يَعَمُعَ' (de plus, VA 13 a ainsi deux

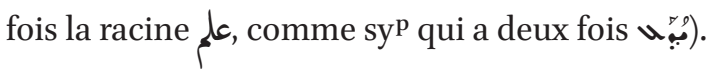

36 La leçon ne se trouve pas dans SA 151, SA 155, dans les témoins syriaques (ALAND), ni dans vg, ni dans sa ou co (HORNER). 
1 Co 2,12

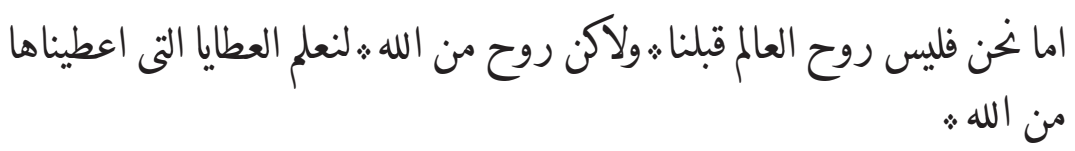

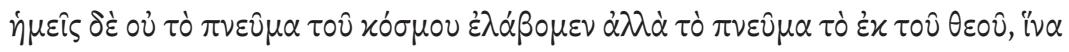

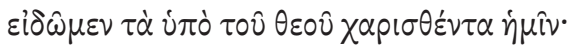

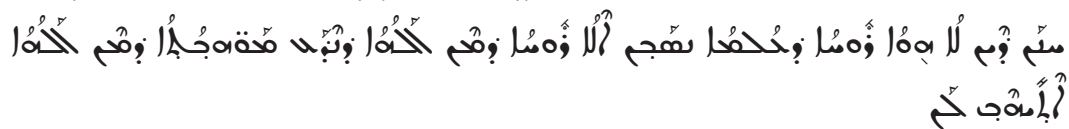

Quant à nous, nous n'avons pas reçu l'esprit du monde, mais un esprit venant de Dieu pour connaître les dons qui nous avons reçu de Dieu,

Nous pouvons noter que VA 13 et sy $\mathrm{p}$ traduisent de manière proche le participe $\tau \dot{\alpha} \chi \alpha \rho 1 \sigma \theta \varepsilon \dot{v} \tau \alpha$ :

les dons qui nous ont été donnés/ les dons qui nous avons reçu ».

\section{Co 2,13}

$$
\text { الى ايصا نتكم : ليس بتعلت الروح : ولروحانين روحانيات نقاس * }
$$

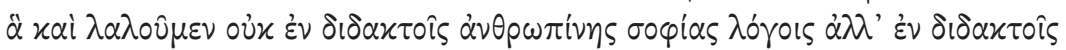

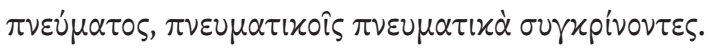

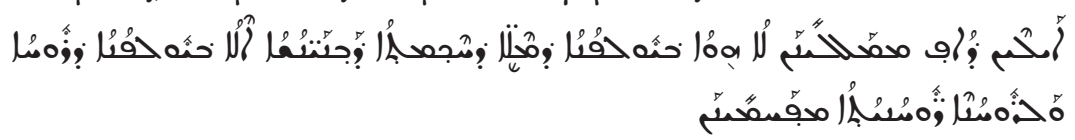

dont aussi nous parlons, non dans l'enseignement (...) de l'esprit, et aux spirituels, nous comparons les choses spirituelles.

Une partie de la phrase manque à la suite d'une erreur de même au même (due à la répétition de بتعليم). Cela a échappé à la correction, contrairement à d'autres exemples $(6,12 ; 7,28)$.

Nous pouvons toutefois constater que VA 13 ne soutient pas les témoins qui

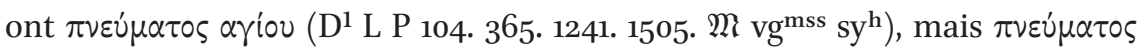
uniquement ( $\mathrm{P} 46$ « A B C $C^{\text {vid }} \mathrm{D}^{*} \mathrm{~F}$ G $\Psi$ 0185. 0289. 6. 33. 81. 630. 1175. 1506. 1739 . 1881. 2464 lat syP co). 
1 Co 2,14

$$
\text { ولا يستطيع ان يعلم انه يدان النفسانى فانه لا نقل دوات }
$$

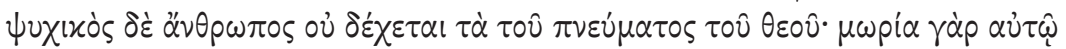

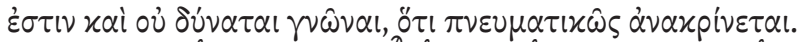

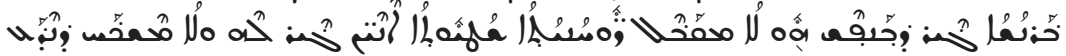

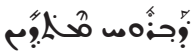

Quant à l'homme psychique, il n'accepte pas les biens de l'esprit de Dieu, car ceci pour lui est folie, et il ne peut pas savoir que cela est jugé spirituellement.

1 Co 2,15

$$
\text { اما الروحاني فكلشى يدين : فاما هو فلا يدان من انسان : }
$$

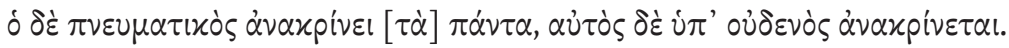

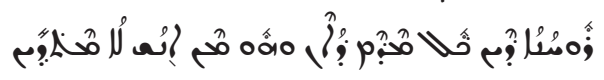

Quant au spirituel, il juge toute chose, or quant à lui, il ne sera jugé par personne.

1 Co 2,16

$$
\text { مى الذى علم تفكر الله : ان يعلمه : اما نخن فان لنا عقل المسيح : }
$$

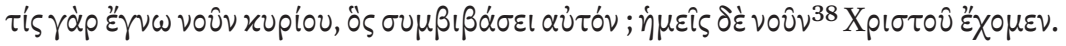

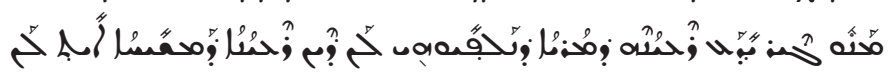

Qui a connu la pensée de Dieu de sorte à l'enseigner? Quant à nous, nous avons l'intelligence du Christ.

37 À propos de l'usage de ذو : «In Asp dhû/dhât/dhawât are used to expressed neutral 'substantivized genitives'. Since this usage is restricted to Biblical translations from Greek, often rendering $\tau \dot{\alpha}$ governing the genitive, one will regard it as an artificial literary feature, influenced by the above mentioned Classical usage of dhû etc., as well as by Aramaic , , employed in a similar manners », BLAU, § 235 .

38 Quelques témoins ont ici xupíov (B D* F G 81 it). 


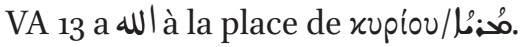

VA 13 a un seul $^{39}$; il nous semble que le traducteur se base ici sur syp, car dans le cas où il suivrait le texte grec, nous trouverions certainement un relatif.

VA 13 traduit voûv/عُصُ par deux substantifs différents عقل et تفكر. Cherchet-il à nuancer entre la pensée de Dieu et celle du Christ ${ }^{40}$ ?

\subsection{Chapitre 3}

\section{Co 3,1}

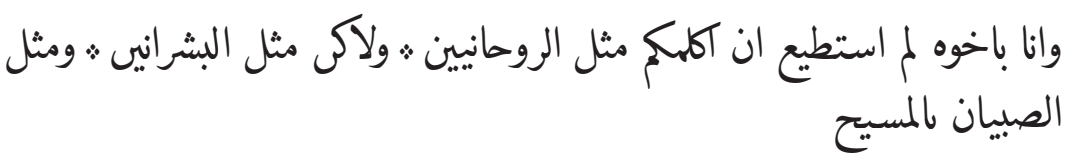

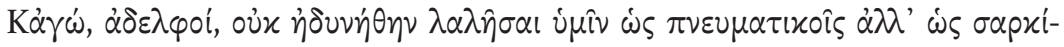

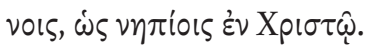

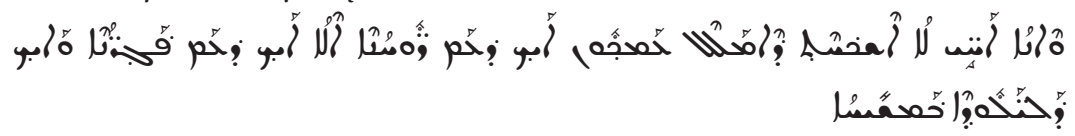

Et moi, frères, je n'ai pas pu vous parler comme aux spirituels, mais comme aux charnels et comme aux enfants en le Christ.

1 Co 3,2

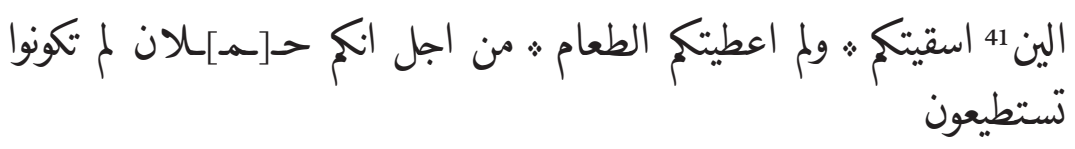

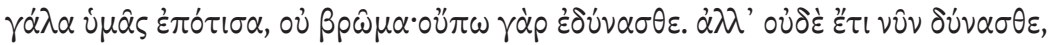

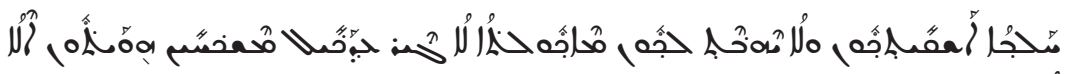

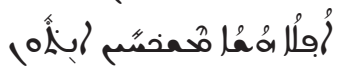

C'est du lait que je vous ai fait boire, et je ne vous ai pas donné de nourriture, parce que vous ne pouviez $[\mathrm{la}]$ supporter, $[\ldots]$

39 « As is often the case in [Classical Arabic] already, simple $ن$ is used instead of a preposition with ا. » BLAU, § 406.

40 Dans SA 151, il y a aussi deux termes différents : عقن

41 For اللبن. Voir BLAU § 26.3.1: «As in the Qur'ânic orthography, when the definite article precedes a word beginning with lâm, only one lâm may be written ». C'est l'unique cas dans notre texte. 
Il manque une partie de la phrase. Il y a certainement eu une erreur de même au même dû à تستطيعون.

1 Co 3,3

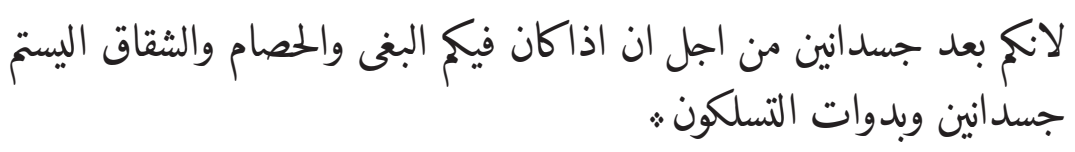

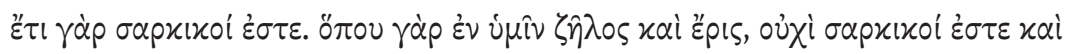

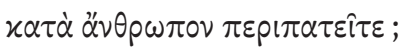

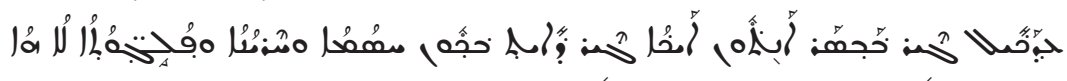

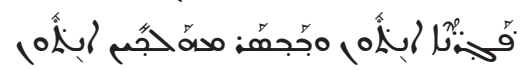

parce que vous êtes encore corporels. Car lorsqu'il y a parmi vous l'envie, la dispute, le désaccord, n'êtes-vous pas corporels et ne vous conduisez-vous pas selon ce qui est propre à l'humain?

VA 13 change de terme entre 3,1 (جسد انين) et (البشرانين) et a deux fois le même terme dans en 3,3 (جسدانين). Cela montre qu'il soutient la variante présente en

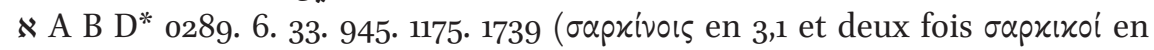
3,3), contrairement à $\mathrm{C}^{3} \mathrm{D}^{1} \mathrm{~L} \mathrm{P} \Psi$ 81. 104. 365. 630. 1241. 1505. 1506. 1881. 2464. M

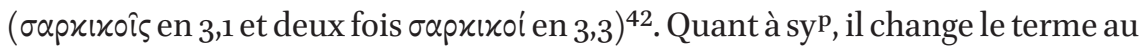

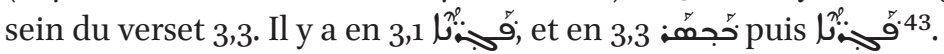

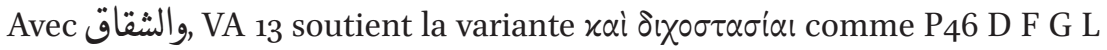
33. 104. 365. 1241. 1505. 2464. $\mathfrak{M}$ ar b sy (contre א A B C P Ч 0289.81. 630. 1175. 1506. 1739. 1881. ar vg co).

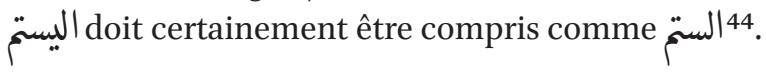

À propos de بذوات البشر, voir notre remarque en 1 Co 15,32.

1 Co 3,4

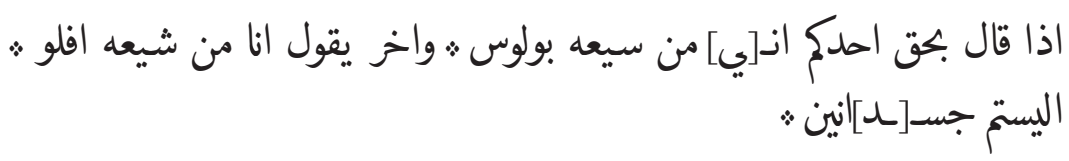

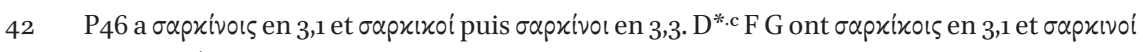
puis бapxivol en 3,3.

43 sy a $^{\mathrm{h}}$ a 3 (3), et 3,3.

44 Voir 2.2 Éléments de moyen arabe dans Vat. Ar. 13 (1 Corinthiens) : :22) Négation ليس. 


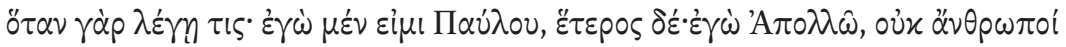
$\dot{\varepsilon} \sigma \tau \varepsilon ;$

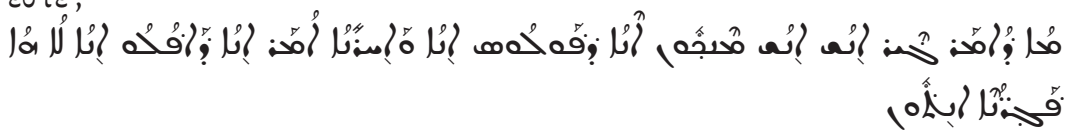

Quand, en vérité, l'un de vous dit: je suis de la secte de Paul, et qu'un autre dit: je suis de la secte d'Apollos, n'êtes-vous pas corporels?

VA 13 a deux fois le verbe « dire », comme syp. Il y a par ailleurs un problème de concordance des temps entre les deux formes et eقال

On notera l'ajout par le traducteur de سيعه « secte » (voir 1,12).

À propos du nom افلو

Avec جسد انين, VA 13 ne suit pas la variante $\alpha^{\prime \prime} v \theta \rho \omega \pi 0 i^{45}$ et il ne traduit pas non

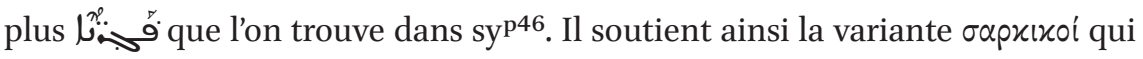
se trouve en $\aleph^{2}$ L P $\Psi$ 104. 365. 630. 1241. 1505. 2464. M.

Les versets 3,1 et 3,4 nous laissent penser que VA 13 traduit par جسد انين le

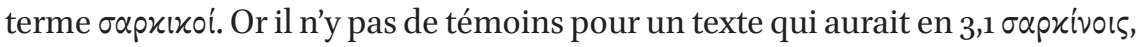

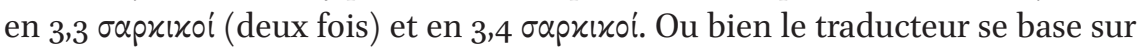
un texte qui ne nous est pas connu, ou bien il n’a pas été systématique dans la traduction, ce qui est plus probable.

doit certainement être compris comme اليستم 47 الستم.

\section{Co 3,5}

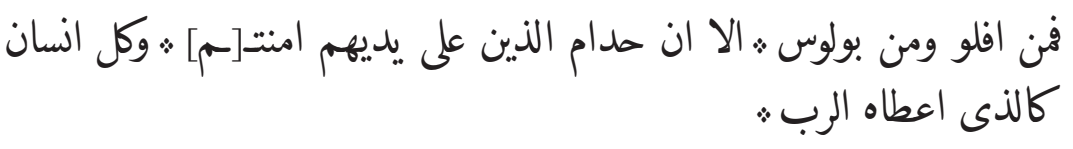

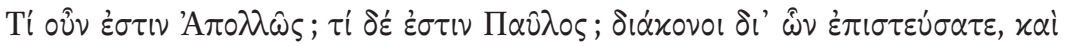

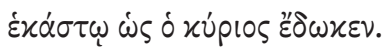

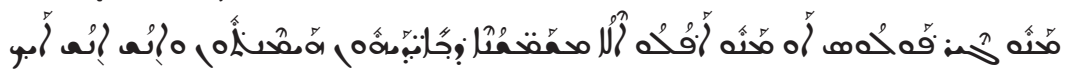
年

45 P46 א* A B C D F G 048. 0289. 33. 81. 629. 1175. 1506. 1739. 1881.

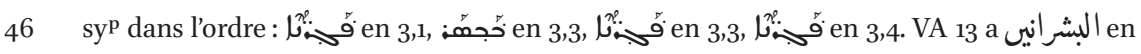

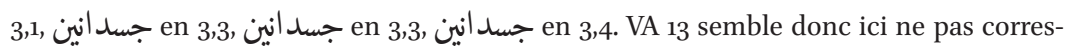
pondre à syp.

Voir 2.2 Éléments de moyen arabe dans Vat. Ar. 13 (1 Corinthiens) : 22) Négation ليس. 
Car qui est Apollos et qui est Paul, sinon des serviteurs, par l'intermédiaire desquels vous avez cru, chacun selon ce que le Seigneur lui a donné?

À propos du nom propre افلو, voir 4.1 Noms propres.

VA 13 et syp ont une expression similaire pour traduire le grec $\delta l^{\prime} \hat{\omega} v$ :

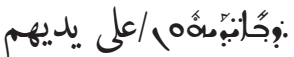

Ici, VA 13 présente un texte qui a Apollos devant Paul, soutenant une variante minoritaire, trouvée chez $\mathrm{P}_{4} 6^{\text {vid }} \aleph \mathrm{A} \mathrm{B} \mathrm{C} \mathrm{D*.2} \mathrm{F} \mathrm{G} \mathrm{P} \mathrm{048}{ }^{\text {vid }}$. 0289. 33. 81 . 629. 630. 1175. 1506. 1739. 1881. lat co (à l'inverse de $\mathrm{D}^{1} \mathrm{~L} \Psi$ 104. 365. 1241. 1505. 2462. 2495. 1241. $\mathfrak{M}$ sy qui ont Paul en premier).

Par contre, avec الا ان, VA 13 soutient la variante majoritaire $\dot{\alpha} \lambda \alpha^{\prime}$, comme D D L P Ч 33. 81. 104. 365. 1241. 1505. 2464 M sy (absent dans « A B C D* F G 0289. 6. 630. 1175. 1506. 1739. latt sa ${ }^{\mathrm{mss}}$ bo).

$1 \operatorname{Co} 3,6$

$$
\text { انا نصبت : وافلـ [و] اسقا : ولاكن الله الذى ربا ؛ }
$$

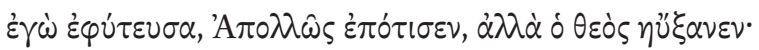

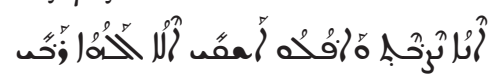

Moi j’ai planté, et Apollos a arrosé mais c'est Dieu qui a fait grandir.

À propos du nom propre افلو, voir 4.1 Noms propres.

${ }_{1} \operatorname{Cos} 3,7$

$$
\text { فاذن ليس الذي ينصب هوشى ثولا الذي يسقى • الا الله الذي ثيربي ؛ }
$$

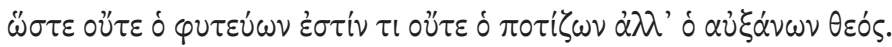

$$
\text { 管 }
$$

Donc ce n'est pas celui qui plante qui est quelque chose, ni celui qui arrose, mais Dieu qui fait croître. 
1 Co 3,8

f. $105 \mathrm{r}$

$$
\text { اما الذي ينصب والذي يسقى فهما واحد ثهوكل واحد منهم |إخد اجره كخو }
$$

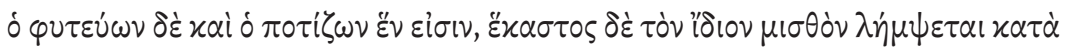

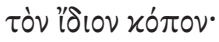

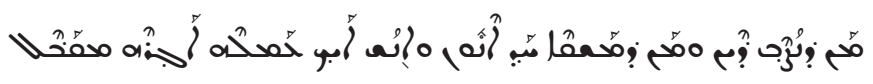

Quant à celui qui plante et celui qui arrose, ils sont un, et chacun d'entre eux prendra son salaire en rapport avec son travail.

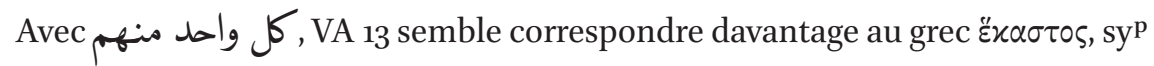
ayant simplement نُ?.

1 Co 3,9

$$
\text { انا بكت مع الله نعل ث:وعمل الله وبنيان الله انتم هم ث }
$$

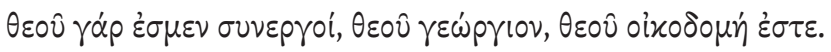

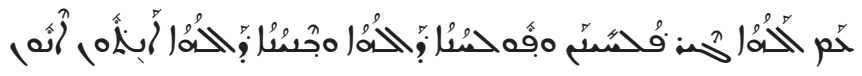

En vérité, nous travaillons avec Dieu, et le travail de Dieu et l'édifice de Dieu, c'est vous.

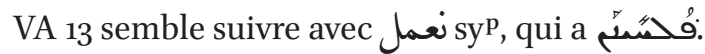

La préposition مع حعَ dans syp.

1 Co 3,10

$$
\begin{aligned}
& \text { وكثثل نعمه الله : التى اعطيت لي وصعت الاس كالا مان الحكيم ؛ واخز عليه } \\
& \text { ينا. : فكل السان فلينطر كفت ليى عليه : }
\end{aligned}
$$

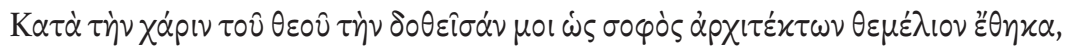

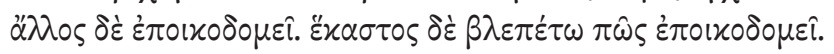

48 ع p peut à la fois signifier le travail et le résultat du travail. Nous traduisons ici par travail et plus loin par œuvre. 


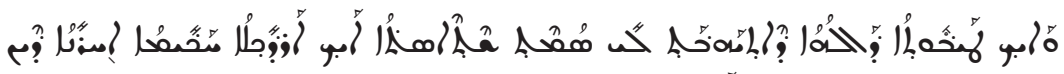

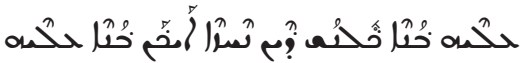

Selon la grâce de Dieu qui m’a été donnée, j'ai posé le fondement, comme le sage artisan, et un autre bâtit sur lui. Or que chacun regarde comment il construit sur lui.

Il est difficile de traduire امان. Est-ce que le terme vient du syriaque, signifie « artisan» ? Voir 4.2 Vocabulaire d'emprunt.

1 Co 3,11

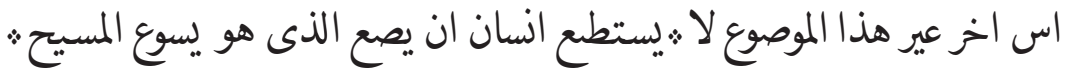

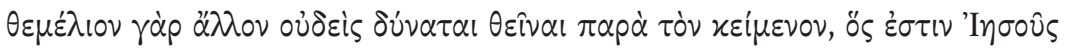
Xpiotós.

U محمُشنُ

De fondement autre que celui qui est posé - qui est Jésus le Christ -, personne ne peut [en] poser.

On attendrait une conjonction de coordination $(\gamma \alpha \dot{\rho} / \mathrm{g})$.

1 Co 3,12

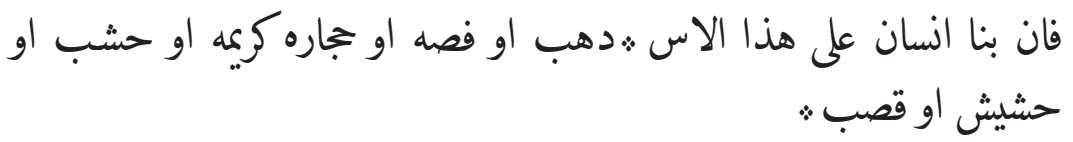

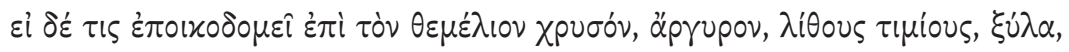

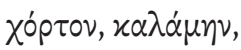

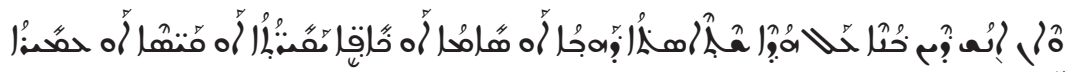

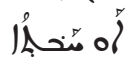

Or si quelqu'un a bâti sur ce fondement or, argent, pierre précieuse, bois, foin ou roseau, 


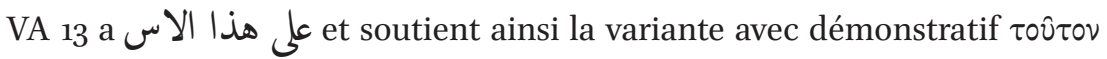
comme $\aleph^{2} \mathrm{C}^{3}$ D L P $\Psi$ 33. 104. 365. 630. 1175. 1241. 1505. 1506. 1739. 1881. 2464. M lat sy samss bo, absent chez $\mathrm{P}_{4} 6 \boldsymbol{\kappa}^{*}$ A B C* $0289.81 \mathrm{vg}^{\mathrm{mss}}$ sa $^{\mathrm{mss}}$ bo $^{\mathrm{mss}}$.

La répétition des $\mathrm{g}$ vient probablement de syp.

1 Co 3,13

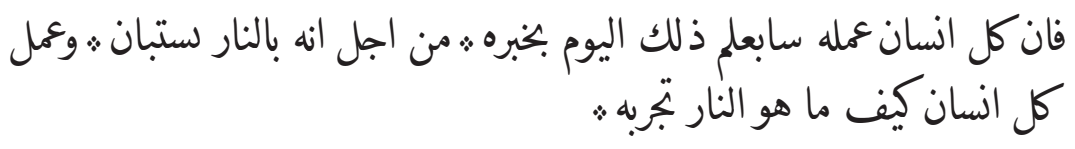

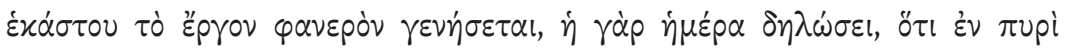

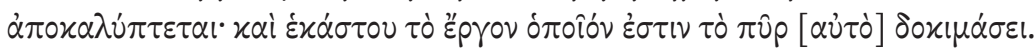

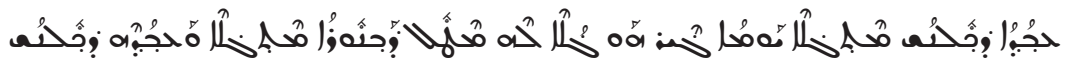
v

alors l'œuvre de chacun sera connue, ce jour-là l'annoncera, car, par le feu, elle sera révélée, et l'œuvre de chacun, tel qu'elle est, le feu la testera.

Au vu du contexte, nous pensons qu'il faut lire يخبره à la place de بخبره; ;'est ce que nous traduisons.

Le traducteur a bien choisi trois racines différentes سايعلم/بخبره/يستبان

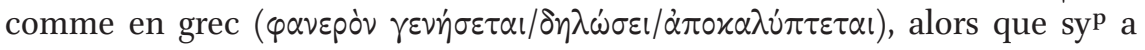
trois fois le verbe .

Le verbe جرب 《mettre à l'épreuve » (KAZIMIRSKI 1, p. 273) est plus proche

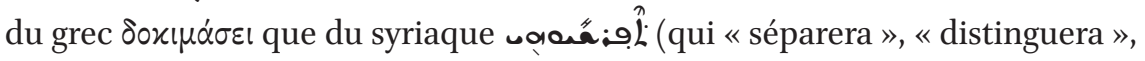
Payne Smith, p. 465).

1 Co 3,14

$$
\text { والذى يثبت عمله : الذى بنا اجره ياحذ : }
$$

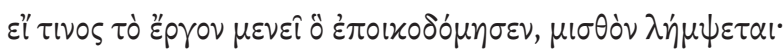

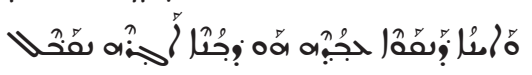

Et celui dont l'œuvre qu'il a construite est stable, il recevra son salaire,

La formulation sans phrase conditionnelle mais avec pronom relatif est proche de syp, qui a, hri?. 
1 Co 3,15

$$
\text { والذى يحترو عمله يخسر : اما هو ويخلص : هكذا مثل ما بالنار : }
$$

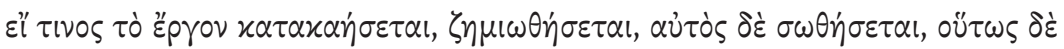

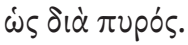

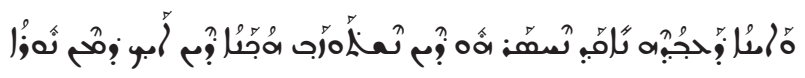

et celui dont l'œuvre sera brûlée, il [la] perdra. Quant à lui, il sera sauvé ainsi, comme ce qui l'est par le feu.

De même qu'au verset précédent, la formulation sans phrase conditionnelle mais avec pronom relatif est proche de syp.

$$
1 \text { Co } 3,16
$$

$$
\text { الا تعلمون انكم هيكل الله : وروحح الله : سآكن فيك : }
$$

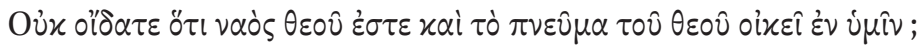

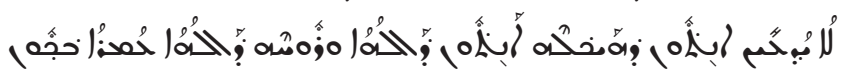

Ne savez-vous pas que vous êtes le sanctuaire de Dieu et que l'esprit de Dieu habite en vous?

\section{Co 3,17}

فن يفسد هيكل الله يفسده الله : ان هيكل الله هو مقدس : الذين هم انتم ؛

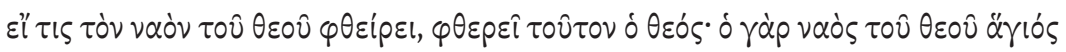

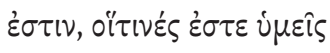

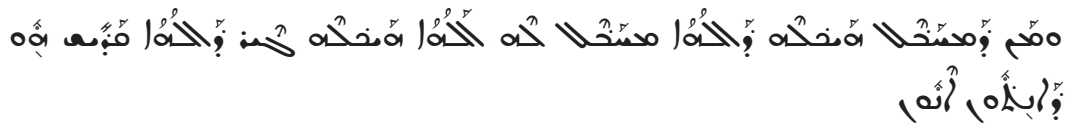

Si quelqu'un détruit le temple de Dieu, Dieu le détruira. Le temple de Dieu est saint, ce que vous êtes.

VA 13 a يفسد, comme syp qui a aussi un pronom suffixe. Cela correspond à la

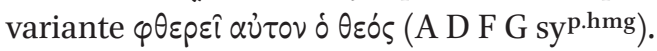


1 Co 3,18

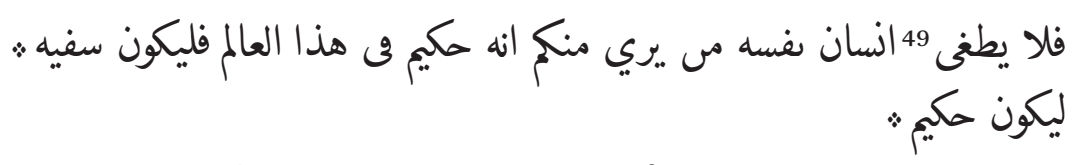

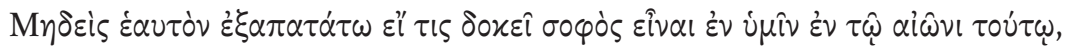

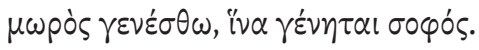

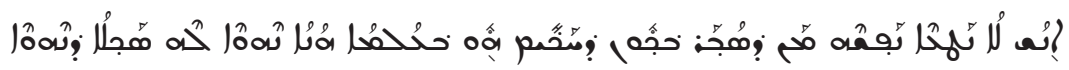

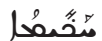

Que personne ne dépasse ses limites. Si quelqu'un parmi vous pense qu'il est sage dans ce monde, qu'il soit fou pour être sage,

1 Co 3,19

من اجل ان حككه هذا العالم هى سفاهه قدام الله انه مكتوب :هانه ياخذ الحلكم مكرغ من

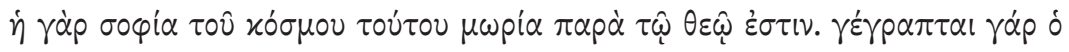

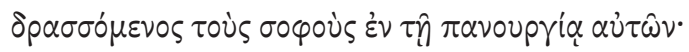

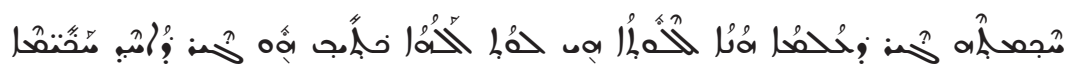

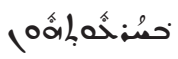

parce que la sagesse de ce monde est folie face à Dieu. Il est écrit : il prendra les sages par leur ruse,

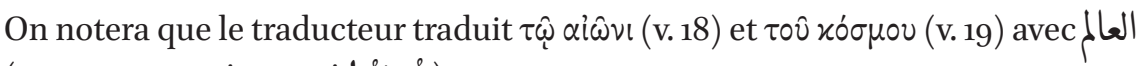
(comme syp qui a aussi حُحمُحا).

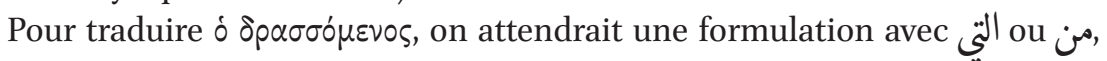
car c'est généralement ainsi que sont traduits les participes avec articlë en grec. انه ياخذ

49 À propos du verbe طنى, voir 6,9. 
1 Co 3,20

$$
\text { وايصا ان الرب يعلم هموم الحكما انزا باطل }
$$

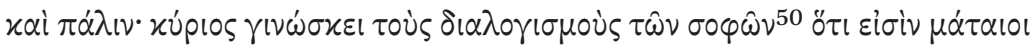

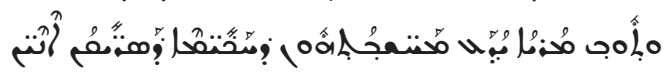

et aussi: le Seigneur connaît les préoccupations des sages, elles sont vaines.

\section{Co 3,21}

ادن لا يفتحر انسان بانسان من اجل ان كلشى هو لى :

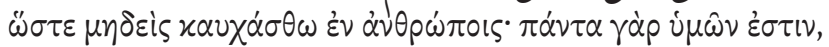

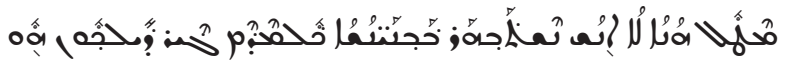

Donc que personne ne s'enorgueillisse en l'homme, parce que toute chose est à vous.

VA 13 est seul à avoir ici un singulier lانسان, que l'on peut toutefois comprendre comme un singulier collectif.

1 Co 3,22

\section{ان بولوس وان افلو ×وان الصفا وان العالم ثوان الحياه وان الموت وان الثابتات : وان الكاينات كل شي هو لم}

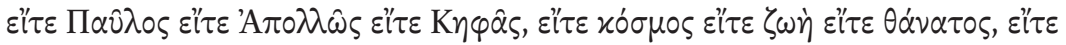

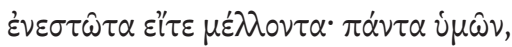

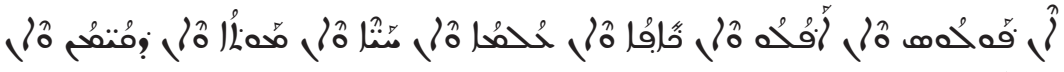

$$
\begin{aligned}
& \text { ợ }
\end{aligned}
$$

Que ce soient Paul, Apollos, Pierre, le monde, la vie, la mort, ce qui est fixe, ce qui est, toute chose est à vous

À propos des noms propres افلو et الصفا, voir 4.1 Noms propres.

50 VA 13 n'a pas la variante $\alpha \nu \theta \rho \omega ́ \pi \omega \nu$, présente dans quelques manuscrits grecs (33. 630. 1506 ar). 
1 Co 3,23

f. $105 \mathrm{v}$

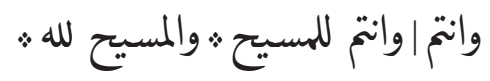

نં

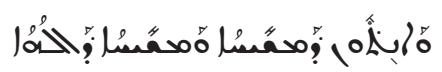

et vous êtes au Christ, et le Christ est à Dieu.

Il y a répétition de وانتم, probablement à cause du changement de folio, ce qui pourrait suggérer un système de réclame. Or il s'agit d'un phénomène rare dans notre texte (ici, en 13,6 et 15,7), ce qui laisse penser qu'il s'agit d'une erreur. Il y a aussi plusieurs cas de répétition lors d'un changement de ligne $(6,15 ; 11,3$; 15,35.54), probablement des erreurs de copie également.

\section{$1.4 \quad$ Chapitre 4}

\section{Co 4,1}

$$
\text { هكذا قليحسبونا الناس مثل خذام المسيح ث وحزان سراير الله ؛ }
$$

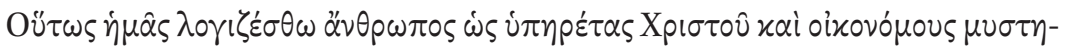

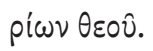

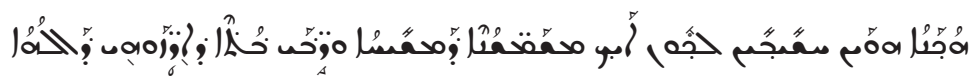

Ainsi, que les gens nous considèrent comme les serviteurs du Christ et les trésoriers des secrets de Dieu.

Ici, VA 13 ne suit pas syp qui est éloigné du grec (مجَّ nous sommes considérés par vous »); VA 13 n'est toutefois pas totalement fidèle au

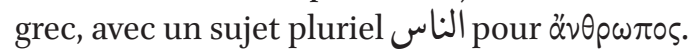

\section{Co 4,2}

$$
\text { فهاهنا ينغفا في الحزّان ان يكون الانسان يوجد امين }
$$

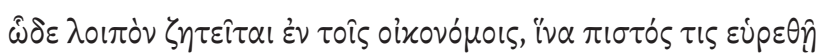

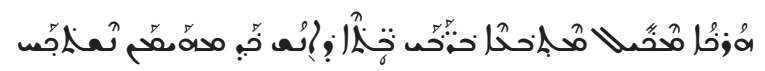

Ici, il convient que, parmi les trésoriers, l'homme soit trouvé fidèle. 


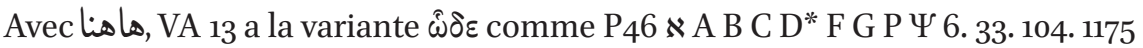
latt sy co, contre $\mathrm{D}^{2} \mathrm{~L}$ 81. 365. 630. 1241. 1505. 1506. 1739. 1881. 2464. M qui ont

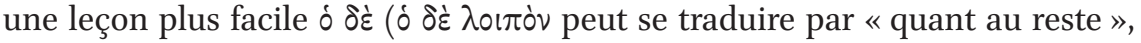
«bref », SENFT, p. 64).

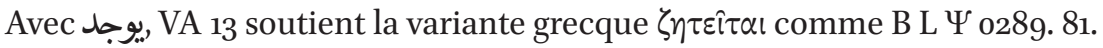
630. 1175. 1241. 1506. M latt sy co, contre P46 א A C D F G P 6. 33. 104. 365. 1505. 1739. 1881. 2464 qui ont l'impératif לท

À propos de $\pi ı \tau$ ós, voir le verset 1,9.

\section{Co 4,3}

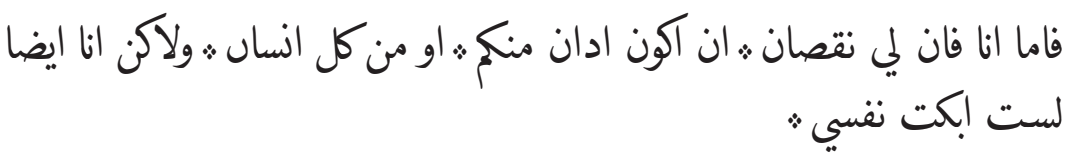

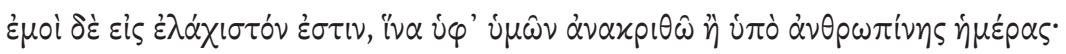

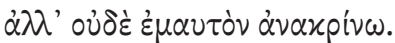

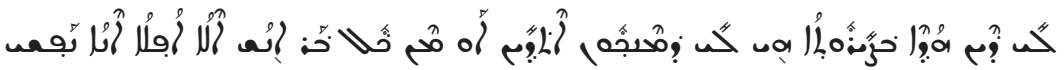

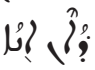

Quant à moi, cela m'est peu de chose que je sois jugé par vous ou par tout homme. Mais aussi, moi, je ne me blâme pas moi-même,

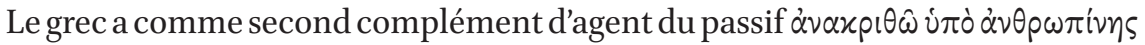

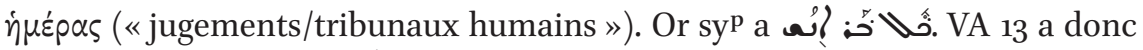
suivi ici syp avec من كل النساט.

ادان: On notera que contrairement au grec et à syp, VA 13 change de verbe

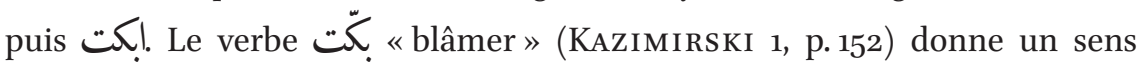
quelque peu différent à la phrase.

1 Co 4,4

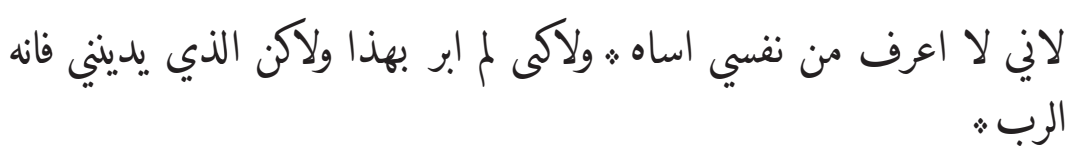

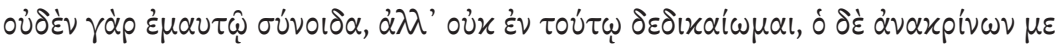

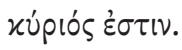




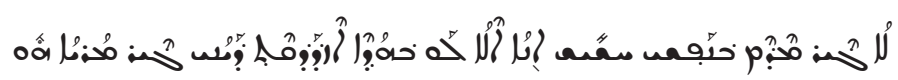

car je ne connais pas de méchanceté de ma part, mais je ne suis pas justifié par cela, mais celui qui me juge, c'est le Seigneur.

VA 13 propose ici un objet à l'examen personnel : اساه. S'agit-il ici de pré-

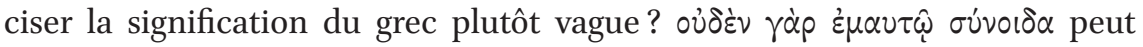
être traduit littéralement par « en effet, je n'ai conscience de rien par moi-

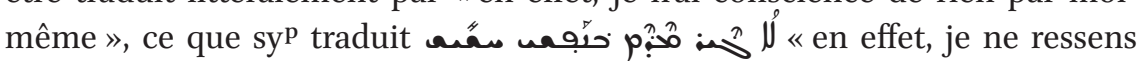

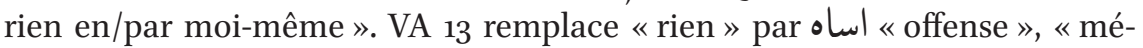
chanceté » et place من devant نقيى pour signifier qu'il s'agit d'offense venant de soi-même.

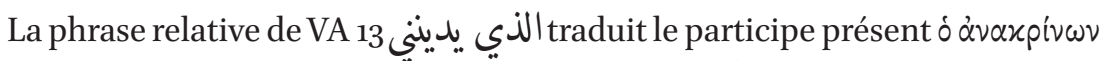
et son objet $\mu \varepsilon$, syp a une formulation différente :

\section{Co 4,5}

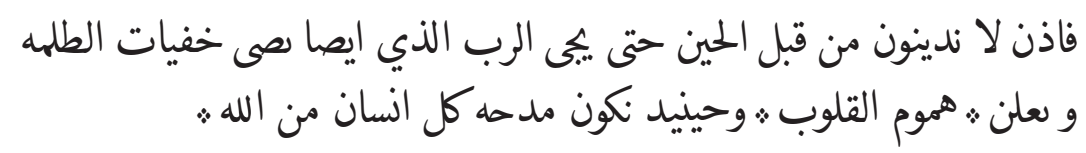

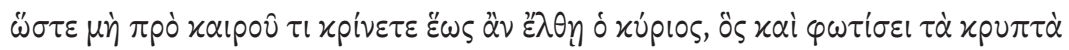

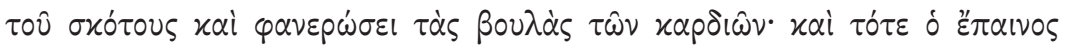

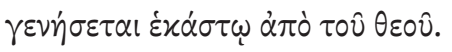

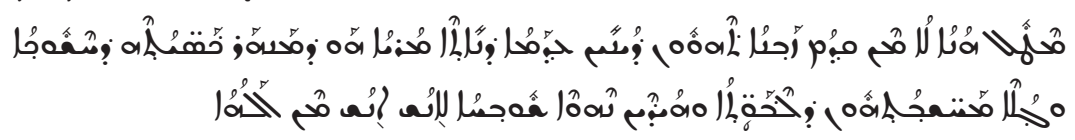

Ainsi, ne jugez pas avant le moment, jusqu'à ce que le Seigneur vienne, lui qui aussi mettra en lumière les choses cachées de l'obscurité et rendra manifeste les préoccupations des cœurs, et à ce moment-là, ce sera léloge de tout homme de la part de Dieu.

ايصا est un traduction du grec $\varkappa \alpha i$, que syp ne traduit pas. 
1 Co 4,6

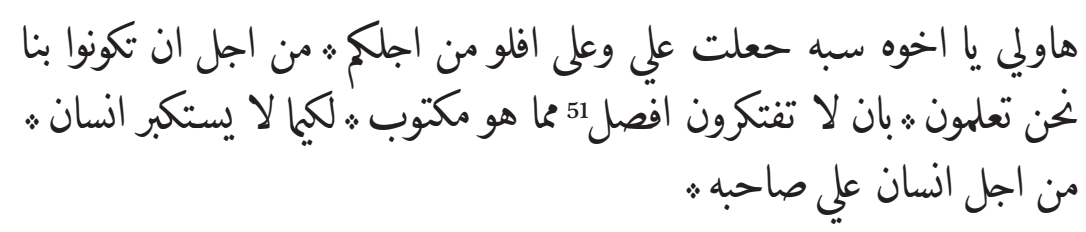

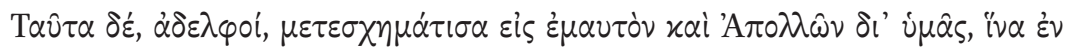

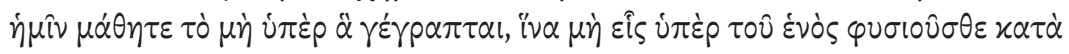
$\tau \circ \hat{~ \varepsilon ่ \tau \varepsilon ́ p o u . ~}$

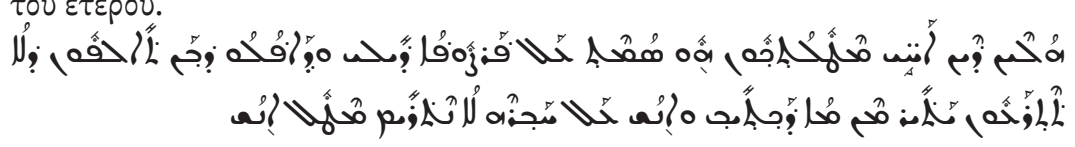

Ces choses-là, frères, je les ai placées en exemple sur moi et Apollos, à cause de vous, afin que vous, en nous, vous appreniez à ne pas penser davantage que ce qui est écrit, pour que personne ne s'élève à cause de quelqu'un au dessus de son prochain.

Le verset est difficile. Que signifie $\mu \varepsilon \tau \varepsilon \sigma \chi \eta \mu \alpha ́ \tau \iota \sigma \alpha$ ? Que Paul applique à luimême et à Apollos ses propos à titre d'exemple, comme on l'interprète en général? (voir SENFT, p. 66; contre cette interprétation, voir FITZMYER, pp. 214-215) VA 13 a pour traduction سبه حعلت. Dans la racine شبه

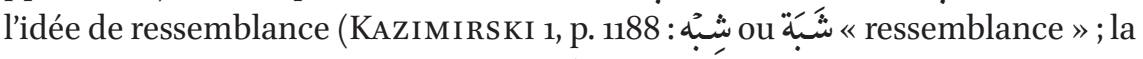
racine est utilisée dans ce sens en 4,16 $)^{52}$. De la ressemblance semble découler la comparaison et l'exemple pour notre traducteur : en effet, c'est bien dans le sens d'exemple qu'on retrouve شَه 10,6 et 10,11, et en 11,1. En SA 155, on trouve ici la même racine sous forme de verbe :شبهت. La traduction de VA 13 semble plus proche du grec, si l'on accepte le sens de « appliquer à titre d'exemple »,

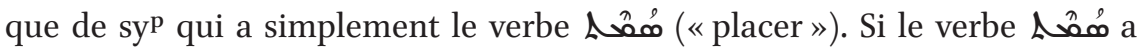
peut-être influencé le traducteur pour جعلت, syp ne peut être l'unique source de la traduction.

Par contre, VA 13, avec على وعلى افلو, nous semble plus proche du syriaque de

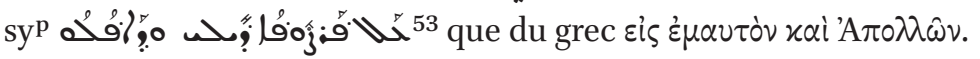

\footnotetext{
51 Dans VA 13, l'élatif افضل (افصل (toujours orthographié) est souvent utilisé dans un sens qui semble quantitatif et pas seulement qualitatif: « davantage», «plus ». Pour comparaison, on trouve افضل en 4,6; 7,31; 9,12; 10,$13 ; 14.5 ; 15,10$.

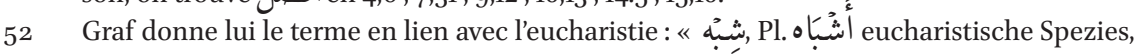
Gestalt von Brot und Wein. », Graf, Termini, p. 65. Céla ne correspond pas à l'usage fait en $4,6,10,6$ ou 10,11 . 
À propos du nom propre افنورن, voir 4.1 Noms propres.

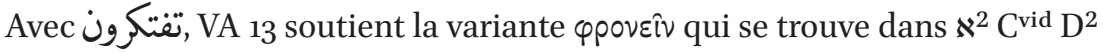
L P $0285^{\text {vid }} \cdot 33 \cdot 104 \cdot 365 \cdot 630.1241 .1505 \cdot 1506.2464 . M^{2}$ vgms sy (absente dans $\mathrm{P}_{4} 6$

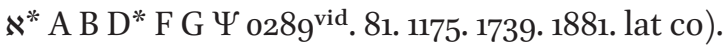

1 Co 4,7

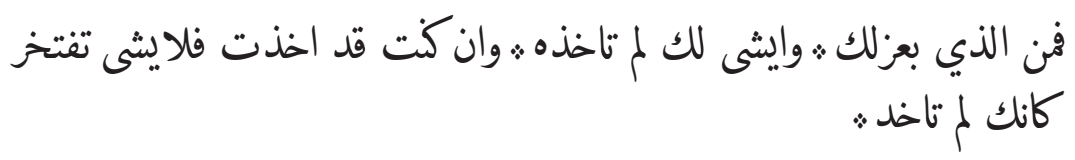

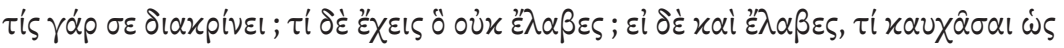
$\mu \grave{\eta} \lambda \alpha \beta_{\nabla} \omega \nu$

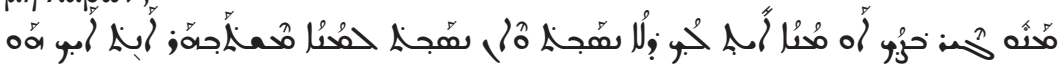

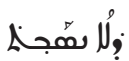

Mais qui est celui qui te met à l'écart? Quelle chose as-tu que tu n'aies pas reçue? Et si tu l'as reçue, pourquoi te vantes-tu comme si tu ne l'avais pas reçue?

Comment comprendre بعزلك? Une possibilité serait de lire بَعََ لَكَ : « t'a élevé ».

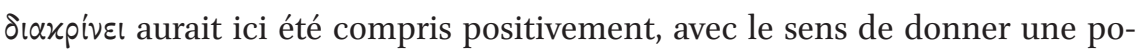

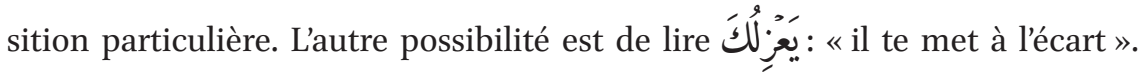

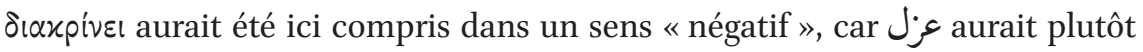
le sens de «destituer». Nous préférons cette deuxième lecture : premièrement, l'inaccompli correspond à l'indicatif présent; deuxièmement, cela nous

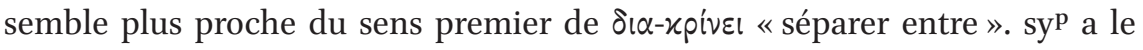
verbe $\int_{3}$ « rechercher », « scruter » et ne semble pas être à la base de la traduction de VA 13.

\section{$1 \mathrm{Co} 4,8$}

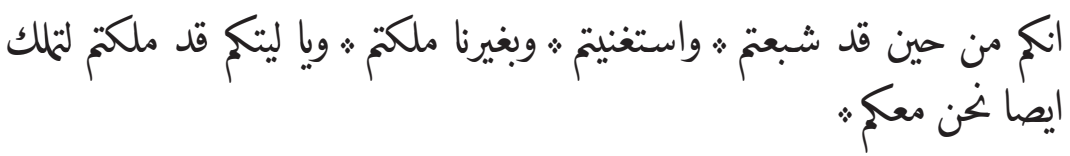

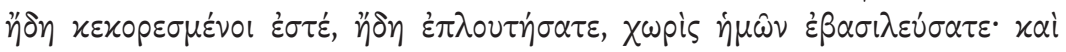

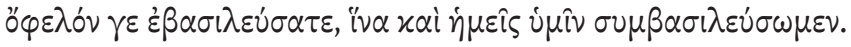




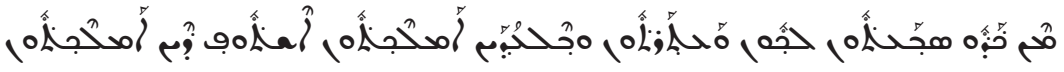

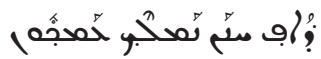

Vous, depuis un moment déjà, vous étiez rassasiés, vous étiez riches, et sans nous, vous régniez déjà. Puissiez-vous régner, pour que nous régnions aussi nous avec vous!

1 Co 4,9

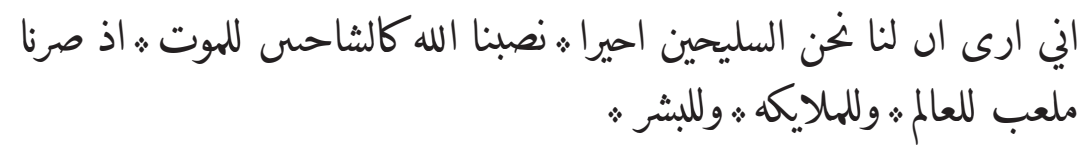

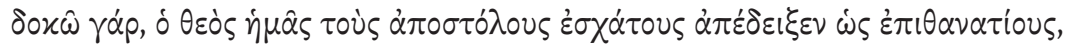

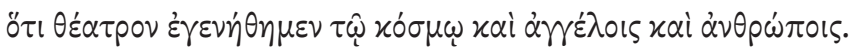

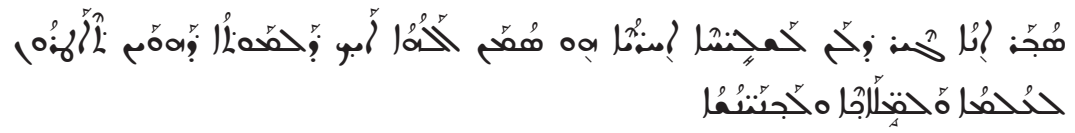

Je pense que nous, les apôtres, Dieu nous a institués en dernier comme les condamnés à la mort, alors que nous sommes devenus un spectacle pour le monde, les anges et les humains.

Le terme سليحين fait partie du vocabulaire chrétien pour désigner les apôtres. Belot orthographie سِلِّحُونون (BELOT, p. 334), précisant qu'il s'agit d'un mot d'origine étrangère; Graf propose سَلِيحُون (GRAF, Termini, p. 61). La même racine

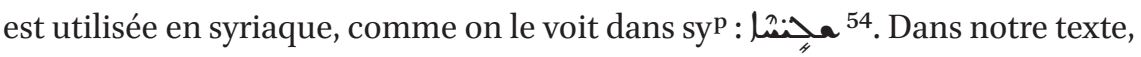

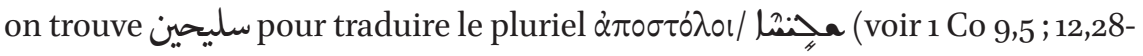

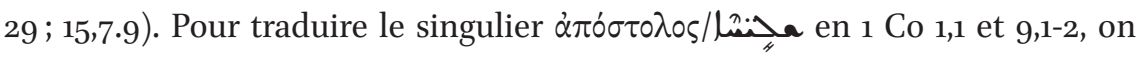
trouve رسول. Voir point 4.3.1.

nous semble plus proche du grec que de syp qui a n'a pas

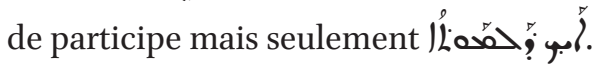

54 Kashouh consacre plusieurs pages à la traduction de l'expression « disciples » dans la partie des évangiles du VA 13 ; il intègre dans son tableau également les passages où on trouve

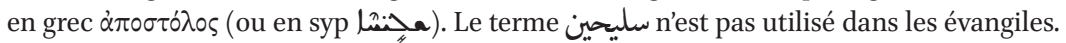
KASHOUH, pp. 159-163.

55 KAZIMIRSKI 1, p. $1191:$ :ُشجبَ 
1 Co 4,10

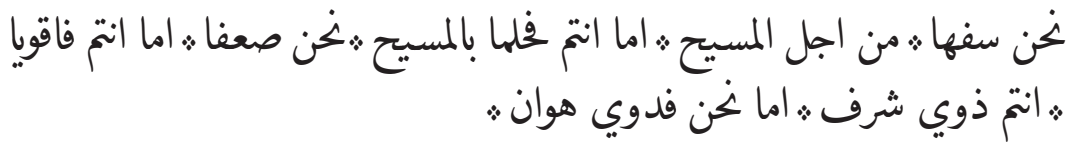

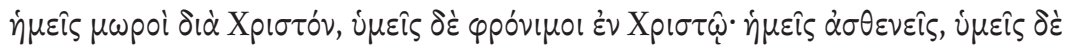

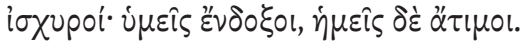

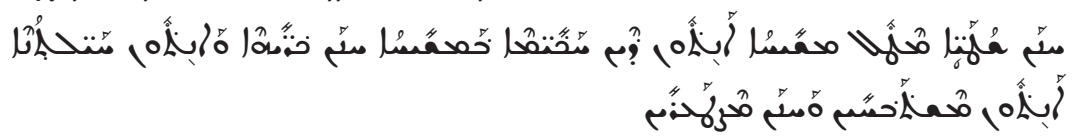

Nous sommes fous à cause du Christ, quant à vous, vous êtes cléments en Christ; nous sommes faibles, quant à vous, vous êtes forts ; vous êtes honorés, quant à nous, nous sommes méprisés ;

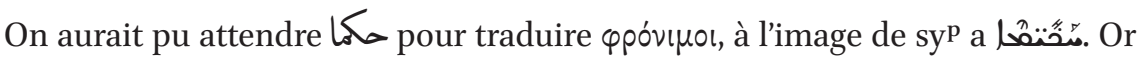
VA 13 a حله «bons », « patients », « cléments ». Le traducteur se tient à cette

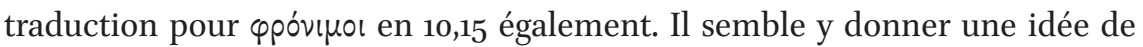
sagesse, vu qu'au verset 6,5, il traduit également бo५ós par حليم.

1 Co 4,11

حتى هذا الحين نخن عراث عطاس عري ونهان : وليس لنا مقاوم 56 .

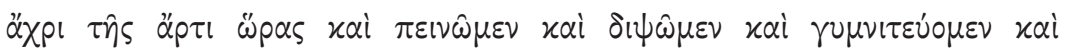

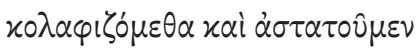

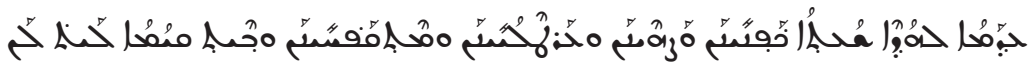
jusqu'à ce moment, nous sommes affamés, assoiffés, nus, et nous sommes méprisés, et nous n'avons pas de place établie.

On notera que pour exprimer le mépris, VA 13 utilise la même racine هان aux v. 10 et 11 (هوان puis نهان), tandis que le grec ( $\alpha$ هı changent de vocabulaire.

56 On ne trouve pas cette orthographe pour un nom de lieu dans les dictionnaires consultés. Nous supposons qu'il s'agit d'un nom de lieu formé sur la forme III : «Die Nomina loci und temporis der abgeleiteten Stämme haben haben die Form des Partic. Pass. [...]», BROCKELMANN, $§ 64$. 


\section{Co 4,12}

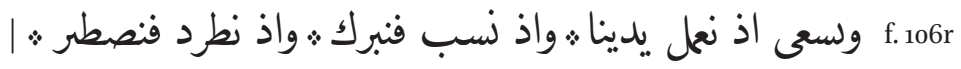

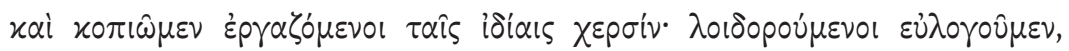

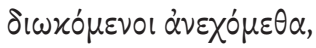

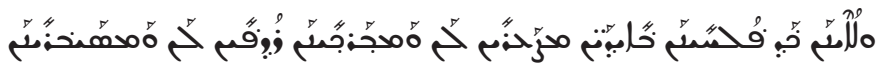

Et nous nous appliquons quand nous travaillons de nos mains; et lorsque nous sommes insultés, nous bénissons ; et lorsque nous sommes repoussés, nous persévérons ;

Vu le contexte, nous supposons que نطب et نطب sont au passif ; cette formulation au passif serait alors plus proche du VA 13 du grec («nous sommes insultés », « nous sommes repoussés ») que de $\mathrm{sy}^{\mathrm{p}}$ qui a des participes actifs («ils nous insultent », « ils nous repoussent »).

\section{Co 4,13}

\section{واد يفترى علينا : فنطلب : ووكا مثل كاسه العالم ؛وونديل كل انسان : حتى الان :}

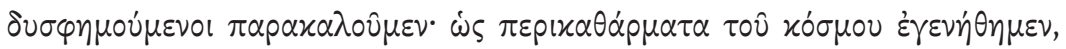

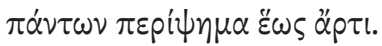

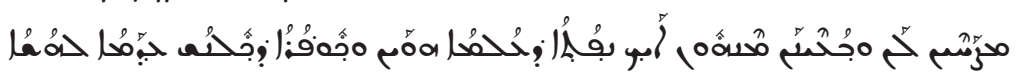
et lorsqu'on nous calomnie, nous demandons; et nous sommes devenus comme les balayures de ce monde et l'essuie-tout de tous, jusqu'à maintenant.

Comment comprendre نطلب? Est-ce une traduction de $\pi \alpha p \alpha \varkappa \alpha \lambda \circ \hat{\text { ن }} \mu \varepsilon \nu$ ou de مُحِّْ (syp)?

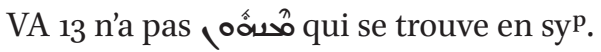

\section{$1 \mathrm{Co} 4,14$}

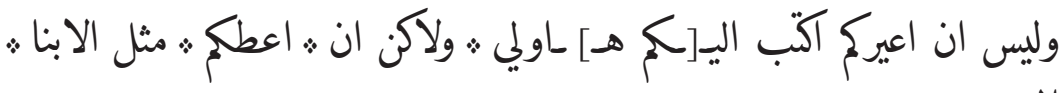

$$
\begin{aligned}
& \text { المحبونين }
\end{aligned}
$$

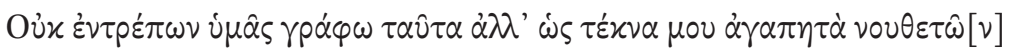

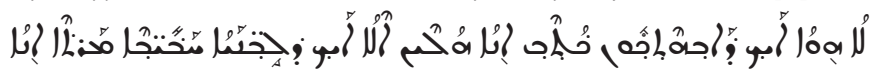


Ce n'est pas pour vous blâmer que je vous écris ceci, mais pour vous avertir comme des fils bien-aimés.

Comme syp, VA 13 n'a pas de possessif après « fils ». Par ailleurs, le choix de

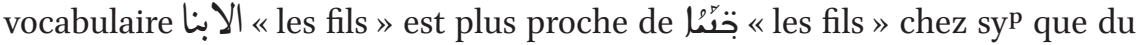
terme neutre $\tau \dot{\varepsilon} x \nu \alpha \ll$ enfants » en grec.

$1 \mathrm{Co} 4,15$

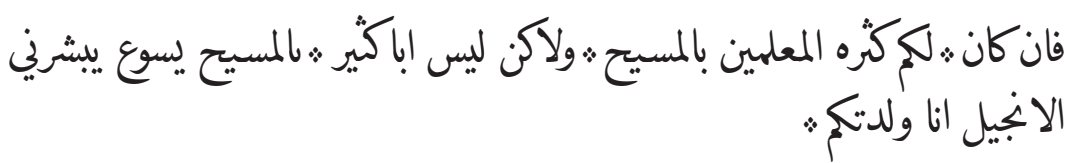

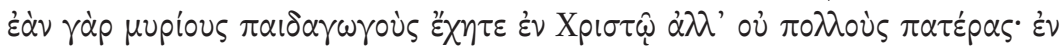

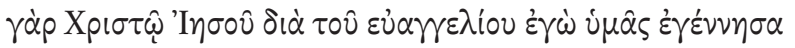

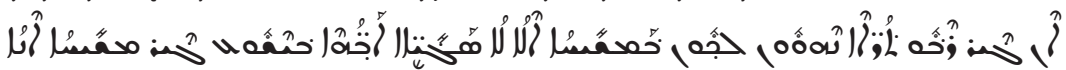

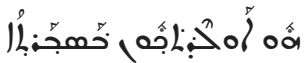

Car si vous avez une multitude d'enseignants dans le Christ, [vous n'avez] par contre pas plusieurs pères : dans le Christ Jésus, dans ma prédication de l'évangile, c'est moi je vous ai enfanté.

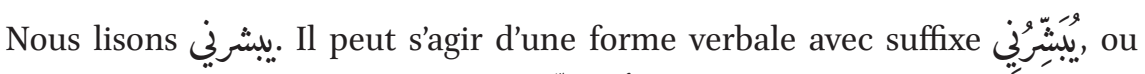

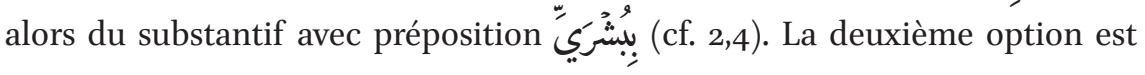
plus proche du grec et du syriaque et nous trouvons plusieurs fois بشرى avec

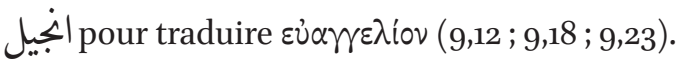

1 Co 4,16

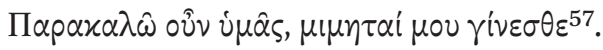

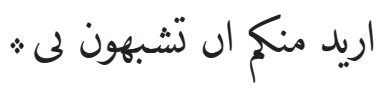

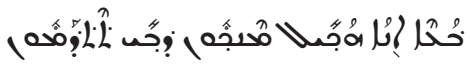

Je veux de votre part que vous me ressembliez.

À propos de la racine شبه, voir ci-dessus 4,7.

57 Quelques témoins ont ici la variante $\kappa \alpha \theta \dot{\omega} \varsigma$ $\varkappa \dot{\alpha} \gamma \dot{\omega}$ Xpı 


\section{$1 \mathrm{Co} 4,17$}

$$
\begin{aligned}
& \text { ومن اجل هذا بعثت اليكم ثياثيوس ث. الذى هو ابنى المحبوب ومومن بالرب ثليذكرك }
\end{aligned}
$$

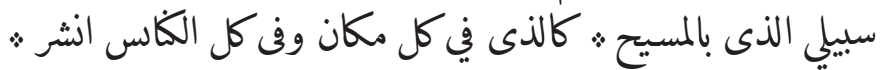

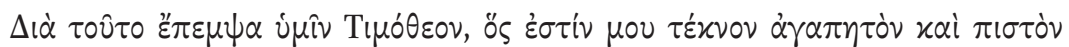

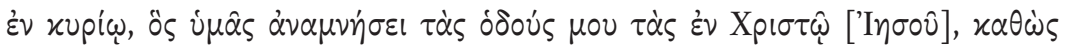

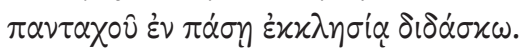

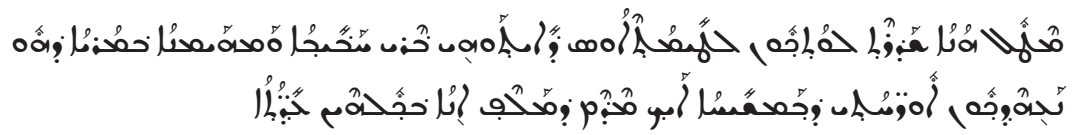

Et à cause de cela, je vous ai envoyé Timothée, qui est mon fils bien-aimé et croyant en le Seigneur, pour vous rappeler mon chemin qui est en le Christ, comme je le promulgue en chaque lieu et dans toutes les églises.

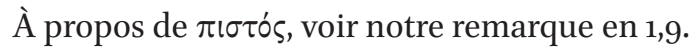

VA 13 propose un singulier «mon chemin », tandis que grec et sy $\mathrm{p}^{\mathrm{p}}$ ont un pluriel.

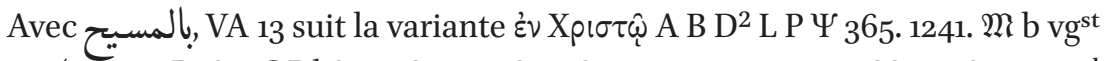
syp sa (contre $\mathrm{P}_{4} 6 \aleph \mathrm{C} \mathrm{D}^{1}$ 6. 33. 81. 104. 629. 630. 1175.1505. 1739.1881. 2464. ar vg ${ }^{\mathrm{cl}}$

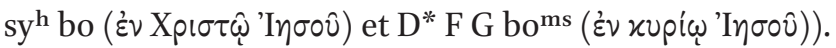

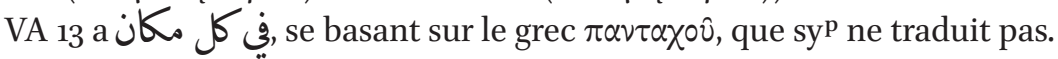

1 Co 4,18

$$
\text { وقد افتخروا اناس : كلى لا اجيكم : }
$$

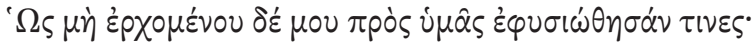

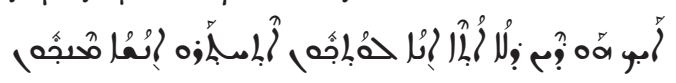

Et des gens se sont enorgueillis, comme si je ne venais pas chez vous,

syp précise avec مصنجمَه certains d'entre vous », ce qui n'est pas repris parVA 13.

\section{Co 4,19}

$$
\begin{aligned}
& \text { بل اجيكم عـاجلا ان احب الرب والعلم كل كلام ه الدس هـم مفتخزين فتط } \\
& \text { ولاك قوتهم : - ولم }
\end{aligned}
$$




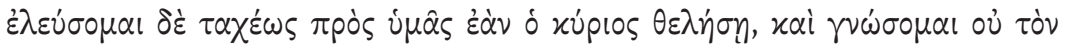

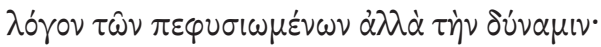

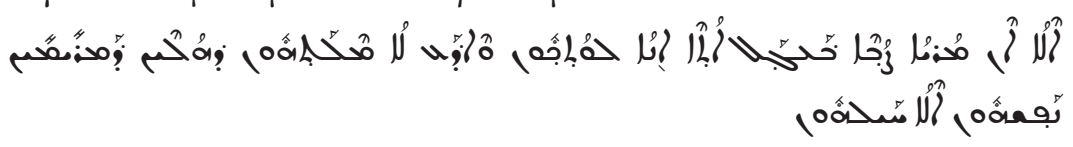

mais je viendrai chez vous incessamment si le Seigneur veut, et je ne prendrai [pas] seulement connaissance de toute parole de ceux qui s'enorgueillissent, mais aussi de leur puissance.

En utilisant deux fois le même verbe افتخ aux v. 18 et 19, le traducteur se base probablement sur le grec et non sur syp qui change de verbe (syp est également le seul à avoir (بố).

Le verset dans VA 13 est difficile à traduire. En effet, il manque la négation que l'on attendrait avant اعلم; à la place, nous trouvons un alif seul. Nous supposons qu'il s'agissait à l'origine d'un لا لا bien qu'il soit étrange qu'un copiste

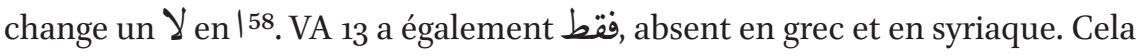
change le sens de la phrase. Le grec et le syriaque peuvent se traduire : «Je ne prendrai pas connaissance de la parole de ceux qui s'enorgueillissent, mais de leur puissance », tandis que VA 13 exprime que Paul ne prendra pas connaissance uniquement de leur parole, mais aussi de leur puissance. Cette interprétation du traducteur semble appuyée par كل كل 6 , propre à VA 13 : il prendra connaissance non seulement de toute parole, mais aussi de leur puissance.

1 Co 4,20

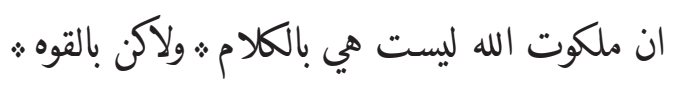

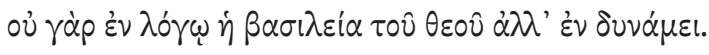

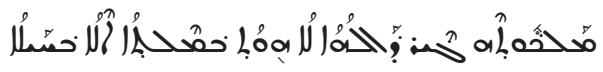

Car le royaume de Dieu n'est pas en parole, mais en puissance.

ملكوت apparaît ici comme féminin, peut-être sous l'influence du grec ou du syriaque.

$5^{8}$ Voir aussi notre remarque sur le phénomène llg en 11,18. 
1 Co 4,21

$$
\text { فكف تحبون ث بالسوط احيك ام بالحب ثمبالروح المحبت }
$$

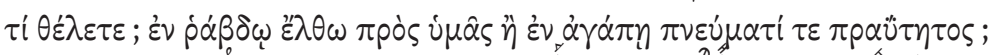

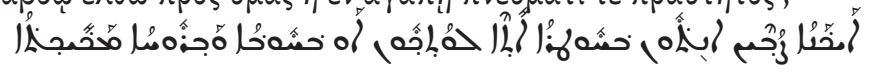

Or comment aimeriez-vous [que] je vienne, avec le fouet ou avec l'amour et l'esprit aimable?

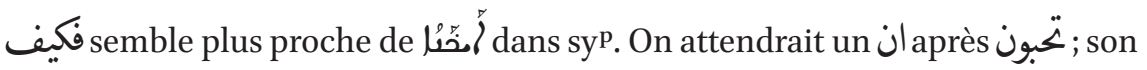
absence vient peut-être d'une traduction littérale de la construction du grec ou de syp.

\subsection{Chapitre 5}

$$
1 \text { Co } 5,1
$$

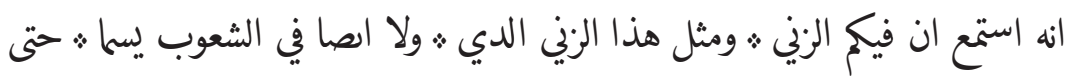

$$
\begin{aligned}
& \text { ان الرجل يتخد امراه ابوه }
\end{aligned}
$$

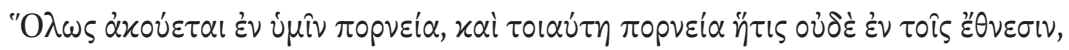

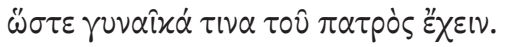

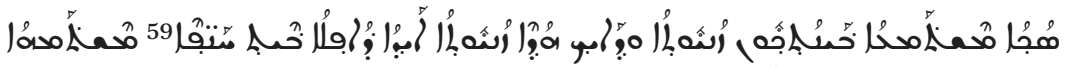

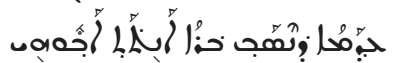

On a entendu parler parmi vous de fornication, et d'une telle fornication elle n'est même pas nommée parmi les nations - qui va jusqu'à l'homme prenant la femme de son père.

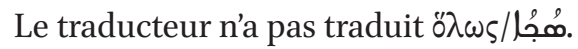

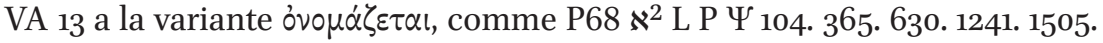

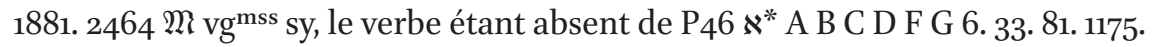
1739 lat co.

\section{Co 5,2}

$$
\text { وانتم تفتخزون ولا تتوحون بزاده ان توخذ من بينك ؛ الدى يعل هذا العل ؛ }
$$

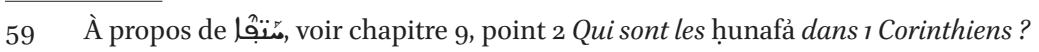




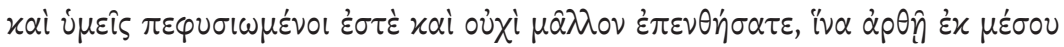

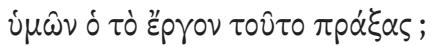

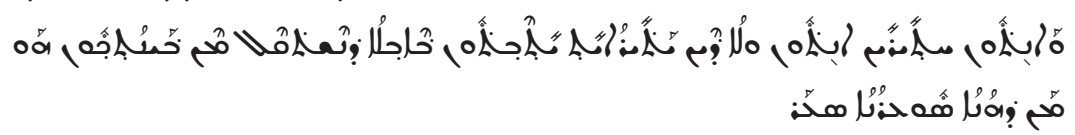

Et vous, vous vous enorgueillissez, et vous ne pleurez pas davantage pour que soit enlevé d'entre vous celui qui fait cet acte.

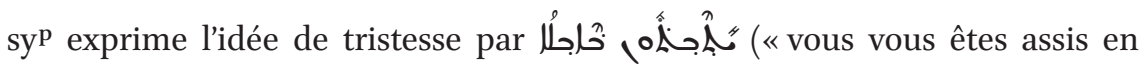
deuil »), une expression qui n'est pas reprise dans VA 13.

\section{Co 5,3}

$$
\begin{aligned}
& \text { اما انا اذ انا بعيد منكم بالجسد : فتريب منكم بالروح ؛ فقد رايت : على الدىعمل هذا }
\end{aligned}
$$

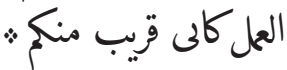

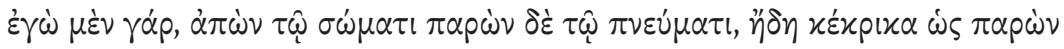

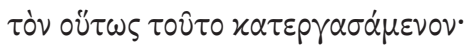

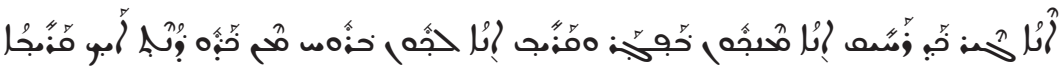

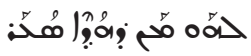

Quant à moi, comme je suis éloigné de vous en corps en étant près de vous en esprit, j'ai déjà mon opinion à propos de celui qui a fait cet acte, comme si jétais près de vous :

Il est difficile de savoir si VA 13 soutient la variante $\omega$ s (présente en $\mathrm{D}^{1} \mathrm{~F}$ G L $\Psi$ 104. 365. 1241. 1505. 2464 M b d sy); en effet, VA 13 a un اذ اذبيد, or ce genre de conjonction est régulièrement utilisé pour traduire un participe grec.

\section{Co 5,4}

$$
\text { ان اسم ربنا يسوع المسيح اذا انتم × مجتمعين × وابصا روحى انا مع قوه ربنا يسوع }
$$

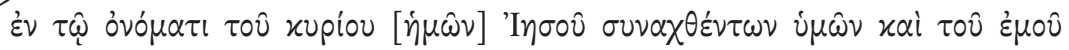

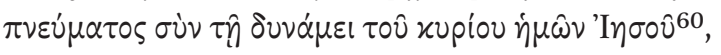

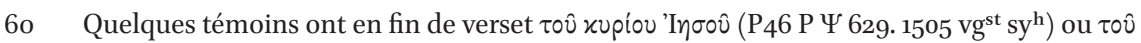
xupíou (630. 1739), variante non soutenue par VA 13. 


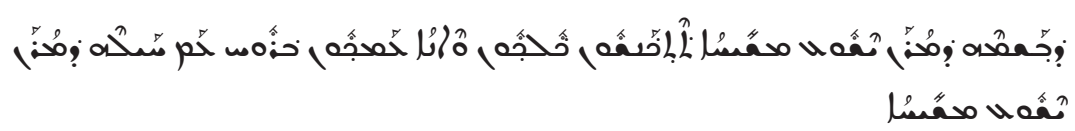

au nom de notre Seigneur Jésus le Christ, quand vous serez rassemblés, et aussi mon esprit, avec la puissance de notre Seigneur Jésus,

La construction des versets 3 à 5 est compliquée mais se comprend bien si l'on considère que رايت au v. 3 est suivi par ان تدفعون au v. 5, le v. 4 présentant les conditions préalables; ici, le traducteur a tenté de traduire le grec fidèlement.

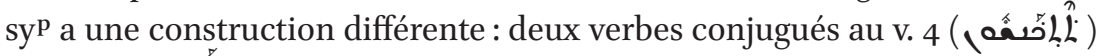

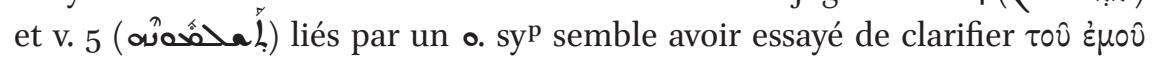

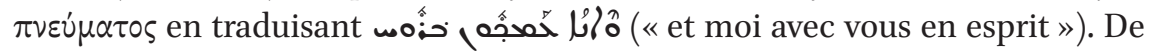

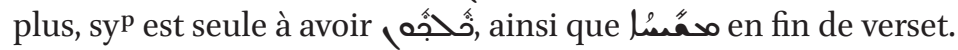

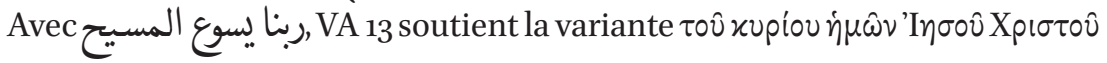

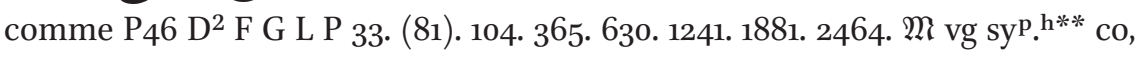

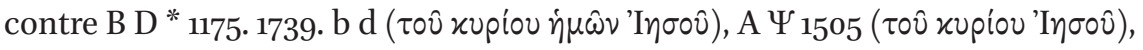

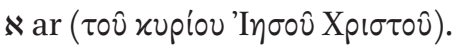

1 Co 5,5

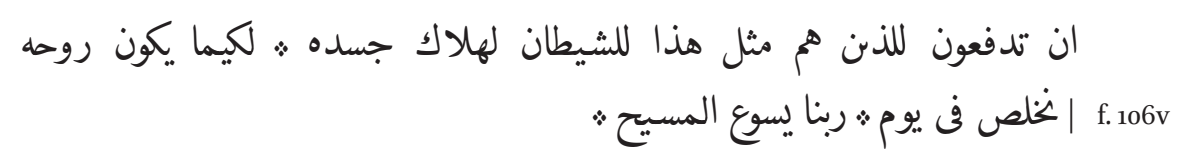

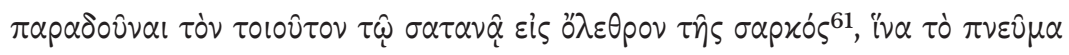

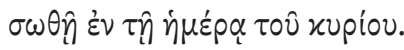

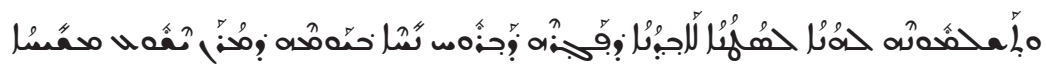

vous livrerez de tels gens à Satan, pour la destruction de leur corps afin que leur esprit soit sauvé au jour de notre Seigneur Jésus le Christ.

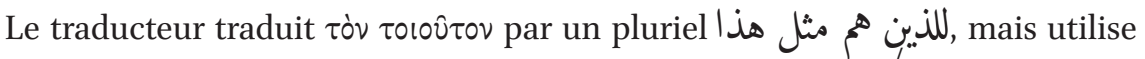

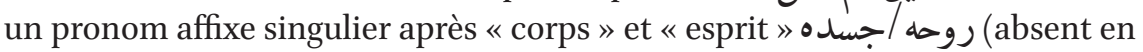

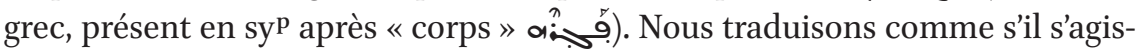
sait d'un pronom pluriel.

À propos de للشيطان, voir 4.3.5 Autres termes.

À nouveau, syp a ici une variante propre

61 Sur $\sigma \alpha ́ p \xi$ et ses traductions, voir notre commentaire en 1,29. 


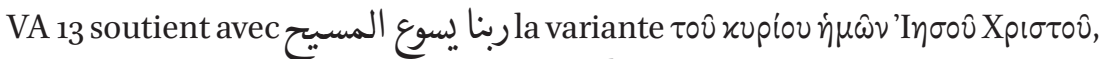
comme A F G P 33. 104. 365. 1241. 1881. ar vg ${ }^{\mathrm{cl}}$ sy co, contre P46 B 630. 1739 ( $\tau \circ \hat{v}$

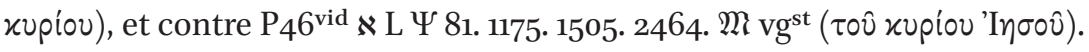

$1 \operatorname{Co} 5,6$

$$
\text { افتخاركم ليس هو بحسن • الا تعلمون ان خمي قليل كل العجين يخمر : }
$$

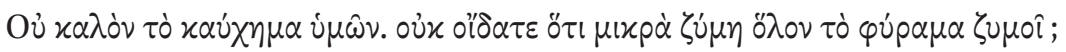

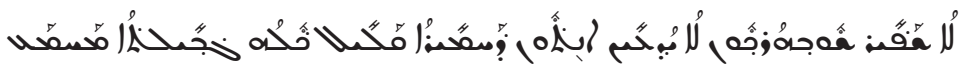
Votre orgueil n'est pas beau; ne savez-vous pas que peu de levain fait lever toute la pâte?

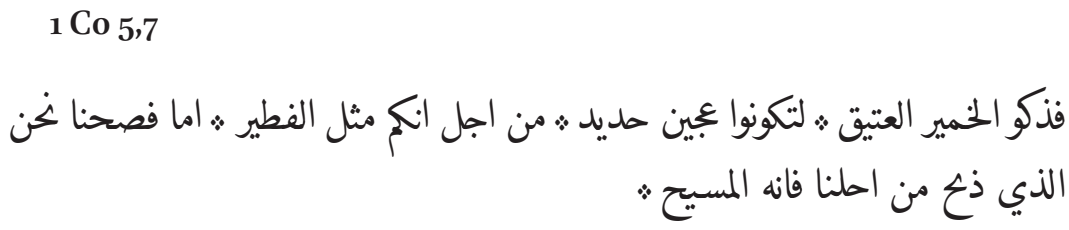

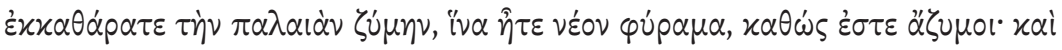

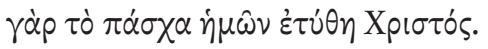

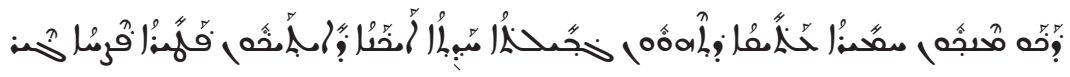

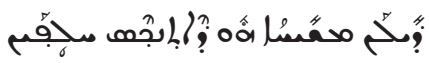

Purifiez le vieux levain pour devenir une pâte nouvelle, parce que vous êtes comme des pains azymes; quant à notre Pâque qui a été immolée à cause de nous, c'est le Christ.

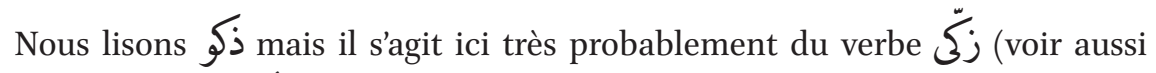
1 Co 5,8). Voir 2.2 Éléments de moyen arabe dans Vat. Ar. 13 (1Corinthiens) : 3) dāal et zāy.

On notera que syp est seul à avoir مُشجُم

Avec $ف$ en début de verset, VA 13 semble proche de la variante oủv, présente dans P11 vid $\aleph^{2}$ C L P $\Psi$ 048. 33. 81. 104. 365. 630. 1175. 1241. 1505. 1739. 1881. $\mathfrak{M}$ ar $v{ }^{\text {mss }}$ sy $^{\text {h }}$ (absent chez P46 $\aleph^{*}$ A B D F G 614. 629. 2464 lat syp).

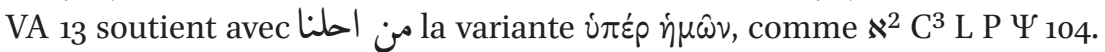
365. 630. $1175^{\mathrm{c}} \cdot 1241.1505 .1881 .2464 \mathrm{M}^{2}$ sy sa bo ${ }^{\mathrm{ms}}$, absente chez $\aleph^{*}$ A B C* D F G 33. $81.1175^{*}$. 1739 latt bo. 


\section{Co 5,8}

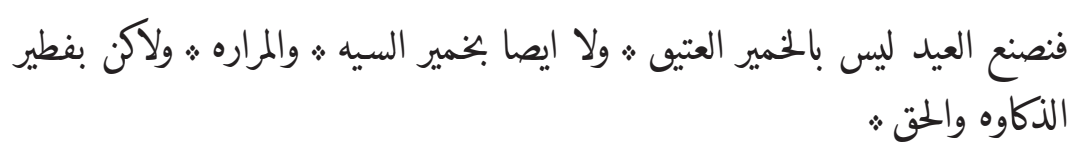

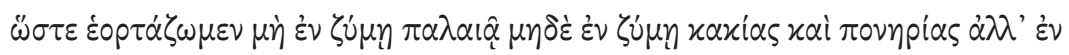

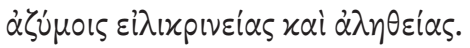

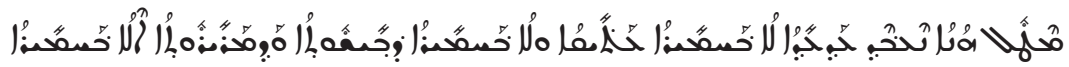

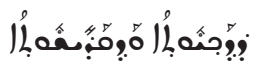

Célébrons la fête, non pas avec du vieux levain ni avec du levain de méchanceté et d'amertume, mais avec des pains azymes de pureté et de vérité.

Comme au verset précédent, nous pensons qu'il s'agit ici de la racine $\widehat{\zeta}_{j}$ et non $5 ; 62$.

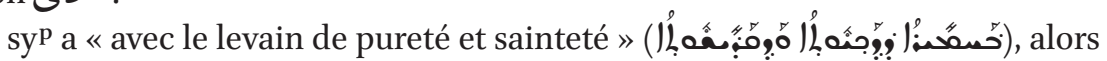

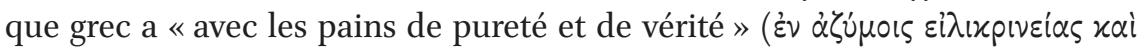
$\alpha \lambda \eta \theta \varepsilon i \alpha \varsigma)$; ici, VA 13 suit le grec.

\section{Co 5,9}

$$
\text { كتبت اليكم في الكّاب بان لا تخالطوا الرناه }
$$

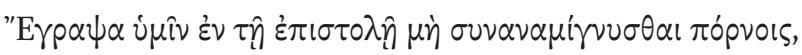

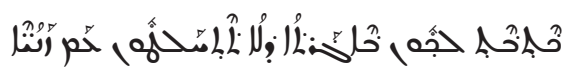

Je vous ai écrit dans un écrit de ne pas fréquenter les fornicateurs.

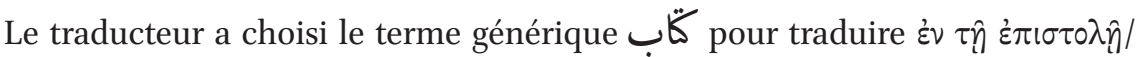

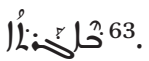

62 Si Kazimirski ne connaît pas l'orthographe زكاوة, il s'agit très probablement du sens «pu-

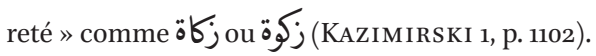

63 À propos des différents usages du terme kitāb, voir ARbache Samir, « Le terme kitāb (Écriture) dans le Coran et dans une ancienne version arabe des Evangiles », in : DE SMET D., Callatay G. De et Reeth J.M.F. Van (éds), Al-Kitab : la sacralité du texte dans le monde de l'islam : actes du Symposium international tenu à Leuven et Louvain-la-Neuve du 29 mai au 1 juin 2002, Bruxelles, Peeters, 2004 (Acta Orientalia Belgica. Subsidia 3), pp. 321-332. 
1 Co 5,10

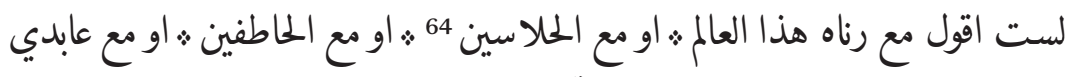

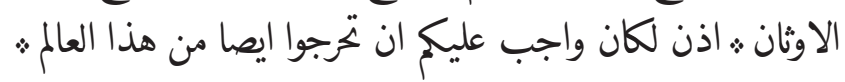

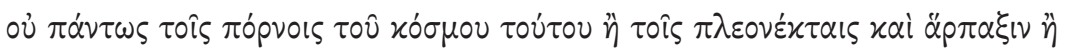

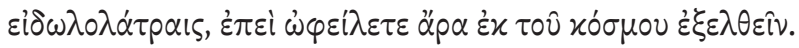

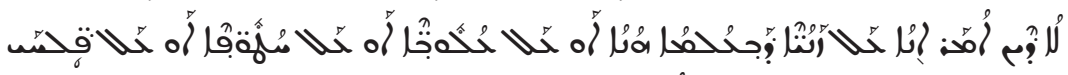

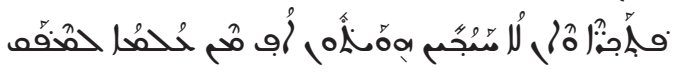

Je ne dis pas: avec les fornicateurs de ce monde ou avec les voleurs, ou avec les kidnappeurs, ou avec les adorateurs d'idoles; alors, il vous faudrait vraiment sortir aussi de ce monde.

VA 13 introduit le verset avec un verbe (et une négation) لسـت اقول, comme syp

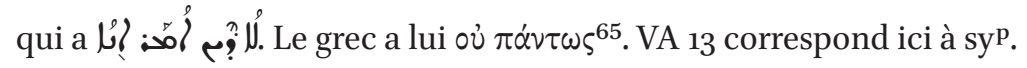

En grec, les groupes de personnes sont au datif et dépendent du verbe au v. 9. VA 13 ne continue pas avec un cas direct comme au verset précédent, mais

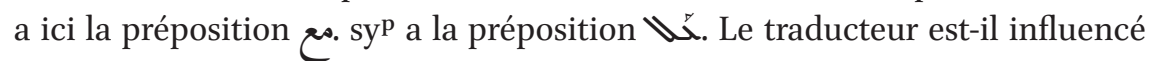
par l'utilisation de prépositions dans syp66 ?

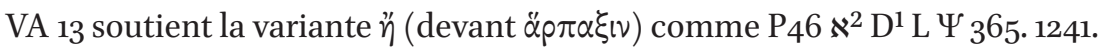
1505. 1881 M lat sy co, contre P61 $\aleph^{*}$ A B C D* F G P 048. 33. 81. 104. 630. 1175. 1739. $2464 \mathrm{~d}(x \alpha i$ äp $\pi \alpha \xi \iota \nu)$.

La formulation positive اذن correspond au grec غ̇ं syp. Par contre, ايضا dans VA 13 semble correspondre à í dans syp.

$$
\begin{aligned}
& 1 \text { Co } 5,11 \\
& \text { اما الان حين كتبت اليكم الا حطوا ه. انكان فيك من يدعا اخ وهو زان ه. او حلاس }
\end{aligned}
$$

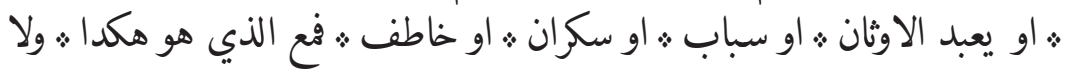

$$
\begin{aligned}
& \text { خبز تاكلون ايصا : مان }
\end{aligned}
$$

64 الخلا سين, LANE 1, p. 785.

65 La majorité des manuscrits grecs ont $x \alpha i$ en début de verset.

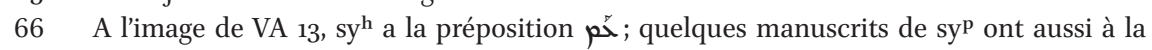
place du premier "ح̌ la préposition حِّ (Londres BL Add. 14.476 ; Londres BL Add. 14.479; Londres BL Add. 14.475 ; Londres BL Add. 17.122, manuscrits du 5-6 ${ }^{\mathrm{e}}$ s., ALAND). 


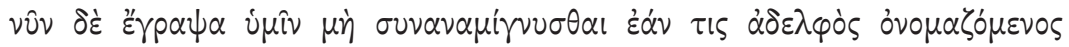

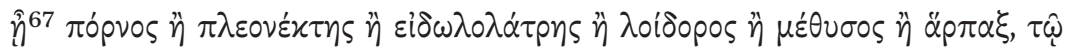

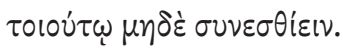

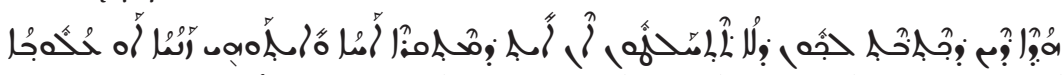

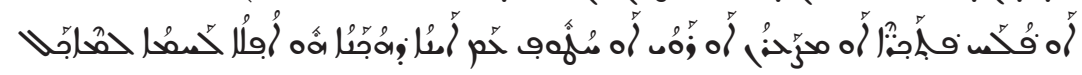
Mais maintenant, du moment que je vous ai écrit de ne pas [les] fréquenter, s'il y a parmi vous quelqu'un qui est appelé frère et qui est fornicateur, ou voleur, ou qui adore les idoles, ou qui blasphème, ou qui est ivrogne, ou rapace : avec celui qui est ainsi, vous ne mangerez pas non plus de pain.

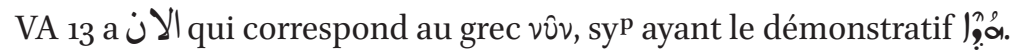

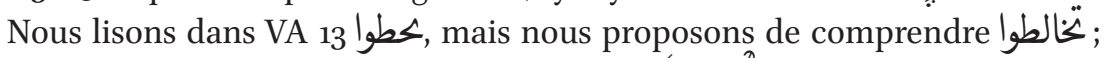

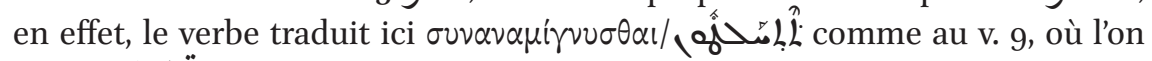
trouve تخالطوا.

VA 13 est seul à avoir فيك.

Le verset se termine avec l'idée de ne pas manger de pain خبن ف de telles personnes. Il ne peut s'agir ici que d'une traduction de syp, le grec n'ayant pas d'objet à $\sigma u v \varepsilon \sigma \theta i \varepsilon v^{68}$.

\section{Co 5,12}

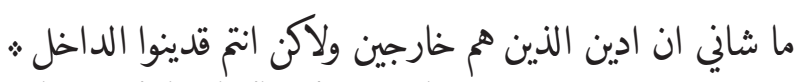

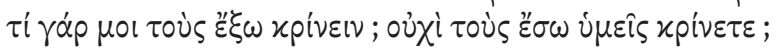

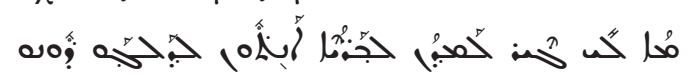

Est-ce mon affaire de juger ceux qui sont à l'extérieur? Mais vous, jugez celui qui est à l'intérieur.

VA 13 soutient la variante sans $x \alpha i$ avant $\tau$ ov่ 33. 81. 104. 630. 1175. 1505. 1739. 1881 latt syp, contre D L $\Psi 365.1241 .2464 \mathrm{M}^{\mathrm{p}} \mathrm{y}^{\mathrm{h}}$.

67 Quelques manuscrits grecs ont ici C D F G P).

68 Il est fort probable que l'interprétation de syP et VA 13 fasse ici référence à l'eucharistie ; les propos de Paul concernerait davantage la commensalité et avec elle les liens sociaux, mais une Anspielung à l'eucharistie n'est pas exclue (Lindemann, p. 131; Fitzmyer, pp. 243-244). 
Dans le second membre du verset, VA 13 n'a pas de négation, et il n'a pas

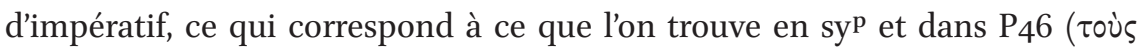

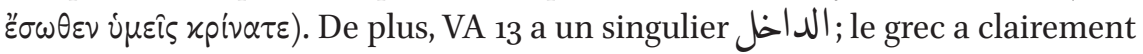
un pluriel, tandis qu'il y a une possible ambiguïté dans syp. VA 13 semble donc ici se baser sur syp.

\section{Co 5,13}

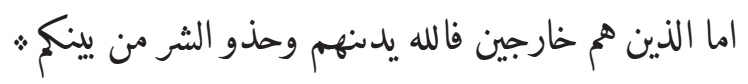

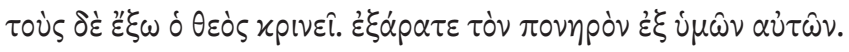

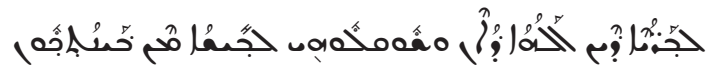

Quant à ceux qui sont à l'extérieur, Dieu les jugera, et arrachez le méchant hors de chez vous.

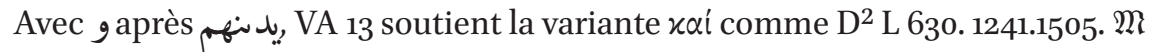
sy, contre P46 א A B C D* F G P Y 6. 33. 81. 104. 365. 1175. 1739. 1881. 2464.

\subsection{Chapitre 6}

1 Co 6,1

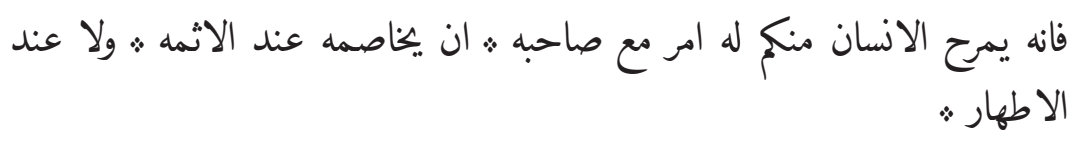

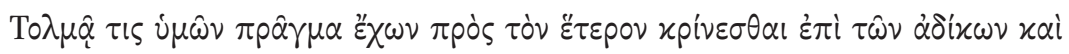

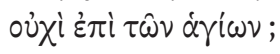

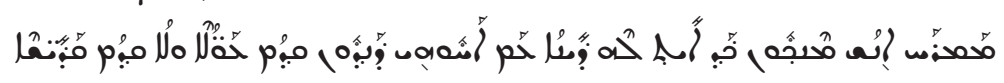

Mais l'un de vous a l'insolence, lorsqu'il a une affaire avec son prochain, de l'attaquer en justice devant les pécheurs et non devant les purs ;

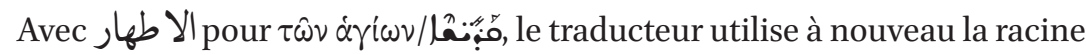
pour exprimer l'idée de sainteté (1 Co 1,30;6,1;6,2; 7,14; 7,34; 16,20). 
1 Co 6,2

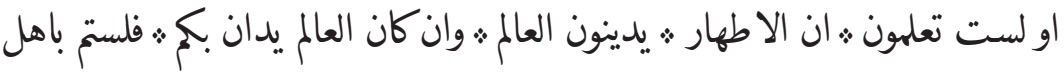

$$
\begin{aligned}
& \text { ان تقصون قصا صغار : }
\end{aligned}
$$

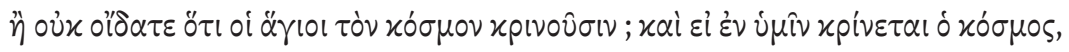

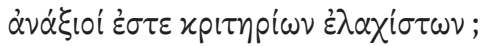

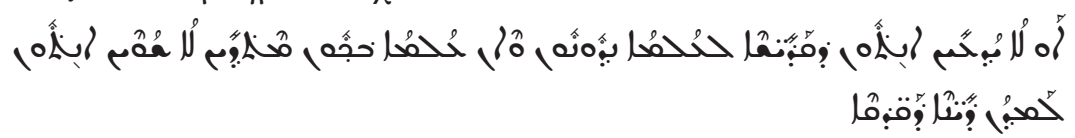

ou bien ne savez-vous pas que les purs jugent le monde? Et si c'est par vous que le monde est jugé, n'êtes-vous pas capables de décider du jugement de petits?

Nous lisons dans le manuscrit لستت; au vu du contexte, nous attendrions ou 69 .

À propos de الا طهار, voir verset précédent.

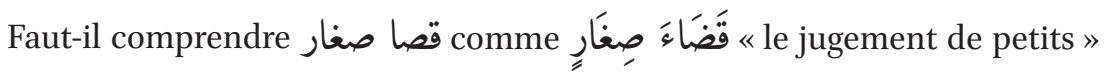
ou les petits jugements»? Bien qu'elle s'éloigne du ductus du texte, nous préférons la première option, car elle est plus proche du texte grec et de syp. $^{\mathrm{p}}$.

La formulation verbale de VA 13 ان تقصون قصا صغار est plus proche de syp

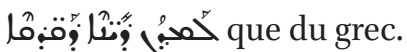

On notera que VA 13, dans ce verset et le verset suivant, utilise deux racines

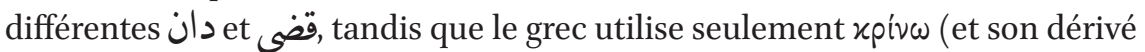
xpırńpıov) et syp la racine

\section{Co 6,3}

$$
\text { ام لا تعلمون انا علي الملايكه نقصى : فكم : بزاده على الذين هم في العالم : }
$$

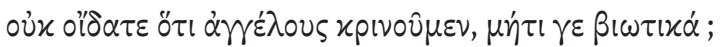

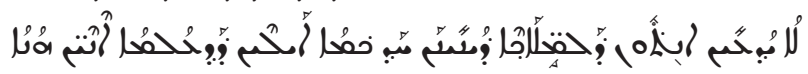

Ou bien ne savez-vous pas que nous jugeons les anges, donc combien plus ceux qui sont de ce monde?

69 Voir 2.2 Éléments de moyen arabe dans Vat. Ar. 13 (1 Corinthiens) : 22) Négation ليس. 
VA 13 est seul à avoir pl en début de verset.

La traduction de VA الذين هـم في العـالم 13 est plus proche du syriaque de syp

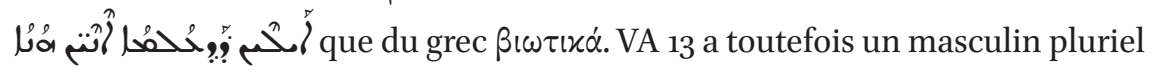
pouvant renvoyer à des hommes (mais également à des choses ${ }^{70}$ ), tandis que le neutre pluriel en grec et le féminin pluriel dans syp renvoient à des choses.

\section{Co 6,4}

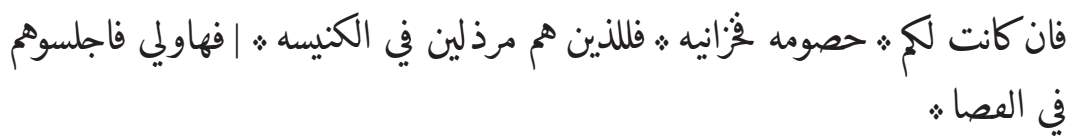

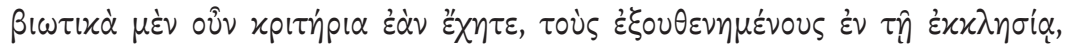

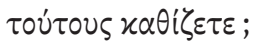

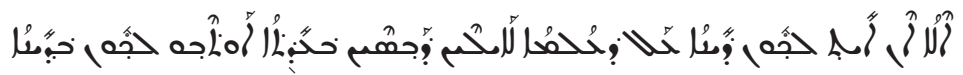

Et si vous avez une dispute d'orgueil, ceux qui sont jugés vils ${ }^{71}$ dans l'Église, établissez-les dans la magistrature.

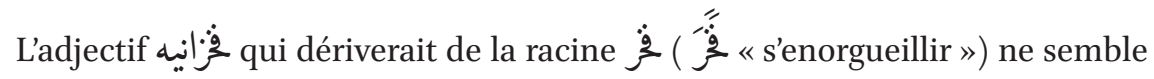
correspondre ni à syp ni au grec; le traducteur voit-il un lien entre l'orgueil et les affaires mondaines? Une autre lecture serait de corriger

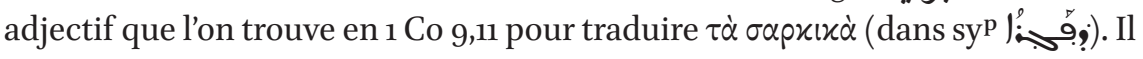
s'agirait dans ce cas d'un dispute d'ordre corporel ou charnel. Nous choisissons la première lecture pour la traduction.

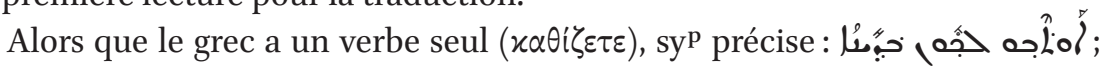
ici, VA 13 suit syp.

1 Co 6,5

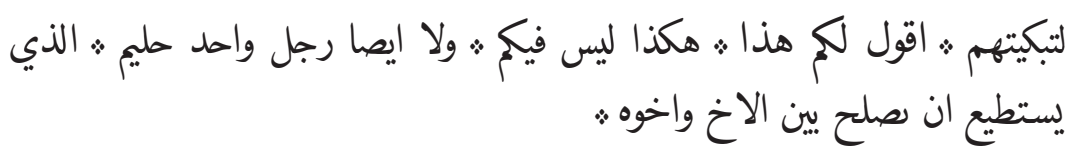

70 Voir 2.2 Éléments de moyen arabe dans Vat. Ar. 13 (1 Corinthiens) : 16) Genre et nombre.

71 Kazimirski donne comme définition de la forme IV de رذل: «rendre vil » (KAZIMIRSKI 1, p. 851); nous pensons que le sens ici est « considérer comme vil ». 


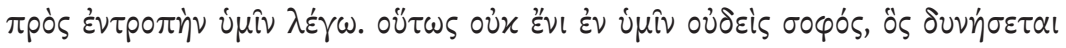

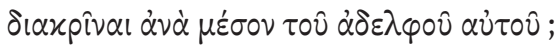

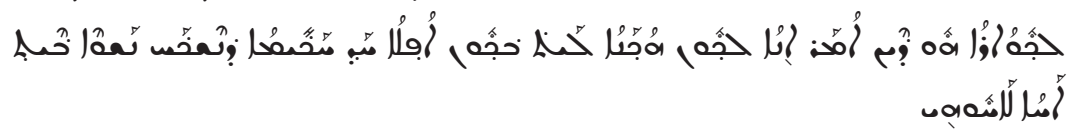

C'est comme reproche que je vous dis cela : ainsi, il n'y a parmi vous pas même un seul homme clément qui puisse réconcilier le frère et son frère,

لتبكيتهـ présente un pronom suffixe de la $3^{\mathrm{e}}$ personne du pluriel, ce qui est inattendu. Nous proposons de lire هو لتبكيت ه c'est pour un reproche que (je vous dis cela) » en supposant une erreur de copie ; cela correspondrait à la formula-

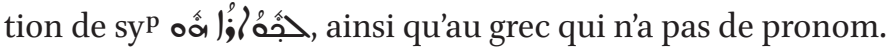

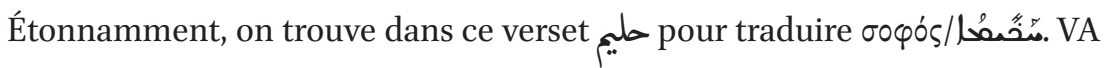

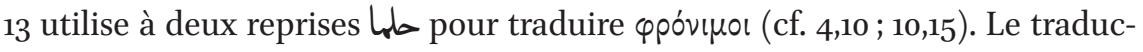
teur semble donc donner à حلي حne idée de sagesse.

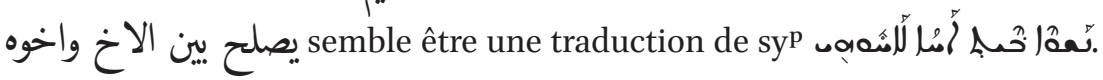
En plus de la construction, صلح contient l'idée de réconciliation, que l'on trouve aussi en syp dans la racine $/ 0 a^{72}$.

1 Co 6,6

$$
\text { ولاكى الاخ : يخاصم اخوه ث. وهذا ايصا قدام ث الذين لا يومنون ث }
$$

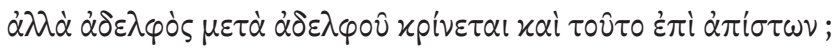

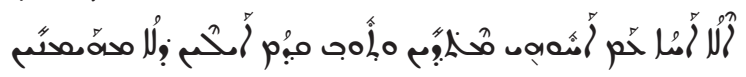

mais le frère attaque en justice son frère et cela aussi devant ceux qui ne croient pas.

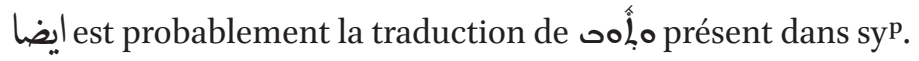

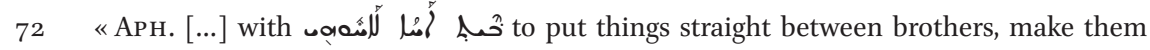
agree », Payne-Smith, p. 562 .
} 
1 Co 6,7

$$
\begin{aligned}
& \text { فالان لم هي الشحابه اذ لم حصومات عصك مع بعض ثمون اجل ايشى لا تطلمون } \\
& \text { : ومن اجل ايشى لا تمتنعون }
\end{aligned}
$$

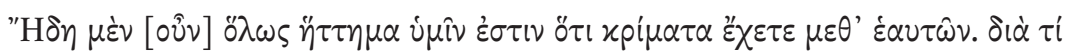

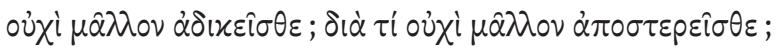

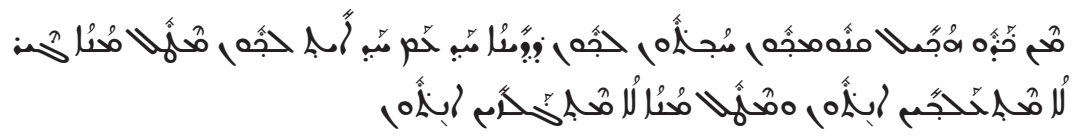

Or c'est déjà le désaveu pour vous quand vous avez des disputes les uns avec les autres. Pour quelle raison ne subissez-vous pas l'injustice? Pour quelle raison ne vous laissez-vous pas priver?

Il est difficile d'évaluer si VA 13 soutient la variante sans oขึv $\left(\mathrm{P}_{4} 6 \aleph^{*} \mathrm{D}^{*}\right.$ 6. 33 . 630. 1505. 1739. 1881) ; en effet, la conjonction ف peut s'expliquer par le $\mu \varepsilon ́ v$ uniquement, mais aussi par $\mu \dot{v}$ o ป̂v.

Le début du verset semble plus proche du grec que de syp, qui a une phrase

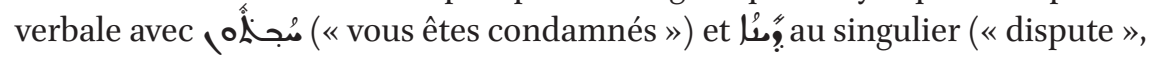
variante qui se trouve aussi en $\aleph 629$. 1241. 1881).

\section{Co 6,8}

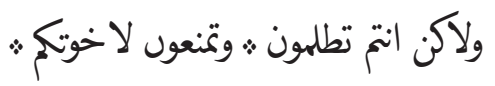

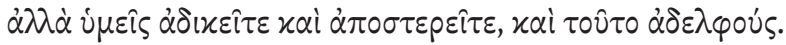

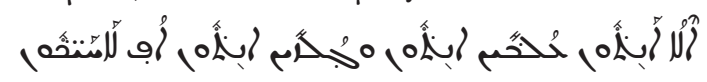

Mais vous, vous faites subir l'injustice et vous privez vos frères.

VA 13 n'a pas dans sa formulation une mise en évidence des frères, contraire-

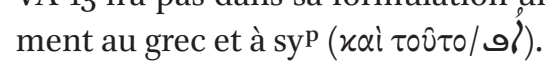

\section{Co 6,9}

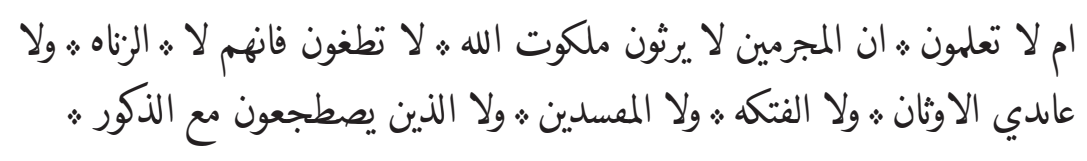




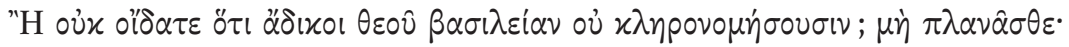

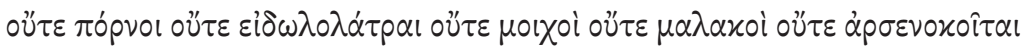

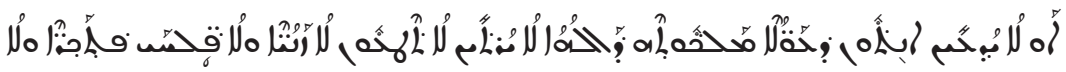
كَّ

Ou bien ne savez-vous pas que les criminels n'héritent pas du royaume de Dieu ? Ne vous égarez pas! Ni les fornicateurs, ni les adorateurs d'idoles, ni les destructeurs, ni les corrompus, ni ceux qui couchent avec des mâles,

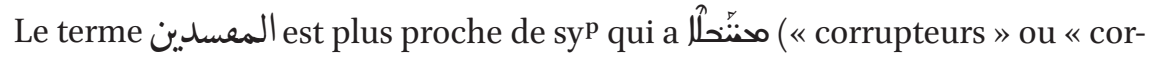
rompus ») que du grec $\mu \alpha \lambda \alpha$ xoi (« doux», « efféminés »). Dans ce verset, l'adjectif $\mu \alpha \lambda \alpha$ xoi pourrait faire référence à une forme d'homosexualité passive et

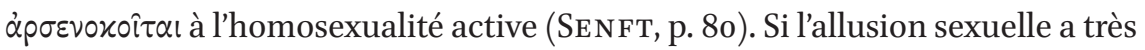
certainement été comprise, il est difficile de savoir s'il nous faut trancher ici

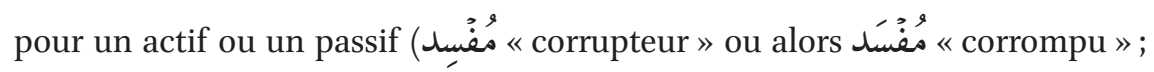
l'ambiguïté existe en syriaque). Nous optons pour la traduction passive qui irait

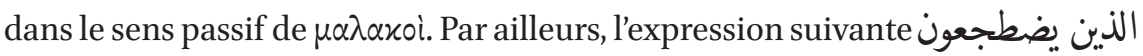

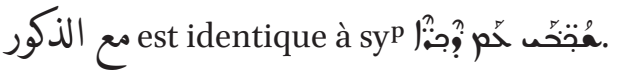

Le verbe طنى ( dépasser les limites ») était déjà utilisé au verset 3,18 ou l'on trouvait en grec $\dot{\xi} \xi \alpha \pi \alpha \tau \dot{\alpha} \omega$ et en $\mathrm{sy}^{\mathrm{p}} \mathrm{\gamma}$. Ici, le grec a $\pi \lambda \alpha \nu \alpha \dot{\alpha} \omega$, et syp à nouveau

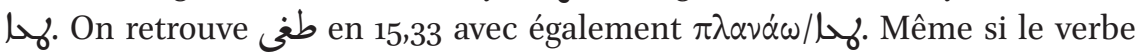
طنى a la même racine que le syriaque هحنى dans ces trois cas, nous ne pouvons dire si la traduction se base sur sy $\mathrm{p}^{\mathrm{p}}$ ou le grec, $\dot{\varepsilon}^{\prime} \xi \alpha \pi \alpha \tau \dot{\alpha} \omega$ et $\pi \lambda \alpha \nu \alpha \dot{\alpha} \omega$ pouvant aussi signifier « sortir des limites».

\section{Co 6,10}

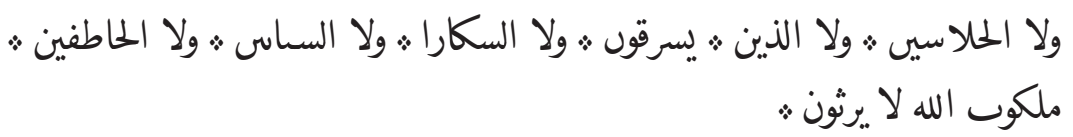

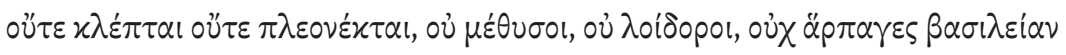

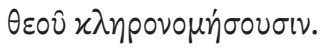

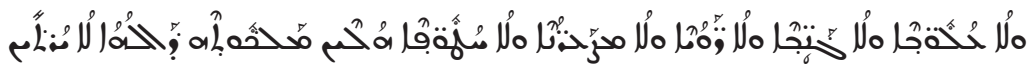
ni les chapardeurs, ni les voleurs, ni les ivrognes, ni les calomniateurs, ni les ravisseurs n'héritent du royaume de Dieu. 


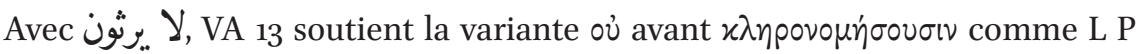

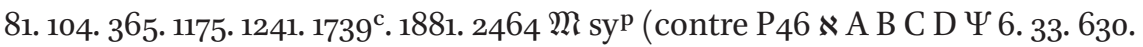
$\left.1505 \cdot 1739 * \mathrm{sy}^{\mathrm{h}}\right)$.

1 Co 6,11

$$
\text { وهاولي فذك فى المس منكم : ولاككم قد اغتسلتم وتقدستم وتبررت باسم ربنا إسوع }
$$

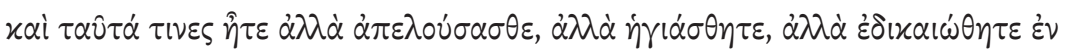

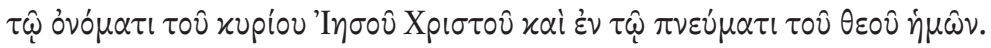

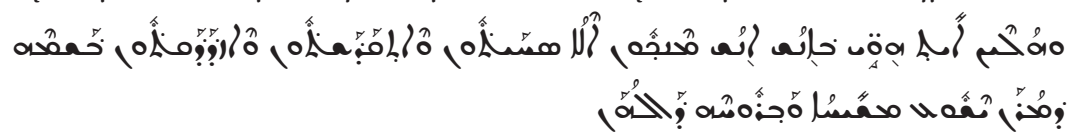

Il y a eu de telles choses parmi des gens de chez vous, mais vous avez été lavés, sanctifiés et justifiés par le nom de notre Seigneur Jésus le Christ et par l'esprit de notre Dieu.

Le début du versetsو وهاولي قد كن في اناس منكsemble traduit littéralement de syp

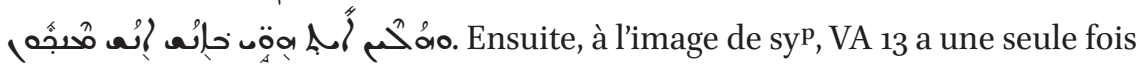
la conjonction gلا 5 , contrairement au grec qui répète $\alpha \lambda \lambda \dot{\alpha}$.

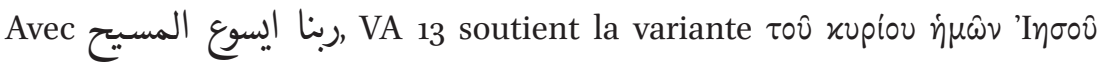

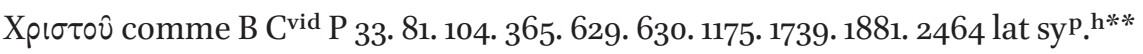

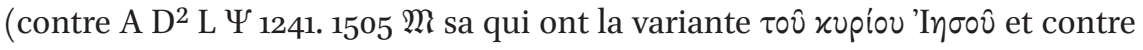

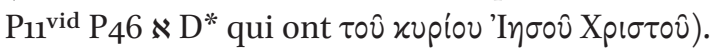

Étonnamment, nous trouvons à cet endroit dans le manuscrit une orthographe différente pour Jésus إسوع, alors que le reste du texte de 1 Co présente .سوع.

1 Co 6,12

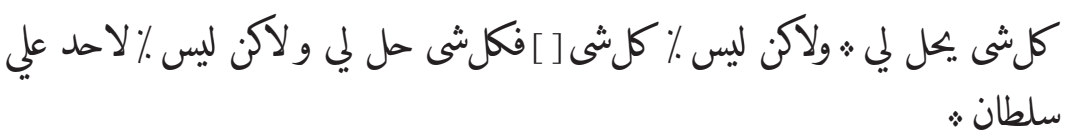

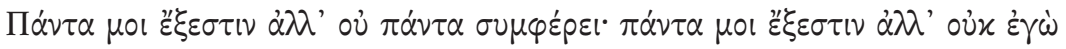
ह̇ं 


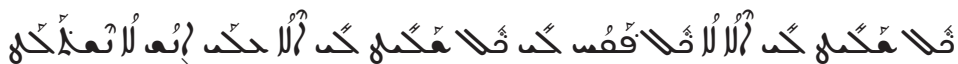

Toute chose m'est permise mais toute chose n'est pas [utile]. Toute chose m'est permise mais personne n'a de pouvoir sur moi.

Ce verset a donné lieu à une erreur de même au même, corrigée à l'aide de signes diacritiques (\%) dans la marge extérieure.

Tout comme syp, VA 13 comprend avec احد que l'acteur de la possession est une personne.

\section{Co 6,13}

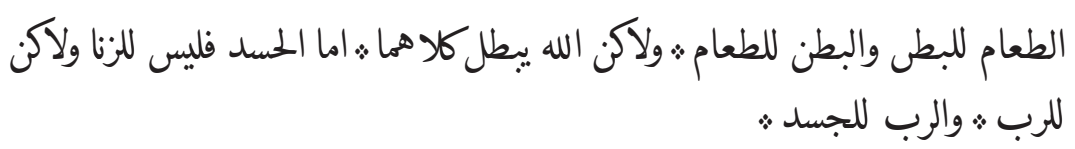

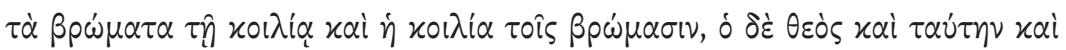

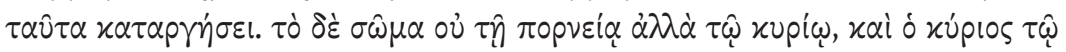
$\sigma \omega \dot{\omega} \mu \alpha \tau \iota^{\circ}$

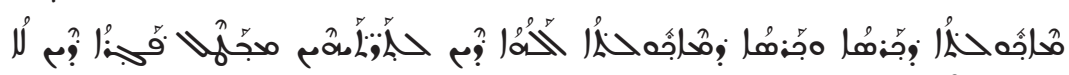

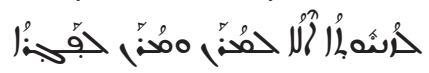

La nourriture est pour le ventre, et le ventre est pour la nourriture, mais Dieu détruit l'un et l'autre. Quant au corps, il n'est pas pour la fornication mais pour le Seigneur, et le Seigneur pour le corps,

\section{Co 6,14}

$$
\text { والله فانه اقام الرب ولنا يقيمنا بقوته : }
$$

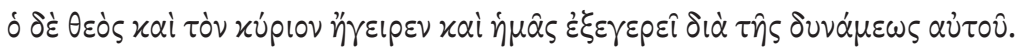

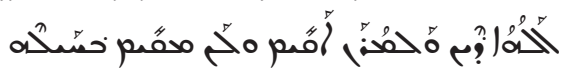

et Dieu a ressuscité le Seigneur et nous, il nous ressuscite par sa puissance.

\section{Co 6,15}

$$
\text { للازانيه : علمون ان احساددكم هى اوصال المسيح ثافاحذ اوصال المسيح واحعلها اوصال }
$$




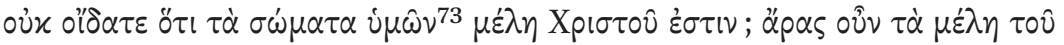

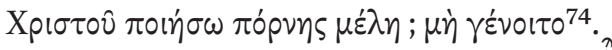

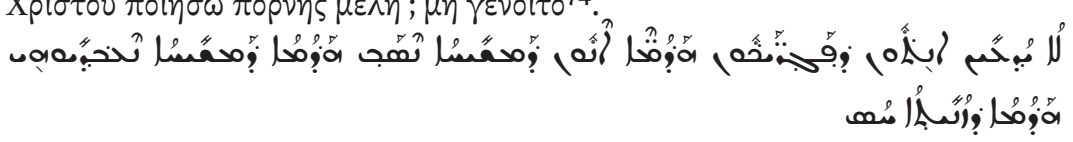

Ne savez-vous pas que vos corps sont les membres du Christ? Est-ce que je prends les membres du Christ et j'en fait des membres pour la prostituée? Que non!

Le redoublement du دans احساددمك est probablement une erreur due à un changement de ligne.

Avec احذ إن devant, VA 13 pourrait traduire oûv du texte grec, absent de syp.

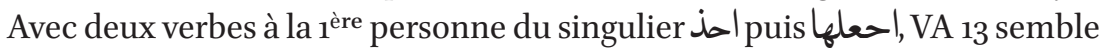
plus proche du grec, qui a un participe $\alpha^{\prime} \rho \varsigma^{75}$ puis un verbe à la $1^{\text {ère }}$ personne du singulier $\pi \circ \eta^{\prime} \sigma \omega$; syp a lui deux verbes à la $1^{\text {ère }}$ personne du pluriel (ou à la

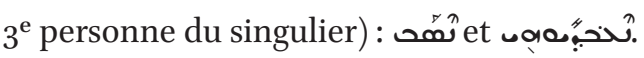

VA 13 a trois fois le pluriel اوصال: comme le grec qui a trois fois $\mu \varepsilon \dot{ }{ }^{\prime} \lambda \eta$, tandis

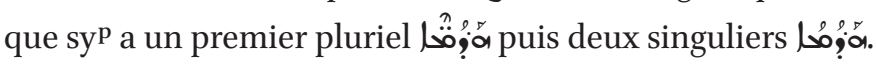

حاش a son équivalent dans syp مُ .

1 Co 6,16

ام لا بعلمون ان الذى يتبع الرانيه : فانه حسد واحد ث.انه يقول 76 بانهما يكونان كلاهما

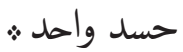

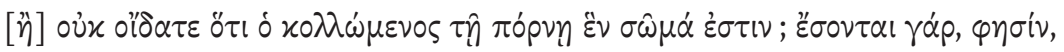

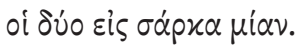

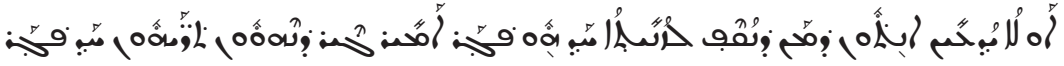

73 Quelques témoins ont $\tau \dot{\alpha} \sigma \dot{\omega} \mu \alpha \tau \alpha \dot{\eta} \mu \hat{\omega} \nu$ ( $\aleph^{*}$ A), une variante qui n'est pas soutenue par VA 13 .

74 Quelques témoins ont $\grave{\eta}$ en début de verset (F G ar) ainsi qu'au début du deuxième membre de phrase $(F(G))$, variante qui n'est pas soutenue par VA 13 .

75 Avec deux verbes, VA 13 soutient la variante äpas (P46 א A B C D K L 33. 365. 1505. 1739*.

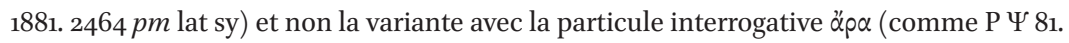
104. 630. 1175. 1241. 1739c. 2495 pm), même si VA 13 a bien le préfixe interrogatif I.

76 Blau note cette manière d'exprimer « on dit», « il est dit »: « [The general subject] may be expressed inter alia : [...] By means of the third person singular active of the verb qâl », BLAU, § 368.1. 
Ou bien ne savez-vous pas que celui qui suit la prostituée, il est un seul corps? On dit : ils seront les deux un seul corps ;

Avec pl en début de verset, VA13 soutient la variante $\ddot{\eta}$ comme « A B C F G P 33. 81. 104. 365. 630. 1175. 1241. 1505. 1739. 1881. 2464 pm lat syp (contre P46 D K L Y $\left.6 \mathrm{pm} \mathrm{r} \mathrm{sy}^{\mathrm{h}}\right)$.

\section{$1 \operatorname{Co~6,17}$}

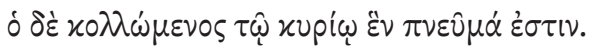

$$
\text { اما الدي يتبع الرب |فانه روح واحد : f. 107v }
$$

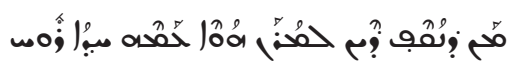

mais celui qui suit le Seigneur, il est un seul esprit.

syp est seul à avoir حمُّم

\section{Co 6,18}

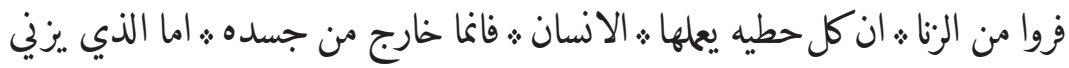
فانه يكطا بجسده :

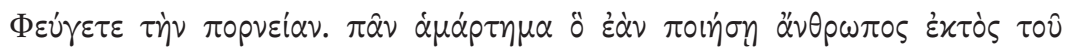

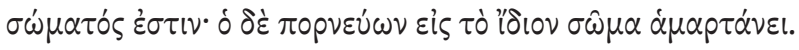

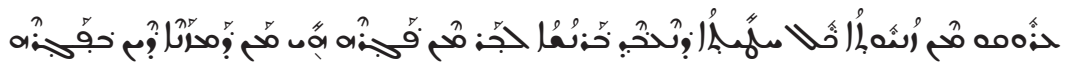

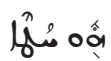

Fuyez la fornication! Tout péché que l'homme fait, c'est seulement à l'extérieur de son corps, mais celui qui fornique, il pèche en son corps.

\footnotetext{
1 Co 6,19

ام لا تعلمون : ان احسادم ؛ فانها هيكل لروح القدس ؛ الذي فيكم ؛ الدى قبلتم من

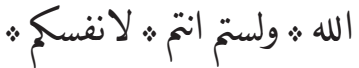

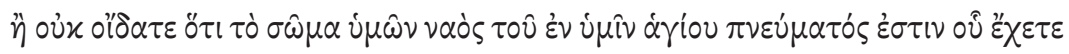

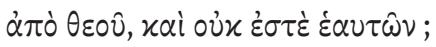




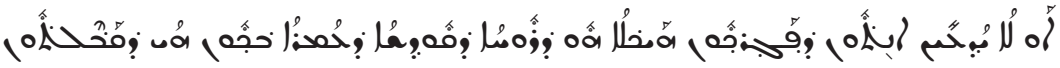

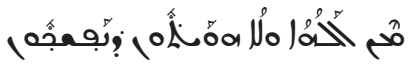

Ou bien ne savez-vous pas que vos corps sont le temple de l'Esprit saint qui est en vous que vous avez reçu de Dieu, et que vous n'êtes pas à vous-même?

Avec le pluriel احسادك:, VA 13 soutient la variante $\tau \dot{\alpha} \sigma \dot{\omega} \mu \alpha \tau \alpha$ comme Ac L $\Psi$ 33. 81. 104. 365. 1175. 1505. 1881. 2464 pm sy bo (contre P46 א A* B C D F G K P 630. 1241. $\left.1739 \mathrm{pm} \mathrm{b} \mathrm{r} \mathrm{syp} \mathrm{sa} \mathrm{bo}^{\mathrm{mss}}\right)$.

Alors que le grec a uniquement èv ن́ $\mu \hat{\imath} v$, suivi par VA 13 avec فيك plus un participe حُمحفُ احثَّه.

À propos de لروح القدسم: voir point 4.3.5. Autres termes.

\section{Co 6,20}

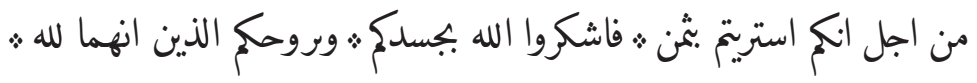

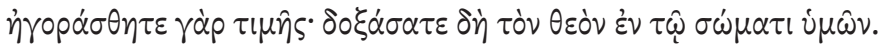

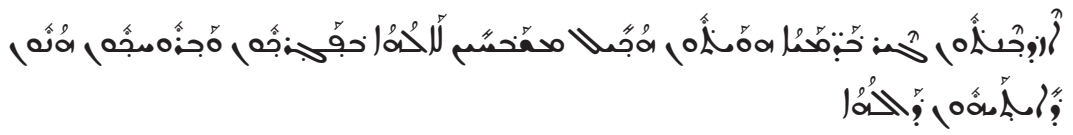

Car vous avez été acheté à un prix ; remerciez Dieu en votre corps et en votre esprit qui sont à Dieu.

Avec وبروحكك الذين انهما له له 13 soutient la variante qui présente à la fin du

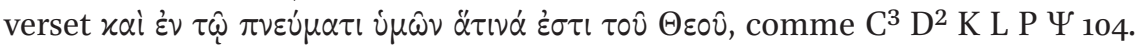
365. 630. 1241. 1505. 1739 ${ }^{\mathrm{mg}}$. 1881. 2464. $\mathrm{M}_{\text {vg }}{ }^{\mathrm{ms}}$ sy (contre P46 א A B C* D* F G 33. 81. 1175.1739 $9^{\text {txt }}$ lat co).

\subsection{Chapitre 7}

$1 \operatorname{Co~} 7,1$

$$
\text { فاما من اجل الدى كبتت به الى ث فانه حسن للرجل ان لا يقرب امراه ؛ }
$$

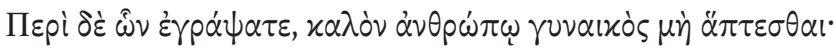

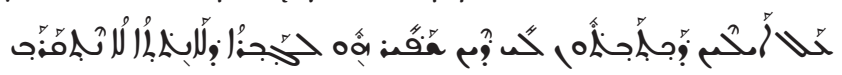


Mais à propos de ce que vous m'avez écrit : il est bon pour l'homme de ne pas approcher une femme.

Avec الم VA 13 soutient la variante grecque $\mu$ or comme A D F G K L P Y 104. 365. 630. 1175. 1241. 1505. $\mathrm{M}$ ar b vg ${ }^{\mathrm{cl}}$ sy co (contre P46 « C 33. 81. 1739. 1881. 2464. $\left.\mathrm{r} \mathrm{vg}^{\mathrm{st}}\right)$.

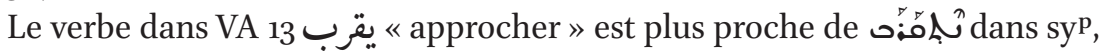
qui signifie aussi « approcher », que de $\ddot{\alpha} \pi \tau \varepsilon \sigma \theta \alpha l$ « toucher», «prendre».

\section{Co 7,2}

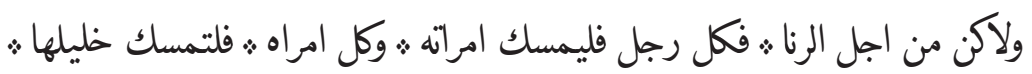

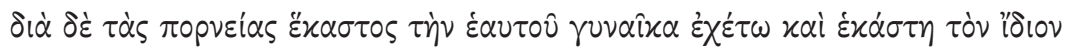

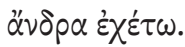

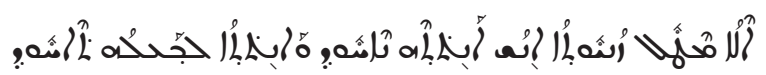

Mais à cause de la fornication, que chaque homme prenne sa femme, que chaque femme prenne son ami,

Dans les passages portant sur le mariage (7,1-16.25-40), le vocabulaire est restreint dans le texte grec: pour homme/époux, on trouve àvíp et pour femme/épouse ruvín. Dans syp, homme/époux est exprimé par (cf. 7,1.3.4.11.14.16.25.28.36) ou بح (cf. 7,2.3.4.10.11.13.34.39), et femme/ épouse par lî.? VA 13 varie encore davantage le vocabulaire. On trouve pour homme/époux : رجل (cf. 7,2.3.4.11.14.16.36), زوج (cf. 7,13.16.34.39) et (cf. 7,2.4.10.13.34); pour femme/épouse : مرل/ (cf. 1,1,2.2.3.4.10.12.13.14.16.27·32.33·3 خليلة (cf. 2,3.4.11). Il est difficile d'expliquer cette variation dans le vocabulaire. On soulignera l'utilisation de خليل خليل/خليلة qui signifie «ami/amie », mais aussi «amant/amante»(KAZIMIRSKI 1, pp.608-609). Ce choix lexical a pour conséquence que les v. 7,2-4 ne semblent pas nécessairement liés au cadre conjugal ; le v. 7,10 montre que خليل /خليلة semblent bien se référer au mariage ${ }^{77}$.

77 Dans trois cas, nous ne lisons pas de point diacritique sur le $\dot{乙}$, voir حليل en 7,4 et 7,11 et حليلة en 7,11. Avons-nous ici une troisième variation dans le vocabulaire, حليل et son équivalent féminin signifiant «celui qui est lié», donc l'époux/-se? L'utilisation plus fréquente de خليل associé à l'usage peu conséquent des points diacritiques dans notre manuscrit laisse pense que non. Toutefois, حليل pourrait faire écho au verset 7,27, ou la racine حلّ est déclinée au maṣdar et participe passif. 
En utilisant خليل en fin de verset, le traducteur « brise la symétrie » dans la phrase.

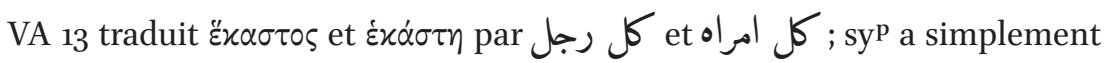
ใُ et lựil.

\section{Co 7,3}

$$
\text { والرجل لخليلته : فليصنع ما يحت عليه : وكدلك المره للرجل : }
$$

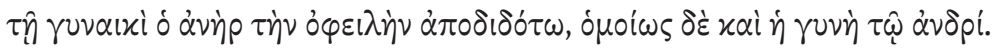

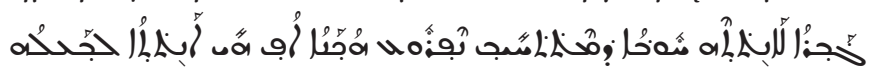

et que l'homme fasse pour son amie ce qu'il lui faut faire, et de même aussi la femme pour l'homme.

On retrouve le terme, ici au féminin, خليلة (voir nos remarques en 7,2). On remarquera qu'ici aussi, la phrase n'est pas symétrique.

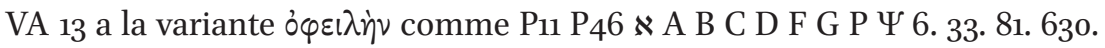

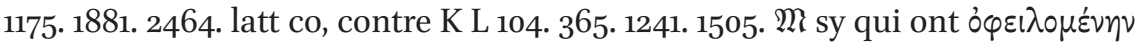

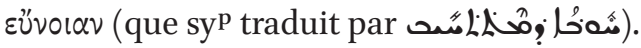

A la fin du verset, syp a un pronom possessif absent du grec et de VA 13.

1 Co 7,4

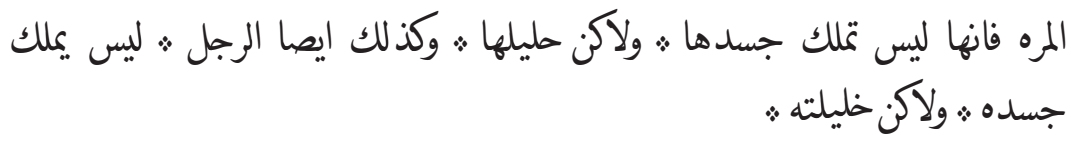

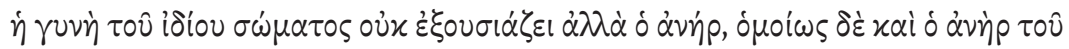

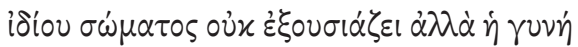

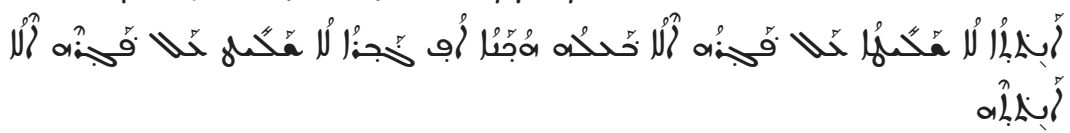

La femme, elle ne gouverne pas son corps, mais c'est son ami, de même aussi, l'homme ne gouverne pas son corps, mais c'est son amie.

Ici, خليله sont utilisés de manière symétrique pour l'homme et pour la femme (voir nos remarques en 7,2). On notera aussi les pronoms possessifs, présents en syp. 


\section{Co 7,5}

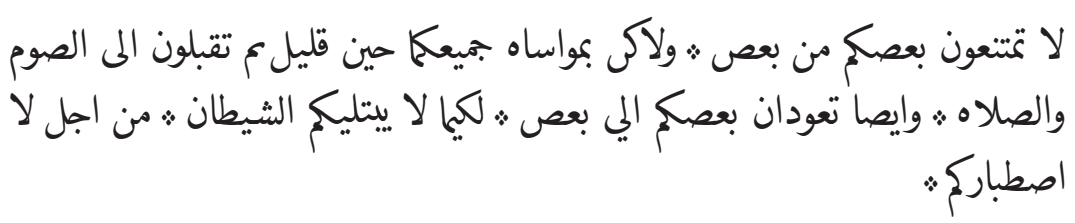

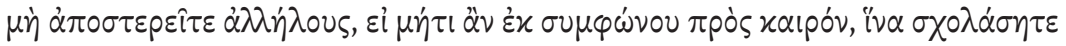

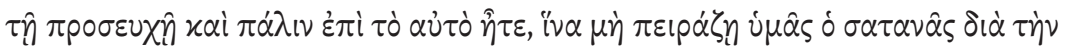
¿x $x \alpha \sigma i \alpha \nu$ i $\mu \omega \hat{\omega}$.

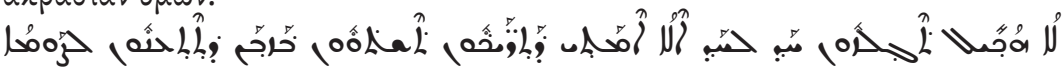

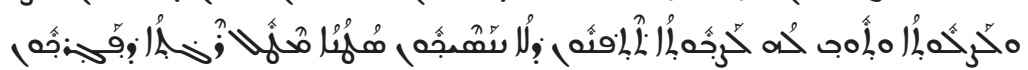

Ne vous abstenez pas l'un de l'autre, sauf dans un réconfort mutuel, pour peu de temps pour vous adonnez au jeûne et à la prière, et à nouveau vous reviendrez l'un vers l'autre pour que le Satan ne vous tente pas à cause de votre impatience.

" جميعك " vous deux ensemble " est certainement une traduction de syp qui a

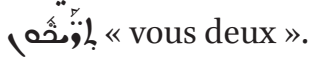

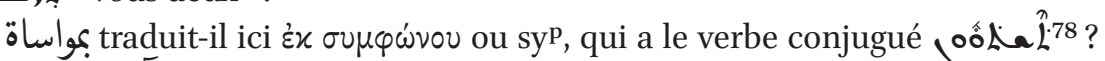
Le verbe آس آس (III) signifie « consoler » et s'éloigne de l'idée de consentement mutuel. On trouve aussi بمواساة dans SA 151, ce que Staal traduit par: «in charity (or by commun consent) » (cf. STAAL, vol. 2). La présence de la même expression dans un texte traduit du syriaque indique peut-être que le traducteur se base ici sur syp.

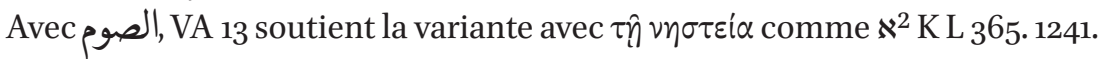
1505. M sy (contre P11 ${ }^{\text {vid }}$ P46 $\aleph^{*}$ A B C D F G P $\Psi$ 6. 33. 81. 104. 630. 1175. 1739. 1881. 2464. latt co).

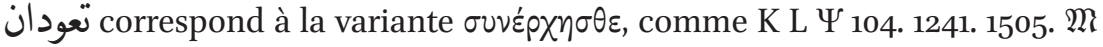

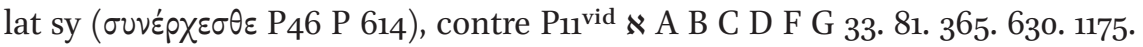
1739. 1881. 2464. b r.

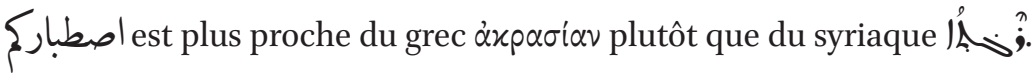

À propos de الشيطان, voir 4.3.5 Autres termes.

Avec اصطباركم, VA 13 traduit àxpariav et non pas l'expression qui se trouve en syp porps 》.

78 lea à l'ethpeal signifie, entre autres, « to be of the same opinion, to agree », PAYNE SMIth, p. 562 . 
$1 \mathrm{Co} 7,6$

$$
\text { هذا اقول : كالمغفره : ولا كالوصيه : }
$$

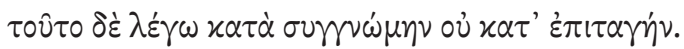

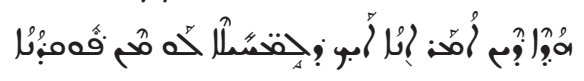

Je dis cela comme miséricorde, non comme ordre.

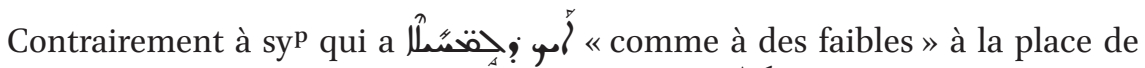
$\varkappa \tau \dot{\alpha} \sigma u \gamma \nu \omega ́ \mu \eta \nu$, VA 13 est fidèle au grec avec كالمغفره.

\section{$1 \mathrm{Co} 7,7$}

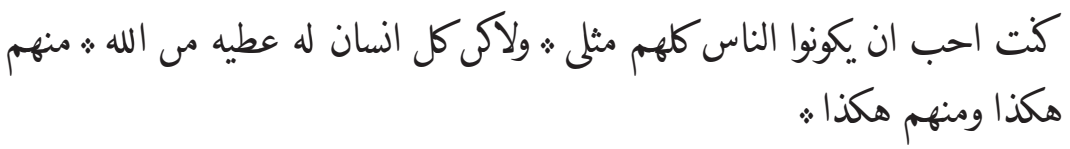

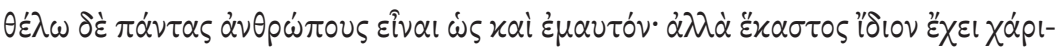

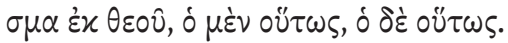

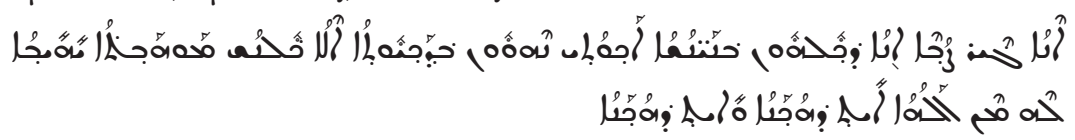

Je voudrais que tous les hommes soient comme moi, mais chaque homme a un don de Dieu, les uns ainsi et les autres autrement.

VA 13 ne soutient pas la variante grecque үáp en début de verset, comme $\mathrm{P}_{4} 6$ $\aleph^{*}$ A C D* F G 33. 81. 826. 629. 2464. it vgst (contre $\aleph^{2}$ B D $^{1}$ K L P $\Psi$ 104. 365. 630. 1175. 1241. 1505. 1739. 1881. $\left.\mathrm{M} \mathrm{vgl}^{\mathrm{cl}} \mathrm{sy}\right)$.

VA 13 a ici كت احب, un parfait qui a certainement une tendance conditionnelle, une interprétation qui s'éloigne des verbes $\theta \varepsilon \dot{z} \lambda \omega$ (indicatif présent) et $\left.\right|_{3} ^{\lambda_{j}}$ (participe actif).

$1 \operatorname{Co} 7,8$

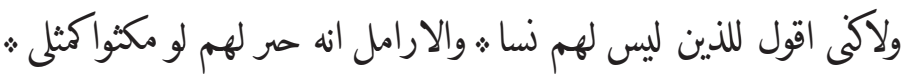

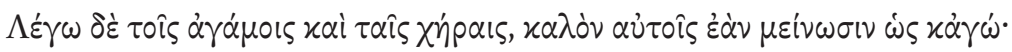

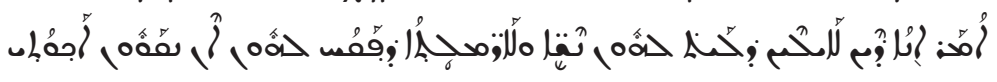


Mais je dis à ceux qui n'ont pas de femmes et aux veuves ${ }^{79}$ : il est bien pour eux qu'ils restent comme moi,

\section{Co 7,9}

$$
\text { فان لم يصطبرون فليتزوجون ث فانه انفع التروبيح من ان يخترو بالشهوه ؛ }
$$

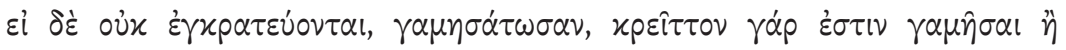
$\pi \cup \rho \circ \hat{\sigma} \theta \alpha$ l

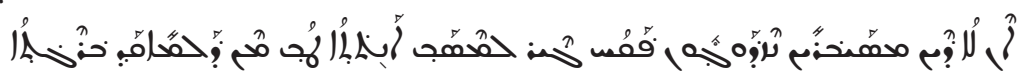

mais s'ils ne le supportent pas, qu'ils se marient ; le mariage est plus utile que de brûler de convoitise.

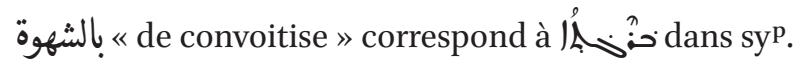

Dans le texte, صبر à la forme viII traduit le fait de supporter une épreuve, d'endurer $^{80}$ (voir 9,$12 ; 9,25 ; 10,13 ; 13,7$ ). La même racine est présente en syp avec محمَّحن:

\section{$1 \operatorname{Co~} 7,10$

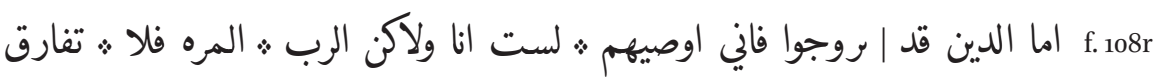 خليلها}

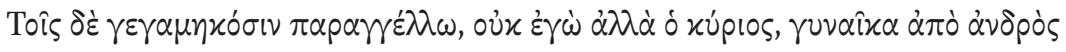
$\mu \grave{\eta} \chi \omega \rho เ \sigma \theta \hat{\eta} \nu \alpha \iota$,

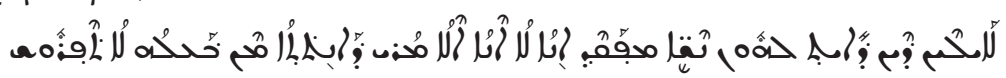

Quant à ceux qui sont déjà mariés, je leur prescris, non pas moi mais le Seigneur: que la femme ne quitte pas son ami.

خليل Dans le passage suivant (7,10-13), on retrouve une nouvelle fois le terme (voir 7,2). Ici, le contexte est clairement celui du mariage : خليلة est (خليل est donc aussi compris dans le sens d'époux.

79 peut être le pluriel de veuf ou de veuve.

80 On associe surtout à la racine ص la patience, mais aussi l'endurance. À la forme VIII, Kazimirski propose la traduction : «Être patient, constant, persévérant », KAZIMIRSKI 1, p. 1306. 
1 Co 7,11

وان هى فارقته : فلتبقا بغير تزوبه ء ام تراصى حليلها ؛ والرجل فلا يطلق حليلته ث.

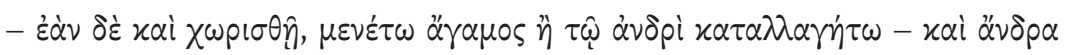

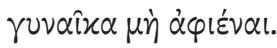

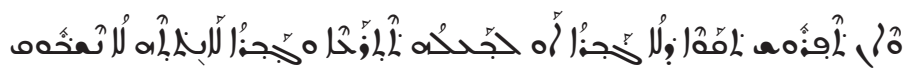

et si elle l'a quitté, qu'elle reste dans le célibat ou qu'elle cherche à plaire à son ami, et que l'homme ne répudie pas son amie.

Au verset précédent, le grec exprime l'abandon de l'homme par la femme avec le verbe $\chi \omega \rho \iota \sigma \hat{\eta} \nu \alpha \iota$ et ici l'abandon de la femme par l'homme par le verbe

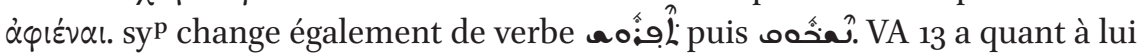
يطلق puis tes trois langues expriment l'idée que, dans le premier cas, la femme s'éloigne de son époux tandis que dans le second cas, la femme est renvoyée.

À propos de حليل, voir notre note en 1 Co 7,2.

\section{Co 7,12}

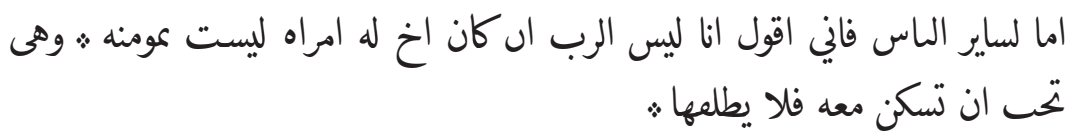

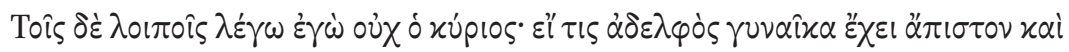

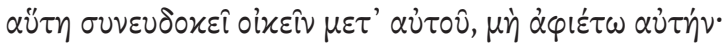

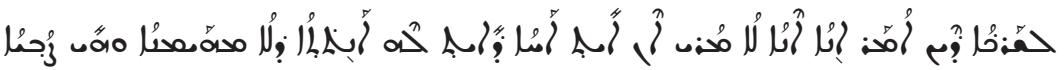

$$
\begin{aligned}
& \text { 草 }
\end{aligned}
$$

Au reste des gens, je dis, moi, non le Seigneur : si un frère a une femme qui n'est pas croyante et qui souhaite habiter avec lui, qu'il ne la répudie pas,

\section{Co 7,13}

$$
\text { والمره التى لها روج ليس مومن ث وهو يحب ان يسكن معها ؛ فلا تترك خليلها ؛ }
$$

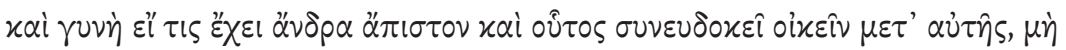

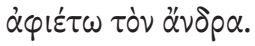

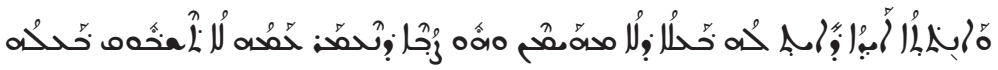


et la femme qui a un mari qui n'est pas croyant et qui souhaite vivre avec elle, qu'elle n'abandonne pas son ami.

Aux v. 7,10-11, le grec, comme syp et VA 13, utilise un verbe différent pour exprimer la fin du mariage quand le sujet est l'homme ou la femme. Aux v. 7,12-13,

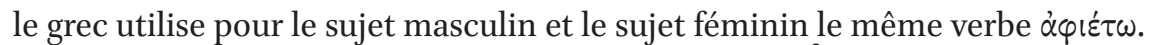
syp a également deux fois le même verbe deux verbes différents يطلت puis gardant « l'inégalité » entre l'homme qui rejette et la femme qui abandonne. Il s'agit d'un mot technique qui, dans le vocabulaire religieux musulman, ne peut avoir que l'homme comme sujet, ce qui peut expliquer ce déséquilibre ${ }^{81}$.

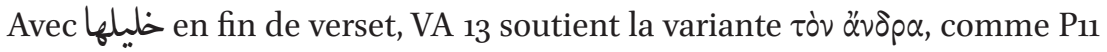
P46. $\boldsymbol{\aleph}^{(*)}{ }^{1}$ A B C D F G 33. 81. 1175. 1739. 2464. latt syP co (contre K L P Ч 104. $365.630 .1241 .1505 .1881 . \mathrm{M} \mathrm{sy}^{\mathrm{h}}$ qui ont un pronom); VA 13 a en plus un pronom possessif, que l'on trouve aussi dans syp حُححْه.

\section{Co 7,14}

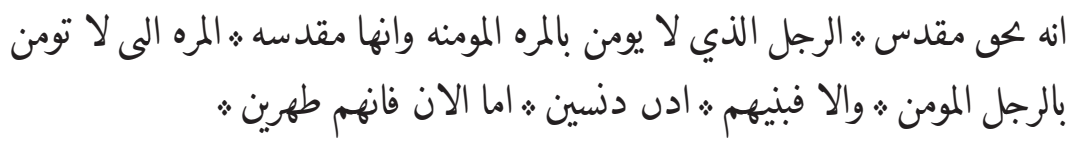

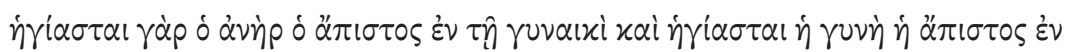

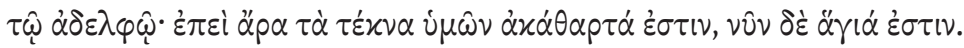

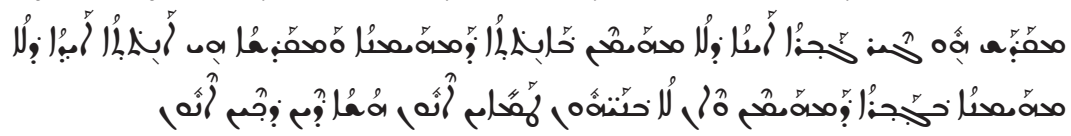

En vérité, l'homme qui ne croit pas est sanctifié en la femme croyante et la femme qui ne croit pas est sanctifiée en l'homme croyant, sinon leurs fils seraient alors impurs, mais maintenant ils sont purs.

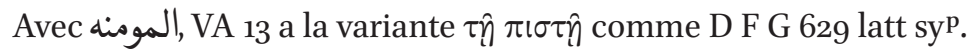

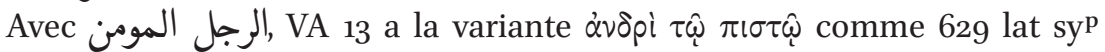

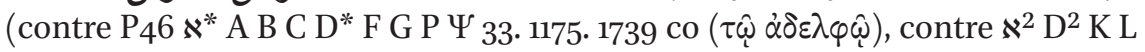

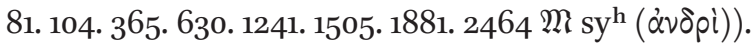

81 Мотzкі Harald, « Marriage and Divorce », in : Encyclopaedia of the Qur'ān, Washington, Brill Online, 2016. En ligne : <http://referenceworks.brillonline.com/entries/encyclopae dia-of-the-quran/marriage-and-divorce-EQCOM_oo111>, consulté le 23.03.2016. 


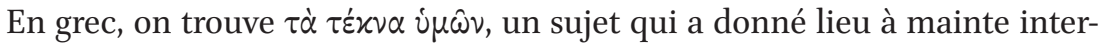

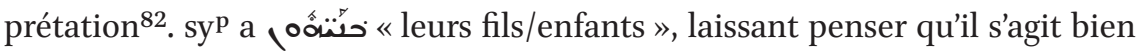
des enfants d'un couple mixte évoqué au début du verset. VA 13 a aussi بنئم « leur fils/enfants », suivant probablement le texte de syp.

On retrouve ici avec طهر pour traduire des dérivés de a la racine $(1,30 ; 6,1 ; 6,2 ; 7,34 ; 16,20) ;$ notons que syp a aussi l'adjectif « pur »

\section{$1 \operatorname{Co~7,15}$}

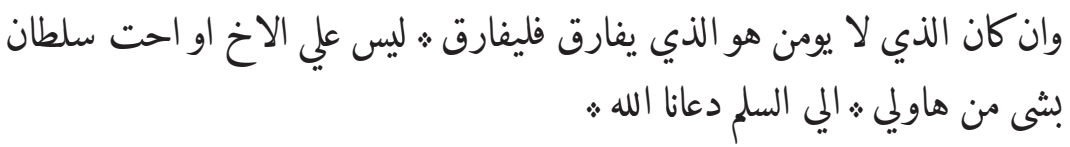

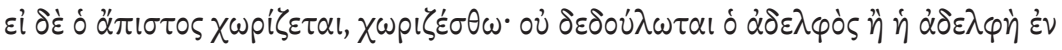

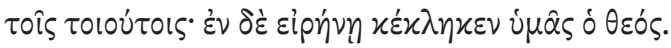

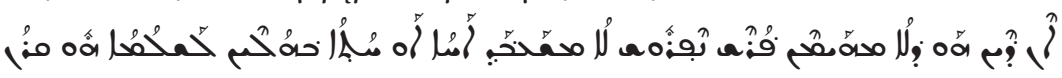
إخ

Et si c'est celui qui ne croit pas qui se sépare, qu'il se sépare, il n'y a sur le frère ou une sœur d'autorité en rien venant de ceux-là ; Dieu nous a appelés à la paix.

« une sœur » est indéfini alors qu'il y a un article en grec $\dot{\eta} \alpha \dot{\delta} \varepsilon \lambda \varphi \eta \dot{~ e t ~ q u e ~}$ خ le frère » est lui défini.

Avec دعانl, VA 13 soutient la variante grecque avec le pronom $\dot{\eta} \mu \hat{\alpha} \varsigma$, comme P46 א ${ }^{2}$ B D F G L Y 33. 104. 365. 630. 1241. 1505. 1739. 1881. 2464. M latt sy sa (contre $\aleph^{*}$ A C K 81. 326. 1175. bo).

\section{Co 7,16}

فاذا نعلمين ايها المراه ان تحلصين زوجك ث. او ماذا نعلم ابه الرجل ان تخلص امراتك

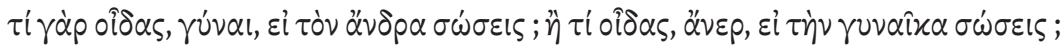

82 «Quand Paul dit: vos enfants, s'adresse-t-il aux couples mixtes ou à des couples chrétiens? S'agit-il d'enfants nés avant la conversion des parents ou d'enfants nés après? De grands enfants non baptisés parce que restés païens ou d'enfants encore petits ? Toutes les suppositions ont été faites et discutées [...] », SENFT, p. 93.

83 L'adjectif avec l'orthographe طَّهر est attesté par KAZIMIRSKI 2, p. 114. 


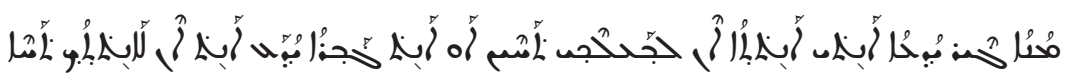
Qu'en sais-tu, ô femme, si tu sauves ton mari ou qu'en sais-tu, ô homme, si tu sauves ta femme?

On attendrait pour la particule vocative au féminin ايتها et pour le masculin ايها (KAZImirski 1, p. 72.); ici, la règle semble être l'ajout du pronom suffixe correspondant. Il pourrait aussi s'agir d'une scriptio defectiva (ايها = ايه) (BLAU, § 92), mais comment expliquer alors le féminin ايها ? On retrouve la particule en 15,36 pour un masculin singulier et إيها en 15,31, pour un masculin pluriel cette fois-ci. Une possible explication serait que le pronom suffixe correspondant est ajouté à ائ cela ne joue toutefois pas dans le cas de 15,31.

\section{Co 7,17}

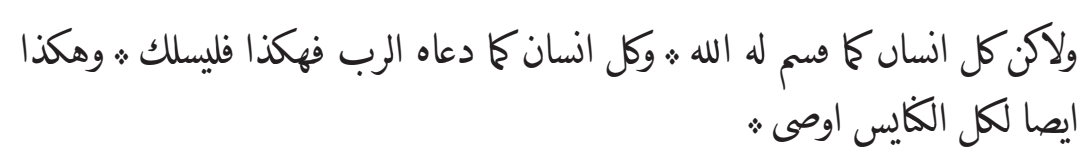

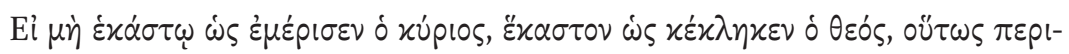

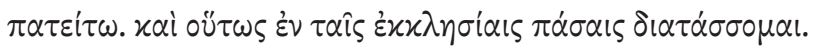

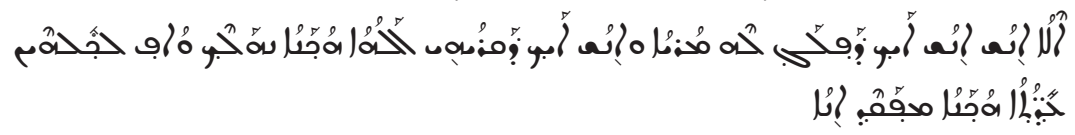

Mais que chacun comme Dieu lui a distribué, et chacun comme le Seigneur l'a appelé, se comporte ainsi, et cela je le prescris aussi à toutes les Églises.

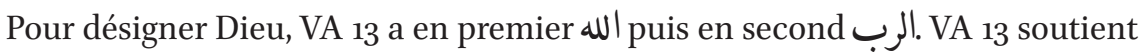

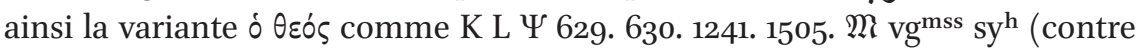
$\mathrm{P}_{4} 6$ « A B C D F G 33. 81. 104. 365. 1175. 1739. 2464. b vg syp co) et la variante $\delta$ xúplos, comme K L 630. 1241. 1505. $\mathrm{M} \mathrm{sy}^{\mathrm{h}}$ (contre $\mathrm{A}$ B C D F $\Psi$ 33. 81. 104. 365. 629. 1175. 1739. 1881. 2464. b vg syp co).

$$
\begin{aligned}
& 1 \text { Co } 7,18 \\
& \text { ان كان انسان دعى وهو مختون ث. فلا برجع الي الازعل ث. وان دعى انسان وهو في }
\end{aligned}
$$

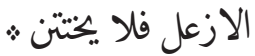




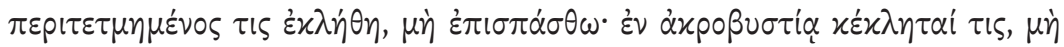
$\pi \varepsilon p(\tau \varepsilon \mu \nu \varepsilon \dot{\sigma} \sigma \omega \omega$

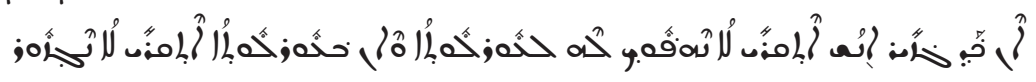

Si un homme a été appelé en étant circoncis, qu'il ne retourne pas à l'incirconcision, et si un homme a été appelé en étant dans l'incirconcision, qu'il ne se fasse pas circoncire,

Nous lisons pour l'incirconcision: الازعل. Or ce terme n'est pas attesté par les

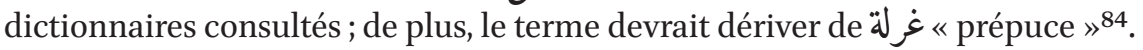
Dans le SA 151, on trouve غرغال. Il semblerait que la racine غرل et ses dérivés soit particulièrement touché par le phénomène de métathèse qui consiste à transposer des lettres dans un mot ${ }^{85}$. Le fait que ce phénomène se répète et qu'il soit présent dans deux témoins, VA 13 et SA 151, laisse penser qu'il ne s'agit pas d'une erreur mais le reflet d'une prononciation alternative en circulation.

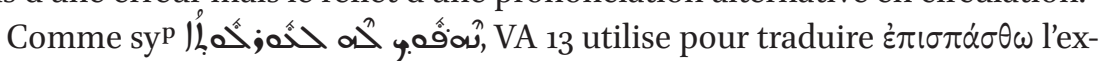
pression « retourner dans l'incirconcision » يرجع الي الازئ

1 Co 7,19

$$
\text { فان الختانه ليس بشى ث، ولا الارعل ث. ولاكن الاحتفاط بوصايا الله : }
$$

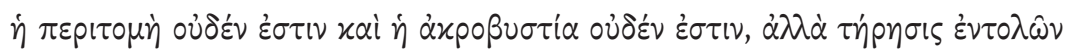
$\theta \varepsilon \circ \hat{\text {. }}$

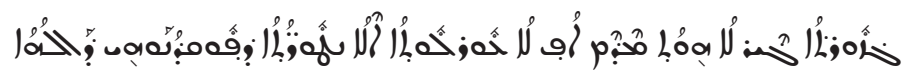

car la circoncision n'est rien, ni l'incirconcision, mais [ce qui importe, c'est] l'observance dans les commandements de Dieu.

Pour الارعل, voir 7,18.

$1 \operatorname{Co}_{7,20}$

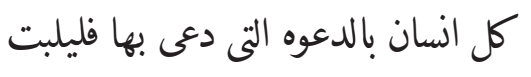

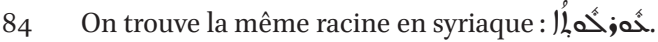

85 GACE K Adam, Arabic Manuscripts : A Vademecum for Readers, Leiden, Boston, Brill, 2009 (Handbook of Oriental Studies. Section 1, the Near and Middle East Ancient Near East 98), p. $15^{8 .}$ 


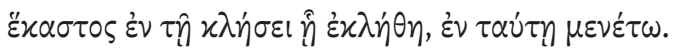

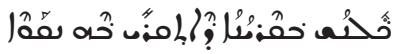

Que chaque homme reste dans l'appel dans lequel il a été appelé ;

1 Co 7,21

ان كزت دعيت وانت عبد فلا يسو عليك : ولاكن ان استطعت ان تكون حر فاخدم

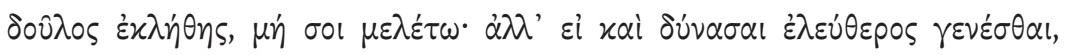
$\mu \hat{\alpha} \lambda \lambda$ ov $\chi p \hat{\eta} \sigma \alpha l$.

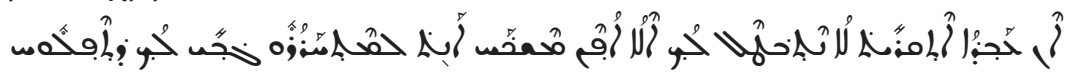

si tu as été appelé étant esclave, que cela ne t'afflige pas, mais si tu peux devenir libre, mets-toi d'autant plus au service.

Senft relève : «Le sens de $21 b$ est à vrai dire depuis toujours controversé. Deux questions avant tout doivent trouver réponse : quel est le sens de $\varepsilon i$ xai ? et quel est le complément sous-entendu de limpératif $\chi p \hat{\sigma} \sigma \alpha$ ? » (SENFT, p. 98) En ayant pour $\chi \rho \hat{\eta} \sigma \alpha l$ ( « fais usage ») le verbe خد خ se mettre au service », 《servir » à l'impératif, VA 13 donne une interprétation claire de l'esclave restant

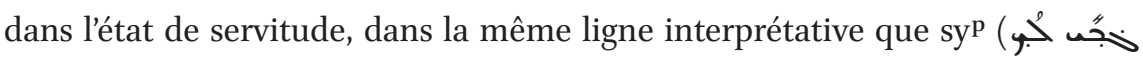

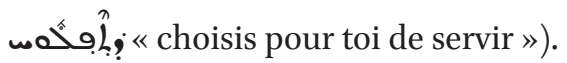

\section{Co 7,22}

اما الذي هو عبد بالرب فانه حر للرب ث | هكدا او الذي دعى وهو حر فانه عبد f.108v • لمسيح

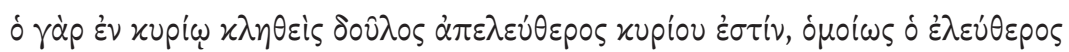

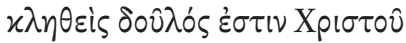

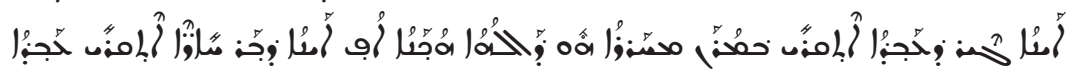

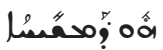

Quant à celui qui est esclave dans le Seigneur, il est libre pour le Seigneur, ou ainsi celui qui a été appelé en étant libre, il est esclave pour le Christ. 
A la place du premier $x \lambda \eta \theta \varepsilon i \varsigma /$ هو هو ment هو.

VA 13 est seul à avoir واو. Est-ce une influence de la variante présentant un $x \alpha i$ í

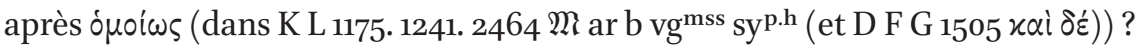

1 Co 7,23

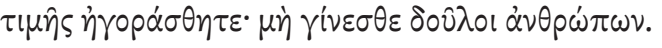

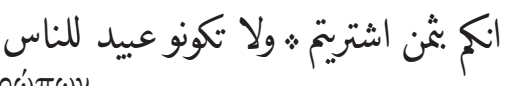

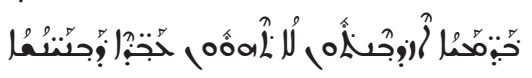

Vous avez été achetés à un prix, ne devenez pas esclaves des hommes.

1 Co 7,24

$$
\text { فكل انسان بالشى الذي [د]عى هو به ياخوه فليثبت به قدام الله : }
$$

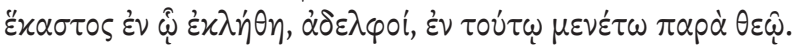

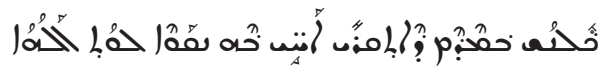

Que chaque homme, dans l'état dans lequel il a été appelé, frères, qu'il y demeure devant Dieu.

Pour s̉v

\section{$1 \mathrm{Co} 7,25$}

فاما من اخل البتوله وصيه من الرب فليس عندي ؛ ولاكى اشير ث من اجل ان الله

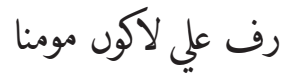

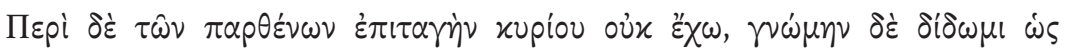

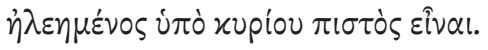

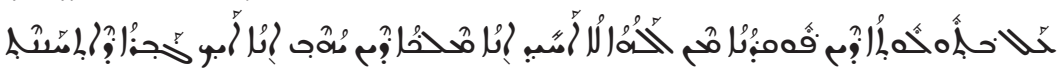

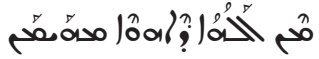

Quant à la virginité, un commandement de la part de Dieu, je n'en ai pas, mais je donne mon avis parce que Dieu m’a fait la grâce d'être croyant.

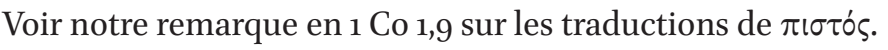




$$
\begin{aligned}
& 1 \text { Co 7,26 } \\
& \text { اني اري ان هدا حسن * من اجل شده هذا الزمان ؛ انه حر للانسان ان يكون } \\
& \text { هكداء }
\end{aligned}
$$

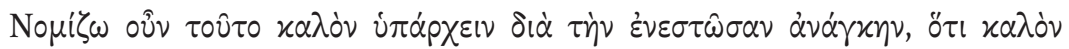

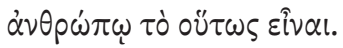

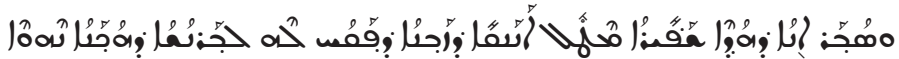

Je pense que cela est bon à cause de la violence de ce siècle, il est meilleur pour l'homme d'être ainsi.

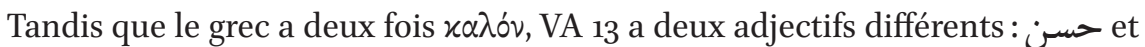

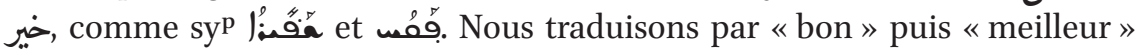
pour les différencier, خي خي habituellement, voir PÉRIER, § 210).

$1 \mathrm{Co} 7,27$

$$
\text { انت مربوط بالمره لا تريد تحل ؛ انت محلول من المره لا تريد امراه ؛ }
$$

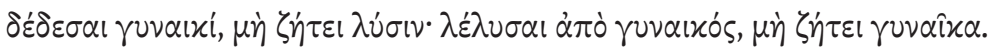

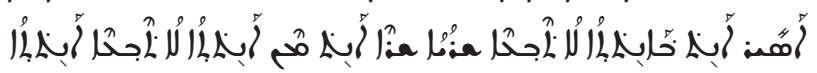

Es-tu lié à la femme ? Ne veuille [te] délier. N'es-tu pas pas lié à la femme? Ne veuille pas de femme.

$1 \mathrm{Co} 7,28$

وان تزوحت ليس تخطا ٪ وان تروحت بتوله هلس تخطا ٪وان الشده هي في الجسد

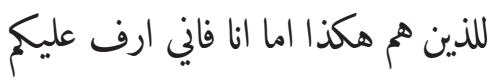

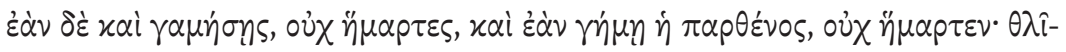

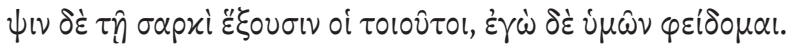

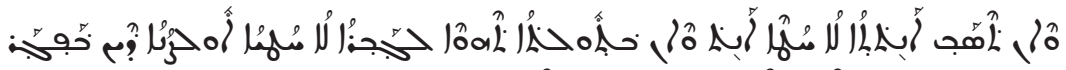

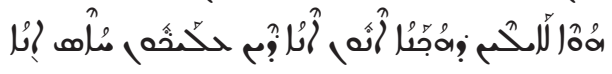


Si tu te maries, tu ne pèches pas, et si une vierge se marie, elle ne pèche pas. La violence est dans le corps pour ceux qui sont ainsi, mais moi, je vous protège ${ }^{86}$.

Ce verset a donné lieu à une erreur de même au même, corrigée à l'aide de signes diacritiques (\%) dans la marge extérieure.

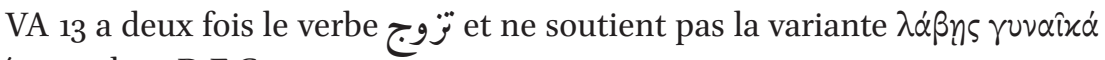
présente dans D F G syp.

On notera que VA 13 utilise شده 7,26 et 7,28, tandis que ni le grec ( $\dot{\alpha}^{2} \nu \alpha \dot{\alpha} \gamma \eta \nu$

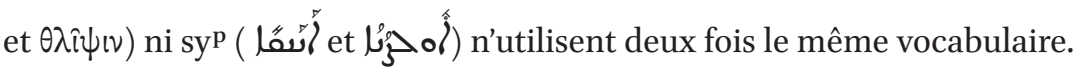

1 Co 7,29

وهدا اقول يا اخوه ث. ان الزمن قد اشتد : فالذين لهم نسا ث. فليكونوكانهم ليس لهم ؛

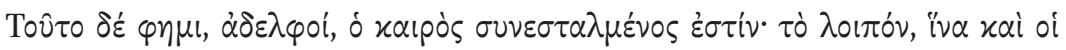

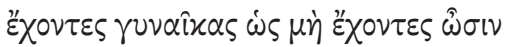

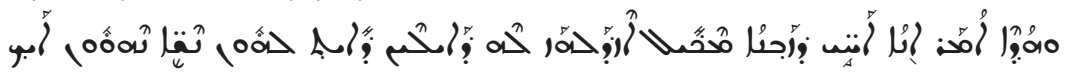

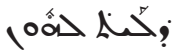

Et je dis ceci, ô frères : le temps s'est déjà aggravé ${ }^{87}$; ceux qui ont des femmes, qu'ils soient comme s'ils n'en avaient pas,

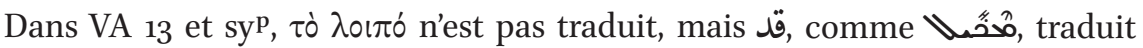
l'urgence de la situation.

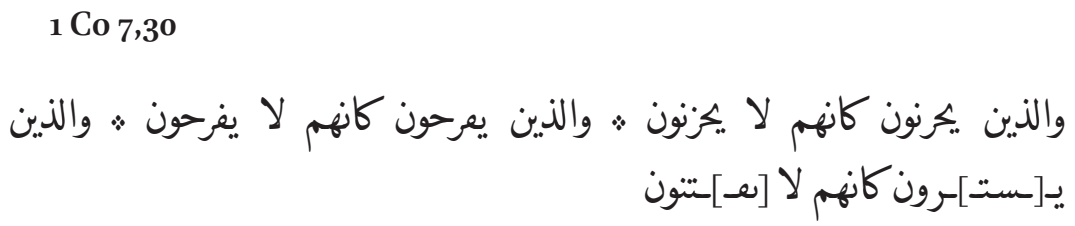

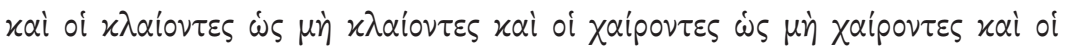

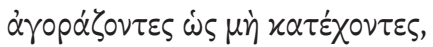

86 رقّ se construit avec على la forme IV et signifie : « étendre les ailes sur quelque chose », KAZIMIRSKI 1, p. 892.

87 Littéralement, « devenir intense », KAZIMIRSKI 1, p. 1203 ; « s'aggraver ; s'intensifier ; s'amplifier ; s'accentuer (...)», REIG, no. 2827 . 


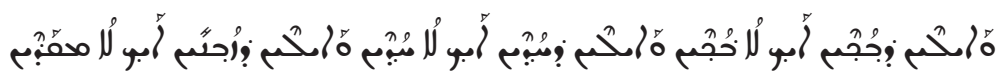
ceux qui sont tristes comme s'ils n'étaient pas tristes, ceux qui sont joyeux comme s'ils n'étaient pas joyeux, et ceux qui achètent comme s'ils ne possédaient pas,

\section{$1 \operatorname{Co~} 7,31$}

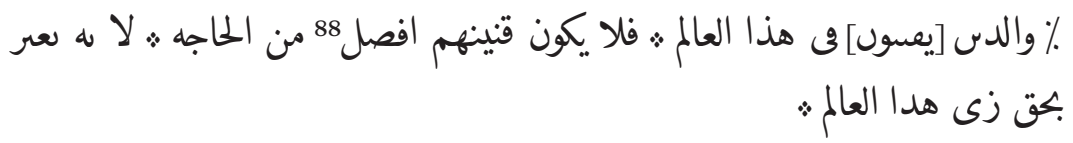

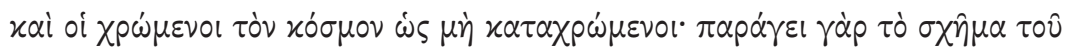

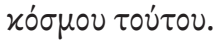

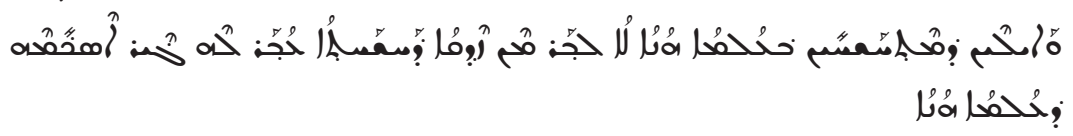

et ceux qui [possèdent] dans ce monde, que leur possession ne soit pas davantage que la nécessité, car en vérité, elle passe l'apparence de ce monde.

والد ي a été ajouté à l'aide d'un signe diacritique (\%) au dessus de la ligne. Malheureusement, le verbe est difficilement lisible. L'oubli qui a donné lieu à la correction est-il une erreur de même au même? Dans ce cas, il s'agit peutêtre du même verbe que celui qui précède, aussi difficilement lisible, que nous pensons être يقتنون. VA 13 serait alors seul à répéter « ceux qui possèdent ».

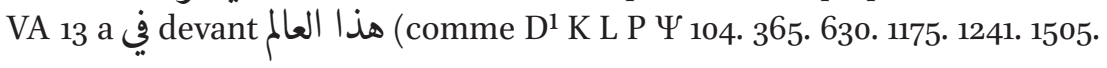
$1739^{c}$. 1881. 2464. M sy; dans le cas du syriaque, la préposition ح est en fait demandée par le verbe manol).

La suite du verset est éloignée du grec : نلا يكون قنينهم افصل من الحاجه que leur possession ne soit pas davantage que la nécessité »; cette traduction cor-

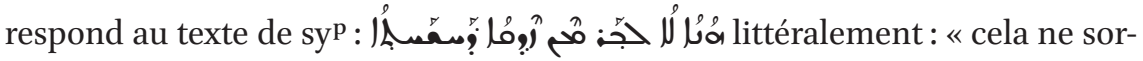
tant pas de la justesse de l'usage ».

88 À propos de افضل, voir 4,6, note 51. 
$1 \mathrm{Co} 7,3^{2}$

$$
\begin{aligned}
& \text { وواريد منكم ؛ ان تكونو بغير هم ث ان الذى ليس له امراه فانه يهتم بدوات الرب ث. } \\
& \text { كف ئ يرصى الرب : }
\end{aligned}
$$

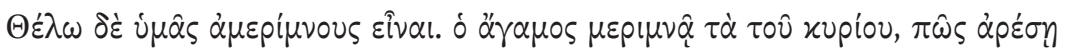
$\tau \hat{\omega}$ xupí.

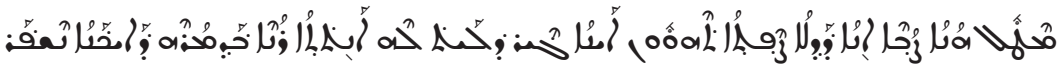

$$
\begin{aligned}
& \text { åُ }
\end{aligned}
$$

Et je vous demande quant à vous que vous soyez dans la quiétude ; celui qui n'a pas de femme se soucie des choses du Seigneur, comment plaire au Seigneur,

La répétition du g en début de phrase semble être une erreur.

syp a un le verbe «penser» $\nu^{\hat{p} ;}$; alors que le grec et VA 13 ont le verbe «se

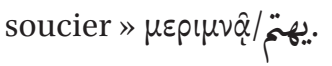

\section{Co 7,33}

$$
\text { والذى قد تروج قانه يهتم بدوات ث. الدنيا كف .رصى امراته ث. }
$$

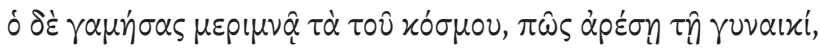

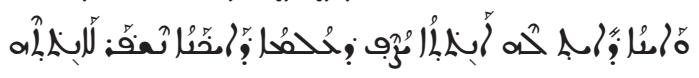

et celui qui est déjà marié, il se soucie des choses d'ici-bas, comment plaire à sa femme.

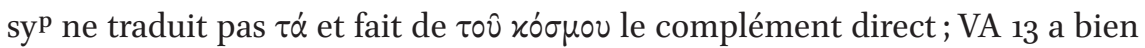
بذوات الدين.

\section{Co 7,34}

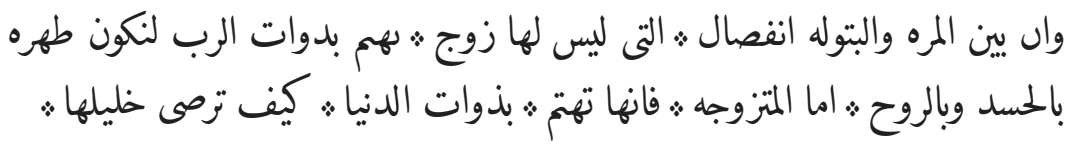

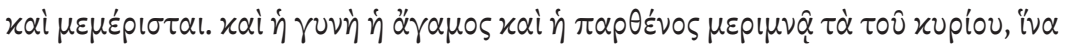

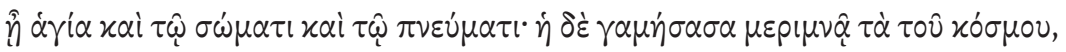

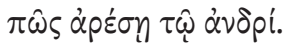




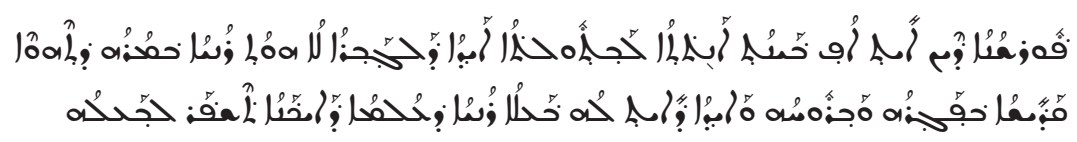

Il y a une séparation entre la femme et la vierge : celle qui n'a pas de mari se soucie des choses du Seigneur afin d'être pure dans le corps et dans l'esprit, quant à la mariée, elle se soucie des choses d'ici-bas, comment plaire à son ami.

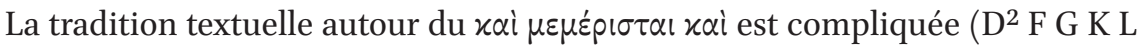

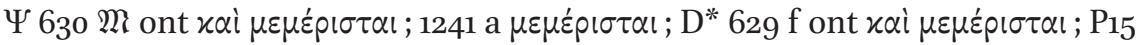

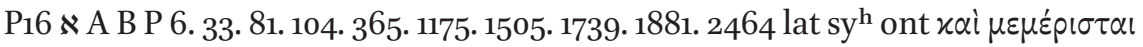

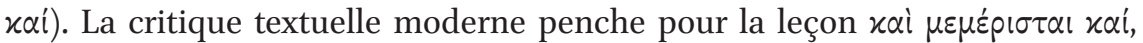

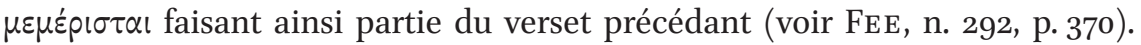
La formulation nominale وان بين المره والبتوله انفصال il y a une différence/

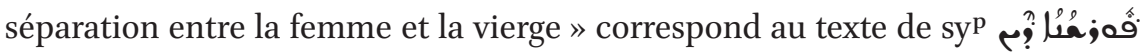

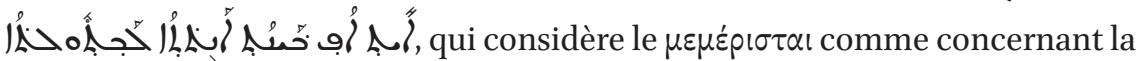
femme et la vierge. Cette interprétation de VA 13 est facilitée car il a la variante

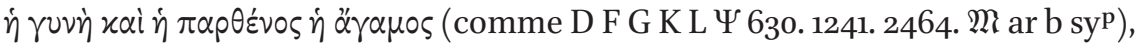

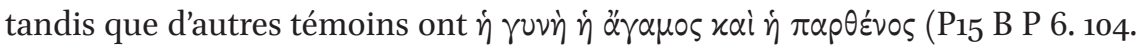

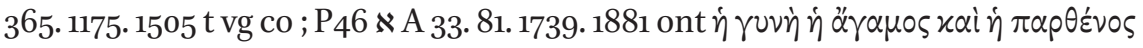

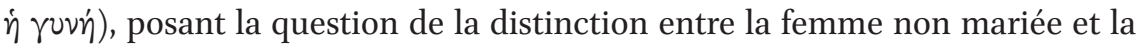
vierge.

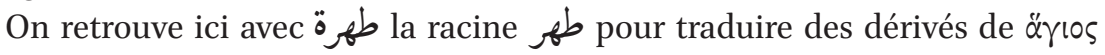
$(1,30 ; 6,1 ; 6,2 ; 7,14 ; 16,20)$.

On retrouve une nouvelle fois le terme خلي (voir 7,2).

1 Co 7,35

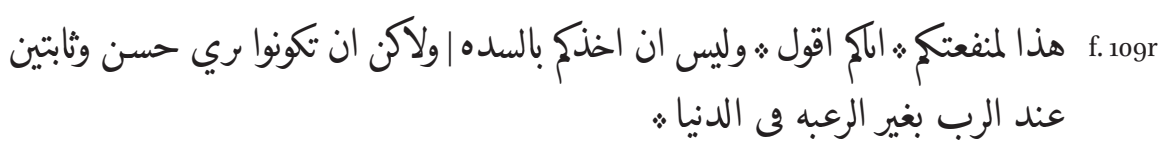

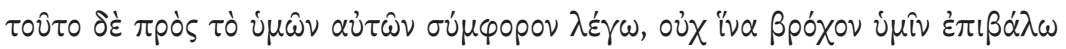

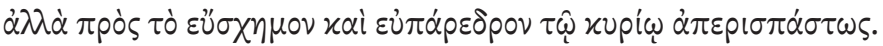

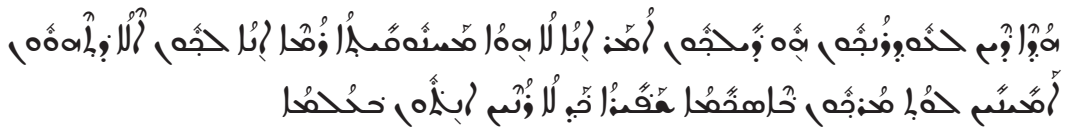

Je dis cela pour votre intérêt à vous et non pas pour vous traiter durement, mais pour que vous soyez dans une bonne forme et demeurant auprès du Seigneur, sans peur ici-bas. 
La formulation ولاكن ان تكونوا ري حسن وثابتين عند الرب , littéralement « mais que vous soyez dans un bon aspect et demeurant auprès du Seigneur », est

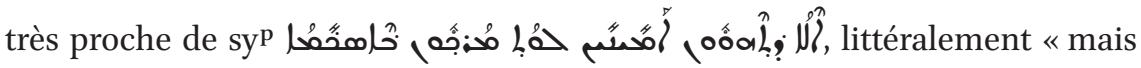
que vous soyez demeurant auprès de notre Seigneur et dans le bon aspect » (excepté le pronom possessif et l'inversion des deux états).

Avec بغير الرعبه, VA 13 est seul à introduire l'idée de peur, le grec ayant

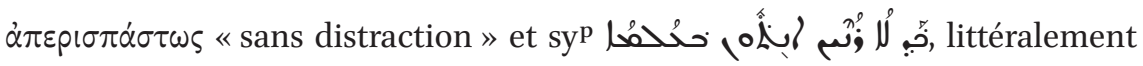
« tandis que vous ne pensez pas au monde». L'équivalent de

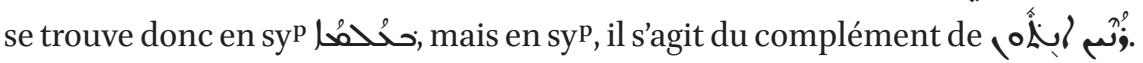

1 Co 7,36

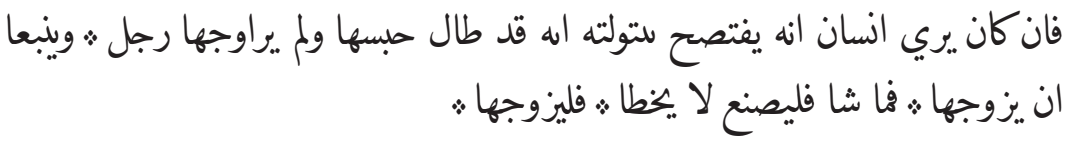

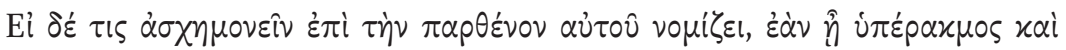

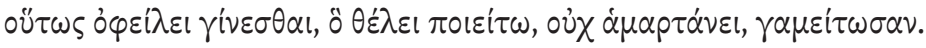

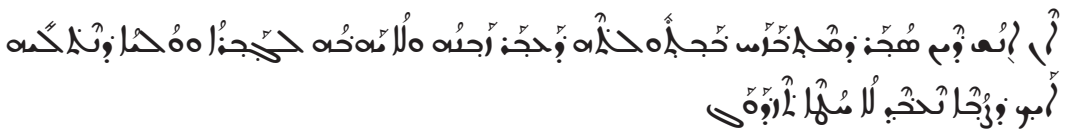

Si un homme pense qu'il se déshonore envers sa vierge, que sa claustration (à elle) s'est prolongée, alors qu'il ne lui a pas uni un homme et qu'il convient de la marier - ce qu'il a voulu, qu'il le fasse, il ne pèche pas, qu'il la marie.

L'interprétation du verset pose problème jusqu'à aujourd'hui. À quoi se réfère

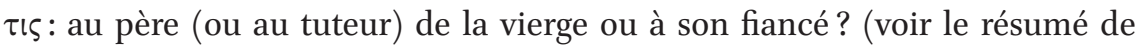
FitzMYE R, pp. 322-324). Dans VA 13, l'ambiguïté n'est pas effacée. Nous notons la présence après le verbe يزاوج 89 d'un pronom suffixe féminin (la fille vierge) et d'un complément indéfini « un homme ${ }^{90}$, qui se comprend mal comme

89 On pourrait attendre, comme en fin de verset, le verbe à la forme II زوّ (« ) زوج («marier une femme à quelqu'un ») plutôt qu’à la forme III زاوج (« être réunis l'un à l'autre ») (KAZIMIRSKI 1, p. 1024). Or en 7,36, la forme III est bien utilisée dans le sens « marier une femme à quelqu'un ».

90 Comme syp, qui est encore plus clair en utilisant le verbe «donner " : « et qu'il ne l'a pas donnée à un homme». 
sujet ${ }^{91}$. Selon nous, on considère donc ici que la personne qui se fait du souci pour la vierge et l'époux sont deux personnes différentes. Cette interprétation est renforcée avec en fin de verset par فليزوجها qui signifie clairement « qu'il la

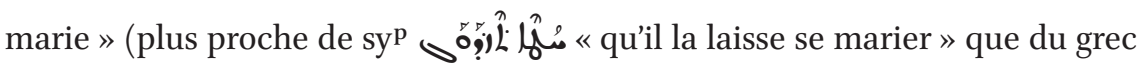
$\gamma \alpha \mu \varepsilon i \tau \omega \sigma \alpha \nu$ «u'ils se marient »).

1 Co 7,37

$$
\text { اما الدي الثبت في قلبه ث ولا يشق عليه ث وهو مسلط في هواه ث وهذا صرم فى قلبه }
$$

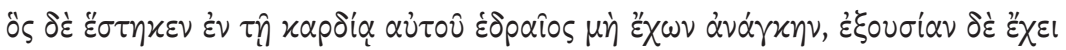

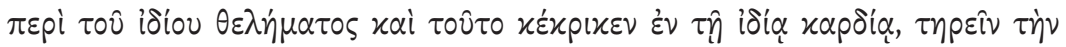

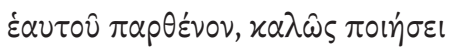

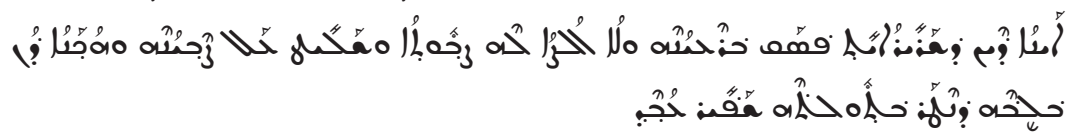

Mais celui qui a fermement établi dans son cœur - alors que cela ne lui est pas pénible, qu'il est maître dans sa volonté et que cela, il l'a tranché dans son cœur - de garder sa vierge, il fait très bien.

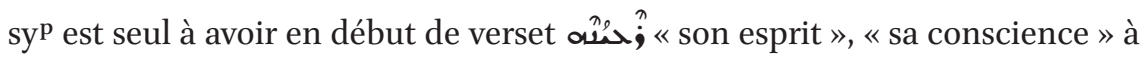
la place de «son cœur».

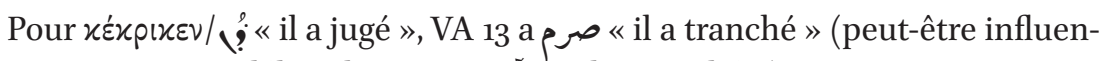
cé par syp qui a au début du verset فمَّم " il a tranché »).

${ }_{1} \operatorname{Co~} 7,38$

$$
\text { والذي يزاوج بتولته فنحا يصنع × والذى لا يراوج فبزياده نحا يصنع ؛ }
$$

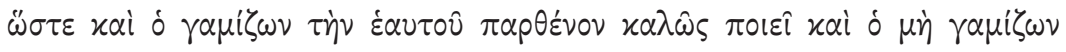

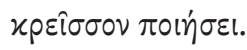

91 Cela dépend de la traduction donnée au verbe, voir note 89 ci-dessus. Or même si رجل est sujet, on comprendrait mal le choix d'un sujet aussi indéterminé pour faire référence à la personne dont on parle depuis le début; une autre traduction serait donc : « et si personne ne lui a été uni ». 


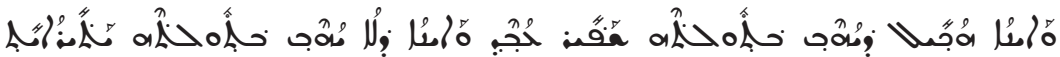

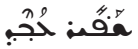

Et celui qui donne sa fille en mariage fait bien, et celui qui ne [la] donne pas en mariage fait encore mieux.

Ici, le même problème se pose qu'en 7,36 : parle-t-on du père qui donne sa fille vierge à marier ou du fiancé qui épouse la vierge? Au vu de notre étude du v. 36, nous pensons que le verbe à la forme III زاوج est bien utilisé dans le sens de « donner une femme en mariage à quelqu'un ».

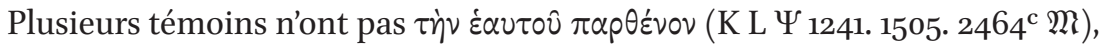
ce qui n'est pas le cas de VA 13 .

1 Co 7,39

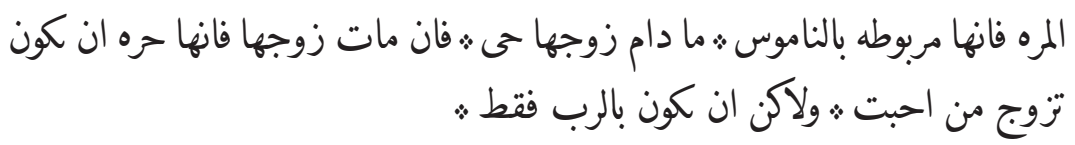

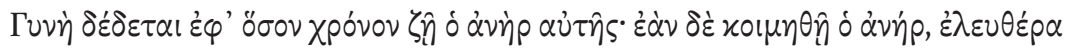

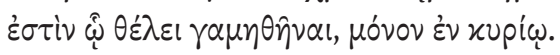

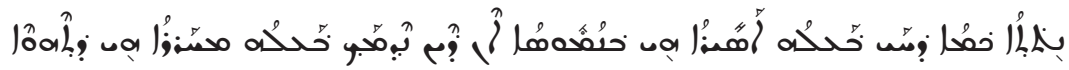

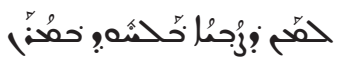

La femme est liée par la loi tant que son mari est vivant, or si son mari meurt, elle est libre d'être mariée à qui elle veut, mais que ce soit dans le Seigneur seulement.

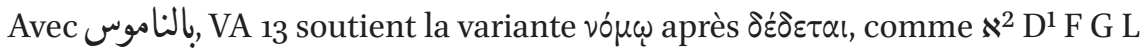
P $\Psi$ 104. 365. 630. 1505. 2464. $\mathrm{M}$ ar vgle sy (contre P15 ${ }^{\mathrm{vid}} \mathrm{P}_{4} 6 \kappa^{*}$ A B D* 0278. 6. 33. 81. 1175.1241. 1739.1881 lat sa $\left.{ }^{\mathrm{mss}}\right)$.

correspond ici à une forme II qui signifie généralement « marier une femme à quelqu'un », et qui semble être utilisé dans ce sens en 7,36 ; nous pensons qu'il s'agit ici d'un passif, comme en grec $\gamma \alpha \mu \eta \theta \hat{\eta} v \alpha$. syp a ici le verbe

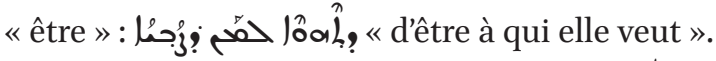

Faut-il voir un sens « romantique » à احبت ou dans le même sens que $\theta \dot{\lambda} \lambda \varepsilon ı /$ احب , احمُر a simplement le sens de « vouloir». VA 13 est seul à avoir pour ce verbe un accompli. 
$1 \mathrm{Co} 7,40$

$$
\text { فطوبيها } 92 \text { ان ثبتت هكذا كهواي انا ثاني اري ايضا ان روح الله في ث }
$$

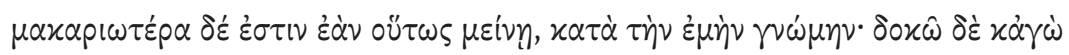
$\pi \nu \varepsilon \hat{\mu} \mu \alpha \theta \varepsilon \circ \hat{~ ह ै \chi \chi \varepsilon เ \nu . ~}$

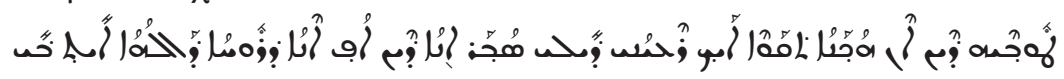
Mais heureuse est-elle si elle demeure ainsi selon mon désir; je pense aussi que l'Esprit de Dieu est en moi.

Le grec a un comparatif $\mu \alpha \varkappa \alpha \rho \iota \tau$ ₹́p $\alpha$ qui n'est pas reproduit dans VA 13 ni dans syp ; les deux versions ont un substantif avec un pronom possessif à la place

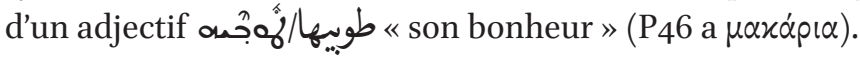

\subsection{Chapitre 8}

1 Co 8,1

فاما من اجل دبيحه الاوثان انا نحلم ان في كلنا علم × والعلم يفتخز : اما الحب

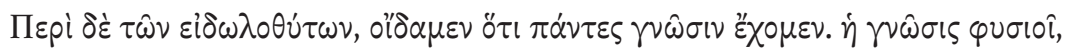

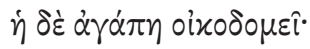

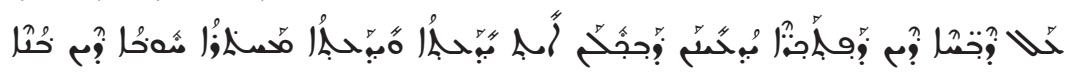
Mais à propos du sacrifice aux idoles, nous savons qu'il y a en chacun de nous une connaissance, et la connaissance se glorifie mais l'amour édifie.

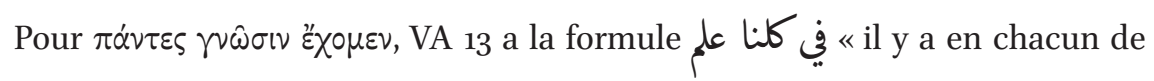

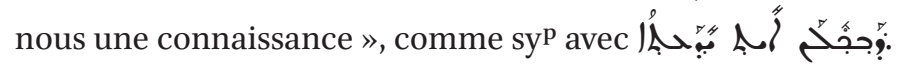

\section{Co 8,2}

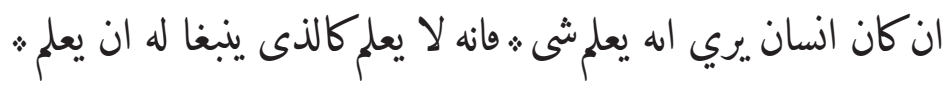

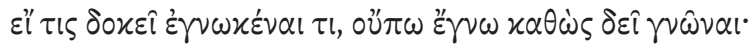

92 «Very rarely is alif maqș̂ra bi-ș̂rat 'al-yâ preserved before pronominal suffixes [...] rem. طوبيك 'blessed are you' Levin Mt 16,17 may be influenced by Aramaic » BLAU, § 10.3. 


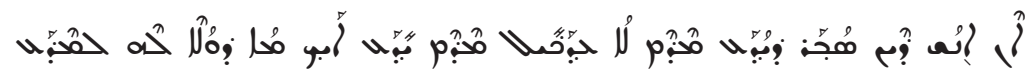

Si quelqu'un pense connaître quelque chose, il ne connaît pas comme il lui faut connaître,

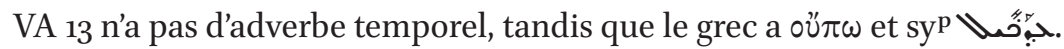

VA 13 n'a pas de complément au verbe يعلم, comme P46 N B D* F G P Y 0278. 33. 81. 104. 630. 1175. 1739. 1881. 2464, alors que $\mathrm{D}^{1} \mathrm{~K}$ L 365.1241. 1505. Mr sy

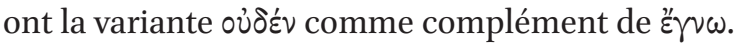

\section{$1 \operatorname{Co} 8,3$}

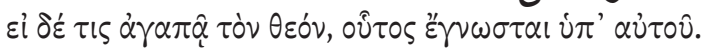

$$
\text { وانكان انسانيحب الله فهذ اقدعرف من هله : }
$$

$$
\text { ? }
$$

et si quelqu'un aime Dieu, celui-ci est connu de lui.

\section{$1 \operatorname{Co} 8,4$}

\section{قاما من اجل آل دبحه الاوثان فقد علمنا ان الاوثان ليست هي بشي في العالم

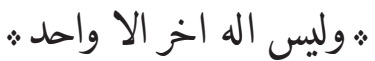

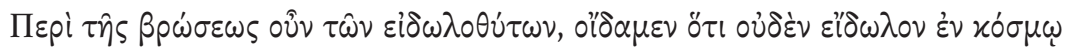

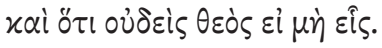

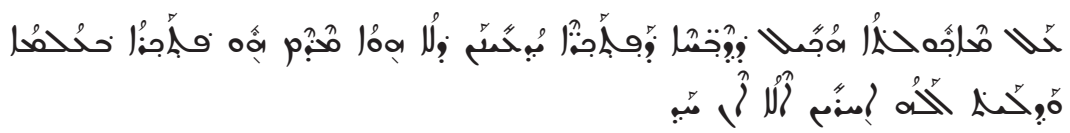

Donc, à propos de la consommation du sacrifice aux idoles, nous savons déjà que les idoles ne sont rien dans le monde et qu'il n'y a pas un autre Dieu qu'un unique [Dieu],

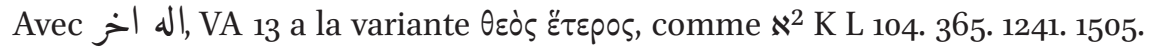

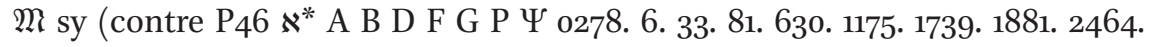
latt co).

On notera que la formulation finale ليس اله اخز الا واحد est proche de la première partie de la šahāda. Voir point 4.3.4 wa laysa ilāhun āḩaru illā wāḥid «il n'y a pas d'autre dieu qu'un unique Dieu ». 


\section{Co 8,5}

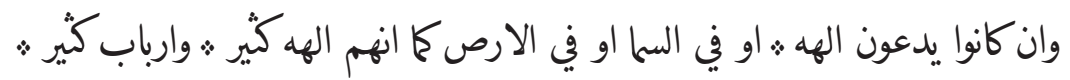

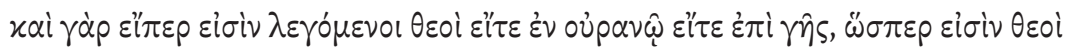

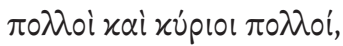

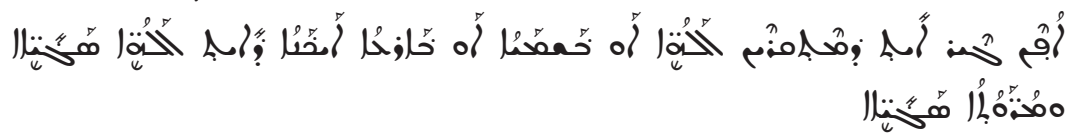

et si elles sont appelées dieux, soit dans le ciel, soit sur la terre - de même qu'il y a de nombreux dieux et de nombreux seigneurs -,

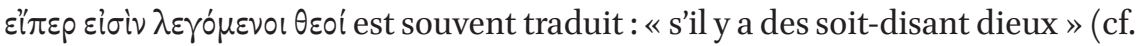
Fee, p. 411 ; Fitzmyer, p. 340 ; Zeller, p. 283). Schottroff est d'avis qu'il faut comprendre ici : «si certaines [idoles] sont appelées dieux 》(SchотTroff, p. 153). C'est cette interprétation que le texte de VA 13 contient afl.

\section{$1 \operatorname{Co} 8,6$}

$$
\begin{aligned}
& \text { ولاكن لنا خن فالواحد الله الاب ث. الذي منه كلشي وخن فيه ث. والواحد الرب يسوع }
\end{aligned}
$$

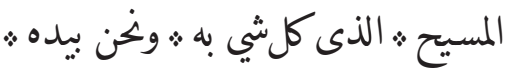

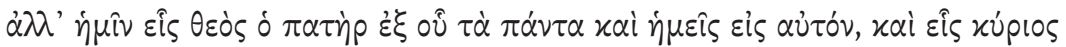

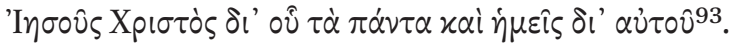

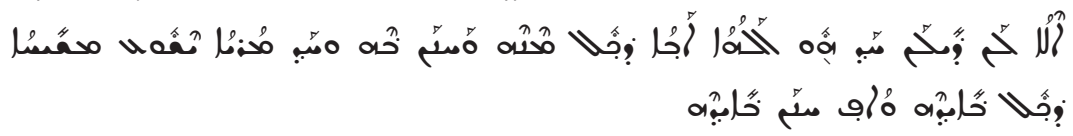

mais pour nous, l'unique c'est Dieu le Père, à partir de qui tout est et en qui nous sommes, et l'unique Seigneur, c'est Jésus le Christ, par qui tout est et par qui nous sommes.

L'ordre des mots الواحد الرب لسوع المسيح الله الابح plutôt inhabituel

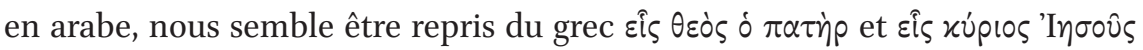

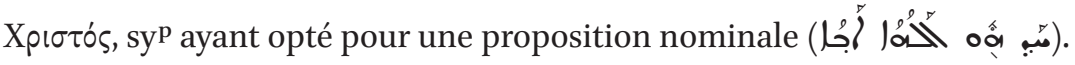

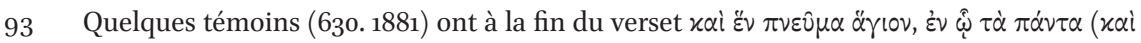
$\dot{\eta} \mu \varepsilon \hat{\varsigma} \varsigma$ ह่v $\alpha \dot{\tau} \tau \hat{\omega} \nu$ chez 630 ), une variante qui n'est pas soutenue par VA 13. 
1 Co 8,7

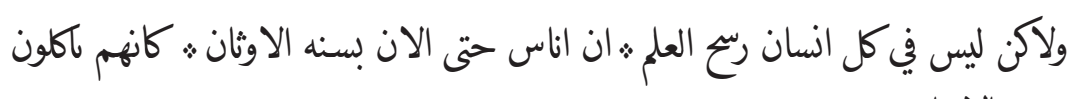

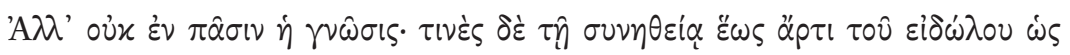

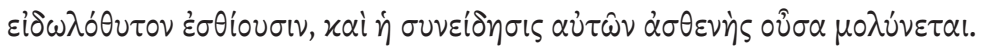

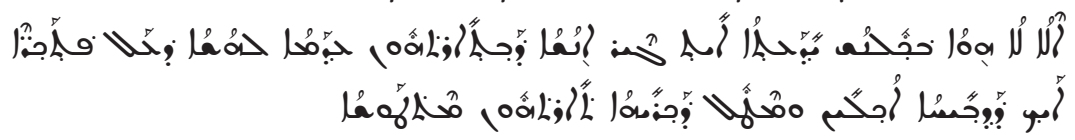

Mais la connaissance n'a pas été affermie en tout homme ; certains sont jusqu'à maintenant dans une pratique idolâtre, comme si c'est le sacrifice aux idoles qu'ils mangent, et leur conscience qui est faible est salie.

Le verbe à l'accompli رِ semble traduire syp, qui a lóa. Le grec a une phrase nominale.

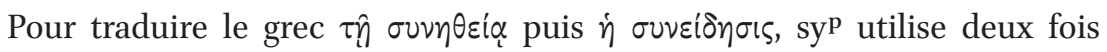

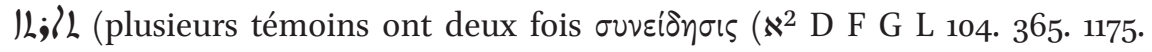
1241. 1505. 2464. M lat sy, contre $\aleph^{*}$ A B P $\Psi$ 33. 81. 630. 1739. 1881. vg ${ }^{\text {mss }}$ symg

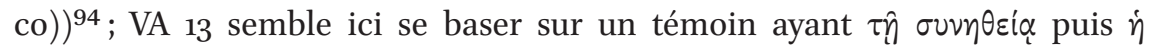

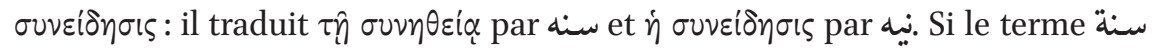
a une place importante en Islam, dans le Coran déjà, il est ici utilisé dans son sens de « usage », « habitude» (voir point 4.3.5). On retrouve سنه traduisant

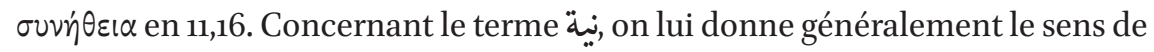
« intention » (KAZIMIRSKI 2, p. 1374.) ; dans notre texte, le traducteur propose

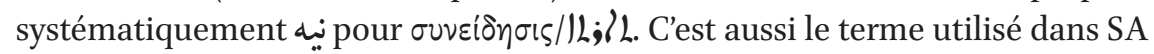
151 et en dans SA 155. Nous le traduisons donc par « conscience », vu qu'il s'agit

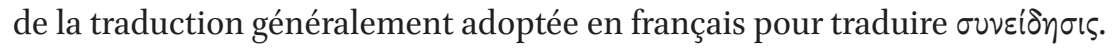

Dans VA 13, « comme » porte sur le verbe, alors que $\dot{\omega} \varsigma$ se rapporte proba-

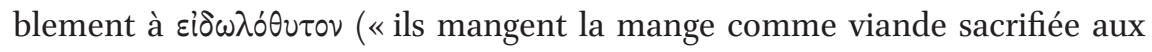
idoles », SENFT, p. 112). VA 13 est donc ici plus proche de syp, mais cela peut

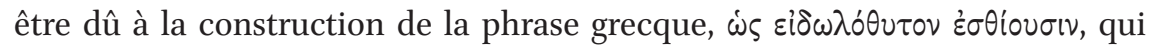
permet cette interprétation.

94 sy ${ }^{\mathrm{h}}$ également. 


\section{Co 8,8}

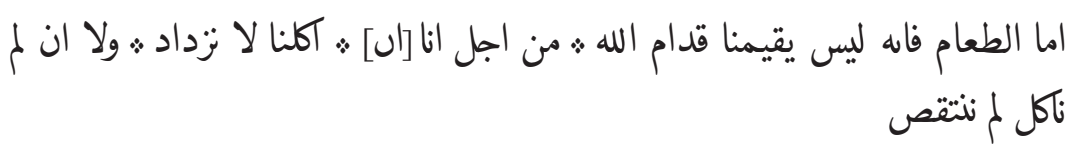

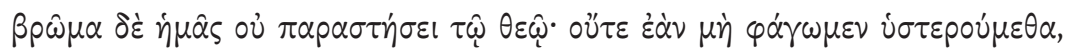

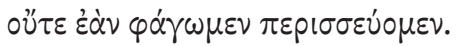

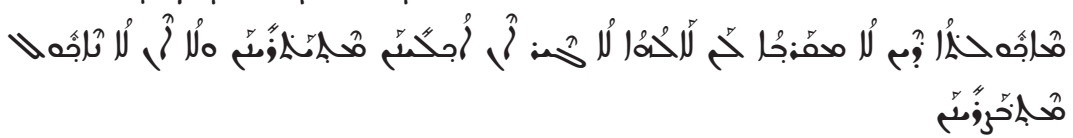

Quant à la nourriture, elle ne nous élève pas face à Dieu, parce que nous, si nous mangeons, nous ne sommes pas augmentés, et non plus, si nous ne mangeons pas, nous ne sommes pas diminués.

VA 13 n'a pas la variante $v \mu \hat{\alpha} \varsigma$ (à la place de $\dot{\eta} \mu \hat{\alpha} \varsigma$ ) qu'on trouve dans $\aleph^{*} \Psi 33$. 365. 1241. $1881^{*}$.

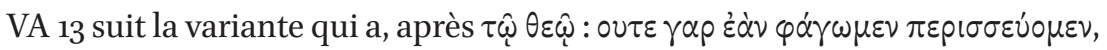

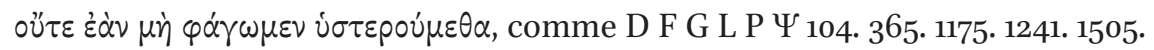
2464. $\mathfrak{M}$ ar b sy ${ }^{95}$.

\section{Co 8,9}

$$
\text { احتفظوا ه لعل سلطانك هذ ا يكون عثره للصعفا ؛ }
$$

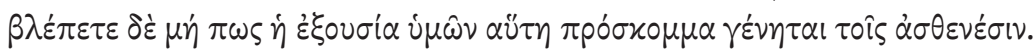

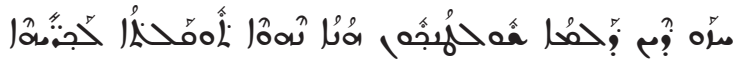

Prenez garde que votre pouvoir ne devienne un écueil pour les faibles.

Comme nous l'avons vu en 1 Co 1,13, VA 13 a souvent لعل là où nous trouvons

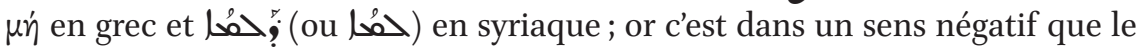
grec et le syriaque utilisent ces particules ici : « prenez garde que ... ne pas ... », négation absente en arabe. Nous supposons ici que لعل a le même sens que $\mu \eta^{\prime}$ et حمُحا (voir notre remarque en 1,13).

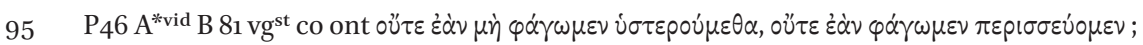

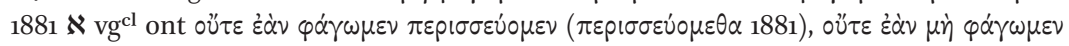

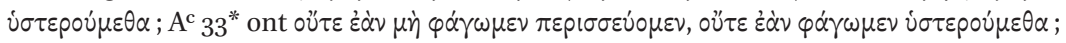

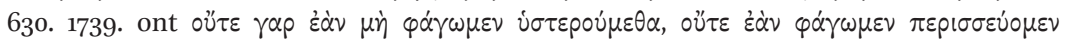

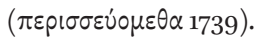


1 Co 8,10

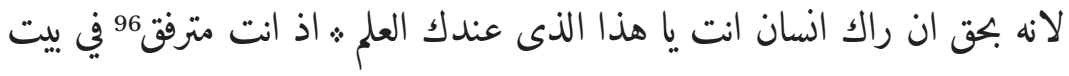

$$
\begin{aligned}
& \text { الاوثان ه. اليست نيته من اجل انها صعيفه تبنا ان تاكل ذيحه الاوثان ؛ }
\end{aligned}
$$

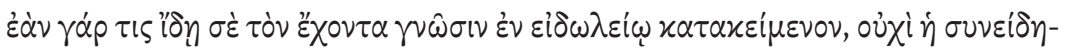

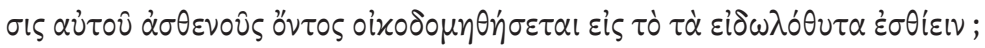

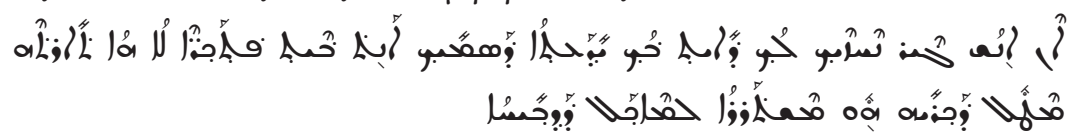

Car, en vérité, si quelqu'un te voit, toi, celui qui a la connaissance, lorsque tu es accoudé dans la maison des idoles, sa conscience, parce qu'elle est faible, ne va-t-elle pas être consolidée dans la consommation du sacrifice aux idoles?

En plus de la particule لانه, VA بكت en vérité », qu'on ne trouve si en grec ni en syp.

1 Co 8,11

$$
\text { وتهلك الاخ الصعيف بعلهك انت م. النَى من احله مات المسيح ؛ }
$$

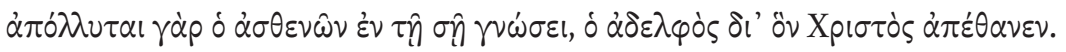

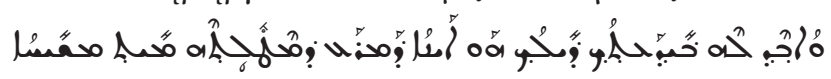

Et le frère faible se perd par ta connaissance, lui pour qui le Christ est mort.

Nous lisons dans le manuscrit ترهلك; il pourrait s'agir d'une forme IV à l'inaccompli à la $2^{\mathrm{e}}$ personne du singulier: «tu fais se perdre le frère faible », ou encore une forme v à l'accompli à la $3^{\mathrm{e}}$ personne du singulier : « le frère faible s'est perdu » ${ }^{97}$. Une autre possibilité est de corriger en يهلك, c'est-à-dire de postuler une forme I à l'inaccompli à la $3^{\mathrm{e}}$ personne du singulier : « le frère faible se perd ». C'est cette dernière lecture que nous favorisons pour la traduction car le grec et $\mathrm{sy}^{\mathrm{p}}$ ont ici des verbes correspondant à une $3^{\mathrm{e}}$ personne du singulier à l'inaccompli.

96 C'est généralement pour la forme vin que le sens de « être accoudé » est donné, mais le traducteur utilise la forme v مترفق dans ce sens. KaZimirski 1, p. 900.

97 La forme $\mathrm{V}$ n'est pas attestée dans les dictionnaires consultés. 
Avec g en début de verset, VA 13 semble plutôt soutenir une variante avec

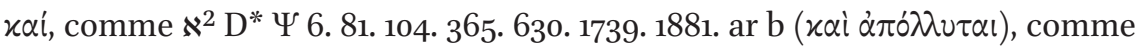

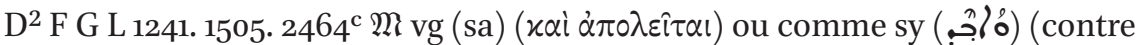

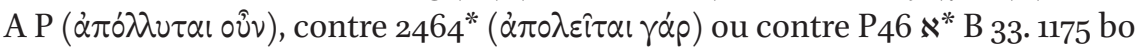
$(\dot{\alpha} \pi \dot{\lambda} \lambda \nu \tau \alpha \iota \gamma \alpha \dot{\rho} \rho))$.

$\mathrm{sy}^{\mathrm{p}}$ est ici seul à ne pas avoir «le frère » (VA 13 a الاخ).

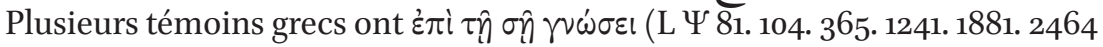

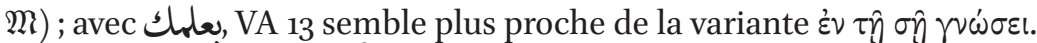

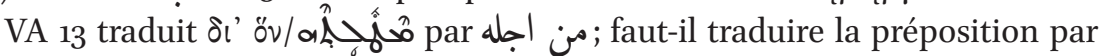
« pour» ou « à cause de»?

\section{Co 8,12}

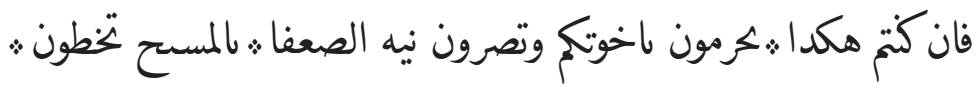

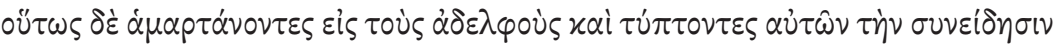

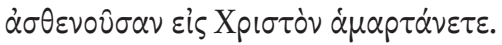

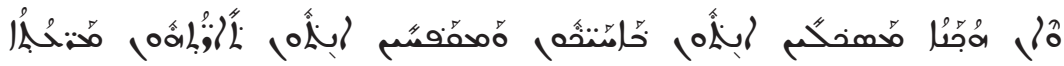

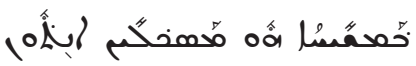

Or si vous faites ainsi quelque chose d'illicite contre vos frères et que vous blessez la conscience des faibles : vous péchez contre le Christ.

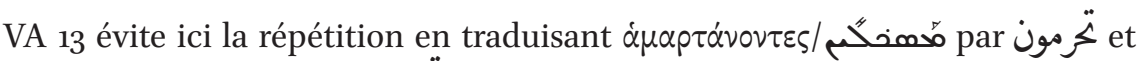

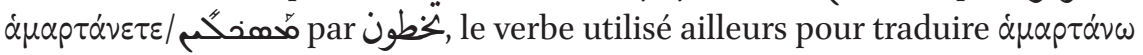
(on notera que syp a normalement la racine oه o).

1 Co 8,13

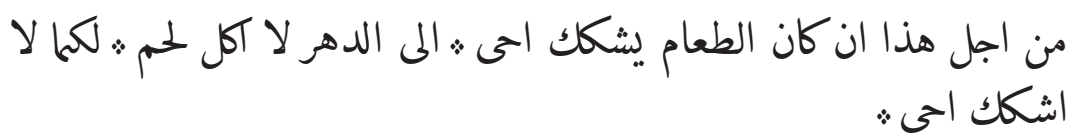

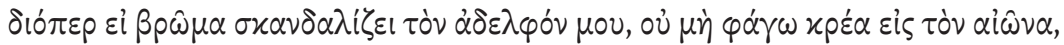

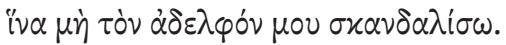

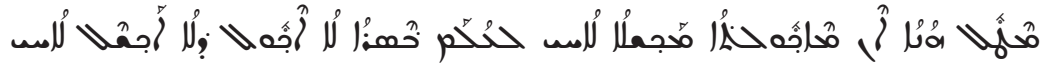

À cause de cela, si la nourriture scandalise mon frère, pour toujours, je ne mangerai pas de viande afin de ne pas scandaliser mon frère.

À propos de la racine شُّكّ, voir 1,23. 
1.9 Chapitre 9

1 Co 9,1

$$
\begin{aligned}
& \text { الست انا رسول : ام لست انا حر ه اليس قد رآيت يسوع المسيح ربنا ه اليس انتم } \\
& \text { عملى بالربـ }
\end{aligned}
$$

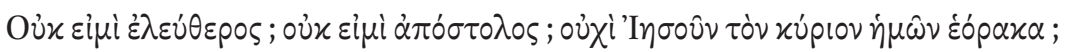

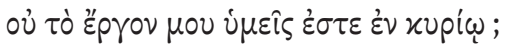

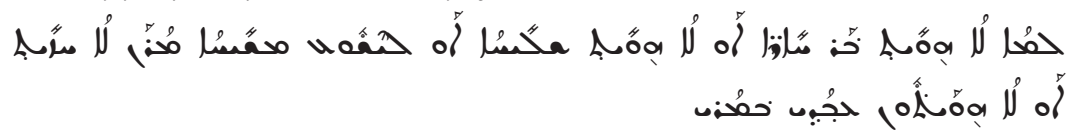

Ne suis-je pas un envoyé ? Ou ne suis-je pas libre? N’ai-je pas vu Jésus le Christ notre Seigneur? N'êtes-vous pas mon œuvre dans le Seigneur?

À propos de رسول, voir 4.3.1 rasūl «envoyé ».

syp ponctue la série de questions par des of, qui ne sont pas présents en grec; VA 13 semble avoir été partiellement influencé, vu qu'il présente un devant la deuxième question.

Avec الست انا رسول ام لست انا حر, VA 13 a la variante qui présente d'abord « apôtre », puis « libre », comme D F G K L Y 81. 1241. 1505. 2464 M ar b sy (contre $\mathrm{P}_{4} 6$ « A B P 33. 104. 365. 629. 630. 1175. 1739. 1881 vg syp co).

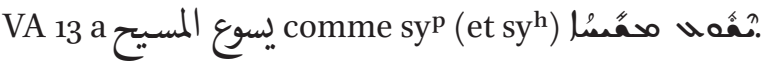

\section{Co 9,2}

$$
\begin{aligned}
& \text { وان كت لست رسول لاحين ث ولاكن : اما لم انت فاني رسول : ان حاع رساتى } \\
& \text { انتم هم بالربت }
\end{aligned}
$$

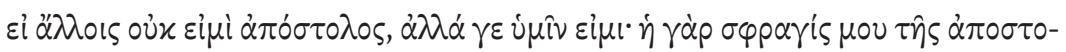

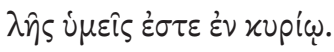

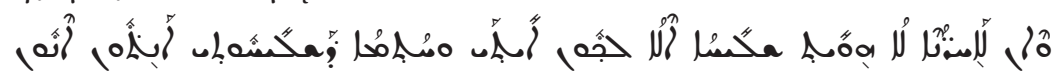

Et si je ne suis pas envoyé pour les autres, je suis toutefois envoyé pour vous. Le sceau de mon apostolat, c'est que vous êtes dans le Seigneur,

À propos de رسول, voir 4.3.1 rasūl «envoyé».

le sceau de mon apostolat » est très proche de l'expression coranique خاتح الأنياء le sceau du Prophète». Voir 4.3.2 hātam risālatī «le sceau de mon apostolat». 
Ici, syp est seul à ne pas avoir « dans le Seigneur », bien présent dans VA 13 بالرب

\section{Co 9,3}

\section{ومعذرتي للذين يحاصموني فانه هذا}

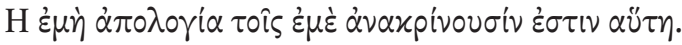

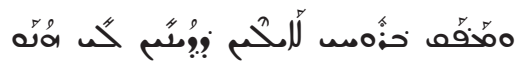

et mon excuse pour ceux qui me prennent à partie, la voici :

$1 \operatorname{Co} 9,4$

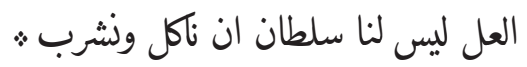

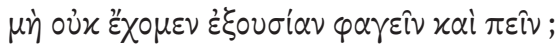

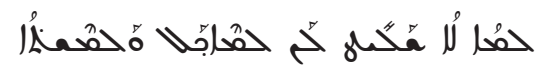

Est-ce que nous n'avons pas l'autorité de manger et de boire?

Une fois de plus, VA 13 a لعمُا// pour traduire $\mu$ لحل (voir 1,13).

$1 \operatorname{Cog} 9$

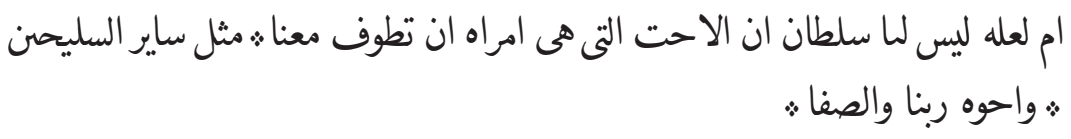

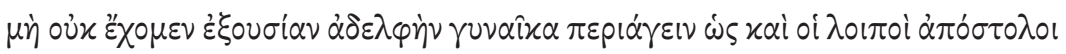

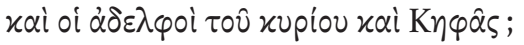

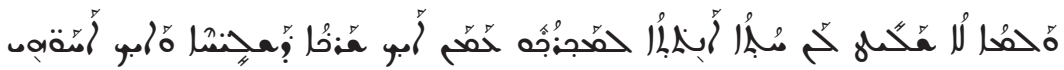

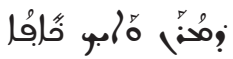

Ou n'avons-nous pas l'autorité que la sœur, qui est une femme, circule avec nous comme les autres apôtres, les frères de notre Seigneur et Pierre?

Comme au verset précédent, VA 13 a لعل pour traduire $\mu \grave{\eta} /$ لحمدا.

Alors que «femme" est simplement accolé à «sœur» en grec $\alpha \dot{\delta} \varepsilon \lambda \varphi \eta े$

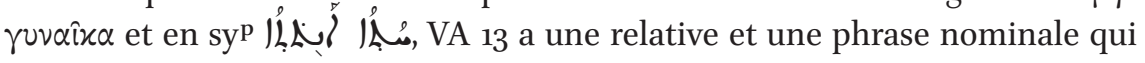


rend l'expression d'autant plus pléonastique. Le traducteur souhaite-il uniquement mettre en évidence cette compagnie féminine, ou faut-il donner un sens matrimonial à امر la sœur qui est (aussi) une épouse »?

À propos de السليحن, voir notre remarque en 4,9 et point 4.3.1.

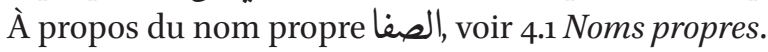

\section{$1 \operatorname{Cog}, 6$}

$$
\text { او انا وبرنبا وحدنا ليس لنا سلطان الا نحل : }
$$

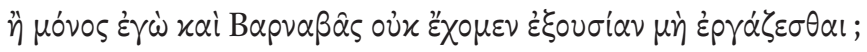

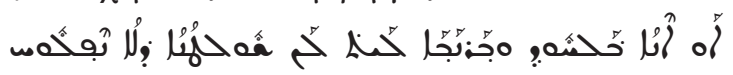

Ou moi et Barnabé, sommes-nous seuls à ne pas avoir l'autorité de ne pas travailler?

À propos du nom propre برنبا, voir point 4.1 Noms propres.

\section{Co 9,7}

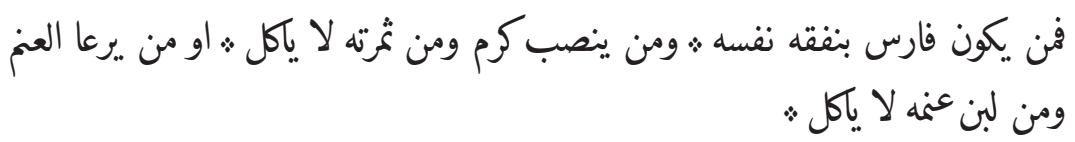

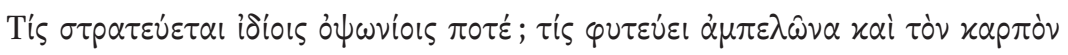

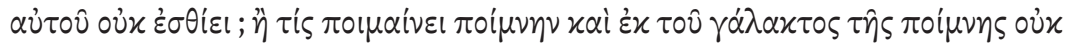

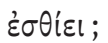

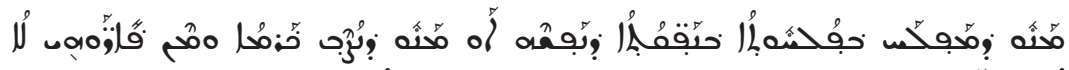

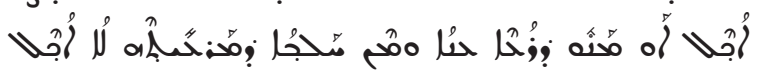

Or qui est cavalier à ses propres frais ? Et qui plante une vigne et ne mange pas de son fruit? Ou qui fait paitre le troupeau de moutons et ne mange pas du lait de son troupeau?

VA 13 utilise le terme فارس, qui signifie «cavalier» (فوس " فوس cheval»), tandis que le grec avec $\sigma \tau p \alpha \tau \varepsilon v ́ \varepsilon \tau \alpha l$ et syp avec ont des termes plus neutres ${ }^{98}$.

98 «advance with an army», Liddell Scott ; cf. PAYNe SMith, pp. 447-448. 


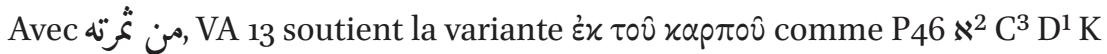
$\mathrm{L} \Psi$ 81. 104. 365. 630. 1241. 1505. 1881. 2464. $M$ it vgll sy bo (contre $\aleph^{*}$ A B C* $\mathrm{D}^{*} \mathrm{~F}$ G P 0222. 33. 1175. 1739. vgst sa).

Avec واو, VA 13 a la variante grecque $\ddot{\eta}$ comme P46 N A C* K L P 33. 365. 1241. 1881. M syp bo (absente dans B C $C^{2}$ D F G $\Psi$ 81. 104. 630. 1175. 1505. 1739. 2464 latt $\left.s y^{\mathrm{h}}\right)$.

\section{Co 9,8}

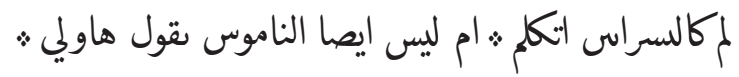

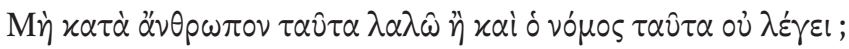

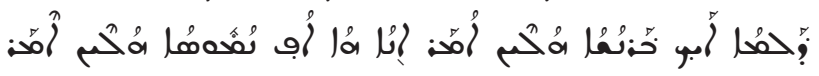

Pourquoi ? Est-ce que je parle comme les humains ou bien la loi ne ditelle pas aussi cela?

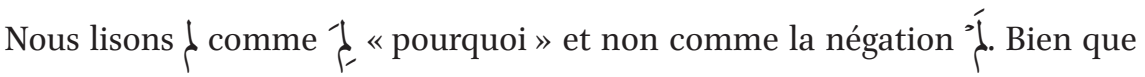
l'on trouve $\mu \eta \dot{~ e n ~ g r e c, ~ l e ~ t r a d u c t e u r ~ i n t r o d u i t ~ c e r t a i n e m e n t ~ i c i ~} 1$ en se basant

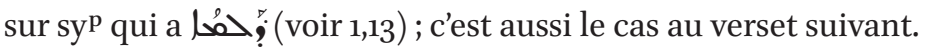

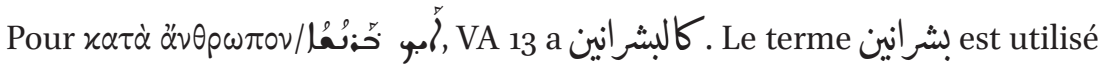

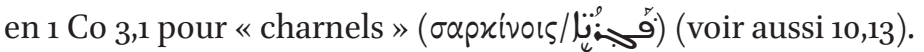

Avec انكلم en début de verset, VA 13 est plus proche du grec $\lambda \alpha \lambda \hat{\omega}$ que de syp qui a deux fois le verbe

\section{Co 9,9}

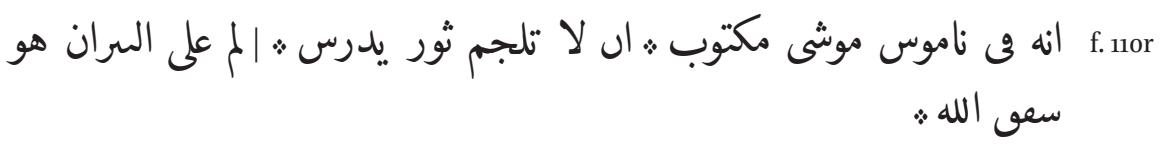

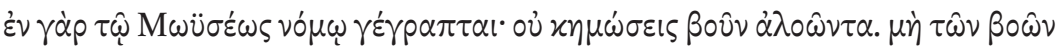
$\mu \varepsilon \dot{\lambda} \varepsilon l \tau \hat{\omega} \theta \varepsilon \hat{\omega}$

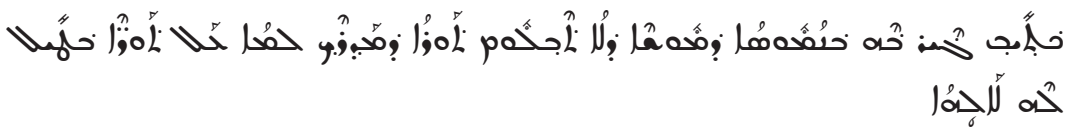

Dans la loi de Moïse, il est écrit : ne muselle pas un bœuf qui foule le blé.

Pourquoi ? Dieu a-t-il eu pitié des bœufs? 
À propos du nom propre موشى, voir 4.1 Noms propres.

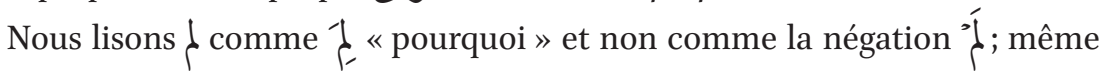
si l'on trouve un $\mu \grave{n}$ en grec, لَ demanderait un apocopé, règle respectée ailleurs dans VA 13. Le traducteur introduit certainement 1 , en se basant sur syp qui a حمُنا (voir 1,13).

La présence du pronom personnel هو est difficile à comprendre ici; est-ce

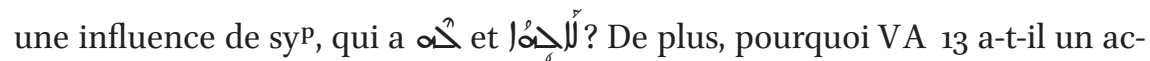
compli et non un inaccompli, comme le grec, ou un participe, comme syp ?

$1 \operatorname{Co~9,10}$

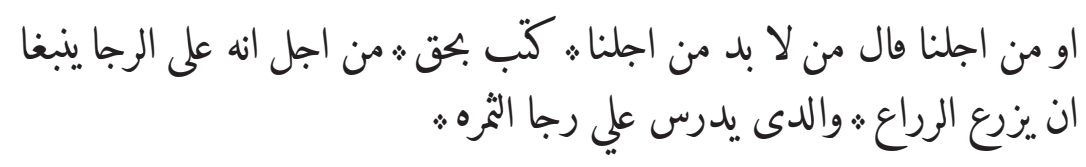

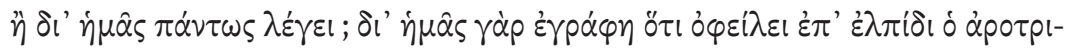

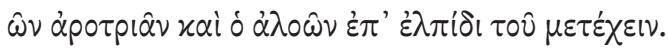

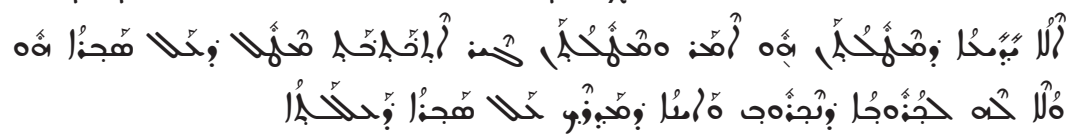

Ou est-ce à cause de nous qu'il a dû dire cela ? C'est à cause de nous que cela a été écrit en vérité, parce qu'il faut que, dans l'espérance, le semeur sème et que celui qui foule [le fasse] dans l'espérance du fruit.

La pluralité de sens de $\pi \dot{\alpha} v \tau \omega \varsigma$ en 9,10a a souvent été relevée (FEE, p. 450; ZeLler, p. 306 $)^{99}$. C'est certainement ce qui explique la traduction avec l'expression لا بـ «il faut» (KAZIMIRSKI 1, p. 93). En grec et dans VA 13, il s'agit d'une question rhétorique pour laquelle une réponse positive est attendue (cf. FEE, pp. 449-450). syp commence la phrase avec (« known, notable», JENNINGS, p. 91), que l'on peut traduire par « il est évident que cela est à cause de nous ... », une formulation qui n'est donc pas interrogative.

L'utilisation de la préposition الرجا devant على semble être une traduction lit-

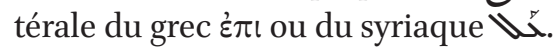

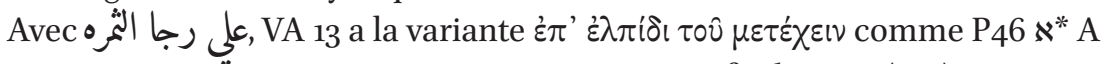
B C P 33. 81. 365. 1175. 1505. 1739. 2464. vg sy, contre $\aleph^{2} \mathrm{D}^{1} \mathrm{~K} \mathrm{~L} \Psi$ (104). 630.1241. 1881. M (

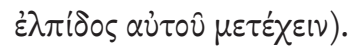


1 Co 9,11

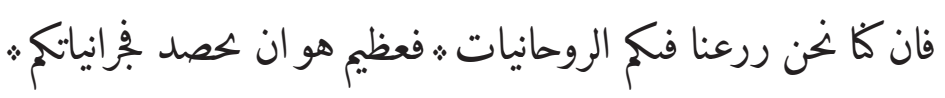

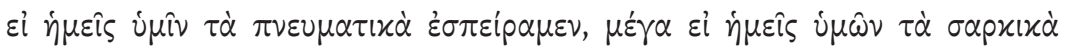

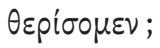

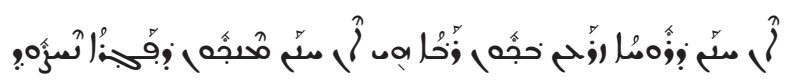

Or si nous avons semé en vous les choses spirituelles, est-ce énorme si nous récoltons vos biens corporels?

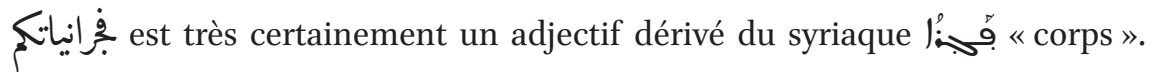
Voir 4.2 Vocabulaire d'emprunt. Voir aussi 6,4.

1 Co 9,12

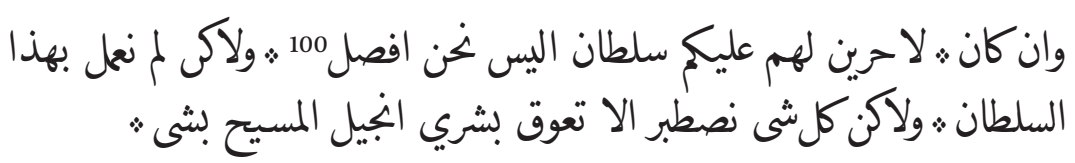

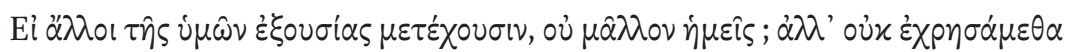

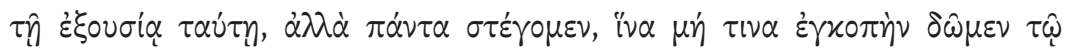

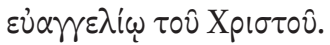

ô.

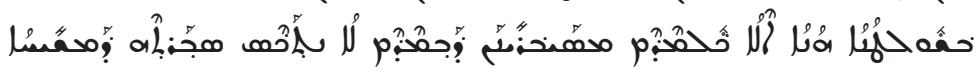

Et si d'autres ont autorité sur vous, n'en est-il pas de même pour nous à plus forte raison? Cependant nous n'avons pas utilisé cette autorité, mais nous supportons toute chose, pour que nous ne fassions obstacle en rien à l'annonce de la bonne nouvelle de l'évangile du Christ.

À propos de نصطبر, voir 7,9.

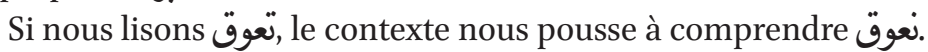

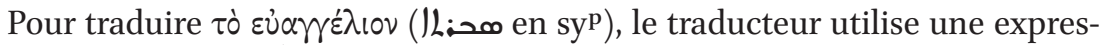

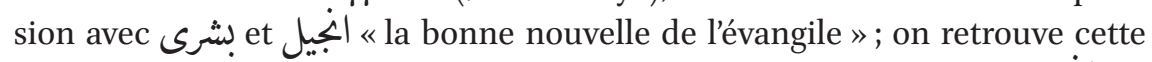
formule en 9,12 ; 9,18a ; 9,23. En 9,14, بشىى est seul et en 9,18b et 15,1, انشيل est seul (voir aussi 4,15).

100 À propos de افضل, voir 4,6, note 51. 
1 Co 9,13

\section{الا تعلمون ثان الذين نعلون في الهيكل من الهيكل آكلون ث.والذين هم في المدبح

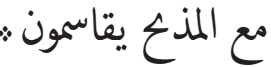

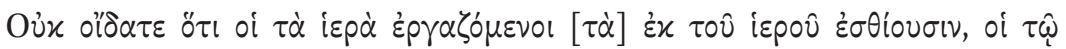

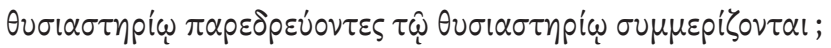

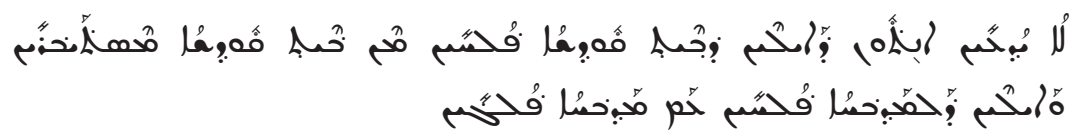

Ne savez-vous pas que ceux qui travaillent au sanctuaire mangent [les produits] du sanctuaire, et ceux qui sont à l'autel prennent part à l'autel ?

Pour le verbe, le grec a un complément $\tau \dot{\alpha}$ iepó «(s'occuper) des choses sacrées», syp aussi (servir) la maison du sacré (c'est-à-dire le sanctuaire)». VA 13 est donc seul à avoir une préposition في الهيكل) dans le sanctuaire », mais la mention du sanctuaire le rapproche de syp.

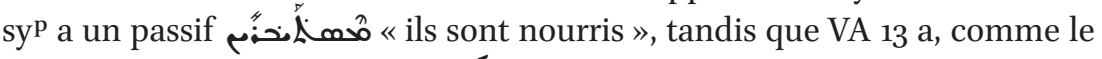

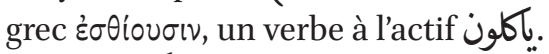

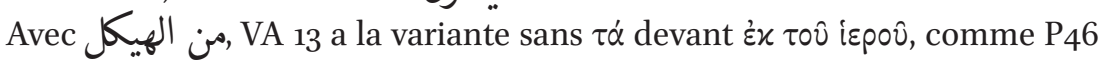

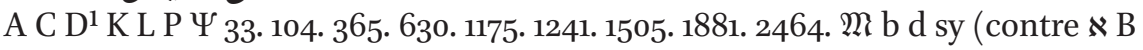
D* F G 6. 81. 1739. lat co).

1 Co 9,14

هكدا ربنا ايصا اوصا ان الذين يكررون ث. البشرى فن البشري يجيون ث

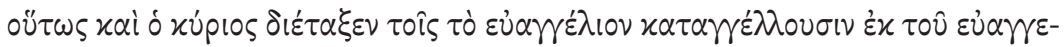

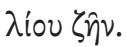

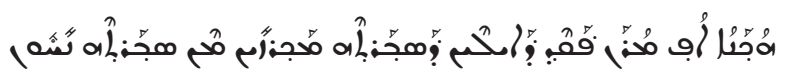

Ainsi notre Seigneur a aussi recommandé que ceux qui prêchent la bonne nouvelle vivent de la bonne nouvelle.

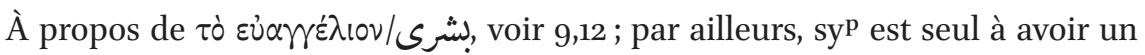

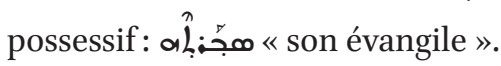




\section{Co 9,15}

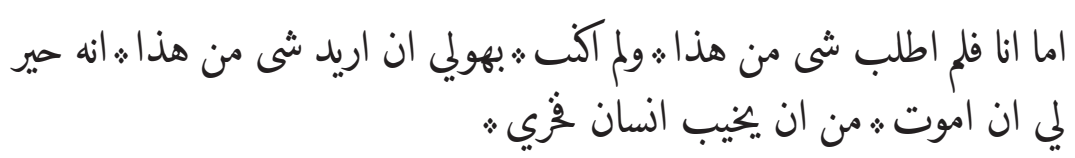

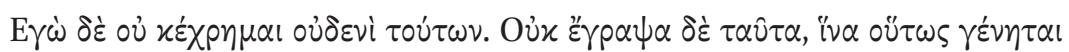

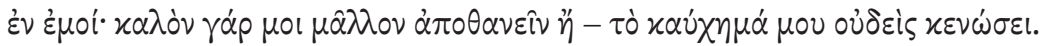

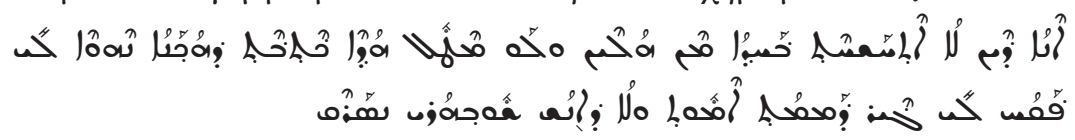

Quant à moi, je n'ai rien demandé de cela et je n'ai pas écrit par ces propos que je veux quelque chose de cela, il vaut mieux pour moi que je meure plutôt que quelqu'un mette en échec ma fierté.

En fin de verset, il semble que VA 13 soutient avec ان يخيب انسان فُري une va-

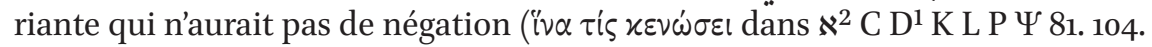

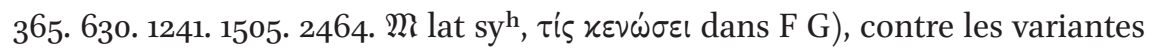

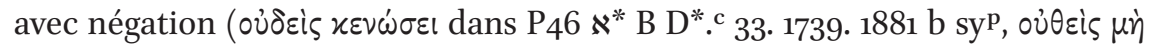

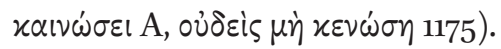

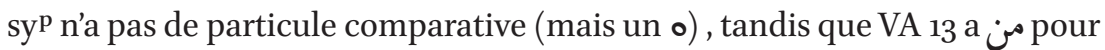
le grec $\ddot{\eta}$.

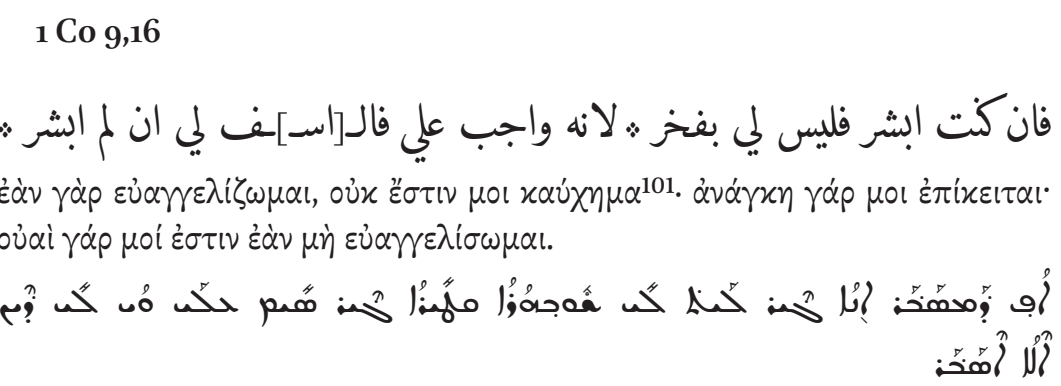

Or si j'annonce la bonne nouvelle, je n'en ai pas de fierté, car cela m'est un devoir ; quel dommage pour moi si je n'annonçais pas la bonne nouvelle!

La conditionnelle introduit par il en début de verset correspond au grec ع̇áv; syp est seul à avoir o?.

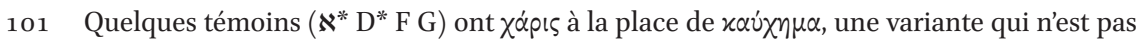
soutenue par VA 13. 
1 Co 9,17

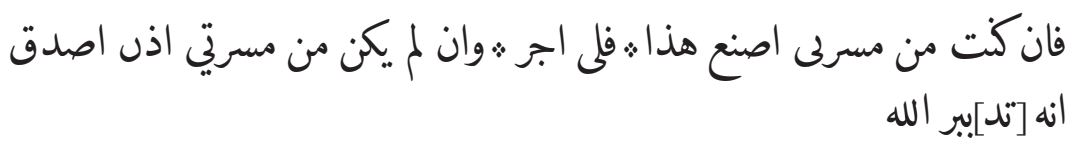

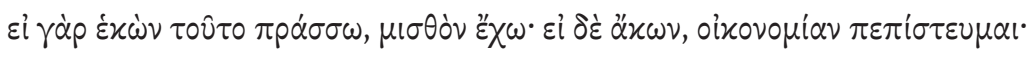

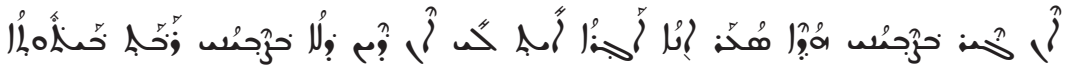

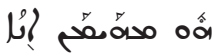

Or si je faisais cela de ma propre volonté, j'aurais un salaire, et si ce n'est pas de ma volonté, alors c'est qu'il m'est confirmé que c'est la charge de Dieu.

L'utilisation de مسرو confirme que ce terme est utilisé dans le sens de volonté dans le VA 13 (voir 1,1).

VA 13 semble avoir en fin de verset une leçon propre, notamment l'ajout de 4 l. Le grec a oixovopiav $\pi \varepsilon \pi i \sigma \tau \varepsilon u \mu \alpha$, que l'on peut traduire par «il m’a été

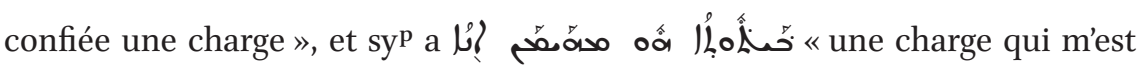
confiée », les deux textes ayant un verbe passif à la $1^{\text {ère }}$ personne du singulier. Dans VA 13, nous avons bien un verbe à la 1ère personne du singulier (ici un inaccompli) اصدق, qu'il faudrait lire comme un passifi102. Par contre, le verbe est suivi d'une phrase subordonnée, au vu de la particule et du pronom af-

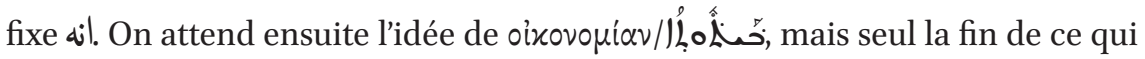
suit, un verbe ou un nom, est lisible; nous supposons qu'il s'agit de 103 تدبير. La construction reste toutefois sujette à discussion. Nous proposons de com-

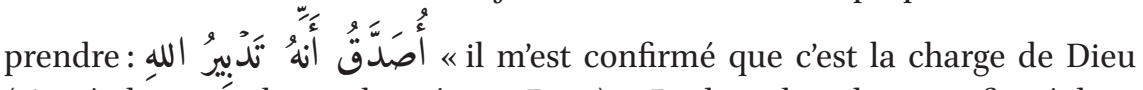
(c'est-à-dire uné charge donnée par Dieu) ». Paul est donc bien confirmé dans sa tâche.

102 Reig donne pour la forme II : «attester; approuver; authentifier; ajouter foi à ; croire ; certifier ; confirmer ; donner son assentiment à ; accorder son crédit à ; entériner ; homologuer; légaliser ; tenir qqch pour vrai ; ratifier, sanctionner ; vérifier », REIG, no. 3071.

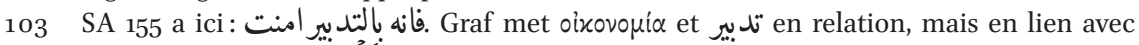

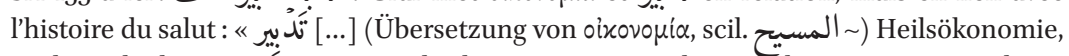
Heilsgeschichte.», p. 45 . Kazimirski donne comme traduction de : "تدير 1. Conduite, direction, maniement d'une affaire, des affaires, mesure que l'on prend, manière de s'y prendre. 2. Discernement », KAZIMIRSKi 1, p. 666. 
$1 \operatorname{Co~9,18}$

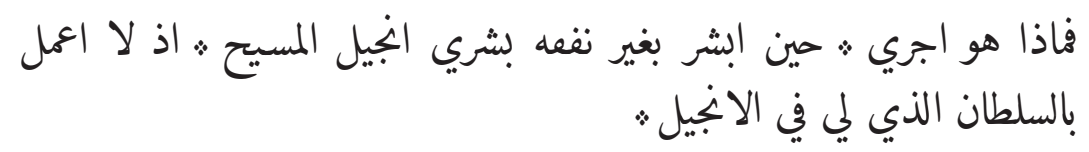

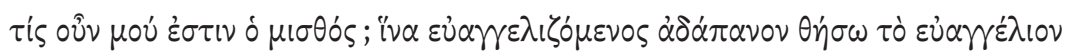

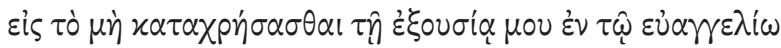

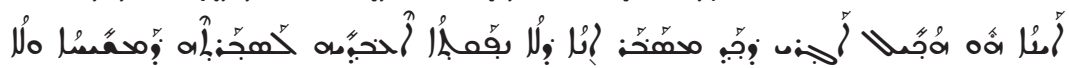

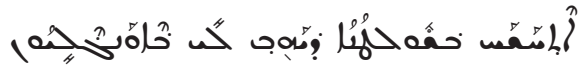

Mais quel est mon salaire? C'est quand je prêche gratuitement la bonne nouvelle de l'évangile du Christ, alors que je n'utilise pas l'autorité qui est la mienne en l'évangile.

Avec اجري, VA 13 a la variante $\mu$ oú comme $\aleph^{*}$ A B C K 6. 33. 81. 365.1739. 2464. lat sy" (contre P46 $\aleph^{2}$ L P $\Psi$ 104. 630. 1175. 1241. 1505. 1881. M sy qui ont $\mu$ ol).

À propos de لشري الخجيل, voir 1 Co 9,12.

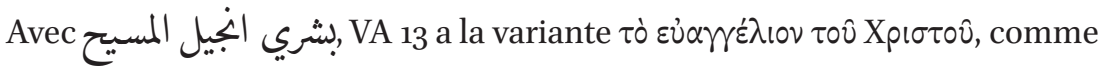

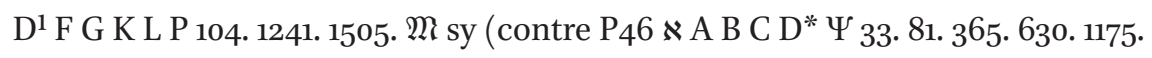

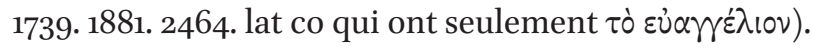

1 Co 9,19

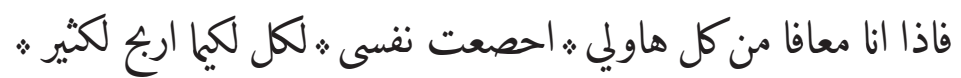

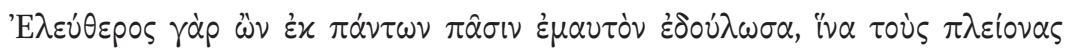

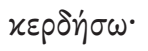

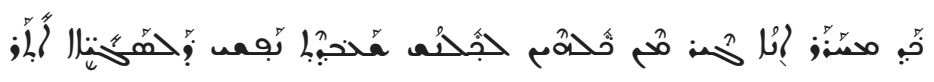

Or voici qu'en étant libre à l'égard de tous, je me suis asservi moi-même à tous, afin d'en gagner beaucoup,

\section{$1 \operatorname{Co~9,20}$}

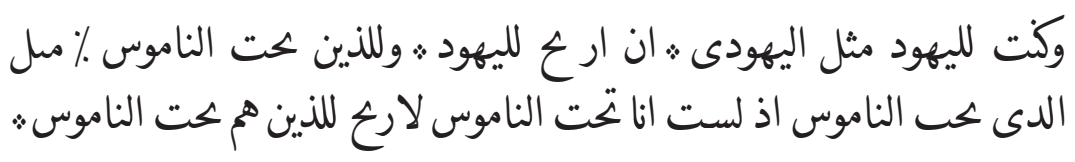




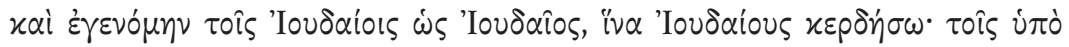

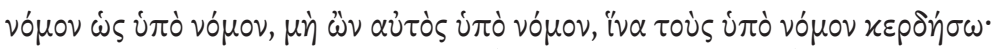

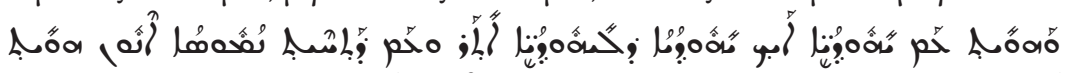

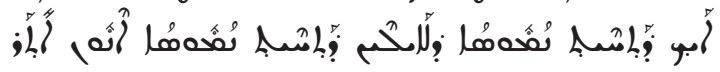
et j'ai été pour les juifs comme le juif, pour gagner les juifs, et pour ceux qui sont sous la loi, comme celui qui est sous la loi - alors que moi, je ne suis pas sous la loi -, afin de gagner ceux qui sont sous la loi,

a été ajouté à l'aide d'un signe diacritique (\%) au dessus de la ligne; il s'agit probablement d'une erreur de même au même corrigée, due à la répétition de الناموس.

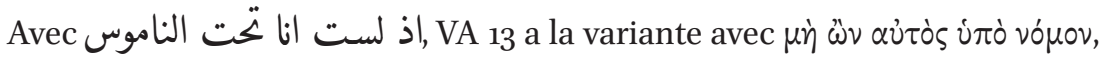
comme « A B C D* F G P 33. 104. 365. 630. 1175. 1505. 1739. latt sy ${ }^{\mathrm{h}}$ co (absent dans $\mathrm{D}^{2} \mathrm{~K} \Psi$ 81. 1241. 1881. 2464. $\mathfrak{M}$ sy).

\section{Co 9,21}

وللدس ليس لهم ناموس مثل الدي للس له ناموس :اذ لست بغير ناموس الله

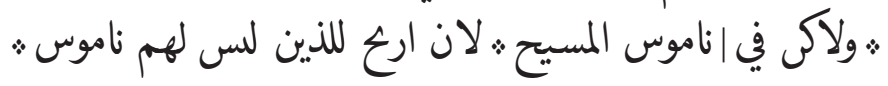

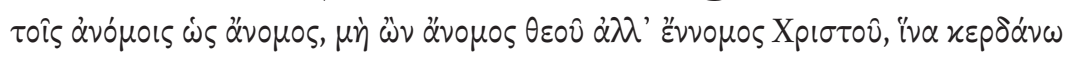

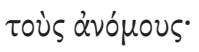

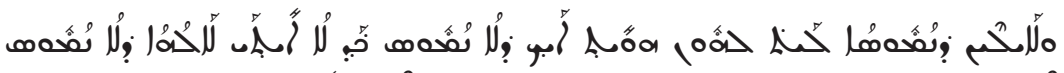

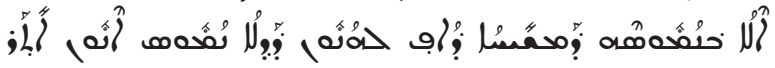

et pour ceux sont sans loi, comme un sans-loi, alors que je ne suis pas sans la loi de Dieu mais dans la loi du Christ, afin de gagner ceux qui n'ont pas de loi ;

Avec ناموس المسيح puis 13 fait partie des témoins qui ont « Dieu » et « le Christ » au genitif (comme P46 « A B C D* F G P 33. 81. 365. 1175. 1739. 1881. 2464 latt sy $^{\mathrm{h}}$ ) et non au datif (comme $\mathrm{D}^{2} \mathrm{KL} \Psi$ 104. 630. 1241. 1505. $\mathrm{M} \mathrm{sy}^{\mathrm{P}}$ ); syp a pour « Dieu » un équivalent du datif lلِّ et pour « le Christ » du génitif : 
1 Co 9,22

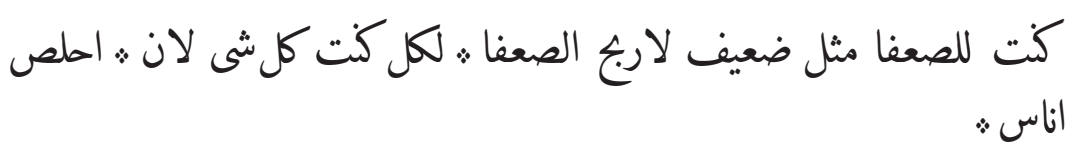

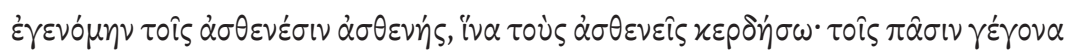
$\pi \dot{\alpha} \nu \tau \alpha, i \nu \alpha \pi \dot{\alpha} \nu \tau \omega \varsigma \tau i \nu \dot{\alpha} \varsigma \sigma \omega \dot{\omega} \sigma \omega$.

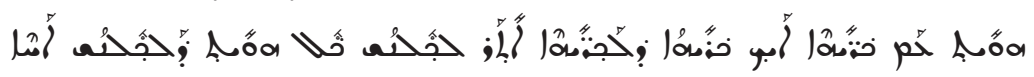
j'ai été pour les faibles comme un faible, pour gagner les faibles ; pour tous j'ai été toute chose, afin de sauver des gens.

Avec مثثل, VA 13 soutient la variante $\dot{\omega} \varsigma$ comme $\aleph^{2}$ C D F G K L P Y 33. 81. 104. 365. 630. 1175. 1241. 1505. 1881. 2464. $\mathrm{M} \mathrm{vg}^{\mathrm{ms}}$ sy co (contre P46 $\aleph^{*}$ A B 1739 lat).

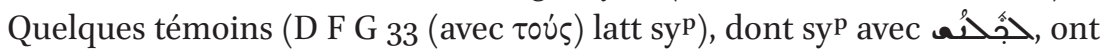

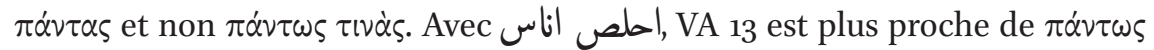

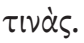

$1 \operatorname{Co~} 9,23$

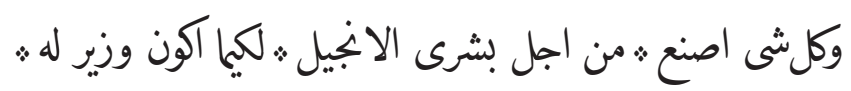

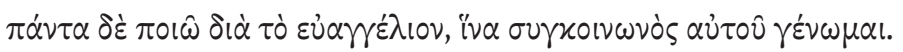

$$
\text { 高 }
$$

Et tout cela, je le fais pour l'annonce de la bonne nouvelle de l'évangile, afin d'être un ministre pour lui.

Avec كلى, VA 13 a la variante grecque $\pi \alpha \dot{~} \nu \tau \alpha$, comme P46 א A B C D F G P 6. 33. 81. 104. 365. 630. 1175. 1739. 1881. 2464. latt (contre K L Ч 1241. 1505. M sy qui ont $\tau 0 \nu \tau 0)$.

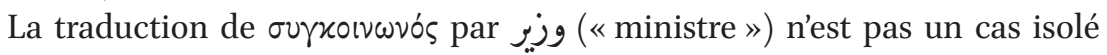

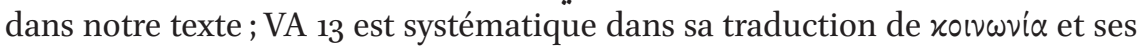
parents (en syp la racine وزر (voir 1,9).

\section{$1 \operatorname{Co~} 9,24$}

$$
\begin{aligned}
& \text { الا تعلمون ان الذين يشتدون : في المحري كلهم يشتدون ث ولاكل واحد هو } \\
& \text { الذى ياخذ الغلبه : فاسعوا لتدركون ث. }
\end{aligned}
$$




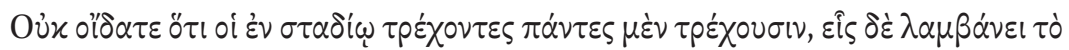

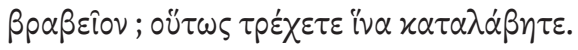

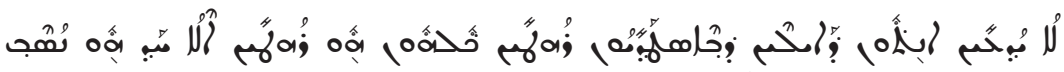

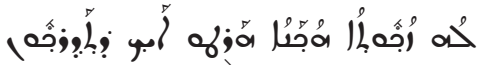

Ne savez-vous pas que ceux qui courent sur la piste, ils courent tous, mais un seul est celui qui atteint la victoire? Courez pour l'atteindre!

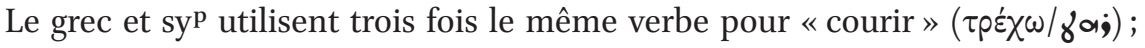
VA 13 a deux fois le verbe اشتد et une fois le verbe سعى.

\section{Co 9,25}

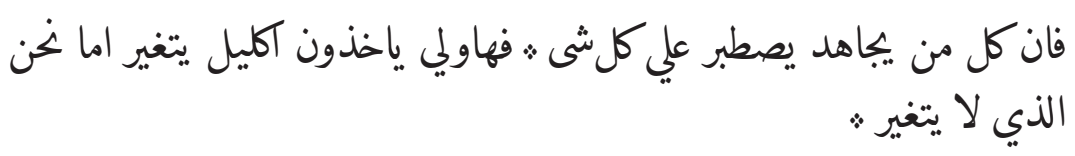

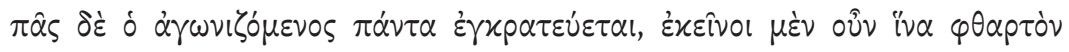

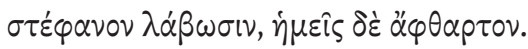

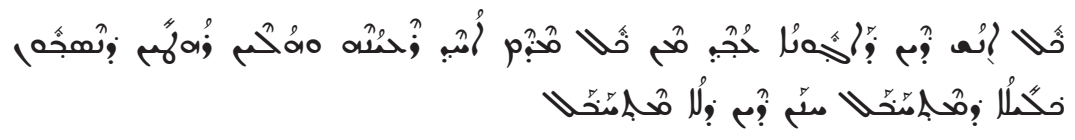

Or tous ceux qui luttent persévèrent en toute chose, mais ceux-ci obtiennent une couronne qui passe, quant à nous, une couronne qui ne passe pas.

À propos de يصطبر, voir 7,9.

$1 \operatorname{Co~} 9,26$

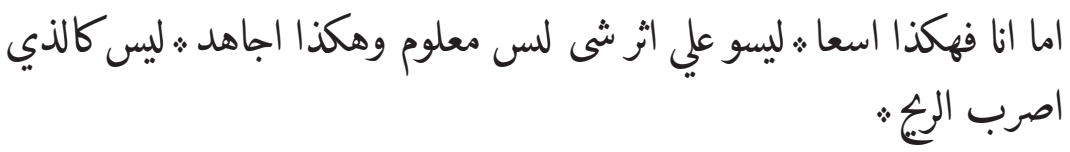

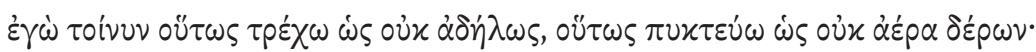

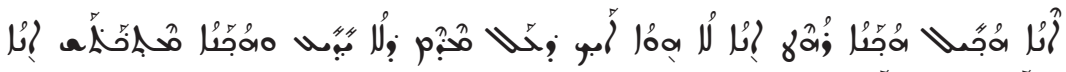

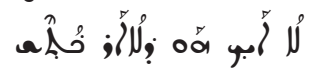

Quant à moi, ainsi je cours, non pas à la suite d'une chose inconnue, et ainsi je lutte, non pas comme celui qui frappe le vent, 
Nous lisons ليسو mais comprenons ليسوا en effet, le pluriel ليسو ne ferait pas sens ici (voir aussi 1,$26 ; 12,14)^{104}$.

1 Co 9,27

ولاكن اذل حسدى واخصعه : لعلى انا الذى بشرت لاخزين : آكون انا مرذل :

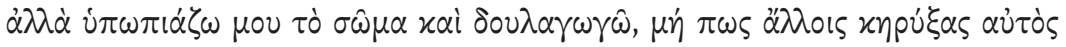

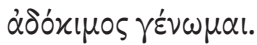

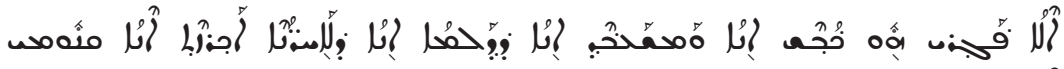
ט.

mais j'humilie mon corps et je le soumets, de peur que moi qui ai annoncé la bonne nouvelle à d'autres, je sois rejeté.

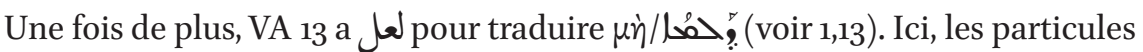
en grec et en syriaque semblent avoir le sens de « de peur que », « afin que ne pas »; nous supposons que لعل a le même sens (voir nos remarques en 1,13 et en 8,9 ).

\subsection{Chapitre 10}

1 Co 10,1

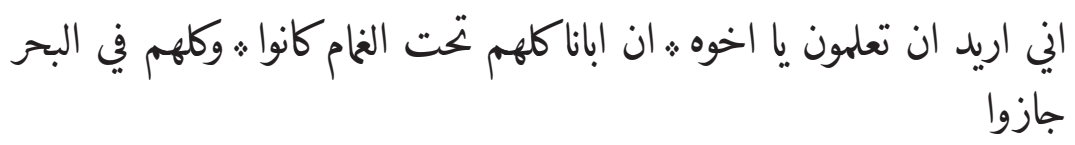

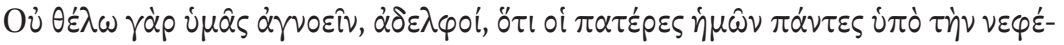
$\lambda \eta \nu \hat{\eta} \sigma \alpha \nu$ xai $\pi \dot{\alpha} \nu \tau \varepsilon \varsigma \delta i \dot{\alpha} \tau \hat{\eta} \varsigma \theta \alpha \lambda \dot{\alpha} \sigma \sigma \eta \varsigma \delta i \hat{\eta} \lambda \theta 0 \nu$

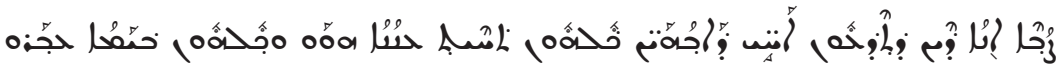
Je veux que vous sachiez, ô frères : nos pères étaient tous sous la nuée et ils ont tous traversé la mer,

Pour traduire $\delta ı \alpha ́$, un complément d'object direct aurait suff ; في correspond à la préposition ص de syp.

104 Voir 2.2 Eléments de moyen arabe dans Vat. Ar. 13 (1 Corinthiens) :22) Négation ليس. 
1 Co 10,2

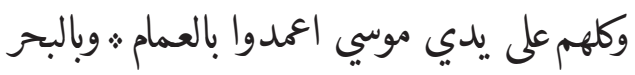

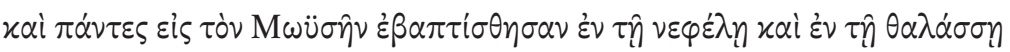

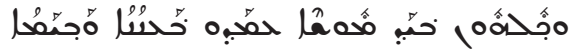
et ils ont tous été baptisés par le biais de Moïse dans la nuée et dans la mer,

À propos du nom propre موسى, voir 4.1 Noms propres.

Nous traduisons اعمد اعد اعدوا au passif car nous pensons que la forme IV VA 13 un sens actif (voir 1,13).

1 Co 10,3

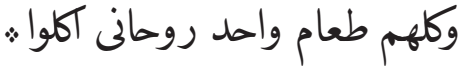

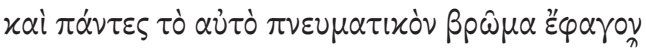

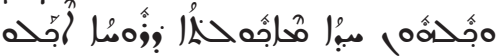

et ils ont tous mangé une même nourriture spirituelle,

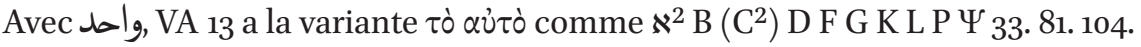

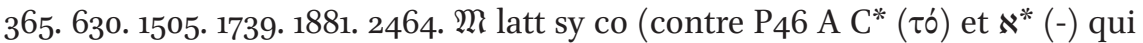
n'ont pas de démonstratif).

\section{Co 10,4}

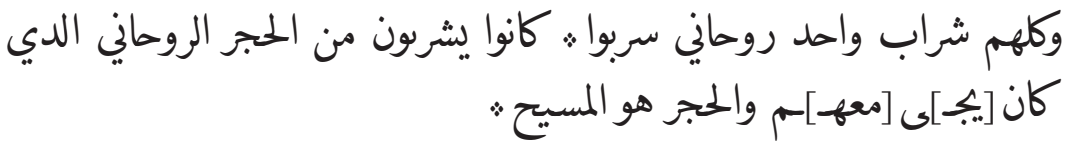

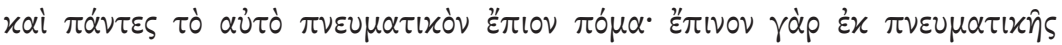

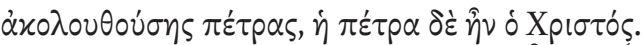

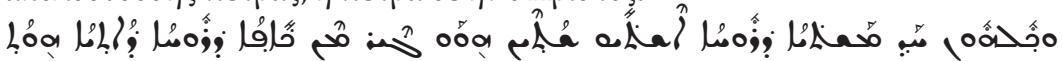

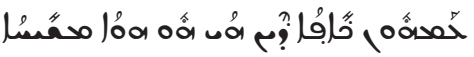

et ils ont tous bu une même boisson spirituelle; ils buvaient au rocher spirituel qui allait avec eux et le rocher, c'est le Christ.

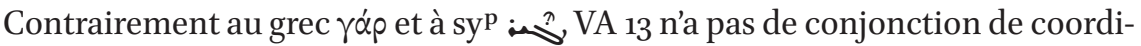
nation pour introduire le deuxième membre du verset. 


\section{Co 10,5}

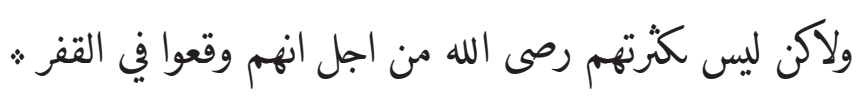

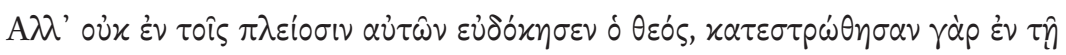

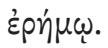

$$
\text { 草 }
$$

Mais de la majeure partie d'entre eux, Dieu ne fut pas satisfait puisqu'ils tombèrent dans le désert.

\section{Co 10,6}

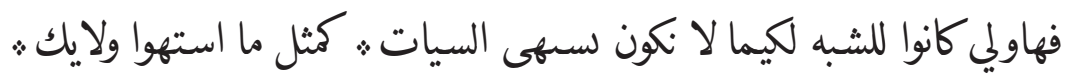

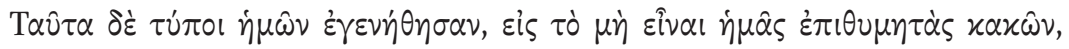

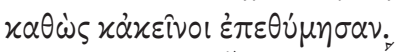

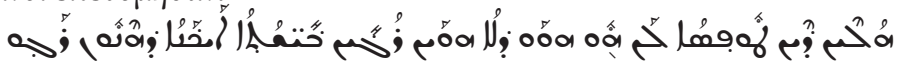

Ces événements ont eu lieu pour l'exemple afin que nous ne désirions pas les mauvaises choses, comme ce qu'ils ont désiré, eux.

Le grec a un neutre pluriel se rapportant aux événements, suivi de $\tau \dot{\tau} \pi 0$ เ avec $\dot{\eta} \mu \omega \nu^{105}$. syp a le terme

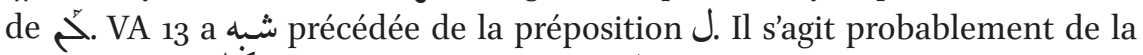
construction $\dot{\zeta}$ suivie de la préposition ل pour « devenir» (BLAU, § 305.2). VA 13 a donc une construction proche à la fois du grec et de syp, sauf qu'il n'a

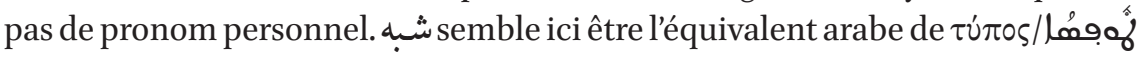
(voir les autres utilisations de cette racine en 4,$7 ; 4,16 ; 10,11$; 11,1. L'utilisation est différente en 15,49 ).

On notera que le grec a comme sujet un neutre pluriel $\tau \alpha \hat{\tau} \alpha$, qui se réfère donc aux faits précédents, tandis que syp et VA 13 avec leur démonstratif pluriel peuvent autant désigner les faits que les personnes tombées dans le désert au verset précédent ${ }^{106}$.

\footnotetext{
105 Selon Senft, il s'agit ici d'une lecture «typologique» de l'histoire, les événements de l'Exode étant des préfigurations pour l'histoire de l'Église (SENFT, p. 130).

106 Voir 2.2 Eléments de moyen arabe dans Vat. Ar. 13 (1 Corinthiens) :16) Genre et nombre.
} 
1 Co 10,7

ولا ايصا نكون نعبد الاوثان : مكما عبدو اناس منهم : مكا انه مكتوب جلس

f. 111r

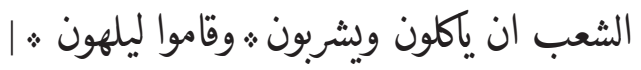

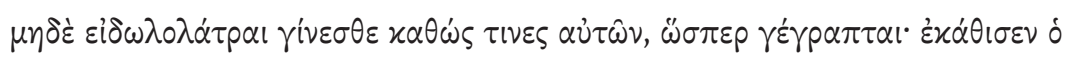

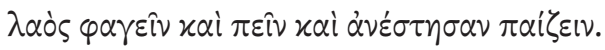

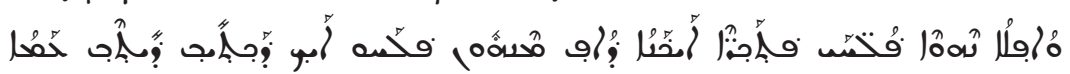

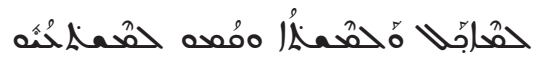

N'adorons pas non plus les idoles comme certains parmi eux [les] ont adorées, comme il est écrit : le peuple s'est assis pour manger et boire et il se leva pour s'amuser.

Le grec a un impératif à la $2^{\mathrm{e}}$ personne du pluriel $\gamma^{\prime} v \varepsilon \sigma \theta \varepsilon$, tandis qu'on trouve une $1^{\text {ère }}$ personne du pluriel chez syp ainsi que sy ( lo $^{n} \alpha^{n}$ à l'inaccompli) et dans VA 13 (ن à l’impératif).

1 Co 10,8

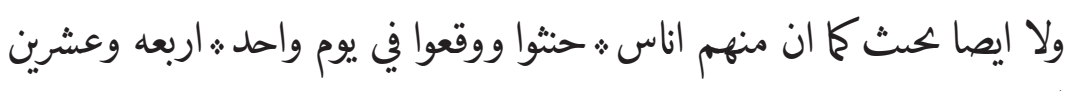

النه

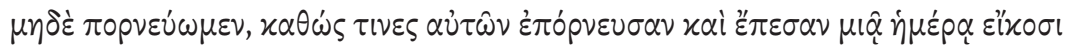

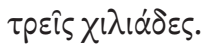

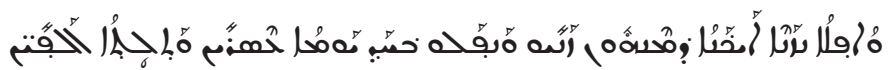

Et ne nous parjurons pas non plus comme certains parmi eux se sont parjurés - et en un jour, il en tomba vingt quatre mille.

حنث «parjurer» (KAZIMIRSKI 1, p. 501) plutôt que زj, racine que l'on trouve lorsqu'il est question de fornication avec en grec $\pi$ opvev́w et ses dérivés et en syp la racine

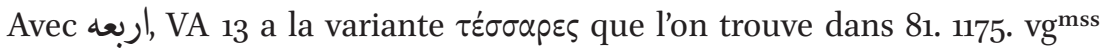
$\mathrm{sy}^{\mathrm{h}}$; cette variante dans le nombre de morts peut être une harmonisation sur le texte de Nombres 25,9. 


\section{Co 10,9}

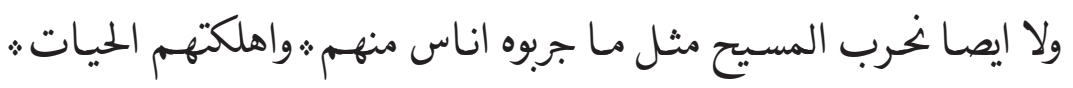

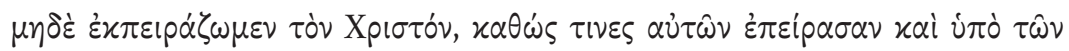
ö $\varphi \varepsilon \omega \nu \alpha \dot{\alpha} \omega^{\prime} \lambda \nu \nu \tau \tau$.

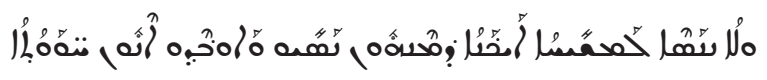

Et ne mettons pas non plus à l'épreuve le Christ, comme certains d'entre eux l'ont mis à l'épreuve - et les serpents les ont anéantis.

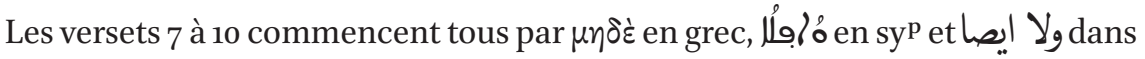
VA 13 (à l'exception du v. 9, au début duquel syp a seulement No). La formulation de VA 13 est plus proche de syp.

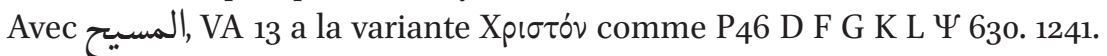
1505. 1739.1881. Ml latt sy co (contre א B C P 33.104. 326. 365. 1175. 2464. sy ${ }^{\text {hmg }}$ qui ont xúprov et A 81 qui ont $\theta$ róv).

Avec ils les ont anéantis », VA 13 a une formulation active, comme syp.

\section{Co 10,10}

$$
\text { ولا ايصا تزعمون كما ان اناس منهم تزعوا : فهلكوا علي يدي المفسد : }
$$

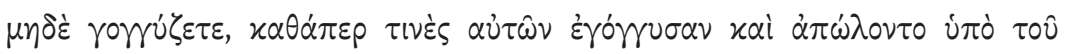

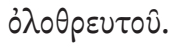

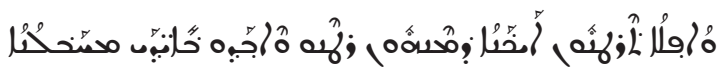

Et ne discutez pas non plus, comme certains d'entre eux ont discuté : ils périrent par la main du corrupteur.

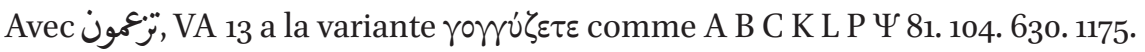

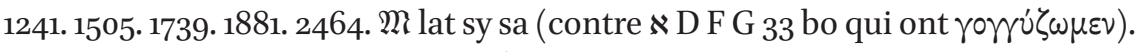

Nous lisons dans le manuscrit تزعمون; la forme v est inattendue, vu que la forme I vient d'être utilisée تزعمون au début du verset .

À propos de المفسد, voir 4.3.5 Autres termes.

\section{Co 10,11}

$$
\text { فهذه شبه عرصت لهاولي : وكبت لعطتنا ثان اخز الدهور علينا بلغت ؛ }
$$




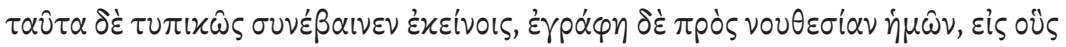

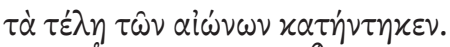

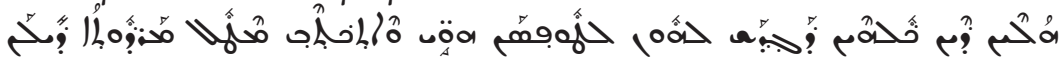

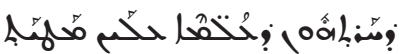

Cela leur est arrivé en exemple et a été écrit pour notre exhortation ; la fin des temps nous est parvenue.

Tout comme A B 33. 630. 1175. 1739. 1881. 2464, VA 13 n'a pas de variante avec

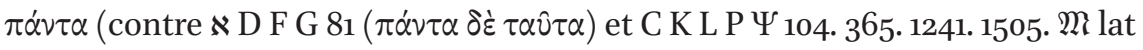
$\operatorname{sy}(\tau \alpha \hat{\tau} \tau \alpha \delta \dot{\varepsilon} \pi \dot{\alpha} \nu \tau \alpha))$.

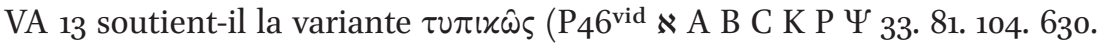

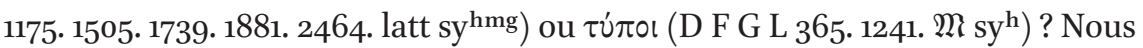
pensons qu'ici شبه est un adverbe, ce qui est plus proche de la variante $\tau 0 \pi i x \omega \hat{~}$

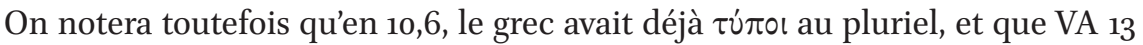

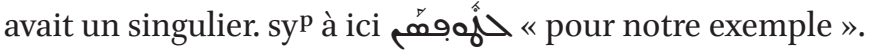

Il manque un relatif ou une conjonction pour lier le dernier membre du verset, ان semblant introduire une nouvelle phrase.

\section{Co 10,12}

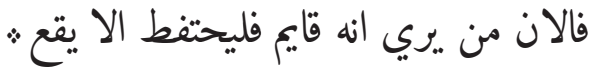

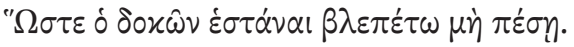

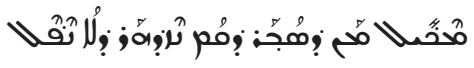

Or maintenant, celui qui pense être debout, qu'il prenne garde de ne pas tomber.

VA 13 a au début de verset un adverbe temporel الان, ce qui le rapproche de syp

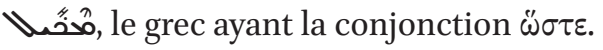

1 Co 10,13

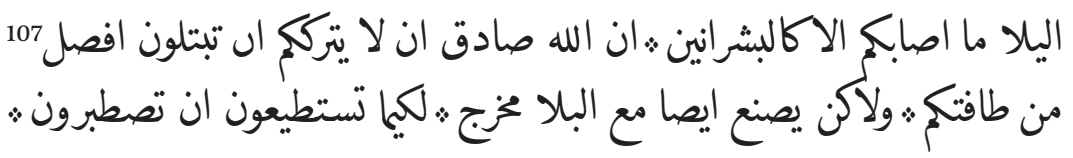

107 À propos de افضل, voir 1 Co 4,6, note 51. 


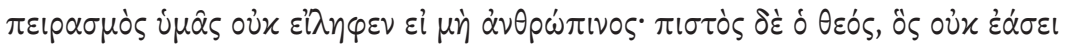

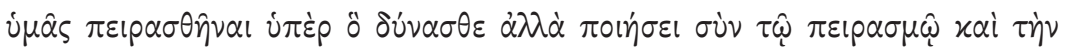

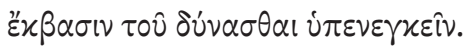

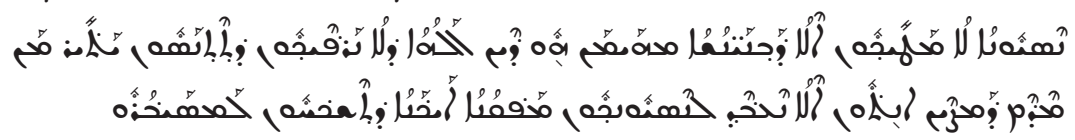

Lépreuve ne vous arrive pas, sauf à la mesure des humains; Dieu est fidèle, il ne vous laissera pas être éprouvés au delà de votre capacité, mais, avec l'épreuve, il crée aussi une issue, afin que vous puissiez persévérer.

Il est difficile de déterminer si VA 13 traduit par كالبشرانين comme aux hu-

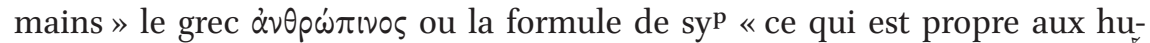

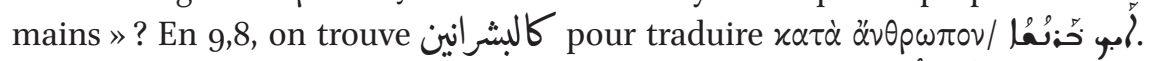

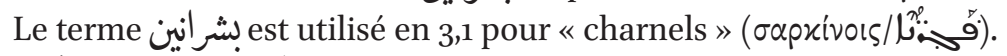

À propos de صادوقين, voir notre remarque en 1,9.

À propos de تصطبرون, voir 7,9.

\section{Co 10,14}

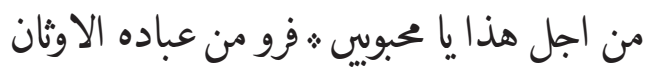

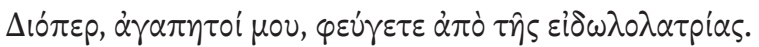

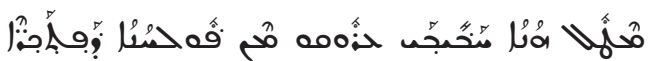

À cause de cela, ô bien aimés, fuyez l'adoration des idoles.

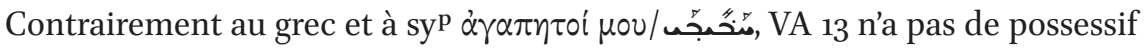
après محبوبي.

\section{Co 10,15}

$$
\text { كلاحلها اقول : اقصوا انتم الشى الذي اقوله : }
$$

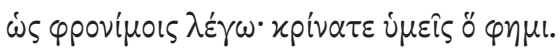

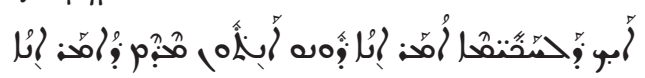

Je parle comme à ceux qui sont cléments; jugez vous-même ce que je dis.

VA 13 a حلم « cléments » pour traduire ppovínoıs comme en 4,10 (voir aussi 6,5).

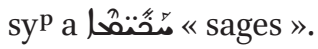


1 Co 10,16

$$
\begin{aligned}
& \text { الكاس : الشكر الذي نبرك ث اليس هو وزير لدم المسيح ث:والخبز الذي نقسم ث } \\
& \text { اليس هو وزيو الجسد الربب }
\end{aligned}
$$

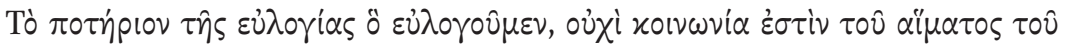

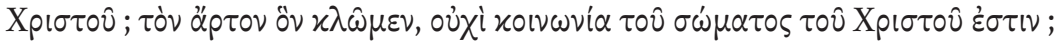

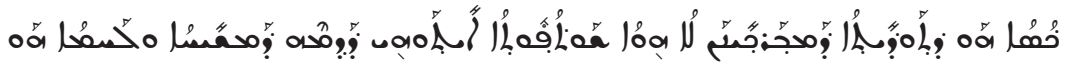

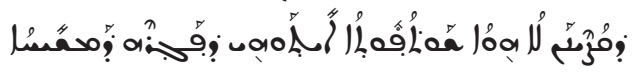

La coupe de remerciement que nous bénissons, n'est-elle pas ministre du sang du Christ? Et le pain que nous partageons, n'est-il pas ministre du corps du Seigneur?

Il semblerait que الكاس الشكs soit une erreur ; vu qu'il y a un rapport d'annexion, le premier article est superflu (voir 1,$28 ; 12,4)$.

On notera que le nom كاس, féminin en arabe classique, est masculin dans notre texte (voir aussi 2.2 Éléments de moyen arabe dans Vat. Ar. 13 (1 Corinthiens) : 16) Genre et nombre).

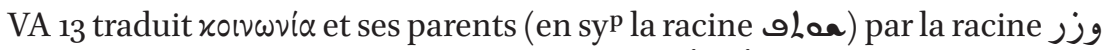

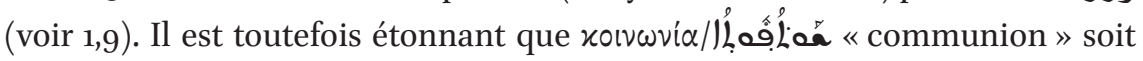
en quelque sorte personnifiée avec le terme de وزي «ministre ».

VA 13 a d'abord le Christ» puis le Seigneur », tandis que le grec et syp ont deux fois « le Christ ».

\section{Co 10,17}

من اجل انه حبز واحد ث فنحن جسد واحد ث وان كا كير ث كلنا خبز واحد ناخد :

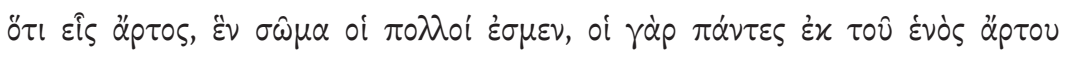
$\mu \varepsilon \tau \varepsilon \dot{\chi} \chi \mu \varepsilon \nu^{108}$.

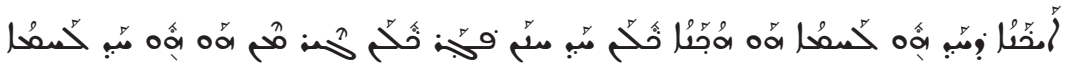

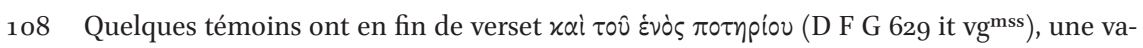
riante qui n'est pas soutenue par VA 13 . 
Puisqu'il y a un seul pain, nous sommes un seul corps et même si nous sommes nombreux, tous, nous prenons un seul pain.

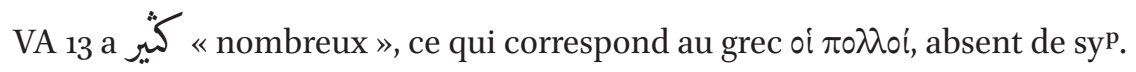

\section{Co 10,18}

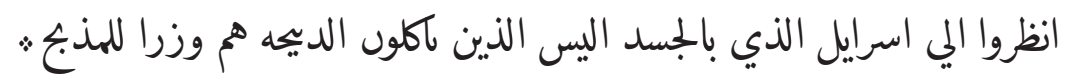

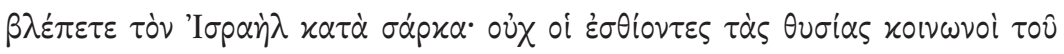

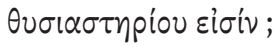

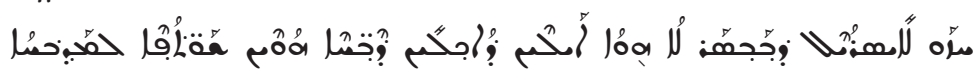

Regardez Israël qui est par le corps : n'est-ce pas ceux qui mangent la viande des sacrifices qui sont ministres de l'autel?

À propos de اسرايل, voir 4.1 Noms propres.

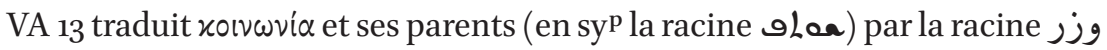

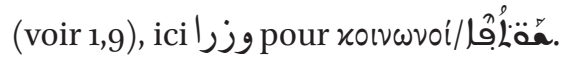

\section{Co 10,19}

$$
\text { فاذا اقول : الاوثان تحد شي ث. او دبيحه الاوثان شي هي }
$$

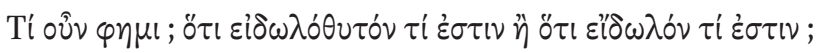

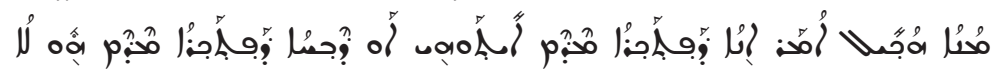

Or que dis-je? Les idoles sont-elles considérées comme étant quelque chose, ou la viande des sacrifices aux idoles est-elle quelque chose?

Dans VA 13, il est d'abord question des idoles الاوثنان puis de la viande sacrifiée aux idoles دبيحه الاوثان; cet ordre de phrase correspond à syp et à sy' pluriel les idoles » tandis que le grec et le syriaque ont des singuliers.

VA 13 est seul à introduire un autre verbe que le verbe «être 》 ع عِّ être considéré ») ; on notera toutefois une construction similaire à syp qui a d'abord

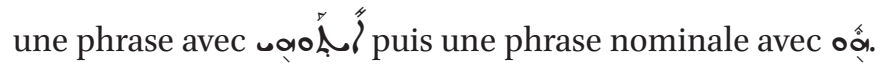

Par contre, la négation introduite par syp en fin de verset $\mathbb{N}$ ne se trouve pas dans VA 13. 
1 Co 10,20

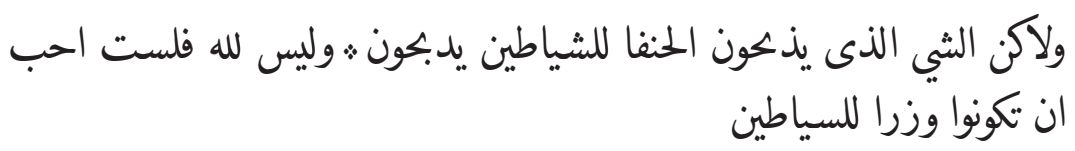

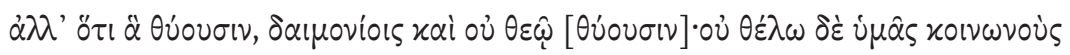

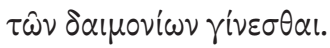

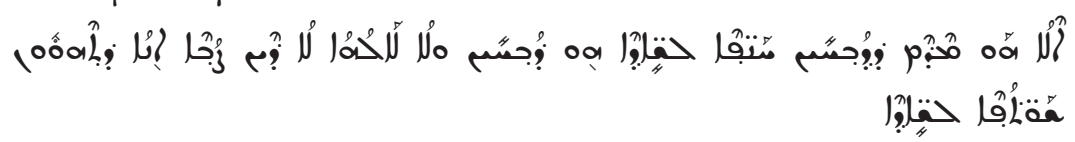

Mais ce que les païens sacrifient, ils le sacrifient aux démons et non à Dieu, or je ne veux pas que vous soyez ministres des démons.

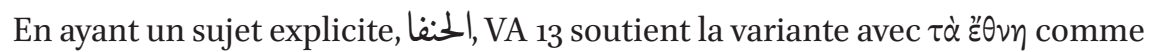
sujet, comme $\mathrm{P}_{4} 6$ vid $\mathrm{A}$ C K (L) P Y 33. 81. 104. 365. 630. 1175. 1241. 1505. 1739.

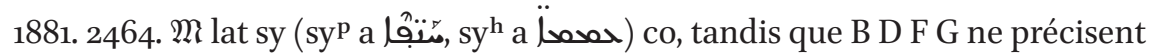
pas le sujet. On notera que l'on trouve ailleurs le terme quand le texte grec

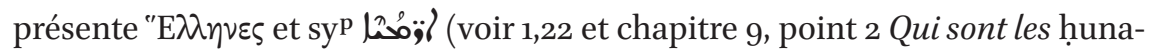
fa'dans 1 Corinthiens?).

1 Co 10,21

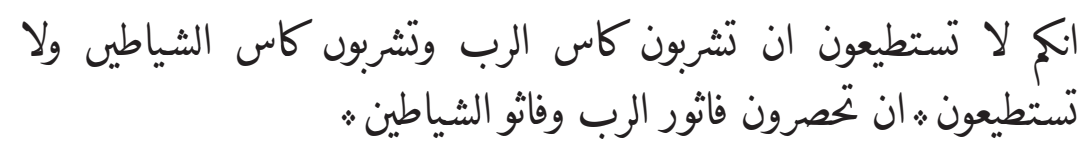

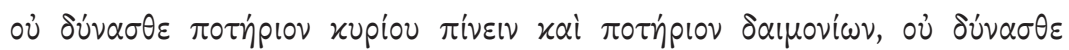

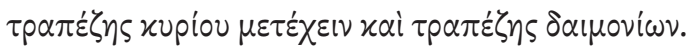

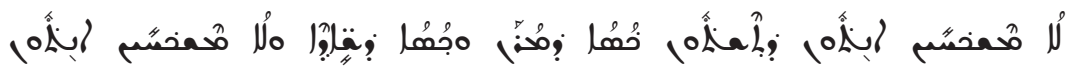

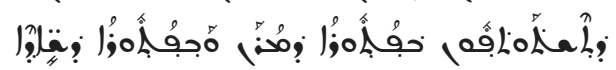

Or vous ne pouvez pas boire la coupe du Seigneur et la coupe des démons, et vous ne pouvez pas être présents à la table du Seigneur et à la table des démons.

فاثور سفاثو الثياطين Lais il s'agit ici de فاثور Nous lisons dans le manuscrit en arabe est un emprunt du syriaque Voir 4.2 Vocabulaire d'emprunt. 


\section{Co 10,22}

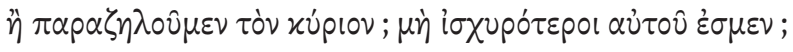

$$
\text { f. ام لعلنا نعي الرب | ام لعلنا اشد منه : }
$$

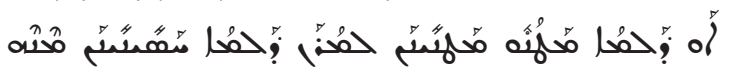

Ou bien est-ce que nous rendons le Seigneur jaloux? Ou est-ce que nous sommes plus forts que lui?

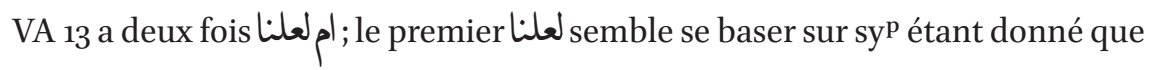
le grec a seulement $\ddot{\eta}$; le second $\mathbf{\rho}$ ne se trouve ni en grec ni en syp. À propos de لعل, voir 1,13.

\section{Co 10,23}

$$
\text { كل }
$$

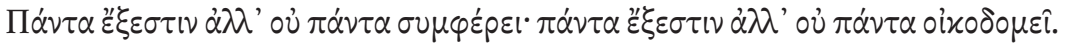

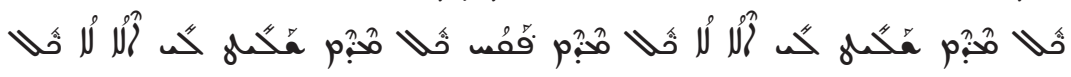

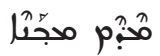

Tout m'est permis mais tout n'est pas utile, tout m'est permis mais tout n'édifie pas.

VA 13 a deux fois الي ce qui correspond aux $\mu$ or que l'on trouve dans $\aleph^{2} \mathrm{C}^{3} \mathrm{H} \mathrm{K} \mathrm{L}$ $\Psi$ 104. 365. 630. 1175. 1241. 1505. ( $\left(\mathrm{P}_{1739^{*}}\right) \mathrm{M} \mathrm{t}$ vg $\mathrm{gl}^{\mathrm{cl}}$ sy (absents dans $\mathrm{P} 46 \aleph^{*}$ A B C* D F G (33). 81. 1739*.1881. 2464 lat co).

\section{Co 10,24}

$$
\text { لا يكون كل انسان يريد لنفسه : ولاكن ايصا لصاحبه : }
$$

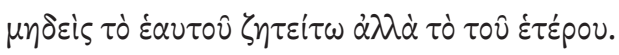

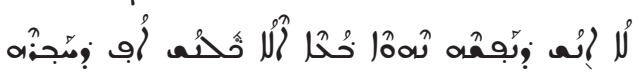

Que personne ne veuille pour lui-même, mais aussi pour son prochain. 


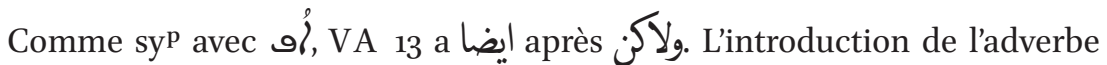
« aussi » tend à changer le sens du verset: que personne ne veuille des choses « que » pour soi, mais aussi pour son prochain.

VA 13 diffère du grec et de syp en ne traduisant pas la tournure $\tau$ tò suivie du génitif (traduit en sy par ?) mais en utilisant la préposition $\mathrm{J}$.

VA 13 n'ayant pas de sujet dans le deuxième membre de la phrase, il sou-

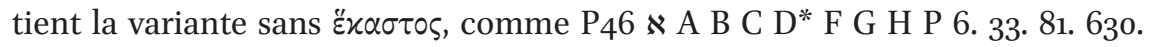
1175. 1241. 1739. 1881. 2464. latt co (contre $\mathrm{D}^{2} \mathrm{~K}$ L $\Psi$ 104. 365. 1505. M sy qui ont

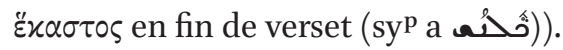

\section{Co 10,25}

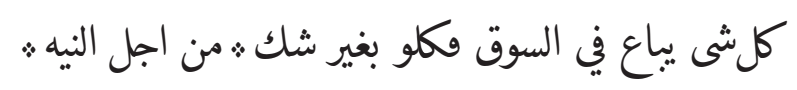

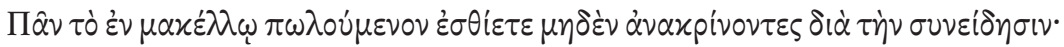

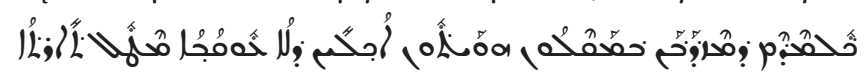

Tout ce qui est vendu au marché, mangez-en sans [faire de] scandale, pour raison de conscience.

VA 13 est seul ici à introduire l'idée de scandale (à propos de شك شur voir 1,23), tandis que le grec et syp partagent l'idée d'interrogatoire ou d'enquête : «sans

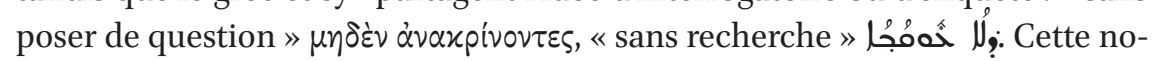
tion n'est pas réintroduite au v. 10,27.

À propos de نية voir 8,7.

1 Co 10,26

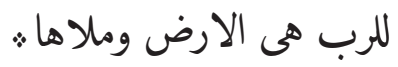

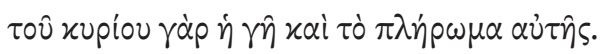

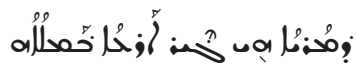

$\mathrm{Au}$ Seigneur est la terre et ce qui la remplit. 


\section{Co 10,27}

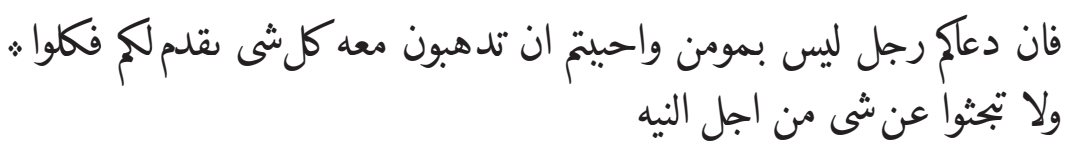

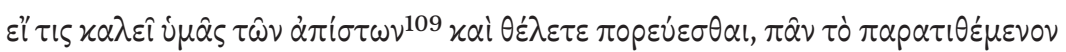

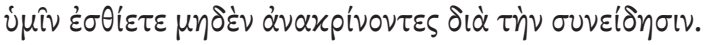

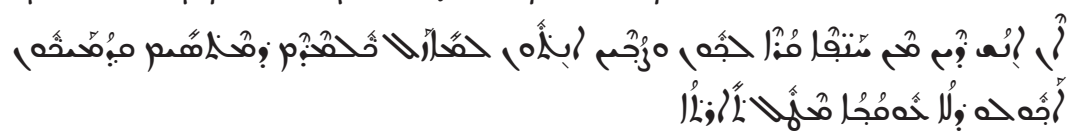

Si un homme qui n'est pas croyant vous invite et que vous voulez aller avec lui, mangez tout ce qui vous est offert et ne posez pas de question à ce propos, pour raison de conscience.

Avec un homme qui n'est pas croyant », VA 13 semble plus proche du grec $\tau \iota \varsigma \tau \hat{\omega} \nu \dot{\alpha} \pi i \sigma \tau \omega \nu$ «quelqu'un des non-croyants", que du choix de vocabulaire de syp

\section{Co 10,28}

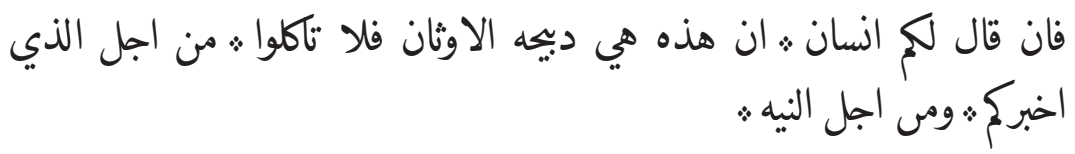

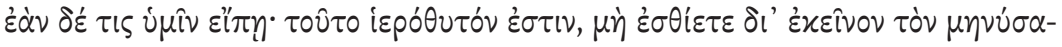

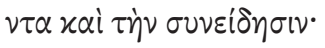

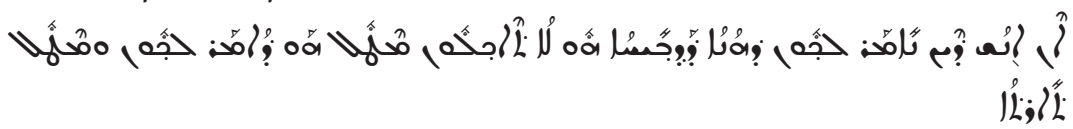

Mais si quelqu'un vous dit qu'il s'agit de viande des sacrifices aux idoles, n'en mangez pas, à cause de celui qui vous a averti et pour raison de conscience.

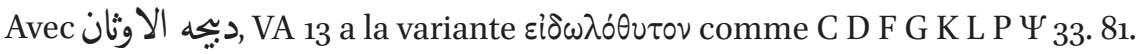
104. 365. 630. $1175^{\mathrm{c}} \cdot 1241.1505 \cdot 1739^{\mathrm{c}} \cdot 1881.2464 \mathrm{M}^{2}$ lat sy bo (contre contre P46

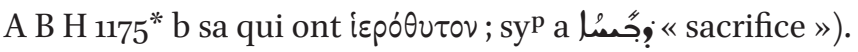

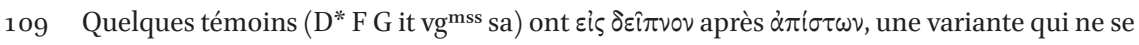
trouve pas dans VA 13. 
Plusieurs témoins $\left(\mathrm{H}^{\mathrm{c}} \mathrm{K} \mathrm{L} \Psi\right.$ 104. $\left.1505 \mathrm{M}^{\mathrm{h}} \mathrm{y}^{\mathrm{h}}\right)$ répètent le verset 26 à la fin du verset 28 ; VA 13 n'a pas cette variante, comme $\mathrm{A} \mathrm{B} \mathrm{C*} \mathrm{D} \mathrm{F} \mathrm{G} \mathrm{H}^{*} \mathrm{P} 33.81 .365$. 630. 1175. 1241. 1739. 1881. 2464. latt syp co.

\section{Co 10,29}

$$
\text { قوالنه التى اقول ليست نيتى * ولاك نيه اخر ث على ايشى حريتى انا تدان ث من }
$$

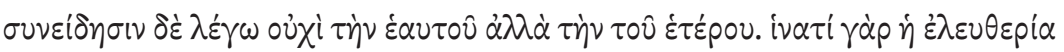

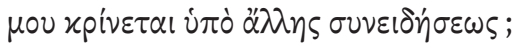

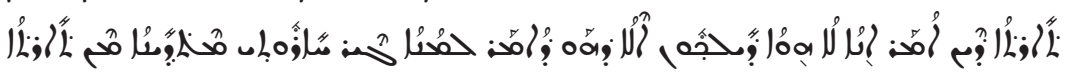

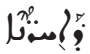

La conscience dont je parle, ce n'est pas ma conscience mais la conscience d'un autre; pour quelle raison ma liberté est-elle jugée selon une conscience autre?

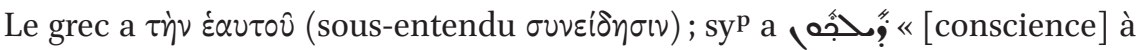
vous ».VA 13 a un suffixe à la 1ère personne du singulier نيتى "ma conscience »,

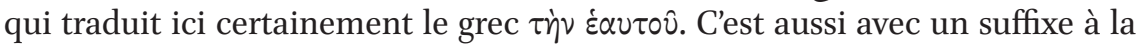
$1^{\text {ère }}$ personne du singulier que sy ${ }^{\text {h }}$ traduit le grec : و moi ».

syp a ensuite

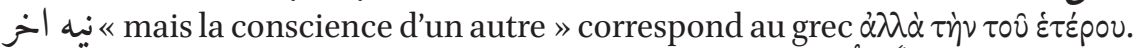

syp a une autre variante propre en fin de verset

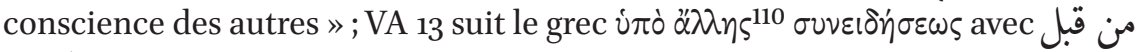
« selon une conscience autre».

\section{Co 10,30}

فان كت انا بالنعمه اعمل هـ لمادا يجدف علي من قل الشى الذي انا اعترف ؛

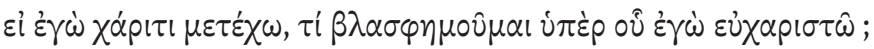

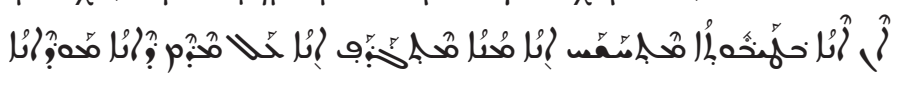

110 Quelques témoins ont ici $\alpha$ đí $\sigma \tau 0 v$ (F G ar b d vg $\left.{ }^{\mathrm{mss}}\right)$. 
Si je fais cela en rendant grâce, pourquoi médit-on contre moi au nom de la chose pour laquelle je suis reconnaissant?

Le choix du verbe اغترف ( confesser », « reconnaître ») semble plus proche du verbe de sy $\mathrm{p}^{\mathrm{p}} \mathrm{ol}$ ( « reconnaître», « confesser», mais aussi «rendre grâce »)

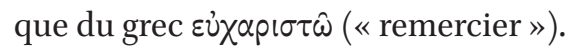

1 Co 10,31

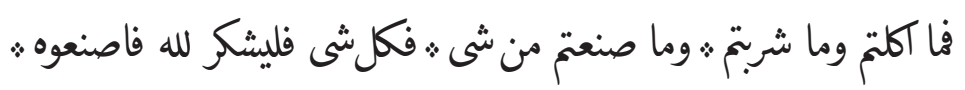

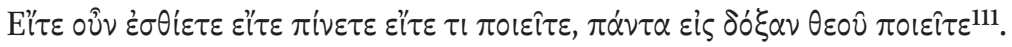

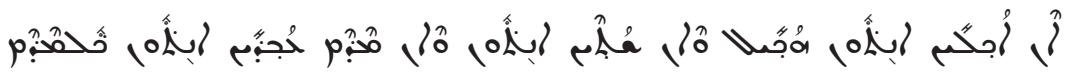

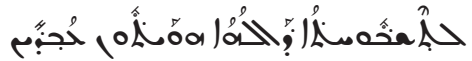

Quoi que vous mangiez, quoi que vous buviez, quoi que vous fassiez, faites tout cela pour que cela glorifie Dieu,

Nous comprenons que فليشك a comme sujet objet (ici indiqué par la préposition ل ل ) «ieu » : toute chose doit être faite en vue que celle-ci rende grâce à Dieu. Le grec et syp ont ici l'idée de gloire : « pour

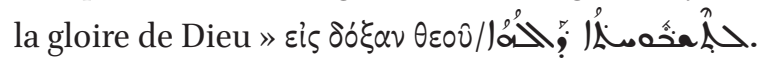

1 Co 10,32

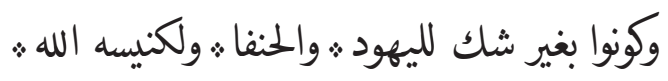

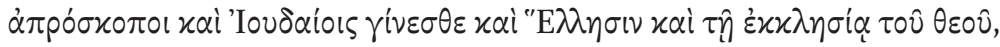

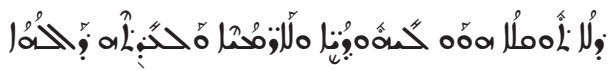
et ne soyez une cause de scandale ni pour les juifs, ni pour les païens, ni pour l'Église de Dieu.

Tandis que le grec a un adjectif $\dot{\alpha} \pi \rho \dot{\sigma} \kappa 0 \pi 0$, VA 13 utilise une expression

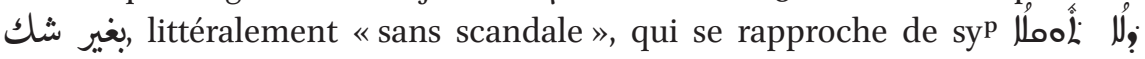

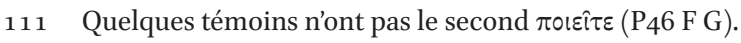


《 sans scandale». Nous traduisons ici وكونوا بغير شك par « et ne soyez pas une

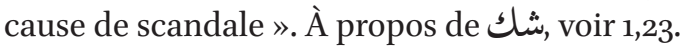

À propos de حنف, voir 1,22 et chapitre 9, point 2 Qui sont les ḥunafả dans 1 Corinthiens?

1 Co 10,33

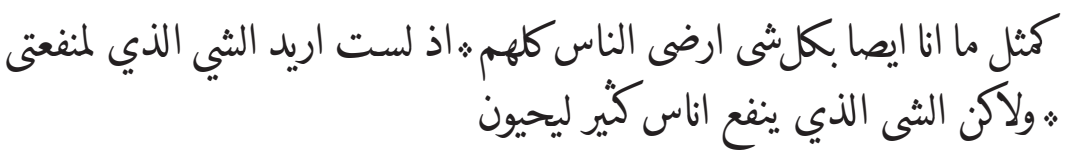

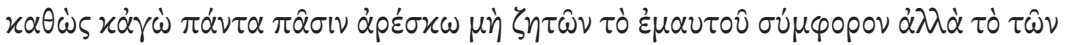
$\pi \circ \lambda \lambda \omega \nu, " i \nu \alpha \sigma \omega \theta \omega \hat{\omega} \sigma \nu$.

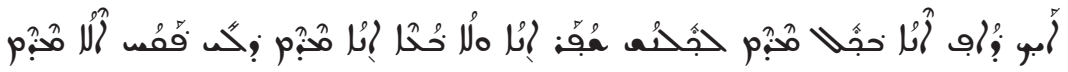

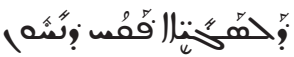

De même, moi, je contente aussi tout le monde en tout, en ne voulant rien pour mon intérêt mais ce qui est utile au grand nombre afin qu'ils vivent.

\section{$1.11 \quad$ Chapitre 11}

1 Co 11,1

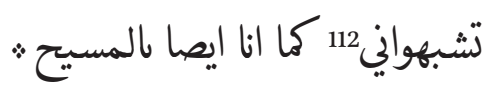

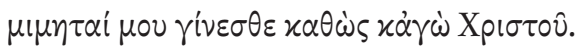

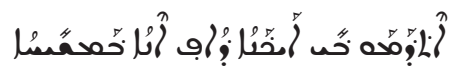

Imitez-moi comme moi aussi [j'imite] le Christ.

1 Co 11,2

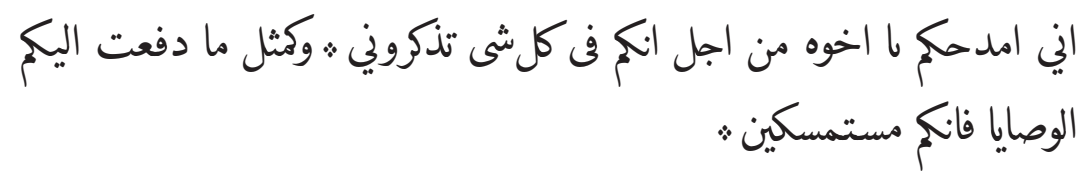

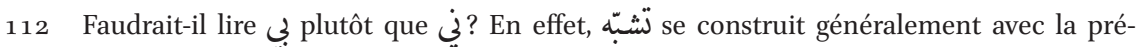
position بـ (KAZ̈ImIRSKI 1, p. 1187). C'est effectivement avec cette construction que l'on trouve ce verbe en 4,16. De plus, avec le pronom affixe, l'alif otiosum est superflu. 


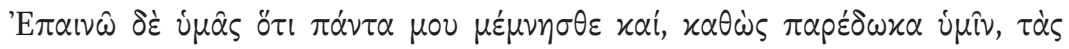

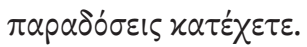

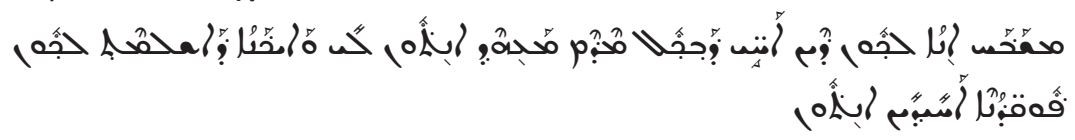

Je vous loue, ô frères, parce qu'en toute chose, vous vous rappelez de moi et que, comme je vous les ai transmis, vous retenez les commandements.

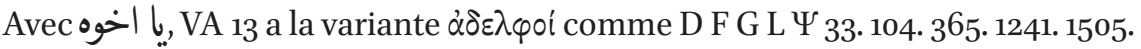
M latt sy (contre P46 « A B C P 81. 630. 1175. 1739. 1881. 2464 co).

\section{Co 11,3}

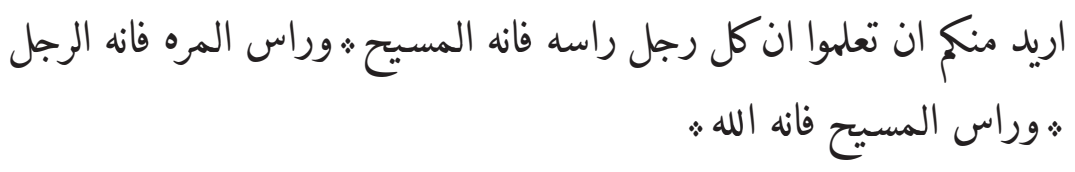

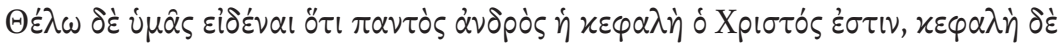

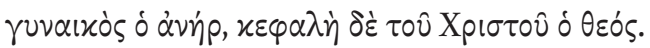

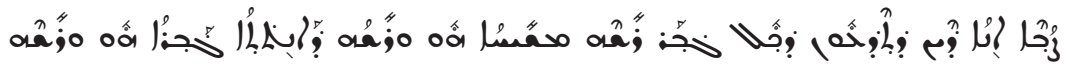

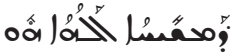

Je veux de vous que vous sachiez : la tête de tout homme, c'est le Christ et la tête de la femme, c'est l'homme, et la tête du Christ, c'est Dieu.

Le redoublement de تكون est probablement une erreur due à un changement de ligne.

\section{Co 11,4}

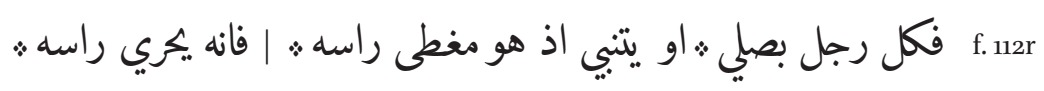

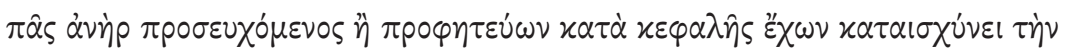
$\varepsilon \varepsilon \varphi \lambda \dot{\eta} \nu \alpha \dot{\tau} \tau 0 \hat{.}$

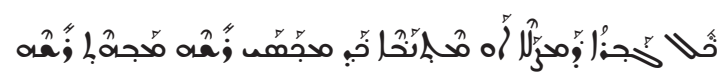

Tout homme qui prie ou prophétise quand sa tête est couverte, il déshonore sa tête, 


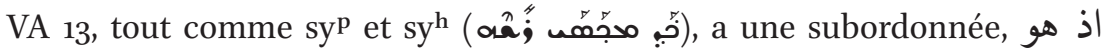
ه quand sa tête est découverte », pour traduire la formule elliptique grecque $\varkappa \alpha \tau \dot{\alpha} \varkappa \varepsilon \varphi \alpha \lambda \hat{\eta} \varsigma$ है $\chi \omega \nu$.

\section{Co 11,5}

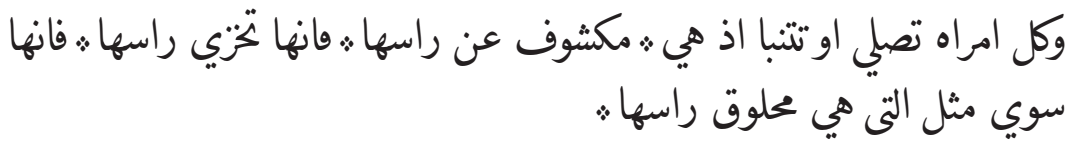

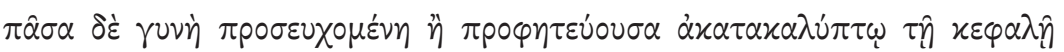

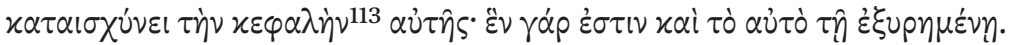

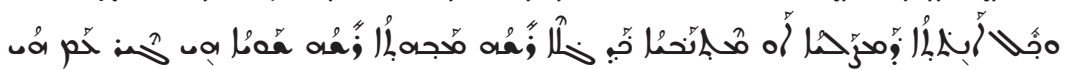

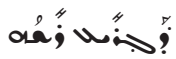
et toute femme qui prie ou prophétise quand sa tête est découverte, elle déshonore sa tête ; elle est exactement comme celle dont la tête est rasée.

Comme au verset précédent, VA 13 a une phrase subordonnée introduite par اذ هي مكشوف عن راسها:اذ اذ la construction de celle-ci est toutefois difficile. Le participe passif dكشوف découvert» se réfère-t-il à la femme ou à la tête de celle-ci ? Si c'est la femme qui est découverte « de la tête», le participe devrait être au féminin (comme en 11,13), et si c'est la tête qui est découverte (comme

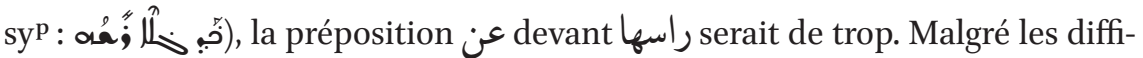
cultés grammaticales, le sens est clair et nous traduisons : « quand sa tête est découverte ».

Comme syp ${ }^{p}{ }^{2}$ cipe passif .

\section{Co 11,6}

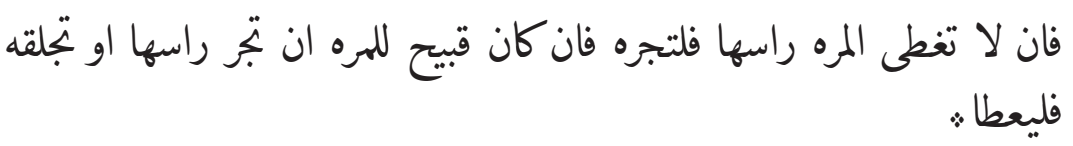

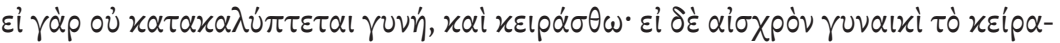

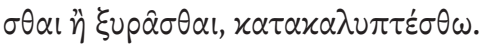

113 Quelques témoins $\left(\mathrm{P}_{4} 6^{\text {vid }} \mathrm{B} \mathrm{D}^{1}\right.$ 6. 629. $\left.945 \mathrm{pm}\right)$ ont ici $\dot{\varepsilon} \alpha \nu \tau \hat{\eta} \varsigma$, variante qui ne se trouve pas dans VA 13. 


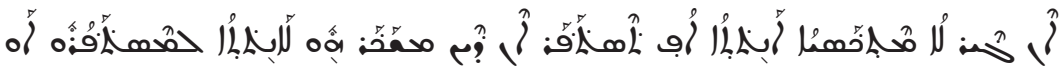

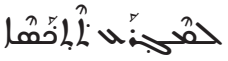

Si une femme ne couvre pas sa tête, qu'elle la tonde! Mais s'il est disgracieux pour la femme de tondre sa tête ou de la raser, qu'elle soit couverte.

Contrairement au grec et à syp, VA 13 a un complément d'objet aux verbes : «lle tond sa tête » ; تجلقي الرم ن elle la rase».

En fin de verset, le verbe est au masculin : c'est la tête qui doit être couverte ; en syp et sy ${ }^{\mathrm{h}}$, le féminin indique que c'est la femme qui doit être couverte; le grec est ambigu.

\section{Co 11,7}

فاما الرجل فلا ينبعا له ان يغطى راسه ث من اجل انه بصوره الله ث: ومجده اما

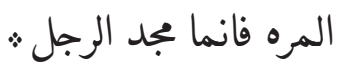

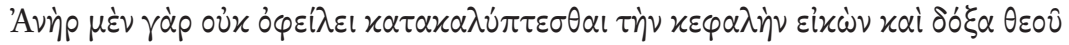

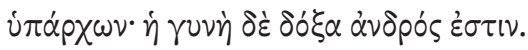

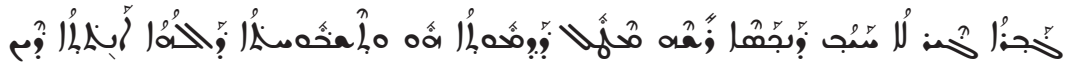

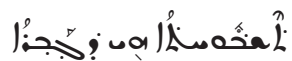

Quant à l'homme, il ne lui faut pas couvrir sa tête, parce qu'il est à l'image de Dieu et sa gloire; quant à la femme, elle est seulement la gloire de l'homme.

VA 13 est seul à avoir une préposition, la préposition بوره الله devant «l'image de Dieu».

VA 13 a انما "ne ... que», « seulement», absent du grec et de syp, et semble ici accentuer le rôle mineur de la femme.

1 Co 11,8

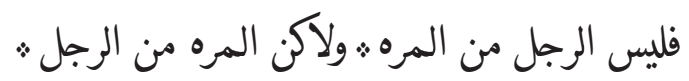

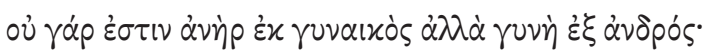

$$
\text { 先 }
$$


Car l'homme n'est pas à partir de la femme, mais la femme à partir de l'homme,

\section{Co 11,9}

$$
\text { ولا ايصا الرجل خلق ث من اجل } 114 \text { المره ولاكن ث. المره من اجل الرجل ؛ }
$$

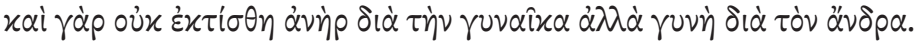

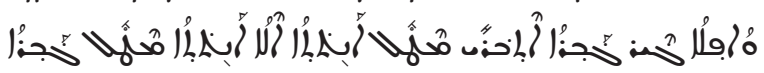

et l'homme n'a pas non plus été créé pour la femme, mais la femme pour l'homme.

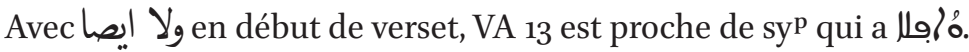

\section{Co 11,10}

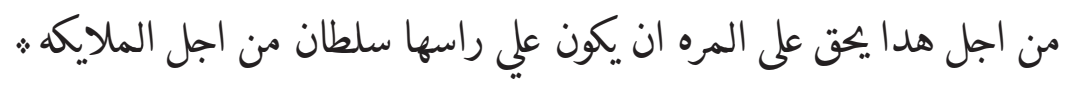

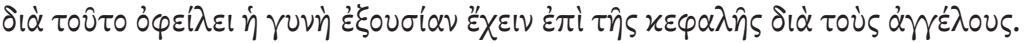

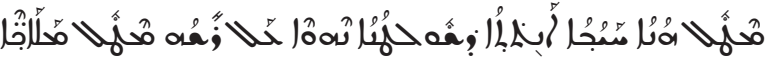

À cause de cela, il est impératif pour la femme qu'il y ait sur sa tête une autorité, à cause des anges.

Pour exprimer la nécessité de ne pas se couvrir pour l'homme et de se couvrir pour la femme, VA 13 n'utilise pas le même verbe : ينبعا au v. 7 et aي au v. 10. Y a-t-il ici une nuance dans l'intensité de la recommandation? Le grec a deux

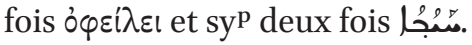

\section{Co 11,11}

$$
\text { بل لا رجل بغير امراه ولا امراه بعير رجل بالرب }
$$

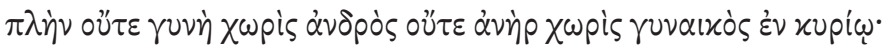

114 On notera que la préposition من اجل a la même ambiguïté qu'en grec $\delta$ ا $\alpha$, pouvant signifier ici « à cause » ou « pour». 


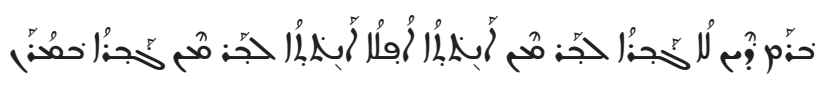

Mais il n'y a pas d'homme sans femme, ni de femme sans homme dans le Seigneur,

VA 13 mentionne en premier l'homme et en second la femme. Cet ordre correspond à $\mathrm{sy}^{\mathrm{p}}$ et sy $\mathrm{y}^{\mathrm{h}}$, tandis que le grec a d'abord la femme, puis l'homme.

\section{Co 11,12}

$$
\text { فكما ان المره من الرجل : فهكذا ايصا الرجل بالمره : وكلشى هو من الله : }
$$

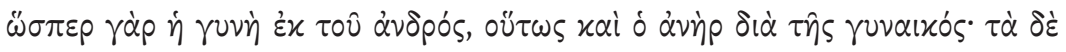
$\pi \dot{\alpha} \nu \tau \alpha \dot{\varepsilon} \chi \tau \circ \hat{v} \theta \varepsilon \circ \hat{v}$.

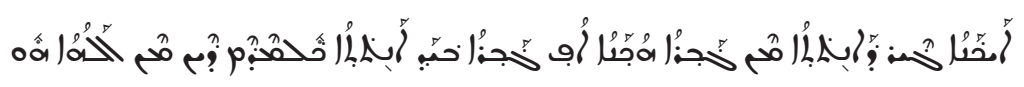

et de même que la femme vient de l'homme, ainsi aussi l'homme est par la femme, et toute chose vient de Dieu.

\section{Co 11,13}

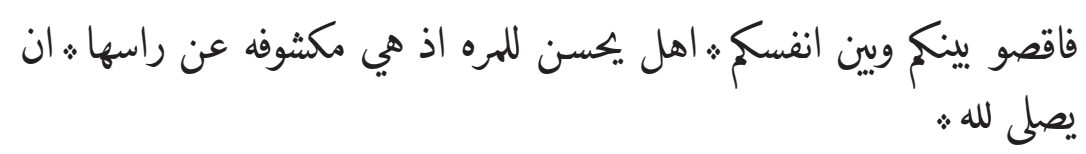

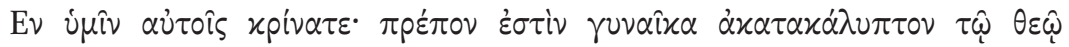
$\pi \rho \circ \sigma \varepsilon \dot{x} \varepsilon \sigma \theta \alpha l$;

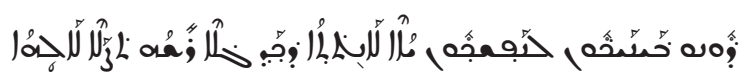

Jugez entre vous et en vous-même : est-ce bien pour la femme quand sa tête est découverte de prier Dieu?

La formulation بينكم ويين انفسك , littéralement «entre vous et entre vous-

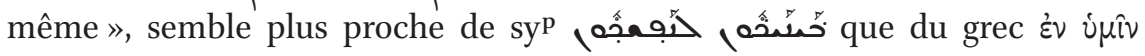

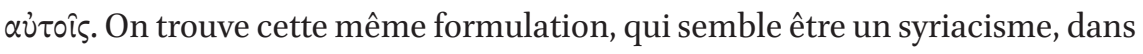
SA 151.

La formulation هي مكشوفه عن راسه elle est découverte de la tête » est la même qu'au v. 11,5, sauf qu'ici le participe est bien au féminin. En grec, c'est la

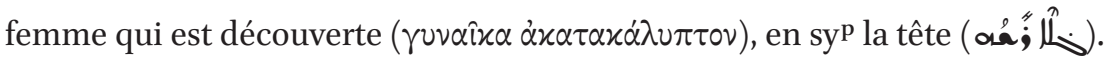




\section{Co 11,14}

$$
\text { او ليس ايصا الدمان يعلهك \& ان الرجل اذا ارخا شعره فانه له شات }
$$

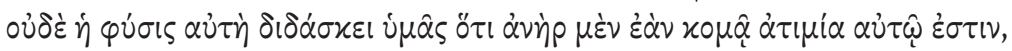

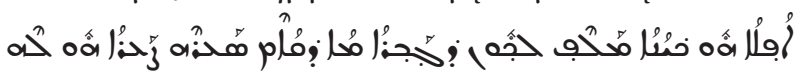

Ou bien l'usage ne vous enseigne-t-il pas aussi que l'homme, quand il relâche ses cheveux, c'est pour lui une cause de déception (vis-à-vis des autres).

Avec و او en début de verset, VA 13 soutient la variante $\ddot{\eta}$ comme $\mathrm{D}^{1} \mathrm{~K}$ L 104. 365.

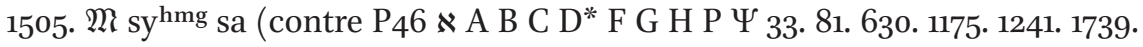
1881. 2464. latt sy bo).

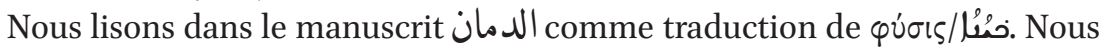
supposons qu'il s'agit de la racine دمن, probablement un mașdar de la forme I,

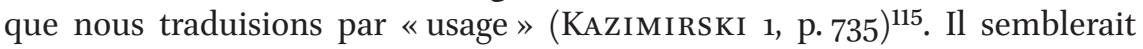
donc que pour le traducteur, ce soit la pratique qui soit normative, et non la nature ${ }^{116}$. Une autre possibilité serait de corriger joj «époque », « siècle». Cette lecture ne pose toutefois pas moins de difficultés de compréhension.

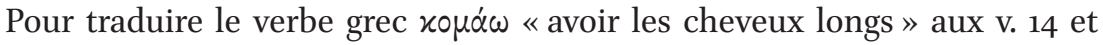
15, VA 13 a le verbe رجى et les cheveux comme complément. Au v. 14, quand

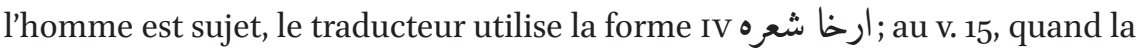
femme est sujet, il utilise la forme I Iرخت شعرها-une nuance dans la manière dont les cheveux sont portés est-elle exprimée ici? syp a aux v. 14 et 15 deux

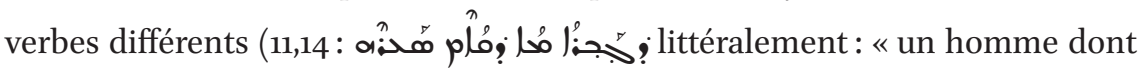
les cheveux sont 'debout' »;11,15: : cheveux sont abondants »).

L'utilisation de شات, que nous traduisions ici par « déception »117, pour tra-

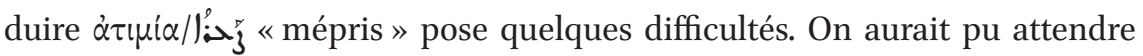

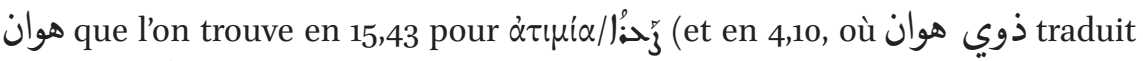

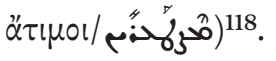

115 Kazimirski donne, entre autres, comme définition pour la forme I : « Faire, pratiquer continuellement quelque chose »; pour le mașdar de la forme IV : « Pratique, habitude, routine».

116 SA 155 et SA 151 ont les deux طبيعة.

117 LANE, p. 1594 : «Disappointment; frustration of one's endeavour or hope [...] »; BELOT, p. 386.

118 SA 155 a هوان SA 151 a ذلة 


\section{Co 11,15}

اما المره : اذا رخت شعرها فانه لها مدحه ان طول الشعر انها اعطيته :

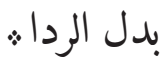

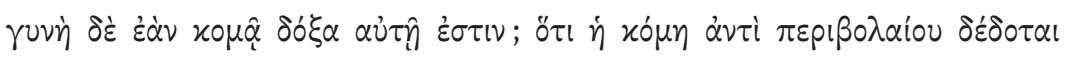

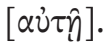

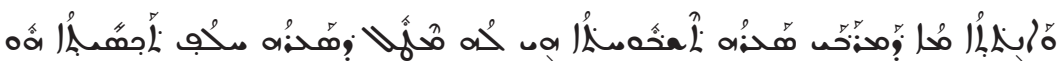
هُ

Quant à la femme, quand elle relâche ses cheveux, c'est une louange pour elle, la longueur des cheveux lui a été donnée en remplacement d'un vêtement.

À propos de رخت شعرها, voir verset précédent.

Avec la formulation au passif اعطيته , il est difficile de juger si VA 13 soutient

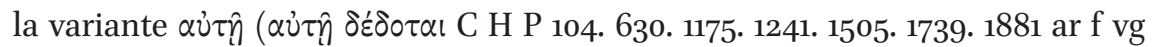

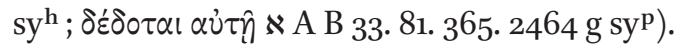

1 Co 11,16

فان كان انسان بجادل في هاولي : فلنا ليس لنا سنه مثل هذه : ولا لجماعاتنا الله

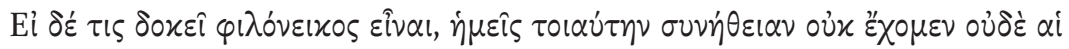

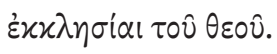

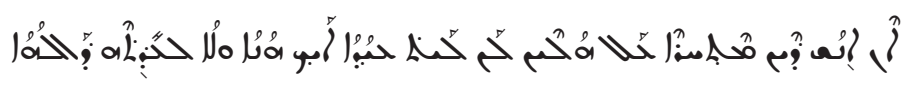

Et si quelqu'un discute ces choses-ci, nous n'avons pas une telle pratique, ni nos communautés, qui sont de Dieu.

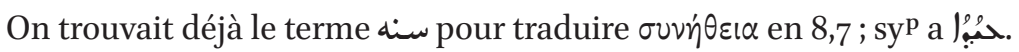

VA 13 a «assemblée » au pluriel جماعاتمأ, comme le grec, tandis que syp a un singulier; VA 13 est par contre seul à avoir un possessif à la 1ère personne du pluriel. Par ailleurs, nous noterons que VA 13 traduit régulièrement $\dot{\varepsilon} \varkappa \varkappa \lambda \eta \sigma^{\prime} \alpha /$

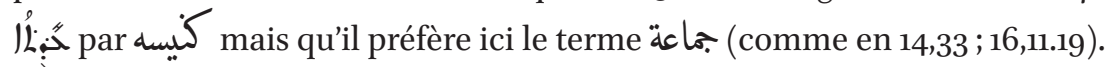

La double détermination لجماعاتنا الله est grammaticalement problématique. 
1 Co 11,17

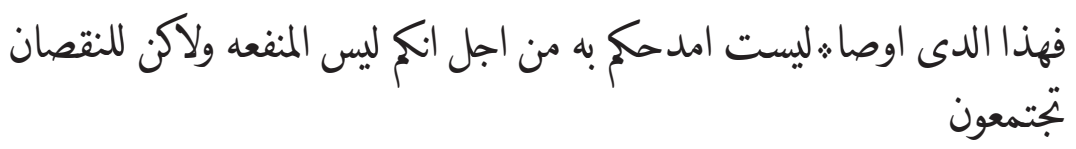

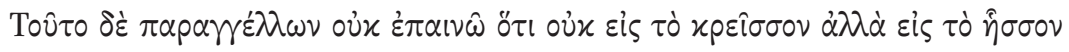

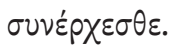

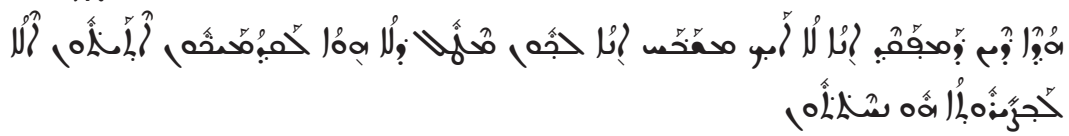

C'est ce que je recommande. Je ne vous loue pas à ce propos, car vous vous réunissez non pour ce qui est utile mais pour la perte :

Nous comprenons ليست comme ليست

syp a une formulation qui s'éloigne du grec

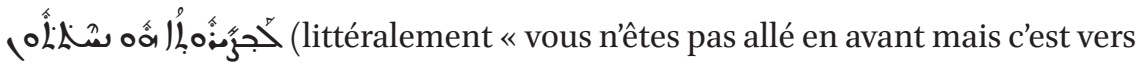
la perte que vous êtes descendus »). VA 13 reste proche du grec, suivant même l'ordre de la phrase.

Nous lisons المنفعه mais il s'agissait peut-être à l'origine de للمنفعة, la préposition J étant nécessaire à la construction de la phrase.

1 Co 11,18

اول شى ث.نانك اذا ما اجتمتح في الكنيسه ثناني اسمع ان فيك شقاق والصدق

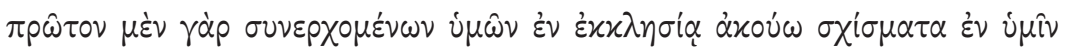

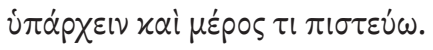

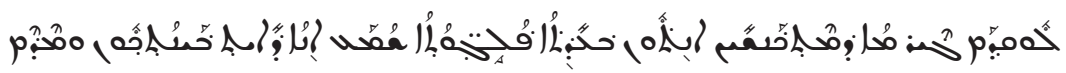

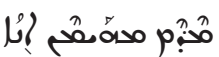

un première chose, lorsque vous êtes réunis en Église, j'entends dire qu'il y a désaccord parmi vous, et je le crois en partie.

Nous lisons والصدق. La présence d'un alif après la conjonction و lorsque celleci est suivie d'un mot commençant par alif avec hamza est un phénomène qui

119 Voir 2.2 Eléments de moyen arabe dans Vat. Ar. 13 (1 Corinthiens) : 22) Négation ليس. 
se répète dans notre texte $(12,27 ; 14,6.15 ; 15,5)$. Est-ce une erreur de copie, un phénomène phonétique ou une influence de l'alif otiosum ${ }^{120}$ ?

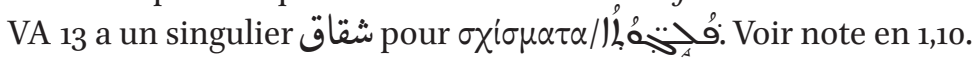

\section{Co 11,19}

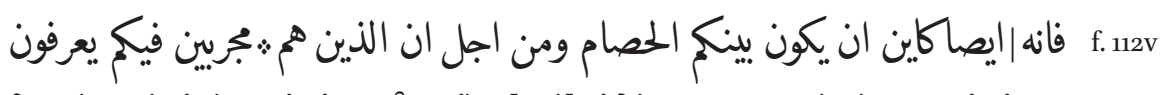

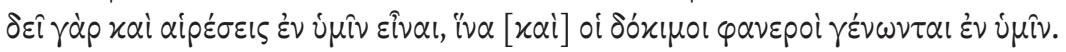

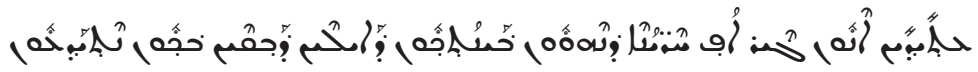

Il se trouve aussi qu'il y aura entre vous querelle et cela pour que ceux qui parmi vous sont éprouvés soient connus.

ك qui exprime le futur immédiat (BLAU, § 324) semble plus proche de syp

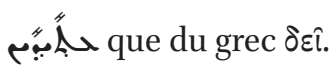

شعام au verset précédent, est un singulier, tandis que le grec

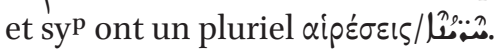

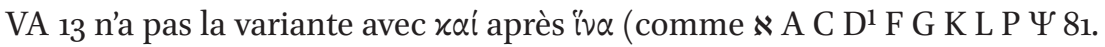
104. 365. 1241. 1505. $2464 \mathrm{M} \mathrm{b}$ vg $^{\mathrm{mss}}$ sy bo, contre $\mathrm{P}_{4} 6 \mathrm{~B}^{*}$ 6. 33. 630. 1175. 1739. 1881. vg sa bo $\left.{ }^{\mathrm{mss}}\right)$.

\section{Co 11,20}

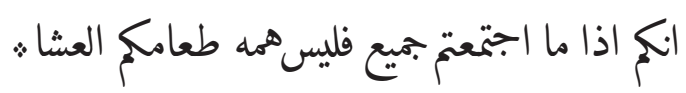

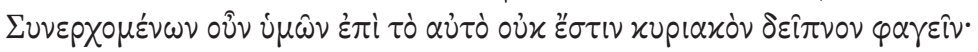

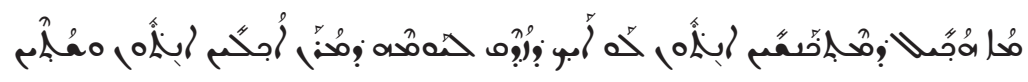

Lorsque que vous vous réunissez tous ensemble, le souci de votre repas, ce n'est pas la Cène,

VA 13 a une formulation فليس همه طعامك العشا qui s'éloigne beaucoup du grec

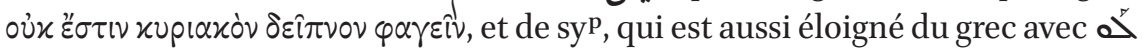

120 Blau donne plusieurs exemples d'alifs otiosa « abusifs », mais pas avec g. À côté de cela, il souligne le phénomène inverse : la disparition d'un aliflorsque l'alif otiosum est suivi d'un mot commençant par alif. BLAU, § 28. Voir 2.2 Eléments de moyen arabe dans Vat. Ar. 13 (1Corinthiens): 9) alif otiosum. 
r ce n'est pas comme il est approprié pour le jour du Seigneur que vous mangez et buvez »121. VA 13 introduit avec هم اهشا l'idée de souci, de préoccupation. Il semblerait que عoit utilisé ici dans

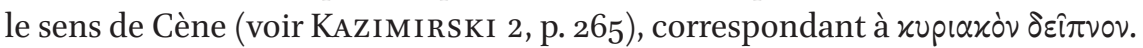
Nous traduisons : « le souci de votre repas, ce n'est pas la Cène ».

\section{Co 11,21}

$$
\text { ولاكن كل انسان يسابت بعشاه فاكله فيكون واحد غرثان : واخر سكان : }
$$

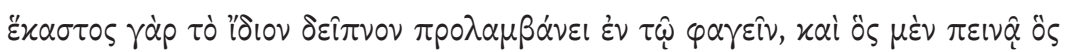
$\delta \dot{\varepsilon} \mu \varepsilon \theta \dot{\varepsilon} \varepsilon$.

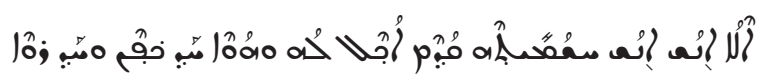

mais chacun se hâte vers son repas puis son souper; l'un est affamé et l'autre est ivre.

\section{Co 11,22}

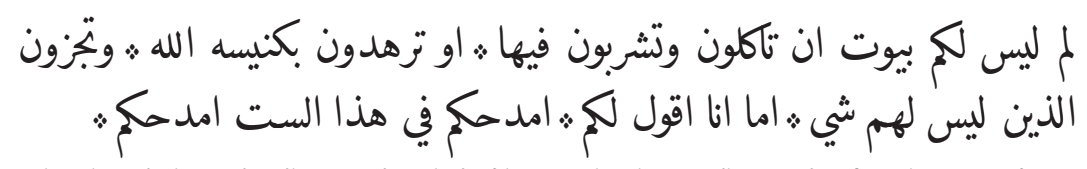

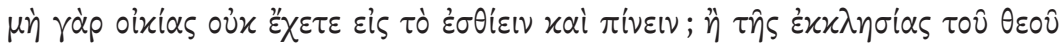

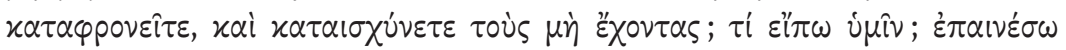

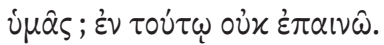

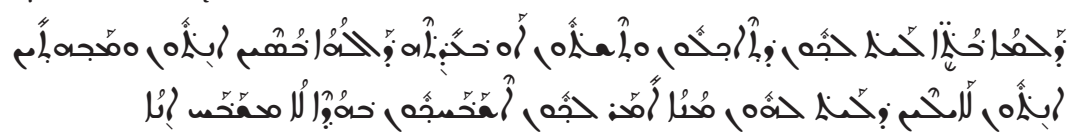

Pourquoi ? N'avez-vous pas de maisons pour y manger et y boire? Ou bien faites-vous peu de cas de l'Église de Dieu et faites-vous affront à ceux qui n'ont rien? Que vous dire? Vous féliciter à ce propos? Je ne vous félicite pas!

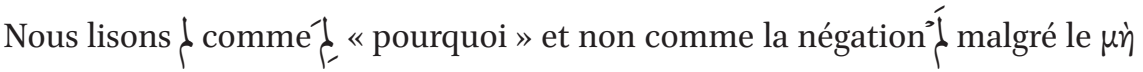
en grec. En effet, le traducteur introduit certainement en se basant sur syp

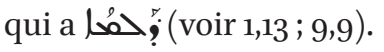

121 On ne trouve cette formulation ni dans SA 151 et SA 155, ni dans les témoins syriaques (Aland), ni dans vg, ni dans sa et co (HoRner). 


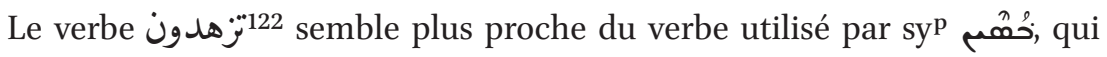
peut avoir le sens de «vous négligez» (PAYNe SMith, p. 48), que du grec

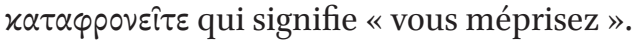

Nous lisons الست mais comprenons لست car la présence d'un I ne s'explique pas. S'agit-il d'une erreur de dittographie suite au 123 ?

\section{Co 11,23}

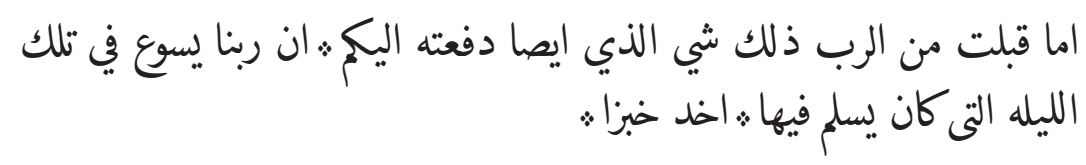

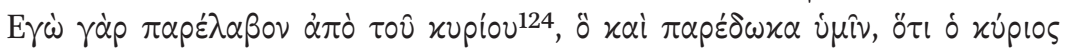

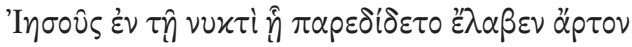

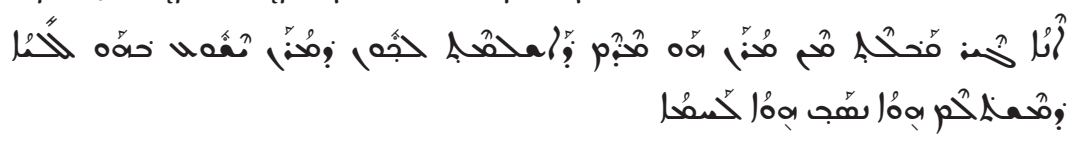

Quant à ce que j'ai reçu du Seigneur, c'est ce que je vous ai aussi transmis : notre Seigneur Jésus, cette nuit durant laquelle il fut livré, prit du pain

La formulation avec ذلك شي الذي (ceci est une chose que », que nous tra-

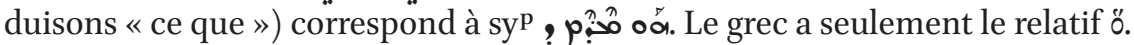

VA 13 a "cette nuit», comme syp et sy ${ }^{\mathrm{h}}$ qui ont également un démonstratif.

1 Co 11,24

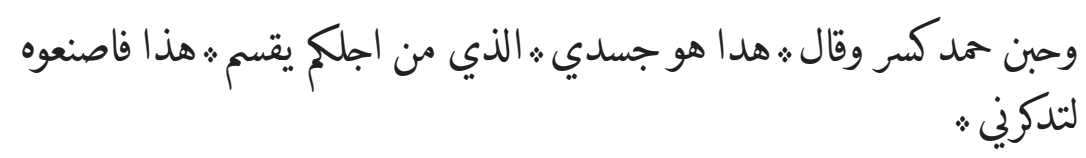

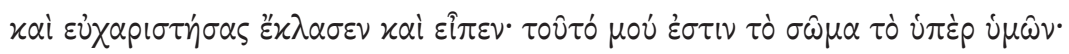

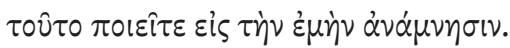

122 Le choix du verbe reste difficile à comprendre. Le verbe suivi de la préposition في (nous avons ici ب) prend le sens de « être entièrement exempt du désir d'une chose" et s'en interdire l'usage, s'en priver »; il peut prendre un sens ascétique : « se vouer au culte de Dieu et à la vie ascétique ». KAZIMIRSKI 1, p. 1018.

123 Autres présences de l inexpliquées : 4,19; 14,39; 15,5.49.

124 Quelques témoins ( $\mathrm{F} \mathrm{G}_{3} 65 \mathrm{~d}^{*}$ ) ont $\alpha$ đ̇ò $\tau 0 \hat{v} \theta \varepsilon \circ \hat{v}$, une variante que VA 13 ne soutient pas. 


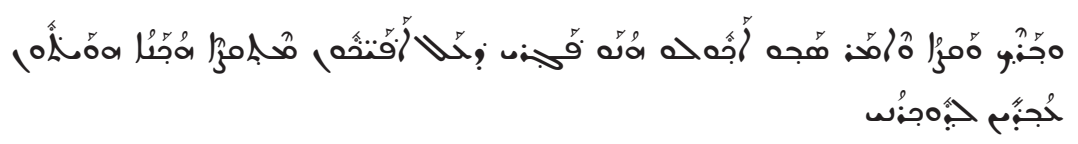

et quand il eut rendu grâce, il le brisa et dit : ceci est mon corps qui est rompu pour vous, faites ceci en mémoire de moi.

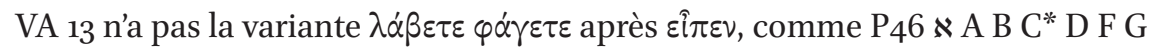
0199. 6. 33. 81* 104. 630. 1175. 1241. 1739. 1881. 2464 it vg ${ }^{\text {st }}$ co (variante présente dans $C^{3}$ K L P $\left.\Psi ~ 81^{\mathrm{c}} \cdot 365 \cdot 1505 \mathfrak{M ~ t ~ v g l ~}^{\mathrm{cl}} \mathrm{sy}\right)$.

Avec يقسم, VA 13 soutient par contre la variante $\chi \lambda \hat{\omega} \mu \varepsilon v o v$ comme $\aleph^{2} C^{3} D^{1} \mathrm{~F}$ G K L P $\Psi$ 81. 104. 365. 630. 1175. 1241. 1505. 1739 $9^{\mathrm{mg}} .1881 .2464$ M sy (contre P46 $\aleph^{*}$ A B C* 6. 33. $\left.1739^{\text {txt }} \mathrm{vg}^{\text {st }}\right)$; on notera le changement de verbe autour du partage du pain : يقسم puis.

\section{Co 11,25}

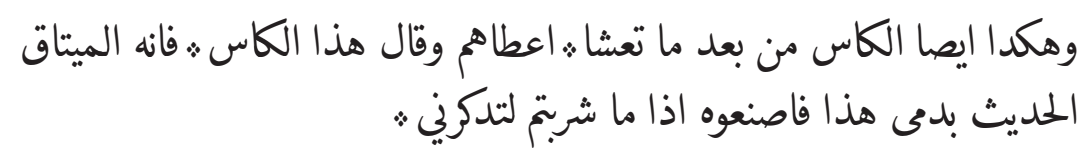

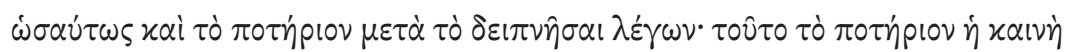

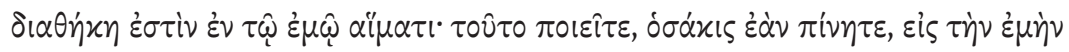
$\alpha \nu \alpha \dot{\mu \nu \eta \sigma \nu . ~}$

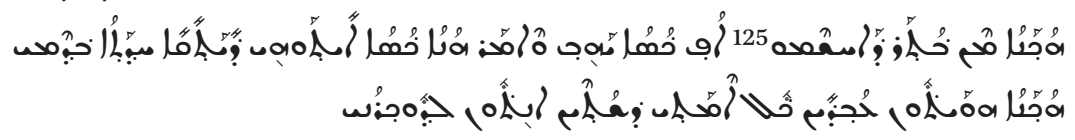

Et ainsi aussi, après qu'il eut mangé, il leur donna la coupe et dit : cette coupe, c'est la nouvelle alliance en mon sang, faites ceci quand vous buvez en mémoire de moi

À propos de الميتاق, voir 4.3.3 mītāq «alliance ».

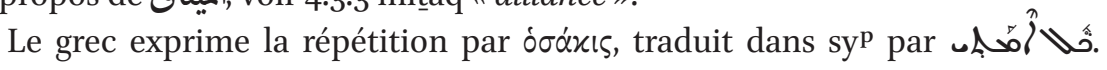
VA 13 n'a pas traduit la répétition.

125 Une partie des manuscrits de syp (cf. AlAnd) ont ici un pluriel, ainsi que sy ${ }^{\mathrm{h}}$

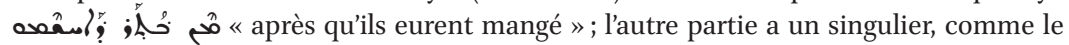
grec et VA 13 . 
1 Co 11,26

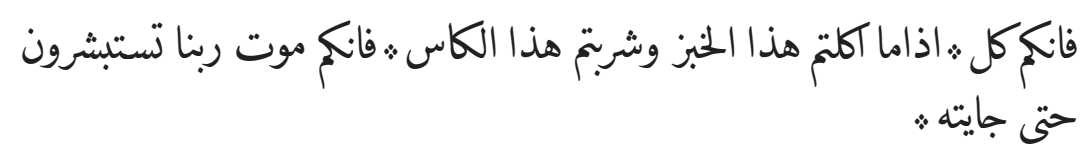

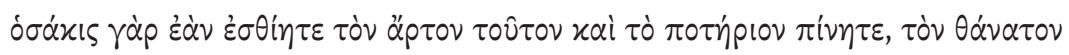

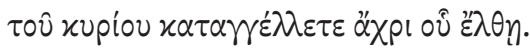

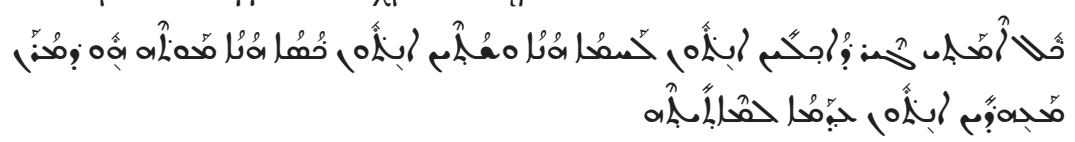

Et à chaque fois que vous mangez ce pain et buvez cette coupe, vous annoncez la bonne nouvelle de la mort de notre Seigneur jusqu'à sa venue.

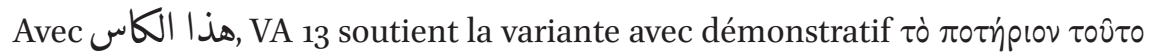
comme P46 $\aleph^{2} C^{2} D^{1}$ K L P Y 81. 104. 365. 1175. 1241. 1505. $1739^{\mathrm{mg}} \mathfrak{M}$ ar t sy bo (contre $\aleph^{*}$ A B C* D* F G 33.630. $1739^{\text {txt }}$. 1881. 2464 lat).

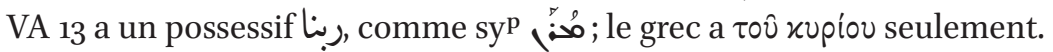

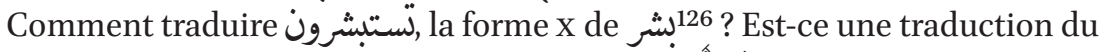

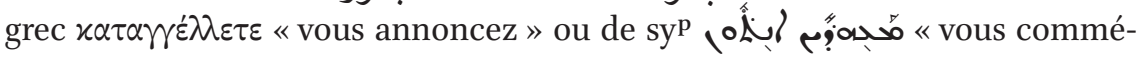

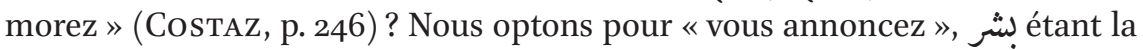

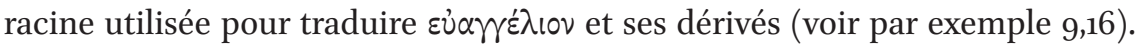
Étonnamment, on retrouve cette forme X de بشر 13,7 et 15,19 dans le sens d'« espérer».

À propos de جايته, voir 1,7.

\section{Co 11,27}

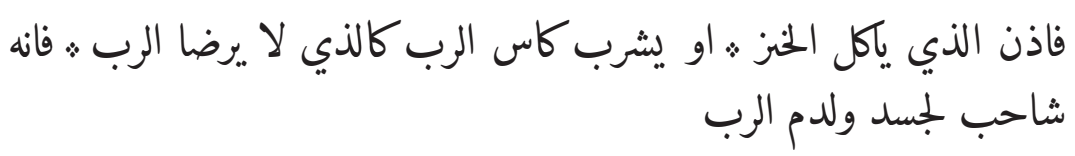

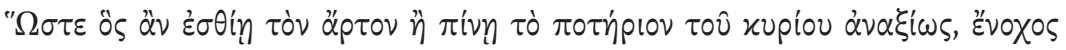

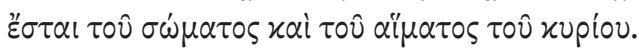

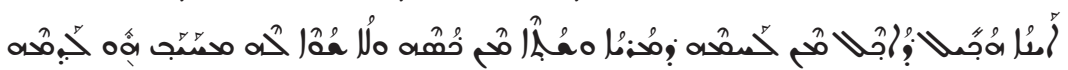

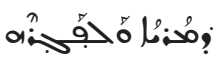

126 Kazimirski donne le sens de « se réjouir », KAZImirski 1, p. 129. 
Dès lors, celui qui mange le pain ou boit la coupe du Seigneur comme quelqu'un qui ne gratifie pas le Seigneur, il est coupable envers le corps et le sang du Seigneur.

On trouve aussi شاجبdans le sens de « coupable », « condamné » en 4,9.

VA 13 n'a pas de démonstratif avec الخبر et ne soutient pas la variante présen-

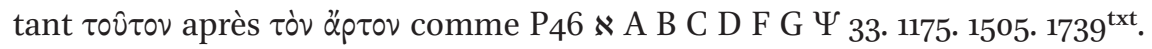
2464 lat sy sa (variante présente dans Ivid K L P 81. 104. 365. 630. 1241. $1739^{\mathrm{mg}}$. 1881. $\mathrm{M}$ ar vg $\mathrm{gl}^{\mathrm{cl}}$ bo).

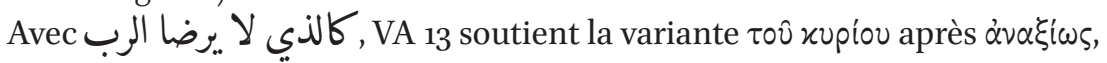
comme $\aleph \mathrm{D}^{2} \mathrm{~L} 326.1505 \mathrm{sy}^{\mathrm{h}}$.

\section{Co 11,28}

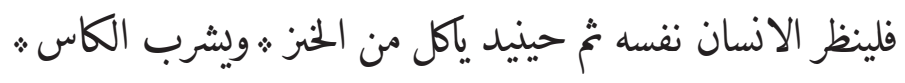

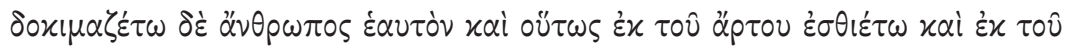
$\pi \circ \tau$ กíu $\pi \mathrm{L} \varepsilon \dot{\tau} \tau$.

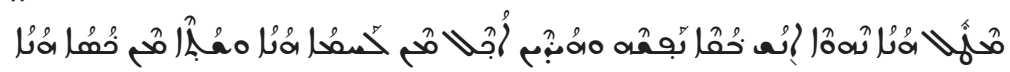
Que l'homme s'examine lui-même, et ensuite à ce moment-là, qu'il mange du pain et boive la coupe.

\section{Co 11,29}

$$
\begin{aligned}
& \text { فاما الذي يآكل ويشرب : كما لا ينبني ث. فانه الشحابه لنفسه يآل ث. ويشرب حيى }
\end{aligned}
$$

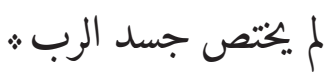

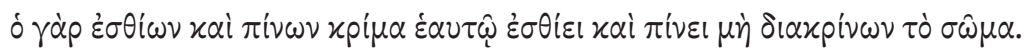

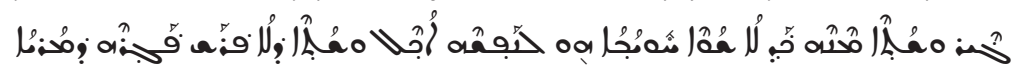

Mais celui qui mange et boit comme il ne faut pas, c'est la condamnation contre lui-même qu'il mange et qu'il boit au moment où il n'a pas distingué le corps du Seigneur.

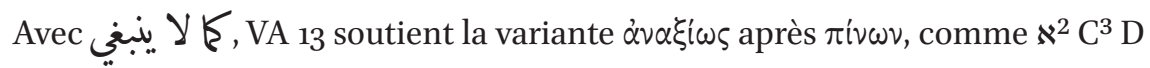
F G K L P Y 81. (104) 365. 630. 1175. 1241. 1505. 1881. 2464 M latt sy (contre P46 $\aleph^{*}$ 
A B C* 6. 33. 1739 co). On notera que VA 13 utilise deux expressions différentes

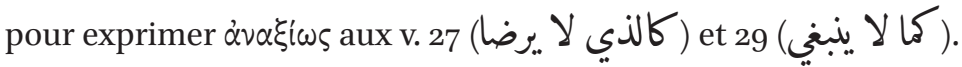

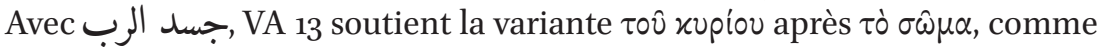

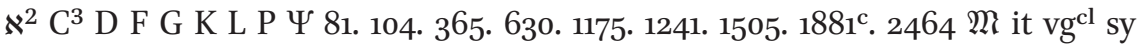
(contre $\mathrm{P} 46 \aleph^{*}$ A B C* 6. 33.1739. $1881^{*}$ co).

\section{Co 11,30}

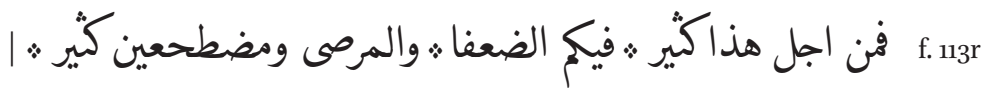

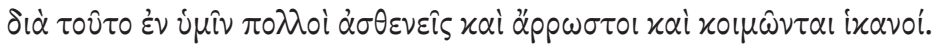

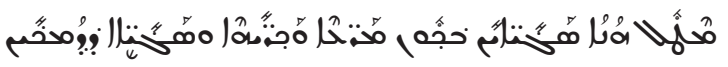

C'est pour cela qu'il y a parmi vous beaucoup de faibles et de malades, et beaucoup de morts.

\section{Co 11,31}

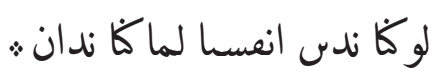

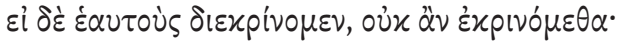

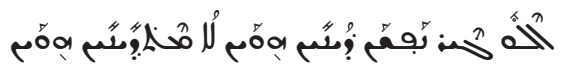

Si nous nous jugions nous-même, nous ne serions pas jugés,

Avec $\delta \dot{\varepsilon}$ en grec et ${ }^{\Uparrow}$ dans syp, on attendrait une conjonction du type de ف en début de phrase.

\section{Co 11,32}

$$
\text { ولاكن اذ ندان من الرب نعط : لكيا لا تشجب مع العالم : }
$$

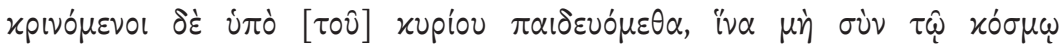

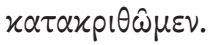

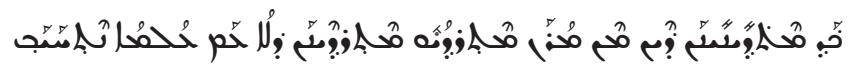

mais lorsque que nous sommes jugés par le Seigneur, nous sommes avertis afin que nous ne soyons pas condamnés avec le monde. 
1 Co 11,33

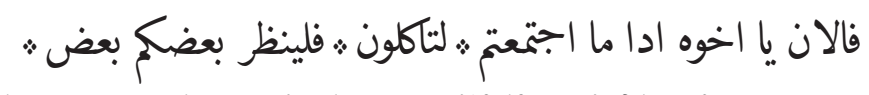

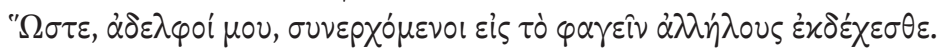

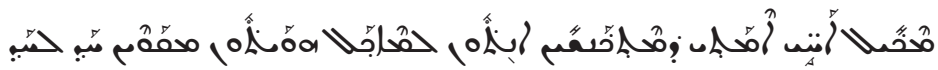

Maintenant, ô frères, quand vous vous réunissez pour manger, attendez-vous les uns les autres,

\section{Co 11,34}

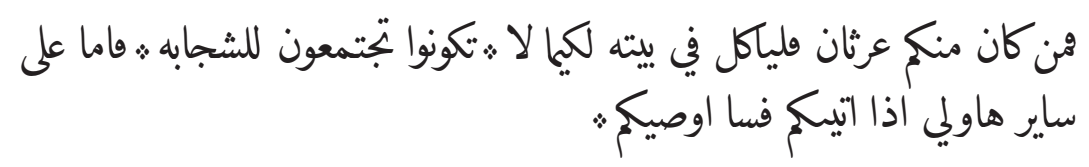

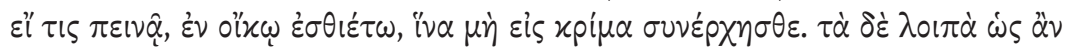
है $\lambda \theta \omega \delta เ \alpha \tau \alpha \dot{\xi} \xi \rho \mu \alpha$.

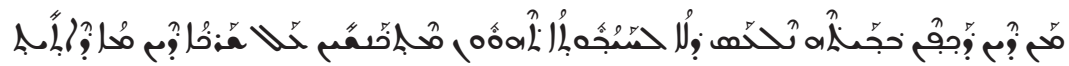
(2) et si quelqu'un de vous a faim, qu'il mange à la maison afin que vous ne vous réunissiez pas pour la condamnation ; quant au reste, quand je viendrai, je vous donnerai des recommandations.

VA 13 est seul à avoir کi « de vous».

Avec ف en début de verset, VA 13 semble soutenir la variante $\delta \dot{\varepsilon}$ comme ${ }^{2}$ $\mathrm{D}^{1}$ K L P Y 104. 365. 630. 1175. 1505. 1739. 1881. $2464 \mathrm{M} \mathrm{b} \mathrm{vg}^{\mathrm{mss}}$ sy (contre P46 $\aleph^{*}$ A B C D* F G 33. 81. 1241 lat).

\section{$1.12 \quad$ Chapitre 12}

1 Co 12,1

$$
\text { من اجل الروحانيات يا اخوه : لا احب ان لا تـ ] [سون : }
$$

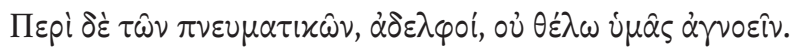

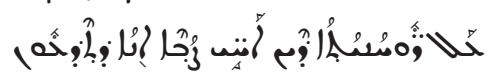

Pour les choses spirituelles, ô frères, je ne veux pas que vous ne perceviez pas. 
La fin du verset لا ت] [حسون pose des problèmes de lecture. Nous supposons qu'il s'agit du verbe حس" حسون, peut-être à la forme IV ${ }^{127}$, dont le $ح$ se lit difficilement. La formulation de VA 13 est dans tous les cas plus proches du grec, qui a deux négations (ov̉ et l'alpha privatif de àrvoeî), que de syp qui a ici une

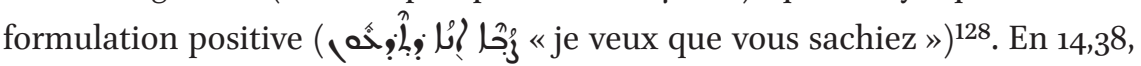
on trouve جهل pour traduire le verbe $\alpha \gamma \gamma v \varepsilon^{\prime} \omega$, tandis que syp utilise la formule

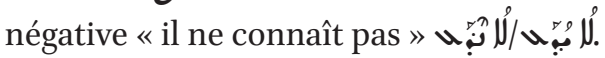

1 Co 12,2

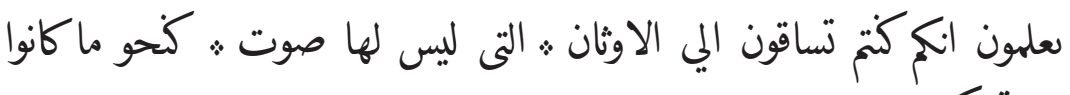
يسوقونم

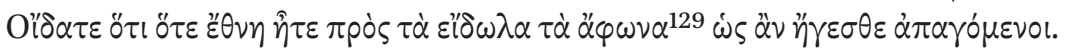

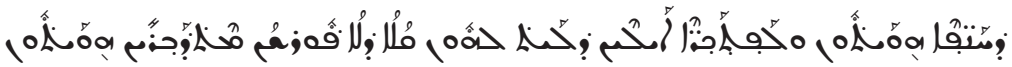

Vous savez que vous étiez menés vers les idoles qui n'ont pas de voix, comme si elles vous menaient.

Le texte de sy $\mathrm{p}^{\mathrm{P}}$ est éloigné du grec et de VA 13. syp n'a pas de verbe en début

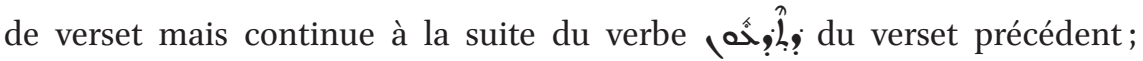

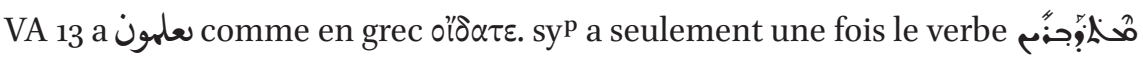

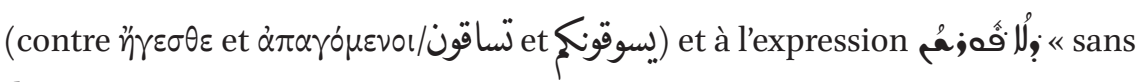
discernement ».

VA 13 semble donc ici plus proche du grec. Toutefois il n'a pas de conjonction temporelle, comme ö $\tau \varepsilon$, mais peut-être que l'imparfait كتم تساقون souhaite en être la traduction?

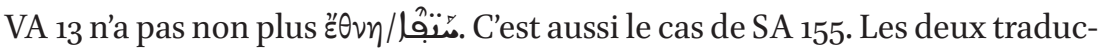

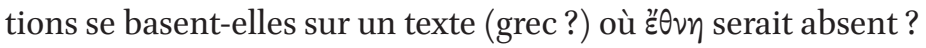

127 Kazimirski donne pour la forme IV (entre autres) les sens de « sentir, percevoir avec les sens » et « connaître (à l'aide des sens) », KAZIMIrsKI 1, p. 422.

128 SA 151 a فاحب ان تعلمون SA 155 a ليس اريد ان تجهلو).

129 Quelques témoins ont ici پ̋ $\mu$ op $\varphi$, une variante que VA 13 se soutient pas. 
1 Co 12,3

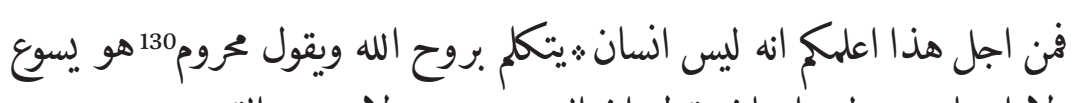

$$
\begin{aligned}
& \text { ولا ايصا • يستطبع اسان يقول ان الرب يسوع ث ولا .بووح القدس ث }
\end{aligned}
$$

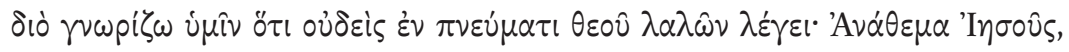

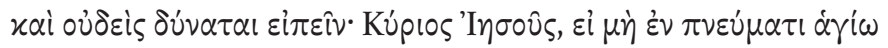

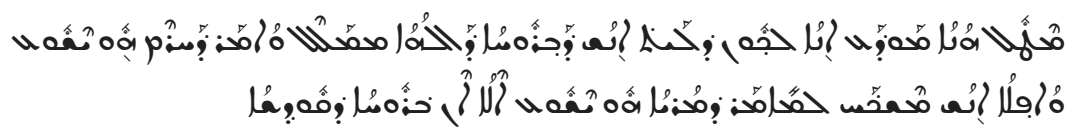

À cause de cela, je vous apprends que personne ne parle par l'esprit de Dieu et dit : anathème soit Jésus ! et personne ne peut dire non plus que Jésus est le Seigneur, si ce n'est par l'Esprit saint.

Il manque انستطع Labrès. L'absence de ان après un verbe qui le demande n'est pas attestée par Blau (voir aussi le cas du subjonctif seul en 1,8).

\section{Co 12,4}

$$
\text { النقسم العطايا فانهن كيت ولاكن. الروح هو واحل }
$$

$\Delta$ เ

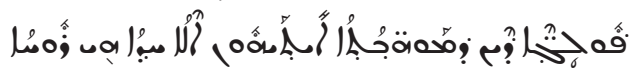

Il y a répartition des dons, et ils sont nombreux, mais l'Esprit est un ;

La phrase فانهن كير ils sont nombreux» ne se trouve pas en grec, ni dans syp ni dans sy ${ }^{\mathrm{h}}$. Cette formulation est répétée aux versets suivants. Dans ce verset et le verset 6 , on trouve un pluriel féminin pour désigner un pluriel inanimé ; au verset 5 , on trouve le « classique » singulier féminin. Voir 2.2 Éléments de moyen arabe dans Vat. Ar. 13 (1 Corinthiens) : 16) Genre et nombre.

Il semblerait que النقسم العطايا soit une erreur; vu qu'il y a un rapport d'annexion, le premier article est superflu (voir 1,28;10,16).

\section{Co 12,5}

$$
\text { وتقسم الخدمات فانها كير ث:ولاكن الرب هو واحد : }
$$

130 GRAF, Termini, p. 38. 


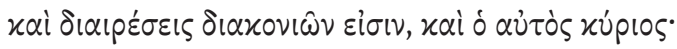

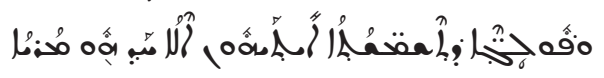

et il y répartition des services, et ils sont nombreux, mais le Seigneur est un ;

Voir 1 Co 12,4 à propos de فانها كيّ.

\section{Co 12,6}

$$
\text { وتقسم الافعال ث. فانهن كير : ولاكن الله هو واحد ث. الدي يعمل كل بكل : }
$$

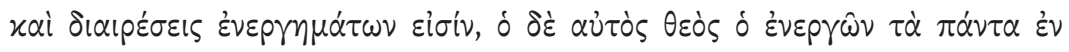
$\pi \hat{\alpha} \sigma v$.

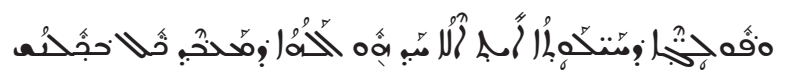

et il y a répartition des actions, et elles sont nombreuses, mais Dieu qui accomplit tout en tout est un.

Voir 1 Co 12,4 à propos de فانهن كيّ"

K. en fin de verset semble davantage se baser sur le grec $\dot{\varepsilon} v \pi \hat{\alpha} \sigma v$, où y a

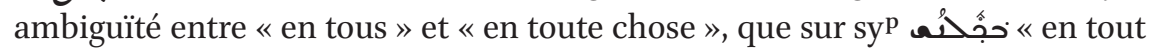
homme».

Avec ولاكن, VA 13 semble soutenir davantage la variante o $\delta \dot{\varepsilon}$, comme א A (D F G) K L P Ч 33. 104. 1505. 1881. 2464 Ml latt sy, que la variante xai ó, présente dans P46 B C 81. 365. 630. 1175. 1241. 1739.

\section{Co 12,7}

$$
\text { اما لانسان انسان . هانه يعطا استعلان الروح كخوا ما ينبغا : }
$$

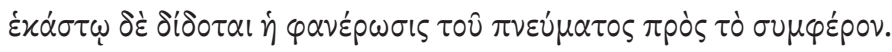

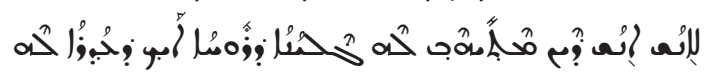

Mais à chacun est donnée la manifestation de l'Esprit comme il convient.

L'expression لانسان انسان semble d'influence syriaque et se base certainement sur syp

131 Blau n'y fait pas référence. 
1 Co 12,8

$$
\text { فنهُم من يعطا بالروح : كله الحلكه : واخز يعطا كله العلم بالروح : }
$$

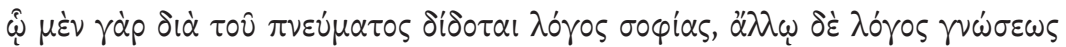

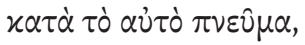

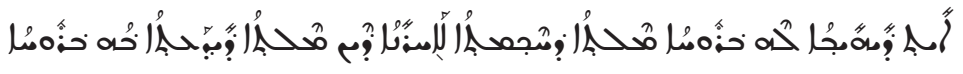

Donc, parmi eux, à l'un il est donné par l'Esprit la parole de la sagesse et à un autre il est donné la parole de la connaissance par l'Esprit,

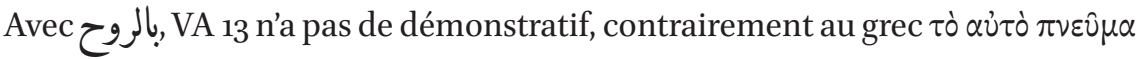

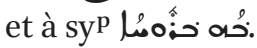

\section{Co 12,9}

$$
\text { واخر امانه باروحح : ولاخ :عطايا الشفا بالروح : }
$$

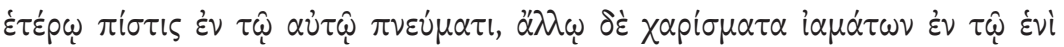
$\pi \nu \varepsilon \cup \dot{\mu} \alpha \tau$,

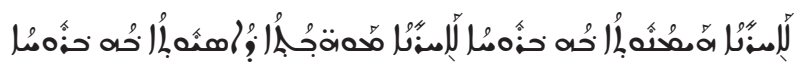

et à un autre une foi par l'Esprit, et à un autre les dons de guérison par l'Esprit,

De même qu'au verset précédent, VA 13 n'a pas d'adjectif accolé à بالروح, contrai-

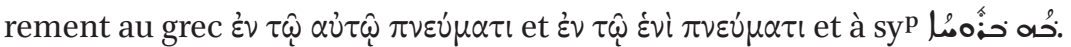

Avec g en début de verset, VA 13 semble soutenir la variante $\delta \dot{\varepsilon}$ comme $\mathrm{P}_{4} 6$ $\aleph^{2}$ A C D ${ }^{2}$ K L P Y 33. 81. 104. 365. 630. 1175. 1241. 1505. 1881. 2464. M sy (absent dans $\aleph^{*}$ B D* F G 6. 1739. latt syp).

En 12,8 et 12,9a, on trouve اخخ seul, que nous comprenons comme sujet du passif : «à un autre il est donné ». En 12,9b, on trouve une construction différente avec الاخز الاخز ne pouvant être alors ni sujet ni complément d'objet direct demandé par عطى iخى est certainement due à

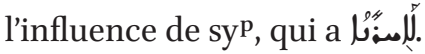




\section{Co 12,10}

$$
\begin{aligned}
& \text { والاخر اعال الجرايح ؛ والاخر النبوه : لاخر تفضيل الارواح : لاخر اجناس } \\
& \text { الالسنه : لاخز ترمه الالسنه : }
\end{aligned}
$$

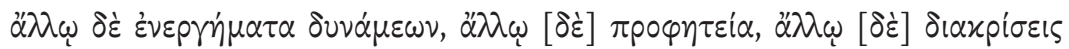

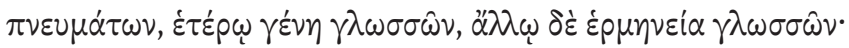

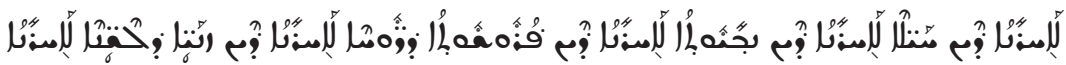

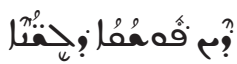

et à l'autre les pratiques miraculeuses, à un autre la prophétie, à un autre le discernement des esprits, à un autre les différentes sortes de langues, à un autre l'interprétation des langues ;

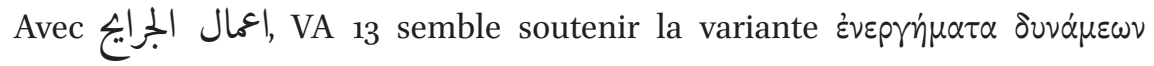

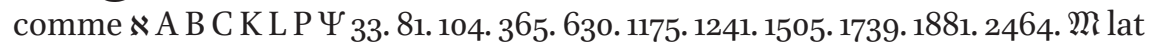

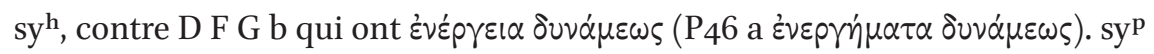

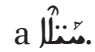

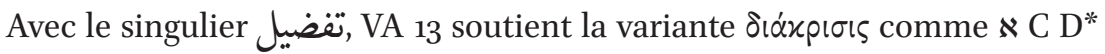
F G P 0201. 33. 1175. latt syp sa (contre P46 A B D ${ }^{2}$ K L Ч 81. 104. 365. 630. 1241.

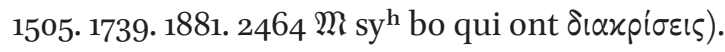

\section{Co 12,11}

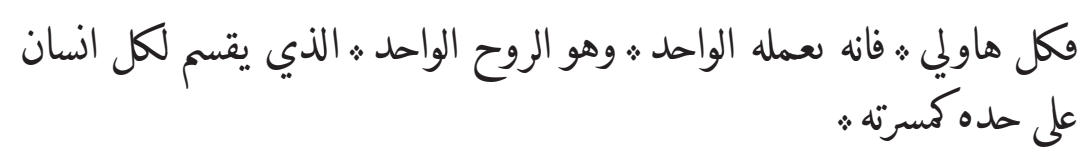

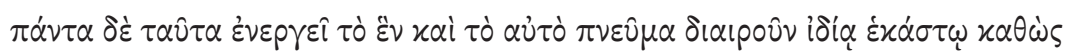

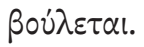

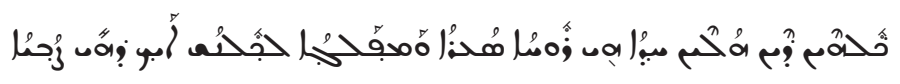

mais toutes ces choses, le seul qui les fait, c'est l'Esprit seul, qui distribue à tous séparément, selon sa volonté.

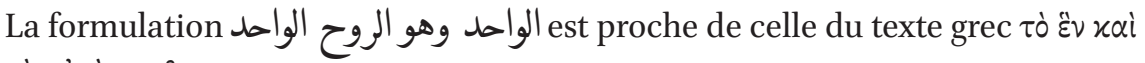

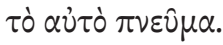

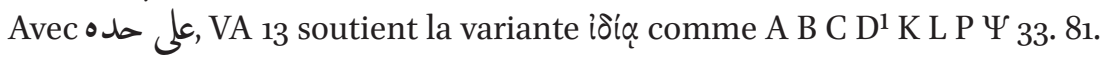
104. 365. 630. 1175. 1241. 1505. 1739. 1881. $2464 \mathrm{M}^{\text {sy }}$ (contre P46 D*. ${ }^{\mathrm{c}}$ F G 0201 ${ }^{\text {vid }}$ latt syp). 
1 Co 12,12

f. $113 \mathrm{v}$

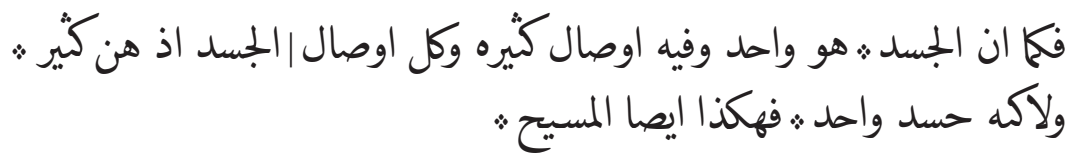

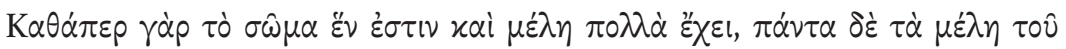

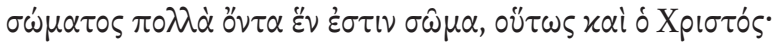

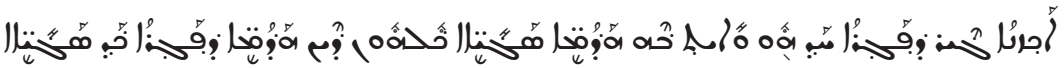

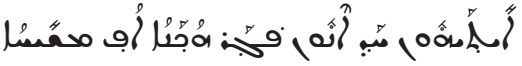

De la même manière que le corps est un et qu'il y a en lui plusieurs membres et que tous les membres du corps, alors qu'ils sont nombreux, sont toutefois un seul corps : ainsi aussi [est] le Christ.

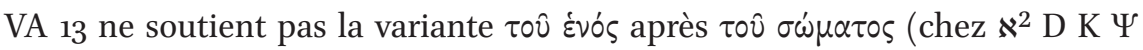
$630 \mathrm{Ml} \mathrm{b} \mathrm{sa}^{\mathrm{mss}}$ bo).

\section{Co 12,13}

$$
\begin{aligned}
& \text { ونخن ايصا كلا ورح واحده لحسد واحد ث. اعدنا ؛ ان كانوا اليهود ث: وان كانوا }
\end{aligned}
$$

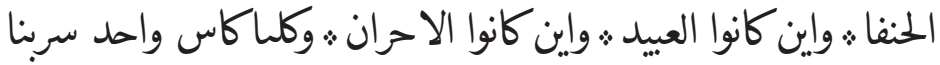

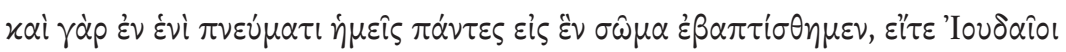

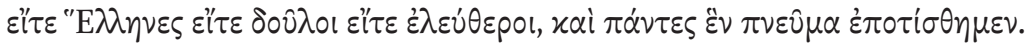

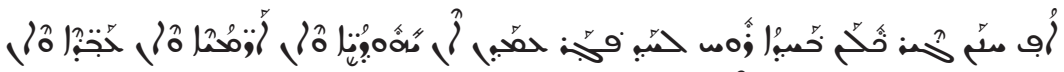

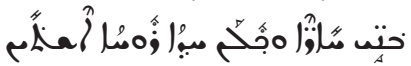

Et nous aussi, tous par un seul Esprit pour un seul corps, nous avons été baptisés, étant juifs, païens, esclaves ou libres, et nous tous, nous avons bu à une seule coupe.

Le verset contient une incohérence grammaticale en passant d'un sujet à

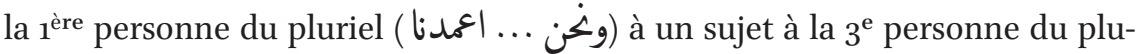
riel (ان كانوا ... الاحران), puis à nouveau à un sujet à la $1^{\text {ère }}$ personne du pluriel

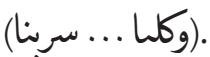

Nous lisons dans le manuscrit واين كانوا العيد mais la présence de l'adverbe إن ne fait pas sens ici. Il faut certainement comprendre اند ان 


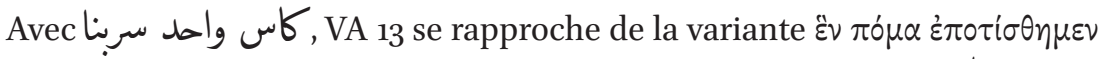
présente dans 630. 1505. 1881. syh. En 10,4, on trouve un autre terme,شراب, pour traduire $\pi \dot{\rho} \mu \alpha$.

\section{Co 12,14}

$$
\text { وايصا الجسد : ليسو وصل واحد : ولاكة كير }
$$

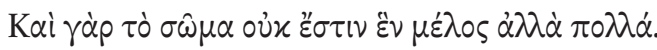

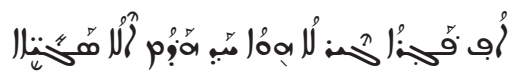

Et de même, le corps n'est pas un seul membre mais plusieurs.

Nous lisons ليس mais comprenons ليسوا ليس ; en effet, le pluriel perait pas sens ici (voir aussi 1,26 ; 9,26 et point 2.2 Éléments de moyen arabe dans Vat. Ar. 13 (1 Corinthiens) : 22) Négation

\section{Co 12,15}

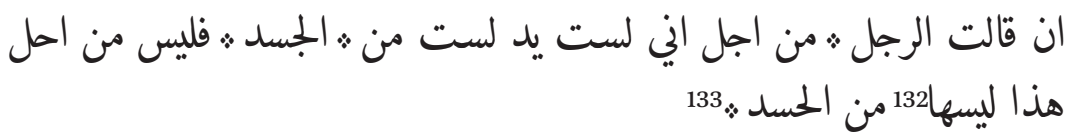

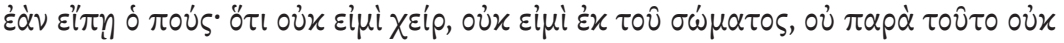

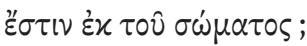

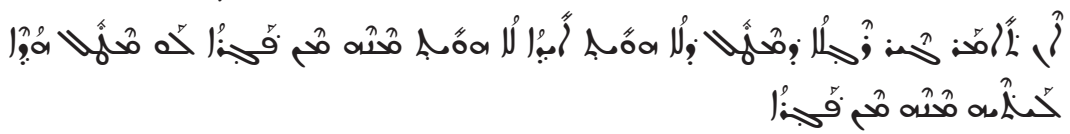

Si le pied disait: puisque je ne suis pas une main, je ne fais pas partie du corps !, ce n'est pas, pour cela, qu'il ne ferait pas partie du corps.

132 À propos de ليس avec suffixe, voir 2.2 Éléments de moyen arabe dans Vat. Ar. 13 (1 Corinthiens) :16) Négation ليس.

133 À propos de ce verset et du suivant, Blau écrit: " Two negatives make an affirmative ; I have noted, so far, only one case, following the Greek original : SS 2 [Studia Sinaitica 2, SA 155 [ Cor 12,15; it is therefore nevertheless of the body' », BLAU, § 212). Nous avons le même cas de figure ici. 
1 Co 12,16

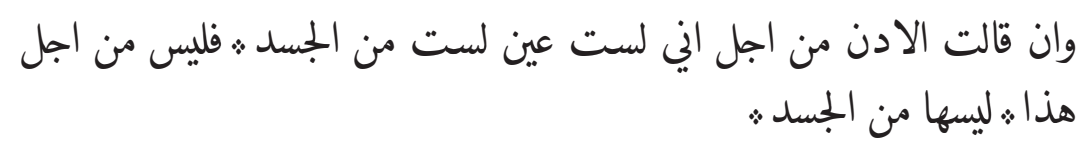

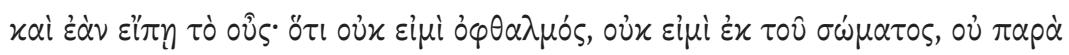

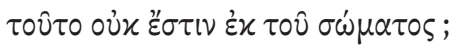

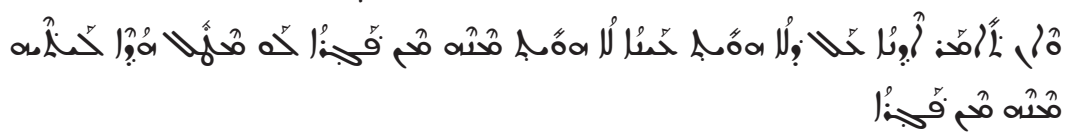

Et si l'oreille disait: puisque je ne suis pas un œil, je ne fais pas partie du corps !, ce n'est pas, pour cela, qu'elle ne ferait pas partie du corps.

1 Co 12,17

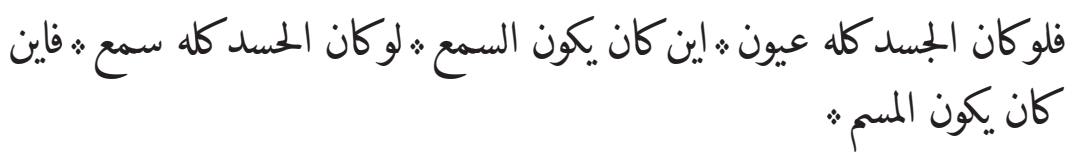

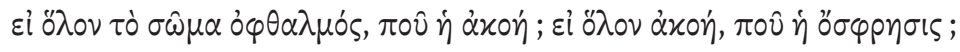

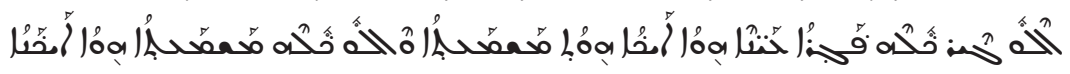

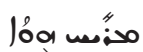

Et si le corps tout entier était des yeux, où serait l'ouïe? Si le corps tout entier était l'ouïe, où serait l'odorat?

VA 13 a une conjonction de coordination ف ف au début de verset, comme syp ; ; le grec n'en a pas.

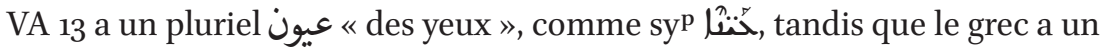
singulier ó $\varphi \theta \alpha \lambda \mu o ́ s$.

VA 13 est seul à répéter le corps » en deuxième partie de verset.

1 Co 12,18

$$
\text { فاما فان الله نصب كل واحد من الاوصال : في الحسد كا احب : }
$$

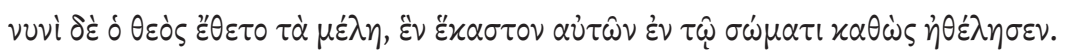

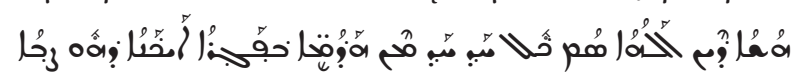

Quant à Dieu, il a placé chacun des membres dans le corps comme il le désirait. 


\section{Co 12,19}

$$
\text { ولو انهن كلهن كن وصل واحد ث. فاين كان يكون الجسد : }
$$

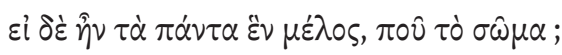

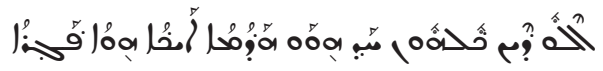

Et si tous étaient un seul membre, où serait le corps?

\section{Co 12,20}

$$
\text { فاما الان فانهن اوصال كيره : والجسد هو واحد : }
$$

$\nu 0 ิ \nu \delta \dot{\varepsilon} \pi 0 \lambda \lambda \dot{\alpha} \mu \dot{\varepsilon} \nu \mu \dot{\varepsilon} \lambda \eta$, हี่ $\delta \dot{\varepsilon} \sigma \hat{\omega} \mu \alpha$.

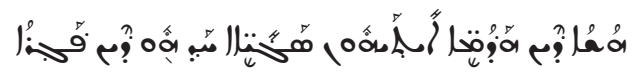

Mais maintenant, il y a plusieurs membres et le corps est un.

\section{Co 12,21}

$$
\text { لا تستطع العس ان تقول لليد اني لست محتاجه اليك : ولا الراس يقول }
$$

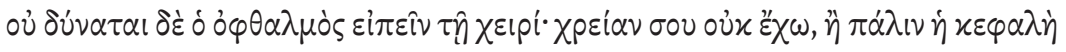

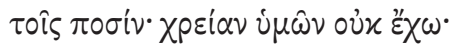

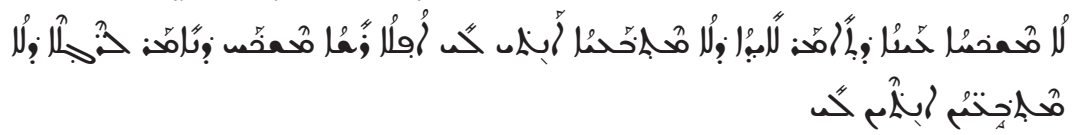

L'œil ne peut pas dire à la main : je n'ai pas besoin de toi !, ni la tête dire aux pieds : je n'ai pas besoin de vous!

VA 13 n'a pas de conjonction de coordination en début de phrase et ne soutient pas, comme A C F G P 33.104. 326. 365. 614. lat syp, la variante $\delta \dot{\varepsilon}$ (présente dans

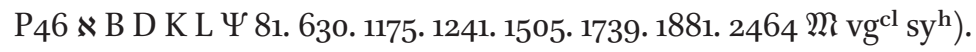

VA 13 introduit la deuxième partie du verset par 9 , ce qui est plus proche de syp ${ }^{p}$ que du grec $\ddot{\eta}$. 
1 Co 12,22

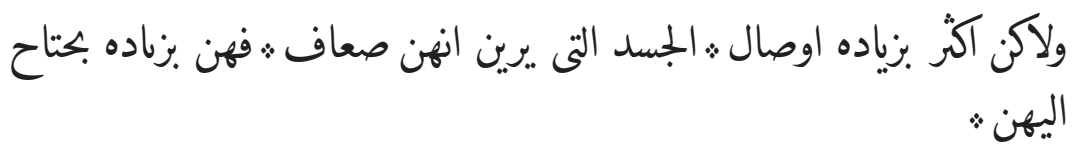

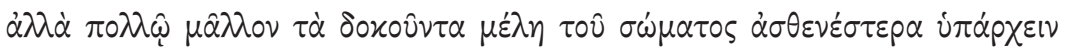

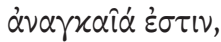

\section{草}

Mais de plus les membres du corps qui sont considérés comme faibles, ce sont eux dont nous avons davantage besoin,

بزياده اوصال semble être traduit du grec $\mu \dot{\varepsilon} \lambda \eta \tau$

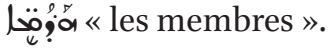

\section{Co 12,23}

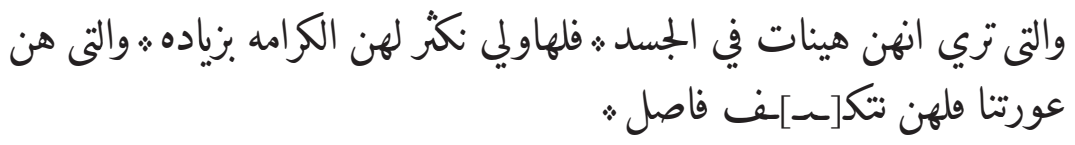

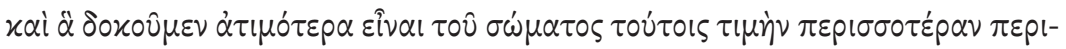

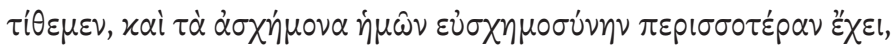

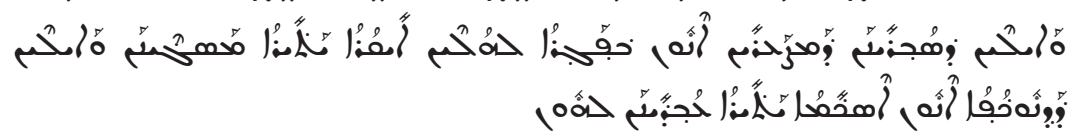
et ceux qui sont considérés comme méprisables dans le corps, à ceux-là, nous donnons plus d'honneur, et à ceux qui sont nos parties sexuelles, nous leur donnons un rang supérieur.

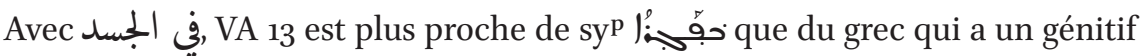

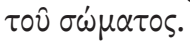

Plus loin, VA 13 avec un possessif comme le grec $\tau \dot{\alpha} \dot{\alpha} \sigma \chi \dot{\eta} \mu 0 \nu \alpha \dot{\eta} \mu \hat{\omega} \nu$,

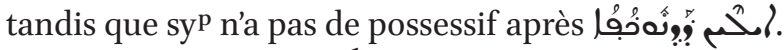

Nous lisons تنك]_ـ , ce qui semble être un verbe à la 1 ère personne du plu-

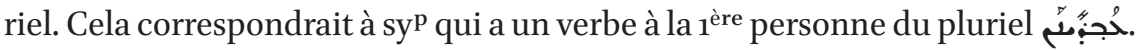

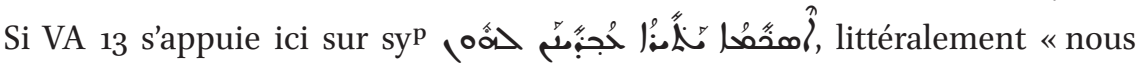
leur donnons forme davantage», il pourrait s'agit du verbe تكِّف donner 
forme $»^{134}$. Nous traduisons par «donner un rang», ce qui correspond au contexte du verset.

\section{Co 12,24}

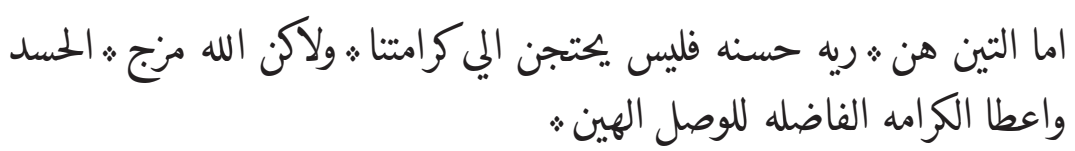

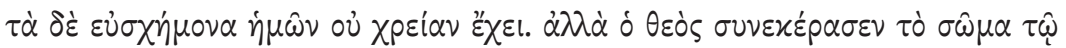

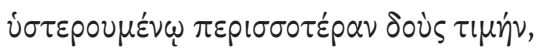

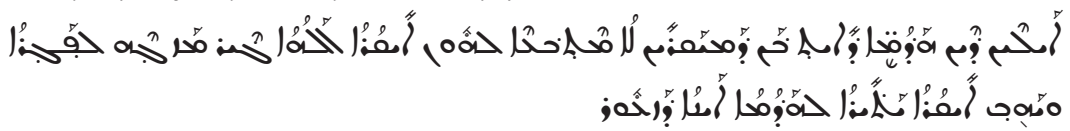

Quant à ceux qu'on estime honorables, ils n'ont pas besoin de notre honneur, mais Dieu a disposé le corps et il a donné le plus grand honneur au membre méprisable,

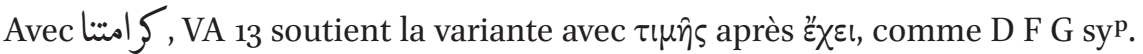
VA 13 a un possessif en plus.

VA 13 reprend le même adjectif qu'au verset précédent الهين «éprisable »; le grec et syp parlent du membre « qui manque [d'honneur] ».

1 Co 12,25

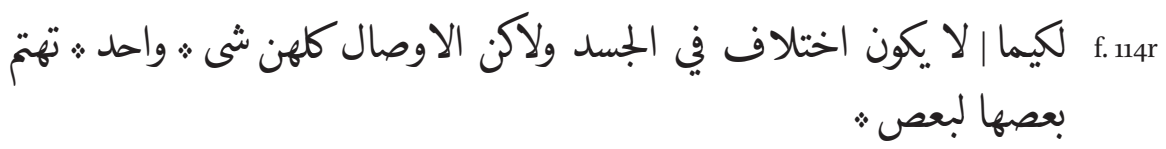

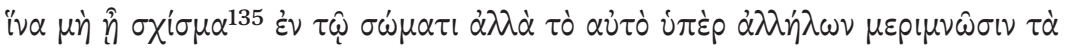
$\mu \dot{\varepsilon} \lambda \eta$.

\footnotetext{
134 La forme II كَف signifie «donner forme à » (BELOT, p. 715; REIG, no. 4730). La forme V prend le sens intransitif: « prendre forme ». Nous supposons ici que la forme $\mathrm{V}$ a le même sens que la forme II (à ce propos voir BLAU, note 58 , p. 155).

135 Plusieurs témoins ont $\sigma \chi i \sigma \mu \alpha \tau \alpha$ ( $\mathrm{D}^{*} \mathrm{~F} \mathrm{G} \mathrm{L} \mathrm{323.} 2464 p m$ ar vgms); VA 13 a un singulier اختلاف, mais comme il s'agit d'un nom d'action, un pluriel aurait été inhabituel. Voir aussi 1,10.
} 


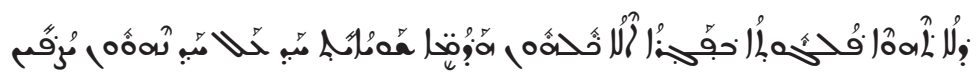
afin qu'il n'y ait pas de différend dans le corps mais que tous les membres unanimement se soucient les uns des autres.

1 Co 12,26

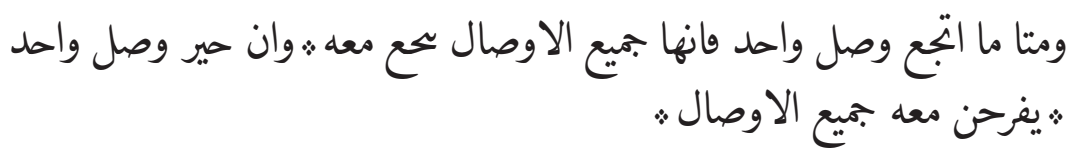

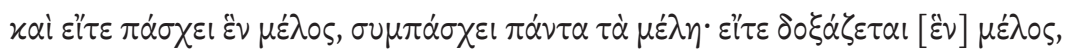

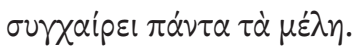

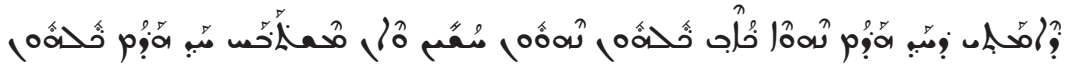

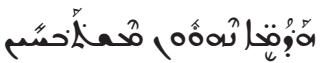

Quand un seul membre souffre, l'ensemble des membres souffre avec lui, et si un seul membre obtient une faveur, l'ensemble des membres se réjouit avec lui.

VA 13 a deux fois le même verbe dans le premier membre du verset آتحع) et (يحع) puis utilise deux verbes différents dans le second membre du verset

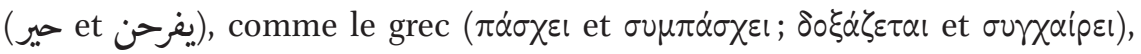
contre syp qui a deux verbes différents dans le premier membre du verset et deux fois le même verbe dans le second membre du verset

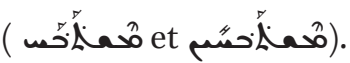

Avec وصل واحد, VA 13 soutient la variante हैं dans la seconde partie du verset, comme $\aleph^{2}$ C D F G K L P Y 0285. 33. 81. 104. 365. 630. 1241. 1505. 1881. 2464 M latt sy (contre $\aleph^{*}$ A B 1739).

\section{Co 12,27}

فائا انتم فانك حسد المسيح ؛:والوصال من اوصاله :

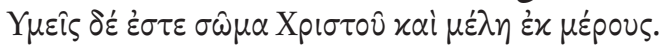

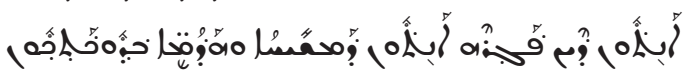

Mais vous, vous êtes le corps du Christ et des membres parmi ses membres. 


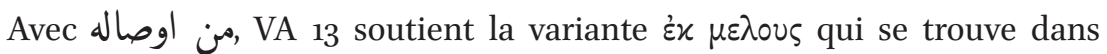
quelques témoins $\left(\mathrm{D}^{*} \Psi \mathrm{t} \operatorname{vg~sy}{ }^{\mathrm{h}}\right)$; VA 13 a un possessif ${ }^{136}$.

\section{Co 12,28}

$$
\begin{aligned}
& \text { وان الله نصب في الكنيسه اول السليحي ث: والثانه الانيا ث. والثالثه : المعلمين }
\end{aligned}
$$

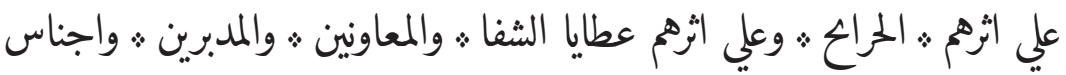

$$
\begin{aligned}
& \text { الالسنه }
\end{aligned}
$$

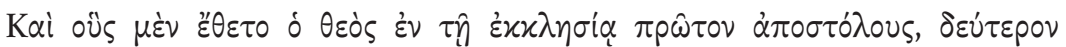

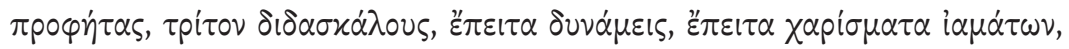

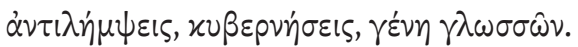

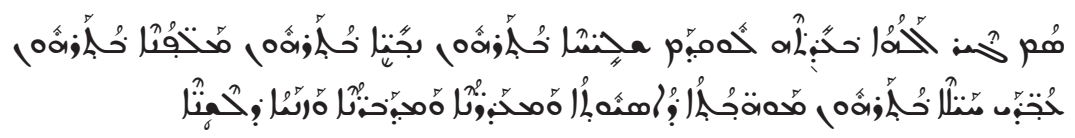

Et Dieu a établi dans l'Église premièrement les apôtres, deuxièmement les prophètes, troisièmement les enseignants, à leur suite les miracles, après cela les dons de guérison, ceux qui portent secours, les intendants et les différentes sortes de langues.

À propos de السليحن, voir notre remarque en 4,9.

est proche du

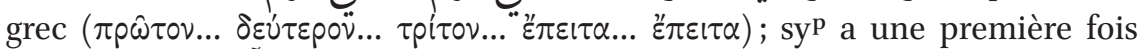

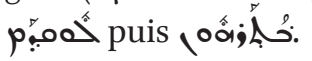

\section{Co 12,29}

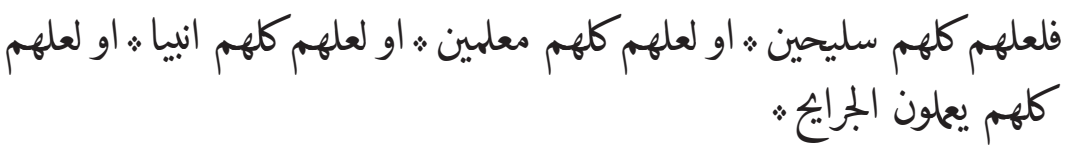

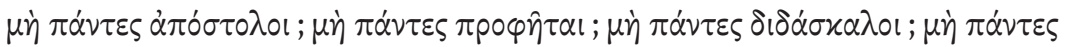

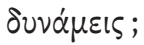

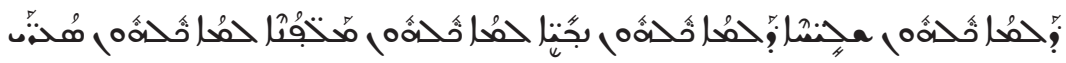

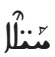

136 On trouve l'équivalent syriaque de cette variante dans les Aphraatis Demonstrationes 1,88/14 (AlAND). 
Or est-ce qu'ils sont tous apôtres? Ou sont-ils tous enseignants ? Ou sontils tous prophètes? Ou font-ils tous des miracles?

Une fois de plus, VA 13 a لعل pour traduire $\mu \eta^{\prime} /$ poir remarque en 1,13). VA 13 est seul à avoir la conjonction de coordination او pour chaque nouvelle interrogation.

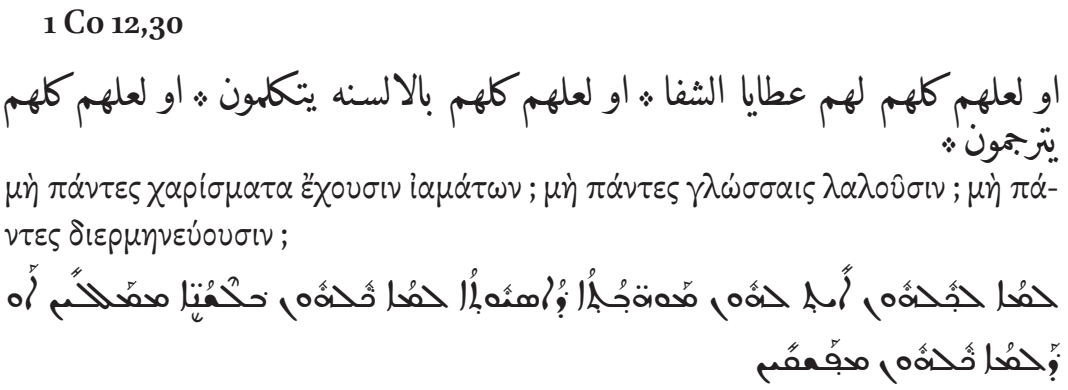

Ou est-ce qu'ils ont tous les dons de guérison? Ou parlent-ils tous en langues? Ou interprètent-ils tous?

Mêmes remarques qu'au verset précédent. syp a également une conjonction de coordination devant la dernière interrogation. Peut-on en déduire que les dans VA 13 aux v. 12,29 et 12,30 se basent sur syp?

1 Co 12,31

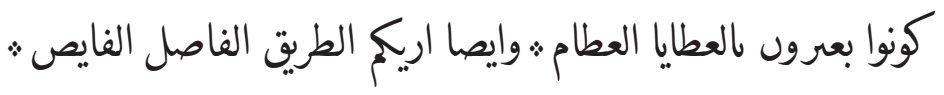

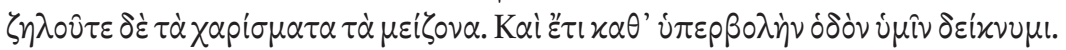

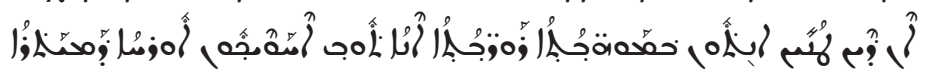

Soyez zélés dans les dons merveilleux et je vous montrerai aussi le chemin excellent et abondant.

L’utilisation de deux adjectifs الفاصل الفايص nous semble une tentative de traduire i $\pi \varepsilon \rho \beta \circ \lambda \eta \dot{\nu}$. 


\section{$1.13 \quad$ Chapitre 13}

\section{Co 13,1}

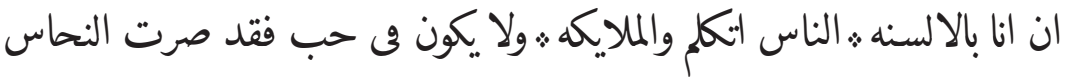

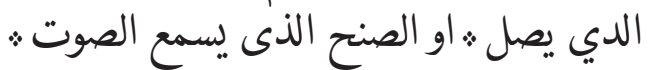

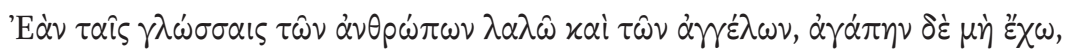

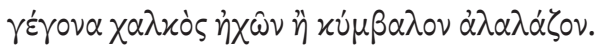

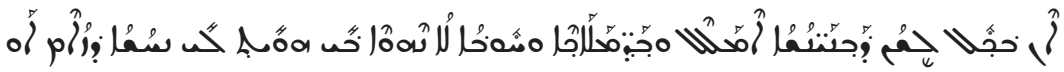

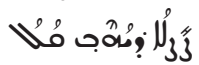

Si je parle les langues des hommes et des anges, et qu'il n'y a pas d'amour en moi, je suis un cuivre qui résonne et une cymbale dont on entend la voix.

La tournure avec في في dans les v. 1-3 est proche de syp.

\section{Co 13,2}

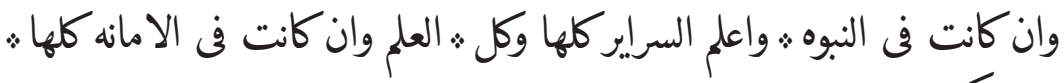

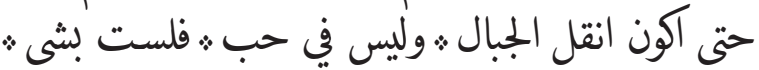

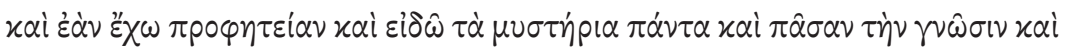

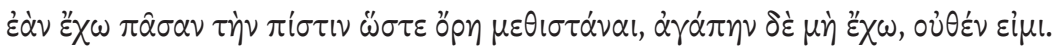

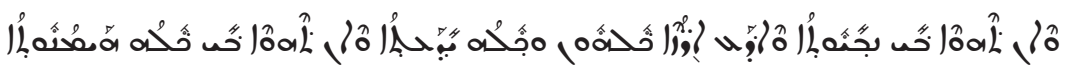

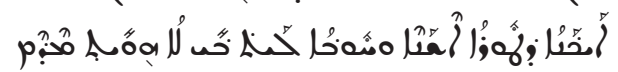

Et si j'ai le don de prophétie et que je connais tous les secrets et toute la connaissance, et si j'ai en moi toute la foi jusqu'à en déplacer des montagnes, et qu'il n'y a pas d'amour en moi, je ne suis rien.

1 Co 13,3

$$
\begin{aligned}
& \text { وان : اطعمت كل شى هو لي ث.وان اسلهت جسدي ان يكترق ثهوليس في حب }
\end{aligned}
$$

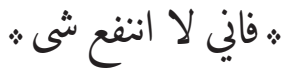




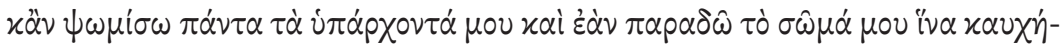

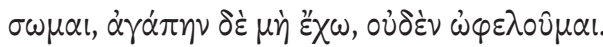

苗

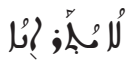

Et si je donne à manger tous mes biens, et si je livre mon corps à être brûlé, et que l'amour n'est pas en moi, je ne profite de rien.

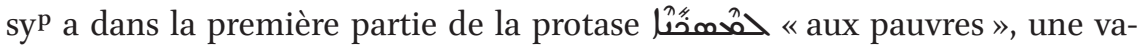
riante qui n'est pas suivie parVA 13.

Avec يحترق à la $3^{\mathrm{e}}$ personne du singulier, VA 13 soutient la variante $x \alpha v \theta \hat{n}$ qui

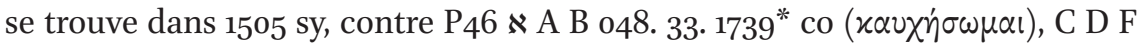

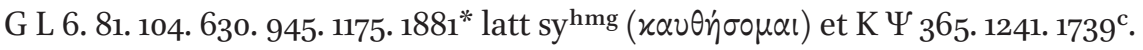
$1881^{c} .2464 \mathfrak{M}($ «

\section{Co 13,4}

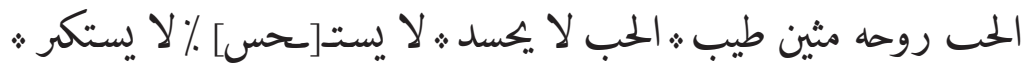

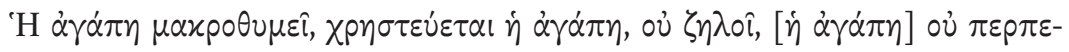

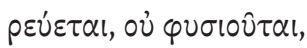

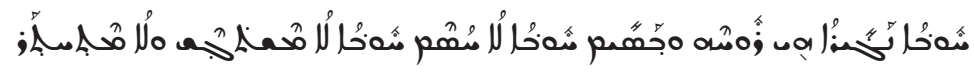

L'amour est stable en esprit, il est bon, l'amour n'envie pas, il n'est pas [troublé], il ne s'élève pas,

Il nous semble déchiffrer لا يستحس. Cette orthographe ne correspond pas à

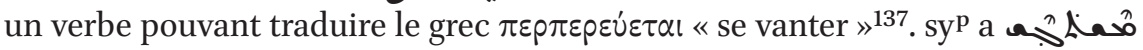
« être troublé » ${ }^{138}$; pourrait-il s'agir de la racine حس山, qui est liée aux émotions $(\text { voir } 12,1)^{139}$ ? Celle-ci n'a toutefois pas un sens négatif comme attendu par le contexte du verset. Une autre possibilité serait de lire سستحير, forme x de حار,

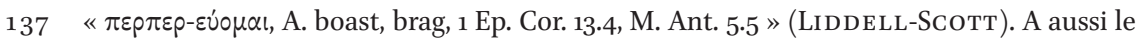
sens de « agir étourdiment» (GEORGIN, p. 592).

138 A l'ethpeal: « to be troubled, perturbed, uneasy, in uproar, noisy ; to be tossed, ruffled [...] », Payne Smith, p. 559 .

139 Un des sens donnés par Kazimirski pour la forme I est « être touché, attendri » (KAZIMIRSKI 1, p. 422); il ne donne par de forme X. 
qui pourrait aussi aller dans le sens du trouble ${ }^{140}$. Nous optons pour la première lecture :لا ستتحس et proposons la traduction «n'est pas troublé ».

Une erreur de copie, probablement de même au même, a conduit à l'omission de لا ستكبر ajouté dans la marge inférieure du folio à l'aide des signes \%

VA 13 ne répète que deux fois الحبر, comme 33.104. 629. 1175. 2464 lat sa bo ${ }^{\mathrm{ms}}$,

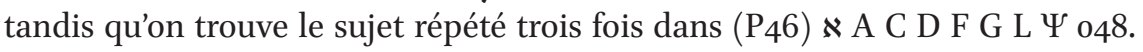
0243. 81. 365. 630. 1241. 1505. 1739. $1881 \mathrm{M}$ sy.

\section{Co 13,5}

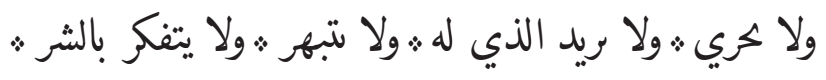

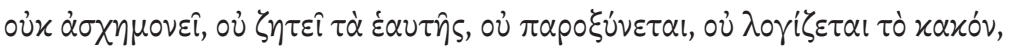

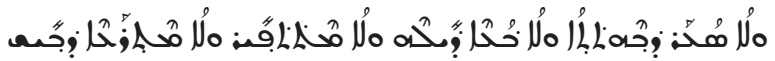
il ne déçoit pas, il ne veut pas son propre intérêt, il ne s'offusque pas ${ }^{141}$, il ne pense pas à mal,

\section{Co 13,6}

$$
\text { : ولا يفرح بالاثٌ : ولا |ولاكن يفرح بالحق f.114v }
$$

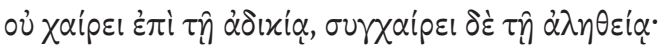

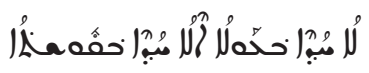

et il ne se réjouit pas du péché mais se réjouit de la vérité.

ولاك ولن vient du changement de folio ; il est difficile de savoir s'il s'agit d'une erreur ou d'une volonté de faciliter la lecture (pour un phénomène similaire, voir 3,23).

\section{Co 13,7}

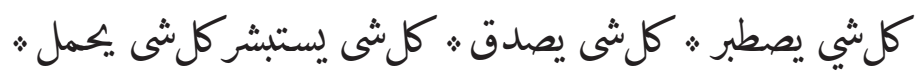

140 Kazimirski donne pour la forme x le sens de « être stupéfait, interdit, immobile » (KAZIMIRSKi 1, p. 525).

141 Pour la forme I, sens de « respirer avec difficulté » chez LANE, p. 265 et KAZIMIRSKi 1, p. 170 ; Reig lui donne le sens de « offusquer», REIG, no 603. 


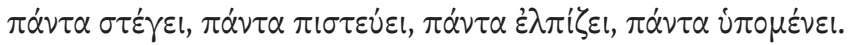

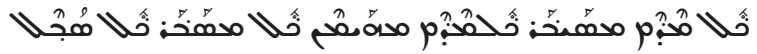

Il endure toute, il croit tout, il espère tout, il supporte tout.

À propos de يصطبر, voir 7,9.

La forme x de بشر vient traduire à deux reprises $\dot{\varepsilon} \lambda \pi i \zeta \omega /$ مصر (ici et en 15,19) et nous traduisons par « espérer ${ }^{142}$.

\section{Co 13,8}

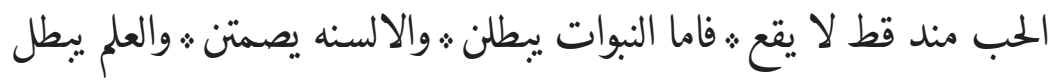

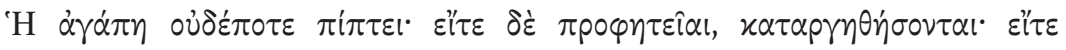

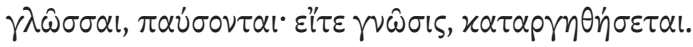

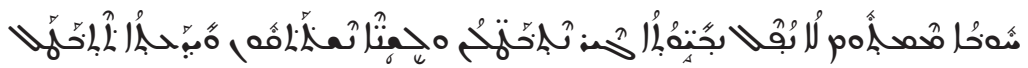

L'amour ne meurt jamais. Quant aux prophéties, elles seront vaines, et les langues se tairont, et la connaissance sera vaine.

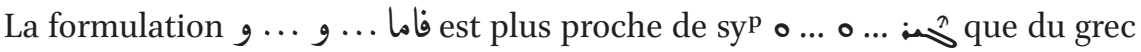

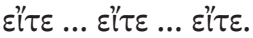

Avec la formulation au singulier العلم يبطل, VA 13 ne soutient pas la variante

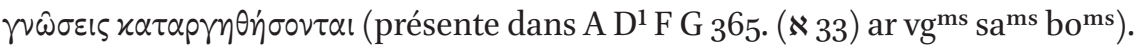

\section{Co 13,9}

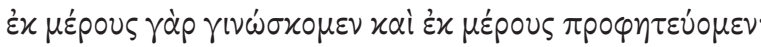
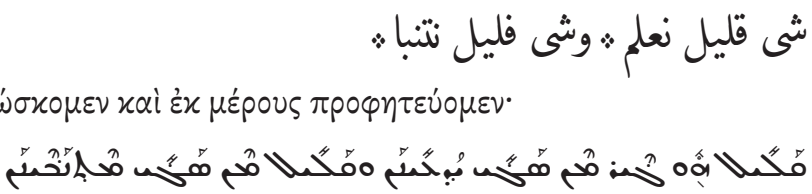

Nous savons peu de choses et nous prophétisons peu de choses,

142 Le sens « espérer » n'est pas attesté dans les dictionnaires consultés. Le verbe prend un autre sens en 11,26. 


\section{Co 13,10}

$$
\text { فاذا جا التمام هنالك يبطل القليل : }
$$

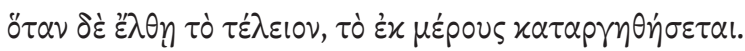

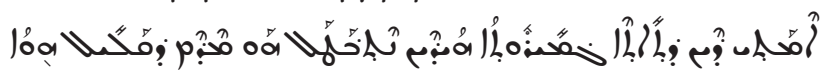

mais quand la perfection viendra, voilà que le peu sera vain.

Avec هنالك, VA 13 soutient la variante $\tau o ́ \tau \varepsilon, ~ c o m m e ~ D^{1}$ K L 630. 1505. 2464 M sy (contre P46 א A B D* F G P Ч 0243. 6. 33. 81. 104. 365. 1175. 1241. 1739. 1881. latt co).

\section{Co 13,11}

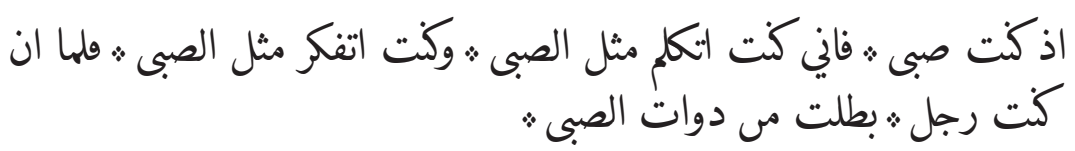

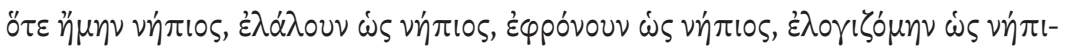

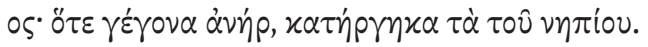

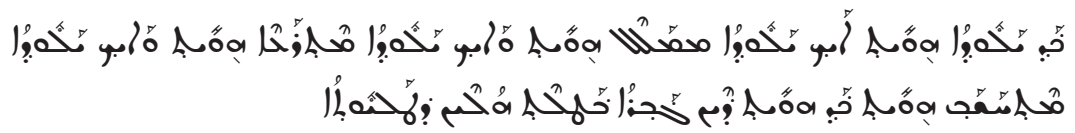

Lorsque j'était un enfant, je parlais comme l'enfant et je pensais comme l'enfant, quand je suis devenu un homme, j'ai mis fin à ce qui appartient à l'enfant.

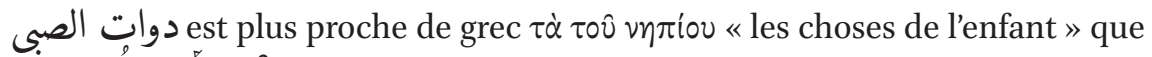

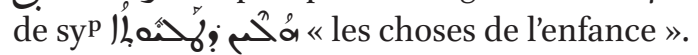

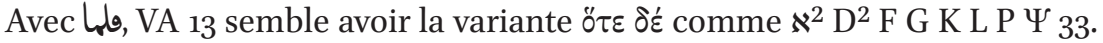
81. 104. 365. 1175. 1241. 1505. 1881. 2464. $\mathcal{M}$ b vg ${ }^{\mathrm{cl}}$ sy ( $\delta \dot{\varepsilon}$ absent dans $\aleph^{*}$ A B D* 048. 0243. 6. $1739 \mathrm{ar}_{\mathrm{vg}} \mathrm{g}^{\mathrm{st}}$.

\section{Co 13,12}

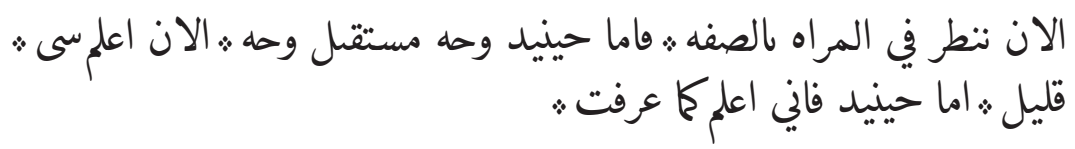

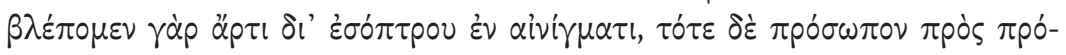

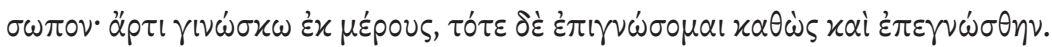




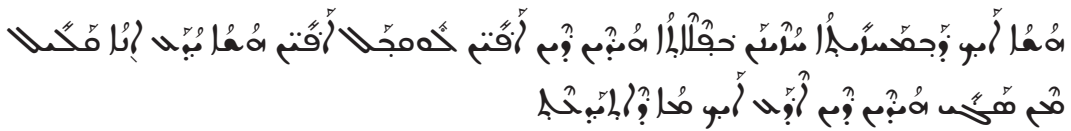

Maintenant, nous regardons dans un miroir, dans l'image, mais à ce moment-là, ce sera face à face ; maintenant je sais peu de chose, mais à ce moment-là, je saurai, comme j’ai été connu.

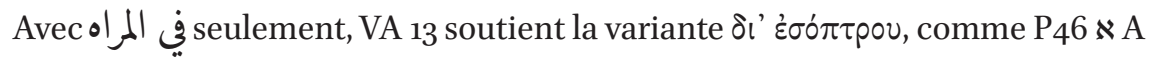
B F G H I K Ч 048. 104. 365. 1241. 1505 M, contre D 0243. 81. 630. 1175. 1739. 1881.

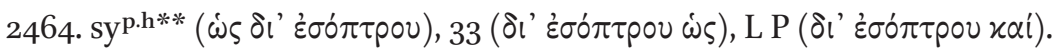

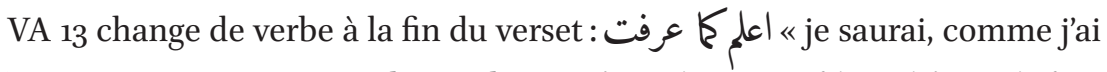

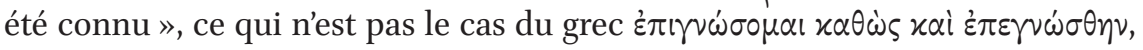
ni de syp

\section{Co 13,13}

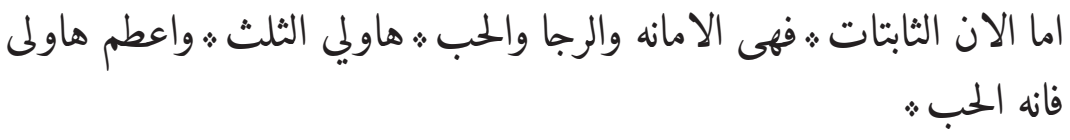

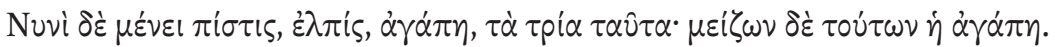

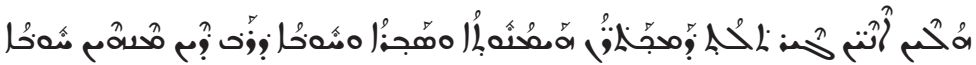
Or ce qui reste maintenant, c'est la foi, l'espérance et l'amour, ces trois, et le plus grand de ceux-là, c'est l'amour.

\section{$1.14 \quad$ Chapitre 14}

1 Co 14,1

$$
\text { فاسعو على اثٔ الحب ث وعيروا بالروحانيات : وبزاده على ان تننبون : }
$$

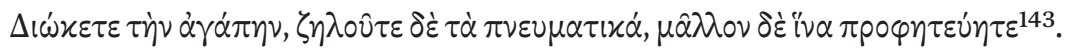

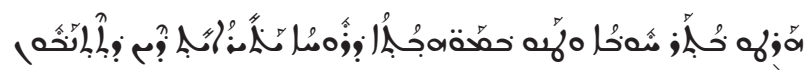
Recherchez l'amour, soyez zélés en les choses de l'esprit et surtout pour prophétiser.

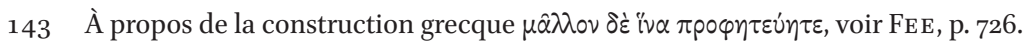




\section{Co 14,2}

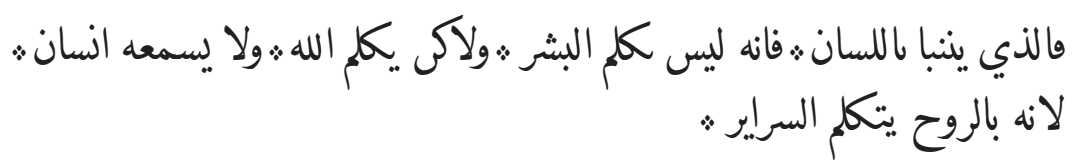

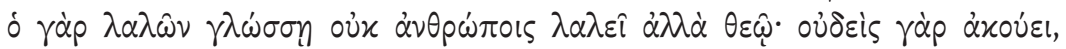
$\pi \nu \varepsilon \dot{\mu} \mu \alpha \tau l^{144} \delta \dot{\varepsilon} \lambda \alpha \lambda \varepsilon \hat{\imath} \mu v \sigma \tau \eta^{\prime} \rho \alpha$.

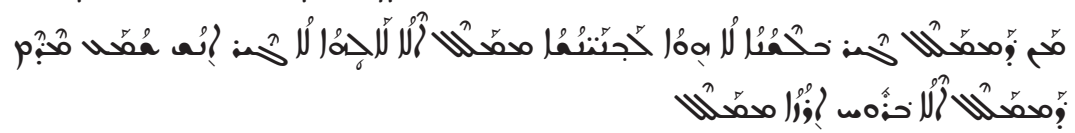

Car celui qui prophétise en langue, il s'adresse non pas aux hommes mais à Dieu et personne ne l'entend puisque, par l'esprit, il parle des secrets.

VA 13 est seul à avoir une conjonction causale لانه devant le dernier membre du verset (le grec a $\delta \dot{\varepsilon}$ ).

\section{Co 14,3}

$$
\text { اما الدى يتنبا : فانه يكم البشر : البنيان والعرا والاعتصام ٪ }
$$

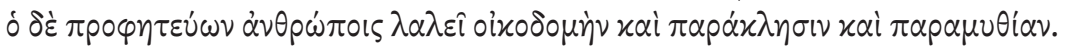

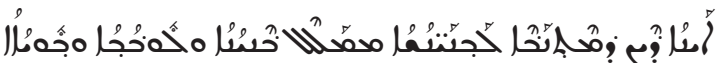

Quant à celui qui prophétise, il parle aux hommes de l'édification, de l'encouragement et du réconfort.

A la suite du verbe ي à la forme II, on attendrait la préposition ب devant l'objet du discours. On notera également que la forme II et la forme v sont utilisées indifféremment pour traduire $\lambda \alpha \lambda \hat{\varepsilon} \omega / \omega^{\prime}$ dans ce chapitre concernant le parler en langues (forme II : 14,2.3.5a.6.9.21.28b.35.39; forme v : 14,4.5b.11.13.1 8.19.23.27.28a.29.34) $)^{145}$.

\footnotetext{
144 Quelques témoins ( $F \mathrm{G} \mathrm{b}^{\mathrm{m}}{ }^{\mathrm{mss}}$ ) ont ici $\pi \nu \varepsilon \hat{u} \mu \alpha$, une variante qui n'est pas soutenue par VA 13 .

145 Cet aspect n'est pas développé par Blau dans sa grammaire.
} 


\section{Co 14,4}

$$
\text { الذى يتكلم بالسان : فانه يبنى نقسه : والذى يتنبا فانه سى الكنيسه : }
$$

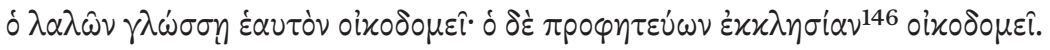

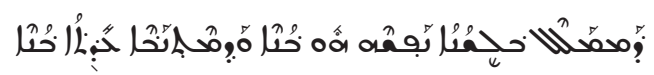

Celui qui parle en langue, il s'édifie lui-même et celui qui prophétise, il édifie l'église.

\section{Co 14,5}

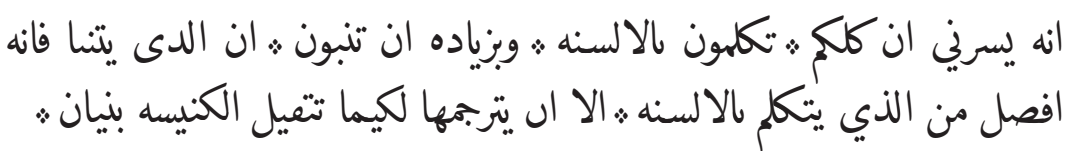

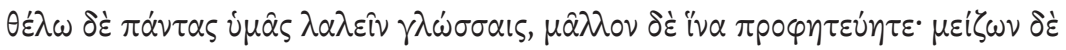

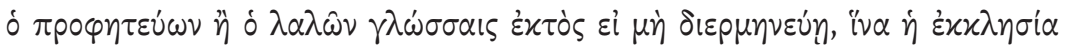

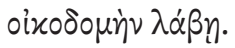

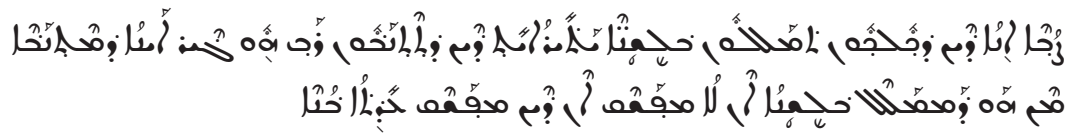

Je veux que tous vous parliez en langues et surtout, que vous prophétisiez. Celui qui prophétise est meilleur que celui qui parle en langues, sauf s'il l'interprète afin que l'Église reçoive une édification.

À propos سمريخي, voir notre remarque sur la racine سرّ en 1,1.

Nous lisons تنبون. Il semble que la forme II et la forme v soient utilisées in-

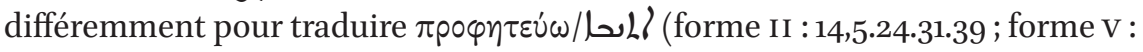
$11,5 ; 13,9 ; 14,1.2 \cdot 3 \cdot 4)^{147}$.

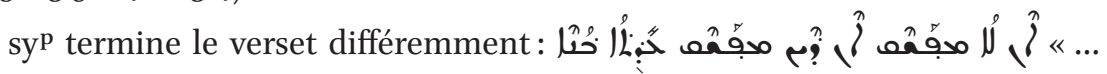
sauf s'il interprète; s'il interprète, il édifie l'Église ».VA 13 a, comme le grec: «sauf s'il l'interprète, afin que l'église reçoive une édification ».

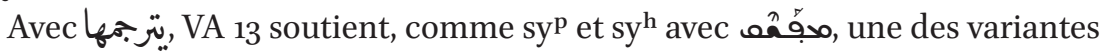

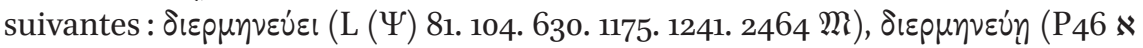

146 Quelques témoins ( $\mathrm{F} \mathrm{G} \mathrm{vg}^{\mathrm{cl}}$ ) ont ici $\theta \varepsilon \circ \hat{v}$, une variante qui n'est pas soutenue par VA 13.

147 Dans le cas de la forme II, il pourrait aussi s'agir d'une forme I ou d'une forme IV, mais notre remarque sur les formes de en 14,3 nous laisse penser qu'il s'agit d'une forme II. 


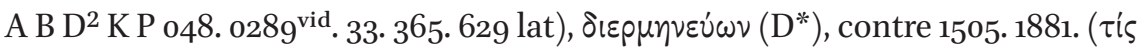

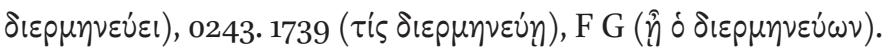

\section{Co 14,6}

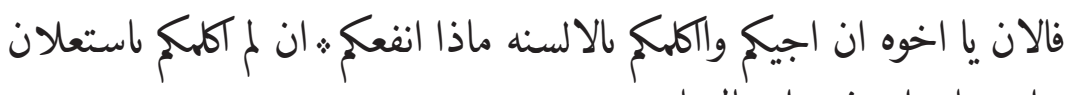

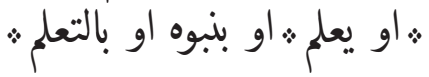

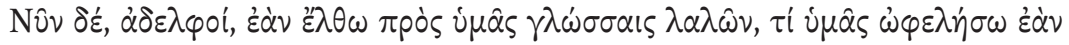

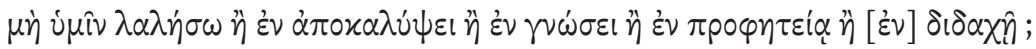

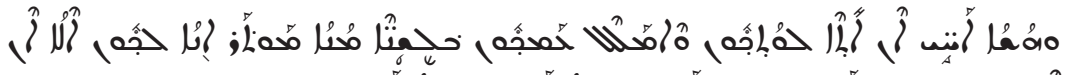

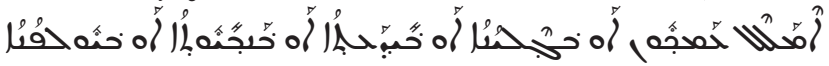

Et maintenant, ô frères, si je viens à vous et parle en langues, en quoi vous suis-je utile, si je ne vous parle pas par manifestation, par connaissance, par prophétie ou par enseignement?

À propos de

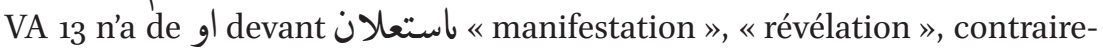

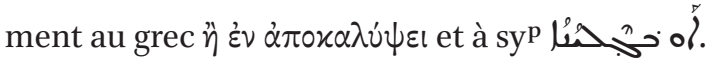

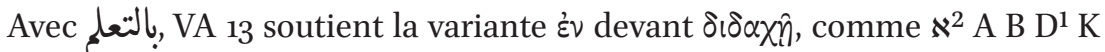
L P $\Psi$ 048. 33. 81. 104. 365. 1175. 1241. 1505. 2464. Ml lat sy (contre $\aleph^{*} \mathrm{D}^{*}$ F G 0243. 630. 1739. $\left.1881 \mathrm{vg}^{\mathrm{mss}}\right)$.

\section{Co 14,7}

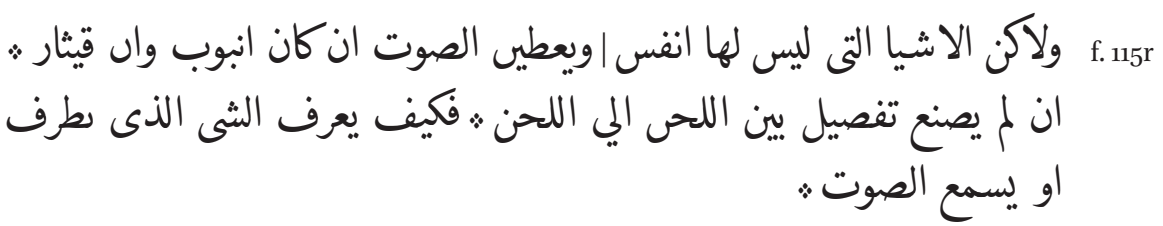

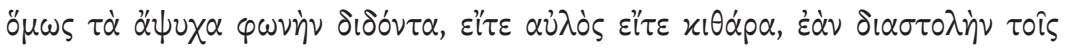

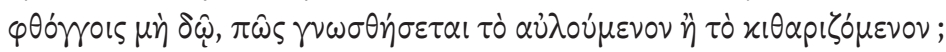

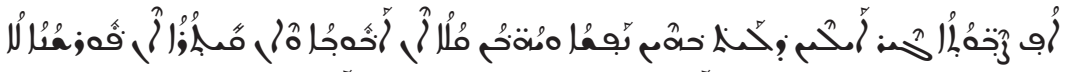

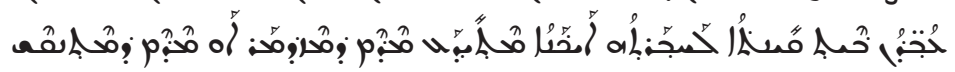


Mais les choses qui n'ont pas d'âme et qui donnent de la voix, que ce soit une flûte ou une harpe, si une distinction n'est pas faite entre les sons, comment sera reconnu ce qui est joué ou ce dont la voix est entendue.

L'expression entre le son et le son » est proche de l'expres-

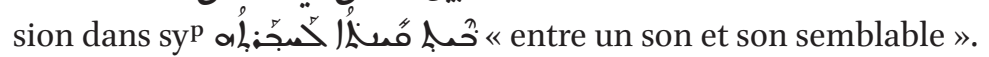

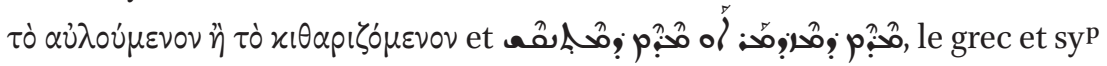
évoquent en premier le son de la flûte puis celui de la harpe. VA 13 a d'abord يطرق, qui se réfère ici à la harpe, puis l'expression neutre يسمع الصوت, expression que l'on trouvait déjà en 13,1.

\section{Co 14,8}

$$
\text { وان القرن اجاب بصوت ليس معلوم ث فن ث يستعد الي القتال ؛ }
$$

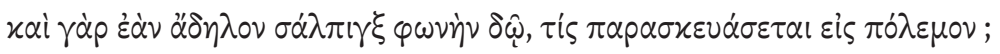

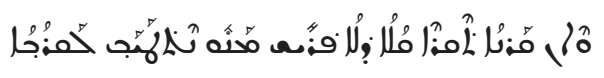

Et si le cor répond par une voix qui n'est pas comprise, qui se préparera au combat?

\section{Co 14,9}

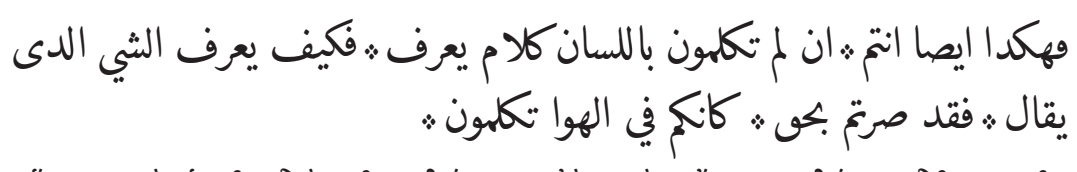

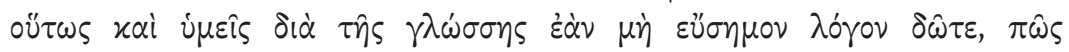

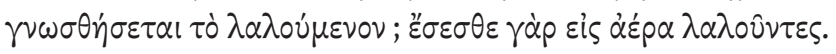

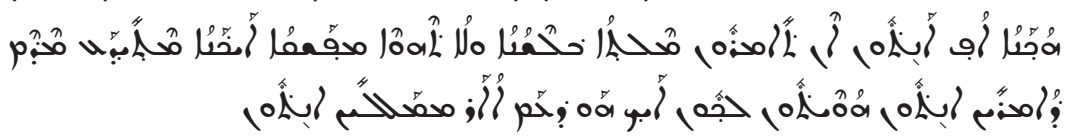

Et il en est ainsi aussi de vous : si vous ne parlez pas en langue une parole qui est comprise, comment connaîtra-t-on ce qui est dit? En vérité, vous êtes devenus comme si vous parliez dans le vent.

Avec ان ان لم تكلمون باللسان كلام يعرف si vous n’adressez pas en langue une pa-

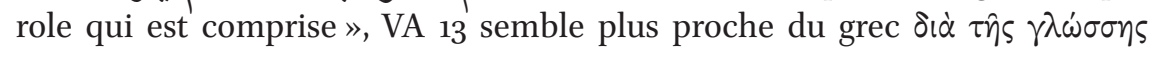

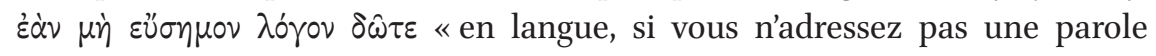


compréhensible», malgré le verbe principal différent, tandis que syp a

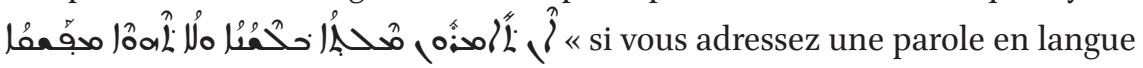
et qu'elle n'est pas interprétée ».

\section{Co 14,10}

$$
\text { فهاولي كل احناس الالسنه هى في العالم ؛ وليس شى نغير صوت ؛ }
$$

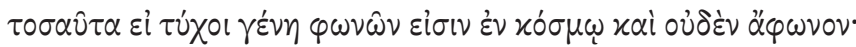

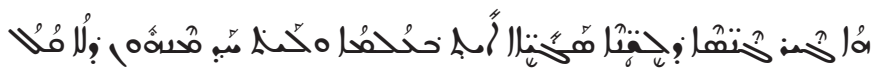

Tous les genres de langues sont dans le monde et rien n'est sans voix.

Avec $\boldsymbol{\zeta}$, VA 13 ne traduit pas exactement la nuance de quantité de $\tau 0 \sigma \alpha \hat{\tau} \tau \alpha$, ni la quantité exprimée pas )

VA 13 ne soutient pas la variante $\alpha \dot{\tau} \tau \hat{\omega} v$ après oủ $\delta \dot{\varepsilon} v$, comme $\mathrm{P}_{4} 6 \boldsymbol{\kappa}^{*} \mathrm{~A} \mathrm{~B} \mathrm{D*F}$

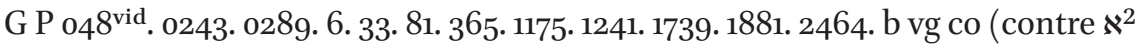
$\mathrm{D}^{2} \mathrm{~K}$ L $\Psi$ 104. 630.1505. $\mathfrak{M}$ ar g vg $\left.{ }^{\mathrm{mss}} \mathrm{sy}\right)$.

\section{Co 14,11}

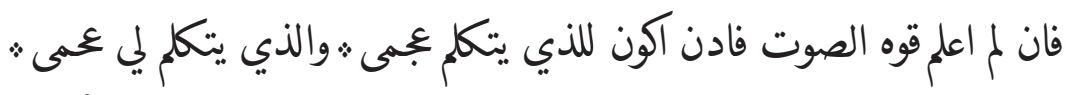

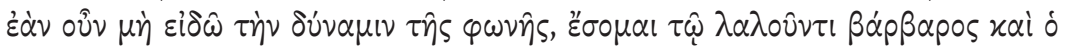

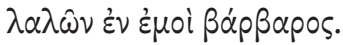

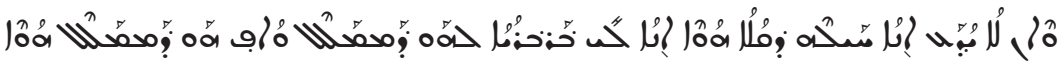

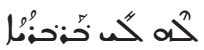

Or si je ne connais pas le pouvoir de la voix, alors je serai pour celui qui parle un étranger, et celui qui parle sera un étranger pour moi.

désigne celui qui est étranger, et celui qui ne parle pas arabe (KAZIMI RSKI 2, p. 184); il s'agit de la traduction exacte de $\beta \alpha ́ p \beta \alpha \rho o s$ en contexte arabophone.

\section{Co 14,12}

$$
\text { الكنيسها :انتم ايصا من اجل انكم غيره الروحانيات ؛ فاجتهدوا ان تتفعون بنيان }
$$




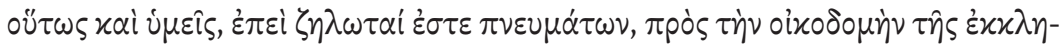

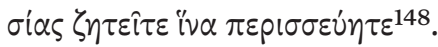

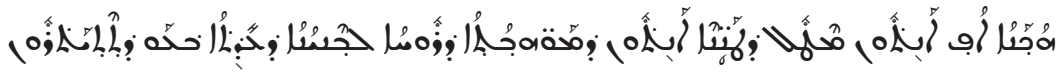

Et ainsi, vous aussi, puisque vous êtes des zélés des choses spirituelles, efforcez-vous d'être utiles à l'édification de l'Église.

Nous lisons تنفعون, mais nous ne pouvons expliquer cette orthographe ; nous proposons de comprendre تثفعون.

Nous lisons غيره ; s'agit-il du substantif غيرة i zèle », 《jalousie » ? Un adjectif

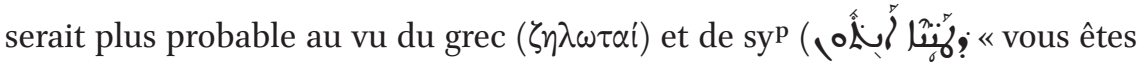
zélés »). Il s'agit peut-être d'une forme plurielle non connue par les dictionnaires consultés.

Avec الروحانيات, VA 13 a la variante $\pi \nu \varepsilon v \mu \alpha \tau i x \omega \hat{\omega}$, comme P 1175 ar vg ${ }^{m s s}$ syp co, et non $\pi \nu \varepsilon u \mu \alpha ́ \tau \omega \nu$.

\section{Co 14,13}

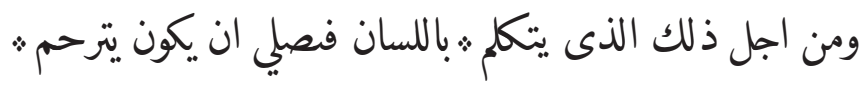

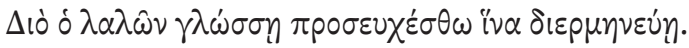

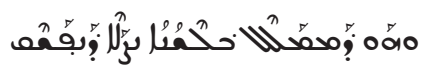

C'est pourquoi celui qui parle en langue, il prie afin d'interpréter.

\section{Co 14,14}

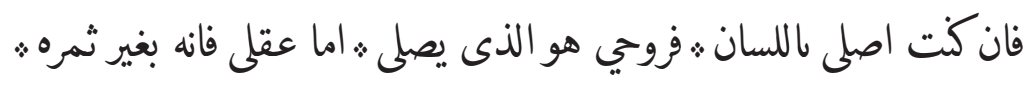

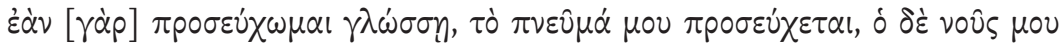

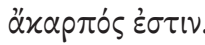

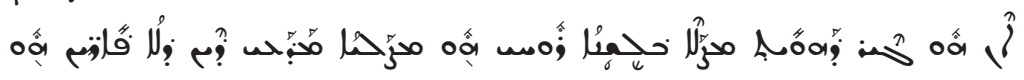

Car si je prie en langue, mon esprit est celui qui prie, mais mon intelligence, elle est sans fruit.

148 Quelques témoins (A I) ont ici $\pi \rho \circ \varphi \eta \tau \varepsilon v \tau \varepsilon$, une variante qui n'est pas soutenue par VA 13 . 
Avec ف ف A D K L P $\Psi$ 048. 81. 104. 365. 630. 1175. 1241. 1505. 2464 Ml lat sy bo (contre P46 B F G 0243. 1739. 1881 b sa).

\section{Co 14,15}

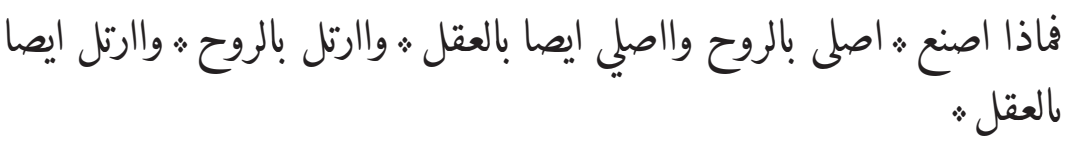

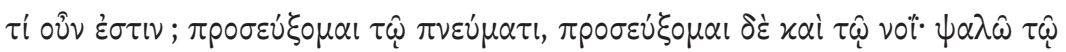

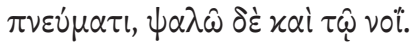

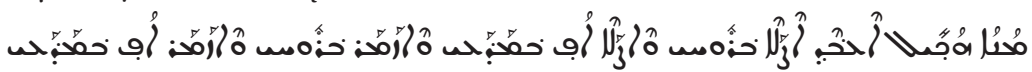

Donc que faire? Je prierai par l'esprit et je prierai par l'intelligence, je psalmodierai par l'esprit et je psalmodierai aussi par l'intelligence.

L'expression فن فاذا اصنع donc que fais-je ? » correspond à l'expression dans syp

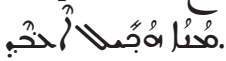

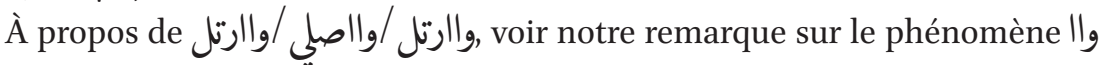
en 11,18 .

\section{Co 14,16}

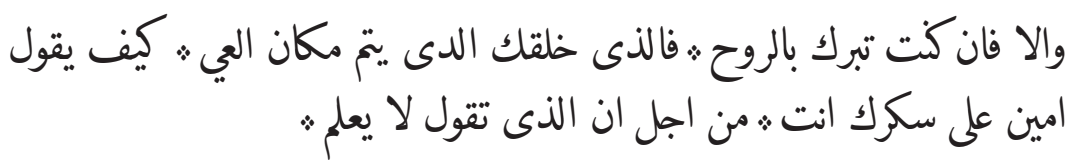

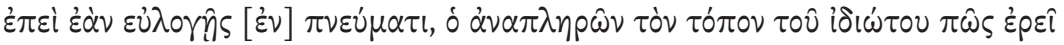

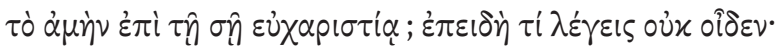

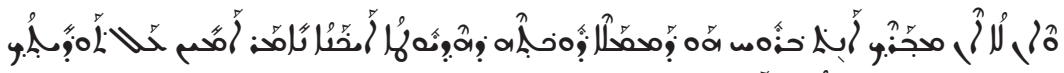

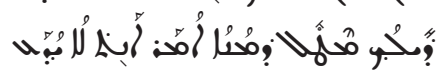

Sinon, si tu bénis par l'esprit, celui qui est à ta suite, qui occupe la position du faible, comment dira-t-il «Amen » à ton action de grâce, puisque ce que tu dis, il ne le comprend pas.

Il n'y a pas d'équivalent à خلفك en grec ou en syp.

La signification de العي الع faible», «bègue» (KAZIMIrski 2, p. 416) s'éloigne

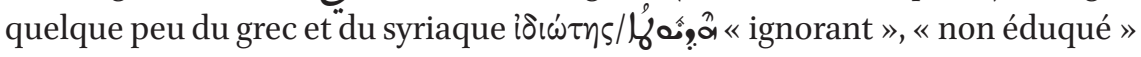
(voir aussi 14,23). 
1 Co 14,17

$$
\text { اما انت فنعما تشكر : ولاكن صاحبك لا يبتاء }
$$

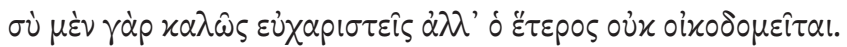

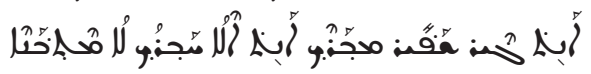

Quant à toi, tu rends très bien grâce, mais ton prochain n'est pas édifié.

\section{Co 14,18}

$$
\text { اني اشك الله : ان افصل من كاك اتهكم بالالسنه : }
$$

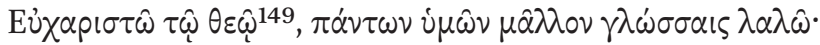

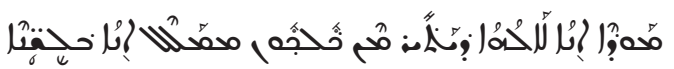

Je remercie Dieu de parler davantage que vous tous en langues.

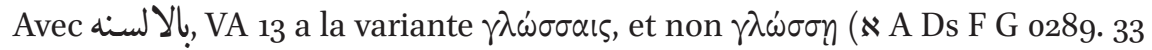
latt bo).

La majorité des témoins (K L 630.1241. 1505. $2464 \mathfrak{M}$ ) ont un participe $\lambda \alpha \lambda \omega \hat{\nu}$; avec اتأكل, VA 13 semble soutenir la variante à l'indicatif $\lambda \alpha \lambda \omega$ (présente chez $B$ D F G P Ч 048. 0243. 0289. 6. 33. 81. 104. 365. 1175. 1739. 1881 latt) - toutefois, VA 13 a généralement un verbe conjugué là où le grec a un participe, ce qui fait ici de VA 13 un témoin de peu de poids ( $\mathrm{P}_{4} 6$ a $\lambda \alpha \lambda \varepsilon i \omega$ et A n'a pas de verbe).

1 Co 14,19

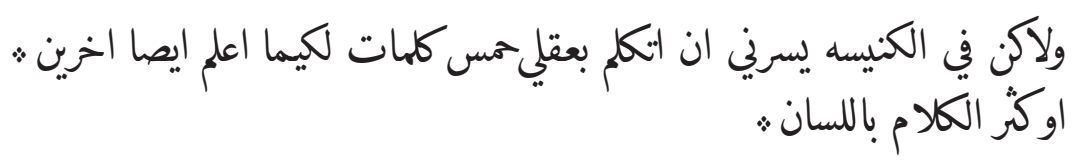

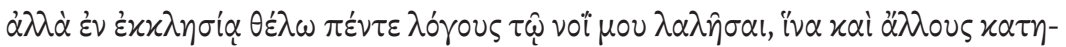

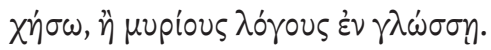

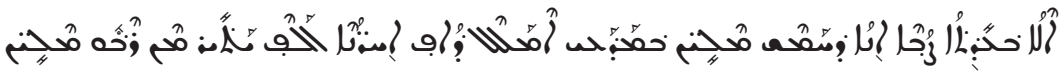

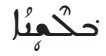

149 Quelques témoins (K L 326. 614. 629. 945. ( $\mathrm{vg}^{\mathrm{cl}}$ ) sa) ont ici $\mu$ ov, variante que VA 13 ne soutient pas ; $\mathrm{P}_{4} 6$ est ici seul à avoir í $\tilde{\varepsilon}$. 
Mais, dans l'Église, je voudrais dire cinq mots avec mon intelligence pour enseigner aussi aux autres, plutôt que beaucoup de paroles en langue.

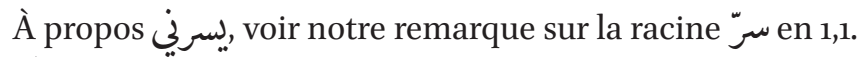

او, qui n'a normalement pas de sens comparatif, semble ici traduit littéralement du grec $\ddot{\eta}$. Ce phénomène est noté par BLAU, $§ 355$.

\section{Co 14,20}

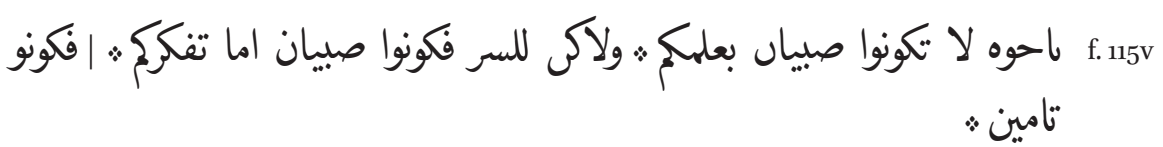

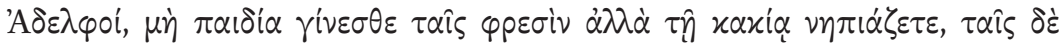

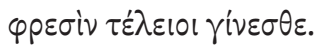

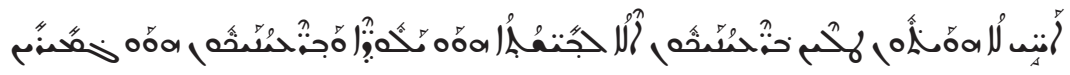

Ô frères, ne soyez pas des enfants dans votre connaissance, mais soyez des enfants pour le mal; mais dans votre réflexion, soyez parfaits.

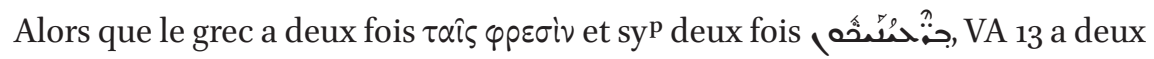
racines différentes :بفكركم et بعلمك; en grec et dans syp, il y a des pluriels, tandis que VA 13 a probablement des singuliers. Les pronoms possessifs sont par contre absents du grec, ceux-ci ont donc sans doute été repris de syp par VA 13 (ils sont aussi présents en sy ${ }^{\mathrm{h}}$ ).

1 Co 14,21

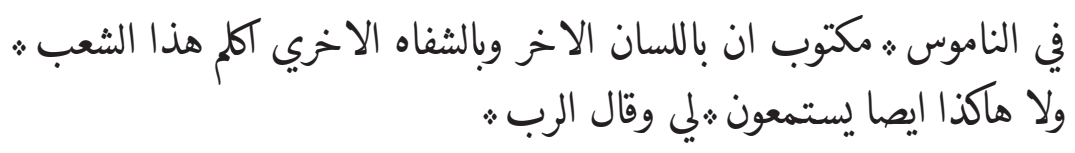

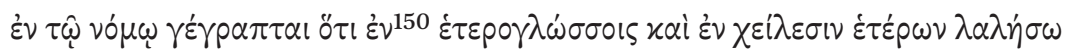

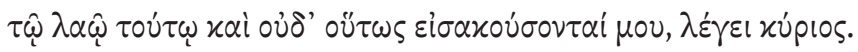

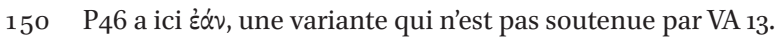




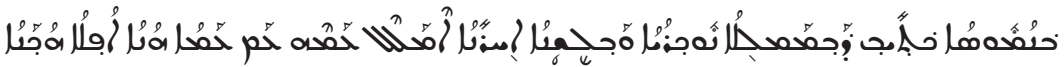

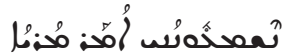

Dans la Loi, il est écrit: Dans la langue autre et par les lèvres autres, je m'adresserai à ce peuple et même ainsi, ils ne m'écouteront pas, [et] dit le Seigneur.

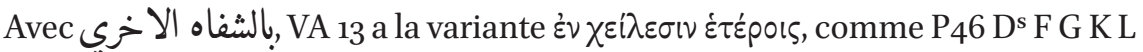
P 365. 630. 1175. 1505. 1881 M lat sy (contre א A B Ч 0201. 0243. 6. 33. 81. 104. 326.

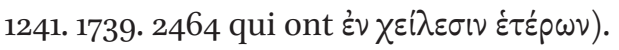

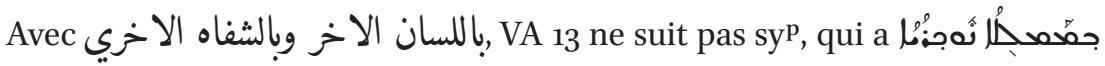

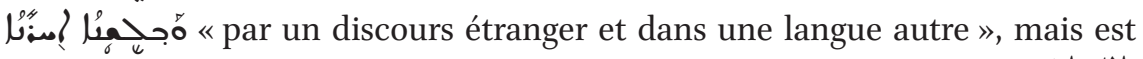

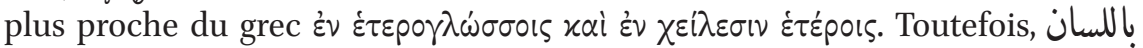
الاخ lier et cela ne fait pas référence aux hommes parlant la langue étrangère. VA 13 semble ici traduire des éléments venant des deux textes ${ }^{151}$.

Le وقال الرب qui a été ajouté en dessous de la ligne, vient peutêtre d'une volonté de correction grammaticale mais est problématique pour la traduction.

\section{Co 14,22}

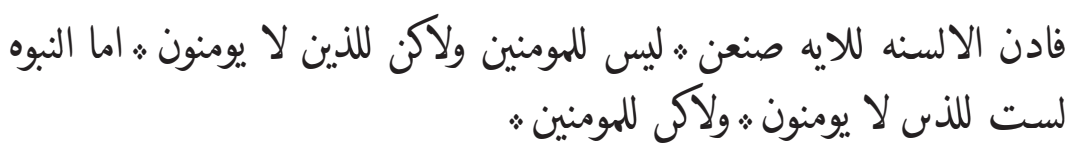

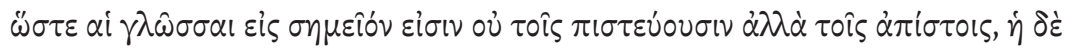

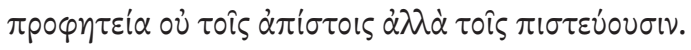

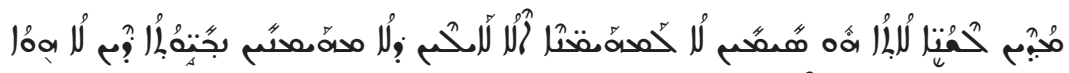

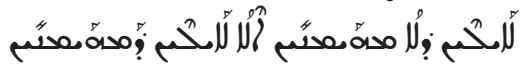

Alors, les langues ont été placées comme signe non pas pour les croyants mais pour les non-croyants; quant à la prophétie, elle n'est pas pour les non-croyants mais pour les croyants.

151 sy a ici إمترال

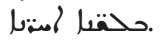


1 Co 14,23

$$
\begin{aligned}
& \text { فان اجتمت الكنيسه كلها ء جميع وكلهم يتكلمون بالالسنه : فيدخلون الاعبا او }
\end{aligned}
$$

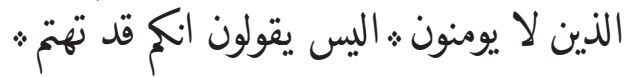

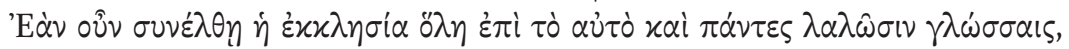

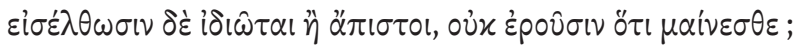

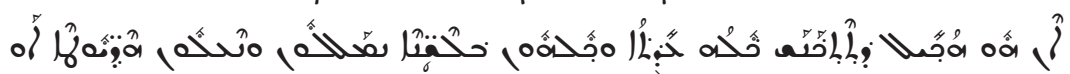

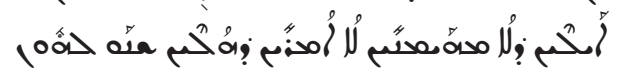

Or si toute l'Église se rassemble ensemble et que tous parlent en langues et qu'il entre des faibles ou des non croyants, ne diront-ils pas que vous vous êtes complètement égarés?

Avec انكى قد تهنت VA 13 est plus proche de la formulation à la $2^{\mathrm{e}}$ personne du pluriel du grec $\mu \alpha i v \varepsilon \sigma \theta \varepsilon$ que de la $3^{\mathrm{e}}$ personne du pluriel de syp VA 13 a toutefois un accompli, souligné par قد, tandis que le grec a un présent. Étonnamment, cela correspond à sy ${ }^{\mathrm{h}}$, qui a jân.

1 Co 14,24

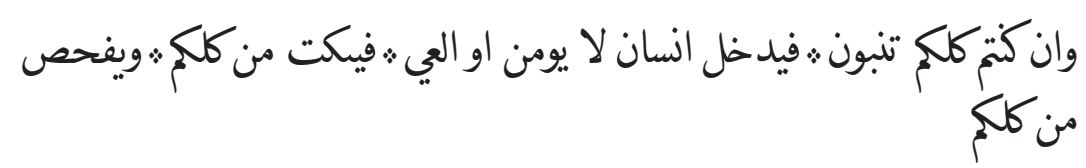

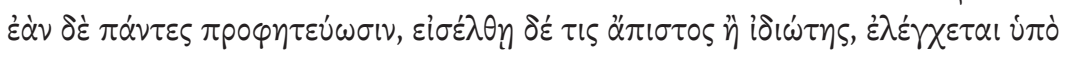

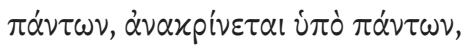

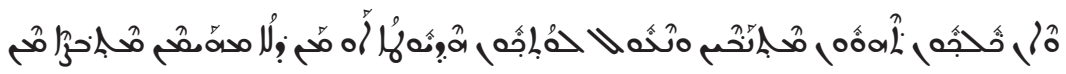

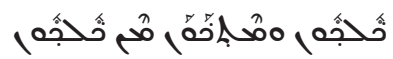

Et si vous prophétisez tous et qu'il entre un homme non-croyant ou un faible, il sera blâmé par vous tous et sera scruté par vous tous,

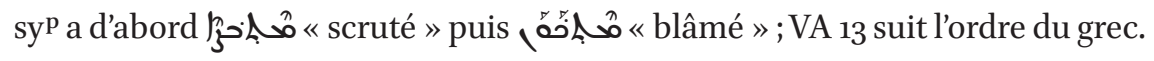

\section{Co 14,25}

وسرير قلبه ستنير • وهكذا شنن على وجهه : ويسحد لله ويقول بحى ان الله 


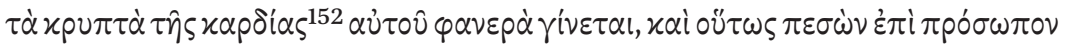

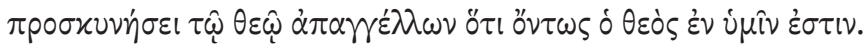

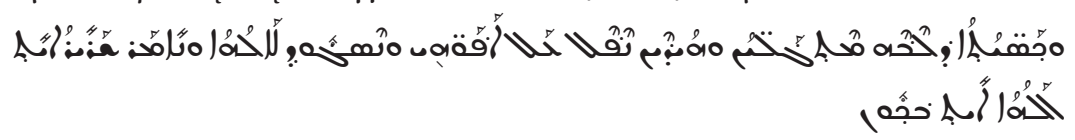

et les secrets de son cœur seront éclairés et ainsi il tombera sur sa face et se prosternera devant Dieu et il dira en vérité: Dieu est parmi vous!

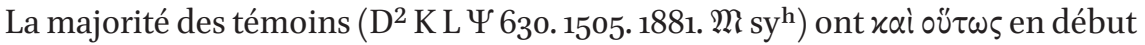
de verset (contre P46 « A B D* F G 048. 0201. 0243. 6. 33. 81. 104. 365. 1175. 1241. 1739. 2464 latt co qui commencent avec $\tau \dot{\alpha} x p v \pi \tau \alpha \dot{\alpha})$; avec g uniquement, VA 13 suit syp qui a 0 .

Nous lisons يخن traduisons. Le copiste s'est-il laissé influencer par la graphie proche?

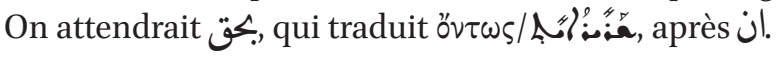

\section{Co 14,26}

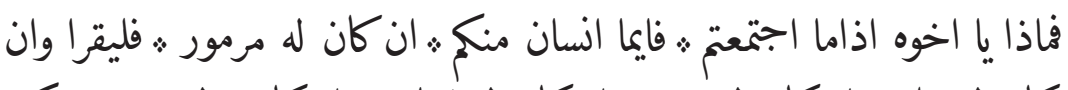

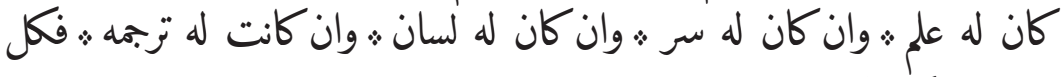
هاولي فليكى للبنيان

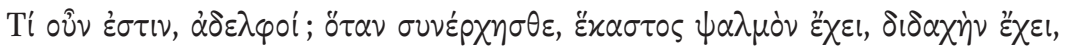

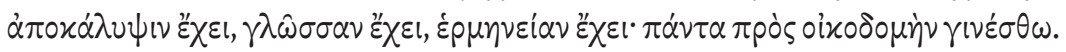

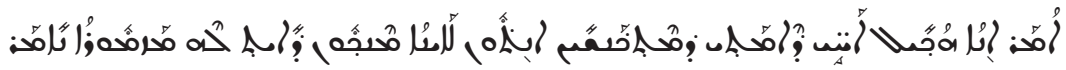

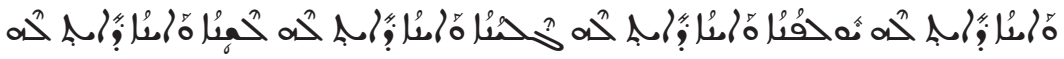

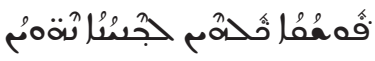
Qu'en est-il, ô frères ? Quand vous vous rassemblez, que quelqu'un parmi vous, s'il a un cantique, qu'il [le] récite, s'il a un savoir, un secret, une langue, une interprétation, que toutes ces choses soient seulement pour l'édification.

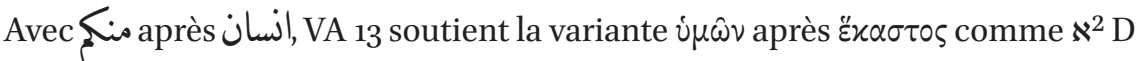

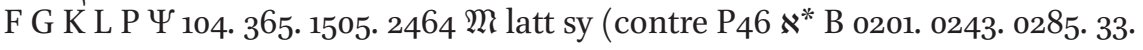
81. 630.1175.1241.1739.1881 co).

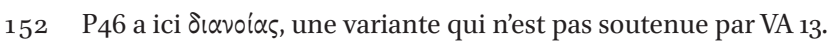


La répétition de lest propre à VA 13.

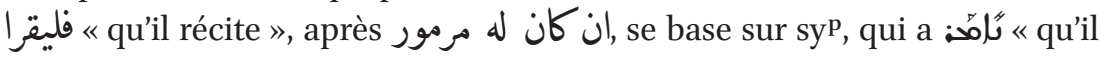
parle »; cette formulation est absente du grec.

\section{Co 14,27}

$$
\begin{aligned}
& \text { وان كان بالسان يتكلم انسان ؛ اتتين يتكلمان وان كز فثلثه ث وواحد ث.وواحد ؛ }
\end{aligned}
$$

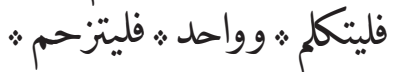

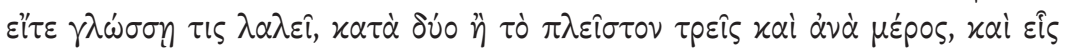

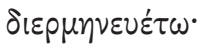

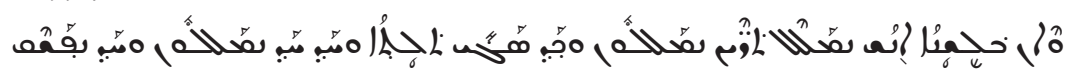

Et si quelqu'un parle en langue, que deux parlent, et si davantage, trois, qu'ils parlent l'un après l'autre et qu'un [autre] interprète,

Comme syp, VA 13 répète le verbe يتكلم trois fois, tandis que le texte grec a seulement $\lambda \alpha \lambda \varepsilon \hat{\imath}$ une fois en début de verset.

\section{Co 14,28}

$$
\text { فان لم يكن الذى يترحم فليصمت المتكلم في الكنيسه فليكلم نقسه ولله ؛ }
$$

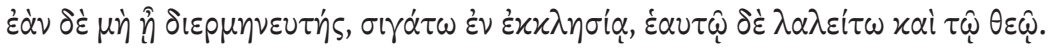

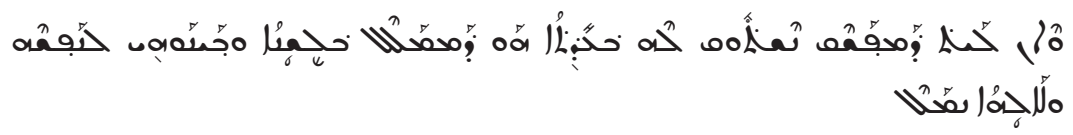
et s'il n'y pas d'interprète, que celui qui parle se taise dans l'Église et qu'il se parle à lui-même et à Dieu.

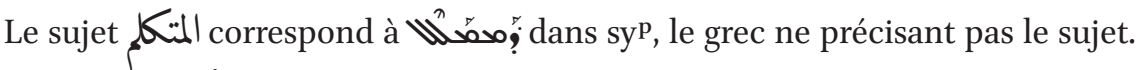

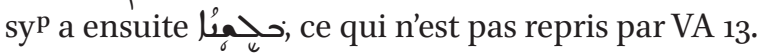

1 Co 14,29

$$
\text { اما الانييا . فاثنين او ثلثه : فليتكلمون ث وهاولي الاخر فليتينون ؛ }
$$

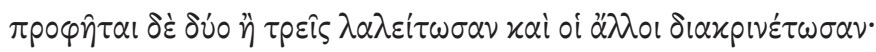




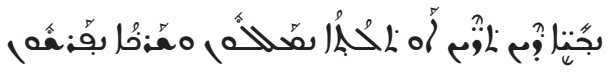

Quant aux prophètes, que deux ou trois parlent, et que les autres éclaircissent.

\section{Co 14,30}

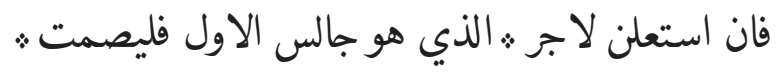

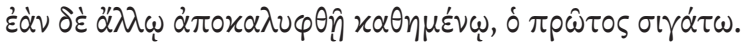

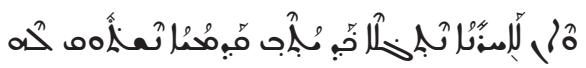

Et si quelque chose est manifesté à celui qui est assis, que le premier se taise.

\section{Co 14,31}

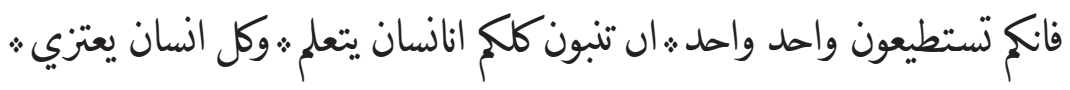

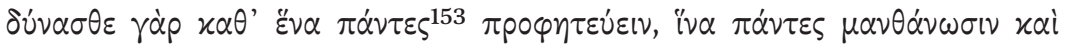
$\pi \alpha \dot{v} \tau \varepsilon \varsigma \pi \alpha \rho \alpha x \alpha \lambda \omega \hat{\omega} \nu \tau \alpha \mathrm{l}$.

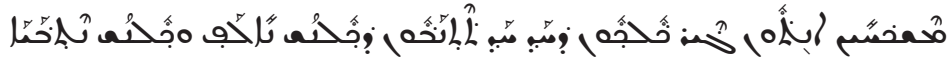

Car vous pouvez l'un après l'autre tous prophétiser [pour] que chacun soit instruit et que chacun soit réconforté.

Nous comprenons ان dans un sens final; il s'agit peut-être d'un syriacisme se basant sur 9. Voir aussi 2,16.

\section{Co 14,32}

$$
\text { وروح الانيا ثيواتي الانيا: }
$$

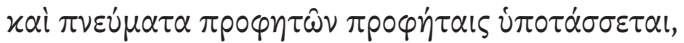

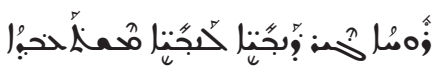

L'esprit des prophètes obéit aux prophètes,

153 Quelques témoins (33. 2464 vg ${ }^{\mathrm{mss}}$ ) n'ont pas ici $\pi \alpha \dot{v} \tau \varepsilon \varsigma$, une variante qui n'est pas soutenue par VA 13. 


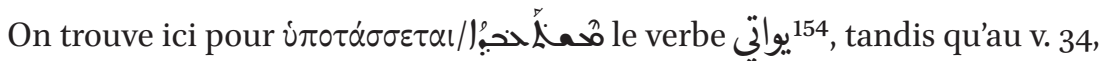
on trouve pour les mêmes verbes en grec et syp le verbe مخصوخ

Avec روح, VA 13 soutient la variante $\pi v \varepsilon u ́ \mu \alpha$, comme P123, D F G $\Psi^{*} 1241$ ar b vg ${ }^{\text {mss }}$ syp. $^{p}$.

\section{Co 14,33}

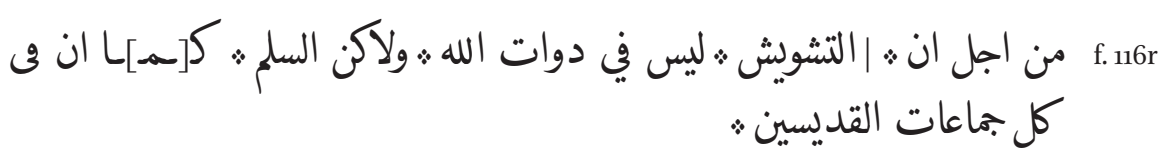

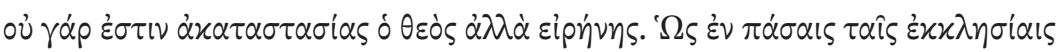
$\tau \hat{\omega} \nu \dot{\alpha} \gamma i \omega \nu$

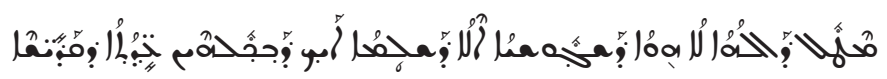
parce que le trouble ne fait pas partie de ce qui appartient à Dieu, mais la paix, de même que dans toutes les assemblées des saints.

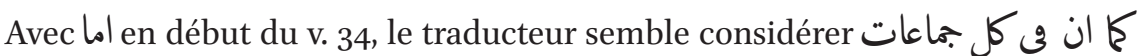

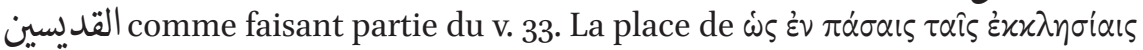
$\tau \hat{\omega} \nu \alpha \dot{\alpha} \gamma \dot{\omega} \omega$ est encore discutée aujourd'hui (Fitzmyer pense que le grec est à comprendre comme le fait le traducteur de VA 13, Fitzmyer, p. 527). ام اost pas repris de $\mathrm{sy}^{\mathrm{p}}$.

\section{Co 14,34}

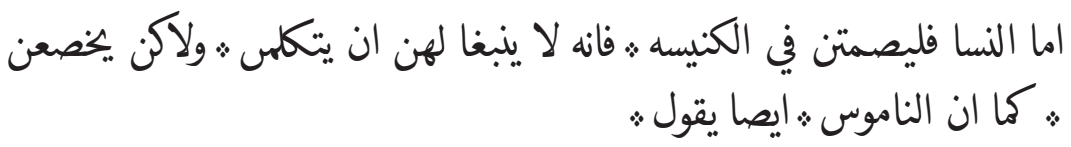

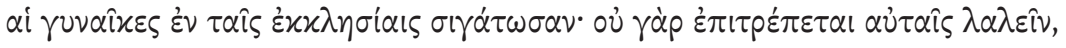

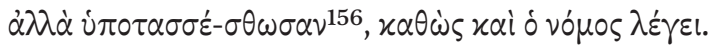

154 Kazimirski donne pour la forme III : « Tomber d'accord avec quelqu'un », « obtempérer à quelqu'un dans quelque chose », KAZIMIRSKI 1, p. 9.

155 C'est le même cas de figure en SA 155. Ce choix de verbe est-il motivé par le fait que l'on trouve plusieurs fois dans le Coran la forme IV « donner » en lien avec les Prophètes? (2:136 ; 3:84).

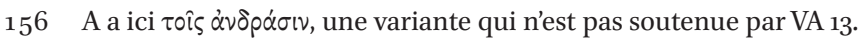




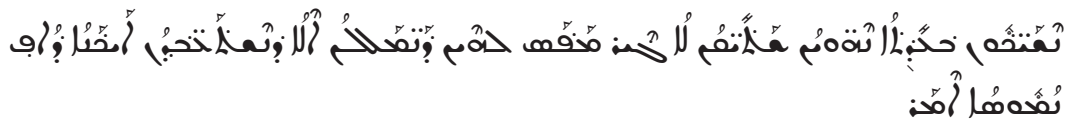

Quant aux femmes, qu'elles se taisent dans l'Église, il ne convient pas qu'elles parlent mais qu'elles se soumettent, comme la Loi le dit également.

À propos delol, voir notre remarque au verset précédent.

La majorité des témoins (D F G K L 630. 1505. M ar b sy) a u $\mu \omega v$ après $\alpha i$

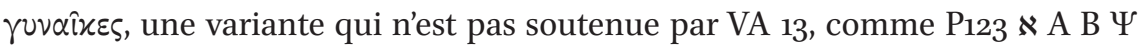
0243. 33. 81. 104. 365. 1175. 1241. 1739. 1881. 2464 lat co.

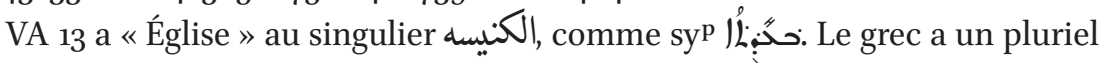

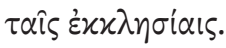

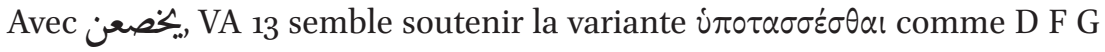
K L Y 0243. 104. 630. 1505. 1739. 1881. M lat(t) sy, contre A B 33. 81. 365. 1175. 1241. 2464, qui ont í $0 \tau \alpha \sigma \sigma \varepsilon \dot{\sigma} \theta \omega \sigma \alpha \nu$. Toutefois, on ne peut pas exclure qu'il s'agisse d'un subjonctif seul, comme constaté en 1 Co 1,8.

\section{Co 14,35}

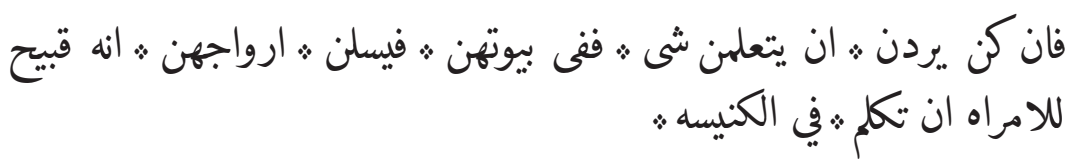

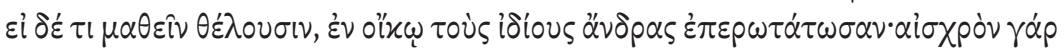

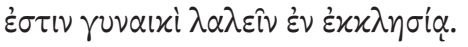

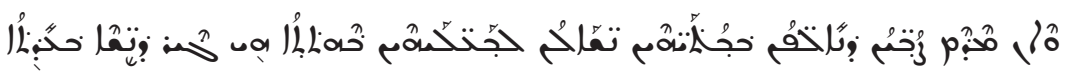

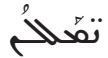

Or si elles veulent apprendre quelque chose, que, dans leur maison, elles demandent à leur mari, car il est honteux pour une femme qu'elle parle dans l'Église ${ }^{157}$.

Nous lisons للاهراه. S’agit-il, accompagné de la préposition ل, du nom défini للهراه ou du nom indéfini لاهر مر مous optons pour le nom sans article, comme

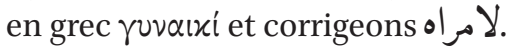

157 Quelques témoins (D F G ar b vgmss) ont les v. 34-35 après le verset 14,40, une variante qui n'est pas soutenue par VA 13 . 


\section{Co 14,36}

$$
\text { او لعل منكم خرجت كله الله : او اليكم بلغت فقط : }
$$

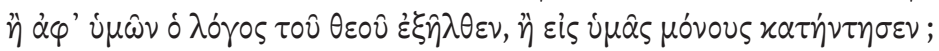

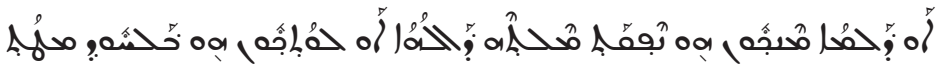

Ou est-ce que la parole de Dieu est sortie de chez vous, ou vous est-elle parvenue à vous seulement?

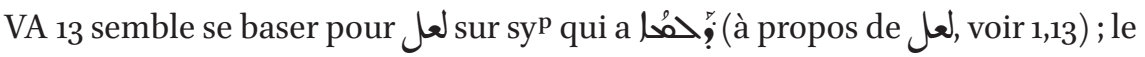
grec a seulement $\ddot{\eta}$, traduit dans VA 13 par glet dans syp par ớ.

\section{Co 14,37}

نان ظن انسان انه بى او روحاني ه فليفهم هاولي التى آكب اليكم ؛ انهن وصايا رن

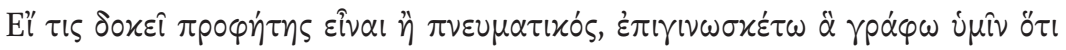

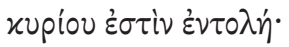

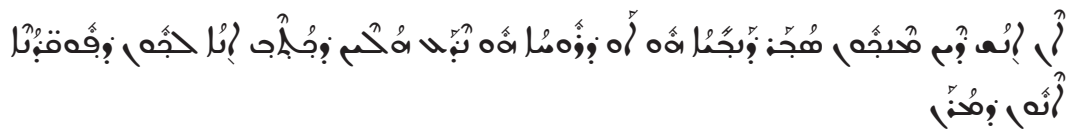

Si quelqu'un pense être prophète ou spirituel, qu'il comprenne ce que je vous écris, ce sont les commandements de notre Seigneur.

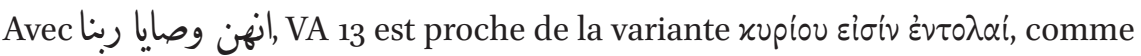
$\mathrm{D}^{1} \mathrm{~K}$ L $\Psi$ 81. 104. 365. 630. 1175. 1505. $2464 \mathrm{M}$ lat sy sa (contre $\boldsymbol{\aleph}^{*}$ et 81 $1^{\text {vid }}$ (xupíou

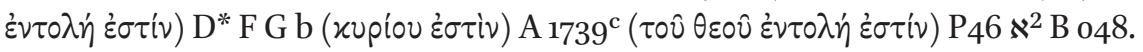

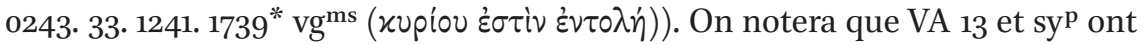

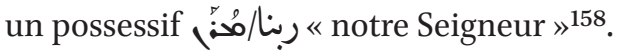

\section{${ }_{1} \operatorname{Co~} 14,3^{8}$}

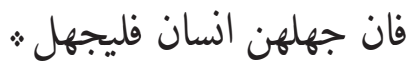

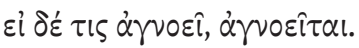

158 Voir notre remarque en 1,13. 
Et si quelqu'un les ignore, qu'il les ignore.

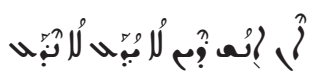

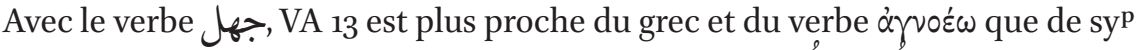

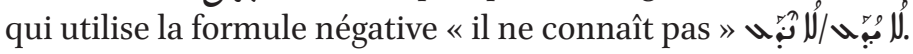

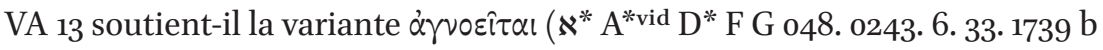

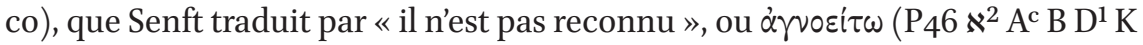
L $\Psi$ 81. 104. 365. 630. 1175. 1241. 1505. 1881. 2464 M sy) (SEN FT, p. 180) ? Il n'est pas possible de trancher, une vocalisation passive étant possible ici ${ }^{159}$.

\section{Co 14,39}

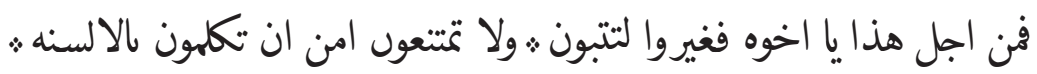

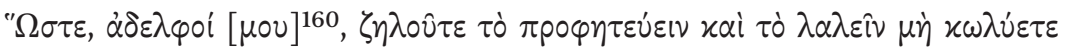
$\gamma \lambda \omega \dot{\omega} \sigma \sigma \alpha ı \varsigma^{\circ}$

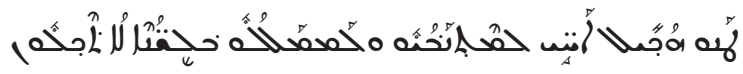

À cause de cela, ô frères, cherchez avec zèle à prophétiser et ne vous retenez pas de parler en langues,

Nous lisons امن Nous n'expliquons pas la présence de l'alif devant la préposition من منتعون demandée par le verbe.

\section{Co 14,40}

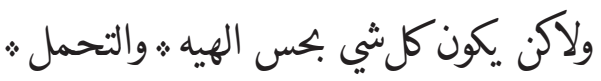

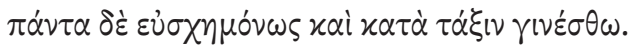

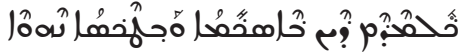

mais que tout soit dans le sens de la forme et de la convenance.

\footnotetext{
159 On trouve souvent dans notre texte des passifs là où il y a des moyens en grec, traduits dans syp par des ethpael (voir par exemple 6,2).

16o À propos de la variante $\mu$ ov, voir notre note en 1,10.
} 


\title{
$1.15 \quad$ Chapitre 15
}

\author{
1 Co 15,1
}

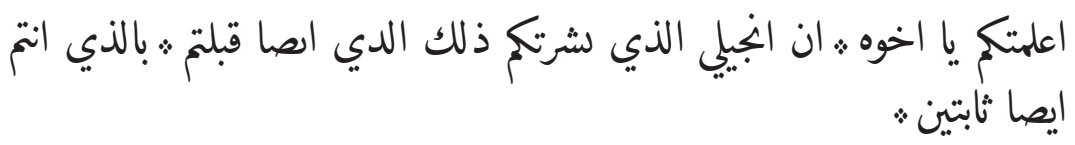

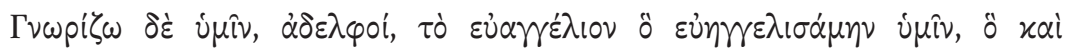

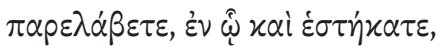

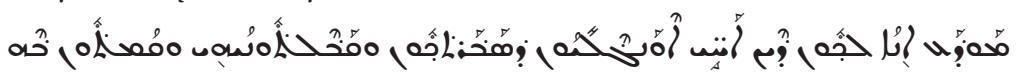

Je vous ai fait connaître, ô frères, que mon évangile est celui que je vous ai annoncé, celui-là qu'aussi vous avez reçu, dans lequel vous êtes, vous aussi, fermes,

VA 13 a un accompli اعلمتكا, tandis que le grec a un présent $\gamma v \omega \rho i \zeta \omega$ et syp un

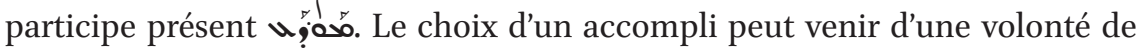
faire concorder les temps.

Nous lisons mon évangile ». VA 13 est seul à avoir un possessif.

\section{Co 15,2}

$$
\begin{aligned}
& \text { الذى انتم انصا احيا ؛ فناي كلهه بشرتك ان كتم حاوطيها ؛ ان لم تكونوا امنت } \\
& \therefore \text { باط }
\end{aligned}
$$

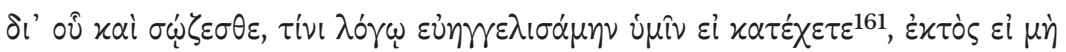

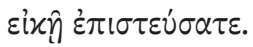

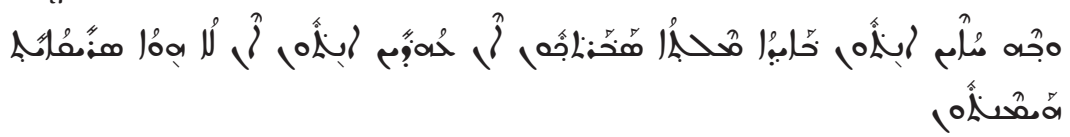
et par lequel vous êtes, vous aussi, vivants, si vous gardez la parole par laquelle que je vous [l']ai annoncé, sinon vous aurez cru en vain.

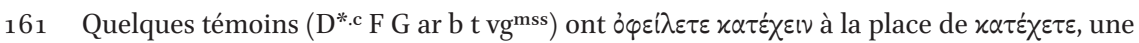
variante qui n'est pas soutenue par VA 13 . 
La construction des v. 15,1-2 est difficile ${ }^{162}$. Le verbe principal est $\gamma \omega \omega i^{\prime} \zeta \omega /$

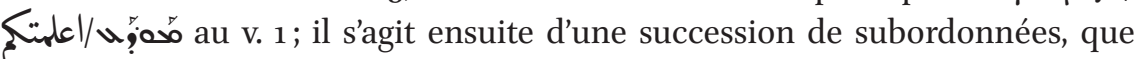
syp a relié par la conjonction 0 . VA 13 reste plus proche du grec en traduisant chaque xai par ايصا. Par contre, VA 13, tout comme syp, ne traduit pas غ̇x còs, ce

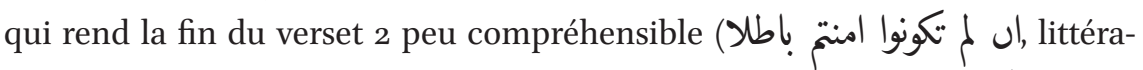
lement: «si vous n'avez pas cru en vain»). Ici, la combinaison de il et de la négation لم doit certainement être comprise comme الإ sinon ».

1 Co 15,3

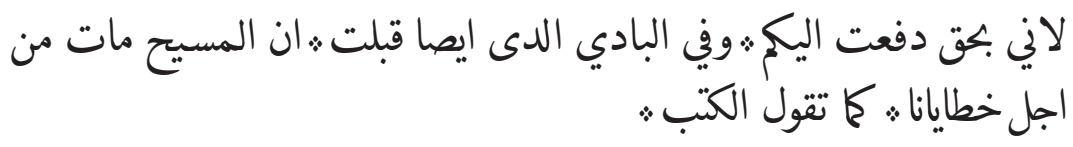

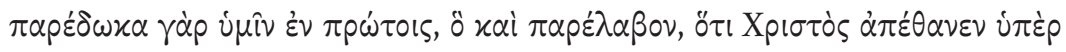
$\tau \hat{\omega} \nu \dot{\alpha} \mu \alpha \rho \tau i \hat{\omega} \nu \dot{\eta} \mu \hat{\omega} \nu$ $x \alpha \tau \dot{\alpha} \tau \dot{\alpha} \varsigma \gamma \rho \alpha \varphi \dot{\alpha} \varsigma$

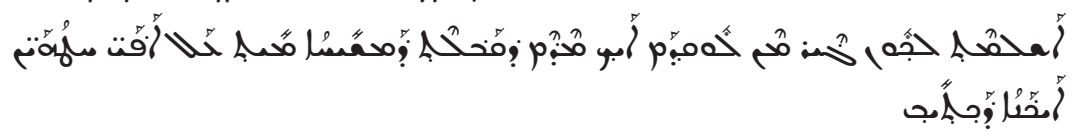

Car, en vérité, je vous ai transmis dès le début ce que j'ai aussi reçu: le Christ est mort à cause de nos péchés, comme le disent les Ecritures.

VA 13 a comme disent les Écritures», formulation qui semble

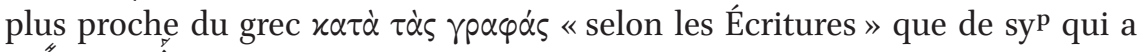
《 comme il est écrit ».

\section{Co 15,4}

$$
\text { وقبر وقام ثي الوم الثالث : كما انه مكتوب : }
$$

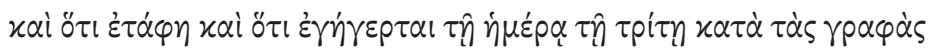

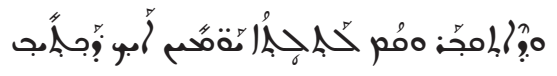

Il a été enseveli et il s'est relevé le troisième jour, comme il est écrit.

162 Pour la construction du grec, voir le résumé de FitzMYer, pp. 544-545. Fee soutient que ces deux versets sont construits en chiasme, FEE, p. 799. 
Par contre, contrairement au verset précédent, la formulation

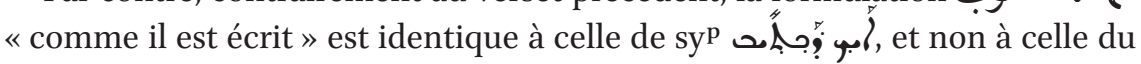

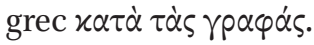

\section{Co 15,5}

$$
\text { والورى للصفا ثُ بعده ارى لاحه عشر ث }
$$

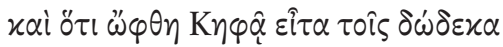

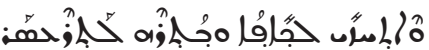

Et il apparut à Pierre, ensuite, après lui, il apparut aux onze.

À propos de والورى, voir notre remarque sur le phénomène llg en 1 Co 11,18.

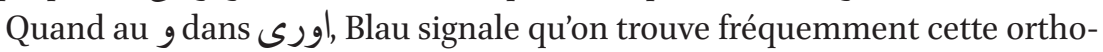
graphe اوري (BLAU, \$ 76.4). Le fait que l'on trouve aux versets suivants l'orthographe montre une fois de plus l'inconstance dans l'orthographe de notre texte (vöir 2.2 Éléments de moyen arabe dans Vat. Ar. 13 (1 Corinthiens)).

À propos du nom propre الصفال voir 4.1 Noms propres.

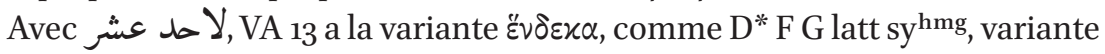
considérée comme étant une harmonisation sur Mt 28,16 (cf. SENFT, p. 188).

\section{Co 15,6}

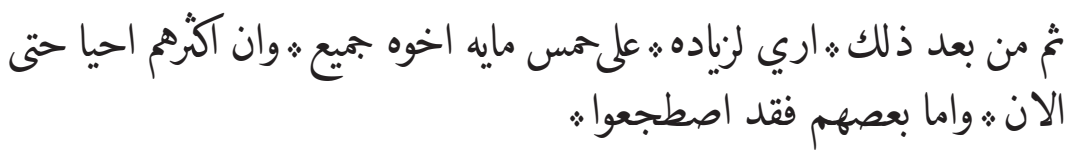

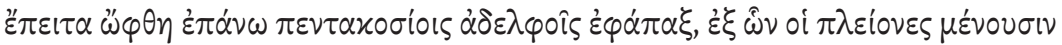

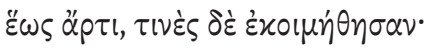

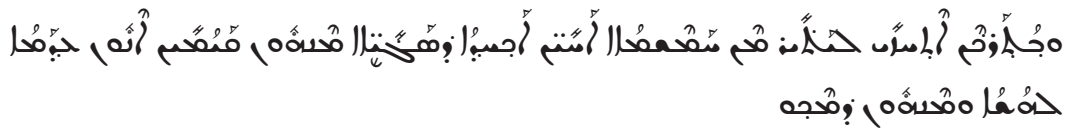

Ensuite, après cela, il apparut à plus de cinq cent frères ensemble, et la grande partie d'entre eux est encore vivante aujourd'hui, mais certains se reposent déjà.

Avec فقد, VA 13 semble soutenir la variante $x \alpha$ a après $\tau \iota v \varepsilon \dot{\zeta} \delta \dot{\varepsilon}$, comme $\aleph^{2} \mathrm{~A}^{\mathrm{c}} \mathrm{D}^{2}$ K L P Y 048. 33. 81. 104. 365. 1175. 1241. 1505. 2464. M (contre P46 $\aleph^{*} A^{* v i d}$ B D* F G 0243. 6. 630. 1739.1881 latt sy). 


\section{Co 15,7}

f. $116 \mathrm{v}$

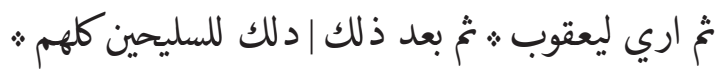

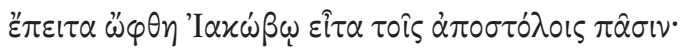

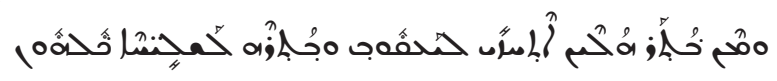

Ensuite, il apparut à Jacques, puis, après cela, à tous les apôtres.

Il y a répétition de ذلك à cause du changement de folio. Voir notre remarque en 3,23 .

À propos de السليحن, voir notre remarque en 4,9.

1 Co 15,8

$$
\text { نامااخزكهم مثل السقط : اري إيصالي }
$$

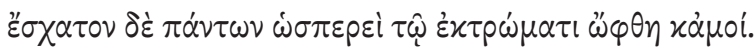

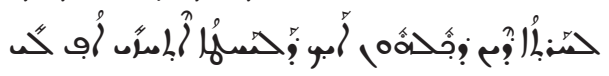

Mais, en dernier après tout le monde, comme l'avorton, il apparut à moi aussi.

\section{Co 15,9}

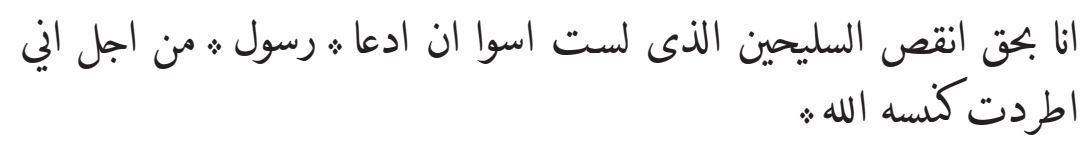

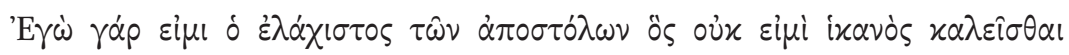

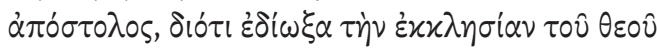

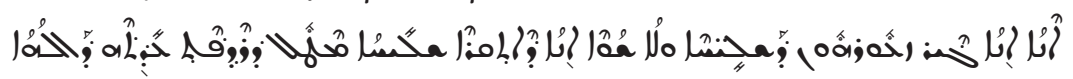

En vérité, je suis le plus faible des apôtres, moi qui ne vaux pas d'être appelé apôtre, parce que j’ai traqué l'Église de Dieu.

Pour traduire $\tau \hat{\omega} \nu \alpha \dot{\alpha} 0 \sigma \tau \lambda^{\lambda} \omega \nu$, le traducteur utilise السليحين, tandis qu'il utilise

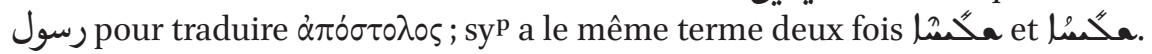
Voir 4.3.1 rasūl «envoyé ». 


\section{Co 15,10}

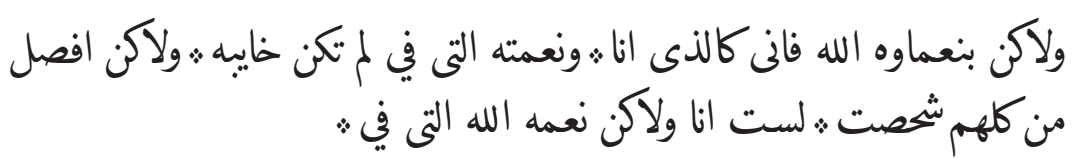

$\chi \alpha \dot{\rho}$

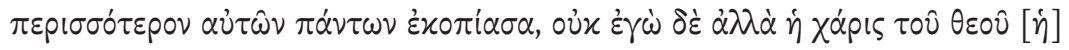

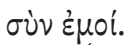

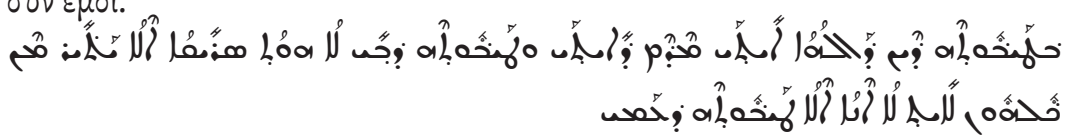

Mais par le bienfait de Dieu, je suis comme je suis, et sa grâce n'a pas été en moi inutile, mais plus que tous, je me suis fatigué ${ }^{163}$, non pas moi, mais la grâce de Dieu qui est en moi.

Nous lisons بنعاوه S'agit-il de نحا avec le « mauvais » support de la hamza et le suffixe masculin singulier ๑? La présence d'un suffixe, ici annonciateur, correspondrait à syp. Nous le supposons, car nous ne trouvons pas d'autre explication à cette orthographe.

VA 13 est toutefois le seul à changer de vocabulaire (le grec a deux fois $\chi \alpha \dot{p} ı \varsigma$ et syp deux fois LLaه).

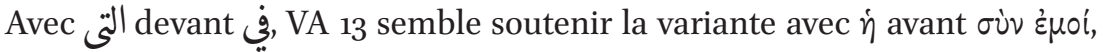
comme P46 $\aleph^{2} \mathrm{~A} \mathrm{D}^{1} \mathrm{~K} \mathrm{~L} \mathrm{P} \mathrm{\Psi} \mathrm{0270}{ }^{\mathrm{c}}$. 33. 81. 104. 365. 630. 1175. 1241. 1505. 1881. 2464 M sy ( $\dot{\eta}$ absent de $\aleph^{*} \mathrm{~B} \mathrm{D}^{*} \mathrm{~F} \mathrm{G} \mathrm{0243.0270*}$. 6. 1739. latt).

\section{Co 15,11}

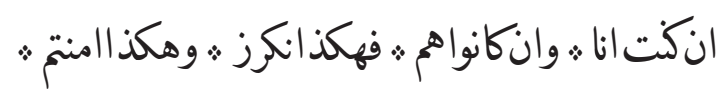

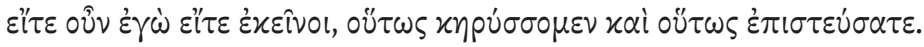

$$
\text { ( }
$$

Que cela soit moi ou eux, ainsi nous prêchons et ainsi vous avez cru.

163 Kazimirski donne pour la forme IV la définition « fatiguer, lasser » (KAZIMIRSKi 1,

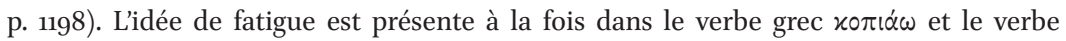
syriaque $/ N$. 
1 Co 15,12

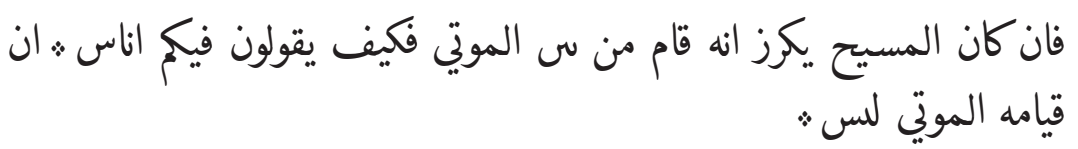

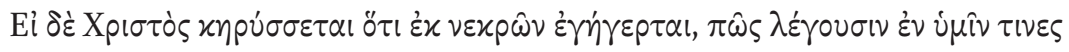

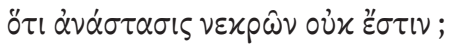

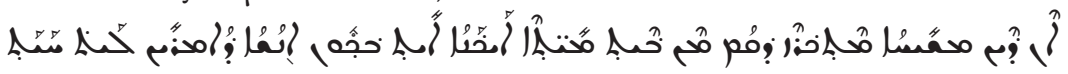

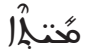

Or s'il est prêché que le Christ s'est relevé d'entre les morts, comment certains d'entre vous disent-ils qu'il n'y a pas de résurrection des morts?

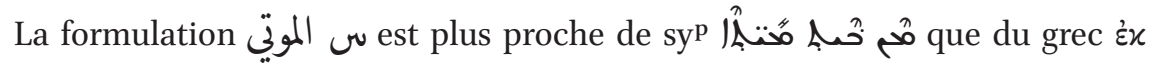
vexpติv.

\section{Co 15,13}

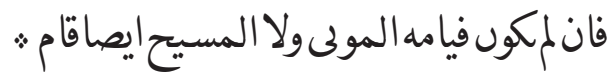

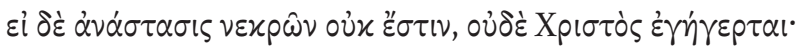

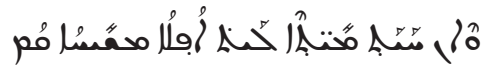

S’il n'y a pas de résurrection des morts, alors le Christ n'est pas ressuscité non plus.

VA 13 a un gau début de l'apodose ; on attendrait plutôt un ف.

1 Co 15,14

$$
\text { نانكان المسيح لم يقوم فادن بشرانا هو ث باطل وامانتم ايصا هى باطله ؛ }
$$

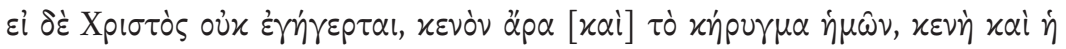
$\pi i \sigma \tau ı \varsigma$ ن $\mu \omega v^{*}$

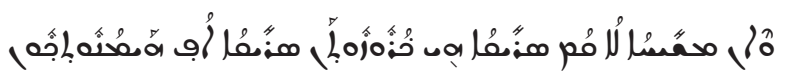

Si le Christ n'est pas ressuscité, alors notre prédication est vaine, et votre foi est vaine aussi, 


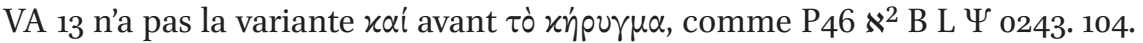
365. 630. 1175. 1505. 1739. 1881. 2464 M ar b d sy (présente dans $\aleph^{*}$ A D F G K P 33. 81.326 .1241$)$.

1 Co 15,15

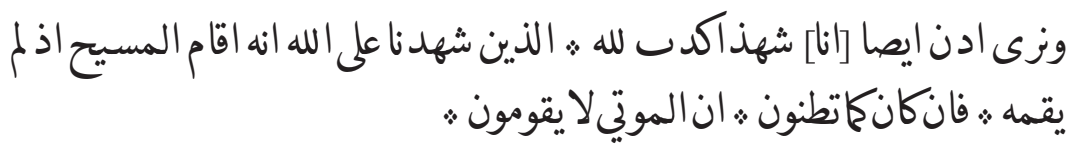

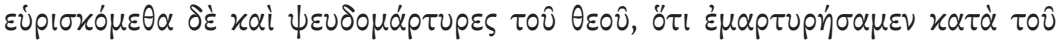

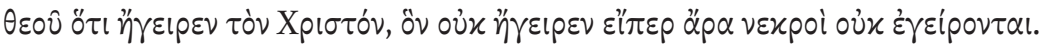

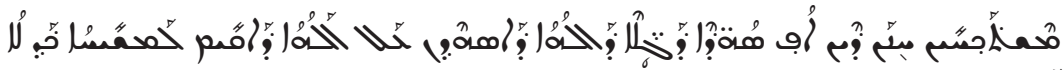
ק" et nous sommes alors considérés aussi comme des témoins du mensonge pour Dieu, nous qui avons témoigné concernant Dieu qu'il avait ressuscité le Christ, vu qu'il ne l'a pas ressuscité, si, comme vous le pensez, les morts ne ressuscitent pas.

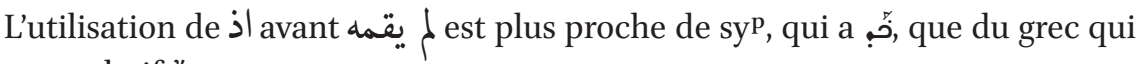
a un relatif oैv.

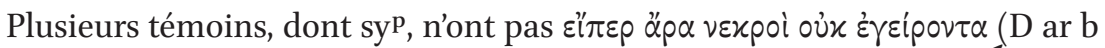

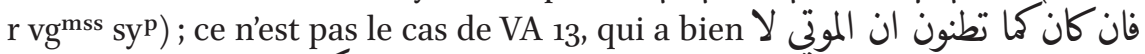
كما تظنون semble être une traduction périphrastique de äpa.

\section{Co 15,16}

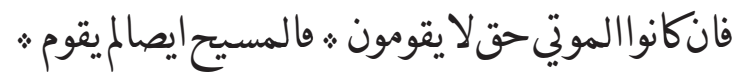

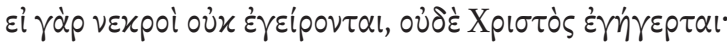

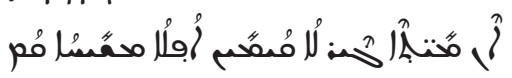

En vérité, si les morts ne ressuscitent pas, le Christ non plus n'est pas ressuscité. 
1 Co 15,17

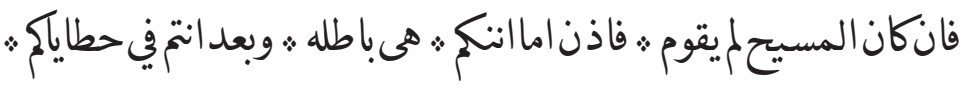

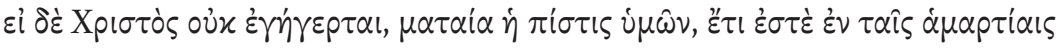
uे $\hat{\omega} v$,

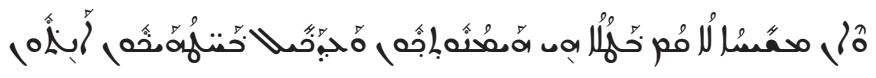

Si le Christ n'est pas ressuscité, alors votre foi est vaine et vous êtes encore dans vos péchés.

Nous lisons اماانتك Ce n'est pas le seul cas où un alif est de trop (voir le phéno-

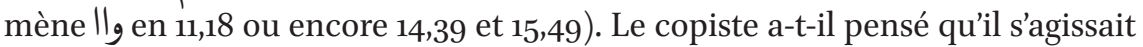

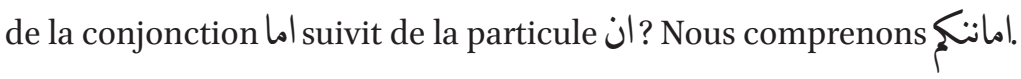

\section{Co 15,18}

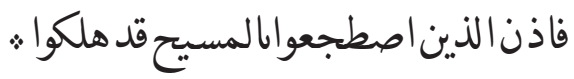

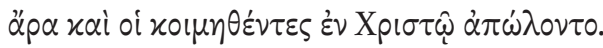

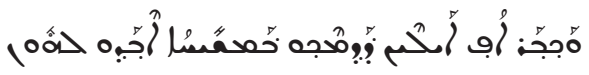

Alors ceux qui se reposent en Christ, ils ont vraiment péri.

\section{Co 15,19}

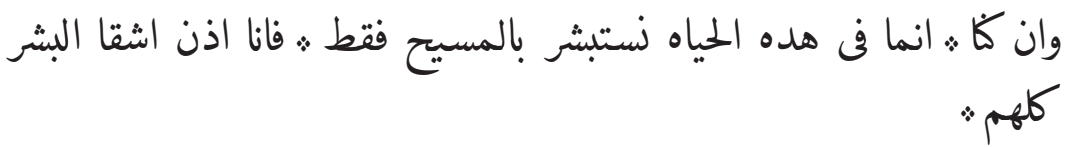

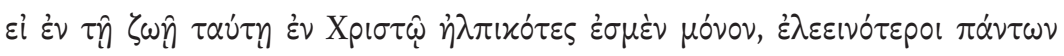

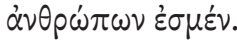

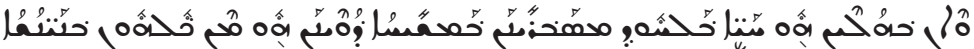

Et si c'est dans cette vie seulement que nous n'espérons qu'en Christ, nous sommes alors les plus misérables de tous les humains.

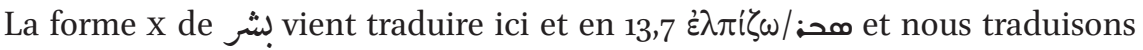
par « espérer » ${ }^{164}$.

164 Le sens « espérer » n'est pas attesté dans les dictionnaires consultés. Le verbe prend un autre sens en 11,26. 
1 Co 15,20

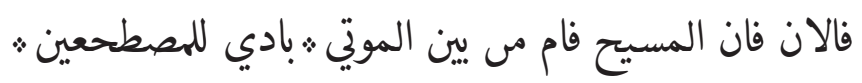

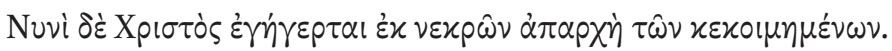

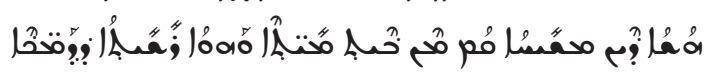

Mais maintenant, le Christ est ressuscité d'entre les morts, un commencement pour ceux qui se reposent,

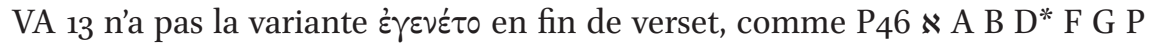
0243. 6. 33. 81. 365. 630. 1175. 1241. 1739. 1881. 2464 latt co (présente dans D ${ }^{2}$ K L $\Psi$ 104. 1505 M sy).

À propos de مس ين المونت voir ci-dessus 15,12.

$1 \operatorname{Co~15,21~}$

$$
\text { من اجل ان بالانسان : كان الموت ث وايصا بالانسان قيامه الموني ث }
$$

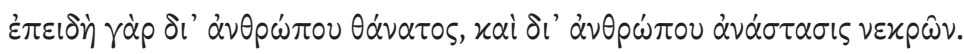

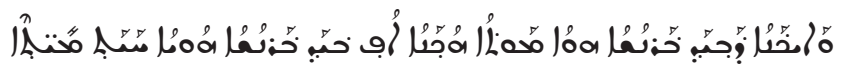

parce que, par l'homme, la mort a existé, et, par l'homme également, la résurrection des morts.

Dans le premier membre du verset, VA 13 crée une antériorité grâce au verbe à l'accompli ib, comme syp qui a lo̊a.

\section{Co 15,22}

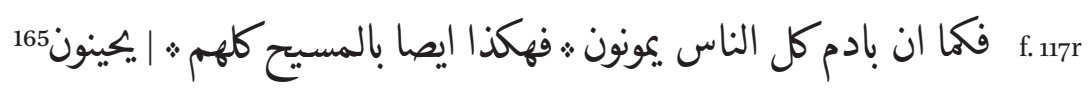

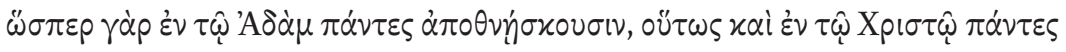
$\zeta \omega \circ \pi 0 i \eta \dot{\eta} \sigma 0 v \tau \alpha \mathrm{l}$.

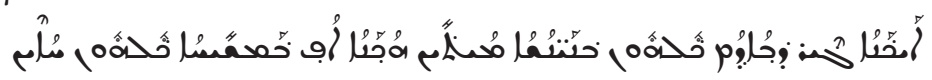

Et comme tous meurent en Adam, ainsi aussi tous vivent en Christ,

165 Faut-il lire يكييون ? Blau mentionne des cas où le verbe خيّ est conjugué selon le schéma d'un verbe fort, BLAU, § 96. En 9,14, on trouvait bien la forme « classique » يحيون. 
1 Co 15,23

$$
\text { كل انسان في مرتبته اياه : اما البدو فهو المسيح ثم بعد ذلك ث. الذين هم }
$$

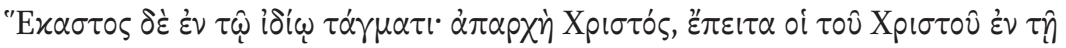

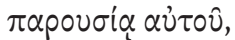

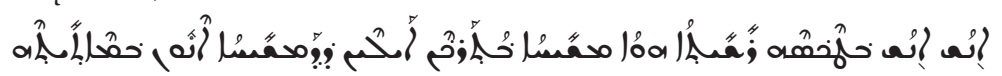

chacun est à son rang à lui ; quant au commencement, c'est le Christ, ensuite après lui, ceux qui sont au Christ à sa venue.

À propos de بجايته, voir 1,7.

1 Co 15,24

$$
\text { ثم هنالك الاحر : اذا ما اسلم الملك الم الله :الاب ادا ما بطل كل راس وكل }
$$

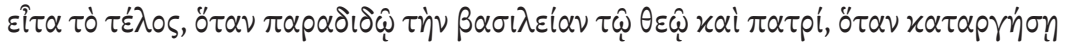

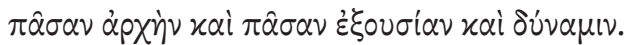

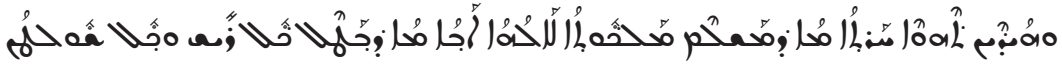

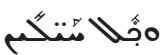

Ensuite, là [sera] la fin, quand il aura livré la royauté à Dieu le père, quand il aura anéanti tout chef, toute autorité et toute puissance.

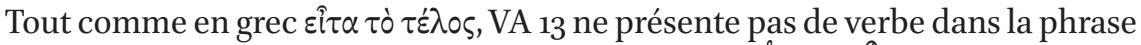

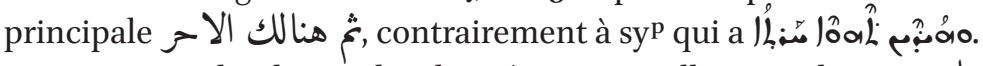

Dans VA 13, les deux subordonnées temporelles introduites par اذا اذا ما sont simultanées, contrairement au grec ayant dans la première un présent $\pi \alpha p \alpha \delta \delta \delta \hat{\omega}$

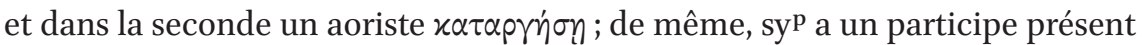

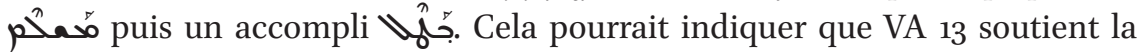
variante avec un aoriste $\pi \alpha p \alpha \delta \hat{\omega}$, comme K L P 81. 104. 365. 630. 1175. 1241. 1881. 2464 M latt (contre P46 N A $\Psi$ 0243. 0270. 1505. 1739. (B F G)).

On notera que syp a متنّمىau pluriel, ce qui n'est pas le cas du grec ni de VA 13 . 
1 Co 15,25

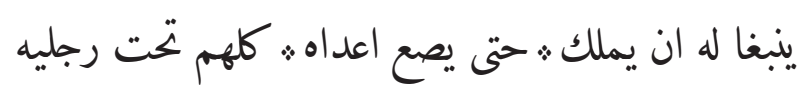

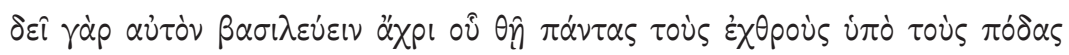

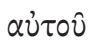

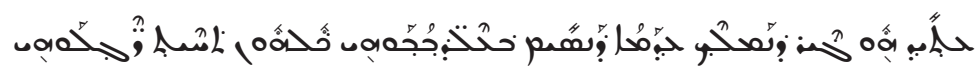

Il faut qu'il règne jusqu'à ce qu'il mette tous ses ennemis sous ses pieds.

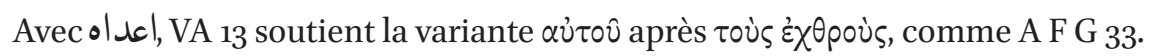
104. 629. ar r vg $^{\mathrm{mss}} \mathrm{sy}^{\mathrm{p}}$.

$1 \operatorname{Co~15,26}$

$$
\text { واحر العدو بيطل الموت }
$$

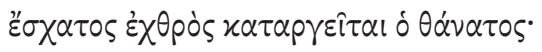

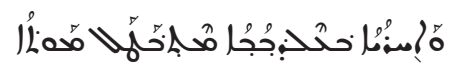

Le dernier ennemi qui sera anéanti, c'est la mort.

\section{Co 15,27}

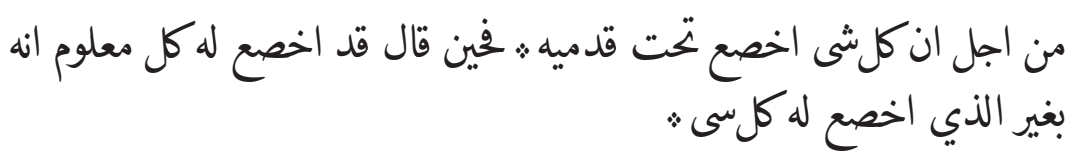

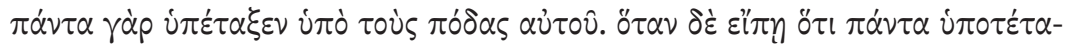

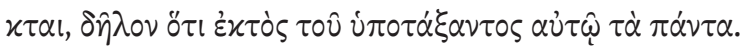

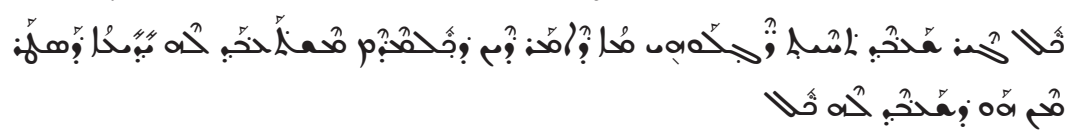

Car il a soumis toute chose sous ses pieds ; or quand il a dit: Tout lui a été soumis, il est connu que c'est à l'exception de celui qui lui a soumis toute chose.

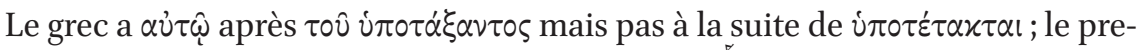

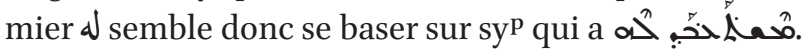


1 Co 15,28

لفاذا ما اخصع له كل شى حيد ايصا هو الابن يخصع للني اخصع له كل ثل

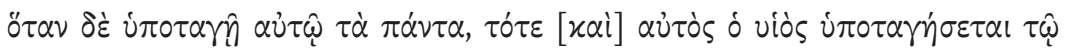

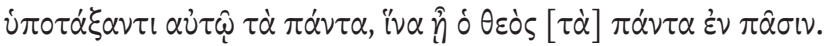

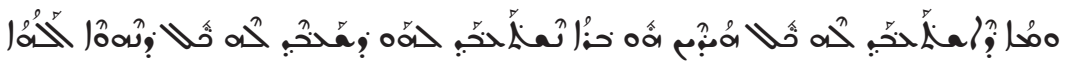

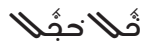

Quand toute chose lui aura été soumise, alors à ce moment-là aussi, le fils lui-même se soumettra à celui qui lui a tout soumis, pour que Dieu soit en tout.

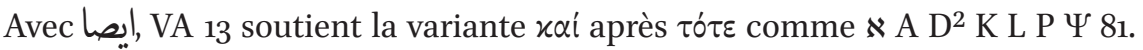
104. 365. 630. 1241. 1505. $2464 \mathrm{M}^{2}$ ar f r vgcl sy bo (contre B D* F G 0243. 33. 1175 . $1739 \mathrm{~b} \mathrm{vg}^{\text {st }}$ syp $^{\mathrm{p}}$ a bo $\left.{ }^{\mathrm{mss}}\right)$.

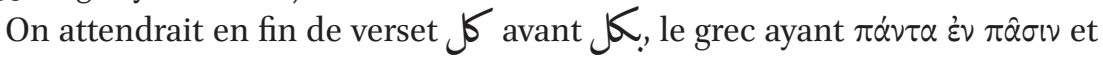

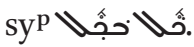

1 Co 15,29

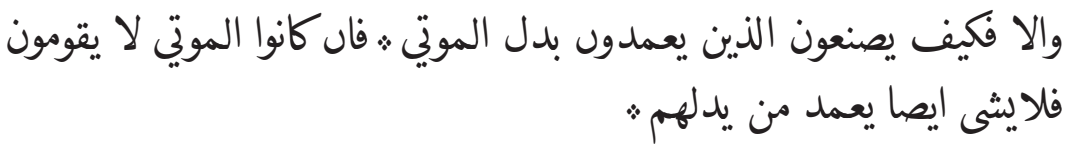

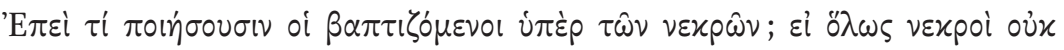

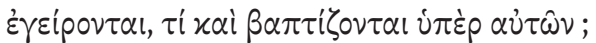

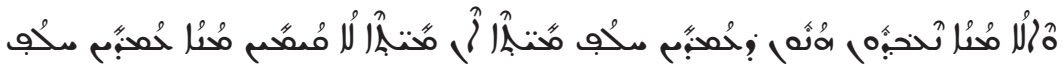

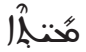

Et sinon, comment font ceux qui se font baptiser à la place des morts, si les morts ne ressuscitent pas, pour quelle raison se faire aussi baptiser à leur place?

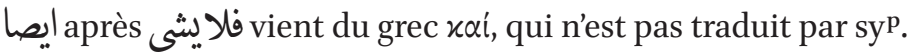

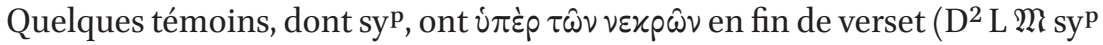

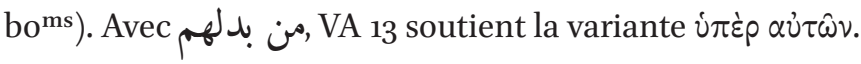




\section{Co 15,30}

\section{ولايشى لحن ايصا في كل حين قيام في البلا الشديد}

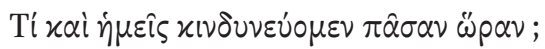

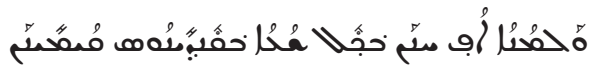

Et pour quelle raison nous tenons-nous, nous aussi, à tout moment dans le grand danger?

\section{Co 15,31}

$$
\text { كل يوم فاني اموت ث. بفخز ايها الاخوه الذى لى بالمسيح لـوع ربناء }
$$

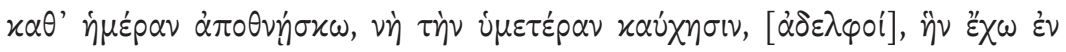

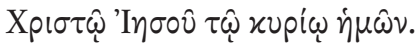

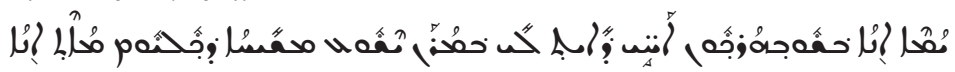

Chaque jour, je meurs, par la fierté que j'ai à cause de vous, ô frères, dans le Christ Jésus notre Seigneur.

كل كل كل يوم signifie-t-elle que le traducteur comprend يوم comme appartenant au verset précédent?

Tout comme le grec, VA 13 n'a pas de verbe exprimant l'idée de serment, mais celle-ci peut être sous-entendue dans la particule 4 : «au nom de votre fierté », «par votre fierté » بفخخ que je traduis «par la fierté que j'ai à cause de vous ». syp explicite à l'aide du verbe ${ }^{p}$ ?ُ

Avec ايها الاخوه, VA 13 soutient la variante grec $\alpha \delta \varepsilon \lambda \varphi o$ í, comme א A B K P 33 . 81. 104. (326). 365. 1175. 1241. 2464 lat sy co (contre P46 D F G L Ч 075. 0243. 630. 1505. 1739. 1881. M). À propos de ايها., voir notre remarque en 7,16.

\section{Co 15,32}

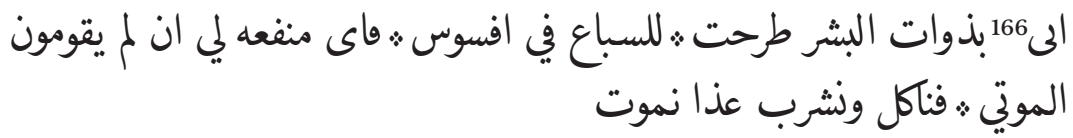

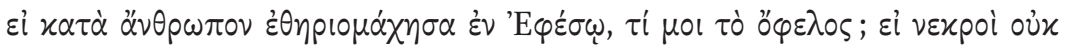

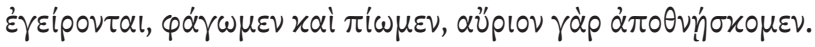

166 Il semble ici que cela soit un cas de pronom suffixe après إٍ , voir BLAU, §281. 


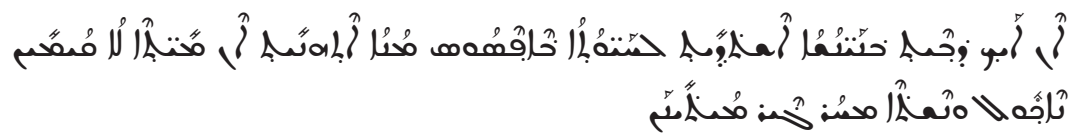

Si j'ai été jeté en tant qu'humain aux bêtes à Éphèse, quel avantage pour moi ? Si les morts ne ressuscitent pas, alors mangeons et buvons, demain nous mourrons!

L'expression بذوات البشر était déjà utilisée en 1 Co 3,3 pour traduire $x \alpha \tau \dot{~}$

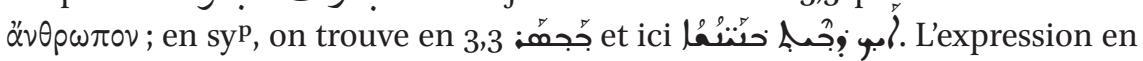
grec est obscure ${ }^{167}$, tout comme en arabe ici, le traducteur ne cherchant pas à expliciter, contrairement à syp

L'utilisation du verbe طjح «jeter », ici probablement au passif, est proche

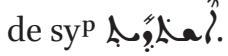

\section{Co 15,33}

$$
\text { لا تطغون ث: يفسد الهموم ث الصالحه الاحاديث السبات }
$$

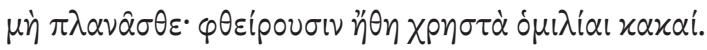

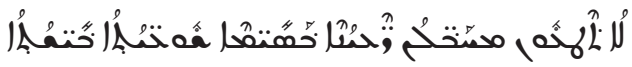

Ne dépassez pas les limites : les mauvaises conversations corrompent les préoccupations honorables.

Le terme الأموم (《les soucis », «les préoccupations ») est quelque peu inattendu, $\eta \ddot{\theta} \eta$ signifiant « mours »; il nous semble plus proche du terme syriaque de

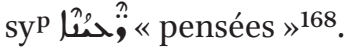

\section{Co 15,34}

استبقطو بالبر ث:ولا تخطون : فان فيك اناس لس فيهم علم الله : لتبكيتم اقول

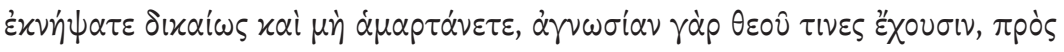

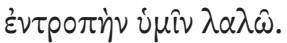

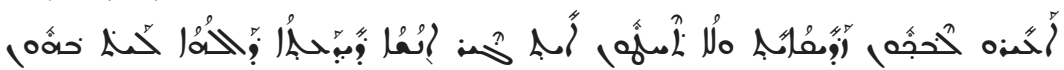

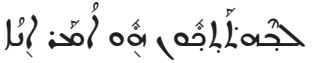

167 SENFT, p. 203.

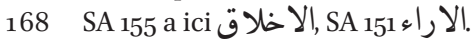


Réveillez-vous à la justice et ne péchez pas, car il y a parmi vous des gens qui n'ont pas la connaissance de Dieu, je le dis pour votre réprimande.

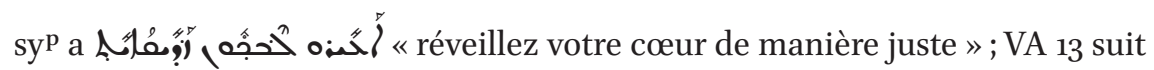
ici le grec et n’a pas d'objet après استبقطو.

\section{Co 15,35}

$$
\text { ولاكن يقول بعص الناس كيف كف يقومون الموتي ثباي جسد يجون ث. }
$$

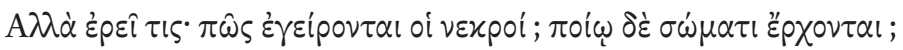

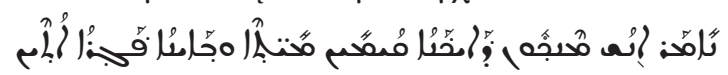

Mais quelques personnes diront: Comment les morts ressusciteront-ils? Avec quel corps viendront-ils?

Le redoublement du كيف est probablement une erreur due à un changement de ligne.

1 Co 15,36

$$
\text { ايه الجاهل انت الشى الذي تزرع : ان لم يموت لا يحيا ؛ }
$$

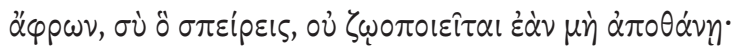

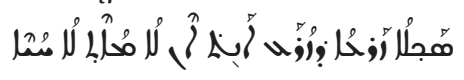

Ô ignorant, toi, ce que tu sèmes, si cela ne meurt pas, cela ne sera pas rendu à la vie.

À propos de ايه, voir notre remarque en 7,16.

\section{Co 15,37}

$$
\begin{aligned}
& \text { f. والسى الدي تزرع : لس الحسد | الذي يكون تزوع ؛ ولاكن حبه عريانه حنطه }
\end{aligned}
$$

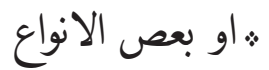

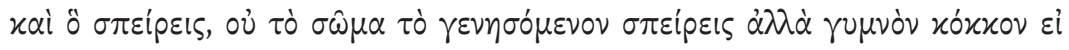

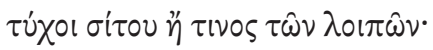




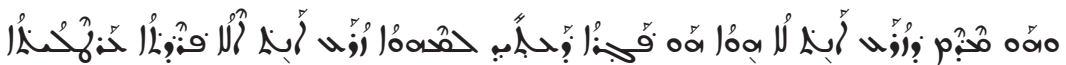
茪.

Et ce que tu sèmes, ce n'est pas le corps en devenir que tu sèmes, mais un grain nu de froment ou de quelque espèce,

syp ajoute une espèce végétale «mais un grain nu de blé, d'orge ou d'une autre des espèces », ce qui n'est pas le cas de VA 13 .

\section{$1 \operatorname{Co~} 15,38$}

$$
\text { والله يعطيه حسد كما يحب : ولكل واحد من الانواع حسده }
$$

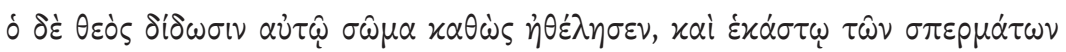
iôı $\sigma \nu \hat{\omega} \mu \alpha$.

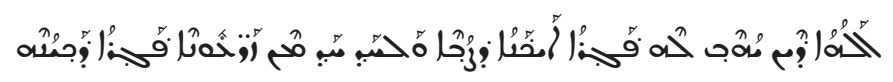

et Dieu lui donne un corps comme il le souhaite, et à chaque espèce son corps,

\section{Co 15,39}

$$
\begin{aligned}
& \text { فليس كل الاجساد واحد : ولاك احر حسد : البشر * واحر جسد الدواب }
\end{aligned}
$$

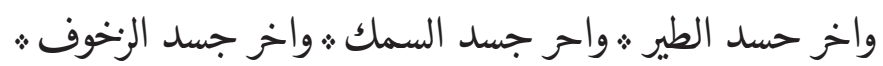

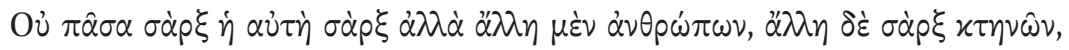

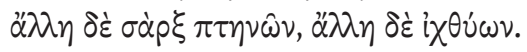

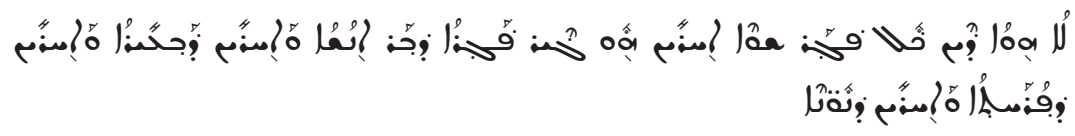

car tous les corps ne sont pas un, mais autre est le corps de l'humain et autre est le corps des bêtes de somme, le corps des oiseaux, le corps des poissons, le corps des reptiles.

VA 13 a un dernier groupe de corps qui n'est présent ni en grec ni en syp. Nous lisons الزخوف mais nous supposons qu'il s'agit de la racine زحف زamper »169.

169 زحوف jeptile »; le pluriel pas attesté dans les dictionnaires consultés. 
Cela peut s'expliquer par une volonté d'harmoniser sur le texte de la Genèse, par exemple (cf. Gn 1,26).

\section{Co 15,40}

$$
\text { واجساد سماويه ث. واجساد ارصانيه * ولاكن احر هو بجد السماوبين * واخز مجد }
$$

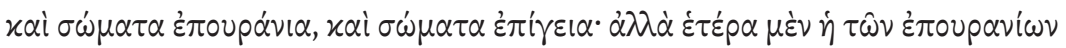

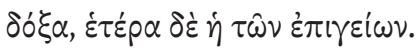

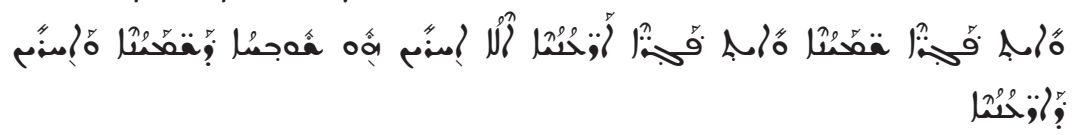

Et il y a des corps célestes et des corps terrestres, mais autre est la gloire des célestes et la gloire des terrestres,

\section{Co 15,41}

$$
\text { والكواكب مجد الشمس : واخر محد القمر : واحر مجد الكواكب : والكوآكب تقاصل }
$$

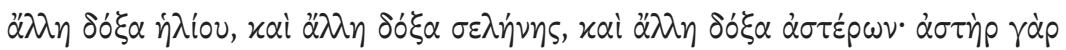

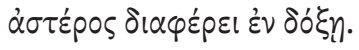

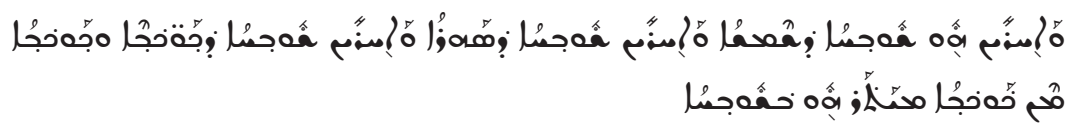
et autre est la gloire du soleil, autre la gloire de la lune, autre la gloire des étoiles; les étoiles rivalisent de gloire avec les étoiles.

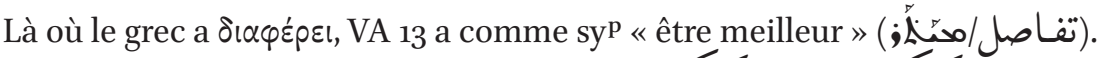

Dans ce dernier membre du verset والكواكب تفاصل الكواكب المحد, VA 13 est seul à avoir un pluriel.

\section{Co 15,42}

$$
\text { فهكدا ايصا قيامه الموتي يزرع الفساد ويعوم بغير فساد }
$$

O 


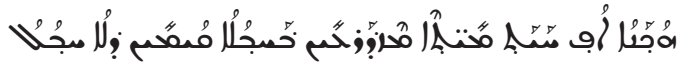

Il en est ainsi également de la résurrection des morts : il est semé dans la corruption et il ressuscite sans défaut,

Dans ce verset et dans le suivant, sy $\mathrm{p}^{\mathrm{P}}$ des verbes au pluriel ; ce n'est pas le cas de VA 13, qui suit ici le singulier du grec.

\section{Co 15,43}

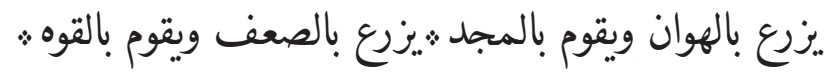

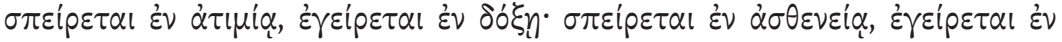

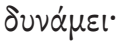

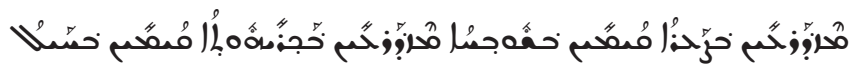

il est semé dans le mépris, il ressuscite dans la gloire, il est semé dans la faiblesse, il ressuscite dans la force,

\section{Co 15,44}

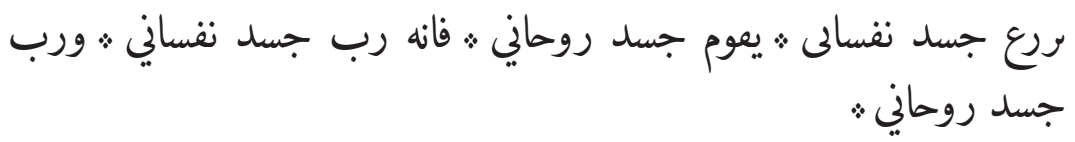

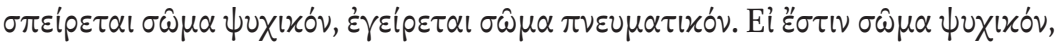

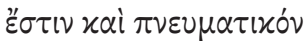

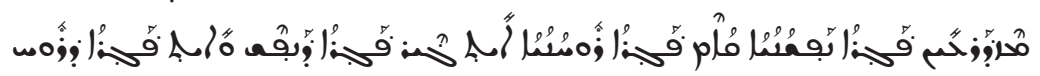

il est semé corps psychique, il ressuscite corps spirituel, car il peut être corps psychique et il peut être corps spirituel.

La construction symétrique avec deux fois l'adverbe («souvent», «parfois », « il se peut que ») est davantage proche de syp, qui a deux fois $\mathrm{A}$, que du grec qui a une phrase conditionnelle. 


\section{Co 15,45}

$$
\text { لمكذا ايصا هو مكتوب : كان ادم البشر الاول للنفس } 170 \text { الحيه : وادم الاخ }
$$

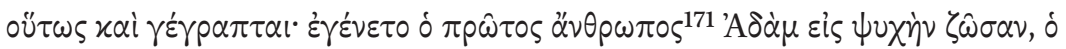

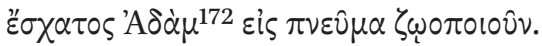

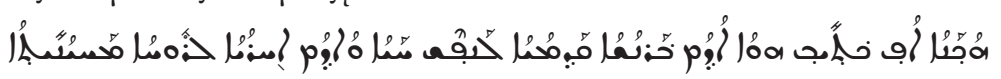
Ainsi, il est aussi écrit: Adam, le premier humain, devint l'âme vivante, et Adam, le dernier, l'esprit vivifiant.

\section{Co 15,46}

$$
\text { ولاكن لم يكن اول الروحاني ث ولاكن النفساني : ثُ بعد الروحاني }
$$

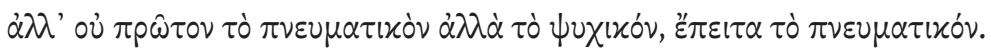

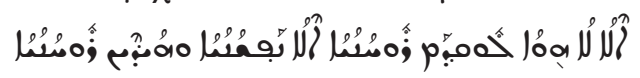

Mais le spirituel ne fut pas en premier, mais le psychique, puis après, le spirituel.

VA 13 a un verbe conjugué (لم يكن), ce qui correspond à syp lơa للمن, le grec ayant une phrase nominale.

\section{Co 15,47}

$$
\text { البشر • الاول ثترابي من الارص *.والبشر الثاني الرب من السماء }
$$

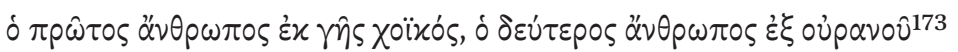

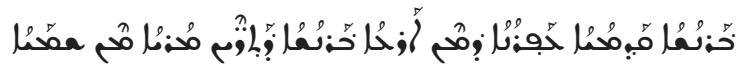

Le premier homme est terreux, à partir de la terre, et le second homme est le Seigneur, à partir du ciel.

170 j $\mathbf{j}$ suivit de la préposition ل pour « devenir » est noté par BLAU, § 305.2.

171 Quelques témoins $\left(B_{3} 326.365 .365\right)$ n'ont pas $\alpha 2 v \theta \rho \omega \pi \circ$; c cette variante n'est pas soutenue parVA 13 .

172 'Ad̊́ $\mu$ est absent de $\mathrm{P} 46$; cette variante n'est pas soutenue par VA 13.

173 Quelques témoins (F G latt) ont ici ó oủpóvios; cette variante n'est pas soutenue par VA 13. 


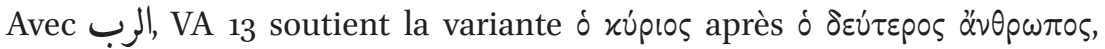

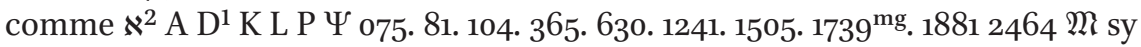
(contre $\aleph^{*}$ B C D* F G 0243. 6. 33. 1175. 1739* latt bo ; $\mathrm{P}_{4} 6$ a ó $\pi v \varepsilon u \mu \alpha \tau$ เxós après

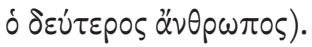

\section{Co 15,48}

وكما انه التراي : فهكدا ايصا : الترابين * وكما انه : السماوي : فهكذا ايصا السماوني

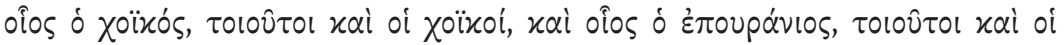

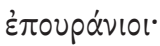

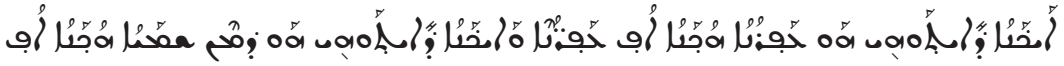

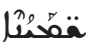

Comme est le terreux, ainsi sont aussi les terreux, comme est le céleste, ainsi sont aussi les célestes.

syp a, comme au verset précédent,

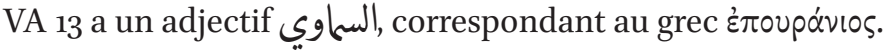

\section{Co 15,49}

$$
\text { وكمثل ما البسنا شبه الترابي ث نلبس ايصا سبه السماوى ث }
$$

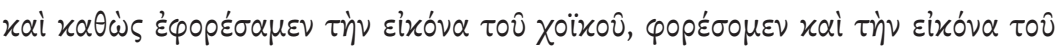
ह่ंกupaviou.

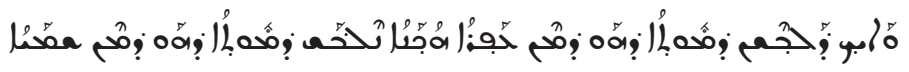

Et comme nous avons revêtu l'image de l'homme terreux, nous revêtirons aussi l'image de l'homme céleste.

Nous lisons البسنا, qui correspond à une forme IV. On attendrait plutôt une forme I car la forme IV est normalement causative ${ }^{174}$, et au v. 54 , c'est la forme I qui est utilisée. L'alif est-il de trop (voir aussi le phénomène IIg en 11,18 ou encore 14,39 et 15,17$)$ ?

174 «Vêtir quelqu'un d'un vêtement », KAZImirski 2, p. 959. 


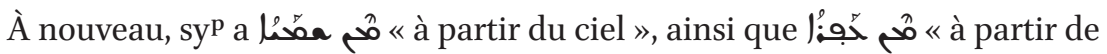
la poussière », tandis que VA 13 a des adjectifs, comme le grec.

Ici, شبه semble bien avoir le sens connu des dictionnaires de « ressemblance ». Voir à propos de شبه nos remarques en 4,6 et 10,11.

1 Co 15,50

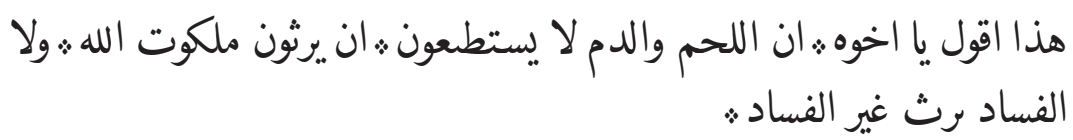

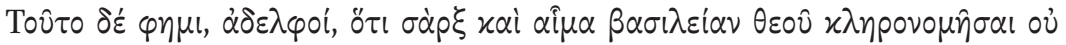

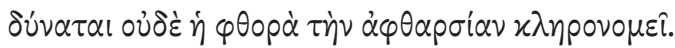

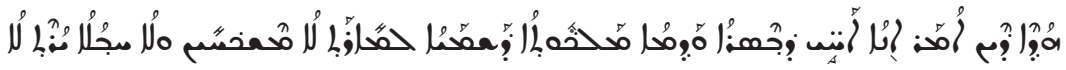

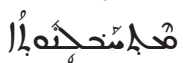

Je dis ceci, ô frères : la chair et le sang ne peuvent pas hériter du royaume de Dieu, et la corruption hériter de l'incorruptibilité.

C'est la seule utilisation de pour traduire $\sigma \alpha \dot{\alpha} p \xi$, normalement traduit par جسد (voir remarque en 1,29).

Avec les verbes au pluriel لا يستطعون ان يرثون, VA 13 soutient la variante

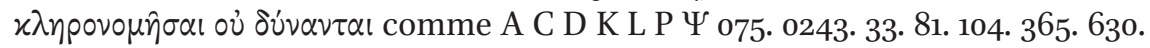
1175. 1241. 1505. 1739. 1881. 2464. M lat syp (contre les singuliers dans $\aleph^{B} 365 . \mathrm{sy}^{\mathrm{h}}$

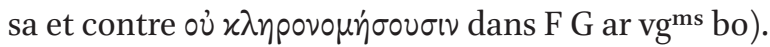

\section{Co 15,51}

$$
\text { | هذا اقول لكم سر ليس كلنا نصطحع : ولكن كلنا نتبدل ل f. 118r }
$$

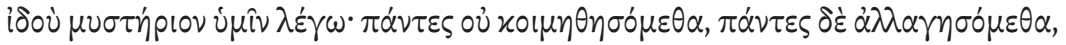

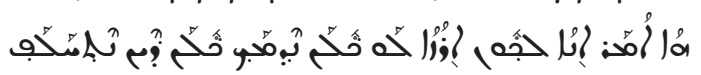

Ceci, je vous dis un secret, nous ne mourrons pas tous mais tous nous serons changés.

VA 13 soutient ici la variante avec la négation portant sur le verbe « mourir »: «nous ne mourrons pas tous, mais tous nous serons changés» ( $\pi \dot{\alpha} \nu \tau \varepsilon \varsigma$ o

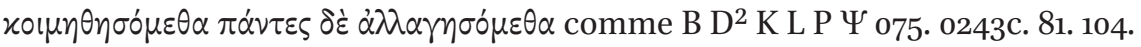
$365 \cdot 630.1175 \cdot 1505 \cdot 1881.2464 \mathrm{M}$ sy co) et non la variante avec la négation portant 
sur le verbe « changer»: « nous mourrons tous, mais tous nous ne serons pas

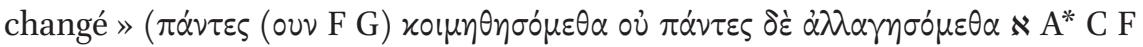
G 0243* 1739 . b ; ou encore $\pi \dot{\alpha} \nu \tau \varepsilon \varsigma \alpha \nu \alpha \sigma \tau \eta \sigma o \mu \varepsilon \theta \alpha$ ov่ $\pi \dot{\alpha} \nu \tau \varepsilon \varsigma \delta \dot{\varepsilon} \alpha \lambda \lambda \alpha \gamma \eta \sigma o ́ \mu \varepsilon \theta \alpha \mathrm{D}^{*}$

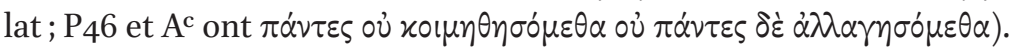

On trouve en fin de ligne et de folio un $\mathrm{J}$ seul, pour lequel nous n'avons pas d'explication.

\section{Co 15,52}

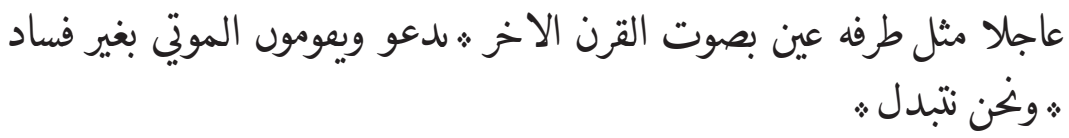

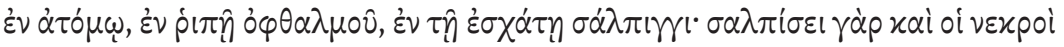

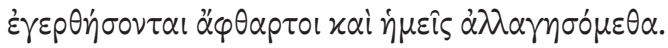

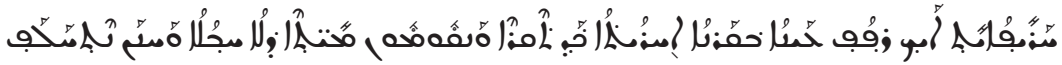

Précipitamment, comme un clin d'œil, au dernier son du cor, il appellera et les morts ressusciteront sans défaut et nous changerons.

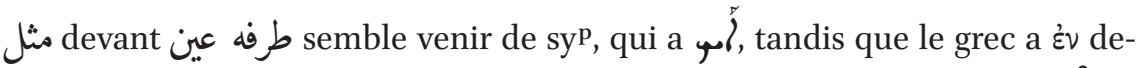

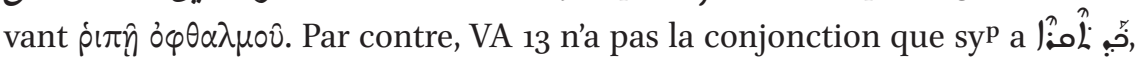
« quand il appellera ».

\section{Co 15,53}

$$
\text { ينبغا لهذا المتغير ان يلبس غير الفساد ؛ وهذا الميت ان يلبس غير الموت ؛ }
$$

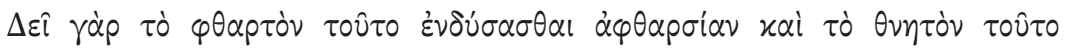
ह่vठ์ $\sigma \alpha \sigma \theta \alpha \mathrm{l} \dot{\theta} \theta \alpha \nu \alpha \sigma i \alpha \nu$.

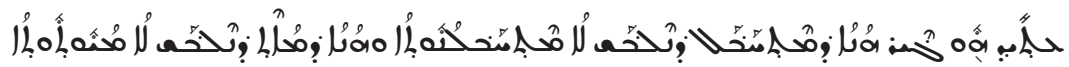
Il faut que cet impermanent revête l'incorruptibilité et que ce mortel revête l'immortalité.

\section{Co 15,54}

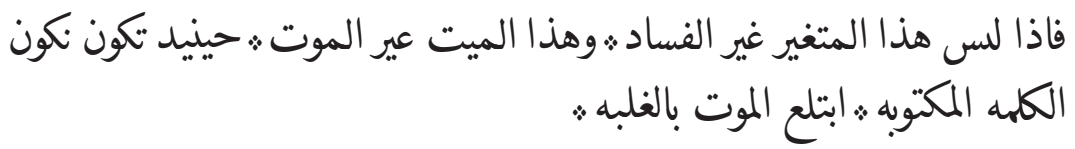




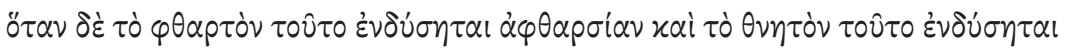

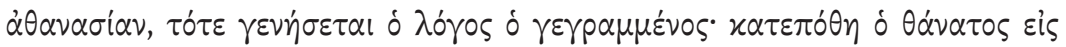
vixos.

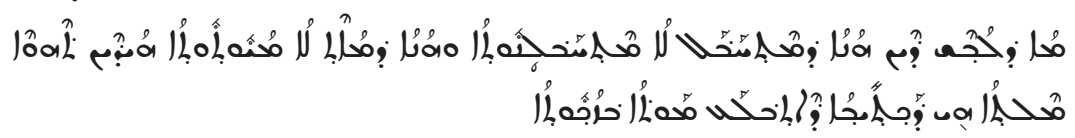

Lorsque cet impermanent aura revêtu l'incorruptibilité et ce mortel l'immortalité, à ce moment-là s'accomplira la parole écrite : La mort a été engloutie par la victoire.

Le redoublement de تكون est probablement une erreur due à un changement de ligne.

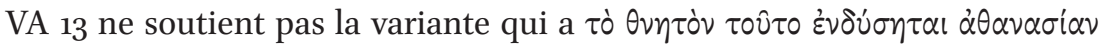

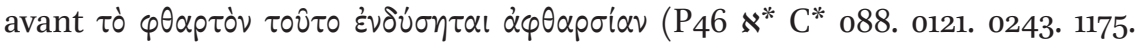
$1739^{*}$ lat sa ${ }^{\mathrm{ms}}$ bo).

\section{Co 15,55}

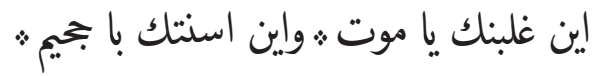

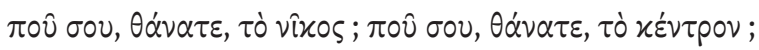

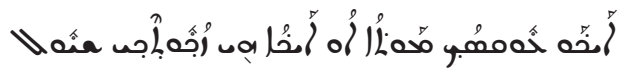

Où est ta victoire, ô mort? Où sont tes aiguillons, ô enfer?

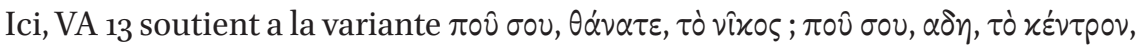
comme 0121. 0243. 33. 81. 326.1175. 1241. $1739^{\mathrm{c}}$. 2464 (contre P46 $\aleph^{*}$ B C 088. $1739^{*}$

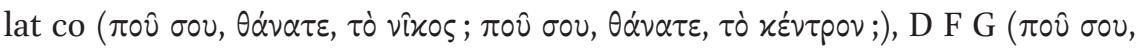

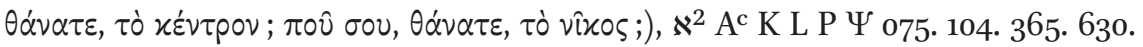

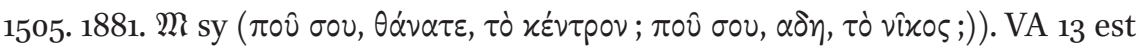
seul à avoir les aiguillons اسنتك ( au pluriel.

\section{Co 15,56}

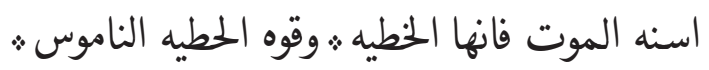

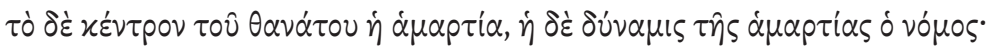




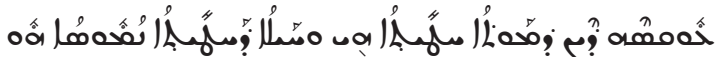

Les aiguillons de la mort, c'est le péché et la puissance du péché, c'est la loi.

1 Co 15,57

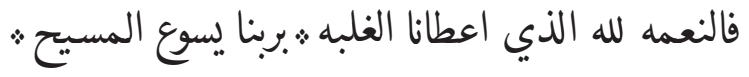

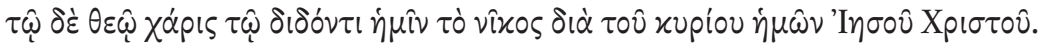

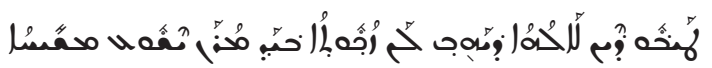

Grâce soit à Dieu qui nous a donné la victoire en notre Seigneur Jésus le Christ!

$1 \operatorname{Co~} 15,58$

$$
\begin{aligned}
& \text { فاذن يا اخوه : المحبوين ؛ كونوا ثابثين ولا تزعزعون ث. اد تفضلون في كل حين }
\end{aligned}
$$

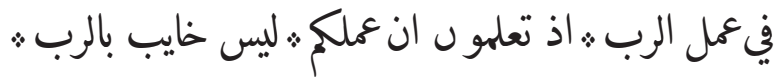

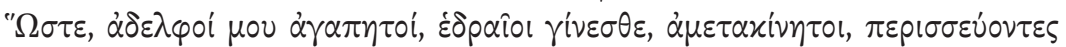

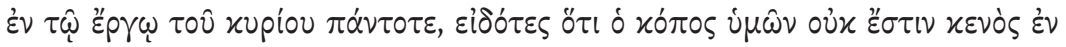
xupíw.

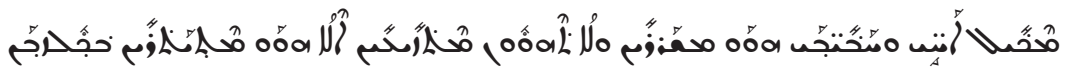

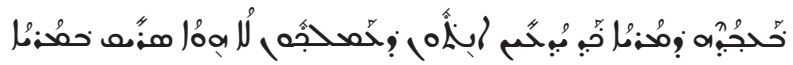
Alors, ô frères bien-aimés, soyez fermes et ne soyez pas ébranlés, en excellant tout le temps dans l'œuvre du Seigneur, en sachant que votre travail n'est pas vain dans le Seigneur.

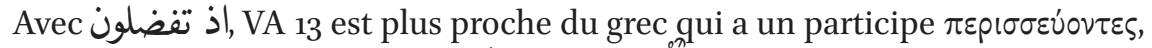
que de syp qui a un impératif: :

\section{$1.16 \quad$ Chapitre 16}

1 Co 16,1

فاما من اجل اصطفايه القديسين : فكما اوصد جماعه علاطيه ؛ وهكذا وانتم ايصا : فافعلوا 


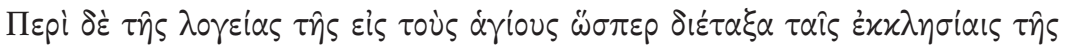

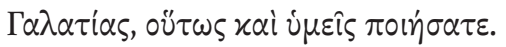

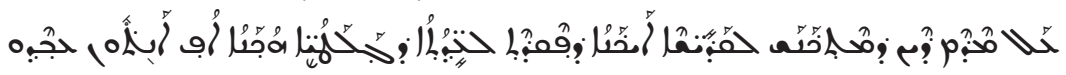
Mais au sujet de la collecte des saints, comme je l'ai recommandé à l'assemblée de la Galatie, ainsi, vous aussi, faites-le!

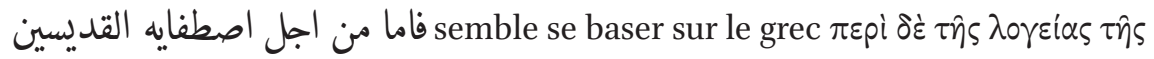

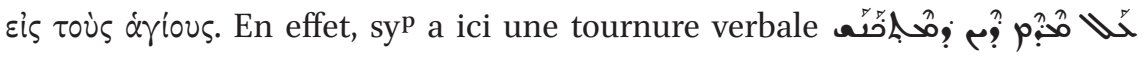

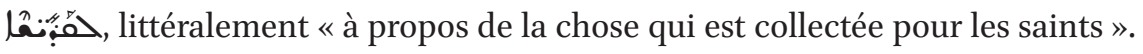

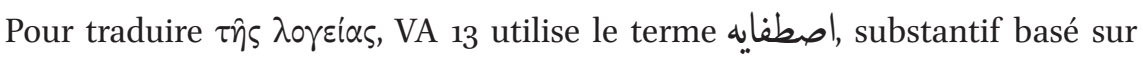
la forme viII de صف « choisir» (Kazimirski 1, p. 1350)175. Ce terme n'est pas

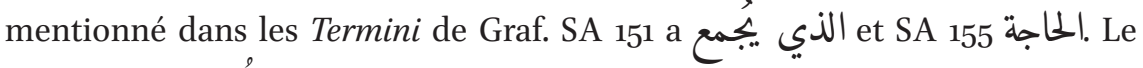

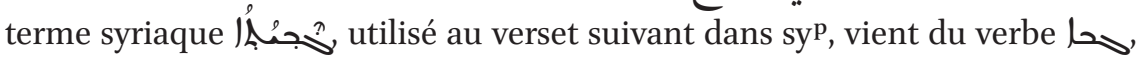
qui peut signifier «percevoir des impôts», mais aussi «choisir» (PAYNE SMIT H, p. 58). C'est peut-être en traduisant le syriaque que le traducteur choisit d'utiliser اصطفايه.

VA 13 a un singulier aماعه, tandis que le grec et syp ont un pluriel $\tau \alpha \hat{\imath} \varsigma$

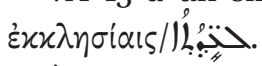

À propos du nom propre علا طيه, voir 4.1 Noms propres.

\section{Co 16,2}

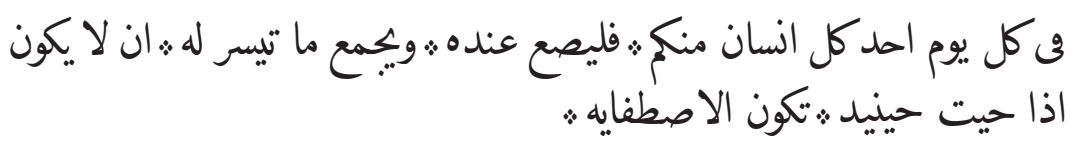

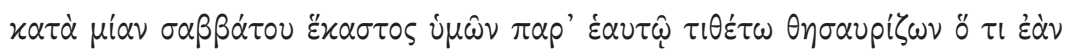

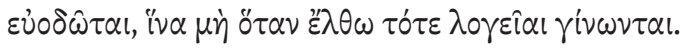

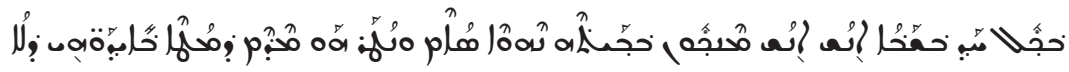

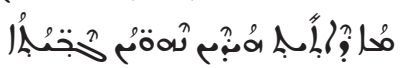

Chaque dimanche (premier jour), que chacun de vous dépose et rassemble chez lui ce qu'il peut, que ce ne soit pas quand je viens qu'il y ait, à ce moment-là, la collecte.

175 Kazimirski mentionne comme synonyme de جبى اصب اصطفا. Il se forme viII drouve que la forme I de جبى signifie « lever, percevoir l'impôt » (KAZIMI RSKI 2, p. 251). 
1 Co 16,3

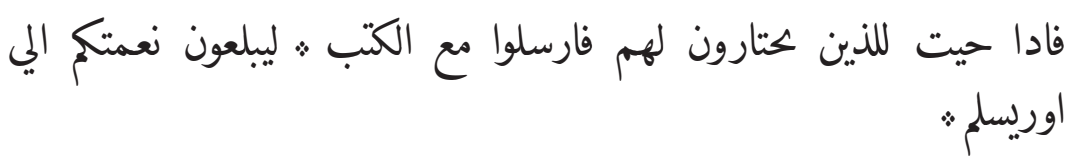

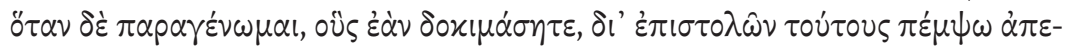

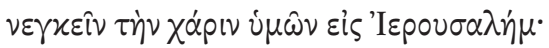

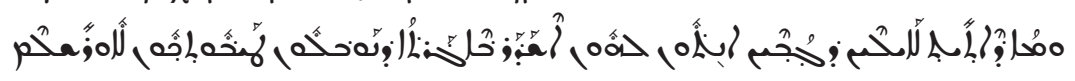

Quand je viendrai, ceux que vous choisissez, vous les enverrez avec des lettres pour faire parvenir votre grâce à Jérusalem,

Alors que le grec et syp ont une $1^{\text {ère }}$ personne du singulier $\pi \dot{\varepsilon} \mu \psi \omega / \%$ : un impératif à la $2^{\mathrm{e}}$ personne du pluriel. Est-ce une erreur de copie due à une graphie proche des deux formes?

À propos du nom propre اوريلم, voir 4.1 Noms propres.

\section{Co 16,4}

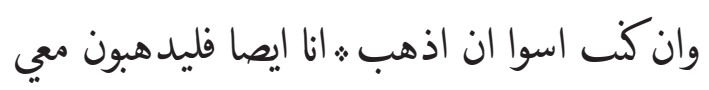

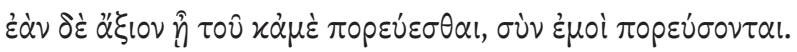

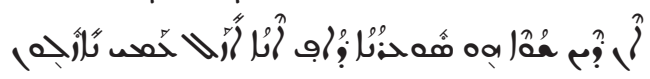

et si cela vaut la peine que j'aille moi aussi, ils iront avec moi.

1 Co 16,5

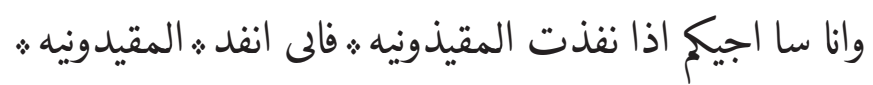

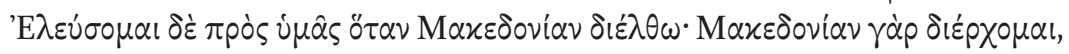

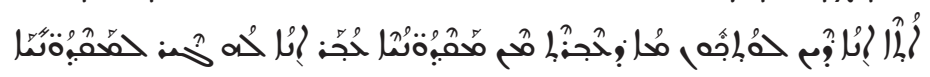

Et je viendrai chez vous quand j'aurai traversé la Macédoine. En effet, je traverserai la Macédoine,

À propos du nom propre المقيذونيه, voir 4.1 Noms propres. 


\section{$1 \operatorname{Co} 16,6$}

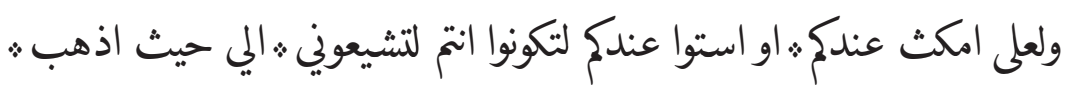

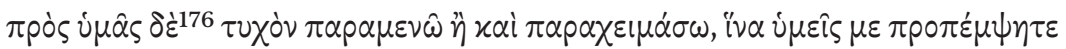

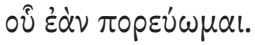

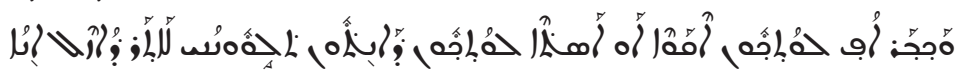

et peut-être que je séjournerai chez vous ou que je passerai l'hiver chez vous, afin que vous m'escortiez jusque là où je vais.

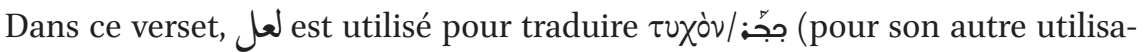
tion dans le texte, voir remarque en 1,13).

Avec او seulement, VA 13 soutient la variante $\ddot{\eta}$, comme P46 B 0121. 0243. 6.

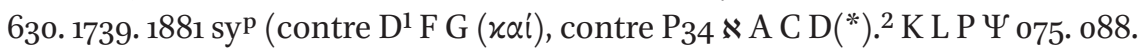

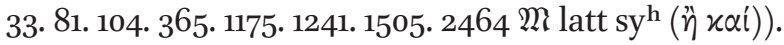

\section{Co 16,7}

$$
\begin{aligned}
& \text { fl.18v }
\end{aligned}
$$

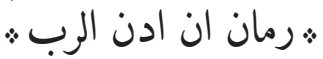

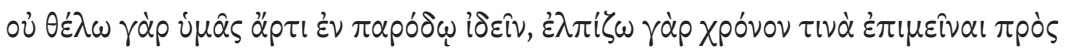

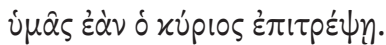

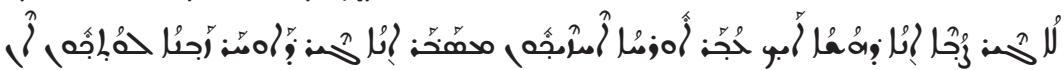

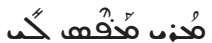

Je ne veux pas vous voir maintenant comme un voyageur qui passe, parce que j'espère rester chez vous un moment, si le Seigneur le permet.

\section{Co 16,8}

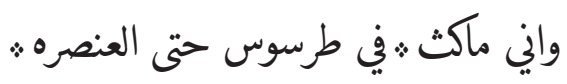

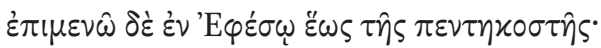

\footnotetext{
176 Quelques témoins $\left(\mathrm{P}_{4} 6\right.$ vg $\left.^{\mathrm{mss}}\right)$ n'ont pas $\delta \dot{\varepsilon}$, une variante qui n'est pas soutenue par VA 13.
} 


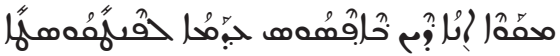

Je reste à Tarse jusqu'à Pentecôte,

Nous lisons طرسوس. Pourquoi le traducteur remplace-t-il la ville d'Ephèse par la ville de Tarse? On trouve pourtant bien dans le manuscrit افسوس en Eph 1,1 ou 1 Tim 1,3, par exemple. Est-ce pour donner de l'autorité à la lettre, Tarse étant la ville de Paul (Ac 22,3)?

\section{Co 16,9}

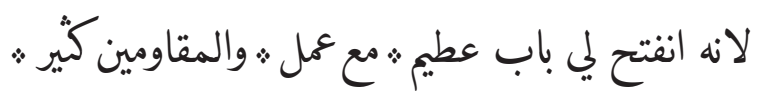

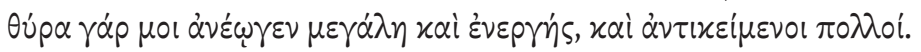

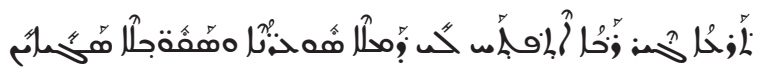

car une énorme porte m’a été ouverte avec du travail, et les opposants sont nombreux.

\section{Co 16,10}

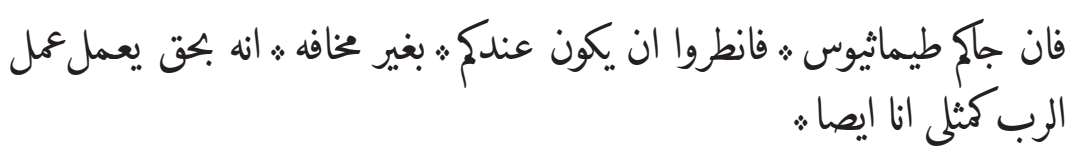

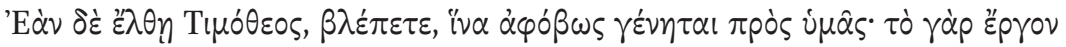

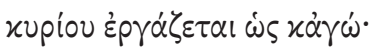

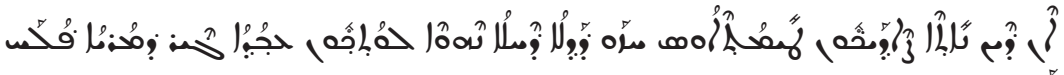
أجهُ

Si Timothée vient chez vous, veillez à ce qu'il soit chez vous sans crainte ; en vérité, il travaille à l'œuvre du Seigneur, comme moi également.

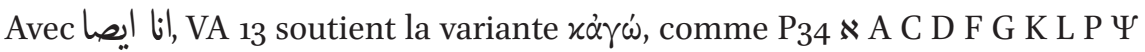
33. 81. 104. 365. 630. 1175. 1241. 1505. 2464. Ml latt sy bo (contre é $\gamma \omega \dot{\omega}$ dans P46 B 0121. 0243. 6. 1739. 1881. syp sa). 


\section{Co 16,11}

$$
\text { نلا يكون احد يرفصه ثهرحوه ان بيمي الي بالسلم ثاني انتطره مع الاخوه : }
$$

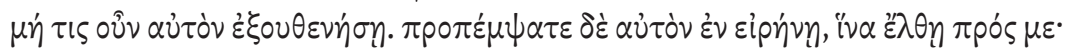

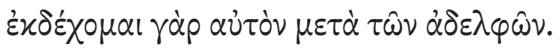

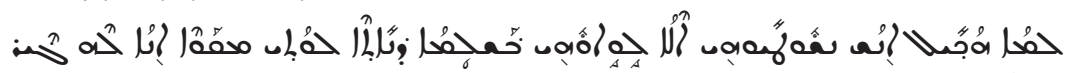

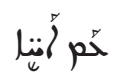

Que personne ne le rejette; envoyez-le, qu'il vienne à moi en paix, je l'attends avec les frères.

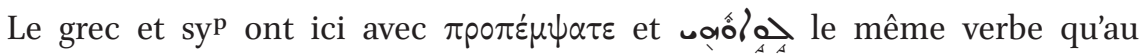
verset 6 ; VA 13 change quant à lui de verbe avec سرحوه

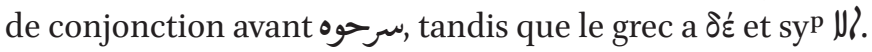

1 Co 16,12

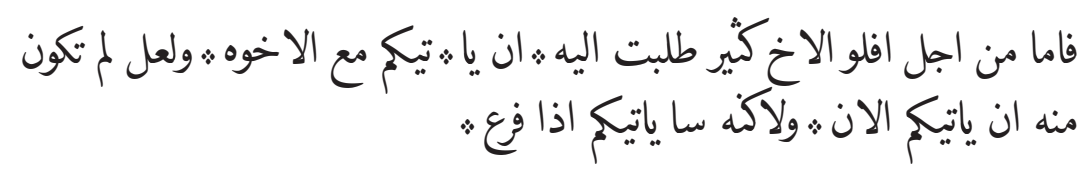

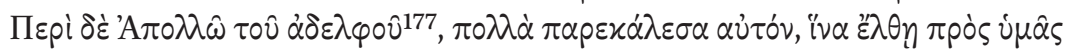

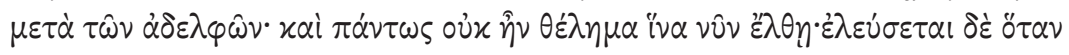

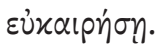

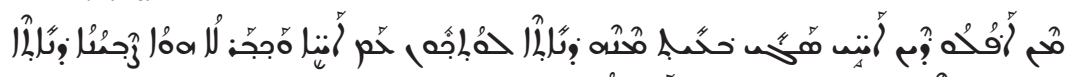

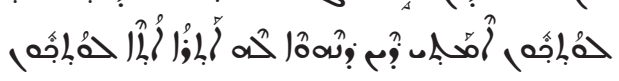

Mais à propos d'Apollos le frère, je lui ai beaucoup demandé de venir chez vous avec les frères; ce n'était peut-être pas un souhait qu'il vienne chez vous maintenant, mais il viendra quand il sera disposé.

À propos du nom افلو, voir 4.1 Noms propres.

Nous lisons منه Au vu des substantifs utilisés en grec ( $(\theta \dot{\varepsilon} \lambda \eta \mu \alpha)$ et en syp

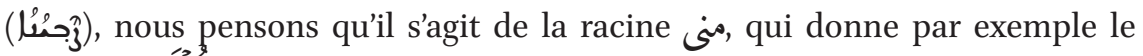

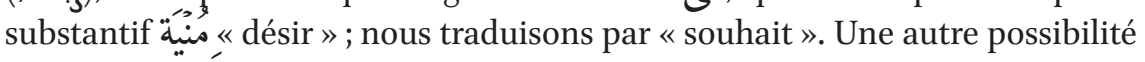

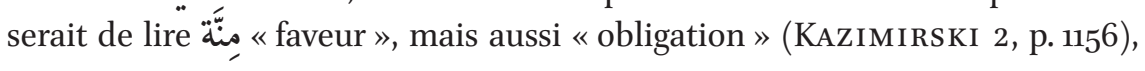

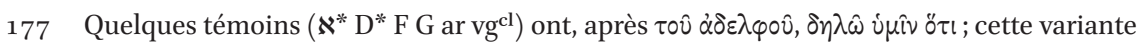
n'est pas soutenue parVA 13 . 
ou encore مِنجة signifierait alors « et peut-être que cela ne lui a pas été possible de venir chez vous »).

لعل semble plus proche de جحّح: dans syp que de $\pi \alpha \dot{\alpha} \nu \tau \omega \varsigma$ dans le texte grec (pour l'autre utilisation de لعل dans le texte, voir remarque 1,13).

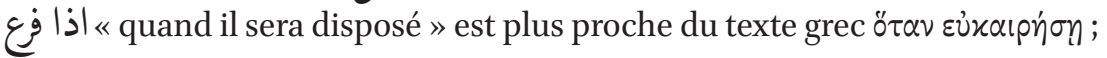

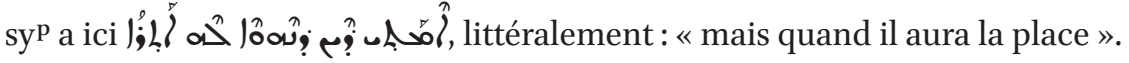

1 Co 16,13

$$
\text { استتقطوا واثبتوا في الا مانه :هتبروا واعتصموا }
$$

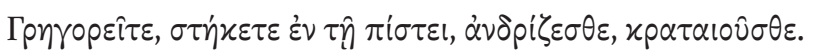

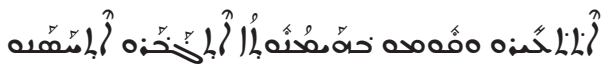

Soyez éveillés et restez fermes dans la foi, soyez forts et protégez-vous.

\section{Co 16,14}

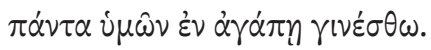

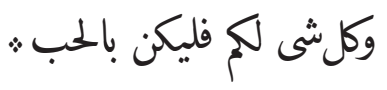

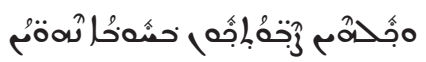

et tout ce qui est à vous, que ce soit dans l'amour.

1 Co 16,15

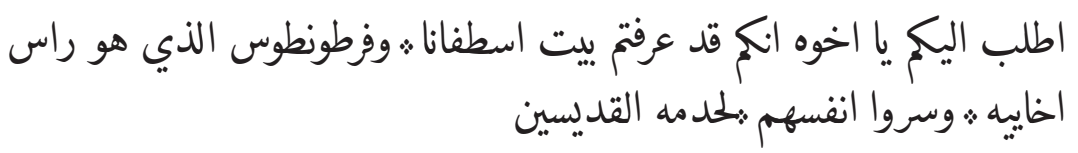

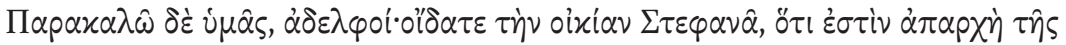

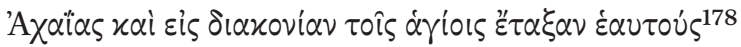

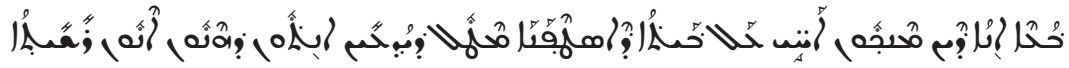

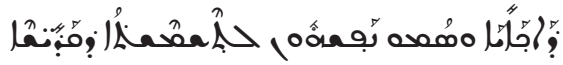

178 Quelques témoins ont ici 'Aбias ( $\mathrm{P}_{4} 6$ bo $^{\mathrm{ms}}$ ), une variante qui n'est pas soutenue par VA 13. 
Je vous demande, ô frères, que, alors que vous connaissez déjà la maison de Stéphane et Fortunatus, qui est la tête de l'Achaïe et qui eux-mêmes se sont plu au service des saints,

VA 13 a un accompli عرفتم. Est-ce qu'il se construit avec le verbe اطلب . Comment comprendre alors le قدف, qui souligne l'aspect accompli ? Les v. 16,15-16 se comprennent difficilement. Nous pensons qu'il faut, comme en grec (FitzmYer, p. 624), comprendre انكم قد عرفتم ... لحدمه القديسين comme une sorte d'incise.

Avec اسطفانا وفوطونطوس, VA 13 soutient la variante $\Sigma \tau \varepsilon \varphi \alpha v \alpha \hat{~ x \alpha i ̀ ~ \Phi o p \tau o u v a ́ \tau o v, ~}$ comme $\aleph^{2}$ D 104. 629. 1175. 1241. 2464 b vg $^{\text {st }}$ bo (contre $C^{* v i d}$ F G 365. 1505 ar

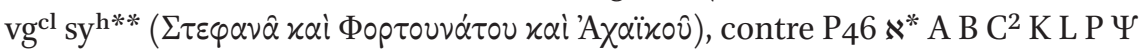
075. 0121. 0243. 33. 81. 630. 1739. $1881 \mathrm{M}$ r syp sa $\left.\left(\sum \tau \varepsilon \varphi \alpha \nu \hat{\alpha}\right)\right)$. À propos des noms propres, voir 4.1 Noms propres.

1 Co 16,16

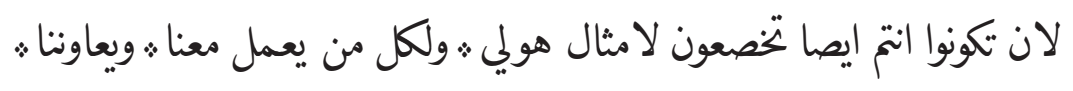

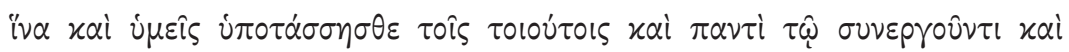
$\varkappa \circ \pi เ \hat{\omega} \nu \tau \iota$.

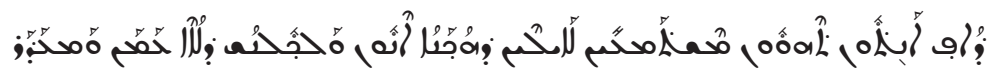
vous vous soumettiez aussi à de telles personnes, et à tous ceux qui travaillent avec nous et qui nous aident.

La présence de لان par iv $\alpha$ dans le texte grec.

\section{${ }_{1} \operatorname{Co} 16,17$}

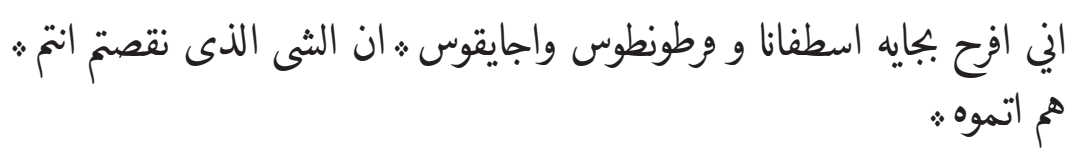

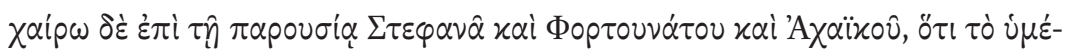

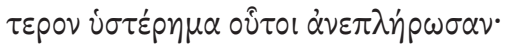

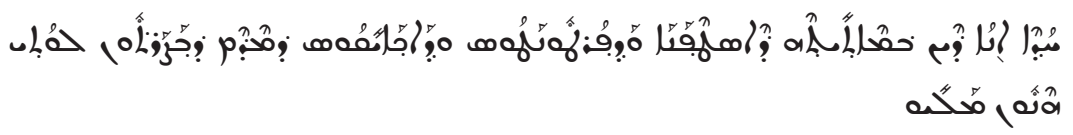


Je me réjouis de la venue de Stéphane, Fortunatus et Achaïcus : ce que vous, vous avez négligé, eux, ils l'ont terminé.

À propos de بكائ, voir 1,7.

À propos des noms propres, voir 4.1 Noms propres.

est proche de الثى الذى نقصتم انتم

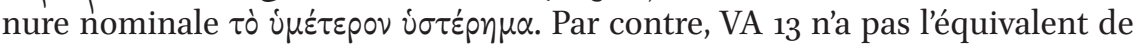
《هُ 《 contre moi », seulement présent en syp.

1 Co 16,18

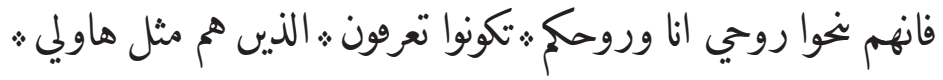

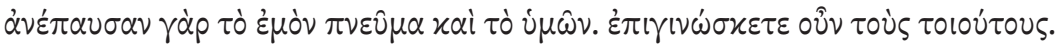

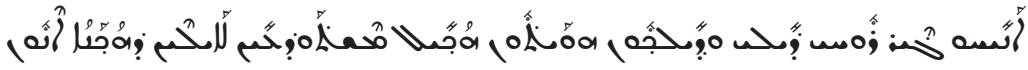

Ils ont donné du repos à mon esprit et au vôtre, soyez reconnaissants de ceux qui sont comme eux.

Le subjonctif تكونوا تعرون est certainement à comprendre ici comme un impératif ${ }^{179}$.

\section{Co 16,19}

$$
\begin{aligned}
& \text { يقرونك السلم جماعات اسيه : بعرونك السلم ربا كيرا ث. افلوس وورسقله : مع }
\end{aligned}
$$

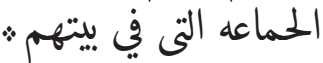

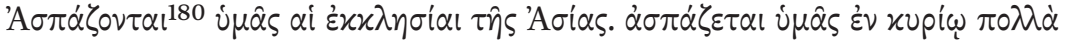

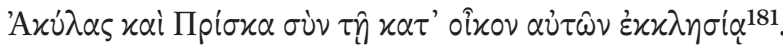

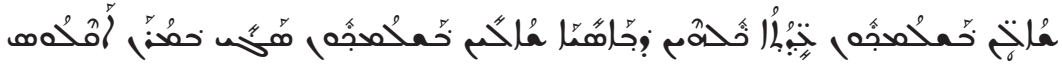

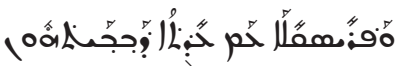

Les assemblées d'Asie vous saluent, Aquilas et Priscilla, avec l'assemblée qui est dans leur maison, vous saluent abondamment dans le Seigneur.

\footnotetext{
179 Voir BLAU, $\$ 172.2:$ « [...] the imperfect has partly supplanted the imperative $[\ldots]$ ».

180 Ici, A n'a pas $\dot{\alpha} \sigma \pi \dot{\alpha} \zeta o v \tau \alpha l$, une variante qui n'est pas soutenue par VA 13.

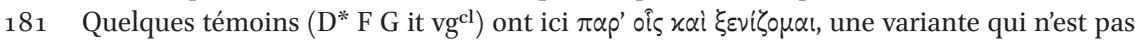
soutenue par VA 13 .
} 
L'expression يقرونك السله utilisée ici et dans les versets suivants, est proche de

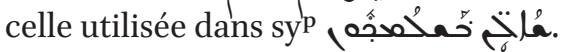

Nous lisons افلوس mais proposons de corriger, s'agissant en grec de

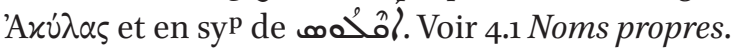

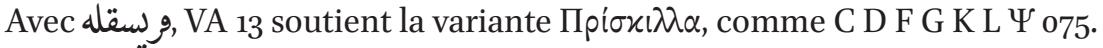
81. 104. 365. 630. $1175^{\mathrm{c}} \cdot 1241.1505 \cdot 1881^{\mathrm{c}} \cdot 2464 \mathrm{M}$ it vgcl sy bo bt (contre (P46) $\mathrm{B}$ P

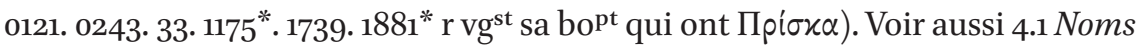
propres.

\section{Co 16,20}

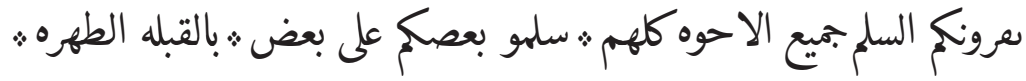

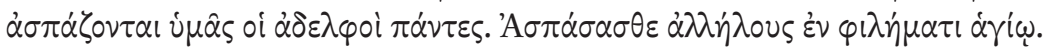

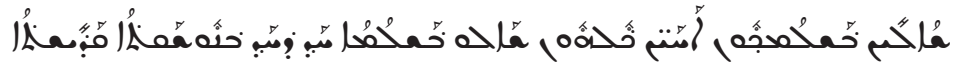

Tous les frères, ensemble, vous saluent. Saluez-vous les uns les autres par le saint baiser.

On retrouve ici avec الطهره la racine pour traduire des dérivés de $\dot{\alpha} \gamma 105$ $(1,30 ; 6,1 ; 6,2 ; 7,34 ; 16,20)$.

1 Co 16,21

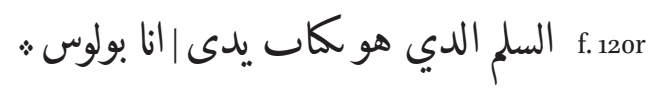

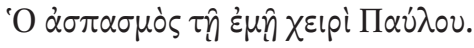

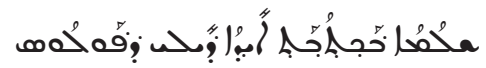

Le salut qui est écrit de ma propre main, moi Paul.

Faut-il comprendre كَّ comme un mașdar ou comme le substantif «un écrit », que l'on trouve dans le sens de « lettre » en 5,9 et 16,3 ? Nous préférons

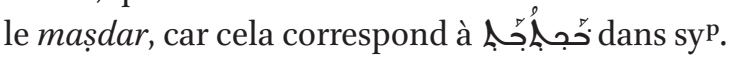

1 Co 16,22

$$
\text { كل من لا يحس ربنا يسوع المسيح يكون محروم ؛ ربنا قد حا }
$$

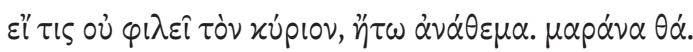




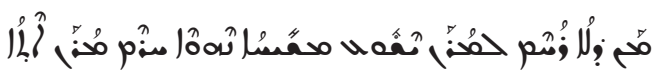

Toute personne qui n'aime pas notre Seigneur Jésus Christ, qu'elle soit anathème. Notre Seigneur est venu.

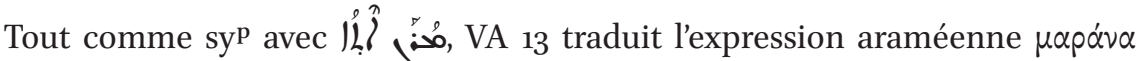
$\theta \alpha \dot{a}:$. Voir 4.2 Vocabulaire d'emprunt. On notera que, comme syp, VA 13 comprend le verbe comme étant à l'accompli (ce qui correspondrait à la variante $\mu \alpha \rho \alpha \dot{\alpha} \alpha \alpha \theta \dot{\alpha} \mathrm{B}^{2} \mathrm{G}^{2} \mathrm{G}^{*}$ vid $\mathrm{KL} \Psi 323.365 .1505 \mathrm{vg}^{\mathrm{cl}} \mathrm{sy}^{182}$ ).

1 Co 16,23

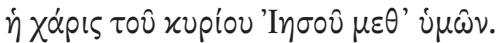

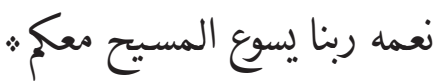

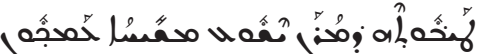

La grâce de notre Seigneur Jésus le Christ est avec vous,

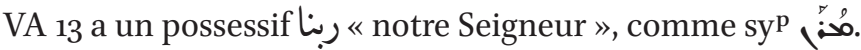

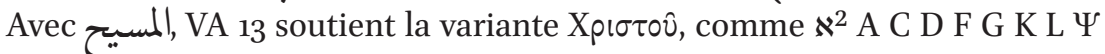
075. 0121. 0243. 81. 104. 365. 630. 1175. 1241. 1505. 1739. 1881. $2464 \mathrm{M}$ it vgcl sy bo (contre $\left.\boldsymbol{\aleph}^{*} \mathrm{~B} 33 \mathrm{sa}\right)$.

1 Co 16,24

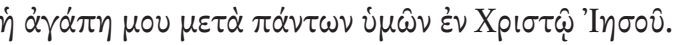
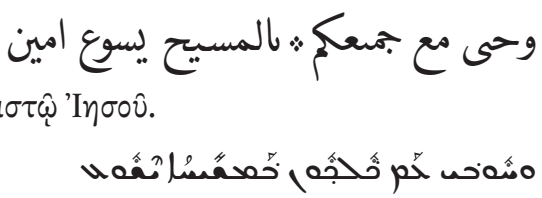

et mon amour avec vous tous, en le Christ Jésus, amen.

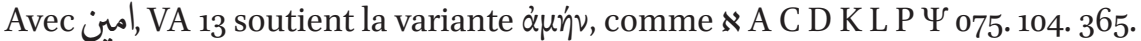
1175. 1241. 1505. 1739c. $2464 \mathfrak{M}_{\text {lat sy }}$ bo (absent dans B F 0121. 0243. 33. 81. 630.

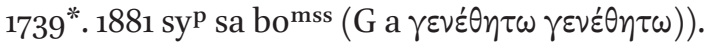

182 Sur la question, voir SENFT, p. 220. 


\section{$2 \quad$ Moyen arabe}

\subsection{Remarques préliminaires: Mittelarabisch, Moyen arabe, Middle Arabic}

Le VA 13 fait partie des manuscrits rédigés en «moyen arabe», une catégorie qui est toutefois discutée par les linguistes. C'est le philologue Heinrich L. Fleischer qui introduit la notion de «mittelarabisch » 183 en discutant l'évolution de la langue arabe (il parle de «Alt-, Mittel- und Neuarabischen » ${ }^{184}$ ), notion qui sera reprise par ses pairs. On trouve par la suite l'ouvrage de grammaire de Graf, qui se concentre sur l'usage chrétien de ce qu'il nomme «Vulgär-Arabisch » ${ }^{185}$. Mais c'est certainement Joshua Blau qui apporta le plus à la thématique, publiant une grammaire d' « arabe chrétien » en $1966^{186}$ et un Handbook of Early Middle Arabic ${ }^{187}$ en 2002, ainsi que de nombreux articles sur le sujet. Blau définit le «Middle Arabic» comme « a general term for the language of those texts, in which classical Arabic, Neo-Arabic and pseudo-correct elements alternate. ${ }^{188}$ Pour Blau, le «Neo-Arabic » se caractérise par sa proximité avec les dialectes arabes modernes : « The importance of the linguistic study of the Middle Arabic is that its Neo-Arabic component, which, as a matter of fact, contains all the features of modern Arabic dialects. ${ }^{189}$ Les pseudo-corrections apparaissent quant à elles lorsque qu'un auteur, souhaitant être fidèle à l'arabe classique, utilise des formes qui n'existent pas en arabe classique, ou du moins pas dans ce contexte.

Si cette définition générale est plutôt bien acceptée, c'est toutefois l'approche historique de Blau qui fut critiquée. Blau soutient que «Middle Arabic is the 'missing link' between Classical Arabic and modern dialects » ${ }^{190}$; de

183 Fleischer Heinrich Leberecht, Kleinere Schriften, vol. 3, Leipzig, S. Hirzel, 1885, pp. $155^{-1} 5^{6}$.

184 Ibid., p. 156.

185 GRAF Georg, Der Sprachgebrauch der ältesten christlich-arabischen Literatur, ein Beitrag zur Geschichte des Vulgär-Arabisch, Leipzig, O. Harrassowitz, 1905.

186 BLAU Joshua, A Grammar of Christian Arabic, Based Mainly on South-Palestinian Texts from the First Millennium, vol. Subsidia 27, Louvain, Secrétariat du CorpusSCO, 1966 (Csco 267).

187 BLAu Joshua, A Handbook of Early Middle Arabic, Jérusalem, The Max Schloessinger Memorial Foundation, The Hebrew University, 2002 (The Max Schloessinger Memorial Studies Monographs 6).

188 BLAu Joshua, Studies in Middle Arabic and Its Judaeo-Arabic Variety, Jérusalem, Magnes Press, 1989, p. 83 .

189 BLAU Joshua, «The State of Research in the Field of the Linguistic Study of Middle Arabic », Arabica (28), 1981, p. 187.

190 BLAU, A Grammar of Christian Arabic, Based Mainly on South-Palestinian Texts from the First Millennium, op. cit., 1966, p. I. Voir aussi BLAU, « The State of Research in the Field of the Linguistic Study of Middle Arabic », art. cit., 1981, p. 188. 
plus, le terme lui-même de «moyen arabe » s'inscrit dans une perspective historique qui rappelle les distinctions que l'on utilise pour d'autres langues, tels que « ancien français », « moyen français » et « français moderne ». Or, comme le dit Fischer: « $[\ldots]$ there is no space between the morphoponemic structure of Classical Arabic and that of the Neo-Arabic dialects for introducting an intermediate stage of Middle Arabic. [...] For, as far as I see, no phonological, morphological or syntactic feature has been found in Middle Arabic texts which are not attested in the Neo-Arabic dialects also. $»^{191}$

La définition de Blau reste donc actuelle, mais pas son approche historique, ce qui élargit le spectre du «moyen arabe » : «In modern studies of Arabic, the collective name for all texts with deviations from Classical grammar is Middle Arabic. ${ }^{192}$

Kouloughli pose alors la question de manière provocatrice : «quel est l'intérêt d'un concept de Moyen-Arabe défini comme un fourre-tout a-historique? N'est-il pas scientifiquement inutile dans la mesure où il ne constitue aucun ensemble textuel cohérent ? ${ }^{193} \mathrm{Il}$ rejoint aussi la critique des chercheurs qui ont mis contre l'idée que le moyen arabe tel que décrit par Blau serait «typiquement chrétien» (ou juif, mais nous n'abordons pas ici la question du «moyen arabe juif» ou judéo-arabe), sous prétexte que les chrétiens étaient moins lettrés ou alors moins soucieux de préserver la langue classique :

Cette sociolinguistique « communautariste » repose sur une représentation par trop simpliste des mécanismes d'instauration, de diffusion et de sanction des normes linguistiques, et fait fi, notamment, du fait que les membres des trois communautés religieuses, musulmane, chrétienne et

191 Fische R Wolfdietrich, «What is Middle Arabic? », in: KAYE Alan S. (éd.), Semitic Studies in Honor of Wolf Leslau, 2 vol., Wiesbaden, Otto Harrassowitz Verlag, 1991, p. 432. Voir aussi Mejdell Gunvor, "Middle Arabic" Across Time and Medium/Mode. Some Reflexions and Suggestions », in: Lentin Jérôme et Grand'henry Jacques (éds), Moyen arabe et variétés mixtes de l'arabe à travers l'histoire. Actes du Premier Colloque International (Louvain-la-Neuve, 10-14 mai 2004), Louvain, Peeters, 2008 (Publications de l'Institut Orientaliste de Louvain 58), pp. 355-372.

192 Versteegh Kees, The Arabic Language, Edinburgh, Edinburgh University Press, 2001, p. 114.

193 Kouloughli Djamel E., «Moyen Arabe et questions connexes», 2007, p. 21. En ligne: $<$ http://cle.ens-lyon.fr/arabe/moyen-arabe-et-questions-connexes-30683.kjsp?RH=CDL_ ARA120000>, consulté le 14.01.2014. Voir aussi la critique de Samir Khalil Samir : SAMIR Samir Khalil, «La tradition arabe chrétienne. État de la question, problèmes et besoins », in: Actes du premier congrès international d'études arabes chrétiennes (Goslar, septembre 1980), Rome, Pontificio Instituto Orientale, 1982 (Orientalia Christiana Analecta 210), pp. 21-120, § 103-131. 
juive, ne constituaient pas chacune un bloc socialement homogène et participant au même degré et dans les mêmes conditions à l'acquisition de la norme linguistique. Elle propose également une image illusoirement homogène des pratiques linguistiques donnant lieu à des productions écrites et des conditions dans lesquelles la censure sociale peut s'exercer sur ces productions et les pousser à se conformer à des modèles et normes ${ }^{194}$.

Pour Kouloughli, une classification plus détaillée des textes est nécessaire afin de continuer à travailler avec la catégorie de moyen arabe. Il propose trois catégories : (1) historique : de quelle époque date le texte en moyen arabe? (2) géographique: d'où vient le texte en moyen arabe? (3) sociolinguistique: quelle est l'appartenance sociale et religieuse des auteurs/destinataires ${ }^{195}$. Dans cette perspective, le travail majeur de Blau de 1966 garderait tout son intérêt. En effet, son étude porte sur un corpus bien défini : la littérature arabe chrétienne (qu'il définit comme la littérature écrite par des chrétiens pour des chrétiens) produite dans la Palestine du Sud durant le premier millénaire de notre ère. Il démontre ainsi la présence constante de moyen arabe, c'est-à-dire, comme nous l'avons vu plus haut, des spécificités «néo-arabes», ainsi que des pseudo-corrections. Nous reviendrons plus bas en détail sur ces éléments. Le fait qu'il s'agisse d'un corpus bien défini ne signifie pas pour autant que les caractéristiques décrites soient propres à celui-ci. Un vaste travail de comparaison avec d'autres textes (ou productions orales) de milieux différents est nécessaire pour déterminer si certaines de ces caractéristiques peuvent être considérées comme déterminantes pour le milieu chrétien sud-palestinien du premier millénaire.

\section{2 Éléments de moyen arabe dans Vat. Ar. 13 (1 Corinthiens)}

Pour son ouvrage, Blau a étudié une soixantaine de manuscrits du $9^{\mathrm{e}}$ au $11^{\mathrm{e}} \mathrm{s}$. provenant des monastères du sud de la Palestine, principalement de SainteCatherine, Saint-Chariton et Mar Saba. Blau note l'influence du grec et du syriaque sur ces textes, qui en sont souvent la traduction : «The most of the ASP

194 Kouloughli, « Moyen Arabeetquestionsconnexes »,art.cit., 2007,p.29.Pourapprofondir la grande diversité du moyen arabe, voir les articles dans LENTIN Jérôme et GRAND'H ENRY Jacques (éds), Moyen arabe et variétés mixtes de l'arabe à travers l'histoire. Actes du Premier Colloque International (Louvain-la-Neuve, 10-14 mai 2004), op. cit.; ZACK Liesbeth et Schippers Arie, Middle Arabic and Mixed Arabic: Diachrony and Synchrony, Leiden, Boston, Brill, 2012 (Studies in Semitic Languages and Linguistics 64).

195 Kouloughli, «Moyen Arabe et questions connexes », art. cit., 2007, p. 21. 
[Arabic South Palestinian] texts are translations from Greek and Syriac [...] Because of the atomistic translations, features peculiars to Greek and Syriac occur rather frequently. » ${ }^{196}$ En plus de ces influences textuelles, l'arabe de ces textes sud-palestiniens « subit» l'influence du dialecte araméen: «At this period Aramaic was still a living language : accordingly, [...] traces of living Aramaic influence are not rare in ASP. ${ }^{197}$ Concernant les traductions néotestamentaires, Monferrer-Sala résume ainsi la situation :

This literary koinè, used for translations as well as for original works in the hands of Christian, Jewish and Muslim authors, shows many Middle Arabic phenomena through the different levels of the Arabic language caused by pseudo-corrections, but also as interferences from the NeoArabic dialects. What is more, the Arabic texts from the 9th-11th centuries of the New Testament were copies from different Vorlagen, with interferences of a third language, as it occurs with Aramaic in texts from the Palestinian area ${ }^{198}$.

Blau et plus récemment Monferrer-Sala constatent que les traductions sont souvent des calques du grec et du syriaque, ce qu'ils nomment des «loantranslations ${ }^{199}$. Nous reviendrons sur cette question au point suivant et nous concentrons pour l'instant sur les caractéristiques de type «moyen arabe » de VA 13.

Blau intègre le VA 13 à son corpus de texte étudié pour sa grammaire. Il semble qu'il ait surtout approfondi les passages transcrits par Guidi (Mt 10, 28-41; 26,1-13), Scholz (Mt 13, Mc 5, Lc 4, Ga 2, 1 Tm 3, Phm) et Vööbus (Mt 2,11b23a). Il écrit ne pas être certain de pouvoir considérer l'intégralité du texte comme étant du moyen arabe, sans donner plus de détails ${ }^{200}$. Kashouh abonde

196 BLAU, A Grammar of Christian Arabic, Based Mainly on South-Palestinian Texts from the First Millennium, op. cit., 1966, p. 54, § 1.9 .

197 Ibid., p. 55, § 1.9.

198 Monferrer-Sala Juan Pedro, «From Antiquity and Late Antiquity to the Middle Ages: Translating in a Multilingual Setting », in: PARra-Membrives Eva, Peinado Miguel Angel Graciá et CLASSEN Albrecht (éds), Aspects of Literary Translation. Building Linguistic and Cultural Bridge in Past and Present, Tübingen, Narr, 2012, p. 62.

199 Blau, A Grammar of Christian Arabic, Based Mainly on South-Palestinian Texts from the First Millennium, op. cit., 1966, p. 54, § 1.9. Monferrer-Sala Juan Pedro, «Loan Translation from Greek in Christian Middle Arabic », in : Monferrer-Sala Juan Pedro et Al Jallad Nader (éds), The Arabic Language Across the Ages, Reichert, Wiesbaden, 2010, pp. 75-91.

200 " Not all the parts of this ms., it seems, belong to ASP. », BLAU, A Grammar of Christian Arabic, Based Mainly on South-Palestinian Texts from the First Millennium, op. cit., 1966, p. 33, § 1.4.3.18. 
dans ce sens, considérant que le texte des évangiles qu'il analyse diffère des textes «ASP »: « The linguistic characteristics of $h^{1}$ suggest, with a high degree of certainty, that this codex, unlike other codices of the eighth/ninth century, was not produced in South Palestine. ${ }^{201}$ Toutefois, Monferrer-Sala soutient le contraire, considérant que les caractéristiques linguistiques de cette partie du corpus rejoignent les caractéristiques décrites par Blau ${ }^{202}$. De même, il considère que Philémon correspond à ces caractéristiques, le texte présentant : «[...] (although not always) linguistic phenomena characteristic of the language register known as 'Middle Arabic' that was used in the text, and indeed in Christian Arabic Mss in general. ${ }^{203}$

En nous basant sur le répertoire de Blau, nous allons exposer les aspects propres au moyen arabe tel que décrit par ce dernier que l'on trouve dans 1 Corinthiens ${ }^{204}$.

\subsubsection{Orthographe et phonétique}

1) taškīl. Le texte n'est pas vocalisé (BLAU, § 3.1), ne présente ni šadda (BLAU, § 26.1), ni hamza (BLAU, § 11) ni toute autre forme de taškïl.

2) i jām. Le texte présente le système du i ijām pour démarquer les consonnes, à l'exception de la $t \bar{a}$ marbūtạ, qui est notée sans point •(BLAU, § 25). On observe que l'usage du i ijām est souple, le scribe omettant assez régulièrement des points diacritiques (ايصا est plus répandu que ايضا ; le point sur le nün final est souvent omis; etc.)

3) dāl et zāy. Nous avons noté un cas où deux consonnes semblent se confondre. Le texte présente la racine ذذ ذ plutôt que l'orthographe classique زj pour «purifier» $(5,7$ et 5,8). Blau pense toutefois qu'il ne s'agit pas d'un phénomène phonétique: « Words containing zây spelled with dhâl do not exhibit a living phenomenon, but have to be interpreted as a pseudo-etymological spelling, caused by the disappearance of dhâl in living speech. It occurs [...] several times in the root $z k y$ 'to be pure', spelled dhky, owing to blend with the root $d h k y[\ldots] »(\mathrm{BLAU}, \S 16.3)$.

201 Kashou H Hikmat, The Arabic Versions of the Gospels, The Manuscripts and their Families, Berlin, Boston, De Gruyter, 2012 (Arbeiten zur neutestamentlichen Textforschung 42), p. 147 .

202 Monferrer-Sala Juan Pedro, «An Early Fragmentary Christian Palestinian Rendition of the Gospels into Arabic from Mar Saba (MS Vat. Ar. 13, 9th c.) », Intellectual History of the Islamicate World 1, 2013, p. 71. Il critique toutefois le concept de « Middle Arabic ».

203 Monferrer-Sala, «The Pauline Epistle to Philemon from Codex Vatican Arabic 13 (Ninth Century CE): Transcription and Study », art. cit., 2015, p. 344.

204 Nous faisons état des phénomènes qui se répètent et les exemples ne sont pas nécessairement exhaustifs; dans le commentaire (point 1), nous faisons aussi référence à la grammaire de Blau lors de phénomènes singuliers. 
4) i'rab. Le texte n'étant pas vocalisé, il ne peut y avoir de marquage casuel à l'aide de voyelles. À propos du alif de la tanwìn, voir : Syntaxe :19) tanwīn.

5) Lettres faibles. On remarque un usage souple et non systématique de alif et du $y \bar{a}$. On trouve indifféremment alif maqșūra et $y \vec{a}$, ce qui s'explique surtout par l'inconsistance dans les points diacritiques. Un exemple parlant se trouve en 9,14, où l'on trouve : البشري البشرى :puis : البشى عutres exemples :

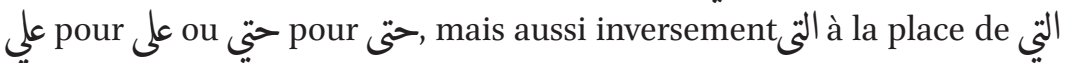
et هي هour on trouve aussi, moins fréquemment, alif mamdūda à la place de alif maqșūra. Exemple. متا pour متى (BLAU, § 10.1). Ces caractéristiques se retrouvent dans les verba tertiae infirmae (voir: Morphologie: 13) Verba mediae infirmae).

6) hamza. La hamza n'est jamais notée (BLAU, § 11). En début de mot, on trouve le alif seul. L'expression ياخ إخوه est écrite en toutes lettres, à l'exception de trois cas $(3,10 ; 7,24 ; 14,20)$, où l'on trouve ياخوه (BLAU, § 11.6.1.3). En position médiane, le support de la hamza est généralement préservé. Exemples : حينيد ; سراير (noté comme un $y \bar{a}^{\prime}$ avec les points diacri-

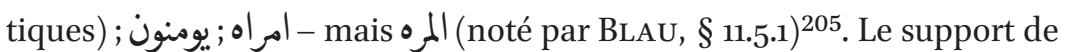
حطيه : حamza n'est pas préservé lorsque deux $y \bar{a}^{\prime}$ seraient nécessaires $(6,18)$. Quand la hamza ne demande pas de support, il n'a plus trace de la hamza: نجاه (16,10). En position finale, la hamza est absente que cela soit après une consonne : ex. شي (شى (orthographié aussi une voyelle : ex. حكما (3,19) ; السما (15,47). Voir aussi : Morphologie : 12) Verba hamzatae.

7) Scriptio plena. On trouve différents cas de scriptio plena (BLAU, § 8). Les rares fois où la préformante marquant le futur est utilisée, elle s'écrit alors سا, à la place de سـ mamdūda là où l'orthographe classique a souvent un alif suscrit (BLAU,

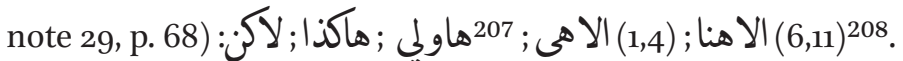

8) Scriptio defectiva. Nous avons noté un seul cas de scriptio defectiva (BLAU, § 9.1) : سلم (1,3; 7,15;14,33;16,11;16,19-21).

205 Dans deux cas, on trouve toutefois المرام (7,16 et 13,12).

206 Le fait que سا 20 soit suivi dans deux cas directement par des alif nous laisse supposer qu'il y a un espace entre wl le verbe سا ساجيك; 116,5$)$. Le même argument est avancé par BLAU, § 8.1.

207 Le traducteur est constant dans sa manière d'orthographier le pronom démonstratif: on trouve هاو لهاولى en 13,13). Cf. BLAU, § 32.3-5 à propos des différentes orthographes possibles.

208 On notera que ces orthographes sont aussi attestées en arabe classique. 
9) alif otiosum. L'alif otiosum est parfois écrit, parfois non, et cela indépendamment du mot qui suit (Blau mentionne l'omission de l'alif otiosum devant alif, § 28.1, et devant la préposition ل, § 283). Voir aussi le phénomène du redoublement du alif après wāw (l|g) aux versets 12,27; $14,6.15 ; 15,5$.

\subsubsection{Morphologie}

10) Terminaison du pluriel masculin externe au cas sujet. On ne trouve pas la terminaison -ûn mais seulement -în pour les pluriels externes masculins, au cas sujet également (BLAU, § 112.1). Exemple : المعسدين الأو6, (6,9). Le phé-

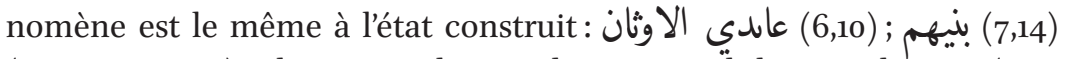
(BLAU, § 112.1.1). Blau met cela en relation avec l'absence des cas (voir BLAU, § 215).

11) Terminaison -iyyīn. La terminaison du pluriel -iyyinn est parfois raccourcie à -īn. Cela n'est toutefois pas systématique, car l'on trouve également souvent -iyyin (BLAU, § 125). Exemple: on trouve en 3,1 الروحانيين puis

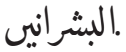

12) Verba mediae hamzatae. La hamza semble préservée sous la forme de son support, comme c'est le cas lorsque la hamza est en position médiane (voir: Orthographe et phonétique : 6) hamza) : يسالون (1,22) (ąc comparer avec BLAU, § 75). Dans le cas du verbe doublement faible راى (1, contrairement aux exemples donnés par Blau (BLAU, § 76), le verbe ne semble رايت : pas connaître de développement phonétique particulier. Exemples $(5,3) ;$ راك $(8,19)$.

13) Verba mediae infirmae. Voir notre point: Syntaxe : 26) Inaccompli : verba mediae infirmae.

14) Verba tertiae hamzatae. Voir: Orthogrape et phonétique 6) hamza. À l'inaccompli, dans plusieurs cas, la hamza finale semble être préservée sous la forme de son support, ici alif:تتنبا: تخا s'agir d'une conjugaison d'un verbe tertiae infirmae. Dans d'autres cas, le verbe est en effet conjugué comme un verbe tertiae infirmae: يتبني (BLAU, § 77). À l'exception du pluriel, où le verbe est toujours conjugué comme un verbe tertiae infirmae تننبون (14,1), l'irrégularité est de mise. Dans le cas du verbe doublement faible جاء (BLAU, § 78.1), en position médiane, le support de la hamza est préservé جيت (2,1). Par

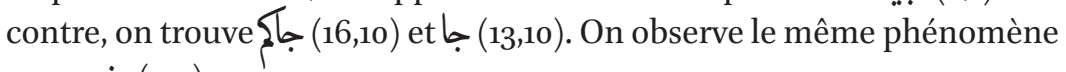
pour يضي (4,5).

15) Verba" tertiae infirmae. À l'inaccompli, on trouve souvent le cas de figure

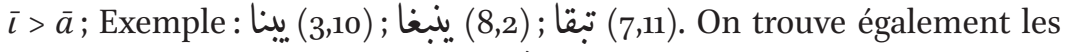
formes «correctes » : ينبني (8,2) ينيني (11,29). De même, on trouve aussi 
$\bar{a}>\bar{\imath}$, exemple: يري (15,15). Ces irrégularités dans les conjugaisons nous semblent venir de la souplesse avec laquelle les lettres faibles sont utilisées et n'indiquent pas qu'une conjugaison a remplacé une autre. (BLAU, § 92, 93). Selon Blau, « Verba tertiae wâw pass into tertiae yâ » (§ 91) et donne en appui de cette évolu-

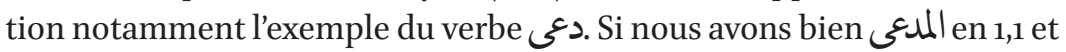
en 1,2, nous ne pouvons exclure qu'il s'agit ici de la forme IV et non de la forme I se conjuguant selon le schéma tertiae y $\bar{a}$.

\subsubsection{Syntaxe}

16) Genre et nombre. Les inanimés au pluriel sont compris comme féminin singulier: واجساد سلمويه واجساد ارصانيه ; $(15,40)$, ou par le féminin pluriel (BLAU, § 185) : انهن" وصائ (14,37); هاولي semble souvent se référer à des propos ou idées $(4,6 ; 11,16)$ (BLAU, $\S 184)$. De manière générale, l'utilisation du genre et du nombre pour les inanimés n'est pas systématique, comme le démontre la construction suivante: اوصال الجسد التى يرين انهن صعاف (12,22), où l'on trouve un relatif au féminin singulier, un verbe au féminin pluriel, un pronom au féminin pluriel et un adjectif au masculin pluriel (voir aussi 12,23-24).

17) Concordance du verbe et du sujet. À l'exception des inanimés au pluriel (voir ci-dessus : Syntaxe : 16) Genre et nombre), il y a concordance quant ان يكونوا: au nombre du verbe et du sujet, même si le verbe précède le sujet (Blau, § 177).

18) Absence des cas. Blau suppose que le marquage des cas a disparu en ASP

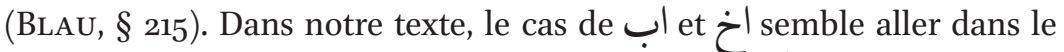
sens d'une absence des cas, vu qu'on trouve بو ابون (1,1) (1,3) pour le cas indirect et اخوه (6,5) pour le cas indirect (BLAU, § 219.1.1.1 et 219.2.1.1).

19) tanwīn. Si le alif suivant le tanwìn au cas direct est généralement absent,

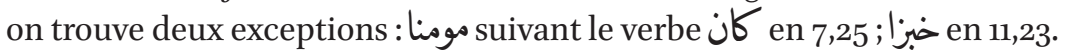
L'alternance entre l'absence et la présence du alif a été notée par Blau (§ 221). Ce point va à l'encontre de la disparition du moins totale des cas. On remarquera que l'adverbe présente généralement le alif (toujours

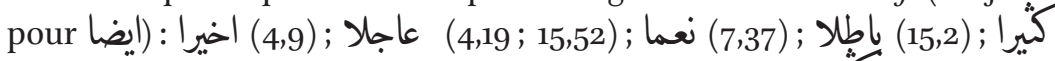

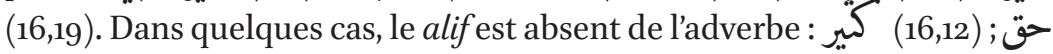
$(15,16)$.

20) Préposition ل ل Dans certains cas, la préposition $ل$ est utilisée pour mar-

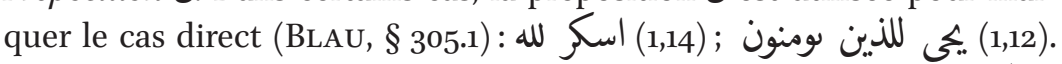
يصلى :Elle peut aussi être utilisée à la place d'autre préposition. Exemple لله (11,13). 
21) Préposition من من La préposition utilisée pour marquer l'agent du passif لان يدان من انسان (Blau, § 306.2).

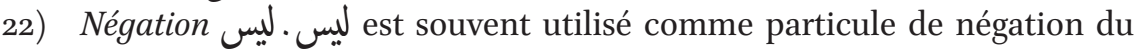
verbe. Dans ce cas, il est invariable, sauf quand il s'agit de la première personne du singulier: لست اسوا ; $(15,9)$; كت لست رسول sic ! (9,2). Nous trouvons aussi dans quelques cas alors que le pluriel n'est pas demandé (1,26;9,26;12,14). En

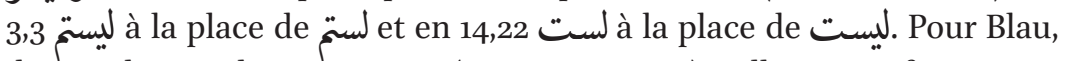
il s'agit de pseudo-corrections (BLAU, § 204.4.2). Ailleurs, ces formes apparaissent correctement $(4,20 ; 6,2)$. Dans deux cas $(12,15-16)$, on trouve la négation avec suffixe :ليسها, une utilisation que Blau décrit comme « very rare » (BLAU, § 204.3).

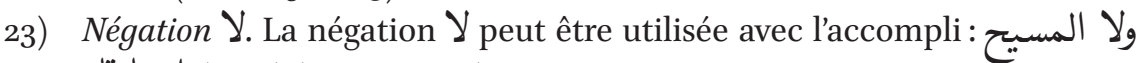
(15,13) (BLAU, § 301).

24) Verbe auxiliaire 6 . On trouve $\mathbf{j}$ à l'accompli suivi d'un inaccompli pour exprimer l'imparfait $(10,3-5)$, mais surtout pour marquer une action hypothétique (usage également « classique», Blau, $§ 316.1$ ). On trouve ن 6 à l'inaccompli suivi d'un inaccompli très fréquemment; il peut ne pas remplir de rôle particulier $(16,18)$ (Blau le qualifie d'« index », § 320.1), ou être utilisé à la suite de لان لان, que le verbe principal soit éloigné de la particule $(10,24)$ ou non $(4,3 ; 5,5 ; 10,7)$ (BLAU, $§ 321-322)$. Dans le cas de $j$ à l'inaccompli suivi d'un inaccompli, cela permet surtout, à notre avis, de suivre la structure de la phrase traduite depuis le grec ou le syriaque tout en respectant la grammaire arabe (voir points 3.3 et 5.1).

25) Inaccompli : terminaisons du pluriel. Blau note que la différence entre les formes de l'inaccompli se terminant avec nūn (indicatif) et celles se terminant sans nūn est devenue floue (subjonctif/apocopé) (§ 171.1). C'est bien notre cas : on trouve là où en «classique » un subjonctif est attendu

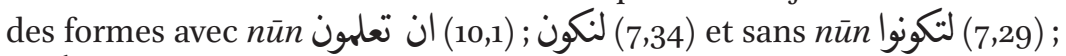
ان (7,32) (voir aussi Orthographe et phonétique : 9) alif otiosum) et là où un apocopé est attendu des formes avec nūn لان

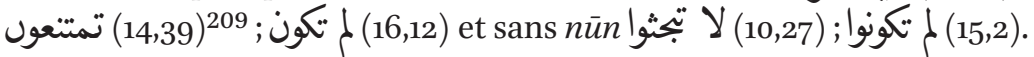

26) Inaccompli : verba mediae infirmae. Le même flou s'installe à l'inaccompli dans le cas des verba mediae infirmae au singulier (BLAU, § 171.1, note 1). L'apocopé entraîne en arabe «classique » le raccourcissement de la

209 Dans le cas où la négation لا est suivi d'une forme avec nūn, c'est le contexte et l'étude des Vorlagen qui nous permet de déterminer qu'il s'agit d'un impératif négatif. 
voyelle médiane. Ici aussi, nous trouvons des formes courtes : يكن (9,17) ن et des formes longues

\subsubsection{Remarques finales}

Une dernière observation, toutes catégories confondues, est la souplesse ou l'inconsistance qui traverse le texte: on trouve ainsi des formes «classiques » ou «irrégulières» en alternance, et pour chaque caractéristique classée comme «moyen arabe», nous trouvons sa forme «correcte» ailleurs. Cette observation correspond à la description de Blau : «It is the alternation of classical, genuine MA and pseudo-Classical features $[. .$.$] that is characteristic of$ MA in general and ASP in particular. » (BLAU, § 1.8).

Ainsi, nous voyons que les phénomènes s'éloignant de l'« arabe classique » présents dans le texte de 1 Corinthiens sont tous répertoriés dans la grammaire de Blau. De même, si on ne retrouve pas toutes les caractéristiques de la grammaire - très détaillée - de Blau dans notre texte, celles qui s'y trouvent suffisent largement pour que le texte soit considéré comme «moyen arabe». La grammaire de Blau est une compilation à partir de manuscrits d'origine melkite du $9^{\mathrm{e}}$ au $1^{\mathrm{e}} \mathrm{s}$; ; l'accumulation de phénomènes linguistiques communs pourraient venir confirmer qu'il s'agit du milieu de production de la traduction de 1 Corinthiens dans le VA 13. Ces éléments linguistiques restent toutefois des arguments de peu de poids, étant donné que le moyen arabe, comme expliqué ci-dessus, est un phénomène des plus diachroniques.

\section{$3 \quad$ Affinités textuelles}

Comme nous l'avons vu dans l'état de la recherche au chapitre 6, point 2 qu'à l'exception du dernier article de Monferrer-Sala, les lettres de Paul étaient considérées par les chercheurs comme étant traduites à partir d'un texte grec. Toutefois, l'analyse verset par verset de 1 Corinthiens (point 1) montre que la traduction se base sur un texte grec et sur la Peshitta, au minimum. Nous proposons ici une synthèse des observations sur les affinités textuelles ${ }^{211}$.

\subsection{Comparaison avec Sin. Ar. 151 et Sin. Ar. 155}

Dans l'introduction du chapitre 6, nous expliquons notre choix d'éditer un manuscrit unique. S’il ne s'agit pas de la motivation principale, nous avançons

210 Même remarque qu’à la note précédente.

211 Pour les détails des versets repris dans ce chapitre, nous invitons le lecteur à se reporter au point 1 Commentaire verset par verset. 
qu'il est possible que que VA 13 soit seul représentant de son groupe. Plusieurs chercheurs considèrent que cela est le cas pour les évangiles ${ }^{212}$; Graf n'associe pas non plus de manuscrits à la partie paulinienne ${ }^{213}$. Si nous comparons 1 Corinthiens dans VA 13 aux éditions de manuscrits existantes, il est clair que le texte de 1 Corinthiens dans VA 13 ne s'apparente ni au texte de SA 151, qui est traduit du syriaque ${ }^{214}$, ni au texte de SA 155 , qui est traduit du grec ${ }^{215}$. Nous reproduisons ici trois passages ${ }^{216}$ :

\section{Co 1,22}

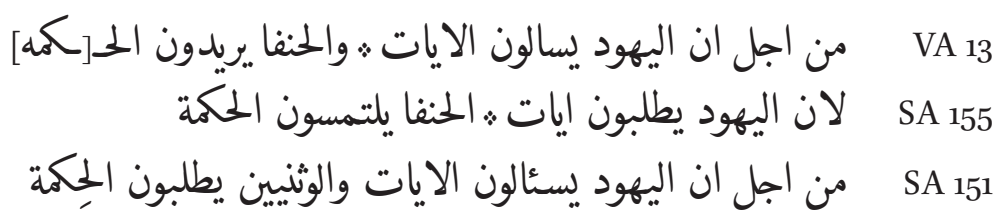

212 Pour Kashouh: " The text of family $h$ survives in a single codex: Codex Vatican, Ar. 13 » (Kashoun, The Arabic Versions of the Gospels, The Manuscripts and their Families, op. cit., 2012, p. 142.) De même, pour Monferrer-Sala : « This translation is clearly an independent text, differing from other South Palestinian Arabic translations. » (MONFERRER-SALA, «An Early Fragmentary Christian Palestinian Rendition of the Gospels into Arabic from Mar Saba (MS Vat. Ar. 13, 9th c.) », art. cit., 2013, p. 95).

213 Graf ne lui associe pas d'autres manuscrits (GRAF Georg, Geschichte der christlichen arabischen Literatur, vol. 1, Rome, Biblioteca Apostolica Vaticana, 1944 (Studi e Testi 118), pp. 140, 150, 171.) Dans son article sur Philémon dans VA 13, Monferrer-Sala propose à la fin le texte de VA 13, de SA 151 et de l'édition de Watts (Kitāb al- 'Ahd al-Jadìd, ya'nī Injül al-Muqaddas li-Rabbinā Yasū'al-Masĭh, Londres, 1820) en synopse, et conclut: « Suffice it to say that the three Arabic versions exhibit different translations». MONFERRER-SALA, « The Pauline Epistle to Philemon from Codex Vatican Arabic 13 (Ninth Century CE):Transcription and Study », art. cit., 2015, p. 369.

214 Staal Harvey, Mt. Sinai Arabic Codex 151 I: The Pauline Epistles, vol. 2, Louvain, Peeters, 1983 (CSCO 453), p. vII.

215 Gibson, An Arabic Version of the Epistles of St Paul to the Romans, Corinthians, Galatians with Part of the Epistles to the Ephesians, op. cit., 1894, p. 7.

216 Pour comparaison également, voici les trois versets dans l'édition de Thomas Erpenius:

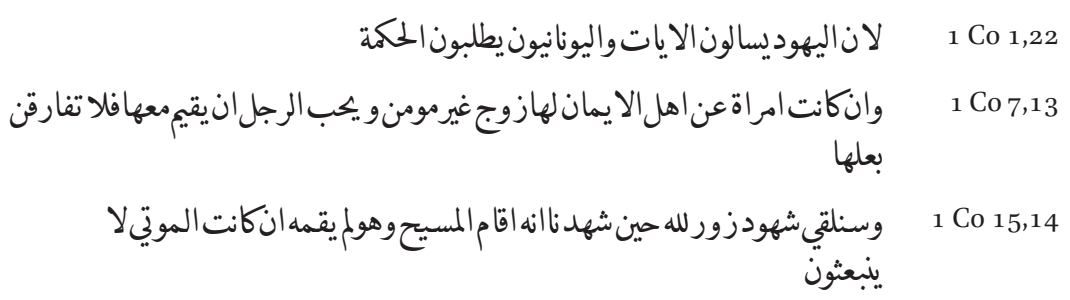


La structure diffère peu entre les trois versions. Au niveau du vocabulaire, si SA 155 utilise aussi le terme الحنفا pour les païens ${ }^{217}$, les verbes utilisés sont différents. SA 151 a comme VA 13 le verbe سمونغألون, mais utilise ensuite un verbe

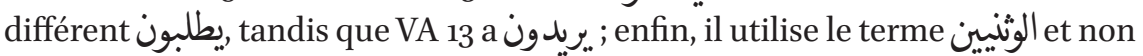
الحنفا

$1 \mathrm{Co} 7,13$

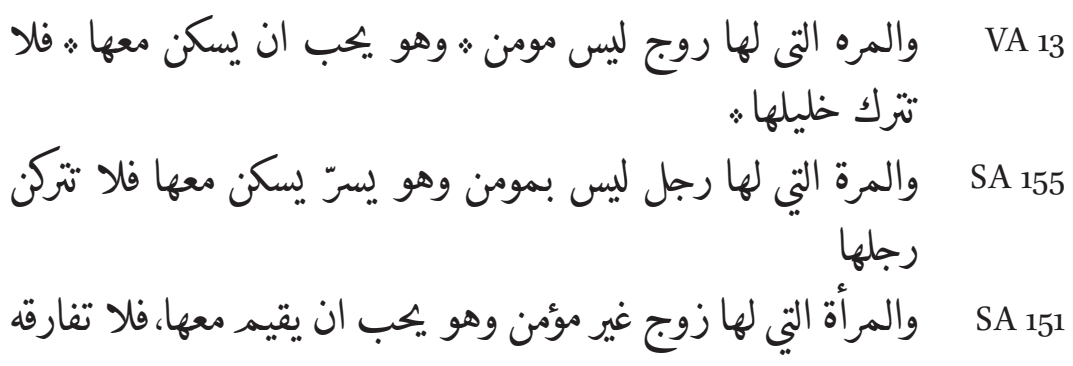

والمره Les débuts des membres du verset sont exprimés de manière identique mais la suite est formulée différemment d'une version à l'autre et VA 13 est le seul à utiliser le terme خليل (voir notre remarque sur 7,3 dans le commentaire au point 1 ).

\section{Co 15,15}

$$
\begin{aligned}
& \text { VA } 13
\end{aligned}
$$

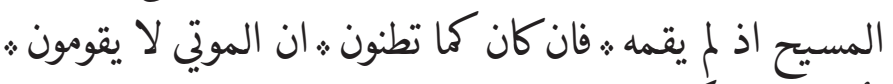

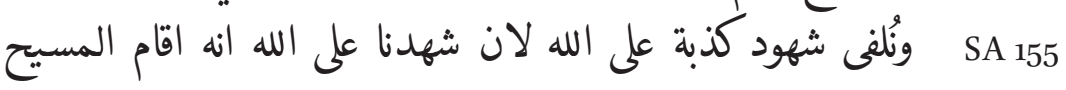

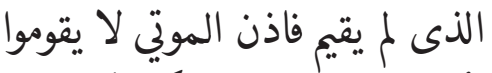

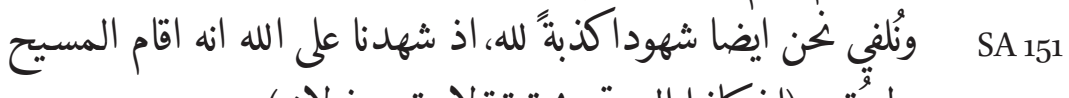

$$
\begin{aligned}
& \text { ولم يقّمه (ان كانوا المونى بحقيقة لا يقومون لانه) }
\end{aligned}
$$

SA 151 et SA 155 ont en début de verset le verbe وزنى ونُون la suite, le vocabulaire utilisé est similaire et les différences sont minimes. À

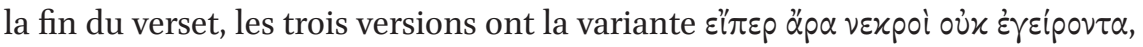
mais celle-ci est exprimée différemment. En VA 13, on trouve, traduisant

217 Voir chapitre 9, point 2 Qui sont les hụuafa' dans 1 Corinthiens? 
certainement äpa, l'incise تطنون. En SA 151, la variante est notée dans un

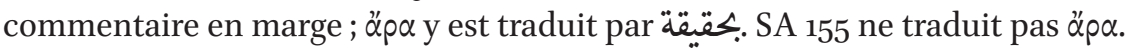

Une comparaison montre que les trois manuscrits présentent des traductions indépendantes, les versions différant constamment les unes des autres, au niveau de la syntaxe, des variantes textuelles ou du vocabulaire choisi.

\subsection{Sources de la traduction de 1 Corinthiens dans Vat. Ar. 13}

Sur quel(s) texte(s) se base donc notre traduction, qui est différente de celle de SA 151 et SA 155 ? De manière générale, les syriacismes ou hellénismes au niveau de la grammaire ou du vocabulaire ne peuvent constituer des indices forts pour déterminer la base de la traduction. En effet, l'arabe peut contenir en soi des influences de l'une ou l'autre des langues sans pour autant en être la traduction directe. Nous avons discuté ces particularités linguistiques dans notre partie consacrée au moyen arabe (voir point 2.2). Pour tenter de déterminer le texte sur lequel se base le traducteur, nous portons une attention aux leçons particulières héritées du texte grec (dont nous tenterons de déterminer le type plus loin) et du texte de la Peshitta, ainsi qu'à la structure de certaines phrases qui, grâce à l'aspect littéral de la traduction, reflète les textes sources.

\subsubsection{Leçons propres à la Peshitta}

Contrairement à l'idée soutenue selon laquelle la traduction est d'origine grecque (voir chapitre 6, point 2), plusieurs leçons présentes dans le texte s'expliquent par une connaissance du texte de la Peshitta. Parmi les plus évidentes, nous pouvons relever 1 Co 5,11. Alors que le texte grec, tous témoins confondus, exhorte à ne pas manger avec le frère fornicateur, voleur, etc. $(\tau \hat{\omega} \tau 010$ í $\tau \omega$

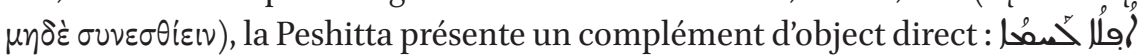

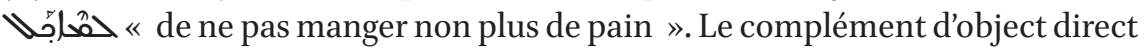
se retrouve dans la traduction de VA 13 : ولا خبز "تاكلون ايصا. VA 13 traduit également l'adverbe إيصا pabsent dans les témoins grecs. La leçon, propre à la Peshitta, semble faire référence à l'eucharistie, et sa présence dans VA 13 ne s'explique que par une influence de la Peshitta sur la traduction. Un autre exemple se trouve en 1 Co 11,11, où l'on trouve dans la Peshitta le membre du verset concernant la femme après celui concernant l'homme («pas de femme sans homme $/ /$ pas d'homme sans femme » $)^{218}$; un tel ordre se trouve aussi dans VA 13. Le verset 1 Co 16,22 offre aussi une leçon intéressante: on y trouve l'expression araméenne transcrite en grec $\mu \alpha p \alpha ́ v \alpha \theta \alpha$. Dans la Peshitta, l'expres-

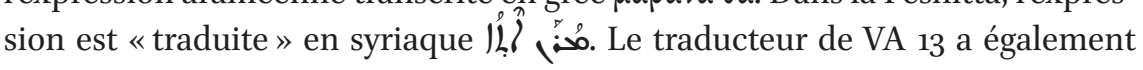

218 Ce même ordre se trouve également en sy $\mathrm{h}^{\mathrm{h}}$. À propos de sy ${ }^{\mathrm{h}}$, voir notre point 3.5. 
préféré traduire l'expression en arabe ربنا قد حا, plutôt que d'offrir une transcription du grec transcrivant de l'araméen $\mu \alpha p \alpha \dot{v} \alpha \theta$ á. Il nous semble probable que le choix de traduire cette expression, qui dans d'autres versions sera transmise telle quelle ${ }^{219}$, prend exemple sur la Peshitta.

Les exemples d'héritages de la Peshitta sont nombreux dans 1 Corinthiens ${ }^{220}$, ils le sont également dans Philémon ${ }^{221}$. On notera également l'influence du syriaque sur les noms propres et le vocabulaire (voir 4.1 Noms propres et 4.2 Vocabulaire d'emprunt).

\subsubsection{Leçons propres au texte grec}

Toutefois, à de nombreuses reprises, le texte du VA 13 ne suit pas les leçons particulières de la Peshitta. Par exemple, VA 13 a bien «dans une faiblesse » en 1 Co 2,3, correspondant à s̀v à $\sigma \theta \varepsilon v \varepsilon i \alpha$, élément de la phrase omis par la Peshitta. Cet exemple montre que le traducteur a bien connaissance du texte grec. Il y a plusieurs exemples démontrant que VA 13 ne suit pas systématiquement le texte de la Peshitta et que le texte grec lui est préféré. C'est le cas en 1

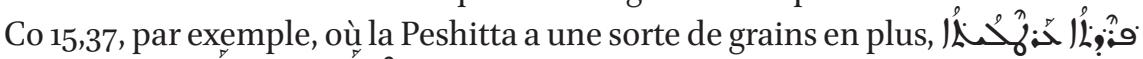

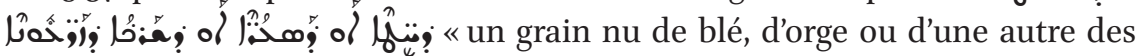
espèces », ce qui n'est pas suivi en VA 13.

\subsection{Une traduction à double Vorlagen}

Les exemples donnés ci-dessus illustrent l'influence certaine de la Peshitta sur la traduction mais montrent également que celle-ci s'en éloigne aussi à de nombreuses reprises. Cette configuration laisserait penser qu'il s'agit donc de corrections faites sur la Peshitta, soit par le traducteur lui-même, soit dans des étapes postérieures. Nous aimerions donc ici souligner que cette influence syriaque nous semble dépasser les simples corrections occasionnelles.

De manière générale, le texte reflète une technique de traduction littérale, sans être pour autant servile (voir aussi 5.1 Peut-on parler d'une «traduction calque»? $)^{222}$. Le traducteur suit le texte d'origine, alternativement le syriaque ou le grec, en respectant la structure et le nombre de mots utilisés, tout en essayant de respecter les conditions de la langue arabe. Les quelques exemples suivants montrent combien le texte est fidèle au texte grec:

\footnotetext{
219 C'est le cas dans les traditions latine et coptes. De même, SA 151 et SA 155 ont الثان.

220 Voir aussi les exemples, non exhaustifs : 1 Co 1,11;1,27; 2,1; 4,3; 7,14; 10,7; 14,28; ;6,22.

221 Monferrer-Sala, «The Pauline Epistle to Philemon from Codex Vatican Arabic 13 (Ninth Century CE): Transcription and Study », art. cit., 2015. Par ex. p. 356, l. 3 ; p. 356, l. 4 ; p. 359, l. 12.

222 Ibid., p. $35^{2}$.
} 


\section{Co 8,6}

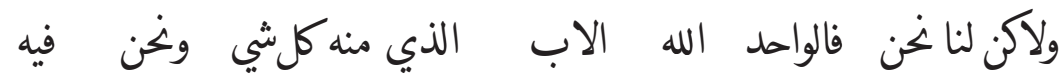

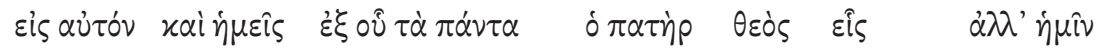

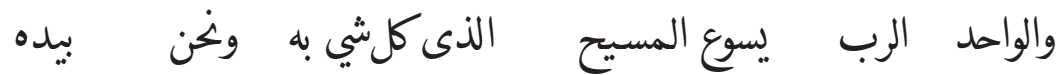

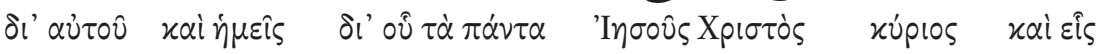
Voici pour comparaison le texte de la Peshitta:

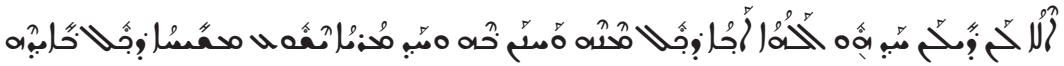

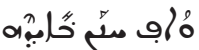

1 Co 15,1-2

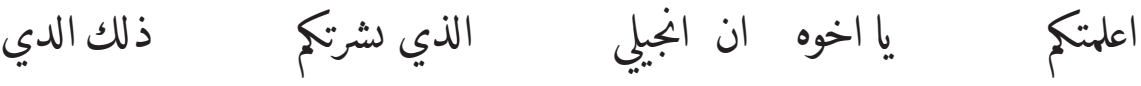

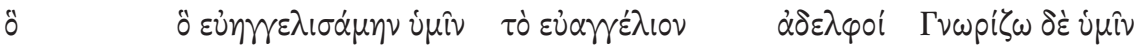

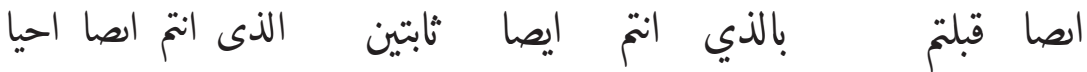

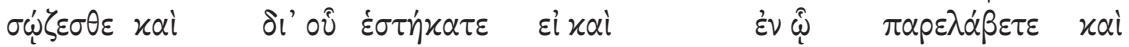

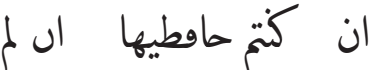

$$
\begin{aligned}
& \text { فناي كله بشرتم }
\end{aligned}
$$

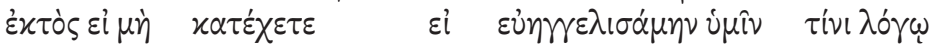

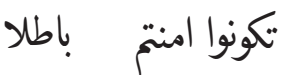

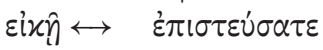

Pour comparaison :

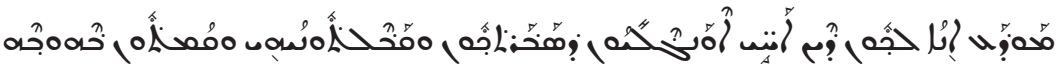

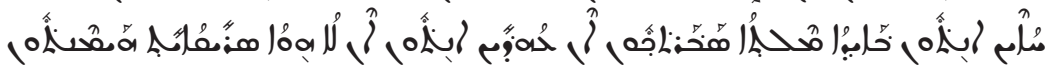

Voir aussi : 1 Co 1,$2 ; 3,2-5 ; 3,8 ; 5,3-4 ; 6,19 ; 11,17 ; 11,24 ; 12,28 ; 14,9 ; 14,38 ; 15,3$; 15,$33 ; 15,34 ; 15,58$.

De même, les exemples suivants montrent que le traducteur applique à d'autres endroits la même méthode en partant du syriaque. 


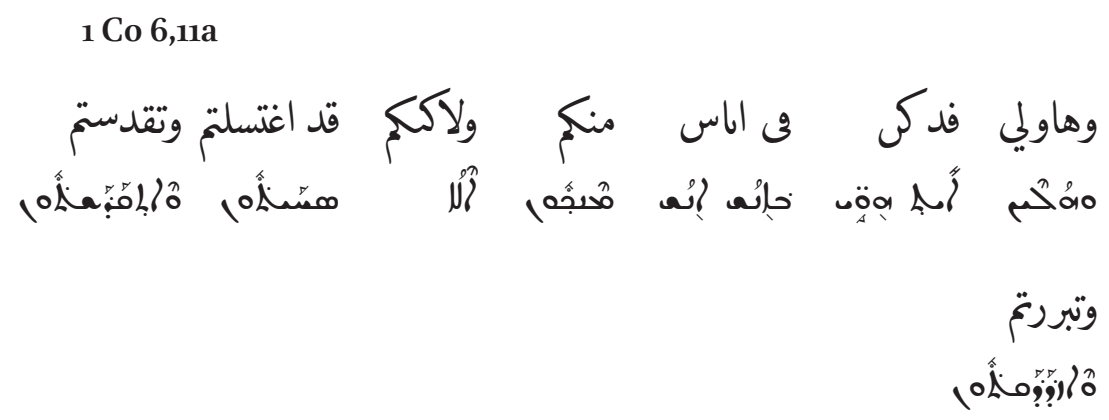

Pour comparaison :

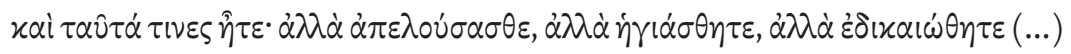

1 Co 14,27b

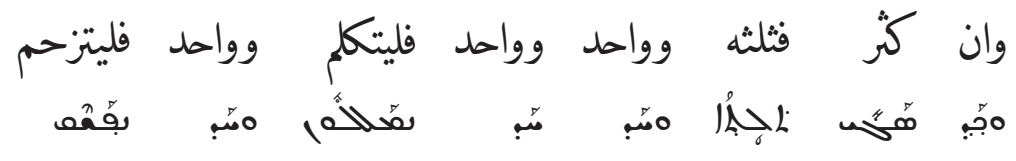

Pour comparaison :

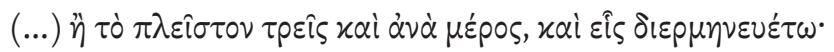

Voir aussi : 1,$10 ; 1,26 ; 2,12 ; 3,14-15 ; 3,18-19 ; 4,21 ; 5,12 ; 11,23 ; 13,1 ; 13,8 ; 16,17$.

Nous observons que le traducteur applique une traduction littérale au texte de la Peshitta à de nombreuses reprises ; cela nous semble refléter un travail de traduction avec ce texte, et pas seulement des corrections postérieures.

Nous suggérons donc que le traducteur travaille avec les deux textes. Plus encore : il ne travaille pas en alternance, traduisant certains passages du grec et certains passages de la Peshitta, mais travaille avec les deux textes en parallèle. C'est en tout cas ce que semble montrer le fait que, dans certains cas, le traducteur semble, au sein d'une même phrase ou d'un même ensemble de phrases, passer d'une langue d'origine à une autre. 
Ainsi, au verset 1 Co 5,10, certains éléments semblent suivre le grec (marqué en bleu) et d'autres suivre la Peshitta (marqué en rouge):

$$
\begin{aligned}
& \text { لست اقول مع رناه هذا العالم ثاو مع الحلاسين ثاو مع الحاطفين ثاو مع عابدي }
\end{aligned}
$$

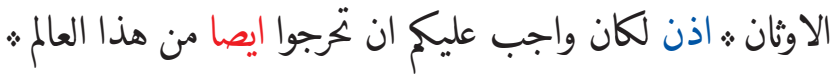

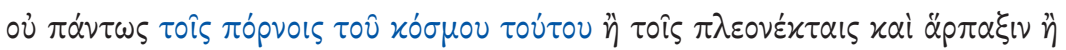

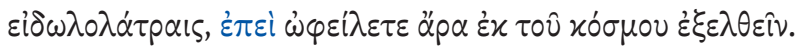

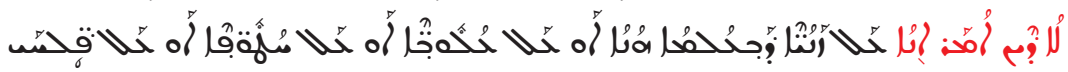

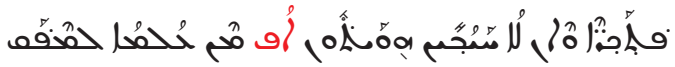

De même, en 1 Co 15,3-4, VA 13 suit, pour la même expression, le texte grec puis le texte de la Peshitta:

$$
\begin{aligned}
& \text { لاني بحق دفعت اليكم ثوفي البادي الدى ايصا قبلت ء ان المسيح مات من اجل }
\end{aligned}
$$

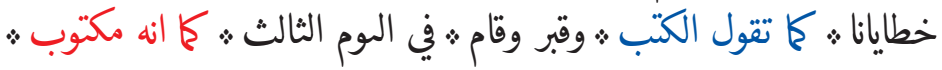

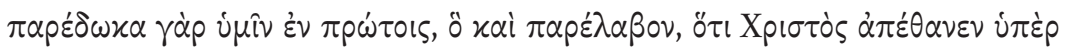

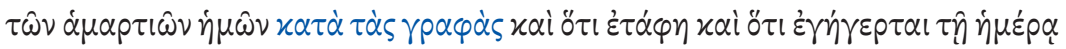

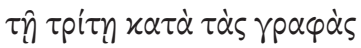

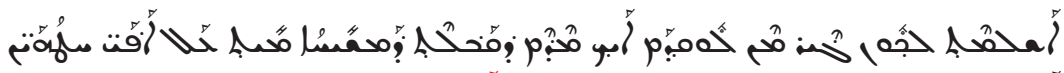

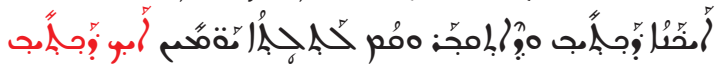

Voir aussi : 4,6; 5,9; 14,27.

Ces quelques exemples mettent en évidence une forte dépendance envers les deux textes, illustrant un processus de traduction puisant à la fois dans un texte grec et dans le texte de la Peshitta.

\subsection{Vorlage grecque}

Nous avons pu voir, à l'aide des exemples ci-dessus, que la Vorlage syriaque est le texte de la Peshitta (à propos de la version harkléenne, voir 3.5. Autres influences textuelles?). Qu'en est-il du texte grec ? Le type de texte grec que le traducteur a utilisé est difficile à déterminer, principalement à cause de l'influence de la Peshitta. Par exemple, en 1 Co 2,1, VA 13 a : ابشرك سراير اله «ous annoncez les secrets de Dieu » Il existe ici une variante: quelques témoins

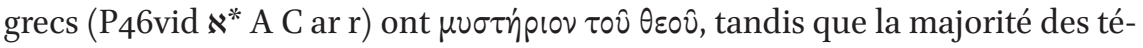

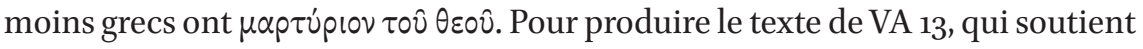


la variante minoritaire, le traducteur s'est-il basé sur un texte grec avec la variante $\mu \nu \sigma \tau$ ńpıv, ou s'est-il ici basé sur le texte de la Peshitta, qui soutient aussi

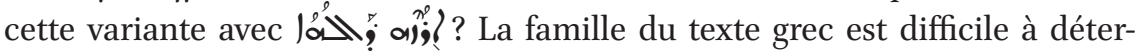
miner, car dans ce cas comme dans d'autres, il n'est pas possible de savoir si les leçons présentes dans VA 13 sont héritées du texte grec ou de la Peshitta. Afin de pallier cette difficulté, nous nous concentrons sur les variantes qui ne peuvent pas être d'«influence Peshitta», la Peshitta présentant clairement un texte différent. Par exemple, en 1 Co 1,15, VA 13 a a فن افلو ومن بولوس Car qui est Apollos et qui est Paul? ». L'ordre de la phrase correspond à une leçon minori-

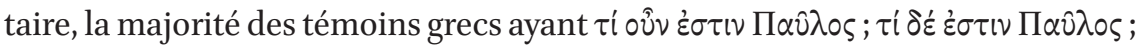
'A $\pi 0 \lambda \lambda \hat{\omega}$; ; Le texte de VA 13 ne se base pas ici sur la Peshitta, puisque celle-ci a محنَ, mais se base, selon toute vraisemblance, sur un

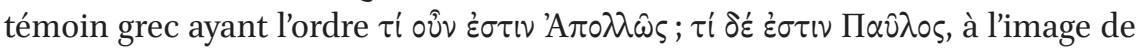
P46vid « A B C D*.2 F G P 048 ${ }^{\text {vid. } 0289.33 . ~ 81 . ~ 629 . ~ 630 . ~ 1175 . ~ 1506 . ~ 1739 . ~ 1881223 . ~}$ Les leçons de VA 13 non soutenues par la Peshitta et présentes dans des témoins grecs sont les suivantes:

\begin{tabular}{|c|c|c|c|}
\hline & Vat. Ar. 13 & Témoins $^{\mathrm{a}}$ & NA2 \\
\hline 1,2 & 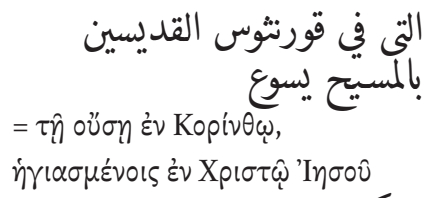 & $\begin{array}{l}\mathrm{P} 61^{\text {vid }} \aleph \mathrm{AD}^{1} \mathrm{LP} \Psi 33.81 .104 . \\
365 \cdot 630.1175 \cdot 1241.15^{0} 5 . \\
15^{\circ} 6.1739 \cdot 1881.2464 \mathrm{M} \text { lat } \\
\text { co sy }\end{array}$ & $\checkmark$ \\
\hline 1,14 & $=\varepsilon \dot{x} \alpha \alpha \rho$ اشك & 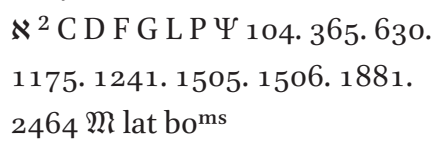 & {$[\sqrt{ }]$} \\
\hline 1,15 & $=\dot{\varepsilon} \beta \alpha \pi \tau i \sigma \theta \eta \tau \varepsilon$ & $\begin{array}{l}\mathrm{P} 46 \text { « А В C* } 6 \cdot 33 \cdot 81 \cdot 365 \cdot \\
630.1175 \cdot 15^{\circ} 6 \cdot 1739 \cdot f^{*} v g \\
\text { symg co }\end{array}$ & $\checkmark$ \\
\hline 1,23 & الشثعوب؟ & $\begin{array}{l}\text { א A B C* D* F G L P } 433.81 . \\
104.1175 .1241 .2464 . \text { latt co }\end{array}$ & $\checkmark$ \\
\hline $3,1 \cdot 3$ & 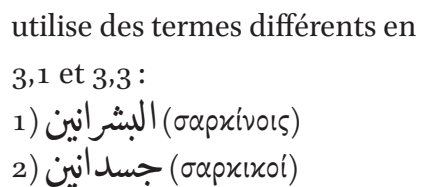 & $\begin{array}{l}\mathrm{P}_{4} 6 \text { א } \mathrm{AB} \mathrm{C} \mathrm{C}^{*} \text { o289. 6.33.945. } \\
1175 \cdot 1739\end{array}$ & $\checkmark$ \\
\hline
\end{tabular}

223 C'est aussi le cas dans la Vulgate et dans les versions coptes (HORNER). 
TABLE (cont.)

\begin{tabular}{|c|c|c|c|}
\hline & Vat. Ar. 13 & Témoins ${ }^{\mathrm{a}}$ & $\mathrm{NA}_{2} 8^{\mathrm{b}}$ \\
\hline 3,5 & 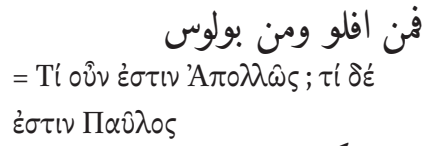 & 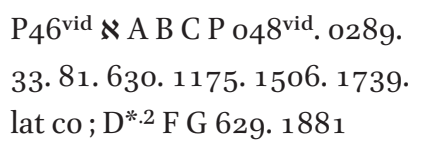 & $\checkmark$ \\
\hline 6,19 & $=\tau \dot{\alpha} \sigma \omega^{\prime} \mu \alpha \tau \alpha \dot{v} \mu \omega \nu$ & $\begin{array}{l}\mathrm{A}^{\mathrm{c}} \mathrm{L} \Psi 33 \cdot 81 \cdot 104 \cdot 365 \cdot 1175 \\
1505 \cdot 1881.2464 \cdot p m \mathrm{sy}^{\mathrm{h}} \text { bo }\end{array}$ & $x$ \\
\hline 7,3 & ما يكق عليه & $\begin{array}{l}\text { P11.46 א A B C D F G P Ч } 6 . \\
33.81 .630 .1175 \cdot 1881.2464 . \\
\text { latt co }\end{array}$ & $\checkmark$ \\
\hline 7,7 & deest róp & $\begin{array}{l}\mathrm{P}_{4} 6 \aleph^{*} \text { A C D F G } 33.81 \cdot 326 . \\
629.2464 . \text { it vg }^{\text {st }}\end{array}$ & $\checkmark$ \\
\hline $7,17 \mathrm{a}$ & = & $\begin{array}{l}\text { K L } \Psi 629 \cdot 630.1241 \cdot 1505 \cdot \mathfrak{M} \\
\operatorname{vg}^{\mathrm{mss}} \mathrm{sy}^{\mathrm{h}}\end{array}$ & $x$ \\
\hline $7,17 \mathrm{~b}$ & كما دعاه الربن & K L 630. 1241. 1505. M syh & $x$ \\
\hline 8,2 & deest oủठદ́v & 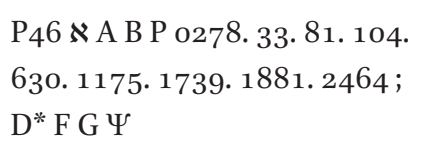 & $\checkmark$ \\
\hline 9,1 & النا حت انا رسول املست & 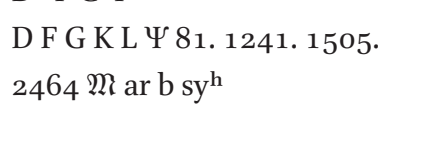 & $x$ \\
\hline 9,20 & 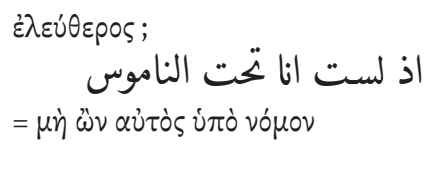 & $\begin{array}{l}\text { N A B C D* F G P } 33 \cdot 104 \cdot 365 \\
630.1175 \cdot 1505 \cdot 1739 \cdot \text { latt } \\
\text { sy }{ }^{\text {h }} \text { co }\end{array}$ & $\checkmark$ \\
\hline 9,23 & $=\pi \alpha^{\prime} \nu \tau \alpha$ & $\begin{array}{l}\text { P46 א A B C D F G P 6. 33. } 81 . \\
\text { 104. 365. 630. 1175. 1739. } \\
\text { 1881. 2464. latt }\end{array}$ & $\checkmark$ \\
\hline 10,4 & $=\tau \varepsilon \dot{\varepsilon} \sigma \sigma \alpha \rho \varepsilon \varsigma$ & $81.1175 \cdot v^{m s s} s y^{h}$ & $x$ \\
\hline 10,11 & deest $\pi \alpha^{\prime} \nu \tau \alpha$ & $\begin{array}{l}\text { А В } 33 \cdot 630.1175 \cdot 1739 \cdot 1881 . \\
2464\end{array}$ & $\checkmark$ \\
\hline 10,24 & deest $\tilde{\varepsilon} \varkappa \alpha \sigma \tau \circ \varsigma$ & $\begin{array}{l}\mathrm{P}_{46} \text { « A B C D* F G H P 6. } 33 . \\
81.630 .1175 .1241 .1739 . \\
1881.2464 . \text { latt co }\end{array}$ & $\checkmark$ \\
\hline 11,14 & $=\ddot{\eta}$ & $\begin{array}{l}\mathrm{D}^{1} \mathrm{KL} 104 \cdot 3^{65} \cdot 1505 \cdot \mathfrak{M} \\
\text { symg sa }\end{array}$ & $x$ \\
\hline
\end{tabular}


TABLE (cont.)

\begin{tabular}{|c|c|c|c|}
\hline & Vat. Ar. 13 & Témoins $^{\mathrm{a}}$ & $\mathrm{NA2} 8^{\mathrm{b}}$ \\
\hline 11,24 & deest $\lambda \alpha \dot{\beta} \beta \varepsilon \tau \varepsilon \varphi \alpha_{\gamma} \varepsilon \tau \varepsilon$ & $\begin{array}{l}\mathrm{P} 46 \text { N A B C* D F G o 199. } 6 . \\
33.81^{*} \cdot 104.630 .1175 \cdot 1241 . \\
\text { 1739. } 1881.2464 \text { it vg }{ }^{\text {st }} \text { co }\end{array}$ & $\sqrt{ }$ \\
\hline 11,27 & كالjي لا يرضا الربن & א D L $326.1505 \mathrm{sy}^{\mathrm{h}}$ & $x$ \\
\hline 12,9 & $=\delta \dot{\varepsilon}$ & 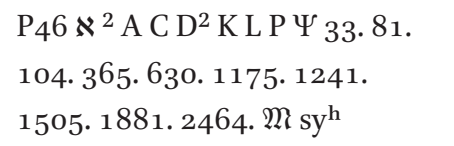 & $x$ \\
\hline 12,10 & 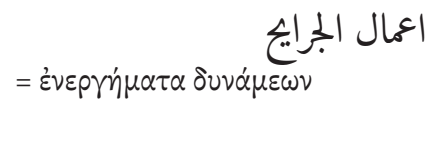 & 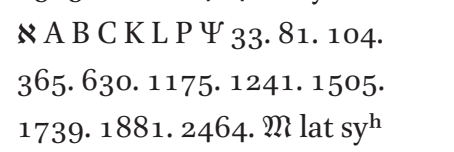 & $\checkmark$ \\
\hline 12,11 & على حده & $\begin{array}{l}\text { א A B C D K L P Y } 33.81 .104 . \\
365 \cdot 630.1175 \cdot 1241.1505 \\
1739 \cdot 1881.2464 \mathrm{M} \mathrm{sy}^{\mathrm{h}}\end{array}$ & $\checkmark$ \\
\hline 12,13 & $=\pi \dot{\mu} \mu \alpha$ & $630.1505 \cdot 1881 . \mathrm{sy}^{\mathrm{h}}$ & $x$ \\
\hline 13,4 & deest $\dot{\eta} \dot{\alpha} \gamma \dot{\alpha} \pi \eta$ (ter) & $\begin{array}{l}33 \cdot 104 \cdot 629 \cdot 1175 \cdot 2464 \text { lat sa } \\
\text { bo }^{\mathrm{ms}}\end{array}$ & $x$ \\
\hline 13,12 & 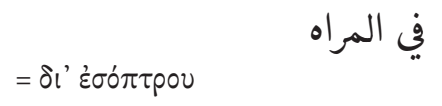 & $\begin{array}{l}\mathrm{P} 46 \text { א A B F G H I K Y 048. } 104 . \\
365.1241 .1505 \text { M }\end{array}$ & $\checkmark$ \\
\hline 14,10 & deest $\alpha \dot{v} \tau \hat{\omega} \nu$ & $\begin{array}{l}\text { P46 } \aleph^{*} \text { A B D* F G P o48vid. } \\
\text { o243. o289. 6. 33. } 81 \cdot 365 \\
\text { 1175.1241. 1739.1881.2464. } \\
\text { b vg co }\end{array}$ & $\checkmark$ \\
\hline 14,34 & deest $i \mu \omega \hat{\omega}$ & 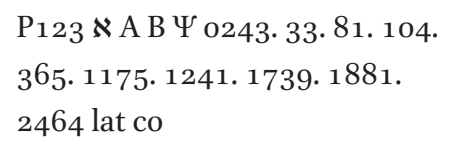 & $\checkmark$ \\
\hline 15,5 & $=\varepsilon " v \delta \varepsilon \kappa \alpha$ & $\mathrm{D}^{*}$ F G latt sy ${ }^{\mathrm{hmg}}$ & $x$ \\
\hline 15,20 & 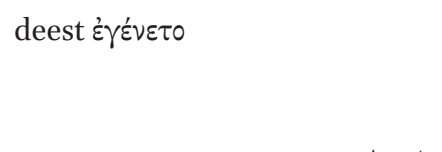 & $\begin{array}{l}\mathrm{P} 46 \text { א A B D* F G P o243. 6. } 33 . \\
81.365 \cdot 630.1175 \cdot 1241.1739 \\
1881.2464 \text { latt co }\end{array}$ & $\checkmark$ \\
\hline 15,28 & $=x \alpha i$ & $\begin{array}{l}\aleph \mathrm{A} \mathrm{D}^{2} \mathrm{KLP} \Psi 81.104 \cdot 365 \\
630.1241 .1505 \cdot 2464 \mathrm{M} \text { ar f r } \\
\operatorname{vg}^{\mathrm{cl}} \mathrm{sy}^{\mathrm{h}} \text { bo }\end{array}$ & {$[\boldsymbol{V}]$} \\
\hline
\end{tabular}


TABLE (cont.)

\begin{tabular}{|c|c|c|c|}
\hline & Vat. Ar. 13 & Témoins $^{\mathrm{a}}$ & $\mathrm{NA} 28^{\mathrm{b}}$ \\
\hline 15,55 & 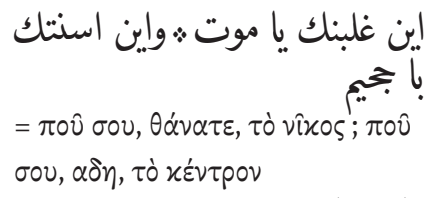 & $\begin{array}{l}0121.0243 \cdot 33.81 .326 .1175 \\
1241.1739^{\mathrm{c}} \cdot 2464\end{array}$ & $x$ \\
\hline 16,10 & انا إيصا & 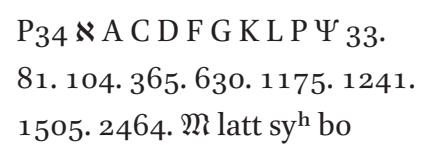 & $\checkmark$ \\
\hline 16,15 & اسطفانا وفرطونطوس & $\begin{array}{l}\aleph^{2} \mathrm{D} 104.629 .1175 \cdot 1241 . \\
2464 \mathrm{~b} \mathrm{vg}^{\text {st }} \text { bo }\end{array}$ & $\times$ \\
\hline 16,24 & امين & 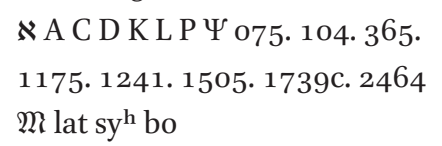 & $\times$ \\
\hline
\end{tabular}

a Comme au point 1 , nous continuons d'utiliser le système d'abréviation et d'identification du $\mathrm{NA} 28$.

b $\checkmark$ signifie que VA 13 soutient la variante retenue dans le texte $\mathrm{NA}_{2} 8 ; \times$ souligne quand VA 13 ne suit pas NA28.

Voici quelques observations :

1) Une première observation possible à partir des variantes proposées est qu'elles ne reflètent pas un texte grec byzantin, ne s'accordant qu'à $36 \%$ avec le texte byzantin (ou majoritaire $\mathfrak{M})^{224}$. Le texte de VA 13, lorsqu'il suit le texte grec, reflète un «meilleur» témoin qui se situerait davantage dans la catégorie I des Aland ${ }^{225}$ Parmi les grands onciaux, il se rapproche du codex Sinaïticus (61\%) et du codex Alexandrinus (64\%), deux représentants du type de texte alexandrin.

2) C'est avec le minuscule GA 1175 que le texte a le plus de leçons en commun $(72,2 \%)$. GA 1175 est un témoin grec important pour les lettres de

224 Nous donnons ici le pourcentage de leçons concordantes sur les 36 variantes sélectionnées. Pour voir les résultats en fonction des autres témoins, voir le tableau en annexe, Annexe : Tableau des leçons de 1 Corinthiens.

225 "Category $I$ : Manuscripts of very special quality which should always be considered in establishing the original text (e.g., the Alexandrian text belongs here ). [...] », ALAND Kurt et Aland Barbara, The Text of the New Testament: An Introduction to the Critical Editions and to the Theory and Practice of Modern Textual Criticism, $2^{\mathrm{e}}$ édition, Grand Rapids, Eerdmans Publishing Co., 1995 (Studies and Documents 46), p. 159. 
Paul qui est classé dans la catégorie I des Aland ${ }^{226}$. Le manuscrit date du $10^{\mathrm{e}} \mathrm{s.27}$ et se trouve au monastère orthodoxe Saint-Jean à Patmos. Les similarités entre les deux textes ne sont pas improbables: les deux se baseraient, GA 1175 par le biais de la copie, VA 13 par celui de la traduction et de la copie, sur un texte grec en circulation dans un milieu byzantin avant le $10^{\mathrm{e}} \mathrm{S}$. Si nous ne pouvons évidemment pas en conclure qu'il s'agit du même texte, cela vient appuyer l'hypothèse de l'origine byzantine de la traduction du VA 13.

3) Nous remarquerons également que les fragments de l'oncial $0289^{228}$ ne présentent que des leçons ${ }^{229}$ qui concordent avec la base grecque de la traduction du VA 13. Le manuscrit étant très fragmentaire, nous ne pouvons tirer de conclusion certaine, mais celui-ci nous dirige vers le milieu d'origine probable de notre manuscrit, vu qu'il s'agit de l'une des nouvelles découvertes du Sinaï et que l'INTF le date du $8^{\mathrm{e}}$ ou $9^{\mathrm{e}} \mathrm{s}$.

Il est clair que ces résultats sont à prendre avec précaution, la sélection de certaines variantes - celles qui s'éloignent du texte de la Peshitta -, présentant un biais certain. Toutefois, nous pouvons affirmer que le texte de VA 13 présente une qualité textuelle inattendue dans la perspective de la critique textuelle du Nouveau Testament privilégiant un texte alexandrin, comme dans le cas du NA28. Les variantes étudiées correspondent ainsi à $61,1 \%$ au texte édité du Nestle-Aland. Cette conclusion est intéressante au vu de la mise à l'écart des

226 Ibid., p. 134. Voir aussi plate 44, p. 151: « The minuscule 1175 [...] is significant for the history of the text »; l'appartenance au groupe alexandrin est discutée. RicHARD W. Larry, « Gregory 1175 : Alexandrian or Byzantine in the Catholic Epistles?», Andrews University Seminary Studies 21, 1983, pp. 155-168. Robert B. Waltz note: « Aland and Aland in the first edition of The Text of the New Testament listed it as Category II ; despite its Byzantine mixture, the second edition lists it as Category I. My opinion inclines towards their earlier assessment [...] », The Encyclopedia of New Testament Textual Criticism, <https:// www.free-ebooks.net/ebook/The-Encyclopedia-of-New-Testament-Textual-Criticism>, 2013, p. 126, consulté le 07.04.2016; nous regrettons le manque de littérature scientifique récente sur le sujet.

227 Le manuel des Aland le date du $11^{\mathrm{e}}$ s., Aland et Aland, The Text of the New Testament: An Introduction to the Critical Editions and to the Theory and Practice of Modern Textual Criticism, op. cit., 1995, p. 134. Cette datation a été remontée par l'INTF; elle est soutenue par le CSNTM, <http://www.csntm.org/Manuscript/View/GA_1175>, consulté le 07.04.2016.

228 ALAND Barbara, «Die neuen neutestamentlichen Handschriften vom Sinai », in : Bericht der Hermann-Kunst-Stiftung zur Förderung der neutestamentlichen Textforschung (19821984), Münster, Hermann-Kunst-Stiftung zur Förderung der neutestamentlichen Textforschung, 1985, pp. 76-89.

229 Trois leçons (1 Co 3,1.3 ; 3,5; 14,10), voir Annexe: Tableau des leçons de 1 Corinthiens. 
versions du Nouveau Testament comme étant des «traductions de traductions $»$ ou trop tardives ${ }^{230}$.

\subsection{Autres influences textuelles?}

On notera que dans deux cas, VA 13 a deux leçons très minoritaires. En 12,13, on trouve وكلا كاس واحد سربن et nous tous, nous avons bu à une seule coupe», ce qui correspond à la variante $\pi$ ó $\mu \alpha$, dont les autres témoins textuels sont 630 . 1505. 1881. syh. En 15,5, ارى لاحد عش عil fut montré aux onze », ce qui cor-

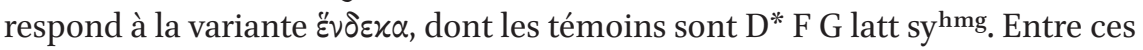
deux variantes, un point commun : $\mathrm{sy}^{\mathrm{h}}$, la version harkléenne. Peut-on en déduire que cette version syriaque a influencé la traduction? La variante en 15,5 pouvant s'expliquer par une harmonisation sur Mt 28,16 (SENFT, p. 188 ; NA28, p. 548), la variante en 12,13 nous semble insuffisante pour tirer des conclusions à ce propos. Une possible connaissance de $\mathrm{sy}^{\mathrm{h}}$ reste de manière générale particulièrement difficile à déterminer étant donné que sy ${ }^{\mathrm{h}}$ suit le texte grec de manière très littérale.

Dans son article sur Philémon dans VA 13, Monferrer-Sala mentionne dans sa conclusion la possible influence d'un texte araméen sur la traduction: «It is possible that an intermediate secondary Aramaic text served for revision purposes during the process of translating the Greek text into Arabic. $»^{231}$ Toutefois, les exemples donnés par Monferrer-Sala sont d'ordre orthographique ou lexical, et se retrouvent par ailleurs également souvent dans la Peshitta ${ }^{232}$. À notre avis, l'intervention d'un texte araméen n'est pas nécessaire pour expliquer l'influence araméenne. L'influence du texte de la Peshitta sur la traduction ainsi que, de manière générale, l'influence du dialecte araméen sur la langue arabe utilisée dans le milieu de production peuvent être des facteurs suffisants. Monferrer-Sala en est également conscient, lorsqu'il dit dans son introduction : «[...] the influence of the Aramaic dialectal milieu on Christian Arab translators from Greek may well raise rather than solve textual doubts. »233

\footnotetext{
230 Voir le chapitre 3: Du désintérêt à la redécouverte: Analyse d'un phénomène scientifique.

231 Monferrer-Sala, «The Pauline Epistle to Philemon from Codex Vatican Arabic 13 (Ninth Century CE): Transcription and Study », art. cit., 2015, p. 368.

232 Quelques exemples donnés par Monferrer-Sala: «Qiddīsin (11): most probably of Aramaic origin, especially of Christian provenance, cf. Syriac مبص (qadī̌s). »; Rabb (8, 10): this term used very widely in Aramaic inscriptions seems to come from Aramaic $(\mathrm{rab})$, specifically from Syriac $\mathbf{}$; (rab), from which it can be deduced that al-Rabb is a neologism in Christian Arabic texts. », Ibid., p. 351.

233 Ibid., p. 343.
} 
4.1.1 Paul

On trouve pour le nom Paul بولوس comme فول come on aurait pu s'y attendre au vu de la transcription 0 / ف que nous expliquons ci-dessous. SA 151 a فولوس et SA 155 a بولس. C'est بولس qui s'établira dans le vocabulaire chrétien (GRAF, Termini, pp. 26-27).

\subsubsection{Jésus}

On trouve dans notre texte l'orthographe يسوع pour Jésus, qui s'établira dans le vocabulaire chrétien (GRAF, Termini, p. 119). Une exception est le v. 6,11, où l'on trouve إسوع. Kashouh note les deux orthographes dans la partie du VA 13 contenant les évangiles ${ }^{234}$. SA 151 et SA 155 ont aussi سوع.

\subsubsection{Moïse}

Le nom propre Moïse apparaît deux fois en 1 Corinthiens. En 9,9, on trouve l'orthographe موسى موشى et en موسى 10,2 موسى (10,2) correspond à

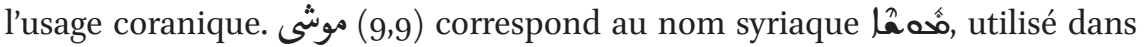
la Peshitta, à la prononciation chuintante. Nous pensons que la présence de l'orthographe coranique موسى vient de l'irrégularité dans la notation des points diacritiques (voir chapitre 6 , point 3.5 et chapitre 8 , point 2.2.1) et non de la prononciation.

\subsubsection{Jérusalem}

Et 16,3, on trouve l'orthographe وريسلم pour Jérusalem. Il s'agit d'une transcription du syriaque ${ }^{n} \mathbf{D}^{n}$; partie des évangiles du VA 13, comme le note Monferrer-Sala ${ }^{235}$.

\subsubsection{Pierre}

On trouve à quatre reprise le nom Pierre dans 1 Corinthiens $(1,11.12 ; 3,22 ; 9,5)$, orthographié الصفا (Kض) en syriaque). En traduisant par الصفا, le traducteur garde ici le sens araméen avec lequel jouait déjà le grec

234 Kashoun, The Arabic Versions of the Gospels, The Manuscripts and their Families, op. cit., 2012, p. 159. Voir Monferrer-Sala, qui pense que ces variations sont dues à des variations dans le texte syriaque, MonfErrer-SALA, « Translating the Gospels into Arabic from Syriac: Vatican Arabic 13 Restored Section, Strategies and Goals », art. cit., 2015, p. 449.

235 Monferrer-SAlA, «Translating the Gospels into Arabic from Syriac: Vatican Arabic 13 Restored Section, Strategies and Goals », art. cit., 2015, p. 442. 


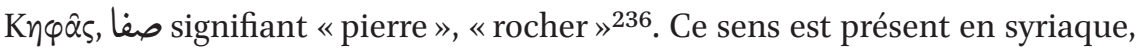
avec بُوَمُ (PAYNe SMith, p. 202). VA 13 a la particularité d'avoir un article défini, traitant ainsi li ص comme un nom commun, «la pierre ». Peut-être le traducteur veut-il souligner ici le sens porté par le prénom de Pierre?

4.1.6 Autres noms propres

\begin{tabular}{|c|c|c|c|}
\hline Versets & VA 13 & Texte grec & Peshitta \\
\hline 1,1 & سستانين & $\Sigma \omega \sigma \theta$ ह́ทท & مُمهمُ مُص \\
\hline & & & a مهملهم \\
\hline 1,2 & فن قورنثوس & ¿่v Kopivew & 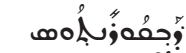 \\
\hline 1,11 & & $\mathrm{X} \lambda$ óns & 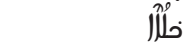 \\
\hline $1,12 / 3,4 / 16,12$ & افلو & 'A $\pi \circ \lambda \lambda \hat{\omega}$ & ; \\
\hline $3,5 / 3,6 / 3,22$ & افلو & 'A $\pi 0 \lambda \hat{\omega} \varsigma$ & اُُفُحْه \\
\hline 4,6 & افلو & 'A $\pi 0 \lambda \lambda \omega \nu$ & . بُ:ُْحه \\
\hline 1,14 & قرسقوس & 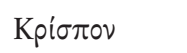 & 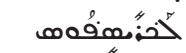 \\
\hline 1,14 & & Гáïov & 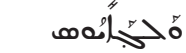 \\
\hline $1,16 / 16,15 / 16,17$ & فانا & $\Sigma \tau \varepsilon \varphi \alpha \nu \hat{\alpha}$ & ? \\
\hline 4,6 & ل & 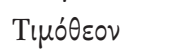 & 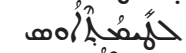 \\
\hline 16,10 & ي يُوس & 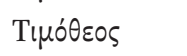 & డ \\
\hline 9,6 & & B $\alpha \rho v \alpha \beta \hat{\alpha} \varsigma$ & 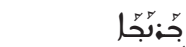 \\
\hline 10,18 & & 'I $\sigma \rho \alpha \eta \dot{\lambda} \lambda$ & لأرم:ُْح" \\
\hline 16,1 & عال & $\Gamma \alpha \lambda \alpha \tau^{i} \alpha \varsigma$ & ؛ \\
\hline $16,5^{\mathrm{a}}$ & المقيخويه & M $\alpha x \varepsilon \delta o v i \alpha \nu$ & 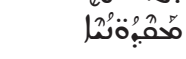 \\
\hline $16,5^{b}$ & المقتّوينه & 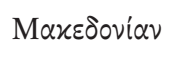 & 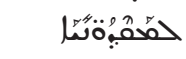 \\
\hline 16,15 & وزطونطوس & 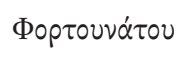 & - \\
\hline 16,17 & ورطونطوس & 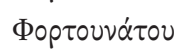 & 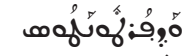 \\
\hline 16,17 & اجايقوس & 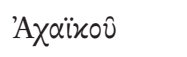 & 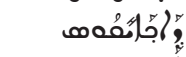 \\
\hline 16,19 & افلوس & 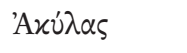 & أُحْحه \\
\hline 16,19 & ورلسقله & $\Pi p i \sigma x \mid \lambda \lambda \alpha$ & 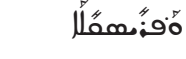 \\
\hline
\end{tabular}

a Il semble y avoir une variation dans l'orthographe syriaque. Aland propose pour syp

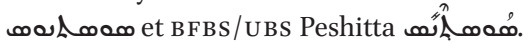

À cause de l'absence ou du décalage réguliers des points diacritiques, il est souvent difficile d'établir si les noms propres se basent sur leur version grecque ou leur version syriaque.

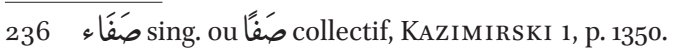


- On remarquera que les terminaisons correspondent toujours au syriaque, mais pas toujours au grec:

contre Bapvaßâs

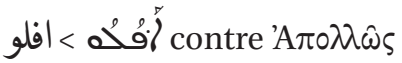

- Souvent, la transcription de certaines consonnes correspond au grec et au syriaque :
$b<\tau / \gamma$
(cf. طيماثيوس, اسطفانا, etc.)
$\omega<\sigma / \infty$
$\stackrel{ث}{*}<\theta /$ ?
$\ddot{\Theta}<x / 0$
(cf. طيماثيوس ,قورنثوس, etc.)

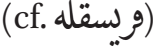

ainsi que d'autres consonnes plus évidentes comme $)<\rho / \dot{j}, \mathrm{~J}<\lambda /$, etc.

- Dans le cas de المقيذونيه, nous lisons bien un ذ en 16,5a. On peut se demander si le fait d'avoir ici une spirante signifie que la transcription se base sur le syriaque, qui a ici une spirante . Costaz note toutefois que la spirante e est la consonne utilisée en syriaque pour transcrire $\delta$; il est possible que cela soit le même phénomène ici (Costaz, Grammaire, § 863).

- Certaines consonnes sont problématiques. C'est le cas du $\dot{\tau}$ ou ج. En effet, dans le cas de خلواس en 1,11, il semblerait que la transcription soit la suivante :

\section{$\dot{\tau}<\chi / y$}

Or en 16,17, on trouve اجايقوس. Nous pensons qu'il s'agit ici d'une erreur dans le point diacritique et proposons de lire اخايقوس.

- Le cas de ف i est plus compliqué. Il semblerait que ف ف فون soit utilisé ainsi :

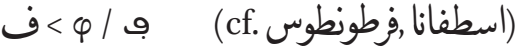

Mais ف est aussi utilisé dans ce cas :

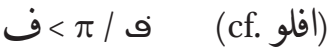

Premièrement, on aurait pu attendre بولو / بوس comme dans. Deuxièmement, cela est étonnant au niveau de la prononciation, $\pi$ et $\boldsymbol{\omega}$ étant des consonnes explosives et فn فn consonne spirante. Il semblerait qu'ici, فimite la graphie syriaque de $\mathbf{~}$ (la consonne $\boldsymbol{\omega}$ étant utilisée en syriaque pour transcrire $\pi$ ).

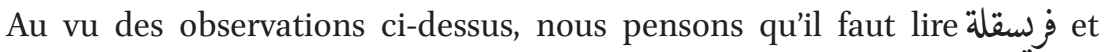
مقرسفوس.

- Enfin, nous pensons que c'est certainement $\dot{\xi}$ qui transcrit $\gamma$ et $\gg$ et propo-

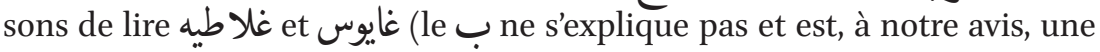
erreur de copie.

- Quant à سستنانين, il nous faut plutôt lire ici en début de mot - سستثا, si cette orthographe suit les règles de transcription mentionnées ci-dessus. Quant à la fin en ـ - elle reste difficile à expliquer. Faut-il corriger سستثان, qui serait plus proche de la terminaison du syriaque et du grec ? Cela reste ouvert. Comme pour la question de la Vorlage de notre texte, on voit que dans le cas des noms propres, on trouve une double influence grecque et syriaque. 


\subsection{Vocabulaire d'emprunt}

Que considérer comme du vocabulaire emprunté à une autre langue ? Dans son article sur Philémon dans VA 13, Monferrer-Sala fait une liste de «Loanwords and Neologisms » qui comprend des mots tels que : Injïl, Kanīsa, Masīh, etc. ${ }^{237}$ Il est évident que de nombreux mots arabes et syriaques ont un bagage araméen commun et que certains mots arabes viennent directement du syriaque. Cela concerne donc la langue arabe en général, voire l'arabe parlé par les chrétiens et non pas des éléments propres à notre texte. Par vocabulaire d'emprunt, nous désignons plutôt le vocabulaire transcrit directement depuis une autre langue pour les besoins du texte. Graf donne de nombreux exemples venant du syriaque, du grec ou du copte. Par exemple, le terme خولوجيون hūlūjiūn pour

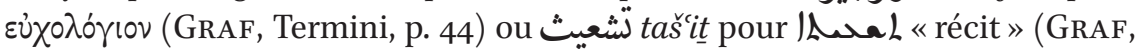
Termini, p. 30). Un exemple tiré de 1 Corinthiens est le traduction dans SA 155

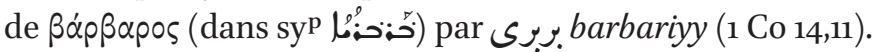

Le texte de 1 Corinthiens présente peu d'exemples de ce genre de vocabulaire d'emprunt. Il choisit par exemple جُمى 'ajamiyy (voir 14,11) plutôt que $\beta \alpha$ a $\beta \alpha$ pos. Par ailleurs, on trouve souvent un vocabulaire correspondant à la racine syriaque (par ex. 7,9), mais il s'agit à notre avis d'un phénomène qui peut être inhérent aux similitudes entre la langue syriaque et la langue arabe. Voici toutefois quelques cas où nous pensons que le terme est emprunté directement d'une autre langue, à savoir du syriaque, ou du moins qu'un détour par le syriaque est nécessaire pour comprendre ce choix de vocabulaire.

syriaque (= (9) fleischlich, körperlich (in der Inkarnationslehre). »(GRAF, Termini, p. $83^{238}$ ) Il s'agirait donc ici de «choses corporelles », une traduction de $\tau \dot{\alpha} \sigma \alpha p x i x \dot{\alpha}$. Cet emprunt est peut-être fait sur la Peshitta, qui a toute-

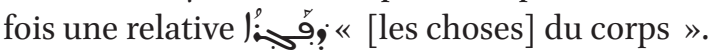

- امان amān (3,10). Nous expliquons en 3,10 nos difficultés à traduire مان là où on trouve en grec $\alpha \rho \chi \imath \varepsilon^{\prime} \chi \tau \omega \nu$. Nous pensons qu'il peut s'agir d'un emprunt

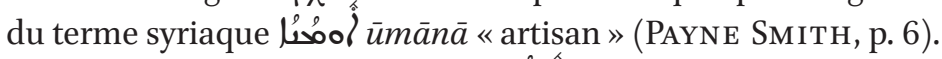

- فاثور fātūr (10,21) vient du syriaque la Peshitta à ce verset. Il est attesté par Graf (GRAF, Termini, p. 80); ce terme est resté dans le lexique arabe classique (KAZIMIRS KI 2, p. 542). S'agit-il ici d'un emprunt ou le terme était-il utilisé comme tel en arabe?

\footnotetext{
237 Monferrer-Sala, «The Pauline Epistle to Philemon from Codex Vatican Arabic 13 (Ninth Century CE): Transcription and Study », art. cit., 2015, pp. 350-351.

238 Il donne comme référence en note un passage d'Abū Qurra (f. 14v) dans Londres BL Or. 4950.
} 
Nous n'avons pas constaté de vocabulaire emprunté directement à d'autres langues, comme au grec, bien que le texte grec soit une des sources de la traduction, ou au copte ou au latin, ce qui aurait été plus inattendu.

\subsection{Vocabulaire religieux musulman ou coranique}

On trouve dans le texte plusieurs termes ayant une place importante dans le Coran et dans la littérature apparentée. Le vocabulaire religieux musulman a-til influencé la traduction? Voici les quelques cas à discuter.

\subsection{1 rasūl « envoyé »}

Il est intéressant de noter que le traducteur propose une traduction diffé-

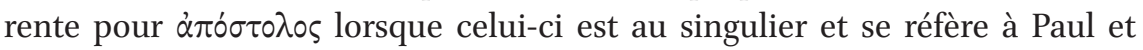

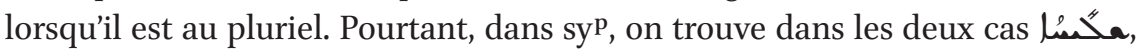

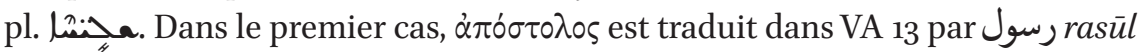

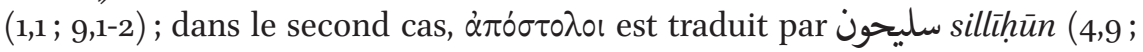
12,28-29; 15,7.9 (239. Là l'apôtre Paul et lui donne ainsi un rôle distinct. Ce titre, réservé à Paul dans notre texte, est un des titres les plus importants et les plus utilisés (plus de 200 fois) dans le Coran pour le Prophète Muhammad, celui d'« envoyé » rasūl, souvent précisé rasūl allāh «envoyé de Dieu» ${ }^{240}$. À quelques reprises, Jésus est également appelé rasūl $(3: 49.53 ; 4: 171 ; 5: 75 ; 61: 6)^{241}$. Les prophètes sont souvent désignés par le pluriel rusul, un titre qui semble plus important que celui de nabī. MonferrerSala dit à propos de rasūl, que l'on trouve aussi associé à Paul dans Philémon: "a neologism connected with Syriac arlị̂no, 'messenger; apostle'), a technical term in both Christian and Gnostic Aramaic literature, which is related to Qur'ānic rasūl from a theological viewpoint. ${ }^{242}$ L'utilisation du terme rasūl fait donc écho à son utilisation coranique à la fois littéralement et

239 Le terme سليحين fait partie du vocabulaire chrétien pour désigner les apôtres (BELOT, p. 334 ; GRAF, Termini, p. 61). Nous suivons l'orthographe proposé par Belot. Le terme vient du syriaque محنم: que l'on trouve notamment dans la Peshitta (voir notre remarque au point 1 en 4,9 ).

240 Rubin Uri, « Muhammad », in : Encyclopaedia of the Qur'ān, Washington, Brill Online, 2016. En ligne: $<\mathrm{http} / / /$ referenceworks.brillonline.com/entries/encyclopaedia-of-the-quran/ muhammad-EQCOM_00126>, consulté le 23.03.2016.

241 Rubin Uri, «Prophets and Prophethood », in : Encyclopaedia of the Qur'ān, Washington, Brill Online, 2016. En ligne : <http://referenceworks.brillonline.com/entries/encyclopae dia-of-the-quran/prophets-and-prophethood-EQCOM_oo160>, consulté le 23.03.2016.

242 Monferrer-Sala, «The Pauline Epistle to Philemon from Codex Vatican Arabic 13 (Ninth Century CE): Transcription and Study », art. cit., 2015, p. 351. Il cite en note Widengren. Selon Widengren, rasūl, comme šlīhō, reflète un concept répandu au ProcheOrient ancien déjà, donné à ceux qui, à la suite d'une ascension royale, sont envoyés pour 
théologiquement. Nous ne pouvons toutefois pas savoir si ce jeu de résonance est suscité de manière consciente par le traducteur, rasūl étant aussi le traduc-

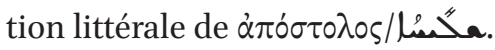

Dans tous les cas, l'utilisation d'un terme spécifique pour Paul, «le» rasūl, lui donne une place spéciale parmi les apôtres, les sillịhūn, de même que rasūl et rusul désignent dans le Coran les prophètes les plus élevés.

\subsection{2 hātam risālatī «le sceau de mon apostolat»}

Concernant également l'apostolat de Paul, il est intéressant de constater que la formulation hàatam risālatī le sceau de mon apostolat », que l'on trouve en 1 Co 9,2, évoque également un autre titre du Prophète Muhammad, celui de hätam al-nabiyyìn « le sceau des prophètes » (33:40). Muhammad vient sceller la chaîne des révélations faite aux prophètes : «The Arabian messenger of God has thus become the peak of the prophetic chain of revelations and this is also demonstrated in his title : 'Seal (khātam) of the prophets' (Q 33:40). »243 Le sens de «sceau » dans 1 Corinthiens est différent; il est question ici de l'attestation de l'apostolat de Paul, qui est l'Église à Corinthe : «Le sceau de mon apostolat, c'est que vous êtes dans le Seigneur », et non du fait que Paul serait le dernier des apôtres. Malgré cela, les conceptions liées au Prophète Muhammad et celles liées à l'apôtre Paul ont certains points communs. Monferrer-Sala fait le lien entre rasūl et le verset 1 Co 9,2, suggérant que à partir de son développement entre šlīhō et rasūl:

Another noteworthy lexical feature is the use of the noun rasūl to translate $\dot{\alpha} \pi \dot{\sigma} \sigma \tau 0 \lambda$ os, this being what might be called the terminus technicus coranicus denoting the Prophet Muhammad in Islamic tradition in general and in the Qur'ān in particular. The term - which reflects an Aramaic substrate among the Christians - is widely used in Islamic texts to allude to the apostles of Jesus. Interestingly, in its translation of 1 Cor. $9: 2$, the

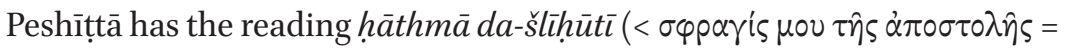
«the seal of my apostleship », which may well have helped to define the concept of prophet as it evolved during the early Islamic period. The noun šlīhō (pl. šlịhê, «messenger; apostle»), a technical term found in

communiquer un message. On pourrait rapprocher le concept de Paul et son expérience en 2 Co 12,1-5. Voir Widengren Geo, Muhammad, the Apostle of God, and his Ascension, Lundequistska bokhandeln, Uppsala, 1955, pp. 15, 55-65, 65-79, pp. 106-107. Peterson Daniel C., Muhammad: Prophet of God, Grand Rapids, Eerdmans, p. 82.

RUBIN, «Prophets and Prophethood», art. cit., 2016. 
Aramaic literature - both Christian and Gnostic - is theologically related to the Qur'ānic technical term rasūl applied to Muhammad, suggesting a conceptual link between the two ${ }^{244}$.

\subsection{3 mițāq «alliance»}

On notera encore l'utilisation du terme الميثاق الميثاق alliance» au v. 11,25, lors de l'institution de la Cène (الميتاق الحديث) mitâtàq (25 occurrences dans le Coran) ou ع ع 'ahd (12 occurrences), est un concept important dans le Coran, en lien avec la révélation divine et les prophètes. Dans la sourate 33, certains prophètes sont désignés comme partenaires d'une alliance avec Dieu: «Souviens-toi que Nous avons pris des Prophètes leur engagement (mîtāà), ainsi que de toi [Muhammad], de Noé, d'Abraham, de Moïse et de Jésus fils de Marie; Nous avons pris avec eux un engagement solennel (mîtāa $q$ ). ${ }^{246}(33: 7)$. C'est dans la même sourate 33 que Muhammad est ensuite désigné comme sceau des prophètes (33:40).

L'utilisation du terme mîtāq peut s'expliquer sans influence directe du Coran, comme c'est le cas aussi pour les termes ci-dessus. Toutefois en le rapprochant ainsi les uns des autres, il forme un champ sémantique très proche de celui utilisé dans le Coran autour des questions de révélation et de prophétie, qui ne manquera pas de trouver écho aux oreilles d'un public qui était sensible aux assonances religieuses musulmanes véhiculées par la langue arabe. Il nous semble impossible de juger si telle était l'intention du traducteur.

$4 \cdot 3 \cdot 4$

wa laysa ilāhun āharu illā wāhid « il n'y a pas d'autre dieu qu'un unique Dieu »

وليس اله Nous souhaitons encore attirer l'attention sur le v. 8,4 et la formulation wa laysa ilāhun āharu illā wāḥid «il n'y a pas d'autre dieu qu'un unique Dieu ». Elle ne manquera pas d'évoquer la première partie de la šahāda, la profession de foi musulmane : lā ilāha illā-llāh «il n'y a pas de dieu sinon Dieu ». La formulation telle que prononcée dans la šahāda se trouve uniquement dans le Coran en 37:35 and 47:19. On trouve ailleurs des variations (plus de 40 occurrences) tel que là ilāha illā huwa («il n'y a pas de Dieu sinon lui », ou se terminant avec « sinon moi », «sinon toi » $)^{247}$. La formulation dans VA 13

244 Monferrer-Sala, «The Pauline Epistle to Philemon from Codex Vatican Arabic 13 (Ninth Century CE): Transcription and Study », art. cit., 2015, pp. 355-356.

245 SA 151 a ici الميثاق الجديد: SA 155 a العهد الجديد.

246 HAFIANE Hachemi, Le Saint Coran et la traduction du sens de ses versets en claire langue française, Paris, Presses du Châtelet, 2008.

247 Rippin Andrews, «Witness to Faith », in : Encyclopaedia of the Qur'än, Washington, Brill Online, 2016. En ligne : <http://referenceworks.brillonline.com/entries/encyclopaedia-ofthe-quran/witness-to-faith-EQCOM_00217>, consulté le 23.03.2016. 
suit le même schéma que ces différentes formules, qui jouent sur l'allitération en «l» et se composent de $: 1$. négation (dans le Coran $l \bar{a}^{248}$, dans VA ${ }_{13}$ laysa) + ilāh litt. « un dieu » (VA 13 a en plus «autre»); 2. illa («sauf», « excepté») + Dieu unique (allāh, huwa, dans VA 13, wāhid « unique»).

Finalement, il n'est pas étonnant de retrouver des formulations qui se ressemblent dans l'expression d'un point théologique commun, celui de l'unité de Dieu. Une possible origine samaritaine de la première partie de la šahāda a été avancée à plusieurs reprises; il est intéressant de voir que la phrase samaritaine, qui a lyt ' $/ h^{\prime} l l^{\prime}$ ' $h d$ est encore plus proche de la formule trouvée dans VA $13^{249}$.

\subsubsection{Autres termes}

Nous relevons ici encore quelques termes qui se trouvent aussi dans le Coran ; le lien à celui-ci nous semble toutefois ténu :

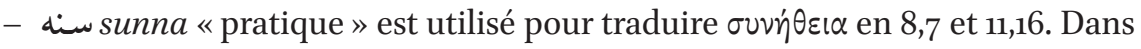
le Coran, sunna peut décrire une manière de faire, dont Dieu ou les hommes peuvent être le sujet; sunna « can roughly be divided into two categories: 'sunna' either denotes God's way of dealing with the as - yet unbelieving people of the world, or it is a word for the behavior of those rebellious unbelievers who refuse to comply with divine institutions by declining to submit to divine messengers. ${ }^{250}$ Le concept de sunna deviendra un concept clé dans la théologie musulmane : «In the development of Islamic theology, it eventually came to be associated with orthodoxy, the bastion against heterodox innovation. ${ }^{251}$ Dans le texte de 1 Corinthiens, sunna semble neutre, désignant une pratique, même si Paul parle ici de pratiques qu'il condamne.

- ض ضāllūn «égarés », utilisé en 1,18. Il s'agit d'une racine fréquente dans le Coran: «The quraanic terms for error derive from the Arabic verb for 'to err, go astray (q.v.), deviate from the right course' (dalla) and are attested at least sixty times in the Qurān. ${ }^{252}$ Le terme dällūn s'éloigne du sens des

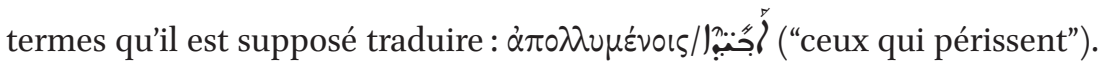

248 On trouve aussi parfois la négation mā min ilāhin ( $3: 62 ; 38: 65)$.

249 MACUCH Rudolf, «Zur Vorgeschichte der Bekenntnisformel lā ilāha illā llāhu », Zeitschrift der Deutschen Morgenländischen Gesellschaft 128 (1), 1978, pp. 20-38. En ligne: JsToR, <http://www.jstor.org/stable/43372505>, consulté le 23.03.2016.

250 JuYnBoll G.H.A, «Sunna», in : Encyclopaedia of the Qur'ān, Washington, Brill Online, 2016. En ligne : $<$ http://referenceworks.brillonline.com/entries/encyclopaedia-of-the-quran/sunna-EQSIM_00408>, consulté le 23.03.2016.

251 Ibid.

252 RUQAYYA Khan, «Error », in : Encyclopaedia of the Qur'ān, Washington, Brill Online, 2016. En ligne: <http://referenceworks.brillonline.com/entries/encyclopaedia-of-the-quran/ error-EQSIM_00135>, consulté le 23.03.2016. 
Toutefois, on trouve aussi dāllūn en SA 155 ; dans le contexte chrétien d'alors, il avait peut-être un autre sens que le sens coranique.

- aš-šayțān «Satan» (5,5; 7,5) est utilisé, avec l'article défini, plus de 70 fois dans le Coran. On le trouve aussi dans SA 151 et SA 155.

- روح القدس rụh al-qudus «l'Esprit saint» $(6,19 ; 12,3)$. L'expression littéralement « l'esprit de sainteté », est présent quatre fois dans le Coran (2:87.253; $5: 110 ; 16: 102)$. Les trois premières occurrences sont clairement reliées à Jésus, fortifié par le saint Esprit. L'expression coranique vient certainement du syriaque

- al-mufsid «le corrupteur» (10,10). mufsid est un terme qui revient régulièrement dans le Coran et est très négatif, désignant ceux qui corrompent sur terre ${ }^{254}$. Dans 10,10, mufsid correspond à l'hapax legomenon

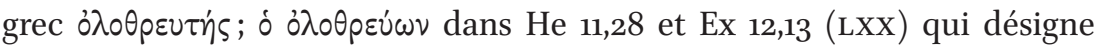
l'ange qui frappe les premiers-nés. Les deux utilisations du terme sont donc plutôt éloignées l'une de l'autre.

5

\section{Conclusions}

5.1 Peut-on parler d'une «traduction calque»?

Nous avons vu que nous avons une Vorlage double, grecque et syriaque, et que la traduction suit la plupart du temps l'un ou l'autre texte. Monferrer-Sala, dans son article sur Philémon, à une conclusion similaire à propos d'une Vorlage double. Il dit à ce propos : «As for syntax, it would suffice to say in the light of the word order of the text that most of the Epistle exhibits evidence of what is known as the 'loan-translation', with interference from the Syriac text used by the translator to give a more accurate version in the final Arabic translation. »255 Dans notre cas, similaire à celui de Philémon par ailleurs, peut-on parler de «loan translation», concept qui peut être traduit par «traduction calque»? Il est évident que la traduction est littérale (voir aussi 4.3 Une traduction à double Vorlagen). Peu de place est laissée à l'interprétation du traducteur, et nous ne relevons que deux cas de traductions périphrastique $(2,10 ; 12,4)$.

253 GRIFFITH Sidney H., «Holy Spirit», in : Encyclopaedia of the Qur'ān, Washington, Brill Online, 2016. En ligne: <http://referenceworks.brillonline.com/entries/encyclopae dia-of-the-quran/holy-spirit-EQSIM_00193>, consulté le 23.03.2016.

254 REINHART Kevin A., «Ethics and the Qur'ān », in : Encyclopaedia of the Qur'ān, Washington, Brill Online, 2016. En ligne : <http://referenceworks.brillonline.com/entries/encyclo paedia-of-the-quran/ethics-and-the-quran-EQCOM_0oo56>, consulté le 23.03.2016.

255 Monferrer-Sala, «The Pauline Epistle to Philemon from Codex Vatican Arabic 13 (Ninth Century CE): Transcription and Study », art. cit., 2015, p. $35^{2}$. 
Il ne s'agit toutefois pas d'une traduction servile, le traducteur prenant déjà la liberté de passer d'une source à l'autre. Dans quelques rares cas, il se permet des ajouts, certainement afin de faciliter la compréhension (voir 1,12; 3,4). De plus, il respecte des aspects syntaxiques élémentaires en arabe, par exemple, le fait de faire suivre إِ suffixe nécessaire), ou أَ directement par le verbe. Évidemment, tout dépend du sens que l'on donne à «traduction calque ». Dans son article descriptif sur la question, Monferrer-Sala donne aussi des exemples d'ajouts ou de suppressions de mots et d'arrangements syntaxiques pour « rester arabe $»^{256}$. Notre traduction entrerait donc bien dans sa définition d'une « traduction calque ». Cette formule nous semble toutefois plutôt réductrice par rapport aux efforts fournis par le rédacteur au niveau lexical et syntaxique.

\subsection{Une traduction aux origines multilingues}

Notre analyse de 1 Corinthiens montre que la traduction est faite à partir d'un texte grec, qui se révèle nêtre pas typiquement byzantin, et d'un texte syriaque, celui de la Peshitta. Le traducteur semble se baser de manière régulière sur l'un et sur l'autre texte, en respectant notamment la structure du texte d'origine. Nous ne pouvons pas reconstruire en détail l'histoire de la traduction. Si nous ne suivons pas Kashouh dans ses datations les plus hautes, il dit avec justesse: «The second half of the eighth century is when we should talk of the history of transmission of the Arabic Gospel text and not the beginning of the Arabic translation of the Gospels. » ${ }^{257} \mathrm{Y}$ a-t-il eu une première traduction en amont? La présence du syriaque s'explique-t-elle par le re-travail d'un texte antérieur? Nous avons vu au chapitre 6 , point 3 que leVA 13 est une copie ; quant à la traduction elle-même, elle a avec certitude une histoire, orale et textuelle, qu'il nous est difficile de reconstruire. Dans tous les cas, nous soulignons que la Peshitta transparait davantage que par des corrections occasionnelles. Afin, nous ne remarquons pas de direction exégétique particulière dans les choix de suivre le texte grec ou le texte syriaque; nous supposons qu'il s'agit ici de choix linguistiques.

Nos conclusions rejoignent donc celles de Monferrer-Sala à propos d'une autre lettre du corpus, la lettre à Philémon. Il conclut: «[...] the translator based his version on a Greek text. However, the text exhibits some translation strategies that suggest that the translator also made use of the Syriac version of the Peshittaa to compare it against the Greek and consult it with a view to

256 Monferrer-Sala, «Loan Translation from Greek in Christian Middle Arabic », art. cit., 2010.

257 Kashoun, The Arabic Versions of the Gospels, The Manuscripts and their Families, op. cit., 2012, p. 291. 
deciding on certain readings for exegetical or linguistic reasons. ${ }^{258}$ Ces conclusions similaires à propos de Philémon laissent penser que le corpus des lettres de Paul a été traduit par un même traducteur 259 .

On notera les similarités du processus de traduction avec la partie la plus ancienne des évangiles, à propos de laquelle Monferrer-Sala conclut:

The foregoing analysis of the fragment of Matthew 11:1-19 suggests that the Arabic translator of Vat. Ar. 13 used a Greek original as the source for his version. However, in the light of the lectiones offered by the fragment, there is every reason to believe that he also made use of other versions, and more specifically of a Syriac text. [...] it may additionally be postulated that the translator made use of other materials, of at least one other text which was in all probability a Syriac version, specifically of the Peshitta, with whose options the Arabic translation coincides at several points ${ }^{260}$.

S'il s'agit ici d'une traduction bien différente, cette partie comportant des périphrases, il pourrait s'agir du même milieu de traduction.

La description détaillée du manuscrit (chapitre 6, point 3) nous a montré que celui-ci a très certainement été produit dans un milieu byzantin, peutêtre antiochien, devenu arabophone (c'est-à-dire melkite). Qu'en est-il de la traduction de 1 Corinthiens contenue dans le manuscrit? À l'image d'autres textes ayant des sources grecques et syriaques, elle est le fruit d'un milieu de production multilingue. C'était le cas des monastères orthodoxes syro-palestiniens, comme l'explique Griffith :

While Greek was the standard language of liturgy and theology in the pre-Islamic Patriarchate of Jerusalem, many other languages flourished in the monastic communities, and were used in the liturgies to interpret the scriptural readings that were proclaimed in Greek. Among the languages for which textual evidence survives in the manuscript collections of several of the monasteries are Syriac, Armenian, Georgian, and the local Christian Palestinian Aramaic [...] When in the second half of the

258 Monferrer-Sala, «The Pauline Epistle to Philemon from Codex Vatican Arabic 13 (Ninth Century CE): Transcription and Study », art. cit., 2015, p. 368.

259 Par ailleurs, tous les chercheurs jusqu’à présent ont considéré les lettres de Paul dans VA 13 comme un même corpus traduit du grec, voir chapitre 6, point 2 Etat de la recherche sur le Vat. Ar. 13 .

260 Monferrer-Sala, « An Early Fragmentary Christian Palestinian Rendition of the Gospels into Arabic from Mar Saba (MS Vat. Ar. 13, 9th c.) », art. cit., 2013, p. 94. 
eighth century CE, as we shall see, Arabic began to take its place among the languages of the Church of Jerusalem, it gradually grew in importance to the point that its use in theological discourse became one of the distinguishing features of a distinct Christian confessional community that emerged in the territories of the Caliphate, the Melkites ${ }^{261}$.

C'est en toute vraisemblance ce milieu qui a produit les versions des évangiles les plus anciennes, comme Griffith le soutient:

The earliest translations of the Gospels were made from Syriac and Greek Vorlagen into Arabic, and, as we shall argue, in the first instance they were most likely all produced in the multilingual monastic communities of Syria/Palestine, and particularly in the environs of Jerusalem and the Judean desert, where the first large-scale Arabic translation movement under Christian auspices was undertaken as early as the second half of the eighth century, if not a bit earlier ${ }^{262}$.

Est-il possible que la traduction ait été faite aux alentours de Ḥoms, milieu possible du manuscrit (voir chapitre 6, point 3.2) ? A priori, rien ne vient remettre en question une situation similaire dans le patriarcat d'Antioche à celle des monastères judéens melkites, du moins en ce qui concerne l'usage du grec, du syriaque et de l'arabe. Nous pouvons rappeler ici l'exemple du Sin. Ar. 151, dont la traduction des lettres de Paul a été faite à Damas par Bišr ibn as-Sirrī : il s'agit d'une traduction faite sur la Peshitta, par un melkite qui devint prêtre et devait donc maitriser le grec ${ }^{263}$. Une forme de trilinguisme dans la communauté melkite était donc bien de mise dans le patriarcat antiochien. Comme l'explique Nasrallah à propos de la liturgie dans le patriarcat antiochien, l'arabe arrive à partir de $75^{\circ}$, existant parallèlement au grec et au syriaque sans les remplacer complètement :

Quant à la langue, jusqu'à cette époque, l'arabe n'avait pas encore fait son apparition dans la liturgie. [...] Nous restons, comme pour la première période, avec le dualisme linguistique dans la liturgie : syriaque pour l'intérieur, grec pour l'élément hellénisé qui était demeuré dans les villes de

261 Griffith Sidney H., The Bible in Arabic. The Scriptures of the «People of the Book» in the Language of Islam, Princeton, Princeton University Press, 2013, p. 112.

262 Ibid., p. 114. Voir aussi Griffith Sidney H., «The Gospel in Arabic: An Inquiry into its Appearance in the First Abbasid Century », Oriens Christianus 67, 1983, pp. 126-167.

263 Nasrallah Joseph, Histoire du mouvement littéraire dans l'Église Melchite du Ve au $X X^{e}$ siècle, vol. II.2, Louvain, Peeters, 1988, p. 186. 
la côte [...] Dans les centres urbains - même à Antioche - où coexistaient les deux langues liturgiques, des interprètes officiels étaient chargés de traduire au fur et à mesure, en syriaque ou en grec, la partie que le peuple ne comprenait pas. [...] Dans les deux patriarcats, timide apparition de l'arabe dès la fin du VIIIe s. qui sera plus certaine durant le IXe et surtout le Xe s. Il pénétra d'abord dans les péricopes scripturaires lues durant les offices, puis dans la Liturgie, dans les leçons de la Vie des Saints, les rubriques des autres livres liturgiques, puis dans quelques morceaux du texte de ces mêmes livres. Durant cette période, l'emploi de l'arabe ne semble pas avoir dépassé ce stade ${ }^{264}$.

Létude de la traduction montre qu'elle a été produite par un traducteur qui était familier avec les langues grecque, syriaque et arabe, mais également avec les Écritures en grec et en syriaque. Cette familiarité explique la double Vorlage grecque et syriaque et semble correspondre au contexte melkite de l'époque du manuscrit, qui date du $9^{\mathrm{e}} \mathrm{s}$. (chapitre 6, point 3 Description du manuscrit Vat. Ar. 13). En conséquence, nous pouvons dire que la traduction, comme le manuscrit, a été faite dans un milieu melkite; il est possible que qu'il s'agisse d'une communauté melkite dans la région de Ḥoms, vu que le manuscrit qui la contient fait mention de la ville de Homs.

264 Ibid., p. 183. Voir aussi CANnuyer Christian, «Langues usuelles et liturgiques des Melkites au XIII' siècle », Oriens Christianus 70, 1986, pp. 110-117. NASRAllaH Joseph, « La liturgie des Patriarcats melchites de 969 à 1300 », Oriens Christianus 71, 1987, pp. 156-181. 


\section{Identité(s) dans 1 Corinthiens dans le Vat. Ar. 13}

Dans la partie précédente, nous avons proposé un commentaire à l'approche philologique, qui a permis principalement de positionner notre traduction par rapport aux textes sources grecs et syriaques. Cette approche, que l'on peut décrire comme source oriented, se place dans une perspective de critique textuelle du Nouveau Testament ainsi que d'histoire du texte biblique en général. Nous avons expliqué au chapitre 1, point 2.3.2 Histoire des lectures que nous nous inscrivons également dans une perpective d'histoire des lectures, soulignant l'intérêt de prendre en considération le texte de 1 Corinthiens tel qu'il est transmis dans le Vat. Ar. 13. En effet, comme le soulignait Clivaz, «nous étudions les textes du Nouveau Testament déjà lus, déjà reçus, déjà interprétés et modifiés, et non pas l'exemplaire tel que sorti de la plume des auteurs. ${ }^{1}$ Si l'on accepte l'état de fait que l'exégète ne travaillera jamais avec un texte original, une interprétation dans le contexte de réception, ou une histoire des lectures, peut devenir une étape logique dans l'étude de tout texte du Nouveau Testament. De plus, une histoire des lectures favorise le renouvellement des interprétations du texte. L'étude de la traduction arabe du Nouveau Testament peut s'intéresser au texte et à sa signification, et pas uniquement aux sources de la traduction, bien que l'étude de celles-ci reste une étape primordiale. Comme pour le texte grec, une exégèse historico-critique, méthodologie dans laquelle nous nous situons, est nécessaire. Celle-ci présente toutefois plusieurs difficultés que nous discutons brièvement ici.

\subsection{Difficultés}

1.1.1 Quelques remarques sur l'analyse de la traduction

Il faut commencer par nous poser la question : comment appréhender une traduction? Une traduction, dans sa définition la plus basique, est le fait de rendre un texte d'une langue source dans une langue cible. Si les aspects philologiques de la traduction peuvent être le sujet d'étude, comme c'est le cas dans notre commentaire, il nous faut souligner que l'étude de la traduction appartient également au champ de la sémiotique, car il s'agit d'un transfert

1 Clivaz Claire, L'ange et la sueur de sang (Lc 22,43-44), ou comment on pourrait bien encore écrire l'histoire, Louvain, Paris, Walpole, Ma, Brepols, 2010 (Biblical Tools and Studies 7), p. 195.

(C) SARA SCHULTHESS, 2019 | DOI:10.1163/9789004378162_010

This is an open access chapter distributed under the terms of the prevailing CC-BY-NC License at the time of publication. 
de sens qui implique des critères extra-linguistiques ${ }^{2}$. Létude d'une traduction nécessite la prise en compte du contexte social et culturel, comme nous allons le voir ${ }^{3}$. Une figure importante des translation studies est Eugene Nida, qui a travaillé sur les traductions bibliques, surtout anglaises, mais dont l'apport dépasse ce champ. Nida développe le concept d'« équivalence formelle ( formal equivalence, ou formal correspondence) et d'« équivalence dynamique» (dynamic equivalence). Dans le cas de la «équivalence formelle», le traducteur essaie de reproduire le texte source dans la forme et le contenu, quitte à faire violence à la langue cible: «[a] quality of translation in which the features of the form of the source text have been mechanically reproduced in the receptor language. ${ }^{4}$ Dans le cas de l'« équivalence dynamique », la traduction doit essayer de susciter la même réponse chez son récepteur que celle suscitée par le texte source chez ses propres récepteurs, et non viser la fidélité au texte source : « [a] quality of a translation in which the message of the original text has been so transported into the receptor language that the response of the receptor is essentially like that of the original receptors. $»^{5} \mathrm{Au}$ final, il s'agit d'une forme de communication ${ }^{6}$ dont le second modèle, l'« équivalence dynamique», serait plus efficace.

La notion d'« équivalence » a souvent été remise en question et on lui préfèrera la notion de $«$ transfert ${ }^{7}$. Christiane Nord notamment définit la traduction comme un intercultural text transfer et souligne que : «Being culturebound communicative signs, both the source and the target text are determined by the communicative situation in which they serve to convey a message. ${ }^{8}$

\subsubsection{Le caractère littéral de la traduction}

Selon les critères de Nida, la traduction de 1 Corinthiens tend à la « équivalence formelle», lorsque l'on voit les efforts faits par le traducteur pour respecter

2 Bassnett Susan, Translations Studies, 4 édition, Londres, New York, Routledge, 2014, pp. 14, 24-25.

3 C'est pourquoi on peut aussi parler de traduction dans une seule et même langue : « Intralingual translation, or rewording (an interpretation of verbal signs by means of other signs in the same language). » Ibid., p. 25.

4 Nida Eugene A. et Taber Charles R., The Theory and Practice of Translation, Leiden, Brill, 1969, p. 201.

5 Ibid., p. 200.

6 Stine Philip C., Let The Words Be Written: The Lasting Influence Of Eugene A. Nida, Leiden, Boston, Brill, 2004, p. 40.

7 Pym Anthony, Translation and Text Transfer. An Essay on the Principles of Intercultural Communication, $2^{\mathrm{e}}$ édition, Tarragona, Intercultural Studies Group, 2010.

8 Nord Christiane, Text Analysis in Translation: Theory, Methodology, and Didactic Application of a Model for Translation-oriented Text Analysis, Amsterdam, Atlanta, Rodopi, 2005, p. 8. 
les textes sources (voir chapitre 8, point 3 Affinités textuelles). Cela n'est pas une surprise car les approches privilégiant le langage de réception sont résolument modernes, comme le souligne Brock: «Virtually all ancient biblical translations, into whatever language, are basically text-oriented rather than reader-oriented. ${ }^{9}$ C'est la culture imprimée qui, dans le cas des traductions bibliques du moins, a mené à des traductions non littérales, car le livre sort le texte de son cadre interprétatif ${ }^{10}$. De plus, dans notre cas, les indications de lecture dans le manuscrit (voir chapitre 6, point 3.8 Indications de lectures) montrent que le texte était utilisé dans un cadre liturgique et qu'il n'était certainement pas affranchi des langues à partir desquelles il a été traduit. Comme l'explique Joseph Nasrallah à propos de la liturgie orthodoxe dans le patriarcat antiochien : « Le patriarcat d'Antioche témoigna d'une grande ouverture pour ce qui concerne l'emploi de la langue vernaculaire dans sa liturgie. De sorte qu'il est bien difficile d'y établir une frontière linguistique entre le grec, le syriaque et l'arabe en usage dans le service divin. $»^{11}$ Larabe, comme le syriaque, était utilisé en parallèle à langue liturgique grecque ; nous développons cela au chapitre 8, point 5.2 Une traduction aux origines multilingues. Une traduction respectant au maximum ces langues d'origine est donc tout à fait logique dans un tel contexte.

\subsubsection{Application à notre cas}

Nous sommes ainsi face à une situation de littéralité et de dépendance visà-vis des textes et des langues sources. Cette situation rend particulièrement intéressante les occasions dans lesquelles la traduction sort du cadre donné, comme c'est le cas dans l'exemple que nous traitons dans ce chapitre - et encore, il est à discuter. Il est important, à notre avis, que l'exégète soit attentif à ne pas « surinterpréter» ces occasions.

En outre, il est difficile d'entrer avec notre traduction dans un schéma simple d'un texte qui passe d'une «langue source» (source language) à une «langue cible» (receptor language). Premièrement, le texte source (transmis par écrit ou par oral) se trouve être non pas dans une langue source, mais dans deux, le grec et le syriaque. Deuxièmement, la question du receptor language n'est pas non plus sans problème. En effet, Nida parle du genius («génie») propre à chaque langue, et que pour communiquer de manière effective, il faut

9 Brоск Sebastian P., The Bible in the Syriac Tradition, $2^{\mathrm{e}}$ édition, Piscataway, Gorgias Press, 2006, p. 11.

$10 \quad$ Ibid., p. 12. Il y a des exceptions, comme la traduction de la Bible de Saint Jérôme, qui ne cherche pas à rester littéral ; voir les explications de Brock, Ibid., pp. 12-13.

11 Nasrallah Joseph, «La liturgie des Patriarcats melchites de 969 à 1300 », Oriens Christianus 71, 1987, pp. 158-159. 
respecter le genius de la langue ${ }^{12}$. Or, dans le cas du moyen arabe, dont nous discutons le concept et exposons les caractéristiques au chapitre 8, point 2 Moyen arabe, il nous est difficile voire impossible de savoir quel est son genius au vu de la fluidité de cet état de la langue. Peut-être que les aspects qui nous semblent aujourd'hui artificiels car empruntés directement du syriaque ou du grec faisaient pourtant bien partie de la langue parlée d'alors.

Enfin, si la définition de l'intercultural text transfer nous semble très juste, nous sommes confrontés à la difficulté de la méconnaissance du contexte exact de production de la traduction et du manuscrit. En effet, comme nous l'expliquons au chapitre 6, point 3 Description du manuscrit Vat. Ar. 13, nous ne savons pas exactement d'où vient le manuscrit ni de quand il date, même si nous pensons avoir suffisamment d'éléments pour discerner le milieu melkite du $9^{\text {e }}$ siècle. Malgré tout, le concept d'intercultural text transfer est pour nous intéressant, car il permet une dynamique, en plus de la dynamique entre le texte traduit et la traduction, entre la traduction et son contexte: c'est le contexte qui peut apporter des clés de compréhension pour la traduction, mais cela fait entrevoir la possibilité d'en savoir plus sur le contexte de la traduction à partir de cette dernière. Il nous faut toutefois à nouveau souligner que nous avançons en eaux troubles, au vu des éléments que nous venons d'esquisser.

\subsubsection{Manques d'outils}

À ce sentiment d'avancer en eaux troubles, il faut ajouter le problème du manque d'outils de recherche à disposition pour effectuer une analyse historico-critique qui nous permettrait de lire le texte dans son contexte. Dans le cas présent, travaillant sur une traduction dont nous avons établi les sources et qui respecte les structures de ces dernières, nous souhaiterions pouvoir nous concentrer sur les questions sémantiques. Malgréla longue histoire de la lexicographie arabe, les dictionnaires, modernes comme anciens, ne donnent pas de référence permettant de consulter les sources utilisant tel ou tel vocabulaire ${ }^{13}$. Concernant le vocabulaire arabe chrétien, il existe le Verzeichnis arabischer kirchlicher Termini de Graf, mais les quelques références données ne permettent pas d'avoir une idée précise de l'étendue de l'utilisation ${ }^{14}$; Blau propose

\footnotetext{
12 NidA et TABER, The Theory and Practice of Translation, op. cit., 1969, p. 4.

13 Kraemer J., «Studien zur altarabischen Lexikographie», Oriens 6, 1953, pp. 201-238; voir aussi HaYwood J.A., MACKenZie D.N. et EcKMANn J., « Kāmmūs », in : Encyclopaedia of Islam, $2^{\mathrm{e}}$ édition, Brill Online, 2016. En ligne : $<$ http://referenceworks.brillonline.com/ entries/encyclopaedia-of-islam-2/indjil-COM_0373>, consulté le 09.02.2016.

14 GRAF Georg, Verzeichnis arabischer kirchlicher Termini, $2^{\mathrm{e}}$ édition, Louvain, Imprimerie orientaliste, 1954.
} 
également un petit glossaire dans son Handbook sur le moyen arabe, qui peut se révéler utile ${ }^{15}$. On regrettera donc l'absence d'un thésaurus, à l'image du Thesaurus syriacus de Payne Smith ou des très puissants Thesaurus Linguae Graecae $^{16}$ et Thesaurus Linguae Latinae ${ }^{17}$. Concernant la littérature musulmane, il existe des concordances pour le Coran ${ }^{18}$ et plusieurs sites internet non académiques répertoriant les hadìțs; le site internet sunnah.com semble être tout-à-fait performant ${ }^{19}$. Il nous faut encore mentionner ici l'existence d'un logiciel très populaire dans le monde arabophone: Al-Maktaba al-Shamela ou Shamela ${ }^{20}$. Il s'agit d'une «bibliothèque virtuelle» contenant plus 1o'ooo ouvrages classiques et contemporains en langue arabe (en texte intégral ou en version scannée). Ce logiciel, qui fonctionne sur Windows et Linux, se trouve dans une zone grise ${ }^{21}$. Shamela est utilisée par de nombreux chercheurs à travers le monde ${ }^{22}$, mais de nombreuses questions se posent à son propos : sous quelle licence les textes sont-ils utilisés ? Comment fonctionne l'outil de recherche (y a-t-il lemmatisation des textes) ${ }^{23}$ ? Les données sont-elles fiables? Comment citer les références? En conséquence, nous n’avons pas utilisé Shamela dans notre travail.

Enfin, nous faisons parfois référence au Glossarium Graeco-Arabicum, un projet de base de données lexicales, qui propose un lexique des traductions arabes médiévales du grec à l'arabe, en construction. La base de données ne

15 BLAU Joshua, A Handbook of Early Middle Arabic, Jérusalem, The Max Schloessinger Memorial Foundation, The Hebrew University, 2002 (The Max Schloessinger Memorial Studies Monographs 6), pp. 175-262.

$16<$ http://stephanus.tlg.uci.edu>, consulté le 09.03.2016.

17 <http://www.degruyter.com/db/tll>, consulté le 09.03.2016.

18 Nous utilisons Kassis Hanna E., A Concordance of the Qur'an, Berkeley, University of California Press, 1983 .

$19<$ http://sunnah.com>, consulté le 09.03.2016.

$20<$ http://www.shamela.ws $>$, consulté le 09.04.2016. Il existe des projets académiques récents, comme $<$ http://kitab-project.org/> que nous n'avons pas encore pu explorer dans le détail.

21 Till Grallert définit Shamela comme une «gray online-library of Arabic literature», $<$ https://tillgrallert.github.io/blog/2015/11/13/online-resource-muqtabas/>, consulté le 09.04.2016.

22 Gilet Julien, «Al-Maktaba al-Shamela = المكتبة الشاملة", Aldébaran, Collections numériques, 12.12.2010. En ligne : <http://aldebaran.revues.org/6597>, consulté le 07.04.2016.

23 On trouve des éléments de réponses ici: Peralta José Haro et Verkinderen Peter, «"Find for Me!" : Building a Context-Based Search Tool Using Python», in : Munanna Elias (éd.), The Digital Humanities and Islamic \& Middle East Studies, Walter de Gruyter, 2016, pp. 200-204. 
comprend toutefois que la littérature profane, philosophique et scientifique, des contextes bien différents de celui du texte de Vat. Ar. $13^{24}$.

Celui qui lit 1 Corinthiens tel que transmis dans le Vat. Ar. 13 ne manquera pas

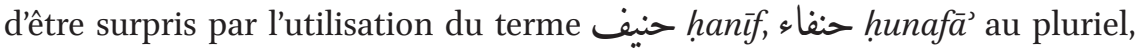
pour désigner les païens ${ }^{25}$. Rencontrant ce mot, un connaisseur du Coran pensera tout de suite à la figure modèle monothéiste d'Abraham. La personne qui consultera un dictionnaire tombera sur une définition comme celle-ci : «orthodoxe, bon croyant »; «attaché à la vrai foi » ${ }^{26}$. Il s'avère que ce terme possède une histoire lexicale particulière et qu'il peut prendre des significations différentes suivant les contextes. À cette particularité lexicale s'ajoute le fait que le terme hanäf apparaît dans des versets importants de 1 Corinthiens, touchant à la question de l'identité du chrétien. Celui-ci apparaît à cinq reprises, en l'occurence au pluriel ḥunafä', dans les versets 1 Co 1,22.24; 10,20.32; 12,13. Ces versets sont à notre avis centraux pour la problématique de l'identité dans 1 Corinthiens. Une recherche s'impose donc sur ces versets et leur traduction dans Vat. Ar. 13 ; il nous faut pour cela commencer par étudier l'arrière-fond de ces versets.

\subsection{La problématique de l'identité dans 1 Corinthiens}

\subsubsection{Est-il question d'identité dans 1 Corinthiens?}

Les chercheurs s'accordent pour dire que la première lettre de Paul aux Corinthiens répond à une situation particulière propre à la communauté de Corinthe. Paul s'adresse ici à une communauté, qu'il appréhende comme un tout, et la question de l'unité dans cette communauté est centrale ${ }^{27}$. En effet, la communauté se compose de différents groupes sociaux, en termes économiques, culturels, religieux. Si l'on prend la définition de l'identité so-

\footnotetext{
$24<$ http://telota.bbaw.de/glossga/>, consulté le 09.03.2016.

25 Nous utilisons ici le terme «païen » selon un sens christiano-centré afin d'exprimer «ni chrétien, ni juif », sans chercher à exprimer de connotation négative.

26 KAZIMIRS Ki-Biberstein Wojciech, Dictionnaire arabe-français, contenant toutes les racines de la langue arabe, vol. 1, Paris, Maisonneuve, 1860, p. 504.

27 Voir par exemple Fitzmyer Joseph A., First Corinthians, Yale University Press, 2008 (The Anchor Yale Bible 32), pp. 51-52. Linde MAnN Andreas, Der Erste Korintherbrief, Mohr Siebeck, 2000 (Handbuch zum Neuen Testament), p. 16. FeE Gordon D., The First Epistle to the Corinthians, Grand Rapids, Eerdmans, 1987 (The New International Commentary on the New Testament), pp. 3-4.
} 
ciale suivante : « that part of an indiviual's self-concept which derives from his knowledge of his membership of a social group (or groups) together with the value and emotional significance attached to that membership ${ }^{28}$, il faut voir comment celle-ci se présente dans une communauté composée de différents groupes sociaux et comment Paul traite cet aspect.

La présence de différences sociales au sein de la communauté de Corinthe ainsi que son influence sur les propos de Paul ont été soulignées il y a plusieurs décennies déjà par Gerd Theissen ${ }^{29}$. Pour Theissen, le message de Paul constitue clairement un dépassement de ces différences sociales :

De fait, le christianisme primitif a franchi étonnement tôt cette grande barrière sociale que Paul, à juste titre, cite en premier : celle entre les Juifs et les païens. C'était, à son début, un mouvement de renouveau à l'intérieur du judaïsme ; mais déjà dans les années 40, il devient un mouvement intellectuel qui s'implanta en dehors du judaïsme et s'adressa à des païens ${ }^{30}$.

L'idée de dépassement proposée par Theissen est à nuancer; c'est l'avis de William S. Campbell, qui soutient que l'originalité de Paul est qu'il ne cherche pas à construire une nouvelle identité chrétienne qui anéantirait les identités précédentes, mais qu'il pense en terme d'identités plurielles et de hiérarchie de celles-ci : «Despite of regarding these as each comprising identity, such components could be described as sub-identities in a nested hierarchy of identity of which being in Christ is the primary. ${ }^{31}$ Les identités propres, notamment l'identité juive, ne disparaissent pas et Campbell note que Paul, en tant que juif, ne perd pas son identité juive : « We must think in term of identities rather than identity. Thus altough Paul is in one sense the model for Christian existence in Christ, he cannot be the prototype of all Christians. [...] Paul therefore

28 Définition de Tajfel, Henri (éd.), Differentiation Between Social Groups: Studies in the Social Psychology of Intergroup Relations, Londres, Academic Press, en coopération avec European Association of Experimental Social Psycholog, 1978, p. 63, citée dans TuCKe R J. Brian, You Belong to Christ: Paul and the Formation of Social Identity in 1 Corinthians 1-4, Eugene, Pickwick, 2011, p. 3.

29 Theissen Gerd, The Social Setting of Pauline Christianity: Essays on Corinth, New York, T\&T Clark, 1982.

30 Theissen Gerd, «Vers une théorie de l'histoire sociale du christianisme primitif», in: Theissen Gerd, Histoire sociale du christianisme primitif. Jésus - Paul - Jean, Genève, Labor et Fides, 1996, pp. 269-270.

31 Campbell William S., Paul and the Creation of Christian Identity, New York, T\&T Clark, 2006 (Library of New Testament Studies 322), p. 157. 
is the paradigm for Jewish Christ-identity but not for gentile. $»^{32}$ À la suite de Campbell, J. Brian Tucker développe le concept de hiérarchie des identités chez Paul, mais relève que, particulièrement dans 1 Corinthiens, c'est l'identité citoyenne romaine qui doit être recadrée par rapport à l'identité chrétienne :

1 Corinthians 1-4 shows that some in Corinth were continuing to identify primarily with key aspects of their Roman social identity rather than their identity « in Christ » and this confusion over identity positions contributed to some of the problems within the $\dot{x} \varkappa \lambda \eta \sigma i \alpha$. Paul seeks to realign their identity hierarchy in order to create an alternative community with a distinct ethos in comparison with the Roman Empire ${ }^{33}$.

\subsubsection{Les usages du couple Hellēnes/Ioudaioi}

Il est intéressant de voir qu'en 1 Corinthiens, le terme Hellènes est toujours associé à Ioudaioi (1 Co 1,22.24; 10,32; 12,13). Il s'agit d'un premier indice que ces catégories fonctionnent en dynamique l'une avec l'autre. Il a déjà été noté que le vocabulaire Hellènes/Ioudaioi prenait sens dans une vision juive de l'humanité : « [Paul] uses the pair, Jew(s) and Greek(s), as a division of humanity, when he speaks about its reaction to the Christ-event [...]. This is a Jewish way of speaking of humanity ; in Rom $1: 14$ he uses the Greek way, Greeks and barbarians [...]. » ${ }^{34}$ Le vocabulaire désignerait, du coup, une distinction religieuse, notamment à travers la circoncision et l'incirconcision (voir 1 Co 7,18-19). Mais est-ce aussi une réalité sociale, avec pour les individus un sentiment d'appartenance à un groupe ou à l'autre? Certains pensent que les Hellènes/Ioudaioi dans 1 Corinthiens désigneraient des individus concrets qui se confrontent à Paul, et qu'il ne s'agirait pas de propos généraux sur les Juifs ou les païens ${ }^{35}$. Qu'il puisse s'agir ici d'interlocuteurs concrets n'exclut pas, à notre avis, la réalité de deux groupes sociaux distincts dans la communauté de Corinthe, comme le développent Theissen, Campbell ou Tucker mentionnés plus haut, et le propos de Paul dans 1 Corinthiens se positionne face à une identité sociale juive et à une identité sociale «païenne », dans le sens de ni juive ni chrétienne.

Que l'on pense qu'il s'agisse d'un dépassement (Theissen) ou d'une hiérarchisation des identités (Campbell, Tucker), il est à notre avis évident que Paul cherche à positionner l'identité de sa communauté vis-à-vis de l'identité des

$32 \quad$ Ibid., p. 156.

33 TUCKen, You Belong to Christ, op. cit., 2011, p. 235.

34 Fitzmyer, First Corinthians, op. cit., 2008, p. 158. Voir aussi la traduction de $\beta \alpha \dot{\alpha} \beta \beta \alpha \rho \varsigma$ en 1 Co 14,11 dans le commentaire au chapitre 8, point 1.

35 Sсноттroff Luise, Der erste Brief an die Gemeinde in Korinth, Stuttgart, Kohlhammer, 2013 (Theologischer Kommentar zum Neuen Testament 7), pp. 36-37. 
Hellēnes et de celle des Ioudaioi. Daniel Gerber note que la construction d'une identité est faite d'intégration et de rejet:

\begin{abstract}
Ainsi parle-t-on de la «construction identitaire» d'un groupe, au sens d'un processus dynamique » par lequel il se démarque en permanence de son environnement, notamment en développant «un nouvel ethos». On distingue alors entre un «ethos inclusif» et un «ethos exclusif», le premier révélant le degré d'intégration d'un groupe dans son contexte sociétal et le second manifestant la distance prise par rapport aux valeurs ambiantes ${ }^{36}$.
\end{abstract}

Les versets présentant le couple Hellēnes/Ioudaioi expriment en effet à la fois l'inclusion et l'exclusion, et cette oscillation est l'illustration d'une construction d'identité en cours. En 1 Co 1,22-24, cette dynamique est bien présente: Une opposition est faite en 1,23 entre «nous» et les Hellènes/Ioudaioi, deux groupes qui s'opposent aussi l'un à l'autre en 1,22. Mais en 1,24, ces oppositions s'atténuent, vu que parmi les appelés, il y a à la fois les Hellēnes et les Ioudaioi. Selon Tucker, ces versets sont un bon exemple de la hiérarchisation que tente d'établir Paul :

First, 1 Cor 1:22-24 may be seen as Paul's instruction with regard to behaviors associated with ethnic groups functioning too high in the identity hierarchy. Paul presents his case in the context of ethnic differentiation. He suggests to the Corinthian Christ-followers that these characteristics of one's ethnic identity are to be reevaluated in Christ who has become the power and wisdom of God. Read this way, Paul is not disparaging Greek pursuits of wisdom nor Jewish longing for power ; he is only recategorizing these in the context of being called by God (1 Cor 1 :24). Calling functions as a means of social cognition and serves as the foundation of the « in Christ » social identity ${ }^{37}$.

Tucker donne ensuite comme exemple 1 Co 10,32 et 12,13, versets qui nous intéressent également. En 10,32, la paire Hellēnes/Ioudaioi apparaît lors de la conclusion aux explications sur les idolothytes: il ne faut être cause de

36 Gerber Daniel, «La construction de l'identité en Christ dans une ville gréco-romaine d'après la première lettre de Paul aux Corinthiens », Revue d'histoire et de philosophie religieuse 93 (1), 2013, p. 106.

37 Tucker, You Belong to Christ, op. cit., 2011, p. 8o. Tucker, comme Campbell, utilise les notions d'ethnicité et d'« ethnic identity ». Nous préférons garder le concept large d'identité sociale, pouvant comprendre les questions d'ethnicité. Voir Ibid., pp. 33-34. 
scandale ni pour les Juifs, ni pour les païens, ni pour l'Église de Dieu. Selon Lindemann, il pourrait ici s'agir de l'attestation la plus ancienne de l'Église de Dieu, présentée comme entité distincte des Juifs et des païens ${ }^{38}$. Selon Tucker, on peut aussi comprendre ce verset de manière inclusive : «Jews and Greeks, even those belonging to the $\dot{\varepsilon} \varkappa \varkappa \lambda \eta \sigma^{i} \alpha .{ }^{39}$ Si la proposition de traduction de Tucker nous semble quelque peu difficile à soutenir, l'intention de Paul de ne scandaliser aucun groupe social montre la prise en considération de toutes les identités, sans rupture.

Enfin, en 1 Co 12,13, on trouve, dans le développement de Paul autour de l'Église comme corps, la formulation qui est très proche de Ga 3,2840 : «Et nous aussi, tous par un seul Esprit pour un seul corps, nous avons été baptisés, étant juifs, païens, esclaves ou libres, et nous tous, nous avons bu à une seule coupe. ». Fitzmeyer dit à propos de 12,13 :

The phrases emphasize the meaning of «we ... all» in the main statement. For all believers, no matter what their diverse religious, ethnic, social or economic background may be, share one and the same union with the Christ through baptism «in the one spirit» and thus belong to the «one body ${ }^{41}$.

Cet aperçu de la question de l'identité dans 1 Corinthiens nous montre que les questionnements identitaires autour du couple Hellênes/Ioudaioi reflètent une réalité dans la communauté de Corinthe, par rapport à laquelle Paul doit se prononcer. Les versets $1,22.24 ; 10,32 ; 12,13$ ont une place importante dans les propos de Paul, qui oscillent, à notre avis, entre inclusion et dépassement, sans rupture avec l'identité parallèle ou précédente.

\section{2 hanif, un concept mouvant}

2.2.1 Utilisation du terme haniff dans le Coran et la tradition islamique ancienne

Qu'en est-il alors du terme hanîf que l'on retrouve dans ces versets importants (nous les détaillons au point 2.3 ci-dessous). Nous allons voir d'abord que le sens de hanīf peut varier suivant le contexte dans lequel il est utilisé. L'Encyclopaedia of Islam propose la définition suivante : « Hanīf : (pl. ḥunafāa),

38 Lindemann, Der Erste Korintherbrief, op. cit., 2000, p. 234.

39 Tucker, You Belong to Christ, op. cit., 2011, p. 81.

$40 \quad$ Ga 3,28: «Il n'y a plus ni Juif, ni Grec; il n'y a plus ni esclave, ni homme libre; il n'y a plus l'homme et la femme; car tous, vous n'êtes qu'un en Jésus Christ» (traduction de la тов).

41 Fitzmye R, First Corinthians, op. cit., 2008, p. 478. 
means in Islamic writing one who follows the original and true (monotheistic) religion. $»^{42}$ On trouve 12 fois le terme hanīf, pl. hunafăà, dans le Coran ${ }^{43}$. Il est généralement associé à Abraham, qui est présenté comme le modèle du croyant monothéiste ${ }^{44}$. Fait intéressant, il est précisé dans deux sourates qu'Abraham n'était ni juif ni chrétien $(2: 125 ; 3: 67)$; en 3:67, on notera qu'Abraham est décrit comme hanîf muslim ${ }^{45}$. Le hanîf est donc celui qui adore le Dieu unique de la bonne manière, contrairement aux polythéistes et aux Juifs et chrétiens qui s'en sont éloignés. Par la suite, hanîf continue à être utilisé pour désigner le bon croyant préislamique. Dérivé de hanīif, on trouve le terme hanīfyya, qui désigne ainsi la religion d'Abraham, ou la juste manière de vivre le monothéisme avant l'Hégire. Dans tous les cas, le sens de hanîf est très positif et le terme sera même utilisé comme équivalent de muslim, et celui de hanīfuyy a comme équivalent d'Islam ${ }^{46}$. Il est possible, comme le suggère Montgomery Watt ${ }^{47}$, que cette dernière utilisation ait été abandonnée notamment à cause du sens donné à hanîff et surtout à son équivalent syriaque hanpā par les auteurs chrétiens. En effet, ce terme est généralement utilisé dans le sens de «païen », «idolâtre », et parfois, en syriaque, comme un dépréciatif à l'égard des musulmans.

\subsubsection{Utilisation du terme hanīf dans le contexte chrétien}

La dichotomie entre le sens des termes hanîf et haniffyya en contexte islamique ou en contexte chrétien a déjà été à plusieurs reprises discutée, notamment à cause de leur présence dans la Risāla al-Kindī, une œuvre apologétique

42 Montgomery Watt William, «Ḥanīf», in : Encyclopaedia of Islam, $2^{\mathrm{e}}$ édition, Brill Online, 2016. En ligne : <http://referenceworks.brillonline.com/entries/encyclopaedia-of-is lam-2/hanif-COM_0264>, consulté le 14.02.2016. $2: 135 ; 3: 67.95 ;$ 4:125; 6:79.161; 10:105; 16:120.123; 22:31; 30:30; 98:5.

44 Par exemple en 6:161: «Dis: 'En vérité, mon Seigneur m’a dirigé dans le droit chemin. C'est une religion immuable : la religion d'Abraham, le croyant sincère [haniff] ; il n'était pas du nombre des polythéistes.' », traduction de Hafiane Hachemi, Le Saint Coran et la traduction du sens de ses versets en claire langue française, Paris, Presses du Châtelet, 2008.

45 «Abraham n'était ni juif ni chrétien, mais il était un pur monothéiste soumis à Dieu [hanīf muslim] ; il n'était pas du nombre des polythéistes. », traduction de HAFIANE, Ibid.

46 Chez Ibn Hišām par exemple, cf. Montg ome RY WATt, « Ḥaniff », art. cit., 2016. Voir aussi ARbACHe Samir, «La naissance du Prophète Muhammad. Approche thématique et littéraire des textes traditionnels », in : CANnuyer Christian et Vialle Catherine (éds), Les naissances merveilleuses en Orient. Jacques Vermeylen (1942-2014) in memoriam, Société belge d'études orientales, 2015 (Acta Orientalia Belgica 28), p. 313.

47 Montgomery Watt William, «Two Interesting Christian-Arabic Usages », Journal of Semitic Studies 2, 1957, pp. 360-365. 
chrétienne datant probablement du $9^{\mathrm{e}} \mathrm{s}{ }^{48}$, où l'on trouve les propos suivants concernant Abraham :

Quand Abraham crut en Dieu et à sa promesse, cela lui fut imputé à justice. Il renonça au « hananafisme » [al-ḩaniffyya] qui est le culte des idoles et il devient croyant monothéiste. Nous savons, en effet, que le « hanafisme» est synonyme de culte des idoles, selon les livres révélés par $\mathrm{Dieu}^{49}$.

Haniffyya, que l'on pourrait traduire par «idolâtrie», a donc un sens qui est ici à l'opposé de celui présenté ci-dessus. On trouve également l'utilisation du terme haniff dans le sens de «païen » chez quelques auteurs chrétiens comme Abū Qurra, Abū Șāliḥ et dans le Kitāb al-Burhāan attribué faussement à Eutychius d'Alexandrie ${ }^{50}$, ainsi que dans des manuscrits bibliques comme le Vat. Ar. 13 ou le Sin. Ar. 151 (voir ci-dessous). Dans ces derniers, le terme fait référence aux « païens » gréco-romains, à rapprocher de Hellēnes.

Cette compréhension de hanîf et haniffiyya est à rapprocher du terme sy-

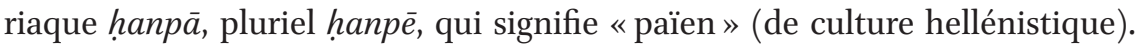
Dans la Peshitta, par exemple, hanpē est utilisé pour traduire oi "E

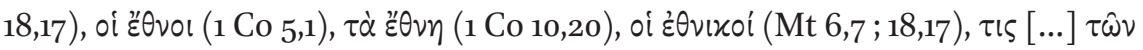
$\dot{\alpha} \pi i \sigma \tau \omega \nu(1$ Co 10,27). On trouve le sens de Hellènes dans d'autres ouvrages syriaques ${ }^{51}$. Par la suite, les auteurs syriaques utilisent régulièrement hanpē pour

48 Il s'agit d'une correspondance fictive entre un chrétien et un musulman, qui est généralement estimé être du début du $9^{\mathrm{e}} \mathrm{s}$. Voir BotTin I Laura, «The Apology of al-Kindī », in : Thomas David Richard et Rog gema Barbara (éds), Christian-Muslim Relations : A Bibliographical History (60o-9oo), Leiden, Boston, Brill, 2009 (The History of Christian-Muslim Relations 11), pp. 585-594.

49 TARTAR Georges, Dialogue islamo-chrétien sous le calife Al-Ma'mûn (813-834): les épitres d'Al-Hashimî et d'Al-Kindî, Paris, Nouvelles Editions Latines, 1985, p. 118. Cet extrait est donné dans sa version anglaise par Griffith Sidney H., « The Prophet Muhammad, His Scripture and His Message according to the Christian Apologies in Arabic and Syriac from the First Abbasid Century », in : La vie du Prophète Mahomet. Colloque de Strasbourg (octobre 1980), Paris, Presses universitaires de France, 1983, p. 120.

50 Montgomery Watt William, «Two Interesting Christian-Arabic Usages », Journal of Semitic Studies 2, 1957, pp. 360-365, p. 360, n. 4. Monferrer-SAla Juan Pedro, « Ḥanif < Hanpā. Dos formas de un mismo concepto en evolución. Notas filológicas en torno a un viejo problema », Anaquel de Estudios Árabes 14, 2003, p. 179.Il semblerait aussi que dans de rares cas, on trouve l'utilisation de hanīf sans le sens de «païen » dans la poésie préislamique (JefFe RY Arthur, Foreign vocabulary of the Qur'ān, Baroda, Oriental Insitute, 1938, p. 114).

51 Payne Smith Robert, Quatremère Étienne Marc, Bernstein Georg Heinrich et al., Thesaurus syriacus, Oxford, Clarendon Press, 1879, p. 1322. Par exemple: Analecta Syriaca 33,13; Spicilegium Syriacum لV, 2. 
désigner les musulmans, par exemple Nonnos de Nisibe ou Michel le Syrien ${ }^{52}$. Mais le terme, en syriaque comme en arabe, peut également désigner des groupes non chrétiens de culture hellénistique, selon Faris et Glidden ${ }^{53}$. Chez Bar Hebraeus, on trouve une attestation dans les Chroniques syriaques où hanpē serait utilisé par un savant de Harrān pour désigner ses habitants selon la religion pratiquée dans cette ville ${ }^{54}$. Cette utilisation est soutenue, en arabe cette fois, par l'auteur musulman al-Bīrūnī qui décrit les habitants de Ḥarrān, avant qu'ils deviennent chrétiens, comme hunafä ${ }^{25}$. Certains expliquent ce glissement sémantique par le fait que hanīf et ḥanpā ainsi que leurs dérivés ont pu être utilisés pour désigner des groupes monothéistes qui étaient contemporains à la naissance de l'Islam, et qui étaient proches du milieu producteur, comme les mandéens ou les sabéens ${ }^{56}$. Cela expliquerait pourquoi, du côté chrétien, la définition est constamment exclusive, et pourquoi, du côté musulman, elle est positive ou même synonyme de muslim dans un premier temps. Nous ne sommes cependant pas certaine que le sens qu'a pris haniff dans la tradition islamique soit lié à de tels groupes. Un tel changement sémantique peut en effet s'expliquer autrement, comme le souligne Montgomery Watt :

The source must be Syriac, probably with the plural hunafä' (representing hanpé) coming first. In some Aramaean circles, however, the primary meaning of «heathen» or «pagan » was overshadowed by secondary connotations, such as « of Hellenistic culture », so that the word could be applied to philosophically-minded persons who were essentially monotheistic. The Kurānic usage neglected the primary meaning and developed some of the secondary connotations, a semantic process not unknown elsewhere (cf. «snob» in French $)^{57}$.

52 Monferrer-Sala, « Ḥanīf < Ḥanpā. Dos formas de un mismo concepto en evolución. Notas filológicas en torno a un viejo problema », art. cit., 2003, p. 180.

53 Faris N.A. et GLidden Harold W., «The Developement of the Meaning of Koranic Hanif », The Journal of the Palestine Oriental Society 19, 1940-1939, pp. 1-13.

54 Bar Hebraeus, The Chronography of Bar Hebraeus, Oxford, Oxford University Press, 1931, p. 153 .

55 Voir la discussion, FAris et GLidden, «The Developement of the Meaning of Koranic Hanī », art. cit., 1939, pp. 7-8.

56 Voir surtout l'article de Monferrer-Sala, « Hanīf < Ḥanpā. Dos formas de un mismo concepto en evolución. Notas filológicas en torno a un viejo problema», art. cit., 2003.

Montgomery WATt, « H̦anīf», art. cit., 2016. 
2.3.1 Occurence de terme hạif dans 1 Corinthiens dans Vat. Ar. 13

$\mathrm{Au}$ vu de cette pluralité de sens, l'utilisation de haniff dans le texte a retenu notre attention. Celui-ci apparaît à cinq reprises, en l'occurence au pluriel ḩunafa $\vec{a}$, dans les versets 1 Co $1,22.24 ; 10,20.32 ; 12,13$. On trouve dans ces versets

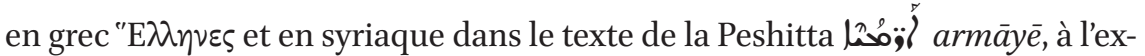
ception du verset $10,20^{58}$. Nous nous concentrons sur les versets 1,22-24; 10,32; 12,13 , dont voici le texte arabe et la traduction ${ }^{59}$ :

1 Co 1,22-24

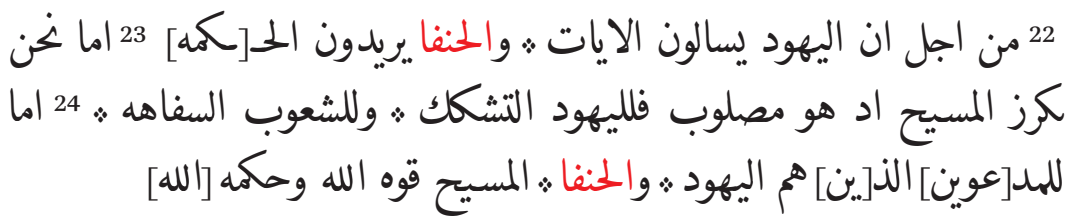

22 Parce que les Juifs demandent des signes et les païens veulent de la sagesse, ${ }^{23}$ mais nous, nous prêchons le Christ comme étant crucifié, pour les juifs scandale, et pour les nations, folie, ${ }^{24}$ mais pour les appelés, ceux qui sont juifs et païens, le Christ est puissance de Dieu et sagesse de Dieu

1 Co 10,32

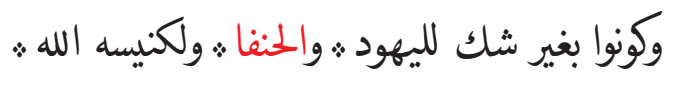

et ne soyez une cause de scandale ni pour les Juifs, ni pour les païens, ni pour l'Église de Dieu.

1 Co 12,13

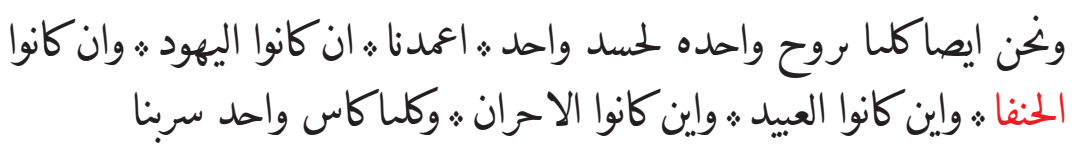

$5^{8}$ Au verset 10,20, notre texte soutient la variante grecque $\tau \dot{\alpha}$ है $\theta v \eta$; la Peshitta a l'équivalent syriaque de hunafă’ que nous avons discuté plus haut. À notre avis, la traduction par hunafä’ se base sur le grec. Voir chapitre 8, point 1 Commentaire verset par verset. Ailleurs $(5,1 ; 12,2)$, le terme $\tau \dot{\alpha}$ हैق

59 Pour consulter les textes en arabe, grec et syriaque, voir chapitre 8, point 1 Commentaire verset par verset. 
Et nous aussi, tous par un seul Esprit pour un seul corps, nous avons été baptisés, étant juifs, païens, esclaves ou libres, et nous tous, nous avons bu à une seule coupe.

Nous choisissons de traduire hunafă’ par «païens », bien qu'il soit difficile de trouver une solution satisfaisante au vu de la pluralité de sens présentée ci-dessus. Nous utilisons ici le terme «païen » selon le sens christiano-centré pour exprimer « ni chrétien, ni juif ».

\subsubsection{Le couple hunafä̀ $/ y a h \bar{u} d$}

Dans le manuscrit Vat. Ar. 13, on trouve donc le terme hanīf en 1 Co 1,22.24; $10,3^{2} ; 12,13^{60}$, qui sont des versets centraux dans la problématique de l'identité chrétienne selon Paul et de sa construction vis-à-vis des deux groupes sociaux que représentent les Juifs et les «païens » greco-romains. Comme dans le texte grec, on trouve les deux termes associés: hunafä'/yahüd. Comment comprendre le sens ḩunafā' ici? À l'époque de la traduction en arabe de 1 Corinthiens telle que transmise dans le Vat. Ar. 13, la situation pour les communautés chrétiennes n'est évidemment plus la même que pour la communauté corinthienne à laquelle Paul s'adresse. La situation a aussi beaucoup changé par rapport aux siècles qui ont suivi l'activité de Paul et l'établissement progressif du christianisme, où le seul vis-à-vis direct pour les chrétiens, du moins en Europe et dans l'Empire byzantin, a longtemps été les communautés juives. En effet, à l'époque de la composition du Vat. Ar. 13, la présence musulmane est une réalité pour les chrétiens de Syrie-Palestine; Homs, ville d'origine probable du manuscrit, est sous autorité arabo-musulane depuis 636. Et si la situation n'a rien à voir avec la « croisée des chemins » du début du christianisme ${ }^{61}$, on peut distinguer une nouvelle composition triangulaire, avec face aux communautés chrétiennes et aux communautés juives, le nouveau groupe social que composent les musulmans. On peut donc se demander ici si le traducteur ne cherche pas, en utilisant le terme polysémique hanīf, à faire référence à sa situation propre et qu'il s'agit ici d'une forme de sous-entendu, d'une Anspielung au sens de haniffen contexte musulman.

Il est possible que le traducteur ne cherche pas à faire référence au sens musulman de hanīf. Nous avons vu le sens syriaque de hanpā, pouvant

6o On le trouve aussi en 10,20, voir note 58 ci-dessus.

61 Le concept de «parting of the ways » a notamment été popularisé par DunN James D. G., Jews and Christians; The Parting of the Ways, $2^{\mathrm{e}}$ edition, Grand Rapids, Eerdmans, 1999. Voir la discussion, Becker A.H., Reed A.Y. (ed.), The Ways that Never Parted: Jews and Christians in Late Antiquity and the Early Middle Ages, TSAJ 95, Tübingen, Mohr Siebeck, 2003 . 
« simplement » désigner le «païen » gréco-romain, et ce même usage chez des auteurs chrétiens arabes. Il nous faut noter également que notre texte n'est pas seul à utiliser ce lexique : le traducteur de Sin. Ar. 155 utilise aussi dans sa traduction de 1 Corinthiens ḩunaf $\tilde{a}^{262}$.

Certains éléments nous permettent malgré tout de soutenir l'hypothèse de lecture d'un choix conscient d'un tel terme. Premièrement, nous avons au chapitre précédent (chapitre 8, point 4.3) déjà discuté plusieurs choix de traduction qui pourrait faire référence au vocabulaire religieux musulman. Il est possible qu'il faille comprendre hanaif $\mathrm{en}$ réseau avec le reste de la traduction. Une étude du reste du corpus paulinien pourrait peut-être permettre d'infirmer ou de confirmer cela. Deuxièmement, l'utilisation hanīf aux versets susmentionnés reste plutôt inattendue. En effet, il ne s'agit pas d'une influence directe du syriaque, car la Peshitta, texte syriaque sur lequel le traducteur s'appuie au côté du texte grec, n'utilise pas hanpē mais armāyē. De plus, d'autres options s'offraient au traducteur. En Sin. Ar. 151, on trouve par exemple pour traduire Hellènes وثنيين wataniyyinna, qui signifie « idolâtres », un choix de traduction à la connotation plutôt négative. On aurait aussi pu attendre يونينيّن yūnāniyyūna, le terme arabe pour désigner les Grecs anciens ${ }^{63}$. C'est d'ailleurs la traduction proposée pour ह̋ $\lambda \lambda \nu \nu$ dans le Glossarium Grceco-Arabicum ${ }^{64}$. C'est aussi le choix de traduction dans la Bible arabe Van Dyke-Smith. Il est intéressant de constater que yūnāniyyūna est utilisé ailleurs dans le corpus paulinien du Vat. Ar. 13, à savoir en Rm 1,14. Les versets 1,14-16 sont traduits ainsi :

Folio 87v :

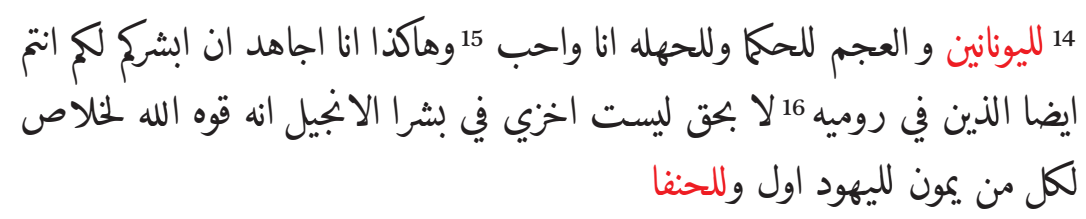

62 Swanson le mentionne au début de son article: Swanson Mark N., «"Folly to the Hunafä": The Crucifixion in Early Christian-Muslim Controversy», in : Tномаs David Richard, Swanson Mark N. et Grypeou Emmanouela (éds), The Encounter of Eastern Christianity with Early Islam, Leiden, Brill, 2006 (The History of Christian-Muslim Relations 5), pp. 237-256.

63 KaZIMIRSKi-Biberstein Wojciech, Dictionnaire arabe-français, contenant toutes les racines de la langue arabe, vol. 2, Paris, Maisonneuve, 1860, p. 1628.

64 Glossarium Greco-Arabicum, <http://telota.bbaw.de/glossga/results.php?gr_lexeme=

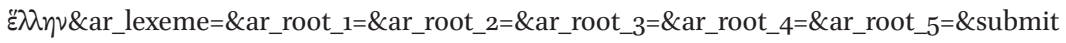
-button=>, recherche effectuée le 21.02.2016. 
${ }^{14}$ Aux Grecs et aux étrangers, aux sages et aux ignorants, je suis obligé, ${ }^{15}$ et ainsi je m'applique à vous annoncer la bonne nouvelle, à vous qui êtes aussi à Rome ; ${ }^{16}$ en vérité, je ne suis pas honteux dans l'annonce de l'évangile, il est puissance de Dieu pour le salut de quiconque croit, pour les Juifs d'abord, pour les païens ensuite.

Alors que dans le texte grec, on trouve hellèn aux versets 14 et 16, le terme yūnāniyyìna est utilisé dans le premier cas alors que, au verset. 16, on trouve à nouveau hunafä̀. Cela donne l'impression que le traducteur utilise consciemment ḥunafă lorsque celui-ci est utilisé conjointement avec yahūd ${ }^{65}$. Il pourrait toutefois aussi être ici influencé dans son choix par la Peshitta, qui a en

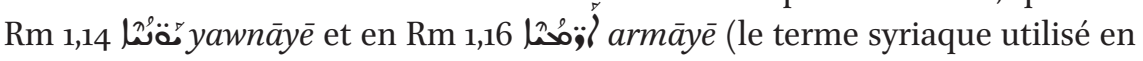
1 Co $1,22.24 ; 10,32 ; 12,13)$. Enfin, comme nous le mentionnons ci-dessus, les auteurs syriaques contemporains utilisent régulièrement le terme hanpē pour désigner les musulmans. Ainsi, Nonnos de Nisibe nomme les musulmans les hadtē hanpēe, les «nouveaux païens ». Selon Griffith, cet usage n'est pas seulement une réactualisation de la signification de hanpā, mais viendrait aussi de la connaissance de la signification de hanîf pour les musulmans :

Of course, in this context, the term does not mean simply pagans. It is used to designate Muslims by the Syriac writers, at least in part, because they would have been well aware of the fact that the Syriac word is cognate to the Arabic term haniff (pl. hunafä), which is used in the Qu'rān [...] One must then conclude that the Syriac apologists of the first Abbasid century employed the term hanpe to designate the Muslims first of all because of the simple fact that the term means «non-Christians ». But one's suspicion must be that these writers were pleased with the double entendre inherent in the meaning of the word in the two languages [...] Such was certainly the intent in several passages to be found in the Arabic Christians apologies ${ }^{66}$.

Si les auteurs syriaques contemporains étaient conscients de ce «double entendre» entre le terme syriaque et le terme arabe et qu'ils en jouent, il nous semble très probable que notre traducteur était aussi conscient de la double signification du terme arabe hanîf. Bien sûr, la situation est ici différente : les

65 Pour comparaison, Sin. Ar. 155 présente dans les deux cas hanīf.

66 Griffith, «The Prophet Muhammad, His Scripture and His Message according to the Christian Apologies in Arabic and Syriac from the First Abbasid Century », art. cit., 1983, pp. 119-120. 
auteurs syriaques et arabes auxquels Griffith fait référence sont bien en train de s'exprimer directement sur leurs rapports aux musulmans, ce qui est un tout autre contexte textuel que celui de notre traduction.

Si l'on renonce à voir une Anspielung dans l'utilisation de hanīf, il reste néanmoins à intégrer les traductions anciennes du Nouveau Testament au dossier de l'évolution de ce terme ${ }^{67}$. Est-il possible d'imaginer pour hanīf une histoire sémantique complètement indépendante de sa réception musulmane? Et si oui, ces réflexions s'appliquent également au reste du vocabulaire trouvé dans la traduction et il faudrait répondre par la négative à la question d'une influence du vocabulaire religieux musulman que nous posions au chapitre 8 , point 4.3.

Si l'on reconnaît une forme d'Anspielung, qu'est-ce que cela signifie ? Il s'agirait d'un exemple de ce que nous avons plus haut décrit comme étant un intercultural text transfer, une prise en compte du contexte de traduction. Derrière les ḥunafä̀ se dessinerait l'autre groupe social composant la société du traducteur, à savoir les musulmans. Il est intéressant que cette question se pose par rapport à des versets si importants pour la question de l'identité chrétienne. Il est important de souligner que cette Anspielung ne porterait pas, à notre avis, de dimension polémique ou insultante. Griffith précise aussi que les auteurs syriaques n'utilisent pas hanpē parce qu'ils considèrent les musulmans comme « idolâtres » ou «polythéistes » ${ }^{68}$. Ce sont simplement les nouveaux «ni juifs et ni chrétiens ». C'est cette nouvelle constellation triangulaire dans la société qui expliquerait le choix de faire apparaître par le traducteur le musulman en filigrane. Nous pourrions aller plus loin en faisant un parallèle entre la résistance des Grecs qui considèrent le message de Paul comme «folie» et les discussions théologiques qu'il y aura entre chrétiens en musulmans à l'époque de notre manuscrit. Mark N. Swanson, dans son article sur les premières controverses islamo-chrétiennes autour de la croix, commence par citer 1 Co 1,22-25 dans la version du Sin. Ar. 155, qui contient aussi le terme hanîf. Il dit alors à propos de ces premières controverses :

67 Faris et Glidden mentionnent en passant Sin. Ar. 155, FARIS et GLIDDEN, « The Developement of the Meaning of Koranic Hanif », art. cit., 1939, p. 6.

68 GRIfFIth, «The Prophet Muhammad, His Scripture and His Message according to the Christian Apologies in Arabic and Syriac from the First Abbasid Century », art. cit., 1983, p. 121. 
Christians who found themselves under Islamic rule as a result of the conquests of the seventh century ad quickly discovered that the New Testament 'word of the cross' had not only been folly to the Greek hunafä' of whom St. Paul had spoken, but was also a puzzle, at the very least, to the Muslim ḥunafă $\bar{a}^{69}$.

Dans tous les cas, la présence du groupe des musulmans dans ces versets pauliniens, qu'elle soit le fruit d'une intention du traducteur ou d'une projection du lecteur qui lira ce texte aujourd'hui, nous semble intéressante et potentiellement porteuse d'un renouvellement des interprétations tel que défendu au chapitre 1, point 2.3.2 Histoire des lectures. En effet, nous avons vu que Paul, dans sa création de la nouvelle identité chrétienne, est dans la continuité et non dans la rupture et travaille au vivre ensemble. C'est en soulignant l'importance et l'actualité de ce message paulinien que Campbell conclut son ouvrage sur Paul et l'identité chrétienne :

The recognition of diversity in Christ has its primary reference within the Church but its significance extend far beyond this. The obligation of acknowledge and accept the other who is and remains different is an inner-Christian stance that is determinated by Christ and life in Christ. It does not depend on the identity of the other, since it is a stance that originates from acknowledging the inherent diversity of God's creation. There is therefore no limit to its extent ${ }^{70}$.

69 Swanson Mark N., «Fì tathlïth Allāh al-wāḥid», in: Thomas David Richard et Rog Gema Barbara (éds), Christian-Muslim Relations: A Bibliographical History (6oo-9oo), Leiden, Boston, Brill, 2009 (The History of Christian-Muslim Relations 11), p. 238. 


\section{Conclusion}

William S. Campbell nous rappelle, dans le message de Paul, la reconnaissance de la diversité humaine et la nécessité d'accepter les différences jusqu'à l'interne des groupes constitués; ou selon la parole imagée de Paul (1 Co 12,20):

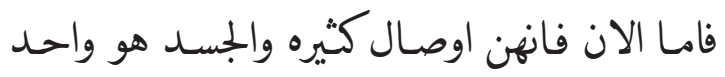

Mais maintenant, il y a plusieurs membres et le corps est un.

Ces propos résonnent tout particulièrement à la fin de cette étude consacrée au manuscrits arabes des lettres de Paul et au témoin Vat. Ar. 13. La transmission du Nouveau Testament se compose de traditions aussi variées qu'il y a de membres dans un corps, et il ne peut y en avoir de plus importantes que d'autres.

Notre recherche a dû se confronter au manque d'intérêt montré par les chercheurs néotestamentaires occidentaux pour la tradition arabe, qui trop longtemps a été déconsidérée. Ce défaut d'intérêt a, d'un côté, été un moteur dans notre recherche : nous souhaitions en explorer les raisons et contribuer à changer cette situation, rejoignant ainsi un mouvement récent porteur de nouvelles recherches. D'un autre côté, la situation de la recherche sur les manuscrits arabes du Nouveau Testament peut représenter plusieurs difficultés pour le chercheur. Nous avons pu thématiser les limites rencontrées dans notre cas: on relèvera par exemple l'impossibilité de croiser nos données avec d'autres, dans le cas de notre répertoire de manuscrits arabes des lettres de Paul (chapitre 5, points 1, 3.1 et 9); le manque d'outils, que cela soit pour l'établissement du répertoire (chapitre 4, point 1 ) ou pour l'approche historico-critique d'un texte en vue de son interprétation (chapitre 9, point 1.1) ; le manque de standard dans l'édition du moyen arabe (chapitre 7 , point 1). Ces discussions, nécessaires pour la recherche, sont accompagnées de résultats concrets au vu des objectifs définis (chapitre 1, point 1) concernant l'évolution de l'histoire de la recherche et de ses défis contemporains, les manuscrits arabes des lettres de Paul et leur transmission, ainsi que le Vat. Ar. 13, sa partie paulinienne et plus particulièrement la première lettre aux Corinthiens.

Dans la première partie de ce travail (Les manuscrits arabes du Nouveau Testament dans la recherche contemporaine), nous montrons, sur la base d'un état de la recherche précis (chapitre 2) que le petit nombre de recherches sur les manuscrits arabes du Nouveau Testament procède d'une «condamnation » de la part de la critique textuelle; cette posture, qui apparait comme peu justifiée scientifiquement, a des racines dans la grande problématique de

(C) SARA SCHULTHESS, 2019 | DOI:10.1163/9789004378162_011

This is an open access chapter distributed under the terms of the prevailing CC-BY-NC License

at the time of publication. 
l'« orientalisme », c'est-à-dire le système de représentation, fait de fascination et de rejet, dans lequel l'Occident a enfermé l'Orient. Quoiqu'il en soit du désintérêt injustifié montré par cette discipline, l'ensemble de ces problématiques est aujourd'hui en voie de renouvellement. Nous montrons notamment que des questions identitaires peuvent se cristalliser autour de ce champ d'études, particulièrement en ce qui concerne les premières traductions du Nouveau Testament et leur potentielle existence préislamique. Certains éléments sont repris de manière polémique dans des discussions qui ont lieu sur internet entre groupes chrétiens et musulmans; ces discussions sont un phénomène non négligeable et peuvent avoir conduit indirectement à la reprise de la recherche que l'on peut observer depuis quelques années, avec un nombre croissant de publications depuis les années 2010. De manière générale, cela montre que la distance entre les productions académiques et non académiques, surtout lorsque celles-ci sont publiées en ligne, est de plus en plus réduite. Il s'agit d'une réalité que la recherche doit prendre en compte. Dans tous les cas, que cela soit face au désintérêt injustifié d'une discipline comme la critique textuelle du Nouveau Testament ou face aux discours identitaires que l'on peut trouver sur certains sites internet, chaque nouvelle recherche approfondie est d'une grande importance (chapitre 3 ).

La deuxième partie de cette recherche (Les manuscrits arabes des lettres de Paul) rassemble les informations nécessaires pour offrir une image plus globale de la transmission du corpus des lettres de Paul en arabe, particulièrement peu étudiée jusqu'à aujourd'hui (chapitre 4). Nos observations (chapitre 5) permettent de relativiser l'idée partagée par les chercheurs, qui considère les traductions des évangiles comme plus anciennes et plus populaires que celles des lettres de Paul. Les lettres de Paul en arabe furent traduites puis copiées parallèlement aux évangiles et le nombre de témoins ayant survécu se rapproche de celui des évangiles. Les données récoltées mettent d'autres aspects intéressants en exergue, comme le lien entre les recensions arabes des évangiles $\mathrm{du} 13^{\mathrm{e}} \mathrm{s}$. et le grand nombre de manuscrits arabes des lettres de Paul à cette même période, un aspect qu'il serait intéressant d'approfondir dans de futures recherches. Nous avons aussi pu mettre en évidence plusieurs manuscrits aux caractéristiques intéressantes, comme par exemple le Venise Marciana Gr. 379, seul manuscrit du Nouveau Testament trilingue grec-arabe-latin, qui est notre objet de recherche actuel.

Après avoir approché les manuscrits arabes des lettres de Paul dans leur ensemble, ce travail se concentre sur le manuscrit Vat. Ar. 13 et sur la première lettre aux Corinthiens (La première lettre aux Corinthiens dans Vat. Ar. 13). Une description du manuscrit sur la base de ses aspects codicologiques, paléographiques et liturgiques met plusieurs éléments en lumière (chapitre 6). 
Elle soutient que la partie paulinienne date du $9^{\mathrm{e}} \mathrm{s}$; ; cela confirme la datation avancée par la recherche pour les parties d'origine du manuscrit, qui jusquà présent s'était surtout concentrée sur quelques folios évangéliques. Nous relevons également les différents éléments byzantins bien présents dans le manuscrit, en rapportant notamment le colophon sur le dernier folio (179v) au genre de l'épigramme byzantin et en décrivant les marques de lecture présents dans tous les cahiers, à l'exception des plus récents. Enfin, nous contestons l'idée, prévalente dans la recherche même récente, que le manuscrit a été composé au monastère de Mar Saba; la mention de la ville de Ḥoms dans l'épigramme grec ainsi que le rôle joué par Joseph Assemani dans l'acquisition du manuscrit placerait plus vraisemblablement son origine dans le patriarcat d'Antioche.

Après cette introduction au Vat. Ar. 13, nous éditons la première lettre aux Corinthiens en privilégiant une approche fidèle au document et à ses particularités (chapitre 7). Nous discutons aussi les potentialités d'une édition sous forme digitale : une telle édition est disponible en libre accès, avec les images du manuscrit, depuis l'été 2016 (<http://tarsian.vital-it.ch/>).

L'étude du texte de 1 Corinthiens (chapitre 8) montre que les lettres de Paul ne sont pas traduites uniquement du grec, contrairement à l'avis général de la recherche (à l'exception de Monferrer-Sala). Il s'agit d'un travail de traduction fait à la fois sur un texte grec et sur un texte syriaque. Le texte syriaque est celui de la Peshitta et son utilisation dans le travail de traduction montre une très grande familiarité avec cette version. Quant au texte grec, nous mettons en évidence la présence dans le texte arabe de plusieurs variantes pré-byzantines ; elles attestent d'une Vorlage grecque d'une qualité textuelle inattendue, dans la perspective de la critique textuelle du Nouveau Testament privilégiant un type de texte alexandrin. Cette étude philologique montre que la traduction a été faite par un traducteur qui maîtrisait le grec, le syriaque et l'arabe; il était familiarisé avec les Écritures en grec et en syriaque. La double Vorlage grecque et syriaque correspond au contexte melkite de l'époque du manuscrit. En conséquence, nous pouvons dire que la traduction comme le manuscrit sont le résultat d'un travail fait dans un milieu melkite; il pourrait s'agir d'une communauté dans la région de Ḥoms.

Dans le dernier chapitre, nous faisons l'essai d'une approche interprétative de passages importants de 1 Corinthiens (chapitre 9). Le choix de nous concentrer sur un manuscrit du Nouveau Testament et son texte vient de notre positionnement en faveur d'une histoire des lectures : éditer ce manuscrit tel qu'il est, c'est donner accès à une lecture particulière du texte du Nouveau Testament, qui n'est plus une simple étape dans la recherche du texte original. C'est aussi soutenir que chacune de ces lectures offre un possible renouvellement des interprétations du texte. Ainsi, l'étude du terme polysémique hanīf et de 
son utilisation dans le Vat. Ar. 13 montre que le texte peut contribuer à une approche renouvelée de la question de l'identité du chrétien.

Les différentes étapes de ce travail, des réflexions générales sur la recherche contemporaine à l'étude d'une lettre de Paul dans un manuscrit unique, en passant par un aperçu de la transmission d'un corpus, constituent une ouverture sur le reste de la tradition. Cette tradition est riche et de nombreux aspects attendent d'être largement explorés. Nous espérons que ce travail aura ouvert une porte sur ce territoire presque inconnu et contribué à le cartographier. 
Sara Schulthess - 978-90-04-37816-2 Downloaded from Brill.come4/26/2023 10:02:45AM via free access 


\section{Bibliographie}

\section{Références du répertoire (chapitre 4)}

\section{$1.1 \quad$ Références générales}

Goussen Heinrich, Die christlich-arabische Literatur der Mozaraber, Leipzig, O. Harrassowitz, 1909. (GousseN)

GraF Georg, Geschichte der christlichen arabischen Literatur, vol. 1, Rome, Biblioteca Apostolica Vaticana, 1944 (Studi e Testi 118). (GCAL I)

GRAF Georg, Geschichte der christlichen arabischen Literatur, vol. 2, Rome, Biblioteca Apostolica Vaticana, 1947 (Studi e Testi 133). (GCAL II)

Horne R George William, The Coptic Version of the New Testament in the Northern Dialect, otherwise called Memphitic and Bohairic, vol. III, Oxford, Clarendon Press, 1905. (HORNER)

LAGaRde Paul, Die vier Evangelien, arabisch aus der Wiener Handschrift herausgegeben, Leipzig, F.A. Brockhaus, 1864. (LAGARDE)

Scholz J.M.A., "Ueber die arabischen Handschriften des N.T. zu Rom», in: Scholz J.M.A., Biblisch-kritische Reise in Frankreich, der Schweiz, Italien, Palästina und im Archipel, in den Jahren 1818, 1819, 1820, 1821, nebst einer Geschichte des Textes N.T., Leipzig, F. Fleischer, 1823, pp. 117-135. (SchOLZ)

Simon Jean, « Répertoire des bibliothèques publiques et privées d'Europe contenant des manuscrits arabes chrétiens », Orientalia N.S. 7, 1938, pp. 239-64.

Tischendorf Constantin, Anecdota sacra et profana ex Oriente et Occidente allata

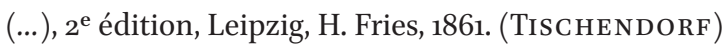

\subsection{Catalogues parville/bibliothèque}

1.2.1 Berlin, Staatsbibliothek

Ahlwardt Wilhelm, Die Handschriften-Verzeichnisse der Königlichen Bibliothek zu Berlin. Bd. 9. Verzeichniss der arabischen Handschriften, Berlin, A. Asher \& Co, 1897. (AHLWARDT)

1.2.2 Beyrouth, Bibliothèque orientale

Cheiк ho Louis, Catalogue raisonné des manuscrits de la bibliothèque orientale: Philosophie et écriture sainte. Mélanges de L'Université Saint-Joseph Beyrouth 10, fasc. 5 , vol. 4, Beyrouth, Imprimerie Catholique, 1925. (СНегкно)

K HALIFÉ Ignace-Abdo, Catalogue raisonné des manuscrits de la bibliothèque orientale: seconde série IV. Mélanges de L'Université Saint-Joseph Beyrouth 39, fasc. 1, Beyrouth, Imprimerie Catholique, 1925. (KHALIFÉ) 
1.2.3 Bzommar, Bibliothèque du Couvent de Bzommar (Liban)

Voir <http://www.vhmml.us/>, consulté le 12.10.2017.

\subsubsection{Caire, Franciscan Center of Christian Oriental Studies}

Maсомвеr William F., Catalogue of the Christian Arabic Manuscripts of the Franciscan Center of Christian Oriental Studies, Muski, Cairo, Jerusalem, Franciscan Press, 1984. (MACOMBER 1)

1.2.5 Caire, Musée copte

GRAF Georg, Catalogue de manuscrits arabes chrétiens conservés au Caire, Rome, Biblioteca Apostolica Vaticana, 1934 (Studi e Testi 63). (GrAF)

Mасомвев William F., Final Inventory of the Microfilmed Manuscripts of the Coptic Museum, Old Cairo, Egypt, 4 vol., Provo (UT), Brigham Young University, 1995. En ligne: <http://cpart.mi.byu.edu/home/manuscripts/cm/>, consulté le 12.10.2017. (MACOMBER 2)

Simaika Pasha Marcus, Catalogue of the Coptic and Arabic Manuscripts in the Coptic Museum, the Patriarchate, the Principal Churches of Cairo and Alexandria and the Monasteries of Egypt, Vol. 1 (Coptic Museum), Le Caire, Goverment Press, 1939. (SIMAIKA 1)

1.2.6 Caire, Patriarcat copte catholique

Maсомвев William F., Final Inventory of the Microfilmed Manuscripts of the Coptic Catholic Patriarchate, Cairo, Egypt, Provo (UT), Brigham Young University, 1995. En ligne: <http://cpart.mi.byu.edu/home/manuscripts/ccp/>, consulté le 12.10.2017. (MACOMBER 3)

\subsubsection{Caire, Patriarcat copte orthodoxe}

GRAF $\rightarrow$ voir 1.2.5. Caire, Musée copte.

Mасомвев William F., Final Inventory of the Microfilmed Manuscripts of the Coptic Orthodox Patriarchate, Al-Azbakiyah, Cairo, Provo (UT), Brigham Young University, 1997. En ligne: <http://cpart.mi.byu.edu/home/manuscripts/cop/>, consulté le 12.10.2017. (MACOMBER 4)

Simaika Pasha Marcus, Catalogue of the Coptic and Arabic Manuscripts in the Coptic Museum, the Patriarchate, the Principal Churches of Cairo and Alexandria and the Monasteries of Egypt, Vol. 2, Fasc. I (Coptic Patriarchate), Le Caire, Goverment Press, 1942. (SIMAIKA 2)

1.2.8 Caire, Bibliothèque du Monastère Mar Menas

Khater Antoine, Khs-Burmester O.H.E., Catalogue of the Coptic and Christian Arabic Mss. Preserved in the Cloister of Saint Menas at Cairo, Le Caire, French Institute of Oriental Archaeology, 1967. (Khater) 
1.2.9 Cambridge, University Library

Browne Edward G., A Hand-List of the Muhammadan Manuscripts, Cambridge, Cambridge University Press, 1900. (BRowne)

Nicholson Reynold A., A Descriptive Catalogue of the Oriental MSS Belonging to the Late E. G. Browne, Cambridge, Cambridge University Press, 1932. En ligne: <http://www.lib.cam.ac.uk/arabic_catalogues/nicholson1932/index.php>, consulté le 12.10.2017. (NICHOLSON)

1.2.10 Charfeh, Bibliothèque patriarcale du monastère syro-catholique de Charfeh

Armalet Isaac, Catalogue des manuscrits de Charfet, Jounieh, Missionnaires Libanais,1936. (ARMALET)

DELAPORTE Louis, «Liste des manuscrits syriaques et carchouni de la bibliothèque du séminaire des syriens à Charfé (Liban). B. Manuscrits carchouni », Nouvelles archives des missions scientifiques et littéraires 17, 1908, pp. 32-41. (DE LAPORTE 1)

1.2.11 Copenhague, Det Kongelige Bibliothek

[s.n], Codices Orientales Bibliothecae Regiae Hafniensis, Pars III. Codices Persici, Turici,

Hindustanici variique alii Bibliothecae Regiae Hafniensis, Copenhague, Schulz, 1857. (Cod. Or. Bibl. Reg. Hafniensis)

\subsubsection{Damas, Bibliothèque du Patriarcat syrien orthodoxe à Homs}

Dōlabānī Yuhanna, Lavenant René, Brock Sebastian P., SAmir Samir K., «Catalogue des manuscrits de la bibliothèque du patriarcat Syrien Orthodoxe à Homs (auj. à Damas) », Parole de l'Orient 19, 1994, pp. 555-661. (DōLABĀNī)

\subsubsection{Deir al-Muharraq, Monastère copte}

Pas de catalogue.

1.2.14 Diyarbakir, Eglise syriaque orthodoxe Meryem Ana

Voir <http://www.vhmml.us/>, consulté le 12.10.2017.

1.2.15 Dublin, Trinity College Library

Аввотт Thomas K., Catalogue of the Manuscripts in the Library of Trinity College, Dublin, Hodges, Figgis \& Co, 1900. (Аввотт)

1.2.16 Duluth, University of Minnesota, Kathryn A. Martin Library, The Ramseyer-Northern Bible Society Collection

Voir <http://www.d.umn.edu/lib/bible/displays/rare/pauline-epistles.htm>, consulté le 12.10 .2017 . 
1.2.17 Escorial, Real Biblioteca de San Lorenzo de El Escorial

Derenbourg Hartwig, Les manuscrits arabes de l'Escurial, vol. 3, révisé par LÉviProvençal E., Paris, Leroux, 1928. (Derenbourg)

1.2.18 Florence, Biblioteca Medicea Laurenziana

Ass emani Stefano Evodio, Bibliothecae Mediceae Laurentianae et Palatinae Codicum

Mss. Orientalium Catalogus [...], Florence, Ex Typographio Albiziniano, 1742. (ASSEMANi)

1.2.19 Göttingen, Staats- und Universitätsbibliothek

Meyer Wilhelm, Die Handschriften in Göttingen. Bd. 3. Universitätsbibliothek.

Nachlässe von Gelehrten, Orientalische Handschriften. Handschriften im Besitz von Instituten und Behörden, Berlin, A. Bath, 1894. (MEYE R)

1.2.20 Groningen, Universiteitsbibliotheek

Brugmans Hajo, Catalogus codicum manu scriptorum universitatis Groninganae bibliothecae, Groningen, J.B. Wolters, 1898. (BRUGMANs)

VOORHOEVE : voir 1.2.25. Leiden, Universiteitsbibliotheek

1.2.21 Halle, Archiv der Franckeschen Stiftungen

PAвsт Erika, Orientalische Handschriften im Archiv der Franckeschen Stiftungen zu Halle, Saale, Archiv der Franckeschen Stiftungen zu Halle, 2003. En ligne: $<$ http://192.124.243.55/orient/orientalia.pdf>, consulté le 12.10.2017. (PABST)

1.2.22 Hambourg, Staats- und Universitätsbibliothek

Brockelmann Carl, Katalog der orientalischen Handschriften der Stadtbibliothek zu Hamburg. Teil 1 : Die arabischen, persischen, türkischen, malaïschen, koptischen, syrischen, äthiopischen Handschriften, Hambourg, O. Meissner, 1908. (BROC KE LMANN)

1.2.23 Jérusalem, Bibliothèque du Monastère grec au Saint-Sépulcre

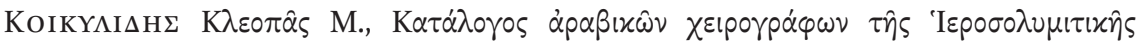

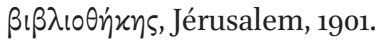

1.2.24 Jérusalem, Bibliothèque du Monastère Saint-Marc Voir <http://www.vhmml.us/>, consulté le 12.10.2017.

1.2.25 Leiden, Universiteitsbibliotheek

De Goeje Michael Jan, Catalogus Codicum Orientalium Bibliothecae Academiae Lugduno Batavae, vol. 5, Leiden, 1873. (DE GOEJE) 
DE Jong Pieter, Catalogus codicum Orientalium Bibliothecae Academiae Regiae Scientiarum, Leiden, Brill, 1862. (DE JoNG)

Voor Hoeve Petrus, Handlist of Arabic Manuscripts in the Library of the University of Leiden and Other Collections in The Netherlands, Leiden, Bibliotheca Universitatis, 1957. (VoORHOEve)

Witкam Jan Just, Inventory of the Oriental Manuscripts of the Royal Netherlands Academy of Arts and Sciences in Amsterdam, Leiden, Ter Lugt Press, 2006. En ligne: $<$ http://islamicmanuscripts.info/inventories/amsterdam/index.html>, consulté le 12.10.2017. (WITKAM 1)

Wiткам Jan Just, Inventory of the Oriental manuscripts in Leiden University Library, Leiden, Ter Lugt Press, 2006-2016. En ligne : <http://www.islamicmanuscripts.info/ inventories/leiden/>, consulté le 12.10.2017. (WIT KAM 2)

Wiткам Jan Just, Catalogue of Arabic Manuscripts in the Library of the University of Leiden and Other Collections in the Netherlands, Leiden, Brill, 1989. (Wiт KAM 3)

1.2.26 Leipzig, Universitätsbibliothek

Volle Rs Karl, Katalog der islamischen, christlich-orientalischen, jüdischen und samaritanischen Handschriften der Universitätsbibliothek zu Leipzig, Leipzig, Harrassowitz, 1906. (VOLLERS)

1.2.27 Londres, British Library

Cureton William, Rie u Charles, Catalogus codicum manuscriptorum orientalium qui in Museo britannico asservantur, Partem secundam, codices Arabicos, Londres, British Museum, 1846. (Cureton)

RIEU Charles, Supplement to the Catalogue of the Arabic Manuscripts in the British Museum, Londres, British Museum, 1894. (RIEU)

Rosen Friedrich, Fors Hall Josiah, Catalogus codicum manuscriptorum orientalium qui in Museo Britannico asservantur, Pars I, codices syriacos et carshunicos amplectens, Londres, British Museum, 1838. (Rosen)

1.2.28 Londres, Library of the School of Oriental and African Studies GACE K Adam, Catalogue of the Arabic Manuscripts in the Library of the School of Oriental and African Studies University of London, Londres, University of London, 1981. (GACEK)

1.2.29 Madrid, Biblioteca Nacional

Guillén Rob les Francisco, Catálogo de los manuscritos árabes existentes en la Biblioteca Nacional de Madrid, Madrid, Tello, 1889. (GuIlléN) 
1.2.30 Manchester, John Rylands Library

Mingana Alphonse, Catalogue of the Arabic Manuscripts in the John Rylands Library Manchester, Manchester, Manchester University Press, 1934. (MInGANA)

1.2.31 Mardin, Bibliothèque de l'Archevêque chaldéen

Sche R Addai, « Notice sur les mss syriaques et arabes conservés dans la bibliothèqe de l'archevêque chaldéen de Mardin », Revue des bibliothèques 18, 1908, pp. 64-94. (SCHER 1)

1.2.32 Milan, Biblioteca Ambrosiana

Löfgren Oscar, Catalogue of the Arabic Manuscripts in the Biblioteca Ambrosiana, Vol. 1. Antico Fondo and Medio Fondo, Vicenza, N. Pozza, 1975• (Löfgren)

\subsubsection{Modène, Biblioteca Estense}

Bernhe imer Carlo, Catalogo dei manoscritti orientali della Biblioteca Estense, Rome, Ist. Poligrafico e Zecca dello Stato, 1960. (BERNHEIMER)

1.2.34 Mor Mattay, Bibliothèque du Monastère syriaque orthodoxe

НАвві, J. et al. (éd.), Catalogue of Syriac Manuscripts in Iraq, II (in Arabic), Baghdad, 1981. (НАв ВІ)

\subsubsection{Mossul, Frères dominicains à Mossul}

Voir <http://www.vhmml.us/>, consulté le 12.10.2017.

\subsubsection{Naples, Biblioteca Nazionale Vittorio Emanuele III}

Guid Ignazio, «Catalogo dei codici siriaci, arabi, turchi e persiani della Biblioteca Vittorio Emanuele», in : Cataloghi dei codici orientali di alcune biblioteche d'Italia: stampati a spese del Ministero della Publica Istruzione, vol. 1, Florence, Le Monnier, 1878, pp. 3-38. (GUIDI)

\subsubsection{Oxford, Bodleian Library}

Nicoll Alexander, Bibliothecae Bodleianae codicum manuscriptorum orientalium catalogi. Partis secundae volumen primum arabicos complectens, Oxford, Ex Typographeo Clarendoniano, 1821. (NICOLL)

Payne Smith Robert, Catalogi Codicum Manuscriptorum Bibliothecae Bodleianae, pars sexta, Codices Syriacos, Carshunicos, Mendaeos, Oxford, E Typographeo Clarendoniano, 1864. (PAYne SMith)

Pusey E. B., Bibliothecae Bodleianae codicum manuscriptorum orientalium catalogi. Partis secundae volumen secundum arabicos complectens, Oxford, Ex Typographeo Clarendoniano, 1835. (PUSEY) 
URI Joannes, Bibliothecae Bodleianae codicum manuscriptorum orientalium, videlicet hebraicorum, chaldaicorum, syriacorum, aethiopicorum, arabicorum, persicorum, turcicorum, copticorumque catalogus. Pars prima, Oxford, E Typographeo Clarendoniano, 1787. (URI).

\subsubsection{Oxford, Queen College Library}

Coxe Henry O., Catalogus codicum mss. qui in collegiis aulisque Oxoniensibus hodie adservantur I, Oxford, Oxford University Press, 1852. (Coxe)

\subsubsection{Paris, Bibliothèque Nationale de France}

Снавот Jean-Baptiste, Inventaire sommaire des manuscrits coptes de la Bibliothèque nationale, Paris, Honoré Champion, 1906. (СНАвот)

Delaporte Louis, Catalogue sommaire des manuscrits coptes de la Bibliothèque nationale de Paris. Première partie. Manuscrits bohaïques, Paris, A. Picard, 1912. (Delaporte 2)

Troupeau Gérard, Catalogue des manuscrits arabes. ière partie : manuscrits chrétiens. Tome I: nos 1-323, Paris, Bibliothèque nationale, 1972. (TroupeAu 1)

Trou PeAu Gérard, Catalogue des manuscrits arabes. ière partie : manuscrits chrétiens. Tome II : manuscrits dispersés entre les nos 780 et 6933 , Paris, Bibliothèque nationale, 1974. (Troupeau 2)

Zotenberg Hermann, Catalogue des manuscrits syriaques et sabéens (mandaïtes) de la Bibliothèque nationale, Paris, Imprimerie nationale, 1874. (ZOTENBERG)

\subsubsection{Princeton, University Library}

Mach Rudolf, Catalogue of Arabic Manuscripts (Yahuda section) in the Garrett Collection Princeton University Library, Princeton, Princeton University Press, 1977. $(\mathrm{MACH})$

1.2.41 Saint-Pétersbourg, Bibliothèque nationale de Russie Voir notre note 39 au chapitre 4 .

1.2.42 Saint-Pétersbourg, Institute of Oriental Manuscripts of the Russian Academy of Sciences

SERI Koff Nikolai, A Descriptive Catalogue of the Christian Arabic Manuscripts Preserved in the St Petersburg Branch of the Institute of Oriental Sudies of the Russian Academy of Sciences, Louvain, Peeters, forthcoming.

\subsubsection{Sinaï, Monastère Sainte-Catherine}

Atrya Aziz Suryal, Catalogue raisonné of the Mount Sinai Arabic Manuscripts: A Hand-List of the Arabic Manuscripts and Scrolls Microfilmed at the Library of the 
Monastery of St. Catherine (en anglais et arabe), Vol. 1, Alexandria, Galal Hazi \& Co, 1970 (ATIYA 1)

AtiYa Aziz Suryal, The Arabic Manuscripts of Mount Sinai, Baltimore, John Hopkins Press, 1954. (AтіYA 2)

KAM I L Murad, Catalogue of all Manuscripts in the Monastery of St. Catherine on Mount Sinai, Wiesbaden, Harrassowitz 1970. (KamıL)

MeIMARĒs Iōannēs Emm., Katalogos tōn neōn arabikōn cheirographōn tēs Hieras Monēs Hagias Aikaterinēs tou Orus Sina (en grec et en arabe), Athènes, National Hellenic Research Foundation, 1985. (MEIMARĒs)

\subsubsection{Vatican, Biblioteca Apostolica Vaticana}

Assemani Stefano Evodio, Biblioteca apostolica vaticana. Bibliothecae Apostolicae Vaticanae codicum manuscriptorum catalogus in tres partes distributus (...), vol. 3 , Paris, Maisonneuve, 1926. (AsSEMANI 2)

Hebbelynck Adolphe et Lantschoot Arnold van, Codices coptici vaticani, Barberiniani, Borgiani, Rossiani. Tomus 1, Rome, Biblioteca Apostolica Vaticana, 1947. (HeBbELYNCK)

Lantschoot Arnold van, Codices coptici vaticani, Barberiniani, Borgiani, Rossiani. Tomus 2, Pars prior, Rome, Biblioteca Apostolica Vaticana, 1947. (LANTsCHоOт)

MAI Angelo, Scriptorum veterum nova collectio e Vaticanis codicibus edita, vol. 4, Rome, Typis Vaticanis, 1831. (MAI)

Sватн Paul, Bibliothèque de manuscrits Paul Sbath. Catalogue, t. 1, Caire, H. Friedrich et Co, 1928. (SвAтн)

SCHE R Addai, Notice sur les manuscrits syriaques du Musée Borgia aujourd'hui à la Bibliothèque Vaticane, Paris, Leroux, 19o9. (SCHER 2)

TISSERANT Eugène, «Inventaire sommaire des manuscrits arabes du fonds Borgia à la Bibliothèque Vaticane », in Scritti di storia e paleografia: Bibliotheca ed archivio biblioteche diverse, vol. 5, Rome, Biblioteca Apostolica Vaticana, 1924, pp. 1-34. (TISSERANT)

\subsubsection{Venise, Biblioteca Nazionale Marciana}

Mion I Elpidio, Bibliothecae Divi Marci Venetiarum Codices Graeci Manuscripti, vol. 1, Rome, Istituto Poligrafico e Zecca dello Sato, 1985. (MIONI)

Veludo Giovanni, « Codices Orientales Bibliothecae ad D. Marci Venetiarum », 1877. En ligne: $<$ http://www.nuovabibliotecamanoscritta.it/Generale/ricerca/Anteprima Manoscritto.html?codiceMan=42707>, consulté le 11.03.2016. (VELUdo)

Zanetti A. M., Bongiovanni A., Graeca D. Marci Bibliotheca codicum manuscriptorum. Londres, Apud Simonem Occhi Bibliopolam, 1740. (ZANETTi) 


\subsubsection{Wolfenbüttel, Herzog August Bibliothek}

Fleischer Henricus Orthobius, Catalogus Codicum Manuscriptorum Orientalium Bibliothecae Regiae Dresdensis : accedit Friderici Adolphi Eberti Catalogus codicum manuscriptorum orientalium Bibliothecae Ducalis Guelferbytanae, Leipzig, 1831. (FLEISCHER)

KöHlen Franz, Milchsack Gustav, Die Handschriften der Herzoglichen Bibliothek zu Wolfenbüttel. 4. Abt. Die Gudischen Handschriften: Die griechischen Handschriften bearbeitet von Franz Köhler; Die lateinischen Handschriften bearbeitet von Gustav Milchsack, Wolfenbüttel, Zwissler, 1913. (KöHLER)

\section{Outils (avec les abréviations pour le chapitre 8)}

\subsection{Sources et éditions}

Aland Barbara et Kurt, Karavido pou los Johannes, Martini Carlo M. et Metzger Bruce M. (éds), Nestle-Aland Novum Testamentum Graece, $28^{\mathrm{e}}$ édition, Stuttgart, Deutsche Bibelgesellschaft, 2012. (NA28)

Aland Barbara, Das Neue Testament in syrischer Überlieferung. II. Die Paulinischen Briefe. Teil ı. Römer- und 1. Korintherbrief, Berlin, New York, de Gruyter, 1991. (ALAND) Bar Hebraeus, The Chronography of Bar Hebraeus, par traduit par E. A. W. Budge, Oxford, Oxford University Press, 1931.

Er Penius Thomas, ed., Novum Domini Nostri Jesu Christi Testamentum arabice, ex Bibliotheca Leidesi, Leiden, 1616.

Gibson Margaret Dunlop, An Arabic Version of the Epistles of St Paul to the Romans, Corinthians, Galatians with Part of the Epistles to the Ephesians, Londres, C. J. Clay, 1894 (Studia Sinaitica 2).

HAFIANE Hachemi, Le Saint Coran et la traduction du sens de ses versets en claire langue française, Paris, Presses du Châtelet, 2008.

Holmes Michael W., The Greek New Testament. SBL Edition, Atlanta, Washington, SBL/Logos Bible Software, 2010. En ligne: <http://www.sblgnt.com>, consulté le o6.03.2016.

Horner George William, The Coptic Version of the New Testament in the Northern Dialect, otherwise called Memphitic and Bohairic, vol. III, Oxford, Clarendon Press, 1905. (HORNER)

Pin Ke Rt on J., Kilg OuR R., The New Testament in Syriac, Londres, British and Foreign Bible Society, Oxford University Press, 1920.

StaAl Harvey, Mt. Sinai Arabic Codex 151 I: The Pauline Epistles, vol. 1, Louvain, Peeters, 1983 (csco 452); Mt. Sinai Arabic Codex 151 I: The Pauline Epistles, vol. 2, Louvain, Peeters, 1983 (CSCO 453). (STAAL) 
Tertullien, Apologétique, texte établi et traduit par J. P. WAltzing avec la collaboration de A. Severyns, Paris, Les Belles Lettres, 1998.

Tischendorf Constantin, Novum Testamentum Graece. Ad antiquissimos testes denuo recensuit apparatum criticum omni studio perfectum, vol. 1, 8 édition, Leipzig, Giesecke \& Devrient, 1869.

Tischendorf Constantin, Novum Testamentum Graece. Ad antiquos testes recensuit, apparatum criticum multis modis auctum et correctum apposuit, commentationem isagogicam praemisit ..., Leipzig, Winter, 1849.

[s.n.], Al-Ingîl al Muqaddas. Evangelium sanctum, Rome, Ex Typographia Medicæ, 1590-1591.

[s.n], Biblia hebraïca, samaritana, chaldaïca, grceca, syriaca, latina, arabica, quibus textus originales totius Scripturce Sacrce (...), éditée par Guy Michel Lejay, imprimée à Paris par Antoine Vitré, 1628-1645.

[s.n], Biblia Sacra polyglotta, complectentia textus originales, hebraicum, cum Pentateucho samaritano, chaldaicum, graecum ; versionumque antiquarum, samaritanae, graecae LXXII interp., chaldaicae, syriacae, arabicae (...), Londres, imprimée par Thomas Roycroft, 1657 .

[s.n.], Biblia sacra Arabica: Sacrae Congregationis de propaganda fide iussu edita ad usum Ecclesiarum Orientalium :Additis è regione Bibliis Latinis vulgatis, Rome, Sacra Congregatio de Propaganda Fide, 1671.

\subsection{Dictionnaires et lexiques}

BELOT Jean-Baptiste, Vocabulaire arabe-français, $6^{\mathrm{e}}$ édition, Beyrouth, Imprimerie catholique, 1899. (BELOT)

Costaz Louis, Dictionnaire syriaque-français, Beyrouth, Impr. Catholique, 1963. (Costaz)

GRAF Georg, Verzeichnis arabischer kirchlicher Termini, 2e édition, Louvain, Imprimerie orientaliste, 1954. (GRAF, Termini)

Jennings William, Gantillon Ulric, Lexicon to the Syriac New Testament (Peshitta), Oxford, Clarendon Press, 1926. (Jennings)

KAZIMIRSKi-Biberstein Wojciech, Dictionnaire arabe-français, contenant toutes les racines de la langue arabe, vol. 1, Paris, Maisonneuve, 1860. (KAZIMIRSKI 1)

KAZIMIRSKi-BIBERSTEIN Wojciech, Dictionnaire arabe-français, contenant toutes les racines de la langue arabe, vol. 2, Paris, Maisonneuve, 1860. (KAZIMIRSKI 2)

LANe Edward William, Arabic-English Lexicon, Londres, Willams \& Norgate, 1863. (LANE)

Payne Smith Robert, Payne Smith Margoliouth Jessie, A Compendious Syriac Dictionary, Founded Upon the Thesaurus Syriacus of R. Payne Smith, Oxford, Clarendon Press, 1957. (PAYNe SMith) 
Payne Smith Robert, Quatremère Étienne Marc, Bernstein Georg Heinrich et al., Thesaurus syriacus, Oxford, Clarendon Press, 1879.

REIG Daniel, Dictionnaire arabe-français, français-arabe, Paris, Larousse, 1983. (REIG)

\subsection{Grammaires}

BLAU Joshua, A Grammar of Christian Arabic, Based Mainly on South-Palestinian Texts from the First Millennium, vol. Subsidia 27, Louvain, Secrétariat du CorpusSCO, 1966 (CsCO 267). (BLAU)

BLAU Joshua, A Handbook of Early Middle Arabic, Jérusalem, The Max Schloessinger Memorial Foundation, The Hebrew University, 2002 (The Max Schloessinger Memorial Studies Monographs 6). (BLAU 2)

Brockelmann Carl, A. Socin's Arabische Grammatik: Paradigmen, Literatur, Übungsstücke und Glossar, Berlin, Reuther \& Reichard, 1904.

Costaz Louis, Grammaire syriaque, Beyrouth, Impr. Catholique, 1964. (Costaz, Grammaire)

PÉrier Augustin, Nouvelle grammaire arabe, Paris, Leroux, 1940. (PÉrIER)

\section{$2.4 \quad$ Commentaires bibliques}

FeE Gordon D., The First Epistle to the Corinthians, Grand Rapids, Eerdmans, 1987. (FEE)

Fitzmyer Joseph A., First Corinthians, Yale University Press, 2008. (FItZMYER)

Lindemann Andreas, Der Erste Korintherbrief, Mohr Siebeck, 2000.

Sс ноттво F Luise, Der erste Brief an die Gemeinde in Korinth, Stuttgart, Kohlhammer, 2013 (Theologischer Kommentar zum Neuen Testament 7). (Sс нотт RоғF)

SEnft Christophe, La première épitre de Saint-Paul aux Corinthiens, Neuchâtel, Delachaux \& Niestlé, 1979. (SENFT)

Zeller Dieter, Der erste Brief an die Korinther, Göttingen, Vandenhoeck \& Ruprecht, 2010. (ZELLER)

\section{Littérature secondaire}

Аввот Nadia, The Rise of the North Arabic Script and Its Kur'ānic Development, with a Full Description of the Kur'än Manuscripts in the Oriental Institute, Chicago, University of Chicago Oriental Institute Publications, 1939.

ACCAD Martin, «Corruption and/or Misinterpretation of the Bible, the Story of the Islâmic Usage of Tahrîf », NEST Theological Review 24 (2), 2003, pp. 67-97.

AlAND Barbara, «Die neuen neutestamentlichen Handschriften vom Sinai», in: Bericht der Hermann-Kunst-Stiftung zur Förderung der neutestamentlichen 
Textforschung (1982-1984), Münster, Hermann-Kunst-Stiftung zur Förderung der neutestamentlichen Textforschung, 1985, pp. 76-89.

Aland Barbara, Das Neue Testament in syrischer Überlieferung. II. Die Paulinischen Briefe. Teil 1. Römer- und 1. Korintherbrief, Berlin, New York, de Gruyter, 1991.

Aland Kurt (éd.), Kurzgefaßte Liste der griechischen Handschriften des Neuen Testaments, 2 édition, Berlin, Boston, De Gruyter, 2011.

Aland Kurt et Aland Barbara, The Text of the New Testament: An Introduction to the Critical Editions and to the Theory and Practice of Modern Textual Criticism, 2 édition, Grand Rapids, Eerdmans Publishing Co., 1995 (Studies and Documents 46).

ALford Henry, The Greek Testament: With a Critically Revised Text, A Digest of Various Readings, Marginal References to Verbal and Idiomatic Usage, Prolegomena, And a Critical and Exegetical Commentary, vol. 1, 4 édition, Londres, Rivingtons, 1859.

Aмpнoux Christian-B., « Les lieux de rédaction des lettres de Paul d'après la tradition manuscrite », BABELAO 2, 2013, pp. 87-104.

Arbache Samir et Roisse Philippe, «Marc 1, 1-11 arabe. Versions anciennes de SyriePalestine et d'al-Andalus », Mélanges de Science Religieuse 2, 2005, pp. 65-78. En ligne : $<$ http://bdr.proxience.net/opac_css/index.php?lvl=notice_display\&id=205053 >.

Arbache Samir, «La naissance du Prophète Muhammad. Approche thématique et littéraire des textes traditionnels », in : CANNUyer Christian et VIALle Catherine (éds), Les naissances merveilleuses en Orient. Jacques Vermeylen (1942-2014) in memoriam, Société belge d'études orientales, 2015 (Acta Orientalia Belgica 28), pp. 305-321.

Arbache Samir, L'Évangile arabe selon saint Luc: texte du VIIIe siècle, copié en 897, Bruxelles, Safran, 2012.

Arbache Samir, «Le texte du Sinaï Arabe 72 : éléments de morphologie verbale», in: LENTIN Jérôme et GRAND'Henry Jacques (éds), Moyen arabe et variétés mixtes de l'arabe à travers l'histoire. Actes du Premier Colloque International (Louvain-laNeuve, 10-14 mai 2004), Louvain, Peeters, 2008 (Publications de l'Institut Orientaliste de Louvain 58), pp. 1-20.

Arbache Samir, «Le terme kitāb (Écriture) dans le Coran et dans une ancienne version arabe des Evangiles », in: De Smet D., Callatay G. De et Reeth J.M.F. VAN (éds), Al-Kitab : la sacralité du texte dans le monde de l'islam : actes du Symposium international tenu à Leuven et Louvain-la-Neuve du 29 mai au 1 juin 2002, Bruxelles, Peeters, 2004 (Acta Orientalia Belgica. Subsidia 3), pp. 321-332.

Arbache Samir, «Les versions arabes des Évangiles», Mélanges de Science Religieuse 3, 1999, pp. 85-94. En ligne: <http://bdr.proxience.net/opac_css/index. php?lvl=notice_display\&id=198619>.

Arbache Samir, Une version arabe des évangiles : Langue, texte et lexique, Ph.D., Université Michel de Montaigne Bordeaux III, 1994. 
Aв вACHe Samir, Le tétraévangile Sinai arabe 72, ses rubriques liturgiques et son substrat grec, Mémoire de licence, Université catholique de Louvain, 1975.

Assemani Joseph Simon, Bibliotheca Orientalis Clementino-Vaticana : In Qua Manuscriptos Codices Syriacos, Arabicos, Persicos, Turcicos, Hebraicos, Samaritanos, Armenicos, Aethiopicos, Graecos, Aegyptiacos, Ibericos, \& Malabaricos, Jussu et Munificentia Clementis XI. Pontificis Maximi Ex Oriente conquisitos, comparatos, avectos, \& Bibliothecae Vaticanae addictos, vol. 1, Rome, Typis Sacrae Congregationis de Propaganda Fide, 1719.

Aube RT J., «Homs », in : Dictionnaire d'histoire et de géographie ecclésiastiques, vol. 24, Paris, Letouzey et Ané, 1993.

Atrya Aziz Suryal, « Codex Arabicus (Sinai Arabic Ms. No. 514) », in : Le HMANN-Haupt Hellmut (éd.), Homage to a Bookman: Essays on Manuscripts, Books and Printing Written for Hans P. Kraus on His 6oth Birthday Oct. 12, 1967, Berlin, Gebr. Mann Verlag, 1967 , pp. $75^{-85}$.

BADY Guillaume, « Petit album de paléographie grecque», Sources chrétiennes, HiSoMa, 2007. En ligne : <http://www.sources-chretiennes.mom.fr/upload/doc/Album_ paleo_grecque.pdf $>$, consulté le 19.10.2015.

BASsnett Susan, Translations Studies, 4 e édition, Londres, New York, Routledge, 2014.

BAUMSTARK Anton, «Eine frühislamische und eine vorislamische arabische Evangelienübersetzung », in : Atti Del XIX Congresso Internazionale Orientalisti, Rome, Tipografia del Senato, 1938, pp. 682-684.

BAUMstark Anton, « Markus Kap. 2 in der arabischen Übersetzung des Isaak Velasquez », Oriens Christianus 9, 1934, pp. 226-239.

Baumstark Anton, «Der älteste erhaltene griechisch-arabische Text von Psalm 110 (109)», Oriens Christianus 9, 1934, pp. 55-66.

BAUMStark Anton, «Eine altarabische Evangelienübersetzung aus dem ChristlichPalästinensischen», Zeitschrift für Semitistik and verwandte Gebiete 8, 1932, pp. 201-209.

BAUmstark Anton, « Das Problem eines vorislamischen christlich-kirchlichen Schrifttums in arabischer Sprache », Islamica 4, 1931, pp. 574-575.

BAUMSTARK Anton, « Die sonntägliche Evangelienlesung im vorbyzantinischen Jerusalem », Byzantinische Zeitschrift 30, 1930, pp. 350-359.

Bentein Klaas et Demoen Kristoffel, «The Reader in Eleventh-century Book Epigrams », in : Be RNARd Floris et Demoen Kristoffel (éds), Poetry and its Contexts in Eleventh-century Byzantium, Farnham, Ashgate, 2013, pp. 69-88.

BE RRA Aurélien, «Faire des humanités numériques », in : Read/Write Book 2 : Une introduction aux humanités numériques [en ligne], Marseille, OpenEdition Press, 2012. En ligne : <http://books.openedition.org/oep/238>, consulté le 07.03.2016.

Bertho Benjamin, «Judaïsme, historiographie et apologétique chez Théophile d'Antioche : d'Abraham à Flavius Josèphe », in : Clivaz Claire, Mimouni Simon et 
POUdE RON Bernard (éds), Les judaïsmes dans tous leurs états aux Ier-IIIe siècles (les Judéens des synagogues, les chrétiens et les rabbins). Actes du colloque de Lausanne, 12-14 décembre 2012, Brepols, Turnhout, 2015 (Judaïsme ancien et origines du christianisme 5), pp. 275-295.

BingGeli André, «Les trois David, copistes arabes de Palestine aux ge-10e s. », in : Binggeli André, Boud'hors Anne et Cassin Matthieu (éds), Manuscripta Graeca et Orientalia. Mélanges monastiques et patristiques en l'honneur de Paul Géhin, Leuven, Peeters, 2016, pp. 79-117.

B LAU Joshua, Studies in Middle Arabic and Its Judaeo-Arabic Variety, Jérusalem, Magnes Press, 1989 .

BLAU Joshua, «The State of Research in the Field of the Linguistic Study of Middle Arabic », Arabica (28), 1981, pp. 187-203.

BLAU Joshua, «Sind uns Reste arabischer Bibelübersetzungen aus vorislamischer Zeit erhalten geblieben ?», Le Muséon 86, 1973, pp. 67-72.

BLAU Joshua, «Über einige christlich-arabische Manuskripte aus dem 9. und 10. Jahrhundert », Le Muséon 75, 1962, pp. 101-108.

Bоттіn L Laura, « The Apology of al-Kindī », in : Thомas David Richard et Rog Gema Barbara (éds), Christian-Muslim Relations : A Bibliographical History (60o-90o), Leiden, Boston, Brill, 2009 (The History of Christian-Muslim Relations 11), pp. 585-594.

Boyd R.H., The Arabic text of I Corinthians in «Studia sinaitica no. II »; a Comparative Linguistic and Critical Study, Princeton, Princeton University, 1942.

Bozzol I Carla et Ornato Ezio, Pour une histoire du livre manuscrit au Moyen Âge: Trois essais de codicologie quantitative, Paris, CNRS, 1983.

Brock Sebastian P., The Bible in the Syriac Tradition, $2^{\mathrm{e}}$ édition, Piscataway, Gorgias Press, 2006.

Brock Sebastian P., «A Neglected Witness to the East Syriac New Testament Commentary Tradition : Sinai Arabic MS 151 », in : EBIED Rifaat et TEUle Herman (éds), Studies on the Christian Arabic Heritage, Louvain, Peeters, 2004 (Eastern Christian Studies 5), pp. 205-215.

Brock Sebastian P., «A Palimpsest Folio of Matt 20 :23-31 (Peshitta) in Sinai Ar. 514 (“Codex Arabicus") », Orientalia. Nova Series 61 (2), 1992, pp. 102-105.

Brock Sebastian P., «The Syriac Euthalian Material and the Philoxenian Version of the New Testament», Zeitschrift für die neutestamentliche Wissenschaft 70, 1979, pp. 120-130.

BuRKITT Francis Crawford, «Arabic Versions», in: Dictionary of the Bible: Dealing with Its Language, Literature, and Contents Including the Biblical Theology, vol. 1, Edinburgh, T\&T Clark, 1898, pp. 136-138.

Busino Giovanni, «Matériaux pour l'histoire de la sociologie de la connaissance», Revue européenne des sciences sociales [En ligne] XLV (139), 2007. En ligne : <http:// ress.revues.org/187>, consulté le 26.02.2016. 
CAmp be Ll William S., Paul and the Creation of Christian Identity, New York, T\&T Clark, 2006 (Library of New Testament Studies 322).

Cannuyer Christian, Les Coptes, Turnhout, Brepols, 1990.

CAnnuyer Christian, «Langues usuelles et liturgiques des Melkites au XIIIe siècle », Oriens Christianus 70, 1986, pp. 110-117.

Carra de Vaux B. et Anawati Georges C., «Indjīl», in: Encyclopaedia of Islam, $2^{\mathrm{e}}$ édition, Brill Online, 2016. En ligne: <http://referenceworks.brillonline.com/ entries/encyclopaedia-of-islam-2/indjil-COM_0373>, consulté le 09.02.2016.

С негк но Louis, An-nașrāniyya wa-ādābuhā bayna 'arab al-jāhiliyya, 3 vol., Beyrouth, Imprimerie Catholique, 1912.

Clivaz Claire, « Mais où est le corps ? L'Homme augmenté comme lieu des Humanités Digitales », in : L’homme augmenté (eTalks), Lausanne, Swiss Institute of Bioinformatics, éditions VITAL-DH, 2015. En ligne: <http://etalk2.vital-it.ch/?dir=Clivaz>, consulté le 07.03.2016.

Clivaz Claire, «Internet Networks and Academic Research : the Example of the New Testament Textual Criticism », in : Clivaz Claire, Gregory Andrew et HamidoVIC David (éds), Digital Humanities in Biblical, Early Jewish and Early Christian Studies, Leiden, Brill, 2013 (Scholarly Communication 2), pp. 151-173.

Clivaz Claire, When «Humanities » Goes beyond History and Sociology in Digital Biblical Studies, Présentation orale, Society of Biblical Literature, International Meeting, St-Andrews, 08.07.2013.

Clivaz Claire, «Common Era 2.0. Reading Digital Culture from Antiquity and Modernity», in : Clivaz Claire, Meizoz Jérôme, Vallotton François et al. (éds), Reading Tomorrow. From Ancient Manuscripts to the Digital Era / Lire Demain. Des manuscrits antiques à l'ère digitale, ebook, Lausanne, PPUR, 2012, pp. 23-6o.

Clivaz Claire, «Homer and the New Testament as "Multitexts" in the Digital Age?», Scholarly Research Communication 3 (3), 2012, pp. 1-15. En ligne: <http://www. src-online.ca/index.php/src/article/view/97>, consulté le 09.02.2016.

Clivaz Claire, L'ange et la sueur de sang (Lc 22,43-44), ou comment on pourrait bien encore écrire l'histoire, Louvain, Paris, Walpole, Ma, Brepols, 2010 (Biblical Tools and Studies 7).

Clivaz Claire, Meizoz Jérôme, Vallotton François et al. (éds), Reading Tomorrow. From Ancient Manuscripts to the Digital Era / Lire Demain. Des manuscrits antiques à l'ère digitale, ebook, Lausanne, PPUR, 2012.

Clivaz Claire, Schulthess Sara et SAnkar Martial, «Editing New Testament Arabic Manuscripts on a TEI-base : Fostering Close Reading in Digital Humanities », Journal of Data Mining and Digital Humanities, Special Issue on Computer-Aided Processing of Intertextuality in Ancient Languages, 2017. En ligne : $<$ https://jdmdh. episciences.org/paper/view?id=3700 $>$. 
Clivaz Claire et Sc hulthess Sara, « On the Source and Rewriting of 1 Corinthians 2.9 in Christian, Jewish and Islamic Traditions (1 Clem 34.8; GosJud 47.10-13; a hadìth qudsī) », New Testament Studies 61 (2), 2015, pp. 183-200. En ligne : Cambridge Journals Online, <http://journals.cambridge.org/article_Soo28688514000307>.

Cloarec Vincent et Laurens Henry, Le Moyen-Orient au 2oe siècle, Paris, Armand Colin, 2003.

Dannaoui Elie, «Digital Arabic Gospels Corpus», in: Clivaz Claire, Gregory Andrew et Hamidovic David (éds), Digital Humanities in Biblical, Early Jewish and Early Christian Studies, Leiden, Brill, 2013 (Scholarly Communication 2), pp. 61-70.

Davidson Samuel, A Treatise on Biblical Criticism: Exhibiting a Systematic View of That Science, Edimburgh, A\&C Black, 1852.

DÉroche François (éd.), Manuel de codicologie des manuscrits en écriture arabe, Paris, Bibliothèque nationale de France, 2000.

Dumper Michael et Stanley Bruce E., Cities of the Middle East and North Africa: A Historical Encyclopedia, Santa Barbara, ABC-CLIO, 2007.

Dussaud René, « Chapitre II. De Tripoli à Carné. - L'Émésène », in : Topographie historique de la Syrie antique et médiévale, Beyrouth, Presses de l'Ifpo, 2015 (Bibliothèque archéologique et historique 4), pp. 75-115. En ligne: OpenEdition Books, <http:// books.openedition.org/ifpo/3699>, consulté le 22.03.2016.

Duteil-Ogata Fabienne, Jonveaux Isabelle, Kuczynski Liliane et al., « Le religieux sur Internet : textes et contextes », in : Duteil-Ogata Fabienne, JonvEAuX Isabelle, KuCZYNs Ki Liliane et al. (éds), Le religieux sur Internet, Paris, L'Harmattan, 2015, pp. 9-30.

Eco Umberto, Vertige de la liste, Paris, Flammarion, 2009.

E hrman Bart D., Misquoting Jesus: The Story Behind Who Changed the Bible and Why, New York, Oxford University Press, 2005.

E Hrman Bart D., The Orthodox Corruption of Scripture: The Effect of Early Christological Controversies on the Text of the New Testament, New York, Oxford, Oxford University Press, 1993.

Ehrman Bart D. et Holmes Michael W., The Text of the New Testament in Contemporary Research: Essays on the Status Quaestionis. Second Edition, Leiden, Brill, 2012 (New Testament Tools, Studies and Documents 42).

ENGBERG Sysse, «Les lectionnaires grecs», IRHT, 2015. En ligne: <http://irht.hypo theses.org/612>, consulté le 23.05.2016.

Epp Eldon J., «It's All About Variants : A Variant-Conscious Approach to New Testament Textual Criticism », Harvard Theological Review 100 (3), 2007, pp. 257-308.

Epp Eldon J., «The Multivalence of the Term “Original Text” in New Testament Textual Criticism », Harvard Theological Review 92, 1999, pp. 245-299.

EpP Eldon J., The Theological Tendency of Codex Bezae Cantabrigiensis in Acts, Cambridge, Cambridge University Press, 1966 (Society for New Testament Studies Monograph Series 3). 
ERrington Joseph, Linguistics in a Colonial World: A Story of Language, Meaning, and Power, Malden, Blackwell, 2008.

Esbroeck Michel van, «Les versions orientales de la Bible: une orientation bibliographique », in : KrAšovec Jože (éd.), The Interpretation of the Bible : the International Symposium in Slovenia, Sheffield, Sheffield Academic Press, 1998 (Journal for the study of the Old Testament 289), pp. 399-509.

EURINGER Sebastian, «Zum Stammbaum der arabischen Bibelhandschriften Vat. ar. 468 und 467 », Zeitschrift für Semitistik und verwandte Gebiete 7, 1929, pp. 259-273.

Ewert David, A General Introduction to the Bible: from Ancient Tablets to Modern Translations, Grand Rapids, Zondervan, 1990.

Faris N.A. et Glidden Harold W., «The Developement of the Meaning of Koranic Hanīf », The Journal of the Palestine Oriental Society 19, 1940.1939, pp. 1-13.

FÉG HAli Paul, «The Holy Books in Arabic: The Example of the Propaganda Fide Edition », in : BInAY Sara et LEDER Stefan (éds), Translating the Bible into Arabic: Historical, Text-Critical and Literary Aspects, Würzburg, Beyrouth, Ergon-Verlag, 2012 (Beiruter Texte und Studien 131), pp. 37-51.

FÉGHALI Paul, «Les épîtres de Saint Paul dans une des premières traductions en arabe », Parole de l'Orient 30, 2005, pp. 103-130.

Fischer Wolfdietrich, «What is Middle Arabic?», in: Kaye Alan S. (éd.), Semitic Studies in Honor of Wolf Leslau, 2 vol., Wiesbaden, Otto Harrassowitz Verlag, 1991, pp. $430-436$.

Fleischer Heinrich Leberecht, «Beschreibung der von Prof. Dr. Tischendorf im J. 1853 aus dem Morgenlande zurückgebrachten christlich-arabischen Handschriften », Zeitschrift der Deutschen Morgenländischen Gesellschaft 8, 1854, pp. 584-587.

FLE ISC HE R Heinrich Leberecht, Kleinere Schriften, vol. 3, Leipzig, S. Hirzel, 1885.

Fraze E Charles A., Catholics and Sultans. The Church and the Ottoman Empire (14531923), Londres, New York, Cambridge University Press, 1983.

Frede Hermann Josef, «Die Ordnung der Paulusbriefe und der Platz des Kolosserbriefs im Corpus Paulinum », in : Frede Hermann Josef, Epistulae ad Philippenses et ad Colossenses, Freiburg, Verlag Herder, 1966 (Vetus Latina 24), pp. 290-303

Fück Johann W., Hartmann Richard et Scheel Helmuth, Die arabischen Studien in Europa bis in den Anfang des 20. Jahrhunderts, Leipzig, Otto Harrassowitz, 1955.

GACEk Adam, Arabic Manuscripts : A Vademecum for Readers, Leiden, Boston, Brill, 2009 (Handbook of Oriental Studies. Section 1, the Near and Middle East Ancient Near East 98).

GÉHIN Paul, «Un manuscrit bilingue grec-arabe, BnF, Supplément grec 911 (année 1043) », in : Déroche François (éd.), Scribes et manuscrits du Moyen-Orient, Paris, Bibliothèque nationale de France, 1997 (Études et recherches / Bibliothèque nationale de France), pp. 162-175. 
GemAYE L Nasser, Les échanges culturels entre les Maronites et l'Europe : du Collège maronite de Rome (1584) au Collège de 'Ayn-Warqa (1789), vol. 1, Beyrouth, Impr. Y. et Ph. Gemayel, 1984 .

Gerber Daniel, «La construction de l'identité en Christ dans une ville gréco-romaine d'après la première lettre de Paul aux Corinthiens », Revue d'histoire et de philosophie religieuse 93 (1), 2013, pp. 105-120.

Gibson Margaret Dunlop, An Arabic Version of the Acts of the Apostles and the Seven Catholic Epistles, Londres, C. J. Clay, 1899 (Studia Sinaitica 6).

Gibson Margaret Dunlop, An Arabic Version of the Epistles of St Paul to the Romans, Corinthians, Galatians with Part of the Epistles to the Ephesians, Londres, C. J. Clay, 1894 (Studia Sinaitica 2).

Gildemeister Johann, De Evangeliis in Arabicum e simplici Syriaca translatis, Bonn, Marcus, 1865.

Gilet Julien, «Al-Maktaba al-Shamela = المكتبة الشاملة», Aldébaran, Collections numériques, 12.12.2010. En ligne: <http://aldebaran.revues.org/6597>, consulté le 07.04.2016.

Gousse n Heinrich, Die christlich-arabische Literatur der Mozaraber, Leipzig, O. Harrassowitz, 1909.

GRAF Georg, Geschichte der christlichen arabischen Literatur, vol. 2, Rome, Biblioteca Apostolica Vaticana, 1947 (Studi e Testi 133).

GRAF Georg, Geschichte der christlichen arabischen Literatur, vol. 1, Rome, Biblioteca Apostolica Vaticana, 1944 (Studi e Testi 118).

GrAF Georg, « Die koptische Gelehrtenfamilie der Aulād al-'Assāl und ihr Schrifttum », Orientalia. Nova Series 1, 1932, pp. 34-56, 129-148, 193-204.

GrAF Georg, « Arabische Übersetzungen der Apokalypse », Biblica 10, 1929, pp. 170-194. GrAF Georg, «Sinaitische Bibelfragmente », Oriens Christianus 14, 1925, pp. 217-220.

GRAF Georg, Der Sprachgebrauch der ältesten christlich-arabischen Literatur, ein Beitrag zur Geschichte des Vulgär-Arabisch, Leipzig, O. Harrassowitz, 1905.

GRAF Georg, Die christlich-arabische Literatur bis zur fränkischen Zeit, Freiburg, Herdersche Verlagshandlung, 1905.

Grafton David D., The Contested Origins of the 1865 Arabic Bible: Contributions to the Nineteenth Century Nahda, Leiden, Boston, Brill, 2015 (History of Christian-Muslim Relations 26).

Gregory Caspar René, Novum Testamentum graece. Ad antiquissimos testes denuo recensuit, apparatum criticum omni studio perfectum apposuit. Editio octava critica maior. Volumen III. Prolegomena IX-XIII, vol. 1, Leipzig, J. C. Hinrichs, 1884.

Gregory Caspar René, Textkritikdes Neuen Testamentes, vol. 2, Leipzig, Hinrichs, 1902. Griffith Sidney H., «Holy Spirit», in : Encyclopaedia of the Qur'ān, Washington, Brill Online, 2016. En ligne: <http://referenceworks.brillonline.com/entries/ encyclopaedia-of-the-quran/holy-spirit-EQSIM_00193>, consulté le 23.03.2016. 
GrIfFit H Sidney H., The Bible in Arabic. The Scriptures of the «People of the Book» in the Language of Islam, Princeton, Princeton University Press, 2013.

Griffit H Sidney H., The Church in the Shadow of the Mosque: Christians and Muslims in the World of Islam, Princeton, Princeton University Press, 2010.

Griffith Sidney H., «Anthony David of Baghdad, Scribe and Monk of Mar Sabas : Arabic in the Monasteries of Palestine », Church History 58 (1), 1989, pp. 7-19.

Griffit H Sidney H., « The Monks of Palestine and the Growth of Christian Literature in Arabic », The Muslim Word 78 (1), 1988, pp. 1-28.

Griffith Sidney H., «The Gospel in Arabic: An Inquiry into its Appearance in the First Abbasid Century », Oriens Christianus 67, 1983, pp. 126-167.

Griffith Sidney H., «The Prophet Muḥammad, His Scripture and His Message according to the Christian Apologies in Arabic and Syriac from the First Abbasid Century », in : La vie du Prophète Mahomet. Colloque de Strasbourg (octobre 1980), Paris, Presses universitaires de France, 1983, pp. 99-146.

Guid I Ignazio, Le Traduzioni degli Evangelii in arabo e in etiopico, Rome, Tipografia della r. accademia dei Lincei, 1888 (Atti della reale accademia dei Lince 4).

Haywood J.A., Mackenzie D.N. et Eckmann J., « Kāmūs», in : Encyclopaedia of Islam, $2^{\mathrm{e}}$ édition, Brill Online, 2016. En ligne: $<$ http://referenceworks.brillonline. com/entries/encyclopaedia-of-islam-2/indjil-COM_0373>, consulté le 09.02.2016.

Hеснаїме́ Camille, Louis Cheikho et son livre «Le christianisme et la littérature chrétienne en Arabie avant l'Islam », Beyrouth, Dar el-Machreq, 1967 (Langue et littérature arabes 38 ).

Henninge R Joseph, « Arabische Bibelübersetzungen vom Frühmittelalter bis zum 19. Jahrhundert », Neue Zeitschrift für die Missionswissenschaft 17, 1961, pp. 201-233.

Heyberger Bernard, Chrétiens du monde arabe: un archipel en terre d'Islam, Paris, Editions Autrement, 2003.

Heyber ger Bernard, Les chrétiens du Proche-Orient au temps de la réforme catholique (Syrie, Liban, Palestine, XVIIe-XVIIIe siècles), Rome, École française de Rome, 1994 (Bibliothèque des écoles françaises d'Athènes et de Rome 284).

Horne Thomas H., Davidson Samuel et Tregelles Samuel P., An Introduction to the Critical Study and Knowledge of the Holy Scriptures. Volume 4. An Introduction to the Textual Criticism, Etc. of the New Testament, $10^{\mathrm{e}}$ édition, Londres, Longman, Brown, Green, Longmans \& Roberts, 1856.

Hull Robert F., The Story of the New Testament Text: Movers, Materials, Motives, Methods, and Models, Atlanta, Society of Biblical Literature, 2010.

Hyve rnat Henri, «Arabes (versions) des écritures », in : Dictionnaire de la Bible, vol. 1, Leipzig, Letouzey et Ané, 1895, pp. 845-856.

Janeras Sebastià, «Les lectionnaires de l'ancienne liturgie de Jérusalem», Collectanea Christiana Orientalia 2, 2005, pp. 71-92. 
JANIN R., «Emèse », in : Dictionnaire d'histoire et de géographie ecclésiastiques, vol. 15, Paris, Letouzey et Ané, 1963.

JEFFE RY Arthur, Foreign vocabulary of the Qur'ān, Baroda, Oriental Insitute, 1938.

JEss up Henry H., Fifty-Three Years in Syria, vol. 1, New York, Fleming H. Revell Co., 1910. JoRDAN Christopher Robert Dennis, The Textual Tradition of the Gospel of John in Greek Gospel Lectionaries from the Middle Byzantine Period, Ph.D., University of Birmingham, 2010. En ligne : <http://etheses.bham.ac.uk/578/>, consulté le 24.12.2015.

Juynboll G.H.A, «Sunna», in : Encyclopaedia of the Qur'ān, Washington, Brill Online, 2016. En ligne : $<$ http://referenceworks.brillonline.com/entries/encyclopaediaof-the-quran/sunna-EQSIM_00408>>, consulté le 23.03.2016.

Kashoun Hikmat, The Arabic Versions of the Gospels, The Manuscripts and their Families, Berlin, Boston, De Gruyter, 2012 (Arbeiten zur neutestamentlichen Textforschung 42).

Kashou H Hikmat, «The Arabic Gospel Text of Codex Beirut, Bibliothèque orientale, 430 : Is It Recent or Archaic ?», Parole de l'Orient 32, 2007, pp. 105-121.

Kashoun Hikmat, «The Arabic Versions of the Gospels. A Case Study of John 1,1 and 1,18 », in : Thомаs David Richard (éd.), The Bible in Arab Christianity, Leiden, Brill, 2007 (The History of Christian-Muslim Relations 6), pp. 9-36.

Kass is Hanna E., An Andalusian Arabic Version of the Four Gospels (Bayer. Staatsbibl., München, cod. arab. 238), Peeters, Louvain, 2016 (csco 663).

KAss is Hanna E., A Concordance of the Qur'an, Berkeley, University of California Press, 1983.

Kerschensteiner Joseph, Der altsyrische Paulustext, vol. Subsidia 37, Louvain, Secrétariat du CorpusSCO, 1970 (Csco 315).

KhouRY Raif Georges, «La ou les premières bibles arabes », in : FAHD Toufic (éd.), L'Arabie préislamique et son environnement historique et culturel: Actes du Colloque de Strasbourg, 24-27 juin 1987, Leiden, Brill, 1989 (Travaux du Centre de Recherche sur le Proche Orient et la Grèce Antiques 10), pp. 549-561.

Khoury Sami et SAmir Samir Khalil, L'Évangéliaire arabe rimé de 'Abdīšū' de Nisibe $\left(\dagger_{1318)}\right.$, Beyrouth, CEDRAC, 2007 (Patrimoine arabe chrétien 19-20).

Koller Guido, «Hybridity, a Cultural and Scientific Model for the Future», 2013. En ligne: <http://wethink.hypotheses.org/926>, consulté le 07.03.2016.

Kouloughli Djamel E., «Moyen Arabe et questions connexes», 2007. En ligne: $<$ http://cle.ens-lyon.fr/arabe/moyen-arabe-et-questions-connexes-30683.kjsp?$\mathrm{RH}=\mathrm{CDL} \_$ARA120000 $>$, consulté le 14.01.2014.

Kraemer J., « Studien zur altarabischen Lexikographie », Oriens 6, 1953, pp. 201-238.

Kraft Robert A., «The Use of Computers in New Testament Textual Criticism », in : Ehrman Bart D. et Holmes Michael William (éds), The Text of the New Testament in Contemporary Research: Essays on the Status Quaestionis, Grand Rapids, Eerdmans Publishing, 1995 (Studies and Documents 46), pp. 268-282. 
Krenkow F., «Two Ancient Fragments of an Arabic Translation of the New Testament », Journal of the Royal Asiatic Society (New Series) 58 (2), 1926, pp. 275-285. En ligne: Cambridge Journals Online, <http://journals.cambridge.org/article_ So035869Xooo69288>, consulté le 11.11.2014.

LA SPISA Paolo, «Perspectives ecdotiques pour textes en moyen arabe : L'exemple des traités théologiques de Sulaymān al Ġazzīı, in : ZACk Liesbeth et ScHIPPE RS Arie (éds), Middle Arabic and Mixed Arabic: Diachrony and Synchrony, Leiden, Boston, Brill, 2012, pp. 187-208.

LAGARDE Paul, Die vier Evangelien, arabisch aus der Wiener Handschrift herausgegeben, Leipzig, F.A. Brockhaus, 1864.

LAM PE Peter, New Testament Theology in a Secular World: A Constructivist Work in Philosophical Epistemology and Christian Apologetics, Londres, New York, T\&T Clark, 2012.

LANG HADE Jacques, « La langue du Coran et du Ḥadīt », in :Du Coran à la philosophie : La langue arabe et la formation du vocabulaire philosophique de Farabi, Beyrouth, Presses de l'Ifpo, 2014 (Études arabes, médiévales et modernes), pp. 17-82.

Lauxtermann Marc D., Byzantine Poetry from Pisides to Geometres. Texts and Contexts, vol. 1, Vienne, Verlag der Österreichischen Akademie der Wissenschaften, 2003 (Wiener Byzantinische Studien 24).

Lavrentiev Alexey, Guillot-Barbance Céline et Marchello-Nizia, «Édition électronique de la Queste del saint Graal», in : Trotтe R David (éd.), Manuel de la philologie de l'édition, Berlin, Boston, De Gruyter, 2015 (Manuals of Romance Linguistics 4), pp. 155-176.

Lentin Jérôme et GRAND'Henry Jacques (éds), Moyen arabe et variétés mixtes de l'arabe à travers l'histoire. Actes du Premier Colloque International (Louvain-la-Neuve, 10-14 mai 2004), Louvain, Peeters, 2008 (Publications de l'Institut Orientaliste de Louvain 58).

Levin Bernhard, Die griechisch-arabische Evangelien-Übersetzung Vat. Borg. Ar. 95 und Ber. Orient. Oct. 1108 , Uppsala, Almqvist \& Wiksell, 1938.

Lewis Agnes Smith et Delmar Morgan E., « Some Ancient Manuscripts of the Arabic New Testament », in: Transactions of the Ninth International Congress of Orientalists, vol. 2, Londres, Committee of the Congress, 1893, pp. 96-98.

LEwis Agnes Smith et Gibs on Margaret Dunlop, Forty-One Facsimiles of Dated Christian Arabic Manuscripts, Cambridge, Cambridge University Press, 1907 (Studia Sinaitica 12).

LiN Yii-Jan, The Erotic Life of Manuscripts: New Testament Textual Criticism and the Biological Sciences, Oxford, Oxford University Press, 2016.

López Y López Ángel C., «La traducción de los Evangelios al árabe por Isaac Ben Velasco de Córdoba en el siglo X a. D. », Boletín Millares Carlo 13, 1994, pp. 79-84. 
Lory Pierre et Troupeau Gérard, «Les musulmans et les autres», in : ChevalLIER Dominique et Miquel André (éds), Les Arabes, du message à l'histoire, Paris, Fayard, 1995, pp. 203-234.

Macé Caroline, BAusi Alessandro, Witakows ki Witold et al., « Textual Criticism and Text Editing », in : Comparative Oriental Manuscript Studies : An Introduction, Hambourg, Tredition, 2015, pp. 321-465. En ligne : <https://www.aai.uni-hamburg.de/en/ comst/publications/handbook.html>, consulté le 31.07.2018.

MACUCH Rudolf, «Zur Vorgeschichte der Bekenntnisformel lā ilāha illā llāhu», Zeitschrift der Deutschen Morgenländischen Gesellschaft 128 (1), 1978, pp. 20-38. En ligne : JSTOR, <http://www.jstor.org/stable/43372505>, consulté le 23.03.2016.

MAI Angelo, Scriptorum veterum nova collectio e Vaticanis codicibus edita, vol. 4, Rome, Typis Vaticanis, 1831.

MALI Franz, «Le canon du Nouveau Testament chez les auteurs syriaques », in : ARAGIONE Gabriella, JunOd Eric et Norelli Enrico (éds), Le canon du Nouveau Testament : regards nouveaux sur l'histoire de sa formation, Genève, Labor et Fides, 2005, pp. 269-282.

MALlon Alexis, « Ibn al-'Assâl. Les trois écrivains de ce nom », Journal Asiatique 10 (6), 1905, pp. 509-529.

Mejdell Gunvor, "Middle Arabic" Across Time and Medium/Mode. Some Reflexions and Suggestions », in : LENTIN Jérôme et GrAND'HENRY Jacques (éds), Moyen arabe et variétés mixtes de l'arabe à travers l'histoire. Actes du Premier Colloque International (Louvain-la-Neuve, 10-14 mai 2004), Louvain, Peeters, 2008 (Publications de l'Institut Orientaliste de Louvain 58), pp. 355-372.

Metzger Bruce Manning et Ehrman Bart D., The Text of New Testament. Its Transmission, Corruption, and Restoration, $4^{\mathrm{e}}$ édition, Oxford, Oxford University Press, 2005 .

Metzger Bruce Manning, «The Arabic Versions », in : The Early Versions of the New Testament: Their Origin, Transmission and Limitations, Oxford, Clarendon Press, 1977, pp. 257-268.

Michaud Louis-Gabriel, "Thomas van Erpe», in: Biographie universelle ancienne et moderne : histoire par ordre alphabétique de la vie publique et privée de tous les hommes avec la collaboration de plus de 300 savants et littérateurs français ou étrangers, vol. 12, $2^{\mathrm{e}}$ édition, 1865-1843.

Miller Peter N., «Les origines de la Bible Polyglotte de Paris: Philologia Sacra, contre-Réforme et raison d'État », XVIIe siècle 49, 1997, pp. 57-66.

MoAwad Samuel, Al-As'ad Abū al-Farağ Hibat Allāh ibn al-'Assāl: Die arabische Übersetzung der vier Evangelien, Le Caire, Alexandria School, 2014.

Monfe Rre R-SAla Juan Pedro, «Scripture and Translation an Arabic Fragment of the Gospel of Mark Preserved in Ms 4971 BNM », Journal of Eastern Christian Studies 70 (1-2), 2018, pp. 35-62. 
Monferrer-Sala Juan Pedro, Evangelio Árabe fragmentario de Marcos (Ms. Qarawiyyīn 730): una traducción árabe andalusí del siglo $X$. Edición diplomática y estudio preliminar, Cordoba, UCOPress, CNERU, CEDRAC, 2016 (Syro-Arabica).

Monferrer-Sala Juan Pedro, «The Pauline Epistle to Philemon from Codex Vatican Arabic 13 (Ninth Century CE): Transcription and Study », Journal of Semitic Studies 60 (2), 2015, pp. 341-371.

Monferrer-Sala Juan Pedro, «Translating the Gospels into Arabic from Syriac: Vatican Arabic 13 Restored Section, Strategies and Goals», Arabica (62), 2015, pp. 435-458.

Monferrer-SAla Juan Pedro, «Estrategias e interferencias en una traducción árabe cristiana surpalestinense (Vat. Ar. 13, S. IX)», in : Meouak Mohamed et Puente Cristina DE LA (éds), Vivir de tal suerte :Homenaje aJuan Antonio Souto Lasala, Cordoue, Madrid, Oriens Academic, 2014 (Serie Abacus 1), pp. 349-365.

Monferrer-Sala Juan Pedro, «An Early Fragmentary Christian Palestinian Rendition of the Gospels into Arabic from Mar Saba (MS Vat. Ar. 13, 9th c.)», Intellectual History of the Islamicate World 1, 2013, pp. 69-113.

Monferrer-Sala Juan Pedro, «Kērýssō and its Arabic Renditions in a Bilingual Gospel of Luke (BnF 'Supl. grec 911', 1043 CE)», in : SAmir Samir Khalil et Monferrer-Sala Juan Pedro (éds), Graeco-Latina et Orientalia: Studia in Honorem Angeli Urbani Heptagenarii, Cordoue, Beyrouth, Oriens Academic, 2013 (Syro-Arabica 2), pp. 221-236.

Monferrer-Sala Juan Pedro, «From Antiquity and Late Antiquity to the Middle Ages: Translating in a Multilingual Setting», in : PARrA-Membrives Eva, PeinADo Miguel Angel Graciá et ClAssen Albrecht (éds), Aspects of Literary Translation. Building Linguistic and Cultural Bridge in Past and Present, Tübingen, Narr, 2012, pp. 61-75.

Monferrer-Sala Juan Pedro, «Loan Translation from Greek in Christian Middle Arabic », in : Monferrer-Sala Juan Pedro et Al Jallad Nader (éds), The Arabic Language Across the Ages, Reichert, Wiesbaden, 2010, pp. 75-91.

Monferrer-Sala Juan Pedro, « Ḥanīf < Ḥanpā. Dos formas de un mismo concepto en evolución. Notas filológicas en torno a un viejo problema », Anaquel de Estudios Árabes 14, 2003, pp. 177-187.

Monferrer-Sala Juan Pedro, «An Eastern Arabic Version of the Three Epistles of Saint John (Codex Ar. 1625) Kept in the Monastery of el Escorial (Madrid)», Parole de l'Orient 27, 2002, pp. 27-49.

Monferrer-SAla Juan Pedro, «Una traducción árabe con "pseudoescolio exegético anónimo". Una nota de crítica textual interna a propósito del MS. Sabaítico Vaticano Arabo 13 », Boletín de la Asociación Española de Orientalistas 37, 2001, pp. 67-82.

Monferrer-Sala Juan Pedro, «Dos antiguas versiones neotestamentarias árabes surpalestinenses: Sin. Ar. 72 , Vat. Ar. 13 y sus posibles Vorlagen respectivas grecoalejandrina y siriaca de la Pešīțāa », La Ciudad de Dios 213 (2), 200o, pp. 363-387. 
Montgomery Watt William, «Hanīf», in : Encyclopaedia of Islam, $2^{\mathrm{e}}$ édition, Brill Online, 2016. En ligne : <http://referenceworks.brillonline.com/entries/encyclopae dia-of-islam-2/hanif-COM_0264>, consulté le 14.02.2016.

Montg omery Watt William, «Two Interesting Christian-Arabic Usages », Journal of Semitic Studies 2, 1957, pp. 360-365.

Moretti Franco, Distant Reading, Londres, New York, Verso, 2013.

Moretti Franco, Graphes, cartes et arbres. Modèles abstraits pour une autre histoire de la littérature, Paris, Les prairies ordinaires, 2008.

Moтzкi Harald, «Marriage and Divorce», in : Encyclopaedia of the Qur'ān, Washington, Brill Online, 2016. En ligne: <http://referenceworks.brillonline.com/entries/ encyclopaedia-of-the-quran/marriage-and-divorce-EQCOM_oo111>, consulté le 23.03.2016.

Mouawad Ray J., Les Maronites. Chrétiens du Liban, Turnhout, Brepols, 2009.

Mouterde Paul, «Un ermitage melkite en Emésène au VIIIe siècle», Mélanges de l'Université Saint-Joseph 18, 1934, pp. 101-106.

Muzerelle Denis, «L'écriture», in: Géhin Paul (éd.), Lire le manuscrit médiéval, $2^{\mathrm{e}}$ édition, Paris, Armand Colin, 2013, pp. 85-120.

NASR Joséphine, Une traduction arabe de l'Évangile de Luc, Beyrouth, CEDRAC, 2011 (Patrimoine arabe chrétien 26).

Nasrallah Joseph, Histoire du mouvement littéraire dans l'Église Melchite du Ve au XXe siècle, vol. II.2, Louvain, Peeters, 1988.

Nasrallah Joseph, «La liturgie des Patriarcats melchites de 969 à 1300 », Oriens Christianus 71, 1987, pp. 156-181.

Nasrallah Joseph, «Deux versions Melchites partielles de la Bible du IXe et du Xe siècles », Oriens Christianus 64, 1980, pp. 202-215.

NeSTLE Eberhard, «Bibelübersetzungen, Arabische », in : Realencyklopädie für protestantische Theologie und Kirche, vol. 3, Leipzig, Hinrichs, 1897, pp. 90-95.

NidA Eugene A. et TABER Charles R., The Theory and Practice of Translation, Leiden, Brill, 1969.

Nord Christiane, Text Analysis in Translation: Theory, Methodology, and Didactic Application of a Model for Translation-oriented Text Analysis, Amsterdam, Atlanta, Rodopi, 2005 .

Ornato Ezio, «La codicologie quantitative, outil privilégié de l'histoire du livre médiéval », in : La face cachée du livre médiéval, Rome, Viella, 1997, pp. 375-402.

PADwick Constance E., «Al-Ghazali and the Arabic Versions of the Gospels. An Unsolved Problem », The Muslim World 29 (2), 1939, pp. 130-140.

PARke R David C., «Though a Screen Darkly: Digital Texts and the New Testament», in : PAR Ke R David C., Manuscripts, Texts, Theology: Collected Papers 1977-2007, Berlin, New York, de Gruyter, 2009 (Arbeiten zur neutestamentlichen Textforschung 40), pp. 287-303. 
Parker David C., The Living Text of the Gospels, Cambridge, Cambridge University Press, 1997.

Parker David C., «Review. The Orthodox Corruption of Scripture. By Bart Ehrmann, Oxford University Press, 1993. », Journal of Theological Studies 45 (2), 1994, pp. 704-708.

PAr Ker David C., Codex Bezae: An Early Christian Manuscript and Its Text, Cambridge, Cambridge University Press, 1992.

Payne Smith Robert, Quatremère Étienne Marc, Bernstein Georg Heinrich et al., Thesaurus syriacus, Oxford, Clarendon Press, 1879.

Peralta José Haro et Verkinderen Peter, «"Find for Me!" : Building a ContextBased Search Tool Using Python », in : Mu hanna Elias (éd.), The Digital Humanities and Islamic \& Middle East Studies, Walter de Gruyter, 2016, pp. 199-232.

PERnot Laurent, «La paléographie grecque et byzantine au colloque de Paris (21-25 octobre 1974) », Revue des Études grecques 91 (432-433), 1978, pp. 165-176.

Peters Curt, «Grundsätzliche Bemerkungen zur Frage der arabischen Bibeltexte», Rivista degli studi orientali 20 (1), 1942, pp. 129-143.

Peters Curt, «Proben eines bedeutsamen arabischen Evangelientextes», Oriens Christianus 11, 1942, pp. 189-211.

Peters Curt, « Von arabischen Evangelientexten in Handschriften der Universitäts-Bibliothek Leiden », Acta Orientalia 18, 1940, pp. 124-137.

Peters Curt, Das Diatessaron Tatians: seine Überlieferung und sein Nachwirken im Morgen- und Abendland sowie der heutige Stand seiner Erforschung, Rome, Pont. Institutum orientalium studiorum, 1939 (Orientalia christiana analecta 123).

Peursen Wido van, «Text Comparison and Digital Creativity: An Introduction», in : Peursen Wido van, Thoutenhoofd Ernst et Weel Adriaan van der (éds), Text Comparison and Digital Creativity: The Production of Presence and Meaning in Digital Text Scholarship, Leiden, Boston, Brill, 2010 (Scholarly Communication 1), pp. 1-27.

Potтнast Daniel, «Die andalusische Übersetzung des Römerbriefs», Collectanea Christiana Orientalia 8, 2011, pp. 65-108.

PyM Anthony, Translation and Text Transfer. An Essay on the Principles of Intercultural Communication, 2 édition, Tarragona, Intercultural Studies Group, 2010.

RAPHAËL Pierre, Le rôle du Collège maronite romain dans l'orientalisme aux XVIIe et XVIIIe siècles, Beyrouth, Université Saint Joseph, 1950.

Reinhart Kevin A., «Ethics and the Qur'ān », in : Encyclopaedia of the Qur'ān, Washington, Brill Online, 2016. En ligne: <http://referenceworks.brillonline.com/en tries/encyclopaedia-of-the-quran/ethics-and-the-quran-EQCOM_ooo56>, consulté le 23.03.2016.

Renouf le Page Peter, «On the Supposed Latin Origin of the Arabic Version of the Gospels », Atlantis : or Register of Literature and Science of the Catholic University of Ireland 4, 1863, pp. 241-259. 
RICHARD W. Larry, «Gregory 1175: Alexandrian or Byzantine in the Catholic Epistles? », Andrews University Seminary Studies 21, 1983, pp. 155-168.

Riddle Donald, «Textual Criticism as a Historical Discipline », Anglican Theological Review 18, 1936, pp. 220-233.

Rif FIER Jean, Les œuvres françaises en Syrie (1860-1923), Paris, L'Harmattan, 2000.

RipPIN Andrews, «Witness to Faith», in : Encyclopaedia of the Qur'ān, Washington, Brill Online, 2016. En ligne : <http://referenceworks.brillonline.com/entries/encyclo paedia-of-the-quran/witness-to-faith-EQCOM_00217>, consulté le 23.03.2016.

Robinson B., «Waraḳa b. Nawfal », in : Encyclopaedia of Islam, $2^{\mathrm{e}}$ édition, Brill Online, 2016. En ligne : <http://referenceworks.brillonline.com/entries/encyclopaediaof-islam-2/waraka-b-nawfal-SIM_7863>, consulté le 09.02.2016.

RoIsse Philippe, «Los Evangelios traducidos del latín al árabe por Isḥāq b. Balašk alQurțubī en 946 d.C. », in: Seco de lucena Paredes luis, Castillo Castillo Concepción, Cortés PeÑa Immaculada et al. (éds), Estudios Árabes. Dedicados a D. Luis Seco de Lucena (En el XXV Aniversario de su muerte), Grenade, University of Granada, 1999, pp. 147-164.

Römer Karl, «Studien über den Codex Arabicus Monacensis Aumer 238 », Zeitschrift für Assyriologie und Vorderasiatische Archäologie 19 (1), 1906, pp. 98-125.

Rosselli Del Turco Roberto, Buomprisco Giancarlo, Pietro Chiara Di et al., «Edition Visualization Technology: A Simple Tool to Visualize TEI-based Digital Editions », Journal of the Text Encoding Initiative (8), 2014. En ligne : jtei.revues.org, $<$ http://jtei.revues.org/1077>, consulté le 16.10.2015.

Roy Olivier, « La communauté virtuelle. L'internet et la déterritorialisation de l'islam », Réseaux 18 (99), 2000, pp. 219-237.

Rubin Uri, «Muhammad», in : Encyclopaedia of the Qurān, Washington, Brill Online, 2016. En ligne: <http://referenceworks.brillonline.com/entries/encyclopae dia-of-the-quran/muhammad-EQCOM_oo126>, consulté le 23.03.2016.

Rubin Uri, «Prophets and Prophethood», in : Encyclopaedia of the Qur'ān, Washington, Brill Online, 2016. En ligne: <http://referenceworks.brillonline.com/entries/ encyclopaedia-of-the-quran/prophets-and-prophethood-EQCOM_oo16o>, consulté le 23.03.2016.

Runesson Anna, Exegesis in the Making: Postcolonialism and New Testament Studies, Leiden, Boston, Brill, 2010.

RUQAYYA Khan, «Error», in: Encyclopaedia of the Qur'ān, Washington, Brill Online, 2016. En ligne: <http://referenceworks.brillonline.com/entries/encyclopae dia-of-the-quran/error-EQSIM_oo135>, consulté le 23.03.2016.

SAID Edward W., L'Orientalisme. L'Orient créé par l'Occident, $2^{\mathrm{e}}$ édition, Paris, Seuil, 2005 . 
SAMIR Samir Khalil, « Rôle des Chrétiens dans la civilisation arabe », in : MonferRERSAla Juan Pedro (éd.), Eastern Crossroads. Essays on Medieval Christian Legacy, New Jersey, Gorgias Press, 2007, pp. 3-30.

SAMIR Samir Khalil, «Survol de la situation des recherches arabes chrétiennes », in: Monferre r-SAla Juan Pedro (éd.), Eastern Crossroads. Essays on Medieval Christian Legacy, New Jersey, Gorgias Press, 2007, pp. 371-385.

SAmir Samir Khalil, «La littérature arabe médiévale des Chrétiens », in : ABUMALHAM Montserrat (éd.), Literatura Árabe-cristiana, Madrid, Universidad Complutense, 2001, pp. 21-49.

SAmir Samir Khalil, «L'avenir des études arabes chrétiennes », Parole de l'Orient 24, 1999, pp. 21-43.

SAmir Samir Khalil, «La version arabe des Évangiles d'Al-As'ad Ibn al-'Assâl », Parole de l'Orient 19, 1994.

SAm IR Samir Khalil, «The Earliest Arab Apology for Christianity (c. 750) », in : SAM IR Samir Khalil et Nie Ls en Jørgen S. (éds), Christian Arabic Apologetics during the Abbasid Period (750-1258), Leiden, Brill, 1994, pp. 57-114.

SAm IR Samir Khalil, « Une réponse implicite à l'i'ğāz du Coran : l'Évangéliaire rimé de 'Abdišū' », Proche-Orient Chrétien 35, 1985, pp. 225-237.

SAMIR Samir Khalil, «La tradition arabe chrétienne. État de la question, problèmes et besoins ", in: Actes du premier congrès international d'études arabes chrétiennes (Goslar, septembre 1980), Rome, Pontificio Instituto Orientale, 1982 (Orientalia Christiana Analecta 210), pp. 21-120.

SAmir Samir Khalil, «Pour une nouvelle histoire de la littérature arabe des Chrétiens », in : SAmi R Samir Khalil (éd.), Actes du premier congrès international d'études arabes chrétiennes (Goslar, septembre 1980, Rome, Pontificio Instituto Orientale, 1982 (Orientalia Christiana Analecta 218), pp. 259-271.

SAUGET Joseph-Marie, « La littérature arabe chrétienne ancienne : son intérêt pour les études sur l'Orient ancien », in: Duval-ARnould Louis et Rilliet Frédéric (éds), Littératures et manuscrits des chrétientés syriaques et arabes, Rome, Biblioteca Apostolica Vaticana, 1998 (Studi e Testi 389), pp. 147-174.

SCHNEEMELCHer Wilhelm, «The Epistle to the Laodiceans », in : SchneEMELCHeR Wilhelm (éd.), New Testament Apocrypha: Writings Relating to the Apostles; Apocalypses and Related Subjects, $2^{\mathrm{e}}$ édition, Cambridge, James Clark \& Co, 2003, pp. 42-46. Scholz J.M.A., «Ueber die arabischen Handschriften des N.T. zu Rom», in: Biblisch-kritische Reise in Frankreich, der Schweiz, Italien, Palästina und im Archipel, in den Jahren 1818, 1819, 1820, 1821, nebst einer Geschichte des Textes N.T., Leipzig, F. Fleischer, 1823, pp. 117-135.

Schulthess Sara, «Vaticanus Arabicus 13: What Do We Really Know About the Manuscript? With an Additional Note on the Ending of Mark», Journal of Eastern 
Christian Studies 70(1-2), numéro spécial édité par Schulthess Sara, Teule Herman et Ver Heyden Joseph, Arabica sunt, non leguntur... Studies on the Arabic Versions of the Bible in Jewish, Christian and Islamic Tradition, 2018, pp. 63-84.

Schulthess Sara, «Important comments on the Arabic translation», HumaRec, 02.05.2017, <https://www.humarec.org/index.php/continuous-publications-blog/ 25-important-comments-on-the-arabic-translation>, consulté le 26.05.2017.

Schulthess Sara, Les manuscrits arabes des lettres de Paul. La reprise d'un champ de recherche négligé, PhD dissertation, Lausanne/Nijmegen, Université de Lausanne/Radboud Universiteit Nijmegen, 2016. En ligne: <http://hdl.handle. net/2066/159141>.

Schulthess Sara, «Tahrīf in the Digital Age », in : Clivaz Claire, Dilley Paul et HaMidovic David (éds), Ancient Worlds in a Digital Culture, Leiden, Brill, 2016 (Digital Biblical Studies 1), pp. 214-230.

Schulthess Sara, «Liste des manuscrits arabes des lettres de Paul : résultats préliminaires », Journal of Eastern Christian Studies 66 (3-4), 2014, pp. 153-167.

Schulthess Sara, «The Role of the Internet in New Testament Textual Criticism: the Example of the Arabic Manuscripts of the New Testament», in : Clivaz Claire, Greg ory Andrew et Hamidovic David (éds), Digital Humanities in Biblical, Early Jewish and Early Christian Studies, Leiden, Brill, 2013 (Scholarly Communication 2), pp. 71-82.

Schulthess Sara, «Les manuscrits du Nouveau Testament, le monde arabe et le digital : l'émergence d'un discours hybride », in : Clivaz Claire, Meizoz Jérôme, VALLotTon François et al. (éds), Reading Tomorrow. From Ancient Manuscripts to the Digital Era / Lire Demain. Des manuscrits antiques à l'ère digitale, ebook, Lausanne, PPUR, 2012, pp. 333-344.

ShafiQ Muhammad et Abu-Nimer Mohammed, Interfaith Dialogue: A Guide for Muslims, Washington, International Institute of Islamic Thought, 2007.

Small Keith E., Textual Criticism and Qur'an Manuscripts, Plymouth, Lexington Books, 2011.

Smith Eli et Van Dyck C.V.A., Brief Documentary History of the Translation of the Scriptures Into the Arabic Language, Beyrouth, American Presbyterian Mission Press, 1900.

Smith Jane I., Muslims, Christians, and the Challenge of Interfaith Dialogue, Oxford, Oxford University Press, 2007.

SPIELMANN Yvonne, Hybridkultur, Berlin, Suhrkamp, 2010.

StaAl Harvey, Mt. Sinai Arabic Codex 151 II : Acts of the Apostles, Catholic Epistles, 2 vol., Louvain, Peeters, 1984 (csco 462-463).

StaAl Harvey, Mt. Sinai Arabic Codex 151 I: The Pauline Epistles, vol. 1, Louvain, Peeters, $1983\left(\operatorname{cscO} 45^{2}\right)$.

StaAl Harvey, Mt. Sinai Arabic Codex 151 I : The Pauline Epistles, vol. 2, Louvain, Peeters, 1983 (CSCO 453). 
StaAl Harvey, Codex Sinai Arabic 151 Pauline Epistles, Studies and Documents. (Rom., I \& II Cor., Phil.), 2 vol., Salt Lake City, University of Utah Press, 1969 (Studies and Documents 40).

Stine Philip C., Let The Words Be Written : The Lasting Influence of Eugene A. Nida, Leiden, Boston, Brill, 2004.

Suermann Harald, Die Gründungsgeschichte der maronitischen Kirche, Wiesbaden, Harrassowitz, 1998.

Sugirtharajah Rasiah S., «The Late Arrival of the "Post" : Postcolonialism and Biblical Studies », in : Exploring Postcolonial Biblical Criticism: History, Method, Practice, Chicester, Wiley-Blackwell, 2011, pp. 31-56.

Sugirtharajah Rasiah S., Postcolonial Reconfigurations : An Alternative Way of Reading the Bible and Doing Theology, Londres, SCM Press, 2003.

Swans on Mark N., «An Apology for the Christian Faith », in : Noble Samuel et TrEIGER Alexander (éds), The Orthodox Church in the Arab World (700-170o): An Anthology of Sources, DeKalb, Northern Illinois University Press, 2014, pp. 40-59.

Swanson Mark N., «Fī tathlïth Allāh al-wāhid», in : Thomas David Richard et RoGgemA Barbara (éds), Christian-Muslim Relations : A Bibliographical History (6oo90o), Leiden, Boston, Brill, 2009 (The History of Christian-Muslim Relations 11), pp. 330-333.

Swans on Mark N., "Folly to the Hunafä" : The Crucifixion in Early Christian-Muslim Controversy », in : Thом Das David Richard, Swanson Mark N. et Grypeou Emmanouela (éds), The Encounter of Eastern Christianity with Early Islam, Leiden, Brill, 2006 (The History of Christian-Muslim Relations 5), pp. 237-256.

Swanson Mark N., «Some Considerations for the Dating of Fì tațlit allāh al-wāhid (Sin. ar. 154) and al-Ğāmi wuğūh al-ìmān (London, British Library Or. 4950)», Parole de l'Orient 18, 1993, pp. 115-141.

Swidler Ann et Arditi Jorge, « The New Sociology of Knowledge », Annual Review of Sociology 20, 1994, pp. 305-329.

TARTAR Georges, Dialogue islamo-chrétien sous le calife Al-Ma'mûn (813-834) : les épitres d'Al-Hashimî et d'Al-Kindî, Paris, Nouvelles Editions Latines, 1985.

Teule Herman, Les Assyro-Chaldéens. Chrétiens d'Irak, d'Iran et de Turquie, Turnhout, Brepols, 2008.

Theissen Gerd, «Vers une théorie de l'histoire sociale du christianisme primitif», in: Theissen Gerd, Histoire sociale du christianisme primitif. Jésus - Paul - Jean, Genève, Labor et Fides, 1996, pp. 263-294.

The Isse n Gerd, The Social Setting of Pauline Christianity : Essays on Corinth, New York, T\&T Clark, 1982.

Tisserant Eugène et BruYne Donatien DE, « Une feuille arabo-latine de l'épître aux Galates », Revue biblique N.S. 7, 1910, pp. 321-343.

Tisserant Eugène, « Mélanges IV. La version mozarabe de l'épître aux Laodicéens », Revue biblique N.S. 7, 1910, pp. 249-253. 
Touati Charlotte, «Pourquoi éditer un manuscrit unique ? L'édition critique des écrits apocryphes : de l'arbre au mycélium », 2013. En ligne : <http://falashas.epfl. ch/data/sources/textes/Manuscrit.pdf >, consulté le 29.02.2016.

Tregelles Samuel P., «Arabic Versions », in : A Dictionary of the Bible Comprising Its Antiquities, Biography, Geography, and Natural History, vol. 3, 2 édition, Londres, John Murray, 1893, pp. 1614-1616.

Treiger Alexander, «From Theodore Abū Qurra to Abed Azrié: The Arabic Bible in Context», in : HJÄLM, Miriam L. (éd.), Senses of Scripture, Treasures of Tradition: The Bible in Arabic among Jews, Christians and Muslims, Leiden, Brill, 2017 (Biblia Arabica 5), pp. 11-57.

Treiger Alexander, «Palestinian Origenism and the Early History of the Maronites: In Search of the Origins of the Arabic Theology of Aristotle », in : Janos Damien (éd.), Ideas in Motion in Baghdad and Beyond: Philosophical and Theological Exchanges between Christians and Muslims in the Third/Ninth and Fourth/Tenth Centuries, Leiden, Brill, 2015, pp. 44-80.

Troupeau Gérard, «Les colophons des manuscrits arabes chrétiens », in : DÉroche François et Richard Francis (éds), Scribes et manuscrits du Moyen-Orient, Paris, Bibliothèque nationale de France, 1997, pp. 224-231.

TuCKe r J. Brian, You Belong to Christ: Paul and the Formation of Social Identity in 1 Corinthians 1-4, Eugene, Pickwick, 2011.

Urbán Fernández Angel et Monferrer-Sala Juan Pedro, «Some Regards on Textual Criticism in a Greek-Arabic Ms. BnF Suppl. grec 911 (A.D. 1043) », Parole de l'Orient 30, 2005, pp. 72-102.

Urbán Fernández Angel, «An Unpublished Greek-Arabic MS of Luke’s Gospel (BnF Suppl. grec 911, A.D. 1043) : A Report», in: Monferrer-SAla Juan Pedro (éd.), Eastern Crossroads. Essays on Medieval Christian Legacy, New Jersey, Gorgias Press, 2007 (Gorgias Eastern Christianity Studies 1), pp. 83-95.

VAlentin Jean, «Les évangéliaires arabes de la bibliothèque du Monastère Ste-Catherine (Mont Sinaï) : Essai de classification d'après l'étude d'un chapitre (Matth. 28). Traducteurs, réviseurs, types textuels », Le Muséon 116, 2003, pp. 415-477. Ve rste g g Kees, The Arabic Language, Edinburgh, Edinburgh University Press, 2001. Vian Paolo, «"Per le cose della Patria Nostra". Lettere inedite di Luigi Angeloni e Marino Marini sul recupero dei manoscritti Vaticani a Parigi (1816-1819)», in : Miscellanea Bibliothecae Apostolicae Vaticanae, vol. XVIII, Rome, Biblioteca Apostolica Vaticana, 2011 (Studi e Testi 469), pp. 693-799.

ViAn Paolo, «Vaticani Arabi », in: Vian Paolo et D’AiUto Francesco (éds), Guida ai fondimanoscritti, numismatici, a stampadella Biblioteca Vaticana. I.Dipartimento Manoscritti, Rome, Biblioteca Apostolica Vaticana, 2011 (Studi e Testi 466), pp. 553-564.

Vollandt Ronny, Arabic Versions of the Pentateuch. A Comparative Study of Jewish, Christian, and Muslim Sources, Leiden, Brill, 2015 (Biblia Arabica 2). 
Vollandt Ronny, « Some Historiographical Remarks on Medieval and Early-Modern Scholarship of Biblical Version in Arabic : A Status Quo », Intellectual History of the Islamicate World 1, 2013, pp. 25-42.

Vöӧв Us Arthur, «The Arabic Versions », in : Early Versions of the New Testament: Manuscript Studies, Stockholm, Estonian Theological Society in Exile, 1954, pp. 271-297.

WASserman Tommy, «The Son of God Was in the Beginning (Mk 1:1) », Journal of Theological Studies 62 (1), 2011, pp. 20-50.

Wilfong Terry G., «The Non-Muslim Communities: Christian Communities », in: Petry Carl F. (éd.), The Cambridge History of Egypt. Islamic Egypt 640-1517, vol. 1, Cambridge, Cambridge University Press, 1998, pp. 175-197.

WILlard Louis Charles, A Critical Study of the Euthalian Apparatus, Berlin, New York, de Gruyter, 2009 (Arbeiten zur neutestamentlichen Textforschung 41).

Zack Liesbeth et Schippers Arie, Middle Arabic and Mixed Arabic: Diachrony and Synchrony, Leiden, Boston, Brill, 2012 (Studies in Semitic Languages and Linguistics 64).

ZAKI Vevian, «The Textual History of the Arabic Pauline Epistles : One Version, Three Recensions, Six Manuscripts », in : HJÄLm Miriam L. (éd.), Senses of Scripture, Treasures of Tradition. The Bible in Arabic among Jews, Christians and Muslims, Leiden, Brill, 2017 (Biblica Arabica 5), pp. 392-424.

Zerdoun Monique, « Les matériaux : support et encre », in: GÉHIn Paul (éd.), Lire le manuscrit médiéval, $2^{\mathrm{e}}$ édition, Paris, Armand Colin, 2013, pp. 15-22.

[s.n], Recensio manuscriptorum codicum qui ex universa Bibliotheca Vaticana (...) procuratoribus Gallorum iure belli, seu pactarum induciarum ergo, et initce pacis traditi fuere (...), Leipzig, 1803 . 


\section{Annexe}

Tableau des leçons de 1 Corinthiens

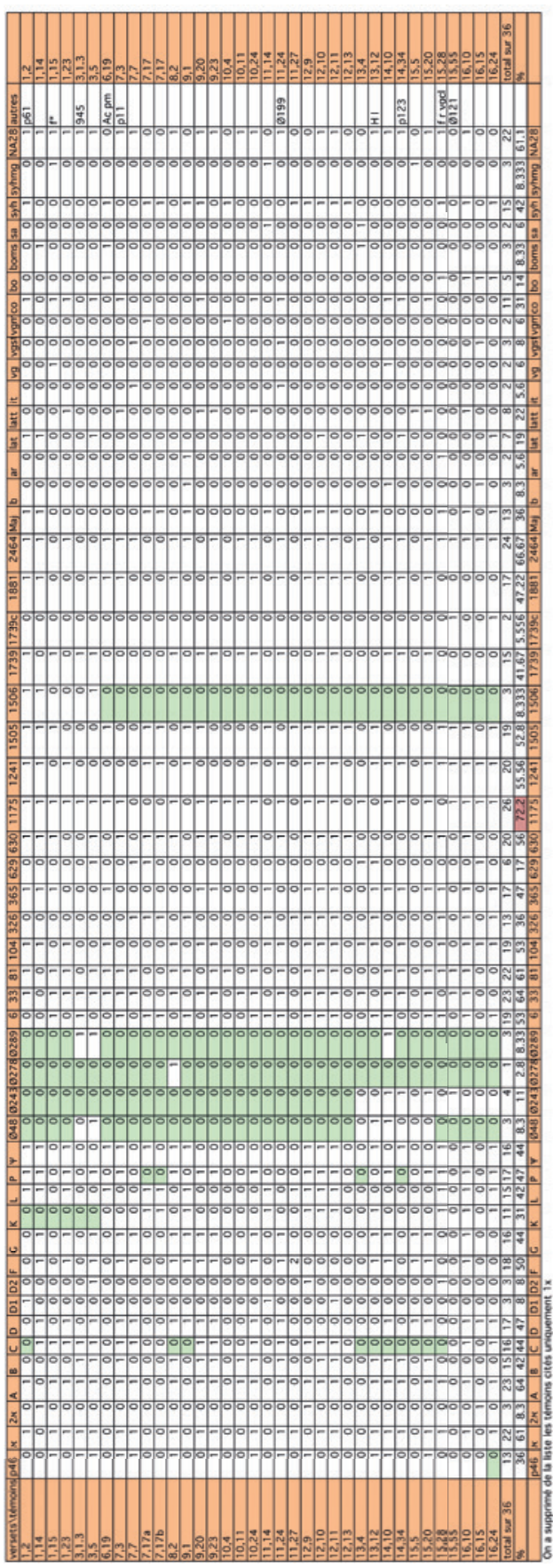

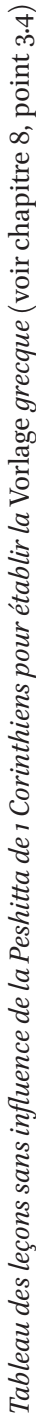




\section{Index des manuscrits arabes}

consulter également le chapitre 4. Répertoire des manuscrits arabes des lettres de Paul (pp. 71-139)

\section{Berlin, Staatsbibliothek}

Berlin Staatsbibl. Or. $1108 \quad$ 22, 23, 25, 30

Berlin Staatsbibl. Or. Folio $115 \quad$ 76, 77, 101, 156,162

Berlin Staatsbibl. Or. Folio $116 \quad 76,77$, 101, 156

Berlin Staatsbibl. Or. Quarto $612 \quad 77,153 n 45$

Berlin Staatsbibl. Or. Quarto 210125

Beyrouth, Bibliothèque orientale

Beyrouth BO $430 \quad 29 n 77$

Caire, Musée copte

Caire Mus. Copt. Bibl. $94 \quad 80,112,159$

Caire Mus. Copt. New 57 (A) 81,82

Caire, Patriarcat copte catholique

Caire Patr. Copt. Cath. 3-3A 83, 153n46

Caire, Patriarcat copte orthodoxe

Caire Patr. Copt. Orth. Bibl. $141 \quad 84,85,155$

Caire Patr. Copt. Orth. Bibl. $142 \quad 85,161$

Caire Patr. Copt. Orth. Bibl. $150 \quad 87,150 n_{3} 6$, 161

Caire Patr. Copt. Orth. Bibl. 154 89, 141, $150{ }^{3} 6$

Caire Patr. Copt. Orth. Bibl. $157 \quad$ 90, 153n46

Caire Patr. Copt. Orth. Bibl. 158 90, 161

Caire Patr. Copt. Orth. Bibl. 162 91, 15on36, 16in 71

Caire Patr. Copt. Orth. Bibl. $166 \quad$ 93, 161n71

Caire Patr. Copt. Orth. Bibl. 169 94, 161

Caire Patr. Copt. Orth. Bibl. 213 96, 150n36

Caire Patr. Copt. Orth. Bibl. $215 \quad$ 97, 153

Cambridge, University Library

Cambridge UL Add. 3212 98, 99, 153n49, 153-154

Cambridge UL Add. $3213 \quad$ 98, 99, 154

Cambridge UL Dd. $15.4 \quad 99,153,161$
Copenhague, Det Kongelige Bibliothek

Copenhague Kong. Bibl. Or. 19 76, 77, 101, 156

Escorial, Real Biblioteca de San Lorenzo de El Escorial

Escorial RB Cas. $1619 \quad 28 n 69,104$

Fes, Hizānat al-Qarawiyyīn

Qarawiyyīn $730 \quad 32$

Florence, Biblioteca Medicea Laurenziana

Florence BML Or. $2 \quad$ 105, 159

Göttingen, Staats- und Universitätsbibliothek

Göttingen SUB orient. $125^{5} \quad 106,150 n 36$, $153 n 49$

Göttingen SUB orient. $125^{6} \quad 106,150{ }^{2} 36,153$, $153 n 49$

Groningen, Universiteitsbibliotheek

Groningen Universiteitsbibliotheek 460 107, 161

Hambourg, Staats- und Universitätsbibliothek Hambourg SUB Orient. 19 107, 153, 160

Jérusalem, Bibliothèque du Monastère grec au Saint-Sépulcre

Jérusalem, Saint-Sépulcre $119 \quad$ 108, 153n46

Jérusalem, Bibliothèque du Monastère Saint-Marc

Jérusalem, Bibl. Saint-Marc $263 \quad 108$, $153 n 49$

Leiden, Universiteitsbibliotheek

Leiden Universiteitsbibliotheek Acad. 2 108, 158n65

Leiden Universiteitsbibliotheek Or. 2083 109, 161

Leiden Universiteitsbibliotheek Or. $217 \quad$ 15, 109

Leiden Universiteitsbibliotheek Or. $5^{61} \quad 3^{1}$ 
Leipzig, Universitätsbibliothek

Leipzig UB Vollers $105^{8} \quad$ 15ng, 110

Léon, Archives de la cathédrale de León

Léon Archives de la cathédrale de León codex $35 \quad 21 n 3^{2}$

\section{Londres, British Library}

Londres BL Arundel Or. 19 111, 153n45

Londres BL Or. $1075 \quad 18$

Londres BL Or. 1318 112, 155

Londres BL Or. $4950 \quad 185,186,475 \mathrm{n} 238$

Londres BL Or. $8612 \quad 33,36,113,128,148$

Madrid, Biblioteca Nacional

Madrid BN 3484 114, 153, 157

Madrid BN $4971 \quad 35,114,153,157$

Milan, Biblioteca Ambrosiana

Milan Biblioteca Ambrosiana B 20 inf. A. $115,158 \mathrm{n} 65,160$

Munich, Staatsbibliothek

Munich Staatsbibliothek Ar. $234 \quad 21 n_{32}$

Munich Staatsbibliothek Ar. $238 \quad$ 21n 32,32

Naples, Biblioteca Nazionale

Naples Bibl. Nazionale Ar. 3 117, 152

Oxford, Bodleian Library

Oxford Bodl. Arch. Seld. B. 50 sup. 118, 153, 161

Oxford Bodl. Laud. Or. $24 \quad$ 119, 153, 161

Paris, Bibliothèque Nationale de France

Paris BNF arabe 63 120, 121, 122

Paris BNF arabe $64 \quad 120$

Paris BNF arabe $65 \quad 120,121$

Paris BNF arabe $66 \quad 121$

Paris BNF arabe $6725 \quad 36,122,127,142,147$, $148,152 n 44$

Paris BNF copte $17 \quad 123$

Paris BNF supplément grec $911 \quad$ 28-29

Paris BNF syriaque $55 \quad 124,159,160$

Saint-Pétersbourg, Bibliothèque nationale de Russie

Saint-Pétersbourg Bibl. Nat. Ar. New Series

327 16ng, 33, 125, 147, 148
Saint-Pétersbourg, Institute of Oriental

Manuscripts of the Russian Academy of

Sciences

Saint-Pétersbourg Institute of Oriental

Manuscripts D 226/3 126, 156

Sinaï, Monastère Sainte-Catherine

Sin. Ar. 2147

Sin. Ar. $54 \quad 195 n 130$

Sin. Ar. $69 \quad 186$

Sin. Ar. $70 \quad 195 \mathrm{n} 130$

Sin. Ar. $72 \quad 26,30,31,61,65,144 \mathrm{n} 12,148,170$, 195n130, 200

Sin. Ar. $73 \quad 36,124,128,143 n 4,149,150$

Sin. Ar. $74 \quad 30,195 \mathrm{n} 130$

Sin. Ar. $75 \quad$ 19n24, 63

Sin. Ar. $82 \quad 25,186$

Sin. Ar. $97 \quad 195 n 130$

Sin. Ar. $117 \quad 186$

Sin. Ar. 135186

Sin. Ar. $151 \quad 27,34-35,64,127,141 n 4,144 n 12$, 147-148, 152n44, 179, 195, 199, 240-242, 257n3o, 262, 263n36, 266n40, 307, 314, 328, 365, 366n116, 366n118, 37on121, 377n128, 439, 459-461, 462n219, 472, $478 \mathrm{n} 245,480,483,496,500$

Sin. Ar. 154 19, 122, 199

Sin. Ar. 155 19, 33, 36, 113, 129, 141n4, 149, 170, 199, 155, 240-241, 249, 251, 26o, 262, 263n36, 279, 328, 340n103, 366n116, 366n118, 37on121, 377, 377n128, 383n133, 411ni55, 428n168, 429, 459-461, 462n219, 472, 475, 478n245, 480, 500, 501065,502

Sin. Ar. $156 \quad$ 128, 153n 46

Sin. Ar. 157 128, 141n4, 153n46

Sin. Ar. 15936

Sin. Ar. $160 \quad 36$

Sin. Ar. 165 129, 153n 45

Sin. Ar. 168 129, 155n46

Sin. Ar. $310 \quad$ 130, $141 \mathrm{In}_{4}$

Sin. Ar. $514 \quad$ 26-27, 186

Sin. Ar. New Finds Parch. 6 148nz26

Sin. Ar. New Finds Parch. 8 et 28 30, 148n26

Sin. Ar. New Finds Parch. 14 et $16 \quad$ 26, 144nı2, 148

Sin. Ar. New Finds Parch. $40 \quad$ 130, 149, 160, 162 
Sin. Ar. New Finds Parch. $5^{2} \quad$ 130, 149, 160, 162

Sin. Ar. New Finds Parch. $60 \quad$ 130, 149, 16o, 162

Sin. Gr. New Finds MG $2 \quad$ 130, 141n4, 148, 155, 159

Vatican, Biblioteca Apostolica Vaticana

Vat. Ar. 13 3, 10-12, 16ng, 28, 29, 30-31, 32, $33,36,39,52,73,131,142,145 \mathrm{n} 13$, $148-149,148 \mathrm{n} 26,152 \mathrm{n} 44,156,158$, $163-507$

Vat. Ar. $17 \quad 31$

Vat. Ar. $18 \quad 31$

Vat. Ar. $23 \quad 108,132$

Vat. Ar. $28 \quad 116,132,157$
Vat. Ar. $467 \quad 21 n 30$

Vat. Ar. 468 21n3o

Vat. Borg. Ar. $95 \quad 22,23,25,30$

Vat. Borg. Sir. 47 136, 159

Vat. Copt. $9 \quad 21 n 30$

Vat. Copt. $12 \quad 133,155$

Vat. Lat. $12900 \quad 2,21,35,134,142,148,152 \mathrm{n} 44$, 157

Vat. Sbath $65_{1} \quad 136,153 n 45$

Venise, Biblioteca Nazionale Marciana

Venise Marciana Gr. 379 22n34, 35, 5on62, $137,156,157,159,160,162,165 \mathrm{n} 3,505$

Vienne, Österreichische Nationalbibliothek

Vienne öNB Or. $1544 \quad 18$ 


\section{Index des sources}

\begin{tabular}{|c|c|}
\hline $\begin{array}{l}\text { Ancien Test } \\
\text { Genèse }\end{array}$ & \\
\hline 1,26 & 431 \\
\hline Exode & \\
\hline 12,13 & 480 \\
\hline Nombres & \\
\hline 25,9 & 348 \\
\hline Nouveau Te & \\
\hline Matthieu & \\
\hline 1,24 & 169 \\
\hline $2,11-23$ & $45^{2}$ \\
\hline $2,18-23$ & $174-175$ \\
\hline $3,1-17$ & 175 \\
\hline 3,5 & 472 \\
\hline $5,14-16$ & $171-172$ \\
\hline 5,41 & $170-171$ \\
\hline 6,7 & 496 \\
\hline $10,28-41$ & $168-169,45^{2}$ \\
\hline $11,1-19$ & 174,482 \\
\hline 13 & $45^{2}$ \\
\hline $13,1-20$ & 167 \\
\hline 16,17 & $325 \mathrm{ng} 2$ \\
\hline 18,11 & $6 o$ \\
\hline 18,17 & 496 \\
\hline $26,1-13$ & $168,45^{2}$ \\
\hline $28,1-8$ & 168 \\
\hline 28,16 & 417,471 \\
\hline
\end{tabular}

Marc

$\begin{array}{ll}1,1 & 58-59 \\ 5 & 45^{2} \\ 5,20-28 & 167 \\ 6,9 & 182\end{array}$

Luc

4

4,1-15 $\quad 167$

$6,23 \quad 201$

$6,58 \quad 201$

$8,27 \quad 201$

$11,52 \quad 201$

$19,11 \quad 60$

24,7
Jean

$\begin{array}{ll}1,1 & 62-63 \\ 1,7 & 62 \\ 7,8 & 61 \\ 7,53-8,11 & 61\end{array}$

Actes

$\begin{array}{ll}18,17 & 496\end{array}$

Romains

$\begin{array}{ll}1,14 & 492 \\ 1,14-16 & 500-501\end{array}$

1 Corinthiens

consulter également les versets au chapitre $8,1$.

Commentaire verset par verset ( $p p$. 240-448)

\begin{tabular}{|c|c|}
\hline $1-4$ & 492 \\
\hline 1,1 & $45^{6}, 472,473,476$ \\
\hline 1,2 & $456,463,466,473$ \\
\hline 1,3 & 454,456 \\
\hline 1,4 & 454 \\
\hline 1,10 & 464 \\
\hline 1,11 & $462 n 220,472,473$ \\
\hline 1,12 & $456,472,473,481$ \\
\hline 1,13 & 472 \\
\hline 1,14 & $456,466,473$ \\
\hline 1,15 & 466 \\
\hline 1,16 & 473 \\
\hline 1,17 & 203 \\
\hline 1,18 & 194,479 \\
\hline 1,22 & $\begin{array}{l}455,459,490,492,493 \\
494,498,499,5^{01}\end{array}$ \\
\hline $1,22-25$ & 502 \\
\hline 1,23 & $466,493,498$ \\
\hline 1,24 & $\begin{array}{l}490,492,493,494,498 \\
499,501\end{array}$ \\
\hline 1,26 & $203,457,464$ \\
\hline 1,27 & $18 \mathrm{on} 78,187 \mathrm{n} 108,462 \mathrm{n} 220$ \\
\hline 2,1 & $455,462 \mathrm{n} 220,465$ \\
\hline 2,3 & $180{ }^{7} 8,462$ \\
\hline 2,10 & 480 \\
\hline 2,12 & 464 \\
\hline 2,13 & $45^{6}$ \\
\hline 2,15 & 457 \\
\hline 3,1 & $455,466,470 n 229$ \\
\hline
\end{tabular}




\begin{tabular}{|c|c|c|c|}
\hline 3,2 & $180 \ln _{7} 8$ & 7,17 & 203,467 \\
\hline $3,2-5$ & 463 & $7,18-19$ & 492 \\
\hline 3,3 & $457,466,470 n 229$ & 7,24 & 454 \\
\hline 3,4 & $472,473,481$ & 7,25 & 194,456 \\
\hline 3,5 & $467,470 n 229,473$ & 7,27 & $45^{8}$ \\
\hline 3,6 & 473 & 7,28 & 18on78, 455 \\
\hline 3,8 & 194,463 & 7,29 & 457 \\
\hline 3,10 & $454,455,475$ & 7,32 & 457 \\
\hline 3,13 & 454 & 7,34 & 457 \\
\hline $3,14-15$ & 464 & 7,36 & 456 \\
\hline 3,18-19 & 464 & 7,37 & $45^{6}$ \\
\hline 3,19 & 454 & 8,2 & 455,467 \\
\hline 3,22 & 472,473 & 8,4 & $478-479$ \\
\hline 4,3 & $457,462 n 220$ & 8,6 & 463 \\
\hline 4,4 & 454 & 8,7 & 479 \\
\hline 4,5 & 455 & $8,7-12$ & 187n108 \\
\hline 4,6 & $45^{6}, 465,473$ & 8,12 & 455 \\
\hline 4,9 & $194,45^{6}, 476$ & 8,19 & 455 \\
\hline 4,10 & $187 \mathrm{n} 108$ & 9,1 & 467 \\
\hline 4,19 & 456 & $9,1-2$ & 476 \\
\hline 4,20 & 457 & 9,2 & 457,477 \\
\hline 4,21 & 464 & 9,5 & 472 \\
\hline 5,1 & $45^{6}, 496,498 n 5^{8}$ & 9,9 & 472 \\
\hline 5,3 & 455 & 9,11 & 475 \\
\hline $5,3-4$ & 463 & 9,14 & 454 \\
\hline 5,5 & 457,480 & 9,17 & $45^{8}$ \\
\hline 5,7 & 453 & 9,20 & 18on 78,467 \\
\hline 5,8 & 453 & 9,22 & 187n108 \\
\hline 5,9 & 465 & 9,23 & 467 \\
\hline 5,10 & 457,465 & 9,26 & 457 \\
\hline 5,11 & 461 & 10,1 & 194,457 \\
\hline 5,12 & 464 & 10,2 & 472 \\
\hline 6,2 & 457 & $10,3-5$ & 457 \\
\hline 6,5 & $45^{6}$ & 10,4 & 467 \\
\hline 6,9 & 194,455 & 10,7 & $457,462 n 220$ \\
\hline 6,10 & 455 & 10,10 & 480 \\
\hline 6,11 & $454,464,472$ & 10,11 & 467 \\
\hline 6,12 & $18 \operatorname{on}_{7} 8$ & 10,18 & 473 \\
\hline 6,18 & 454 & 10,20 & $457,490,496,498$ \\
\hline 6,19 & $463,467,480$ & 10,21 & 475 \\
\hline 7,3 & 467 & 10,24 & 457,467 \\
\hline 7,5 & 480 & 10,27 & 457,496 \\
\hline 7,7 & $45^{6}, 467$ & 10,32 & $490,492,493,494,498$ \\
\hline 7,9 & 475 & & 499,501 \\
\hline 7,11 & 455 & 11,5 & 455 \\
\hline 7,13 & 459n216, 46o & 11,4 & 455 \\
\hline 7,14 & $455,462 n 220$ & 11,11 & 461 \\
\hline 7,15 & 454 & 11,13 & $45^{6}$ \\
\hline 7,16 & $454 \mathrm{n} 205$ & 11,14 & 467 \\
\hline
\end{tabular}




\begin{tabular}{|c|c|c|c|}
\hline \multicolumn{2}{|c|}{${ }_{1}$ Corinthiens (cont.) } & \multirow{2}{*}{$\begin{array}{l}15,1 \\
15,1-2\end{array}$} & \multirow{2}{*}{$\begin{array}{c}194 \\
463\end{array}$} \\
\hline 11,16 & 456,479 & & \\
\hline 11,17 & 463 & 15,2 & 456,457 \\
\hline 11,23 & $194,456,464$ & 15,3 & 463 \\
\hline 11,24 & 463,468 & $15,3-4$ & 465 \\
\hline 11,25 & 478 & 15,5 & $455,468,471$ \\
\hline 11,27 & 468 & 15,7 & 476 \\
\hline 11,29 & 455 & 15,9 & 457,476 \\
\hline 11,34 & 454 & 15,12 & 194 \\
\hline 12,2 & $498 n 5^{8}$ & 15,13 & 457 \\
\hline 12,3 & 480 & 15,14 & $458,459 n 216$ \\
\hline 12,4 & 480 & 15,15 & $45^{6}, 45^{8}, 460$ \\
\hline 12,9 & 468 & 15,16 & $45^{6}$ \\
\hline 12,10 & 468 & 15,20 & 468 \\
\hline 12,11 & 468 & 15,28 & 468 \\
\hline \multirow[t]{2}{*}{12,13} & 468, 471, 490, 492, 493, & 15,33 & 463 \\
\hline & $494,498,499,5^{01}$ & 15,34 & 194,463 \\
\hline 12,14 & 457 & 15,37 & 462 \\
\hline $12,15^{-16}$ & 457 & 15,40 & $45^{6}$ \\
\hline 12,20 & 504 & 15,41 & $45^{6}$ \\
\hline 12,22 & $187 \mathrm{n} 108,456$ & 15,47 & 454 \\
\hline $12,23-24$ & $45^{6}$ & $15,5^{1}$ & 194 \\
\hline 12,27 & 194,455 & $15,5^{2}$ & $45^{6}$ \\
\hline 12,28 & 463 & 15,55 & 469 \\
\hline $12,28-29$ & 476 & 15,58 & 463 \\
\hline 13,1 & 464 & 16,1 & 473 \\
\hline 13,4 & 18on 78,468 & 16,3 & 472 \\
\hline 13,8 & 464 & 16,5 & $454,473,474$ \\
\hline 13,10 & 455 & 16,10 & $454,455,469,473$ \\
\hline 13,11 & 194 & 16,11 & 454 \\
\hline 13,12 & $454 \mathrm{n} 205,468$ & 16,12 & $454,456,457,473$ \\
\hline 13,13 & $454 \mathrm{n} 207$ & 16,15 & 469,473 \\
\hline 14,1 & 455 & 16,17 & $464,473,474$ \\
\hline 14,6 & 455 & 16,18 & 457 \\
\hline 14,9 & 463 & 16,19 & $45^{6,}, 473$ \\
\hline 14,10 & $468,470 n 229$ & $16,19-21$ & 454 \\
\hline 14,11 & $475,492 n 34$ & 16,21 & 472 \\
\hline 14,15 & 455 & 16,22 & $461,462 n 220$ \\
\hline 14,20 & 194,454 & 16,24 & 469 \\
\hline 14,22 & 457 & & \\
\hline 14,27 & 464,465 & 2 Corinthiens & \\
\hline 14,28 & $462 n 220$ & $12,1-5$ & $476-477 \mathrm{n} 242$ \\
\hline 14,29 & 457 & & \\
\hline 14,33 & 454 & Galates & \\
\hline 14,34 & 468 & 2 & $45^{2}$ \\
\hline 14,37 & $45^{6}$ & $2,1-3$ & 167 \\
\hline 14,38 & 463 & 3,28 & 494 \\
\hline 14,39 & 457 & & \\
\hline
\end{tabular}




$\begin{array}{clll}\text { Éphésiens } & & 4: 125 & 495 \mathrm{n} 43 \\ 1,1 & 442 & 4: 171 & 476 \\ & & 5: 110 & 480 \\ \text { 1Timothée } & & 5: 75 & 476 \\ 1,3 & 442 & 6: 79 \cdot 161 & 495 \mathrm{n} 43 \\ 3 & 45^{2} & 10: 105 & 495 \mathrm{n} 43 \\ 3,14-16 & 167 & 16: 102 & 480 \\ & & 16: 103 & 54 \mathrm{n} 74 \\ \text { Hébreux } & & 16: 120.123 & 495 \mathrm{n} 43 \\ \text { He } 11,16-12,2 & 182 & 22: 31 & 495 \mathrm{n} 43 \\ \text { He } 11,28 & 480 & 26: 195 & 54 \mathrm{n} 74 \\ & & 30: 30 & 495 \mathrm{n} 43 \\ \text { Coran } & & 33: 40 & 477,478 \\ 2: 125 & 495 & 33: 7 & 478 \\ 2: 135 & 495 \mathrm{n} 43 & 37: 35 & 478 \\ 2: 136 & 411 n 155 & 47: 19 & 478 \\ 2: 87 \cdot 253 & 480 & 61: 6 & 476 \\ 3: 49 \cdot 53 & 476 & 98: 5 & 495 \mathrm{n} 43 \\ 3: 62 & 479 n 248 & & \\ 38: 65 & 479 n 248 & & \\ 3: 67 & 495,495 \mathrm{n} 43 & & \\ 3: 95 & 495 \mathrm{n} 43 & & \\ 3: 84 & 411 n 155 & & \end{array}$




\section{Index des sujets et des noms}

'Abdišū' bar Brikhā 31, 32ngo

Abū Qurra, Théodore $\quad 475 n 238,496$

Abū Șāliḥ $\quad 496$

apocryphe

Lettre aux Laodicéens 155

évangile arabe de Jean $\quad 262$

araméen

dialectes araméens $\quad 448,452,461,482$

source araméenne $\quad 175,471,475,477$

Assemani, Joseph Simon $\quad$ 166-167, 176-178,

183, 184ngo, 196, 506

Bezae, codex 48 ; consulter également chapitre 8 , point 1 . Commentaire verset parverset (pp. 240-448)

Bible en arabe, traduction ; consulter

également Index des sources et Index des manuscrits arabes

évangiles 4n4, 17-19, 21-23, 25-32, 34-35, 37, 52, 54-55, 71, 144n12, 146-151, 155n54, 156-158, 162, 165, 168-176, 180-184, 189, 196, 200-201, 240, 281n54, 453, 459, 472, 482-483, 505 ; consulter également chapitre 4. Répertoire des manuscrits arabes des lettres de Paul (pp. 71-139)

Actes 19, 20, 27, 34, 38, 144n12, 151-153, $160,183,189,196$; consulter également chapitre 4. Répertoire des manuscrits arabes des lettres de Paul (pp. 71-139)

Lettres de Paul 20, 27, 33-36, 140-162 ; consulter également chapitre 4. Répertoire des manuscrits arabes des lettres de Paul (pp. 71-139)

Romains $\quad 15 \mathrm{n} 4,33,35,191 \mathrm{n} 124$

1 Corinthiens $33,35,38,165-507$

2 Corinthiens 33,38

Galates 2, 15n4, 21, 33, 35, 157

Éphésiens 33

1 Thessaloniciens $152,154-156,162$

2 Thessaloniciens $\quad 154-155$

1 Timothée 155

Philémon $35,36,153,154-156,160$, $162,167,175,177,201,240,452$,

453, 459n213, 462, 471, 475, 476, 480-482

Hébreux $\quad 33,153,154-156,162,187$
Lettres catholiques $\quad 19,20,27,28,34$, 151-153, 160, 183, 189, 196 ; consulter également chapitre 4. Répertoire des manuscrits arabes des lettres de Paul (pp. 71-139)

Apocalypse 20,151-153; consulter également chapitre 4. Répertoire des manuscrits arabes des lettres de Paul (pp. 71-139)

Bible hébraïque $\quad 2,38,147$

Genèse 107,135

Exode 135

Psaumes 153, 183, 189, 196

Bible en arabe, traduction moderne van Dyke 44-45, 64, 500

bilingue, voir copte, manuscrit bilingue copte-arabe ; voir grec, manuscrit bilingue grec-arabe ; voir latin, manuscrit bilingue latin-arabe ; voir syriaque, manuscrit syriaque-arabe

al-Bīrūnī 497

Bišr ibn al-Sirrī $\quad 34,64,483$

byzantin, voir aussi melkite et grec

épigramme byzantin $166 \mathrm{n} 4,167,177,178$, $183,187-191,196,506$

texte grec byzantin (ou majoritaire) 192, 465-477, 481, 506 ; voir également chapitre 8, point 1 . Commentaire verset parverset (pp. 240-448)

Chrysostome, Jean $\quad 83,90,108,128,129,153$ codicologie $160,171,179-180$

quantitative $\quad 72,140-142,144$ copte

église copte orthodoxe $1-2,44,52$, 144-145, 149-151, 156

Bible en copte $24,152,155,462 n 219$, 466n223, 475; consulter également chapitre 8, point 1. Commentaire verset parverset (pp. 240-448)

manuscrit bilingue copte-arabe 73-75, 159-160 ; consulter également chapitre 4. Répertoire des manuscrits arabes des lettres de Paul (pp. 71-139)

Coran 31, 34, 51, 54-58, 62, 68, 107, 173, 251, 266n $41,311,328,332,472,476-480,489$, 
490, 494-495; consulter également

Index des sources

critique textuelle ( $\mathrm{du}$ Nouveau

Testament) $\quad 8-10,11,27,37-41,43,46-50$, $57,65,67-68,195,465-471,504-506$, voir aussi édition critique

Diatessaron $1,25,169,170$

digital

projets digitaux et manuscrits arabes 6 , 50, 162, 203-206, 506

changements épistémologiques liés au

digital $6,8-9,49-50,165,489-490$

sites internet polémiques $6,55^{-67}$

hybridité $\quad 6,64-68$

édition

de manuscrit $\quad 8-9,165-166,197-206$

critique $8-10,16-18,29 n 74,32,47,165$ voir aussi critique textuelle

de la Bible en arabe

édition de Raimundi 15, 18n14

édition de Thomas Erpenius 15, 16ng, 38, 39, 109, 149, 156-157, 167, $459 n 216$

Polyglottes de Paris et de Londres 15 , 16ng, 38, 167

édition de la Propaganda Fide 15, 39, 146

édition du patriarche melkite

Athanase IV Dabbās

d'Antioche $\quad 135,146,156$

falsification, voir taḥrīf

grec, voir aussi byzantin et melkite

manuscrit bilingue grec-arabe 28-29, 73, $148,155,156,159-160$

hadìt $51,54-55,262,489$

harkléenne, voir Bible en syriaque, version harkléenne

Homs 102, 177-179, 190, 483-484, 499, 506 hunafä', hanpā $\quad 253,287,354,360,460$, 490-502

Ibn al-'Assāl

Abū l-Farağ al-As'ad Ibn al-'Assāl 1, $27-28,32,34,149-15^{1}$
Aṣ-Ṣafī Abū al-Faḍāìl Ibn al-'Assāl 150

Al-Mu'taman Abū Isḥaq Ibn al-'Assāl 150-151

Ibn Hazm 28, 35, 57

Ibn Hišām 23, 26, 495n46

Ibn Isḥāq, voir Ibn Hišām

Ibn Qutayba 23, 26

identité

enjeux identitaires 51-64, 144

identité et Nouveau Testament $\quad 490-503$

Internet, voir digital

Ishāq ibn Balašk 21, 28, 32

al-Jāhiz $\quad 23$

karshouni $1,73-75,101,103,105,117,124,136$, 159-160

al-Kindī, Risāla $\quad 495-496$

Laodicéens, voir apocryphe, lettre aux Laodicéens

latin

Bible en latin $17-18,24,39,42,107,154$, 159, 462n216, 466n223, 476, 487n1o ; consulter également chapitre 8, point 1. Commentaire verset par verset ( $p p$. 240-448)

manuscrit bilingue latin-arabe 2, 21, 73, $99,113,134,137,142,148,156,159-160$, 162,505

lectionnaires $\quad 72-73$, voir aussi lecture, indications de lecture

lecture

distant reading 6-7,voir aussi codicologie quantitative

close reading 8-11

histoire des lectures $\quad 11-12,485,503,506$ indications de lectures $73,167,178-179$, $183,189,192-196,202,487,506$

liturgie $1,15 \mathrm{n} 1,22,24,73,163,195 \mathrm{n} 130$, 482-484, 487 voir aussi lecture, indications de lectures

Mar Saba $\quad$ 145n13, 156, 168-169, 171, 172n42, 174n49, 176-179, 451, 506

Maronite

Collège maronite

39 
melkite (grec orthodoxe), voir aussi byzantin milieu melkite $1,26,143-144,177-178$, $458,482-484,488,506$

Michel le Syrien 497

mission, activités missionnaires $\quad 22,38-39$, $44-45,57-58,63-64,146$

moyen arabe $3,25 \mathrm{n} 49,186 \mathrm{n} 104,197-198,201$, 202, 204, 245n12, 248n15, 249n19, 254n24, 255n26, 256, 267n44, 268n47, 290, 295n69, 296n7o, 345n104, 347n106, 352, 368n119, 369n12o, 378, 383, 417, 449-458, 461, 488-489, 504

mozarabes (chrétiens d'al-Andalus) 1-2, 5n11, 21, 32, 35, voir aussi latin

Nonnos de Nisibe $\quad 497,501$

numérique, voir digital

“Orient" 5n11, voir aussi orientalisme orientalisme $4,41-45,505$

paléographie 184-186, 189, 195 polyglotte, voir édition de la Bible en arabe postcolonial studies, post-colonialisme 4, $5^{\text {n11, } 49}$

préislamique

Arabie préislamique $\quad 43,5^{1}$

traduction arabe préislamique de la Bible 1, 22-26, 30-31, 51-56, 155n 54 , 172-173, 505

Pseudo-Dionysius, lettre à Timothée sur le martyre de Pierre et Paul 98, 106, 108, 153

Sa'adya Gaon 2

Sinaïticus, codex $\quad 58-59,15^{2}, 155,165 \mathrm{n} 3$, 466-471; consulter également chapitre
8, point 1. Commentaire verset par verset (pp. 240-448)

syriaque

Bible en syriaque, version harkléenne 154,192, 471 ; consulter également chapitre 8 , point 1. Commentaire verset par verset (pp. 240-448)

Bible en syriaque, Vielle syriaque $\quad 25$, 155n54, 169

église syriaque orientale $1-2,34,35$, 39n11, 144, 156

église syriaque occidentale $1,144,178$ manuscrit bilingue syriaque-arabe 73 , $116,124,159-160$

aț-Ṭabarī, 'Alī ibn Sahl $\quad$ 23, 26

tahrīf $55 \mathrm{n} 80,57-62,67$

Tertullien $\quad 53-54$

traduction

de la Bible en arabe, voir Bible en arabe, traduction

loan-translation $\quad 452,462,475$, 480-481

translation studies $\quad 485-490$

Vaticanus, codex 66,155; consulter également chapitre 8 , point 1. Commentaire verset par verset (pp. 240-448)

vocabulaire d'emprunt $\quad 475-476$ vocabulaire religieux musulman 476-479 Vulgate alexandrine 1,149-151, 157-158

Vulgate égyptienne, voir Vulgate alexandrine 